Anna Sulikowska

\title{
Kognitive Aspekte der Phraseologie
}

Konstituierung der Bedeutung von Phraseologismen aus der Perspektive der Kognitiven Linguistik

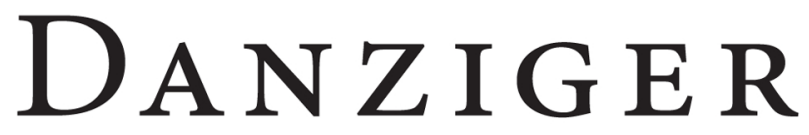

\section{Band 57 B E I T R Ä G E Z U R}

\section{GE R M A N I S T I K}


Diese Monographie verfolgt das Ziel, die zentralen Begriffe der Semantik von Phraseologismen - ihre Idiomatizität, Motiviertheit, Bildhaftigkeit, Bildlichkeit, Ambiguität - aus kognitiver Perspektive zu beschreiben. Es wird ein Verfahren herausgearbeitet und in korpusbasierten Detailstudien erprobt, mit dem semantische Aspekte der Idiome in ihrer Komplexität und Vielfalt anhand eines kongruenten Instrumentariums, unter kohärenten theoretischen Prämissen, erläutert werden. Der wissenschaftliche Wert des Buches liegt in seiner Interdisziplinarität: Hier treffen die empirisch breit abgesicherten Theorien zu Metapher und Metonymie, kognitiver Semantik, mentalen Repräsentationen, literaler und figurativer Sprache, mit der Korpuslinguistik und Phraseologie zusammen.

Anna Sulikowska, Dr. phil., studierte Germanistik an der Universität Szczecin und promovierte an der Universität Gdańsk mit der Arbeit Gedächtnisstützende Lernstrategien im gesteuerten Fremdsprachenerwerb. Seit 2007 ist sie als didaktisch-wissenschaftliche Mitarbeiterin am Institut für Germanistik an der Universität Szczecin tätig. 
Kognitive Aspekte der Phraseologie 


\section{DANZIGER \\ BEITRÄGE ZUR \\ GERMANISTIK}

Herausgegeben von Andrzej Kątny, Katarzyna Lukas und Czesława Schatte

BAND 57

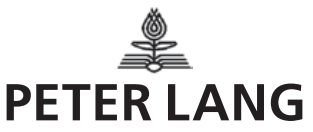




\section{Anna Sulikowska}

\section{Kognitive Aspekte der Phraseologie}

Konstituierung der Bedeutung von Phraseologismen aus der Perspektive der Kognitiven Linguistik

\section{PETER LANG}




\section{Bibliografische Information der Deutschen Nationalbibliothek}

Die Deutsche Nationalbibliothek verzeichnet diese Publikation in der Deutschen Nationalbibliografie; detaillierte bibliografische

Daten sind im Internet über http://dnb.d-nb.de abrufbar.

Gedruckt mit finanzieller Unterstützung der Universität Szczecin.

Umschlagabbildung: Panorama von Danzig mit dem Motto der Universität Gdańsk.

Abdruck mit freundlicher Genehmigung der Universität Gdańsk.

Gutachter:

Prof. Dr. habil. Roman Sadziński

Dr. habil. Małgorzata Guławska-Gawkowska

ISSN $1617-8440$

ISBN 978-3-631-77189-1 (Print)

E-ISBN 978-3-631-77348-2 (E-PDF)

E-ISBN 978-3-631-77349-9 (EPUB)

E-ISBN 978-3-631-77350-5 (MOBI)

DOI $10.3726 / \mathrm{b} 14882$

\section{PETER LANG

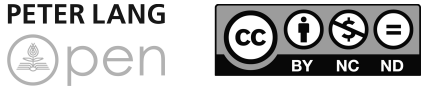

Open Access: Dieses Werk ist lizensiert unter der Creative Commons Lizenz Namensnennung - Nicht kommerziell -

Keine Bearbeitungen 4.0 International (CC BY-NC-ND 4.0).

Den vollständigen Lizenztext finden Sie unter:

https://creativecommons.org/licenses/by-nc-nd/4.0/deed.de

(C) Anna Sulikowska, 2019

Peter Lang - Berlin · Bern · Bruxelles · New York ·

Oxford $\cdot$ Warszawa $\cdot$ Wien

Diese Publikation wurde begutachtet.

www.peterlang.com 
Meinen Eltern gewidmet

Moim Rodzicom 



\section{Danksagung}

Die vorliegende Studie wäre ohne Unterstützung zahlreicher Personen in dieser Form nicht entstanden. An dieser Stelle möchte ich mich bei allen herzlich bedanken, die zur Verfassung und Vollendung des Buches beigetragen haben.

Für die inhaltliche Ausrichtung sei meinen bisherigen wissenschaftlichen Betreuern von der Stettiner Universität: Prof. Dr. habil. Ryszard Lipczuk, dem Leiter des Lehrstuhls für Deutsche Sprache und Prof. Dr. habil. Jolanta MazurkiewiczSokołowska, der Leiterin des Lehrstuhls für Angewandte Linguistik gedankt. Ohne das von Prof. Lipczuk geleitete Projekt Phraseologismen in deutsch-polnischen und polnisch-deutschen Wörterbüchern wäre ich möglicherweise auf das faszinierende Forschungsfeld der Phraseologie nicht aufmerksam geworden. Prof. Mazurkiewicz-Sokołowska verdanke ich die konstruktive Anregung für die Befassung mit der Kognitiven Linguistik. Zugleich bin ich ihr für das Wohlwollen, eine große wissenschaftliche Handlungsfreiheit, die ich unter ihrer Leitung genieße sowie genaue Korrektur des Manuskripts zu Dank verpflichtet.

Mein Dank gilt ebenfalls den Gutachtern des vorliegenden Buches: Dr. habil. Małgorzata Guławska-Gawkowska und Prof. Dr. habil. Roman Sadziński. Ihre fachlichen Hinweise und professionelles Lektorat haben wesentlich zur Qualität der Publikation beigetragen. Prof. Dr. habil. Andrzej Kątny danke ich für die Aufnahme des Buches in die Reihe Danziger Beiträge zur Germanistik.

Im Rahmen der Drucklegung danke ich meiner Universität für die Finanzierung der Publikation sowie Magdalena Kalita und Sandra Bennua vom Peter Lang Verlag, die die Durchführung der Veröffentlichung der Monographie umsichtig und engagiert begleitet haben.

Mein besonderer Dank gilt dennoch meiner Familie: meinem Mann Piotr, der mir fast drei Jahre lang den Rücken frei zu halten versuchte, mich unermüdlich unterstützte, mir jederzeit zur Seite stand und meinen Kindern, Iga und Konrad, die ihrer Mutter gegenüber viel Geduld entgegenbringen mussten. Das Buch widme ich meinen Eltern, Helena und Marian, die immer unerschütterlich an mich geglaubt haben.

Anna Sulikowska

Szczecin, 30.11.2018 



\section{Inhaltsverzeichnis}

Einführung 15

1. Phraseologie und Phraseologismen ................................................ 23

1.1 Geschichte und Forschungsstand der Phraseologie in Deutschland .. 23

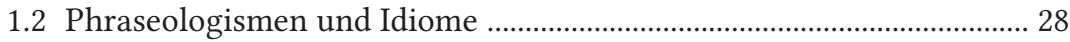

1.2.1 Primäre Merkmale der Phraseologismen ……………………….... 29

1.2.1.1 Polylexikalität ..................................................................... 29

1.2.1.2 Festigkeit ............................................................................ 32

1.2.1.3 Idiomatizität ...................................................................... 35

1.2.2 Sekundäre Merkmale der Phraseologismen ................................... 37

1.3 Klassifikationen der Phraseologismen .................................................... 43

1.4 Zusammenfassung und Ausblick ................................................................. 46

\section{Kognitive Linguistik: Entwicklung,}

Grundvoraussetzungen, Ansätze ………………………………….... 49

2.1 Grundprämissen des holistischen Ansatzes ............................................. 52

2.1.1 Erfahrungsrealismus als philosophische Grundlage holistischer Ansätze ......................................................................... 54

2.1.2 Embodied Cognition ...................................................................... 58

2.1.3 Kategorisierung und Konzepte ......................................................... 64

2.1.4 Grammatik und Lexikon ............................................................... 70

2.1.5 Weltwissen und Sprachwissen ....................................................... 76

2.1.5.1 Frames von Fillmore ............................................................ 77

2.1.5.2 ICMs von Lakoff .............................................................. 79

2.1.5.3 Domänen und Profilierungen von Langacker .................. 81

2.1.6 Interaktionismus und die Rolle des Sprachgebrauchs ................... 86 EXKURS: Bedeutung in modularen und holistischen kognitiven

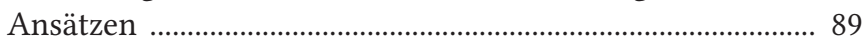

2.1.7 Zusammenfassung und Ausblick ...................................................... 91 
2.2 Analoge Repräsentationsformate und anschauliches Denken in der Kognitiven Linguistik ...................................................................... 94

2.2.1 Repräsentationsformate ............................................................. 96

2.2.2 Repräsentationstheorien ............................................................. 98

2.2.2.1 Unitäre Repräsentationstheorie ....................................... 98

2.2.2.2 Duale Repräsentationstheorie .......................................... 100

2.2.2.3 Multimodale Repräsentationstheorie:

Grounded Cognition .............................................................. 101

2.2.3 Mentale Bilder und Basisbegriffe in der

Prototypensemantik von Rosch ....................................................... 113

2.2.4 Vorstellungsschemata von Johnson ............................................... 116

2.2.5 Verbildlichung bei Langacker ....................................................... 118

2.2.6 Zusammenfassung und Ausblick ................................................... 120

2.3 Metapher und Metonymie als kognitive Prozesse ............................... 121

2.3.1 Metapher und Metonymie in der traditionellen Auffassung ..... 122

2.3.2 Grundzüge der konzeptuellen Metapherntheorie von

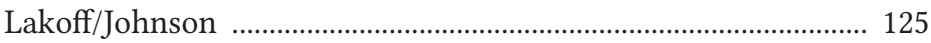

2.3.3 Kritik der konzeptuellen Metapherntheorie ................................... 132

2.3.4 Moderne Auffassung der Metapher und der Metonymie Update ....................................................................................... 137

2.3.4.1 Property attribution model von Glucksberg .................... 139

2.3.4.2 Klassifikationen der Metaphern ....................................... 141

2.3.4.2.1 Konzeptuelle und epistemische Metaphern ... 141

2.3.4.2.2 Innovative und konventionalisierte Metaphern …………………………………..... 145

2.3.4.2.3 Propositionale und bildbasierte Metaphern ... 147

2.3.4.2.4 Die Einteilung nach dem Generalitätsgrad .... 149

2.3.4.2.5 Strukturbezogene Klassifikation der konzeptuellen Metaphern .................................. 150

2.3.4.3 Metonymie ...................................................................... 152

2.3.4.4 Zur Abgrenzung von Metapher und Metonymie ........... 158

2.3.4.4.1 Metapher und Metonymie vor dem Hintergrund des Domänenbegriffes ................. 159

2.3.4.4.2 Metaphtonymie .................................................... 161 
2.3.5 Die literale, non-literale und figurative Sprache 163

2.3.6 Zusammenfassung und Ausblick 167

\section{Semantische Besonderheiten der Idiome aus kognitiver Perspektive} 171

3.1 Literale und phraseologisierte Lesart von Idiomen ............................. 171

3.1.1 Semiotische Perspektive .................................................................. 173

3.1.2 Psycholinguistisch-kognitive Perspektive .................................... 173

3.1.3 Zwischenbilanz ............................................................................... 177

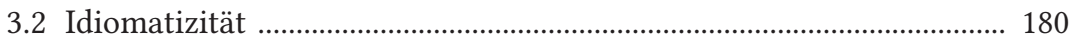

3.2.1 Idiomatizität aus struktureller, pragmatischer und konstruktionsgrammatischer Perspektive .................................... 181

3.2.2 Idiomatizität in der Phraseologie - Versuche der Parametrisierung ................................................................................. 183

3.2.3 Zwischenbilanz ………………………………........................... 190

3.3 Motiviertheit der Idiome ........................................................................... 192

3.3.1 Motivation, Motivierbarkeit und Motiviertheit ............................ 194

3.3.2 Typen der Motiviertheit ................................................................ 197

3.3.2.1 Motivertheitstypologie von Munske ............................... 198

3.3.2.2 Motiviertheitstypologie von Dobrovol'skij/Piirainen ... 202

3.3.2.3 Motiviertheitstypologie von Burger ................................ 207

3.3.3 Zwischenbilanz ………………………………............................. 210

3.4 Bildlichkeit und Bildhaftigkeit der Idiome ............................................ 213

3.4.1 Materielles, mentales und sprachliches Bild .................................. 216

3.4.2 Bildlichkeit und Bildhaftigkeit ..................................................... 219

3.4.3 Das mentale und das idiomatische Bild ......................................... 221

3.4.4 Mentale Bilder und die Konstituierung idiomatischer

Bedeutung - Hypothesen .............................................................. 224

3.4.4.1 Mentale Bilder und konzeptuelle Metaphern: die kognitiv-konzeptuelle Hypothese von Gibbs/O’Brien .. 224

3.4.4.2 Mentale Bilder und literale Lesart: propertyattribute modell von Glucksberg u.a. 
3.4.4.3 Die Theorie des bildlichen Lexikons von Dobrovol'skij/Piirainen ..................................................... 228

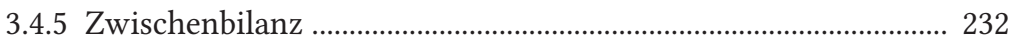

3.5 Zusammenfassung ............................................................................... 236

EXKURS: Korpuslinguistik ..................................................................... 240

\section{Mechanismen der Bedeutungskonstituierung}

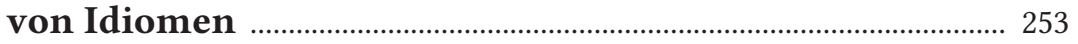

4.1 Daten und Methoden ............................................................................. 253

4.1.1 Untersuchungsmaterial ................................................................. 255

4.1.2 Methoden der Untersuchung .......................................................... 265

4.1.2.1 Methoden der Eruierung von konzeptuellen

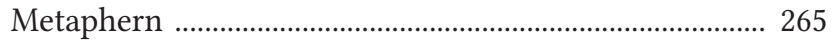

4.1.2.2 Methoden der semantisch-kognitiven Untersuchung am Korpusmaterial ................................... 266

4.1.2.2.1 Die Auswahl der zu beschreibenden Idiome .. 266

4.1.2.2.2 Methoden der semantischen Analyse von Idiomen 267

4.1.2.2.2.1 Erstellung der Belegsammlung ...................... 268

4.1.2.2.2.2 Ermittlung der Verwendungsprofile und Verwendungsmuster ........................................... 270

4.1.2.2.3 Methoden der kognitiven Analyse von Idiomen ................................................................... 273

4.2 Analyse und Interpretation ................................................................. 274

4.2.1 Konzeptuelle Metaphern als Strukturierungsprinzip des semantischen Feldes der Schwierigkeit/der schwierigen Lage ..... 274

4.2.1.1 LEBEN IST EIN WEG, SCHWIERIGKEITEN SIND VERHINDERUNGEN DER (VORWÄRTS-)BEWEGUNG 277

4.2.1.1.1 SCHWIERIGKEITEN SIND HINDERNISSE AUF DEM WEG 279

4.2.1.1.2 SCHWIERIGKEITEN SIND EINE LAST 281

4.2.1.1.3 SCHWIERIGE LAGE IST EINSCHRÄNKUNG DER BEWEGUNGSFREIHEIT 
4.2.1.2 SCHWIERIGKEIT IST UNGENIESSBARES ESSEN .................... 283

4.2.1.3 SCHWIERIGE LAGE IST FEHLENDE LUFT/LUFTENTZUG ..... 284

4.2.1.4 SCHWIERIGE LAGE IST HITZE .............................................. 284

4.2.1.5 SCHWIERIGE LAGE IST SCHLECHTES WETTER .................... 284

4.2.1.6 SCHWIERIGE LAGE IST EIN VERLORENES SPIEL ................... 285

4.2.2 Mechanismen der Bedeutungskonstituierung von Idiomen ...... 292

4.2.2.1 Die Weg-Metaphorik im Deutschen: SCHWIERIGKEITEN SIND VERHINDERUNGEN DER VORWÄRTSBEWEGUNG 294

4.2.2.1.1 SCHWIERIGKEITEN SIND HINDERNISSE AUF DEM WEG 295

4.2.2.1.1.1 SCHWIERIGE LAGE IST UNSICHERER BODEN ... 295

4.2.2.1.1.1.1 schwankender Boden ..................................... 295

4.2.2.1.1.1.2 dünnes Eis ......................................................... 314

4.2.2.1.1.1.3 glattes Parkett ................................................. 325

4.2.2.1.1.1.4 Resümee mit Schwerpunkt: Epistemische Metaphern und Konstituierung der Idiom-Bedeutung ..................................... 335

4.2.2.1.1.2 SCHWIERIGKEITEN SIND HINDERNISSE, DIE EINEN ZU FALL BRINGEN ............................... 343

4.2.2.1.1.2.1 ein Bein stellen ............................................... 343

4.2.2.1.1.2.2 Knüppel zwischen die Beine werfen 352

4.2.2.1.1.2.3 Resümee mit Schwerpunkt:

Konzeptuelle Metonymien und

Konstituierung der Idiom-Bedeutung ........ 359

4.2.2.1.2 SCHWIERIGKEITEN SIND EINE LAST …….......... 364

4.2.2.1.2.1 Klotz am Bein ................................................... 364

4.2.2.1.2.2 am Hals haben ................................................... 372

4.2.2.1.2.3 Resümee mit Schwerpunkt: Ontologische Metaphern, Embodiment und Bedeutung von Phraseologismen 382

EXKURS: Somatismen in der Phraseologie und in der Kognitiven Linguistik ................... 385

4.2.2.1.3 SCHWIERIGE LAGE IST RÄUMLICHE BESCHRÄNKTHEIT 
4.2.2.1.3.1 in die Enge treiben

394

4.2.2.1.3.2 jmdn. an die Wand drücken 403

4.2.2.1.3.3 Resümee mit Schwerpunkt: Interlinguale Äquivalenz, Arbitralität und Motiviertheit von Phraseologismen aus kognitiver Perspektive 414

4.2.2.2 SCHWIERIGKEITEN SIND UNGENIESSBARES ESSSEN 425

4.2.2.2.1 ein hartes Brot 426

4.2.2.2.2 eine harte Nuss 435

4.2.2.2.3 in den sauren Apfel beißen 448

4.2.2.2.4 ein dicker Brocken 453

4.2.2.2.5 Resümee mit Schwerpunkt: Mentales Bild und die Konstituierung der phraseologisierten Bedeutung 465

5. Resümierende Schlussbemerkungen 475

Anhang 485

\section{Abbildungsverzeichnis} 505

Tabellenverzeichnis 513

Literatur 517

Index 565 


\section{Einführung}

Idioms are the poetry of daily discourse.

(Fohnson-Laird 1993: IX)

Anstelle der theoretischen Erwägungen wird einleitend am Beispiel eines meisterhaften, aber keinesfalls vereinzelten Gebrauchs die besondere semantische Potenz der Phraseologismen diskutiert:

Männer würden ihren Frauen viel mehr zu den Füßen liegen, würden diese ihnen nicht so oft auf die Zehen treten. Frauen verbrennen sich gerne die Zunge an der Suppe, die sie sich mit den falschen Männern eingebrockt haben. (Ruth W. Lingenfelser)

Aus traditionell-sprachwissenschaftlicher Perspektive sind es zwei zusammengesetzte Sätze, die vier Phraseologismen im engeren Sinne (= Idiome) enthalten. Diese Idiome - definiert als feste Mehrwortverbindungen, deren Bedeutung sich nicht aus Bedeutungen der einzelnen Konstituenten ableiten lässt - werden als arbiträre Sprachzeichen betrachtet. Als solche lassen sie sich ohne größere Schwierigkeiten mit Paraphrasen umschreiben, so wie es z.B. im Duden Universalwörterbuch der Fall ist:

jmdm. zu Füßen liegen (gehoben: jmdn. über die Maßen verehren)

jmdm. auf die Zehen treten (1. umgangssprachlich: jmdm. zu nahe treten; jmdn. beleidigen. 2. jmdn. unter Druck setzen, zur Eile antreiben)

sich die Zunge verbrennen (seltener; Mund 1a) sich <Dativ> den Mund verbrennen (umgangssprachlich: sich durch unbedachtes Reden schaden)

jmdm., sich eine schöne Suppe einbrocken (umgangssprachlich: jmdn., sich in eine unangenehme Lage bringen) (DUW online, Zugriff am 29.12.2017)

Das Erste, was auffällt, ist die Tatsache, dass die Bedeutungsparaphrasen selbst viele Phraseologismen (= feste Wortverbindungen) enthalten (über die Maßen, jmdm. zu nahe treten, jmdn. unter Druck setzen, zur Eile antreiben). Versucht man das Zitat mit möglich wenigen Idiomen anhand der angeführten Bedeutungsumschreibungen wiederzugeben, dann könnte man folgende Paraphrase vorschlagen:

Männer würden ihre Frauen mehr verehren, würden diese sie nicht so oft beleidigen (belästigen? bedrängen?). Frauen schaden sich gerne (durch unbedachtes Reden?), indem sie sich mit falschen Männern in eine unangenehme Lage bringen.

Dieser Text hätte den Status eines Aphorismus wahrscheinlich nie erreicht. Das Bildhafte, Raffinierte, Sprachspielerische ist verloren gegangen. Unter lexikalisierten Spracheinheiten kommt Idiomen nämlich eine besondere Stellung zu: Einerseits fest, alltäglich, lexikalisiert, entfalten sie doch (unter bestimmten 
kontextuellen Bedingungen) ein besonderes Inferenz- und Emotionspotenzial; sie eröffnen Auslegungsspielräume, rufen individuelle Assoziationen wach, evozieren mentale Bilder, heben bestimmte Bedeutungsaspekte hervor und lassen andere in den Hintergrund treten.

So geht die Bedeutung des Idioms jmdm. $z u$ den Füßen liegen in der einfachen Paraphrase ,verehren' nicht auf, viele konnotative Werte schwinden in der Bedeutungsumschreibung dahin. Der sprachliche Ausdruck (der phonologische oder graphematische Pol einer sprachlichen Einheit) funktioniert nämlich als ein kognitiver Stimulus, der den Rezipienten zur Konstruktion einer aktuellen Bedeutung, einer Konzeptualisierung veranlasst. Dabei ist die konnotative Potenz des Idioms um Vielfaches reicher als die eines Einwortlexems: Das mentale Bild des einer Frau zu Füßen liegenden Mannes ruft unwillkürlich Inferenzen wach, die beim Lexem ,verehren' nur infolge einer vertieften linguistischen Reflexion zustande kommen könnten. Dementsprechend weiß der Rezipient, dass die Frau wie eine Göttin behandelt wird, dass sie angebetet, vergöttert, verhimmelt, angeschwärmt ist. Aus der Lage des Mannes, der unten ist, aufblicken muss, kann des Weiteren geschlussfolgert werden, wer das Sagen in der Beziehung hat: In ähnlicher Stellung, zu Füßen kniend, huldigte man doch früher einem Herrscher. Da diese Position ebenfalls als Unterwerfungsposition gilt, wird ersichtlich, in welchem affektiven Zustand (einer hoffnungslosen Verliebtheit) sich der Verehrende befindet. Das mentale Bild vermittelt eine emotionale Dramatik, die der Paraphrase nicht eigen ist.

Ein anderes, für Phraseologismen im authentischen Gebrauch typisches Phänomen - die Vagheit der Bedeutung - liegt im Idiom jmdm. auf die Zehen treten vor. Die beiden lexikographisch erfassten Teilbedeutungen (1. jmdm. zu nahe treten; jmdn. beleidigen. 2. jmdn. unter Druck setzen, zur Eile antreiben) schöpfen potenzielle Auslegungsmöglichkeiten keinesfalls aus. Die literale Lesart des Idioms nimmt Bezug auf eine wohl von allen Menschen geteilte körperliche Erfahrung: Jeder weiß, wie empfindlich und innerviert die Zehen sind, wie schmerzhaft und unangenehm das Treten auf einen Fuß ist. Aktiviert wird auch das Wissen, dass diese Handlung einen unmittelbaren körperlichen Kontakt voraussetzt, der als eine Verletzung der Privatsphäre, Eindringen in interne, intime Angelegenheiten empfunden werden kann. Diese Wissensinhalte werden in die komplexe psychologische Domäne der männlich-weiblichen Beziehungen projiziert und eröffnen den Spielraum für die Interpretationen, die im vorliegenden Fall folgendermaßen aussehen können:

(i) Frauen sind den Männern gegenüber zu kritisch. Sie verletzen, kränken, beleidigen die Männer. Die schmerzhaften Aspekte der körperlichen Erfahrung werden hervorgehoben und auf die psychologische Domäne projiziert.

(ii) Frauen sind zu aufdringlich, ihr verbales Verhalten in der Beziehung ist $\mathrm{zu}$ invasiv, ihre Forderung nach hundertprozentiger Offenheit und Ehrlichkeit zu penetrant. Die physische Überschreitung der Privatsphäre wird fokussiert und in den Bereich der verbalen Handlungsweise übertragen. 
(iii) Frauen wollen zu viel Nähe in der Beziehung, sie streben Unzertrennlichkeit an. Dies wird von Männern als Einengung der Freiheit, der Entfaltungsmöglichkeiten empfunden, ist belästigend, einschränkend, ruft Verärgerung aus.

(iv) Frauen sind zu ehrgeizig, zu aktiv, schwer zu befriedigen. Sie lassen die Männer nicht in Ruhe, wollen immer mehr, setzen sie unter Druck. Das idiomatische Treten auf die Zehen wird hier als nachdrückliches Ermahnen zur Aktivität, irritierendes Antreiben ausgelegt.

Die interindividuelle Variabilität der potenziellen Auslegungsmöglichkeiten ist darauf zurückzuführen, dass das Idiom hier in gewissem Maße wie eine innovative Ad-hoc-Metapher funktioniert: Das sprachliche Zeichen bildet den Impuls, der beim Sprachproduzenten und dem Sprachrezipienten die geteilten Wissens- und Erfahrungsinhalte evoziert. Zwar ist der Interpretationsraum durch die lexikalisierte Bedeutung teilweise abgegrenzt, aber zugleich groß genug, um eine Vielzahl der Auslegungen zuzulassen. Viele Idiome sind durch derartige semantische Unschärfe und Dehnbarkeit gekennzeichnet.

Der zweite Satz: Frauen verbrennen sich gerne die Zunge an der Suppe, die sie sich mit den falschen Männern eingebrockt haben veranschaulicht textbildende Potenzen, kontextuelle Abwandlungen und semantischen Mehrwert der Idiome. Das Idiom sich die Zunge verbrennen wird modifiziert (okkasionell abgewandelt) und um das Nomen Suppe erweitert, das zugleich eine integrale Konstituente des Idioms sich/jmdm. die Suppe einbrocken ausmacht. Durch die Extension der ersten Wortverbindung wird die Verschränkung der beiden Idiome erzielt und um die ,Suppe herum ein leicht visualisierbares Szenario ausgebaut. Die angestrebte und erreichte Bildhaftigkeit und stilistische Auffälligkeit des Satzes ziehen die Notwendigkeit eines innovativen und kreativen Umgangs mit Idiomen nach sich und setzen einen größeren kognitiven Aufwand seitens des Sprachrezipienten voraus: So ist die lexikographisch erfasste Paraphrase des Idioms sich die Zunge verbrennen ,sich durch unbedachtes Reden schaden' an dieser Stelle nur eingeschränkt einsetzbar. Möglicherweise wird konzeptuell an ein in seinem Konstituentenbestand ähnliches Idiom sich die Finger verbrennen, [durch Unvorsichtigkeit] bei etwas Schaden erleiden" (DUW online, Zugriff am 16.03.2018) angeknüpft, die Autorin hat sich für das Zungen-Idiom der Kohärenz des ausgebauten Szenarios halber entschieden. Aus demselben Grund wird unter zahlreichen Idiomen der schwierigen Lage das Idiom sich die Suppe einbrocken gewählt. Die Fokussierung der Sprachproduzentin auf die "Suppe‘ ist dennoch nicht zufällig und lässt sich möglicherweise nicht ausschließlich auf die ästhetisch-semantische Funktion der Sprache reduzieren: Die Suppe als warme, gekochte Mahlzeit wird mit häuslichem Herd, dem weiblich-mütterlichen Element, dem Alltag assoziiert. Sie lässt einen zusätzlichen, nuancierenden, emotiven Wert in der Konzeptualisierung der männlich-weiblichen Beziehungen mitschwingen (Nähe suchende Frauen, bindungsunwillige bzw. -unfähige Männer, Einzug des Alltags in die Beziehung), der in der „idiomfreien“ Paraphrasierung ,Frauen lassen sich gerne auf Beziehungen mit falschen Männern ein, wodurch sie sich selber schaden" verloren geht. 
Die besprochenen Idiome führen semantische Potenzen vieler Phraseologismen im engeren Sinne, ihre vielfältigen Assoziierungs- und Modifizierungsmöglichkeiten vor Augen. Idiome sind in ihrer Struktur fest und flexibel zugleich, holistisch und doch auch in Bezug auf einzelne Komponenten analysierbar. Sie sind bildhaft, d.h. sie evozieren mentale Bilder, woraus ihre erhöhte Expressivität sowie Inklination zum sprachspielerischen Gebrauch resultiert. Ihre Bedeutungen sind zwar konventionalisiert, oft werden sie aber idiosynkratisch gebraucht und modifiziert: erweitert, reduziert oder in ihrem Konstituentenbestand verändert. Als Sprachzeichen mit einer phraseologisierten Bedeutung sind sie arbiträr, dennoch gleichzeitig für viele Muttersprachler post festum motiviert: Wären die Sprachrezipienten ausschließlich an die lexikalisierten Bedeutungen gebunden, wären die Hinzuinterpretationen - so wie es im Falle von jmdm. auf die Zehen treten oder sich die Zunge verbrennen ist, nicht möglich. Die vielen Idiomen eigene Unschärfe, semantische Dehnbarkeit und Vagheit, ihre konnotative und kreative Potenz lassen schlussfolgern, dass die jeweiligen Ko- und Kontexte nicht die Bedeutungen, sondern Bedeutungspotenziale aktivieren.

Dabei muss hervorgehoben werden, dass Phraseologismen eine äußerst heterogene Gruppe der sprachlichen Einheiten bilden. Die Probleme mit ihrer Beschreibung sind einerseits auf die terminologische Vielfalt einer sich etablierenden sprachwissenschaftlichen Disziplin zurückzuführen - die germanistische Phraseologie hat sich als wissenschaftliche Disziplin erst in den 70er Jahren des 20. Jh. herausgebildet. Andererseits gehört es zur Natur der Phraseologismen, dass sie sich aufgrund der Phraseologizitätskriterien (Polylexikalität, Stabilität, Idiomatizität, Lexikalisierung, Motiviertheit, Bildhaftigkeit) intuitiv klar erfassen lassen, keines der genannten Kriterien ist aber - für sich genommen - ausreichend trennscharf, um die Grenze zwischen dem Phraseologischen und dem Nicht-Phraseologischen eindeutig ziehen zu können. Die Phraseologismen sind mehr oder weniger stabil, mehr oder weniger idiomatisch, mehr oder weniger bildhaft und motiviert, selbst die Polylexikalität gilt in manchen Fällen als umstritten (vgl. die Meinungsunterschiede bezüglich des Status von metaphorischen Komposita wie Strohwitwe oder sog. strukturellen Phraseologismen wie weder ... noch, sowohl ... als auch im Deutschen, Burger 2010: 15, Ehegötz 1990: 3, Fleischer 1982: 72, Stöckl 2004: 156). Insgesamt gilt es zu betonen, dass die Phraseologie einen sprachwissenschaftlichen Bereich darstellt, in dem man grundsätzlich mit skalaren und nicht mit absoluten Größen operiert. Ein kurzer Forschungsüberblick über die Phraseologie im weiteren und im engeren Sinne (= Idiomatik) und somit eine einleitende Bestimmung des Untersuchungsgegenstandes erfolgen im ersten Kapitel.

Kapitel 2 reflektiert den linguistisch-theoretischen Rahmen der vorliegenden Arbeit. Zahlreiche semantische Aspekte der Phraseologismen im engeren Sinne: ihre Bildhaftigkeit, Motiviertheit, ihr konnotativer Mehrwert lassen sich im Rahmen reduktionistischer ${ }^{1}$ Sprachtheorien nicht erklären. Theoretische Ansätze,

1 „Reduktionistisch ist eine Sprachtheorie dann, wenn ihre methodischen Prämissen zu einer unzureichenden Erfassung verstehensrelevanter Bedeutungsaspekte führen oder deren Erfassung sogar verhindern“ (Ziem 2008: 3), vgl. auch Kardela (2006). 
die die Sprache als ein von anderen kognitiven Fähigkeiten abgegrenztes Modul beschreiben, sind nicht imstande, die Motiviertheit der Idiome zu erfassen. Die idiomatische Bildhaftigkeit setzt Herangehensweisen voraus, die die psycholinguistische Relevanz der modalitätsspezifischen mentalen Repräsentationen des gesammelten Wissens anerkennen und Erklärungsansätze dafür liefern. Die kreativ-emotiven Potenzen und Interpretationsbreite der idiomatischen Einheiten sind mit den traditionellen semantischen Merkmalstheorien nicht erläuterbar, sie entziehen sich den strengen Formalisierungen. Einen geeigneten Rahmen für die Erklärung der semantischen Besonderheiten der Idiome im Gebrauch bildet der holistische Ansatz der Kognitiven Linguistik. Generell liegt der Kognitiven Linguistik ein ganzheitliches Bild des Menschen zugrunde, in dem keine trennscharfen Abgrenzungen zwischen Körper und Geist, Sprache und anderen kognitiven Fähigkeiten, Perzeption, Kognition und Emotion vorausgesetzt werden. Sprachliche Zeichen beziehen sich nicht auf außersprachliche Entitäten (Gegenstände, Phänomene und Personen), sondern auf mentale Konstrukte von diesen Entitäten, anders gesagt, sie beziehen sich nicht auf die wirkliche, sondern auf die projizierte Welt. Jede Erfahrung konstituiert somit das konzeptuelle System eines Menschen, darunter sein sprachliches Weltbild (Bartmiński/Tokarski 1986, Bartmiński 1990). Dementsprechend fasst die Kognitive Linguistik Bedeutungen als dynamische, gebrauchsbasierte Konstrukte des menschlichen Geistes auf. So verstandene Bedeutungen weisen weder strikte Grenzen noch exakt zugewiesene stabile Werte auf. Im Gegenteil: Es wird angenommen, dass bei der Konstituierung der Bedeutungen auf die Gesamtheit des aufgesammelten Wissens und die ganze Erfahrung Bezug genommen wird. Das zweite Kapitel untergliedert sich in drei größere Themenbereiche: Zuerst wird auf die Grundprämissen des holistischen Ansatzes mit besonderer Hervorhebung der Bedeutungsauffassung aus der kognitiven Perspektive eingegangen. Demnächst werden die Theorien dargelegt, die Einsicht in die Frage der mentalen Repräsentationen geben. Abschließend werden Metonymien und Metaphern thematisiert - kognitive Mechanismen, denen sowohl in der Kognitiven Linguistik als auch in der Phraseologie ein besonderer Stellenwert zugewiesen wird.

Im dritten Kapitel werden semantisch relevante Aspekte von Idiomen aus kognitiver Perspektive diskutiert. Im Zentrum des Interesses steht dabei die Doppelbödigkeit der semantischen Struktur von Phraseologismen im engeren Sinne, d.h. die Tatsache, dass viele Idiome aus einer literalen und einer phraseologisierten Lesart bestehen. Im Spannungsfeld zwischen den beiden Lesarten konstituieren sich ihre Bedeutungen. Ebenfalls die zentralen und in der traditionellen Phraseologie als problematisch betrachteten Merkmale der Phraseologismen wie Idiomatizität, Motiviertheit/Motivierbarkeit und Bildlichkeit/Bildhaftigkeit können erst vor dem Hintergrund der beiden Lesarten und den zwischen ihnen festzustellenden Beziehungen beschrieben werden.

Angesichts der Annahmen zur Dynamik, Emergenz der Bedeutungskonstituierungsprozesse und der fundamentalen Rolle des Sprachgebrauchs bei der Konstituierung von konzeptähnlichen Strukturen ist der Rückgriff auf authentische 
Sprachbelege unumgänglich. Die Bedeutung einer sprachlichen Einheit wird als eine Spur der vorausgehenden kognitiven Erfahrungen betrachtet. Die aktuellen Bedeutungen bilden somit den Ausgangspunkt zur Untersuchung der Semantik der sprachlichen Einheiten, was in der Praxis in der Zuwendung zu korpusbasierten Analysen innerhalb der kognitiv ausgerichteten Forschung ersichtlich wird. Aus diesem Grunde wird der theoretische Teil der vorliegenden Arbeit im Rahmen eines Exkurses mit einer kurzen Darstellung der Korpuslinguistik abgerundet, in der eine Übersicht über die Desiderata und Errungenschaften des neuen linguistischen Forschungszweiges gegeben wird.

Das Ziel des vierten Kapitels, das den empirischen Teil der vorliegenden Arbeit darstellt, liegt in der Veranschaulichung der Bedeutungskonstituierungsprozesse in ihrer Vielfalt und Komplexität. Einer semantisch-kognitiven Analyse werden Phraseologismen unterzogen, die sich onomasiologisch einem ausgebauten Erfahrungs- und Diskursbereich Schwierigkeit/schwierige Lage zuordnen lassen. Auf eine kurze Darstellung der methodologischen Herangehensweise folgt eine eingehende semantisch-kognitive Analyse des zu besprechenden semantischen Feldes. Idiome als konventionalisierte, d.h. weitgehend von den Sprachgemeinschaften akzeptierte und gebrauchte Einheiten der figurativen Sprache sind zur Erforschung der Reichweite der konzeptuellen Metapherntheorie (Conceptual Theory of Metaphor von Lakoff/Johnson 1980) von Natur aus par excellence geeignet: Aus der anhand lexikographischer Werke zusammengestellten Phraseologismensammlung lassen sich problemlos konzeptuelle Metaphern eruieren, die dem zu besprechenden semantischen Feld eine Struktur auferlegen. Es bleibt dennoch zu betonen, dass die Theorie der konzeptuellen Metaphern nicht auf die Beschreibung der den einzelnen sprachlichen Ausdrücken zugrunde liegenden metaphorischen Übertragungen, sondern vor allem auf die Entdeckung eines Systems von vernetzten Metaphern und die Beschreibung der dahinter liegenden konzeptuellen Strukturen ausgerichtet ist. Die konzeptuellen Metaphern sind in vielen Konzeptualisierungen richtungsweisend, keinesfalls aber ausreichend, um die Vielschichtigkeit der semantischen Struktur von Idiomen und ihre semantischen Potenzen aufzufassen. Der umfangreichste Analyseteil ist demzufolge auf detaillierte semantisch-kognitive Fallstudien ausgerichtet. Es wird an Korpusbelegen untersucht, wie sich im Spannungsfeld zwischen der literalen und der phraseologisierten Lesart unter dem Einfluss der epistemischen und konzeptuellen Metaphern, Metonymien, Metaphtonymien, mentalen Bildern und grundlegenden kognitiven Mechanismen von einem sehr hohen Generalitätsgrad wie Vorstellungsschemata (image schemas) die Bedeutungen von Idiomen konstituieren.

In resümierenden Schlussbemerkungen werden die wichtigsten Ergebnisse des Buches zusammengefasst.

Die Arbeit lässt sich in mehrere Subdisziplinen der Phraseologie einordnen. Primär ist es die kognitive Phraseologie: Der Schwerpunkt der Untersuchung liegt auf der Modellierung von kognitiven Bedeutungskonstituierungsprozessen. Den theoretischen Ausgangspunkt bildet die enzyklopädische Bedeutungsauffassung, ausgehobene Rolle spielen die Metaphern und Metonymien, die die phraseologische 
Motiviertheit und Bildlichkeit weitgehend bedingen. Da dabei näher auf phraseologische Merkmale: Idiomatizität, Motiviertheit und Bildlichkeit/Bildhaftigkeit eingegangen wird, dürfte das Buch ebenfalls einen Beitrag zur allgemeinen Phraseologie leisten, in dessen Zentrum sich u.a. die Fragen nach der Abgrenzung des Phraseologischen von dem Nicht-Phraseologischen und den Indizien der Phraseologizität befinden. Durch die gebrauchsgestützte Ermittlung der Bedeutungen und Unterbedeutungen (Verwendungsprofile und Verwendungsmuster) einzelner idiomatischer Einheiten anhand eines gegenwärtigen Korpus trägt die vorliegende Arbeit zu der Phraseographie und der phraseologischen Metalexikographie bei. Die vorgeschlagene Herangehensweise zur Beschreibung der Bedeutungskonstituierungsprozesse dürfte des Weiteren erfolgreich in kontrastiven und kontrastivtranslatorischen Studien eingesetzt werden. 



\section{Phraseologie und Phraseologismen}

Phraseologismen, als (mehr oder weniger) feste Wortverbindungen verstanden, bilden eine inhomogene Gruppe der sprachlichen Einheiten, deren Beschreibung im Rahmen einer Theorie und unter dem Einsatz eines einheitlichen methodologischen Verfahrens Probleme bereitet. Die Schwierigkeiten sind einerseits auf die terminologische Vielfalt einer jungen sprachwissenschaftlichen Disziplin ${ }^{2}$ zurückzuführen, andererseits gehört es zum Wesen der Phraseologie, dass ihre zentralen Bereiche sich relativ leicht und ohne Kontroversen erfassen lassen, wohingegen die Randgebiete umstritten sind. Während also die Mehrwortverbindungen wie sich in die Höhle des Löwen begeben, ins Gras beißen, ein heißes Pflaster aufgrund ihrer Polylexikalität, Festigkeit, Idiomatizität, Motiviertheit und Bildhaftigkeit eindeutig als Phraseologismen eingestuft werden, ist der Status der sprachlichen Einheiten: Blaustrumpf, hierzulande/hier zu Lande, blondes Haar, etw. in Erwägung ziehen, gleichschenkliges Dreieck, Wenn ich fragen darf, oder Zu Risiken und Nebenwirkungen lesen Sie die Packungsbeilage und fragen Ihren Arzt oder Apotheker als phraseologische Einheiten eher kontrovers.

Im folgenden Kapitel wird der Versuch vorgenommen, einen kurzen Überblick über die Geschichte und den Forschungsstand der germanistischen Phraseologie zu geben, sowie die für die weiteren Erörterungen zentralen Termini: ,Phraseologie', ,Phraseologimus' und ,Idiom zu definieren.

\subsection{Geschichte und Forschungsstand der Phraseologie in Deutschland}

Phraseologie als ein Zweig der Linguistik stellt eine relativ junge Forschungsdisziplin dar, die allerdings auf eine Jahrhunderte lange vorwissenschaftliche Phase zurückblicken kann. Demnach teilt Kühn (2007: 620) die Geschichte der germanistischen Phraseologie in drei Etappen ein, die er als (vorwissenschaftliche) Vorphase ${ }^{3}$

2 Auch wenn die europäische Phraseologie eine über jahrhundertlange Tradition hat - Ballys Monographie Traité de stylistique française ist bereits 1909 veröffentlicht worden - entwickelte sie sich erst in den 70er Jahren des 20. Jh. zu einer international anerkannten linguistischen Forschungsdisziplin (Burger/Dobrovol'skij/Kühn/ Norrick 2007b: III).

3 Eine detaillierte Beschreibung der vorwissenschaftlichen Entwicklungsphase der Phraseologie findet man bei Pilz (1978: 57-466). Die folgende Darstellung stützt sich hauptsächlich auf die wesentlich kürzere, bis in die Gegenwart hinreichende Darstellung von Kühn (2007: 619-643). Einen ähnlichen Entwicklungsgang mit den Wendepunkten 1970, 1982 verzeichnet auch Stein (1995: 22-23). 
(bis zur Veröffentlichung von Černyševa 1970), die Anfangsphase (1970-1982) und die gegenwärtige Konsolidierungsphase bezeichnet.

In der ersten historischen Periode, deren Anfänge auf das 16. Jh. zurückgreifen und bis zu den 70er Jahren des 20. Jh. dauern, befassen sich vor allem die Lexikographen mit den sog. sprichwörtlichen Redensarten und Sprichwörtern. Beispiele für die deutschen Phraseologismen sind in dem sog. Großen Fries, dem Dictionarium Latinogermanicum von Johannes Frisius (1556) und im Lexicon trilingue von Schelling/Emmel (1586) zu finden (Müller/Kunkel-Razum 2007: 940). Im Jahr 1529 verzeichnet Johann Agricola sog. ,metaphoricae phrases' in der ersten deutschen Sprichwörtersammlung, 1607 taucht der Begriff ,Phraseologie‘ im Titel einer Synonymensammlung von Johann Rudolph Sattler Teutsche Orthographey und Phraseologey auf (Pilz 1978: 781). Bis ins 19. Jh. befindet sich allerdings die Parömiologie im Zentrum des Interesses. Dabei dient die Sprichwörterforschung und -lexikographie in der ersten Reihe den kulturell-erzieherischen Zielen: Die Sprichwörtersammlungen werden nämlich „für gebildete Leser, die sich freuen Deutsche zu sein und die unsre prächtige Sprache lieb haben“ (Schrader 1894: X), zur „Pflege vaterländischer Sprachkenntnis in der Volksschule" (Wunderlich 1886) angelegt, die linguistischen Versuche, Sprichwörter und sprichwörtliche Redensarten auseinanderzuhalten, werden nicht vorgenommen (z.B. Eiselein 1840) oder nicht konsequent durchgeführt (vgl. Kühn 2007: 620). Ein wichtiger Schritt für die Entwicklung der Parömiologie erfolgt erst in den 80er Jahren des 19. Jh. mit der Veröffentlichung des Deutschen Sprichwörter-Lexikons von Karl Friedrich Wilhelm Wander (1867-1880).

Die Konstituierung der Phraseologie als ein sprachwissenschaftlicher Bereich vollzieht sich in Deutschland am Anfang der 70er Jahre des 20. Jh. ${ }^{4}$ Ein wichtiger Forschungsimpuls geht dabei von der sog. Auslandsgermanistik aus. Eine sowjetische Forscherin, Irina Černyševa, macht in ihrer Monographie Frazeologija sovremennogo nemeckogo jazyka (1970) auf eine Lücke in der Erforschung von festen Mehrwortverbindungen im Deutschen aufmerksam und schlägt in Anlehnung an die bereits anerkannten Definitionen der slawischen Phraseologie die Termini, Ziele und Desiderate der neuen Disziplin vor (Fleischer 1982: 24, Kühn 2007: 621). Einen wichtigen Beitrag leistet des Weiteren die ein Jahr später veröffentlichte Doktorarbeit von Ulla Fix Versuch einer objektivierten Klassifizierung und Definition des Wortgruppenlexems (1971) sowie die im Jahre 1973 erschienene erste Einführung in die deutsche Phraseologie von Harald Burger Idiomatik des Deutschen. Der Forschungsschwerpunkt liegt in der Anfangsphase der Entwicklung der deutschen Phraseologie auf der Definition und Klassifikation der Phraseologismen (vgl. z.B. Burger 1973, Rothkegel 1973, Häusermann 1977, Jaksche/Sialm/Burger 1981). Die Versuche der klaren Abgrenzung des sich etablierenden sprachwissenschaftlichen

4 Näheres zu der Frühgeschichte der europäischen Forschung, dem Beitrag des schweizerischen Strukturalisten Charles Bally und der sowjetischen Phraseologie zur Entwicklung der deutschsprachigen Phraseologie stellen Burger (2005) und Milczarek (2009) dar. 
Forschungsbereiches, der Herausbildung einer konsistenten Terminologie und Aufstellung von exakten Klassifikationen haben dennoch zu einem fachbegrifflichen, die Kommunikation erschwerenden Chaos geführt (Kühn 2007: 621). Neben dem Begriff ,Phraseologismus' funktionieren beispielshalber ebenfalls die Termini: ,idiomatische Phrase', ,idiomatische Lexemkette', ,Floskel', ,Frasmus', ,Fügung', ,Phraseolexem', ,Redensart', ,Redewendung', ,Stereotyp', ,Sprachformel', ,Schematismus', ,Wortverbindung', ,Wortgruppenlexem', ,Verbindung', ,Wortfügung ${ }^{6}$, ,Wortgefüge', ,Wendung ${ }^{{ }^{5}}$.

Der Umbruch und die Überführung in die Konsolidierungsphase erfolgen mit der Veröffentlichung von zwei Monographien: der Phraseologie der deutschen Gegenwartssprache von Wolfgang Fleischer (1982) sowie des Handbuches der Phraseologie von Burger/Buhofer/Sialm (1982), deren Autoren terminologische Vereinheitlichung anstreben. Dementsprechend wird in diesen Arbeiten eine flexible Definition des Begriffes ,Phraseologismus' angenommen, der als Oberbegriff für eine uneinheitliche Klasse fester Wortverbindungen gilt. Die Heterogenität und Vielfalt der sprachlichen Phänomene, die man als Phraseologismen bezeichnet sowie die Undurchführbarkeit von eindeutigen Klassifizierungen und Kategorisierungen der Phraseologismen werden dabei als Merkmale der Phraseologie akzeptiert. Es konstituiert sich in terminologischen Fragen ein Zentrum-Peripherie-Modell: Phraseologismen werden als eine radiale Kategorie mit fließenden Übergängen dargestellt, deren Kernbereich sich relativ gut erfassen lässt, für die Grenzbereiche dennoch unterschiedliche Auffassungen zu akzeptieren sind (Fleischer 1982: 34).

Diese liberale Auffassung der Phraseologismen ist ebenfalls für die gegenwärtige Forschung gültig. Zwar besteht immer noch die Notwendigkeit, das Verständnis des Begriffes ,Phraseologie‘ und ihrer Grenzen für die Bedürfnisse der jeweiligen Fragestellung zu definieren und dieser Notwendigkeit wird auch in neueren Monographien nachgegangen (vgl. z.B. Folkersma 2010, Guławska-Gawkowska 2013, Hümmer 2009, Komenda-Earle 2015, Ptashnyk 2009, Szczęk 2010a), zugleich ist aber ein weitgehender Konsens in der Auffassung der zentralen Bereiche der Phraseologie herausgearbeitet worden. So wird der Terminus ,Phraseologismus ${ }^{6}$ als ein Hyperonym einer ganzen Klasse von heterogenen festen Wortverbindungen angesehen, die durch die Polylexikalität (Mehrwortcharakter) und Festigkeit

5 Eine ausführliche Liste der in den 70er Jahren üblichen Begriffe hat Pilz (1978: VIIIXII) zusammengestellt.

6 Gelegentlich wird auch der Terminus ,Phrasem ‘ als Synonym zu dem weitverbreiteten ,Phraseologismus' gebraucht (vgl. z.B. Donalies 1994, Palm 1995, Sabban 2007b). Wie Burger/Dobrovol'skij/Kühn/Norrick (2007: 3) bemerken, hat der Terminus ,Phrasem“ den Nachteil, durch das Suffix ,-em“ stark den Systemaspekt zu betonen (vgl. Phonem, Morphem, Lexem, Textem). Darüber hinaus haftet den Termini Phonem, Morphem, Lexem die Assoziation der kleinsten sprachlichen Einheit an: Diesbezüglich verweist Pilz (1978: 43) darauf, dass z.B. Amosova als Phraseme nur die nominalen Phraseologismen vom Typ ägyptische Finsternis oder etw. zur Diskussion stellen bezeichnet. Nähere bibliographische Angaben werden nicht angeführt. 
gekennzeichnet sind. Das Spektrum der als Phraseologismen im weiteren Sinne angesehenen Spracheinheiten reicht folglich von Funktionsverbgefügen (in Erwägung ziehen), phraseologischen Termini (das rechteckige Dreieck), Kollokationen (blondes Haar), onymischen Phraseologismen (das Rote Kreuz), über Routineformeln (Guten Tag!), Sprichwörter (Der Apfel fällt nicht weit vom Stamm), geflügelte Worte (Verweile doch! Du bist so schön!) bis zu formelhaften Texten (vgl. dazu Dausendschön-Gay/Gülich/Krafft 2007). Die Phraseologismen im engeren Sinne weisen zusätzlich das Merkmal der Idiomatizität auf (vgl. Burger/Dobrovol'skij/ Kühn/Norrick 2007b: 2, Burger 2010: 11-12, Dobrovol'skij/Piirainen 2009: 11, Palm 1995: 2-3).

Die für die Anfangsphase charakteristischen theoretischen Diskussionen zu terminologischen und klassifikatorischen Kontroversen werden zurzeit durch stärker anwendungsorientierte, z.T. empirisch untermauerte Herangehensweisen ersetzt. Die Phraseologie ist als eine von Natur aus heterogene Disziplin mit unscharfen Rändern und zahlreichen Überschneidungen mit anderen sprachwissenschaftlichen Bereichen aufgefasst. Daraus ergeben sich interdisziplinäre Zugänge ${ }^{7}$ zur Phraseologie. Viel Aufmerksamkeit wird beispielshalber der Phraseopragmatik (vgl. z.B. Coulmas 1981, Elspaß 2007, Hyvärinen 2011, Stein 2001, Übersicht in Filatkina 2007), der Phraseographie (vgl. u.a. Bergenholtz 2005, 2006, Bergenholtz/Tarp 2005, Burger 1992, 2009, Dobrovol'skij 2002b, 2009, Ettinger 1989, 2004, Filipienko 2009, Guławska-Gawkowska 2013, Hahn 2006, Hallsteinsdóttir 2006a, 2006b, 2007, 2009, Hartmann 2002, Hessky 1992c, Jesenšek 2008, 2009, Kątny 2011, Komorowska 2011, Lipczuk/Lisiecka-Czop/Misiek 2011, Mellado-Blanco 2009a, 2009b, Müller/Kunkel-Razum 2007, Nerlicki 2011, Pilz 1987, Steffens 1989, Szczęk 2010b, Worbs 1994, 1997), der Phraseodidaktik (vgl. z.B. Baur/Chlosta 1996, Chrissou 2018, Czarnecka 2010, Ettinger 2007, 2009, 2011, Hallsteinsdóttir 2001, Hallsteinsdóttir/Šajánková/Quasthoff 2006; Hessky 1992a, 1997, Jesenšek 2006, Kühn 1992, Schatte 1993, 1995, 2008a, 2008b, Schmale 2009, Zenderowska-Korpus 2017), der Fachphraseologie (u.a. Duhme 1991, Gläser 2007, Gréciano 2007) sowie stilistischen (z.B. Fleischer/Michel/Starke 1993, Sabban 2007b, 2014, Sandig 2007), arealen (z.B. Burger 2002b, Ernst 2011, Piirainen 2001, 2007, Zürrer 2007), kontrastiven und kontrastiv-translatorischen (z.B. Chrissou 2000, Dobrovol'skij 1997b, 1999, Eismann 1989, Földes 1996, Koller 2007, Komenda-Earle/Staffeldt 2009, Korhonen 2007, Łabno-Falęcka 1995, Piirainen 2004), interkulturellen (z.B. Dobrovol'skij/Piirainen 1997, Dobrovol'skij 2006, Sabban 2007a, Stypa 2009, Szczęk 2013), kognitiven (z.B. Dobrovol'skij 1995a, 1995b, Dobrovol'skij/Piirainen 2009, Feyaerts 1999, Folkersma 2010, Hartmann 1999, Mellado-Blanco 2014, Pohl/Kaczmarek 2014, Roos 2001, Staffeldt/Ziem 2008, Vega-Moreno 2001), psycholinguistischen (z.B. Dobrovol'skij 1997a, Häcki-Buhofer 1989, 1993, 1996, 2004, 2007a, 2007b, Hallsteinsdóttir

7 Einen Überblick über die phraseologische Forschung in der polnischen Germanistik sowie eine biographische Zusammenstellung der Monographien und Beiträge zur Phraseologie und Phraseographie findet man bei Lipczuk (2011a, b). 
2001, Levorato 1993, Wray 2007) Aspekten gewidmet. Einen wichtigen Platz nehmen innerhalb der Phraseologie die Sprichwörterforschung (Parömiologie) (vgl. u.a. Mieder 1992, 1995, 2007, Steyer 2012) sowie historische Aspekte der Phraseologie (z.B. Komenda-Earle 2015) ein. Zahlreiche Beiträge sind der sog. Autorenphraseologie - der Erforschung des Einsatzes und der Funktion von Phraseologismen in literarischen Werken (Palm 1989, Eismann 2007, Baranov/Dobrovol'skij 2007) und dem Gebrauch der Phraseologismen im Diskurs sowie in unterschiedlichen Text- und Gesprächssorten gewidmet (z.B. zur Phraseologie der Jugendsprache vgl. Ehrhardt 2007, zur Phraseologie der Fernsehnachrichten vgl. Burger 1999, zur Phraseologie des Wetters vgl. Burger 2006, zu Phraseologismen in politischen Reden vgl. Elspaß 2007, zu Phraseologismen in Pressetexten vgl. Pociask 2007).

Neue, vielversprechende Perspektiven der Erforschung der Phraseologismen eröffnet die sich in den letzten Jahrzehnten intensiv entwickelnde Korpuslinguistik. Die Stellung der Korpuslinguistik in der Sprachwissenschaft ist umstritten: Manche weisen ihr den Status einer neuen linguistischen Disziplin zu, andere sehen darin eher einen methodologischen Ansatz. Auf jeden Fall stellen Korpora Zugang zu riesengroßen Sammlungen natürlichsprachlicher Daten, durch deren Analyse Einsichten in die Struktur, Funktionen und Gesetzmäßigkeiten der Sprache gewährleistet werden können. Damit stellt der Einsatz der Korpora eine Wende in der Methodologie sprachwissenschaftlicher Forschung dar: Die bisherige, von künstlich konstruierten Sätzen ausgehende „Lehnstuhl-Linguistik“ (Fillmore 1992: 35) wird immer häufiger durch den datenorientierten, empirischen Ansatz ersetzt. Dies eröffnet neue Perspektiven, lässt grundlegende Fragestellungen traditioneller Sprachwissenschaft aufgreifen und führt zu ihrer Revidierung.

Die korpuslinguistisch ausgerichteten Projekte, Untersuchungen und Beiträge gewähren neue Einblicke in das Wesen der phraseologischen Frequenz, Stabilität, Modifizierbarkeit, Variabilität sowie Semantik und distributionellen Lexikongrammatik (vgl. z.B. Bubenhofer/Ptashnyk 2010, Dräger/Juska-Bacher 2010, Ettinger 2009, Hein 2012, Parina 2014, Quasthoff/Schmidt/Hallsteinsdóttir 2010, Stathi 2006, Taborek 2011). Damit leisten sie einen wesentlichen Beitrag zu der Erforschung der Idiome und Phraseologismen. Zu bahnbrechenden Erkenntnissen der von den authentischen Sprachdaten ausgehenden Forschung gehört aber vor allem die Neueinschätzung des Vorgeprägten, Formelhaften, Routinierten, Idiomatischen in der Sprache. Insbesondere induktive, korpusgesteuerte Verfahren, die unvoreingenommen an das Korpus herangehen und rein automatisch nach sich wiederholenden Sprachgebrauchsmustern ${ }^{8}$ suchen wie die korpusgesteuerten Analysen der Kookkurrenz (das statistisch überproportional häufige gemeinsame Auftreten von sprachlichen Einheiten in den Korpora) führen zu wegbreitenden Ergebnissen, die in der extremen Form in der Behauptung zum Ausdruck kommen, dass „die irrige Idee von der völlig freien Kombinierbarkeit von Lexemen ad acta gelegt

8 Vgl. u.a. das von Steyer geleitete IDS-Projekt Usuelle Wortverbindungen, Näheres im Exkurs: Korpuslinguistik. 
werden" kann (Schmale 2017: 44). Ob derart radikale Stellungnahmen berechtigt sind, ist zweifelhaft, es liegt dennoch empirische Evidenz dafür vor, dass die Sprache in einem erheblichen Maße aus formelhaften, reproduzierbaren Fügungen, aus usuellen Wortverbindungen (Terminus von Steyer 2013) besteht, die als „Halbfertigprodukte der Sprache“ (Hausmann 1984: 398) aufzufassen sind. Somit verweist Feilke (1996: 366) darauf, dass die Sprache als Mittel der Kommunikation nicht nur auch, sondern wesentlich idiomatisch ist. Dies führt zur Neudefinierung zentraler Begriffe der Phraseologie: der Festigkeit und Idiomatizität. ${ }^{9}$

Die empirischen Daten finden theoretische Fundierung: In der Kognitiven Linguistik, der daraus entspringenden Konstruktionsgrammatik sowie dem Forschungsstrang zu der sog. ,formelhaften Sprache (Stein 1995) wird davon ausgegangen, dass eine natürliche Sprache aus Form-Bedeutungspaaren (Konstruktionen) besteht. Die Sprache ist also weitgehend vorgeprägt und verfestigt, während die (mehr oder weniger) festen Wortverbindungen nicht die Krönung der Sprachbeherrschung, sondern ihre Grundlage bilden. Dies hat natürlich Folgen für die sich per definitionem mit festen Wortverbindungen befassende Phraseologie. $\mathrm{Ob}$ sich der Gegenstandsbereich der Phraseologie unter dem Einfluss von neuen theoretischen Ansätzen und Forschungsmethoden weiter ausweitet oder - wie Stumpf (2015) postuliert - sich gegen die Konstruktionsgrammatik und formelhafte Sprache abgrenzt, lässt sich im Moment schwer vorhersagen. Möglicherweise steht die Phraseologie vor einer Wende, die entweder zu einer enormen Ausweitung ihres Gegenstandsbereiches und Umformulierung der Grundbegriffe, oder zur Etablierung von einer neuen, sich in dem Forschungsgegenstand mit der Phraseologie verzahnenden linguistischen Disziplin führen wird. Welcher Weg eingeschlagen wird, ist im Moment nicht voraussehbar, fest steht, dass vor dem Hintergrund gegenwärtig vorherrschender theoretischer Ansätze (Kognitive Linguistik, Konstruktionsgrammatik, Untersuchungen zur formelhaften Sprache) und innovativer Forschungsmethoden (Korpuslinguistik) neue Zugänge und Abgrenzungen erwünscht und notwendig sind (vgl. u.a. Berdychowska/Schatte 2017, Feilke 2007, Schmale 2017, Stumpf 2015).

\subsection{Phraseologismen und Idiome}

Trotz der terminologischen Schwierigkeiten der Anfangsphase herrscht in der gegenwärtigen Phraseologie eine weitgehende Einstimmigkeit in der Auffassung der Phraseologismen unter der Berücksichtigung von drei zentralen Bestimmungsmerkmalen: der Polylexikalität, der Festigkeit (Stabilität) und der (eventuellen) Idiomatizität (Burger/Dobrovol'skij/Kühn/Norrick 2007b, Burger 2002a, 2010, Donalies 1994, Fleischer 1982, 1997, Palm 1995, Ptashnyk 2009, Wotjak 1992). Diese Kriterien dienen vorerst der Abgrenzung der Phraseologismen gegenüber anderen sprachlichen Einheiten, wobei polylexikale und feste Wortverbindungen als

$9 \quad$ Vgl. auch die Kap. 1.2.1.3, 3.2.1. 
Phraseologismen im weiteren Sinne, polylexikale, feste und idiomatische Wortverbindungen als Phraseologismen im engeren Sinne (Idiome) bezeichnet werden. Zahlreiche Forscher führen auch weitere Phraseologizitätsmerkmale wie Lexikalisierung, Reproduzierbarkeit, unikale Komponenten, Motiviertheit, Bildlichkeit, Bildhaftigkeit, semantischer Mehrwert, Sprachüblichkeit heran, die sich entweder mit den primären Phraseologizitätskriterien decken oder verschiedene Facetten der Komplexität der Phraseologismen in den Fokus des Interesses rücken, ohne dennoch für alle als Phraseologismen bezeichneten Sprachphänomene repräsentativ zu sein. Diese Merkmale werden als sekundäre Phraseologizitätsaspekte im Kap. 1.2.2 dargestellt.

\subsubsection{Primäre Merkmale der Phraseologismen}

Unter primären Phraseologizitätskriterien werden im Folgenden diejenigen Kriterien verstanden, die in der Meinung der meisten Forscher als entscheidende und notwendige Merkmale den Bereich des Phraseologischen von anderen Bereichen abheben: die Polylexikalität und Festigkeit (Stabilität) sowie die für Idiomatik obligatorische Prämisse der Idiomatizität.

\subsubsection{Polylexikalität}

Das Merkmal der Polylexikalität (Mehrgliedrigkeit) bezieht sich auf den Mehrwortcharakter der Phraseologismen: Ein Phraseologismus besteht aus mindestens zwei Wörtern. Auch wenn dieses Phraseologizitätskriterium auf den ersten Blick wegen seines formal-strukturellen Charakters als unproblematisch erscheint, bereitet es bei näherer Betrachtung wesentliche Schwierigkeiten: Zum einen ist man in der Sprachwissenschaft immer noch weit von dem Konsens in der Definition des Terminus ,Wort' entfernt (vgl. dazu Miodunka 1989: 69, Reichmann 1976: 4). Zum anderen liegen umstrittene Grenzfälle vor, die phraseologiespezifisch sind. Die Kontroversen beziehen sich dabei sowohl auf die obere als auch die untere Grenze des phraseologischen Bereiches.

So herrscht beispielshalber keine Einigkeit in Bezug auf die Stellung der sog. Ein-Wort-Phraseologismen, d.h. (teil-)idiomatischer Wortbildungskonstruktionen wie Strohwitwe, Achillesferse, Augiasstall in der Phraseologie. Der Terminus wurde von Duhme $(1991,1995)$ eingeführt, von zahlreichen Forschern wird er aber zurückgewiesen (Fleischer 1997: 248, Burger 2001: 38, Burger/Dobrovol'skij/ Kühn/Norrick 2007b: 9). Im Deutschen, als einer aus sprachtypologischer Sicht die Tendenz zum synthetischen Sprachbau aufweisenden Sprache (Ehegötz 1990: 500, Munske 2015 [1993] ${ }^{10}:$ 91), müssten derartige Komposita aus dem phraseologischen Bereich ausgeklammert werden; in anderen, analytischen Sprachen (engl.

10 Munskes Beitrag wurde ursprünglich 1993 in einem von Hoffmann/Macha/Solms herausgegebenen Band Vielfalt des Deutschen veröffentlicht. Im Folgenden bediene ich mich seines Abdrucks aus dem 2015 von Lee digital herausgegebenen Band: Horst 
Achilles heel, poln. pięta Achillesa) funktionieren sie dagegen als Phraseologismen. Topczewska (2017: 29) führt weitere Beispiele für idiomatische Komposita an, deren Ausklammerung aus dem phraseologischen Bereich kontrovers ist: So werden die Wortverbindungen ein Mann von der Welt, hart wie Stein als Phraseologismen angesehen, während Komposita Weltmann und steinhart das Kriterium der Polylexikalität nicht erfüllen.

Darüber hinaus ist der Status einer sprachlichen Einheit als eines Lexems oder eines Syntagmas in der Sprachwissenschaft weitgehend an die orthographische Norm gebunden: Die Getrennt- und Zusammenschreibung entscheiden in der Phraseologie, was in ihren Bereich eingenommen oder aus diesem Bereich ausgeschlossen wird. Viele Phraseologismen hat demzufolge im Deutschen die Orthographiereform erzeugt, die die Getrenntschreibung der Verben vom Typ spazieren gehen (zuvor spazierengehen) durchgesetzt hat (vgl. Ewald 2002: 153, Levin-Steinmann 2007: 40, Heine 2010: 13). Die Grenzen zwischen Wort und Syntagma lassen sich aber nicht immer eindeutig ziehen (Heine 2010: 16), eine Reihe von sprachlichen Einheiten, deren Zugehörigkeit zur Phraseologie umstritten ist, liegt vor: Es funktionieren nach 1996 beispielshalber orthographische Varianten: zugunsten/zu Gunsten, hierzulande/hier zu Lande, zumute/zu Mute (Ewald 2002: 153), die je nach willkürlicher Entscheidung des Schreibenden als Phraseologismen oder Einwortlexeme betrachtet werden können, während unzweifelhafte Phraseologismen ihren phraseologischen Status verlieren, sobald sie als Erstglied in Komposita vorangestellt werden: Nacht-und-Nebel-Aktion, Friede-Freude-Eierkuchen-Stimmung (Topczewska 2017: 30). Deswegen verweisen viele Forscher (Korhonen 1992a: 2, Kühn 2007: 623, Topczewska 2017: 30) zu Recht auf die Künstlichkeit der Grenzziehung zwischen Wortbildung und Phraseologie aufgrund orthographischer Konventionen. Univerbierungsprozesse ${ }^{11}$ beeinflussen Inventar und Merkmalausprägung auf so gravierende Weise, dass ihre stärkere Beachtung seitens der Phraseologie dringend geboten scheint (Ewald 2002: 153).

Kontrovers diskutiert wird ferner, ob Wortverbindungen aus Synsemantika als Phraseologismen angesehen werden können. So bezeichnet Burger (2010: 37) die festen Wortverbindungen weder ... noch, entweder ... oder, sowohl ... als auch, so dass) als strukturelle Phraseologismen, Korhonen (2002: 402) spricht von „Minimaleinheiten" der Phraseologismen, wohingegen Fleischer (1982: 72) und Lipczuk (2011b: 44) das Kriterium der Polylexikalität auf Wortverbindungen mit wenigstens einem Autosemantikum einschränken und synsemantische Wortverbindungen aus dem Bereich der Phraseologie ausschließen.

Haider Munske. Ausgewählte sprachwissenschaftliche Schriften (1970-2015). Die Seitenangaben entstammen diesem Abdruck.

11 Unter Univerbierung wird an dieser Stelle nach Bußmann (1990: 563) der Vorgang und Ergebnis des Zusammenwachsens mehrgliedriger syntaktischer Konstruktionen zu einem Wort verstanden, z.B.: $o b+$ schon zu obschon. 
Keine Einstimmigkeit herrscht ebenfalls bezüglich der Frage, wie man den phraseologischen Bereich von oben abstecken könnte. Als eine etablierte obere Grenze der Phraseologie wird traditionellerweise der Satz angesehen, womit Sprichwörter, Antisprichwörter, Wellerismen, geflügelte Worte zu den Phraseologismen zählen (vgl. Burger/Dobrovol'skij/Kühn/Norrick 2007b, Burger 2010, Donalis 1994, Hartmann 1999, Hessky 1992b, 2000, Munske 1993, Palm 1995). Unter dem Einfluss der Textlinguistik und Pragmatik taucht dennoch immer häufiger die Frage auf, ob man formelhafte Texte: Todesanzeigen, Ansagen im Zug und auf dem Bahnhof (wie z.B. Verehrte Fahrgäste! Wir befinden uns in der Anfahrt auf .... Sie erreichen dort alle planmäßigen Anschlussmöglichkeiten ...), die zwar die Satzgrenze überschreiten, aber zugleich fest sind und reproduziert (nicht konstruiert) werden, in den Gegenstandsbereich der Phraseologie aufnehmen soll. (Näheres zu Beziehung Phraseologismus und Text bei Fix 2007: 460-462 und Dausendschön-Gay/Gülich/Krafft 2007). Wie Stein (1995: 17) überzeugt, können bei weiter Auslegung des Terminus ,Phraseologie die Attribute ,phraseologisch' und ,formelhaft" gleichgesetzt werden. ${ }^{12}$ Stein (ebd.) veranschaulicht das erweiterte Verständnis der Phraseologie in der folgenden Tabelle:

Tab. 1: Die Ausweitung des phraseologischen Begriffsverständnisses und Gegenstandes nach Stein (1995: 25).

\begin{tabular}{|c|c|c|c|}
\hline $\begin{array}{l}\text { Begriffsver- } \\
\text { ständnis }\end{array}$ & $\begin{array}{l}\text { Phraseologie im } \\
\text { engen Sinne }\end{array}$ & $\begin{array}{l}\text { Phraseologie im weiten } \mathrm{Si} \\
\text { phraseologisch }=\text { forme }\end{array}$ & $\begin{array}{l}\text { nne } \\
\text { lhaft }\end{array}$ \\
\hline Gegenstand & $\begin{array}{l}\text { Idiomatische } \\
\text { Wendungen }\end{array}$ & $\begin{array}{l}\text { Formelhafte Wendungen } \\
\text { (pragmatische } \\
\text { Idiome, pragmatische } \\
\text { Phraseologismen, } \\
\text { Routineformeln) }\end{array}$ & $\begin{array}{l}\text { Formelhafte Textteile und } \\
\text { Texte }\end{array}$ \\
\hline $\begin{array}{l}\text { Beschrei- } \\
\text { bungsansatz }\end{array}$ & $\begin{array}{l}\text { Syntaktisch- } \\
\text { semantisch }\end{array}$ & $\begin{array}{l}\text { Pragmatisch } \\
\text { (kommunikativ- } \\
\text { funktional) }\end{array}$ & $\begin{array}{l}\text { Pragmatisch } \\
\text { (kommunikativ-funktional) } \\
\text { und textlinguistisch bzw. } \\
\text { formulierungstheoretisch }\end{array}$ \\
\hline Bezugsgröße & $\begin{array}{l}\text { Satzglieder } \\
\text { Sätze }\end{array}$ & $\begin{array}{l}\text { Äußerungen } \\
\text { Äußerungssequenzen }\end{array}$ & $\begin{array}{l}\text { Textteile } \\
\text { Texte }\end{array}$ \\
\hline Beispiele & $\begin{array}{l}\text { jmdm. ins offene } \\
\text { Messer laufen } \\
\text { Tag für Tag }\end{array}$ & $\begin{array}{l}\text { Guten Tag } \\
\text { Paß mal auf }\end{array}$ & $\begin{array}{l}\text { Danksagungen } \\
\text { Unfallberichte }\end{array}$ \\
\hline
\end{tabular}

12 Vgl. dazu „Das Gesicht der Phraseologieforschung hat sich also stark verändert: Wurde mit der Berücksichtigung von Routineformeln/pragmatischen 
Die Tendenz, formelhafte Texte doch als einen peripheren Bereich der Phraseologie zu betrachten, scheint sich in den letzten Jahren durchzusetzen, wovon ihre Berücksichtigung z.B. im HSK Handbuch der Phraseologie (Burger/Dobrovol'skij/ Kühn/Norrick 2007a) zeugt.

\subsubsection{Festigkeit}

Die Festigkeit, ebenfalls als Festgeprägtheit (Reichstein 1973), Fixiertheit (Thun 1978), Kohäsion (Gréciano 1983) und Stabilität (Fleischer 1997) bezeichnet, beruht darauf, dass der Komponentenbestand und die Bedeutung der Phraseologismen (mehr oder weniger) fest, stabil, nicht veränderlich sind. Die Festigkeit stellt ein komplexes Merkmal der Phraseologismen dar, das aus wenigstens zwei Perspektiven - einer strukturellen und einer psycholinguistischen Perspektive - beschrieben werden kann (Burger 2010: 15-29).

Aus struktureller Sicht beruht die Festigkeit darauf, dass die Komponenten von Phraseologismen auf der paradigmatischen Ebene nicht substituierbar sind (mit einem blauen Auge davon kommen, aber *mit einem blauen Äuglein davonkommen) und ihre Kombinierbarkeit auf syntagmatischer Ebene eingeschränkt ist. Dabei weisen Idiome oft morphosyntaktische Anomalien ${ }^{13}$ auf, die in lexikalisierten Abweichungen von den gegenwärtigen Sprachregeln erfasst werden, wie z.B.: unflektierte Adjektive (auf gut Glück), oder Restriktionen in der Tempusbildung:

Otto hat an Emma einen Narren gefressen.

*Otto frisst einen Narren an Emma.

* Otto fraß an Emma einen Narren (nur Perfekt möglich). (Burger 2002a: 395)

Aus psycholinguistischer Perspektive wird unter phraseologischer Festigkeit verstanden, dass ein Phraseologismus als eine Einheit gespeichert wird, d.h. dass er als eine Ganzheit abgerufen und nicht wie freie Wortverbindungen in jeder konkreten Äußerung ad hoc unter Einbezug der Sprachregeln und des Lexikons

Phraseologismen in einem ersten Schritt die rein semantische Betrachtungsweise um die pragmatische Dimension erweitert, so vollzieht sich nun in einem zweiten Schritt die Ergänzung der pragmatischen Betrachtungsweise um die textlinguistische Dimension. Die kontinuierliche Ausweitung des Gegenstandbereiches der Phraseologie bedingt, daß formelhafte Wendungen und formelhafte Texte nicht mehr (allein) mit den klassischen syntaktischen und semantischen Mitteln der Phraseologie beschrieben werden können, sondern auch und vor allem der Analyse mittels pragmatischer und textlinguistischer Kriterien bedürfen. Die Phraseologie ist, so könnte man sagen, im Laufe ihrer recht kurzen Entwicklungsgeschichte quasi zu einem Sammelbecken geworden für alle in fester Form verwendeten sprachlichen Einheiten - gleich welcher Größe und Bauart" (Stein 1995: 24).

13 Fleischer (1982: 54) bedient sich hier des Begriffes ,transformationelle Defektivität‘. 
generiert wird (diese Eigenschaft wird manchmal auch als Reproduzierbarkeit oder Lexikalisierung bezeichnet, vgl. Bogusławski 1989, Dobrovol'skij 1995a).

Relativ schnell wurde in der Phraseologie wahrgenommen, dass die Festigkeit als absolute Unveränderlichkeit der Form und der Bedeutung verstanden - nur auf wenige Gruppen der Phraseologismen (vor allem auf opake Idiome sowie Phraseologismen mit unikalen Komponenten) zutrifft (Burger 2010: 25). So bemerkt Häusermann im Jahre 1977:

In der Sprache gibt es Tendenzen zur Bildung fester Wortverbindungen und Tendenzen zur Auflösung derselben. Den Grund dazu bildet die (...) Doppelnatur des Frasmus (die Reproduzierbarkeit), die zu der Tatsache führt, daß der Sprecher zwischen freien und festen Wortverbindungen auswählen muß und daß dabei oft Gesetze der freien Wortverbindungen auf die festen angewendet werden und umgekehrt. Man kann vom Sprecher nicht erwarten, daß er freie und feste Verbindungen so gut auseinanderhalten kann wie Lexeme und Morpheme oder wie Lexeme und freie Wortverbindungen.

(Häusermann 1977: 83, zit. nach Barz 1992: 27)

Viel Aufmerksamkeit wird aus diesem Grunde den phraseologischen Variationen (Barz 1992, Korhonen 1992b) und Modifikationen (Krawczyk 2006, Ptashnyk 2009, Sabban 2014) gewidmet.

Unter Variation wird verstanden, dass ein Phraseologismus keine vollständig fixierte Nennform hat, sondern zwei oder mehrere ähnliche Varianten zulässt (Burger 2010: 24): keinen Finger rühren/krumm machen/regen; jmdm. fällt die/ eine Binde von den Augen, auf/unter den Nägeln brennen, weder aus noch ein wissen/nicht aus und ein wissen, Daumen/Däumchen drehen. Die Variabilität der Phraseologismen wird als ein Spielraum aufgefasst, ,innerhalb dessen formale Veränderungen des Phraseologismus möglich sind, ohne dass phraseologische Bedeutung verloren geht, wobei dieser Spielraum lexikographisch erfasst werden kann und soll“" (Burger/Buhofer/Sialm 1982: 69). Korhonen (1992b: 49-50) unterscheidet dabei zwischen morphosyntaktischer und lexikalischer Variabilität.

Die morphosyntaktische Variabilität bezieht sich auf Möglichkeiten der Veränderung der Form bei völlig oder weitgehend konsistenter denotativer Bedeutung, d.h., die einzelnen Ausdrücke werden als verschiedene morphosyntaktische Realisationen (Form- bzw. Strukturvarianten) eines bestimmten Phraseologismus angesehen (Korhonen 1992b: 50). Die lexikalische Variabilität betrifft dagegen Austauschmöglichkeiten von lexikalischen Komponenten (Autosemantika), bei dieser Variabilitätsart kann die Bedeutung entweder konsistent bleiben (z.B. jmdn. in die/seine Schranken weisen/zurückweisen/verweisen), leicht variieren (z.B. sich das Maul/den Mund/die Zunge verbrennen) oder sogar ins Gegenteil verkehrt werden (z.B. sich jmdm. in den Weg stellen, jmdm. aus dem Weg gehen). Auf diese Art und Weise werden synonyme und antonyme Idiome erzeugt (ebd.).

Im Gegensatz zu den phraseologischen Varianten, die einen usualisierten (konventionellen, lexikographisch kodifizierten) Charakter haben, sind die phraseologischen Modifikationen okkasionell. Hier handelt es sich um eine spontane, für 
die Zwecke eines bestimmten Textes hergestellte Abwandlung der Phraseologismen (Burger 2010: 26). Als Beispiel führt Burger eine Modifikation des Sprichwortes Guter Rat ist teuer in der Schlagzeile heran:

\section{Schlechter Rat ist teuer}

Eine Berufs-Hotline verspricht für 3.13 Franken pro Minute Hilfe

Guter Rat ist teuer, heißt es. Für unsichere Arbeitnehmer, die sich mit ihren Fragen an die 157er-Berufs-hotline wenden, ist der teure Rat noch schlecht (...) (Tages-Anzeiger Zürich, 04.09.1996, zit. nach Burger 2010: 26)

Phraseologische Modifikationen gelten als nahezu typische Verwendungsweisen von Phraseologismen, denn Phraseologismen fordern aufgrund ihrer textbildenden Potenzen die Sprecher zu kreativem Sprachgebrauch heraus (Fleischer 1982: 217). Die Ursachen für okkasionelle Abwandlungen sind vielfältig:

Die den konventionellen, normalen Phraseologismen eigene Expressivität kann sich abnutzen und innerhalb der Sprachgemeinschaft als überholt und abgedroschen empfunden werden. Solche tradierten Phraseologismen können umfunktioniert werden, indem sie in Inhalt, Form und Funktion der spezifischen Kommunikationssituation angepasst werden (Bebermeyer/Bebermeyer 1977: 1): Sie werden so zum Ausdruck kreativer Individualität, innovatorischer Originalität und subjektiver Funktions- und Aussageintentionen. Oftmals muss der komplexe, vielschichtige Inhalt von Phraseologismen auch bei einer Verwendung innerhalb eines Textes konkretisiert werden: Gréciano nennt diese Konkretisierung eine „situative Füllung von Leerstellen“ (1983: 239). Schließlich ist die Freude am Sprachspiel ein nicht zu unterschätzender Grund für die Vielzahl okkasioneller Abwandlungen in bestimmten Textsorten der Belletristik, Publizistik und Werbung. (Drumm 2004: 76)

Selbstverständlich ist die Unterscheidung zwischen den usuellen Variationen und okkasionellen Modifikationen in vielen Fällen wegen der Verschwommenheit der Grenzen zwischen dem Individuellen/Idiosynkratischen und dem Überindividuellen/Sich-Konventionalisierenden äußerst schwierig. Nicht immer zuverlässig sind in dieser Hinsicht auch lexikographische Nachschlagewerke (vgl. die Diskussion um die Nennform der Phraseologismen, z.B. Lisiecka-Czop/ Misiek 2011, Misiek 2011). Die sich schnell entwickelnde Korpuslinguistik liefert dennoch empirisch gut untermauerte Evidenz dafür (Burger 2010: 29; Hümmer 2009: 83; Kühn 2007: 623), dass die Variationen und Modifikationen im authentischen Sprachgebrauch weit verbreitet sind und die Festigkeit ein relatives Kriterium darstellt. Hümmer (2009: 248-249) veranschaulicht beispielshalber anhand einer Korpusanalyse, dass Modifikationen des Idioms $j d$. ist mit allen Wassern gewaschen in $36 \%$ von 548 Belegen auftreten, im Falle des Idioms $j d$. schüttelt etw. aus dem Ärmel sind es $14 \%$ der Belege und bei Idiom $j d$. hat es faustdick hinter den Ohren - $6 \%$. 


\subsubsection{Idiomatizität}

Das letzte Kriterium der Idiomatizität dient als eine Trennungslinie, die Phraseologismen im weiteren Sinne von den Phraseologismen im engeren Sinne (= Idiomen) abgrenzt. Dieses Kriterium ist schwer fassbar und facettenreich, wovon beispielshalber eine Reihe der von Kühn (2007: 623) als Synonyme angeführten Begriffe: ,Bedeutungsübertragung', ,Metaphorizität', ,Bildlichkeit', ,Motiviertheit zeugt. Diese Begriffe sind mit der Idiomatizität - als semantischer Undeutbarkeit eines Mehrwortausdrucks aus seinen Komponenten verstanden - eng verbunden, heben aber zugleich ihre unterschiedlichen, nicht unbedingt gleichzeitig aufzutretenden Aspekte hervor.

Idiomatizität wird zurzeit in der Linguistik, insbesondere in der Pragmatik und Konstruktionsgrammatik viel weiter aufgefasst als in der Phraseologie ${ }^{14}$. In einer weiten pragmalinguistischen Auffassung wird unter Idiomatizität das Formelhafte in der Sprache verstanden. Zahlreiche alltägliche sprachliche Äußerungen, wie Grüßen, Vorstellen, Verabschieden, Ess- und Trinkformeln, Danken und Entschuldigen, Kontakteröffnung und Kontaktbeendigung sind habitualisiert (Filatkina 2007: 139), d.h. nach Feilke (1994) idiomatisch geprägt. Idiomatisch geprägt sind demnach Ausdrücke, die als „Handlungsmodelle fungieren können, indem sie Schemata sozialer Koorientierung indizieren" (Feilke 1994: 369). In weiteren Publikationen baut Feilke $(1998,2004)$ den Terminus der ,idiomatischen Prägung ${ }^{{ }^{1} 5}$ aus und definiert sie als eine pragmatische, durch den Gebrauch bedingte Bindung. So ist die Präpositionalphrase in der Äußerung: Er sitzt in der Sonne idiomatisch geprägt, weil die semantischen Adäquatheitsbedingungen alleine durch den Gebrauch erzeugt sind: Die gegen grammatische Regeln nicht verstoßenden Substitutionen *Er sitzt im Mond, *Er sitzt unter der Sonne sind nicht konventionalisiert

14 Allerdings eröffnet die neueste Forschung erweiterte Perspektiven und innovative Zugänge zur Auffassung der Idiomatizität in der Phraseologie. So greifen z.B. Berdychowska/Schatte (2017: 8-10) das von Feilke (2004) vorgeschlagene Konzept der „Pragmatisierung der Phraseologie" auf und sehen darin eine deutliche Tendenz in der Entwicklung der phraseologischen Forschung, deren Verlauf in drei Etappen eingegliedert werden kann: (i) In der vorpragmatischen Phase haben sich die zentralen Bestimmungsmerkmale der Phraseologismen: Polylexikalität, Festigkeit und Figuriertheit herausgebildet. (ii) In der Phrase der Pragmatisierung der Idiomatik wurde die situative Bindung der Phraseologismen hervorgehoben, was in der Herausbildung von neuen Klassen der Phraseologismen: pragmatischen Idiomen (Burger/Buhofer/Silam 1982), Routineformeln (Coulmas 1981) oder situativen Idiomen (Szulc 1981, 1982) zum Ausdruck kommt. (iii) Die dritte Phrase der „konstruktiven Pragmatik" ist durch die Verschiebung vom Zentrum-Peripherie-Modell zum Ebenen-Modell gekennzeichnet: „Was im Zentrum-Peripherie-Modell bisher peripher erscheint, wird hier zum Fundament" (Feilke 2004: 57, zit. nach Berdychowska/ Schatte 2017: 10), womit das Ausmaß des Vorgeprägten/Formelhaften in der Sprache hervorgehoben wird.

15 Vgl. auch das Kap. 3.2.1. 
und aus diesem Grunde unzulässig (Feilke 1998: 72). Idiomatizität bedeutet in dieser weiten Auffassung, dass aus einem Spektrum von Konstruktionsmöglichkeiten für Ausdrücke durch die Konventionalisierung von Selektions- und Kombinationsmöglichkeiten bestimmte verbindlich geworden sind (ebd., 74). Es ist dennoch zu betonen, dass derart weit verstandene Idiomatizität aus phraseologischer Perspektive an dem Schnittpunkt zwischen zwei Merkmalen, der Festigkeit und der Idiomatizität, anzusiedeln ist.

In der Phraseologie wird die Idiomatizität auf zwei Weisen aufgefasst. In der weiten Auffassung versteht man unter der Idiomatizität die morphosyntaktische oder semantische Irregularität in der Sprache (Burger/Buhofer/Sialm 1982: 1, Burger 2010: 29, Fleischer 1982: 35, Lewicki/Pajdzińska 2001: 315). So definieren Lewicki/ Pajdzińska (2001: 315) idiomatische Wortverbindungen als „sozial konventionalisierte Wortverbindungen, die in einer Hinsicht Irregularität aufweisen " ${ }^{16}$. Derart aufgefasste Idiomatizität kann auf der Formebene in Gestalt der lexikalen, Flexions-, Wortbildungsirregularitäten oder syntaktischen Archaismen zum Vorschein kommen (vgl. dazu die morphosyntaktischen Anomalien wie unübliche Wortstellung: auf des Messers Schneide stehen, undeklinierte Adjektive: sich bei jmdm. lieb Kind machen), oder auf der semantischen Ebene als die Non-Kompositionalität der Bedeutung erachtet werden.

In der zweiten, engeren Auffassung bezieht sich die Idiomatizität ausschließlich auf den semantischen Aspekt und bedeutet, dass die phraseologische Bedeutung sich nicht regulär (oder nur partiell regulär) aus den freien Bedeutungen der Komponenten ableiten lässt (Böhmer 1997: 1, Hartmann 1999: 221, Palm 1995: 9, Roos 2001: 9). „Idiomatizität bedeutet, daß das Frege-Prinzip außer Kraft gesetzt ist, daß die Bedeutung eines komplexen Ausdrucks nicht gleich der Summe der Einzelbedeutungen der jeweiligen Lexeme ist" (Stein 1995: 30). Palm $(1995: 9,12)$ spricht hier von der semantischen Transformation der Phraseologismuskomponenten. Es ist dabei hervorzuheben, dass die Idiomatizität einen graduellen Charakter hat. Je nachdem, wie viele Phraseologismuskomponenten einer semantischen Derivation unterzogen wurden, unterscheidet man zwischen:

(i) vollidiomatischen Idiomen, in denen alle Komponenten semantisch transformiert sind, z.B. sein Schäfchen ins Trockene bringen ,für sich großen Gewinn verschaffen', vom Fleische fallen ,abmagern';

(ii) teilidiomatischen Idiomen, in denen manche Komponenten semantisch transformiert sind, andere (hier mit Fettdruck markiert) aber ihre phrasemexterne Bedeutung beibehalten, z.B. einen Streit vom Zaune brechen, einen Streit herausbeschwören', sich ins Fäustchen lachen ,heimliche Schadenfreude empfinden', von Tuten und Blasen keine Ahnung haben ,etw. nicht wissen oder nicht können';

16 „społecznie utrwalone połączenia wyrazów wykazujące nieregularność pod jakimś względem“" (Lewicki/Pajdzińska 2001: 316). 
(iii) nicht idiomatischen Phraseologismen, z.B. sich die Zähne putzen (Burger 2010: 30, Palm 1995: 12).

Außer der Einteilung nach dem Grade der Idiomatizität sind auch andere Klassifikationskriterien möglich. Palm (1995: 12-13) differenziert beispielsweise zwischen folgenden Arten der Idiomatizität:

(i) Von durchsichtigen Metaphorisierungen spricht man bei Phraseologismen mit einer literalen Lesart, bei denen die semantische Transformation aufgrund metaphorischer Prozesse nachvollziehbar ist.

(ii) Undurchsichtige Metaphorisierungen liegen vor, wenn der Bildspenderbereich der Metapher dem heutigen Sprecher nicht mehr vertraut ist, aus einem historischen Milieu stammt, z.B.: einen Narren an jmdm. gefressen haben ,DUW ${ }^{17}$ : umgangssprachlich: jemanden, etwas in übertriebener Weise gern mögen; nach der alten Vorstellung, jemand habe einen Dämon in seinem Innern stecken', alle(s) über einen Leisten schlagen ,DUW: umgangssprachlich: alles mit dem gleichen Maßstab messen; ohne Rücksicht auf wesentliche Unterschiede alles gleich behandeln; wohl nach dem Bild eines nachlässig arbeitenden Schusters, der alle Schuhe über einen Leisten schlägt und so nur Schuhe gleicher Größe anfertigt'.

(iii) Als Spezialisierungen bezeichnet Palm die Phraseme, die aus Synsemantika hier als bedeutungsschwache Wörter ${ }^{18}$ verstanden - bestehen. Die Bedeutungsschwäche der Komponenten erschwert die bildhafte Vorstellung der Wortverbindungsbedeutung, da keine metaphorische Relation zwischen der wörtlichen und der idiomatisierten Lesart besteht, z.B. nicht ganz ohne sein ,nicht ganz harmlos sein', es in sich haben, schwierig oder toll sein'.

Da der Idiomatizität aus pragmatischer, konstruktionsgrammatischer und vor allem phraseologischer Perspektive viel Aufmerksamkeit im Kap. 3.2 gewidmet wird, werden an dieser Stelle weitere Erörterungen zu diesem Thema vorerst ausgespart. Festzuhalten bleibt, dass für die Bedürfnisse der vorliegenden Arbeit die enge, semantische Auffassung der Idiomatizität richtungsweisend ist. Somit wird die Idiomatizität als semantische Undeutbarkeit der Gesamtbedeutung eines Mehrwortausdrucks aus den Bedeutungen seiner Konstituenten definiert.

\subsubsection{Sekundäre Merkmale der Phraseologismen}

Außer den bereits beschriebenen primären Merkmalen der Phraseologismen, die als konstitutive Aspekte angesehen werden, tauchen in der Fachliteratur auch sog.

17 DUW = Duden Universalwörterbuch 2006

18 Synsemantika beziehen sich auf Lexeme mit der Funktion der grammatischen Verknüpfung im Satz. Verben werden traditionellerweise den Autosemantika zugeordnet, aber Palm (1995: 13) betrachtet beziehungsweise Verben mit sehr offener und vager Bedeutung als „fast Synsemantika“. 
sekundäre Merkmale der Phraseologizität auf: Lexikalisierung, Reproduzierbarkeit, unikale Komponenten, Motiviertheit, Bildlichkeit, Bildhaftigkeit sowie eine Reihe der Begriffe, die sich auf den besonderen pragmatisch-konnotativen Wert vieler Phraseologismen beziehen und als semantischer Mehrwert (Kühn 1985), stilistische Potenz (Burger 1973: 95), textbildende Potenz (Sabban 2007b: 237, Wotjak 1994: 622-623) oder Mehrdimensionalität des Inhalts (Gréciano 1982: 298) bezeichnet werden. Die sekundären Merkmale treten in unterschiedlichen Kombinationen auf, sind nicht obligatorisch und für die Abgrenzung der Phraseologismen von anderen Spracheinheiten nicht ausschlaggebend, können dennoch als Behelfskriterien zu ihrer Identifizierung herangezogen werden. Zum großen Teil sind die sekundären Phraseologizitätsmerkmale auf den besonderen Status der Idiome aus semiotischer Perspektive zurückzuführen: Idiome als sekundäre Sprachzeichen weisen nämlich zwei Lesarten auf, aus deren Beziehung sich die Motiviertheit, Bildhaftigkeit/Bildlichkeit, gesteigerte Expressivität sowie semantischer Mehrwert der Phraseologismen im engeren Sinne ergibt. Da diesen Eigenschaften viel Aufmerksamkeit im dritten Kapitel geschenkt wird, werden sie an dieser Stelle nur skizzenhaft umrissen.

\section{Lexikalisierung und Reproduzierbarkeit}

Die Phraseologiziätsmerkmale, Lexikalisierung und Reproduzierbarkeit, hängen aufs Engste mit der Festigkeit/Stabilität zusammen: Sie heben verschiedene Aspekte der phraseologischen Festigkeit und den Einheitsstatus (Begriff von Donalies 1994: 341342) der Phraseologismen hervor. Diese Verflochtenheit kommt bereits in Fleischers Definition der Phraseologismen zum Ausdruck:

Ihr besonderer Charakter als feste Wortverbindungen ergibt sich vor allem aus ihrer (semantischen) Idiomatizität und ihrer (semantisch-syntaktischen) Stabilität. Damit zusammen hängt ihre Speicherung (Lexikalisierung) als lexikalische Einheit, die bei der Textgestaltung reproduziert wird. (Fleischer 1983: 307)

Die Lexikalisierung unterstreicht also den Einheitsstatus der Phraseologismen im Langzeitgedächtnis, sie kann aber auch auf die Systemebene bezogen werden, wo sie der Tatsache Rechnung trägt, dass „die Wortverbindung in einer Sprachgemeinschaft ähnlich wie ein Lexem gebräuchlich" ist (Burger/Buhofer/Sialm 1982: 1). Wie Donalis (1994: 394) bemerkt, ist bereits in den Benennungen: ,komplexe Einheit' (Daniels 1978), ,lexikalische Einheit', syntaktische Einheit' und ,phraseologische Einheit' (Pilz 1978) eine Vorstellung von sprachlichen Gebilden enthalten, die „Zwar aus mehreren Wörtern bestehen, die sich aber wie ein Wort verhalten" (Pilz 1981: 25).

Mit der mentalen Festigkeit ${ }^{19}$ wird die Reproduzierbarkeit gleichgesetzt: Dieser Terminus hebt den psycholinguistischen Status der Phraseologismen hervor,

19 Burger (2002) unterscheidet zwischen grammatischer, syntaktischer und mentaler Festigkeit. 
die aus dem Langzeitgedächtnis als Ganzheiten abgerufen werden. Dies bedeutet, dass Phraseologismen im Gegensatz zu freien Wortverbindungen nicht mithilfe sprachlicher Regeln produziert, sondern als Mehrwortverbindungen reproduziert werden. Selbstverständlich sind beide Kriterien wenigstens teilweise an den individuellen Usus gebunden:

Die Differenzierung zwischen den lexikalisierten und den nicht lexikalisierten, nach produktiven Regeln generierbaren Entitäten basiert, kognitiv gesehen, auf dem lexikalischen Wissen der Sprecher. Wenn ich irgendein Idiom zum ersten Mal höre und aufgrund seines Bildes bzw. der kontextuellen und situativen Einbettung seine Bedeutung verstehe, kann ich nicht entscheiden, ob es sich dabei um ein Idiom oder einen ad hoc gebildeten metaphorischen bzw. metonymischen Ausdruck handelt. Diese Entscheidung ist nur aufgrund eines spezifischen Wissens der Muttersprachler möglich, das als eine Art des Usus-Wissens definiert werden kann und eine Komponente des mentalen Lexikons darstellt. Die Grenzen der Klasse der Idiome sind also u.a. im individuellen Idiolekt des Sprechers begründet. Real operieren die Sprecher mit einer intersubjektiven Schnittmenge, an deren Peripherie ambivalente Entscheidungen möglich sind. (Dobrovol'skij 1995a: 16)

\section{Sprachüblichkeit}

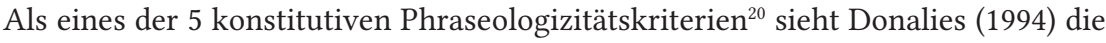
Sprachüblichkeit an. Darunter wird „nicht die statistische Frequenz, sondern die Verfügbarkeit einer sprachlichen Einheit, ihre Präsenz im Wortschatz, die sich aus dem in einer Sprachgemeinschaft wiederholten Gebrauch tradiert" (Donalies 1994: 342) verstanden. Dieser Aspekt wird auch von anderen Phraseologieforschern zum Ausdruck gebracht: Pilz (1978: 33) spricht z.B. von „usuellen Einheiten des Sprachschatzes", der Aspekt der Tradierung, eines von Sprechergeneration zu Sprechergeneration wiederholten Gebrauchs sprachlicher Einheiten ist in Termini wie Topos, Stereotyp, Klischee, Phrase, Formel, Floskel, Redensart und Redeweise aufgegriffen, die häufig synonym oder teilsynonym verwendet oder zur gegenseitigen Definition herangezogen werden (ebd.).

\section{Unikale Komponenten}

Manche Phraseologismen weisen des Weiteren unikale Komponenten auf. Hier handelt es sich um Komponenten, die außerhalb des Phraseologismus (phrasemextern) nicht verwendet werden und denen man innerhalb eines Phraseologismus (phrasemintern) keine isolierbare Bedeutung zuschreiben kann (Burger 2002a: 393,

20 Als relevante Kriterien der Phraseologizität werden von Donalis (1994: 336): Mehrwortcharakter, Stabilität, Idiomatizität, Einheitsstatus und Sprachüblichkeit angesehen. 
Burger 2010: 22). Als unikale Komponenten fungieren Nekrotismen (ausgestorbene Wörter) wie im Idiom Zeter und Mordio, Archaismen (veraltete Wörter) oder sog. Cranberry-Wörter, deren Vorkommen ausschließlich auf die Phraseologismen eingeschränkt ist, z.B. aus dem Stegreif, in Mitleidenschaft ziehen, Fersengeld geben.

\section{Motiviertheit}

Die Motiviertheit der Phraseologismen beruht darauf, dass ihre Bedeutung auf der Basis von Komponentenbedeutungen, Struktur und Metapher oder Metonymie verstehbar/nachvollziehbar ist (Burger 2003: 66). Dies bedeutet, dass der Sprachproduzent oder -rezipient, der den Ausdruck und seine phraseologische Bedeutung kennt, einen Zusammenhang zwischen der literalen und der phraseologisierten Ebene erkennen kann (Hümmer 2006: 35). Viele Phraseologismen sind also „nachträglich interpretierbar“ (Dobrovol'skij 2001: 90), d.h., die Verbindung zwischen der literalen und der phraseologisierten Lesart ist nachvollziehbar, wenn man mit der phraseologisierten Lesart vertraut ist (Beispiele im Kap. 3.3). Motiviertheit stellt ein weitgehend individuelles, intersubjektiv schwer fassbares Merkmal der Phraseologismen dar: Ob ein Idiom für einen Sprachteilhaber motiviert oder nicht motiviert ist, hängt zu einem erheblichen Maße von seinen individuellen Wissensbeständen ab. Dieses Kriterium steht des Weiteren in einer komplementären Beziehung zu der Idiomatizität: Je höher die Idiomatizität, desto niedriger ist die Motiviertheit eines Phraseologismus und umgekehrt. Idiome, die nicht im Geringsten motiviert sind, werden als opake Idiome bezeichnet (vgl. Dobrovol'skij 1995a).

\section{Bildhaftigkeit}

In der neueren Forschung wird zwischen der Bildlichkeit und der Bildhaftigkeit differenziert (Burger 1989, 2007a, 2010, 2015, Häcki-Buhofer 1989, Kapuścińska 2014, Rothkegel 2004, 2014, Stöckl 2004, Topczewska 2004).

Die Bildhaftigkeit besteht darin, dass manche Phraseologismen mentale Bilder zu evozieren vermögen, auch wenn sich nicht immer ein Verhältnis zwischen dem Bild und der phraseologischen Bedeutung feststellen lässt. Fix (2002: 18, zit. nach Kapuścińska 2014: 34) definiert Bildhaftigkeit als „Anschaulichkeit der Bedeutung“, denn die Bedeutung selbst „stellt uns Inhalte vor unser inneres Auge“ (ebd.). Bildhaftigkeit ist nicht auf Phraseologismen eingeschränkt: Mentale Bilder können Einzellexeme evozieren, wie die Verben schlurfen, trippeln, latschen (Beispiele von Fix 2002: 19, zit. nach Kapuścińska 2014: 34), bildhaft können allerdings auch die Texte sein: Bei der Lektüre der Belletristik setzt man das Gelesene in Bilder um, man entwickelt Imaginationen, was die Verfilmungen bekannter Literaturwerke so schwierig macht (Diekmannshenke 2008: 85, nach Kapuścińska 2014: 34). Bildhaftigkeit ist von großer Relevanz für die Entstehung und Semantik der Phraseologismen. So führt Häusermann (1977: 20) den Prozess der Entstehung der Phraseologismen auf zwei grundsätzliche Prozeduren zurück: Entweder bilden sie sich aus ursprünglich freien Wortverbindungen heraus, die sich zu einer festen 
Gesamtbedeutung entwickelt haben, oder sie werden aufgrund ihrer Bildhaftigkeit von Anfang an in ihrer übertragenen Gesamtbedeutung verwendet. Als Beispiel für den ersten Entstehungsprozess dient das Idiom nach Canossa gehen, sich unterwerfen', das vor der (historisch motivierten) Bedeutungsübertragung als eine freie Wortkombination funktionierte. Die zweite Prozedur illustriert Häusermann mit den Idiomen: vom Regen in die Traufe kommen, über seinen eigenen Schatten springen. Das von der literalen Lesart evozierte mentale Bild hatte einen entscheidenden Einfluss auf ihre Herausbildung, wörtlich genommen stellen sie kaum sinnvolle Konstruktionen dar.

\section{Bildlichkeit}

Bildlichkeit hängt mit der Metaphorizität (ev. Metonymisierung und Symbolisierung), der Motiviertheit und Bildhaftigkeit zusammen. Bildlich sind die Äußerungen, in denen ein abstrakter, schwieriger, komplexer Sachverhalt über einen konkreteren (das Bild) konzeptualisiert wird. Im phraseologischen Bereich handelt es sich vor allem um metaphorisch motivierte Idiome. Zugleich wird allerdings die Bildlichkeit sehr oft von der Bildhaftigkeit, d.h. der Fähigkeit, mentale Bilder auszulösen, begleitet.

In den meisten Fällen sind die Begriffe ,Bildhaftigkeit' und ,Bildlichkeit" aufs Engste verbunden und kommen gleichzeitig vor: Bildhafte Idiome sind aufgrund der ihnen zugrunde liegenden Metapher bildlich, bildliche Idiome sind bildhaft, vgl. die Idiome: Öl ins Feuer gießen, in die Zange nehmen, wie ein begossener Pudel dastehen. Beachtenswert ist allerdings, dass sich bildhafte Phraseologismen herausfinden lassen, die nicht bildlich sind (vgl. die Kollokationen wie blondes Haar) sowie - auch wenn hier unterschiedliche Interpretationen möglich sind - bildliche Idiome, die keine mentalen Bilder evozieren, also nicht bildhaft sind, z.B. jmdn. im Stich lassen. Die Abgrenzung der beiden Termini stellt eine der methodologisch schwierigsten Aufgaben der Phraseologie dar, zumal sowohl die Bildlichkeit als auch die Bildhaftigkeit weitgehend durch individuelle Faktoren beeinflusst sind. Ein Versuch, beide Begriffe näher zu erörtern sowie die Unterschiede zwischen einem mentalen, sprachlichen und idiomatischen Bild festzulegen, wird im Kap. 3.4.2 unternommen.

\section{Semantischer Mehrwert}

Bereits Černyševa macht darauf aufmerksam, dass die Phraseologismen „gebrauchssemantisch hochgradig komplex“ sind (Černyševa 1984: 18). Dieses Merkmal trifft insbesondere auf idiomatische Phraseologismen zu, die im Vergleich zu Lexemen über mehr differenzierende und konkretisierende Seme verfügen (Wotjak 1992: 24).

Gläser (1986: 42) und Roos (1992: 192) sprechen den Phraseologismen eine in stilistisch-konnotativer Hinsicht intensivierende Funktion zu: a rolling stone ist mehr als seine nicht-idiomatische Paraphrase ,an unsteady person' (Roos 1979: 124), 
genauso wie ein heißes Eisen anschaulicher, expressiver und emotionsbeladener als die freie Wortverbindung ,ein unbeliebtes Thema' ist. Die semantische Komplexität der Idiome fällt besonders auf, wenn man Idiome ihren nicht-idiomatischen Paraphrasen gegenübersetzt:

Will man die Bedeutung einer phraseologischen Einheit bestimmen, so ist es überaus nützlich herauszufinden, wie sich der jeweilige Phraseologismus von seiner nichtphraseologischen Entsprechung unterscheidet. Hierzu ist sowohl eine Interpretation des situativen Kontextes, in dem der Phraseologismus geäußert wird, als auch die Berücksichtigung seiner Einbettung in den gesamten Textverlauf unumgänglich. (Kühn 1987: 127)

Für den schwer fassbaren Komplex der semantisch-pragmatisch-stilistischen Eigenschaften der Phraseologismen im engeren Sinne hat Kühn den Begriff des semantischen Mehrwerts eingeführt:

Phraseologismen haben gewissermaßen einen semantischen Mehrwert, ihre Bedeutung geht über ihre nicht-phraseologische Entsprechung insofern hinaus, als man mit dem Gebrauch von Phraseologismen immer bestimmte Einstellungen ausdrückt. Phraseologismen dieses Typs können also als eine besondere Art stilistischer Formulierungen angesehen werden. (Kühn 1985: 42)

Für das stilistisch-konnotative Plus der Phraseologismen gegenüber einfachen Lexemen funktionieren in der Literatur außer dem Begriff des semantischen Mehrwerts auch andere Termini. Burger (1973: 96) spricht beispielshalber von stilistischen Potenzen der Phraseologismen, die auf zwei grundlegende Aspekte: die bildhafte Motivierung der Idiome sowie ihre feste, vorgeformte Gestalt zurückzuführen sind.

Eines großen Interesses erfreuen sich auch gebrauchssemantische Funktionen und Potenziale der Phraseologismen in Texten, die als Potenzen beschrieben werden. Den Begriff führt Černyševa (1980) ein, weiterentwickelt wird das Konzept von Dobrovol'skij (1987), Wotjak (1994) und Sabban (2004, 2006, 2007b, 2014). Die Potenzen von Phraseologismen beziehen sich nach Sabban (2007b: 238) auf das in ihrer Beschaffenheit begründete und daher im Vergleich zu Einzellexemen besondere Potenzial von Phrasemen, zu verschiedenen Dimensionen des Textes einen wesentlichen oder gar entscheidenden Beitrag zu leisten. Wotjak (1994: 662) sieht den besonderen Wert der Phraseologismen in einer „vielfältigen Assoziierungsund Modifizierungsfähigkeit, die über die von Einzellexemen bei aller prinzipiellen Ähnlichkeit hinausgeht“.

\section{Expressivität}

Für ein wichtiges Merkmal der Phraseologismen wird ebenfalls ihre Expressivität gehalten (Burger 2007a: 82, Ehegötz 1990: 499, Hümmer 2006: 30, Worbs 1998: 262-263). Unter Expressivität wird verstanden, dass Phraseologismen Bedeutungsaspekte in sich tragen, die auf besondere emotionale Involvierung 
des Sprachproduzenten verweisen. Fleischer/Michel/Starke (1993: 15) sehen in Phraseologismen „expressive Konkurrenzformen zu Benennungseinheiten in der Wortstruktur“, Hümmer (2006: 30) verweist darauf, dass phraseologischen Einheiten nur selten die primäre Funktion der Benennung von Sachverhalten zugesprochen wird: Vielmehr erfüllen sie die Funktion der Kommunikation emotionaler Zustände, der Expressivitätssteigerung (Fleischer 1996: 336), welche sich aus ihrer Bildlichkeit, eventuellen besonderen lautlich-rhythmischen Eigenschaften, semantischen Verdoppelungseffekten etc. speisen.

Gesteigerte Expressivität der Phraseologismen hat zur Folge, dass phraseologische Einheiten sich schnell „abnutzen“, aus dem Usus verdrängt und durch Neologismen ersetzt werden. Auf die Dynamik in der Entwicklung des phraseologischen Bestandes der Sprache machen Worbs (1998: 262) und Lewicki/Pajdzińska/Rejakowa (1987: 40) aufmerksam.

\subsection{Klassifikationen der Phraseologismen}

In der germanistischen Phraseologie sind mehrere Klassifikationen entstanden, die anhand unterschiedlicher Kriterien Ordnung und Hierarchie in den vielfältigen und komplexen Bereich einzuführen versuchen. So wurden die Phraseologismen nach semantischen (z.B. Agricola 1977, Korhonen 2002), morpho-syntaktischen (Fix 1974, Fleischer 1982) oder semantischen und syntaktischen (z.B. Černyševa 1975, Rothkegel 1973) Kriterien eingegliedert. Die pragmatische Klassifikation von Coulmas (1981) bezieht sich auf den kommunikativen Wert der Phraseologismen und hat einen funktionalen Charakter.

Da mit einzelnen Kriterien der ganze phraseologische Bestand nicht erfasst werden kann, sind die neuesten Systematisierungsversuche durch die Kombination von verschiedenen Kriterien gekennzeichnet. Im Folgenden sei hierfür stellvertretend und repräsentativ an der Klassifizierung von Harald Burger (2010: 36-42) die Probe aufs Exempel gemacht. Als Erstes werden die Phraseologismen im weiteren Sinne nach dem Kriterium der Zeichenfunktion in 3 Gruppen eingeteilt: Referentielle Phraseologismen beziehen sich auf Objekte, Vorgänge oder Sachverhalte der Wirklichkeit (z.B. blondes Haar, Schwarzes Brett, jmdm. Sand in die Augen streuen). Die strukturellen Phraseologismen (z.B. sowohl ... als auch, so ... dass, weder ... noch) stellen grammatische Relationen her. Kommunikative Phraseologismen (z.B. Wie geht's?, meines Erachtens, Sie wünschen?) sind dagegen für die Herstellung, Definition, den Vollzug und die Beendigung kommunikativer Handlungen von Relevanz (Burger 2010: 36).

Die referentiellen Phraseologismen machen wohl die größte Gruppe der Phraseologismen aus. Sie lassen sich weiter in nominative und propositionale Phraseologismen eingliedern. Die nominativen Phraseologismen bezeichnen in semantischer Hinsicht Objekte und Vorgänge, in syntaktischer Hinsicht sind sie satzgliedwertig, d.h., sie umfassen die Spracheinheiten unterhalb der Satzgrenze (z.B. Schwarzes Brett, Tomaten auf den Augen haben). Die propositionalen Phraseologismen dagegen fungieren als Aussagen über Objekte und Vorgänge und 
sind - syntaktisch gesehen - satzwertig (z.B. Ihr habt zu Hause wohl die Säcke an den Türen?, Morgenstunde hat Gold im Munde).

Bei der weiteren Untergliederung der nominativen Phraseologismen bedient sich Burger des semantischen Idiomatizitätskriteriums. Nach dem Grad der Idiomatizität lassen sich die satzgliedwertigen Phraseologismen in Idiome (z.B. den Löffel abgeben, ins Gras beißen), Teil-Idiome, in denen nicht alle Komponenten umgedeutet sind (z.B. einen Streit vom Zaune brechen) und nicht-idiomatische bzw. schwach-idiomatische Kollokationen (z.B. blondes Haar, Zähne putzen) subklassifizieren.

Da die Anwendung des Idiomatizitätsgrades als Klassifikationskriterium der propositionalen Phraseologismen die traditionell gut etablierte Klasse der Sprichwörter auseinanderreißen würde (vgl. das idiomatische Sprichwort: Der Apfel fällt nicht weit vom Stamm vs. das nicht-idiomatische Sprichwort: Durch Schaden wird man klug), entscheidet sich Burger (ebd., 38-39) bei der Einteilung dieser Gruppe für eine Eingliederung nach einem syntaktisch-textlinguistischen Aspekt und teilt die propositionalen Phraseologismen in feste Phrasen und topische Formeln ein. Feste Phrasen sind explizit an den Kontext durch bereits verfestigte Komponenten (vgl. das deiktische Demonstrativpronomen Das schlägt dem Fass den Boden aus) oder ad hoc formulierte Elemente (z.B. jmds. Aktien steigen) angeschlossen. Topische Formeln umfassen satzwertige Phraseologismen, die durch kein lexikalisches Element mit dem Kontext verbunden sein müssen, vgl. die Sprichwörter (z.B. Ohne Fleiß kein Preis) oder Gemeinplätze (z.B. Was sein muss, muss sein; Man lebt nur einmal).

In Form eines Schemas lässt sich die Klassifikation von Burger wie folgt (Abb. 1) veranschaulichen:

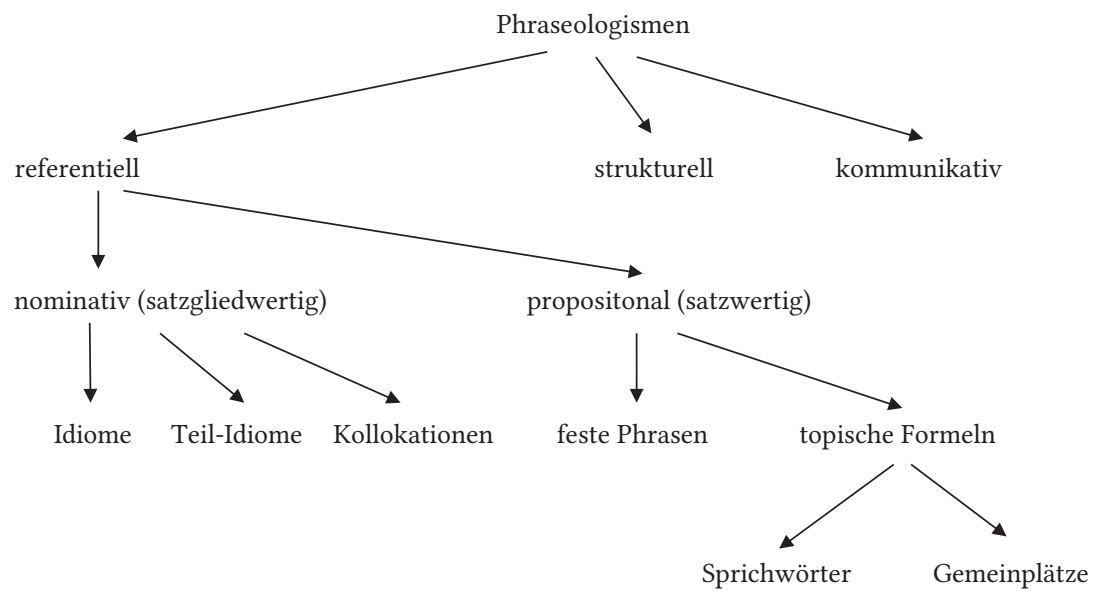

Abb. 1: Klassifikation der Phraseologismen nach Burger (2010). 
Dank der Kombination von mehreren Kriterien ist es Burger gelungen, verschiedene Klassen der Phraseologismen einzubeziehen. Somit gibt diese Basisklassifikation vorerst einen Überblick über die Vielfalt und Komplexität der Phraseologismen. Dennoch muss nachdrücklich betont werden, dass die auch so vielseitige Einteilung aufgrund der offenen Grenzen des phraseologischen Bereiches keinen exhaustiven Charakter hat und der Fülle der zur Phraseologie zählenden Sprachphänomene nicht gerecht wird. Phraseologismen können aus unterschiedlichen Perspektiven beschrieben werden: Zum einen gibt es Phraseologismengruppen (Zwillingsformeln, Kinegramme, komparative Phraseologismen, geflügelte Worte, Modellbildungen, onymische Phraseologismen, phraseologische Termini u.a.), die in der phraseologischen Tradition fest verankert sind, von den Basisklassifikationen allerdings nicht erfasst werden bzw. sich mit ihnen verzahnen. Zahlreiche Beispiele für spezielle Klassen der Phraseologismen führt für das Deutsche Burger (2007a: 45-52), für das Polnische Chlebda ${ }^{21}$ (2005: 82-83) heran. Zum anderen ist die semantische, syntaktische, pragmatische Struktur vieler Phraseologismen von Natur aus facettenreich - ein und derselbe Phraseologismus kann aus verschiedenen Perspektiven unterschiedlich beschrieben und klassifiziert werden:

So gehört z.B. engl. live and learn strukturell zu den „Zwillingsformeln“/,binominals“, und zwar zum speziellen Typus der irreversiblen „Zwillingsformeln“/,irreversible binominals" und syntaktisch zum Typus V+V, kann aber hinsichtlich Gebrauch und Verbreitung als „Sprichwort“ gelten. Idiomatisch ist live and learn bei manchen Verwendungen, wo es so viel bedeutet wie ,man lernt nie aus', aber manchmal ist es auch wörtlich zu verstehen, z.B. als einfache Aufforderung. Je nach Interesse des Forschers (Systemlinguistik oder Pragmatik/Diskursanalyse oder Phraseographie) kann die eine oder andere Typisierung im Vordergrund stehen. (Burger/Dobrovol'skij/Kühn/Norrick 2007b: 6)

Darüber hinaus muss man sich des dichotomischen Entweder-Oder-Prinzips bewusst sein, auf dem alle Klassifikationen aufbauen. Dichotomien vereinfachen das Wesen der Phraseologie, für die unscharfe Grenzen charakteristisch sind. In Chlebda (2003: 35) heißt es dazu:

21 Vgl. unter anderem klassische Phraseologismen (frazeologizmy klasyczne) z.B. pięta Achillesa ,Achillesferse'; metasprachliche und metatextuelle Operatoren (operatory metajęzykowe i metatekstowe) z.B. jak to sie mówi, wie man sagt', ciag dalszy nastapi, die Fortsetzung folgt'; Sprichwörter; geflügelte Worte; rekursive Aphorismen (aforyzmy rekursywne) z.B. Sumienie miat czyste. Nie używane. ,Er hatte ein reines Gewissen. Ein nicht gebrauchtes Gewissen'; Gattungsformeln (formuly gatunkowe) z.B. W pierwszych stowach mojego listu ,In den ersten Worten meines Briefes'; Mitteilungen (komunikaty) z.B. Die Beamten suchen nun nach Zeugen (Chlebda 2005: 82-83). 
... Dichotomisierung des Weltbildes, auch wenn sie in der Anfangsphase der Realitätserkennung unerlässlich ist, befindet sich doch im „steten Nicht-Anpassungskonflikt“ (A. Schaff) mit seiner faktischen Natur. Die Realität ist dynamisch, unbeständig, sie beruht, einem klassischen Ausdruck nach, auf „Einheit und Kampf der Gegensätze“, wodurch ihre Bestandteile einen relativen, dialektisch widersprüchlichen Charakter $(p / q)(q / p)$ haben. (Chlebda 2003: 35, übers. von A. S.) $)^{22}$

\subsection{Zusammenfassung und Ausblick}

Phraseologie hat sich als wissenschaftliche Disziplin in Deutschland in den 70er Jahren etabliert. Seit ihrer Entstehung waren die Phraseologieforscher damit befasst, den Forschungsgegenstand zu definieren und die neu etablierte Forschungsdisziplin von anderen linguistischen Bereichen abzugrenzen. Diese Versuche werden (auch in Bezug auf die Vereinheitlichung der internationalen Terminologie) immer noch vorgenommen. Angesichts der sich schnell entwickelnden Pragma-, Text- und Korpuslingustik, der Hinwendung zu den Fragen des authentischen Sprachgebrauchs, der (Online-)Verfügbarkeit der Sprachkorpora, die Zugang zu empirischen Daten in einem bisher unbekannten Umfang verschaffen, ist allerdings die Tendenz erkennbar, auf die Ausweitung des Gegenstandsbereiches hinzuarbeiten (Burger/Dobrovol'skij/Kühn/Norrick 2007b: 9, Filatkina 2007: 132).

Phraseologie wird heutzutage vorwiegend interdisziplinär betrieben: Dies kommt in den neuesten Publikationen, in denen sie als eine Schnittstelle aufgefasst wird (z.B. Berdychowska/Schatte 2017), plakativ zum Vorschein. Somit wird eine enge, strukturalistisch ausgerichtete Konzeption immer mehr durch die Phraseologie im weiteren Sinne ersetzt, die ein sehr breites Spektrum sprachlicher Phänomene und Fragestellungen umfasst. Deutlich erkennbar ist des Weiteren die Verlagerung des Forschungsschwerpunktes vom Zentrum auf die Peripherie: Viel Aufmerksamkeit wird in der neueren Forschung der Musterhaftigkeit/Formelhaftigkeit der Sprache, den usuellen Wortverbindungen, Kollokationen, Routineformeln, formelhaften Texten gewidmet, was neue Abgrenzungen und Definierungen mit sich bringt. Dies bedeutet aber bei Weitem nicht, dass das Zentrum der Phraseologie ausreichend erforscht wurde.

Die vorliegende Arbeit fügt sich in die gegenwärtige Tendenz der interdisziplinären Forschung ein, indem sie den methodologischen Apparat der Kognitiven Linguistik einsetzt und korpuslinguistische Zugangsweisen praktiziert. Zugleich wird aber das Zentrum der Phraseologie - die Idiomatik - in den Fokus des Interesses gerückt. Dementsprechend besteht hier keine Notwendigkeit neuer

22 ,...dychotomizowanie obrazu świata, jakkolwiek nieodzowne we wstępnym poznawaniu rzeczywistości, znajduje się w stałym „konflikcie niedopasowania“(A. Schaff) z jego faktyczną naturą. Rzeczywistość jest dynamiczna, zmienna, stanowi ją, wedle klasycznego wyrażenia ,jedność i walka przeciwieństw“, przez co jej elementy mają charakter względny, dialektycznie sprzeczny: (p/q) (q/p)" (Chlebda 2003: 35). 
Abgrenzungen. Etablierte, weitgehend akzeptierte Definitionen der Grundbegriffe werden angenommen und herangeführt: Als ein übergeordneter Begriff der Phraseologie wird der ,Phraseologismus' angesehen, der durch zwei obligatorische Kriterien, die Polylexikalität und Festigkeit, definiert wird. Als ein zusätzliches, für die Phraseologie im engeren Sinne (= das Zentrum der Phraseologie) unabdingbares Phraseologizitätsmerkmal gilt die Idiomatizität. Die Termini: ,Phraseologismus ' und ,Idiom ' werden im Folgenden, insbesondere im empirisch ausgerichteten vierten Kapitel, abwechselnd verwendet: Die Klasse der Phraseologismen schließt nämlich die Klasse der Idiome mit ein. Sekundäre Aspekte wie Lexikalisierung, Reproduzierbarkeit, Sprachüblichkeit, Bildhaftigkeit, Bildlichkeit, Motiviertheit, unikale Komponenten oder Expressivität fungieren bei der Grenzziehung zwischen den Phraseologismen und den freien Wortverbindungen als Behelfskriterien.

Demnach umfassen die Phraseologismen im weiteren Sinne u.a. Kollokationen (blondes Haar), Funktionsverbgefüge (in Erwägung ziehen), Routineformeln (Guten Tag!), geflügelte Worte (Sein oder nicht sein, das ist hier die Frage!), onymische Phraseologismen (der Ferne Osten) oder phraseologische Termini (Dividende ausschütten). Weit verstandene Phraseologie schließt ebenfalls Parömien ein, wobei Sprichwörter idiomatisch oder nicht-idiomatisch sein können. Als Idiome (Phraseologismen im engeren Sinne) werden Phraseologismen bezeichnet, die außer der Polylexikalität und Festigkeit das Merkmal der Idiomatizität aufweisen, d.h., im Laufe des Phraseologisierungsprozesses einer semantischen Derivation (Neusemantisierung) unterzogen wurden.

Hervorzuheben ist an dieser Stelle der relative Charakter der Phraseologizitätskriterien. Sowohl die Festigkeit als auch die Idiomatizität stellen skalare und nicht absolute Größen dar. Viele Phraseologismen sind mehr oder weniger fest, mehr oder weniger idiomatisch, sogar bezüglich ihres Mehrwortcharakters gibt es umstrittene Randerscheinungen, was Heine (2010: 12) überzeugend am Beispiel von der Wortverbindung Dank sagen/danksagen veranschaulicht: Je nach der Schreibpräferenz kann der Ausdruck als Kollokation Dank sagen oder als Wortbildungskonstruktion danksagen angesehen werden. 



\section{Kognitive Linguistik: Entwicklung, Grundvoraussetzungen, Ansätze}

Die weit gefasste Kognitive Linguistik stellt keine einheitliche Sprachtheorie dar, deren Vertreter sich in allen wichtigen Punkten einig sind. Es ist eher ein Bündel von verschiedenen Ansätzen und mehr oder weniger detailliert ausgearbeiteten und akzeptierten Hypothesen und Thesen, die sich zum Teil miteinander verzahnen, zum Teil in Konkurrenz zueinanderstehen (Evans/Green 2006: XX, 156, Fabiszak/Konat 2013: 132, S. Grucza 2012: 90-93, Osmańska-Lipka 2012: 47, Schwarz 2008: 40-41). Generell lässt sie sich folgendermaßen definieren:

Die Kognitive Linguistik ist eine auf mentalistischen Prämissen basierende Forschungsrichtung, die sich als diejenige Disziplin innerhalb der Kognitiven Wissenschaft versteht, welche sich mit Sprache als einem bestimmten Teil der Kognition beschäftigt. (Schwarz 2008: 41)

Im Rahmen der so verstandenen kognitivistisch ausgerichteten Sprachwissenschaft werden zwei Leithypothesen, Modularismus und Holismus, vertreten. Der Konzeption des Modularismus zufolge sei der menschliche Geist ein zu unterteilender Komplex von verschiedenen Fähigkeiten, unter denen der Sprache ein besonderer Status zukommt. Die Vertreter des Holismus sind dagegen der Ansicht, dass der Geist ein unteilbares Ganzes darstellt, das von einer Reihe fundamentaler Prinzipien determiniert wird (Schwarz 2008: 26). Da die Entwicklung der Kognitiven Linguistik zuerst mit der modularistischen Auffassung einherging, heutzutage dagegen vom Holismus dominiert wird, spricht Wierzbicka (1999: 5) von der ersten und der zweiten kognitiven Revolution (cognitive revolution).

Die erste kognitive Revolution hat Noam Chomsky (1959) mit seiner Kritik an Skinners Buch Verbal Behavior in die Wege geleitet. Chomsky stellt sich mit seiner mentalistischen Sprachauffassung entschieden dem Behaviorismus entgegen. Mentalistisch ist Chomskys generative Sprachtheorie, weil sie mit der behavioristischen Forschung des menschlichen Verhaltens im Sinne Reiz-Reaktions-Schema bricht und sich der Untersuchung der menschlichen Kognition zuwendet. Es ist "the shift (...) from behavior and products of behavior to states of the mind/brain that enter into behavior" (Chomsky 1986: 1). Diese Verschiebung ist nicht nur für die Linguistik, sondern für alle Geisteswissenschaften folgenreich, aber nach Wierzbicka (1999: 6) nicht folgerichtig genug, indem sie nicht zuletzt eine asemantische Positionierung bezog.

Die im Rahmen des Modularismus entstandenen semantischen Theorien verweisen - Chomskys Leitgedanken von der streng modularen Organisationsform menschlicher Kognition und besonderer Rolle der Sprache unter anderen kognitiven Fähigkeiten folgend - auf die Notwendigkeit der Trennung des Sprachlichen von dem Nicht-Sprachlichen. Demnach ist den modularistisch geprägten 
Semantik-Theorien ein Versuch gemeinsam, das semantische Wissen von dem konzeptuellen Wissen zu trennen. Modularistische Semantiktheorien werden dementsprechend öfter als Ebenen-Semantiken bezeichnet: z.B. Zwei-EbenenSemantik von Bierwisch/Lang (1987), Drei-Ebenen-Semantik von Schwarz (1992; 2008), Mehr-Ebenen-Modell der Bedeutungsrepräsentation von Dölling (2001), vgl. hierzu eine komprimierte Darstellung und Diskussion der dargestellten Modelle in Ziem (2008: 46-103).

Die zweite Revolution wird in den 80er Jahren von amerikanischen Forschern wie u.a. Langacker, Lakoff, Fillmore eingeleitet und hängt mit der holistischen Sprachauffassung zusammen. Die Sprache wird nicht als ein autonomes Subsystem, sondern eher als Epiphänomen der Kognition betrachtet (Schwarz 2008: 53). Somit unterliegt sie auch einer Menge universeller Prinzipien und Operationen, die für die ganze Kognition ausschlaggebend sind, wie z.B. Kategorisierung, Schematisierung, Vordergrund/Hintergrund-Unterscheidung oder Automatisierung ${ }^{23}$. Die Besonderheit der Sprache liegt also nicht in ihrem modularen Status unter anderen kognitiven Fähigkeiten, sondern ist eher methodologischer Natur: Sprache verschafft uns den Zugang zur Untersuchung der Kognition, denn sie ist „eine Widerspiegelung der kognitiven Prozesse, die sich im Menschen vollziehen und sie stellt deshalb einen inhärenten Bestandteil der menschlichen Erkenntnis dar" (Tabakowska 1995: 12) ${ }^{24}$. Sprachliche Manifestationen, z.B. Flexion- und Derivationseigenschaften, Phraseologismen, Synonymiegruppen gewähren uns den Einblick in die Art und Weise, wie die Welt wahrgenommen und konzeptualisiert wird (Grzegorczykowa 1999: 41).

Auf die engste Verflochtenheit zwischen der Sprache und dem Menschen verweist ebenfalls F. Grucza, der Begründer der anthropozentrischen Linguistik: Der Mensch sei demnach von Natur aus ein sprachliches Wesen, die Ausdrücke wie „der Mensch und seine Sprache" sind inadäquat und irreführend (F. Grucza 1997b: 81). Weder können wir den Intellekt des Menschen losgelöst von seiner Sprache untersuchen, noch die Sprache isoliert von dem sprechenden Menschen erforschen:

Der Gegenstand der Linguistik, die sich mit den wirklichen Sprachen befasst, wird von konkreten Menschen bestimmt, deren konkrete sprachliche Eigenschaften (Fähigkeiten) das Interesse der Linguistik finden. Es sind sprachliche Eigenschaften, die den Menschen die Erzeugung und Sendung eigener sowie die Rezeption und das

23 Vgl. dazu Langacker (2008: 16): „Clearly apparent in lexicon are several very basic phenomena that are quite evident in many other facets of cognition. The central role accorded to them is one aspect of CG's [CG = Cognitive Grammar, A. S.] psychological plausibility. They also illustrate the general notion that language recruits, and thus manifests in its own organization, a broad array of independently existing cognitive processes. The phenomena in question are association, automatization, schematization, and categorization“.

24 Język jest „odbiciem procesów poznawczych, które zachodzą w umyśle człowieka, i wobec tego stanowi inherentny element ludzkiego poznania“"(Tabakowska 1995: 12). 
Verstehen (Interpretieren) sprachlicher Äußerungen anderer Sprecher/Hörer ermöglichen. Den zentralen und hauptsächlichen Forschungsgegenstand der Linguistik bilden daher nicht die sprachlichen Äußerungen, sondern Menschen als Sprecher/Hörer und derer sprachliche Eigenschaften. (F. Grucza 1983: 292)

Heutzutage werden immer häufiger unter der Kognitiven Linguistik ausschließlich die holistischen ${ }^{25}$, mit der modularen Sprachauffassung brechenden Modelle bezeichnet $^{26}$ (vgl. Kardela 2006, Ziem 2008: 48, Ziem 2014a). Von der generellen Untrennbarkeit der Sprachfähigkeit von allgemeinen kognitiven Fähigkeiten gehen Vorreiter der Kognitiven Linguistik aus: z.B. Langacker $(1987,2008)$ in seiner Kognitiven Grammatik, Lakoff und Johnson (Lakoff/Johnson 1980, Lakoff 1987, 1993) in der konzeptuellen Metapherntheorie, Goldberg (1995) in der Konstruktionsgrammatik, Fillmore (1975, 1988, Fillmore/Atkins 1992, Fillmore/Baker 2009) in der Frame-Semantik sowie Fauconnier und Turner (1998, 2002; vgl. auch Libura 2010) in der Theorie der mentalen Räume. Oft wird auf die sich keiner Strömung zuzuordnenden Untersuchungen zu Lingua Mentalis von Wierzbicka $(1980,1999)$ Bezug genommen.

Da auch ein schematischer Umriss der wichtigsten Standpunkte der in der Kognitiven Linguistik vertretenen Ansätze in ihrer Vielfalt und Komplexität den Rahmen der vorliegenden Arbeit sprengen würde, wird im Folgenden eine Auswahl getroffen: Weil die Erklärung von Bedeutungskonstituierungsprozessen der Idiome nur aus einer weiten, das enzyklopädische Wissen einschließenden Perspektive möglich ist, werden holistische Erklärungsansätze in den Fokus der Aufmerksamkeit gerückt. Aber auch innerhalb des Holismus weisen die Modelle und Hypothesen auf der begrifflich-terminologischen Ebene deutliche Unterschiede auf und beschreiben die Sprache und ihre Verankerung in der Kognition mit unterschiedlichen Schwerpunkten und unter Einbezug unterschiedlicher methodologischer Instrumente. In den Unterkapiteln 2.1.1-2.1.7 wird also eher eine generelle Darlegung der Grundvoraussetzungen und Entwicklungstendenzen der holistisch geprägten Kognitiven Linguistik denn als eine detaillierte Beschreibung einzelner Positionen angestrebt.

In diesem Sinne wird zuerst auf die philosophischen Grundprämissen eingegangen, die Lakoff (1987) als experiential realism (dt. Erfahrungsrealismus) bezeichnet. Die Annahmen des Erfahrungsrealismus bilden die Opposition zu dem in den Geisteswissenschaften traditionell vorausgesetzten objektivistischen Realismus und liegen (von den einzelnen Forschern mehr oder weniger explizit genannt und unterschiedlich betont) dem Holismus zugrunde. Nach kurzer Darstellung der

25 Ziem (2008: 103) verweist dabei darauf, dass der Begriff ,Holismus' nur in der deutschen Literatur zu finden ist, wo er von Schwarz $(1992,2008)$ eingeführt und populär gemacht wurde. In der angloamerikanischen Literatur spricht man von einem integralen oder einheitlichen (unitary, uniform) Modell.

26 Darauf macht auch Schwarz (2008: 8) mit Verweis auf neuere englischsprachige Einführungen in die Kognitive Linguistik aufmerksam. 
allgemein akzeptierten philosophischen Prämissen und der Rolle von Embodiment, der verkörperten Erfahrung, wird überblicksartig geschildert, wie die Bedeutung in den holistisch geprägten Ansätzen der Kognitiven Linguistik aufgefasst wird. $\mathrm{Zu}$ diesem Zweck wird zuerst auf die kognitive Auffassung der Kategorisierung, des für die Kognition und mentale Repräsentation der äußeren Welt grundlegenden Prozesses, eingegangen. Danach werden die Grundannahmen der Kognitiven Linguistik zur Wechselbeziehung von Grammatik und Lexikon, Weltwissen und Sprachwissen sowie die wichtigsten theoretischen Konstrukte (Frames, ICMs, Domänen), die die konzeptuelle Struktur (conceptual structure) und ihre Funktionsweise modellhaft darzulegen versuchen, umrissen. Im Fokus der Aufmerksamkeit steht dabei die Kognitive Grammatik von Langacker (2008) mit ihren inhärenten Begriffen: Domänen und Profilierungen. Anschließend werden die Themen angeschnitten, die für die Darstellung der phraseologischen Bildhaftigkeit und Motiviertheit von Relevanz sind:

(i) Für die Erklärung der potenziellen Bildhaftigkeit sprachlicher Einheiten sind diejenigen Ansätze ausschlaggebend, die der Frage von Repräsentationsmodi nachgehen. Nicht alle Forscher befassen sich explizit mit dieser Problematik - gleichwohl gehört zu den großen Vorteilen des holistischen Ansatzes der Kognitiven Linguistik die Tatsache, dass sie außer den Propositionen auch andere Repräsentationsformate zulässt. Besonders intensiv wird die Frage der mentalen Repräsentationen im Rahmen der sog. Grounded Cognition erforscht. Generell wird davon ausgegangen, dass mentale Repräsentationen in verschiedenen Modalitäten (z.B. visuell, taktil, olfaktorisch) aufbewahrt werden: Die analogen und propositionalen Repräsentationen sind dabei am besten erforscht (Anderson 1988, Schwarz 2008).

(ii) Für die Darstellung der Bedeutungskonstituierungsprozesse in der Idiomatik sind die Theorien unumgänglich, die die Beziehungen zwischen der literalen und der phraseologisierten Lesart eines Phraseologismus erklären können. Von unüberschätzbarer Bedeutung für die Entwicklung der Kognitiven Linguistik und die moderne Auffassung von Metonymien und Metaphern ist die konzeptuelle Metapherntheorie (Conceptual Metaphor Theory, im Weiteren: CTM-Theorie) von Lakoff und Johnson (1980). Auf der revidierten und erweiterten Version dieser Theorie baut der sog. Zwei-Domänen-Ansatz auf, der im Kap. 2.3 dargestellt wird. Auch diese Darlegung erhebt keinen Anspruch auf die Vollständigkeit: Es handelt sich eher um eine Zusammenstellung ausgewählter Ansätze, die im Rahmen der Metapher- und Metonymie-Theorie vertreten werden.

\subsection{Grundprämissen des holistischen Ansatzes}

Allen kognitiven Ansätzen ist im holistischen Paradigma ein komplexes Bild des Menschen und seiner geistigen Fähigkeiten gemeinsam: Zwischen Körper und Kognition (vgl. Embodiment, Kap. 2.1.2), Perzeption und Kognition (vgl. Grounded 
Cognition, Kap. 2.2.2.3), Emotion, Kognition und Sprache (vgl. Schwarz 2007, Schwarz-Friesel 2008, Mazurkiewicz-Sokołowska 2014, 2015, 2016, 2017b), Sprache und anderen kognitiven Fähigkeiten bestehen keine strikten Abgrenzungen. Dem Holismus liegt die generelle Überzeugung von

... the unity of human cognition, that is, that all the higher cognitive processes, such as memory, language, problem solving, imagery, deduction and induction, are different manifestations of the same underlying system. (Anderson 1996: 1)

zugrunde. Demnach bilden die einzelnen Subsysteme der menschlichen Kognition (Wahrnehmung, Gedächtnis, Sprache, logisches Denken und Schlussfolgern, Problemlösen usw.) und Emotion ein Rückkopplungsgefüge, das bestimmten allgemeinen Regeln unterliegt, die über die in einzelnen Subsystemen herrschenden Gesetzmäßigkeiten hinausgehen und sich nur aus einer weiten, ganzheitlichen Perspektive erfassen lassen. Holisten gehen von einem Kontinuum zwischen der Sprache und dem weit verstandenen Weltwissen aus und setzen deren Verzahnung, das Durchdringen voraus.

Im Kognitivismus behauptet man, dass die Sprache ein in der menschlichen körperlichen, psychischen und kulturellen Erfahrung verankertes Werkzeug der Erkenntnis ist, und dass sie zugleich eine Widerspiegelung des Erkenntnisprozesses ist, das Bild unserer Welt ausmacht. Wenn es so ist, muss die Sprache als Gegenstand der linguistischen Untersuchung in einem weiten psychologischen, soziologischen und kulturellen Kontext angesiedelt werden. Die Kontinuität zwischen Weltwissen und Sprache sowie deren gegenseitiges Durchdringen werden unterstrichen, der Wert des Weltwissens in den kommunikativen Prozessen hervorgehoben. (Pajdzińska 2001: 13-14, übers. von A. S. $)^{27}$

Von dem operationalen, prozessualen, ganzheitlichen Charakter der Sprache geht ebenfalls F. Grucza aus, der die Sprache als eine Art des praktischen Wissens definiert:

Die menschliche Sprache ist das praktische Wissen eines Individuums, das ihm ermöglicht, (a) Formen (Strukturen) von Ausdrücken/Äußerungen bestimmter Art zu bilden und diese einzusetzen, um (b) mit deren Hilfe bestimmte Ziele zu erreichen, d.h., der Mensch bedient sich dieser Formen/Strukturen gezielt, um etwas zu bewirken, (c) den Formen bestimmte Werte, vor allem Zeichenfunktionen, zuzuschreiben, (d) die von anderen Menschen erzeugten analogen Ausdrücke/Äußerungen zu

27 „Kognitywizm natomiast uznaje, że język jest narzędziem poznania, zakotwiczonym w ludzkim doświadczeniu cielesnym, psychicznym i kulturowym, a jednocześnie stanowi odbicie procesu poznania, jest obrazem naszego świata. Skoro tak - jako przedmiot badań lingwisty musi zostać osadzony w szerokim kontekście psychologicznym, socjologicznym i kulturowym. Podkreśla się ciągłość między językiem a wiedzą o świecie i ich wzajemne przenikanie się, uwypukla wagę wiedzy o procesach komunikacji językowej." (Pajdzińska 2001: 13-14) 
erkennen, d.h. sie zu identifizieren und differenzieren, (e) die den Ausdrücken/Äußerungen gegebenen Werte, vor allem ihre Bedeutungen zu entziffern und zu verstehen. Das praktische Wissen, das die einzelnen Sprachen ausmacht, ist einfach ein gewisser Typ oder Umfang des Operationswissens, das bestimmte Menschen innehaben, d.h. eines solchen Wissens, das ihnen ermöglicht, bestimmte Bewegungen, Handlungen, Akte u.Ä. sowohl mit dem Körper (den Muskeln) als auch mit dem Gehirn (Verstand) auszuführen. (F. Grucza 1993b: 31-32, übers. von A. S.) $)^{28}$

Vor diesem Hintergrund wird argumentiert, dass die Sprache nicht als eine abstrakte, vom Sprecher losgelöste Entität betrachtet und analysiert werden kann. Die Sprache verschafft uns Einblicke in die konzeptuelle Struktur eines Menschen, darf aber nicht von ihr abgesondert werden. Nur aus ganzheitlicher, holistischer Betrachtungsweise kann man das Wesen der Sprache und der Bedeutung erfassen.

Diese Grundprämissen finden Widerspiegelung in den philosophischen Fundamenten des holistischen Paradigmas: dem Erfahrungsrealismus, der Embodied und Grounded Cognition sowie in der Aufhebung der traditionellen Dichotomien zwischen dem Welt- und dem Sprachwissen, der Grammatik und dem Lexikon, auf die im Folgenden näher eingegangen wird.

\subsubsection{Erfahrungsrealismus als philosophische Grundlage holistischer Ansätze}

Die traditionellen Theorien der Sprachwissenschaft fußen auf einer epistemologischen Annahme, die Lakoff (1987: 158) als objektivistischen Realismus bezeichnet. Dem Realismus liegen folgende zentrale Voraussetzungen zugrunde:

(i) Die reelle Welt existiert.

(ii) Es existiert eine Verbindung zwischen dem menschlichen konzeptuellen System und anderen Aspekten der Wirklichkeit.

(iii) Es besteht stabiles Wissen über die außersprachliche Welt.

28 „Język ludzki to praktyczna wiedza poszczególnej osoby, na podstawie której (a) tworzy ona formy (struktury) wyrażeń/wypowiedzi określonego typu i substancjalizuje (uzewnętrznia) je, (b) realizuje (spełnia) określone cele za pomocą wyrażeń/ wypowiedzi tego typu, tzn. posługuje się nimi jako pewnymi środkami, (c) przypisuje im określone wartości, przede wszystkim funkcje znakowe, (d) poznaje analogiczne wyrażenia/wypowiedzi wytworzone przez inne osoby, tzn. identyfikuje je i dyferencjuje, (e) odczytuje i rozumie nadane im wartości, przede wszystkim ich znaczenia. Praktyczna wiedza, składająca się na poszczególne języki, to po prostu pewien rodzaj, czy zakres posiadanej przez konkretne osoby wiedzy operacyjnej, tj. wiedzy umożliwiającej jej „wykonanie“ określonych ruchów, działań, aktów itp. zarówno mózgowych (umysłowych), jak i cielesnych (mięśniowych)“ (F. Grucza 1993b: 31-32). 
Diese Annahmen werden auch von den Vertretern des holistischen Paradigmas in der Kognitiven Linguistik akzeptiert (Lakoff 1987: 266, Kardela 1992: 15-16). Der philosophische Realismus wird demnach zugelassen, auch wenn zugleich hervorgehoben wird, dass das Signifikat der sprachlichen Zeichen einen mentalen Charakter hat, indem es kein direktes, sondern sinnlich und geistig projiziertes Bild der Welt darstellt ${ }^{29}$ (Grzegorczykowa 2011: 31). Umstritten und von den Vertretern der holistisch geprägten Kognitiven Linguistik abgelehnt sind somit die Grundvoraussetzungen des Objektivismus (vgl. Lakoff 1987: 266, Langacker 2008: 28), dessen wichtigsten Hypothesen wie folgt formuliert werden können:

(i) Die Konzepte und das Denkvermögen (reason) sind transzendent, d.h. von der Natur und dem Körper unabhängig.

(ii) Konzepte liefern die internen Repräsentationen der externen Realität. Die Vernunft ist „der Spiegel der Natur" ${ }^{\text {"30 }}$ : Die korrekte Schlussfolgerung spiegelt die Logik der externen Welt wider, während das Denken auf mechanistischer Manipulation mit abstrakten, an sich selbst bedeutungslosen Symbolen beruht. (Lakoff 1987: 162-163)

Die Omnipräsenz der objektivistischen Voraussetzungen in der abendländischen Wissenschaft hat dazu geführt, dass sie zweitausend Jahre lang eine implizit angenommene epistemologische Prämisse bildeten ${ }^{31}$. Die Grundüberzeugung, dass man die Sprache so wie ein Tier- oder Pflanzenreich taxonomisch einteilen und präzise beschreiben oder ihre Elemente nach klaren logischen Regeln so wie in der Mathematik handhaben kann, entspricht den Vorstellungen der objektiven Wissenschaft. Zu den großen Leistungen der Kognitiven Linguistik gehört in diesem Zusammenhang die Tatsache, dass sie diese gut etablierten und für selbstverständlich gehaltenen Grundannahmen hinterfragt. In philosophisch-methodologischer

29 W ujęciu kognitywnym „dopuszcza się wprawdzie realizm filozoficzny (istnienie świata), ale to, co jest komunikowane przez znaki językowe ma charakter mentalny, jest obrazem świata w umysłach ludzi mówiących" (Grzegorczykowa 2011: 31) [In der kognitiven Auffassung wird „der philospohische Realismus (die Existenz der reellen Welt) zwar zugelassen, aber Dasjenige, was durch sprachliche Zeichen kommuniziert wird, hat einen mentalen Charakter, stellt ein Bild der Welt in den Geistern der Sprechenden dar"]. Zu dieser Problematik vgl. auch Grzegorczykowa (1992).

30 Die Metapher von Richard Rorty (1979), vgl. auch Unterkap. 2.1.3.

31 Vgl. die Bemerkung von Lakoff: „Philosophy matters. It matters more than most people realize, because philosophical ideas that have developed over centuries enter our culture in the form of a world view and affect us in thousands of ways. Philosophy matters in the academic world because the conceptual frameworks upon which entire academic disciplines rest usually have roots in philosophy - roots so deep and invisible that they are usually not even noticed. This is certainly true in my own field, linguistics, where the classical theory of categories and certain attendant philosophical assumptions have been taken so much for granted that alternative assumptions seem unthinkable" (Lakoff 1987: 157). 
Hinsicht fußt das holistische Paradigma der Kognitiven Linguistik auf dem von Lakoff eingeleiteten experientalism/experiential realism (in Lakoffs und Johnsons 1999 erschienenem Werk Philosophy in the Flesh auch als embodied realism bezeichnet), was im Folgenden mit dem im Deutschen bereits etablierten Begriff ,Erfahrungsrealismus' wiedergegeben wird (vgl. Kleiber 1983, Baldauf (1997). Die Leithypothesen des Erfahrungsrealismus lassen sich in Anlehnung an Lakoff (1987) folgendermaßen zusammenfassen:

(i) Kognition und Sprache sind an unseren Körper gebunden, sie sind embodied. Die Strukturen, die unser konzeptuelles System aufbauen, sind durch Erfahrung geprägt, weswegen der Kern des konzeptuellen Systems eines Menschen direkt mit der Wahrnehmung, Körperbewegungen, körperlicher und sozialer Erfahrung zusammenhängt (Lakoff 1987, Langacker 2008: 28). Kognition und Sprache sind untrennbar an das denkende und sprechende Subjekt gebunden und können nicht unabhängig von ihm beschrieben werden.

(ii) Die mentalen Repräsentationen der äußeren Reize können nicht als interne 1:1-Repräsentationen der externen Realität aufgefasst werden, der Verstand ist „kein Spiegel der Natur“. Mentale Repräsentationen aller Modalitäten haben einen konstruktiven Charakter, es sind Gebilde des menschlichen Geistes. In jedem Repräsentationsmodus werden die sich neu bildenden mentalen Repräsentationen durch die bereits vorhandenen kognitiven Strukturen - Domänen, Schemata, Frames, Skripts - beeinflusst ${ }^{32}$.

(iii) Konzepte bestehen nicht aus „Bausteinen“, die mit allgemeinen logischen Regeln gebunden werden, der Gedanke hat eine Gestalt-Struktur. Somit ist der Gedanke mehr als mechanistische Operationen, die an abstrakten Symbolen durchgeführt werden. Der Gedanke hat eine ökologische Struktur: Die Geschwindigkeit und Effizienz der Informationsverarbeitung, das Lernen und Gedächtnis hängen von der Struktur des konzeptuellen Systems ab.

(iv) Kognition muss sich nicht ausschließlich in Propositionen manifestieren, sie kann ebenfalls eine bildhafte/bildliche Struktur aufweisen. Begriffe, die nicht auf direkter Erfahrung fußen, können z.B. mittels Metapher, Metonymie und anderer Verbildlichungsmechanismen ausgedrückt werden.

32 Darauf, dass alle kognitiven Prozesse, darunter Sprachwahrnehmung und Sprachverarbeitung von Strukturen höherer Ordnung beeinflusst werden, hat Bartlett bereits 1932 in seinen Experimenten verwiesen. Zu diesem Zweck las er den Probanden die für ihren Kulturkreis ungewöhnlichen Indianergeschichten vor, die sie nach einiger Zeit wiedergeben mussten. Die Probanden passten die ihren kulturellen Vorstellungen nicht entsprechenden Erzählungsfäden beim Abruf ihrem üblichen Weltwissen an, indem sie die unverständlichen Stellen, z.B. mit Spukgestalten, eliminierten oder nach einer - für unseren Kulturkreis - rationalen Erklärung suchten. Bartletts Forschungen zu Schemata wurden nach der kognitiven Wende fortgesetzt und erweitert (vgl. Fortmüller 1991: 171, Mandl/Spada 1998: 3). 
Betonenswert ist dabei, dass der Erfahrungsrealismus nicht als subjektivistischidealistische Theorie (im Sinne von George Berkeleys Subjektivismus, vgl. Ajdukiewicz 2004 [1949]: 55) aufgefasst wird: Obwohl Erfahrungen zum Teil individuell und subjektiv sind, haben sie doch eine Struktur, die sich aus der Interaktion des Menschen mit der Umwelt ergibt und bestimmte universelle Züge aufweist (Kardela 1992: 15-16). Diese Erfahrungsbasis spiegelt sich in der Sprache beispielshalber in Form von präkonzeptuellen Strukturen wie image schemas (Vorstellungsschemata) wider. Zugleich unterstreichen Lakoff und Johnson nachdrücklich, dass der Erfahrungsrealismus auch nicht rein empiristisch ist. Im Erfahrungsrealismus lehnt man nämlich die die Philosophie Jahrhunderte lang prägende Rationalismus-Empirismus-Dichotomie ${ }^{33}$ in ihrer strikten Form ab - zugunsten der Annahme, dass die Kognition zugleich auf angeborenen und erfahrungsbasierten Mechanismen (built-in and learned cognitive mechanisms, Johnson/Lakoff 2003: 248) fußt. Diese Prämisse ist nicht a priori, sondern ergibt sich zwingend aus der neueren entwicklungspsychologischen (Überblick in Lewkowicz 2011, vgl. auch Mandler 2005: 140), psycholinguistischen (Überblick in Mazurkiewicz-Sokołowska 2010: 83-103) und neurologischen (vgl. u.a. Regier 1996, zit. nach Johnson/Lakoff 2003: 248) Forschung:

Modern neuroscience has thrown out the innate-learned, nature-nurture, and rationalism-empiricist dichotomies. There is no way to sort out exactly what is „inborn“ from what is learned. The recent revelation that babies learn part of their mothers' intentional system in the womb brings into question the innate-learned dichotomy: it's learned, but you are born with it. The dichotomy is also challenged by the discovery that our visual systems are tuned in the womb via neural patterns activated across the retina. Neural „learning“ is taking place, with input from the perceptual organs, but with no perception of anything external - and well before birth. (Johnson/ Lakoff 2003: 247-248)

Damit lässt sich der Erfahrungsrealismus keiner der klassischen philosophischen Richtungen zuordnen, er ist weder strikt rationalistisch noch rein empiristisch. Lakoff und Johnson verzichten auf die Dichotomien nature-nurture, Geist-Körper, Empirismus-Rationalismus und argumentieren, dass sich solche Abgrenzungen vor dem Hintergrund der neueren Forschung nicht aufrechterhalten lassen:

... we reject the rationalist-empiricist dichotomy in favor of the evidence indicating a third alternative that allows both inborn and learned aspects of our conceptual systems, as well as many that cannot clearly be called either inborn or learned. (Johnson/ Lakoff 2003: 248)

... the question of the necessity and cognitive reality of embodied realism is an empirical issue, not a matter of armchair speculation but rather a question of what view

$33 \mathrm{Zu}$ den Dichotomien Realismus-Idealismus, Rationalismus-Empirismus in der Philosophie vgl. Ajdukiewicz 2004 [1949]: 34-67. 
of human cognition is supported by the evidence and is necessary to explain human meaning and all forms of symbolic expressions. (Johnson/Lakoff 2003: 246)

\subsubsection{Embodied Cognition}

Das Fundament des objektivistischen Realismus bildet die Grundvoraussetzung, dass Konzepte und das Denkvermögen (reason) transzendent, d.h. von der Natur und dem Körper unabhängig sind. Dies bedeutet, dass die menschliche Kognition und Sprache losgelöst von körperlicher Bedingtheit untersucht werden können. Diese Annahmen werden bildlich durch die Computer-Metapher ${ }^{34}$ veranschaulicht: So wie die Software von der Hardware eines Computers unabhängig ist und an einen anderen Computer übertragen werden kann, so sind die Kognition und Sprache abstrakt und können von dem erkennenden Subjekt losgelöst untersucht werden. Das symbolische System, das der menschlichen Kognition unterliegt, ist somit disembodied. Dies impliziert zum einen, dass seine Eigenschaften erfolgreich auf andere Systeme, z.B. auf einen anderen Computer, übertragen werden können. Zum anderen wird vorausgesetzt, dass das symbolische System bei allen Menschen gleich ist: So wie man eine Software unabhängig von dem Computer beschreiben kann, so kann man auch das menschliche symbolische System unabhängig von seiner biologisch-neuronalen Grundlage, von der Beschaffenheit des Körpers und von sensomotorischer Erfahrung charakterisieren.

An dieser Prämisse rütteln die Vertreter der Embodied/Grounded Cognition, die auf die leibliche Verankerung aller kognitiven Prozesse ${ }^{35}$ sowie die tief gehende Verwurzelung der Sprache in den allgemeinen perzeptiven und sensomotorischen Aktivitäten verweisen. Die Embodiment-Hypothese wurde explizit von Lakoff, Johnson und ihren Mitarbeitern (Lakoff/Johnson 1980, 1999, Lakoff 1987, Johnson 1987, Johnson/Rohrer 2007) formuliert, sie liegt dennoch auch der Sprachauffassung anderer kognitiver Forscher (z.B. Langacker 1987, 2008) zugrunde.

Auf die Verankerung der Sprache in der körperlichen Erfahrung machten Lakoff und Johnson bereits 1980 aufmerksam. Sie argumentieren in der Theorie der Kognitiven Metapher, dass zahlreiche abstrakte Konzepte auf die einfacheren, körperlich verankerten Konzepte zurückzuführen sind und durch die metaphorische Projektion aus der körperlichen in die abstrakte Domäne entstehen. 1987 führt Johnson den Begriff der image schemas (dt. Vorstellungsschemata) ein:

Image schemas constitute a preverbal and pre-reflective emergent level of meaning. They are patterns found in the topologic neural maps we share with other animals,

34 Die Computer-Metapher liegt dem sog. Funktionalismus zugrunde (vgl. Barsalou 1999: 598, Schwarz 2008: 20-26).

35 „Mind is embodied, meaning is embodied and thought is embodied in the most profound sense. This is the substance of an embodied realism" (Johnson/Lakoff 2003: 249). 
though we as humans have particular image schemas that are more or less peculiar to our types of bodies. (Johnson/Rohrer 2007: 30)

Der Herausbildung sprachlicher Einheiten gehen ontogenetisch zahlreiche IchWelt-Kontakte voraus, infolge deren schematische räumlich-analoge Vorstellungsschemata entstehen. Die Erfahrung des CONTAINTERs/CONTAINMENTs ist im Alltag seit der frühesten Lebensphase omnipräsent: Es liegt empirische Evidenz dafür vor, dass Säuglinge bereits im Alter von 2,5 Monaten über dieses image schema verfügen $^{36}$ (Mandler 2005: 145-146). Eine Art Behälter bilden Mutterleib, Kinderwagen, Kinderbett, Milchflaschen, Umarmungen. Wir nehmen unseren Körper als ein Objekt in einem Behälter wahr, wenn wir einen engen Raum verlassen und in die Weite blicken. Zugleich erfahren wir den Körper als einen Behälter, wenn wir satt werden oder Schluckauf haben. Die sensomotorisch-räumlichen image schemas und die darauf fußenden ontologischen Metaphern liegen dann zahlreichen abstrakten sprachlichen Ausdrücken zugrunde: Als Gefäße werden z.B. Ereignisse, Handlungen, Tätigkeiten und Zustände konzeptualisiert, was sich beispielshalber im metaphorischen Gebrauch der Präpositionen manifestiert:

Bist du am Sonntag im Rennen?

Gehst du zum Rennen?

Langsam komme ich in Form.

Wir sind jetzt aus allen Schwierigkeiten heraus.

Er fiel in eine tiefe Depression. (vgl. Lakoff/Johnson 2000 [1980]: 41-43)

Ein anderes präkonzeptuelles image schema UP-DOwN motiviert konzeptuelle Orientierungsmetapher GOOD IS UP, BAD IS DOWN (GUTES IST OBEN, SCHLECHTES IST UNTEN), die wiederum eine Grundlage für weitere konzeptuelle Metaphern von niedrigerem Abstraktionsgrad bildet, z.B.:

GLÜCKLICH SEIN IST OBEN; TRAURIG SEIN IST UNTEN

Ich fühle mich obenauf. Das beflügelte meinen Geist. Meine Stimmung stieg. (...) Er ist zur Zeit wirklich unten. Ich verfiel in eine tiefe Depression. Meine Stimmung sank.

36 Entwicklungspsychologische Experimente verweisen darauf, dass schon 2,5 Monate alte Babys wissen, dass die Behälter eine Öffnung haben müssen, um etwas darin aufbewahren zu können sowie dass die in Behältern versteckten Objekte sich zusammen mit einem Behälter bewegen. Im sechsten Lebensmonat ist den Babys klar, dass größere Objekte nicht in die kleineren Objekte hineinpassen, eineinhalb Monate später verstehen sie, dass höhere Objekte in niedrigeren Behältern nicht versteckt werden können (Mandler 2005: 145-146). Diese auf den ersten Blick offensichtlichen Errungenschaften erfordern - aus entwicklungspsychologischer Perspektive - einen großen kognitiven Aufwand. Mandler stellt deswegen Hypothese der perzeptuellen Bedeutungsanalyse (perceptual meaning analysis) auf: „(...) infants come equipped with a concept-creating mechanism that analyzes perceptual information and redescribes it into a simpler form“" (2005: 140) und leistet somit einen Beitrag zu der von Lakoff und Johnson postulierten Auflösung der Empirismus-Rationalismus-Dichotomie (vgl. Kap. 2.1.1). 
Physische Grundlage: Eine gebeugte Körperhaltung geht typischerweise einher mit Traurigkeit und Depression, eine aufrechte Körperhaltung mit einem heiteren Gemütszustand.

WACH SEIN IST OBEN; SCHLAFEN IST UNTEN

Steh auf. Ich bin schon auf. Er versank in tiefen Schlaf. Er glitt in den Schlaf. Sie steht unter Hypnose. Er fiel ins Koma.

Physische Grundlage: Der Mensch und die meisten Säugetiere schlafen im Liegen und stehen auf, wenn sie wach sind.

KONTROLLE ODER MACHT AUSÜBEN IST OBEN; DER KONTROLLE ODER DER MACHT AUSGESETZT SEIN IST UNTEN

Ich habe die Kontrolle über sie. Ich stehe über der Situation. Er ist in einer Position der Überlegenheit. Er ist auf der Höhe seiner Macht. (...) Seine Macht ist im Fallen inbegriffen. Er ist mir unterlegen. Er ist am untersten Ende der Gesellschaft.

Physische Grundlage: Die Körpergröße eines Menschen entspricht typischerweise seiner körperlichen Stärke und der Sieger in einem Kampf ist typischerweise oben. (Lakoff/Johnson 2000 [1980]: 23-24)

Würden sich die Menschen nicht in der aufrechten Position bewegen, sondern wie beispielshalber Schlangen kriechen, entstünden wahrscheinlich keine derartigen Konzeptualisierungen. Die Sprache ist somit embodied, d.h. sie ergibt sich weitgehend aus den präkonzeptuellen körperlichen Erfahrungen und ist eng an sie gebunden (Lakoff 1987: 267). Der Begriff der Erfahrung wird dabei sehr weit aufgefasst:

"Experience" is not taken in the narrow sense of the things that have "happened to happen" to a single individual. Experience is instead construed in the broad sense: the totality of human experience and everything that plays a role in it - the nature of our bodies, our genetically inherited capacities, our modes, our physical functioning in the world, our social organization etc. In short, it takes an essential much of what is seen as irrelevant in the objectivist account. (Lakoff 1987: 266)

Die Vertreter der Embodied Cognition lehnen also die klassische Annahme ab, dass die Kognition auf der Verwendung von universellen logischen Regeln beruht, die interne mentale, die äußere Welt in abstrakter Form repräsentierende Einheiten regieren. Die Sprache bildet keine objektiv (in der Natur) existierende Entität, die unabhängig von dem Menschen und seiner Natur beschrieben werden kann. Damit verzichtet die Embodied Cognition auf den auf René Descartes zurückzuführenden Körper-Geist-Dualismus (Kardela 2006: 210; Johnson/Rohrer 2007: 17) sowie den darauf fußenden modernen Funktionalismus. Stattdessen knüpft sie an die Ansichten amerikanischer Pragmatiker - James (1990) und Dewey (1925) - an, die davon ausgehen, dass

... everything we attribute to „mind“ - perceiving, conceptualizing, imagining, reasoning, desiring, willing, dreaming - has emerged (and continues to develop) as part of 
a process in which an organism seeks to survive, grow, and flourish within different kinds of situations. (Johnson/Rohrer 2007: 22)

Dewey und James gehen in ihrer Theorie von einer in den Naturwissenschaften für offensichtlich gehaltenen These aus: Die Kognition entwickelt sich aus den verkörperten Prozessen (embodied processes) eines Organismus, der sich ständig an die sich ändernde Umwelt adaptieren muss (ebd.). Kognitive Prozesse sind in den perzeptuellen und senso-motorischen Interaktionen mit der äußeren Welt verankert: „Biological brains are first and foremost the control systems for biological bodies. Biological bodies move and act in rich real-world surroundings" (Clark 1998: 506). Embodiment bezieht sich dabei nicht nur auf niedrigere kognitive Prozesse. Es besteht keine Erfahrungskluft zwischen Wahrnehmen, Fühlen und Denken. Nach dem Prinzip der Kontinuität

... any explanation of the nature and working of mind, even the most abstract conceptualization and reasoning, must have its roots in our organismic capacities for perception, feeling, object manipulation, and bodily movement. Furthermore, social and cultural forces are required to develop these capacities to their full potential, including language and symbolic reasoning. (Johnson/Rohrer 2007: 23)

Die Menschen denken, um zu handeln und handeln als Teil des Denkens. Unsere körperlichen Erfahrungen sind in unserem Verstand (mind) als präkonzeptuelle Strukturen verankert und als solche bilden sie die Grundlage für Prozesse höheren Abstraktionsgrades: Konzeptualisierungen, Denken (ebd., 26) und Sprache.

Von der fundamentalen Rolle des Embodiments in der menschlichen Kognition geht ebenfalls der zurzeit intensiv diskutierte Ansatz der Grounded Cognition ${ }^{37}$ aus. Der Schwerpunkt der Grounded Cognition liegt auf dem Format der mentalen Repräsentationen:

Grounded Cognition reflects the assumption that cognition is typically grounded in multiple ways, including simulations, situated action and, on occasion, bodily states. (Barsalou 2008: 619)

Zentral ist der Begriff der Simulation. Die Simulation beruht auf der Wiederaktivierung der perzeptuellen, motorischen und introspektiven Zustände, die in der Interaktion mit der Welt, dem Körper und dem Verstand erworben worden sind (ebd.). Wenn wir also etwas erfahren (z.B. uns in einem Sessel ausruhen), erfasst das Gehirn die Zustände aller Modalitäten und integriert sie zu einer multimodalen,

37 Die Embodied- und Grounded-Cognition-Ansätze werden nicht immer auseinandergehalten (vgl. Rickheit/Weiss/Eikmeyer 2010: 66). In Barsalous Auffassung (2008: 618-619) wird die Embodied Cognition als Teil des Grounded Cognition-Ansatzes angesehen. Embodied Cognition konzentriert sich vor allem auf den Einfluss von körperlichen Zuständen (bodily states) auf kognitive Zustände (cognitive states), Grounded Cognition umfasst auch andere Zustände, z.B. Introspektion und Propriozeption. 
in dem Gedächtnis gespeicherten Repräsentation (z.B. wie ein Sessel aussieht und wie er sich taktil anfühlt, die Körperposition des Sitzenden, das introspektive Gefühl der Bequemlichkeit und Entspannung). Selbstverständlich sind unsere Wahrnehmungen auf dieser Etappe bis zu einem gewissen Grade individuell und unterliegen der selektiven Aufmerksamkeit. Neuronale Repräsentationen aus verschiedenen sensomotorischen Gehirnarealen werden dann in einem Simulator zu einem Konzept verwandelt, der bei Bedarf aktiviert werden kann. Falls man also das Wissen über die Kategorie „Sessel“ abruft, werden die multimodalen Repräsentationen, die wir in zahlreichen Erfahrungen mit verschiedenen Sesseln gesammelt haben, reaktiviert, um die damit verbundenen Wahrnehmungen, Handlungen und introspektive Beobachtungen zu simulieren:

According to this account, a diverse collection of simulation mechanism, sharing a common representational system, supports a common representational system, supports the spectrum of cognitive activities. The presence of simulation mechanism across diverse cognitive processes suggests that simulation provides a core form of computation in the brain. Mental imagery constitutes the best known case of these simulation mechanisms. (Barsalou 2008: 619)

Die Grounded Cognition-Hypothese wird zurzeit intensiv erforscht. Zur Etablierung der Embodied/Grounded Cognition tragen u.a. neurolinguistische Erkenntnisse bei, die mit der Entdeckung der Spiegelneuronen einhergehen (Rickheit/ Weiss/Eikmeyer 2010: 108). Die im prämotorischen Cortex bei Makaken entdeckten und demnächst bei Menschen nachgewiesenen Spiegelneuronen werden auch dann aktiviert, wenn Menschen einander bei einer Handlung oder bei emotiven Reaktionen beobachten, ohne die Handlung selbst auszuführen bzw. selber zu empfinden. Spiegelneuronen werden sogar durch die Wahrnehmung typischer, eine Handlung begleitender Geräusche oder durch die verbale Beschreibung einer Handlung aktiviert (Barsalou 2008: 623, Rickheit/Weiss/Eikmeyer 2010: 108). Diese Erkenntnisse lassen auf die enge Verbindung auf der neuronalen Ebene zwischen höheren kognitiven Funktionen wie die Sprache und niedrigeren kognitiven Funktionen wie die Perzeption schlussfolgern. Auch wenn der mögliche Einfluss der Spiegelneuronen auf die Evolution der Sprache sowie auf das Verstehen sprachlicher Ausdrücke diskutiert wird, liefern zahlreiche Experimente empirische Evidenz dafür, dass die sog. mentalen Simulationen eine wichtige Rolle bei der Sprachverarbeitung spielen.

Zusammenfassend: Die Embodiment-Hypothese geht davon aus, dass die Erkenntnis von dem erkennenden Subjekt nicht unabhängig ist. Zahlreiche konzeptuelle Strukturen ergeben sich aus sensomotorischen Erfahrungen des Menschen, die wiederum den Wahrnehmungsgrenzen ${ }^{38}$ des menschlichen Organismus unterworfen sind. Mit dieser Annahme steht der Erfahrungsrealismus im

38 Dementsprechend nehmen wir nur einen Ausschnitt des Spektrums der Farben oder Schallwellen von bestimmten Frequenzen wahr. 
Widerspruch zu dem die Transzendenz der Konzepte und des Denkvermögens voraussetzenden Objektivismus. Da die analogen Repräsentationsformate für die Erklärung der idiomatischen Bildhaftigkeit von Relevanz sind, wird in einem separaten, den mentalen Bildern gewidmeten Kap. 2.2.2.3 detailliert auf die Theorie und die empirischen Erkenntnisse der Grounded Cognition eingegangen.

Abschließend sei erwähnt, dass der Einfluss der körperlichen Erfahrung auf Konzeptualisierungen ebenfalls von den polnischen Forschern des Sprachlichen Weltbildes (sog. Językowy obraz świata, JOS ${ }^{39}$, sog. Lubliner Schule, vgl. u.a. Bartmiński 2006, Bartmiński/Żuk 2009, Głaz 2010, Grzegorczykowa 2009, Pajdzińska/ Tokarski 1996; Pajdzińska 2001, Tokarski 1991, Żuk 2010, historischer Umriss in Grzegorczykowa 1999: 39) hervorgehoben wird. Der Anthropozentrismus macht den am besten ausgeprägten Teil des Sprachlichen Weltbildes aus: Der Mensch erfasst die Realität nach seinem Ebenbild, stellt sich selbst in ihr Zentrum, setzt das Äußere in Beziehung zu sich selbst und zu seinem Körper. Dies ist sehr deutlich in der Phraseologie erkennbar ${ }^{40}$ :

Der phraseologische Sprachbestand spiegelt wohl am besten eine typische Einstellung der Menschen der Welt gegenüber wider. Für einen durchschnittlichen Menschen ist der Mensch das Zentrum und das Maß aller Dinge (anthropos metron panton). Unter den festen Wortverbindungen ist es schwer, sogar einzelne Beispiele für das Streben nach einer Unparteilichkeit und einem Objektivismus zu finden. Bereits der Komponentenbestand der Phraseologismen zeugt davon, dass der wichtigste Bestandteil der Wirklichkeit - so wie sie im Alltag wahrgenommen und sprachlich ausgedrückt wird - der Mensch selbst ist. Eine große Anzahl der Phraseologismen beinhaltet in ihrem Konstituentenbestand die Bezeichnungen der Körperteile und deren Eigenschaften - sowohl diejenigen, die wirklich vorkommen als auch diejenigen, die ihnen von der Sprachgemeinschaft zugeschrieben werden - sie motivieren die Bedeutung vieler Phraseologismen. Der Anthropozentrismus kommt in der Phraseologie auch in der überwältigenden Überzahl der Wortverbindungen, die sich unmittelbar auf die Menschen beziehen, zum Vorschein. Von dem Anthropozentrismus zeugt des Weiteren die Mehrheit der Metaphern und der Vergleiche, die in den Phraseologismen lexikalisiert sind. (Pajdzińska 1990: 61, übers. von A. S.) $)^{41}$

39 JOS (Sprachliches Weltbild) entspricht ungefähr dem, was die amerikanischen Kognitivisten als in der Sprache enthaltene Konzeptualisierung und die russischen Sprachwissenschaftler als naives Weltbild bezeichnen (Grzegorczykowa 1999: 39).

40 Vgl. dazu auch die Studien von Szczęk zu thematischen Quellen der Motiviertheit (2010a, 2013), aus denen sich ergibt, dass die in 818 Idiomen vertretenen Körperteile die dem Menschen vertrauteste Bezugssphäre bilden.

41 „Zasób frazeologiczny najlepiej chyba odbija typowa postawę ludzi wobec świata dla przeciętnego człowieka centrum i miarą wszechrzeczy jest właśnie człowiek. Wśród złożonych jednostek leksykalnych trudno nawet znaleźć przykłady ilustrujące dążenie do bezstronności i obiektywizmu. Już skład komponentowy frazeologizmów świadczy o tym, że najważniejszym elementem rzeczywistości - takiej, jaką człowiek widzi i opisuje codziennym językiem - jest sam człowiek. Ogromna liczba związków 


\subsubsection{Kategorisierung und Konzepte}

Von grundlegender Bedeutung für die Semantik ist der Prozess der Kategorisierung, d.h. der Herausbildung von mentalen Kategorien:

Human category structure has been a major object of study in cognitive science, and remains of major interest to linguistics - after all, words name conceptual categories.

(Dancygier/Sweetster 2014: 11)

Die Auffassung der Kategorisierung ist in den beiden Ansätzen - in dem Erfahrungsrealismus und objektivistischen Realismus - von Grund auf unterschiedlich. Das objektivistische Paradigma setzt ein Abbildverhältnis zwischen der realen Welt und der mentalen Repräsentation dieser realen Welt voraus, was in der Metapher von Richard Rorty (1979) „der Verstand sei der Spiegel der Natur“ zum Ausdruck kommt. Demnach wird die Erkenntnis im Rahmen der objektivistisch ausgerichteten Theorien folgendermaßen verstanden:

Objectivist cognition: Thought is the manipulation of abstract symbols. Symbols get their meaning via correspondences to entities and categories in the world. In this way, the mind can represent external reality and be said to "mirror nature“.

Objectivist concepts: Concepts are symbols that (a) stand in a relation to other concepts in a conceptual system and (b) stand in correspondence to entities and categories in the real world (or possible worlds). (Lakoff 1987: 163)

Diese Prämissen haben in der Sprachwissenschaft eine lange Tradition. Der klassischen Auffassung der Sprache lag jahrelang die objektivistische Annahme zugrunde, dass die Sprache aus einer Reihe von Einheiten (sprachlichen Zeichen) bestünde, die sich durch bestimmte Regeln (grammatikalische Regeln) zu jeweils komplexeren Gebilden kombinieren lassen. Die Aufgabe der Sprachwissenschaft liege in der Auffindung und Beschreibung dieser Regeln mithilfe eines objektiven Instrumentariums. Weitreichende Folgen für die Semantik hatte dabei die Kategorisierung, weil Konzepte als mentale Repräsentationen der Kategorien und Gegenstände der realen Welt aufgefasst werden. Der Begriff der Kategorie mit klar umrissenen Grenzen ist für die objektivistisch geprägte Wissenschaft von zentraler Bedeutung: So wie in der Mathematik eine Entität entweder einer Menge zugehört oder nicht, so gilt dies auch für Konzepte. Die Kategorien werden im objektivistischen Paradigma wie folgt definiert:

frazeologicznych zawiera w swoim składzie nazwy ciała ludzkiego, których cechy zarówno rzeczywiste, jak i tradycyjnie im przypisywane przez pewną wspólnotę językową, motywują znaczenie bardzo wielu frazeologizmów. Antropocentryzm frazeologii przejawia się także w przygniatającej przewadze liczbowej związków, które odnoszą się bezpośrednio do ludzi. O antropocentryzmie świadczy również większość metafor i porównań, utrwalonych we frazeologizmach“ (Pajdzińska 1990: 61). 
A conceptual category is a symbolic representation in the real world (or some possible world). Members of a conceptual category are those symbolic entities that correspond to entities in the corresponding real-world category (or possible world category). (...) A conceptual category is defined in terms of necessary and sufficient conditions shared by all members. Such conditions include properties of entities and relation holding among entities. (Lakoff 1987: 166)

Diese Definition der Kategorien kommt in dem sog. klassischen aristotelischen Modell der notwendigen und hinreichenden Bedingungen (NHB-Modell, vgl. Löbner 2003: 259) zum Vorschein, der zwei Millennien lang den Ausgangspunkt semantischer Untersuchungen ausmachte. Die Bedeutung fasste man als Merkmalsbündel notwendiger und hinreichender Merkmale auf, wobei vorausgesetzt wurde, dass sich die Konzepte restlos in Merkmale zerlegen, präzise beschreiben und als Oppositionspaare auseinanderhalten lassen. Die Grundannahmen dieses Modells fasst Löbner in folgenden Punkten zusammen:

Kategorisierung beruht auf einer festen Menge von Bedingungen.

Jede dieser Bedingungen ist unabdingbar notwendig.

Die Bedingungen sind binäre (Entweder-Oder-) Bedingungen.

Zugehörigkeit zu einer Kategorie ist eine binäre Angelegenheit.

Kategorien haben klare Grenzen.

Alle Mitglieder einer Kategorie haben denselben Status. (Löbner 2010: 850)

Dementsprechend kann ein Konzept von Hund durch folgende Merkmale (vgl. Tab. 2) von fünf weiteren Tierarten abgehoben werden ${ }^{42}$ :

Tab. 2: Die Beschreibung des Konzeptes HUND als Merkmalsbündels (Sulikowska 2014c: 58).

\begin{tabular}{llllll}
\hline & lebendig & Raubtier & $\begin{array}{l}\text { in Europa } \\
\text { heimisch }\end{array}$ & domestiziert hundeartig \\
\hline Hund & + & + & + & + & + \\
Wolf & + & + & + & - & + \\
Katze & + & + & + & + & - \\
Löwe & + & + & - & - & - \\
Pferd & + & - & + & + & - \\
\hline
\end{tabular}

Die Beschreibung ist propositional, alle genannten Prädikationen weisen den gleichen Status $^{43}$ auf. Durch präzise Zuteilung der Merkmale lässt sich die Kategorie

42 Die folgende Beschreibung ist z.T. in Anlehnung an Sulikowska 2014b, 2014c entstanden.

431963 führten Katz/Fodor zu der Semanalyse eine Differenzierung zwischen immanenten, elementaren, universellen Markern und optionalen Distinguishern ein. 
HUND eindeutig von anderen Kategorien abgrenzen: Alle Lebewesen, die die Bedingungen [lebendig], [Raubtier], [in Europa heimisch], [domestiziert], [hundeartig] erfüllen, werden als HUNDE kategorisiert. Für die nicht-propositionalen psychologischen Konstrukte wie mentale Bilder, Grenzphänomene sowie individuelle Kategorisierungsunterschiede bietet das Merkmalsmodell keine Erklärung.

Deswegen ist in den letzten Jahrzehnten auf die Unzulänglichkeiten des klassischen Merkmalsmodells verwiesen worden. Im Gegensatz zur Phonologie, in der artikulatorische Eigenschaften der Phoneme eindeutig in Form einer Liste von binären Oppositionspaaren festgelegt werden konnten, ist es der Semantik trotz jahrelanger Forschung nicht gelungen, eine Liste der notwendigen und hinreichenden Merkmale zusammenzustellen. Die natürlichen sprachlichen Zeichen weisen eine zu komplexe Natur auf, als dass sie sich derart rigiden Beschreibungsmodellen unterziehen ließen:

Der Ansatz ist eine viel zu simple Theorie, um der Komplexität der semantischen Phänomene im Lexikon gerecht zu werden. Die Verwendung binärer Merkmale mag adäquat sein, wenn es mit kleinen und begrenzten Phänomenbereichen wie in der Phonologie zu tun hat, wo nur vergleichsweise wenige Einheiten zu unterschieden und ihre Systemeigenschaften zu erklären sind. Aber das Lexikon einer Sprache ist von einer Größenordnung, die mit der des Lautsystems nichts mehr gemein hat. Das Lexikon bildet einen beträchtlichen Teil unseres überaus komplexen kognitiven Systems. Es ist nicht adäquat anzunehmen, dass sich die Zusammensetzung von Wortbedeutungen in so simplen Strukturen erschöpft, wie sie die BMS [BMS = Binäre Merkmalstheorie, A. S.] erzeugt. (Löbner 2003: 214-215)

Argumente dafür, dass die objektivistischen Grundannahmen für die alltäglichen Konzepte nicht oder nur eingeschränkt gelten, wurden von Philosophen, Psychologen und Linguisten geliefert. So führt z.B. Wittgenstein (1958) in seiner inzwischen schon plakativen Analyse des SPIEL-Konzeptes überzeugend vor Augen, dass es Konzepte gibt, die einer Kategorie zugerechnet werden, ohne dass es ein einziges Merkmal gibt, das allen Instanzen der Kategorie gemeinsam wäre:

66. Betrachte z.B. einmal die Vorgänge, die wir „Spiele“ nennen. Ich meine Brettspiele, Kartenspiele, Ballspiel, Kampfspiele, usw. Was ist allen diesen gemeinsam? Sag nicht

Sadziński (2018: 62) veranschaulicht die Unterscheidung am Beispiel der Komposita: Seehund und Meerestier. Seehund ist kein Hund, der im Meer lebt, weswegen die Komponente See-als ein immanenter Marker angesehen wird. Da ein Meerestier als ein Tier, das im Meer lebt beschrieben werden kann, ist Meer- ein Bestimmungsglied ein optionaler Distinguisher. Diese Differenzierung vergrößert zwar die Leistungsfähigkeit der Merkmalssemantik, ändert allerdings nichts an ihrer Grundannahme, dass Konzepte propositionale Strukturen mit scharf umrissenen Grenzen sind. Diese Annahme ist vor dem Hintergrund der weitgehenden semantischen Ambiguität der Lexeme und insbesondere der Idiome im authentischen Sprachgebrauch schwer aufrechtzuerhalten. 
„Es muß ihnen etwas gemeinsam sein, sonst hießen sie nicht ,Spiele“ “ - sondern schau, ob ihnen allen etwas gemeinsam ist. (...) Sind sie alle unterhaltend? Vergleiche Schach mit dem Mühlfahren. Oder gibt es überall ein Gewinnen oder Verlieren, oder eine Konkurrenz der Spielenden? Denk an die Patiencen. In den Ballspielen gibt es Gewinnen und Verlieren; aber wenn das Kind den Ball an die Wand wirft und wieder auffängt, so ist dieser Zug verschwunden. Schau, welche Rolle Geschick und Glück spielen. Und wie verschieden ist Geschick im Sprachspiel und Geschick im Tennisspiel. Denk nur an die Reigenspiele: Hier ist das Element der Unterhaltung, aber wie viele der anderen Charakterzüge sind verschwunden! Und so können wir durch die vielen, vielen anderen Gruppen von Spielen gehen, Ähnlichkeiten auftauchen und verschwinden sehen.

Und das Ergebnis dieser Betrachtung lautet nun: Wir sehen ein kompliziertes Netz von Ähnlichkeiten, die einander übergreifen und kreuzen. Ähnlichkeiten im Großen und Kleinen. (Wittgenstein 2010 [1958]: 110-111)

Zu ähnlichen Resultaten kommt Lakoff (1987: 204) bei der Analyse des Konzeptes MUTTER: Als Mütter werden heutzutage Frauen bezeichnet, die genetisches Material liefern (genetische Mutter), das Kind zur Welt bringen (biologische Mutter), das Kind nur erziehen (Adoptivmutter), die Schwangerschaft einer anderen Frau austragen (Ersatz- oder Tragemutter), mit dem Vater des Kindes verheiratet sind usw. Das Konzept der mUTTER bildet demzufolge eine radiale Kategorie, in dessen Zentrum sich die prototypische Mutter befindet, die das Kind geboren hat, erzieht und mit seinem Vater verheiratet ist. Die Erstellung eines Merkmalsbündels, das allen genannten, mit der Mutterschaft zusammenhängenden Situationen gerecht werden könnte, ist sowohl beim Konzept SPIEL, als auch beim Konzept MUTTER äußerst problematisch.

Fillmore (1975) macht in seinen detaillierten Untersuchungen alltäglicher Konzepte auf die Verschwommenheit der Kategoriegrenzen aufmerksam. In den Überlegungen zum Konzept JUNGGESELLE verweist er (1975: 128-129) darauf, dass sich notwendige und hinreichende Merkmale von JUNGGESELLE zwar leicht identifizieren lassen [erwachsen], [unverheiratet], [männlich], als Merkmalsbündel aber keine Erklärung für die individuellen Unterschiede und Probleme liefern, die die Probanden bei der Beantwortung folgender Fragen haben:

Given a checklist theory of meaning, boundary research on words like bachelor and widow would take seriously such questions as these: How old does an unmarried man have to be before you call him a bachelor? Is somebody who is professionally committed to the single life properly considered a bachelor? (Is it correct to say of Pope John XXIII that he died a bachelor?) If so, is bachelorhood a state one can enter? That is, if a man leaves the priesthood in middle life, can we say that he became a bachelor at age 47 ? When we say of a divorced man or a widower that he is a bachelor, are we speaking literally of metaphorically? How can we tell? (Fillmore 1975: 128)

Labov (1973, zit. nach Schwarz 2008: 111) liefert dagegen mit seinem Tassen-Experiment empirische Evidenz dafür, dass die Kategoriengrenzen vom 
Kontext abhängig sind. Die Probanden, denen man verschiedene Gefäße vorlegte, akzeptierten wesentlich mehr Behälter als Tassen, wenn sie gebeten wurden, sich das Trinken aus diesen Gefäßen vorzustellen als ohne diese Anweisung.

In der Kognitiven Linguistik wird demnach die Annahme der eindeutigen, erfahrungsunabhängigen Kategoriengrenzen aufgegeben. Einen wichtigen Beitrag zur Herausbildung der modernen Auffassung der Kategorisierung leistet die Prototypentheorie von Rosch et al. Rosch $(1975,1976)$ lieferte in psychologischen Experimenten die empirische Evidenz dafür, dass nicht alle zu subsumierenden Exemplare einer bestimmten Kategorie von Probanden als gleich gute Vertreter dieser Kategorie betrachtet werden. So wird beispielshalber ein SPATZ oder ein ROTKEHLCHEN als ein besserer Vertreter der Kategorie VOGEL als HAHN oder PINGUIN angesehen, womit Kategorien eine abgestufte Binnenstruktur aufweisen: Die besten Exemplare einer Kategorie, die Prototypen genannt werden, sind in der Mitte einer Kategorie; die nicht-prototypischen Exemplare werden in einer Reihenfolge von den guten zu den weniger guten Exemplaren angeordnet, die dann die Peripherie bilden. Das Modell der Kategorisierung charakterisiert Löbner durch folgende Eigenschaften:

\section{Abgestufte Struktur der Kategorien \\ Mitglieder einer Kategorie haben nicht denselben Status. \\ Prototypen als beste Beispiele}

Es gibt prototypische Fälle, die übereinstimmend als die besten Beispiele für die Kategorie betrachtet werden.

\section{Keine feste Menge von notwendigen Bedingungen}

Die Zugehörigkeit zu einer Kategorie ist nicht an die Erfüllung einer festen Menge notwendiger Bedingungen geknüpft. Der Prototyp einer Kategorie kann durch Eigenschaften definiert sein, die nicht alle Mitglieder der Kategorie teilen.

\section{Familienähnlichkeit}

Die Mitglieder einer Kategorie verbindet Familienähnlichkeit.

\section{Prototypen als Referenzfälle der Kategorisierung}

Prototypen dienen als Referenzfälle für die Kategorisierung. Die Zugehörigkeit zu einer Kategorie ist eine Frage der Ähnlichkeit mit dem Prototyp.

\section{Graduelle Zugehörigkeit}

Die Zugehörigkeit zu einer Kategorie ist graduell.

\section{Unscharfe Grenzen}

Kategorien haben unscharfe Grenzen. (Löbner 2003: 265)

Die Prototypikalität wird dabei mittels des sogenannten Goodness-of-Exemplar (= GOE) sowie Degree-of-Membership (= DOM)-Wertes ermittelt (Croft/Cruse 2004: 80). Damit ist Karotte, der die Probanden GOE-Wert 1 zugewiesen haben, ein prototypisches Gemüse für unseren Kulturkreis. Die Prototypentheorie in der von Rosch (1975) sowie Rosch et al. (1976) vorgeschlagenen Form wird heutzutage als problematisch angesehen: Sie ist erstens nur bei bestimmten Wortklassen einsetzbar, zweitens nicht imstande, den universellen Mechanismus der 
Polarisierung zu erklären ${ }^{44}$, drittens auf kontextuelle Gegebenheiten unsensibel. Die Prototypikalitätseffekte spielen dennoch in der Kognitiven Linguistik eine wichtige Rolle und werden von vielen Forschern (u.a. von Lakoff in den ICMs ${ }^{45}$ sowie von Langacker bei der Bestimmung des Zentralitätsgrads der Domänen) mit einbezogen.

Dementsprechend wird in der modernen Auffassung der Kategorisierung davon ausgegangen, dass Konzepte - mentale Repräsentationen der Kategorien, die infolge der Kategorisierungsprozesse entstehen - die Gesamtheit des menschlichen Wissens und der menschlichen Erfahrung zu einer Kategorie in ihrer ganzen Komplexität und Vielschichtigkeit umfassen. Nur in Ausnahmefällen ${ }^{46}$ lassen sich Konzepte anhand der klaren Dichotomien begreifen, so wie es in dem Modell der notwendigen und hinreichenden Bedingungen vorausgesetzt wurde. Die Grenzen von den meisten

44 Auf Unzulänglichkeiten der Prototypentheorie machen u.a. Löbner (2003: 276-284) und Croft/Cruse (2004: 79-81) aufmerksam. So lässt sich z.B. die graduelle Zugehörigkeit zu den Kategorien, die in der Prototypentheorie vorausgesetzt ist und mit GOE-Werten ermittelt wird, mit dem universellen Prinzip der Polarisierung nicht in Einklang bringen. Das Prinzip der Polarisierung besagt, das in einem gegebenen Äußerungskontext, mit einer gegebenen Lesart, ein Deklarativsatz entweder wahr oder falsch ist. Wie Löbner (2003: 288-289) überzeugt, ist der Satz: Die Maus isst ein großes Reiskorn entweder falsch oder richtig, eine 80 \%-Maus kann keine Tätigkeit ausführen, die man zu $50 \%$ als Essen bezeichnen würde.

45 ICMs (= Idealized Cognitive Models) wurden als modellhafte kognitive Strukturen von Lakoff (1987: 68) eingeführt, vgl. dazu Unterkap. 2.1.5.2.

46 Einen erwähnenswerten Versuch der Klassifizierung der sprachlichen Begriffe in Hinsicht auf ihre ontologische Referenz hat Krzeszowski (2006: 39) vorgenommen. Krzeszowski verweist darauf, dass sprachliche Formen auf drei Mengentypen referieren können: finite Mengen, abzählbare indefinite Mengen (denumerably infinite) und unabzählbare indefinite Mengen (nondenumerably infinite). Finite Mengen bestehen aus Schöpfungen des menschlichen Geistes: Es handelt sich um formale Begriffe, die als Bestandteile einer Menge definiert worden sind, sie entsprechen synthetischen Urteilen in Kants Philosophie. Zu dieser Menge gehören z.B. mathematische Begriffe, die man eindeutig mithilfe notwendiger und hinreichender Merkmale definieren kann. Abzählbare indefinite Mengen bestehen aus Kategorien (Klassen), die aufgrund ihrer gemeinsamen Eigenschaften abgegrenzt werden (Kant bezeichnet sie als analytische Urteile). Die abgesonderten Merkmale sind abzählbar, weil man sie individuell im Spracherwerbsprozess ,abstrahiert', ihre Anzahl ist aber indefinit (unendlich), weil die Anzahl der Eigenschaften, die zwei Sachen gemeinsam haben, unendlich ist. Die unabzählbaren indefiniten Mengen beinhalten mentale Abbildungen der einzelnen Sachen, es handelt sich hier um unikale Phänomene, deren Zugehörigkeit zur Menge durch Beschreibung (description or depiction) bestimmt wird. Interessanterweise liegt psycholinguistische Evidenz dafür vor, dass finite Mengen, z.B. gerade oder ungerade Zahlen, sich zwar mithilfe notwendiger und hinreichender Merkmale definieren lassen (die Kategorien haben scharfe Grenzen), aber zugleich Prototypikalitätseffekte aufweisen: 1, 3, 5, 7 und 9 gelten als bessere Vertreter der Kategorie UNGERADE ZAHLEN als 18764098376542141 (vgl. Löbner 2003: 277). 
Konzepten sind verschwommen und vage, Randphänomene und fließende Übergänge zwischen den Kategorien werden akzeptiert. Darüber hinaus sind die Konzepte nur relativ stabil und unterliegen Modifikationen: Das Konzept der MUTTER ist - aufgrund des Zuwachses der Erfahrung und der Wissensbestände - anders im Alter von 5 und anders im Alter von 55 Jahren, das Konzept von TELEFon hat sich innerhalb der letzten 30 Jahre wegen des technischen Fortschritts wohl in der ganzen Gesellschaft wesentlich geändert. In diesem Sinne sind die Konzepte z.T. individuell: Jeder Mensch hat eine andere Lerngeschichte und Erfahrungen.

Darüber hinaus wird unterstrichen, dass Konzepte als Teil der Kognition embodied sind, sie vollziehen sich in einem Menschen und können ohne Berücksichtigung der Eigenschaften des erkennenden Subjektes nicht erfasst werden. Schematisierungs- und Kategorisierungsprozesse werden als teilweise angeborene Mechanismen angesehen, sodass die Entstehung der mentalen Kategorien durch universelle Faktoren, wie z.B. die Beschaffenheit des menschlichen Körpers, bedingt ist. Bereits bei der perzeptuellen Wahrnehmung ist der Mensch durch seine biologische Ausstattung (z.B. das Spektrum der vom menschlichen Auge wahrzunehmenden Farben) eingeschränkt. Jackendoff (1983, zit. nach Ziem 2008: 160) spricht in diesem Zusammenhang von einer projizierten Realität - einer mentalen Repräsentation von Wirklichkeit, die wir über unsere eigentümliche sensomotorische Verfasstheit vermittelt konstruieren. Kategorisierung vollzieht sich also in einem Zusammenspiel von universellen und individuellen Faktoren, sie kann nur vor dem Hintergrund des Menschen und seiner Körpereigenschaften, seiner Weltauffassung, seiner kulturellen Zugehörigkeit erfasst werden.

Das Ziel der kognitiven Bedeutungsauffassung ist deswegen, wie Bartmiński bemerkt, weitreichend:

Kognitive Definition stellt sich zum Hauptziel, das Begreifen eines Gegenstandes von dem eine Sprache sprechenden Menschen zu erfassen. Es handelt sich um die Erfassung von dem sozial verfestigten und sich über die Sprache und Sprachgebrauch erkennen lassenden Weltwissen, von der Kategorisierung der Weltphänomene, ihrer Beschreibung und Evaluierung. (Bartmiński 1988: 169) ${ }^{47}$

\subsubsection{Grammatik und Lexikon}

Die holistisch geprägten Ansätze der Kognitiven Linguistik brechen nicht nur mit der Annahme, dass die Bedeutung die in der reellen Welt existierenden Beziehungen vollkommen und verzerrungsfrei widerspiegelt, sondern auch mit dem Postulat, dass das Denken auf mechanistischer Manipulation mit abstrakten, transzendenten Symbolen beruht (Lakoff 1987: 154). Die Grundprämissen der

47 „Definicja kognitywna za cel główny przyjmuje zdanie sprawy ze sposobu pojmowania przedmiotu przez mówiących danym językiem, t.j. ze sposobu utrwalonej społecznie i dającej się poznać przez język i użycie języka wiedzy o świecie, kategoryzacji jego zjawisk, ich charakterystyki i wartościowania“ (Bartmiński 1988: 169). 
traditionell ausgerichteten Semantik: (i) die Homogenitätsprämisse, die besagt, dass alles, was als ,Bedeutung' bezeichnet wird, seiner Natur nach ähnlich oder identisch sei (Lyons 1983: 128 zit. nach Busse 2009: 18) sowie (ii) die Kompositionalitätsprämisse (das sog. Frege-Prinzip), nach der sich die Bedeutung eines Syntagmas oder eines Satzes aus den lexikalischen Bedeutungen seiner Teilausdrücke ermitteln lasse (Busse 2009: 112), werden in der Kognitiven Linguistik stark relativiert. Wie oben dargelegt, ist die Bedeutung einer sprachlichen Einheit nicht auf abstrakte Referenz- und Wahrheitsbedingungen zurückzuführen, sondern sie beruht auf der Aktivierung von konzeptuellen Strukturen, die sich ein Mensch in seiner Phylo- und Ontogenese angeeignet hat. Infrage wird ebenfalls die Omnipräsenz der Kompositionalitätsprämisse gestellt: Es wird darauf verwiesen, dass zur Verständigung zahlreiche Elemente beitragen, die über die Gleichung

„Satzbedeutung = lexikalische Wortbedeutungen + syntaktische Regeln“

hinausgehen. Busse (2009: 112) macht darauf aufmerksam, dass die Unzulänglichkeiten der Kompositionalitätsthese immer da deutlich werden, wo zum Ausgangspunkt der Analyse nicht solche Beispielsätze herangezogen werden, die von den Linguisten hypothetisch konstruiert wurden (die sog. „Lehnstuhl-Semantik“), sondern diejenigen, die im authentischen Sprachgebrauch tatsächlich vorkommen.

Dabei handelt es sich bei der kognitiven Betrachtung der Äußerungen keinesfalls ausschließlich um pragmatische Aspekte des Sprachgebrauchs ${ }^{48}$, sondern auch um Grammatik und Lexikon. Die kognitiven Linguisten führen vor Augen, dass es selbst bei auf den ersten Blick einfachen und regulären Wortverbindungen wie der Ball unter dem Tisch nicht immer möglich ist, die Bedeutung der ganzen Wortverbindung aus den lexikalischen Bedeutungen der Einzelkonstituenten abzuleiten. So argumentiert Taylor (2007: 126-130) in Anlehnung an Langacker (1987: 279-282) dafür, dass die Interpretation der genannten Mehrwortverbindung notwendigerweise über das linguistische Wissen und über die Bedeutung der Einzelkonstituenten hinausgeht ${ }^{49}$. Bei der Rezeption des Syntagmas der Ball unter dem

48 Die pragmatischen Aspekte der Bedeutung veranschaulicht Schwarz (2008: 60) am Beispiel des Satzes Der Kanzler hält gleich eine Rede! Dieser Satz weist eine ganz andere Bedeutung in dem Kontext 1: Saaldiener sagt dies 2000 bei einer Publikumsführung im Bundestag, als im Kontext 2: Generalsekretär der CDU sagt dies 1996 zur Fraktion, die gerade beim Frühstück sitzt.

49 Die semantische Insuffizienz der Kompositionalitätsanalyse wurde auch früher wahrgenommen. Bereits 1964 führt Morciniec den Terminus ,Sachsteuerung' ein, unter dem ,auf Sachkenntnis beruhende stoffliche Steuerung, welche die Beziehungen zwischen den Bedeutungen der Bestandglieder [...] determiniert" (Morciniec 1964: 97, zit. nach Sadziński 2012: 1305) aufgefasst wird. Sadziński (2012) veranschaulicht das Prinzip der Sachsteuerung an Beispielen von (i) verletzter Kongruenz im Numerus zwischen Subjekt und Prädikat, (ii) inferenziell basierten Einsparungen prädiktabler Elemente (vor allem Objekte) auf der Satzebene sowie (iii) disambiguierungsoffenem Status sprachlicher Wortelemente auf der Wortebene, der am Beispiel der deutschen Komposita besprochen wird. 
Tisch nimmt die Konzeptualisierung bei den meisten Menschen folgende Gestalt an (vgl. Abb. 2):

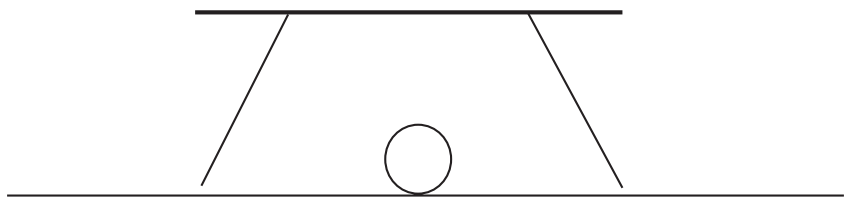

Abb. 2: Der Ball unter dem Tisch - die erste Interpretation.

In der prototypischen Vorstellung befindet sich der Tisch in der klassischen Position: Die Tischbeine stehen auf einem flachen Fußboden, der Ball liegt auf der durch die Tischbeine abgegrenzten Fläche. Von Relevanz ist für diese Konzeptualisierung folglich der Fußboden, der sprachlich nicht kodiert wird. Interessanterweise wird hier die Präposition unter abweichend von ihrer räumlichen Grundbedeutung ,kennzeichnet einen Abstand in vertikaler Richtung und bezeichnet die tiefere Lage im Verhältnis zu einem anderen Genannten` (DUW) gebraucht: Der Ball befindet sich zwar unter der Tischplatte, aber zwischen den Tischbeinen, die doch als ein konstitutives Merkmal des Tisches angesehen werden, vgl. Tisch: ,Möbelstück, das aus einer waagerecht auf einer Stütze, in der Regel auf vier Beinen ruhenden Platte besteht, an der gegessen, gearbeitet, auf die etw. gestellt, gelegt werden kann' (DUW).

Mit etwas Einbildungskraft kann man sich auch andere mögliche Interpretationen der besprochenen Mehrwortverbindung vorstellen: Wenn in einer mit Gerümpel vollgestopften Garage sich ein verkehrt aufgestellter Tisch befindet, unter dessen Tischplatte ein Ball liegt, dann haben wir es ebenfalls mit einer Referenzvariante zu der Ball unter dem Tisch zu tun (vgl. Abb. 3):

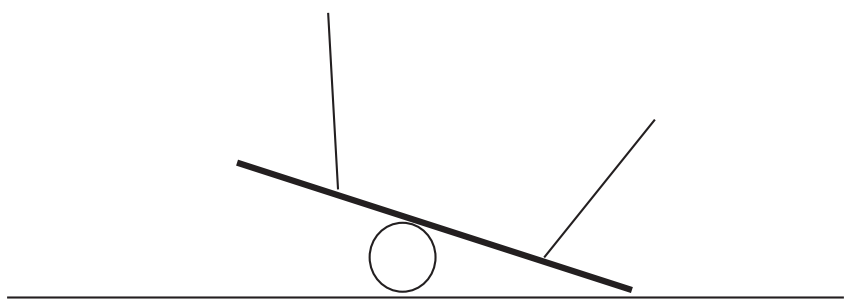

Abb. 3: Der Ball unter dem Tisch - die zweite Interpretation. 
Der kompositionellen Bedeutung aller Konstituenten würde am besten eine Konzeptualisierung Rechnung tragen, die in dem alltäglichen Sprachgebrauch unwahrscheinlich ist: Der Ball befindet sich unter dem Tisch, der z.B. an ein aus dem Hubschrauber herabhängendes Seil befestigt worden ist (vgl. Abb. 4):

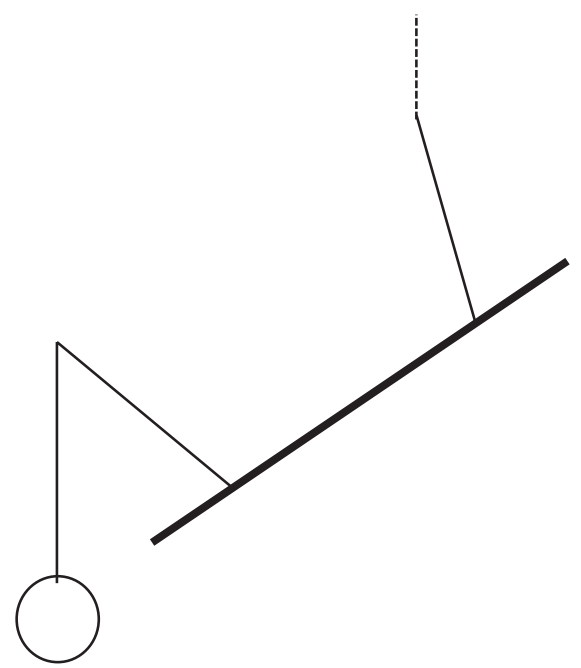

Abb. 4: Der Ball unter dem Tisch - die dritte Interpretation.

Erst in dieser Konzeptualisierung realisiert sich die Bedeutung der Präposition unter, die die tiefere Lage eines Gegenstandes im Verhältnis zu einem anderen Gegenstand zum Ausdruck bringt.

Selbstverständlich schöpfen die drei Interpretationen keinesfalls alle denkbaren Konstellationen aus, den potenziellen Konzeptualisierungen können nur durch (mangelnde) Einbildungskraft des Individuums Grenzen gesetzt werden. Das angeführte Beispiel veranschaulicht aber deutlich, wie eng das sprachliche Wissen an das allgemeine (enzyklopädische, kulturelle) Wissen gebunden ist. Die Bedeutung, die sich aus der Zusammenstellung von lexikalischen Bedeutungen der Komponenten ermitteln lässt, eröffnet nur einen Spielraum, in dem verschiedene Interpretationen aufgebaut werden. In der prototypischen Interpretation (1) befindet sich der Ball nicht unter dem Tisch, sondern unter der Tischplatte: Sollte sich der Ball wirklich unter dem Tisch befinden, dann müsste er unter den Tischbeinen, also unterhalb des Fußbodens platziert sein. Es ist des Weiteren zu betonen, dass die vorhin demonstrierte Position des Balls anders ist als die des typischerweise klebenden Kaugummis - der Kaugummi unter dem Tisch. Damit stellt dieses Beispiel unter Beweis, dass selbst eine anscheinend einfache, aus Konkreta 
zusammengesetzte Wortverbindung Bedeutungen aufweist, die dem Prinzip der absoluten Kompositionalität widersprechen und - bei entsprechend weiter Auslegung des Kriteriums - als idiomatisch gelten können. Selbstverständlich tragen die Bedeutungen der einzelnen Komponenten Ball, unter, Tisch zur Gesamtbedeutung bei - die Kompositionalitätsthese wird nicht abgelehnt, sondern relativiert. Nichtsdestoweniger geht die Gesamtbedeutung einer Wortverbindung über deren Teilbedeutungen unübersehbar hinaus. Auch in den scheinbar regulären freien Wortverbindungen kommt das gestaltpsychologische Ehrenfels-Gesetz der Übersummativität zur Geltung: Ein Ganzes ist mehr als Summe seiner Teile, wodurch die Grenzen des Idiomatischen in den neueren Ansätzen weitgehend aufgeweicht werden.

Derartige Analysen führen zur Schlussfolgerung, dass man die Semantik und Grammatik nicht getrennt betrachten kann. Die holistisch ausgeprägten Sprachtheorien sind konzeptualistisch: So besteht nach Langackers Kognitiver Grammatik (2008) die Sprache aus symbolischen Einheiten, die wiederum aus einem phonologischen und einem semantischen Pol zusammengesetzt sind. Unter dem phonologischen Pol versteht Langacker materielle (graphematische oder phonologische) Aspekte einer symbolischen Einheit, als der semantische Pol wird das Bedeutungskorrelat verstanden, das vom phonologischen Pol evoziert wird: Es sind weit aufgefasste konzeptuelle Strukturen, die ein Sprachteilhaber mit einer Form (dem phonologischen Pol) verbindet. Symbolisch ist in einer sprachlichen Einheit die Relation zwischen den beiden Polen, die sich durch den wiederholten Gebrauch und die damit verbundene Konventionalisierung konstituiert. Als symbolische Einheiten werden nicht nur Lexeme, sondern auch Strukturen von größerer Komplexität bezeichnet, womit man die traditionelle strikte Aufteilung in Lexikon und Grammatik auflöst und die Übergänge zwischen beiden Bereichen als ein Kontinuum auffasst (vgl. Abb. 5):

(a)

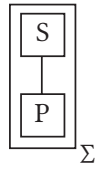

(b)

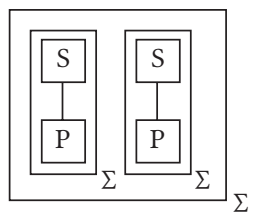

(c)

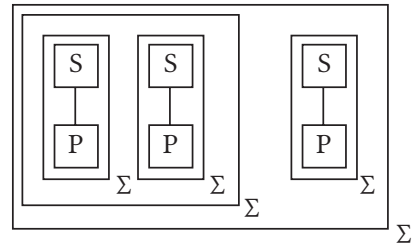

Abb. 5: Die Darstellung von (a) moon [[MOON]/[moon]], (b) moonless [[[MOON]/ [moon $]]--[[$ LESS $] /[$ less $]]]$, (c) moonless night $[[[[$ MOON $] /[$ moon $]]-[[$ LESS $] /[$ less $]]]-$ [[NIGHT]/[night]]] als symbolische Strukturen: $S$ bezieht sich auf den semantischen Pol, $P$ auf den phonologischen Pol, mit $\Sigma$ wird die symbolische Struktur dargestellt (Langacker 2008: 15). 
Zwischen Lexikon und Grammatik wird demnach keine strikte Grenzziehung vorgenommen: Grammatische Formen erfüllen symbolische Funktionen. Symbolische Einheiten sind niemals abstrakter Natur im Sinne von selbstgenügsamen, rein formalen Einheiten (Ziem 2008: 187). Grammatik und grammatische Regeln werden nicht als Restriktionen oder Einschränkungen, sondern als Schematisierungen aufgefasst:

In CG [Cognitive Grammar, A. S.] rules take the form of schemas. Patterns and regularities of any sort, at any level of specificity, reside in schematic units abstracted from occurring expressions. Even lexical items have this character. Though often regarded as idiosyncratic, lexical items are better thought of as regularities of limited scope. The lexeme cat, for instance, embodies the generalization that creatures of a certain sort are conventionally designated by this form. There is no inconsistency in describing lexical items as specific fixed expressions, on the one hand, and as schemas, on the other. (Langacker 2008: 219)

Einer konzeptualistischen Prämisse folgen ebenfalls die sich zurzeit schnell entwickelnden Konstruktionsgrammatiken (Croft 2001, Fillmore 1988, Fillmore/Kay/ O’Connor 1988, Goldberg 1995, Ziem/Lasch 2013). Den Status einer Konstruktion hat jede Form-Bedeutungspaarung, die konventionalisiert ist und sich nicht auf andere Form-Bedeutungspaarungen reduzieren lässt. Der Formseite einer Konstruktion werden neue Komponenten zugeordnet, sie umfasst Informationen phonologischer, syntaktischer und morphologischer Art. Die Bedeutungsseite einer Konstruktion bezieht sich dagegen auf Informationen semantischer, pragmatischer und diskursfunktionaler Art. Ziem veranschaulicht den Aufbau einer Konstruktion mithilfe des folgenden Schemas (Abb. 6):

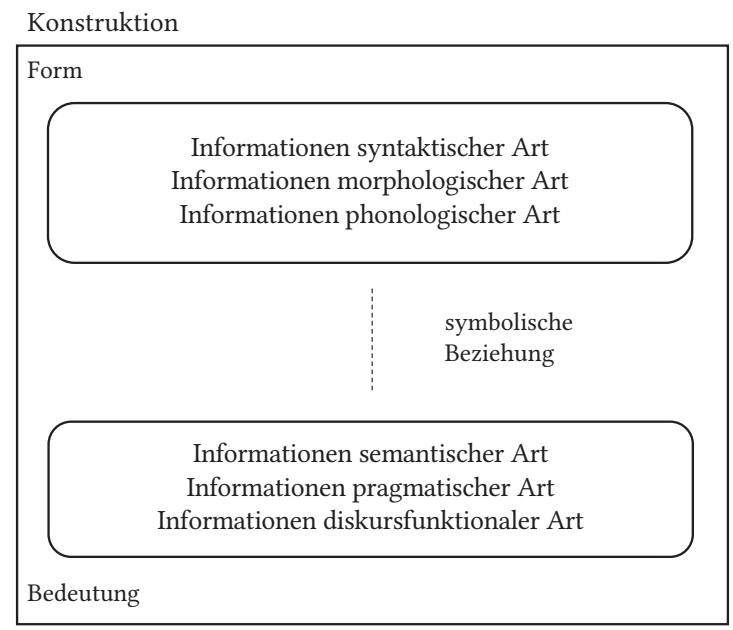

Abb. 6: Konstruktion als Form-Inhaltspaar (Ziem 2008: 185 in Anlehnung an Croft 2001: 18). 
Konstruktionen gelten somit in den Konstruktionsgrammatiken als einzige und basale Einheiten eines sprachlichen Systems (Ziem 2008: 180):

Was eine Konstruktion und den Aufbau komplexer Konstruktionen möglich macht, ist unsere Fähigkeit zu kategorisieren, also Schema-Instanzbeziehungen mannigfaltiger Art gleichsam automatisch herzustellen. Ein so verstandener sprachkonstruktivistischer Ansatz kommt (anders als die generative Grammatik) ohne Regeln aus. Er baut allein auf menschliche Kategorisierungskompetenz auf, die sich ebenso in anderen Domänen - wie z.B. der kognitiven Verarbeitung visueller oder auditiver Daten - als konstitutiv erweist. (Ziem 2008: 190)

Konstruktionsgrammatiken sind relativ neu und bedürfen weiterer Forschung: Ungelöst bleibt beispielshalber das Problem des Spracherwerbs: Ob man den Vorsprung des frühkindlichen Spracherwerbs anderen kognitiven Fähigkeiten gegenüber ausschließlich mit konstruktionsgrammatischen Annahmen erklären kann, bleibt umstritten. Zweifelsohne verweisen sie dennoch auf die Relevanz des Vorgeformten in der Sprache, darunter auf die Relevanz der Kollokationen und der Phraseologismen, die in der traditionellen Linguistik als Randphänomene betrachtet wurden.

\subsubsection{Weltwissen und Sprachwissen}

Eine andere folgenreiche Annahme der holistisch ausgeprägten Kognitiven Linguistik liegt in der Aufhebung einer strikten Grenze zwischen der linguistischen und der generellen (enzyklopädischen, Weltwissen-)Repräsentation. Sprachliche Strukturen sind von nicht-sprachlichen Phänomenen weder unterschiedlich noch von ihnen losgelöst, sprachliches Wissen ist denselben kognitiven Operationen wie andere Wissensformen unterworfen ${ }^{50}$, sowie eng an nicht-linguistisches Wissen gebunden:

The cognition envisaged by cognitive linguists is noninsular, being grounded in perception and bodily experience. Since mental development is stimulated and guided by social interaction, the skills and knowledge acquired are very much attuned to the sociocultural surroundings. The conceptualizations we entertain are undeniably internal, in the sense of taking place in the brain, yet reach beyond it in the sense of being conceptualizations of some facet of the world. In speaking, we conceptualize not only what we are talking about but also the context of dimensions, including our assessment of the knowledge and intentions of our interlocutor. Rather than being insular, therefore, conceptualization should be seen as a primary means of engaging the world. And empty head cannot talk, interact, or negotiate meanings. (Langacker 2008: 29)

$50 \mathrm{Zu}$ diesen fundamentalen kognitiven Operationen gehören z.B.: Kategorisierung, Schematisierung, Automatisierung, Vordergrund/Hintergrund-Unterscheidung. 
Die Konzeptualisierung von Spracheinheiten ist nur vor dem Hintergrund ausgebauter epistemologischer Wissensstrukturen möglich. Den konzeptuellen (semantischen) Pol einer Spracheinheit bildet kein sprachspezifisches Wissen. Wie bereits im Kap. 2.1.3 über die Kategorisierung und Konzepte erwähnt, lehnen die Vertreter der holistisch geprägten Linguistik sowohl die klassische Merkmalstheorie wie auch Chomskys modulare Auffassung der Sprachfähigkeit ab und führen zahlreiche Beispiele dafür heran, dass selbst alltägliche Konzepte (vgl. z.B. ALIMONY, ON LAND, PEDESTRIAN u.a. bei Fillmore/Baker 2009: 319) ohne Hintergrundinformationen nicht verstanden werden können. So kann z.B. die Bedeutung von einer HYPOTHENUSE ohne entsprechendes Wissen von einem Dreieck und einem rechten Winkel nicht erfasst werden (Langacker 1988: 59). Auch alltägliche Konzepte, z.B. DIENSTAG, setzen relevante Wissensstrukturen voraus, die die Aufzählung der Wochentage, Wissen über Zeiteinheiten sowie den in unserer Kultur üblichen Kalender und ggf. seine astronomischen Grundlagen umfassen (Lakoff 1987: 68-69).

Jede sprachliche Bedeutung ist damit in ein Netz epistemischer Annahmen über die Welt eingebettet (Ziem 2008: 173). Croft drückt es in einem einprägsamen Satz aus: „Everything you know about the concept is part of its meaning“ (Croft 2003: 163). Damit wird der Gegenstand der linguistischen Forschung wesentlich erweitert: „the study of linguistic semantics is the study of commonsense human experience" (ebd.).

Bei einer so komplexen Auffassung der konzeptuellen Seite eines sprachlichen Zeichens werden Versuche unternommen, den konzeptuellen Pol von sprachlichen Einheiten zu modellieren. Als drei populäre Modelle der konzeptuellen Struktur (conceptual structure), die der Verflochtenheit der Sprach- und Wissensstrukturen gerecht zu werden versuchen, werden Frames von Fillmore, ICMs von Lakoff und Domänen von Langacker angesehen: Die Frames und ICMs werden im Folgenden der Vollständigkeit der Beschreibung halber überblicksartig dargestellt, auf die enzyklopädische Semantik Langackers wird näher eingegangen.

\subsubsection{Frames von Fillmore}

Frames als Wissensorganisationsstrukturen wurden zuerst von einem der Begründer der Künstlichen Intelligenz-Forschung, Marvin Minsky (1975), in Nordamerika postuliert, der sie allerdings vor allem in Bezug auf die visuelle Wahrnehmung untersuchte. In die Sprachwissenschaft wurden Frames von Charles J. Fillmore übertragen und weiterentwickelt, wobei die Forschung unterschiedliche Stadien durchlief: von der Kasusgrammatik zu einem integrativen Modell eines Frames, das unterschiedliche Aspekte des verstehensrelevanten Wissens umfasst. Frames definiert Fillmore wie folgt:

By the word ,frame ' I have in mind any system of concepts related in such a way that to understand any of them you have to understand the whole structure in which it fits, when one of the things in such a structure is introduced into a text, or into a conversation, all of the other are automatically made available. I intend the word ,frame' as 
used here to be a general cover term for the set of concepts variously known, in the literature on natural language understanding, as ,schema', script', ,scenario', ,ideational scaffolding', ,cognitive model', or ,folk theory‘. (Fillmore 1982: 111)

Die Formseite einer Konstruktion (vgl. Konstruktionsgrammatiken) oder der phonologische Pol einer sprachlichen Einheit (vgl. die Kognitive Grammatik von Langacker) evozieren also Frames: Wissensstrukturen über rekurrente Erfahrungen und Ereignisse sowie die damit verbundenen Beteiligten und Situationsparameter, die als Frame-Elemente (FEs) bezeichnet werden (Fillmore/Baker 2009). Über die Frames lassen sich sprachliche Bedeutungen erfassen. Als typisches Beispiel eines Frames wird ,kommerzielles Ereignis' (vgl. z.B. Petruck 2003, Commercial Transaction Frame) angeführt. Dieses Frame beinhaltet folgende Informationen: Es gibt einen Käufer, einen Verkäufer, eine Ware und Geld. Ein Verkäufer erhält das Geld und überlässt dafür einem Käufer eine Ware, der Käufer gibt dem Verkäufer das Geld und darf dafür die Ware behalten. Das Kaufen-Verkaufen-Ereignis kann aus verschiedenen Perspektiven beschrieben werden:

Ich kaufte das Fahrrad (von Thomas) (für 100 Euro).

Thomas verkaufte (mir) das Fahrrad (für 100 Euro).

Das Fahrrad kostete (mich) 100 Euro.

Ich habe 100 Euro (für das Fahrrad) ausgegeben.

Ich habe (Thomas) 100 Euro (für das Fahrrad) gezahlt.

Die Verben kaufen, verkaufen, kosten, ausgeben, zahlen heben verschiedene Aspekte des Frames hervor: kaufen schiebt den Käufer und die Ware in den Fokus der Aufmerksamkeit, während der Verkäufer und der Betrag in den Hintergrund treten. Anders ist es bei dem Verb verkaufen, mit dem der Verkäufer und die Ware fokussiert werden. Beim kosten spielen die Ware und der Betrag (Geld) erstrangige Rolle, bei zahlen der Käufer, der Betrag und eventuell der Verkäufer. Das Frame ,kommerzielles Ereignis' integriert somit all die genannten Verben, setzt sie zueinander in Beziehung:

The idea is that knowing the meaning of any one of these verbs requires knowing what takes place in a commercial transaction and knowing the meaning of any one verb means, in some sense, knowing the meaning of all of them. The knowledge and experience structured by the Commercial Transaction Frame provided the background and motivation for the categories represented by the words. The words, that is, the linguistic material, evoke the frame (in the mind of a speaker/hearer); the interpreter (of an utterance or a text in which the words occur) invokes the frame. (Petruck 2003: 1)

Vor dem Hintergrund dieser geordneten Wissensstrukturen sind auch die Äußerungen verständlich, in denen die Informationen nicht explizit genannt, sondern „hinzugedacht“ werden müssen. Durch die Frame-Aktivierung ist es für den Rezipienten der Äußerung: 
Ich habe das Fahrrad von Thomas gekauft. Es hat mich 100 Euro gekostet.

verständlich, das Thomas Geld erhalten hat.

Frames sind innerhalb der sog. Frame-Semantik in Bezug auf ihre Struktur intensiv erforscht (vgl. das von Fillmore ins Leben gerufene FrameNet Projekt, Fillmore/ Baker 2009). Drei Strukturelemente werden für Frames postuliert (Ziem 2005: 4):

(i) Slots, also konzeptuelle Leerstellen, die in Gestalt von sinnvoll zu stellenden Fragen identifiziert werden können;

(ii) Fillers, Füllelemente dieser slots, die der Menge der in der gegebenen Datenbasis enthaltenen Informationseinheiten (das Gesagte, das Gesehene, das Gehörte) entsprechen;

(iii) Default-Werte, vorausgesetzte und prototypisch erwartbare Füllelemente der slots. Obwohl sie in der gegebenen Datenbasis nicht auftreten, sind sie verstehensrelevant. Jeder Filler-Default-Wert bildet dabei selbst einen Frame, sodass Frames insgesamt eher in einer netzwerkartigen als in einer hierarchischen Struktur verbunden sind.

Frames als Wissensstrukturen weisen viele Ähnlichkeiten mit den Domänen in der Kognitiven Grammatik auf, worauf Langacker (2008: 46) und Fillmore/Baker (2009: 317) explizit verweisen. Beide Theorien unterstreichen die Kreativität, den konstruktiven Charakter sowie die Gebrauchsbasiertheit der sprachlichen Einheiten. Die Unterschiede liegen darin, wie die Schwerpunkte gesetzt werden: FrameSemantik ist als Fortsetzung der Kasusgrammatik entstanden, Fillmores Interesse gilt weitgehend grammatischen Fragen. Heutzutage ist die Frames-Theorie eng an Konstruktionsgrammatiken gebunden. Frames werden hauptsächlich in propositionaler Form beschrieben: Zwar umfassen sie in der gegenwärtigen Auffassung auch Szenen, diesen Begriff lässt Fillmore aber intentional unklar, da die Szene sich nicht leicht in die Struktur von Slots und Standardwerten einfügen lässt (Ziem 2008: 190). Ein wesentlicher Vorteil der Frame-Semantik liegt darin, dass Frames ein einheitliches Format der Bedeutungsbeschreibung darstellen (vgl. das Projekt FrameNet $\left.{ }^{51}\right)$.

\subsubsection{ICMs von Lakoff}

Idealized Cognitive Models (= ICMs), die in Anlehnung an Lakoffs (1987: 68) Woman, Fire and Dangerous Things. What Categories Reveal about the Mind (1987) beschrieben werden, sind als integrierendes Modell zu betrachten, dessen Wurzeln nach Lakoff (1987: 68) in vier wichtigen kognitiven Theorien: Frame-Semantik

51 Unter dem Namen FrameNet wird ein Projekt in Berkeley (in den USA) betrieben, in dem lexikalische Einheiten aus der Perspektive der Frame-Semantik beschrieben werden. Näheres unter: https://framenet.icsi.berkeley.edu/fndrupal/ (Zugriff am 22.10.2016) sowie in Baker/Fillmore/Lowe (1998); Johnson Ch. et.al. (2001) und Fillmore/Johnson, Ch./Pertuck (2003). 
von Fillmore (1982), Metaphern- und Metonymietheorie von Lakoff und Johnson (1980), in der Kognitiven Grammatik von Langacker (1987) sowie in der Theorie der mentalen Räume von Fauconnier (1985) liegen. Dementsprechend wird ein ICM als komplexe Gedankenstruktur aufgefasst, die vier Strukturierungsprinzipien aufweist (ebd.):

(i) die propositionale Struktur wie in Fillmores Frame-Semantik. Die Struktur unseres Wissens ist im großen Maße durch propositionale Modelle bedingt (Lakoff 1987: 113). Als propositionale Strukturen bezeichnet Lakoff außer Frames auch mentale Räume (mental spaces) von Fauconnier, Szenarien und Skripte, Taxonomien, Merkmalsbündel, prototypisch organisierte Kategorien (Lakoff 1987: 284);

(ii) die bildlich-schematische Struktur, so wie sie in image schemas von Johnson oder z.B. in Trajektorienschemata ${ }^{52}$ in Langackers Kognitiver Grammatik vorhanden ist (Lakoff 1987: 114);

(iii) metaphorische Projektionen wie in der CTM-Theorie von Lakoff und Johnson (1980). Sie beruhen auf der Abbildung (mapping) eines propositionalen oder bildlich-schematischen Modells von einer Domäne auf eine andere (ebd.);

(iv) metonymische Projektionen, wie sie bei Lakoff und Johnson beschrieben werden (1980). Diese Modelle gehören zu einem oder mehreren der oben dargestellten Typen, wobei ein Element von dem Modell auf ein anderes Modell projiziert wird. In dem Teil-Ganzes-Modell kann ein Teil des Modells auf das Ganze abgebildet werden (Lakoff 1987: 114). Metonymische Modelle gibt es in zahlreichen Ausprägungen: Sie fungieren als soziale Stereotype, typische Beispiele, Ideale, Musterbeispiele, Generatoren, untergeordnete Modelle oder saliente (sinnfällige) Beispiele (salient examples) (Lakoff 1987: 90).

Während sich die propositionalen und die bildlich-schematischen Modelle auf die Struktur beziehen, verweisen metaphorische und metonymische Modelle auf die Beziehungen zwischen den ICMs und machen von den strukturellen Modellen Gebrauch (Lakoff 1987: 154). Jedes ICM verleiht dabei einem mentalen Raum (wie in Fauconniers Theorie, 1985, 1997) Struktur (Lakoff 1987: 68).

Die Eigenschaften der ICMs und ihre Rolle im menschlichen kognitiven System stellt Lakoff (1987: 153-154) folgendermaßen dar:

(i) ICMs charakterisieren die Struktur unserer Gedanken;

(ii) die Kategorien unseres Verstandes (mind) entsprechen den Elementen von ICMs;

52 Die Trajektor und Landmark-Unterscheidung ist für die Kognitive Grammatik Langackers sehr relevant. Als Trajektor wird der wichtigste Teilhaber an einer Szene genannt, der Landmark bildet den Hintergrund: „The most prominent participant, called the trajector (tr), is the entity construed as being located, evaluated or described. Impressionistically, it can be characterized as the primary focus within the profiled relationship" (Langacker 2008: 58). 
(iii) manche ICMs haben eine Skalarstruktur, die eine der Quellen für Prototypikalitätseffekte bildet;

(iv) manche ICMs sind klassisch: Sie haben scharf umrissene Grenzen und werden durch nötige und ausreichende Bedingungen definiert;

(v) manche ICM haben einen metonymischen Charakter: Ein Teil der Kategorie (ein einzelnes Element oder eine Subkategorie) repräsentiert die ganze Kategorie zu einem bestimmten Zweck. Auch dies kann prototypikalische Effekte auslösen;

(vi) die radikalsten prototypischen Erscheinungen treten in den radialen Kategorien auf. Diese Kategorien können nicht durch ein einzelnes Modell samt generellen Prinzipien repräsentiert werden. Radiale Kategorien bestehen aus mehreren Modellen, die um ein Zentrum organisiert werden und die Beziehungen zum Zentrum aufweisen. Diese Beziehungen werden durch andere ICMs in einem bestimmten Begriffssystem motiviert oder sind durch eine Ähnlichkeitsrelation bedingt.

\subsubsection{Domänen und Profilierungen von Langacker ${ }^{53}$}

Die kurz umrissenen Modelle der Strukturierung des semantischen Gehalts heben zahlreiche Unzulänglichkeiten der klassischen Bedeutungsbeschreibung auf und sind in der einschlägigen Literatur auf große Resonanz gestoßen. Für die Beschreibung der Bedeutungskonstituierung von idiomatischen Einheiten wird dennoch ein Modell benötigt, das sowohl der Dynamik und Vagheit der idiomatischen Bedeutungen im authentischen Sprachgebrauch als auch der Bildhaftigkeit der Idiome Rechnung tragen kann. Fillmores Frames sind aufschlussreich, dennoch hauptsächlich an die propositionale Repräsentationsform gebunden und deswegen zur Erfassung der Bildhaftigkeit nicht geeignet. Lakoffs Modell ist zwar integrativ, scheint aber vage zu sein ${ }^{54}$ : Außer Acht wird beispielsweise die hierarchische Struktur der ICMs gelassen: Das Konzept FINGER kann nur vor dem Hintergrund des ICMs HAND verstanden werden, auch weitere allgemeinere ICMs wie KÖRPER, MENSCH, LEBEWESEN leisten zu der Konzeptualisierung von FINGER einen wichtigen Beitrag. Viele Fragen wirft ebenfalls die mentale Repräsentation von Abstrakta auf: Ob metaphorische und metonymische Projektionen als kognitive Mechanismen ausreichend sind, um komplexe Abstrakta wie Zeit, Liebe, Ärger zu konstituieren, ist fraglich (vgl. Kap. 2.3.3). Aus diesem Grunde wird im Folgenden näher auf die Kognitive Grammatik Langackers eingegangen, die sowohl unterschiedliche

53 Die Unterkap. 2.1.5.3, 2.1.6 sind z.T. in Anlehnung an Sulikowska (2014b, 2014c) entstanden.

54 Eine gewisse Vagheit und die Tendenz, Termini einzuführen, ohne sie genauer zu definieren, in späteren Werken wieder aufzugreifen und zu entwickeln, ist übrigens für Lakoffs Schaffen charakteristisch, was öfters auf Kritik gestoßen ist. (vgl. z.B. Baldauf 1997: 28, Hampton 1989: 135) 
Repräsentationsmodi (darunter analoge Formate, vgl. Langacker 2008: 32) zulässt, als auch eine detaillierte Darstellung bietet, wie die Bedeutungen entstehen. Die Schilderung der Bedeutungskonstituierung im Rahmen eines ganzheitlich ausgearbeiteten Modells mit einer einheitlichen Terminologie, die hier in Anlehnung an Langackers Cognitive Grammar. An Introduction (2008) erfolgt, gibt Einsicht in die Vielfalt, Komplexität und Dynamik der zu beschreibenden Prozesse.

Als einer der Begründer und prominenter Vertreter des Holismus plädiert Langacker (2008) selbstverständlich für die enzyklopädische Auffassung der Bedeutung. Sprachliche Einheiten bestehen aus einem phonologischen und aus einem semantischen Pol. Der phonologische Pol eröffnet den mentalen Zugang zum semantischen Pol, d.h. einer offenen Wissensmenge, die sowohl sprachliche als auch enzyklopädische, auf dem allgemeinen Weltwissen basierende Strukturen umfasst. Dieses Wissen wird auf der nachstehenden Abbildung 7 schematisch in Form von konzentrischen Kreisen dargestellt, die (wie in der Prototypentheorie) dem unterschiedlichen Gewichtswert der einzelnen Wissenskomponenten bei der Bedeutungskonstruierung Rechnung tragen: Manche Komponenten sind zentral und werden prinzipiell bei jeder Aktivierung einer sprachlichen Einheit abgerufen; andere Komponenten liegen an der Peripherie - auf sie wird nur in besonderen Kontexten zurückgegriffen (Langacker 2008: 39).

\section{Encyclopedic Sematics}

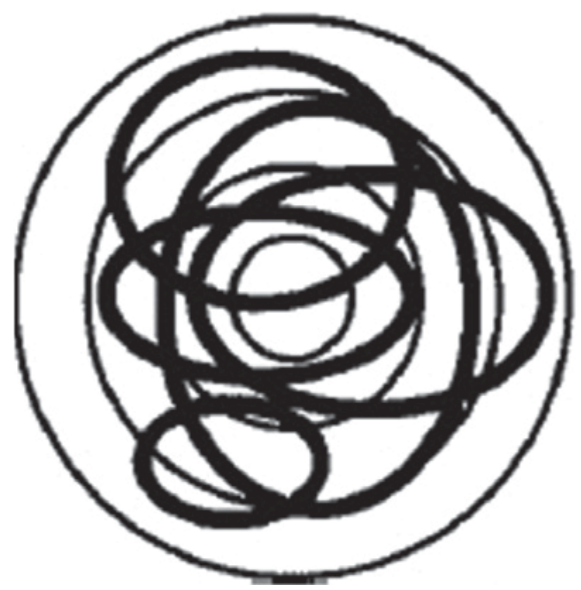

Abb. 7: Konzeptualisierung in der Kognitiven Grammatik (Langacker 2008: 39).

Außer den konzentrischen Kreisen sind auf der Abbildung ebenfalls Ellipsen zu sehen, die Domänen schematisch wiedergeben. Unter Domänen werden geordnete 
mentale Vorstellungs- oder Erfahrungsbereiche (Taylor 2007: 528), „structured blocks of knowledge based on experience" (Barcelona 2003: 232-233) verstanden. Langacker (1991a: 547) definiert sie als „any coherent area of conceptualisation relative to which semantic structures can be characterized (including any kind of experience, concept or knowledge system)" und verweist darauf, dass die Domänen innerhalb der ganzen Kognition hierarchisch strukturiert sind.

Basisdomänen (basic domains) sind kognitiv nicht reduzierbar: „A basic domain is therefore cognitively irreducible, neither derivable from nor analyzable into other conceptions" (Langacker 2008: 44). Zu den Basisdomänen gehören die Domänen des Raumes, der Zeit und eine Menge der nicht analysierbaren, mit Sinnen assoziierten Erfahrungsdomänen: z.B. des Farbspektrums, der Tonhöhe, der Temperatur, des Geruchs und Geschmacks. Basisdomänen sind weder Konzepte noch Konzeptualisierungen; sie sind eher ein Erfahrungspotenzial, in dem Konzeptualisierungen auftauchen und spezifische Konzepte mitschwingen können („realms of experiential potential, within which conceptualization can occur and specific concepts can emerge“, Langacker 2008: 44-45). Möglicherweise sind sie auf derselben präkonzeptuellen Ebene angesiedelt, auf der image schemas von Johnson platziert sind.

Die meisten Domänen sind nonbasic/nicht elementar und differieren wesentlich in der Komplexität ihrer inneren Struktur: $:^{55}$

Any kind of conceptualization counts as a nonbasic domain capable of being exploited for semantic purposes. Conceptions fall under this rubric whether they are sensory or intellectual, static or dynamic, fixed or novel, simple or complex. Included as nonbasic domains are instances of immediate sensory, emotive, and motor/kinesthetic experience (e.g. the sensation of wetness, of being afraid, or of blowing up a balloon), as well as the abstracted products of intellectual operations (e.g. concepts like JUSTICE, VERTEBRATE, and BATTING AVERAGE). Also included are conceptions manifested instantaneously at the level of conscious awareness (e.g. the image of a circle), as well as elaborated scenarios that we can only conceptualize stage by stage through processing time (like the successive steps in a complicated recipe). (Langacker 2008: 45)

Alle Domänen, die durch eine lexikalische Entität abgerufen werden, bilden eine Domänenmatrix. Der Ausdruck glass in der Bedeutung eines Trinkgefäßes eröffnet beispielshalber folgende Domänen (Langacker 2008: 47):

(1) Raum (Basisdomäne);

(2) Form (meistens zylindrisch, von unten geschlossen), nicht-elementare Domäne, präsupponiert Raum als Domäne, in der sich eine Form manifestiert;

(3) typische Orientierung im Raum (die lange Seite des Glases aus der senkrechten Perspektive betrachtet), nicht-elementare Domäne, präsupponiert die Domänen des Raumes, der Vertikalität und der Form;

(4) Funktion ${ }_{1}$ (Behälter für eine Flüssigkeit) präsupponiert typische Orientierung im Raum, das Konzept der Flüssigkeit und des Behälters, die wiederum

552008 verzichtet Langacker auf die frühere Bezeichnung ,abstrakte Domänen`. 
Rauminklusion, potentielle Bewegung, die Kraft und Stabilität in der Zeit voraussetzen;

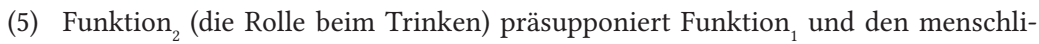
chen Körper, Halten in der Hand, Armbewegung, Verdauung usw.);

(6) Stoff (meistens Glas);

(7) Größe (leicht in der Hand zu halten);

(8) andere (Domänen des Preises, Waschens, Zerbrechens, Abstellens auf den Tisch bei der Mahlzeit usw.).

Die Domänen liegen auf der voranstehenden Abbildung unterschiedlich zentral. Die Zentralität kann als Wahrscheinlichkeit interpretiert werden, mit der eine Domäne beim Gebrauch eines Wortes mental zugänglich wird (Langacker 2008: 48). Domänenaktivierung in Abhängigkeit vom Wahrscheinlichkeitsgrad bezeichnet Langacker als Zentralitätsgrad, gleichzeitig wird dennoch hervorgehoben, dass die Rolle des Kontextes in diesem Prozess von ausschlaggebender Bedeutung ist (Langacker 2008: 49-50). Unterzieht man die folgenden Aussagen einer Analyse bezüglich der aktivierten Domänen:

(i) He took another sip from his glass. (Er hat noch einen Schluck aus dem Glas genommen);

(ii) This antique glass is quite fragile. (Dieses antike Glas ist zerbrechlich);

(iii) The glasses on that table don't match. (Die Gläser auf dem Tisch passen nicht zusammen);

(iv) Plastic wine glasses are hard to wash. (Weingläser aus Plastik sind schwer zu waschen).

dann stellt sich heraus, dass nur im Satz (i) alle zentralen Domänen (1-7) aktiviert werden. In den Sätzen (ii)-(iv) treten die zentralen Domänen in den Hintergrund, während den deutlicher peripheren Domänen (das Zerbrechen, Passen und Waschen) eine wichtige Rolle zukommt. Im letzten Satz (iv) werden sogar manche zentralen Attribute des Glases (Stoff, Form und Funktion) aufgehoben, während man eher marginale Wissensbestände über Abwaschen in den Vordergrund schiebt. Somit muss man sich dessen bewusst sein, dass die Domänenzentralität ausschließlich einen Orientierungswert hat:

A ranking of domains for centrality measures their likelihood of being accessed and strongly activated, other things being equal. Yet other things are never really equal, since language use is never truly acontextual; an expressions manifestation is always subject to influence from the physical, linguistic, social, and psychological circumstances. (Langacker 2008: 50)

Die geschilderten kognitiven Strukturen: Basisdomänen, Domänen, der Zentralitätsgrad der Domänen sowie Domänenmatrix bilden den konzeptuellen Inhalt (conceptual content), der zur detaillierten Beschreibung der Bedeutung allerdings nicht ausreicht und erst den Ausgangspunkt für das Zustandekommen der Bedeutungen/ Konzeptualisierungen ausmacht. Bedeutungen sind nämlich in Konzeptualisierungen 


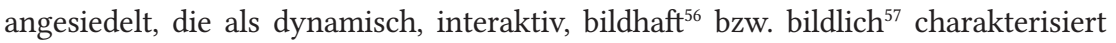
werden (Langacker 2008: 43). Insbesondere in diesem Punkt ist die Nähe zwischen der perzeptuell-optischen Wahrnehmung ${ }^{58}$ und der Konstituierung der sprachlichen Bedeutungen in der Kognitiven Grammatik gut sichtbar, Langacker bedient sich zur Veranschaulichung der Beziehung zwischen dem konzeptuellen Inhalt (conceptual content) und dem sog. construal einer Szene-Metapher: Der konzeptuelle Inhalt wird als Szene dargestellt, die man aus verschiedenen Punkten betrachten kann. Wie die Szene wahrgenommen wird, hängt von mehreren Faktoren ab: dem Abstand des Betrachters zur Szene, den Objekten, auf denen er seinen Blick länger ruhen lässt, oder der Betrachtungsperspektive. Parallel dazu besteht auch die Bedeutung aus zwei Komponenten, nämlich aus der Szene - dem konzeptuellen Inhalt und aus der Art und Weise, wie diese Szene angesehen und was in der Szene fokussiert wird - die Letztere wird von Langacker construal (Konstruktion, Interpretation, Deutung) genannt: „Most broadly, a meaning consists of both conceptual content and a particular way of construing that content" (ebd.). Derselbe konzeptuelle Inhalt kann folglich aus verschiedenen alternativen Perspektiven und mit dem Fokus auf unterschiedliche Aspekte beschrieben werden. Bemerkenswert ist dabei, dass er nur analog, bildhaft abgebildet, neutral bleibt (vgl. Abb. 8a): Jede Versprachlichung ist unausweichlich mit einer interpretativen Konstruktion (construal) aus der Betrachterperspektive verbunden (vgl. Abb. 8b-d): das Glas mit Wasser (Abb. 8b) profiliert ,Glas‘, das Wasser im Glas profiliert ,Wasser` (Abb. 8c), das Glas ist halbvoll profiliert den Bereich vom Glasboden bis zur Wasseroberfläche (Abb. 8d), das Glas ist halbleer profiliert den Bereich von der Wasseroberfläche bis zum Glasrand (Abb. 8e).

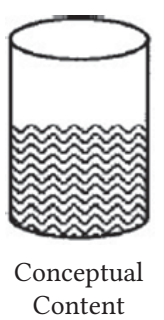

a) Konzeptueller

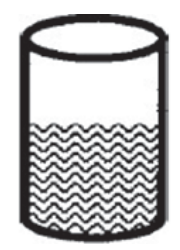

Construal $_{1}$

b) Interpretation (construal) 1: das Glas mit Wasser

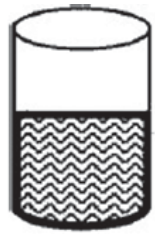

Construal $_{2}$

c) Interpretation (construal) 2: das Wasser im Glas

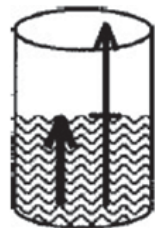

Construal $_{3}$

d) Interpretation (construal) 3: das Glas ist halb- das Glas ist halbvoll

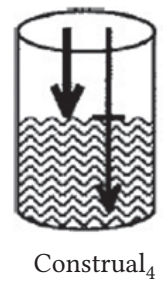

e) Interpretation (construal) 4: leer

Abb. 8: Konzeptueller Inhalt (conceptual content) und Interpretation (construal) (Langacker 2008: 44).

56 Engl. imagistic - als Gegensatz zu propositional.

57 Engl. imaginative - Metapher, Blending, Mental-Space-Konstruktion umfassend.

58 Näheres dazu im Unterkap. 2.2.5. 
Die Fokussierung hängt mit der Domänenselektion zusammen: Von allen zugänglichen Domänen innerhalb einer Domänenmatrix wird in einem bestimmten Kontext nur eine eingeschränkte Anzahl aktiviert, wobei der Aktivierungsgrad variieren kann und der Hervorhebung (engl. foregrounding) entspricht. Darüber hinaus konstituiert sich aus den aktivierten Domänen ein Bereich (engl. scope), in dem sie sich decken ${ }^{59}$. Dieser Überlappungsbereich aller aktivierten Domänen nennt Langacker Basis, während besonders hervorgehobene Strukturen, auf denen die Aufmerksamkeit fokussiert ist, Profile genannt und auf den Abbildungen durch fett gedruckte Linien markiert werden (ebd.).

Langackers Auffassung der linguistischen Bedeutung ist in größerem Maße auf die Erforschung der konzeptuellen Ontologie (Evans/Green 2006: 231) gerichtet. Sein Bedeutungsverständnis zeichnet sich sowohl auf der Ebene eines (mehr oder weniger) stabilen Konzepts als auch auf der Ebene einer kontextbedingten Konzeptualisierung durch die Subjektzentriertheit aus. Eine Lautkette kann eine unbestimmbare Anzahl der Domänen aktivieren, deren Grenzen nur in dem von einem Menschen im Langzeitgedächtnis gespeicherten Wissen liegen. Damit werden die Domänen als kognitive Konstruktionen eines Individuums, nicht als objektive Beschreibungsgrößen betrachtet. Dies macht eine nach Objektivität strebende wissenschaftliche Beschreibung einer Konzeptualisierung enorm schwierig: Weder eine genaue Anzahl der jeweils aktivierten Domänen noch deren eindeutige hierarchische Strukturierung lässt sich spezifizieren. Die Konzeptualisierungen sind dynamisch, vage, zu einem gewissen Grad individuell, weisen keine scharfen Grenzen und keine konstanten Werte auf. Auf der anderen Seite lässt Langackers Auffassung die multimodale Struktur der Domänen zu: Das aufgespeicherte Wissen kann sowohl einer propositionalen, als auch einer analogen, motorischen u.a. Natur sein, die interpretative Konstruktion einer Bedeutung (construal) ist von Natur aus verbildlichend. Damit wird auf die Gesamtheit der menschlichen Erfahrung Bezug genommen.

\subsubsection{Interaktionismus und die Rolle des Sprachgebrauchs}

Die Kognitive Linguistik bricht mit der für die Sprachwissenschaft klassischen Aufteilung in Sprachsystem und Sprachgebrauch (langue und parole von de Saussure). Stattdessen wird ein gebrauchsfundiertes Modell der Sprache vorgeschlagen: Die Bedeutung einer sprachlichen Einheit wird als eine Spur der vorausgehenden kognitiven Erfahrungen eines Menschen betrachtet, dem sprachlichen Gebrauch kommt eine zentrale Rolle zu, die Sprache wird als weitgehend soziokulturell fundiertes kognitives Phänomen angesehen:

59 „For each domain in its matrix, an expression has a scope consisting of its coverage in that domain" (Langacker 2008: 62). 
A language does not reside in grammar books and dictionaries, and looking in a speaker's brain does not reveal a box labeled L. The basic reality is simply that people talk, in ways that are similar to vary in degrees. Talking is a complex activity, so ultimately a language must be viewed dynamically, as something people do rather than something they have. The various facets of this activity - motor, perceptual, and mental - are either controlled or constituted by neural processing, so in a broad sense talking is cognitive activity. Moreover, since a language is acquired and used by way of interacting with others in a social and cultural context, the activity is socio-cultural in nature. (Langacker 2008: 216)

Sprache hat einen dynamischen, konstruktiven Charakter. „Die lexikalische Bedeutung eines Wortes ist im Grunde genommen eine Hypostasierung, denn die Sprachbenutzer werden eher mit jeweils neuen aktuellen Bedeutungen konfrontiert" (Sadziński 2018: 60). Sprachlich aktuelle Bedeutungen konstituieren sich direkt in der Kommunikation; als die kleinste Analyseeinheit wird eine sprachliche Einheit angesehen. Grundlegend für die Entstehung der Konzepte sind rekurrente Erfahrungen, sich wiederholende Sprachgebrauchsereignisse (engl. events of language use), wobei die Beziehung zwischen den Konzepten und den ihnen zugrunde liegenden Sprachgebrauchsereignissen durch die Inhaltsbedingung (engl. content requirement) eingeschränkt ist (Langacker 2008: 220). Nach dieser Bedingung werden als sprachliche Einheiten ausschließlich:

(i) semantische, phonologische und symbolische Strukturen, die in den Sprachausdrücken wirklich vorkommen;

(ii) die Schematisierungen von diesen Strukturen;

(iii) sowie die kategorisierenden Relationen zwischen diesen Strukturen betrachtet (ebd., 25).

Von ausschlaggebender Bedeutung ist deswegen das Prinzip der Rekurrenz: Die grundlegenden, sich auf alle Sprachebenen beziehenden Prozesse der Schematisierung und der Kategorisierung sind dann möglich, wenn die Ausdrücke mit bestimmter Frequenz auftauchen, d.h. - in der Terminologie der Kognitiven Grammatik ausgedrückt - wenn eine ausreichende Anzahl der Konkretisierungen (Sprachgebrauchsereignisse) vorliegt.

Die Schematisierung wird als ein allgemeiner, die ganze menschliche Kognition bedingender Prozess aufgefasst. Im Spracherwerb beruht der Schematisierungsprozess auf dem Abstrahieren vom kontextuellen Verständnis des jeweiligen Ausdrucks auf der phonetischen und semantischen Ebene. Erst nachdem der Ausdruck in einer ausreichenden Anzahl der Gebrauchsereignisse vorgekommen ist, können sich die kognitiven Routinen herausbilden (Langacker 2008: 220). Schemata werden als verstärkte Regularitäten der auftauchenden Ausdrücke (Konkretisierungen) definiert, was Taylor (2007: 148) in folgender Form (vgl. Abb. 9) darstellt: 


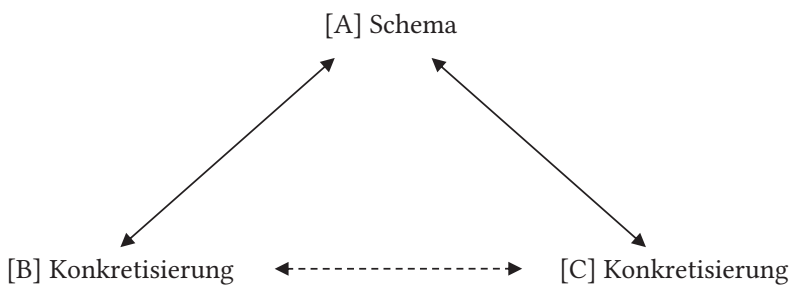

Abb. 9: Schema und Konkretisierungen nach Taylor (2007: 148).

Die sprachlichen Einheiten, die sich durch ursprüngliche Sprachgebrauchsereignisse etabliert haben, üben bei allen weiteren Gebrauchsereignissen die Funktion der Schablonen aus. Bei jedem Sprachgebrauchsereignis, in dem sie vorkommen, werden sie dennoch einer Verifikation unterzogen. Die Beziehung zwischen den etablierten Spracheinheiten und den Ausdrücken in der neuen ko- bzw. kontextuellen Umgebung ist auf die Relation der Kategorisierung zurückzuführen (Langacker 2008: 222). Falls sich das Schema in einem Sprachgebrauchsereignis voll und ohne Verzerrungen manifestiert, liegt die elaborative Kategorisierung vor - der Gebrauch eines Ausdrucks verstärkt dann das Schema. In manchen Fällen stellt der Gebrauch eines Ausdrucks in einem konkreten Sprachgebrauchsereignis eine Innovation dar, was seine Extension zur Folge hat. Dies erklärt, warum die Konzepte im Laufe des Lebens und unter dem Einfluss äußerer Umstände variieren können: Das Konzept eines Computers ist in den letzten 20 Jahren einer grundlegenden Revision unterzogen worden und hat sich an die veränderte Realität angepasst. Der Spracherwerb dauert im gewissen Sinne lebenslang.

Die konventionellen Bedeutungen von Spracheinheiten konstituieren sich demnach auf der Grundlage rekurrenter Sprachgebrauchsereignisse. Da die Schematisierungs- und Kategorisierungsprozesse weitgehend auf persönlichen, individuellen Erfahrungen basieren und bei jedem Sprachbenutzer bis zu einem gewissen Grad variieren können, sind die Kategoriengrenzen verschwommen, unscharf; da sie bei jedem Gebrauch einer Verifikation unterliegen, weisen sie einen dynamischen Charakter auf. Die sprachlichen Einheiten sind „soziale Tatsachen“ (Busse 1987: 272, zit. nach Ziem 2008: 152), sie sind dynamisch, aufs Engste an andere kognitive Bereiche gebunden, kontextabhängig, passen sich an die sich ändernde Wirklichkeit an (Piotrowska 2012, Waszakowa 2012). Sie können immer wieder aufs Neue ausgehandelt werden: Jeder Gebrauch einer sprachlichen Äußerung kann die etablierten Strukturen modifizieren, verschieben oder ändern. Die Stabilisierung ist immer relativ und beruht auf der Routinierung von Kategorisierungen der einer Sprachgemeinschaft zugehörenden Menschen: Die Kenntnis der sprachlichen Bedeutung eines Ausdrucks gründet selbst in der kommunikativen Praxis (Ziem 2008: 138).

Sprachliche Bedeutungen stehen am Ende eines dynamisch-kognitiven Konstruktionsprozesses, den Sprachzeichen initiieren. Anstatt eines gleich bleibenden semantischen „Kerns“ sorgen kognitive Routinen für eine effektive Erschließung sprachlicher 
Bedeutungen. Zur Routine wird Inferenzbildung dann, wenn sie durch rekurrent auftretende Wissens- und Handlungsmuster motiviert ist. (Ziem 2008: 170)

\section{EXKURS: Bedeutung in modularen und holistischen Ansätzen}

Der holistische Ansatz der Kognitiven Linguistik hebt damit die deutliche Abgrenzung zwischen dem Sprachsystem und dem Sprachgebrauch, dem Lexikon und der Grammatik, dem Weltwissen und dem Sprachwissen auf. Um die Einheitlichkeit der Bedeutungsauffassung in diesem Paradigma zu demonstrieren, werden im Folgenden zwei Beschreibungsansätze - ein modularistischer (das sog. Drei-Stufen-Modell von Schwarz) und ein holistischer (Langackers Kognitive Grammatik), die im Rahmen der Kognitiven Linguistik anzusiedeln sind - miteinander konfrontiert.

Schwarz (2008: 114) geht in ihrem Drei-Stufen-Modell, das als moderne Bedeutungsauffassung im modularistischen Paradigma angesehen wird, von der Annahme aus, dass Wortbedeutungen sprachlich relevante Ausschnitte von konzeptuellen Domänen sind. Sie unterscheidet in ihrem Drei-Ebenen-Modell zwischen Konzeptualisierungen, Konzepten und Bedeutungen. Konzepte basieren auf dem Prozess der Konzeptualisierung, d.h. der Bildung von geistigen, intern gespeicherten Repräsentationen. Konzepte werden also als stabile, im Langzeitgedächtnis gespeicherte, durch Schemata determinierte Repräsentationen verstanden. Unter Bedeutung versteht Schwarz versprachlichte Konzepte, d.h. mentale Inhalte, die mit einer verbalen Formrepräsentation versehen sind (Schwarz 2008: 114, Schwarz/Chur 2007: 26). Bedeutungen lassen sich folgendermaßen darstellen:

$$
\text { Kon }\left(\mathrm{x}_{1}-\mathrm{x}_{\mathrm{n}}\right) \leftrightarrow \operatorname{Sem}_{\text {syn }}\left(\mathrm{x}_{2}-\mathrm{x}_{5}\right) \leftrightarrow \mathrm{R}_{\text {phon }}
$$

Eine Bedeutung (Sem) entsteht also aus einer selektiven Lexikalisierung $\left(\mathrm{x}_{2}-\mathrm{x}_{5}\right)$ von Konzeptinformationen Kon $\left(\mathrm{x}_{1}-\mathrm{x}_{\mathrm{n}}\right)$ und der Bindung an eine phonologische/graphemische Repräsentation $\mathrm{R}_{\text {phon }}$ sowie an ein syntaktisches Subkategorisierungs$\operatorname{raster}\left({ }_{\text {syn }}\right)$ :

Bedeutungen werden somit nur als spezifische Selektionen von enzyklopädischen Wissenselementen abgegrenzt. Die Semantik bezieht ihre Inhalte aus dem konzeptuellen System, ihre Formen aber aus dem sprachlichen System. Konzeptuelle Inhalte werden also sprachspezifisch durch phonologische Repräsentationen und syntaktische Raster gebunden. In diesem Sinne ist das semantische Kenntnissystem Schnittstelle zwischen zwei kognitiven Subsystemen. (Schwarz 2008: 114)

Von Relevanz für diese Auffassung der Bedeutung ist die Annahme, dass die Konzepte von resistenter Natur sind. Die Erfahrung mit mehreren Vertretern der Hundefamilie führt zur Etablierung eines HUND-Konzeptes, das vereinfacht folgendermaßen beschrieben werden könnte: [ist ein Tier, hat vier Beine, hat einen Schwanz, kann bellen]. „Dieses Konzept fungiert als eine Art Klassifikationsregel für alle Hunde, da jedes Exemplar der Klasse Hund als Mitglied oder NichtMitglied des HUND-Konzepts identifiziert werden kann" (Schwarz 2008: 110). Der 
Inhalt eines Konzepts, der durch die jeweilige Menge an Merkmalen festgelegt wird, bestimmt die Menge aller Instanzen, die dem jeweiligen Konzept zugerechnet werden können (ebd.). Schwarz' Bedeutungsauffassung berücksichtigt also die Rolle der pragmatischen und enzyklopädischen Aspekte bei der Bedeutungskonstituierung, die Trennung zwischen einer semantischen, einer konzeptuellen und einer pragmatischen Bedeutungsebene wird aber aufrechterhalten.

Der holistische Ansatz unterscheidet sich von dem Drei-Ebenen-Modell in Bezug auf die Bedeutungsauffassung in zwei wichtigen Grundvoraussetzungen, die sich eng miteinander verzahnen. Zum einen wird keine Grenze zwischen dem konzeptuellen und dem sprachlichen System gezogen, man spricht von einer Ein-Ebenen-Semantik. Zum anderen verweist man nachdrücklich auf den dynamischen Charakter der als Konzepte und Konzeptualisierungen bezeichneten Phänomene. So argumentiert Langacker in seiner Kognitiven Grammatik, dass es keine stabilen Konzepte mit scharf umrissenen Grenzen gibt, denen man - so wie dies vom Schwarz am Konzept HUND gezeigt wurde - bestimmte feste Merkmale zuschreiben könnte. Was in der Wirklichkeit existiert und linguistisch untersucht werden kann, ist nicht Gegenstand stabiler Konzepte, sondern dynamischer Konzeptualisierungen. Die Bedeutung wird demnach mit den Konzeptualisierungen gleichgesetzt:

Meaning is not identified with concepts but with conceptualization, the term being chosen precisely to highlight its dynamic nature. Conceptualization is broadly defined to encompass any facet of mental experience. It is understood as subsuming (1) both novel and established conceptions; (2) not just „intellectual“ notions, but sensory, motor, and emotive experience as well; (3) apprehension of the physical, linguistic, social, and cultural context; and (4) conceptions that develop and unfold through processing time rather than being simultaneously manifested. (Langacker 2008: 30)

Erklärungsbedürftig ist dabei das Verhältnis zwischen Konzeptualisierungen und Konzepten. Wie bereits erwähnt, verweigert Langacker der Sprache und den sprachlichen Einheiten den Status einer resistenten Entität:

Meanings are seen as emerging dynamically in discourse and social interaction. Rather than being fixed and predetermined, they are actively negotiated by interlocutors on the basis of the physical, linguistic, social, and cultural context. Meaning is not localized but distributed, aspects of it inhering in the speech community, in the pragmatic circumstances of the speech event, and in the surrounding world. (...) The static, insular view ascribed to cognitive semantics is deemed incapable of handling the dynamic, intersubjective, context-dependent nature of meaning construction in actual discourse. (Langacker 2008: 28)

Andererseits gibt er an einer anderen Stelle zu, dass bei aller Dynamik der Sprache den Konzeptualisierungen etwas Stabiles, Konventionalisiertes, Erwartbares zugrunde liegen muss, damit sich die Menschen verständigen können (Langacker 2008: 30). Die Kognitive Semantik lehnt sowohl die objektivistische Annahme der traditionellen Semantik von der stabilen, unflexiblen Bedeutung ab, als auch das 
andere Extrem - die interaktionistische Annahme, laut derer die Bedeutung einer sprachlichen Einheit jedes Mal von Grund auf, von Null im Diskurs interaktiv ausgehandelt wird (ebd.):

Clearly, there must be something inside the head. Speakers must have some preconception of what the words they use are normally expected to mean. Otherwise the meanings negotiated would be completely random, and cat would have no greater likelihood of meaning 'feline' than 'walnut', 'book', or 'through'. While everything may be negotiable, something has to be learned and conventionalized as a basis for negotiation. (Langacker 2008: 30)

Damit dürfte wohl die Existenz einer mentalen Repräsentation (eines Konzeptes) angenommen werden: Konzepte werden aber nicht als Entitäten mit scharfen Konturen und festen Merkmalen verstanden, sondern eher als gebrauchsbasierte kognitive Routinen, die sich dynamisch ändern, den jeweiligen Kontexten flexibel anpassen und in denen sich - wenigstens teilweise - die individuellen Lerngeschichten der Sprachteilhaber widerspiegeln. Bei aller Dynamik und Unschärfe der Konzeptualisierungsprozesse ist Langackers Theorie - im Gegensatz zu radikal gebrauchsbasierten Ansätzen - als repräsentionalistisch einzustufen.

\subsubsection{Zusammenfassung und Ausblick}

Die Beschreibung der Sprache aus holistischer Perspektive zeichnet sich durch eine ganzheitliche Sicht auf die Kognition und Sprache, die Veranschaulichung zahlreicher Wechselbeziehungen und verschwommener Grenzen zwischen unterschiedlichen Sprachebenen, sublime Darstellung der Phänomene, die Dasjenige aufbauen, was wir als Bedeutung bezeichnen, aus. Das einfachste Lexem kann die Grundlage einer wissenschaftlichen Monographie bilden, die ungeheure Menge und Komplexität des Wissens, das die jeweiligen Konzeptualisierungen bildet, sowie ihre partielle Subjektivität erleichtern die Arbeit eines Linguisten bestimmt nicht. Vor dem Hintergrund ihrer Dynamik, Prozessualität und ihres interaktionalen Charakters verweist man auf die Relativität der Sprache in der klassischen Auffassung dieses Phänomens:

There is not such a thing as „a language“, at least as this term is commonly understood, both by linguists as ordinary people. (Langacker 2008: 215) (...) Objectively, there is no single entity that can be so identified. There are simply lots of people - hundreds of millions of them - who talk in rough similar ways (sometimes very roughly indeed). Strictly speaking, each person has a distinct linguistic system (or idiolect). These individual systems do exhibit a strong family resemblance, however and like the members of an extended family, some systems resemble one other quite closely, others more distantly (...). If thought of a clearly delimited entity with definite boundaries, neither a dialect nor a language exists in the wild, but only as a mental construction the product of idealisation, reification and metaphor. The mental construction of the 
language is itself grounded in social interaction and cultural attitudes. (Langacker 2008: 228)

Vor diesem Hintergrund wird ebenfalls bei der Definierung der Bedeutung auf ihre „schimmernde“ Natur im natürlichen Sprachgebrauch - ihre verschwommenen Grenzen, ihre Dynamik und Gebrauchsbasiertheit - verwiesen. Die sprachlichen Bedeutungen werden nicht als stabile Gebilde, denen A- oder B-Werte zugewiesen werden, sondern als dynamische Konstrukte aufgefasst. Die Charakteristika der Bedeutungen lassen sich aus der Perspektive der Kognitiven Linguistik in folgenden Punkten zusammenfassen:

(i) Bedeutungen sind in mentalen Repräsentationen angesiedelt, d.h., sie referieren nicht auf die Objekte der realen Welt, sondern auf mentale Repräsentationen dieser Objekte, die als Konstrukte des menschlichen Geistes gewissen Verzerrungen unterliegen. Die innere Welt der mentalen Repräsentationen steht nie in einem 1:1-Verhältnis zu der realen Welt: Selbst die Wahrnehmung ist durch selektive Aufmerksamkeit gesteuert; die darauf folgende Speicherung der wahrgenommenen Inhalte ist weitgehend durch die bereits bestehenden kognitiven Strukturen beeinflusst und an diese angepasst. ${ }^{60}$ Die Bedeutungen werden als Manifestationen der konzeptuellen Struktur eines Menschen angesehen und als solche widerspiegeln sie diese Struktur in ihrer ganzen Komplexität, Verflochtenheit, individuellen Zügen und Veränderlichkeit: „Research on cognitive semantics is research on conceptual content and its organisation in language" (Talmy 2000: 4).

(ii) Die Bedeutungen sind embodied. Sie bauen auf präkonzeptuellen Strukturen auf, die das Kind in der Interaktion mit seiner physischen, sozialen und kulturellen Umwelt erwirbt. Der Körper und die über Körper vermittelte Erfahrung bilden somit den Ausgangspunkt zur Konstituierung der kognitiven Struktur und Wissensorganisation eines Individuums, die unumgänglich durch die Eigenschaften des Körpers und seine biologischen Einschränkungen eingeengt sind:

We have a species-specific view of the world due to the unique nature of our physical bodies. In other words, our construal of reality is likely to be mediated in large measure by the nature of our bodies. (Evans/Green 2006: 45)

Die Beschaffenheit des menschlichen Körpers beeinflusst damit auf einer tiefen Ebene die kognitiven Strukturen, die den konzeptuellen Pol einer sprachlichen Einheit bilden. In diesem Sinne sind die Bedeutungen durch biologische Eigenschaften der Menschen sowie seine körperliche und soziale Erfahrung determiniert.

(iii) Die Bedeutungen sind holistisch. Sprachliche Fähigkeiten sind aufs Engste mit den Denkfähigkeiten verbunden, sprachliche Operationen stellen spezifische Ausprägungsformen von Konzeptualisierungsleistungen dar (Ziem 2008: 103). Es werden keine Grenzen zwischen dem Sprachlichen und dem Konzeptuellen

60 Wenn sich mehrere Menschen ein Bild ansehen, werden sie es aller Wahrscheinlichkeit in gewissen Rahmen doch unterschiedlich beschreiben und interpretieren. 
gezogen, der phonologische Pol einer sprachlichen Einheit verschafft dem Sprechenden und dem Rezipierenden einen direkten Zugang zu vorstrukturierten Wissensstrukturen, die im Langzeitgedächtnis als mentale Repräsentationen von (rekurrenten) Erfahrungen gespeichert sind. Die Sprache greift auf allgemeines Weltwissen zurück und es bestehen keine eindeutigen und festen Indikatoren dafür, welche Elemente dieses Weltwissens durch den phonologischen Pol einer sprachlichen Einheit evoziert werden. Wie Langacker (1987: 154) am Beispiel des Wortes banana veranschaulicht, sind die semantischen Merkmale, die einer Banane im Rahmen der Merkmalstheorie zugewiesen werden müssten [Frucht, gelb, längliche Form, süßlich, wohlschmeckend] für die Konzeptualisierung der Wortverbindung banana republic zweitrangig. Fundamental für die Konzeptualisierung einer Bananenrepublik ist nämlich ein spezifisches, peripheres Wissen über die Rolle der Bananen als einer Exportware für die Wirtschaft mancher kleinen, vom fremden, hauptsächlich US-amerikanischen Kapitel abhängigen Länder Mittelamerikas. Jede sprachliche Bedeutung ist damit in ein Netz epistemischer Annahmen über die Welt eingebettet (Ziem 2008: 173), es existieren keine Zwischenebenen, die zwischen dem semantischen und dem konzeptuellen Wissen vermitteln. Alle Wissensstrukturen, die im Langzeitgedächtnis gespeichert sind, können in bestimmten Kontexten von Relevanz sein und die Bedeutung konstruieren.

(iv) Die Bedeutungen sind dynamisch: Der phonologische Pol einer sprachlichen Einheit aktiviert Wissensdomänen, unter denen diejenigen profiliert werden, die für die Rezeption einer sprachlichen Einheit in einem Kontext notwendig sind. Weder der Sprache noch den sprachlichen Bedeutungen wird der Status eines konstanten Phänomens zugewiesen, das objektiv existiert und beschrieben werden kann (Langacker 2008: 217-219). Die Bedeutungen werden mit emergenten, in der Interaktion entstehenden Konzeptualisierungen gleichgesetzt, sie konstituieren sich in einzelnen kommunikativen Akten.

(v) Die Bedeutungen sind gebrauchsbasiert: Die Kenntnis der sprachlichen Bedeutung eines Ausdrucks gründet in der kommunikativen Praxis (Ziem 2008: 138). Die Konzeptualisierungen sind emergent, dynamisch, vage. Auf ihrer Grundlage entstehen Konzepte, die dennoch nicht als resistente Strukturen mit scharf umrissenen Grenzen, sondern als kognitive Routinen, schematisierte Kategorisierungsleistungen des Individuums aufgefasst werden. Das traditionelle Bild von sprachlichen Ausdrücken als Behälter für kleine Mengen semantischer Information wird ersetzt durch die Betrachtung sprachlicher Ausdrücke als Zugang (access, Langacker 1987: 161) zu einem umfassenden Wissenssystem, das ein Netzwerk von Beziehungen, den sog. kognitiven Routinen, bildet. (Baldauf 1997: 38)

Dies bedeutet zum einen, dass sie keine scharfen Grenzen, keine feste Struktur und keine eindeutig zuzuordnenden Werte/Merkmale haben und mit jedem Gebrauch modifiziert werden können. Zum anderen erklärt die Auffassung der Konzepte als kognitiver Routinen die individuellen Unterschiede bei den Konzeptualisierungen: Jeder Mensch hat eine andere Vorstellung des Hauses, des Autos, des Hundes, weil jeder Mensch andere Erfahrungen mit diesen Entitäten gesammelt hat. Gleichzeitig ergibt sich aus den wiederholten Erfahrungen ein mehr oder 
weniger umrissenes mentales Konstrukt, das in seinen Grundzügen allen Sprachteilhabern gemeinsam ist.

\subsection{Analoge Repräsentationsformate und anschauliches Denken in der Kognitiven Linguistik}

Wie aus dem vorangegangenen Kapitel ersichtlich ist, hebt der holistische Ansatz der Kognitiven Linguistik die traditionelle Auseinandergrenzung zwischen der Sprache und anderen kognitiven Fähigkeiten auf, sowie relativiert die Grundannahmen der traditionellen Semantik: die Homogenitäts- und Kompositionalitätsannahme (Busse 2009: 18-19). In den Mittelpunkt des Interesses wird dagegen die Einsicht gerückt, dass das Ganze oft mehr als die Summe der Komponenten impliziert. Diese Einsicht teilt die Kognitive Linguistik mit der Gestaltpsychologie, die sich in den 30er Jahren in Europa, insbesondere in Deutschland, entwickelt hatte und eine Reihe von Gestaltgesetzen und -prinzipien, die die menschliche Wahrnehmung steuern, aufstellte. Interessanterweise bezogen sich die Gesetze der Gestaltpsychologie in erster Linie auf die visuelle Wahrnehmung: Die Gestaltpsychologen stellten unter Beweis, dass der Wahrnehmungsapparat die dargebotenen Reize nicht nur mechanisch abbildet, sondern bereits einer Interpretation unterzieht. Als Beispiel kann an dieser Stelle das von Wertheimer (1923: 83) vorgeschlagene Gestaltgesetz der Geschlossenheit herangeführt werden: Die Punkte, die auf imaginären Kreislinien mit entsprechender Dichte angeordnet sind, werden trotz der Lücken als Kreise wahrgenommen.

Der Einfluss der Gestaltpsychologie auf die Begründer der Kognitiven Linguistik, Lakoff, Johnson, Langacker und Talmy, ist unverkennbar, auch wenn er in der zweiten Hälfte des 20. Jh. bevorzugt indirekt erfolgte (Wildgen 2008: 24). Rosch (1975) weist den Begriffen der Basisebene die Form von ganzheitlich wahrgenommenen und aufbewahrten Gestalten zu, einen Gestaltcharakter haben ebenfalls Lakoffs und Johnsons Domänen in der konzeptuellen Metapherntheorie ${ }^{61}$. Das Figur-Grund-Gesetz findet Widerspiegelung in der Trajektor (Figur) und Landmark (Grund)-Unterscheidung, der ein wichtiger Stellenwert in Langackers Kognitiven Grammatik zukommt. Auf den Einfluss des Figur-Grund-Gesetzes auf unsere Konzeptualisierungen verweist des Weiteren Talmy (2000: 314): Auch wenn die Präposition near an sich symmetrisch ist, neigen die Menschen dazu, den Satz (ii) als unüblich oder gar dubios zu bezeichnen:

(i) The bike is near the house.

61 Gestalten definieren Lakoff und Johnson (1980: 117) als strukturierte Ganzheiten innerhalb unserer Erfahrung, die „coherent organisations of our experiences in terms of natural dimensions (parts, stages, causes etc.)“ repräsentieren. 
(ii) ? The house is near the bike ${ }^{62}$.

Insgesamt lässt sich feststellen, dass der weit gefassten Bildhaftigkeit ein wichtiger Stellenwert innerhalb des holistischen Paradigmas eingeräumt wird.

Knowing the meaning of a word that denotes a physical object involves in part knowing what such an object looks like. (Jackendoff 1987: 201)

Die neuere Forschung geht dabei über das Visuelle hinaus: Sprache ist eng an das konzeptuelle System gebunden, in dem Erfahrungen des Menschen in allen Modalitäten mental repräsentiert sind. Johnson-Laird spricht in diesem Sinne schon 1983 von mentalen Modellen, die prinzipiell als Kombinationen von ganzheitlichen analogen und propositionalen, symbolmanipulierenden (digitalen) Repräsentationen verstanden werden (Stöckl 2004: 56). Diese mentalen Repräsentationen, die allen kognitiven Prozessen zugrunde liegen, werden als Produkte eines konstruktiven Prozesses angesehen. $\mathrm{Zu}$ ihrer Herausbildung ist eine bestimmte Anzahl rekurrenter Erfahrungen notwendig, die sich auf komplexe Mensch-Umwelt-Kontakte beziehen. Dementsprechend ist die Inhaltsseite der sprachlichen Einheit HUND auf der Grundlage zahlreicher Erfahrungen entstanden, in denen das Kind den Hund gesehen, gestreichelt, die von ihm gegebenen Laute (bellen, winseln usw.) oder seinen Geruch wahrgenommen hat. Diese Mensch-Umwelt-Kontakte involvieren normalerweise mehrere Sinnesmodalitäten (sensomotorische Modalitäten des Olfaktorischen, Motorischen/Kinesthätischen, Taktilen, Auditiven und Visuellen), in unterschiedlichen Modalitäten sind dementsprechend auch die in das Ultrakurzzeit- und demnächst in das Kurzzeitgedächtnis gelangenden Reize, die dann bei der Überführung in das Langzeitgedächtnis in dauerhaftere Repräsentationsformen umgestaltet werden müssen und mentale Konstrukte bilden. Die Frage, in welcher Modalität diese Konstrukte dann langfristig aufbewahrt werden, d.h., welche Modalität die mentalen Repräsentationen aufweisen, gehört zu den wichtigsten, kontrovers diskutierten und besonders schwierigen Problemen der Gedächtnisforschung und der kognitiven Psychologie, auf die beim derzeitigen Forschungsstand keine unumstrittene Antwort vorliegt.

62 Im Bereich der räumlichen Beziehungen identifizierte Talmy (2000: 315-316) folgende Objekteigenschaften, die für die Figur-Ground-Unterscheidung verantwortlich sind:

Figur

location less known

smaller

more mobile

structurally simpler

more salient

more recently in awareness

\author{
Ground \\ location more known \\ larger \\ more stationary \\ structurally more complex \\ more backgrounded \\ earlier on scene/in memory
}


Kontrovers diskutiert wird ebenfalls die Frage, ob die mentalen Repräsentationen in einem einheitlichen, alle Sinnesmodalitäten umfassenden Format aufbewahrt werden oder ob mit mehreren Modalitäten zu rechnen ist. Unitäre Repräsentationstheorien setzen die Existenz von amodalen Repräsentationen voraus, die neueren Theorien gehen von der Annahme aus, dass die mentalen Repräsentationen menschlichen Wissens multimodalen Charakter haben.

Da die erwähnten Probleme bei all ihrer Komplexität und Umstrittenheit einen Einblick in die phraseologische Bildhaftigkeit gewähren und bei ihrer Behandlung relevant sind, werden in den folgenden Unterkapiteln zuerst mentale Repräsentationsformate dargestellt, dann unitäre, duale und multimodale Repräsentationstheorien geschildert. Im Fokus der Aufmerksamkeit steht dabei der neuere Grounded Cognition-Ansatz, der die multimodale Natur mentaler Repräsentationen mit zahlreicher empirischer Evidenz unterstützt. Von großer Relevanz für die Erklärung der Rolle von mentalen Bildern in der Phraseologie scheinen auch sog. Begriffe der Basisebene (Rosch et al. 1976) zu sein, die im Kap. 2.2.3 behandelt werden.

\subsubsection{Repräsentationsformate}

Kognitive Wissensstrukturen umfassen alle Informationen, die modalitätsspezifisch (visuell, motorisch, olfaktorisch, sprachlich usw.) in Erfahrungssituationen verarbeitet worden sind (Schwarz 2008: 119-120). Die im Langzeitgedächtnis aufbewahrten mentalen Repräsentationen definiert Schwarz (ebd., 120) allgemein als systeminterne Zustände, die externe Umstände der Umwelt in einer bestimmten Art und Weise abbilden. Die Frage, ob die mentalen Repräsentationen modalitätsspezifisch (visuell, olfaktorisch, gustatorisch) oder amodal aufbewahrt werden, ist für die Kognitionswissenschaften von zentraler Bedeutung: Die permanent gespeicherten mentalen Repräsentationen bilden den Ausgangspunkt aller Verhaltens- und Denkleistungen. Dabei ist das Interesse der Forscher nicht gleichmäßig auf alle Modalitäten gerichtet: Die Übersicht über die durchgeführten Experimente (vgl. Anderson 1988: 79-120) lässt schlussfolgern, dass besonderes Interesse der Aufbewahrung von visuellen und sprachlichen Reizen zukommt. Ebenfalls Lakoff hebt die Rolle des Visuellen und der Sprache hervor:

Two of our major sources of information are vision and langugage. We can gain information through either perceiving something directly or being told it. (Lakoff 1987: 440)

Es kann also nicht wundern, dass zwei entsprechenden Repräsentationsmodi: der aussagenartigen und der analogen Repräsentation besonders viel Aufmerksamkeit gewidmet wird (Anderson 1988: 79-120; Schwarz 1992: 91-93, Schwarz 2008: 121123). Betonenswert ist dabei die von Grund auf unterschiedliche Natur der mentalen Repräsentation: Während bei einigen der dauerhaften Repräsentationen die Tendenz besteht, die Struktur der ursprünglichen Wahrnehmung weitgehend zu 
erhalten, wird in anderen Fällen von Wahrnehmungsdetails abstrahiert, sodass nur die Bedeutung des Wahrgenommenen kodiert ist (Anderson 1988: 80).

Analoge (bildhafte, bei Anderson (1988: 86) wahrnehmungsmäßige) Repräsentationen geben die Wirklichkeit in Form von anschaulichen Vorstellungsbildern wieder. Sie werden als mentale Abbilder oder Szenen aufgefasst, die visuelle Charakteristika von repräsentierten Objekten beinhalten. In diesem Modus werden beispielshalber Bilder oder menschliche Gesichter aufbewahrt, die als Ganzes wahrgenommen und abberufen werden. Die ursprüngliche Annahme, dass die Wirklichkeit in dem analogen Repräsentationsformat „spiegelbildlich“ wiedergegeben wird, ist vor dem Hintergrund der neueren Erkenntnisse schwer aufrechtzuerhalten. Selbstverständlich ist für die visuelle Modalität eine bestimmte Ganzheitlichkeit der Wahrnehmung vorauszusetzen, der konstruktive Aspekt des Prozesses - sowohl bei der Wahrnehmung als auch in der Verarbeitung und Überführung der Reize in das Langzeitgedächtnis, wo sie als mentale Repräsentationen aufbewahrt werden - darf dennoch nicht vernachlässigt werden: „Das, was wir sehen, hängt nicht alleine vom optischen Input (Bildmerkmalen) ab, sondern auch ganz maßgeblich von erworbenen mentalen Schemata bzw. Modellen, die die Wahrnehmung in entscheidendem Maße steuern“ (Stöckl 2004: 57). Bildwahrnehmung und Bildverstehen werden des Weiteren von Emotionen, Einstellungen, Erwartungen, kulturellem und sozialem Vorwissen und vor allem von der Aufmerksamkeit beeinflusst (ebd., 58; vgl. auch Barsalou 1999, 2012).

Aussagenartige (propositionale, bei Anderson (1988: 103) bedeutungsmäBige) Repräsentationen stellen menschliches Wissen auf eine abstrakte Weise dar, indem sie von den modalitätsspezifischen Eigenschaften abstrahieren. Zahlreiche psychologische Experimente liefern Belege dafür, dass das Gedächtnis für verbale Kommunikationsinhalte nicht den genauen Wortlaut, sondern lediglich die Bedeutung der Botschaft aufbewahrt: So können sich die Menschen nach einigen Minuten nicht erinnern, ob der Satz im Aktiv oder im Passiv formuliert war, nur die Botschaft bleibt im Gedächtnis haften ${ }^{63}$. Als entsprechendes Repräsentationsformat werden Propositionen - kleinste Wissenseinheiten, die selbstständige Aussagen bilden können - angenommen. Propositionen setzen sich aus einem Prädikat und einem oder mehreren Argumenten zusammen. Die propositionale Darstellung des Satzes Birgit isst Schokolade sieht folgendermaßen aus (Schwarz 1992: 95):

((ESSEN (BIRGIT, SCHOKOLADE))

Propositionen bilden dann die Strukturen höherer Ordnung: Die Bedeutung eines Satzes oder eines Bildes wird als Netzwerk von Propositionen dargestellt (Anderson 1988: 103). Als Schemata bezeichnet Anderson (ebd.) große, komplexe Wissenseinheiten, die typische Eigenschaften von Mitgliedern allgemeiner Kategorien beinhalten.

63 Dasselbe bezieht sich auf die Bilder: Bedeutungshaltige Interpretation des Bildes ist wesentlich besser gespeichert als die visuellen Details (Anderson 1988: 103, 106-108). 
Handlungsmäßige Repräsentationen (Edelmann 1996: 221, 2000: 152) bilden sich durch den handelnden Umgang mit Dingen aus. Das Lernen erfolgt durch unmittelbare Erfahrung und Ausführung von Tätigkeiten, diese Repräsentation ist für Kleinkinder von besonderer Relevanz. Möglicherweise ist die handlungsmäßige Repräsentation ebenfalls für das sog. Körpergedächtnis zuständig: Einmal gelernte Bewegungsabläufe wie Fahrradfahren, Schwimmen oder Tanzen bleiben lebenslang erhalten.

Es liegt nahe, dass außer besprochenen Repräsentationsformaten auch andere Formate für entsprechende Sinnesmodalitäten möglich sind. Wie die Gerüche, Geschmäcke, Tasterlebnisse, innere Zustände aufbewahrt werden, wird zurzeit intensiv erforscht (vgl. u.a. Schack 2010).

\subsubsection{Repräsentationstheorien}

Bezüglich der Repräsentationsfrage herrschen zwei Positionen vor, die im Folgenden als die unitäre bzw. multimodale Repräsentationstheorie bezeichnet werden. Die unitären (amodalen) Repräsentationstheorien, die man öfters auch klassisch benennt (vgl. Rickheit/Weiss/Eikmeyer 2010: 105, Barsalou 2012: 246), gehen von der Annahme aus, dass die konzeptuelle Seite eines sprachlichen Zeichens durch abstrakte, amodale Symbole konstituiert wird. Im Gegensatz dazu liegt den neueren Embodied/Grounded-Cognition-Ansätzen die Voraussetzung zugrunde, dass Kognition und Wahrnehmung ein gemeinsames System bilden, in dem mentale Repräsentationen in verschiedenen Modalitäten aufbewahrt werden. Einen interessanten Übergang zwischen den beiden Standpunkten stellt die duale Repräsentationstheorie von Paivio dar, auf die im Kap. 2.2.2.2 kurz eingegangen wird.

\subsubsection{Unitäre Repräsentationstheorie}

Zahlreichen kognitiven Theorien des 20. Jh. liegt die Annahme von amodalen Symbolen als wichtigsten Repräsentationseinheiten zugrunde (Newell/Simon 1972, Fodor 1975, Pylyshyn 1984). Die unitäre Repräsentationstheorie nimmt an, dass für alle Informationen nur ein einziges, amodales, abstraktes Repräsentationsformat existiert (Pylyshyn 1973, 1984; Anderson 1976). Auch wenn Menschen perzeptuelle Reize über verschiedene Sinneskanäle aufnehmen, werden die Reize verschiedener Sinnesmodalitäten im Arbeitsgedächtnis zu amodalen Repräsentationen in Form von feature lists, Propositionen, Schemata, semantischen Netzwerken und Produktionssystemen umgewandelt. Diese amodalen Strukturen fungieren dann als vermittelnde und integrierende Kognitionsebene und konstituieren ein System, das allen Funktionen der höheren Kognition wie Gedächtnis, Wissen, Sprache und Denken zugrunde liegt. Die höheren kognitiven Funktionen, darunter die Sprache, operieren demnach auf einem System abstrakter symbolischer Repräsentationen, die - einmal etabliert - auch stabil bleiben. Abbildung 10 veranschaulicht, wie die perzeptuellen Reize den amodalen Repräsentationstheorien zufolge in ein neues amodales System überführt werden: 


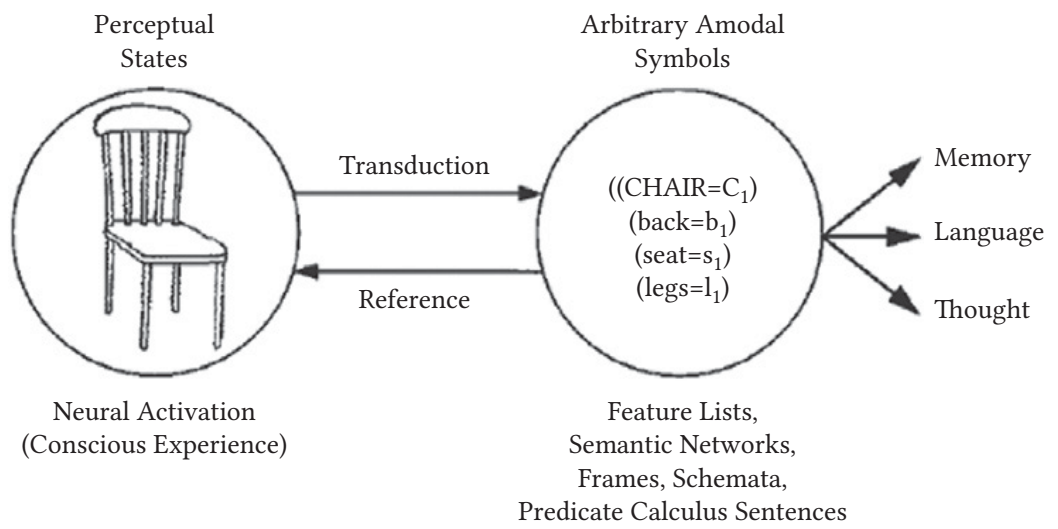

Abb. 10: Die Grundannahmen der amodalen Repräsentationsysteme (Barsalou 1999: 579).

Wie Barsalou (2008: 620, 631) bemerkt, ist die Popularität der unitären Repräsentationstheorie vor allem darin begründet, dass sie einen eleganten und ausdrucksstarken Formalismus zur Wissensrepräsentation liefert, intuitiven Annahmen zum symbolischen Charakter der Kognition gerecht wird und sich gut in den Künstliche-Intelligenz-Studien einsetzen lässt. Die unitäre Theorie des konzeptuellen Systems erklärt z.B. die Unterschiede zwischen types und tokens ${ }^{64}$, erlaubt die kategorialen Schlussfolgerungen und eignet sich zur Darstellung, wie abstrakte Konzepte repräsentiert werden. Pecher/Zwaan (2005) verweisen auf zwei fundamentale Probleme der amodalen Repräsentationstheorien: das Problem der Übersetzbarkeit der modalen Sinnesreize in arbiträre Symbole, die die Konzepte konstituieren (transduction problem), sowie die Frage, wie sich diese Symbole zurück auf die reale Welt beziehen. Darüber hinaus stellen unitäre Repräsentationstheorien vor allem theoretisches Modell dar, das empirisch kaum überprüft und revidiert wurde (Barsalou 1999: 578). Demgegenüber legt die Neurolinguistik immer mehr Evidenz dafür vor, dass das menschliche kategoriale Wissen doch an sensorisch-motorische Gehirnareale gebunden ist und Läsionen von bestimmten Gehirnregionen zu Problemen in der konzeptuellen Verarbeitung von Kategorien führen können.

64 Type-Konzepte sind Konzepte, die Informationen über ganze Klassen von Objekten speichern, Token-Konzepte repräsentieren individuelle Konzepte (Schwarz 2008: 109). 


\subsubsection{Duale Repräsentationstheorie}

Parallel zu unilateralen Repräsentationstheorien stellte Paivio in den 70er Jahren des 20. Jh. die duale Repräsentationstheorie vor, die sich besonders auf die Aufbewahrung und Verarbeitung von verbalen und visuellen Informationen konzentriert. Paivio $(1971,1986)$ setzt die Existenz von zwei modalitätsspezifischen Systemen voraus: Im imaginalen Subsystem werden imagene, d.h. nonverbale, bildhafte Gedächtnisspuren in einer analogen Form aufbewahrt. Das verbale Subsystem der logogene umfasst abstrakte Repräsentationseinheiten, die eng an die menschliche Sprache gebunden sind. Imagene und logogene weisen unterschiedliche Charakteristika auf: Die Erstgenannten werden synchronisch (simultan) verarbeitet und aufbewahrt (Paivio 1986: 59), die Zweitgenannten - als verbale Repräsentationseinheiten - zeichnen sich durch eine sequenzielle Struktur aus. Einzelne Entitäten sind in beiden Systemen miteinander verknüpft und organisiert, während die Subsysteme selbst autonom existieren und arbeiten können. Paivio (1986: 69-70) geht dabei von drei Arten der Beziehungen (connections) innerhalb des ganzen Systems aus: Repräsentationale Beziehungen (representational connections) verbinden modalitätsspezifische Reize der repräsentierten Welt und ihre mentalen Repräsentationen (imagene und logogene). Auf dieser Ebene werden logogene durch sprachliche Stimuli und imagene durch nonverbale Stimuli mental repräsentiert. Assoziative Verknüpfungen (associative structure) finden innerhalb jedes Subsystems statt und bedeuten, dass eine modalitätsspezifische Repräsentation eine andere Repräsentation derselben Modalität aktivieren kann. Referentielle Beziehungen (referential connections) stellen die Verknüpfungen zwischen dem System der logogene und dem System der imagene her: Ein typisches, von Paivio herangeführtes Beispiel dafür ist das Beschreiben von Bildern sowie das Evozieren von mentalen Bildern zu Wörtern. Die dual-coding-Theorie veranschaulicht schematisch Abb. 11.

Paivios duale Repräsentationstheorie stellt einen Übergang zwischen den unitären und multimodalen Repräsentationstheorien dar. Sie trägt dem empirisch in zahlreichen Untersuchungen nachgewiesenen Überlegenheitseffekt $t^{65}$ der imaginalen Speicherung gegenüber der verbalen Speicherung Rechnung. Die doppelte Kodierung erklärt des Weiteren, warum die Informationen von einem hohen Bildhaftigkeitsgrad leichter verstanden und besser aus dem Gedächtnis abberufen werden als nur verbal kodierte Wissensinhalte. Außer Acht gelassen werden dagegen andere Aspekte der menschlichen Kognition: Das Verbale und das Visuelle sind zweifelsohne besonders relevante, dennoch keinesfalls einzige Repräsentationsformate: Das Taktile, Gustatorische, Kinästhetische sowie Emotionen können weder als logogene noch als imagene gespeichert werden.

65 Das sog. picture/pictorial superiority effect ist in den psychologischen Experimenten mehrmals nachgewiesen worden (Stöckl 2004: 9). Das visuelle Gedächtnis ist dem verbalen Gedächtnis deutlich überlegen (vgl. Chlewiński 1997: 38). 


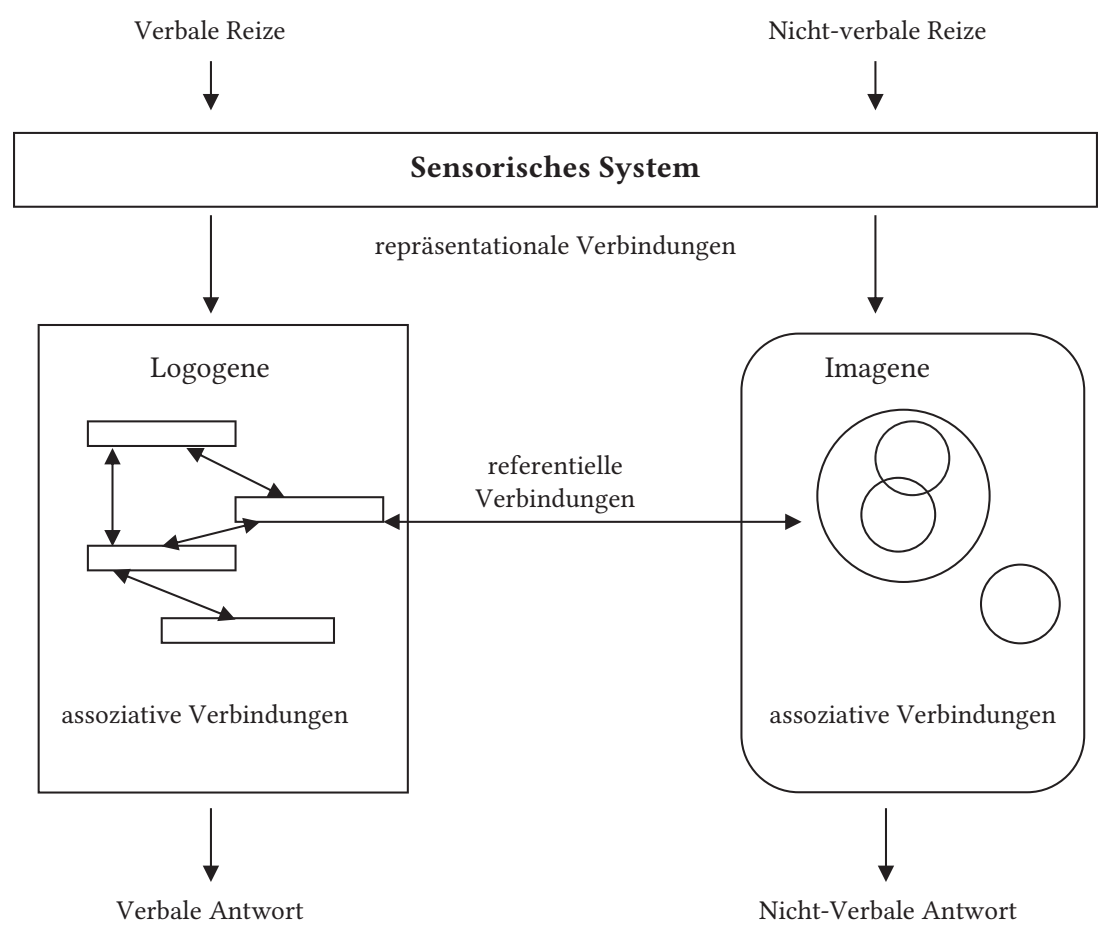

Abb. 11: Schematische Darstellung der dualen Repräsentationstheorie mit repräsentationalen, referentiellen und assoziativen Beziehungen zwischen dem System der logogene und der imagene nach Paivio (vereinfacht nach Paivio 1986: 67, übers. von A. S.).

\subsubsection{Multimodale Repräsentationstheorie: Grounded Cognition}

Eine immer größere Bedeutung wird in der Kognitiven Linguistik heutzutage den Ansätzen beigemessen, die auf die tief gehende Verwurzelung der Sprache in den allgemeinen perzeptiven und sensomotorischen Aktivitäten verweisen. Der Forschungsstrang der Embodied Cognition geht von dem Körper und körperbezogenen Erfahrungen als Grundlage der Kognition aus: Lakoff/Johnson (1980), Lakoff (1987, 1990) und Johnson (1987) machen darauf aufmerksam, dass zahlreiche abstrakte Konzepte metaphorisch in dem auf der Körpererfahrung basierenden Wissen verankert sind: Bei der Herausbildung sprachlicher Einheiten wird beispielshalber auf image schemas zurückgegriffen. Die Ansätze neuester Generation (Barsalou 1999, Simmons/Barsalou 2003) gehen einen Schritt weiter: Barsalou (1999, 2008, 2012) erweitert den Gedanken von Lakoff und Johnson zu einem umfassenderen 
Grounded Cognition-Ansatz, in dem er nicht nur der Körpererfahrung, sondern auch den Simulationen und den situierten Handlungen eine wichtige Rolle in der menschlichen Kognition einräumt. Grounded Cognition stellt zugleich eine Repräsentationstheorie dar: Im Fokus des Interesses befindet sich nämlich die Frage, wie die mentalen Repräsentationen menschlicher Erfahrungen gestaltet und aufbewahrt werden.

Grounded Cognition, die im Folgenden in Anlehnung an Barsalou (1999, 2010, 2012, 2016) beschrieben wird, setzt zwei grundlegende Annahmen voraus: Erstens wird das konzeptuelle System nicht-modular aufgebaut. Es besteht keine strikte Grenze zwischen der Perzeption und Kognition, im Gegenteil, die Perzeption bildet eine natürliche Grundlage der Kognition. Anstatt der separaten Systeme für modal-spezifische und konzeptuelle Prozesse wird ein gemeinsames repräsentationales System postuliert (Barsalou 2012: 250). Die Vertreter der Grounded Cognition lehnen also das nach der kognitiven Wende vorherrschende Sandwich-Modell ab, das die Kognition zwischen der Perzeption und Aktion (Handlung) ansiedelt und sich auf die Erforschung der Aufmerksamkeit, des Arbeitsgedächtnisses, des Langzeitgedächtnisses, der Sprache und des Denkens als relativ modularer Phänomene konzentriert. Stattdessen wird angenommen, dass „,cognition will be only understood once the relevant domains of study are expanded significantly beyond classic cognitive mechanisms" (Barsalou 2016: 13). Nur unter Einbezug der Perzeption, der Interozeption ${ }^{66}$, der körperlichen Zustände, der Sensomotorik, der Handlung, der sozialen und physischen Umgebung kann man der Kognition in ihrer ganzen Komplexität Rechnung tragen (ebd.).

Zweitens beruht dieses System auf modalen Repräsentationen:

The same types of representation underlie perception and conception. When the conceptual system represents an object's visual properties, it uses representation in the visual system; when it represents the action performed on an object, it uses motor representations. Depending in the distribution of modalities on which people experience a category, a particular distribution of modality specific information becomes established for it. (Barsalou 2012: 250)

Barsalou postuliert die Existenz der perzeptuellen Symbole (= PS) von einer multimodalen Struktur, die eng an die sensorisch-motorische, introspektive und propriozeptive (mit Eigenempfindung verbundene) Erfahrung gebunden sind. Im Gegensatz zu den amodalen Repräsentationstheorien nehmen perzeptuelle Symbole die an perzeptuelle Modi gebundenen Formen an, was in dem folgenden Bild - stark vereinfacht und modellhaft dargestellt - durch den Umriss eines Stuhls (Abb. 12) veranschaulicht wird:

66 Unter Interozeption versteht Barsalou (2012: 247) die Wahrnehmung von mentalen Zuständen, die dem Bewusstsein zugänglich sind. 


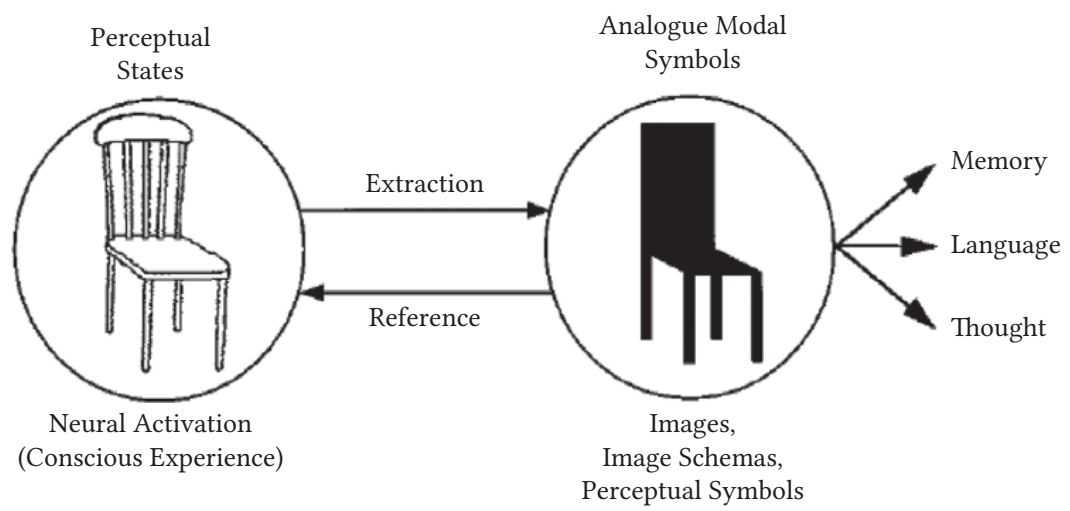

Abb. 12: Die Grundannahmen der Perceptual-Symbol-Theorie nach Barsalou (1999: 578).

PS stellen fundamentale Einheiten konzeptueller Struktur dar, sie bauen das grundlegende konzeptuelle System (basic conceptual system) auf, das den Ausgangspunkt zur Herausbildung von komputationalen Operationen bildet. Die perzeptuellen Symbole und das Perceptual Symbol System (= PSS) sind durch folgende Eigenschaften gekennzeichnet (Barsalou 1999: 582-592):

(i) Perzeptuelle Symbole bilden neuronale Repräsentationen in sensorisch-motorischen Gehirnarealen.

Sie stellen dabei keine physischen Bilder dar, es sind Aufzeichnungen der neuronalen Aktivität, die sich aus der Wahrnehmung ergibt.

(ii) Perzeptuelle Symbole sind schematischer Natur.

PS repräsentieren schematische Komponenten der perzeptuellen Erfahrung und nicht die ganze Erfahrung in allen Einzelheiten. „Rather than containing an entire holistic representation of a perceptual brain state, a perceptual symbol contains only a schematic aspect" (ebd., 583). Dieses Merkmal der PS hebt das Perceptual Symbol System deutlich von Aufnahmesystemen (recording system) ab und verleiht ihm den Status eines konzeptuellen Systems mit seinen inhärenten Eigenschaften: Produktivität, Kategorisierung, Fähigkeit zur Bildung von Präpositionen und abstrakten Konzepten. Die schematische Natur der PS ergibt sich aus zwei axiomatischen Annahmen zur Rolle der selektiven Aufmerksamkeit in der kognitiven Psychologie: Die selektive Aufmerksamkeit (i) isoliert die Informationen in der Wahrnehmung (vgl. dazu die Szene-Profil-Differenzierung in der Kognitiven Grammatik von Langacker) und (ii) speichert diese Information im Langzeitgedächtnis (= LZG) auf. Im Entstehungsprozess der PS werden also Teilmengen von den einer Wahrnehmung zugrunde liegenden aktivierten Neuronen selektiert und gespeichert. Im Resultat sind PS dynamisch: Da sie als ein assoziatives neuronales 
Muster aufgefasst werden, sind die Änderungen in den neuronalen Verbindungen bei den darauf folgenden Aktivierungen durchaus möglich: Die Zuführung von zusätzlichen PS in einen zusammenhängenden Bereich kann zur Rekonstruktion der ursprünglichen Patterns führen. Als schematische Konstrukte können PS ebenfalls vage sein: Die mentale Repräsentation eines Tigers zieht keinesfalls die Notwendigkeit mit sich, die genaue Anzahl der Streifen bestimmen zu können.

(iii) Perzeptuelle Symbole sind multimodal.

PS sind multimodal, d.h., in ihrem Entstehungsprozess können beliebige Aspekte der Erfahrung involviert sein. Sie entstehen auf der Grundlage der Wahrnehmungen verschiedener sensorischer Modalitäten (optischer, auditiver, olfaktorischer, gustatorischer und taktiler Sinnesmodalität), der Propriozeption (der Wahrnehmung der eigenen Körperbewegung und Körperlage im Raum) und der Interozeption (der Wahrnehmung von mentalen Zuständen). In jeder Modalität konzentriert sich die selektive Aufmerksamkeit auf ausgewählte Aspekte einer Erfahrung und speichert sie im Langzeitgedächtnis, wo sie als Symbole fungieren, auf. Im Resultat kann eine sensorische Wahrnehmung zur Etablierung zahlreicher PS in verschiedenen Gehirnarealen führen: Visuelle Symbole werden in visuellen Gehirnarealen gegründet, auditive Symbole in auditiven Gehirnarealen, propriozeptive Symbole in motorischen Gehirnarealen usw. Die neueren, auf Neuroimaging beruhenden Untersuchungsergebnisse legen dabei die Vermutung nahe, dass bestimmten Gehirnarealen eine besondere Rolle bei der Verarbeitung von bestimmten konzeptuellen Kategorien zukommt: Für die Kategorie ,Tiere sind beispielsweise visuelle Gehirnregionen, für die Kategorie ,Werkzeug' motorische und sensomotorische Gehirnareale von besonderer Relevanz (Pulvermüller 1999; Rösler u.a. 1995). Neuropathologische Evidenz bestätigt diese Annahme: Falls sensorisch-motorische Gehirnareale beschädigt werden, spiegelt sich die Läsion in den Schwierigkeiten bei der konzeptuellen Verarbeitung innerhalb der Kategorien wider, bei deren Herausbildung diese Gehirnareale von größter Relevanz waren (Damasio/ Damasio 1994; Gainotti u.a. 1995; Pulvermüller 1999).

\section{(iv) Simulatoren und Simulationen}

Perzeptuelle Symbole existieren im Langzeitgedächtnis nicht unabhängig voneinander, verwandte PS werden in einem Simulator organisiert, der das kognitive System zur Konstruktion spezifischer Simulationen von nicht vorhandenen Entitäten oder Ereignissen befähigt. Die von einer Erfahrung abgesonderten PS werden in einen Frame integriert, der PS aus den früheren Erfahrungen beinhaltet: So entstehen z.B. beim Seitenanblick eines Autos PS visueller Art, beim Treten des Gaspedals werden kinästhetische und bei der Wahrnehmung des Motorgeräusches auditive PS erzeugt. Nach der Verarbeitung von vielen Wagen wird eine riesige Anzahl der multimodalen Informationen gespeichert, die bestimmt, wie man ein Auto sensorisch, introspektiv und propriozeptiv zu spüren bekommt: „The frame ,car' contains extensive information of what it is like to experience this type of thing" (Barsalou 1999: 586). 
Bezüglich der Funktionsweise von Simulatoren müssen dennoch einige Vorbehalte angemerkt werden: Erstens produzieren die Simulatoren immer partielle und schematische Simulationen. Während der Wahrnehmung extrahiert die selektive Aufmerksamkeit jeweils bestimmte PS, nie werden alle potenziell verfügbaren Informationen gespeichert. Bei der Rezeption eines Ausdrucks bestimmen z.B. kontextuelle Begebenheiten, welche der vielen im Simulator gesammelten Aspekte in die Simulation übernommen werden. Zweitens sind die Simulationen verschiedenartigen Verzerrungen ausgesetzt, so wie sie in der Gestaltpsychologie für die visuelle Perzeption beschrieben wurden. Drittens gehen die Simulatoren über eine rein erfahrungsbasierte Aufsammlung sensorischer Eindrücke hinaus, ihre Funktionsweise ist z.T. durch genetische Ausrüstung der Menschen bedingt:

Mechanism with strong genetic constraints almost certainly play central roles in establishing, maintaining, and running simulators. For example, genetic predispositions that constrain the processing of space, objects, movement, and emotion underlie the storage of perceptual symbols and guide the simulation process (...). Thus, a simulator is both a „rational“ and an „empirical“ system, reflecting intertwined genetic and experiential histories. (Barsalou 1999: 586)

Nach Barsalou (1999: 587) entsprechen also Simulatoren den Konzepten: Es ist das Wissen und die dieses Wissen begleitenden Prozesse, die einem Individuum eine adäquate Repräsentation einer Entität oder eines Ereignisses ermöglichen. Ein Simulator kann uneingeschränkt viele Simulationen produzieren, von denen jede eine spezifische Denkweise - Konzeptualisierung - widerspiegelt. „Whereas a concept represents a kind generally, a conceptualisation provides one specific way of thinking about." (ebd.)

So aufgefasste Simulatoren erklären auch die dynamische, auf die Körpererfahrung zurückgreifende Herangehensweise zum Problem der Kategorisierung:

If the simulator for a category can produce a satisfactory simulation of a perceived entity, the entity belongs to the category. If the simulator cannot produce a satisfactory simulation, the entity is not a category member. (Barsalou 1999: 587)

\section{(v) Frames}

Ein großer Stellenwert kommt in der PPS-Theorie den Frames zu. Simulatoren werden nämlich durch Frames und Simulationen konstituiert. Unter Frames versteht Barsalou „an integrated system of perceptual symbols that is used to construct specific simulations of a category“ (Barsalou 1999: 590). In einem Frame werden zahlreiche Informationen gesammelt: Je häufiger eine Entität in der alltäglichen Erfahrung vorkommt, desto reichhaltiger ist der entsprechende Frame ${ }^{67}$.

67 Diese allgemeine Regel muss dennoch nicht für alle Fälle gelten. Nicht nur die Quantität, sondern auch die Qualität der Erfahrung ist für seine mentale Aufbewahrung ausschlaggebend. Dafür liegt in der Gedächtnispsychologie handfeste Evidenz 
Barsalou (1999: 590) erklärt den Entstehungsprozess eines Frames AUTO anhand einer Illustration (Abb. 13). Ein Frame repräsentiert räumliche (spatial) und inhaltliche (content) Informationen separat (ebd.). Auf der ersten Ebene wird ein Objekt volumetrisch dargestellt (die schematische Gestalt in der Abb. 13.A oben). Auf der anderen Ebene werden bestimmte wichtige Subbereiche dieses Objektes (Autotür, Autoräder) repräsentiert, denen bei der Perzeption selektive Aufmerksamkeit zugekommen ist. Diese zusätzlichen Informationen stellen Spezialisierungen innerhalb des sich herausbildenden Frames dar: Die volumetrische Repräsentation stellt ein Gerippe eines Frames auf, das mit Spezialisierungen untermauert wird.

Bei der perzeptuellen Wahrnehmung eines anderen Autos ruft man die bereits gespeicherte mentale Struktur aus dem Langzeitgedächtnis ab und die Verarbeitung in einem Top-Down-Prozess wird eingeleitet. Gleichzeitig kommen weitere PS hinzu - in Abb. 13.B sind es beispielsweise eine Antenne und ein Tankverschluss. Die aus beiden Erfahrungen gewonnenen Informationen werden miteinander integriert und bilden die Basis zur Herausbildung eines car-Frames.

Die Abb. 13.C veranschaulicht, wie das kognitive System einen Frame zur Konstituierung einer spezifischen Simulation verwenden kann. Zuerst wird die allgemeine volumetrische Repräsentation samt aller Subregionen aktiviert. Ist die Simulation oberflächlich, dann beinhaltet sie ausschließlich die wichtigsten, bisher am häufigsten verarbeiteten Subregionen. In bestimmten kontextgeleiteten Situationen kann dennoch untergeordneten Subregionen ein besonderer Stellenwert bei der Konstituierung einer Simulation zukommen (vgl. die Produktivität).

An dieser Stelle muss hervorgehoben werden, dass bei der Konstituierung einer Simulation ein Frame nicht nur aufgerufen wird, sondern auch Modifikationen unterzogen werden kann:

During a simulation, processing is not limited to the retrieval of frame information but can also include transformation of it. Retrieved information can be enlarged, shrunk, stretched, and reshaped; it can be translated across the simulation spatially or temporally; it can be rotated in any dimension; it can remain fixed while the perspective on it varies; it can be broken into pieces; it can be merged with other dimensions. Other transformations are no doubt possible as well. (Barsalou 1999: 591)

Vor diesem Hintergrund schlagen Barsalou/Hale (1993) und Barsalou (1999) vier grundlegende Eigenschaften eines Frames vor: (i) predicates, (ii) attribute-value bindings, (iii) constraints, (iv) recursion. (i) Predicates entsprechen den unspezialisierten Frames, z.B. CAR (Door $=\mathrm{x}$, Windows = y, ...). (ii) Attribute-value bindings entstehen durch die Spezialisierungen von bestimmten Subbereichen in einer Simulation. Wenn verschiedene Spezialisierungen zu demselben Bereich

vor: Baddeley (1998: 77-78) berichtet beispielshalber von der Effektivität einer Werbekampagne, die mit der Umstellung der Wellenlänge des BBC-Radios verbunden war. Trotz der schätzungsweise tausendmaligen Wahrnehmung der Information im Radio konnte die Mehrheit der Probanden die neue Wellenlänge nicht angeben. 

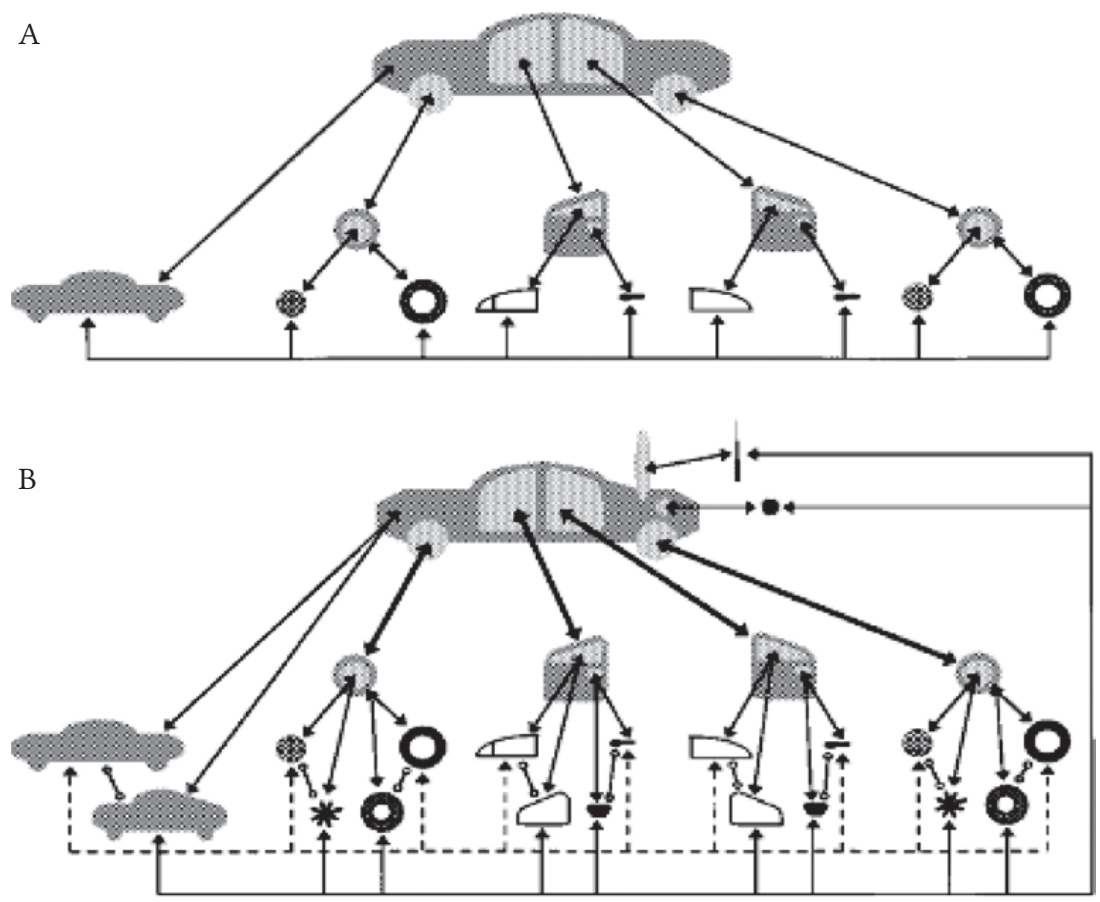

C

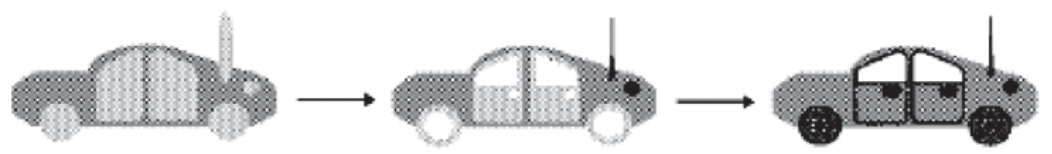

Abb. 13: Die Konstituierung eines Frames für ein Auto nach Barsalou (1999: 590). (A) Ein Beispiel für die Errichtung eines Anfangsframes nach der ersten Wahrnehmung eines Autoexemplars. (B) Evaluierung des Frames nach der Bearbeitung des zweiten Exemplars. (C) Konstruktion von einer Simulation von dem zweiten Exemplar aus dem Frame in Abb. 13B.

auftauchen, ordnen sie unterschiedliche Werte (values) einem Attribut (attribute, slot) zu. Demzufolge werden genauere Informationen zu den Subregionen, z.B. zu dem Aussehen einer Autotür oder einer Autortürklinke aufgespeichert. (iii) Einschränkungen (constraints) entstehen durch assoziative Verbindungen zwischen zwei Spezialisierungen, die Individuen oder Subkategorien in einem Frame verbinden. Die Aktivierung einer Spezifizierung von einer bestimmten Autotür aktiviert die Spezialisierungen des entsprechenden Autos in anderen 
Bereichen (Autoräder, Autohaube), sodass das ganze Auto simuliert wird. (iv) Rekursionen (recursion) ergeben sich aus der Bildung von einer Simulation innerhalb eines bestehenden Simulators. Bei der ersten Wahrnehmung eines Autos könnte der Simulator bloß über eine äußerst schematische Simulation eines Autorads als eines kreisförmigen Autoteils verfügen. Erst durch die weiteren Simulationen bei den späteren Betrachtungen des Autos wird der Simulator um detailliertere Spezifizierungen zum Subbereich Autorad (Reifen, Radkappe) bereichert. Frames stellen bei der Simulation Hintergrund-Informationen zur Verfügung, die Framing unterstützen:

Frames offer a natural account of background dependent meaning. Foot, for example, is conceptualized differently when human is simulated in the background than when horse or tree is simulated. Because different perceptual symbols are accessed for foot in the context of different frames, simulations of foot vary widely. Similarly, different conceptualizations of red reflect different perceptual symbols accessed in frames for fire truck, brick, hair, and wine. (Barsalou 1999: 592)

(vi) Die Rolle der linguistischen Symbole

Bei der menschlichen Ontogenese wird die Herausbildung der PS durch die gleichzeitige Herausbildung der linguistischen Symbole begleitet ${ }^{68}$. Wie perzeptuelle Symbole stellen ebenfalls linguistische Symbole schematische Erinnerungen an wahrgenommene Entitäten dar, wobei es sich hier um gesprochene bzw. geschriebene Wörter (gemeint ist die Ausdrucksseite des sprachlichen Zeichens, der phonologische oder graphematische Pol einer sprachlichen Einheit) handelt. Linguistische Symbole, genau wie perzeptuelle Symbole, unterliegen den Mechanismen der selektiven Aufmerksamkeit, schematische Repräsentationen einzelner Erfahrungen werden zu einem Simulator überführt und stehen dann allen anderen Simulationen zur Verfügung (Barsalou 1999: 592).

Die Simulatoren für Wörter werden demnächst mit den Simulatoren für Objekte bzw. Ereignisse, auf die sie sich beziehen, assoziiert. Sobald die Simulatoren für Wörter an die Simulatoren für Konzepte gekoppelt werden, können sie die Kontrolle über Simulationen übernehmen:

(...) the productive nature of language, coupled with the links between linguistic and perceptual simulators, provides a powerful means of constructing simulations that go far beyond an individual's experience. As people hear or read a text, they use productively formulated sentences to construct a productively formulated simulation that constitutes a semantic interpretation. (...) Conversely, during language production,

68 Für die frühkindliche Entwicklung müsste wohl eine Verschiebung angenommen werden: Zuerst konstituiert sich das konzeptuelle System, linguistische Symbole entstehen erst nach der Vollendung des ersten Lebensjahres, wenn die Kinder zu sprechen beginnen. 
the construction of a simulation activates associated words and syntactic patterns, which become candidates for spoken sentences designated to produce a similar simulation in a listener. Thus, linguistic symbols index and control simulations form a wide variety of useful perspectives. (Barsalou 1999: 592)

Die solche Eigenschaften aufweisenden perzeptuellen Symbole bilden die Grundlage unserer Kognition - das sog. basic conceptual system. Beachtenswert ist dabei, dass der PSS-Ansatz ebenfalls eine überzeugende Theorie zur Aufbewahrung des konzeptuellen Inhalts von abstrakten Begriffen, wie beispielshalber Emotionen liefert. PS umfassen nämlich alle Repräsentationsformate, darunter Introspektion und Propriozeption. Auch abstrakte Inhalte, wie z.B. Emotionen, können als PS aufbewahrt werden. Die Menschen verfügen beispielshalber über unmittelbares Erfahrungswissen darüber, was ÄRGER ist und wie er sich „anfühlt“, wobei sich dieses Wissen auf zwei Erfahrungsaspekte bezieht:

Ein zentraler Stellenwert kommt den perzeptuellen Symbolen für Introspektion zu, die die Speicherung der emotionalen Zustände ermöglichen. So wie gustatorische, visuelle, auditive u.a. Wahrnehmungen mental als PS Symbole in den entsprechenden Gehirnregionen repräsentiert werden, so werden auch introspektive Zustände wahrgenommen und als introspektive Symbole in den für Emotionen zuständigen Gehirnarealen aufbewahrt. Jeder Erwachsene hat wenigstens einmal im Leben die Basisemotion ÄRGER gespürt, dementsprechend verfügt er auch über direktes, erfahrungsbezogenes Wissen darüber, was der ÄRGER ist und wie er sich „anfühlt“.

Von Bedeutung für die Konzeptualisierung von Emotionen und Gefühlen ist ebenfalls das Wissen von den Situationen, in denen sie auftauchen. ÄRGER wird z.B. typischerweise durch eine Sequenz von Ereignissen hervorgerufen, deren Kenntnis eine wichtige Voraussetzung zur Abhebung des ÄRGERs von anderen Emotionen bildet:

Ärger, das ist Konsens, wird ausgelöst durch die Bewertung, dass irgendetwas meinen Bedürfnissen und Motiven zuwiderläuft und dem Urteil, dass an diesem Zustand (in der Regel) ein anderer Mensch schuld ist, der mit seinem Verhalten gegen Standards und Normen verstößt. (Weber 1994: 34)

Diese Szenario-Informationen konstituieren den Frame des abstrakten Konzeptes mit, wobei das Ganze durch die selektive Aufmerksamkeit gesteuert wird: „An abstract concept is not the entire event simulation that frames it but is a focal part of it“ (Barsalou 1999: 600). Anders als in der CTM-Theorie von Lakoff/Johnson (1980), in der davon ausgegangen wird, dass sich abstrakte Begriffe über konzeptuelle Metaphern konzeptualisieren lassen, vertritt Barsalou einen Standpunkt, nach dem die Emotionen unmittelbar in einem entsprechenden Format - als PS für Introspektion - mental repräsentiert werden. 
(vii) Kategorisierung, Inferenz, Propositionenbildung und Produktivität im Perceptual Symbol System

Sehr relevant und von Barsalou mehrmals betont wird die schematische Natur der PS, die immer durch ein Individuum unter dem Einfluss individueller Faktoren konstruiert und nicht einfach aufgenommen werden. Wie bereits erwähnt (Pkt. ii), besteht zwischen dem Repräsentierten und der mentalen Repräsentation kein Abbild-, sondern ein Konstruktionsverhältnis. PSS stellt somit ein interpretatives System dar. Dieses Merkmal hat weitreichende Folgen: Nur in einem konstruktiven, interpretativen System sind Operationen möglich, die die Gebundenheit der menschlichen Kognition an die Perzeption und der Sprache an das Hier und Jetzt aufheben. $\mathrm{Zu}$ diesen kognitiven Operationen zählt Barsalou (2012: 241) Kategorisierung, Inferenz, Propositionenbildung und Produktivität.

Während der Kategorisierung ordnet das kognitive System die neu wahrgenommenen einzelnen Objekte den konzeptuellen Wissenseinheiten zu: Das auf der Straße wahrgenommene Fahrzeug wird als Auto kategorisiert. Die reine Kategorisierung ist noch nicht ausreichend, von Relevanz sind erst die Inferenzen, die sich aus dieser Zuordnung ergeben (Barsalou 2012: 241) und zahlreiche im LZG aufbewahrten Wissensbestände zu dieser Kategorie erschließen. Dementsprechend aktiviert die Kategorisierung Inferenzen, die sich auf das Artefakt AUTO und sein Aussehen, die von ihm gegebenen Geräusche, seine Funktionsweise usw. beziehen. Infolge der Kategorisierung entstehen Propositionen, die man in einer Vereinfachung als type-token Beziehungen beschreiben kann (Barsalou 2012: 242):

Categorizing an individual chicken, for example, creates a proposition that consists of the individual chicken (a token) being bound to the concept for chicken (a type). In text comprehension, similar type-token propositions arise as the meanings of words are combined. Hearing „Ralph is a chicken“, for example, produces the proposition, chicken (Ralph), where the notation used is type (token). As this example illustrates, chicken is a predicate that takes individuals as arguments, such as Ralph. (Barsalou 2012: 242)

Die schematische Struktur der perzeptuellen Symbole gewährleistet letzten Endes eine Eigenschaft, der seit der kognitiven Wende ein besonderer Stellenwert zukommt - die Produktivität der menschlichen Sprache und des menschlichen kognitiven Systems. Die Produktivität, unter der die Fähigkeit zur Konstruktion von unendlich vielen komplexen Repräsentationen anhand einer begrenzten Anzahl von Symbolen verstanden wird, befähigt den Menschen dazu, weitaus mehr konzeptuelle und linguistische Strukturen zu produzieren, als er direkt erfahren hat: Niemand hat eine Cheshire-Katze ${ }^{69}$ gesehen, trotzdem können sich viele eine grinsende Katze vorstellen (Barsalou 1999: 592).

Zusammenfassend lässt sich feststellen, dass die PSS-Theorie eine überzeugende Modellierung der Struktur des konzeptuellen Pols von einer sprachlichen Einheit

69 Die Grinsekatze aus dem Roman Alice im Wunderland von Lewis Caroll. 
darstellt, die mit Annahmen des holistischen Ansatzes der Kognitiven Linguistik durchaus kompatibel ist. Das PSS rückt den Repräsentationsaspekt in den Vordergrund und beschreibt die mentalen Repräsentationen aus psychologischer Perspektive und unter Rückgriff auf andere Termini: Die Parallelen zwischen den Simulatoren und Konzepten, oder Simulationen und Konzeptualisierungen liegen dennoch auf der Hand.

Die mentalen Repräsentationen der Wissensstrukturen, auf die man bei Konzeptualisierungen zurückgreift, sind demnach multimodal, d.h. in unterschiedlichen Modalitäten aufbewahrt. Dies liefert eine Erläuterung für Phänomene, die mit den traditionellen amodalen Repräsentationsformaten nicht erklärbar sind, zugleich aber einen wesentlichen Bestandteil unserer täglichen Erfahrung ausmachen: Viele Menschen sind beispielsweise imstande, sich den Duft einer bestimmten Rosengattung zu merken und ihn unter ähnlichen Düften wiederzuerkennen, obwohl sie die beiden Gerüche nicht in propositionaler Form beschreiben könnten. Jeder hat wahrscheinlich Emotionen und Gefühle erfahren, die in ihrem schimmernden Wesen und allen subtilen Schattierungen kaum in Worte fassbar sind. Dasselbe bezieht sich auf andere, für den Alltag konstitutive Bereiche der menschlichen Erfahrung, denen bisher weniger Aufmerksamkeit in der Forschung gewidmet wurde: das Taktile, Gustatorische, Kinästhetische u.a. Einerseits beinhaltet das konzeptuelle System also viel mehr Informationen, als man in Worte fassen kann, weil nicht allen Konzepten Ausdrücke zugeordnet sind:

Viele Konzepte für körperliche Empfindungen, Gefühle oder Stimmungen, für Gesichtsausdrücke und Physiognomien, für Gerüche und Geschmäcker, für Melodien und Harmonien usw. sind kaum oder gar nicht in Worte zu fassen. Zum Beispiel kann eine verbale Beschreibung eines Gesichts nie auch nur annährend den visuellen Eindruck wiedergeben, den wir aufnehmen, kategorisieren und abspeichern und unter Hunderten herauskennen würden. Wörter können nie vollständig beschreiben, wie eine Apfelsine schmeckt, eine Nelke duftet oder eine Geige klingt. Insgesamt ist es plausibel anzunehmen, dass nur ein kleiner Teil unserer Konzepte sprachlich ausgedrückt werden kann. (Löbner 2003: 258)

Andererseits evozieren Ausdrücke mehr als Propositionen: Mentale Bilder, flüchtige Aktivierungen der olfaktorischen, taktilen, motorischen Empfindungen, Emotionen sind psychologisch real, bilden einen integralen Bestandteil der Sprachverarbeitung. Ein emotionaler Gehalt steckt in jeder Konzeptualisierung und deren Versprachlichung (Mazurkiewicz-Sokołowska 2014: 43), auch in den auf den ersten Blick neutralen Konzepten wie sTUHL, AUTO, HUND. Es ist kaum möglich, von Menschen zu sprechen, ohne ihre mentalen Bilder vor dem inneren Auge aufkommen zu lassen: Die Namen: Helmut Kohl, Angela Merkel, Charlie Chaplin oder der Mann meiner Nachbarin lösen unwillkürlich mentale Bilder ihrer Gesichter aus. Eine mentale Repräsentation bestimmter Gerüche und Geschmäcke bildet eine wichtige Komponente des Konzeptes weinnachten, das Konzept Haus evoziert ein weitgehend individuelles mentales Bild (von einem Landhaus bis zu einer 3-Zimmer-Wohnung in einem Wohnblock) und Emotionen. 
Die enge Bindung der PSS an die körperliche menschliche Erfahrung liefert eine plausible Erklärung für die inter- und intraindividuelle Vagheit der Konzepte und Konzeptualisierungen (Simulatoren und Simulationen): Die Menschen können sich in ihren Erfahrungen mit Autos unterscheiden, gute oder gar keine Fahrer, begeisterte Autofreunde oder Autobenutzer ohne jegliches Technikverständnis sein. Zugleich weisen dennoch ihre Erfahrungen mit Autos, wenigstens innerhalb einer kulturellen Gemeinschaft, genügend gemeinsame Züge auf, dass die Kommunikation möglich ist ${ }^{70}$. Das so aufgefasste konzeptuelle System trägt ebenfalls der Dynamik und Anpassungsfähigkeit der menschlichen Kognition Rechnung: Mit jeder neuen Autogeneration ändern sich allmählich unsere Wahrnehmungen und in Folge unsere Simulationen von Autos, was in der lebenslangen Modifizierung der Simulatoren resultiert. Durch die Fülle der aufgespeicherten PS und die einordnende Funktion von Frames wird die PSS-Theorie ebenfalls der Kontextabhängigkeit gerecht: Die Konzeptualisierungen sind flexibel, tentativ. In Abhängigkeit vom gegebenen Kontext oder der Situation stehen z.B. entweder die visuellen, taktilen oder auditiven Eigenschaften des Autos im Vordergrund.

Die theoretischen Modellierungen, die annehmen, dass die kognitiven Prozesse, die in höhere kognitive Leistungen wie die Sprache involviert sind, in denselben Systemen wie die Perzeption, Motorik, Emotionen ihre Verankerung finden, werden durch die empirische Forschung untermauert. Es liegt neuro- und psycholinguistische Evidenz $^{71}$ dafür vor, dass die neuronale Aktivität des Gehirns bei Sprachverarbeitung keinesfalls auf die Sprachzentren eingeschränkt ist, sondern ebenfalls die Gehirnregionen umfasst, die bei der Wahrnehmung von Belang waren: Bei der Verarbeitung der Nomen aus der Kategorie ,Essen ' sind die gustatorischen Gehirnareale aktiv, bei den mit Geruch assoziierten Begriffen - olfaktorische Bereiche (Rickheit/Weiss/Eikmeyer 2010: 110). Martin (2007) gibt einen Überblick über eine Reihe von neurologischen Untersuchungen an gesunden Probanden sowie den Patienten mit unterschiedlichen Gehirnläsionen, die sich hauptsächlich auf die mentalen Repräsentationen der Tiere sowie der menschlichen Artefakte (,Werkzeuge') beziehen. Es steht fest, dass bei der Verarbeitung beider Kategorien andere Gehirnregionen aktiviert werden: Bei der Kategorie ,Tiere' werden vor allem visuelle Gehirnareale aktiv, bei ,Werkzeugen' sind es hauptsächlich die mit der Motorik verbundenen Regionen. Ebenfalls bei Gehirnschädigungen kann die Verarbeitung von beiden Kategorien separat gestört werden:

70 In diesem Zusammenhang kann die PSS-Theorie auch nicht als rein empiristisch aufgefasst werden. So wie unsere Wahrnehmung durch genetische Veranlagung der ganzen Spezies homo sapiens eingeschränkt ist, so können ebenfalls die die Entstehung von Simulationen und Simulatoren regierenden Mechanismen bei allen Menschen gemeinsame, genetisch bedingte Eigenschaften aufweisen, sodass die Konzeptualisierungen und Konzepte ab einem bestimmten Abstraktionsgrad intersubjektive Gemeinsamkeiten erkennen lassen.

71 Eine Übersicht über den Stand der neurolinguistischen Forschung bieten u.a. Rickheit/Weiss/Eikmeyer (2010: 108-115) sowie Borghi/Pecher (2011: 5) an. 
Evidence from functional neuroimaging of the human brain indicates that information about salient properties of an object - such as what it looks like, how it moves, and how it is used - is stored in sensory and motor systems active when that information was acquired. As a result, object concepts belonging to different categories like animals and tools are represented in partially distinct, sensory- and motor property-based neural networks. This suggests that object concepts are not explicitly represented, but rather emerge from weighted activity within property-based brain regions. However, some property-based regions seem to show a categorical organization, thus providing evidence consistent with category-based, domain-specific formulations as well. (Martin 2007: 25)

Außer der Neurolinguistik stellt ebenfalls die Psycholinguistik empirische Evidenz für die multimodale Natur der mentalen Repräsentationen zur Verfügung. Zwaan/ Stanfield/Yaxley (2002) ließen die Versuchspersonen in einem psycholinguistischen Experiment folgende Sätze lesen:

The ranger saw an eagle in the sky.

The ranger saw an eagle in the tree.

Nach der klassischen amodalen Repräsentationstheorie unterscheiden sich die beiden Sätze, in der propositionalen Form dargestellt: [[SAW[RANGER,EAGLE]], [IN[EAGLE,SKY]]] und [[SAW[RANGER,EAGLE]], [IN[EAGLE,NEST]]], nur in der lokalen Angabe (ebd., 168). Der Adler, als ein abstraktes, amodales Konzept, sollte in beiden Sätzen eine ähnliche Form haben. Demgegenüber erkannten die Versuchspersonen das Bild eines Adlers mit ausgebreiteten Flügeln schneller, nachdem sie den ersten Satz gelesen haben, als nach dem Lesen des zweiten Satzes. Ähnliche Resultate erzielten die Forscher auch für andere Paare (das Ei im Kühlschrank und das Ei auf der Pfanne, der sitzende und der hüpfende Frosch, ein Laib Brot und eine Scheibe Brot). Die Ergebnisse deuteten sie als Beweis, dass die Rezipienten beim Sprachverstehen eine visuelle Simulation bilden, die stark durch die kontextuellen Informationen beeinflusst wird.

\subsubsection{Mentale Bilder und Basisbegriffe in der Prototypensemantik von Rosch}

Aufschlussreiche Einblicke in das Wesen des für die Sprache und Kognition grundlegenden Prozesses der Kategorisierung gewährt die Prototypensemantik von Eleanor Rosch $(1975,1976)$. In zahlreichen Experimenten stellt die amerikanische Psychologin unter Beweis, dass nicht alle Elemente einer Kategorie den gleichen Status aufweisen. Rosch und Mitarbeiter (1976) liefern Evidenz dafür, dass in der Taxonomie der Kategorien ein Niveau existiert, das aus der psychologischen, ontogenetischen und kommunikativen Perspektive Vorrang vor anderen Hierarchieniveaus hat. In den Untersuchungen bediente sich Rosch einer Taxonomie der Kategorien, die u.a. die in der Tabelle 3 zusammengestellten Begriffe umfasste. 
Tab. 3: Taxonomie der Kategorien nach Rosch et al. (1976: 388, übers. und gekürzt von A. S.).

\begin{tabular}{lll}
\hline Übergeordnete Ebene & Basisebene & Untergeordnete Ebene \\
\hline Baum & Eiche & Erlenblättrige Eiche \\
& Birke & Libanon-Eiche \\
\hline Möbel & Tisch & Büro-Arbeitstisch \\
& Stuhl & Esstisch \\
& Lampe & Steintisch \\
\hline Musikinstrument & Gitarre & Akustische Gitarre \\
& Geige & Hawaigitarre \\
& Piano & Resonatorgitarre \\
\hline Tier & Hund & Schäferhund \\
& Katze & Dackel \\
\hline \multirow{2}{*}{ Werkzeug } & Hammer & Spitzhammer \\
& Säge & Gummihammer \\
& & Sickenhammer \\
\hline
\end{tabular}

Ein aus psychologischer Perspektive besonderer Status kommt dabei dem mittleren Niveau, das Rosch Basisebene nennt:

In general, the basic level of abstraction in a taxonomy is the level at which categories carry the most information, possess the highest cue validity, and are, thus, the most differentiated from one another. (Rosch et al. 1976: 383)

Von dem besonderen Status der Basisebene zeugt die Tatsache, dass sich die Kleinkinder zuerst die auf diesem Niveau liegenden Begriffe wie HUND, KATZE, TISCH, sTUHL aneignen: Die Kategorisierung auf der Basisebene wird bis zum 3. Lebensjahr beherrscht (Lakoff 1987: 49, Langacker 1987: 48). Den Begriffen der höheren Ordnung wie TIER, MÖBEL sowie den Begriffen der niedrigeren Ordnung wie DACKEL, PERSERKATZE, SCHAUKELSTUHL kommt sowohl in der Ontogenese als auch in der Kommunikation eine untergeordnete Rolle zu: Sie werden später erworben und weisen eine niedrigere Frequenz auf. Ebenfalls aus der wahrnehmungspsychologischen Perspektive kommt den Basisbegriffen eine besondere Funktion zu: Es ist ein Niveau, auf dem die Kategorisierung durch ganzheitliche Wahrnehmung - ohne Analyse der distinktiven Eigenschaften - determiniert wird. Lakoff (1987: 46) führt unter Verweis auf Rosch u.a. (1976) folgende Eigenschaften für die Begriffe der Basisebene an:

(i) Es ist die höchste Ebene, auf der die wahrgenommenen Kategorienelemente ähnliche Formen aufweisen.

(ii) Es ist die höchste Ebene, auf der das mentale Bild die ganze Kategorie widerspiegeln kann.

(iii) Es ist die Ebene, auf der die Probanden die Kategorienelemente am schnellsten identifizieren. 
(iv) Es ist die erste Ebene, die sich die Kinder im Spracherwerb aneignen und die ins Lexikon einer Sprache in der ersten Reihe Eingang findet.

(v) Es ist die Ebene mit den kürzesten Grundlexemen.

(vi) Es ist die Ebene, deren Namen im neutralen Kontext aufgeführt werden. Der Satz Auf der Veranda sitzt ein Hund kann im neutralen Kontext aufgeführt werden, während die Sätze Auf der Veranda sitzt ein Säugetier und Auf der Veranda sitzt ein rauhaariger Foxterrier besonderer Kontexte bedürfen.

(vii) Es ist die Ebene, auf der die Mehrheit unseres Wissens organisiert wird.

Die Entdeckung der Basisebene ist für weitere Ausführungen aus zwei Gründen wichtig: Zum einen verweist sie darauf, dass die wichtigsten Kategorien in Anlehnung an die Strukturen entstehen, die zur Sphäre unserer körperlichen Erfahrung gehören. Die Kategorisierung auf der Basisebene ist durch allgemeine Gestalt und eventuelle motorische Interaktion gekennzeichnet, woraus sich der zweite Grund ergibt: Es ist die Ebene, auf der man mühelos mentale Bilder generieren kann. Während man sich nur schlecht vorstellen kann, wie ein Werkzeug, Tier oder Musikinstrument aussieht oder wie man mit diesen Gegenständen in Kontakt treten könnte, bereitet die Evozierung des mentalen Bildes auf der Basisebene keine Schwierigkeiten, auch wenn sich die Menschen in ihren Bildern wesentlich unterscheiden können. Es ist bemerkenswert, dass die nominalen Begriffe in der überwiegenden Mehrheit der Phraseologismen auf der Basisebene angesiedelt sind ${ }^{72}$ (den Hammer fallen lassen, zwischen Hammer und Amboss, eine Schraube ohne Ende, jmdn. in der Zange haben).

72 Vgl. die von Quasthoff/Schmidt/Hallsteinsdóttir (2010: 39-41) zusammengestellte Liste der häufigsten Substantive, die anhand eines Korpus aus 5058 Phraseologismen ermittelt wurde. Die in den Phraseologismen häufigsten Substantive referieren in überwiegender Mehrzahl hauptsächlich auf die Dinge der Alltagswelt, dazu gehören dem Rang nach: 1. Kopf, 2. Hand. 3. Welt, 4. Augen, 5. Ohren, 6. Zeit, 7. Nase, 8. Sache, 9. Mund, 10. Weg, 11. Herz, 12. Leben, 13. Tag, 14. Licht, 15. Mann, 16. Auge, 17. Gott, 18. Hals, 19. Wort, 20. Geld, 21. Teufel, 22. Zunge, 23. Finger, 24. Hände, 25. Wasser, 26. Boden, 27. Luft, 28. Himmel, 29. Kind, 30. Blut, 31. Ende, 32. Rücken, 33. Ohr, 34. Wind, 35. Beine, 36. Fuß, 37. Füßen, 38. Hund, 39. Tod, 40. Tür, 41. Gesicht, 42. Spiel, 43. Stein, 44. Haut, 45. Herzen, 46. Händen, 47. Schritt, 48. Seite, 49. Tisch, 50. Brot. Diesen Tatbestand erklären die Autoren folgenderweise: „Phraseologismen entstehen durch sprachlich gezogene Analogien zu Alltagserfahrungen oder die Bezugnahme auf die Dinge und Begebenheiten des Alltags. In diesen Bereichen existieren viele kurze Erbwörter. Die bevorzugte Verwendung kurzer Wörter in Phraseologismen könnte zusätzlich durch das Streben nach sprachlicher Ökonomie erklärt werden. Phraseologismen sind an sich komplexe Zeichen, die aus anderen Zeichen bestehen. Sprachökonomisch ist es daher sinnvoll, bevorzugt einfache Wörter als Komponenten in Phraseologismen zu verwenden" (Quasthoff/Schmidt/Hallsteinsdóttir 2010: 40). 


\subsubsection{Vorstellungsschemata von Johnson}

In diesem Unterkapitel wird auf mentale Strukturen eingegangen, die am Schnittpunkt zwischen mehreren Themenbereichen liegen (Embodiment, Repräsentationsmodi, Metapherntheorie), wegen ihrer Abstraktheit schwer erfassbar sind, dennoch einen wichtigen Ankerpunkt für das ganze konzeptuelle System bilden (vgl. Hampe 2005). Es handelt sich um image schemas (dt. Vorstellungsschemata, Bildschemata), die als Terminus und Modell 1987 von Johnson in die kognitiv ausgerichtete Forschung eingeführt wurden.

Unter image schemas werden die in der frühesten Kindheit herausgebildeten mentalen Strukturen verstanden, die sich in der rekurrenten Interaktion mit der umgebenden Welt entfalten und zur Kohärenz und Struktur menschlicher Erfahrungen einen grundlegenden Beitrag leisten:

An image schema is a recurring dynamic pattern of our perceptual interactions and motor programs that gives coherence and structure to our experience. (Johnson 1987: xiv)

Image schemas sind tief embodied, an die Beschaffenheit unseres Körpers gebunden, in Sinneswahrnehmungen, perzeptuellen Interaktionen und sensomotorischen Abläufen verankert, was Johnson u.a. am Beispiel des image schemas BALANCE (GLEICHGEWICHT) veranschaulicht:

It is crucially important to see that balancing is an activity we learn with our bodies and not by grasping a set of rules or concepts. First and foremost, balancing is something we $d o$. The baby stands, wobbles, and drops to the floor. It tries again, and again, and again, until a new world opens up - the world of the balanced erect posture. There are those few days when the synapse connections are being established and then, fairly suddenly, the baby becomes a little homo erectus. Balancing is a preconceptual bodily activity that cannot be described propositionally by rules. As Michael Palanyi has argued, you cannot tell another what steps to take to achieve the balanced riding of a bicycle. (Johnson 1987: 74)

Image schemas bilden somit grundlegende Strukturen von einem ganzheitlichen Charakter, „inkorporierte Muster sensomotorischer Körpererfahrungen“ (Jäkel 2003: 288) von einem sehr hohen Schematizitätsgrad. Zu ihrer Darstellung bedient man sich - zur Not - der Propositionen oder schematischer Bilder, man muss sich aber dessen bewusst sein, dass sie nur als Behelfsmittel fungieren. Image schemas als gestalthafte Strukturen - integrieren nämlich unterschiedliche Sinnesmodalitäten. Obgleich die erste Komponente image (Bild) auf ihren bildhaften Charakter verweist, sind sie nicht ausschließlich an visuelle Modalität gebunden (Johnson 1987: xx, Hampe 2005: 1): Vorstellungsschemata sind in ihrer Natur weder propositional noch bildhaft, sie sind cross-modal und liegen der menschlichen Fähigkeit zugrunde, „to share activation contours across perceptual modalities" (Rohrer 2005: 168). In der neueren psychologischen (Mandler 2005) und neurolinguistischen 
(Rohrer 2005) Fachliteratur wird der prozessuale Charakter der image schemas unterstrichen:

An image schema might be a particular pattern of neural activations in a neural map of pitch, say something corresponding to the musical scale in sequence (do-re-mifa-so-la ...). From such an example we can see that image-schemas patterns are not temporally static, but take place in and through time. The musical scale is a sequence of activity in time; hearing an ascending pitch scale causes us to anticipate its next step. Given those first six notes, we sense its next step - ti - and expect the pattern to continue. The temporal character of image schemate creates the possibility of a normal pattern completion, which in turn serves as the felt basis for their inferential capacity. Image schemata are thus temporally dynamic in the sense that once they are triggered, we tend to complete the whole perceptual contour of the schema. (Rohrer 2005: 168-169)

Als grundlegende Vorstellungsschemata werden von Johnson (1987: 126) und Lakoff (1987: 267) folgende image schemas angesehen ${ }^{73}$ :

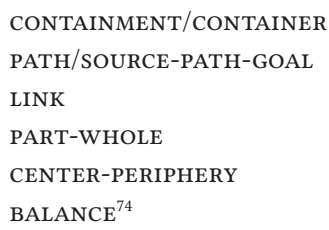

Diese gestalthaften Strukturen beeinflussen dann wesentlich die Konzeptbildung und bieten einen Ansatzpunkt für weitere Konzeptualisierungen:

Image schemas constitute a preverbal and pre-reflective emergent level of meaning. They are patterns found in the topologic neural maps we share with other animals, though we as humans have particular image schemas that are more or less peculiar to our types of bodies. (Johnson/Rohrer 2007: 30)

So stellt das image schema PATH (WEG) und seine inhärenten Eigenschaften: Punkt A, Punkt B, Direktionalität, zeitlicher Ablauf eine präkonzeptuelle Grundlage für die Konzeptualisierung vieler Abstrakta: Als Wege werden u.a. Vorgehensweisen, Fortschritt, Handeln, Führung, Zeit, Karriere und Leben konzeptualisiert (vgl. Baldauf 1997: 151). Das Vorstellungsschema CONTAINER (BEHÄLTER) mit seiner Innen-Außen-Dichotomie beeinflusst sowohl die Konzeptualisierungen von

73 Diese Liste wird keinesfalls als abgeschlossen angesehen, sie wird ständig erweitert (Jäkel 2003: 289-290, Grady 2005).

74 „Image schemas are relatively simple structures that constantly recur in our everyday bodily eXperience: CONTAINERS, PATHS, LINKS, FORCES, BALANCE, and in various orientation and relations: UP-DOWN, FRONT-BACK, PART-WHOLE, CENTER-PERIPHERY.“ (Johnson 1987: 267) 
Präpositionen (in die Schule gehen, aus der Schule zurückkehren) als auch die Art und Weise, wie wir unseren Körper, unsere Emotionen, Gefühle und Sprache konzeptualisieren: KÖRPER IST BEHÄLTER; GEFÜHLE, EMOTIONEN, GEDANKEN, WÖRTER SIND ENTITÄTEN IN DIESEM BEHÄLTER. Die image schemas stellen damit einen wichtigen Ankerpunkt für viele konzeptuelle Metaphern von einem großen Generalitätsgrad dar, vgl. z.B. bildschematische Metaphern von Baldauf (Unterkap. 2.3.4.2.5).

Die Eigenschaften der Vorstellungsschemata werden von Johnson/Rohrer folgendermaßen zusammengefasst:

Image schemas can be characterized more formally as:

(1) recurrent patterns of bodily experience,

(2) "image"-like in that they preserve the topological structure of the perceptual whole, as evidenced by pattern-completion,

(3) operating dynamically in and across time,

(4) realized as activation patterns (or "contours") in and between topologic neural maps,

(5) structures which link sensimotor experience to conceptualization and language and

(6) structures which afford „normal“ pattern completions that can serve as a basis for inference. (Johnson/Rohrer 2007: 37)

\subsubsection{Verbildlichung bei Langacker}

Abschließend wird auf die Rolle der Bildhaftigkeit in der Grammatik verwiesen. Den bildhaften Charakter semantischer und grammatischer Strukturen hebt Langacker $(1991,2008)$ in seiner Kognitiven Grammatik nachdrücklich hervor. Wie bereits im Kap. 2.1.5.3 dargestellt, sind die Bedeutungen mit den Konzeptualisierungen gleichgesetzt:

Linguistic meaning resides in conceptualization, which I have so far characterized as being dynamic, interactive, imagistic (as opposed to propositional), and imaginative (involving metaphor, blending, fictivity, and mental space construction). (Langacker 2008: 43)

Die Bedeutung umfasst dabei zwei Aspekte: den konzeptuellen Inhalt (conceptual content) und eine spezifische Art und Weise, wie dieser Inhalt konstruiert wird (construal). Der konzeptuelle Inhalt kann in Bezug auf Repräsentationsformen multimodal sein, bei dem construal, d.h. der interpretativen Konstruktion einer Konzeptualisierung wird aber unwillkürlich auf Phänomene zurückgegriffen, die mit den visuellen Mustern zusammenhängen. Langacker bedient sich der Metapher der Szenenbetrachtung, um dies verständlich zu machen: 
An expression meaning is not just the conceptual content it evokes - equally important is how that content is construed. As part of its conventional semantic value, every symbolic structure construes its content in a certain fashion. It is hard to resist the visual metaphor, where content is likened to a scene and construal to a particular way of viewing it. Importantly, CG does not claim that all meanings are based on space or visual perception, but the visual metaphor does suggest a way to classify the many facets of construal, if only for expository purposes. In viewing a scene, what we actually see depends on how closely we examine it, what we choose to look at, which elements we pay most attention to, and where we view it from. The corresponding labels I will use, for broad classes of construal phenomena, are specificity, focusing, prominence, and perspective. (Langacker 2008: 55)

Als erste Verbildlichungsdimension wird also ein graduierbarer Spezifizierungsgrad (level of specificity, granularity, resolution) angesehen, d.h. „the level of precision and detail at which a situation is characterized" (Langacker 2008: 55). Diese Dimension kommt beispielsweise in semantischen Hierarchien deutlich zum Ausdruck: thing $\rightarrow$ object $\rightarrow$ tool $\rightarrow$ hammer $\rightarrow$ claw hammer (Langacker 2008: 56).

Die zweite Dimension bildet focusing: Aus der Fülle der im konzeptuellen Inhalt gesammelten Informationen werden diejenigen fokussiert, die in einem bestimmten Kontext von Relevanz sind. Fokussierung beinhaltet die foreground/background-Orientierung. Die in den Vordergrund gerückten Inhalte sind auffälliger als diejenigen, die den Hintergrund bilden.

Prominenz (prominence auch salience genannt) hängt damit zusammen, dass die interpretative Konstruktion (construal) asymmetrisch ist. Diese Dimension ist an die Trajektor- und Landmark-Unterscheidung gebunden: have a parent und have a child aktivieren dieselben konzeptuellen Inhalte, die Konzeptualisierungen unterscheiden sich aber in der Direktionalität. Die Konzeptualisierungen sind somit von Natur aus asymmetrisch. Das, was in den Vordergrund gerückt wird, hat immer eine höhere Salienz als die Hintergrundinformationen.

Die Perspektive stellt die letzte Verbildlichungsdimension dar und umfasst mehrere Aspekte wie Orientierung, Standpunkt und Blickwinkel (die Position, aus der die Szene beobachtet wird), Gerichtetheit und Objektivität.

Dabei stellt die Bildhaftigkeit nicht nur ein Merkmal des Lexikons dar, bildhaft ist auch die Grammatik, die konventionalisierte Mittel für die Strukturierung und sinnbildliche Darstellung des konzeptuellen Inhaltes bietet (Langacker 1991b: 12). Dieselbe Szene kann mithilfe von verschiedenen Mitteln beschrieben werden, infolge deren unterschiedliche Bilder entstehen:

The symbolic resources of a language generally provide an array of alternative images for describing a given scene, and we shift from one to another with great facility, often within the confines of a single sentence. (Langacker 1991b: 12)

Da die vorliegenden Untersuchungen primär semantisch ausgerichtet sind, wird auf eine detaillierte Beschreibung der Rolle der Verbildlichung in der Grammatik nicht eingegangen. An dieser Stelle ist es nur erwähnenswert, dass die 
Perspektivierung für die Erklärung der in der Phraseologie häufigen Variationen in den Aktionsarten herangezogen werden kann, vgl.

ingressiv: den Karren/die Karre in den Dreck fahren

durativ: die Karre/den Karren im Dreck stehen lassen

egressiv: die Karre/den Karren aus dem Dreck ziehen

\subsubsection{Zusammenfassung und Ausblick}

Der Kognitiven Linguistik liegt ein komplexes Bild eines in die Interaktion mit der Umwelt involvierten Menschen zugrunde. Kognitive und sprachliche Prozesse vollziehen sich nicht in einer Welt der abstrakten, symbolischen Repräsentationen, sondern sind von der Sensorik, Motorik und dem zeitlichen Geschehen in der Außenwelt abhängig: Körperliche und perzeptuelle Zustände stellen die Grundlage der Sprache dar (Rickheit/Weiss/Eikmeyer 2010: 103).

Besonders viel Aufmerksamkeit wird dabei der Rolle der analogen Repräsentationen $^{75}$ gewidmet:

Cognitive linguists incline to imagistic accounts (...).... images seem particularly well suited (and formulas unsuited) for certain aspects of conception. Central to the concept of a trumpet, for instance, is a visual image of its shape, as well as an auditory image of its sound. (Langacker 2008: 32)

Auch wenn sich nicht alle Forscher explizit mit der Frage auseinandergesetzt haben, in welchem Repräsentationsformat die konzeptuellen Strukturen aufbewahrt werden, so spielen doch anschauliches Denken und die dahinter stehenden die analogen Strukturen von verschiedenem Schematizitätsgrad in zahlreichen kognitiven Sprachtheorien eine wichtige Rolle. Auf den fundamentalen Status und die analoge, gestalthafte Struktur der Begriffe der Basisebene verweist Rosch (1976), ebenfalls die image schemas von Johnson (1987) sowie Perspektive, Profilierung und Scanning bei der Bedeutungskonstituierung von Langacker $(1987,2008)$ setzten die Existenz konzeptueller Strukturen von einem analogen Charakter voraus.

Die neuesten Ansätze der Grounded Cognition gehen von der Annahme aus, dass jede Erfahrung zum Aufbau des konzeptuellen Systems eines Menschen einen Beitrag leistet. Dabei konstruieren diese Erfahrungen multimodale Repräsentationen: sensorische, motorische, introspektive, propriozeptive, affektive perzeptuelle Symbole, die dann - zu Simulatoren zusammengefügt - konzeptähnliche Strukturen von multimodaler Struktur bilden. Von größter Bedeutung ist der konstruktivistische Charakter dieser Repräsentationen: Zwischen dem Repräsentierten und der mentalen Repräsentation besteht kein Abbild-, sondern

75 Zur Relevanz der visuellen Reize für die Kognition stellt die Entwicklungspsychologin Jean Mandler fest: „We are visual creatures first and foremost, which is one of the reasons we are most adept at spatial analysis" (Mandler 2005: 149). 
ein Konstruktionsverhältnis, wodurch interpretative Operationen wie Kategorisierung, Bildung der Inferenzen oder Propositionen durchaus möglich sind und die Produktivität der Sprache gewährleisten. Der sprachliche Ausdruck (der phonologische Pol einer sprachlichen Einheit) reaktiviert den konzeptuellen Pol, also perzeptuelle, motorische, introspektive, körperliche, affektive Zustände und ermöglicht die Simulation aus den für eine konkrete kommunikative Situation wichtigen Wissensbeständen. Die Konzeptualisierungen sind demnach nicht nur dynamisch und tentativ, sondern auch multimodal.

Die skizzenhaft umrissenen Ansätze gewähren uns Einblick in die Natur der phraseologischen Bildhaftigkeit. Die literale Lesart der meisten Idiome ist auf der Basisebene angesiedelt, was zahlreiche Konsequenzen mit sich bringt: Die Idiomkonstituenten weisen im alltäglichen Sprachgebrauch hohe Frequenz auf, haben deswegen eine ausgebaute kognitive Struktur (das Prinzip der Rekurrenz) und evozieren unwillkürlich mentale Bilder, die - aufgrund unterschiedlicher Erfahrungen - individuelle Eigenschaften aufweisen können. Auch wenn die mentalen Bilder im normalen Sprachfluss äußerst flüchtig sind und möglicherweise nur minimal über der Bewusstseinsschwelle liegen, so sind sie doch vorwiegend an die literale Lesart gebunden, aktivieren die mit der literalen Lesart verbundenen Wissensstrukturen und tragen zur jeweiligen Konzeptualisierung bei.

\subsection{Metapher und Metonymie als kognitive Prozesse}

Spricht man von Metapher und Metonymie, dann muss auf die Vielfalt der Forschungstraditionen verwiesen werden (Dobrzyńska 1992: 232), aus deren Koexistenz sich unterschiedliche Auffassungen der beiden Begriffe ergeben. In der klassischen Auffassung werden Metapher und Metonymie als Ausdruck poetischer Kreativität oder eine rhetorische Ausnahmeerscheinung verstanden, als Phänomene also, die auf der sprachlichen Ebene angesiedelt sind. Die kognitive Auffassung der Metapher und Metonymie war lange Zeit durch die konzeptuelle Metapherntheorie geprägt, deren Autoren - Lakoff und Johnson (1980) - anhand zahlreicher Belege von der Omnipräsenz der konzeptuellen Metaphern in der Sprache und in der Kognition überzeugen. Die modernen kognitiven Ansätze (vgl. z.B. Barcelona 2003, Croft 2003, Dancygier/Sweetster 2014, Goosens 2003, Spieß/Köpcke 2015, Taylor 2003) versuchen der Mannigfaltigkeit der beiden Mechanismen Rechnung zu tragen: Die als Metapher und Metonymie bezeichneten Mechanismen sind komplex und unterscheiden sich in ihrer Festigkeit, ihrem Generalitätsgrad, in der kognitiven Funktion und dem Kreativitätsgrad, woraus sich verschiedene Typen ergeben. Grundsätzlich wird dennoch davon ausgegangen, dass sich beide Mechanismen auf einer konzeptuellen Ebene vollziehen und als Mappings - mentale Verbindungen von zwei konzeptuellen (Sub-)Strukturen - verstanden werden.

Es ist auch erwähnenswert, dass der Metapher lange Zeit wesentlich mehr Aufmerksamkeit als der Metonymie geschenkt wurde, woraus die Überzahl der Literatur und der Theorien zum Thema Metapher resultiert. Diese Überzahl kann dennoch nicht als Überlegenheit gedeutet werden: Metonymie gilt heutzutage als 
ein für die Sprache und Kognition genauso wichtiger kognitiver Mechanismus wie die Metapher (Barcelona 2003: 215, Feyaerts 1999: 173, Spieß/Köpcke 2015: 3), manche Forscher weisen ihr sogar eine grundlegendere Rolle zu (vgl. Barcelona 2003: 215, Dancygier/Sweetster 2014: 4, Panther/Radden 1999: 1).

Generell können Metonymie und Metapher als fundamentale Mechanismen der Bedeutungserweiterung definiert werden, die dafür verantwortlich sind, dass eine Grundbedeutung zu einer erweiterten, polysemen Bedeutung ausgeweitet wird:

Metaphor and metonymy figure prominently in most discussions of meaning relations as the primordial mechanism of semantic extension from a ,basic ' or ,root ${ }^{\text {' mea- }}$ ning to an ,extended' or ,polysemous' one. (Riemer 2003: 380)

Den großen Wirkungsskopus dieser Mechanismen drückt René Dirven vor dem Hintergrund der neueren Theorien (etwas überspitzt) mit der Bibelparaphrase aus: „At the beginning was the word, and then came metonymy and metaphor" (Dirven 2003a: 38). Im Folgenden werden Metapher und Metonymie vor allem aus der Perspektive der Kognitiven Linguistik im Rahmen des sog. Zwei-DomänenAnsatzes beschrieben. Nach dem kurzen Umriss der klassischen Auffassung von Metapher und Metonymie wird auf die konzeptuelle Metapherntheorie (CTMTheorie) von Lakoff und Johnson (1980) eingegangen, die - einigen Revisionen und Erweiterungen unterzogen - einen wichtigen Ausgangspunkt für die moderne, kognitiv ausgerichtete Auffassung der beiden Prozesse bildet. In den Fokus des Interesses werden des Weiteren die Probleme bei der Definierung von Metapher und Metonymie gerückt, die sich (i) aus den von Natur aus verschwommenen und offenen Domänengrenzen und der Abhängigkeit der Metapher und Metonymie von individuellem und kontextuellem Wissen sowie (ii) aus den Interaktionen zwischen Metapher und Metonymie ergeben.

\subsubsection{Metapher und Metonymie in der traditionellen Auffassung}

Die klassische Auffassung der Metapher und Metonymie als tropischer Figuren, die für den künstlerischen Umgang mit der Sprache charakteristisch sind, ist auf Aristoteles zurückzuführen. Metapher (z.B. Achilles ist ein Löwe) wird dabei als ein stilistisches Mittel betrachtet, das auf der Ähnlichkeits- bzw. Analogiebeziehung aufbaut: Aristoteles (Poetik, Kap. 21) betrachtet die Metapher als „die Übertragung eines Wortes (...) nach den Regeln der Analogie.“ Das Alter steht demnach in einem analogen Verhältnis zum Leben, wie der Abend zu dem Tag; der Dichter nennt also den Abend ,Alter des Tages', oder, wie Empedokles, das Alter ,Abend des Lebens' bzw. ,Sonnenuntergang des Lebens' (ebd.). Ein Sachverhalt wird also aufgrund von Ähnlichkeitsbeziehungen (tertium comparationis) mit Ausdrücken eines anderen thematischen Bereiches benannt und erhält dadurch eine spezifische Motivationsbedeutung (Munske 2015 [1993]: 109). Da das tertium comparationis nicht explizit benannt wird, eröffnet metaphorischer Gebrauch einen breiten interpretativen Spielraum (ebd.). Lakoff fasst zusammen: 
The word „metaphor" was defined as a novel or poetic linguistic expression where one or more words for a concept are used outside of their normal conventional meaning to express a „similar“ concept. (Lakoff 1993: 202)

Die so verstandene Metapher wird hauptsächlich als ein sprachliches Phänomen aufgefasst. Pajdzińska (1991: 131) definiert sie - dieser Tradition folgend - als „Verstoß gegen die Sprachregeln, der einen Empfänger zur sinnbildenden Kooperation zwingt. ${ }^{\text {"76 }}$ Auf ähnliche Aspekte verweist Dobrzyńska (1992: 233):

Die Metapher ist eine Ausdruckweise eines im Begriffsrahmen eines Kodes nicht enthaltenen Sinnes. Der Sender setzt voraus, dass der Mitteilungsempfänger die Haltung annimmt, die von H.P. Grice einst als Kooperationseinstellung bezeichnet wurde und dass er im Stande sein wird, einen wenigstens vom Originalsinn des Senders nicht weit entfernten Sinn herzustellen. ${ }^{77}$ (Dobrzyńska 1992: 233, übers. von A. S.)

Metonymie stellt in der klassischen Auffassung ein Beispiel für eine Ersatzrelation $^{78}$ in der Sprache dar. Die Ausweitung der Bedeutung beruht nicht auf der Ähnlichkeits-, sondern auf der Kontiguitätsbeziehung, X steht für Y, wobei zwischen X und Y ein Zusammenhang besteht, so wie in dem folgenden Beispiel:

The ham sandwich is waiting for his check.

in dem sich ham sandwich auf den Kunden, der diese Speise bestellt hat, bezieht.

Die Auffindung der Metonymien im Sprachgebrauch ist wesentlich schwieriger als es bei Metaphern der Fall ist: Es handelt sich hier um die Sinnberührung (Ullmann 1972), um Übertragungen innerhalb thematischer Zusammenhänge (Munske 2015 [1993]: 111). In der traditionellen Rhetorik wird die Metonymie als eine Figur bezeichnet, in der

(...) the name of one entity $\mathrm{e}^{1}$ is used to refer to another entity $\mathrm{e}^{2}$, which is contiguous to $\mathrm{e}^{1}$. This process of transferred reference is possible in virtue of what Nunberg (1978) calls a 'referring function'. There is a referring function which permits the name of a container to refer to the contents of the container, as when we say The kettle's boiling.

76 „(...) naruszenie reguł języka, które zmusza odbiorcę do sensotwórczego współdziałania." (Pajdzińska 1991: 131)

77 „Metafora to sposób na wyrażenie sensu nie objętego zasobami pojęciowymi kodu. Nadawca zakłada, że odbiorca wypowiedzi przyjmie postawę, którą H.P. Grice określił jako postawę współdziałania (kooperacji) i że będzie on w stanie wytworzyć sens przynajmniej bliski temu, jaki nadawca miał na myśli“ (Dobrzyńska 1992: 233).

78 Radden und Kövecses fassen die traditionelle Definition der Metonymie folgendermaßen zusammen: (...) „metonymy was mainly seen as a figure of speech, i.e. it was basically thought of as a matter of language, especially literary or figurative language. (...) metonymy operates on names of things, involves the substitution of the name of one thing for that of another thing and assumes that the two things are somehow associated“ (Radden/Kövecses 1999: 18). 
Similarly, a referring function permits the name of a producer to refer to the product (Does he own any Picassos?; Dickens is on the top shelf). (Taylor 2003: 324)

Eine besondere Spielart der Metonymie, die traditionell zur Sprache gebracht wird, stellt die Synekdoche dar, die als eine Pars-pro-toto (Teil für das Ganze) Beziehung, z.B. She is just a pretty face oder eine Genus-Spezies-Relation definiert wird. Die klassische Rhetorik unterscheidet dabei eine generalisierende (Genus für Spezies, totum pro parte) und eine partikularisierende (Spezies für Genus, pars pro toto) Synekdoche (Munske 2015 [1993]: 114).

Einen interessanten Zwischenschritt zwischen der traditionellen und kognitiven Auffassung der Metapher und Metonymie stellt ein kurzer Beitrag von Roman Jakobson dar. Bereits 1956 bezeichnet er die Ähnlichkeitsrelation der Metapher und die Kontiguitätsrelation der Metonymie als zwei grundlegende Prinzipien, die das menschliche Handeln ${ }^{79}$ strukturieren und siedelt sie an der paradigmatischen und der syntagmatischen Sprachebene an. Seiner Zeit voraus ${ }^{80}$ ist vor allem die Bemerkung, dass sowohl Metapher als auch Metonymie ein Kontinuum bilden (Jakobson 2003 [1956]: 46-47) und keine absoluten Größen sind - eine Hypothese, die in der gegenwärtigen Forschung auf große Resonanz stößt und empirisch untermauert wird (Barcelona 2000, 2003; Croft 2003; Dirven 2003b; Radden 2003). Dirven (2003b: 77) veranschaulicht die Beziehung zwischen derart verstandener Metapher und Metonymie und den paradigmatischen und syntagmatischen Sprachebenen anhand folgenden Schemas (Abb. 14):

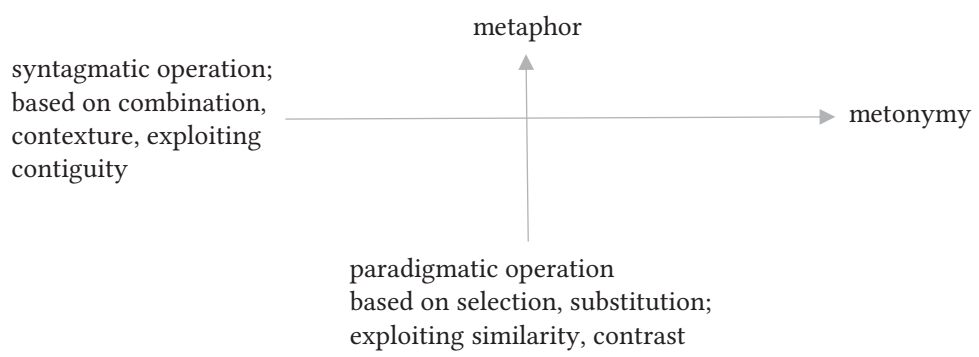

Abb. 14: Metapher und Metonimie auf der paradigmatischen und syntagmatischen Achse (Dirven 2003b: 77).

79 Im Original behaviour (2003 [1956]: 42), heutzutage würden wir an dieser Stelle eher von Konzeptualisierungen sprechen.

80 Vgl. dazu die moderne Auffassung der Kognitiven Linguistik: „Die Kognitive Linguistik lehnt alle Kriterien ab, die eine strikte Abgrenzung zwischen der literalen und der figürlichen Sprache anstreben“" (Tabakowska 1990: 100, übers. von A. S.). [Językoznawstwo kognitywne odrzuca wszelkie kryteria zmierzające do ścisłego rozróżnienia między językiem dosłownym a przenośnym]. 
In den letzten drei Jahrzehnten hat sich die Auffassung der Metapher und Metonymie unter dem Einfluss der konzeptuellen Metapherntheorie von Lakoff und Johnson (1980) wesentlich erweitert. Lakoff und Johnson führen in ihrem programmatisch betitelten Buch Metaphors We Live By (1980) zahlreiche Beispiele dafür heran, dass die Metapher keineswegs als ein ausschließlich schöpferisches, einmaliges Sprachphänomen interpretiert werden kann, sondern das sie ebenfalls in der Alltagssprache präsent ist. Die sprachlichen Ausdrücke wie be-greifen, Geld anlegen, Die Inflation steigt sind metaphorisch, auch wenn dies aufgrund der Konventionalisierung erst bei genauerer Betrachtung auffällt. Die Begründer der CTM-Theorie gehen des Weiteren davon aus, dass die Metapher nicht nur die Sprache, sondern auch das Denken und Handeln ${ }^{81}$ beeinflusst (Lakoff/Johnson 2000 [1980]: 11). Die konzeptuelle Metapher ist somit:

[in the cognitive linguistic view metaphor is] only derivatively a linguistic phenomenon. It exists in language only because it exists in the body/brain and thought. Linguistic metaphors (i.e. metaphors in language) are expressions of metaphorical concepts in the brain's conceptual system. (Kövecses 2005: 21)

Weitere Charakteristika der konzeptuellen Metaphern werden im Folgenden in Anlehnung vor allem an Lakoff/Johnson (1980) und Lakoff (1993) kurz umrissen und diskutiert.

\subsubsection{Grundzüge der konzeptuellen Metapherntheorie von Lakoff/Johnson}

Die Entdeckung der konzeptuellen Metapher führt man hauptsächlich auf die bahnbrechende Publikation von Lakoff und Johnson zurück, die auf große

81 Lakoff und Johnson veranschaulichen die Beziehung zwischen Sprache - Denken Handeln am Beispiel der Metapher ARgumentieren IST KRIEG. Da in der abendländischen Kultur DisKussion und ARGUMENTIEREN auf der Basis dieser Metapher konzeptualisiert werden, stellen wir uns die erwähnten Konzepte in Kriegsbegriffen vor: Beim Argumentieren kann man gewinnen oder verlieren, der Diskussionspartner ist unser Gegner, den wir angreifen oder vor dem wir uns verteidigen. Dies manifestiert sich in zahlreichen (mehr oder weniger festen) sprachlichen Ausdrücken, die von vielen Muttersprachlern nicht mal als metaphorisch (im traditionellen Sinne) betrachtet werden: Er griff jeden Schwachpunkt in meiner Argumentation an. Seine Kritik traf ins Schwarze. Ich schmetterte sein Argument $a b$. Ich habe noch nie eine Auseinandersetzung mit ihm gewonnen. Würden wir dagegen in einer Kultur leben, in der dem Konzept ARgUMENTIEREN die konzeptuelle Metapher ARGUMENTIEREN IST TANZ zugrunde läge, dann hätte es Einfluss nicht nur auf unsere Sprache, sondern ebenfalls auf unser Denken und Handeln. „In einer solchen Kultur würden die Menschen die Argumentationshandlung in einem anderen Licht sehen, sie anders erleben, anders ausführen und anders darüber sprechen" (Lakoff/Johnson 2000 [1980]: 12-13). 
Resonanz stieß und in den folgenden Jahren einen wichtigen Impuls zur Entwicklung der Kognitiven Linguistik ausmachte. Den Ausgangspunkt der Theorie bildet die bereits erwähnte These von der Allgegenwärtigkeit metaphorischer Ausdrücke in der Alltagssprache. Die richtungsweisende Wirkung dieser Festlegung ist vor dem Hintergrund des in den 80er Jahren des 20. Jh. vorherrschenden Generativismus gut sichtbar. Dazu schreibt Tabakowska:

Die Kognitive Linguistik entstand in der Opposition zu den generativen Grammatiken, die - nach der Meinung der Kognitivisten - so fortgeschrittenen Formalisierungund Abstraktionsgrad erreichten, dass sie die lebendige Sprache kaum wahrnehmen konnten. Den Generativisten wird vorgeworfen, dass sie nur prototypische Strukturen beschreiben können, die lediglich einige Prozent aller in der authentischen Kommunikation gebrauchten Strukturen ausmachen. (Tabakowska 1990: 90, übers. von A. S. $)^{82}$

Der Generativismus fasste Metaphern, Metonymien und figurative Sprache als peripheres Sprachphänomen, eine Ausnahmeerscheinung auf. Der Publikation von Lakoff und Johnson ist dagegen zu verdanken, dass Metapher und Metonymie nicht mehr als Randerscheinungen des menschlichen Geistes, sondern als für Sprache und Denken konstitutive Prozesse, als wichtiger Bestandteil menschlicher Sprachkompetenz betrachtet werden. Dies wurde schnell von anderen Forschern aufgegriffen: 1987 räumt Langacker in Foundation to Cognitive Grammar. Theoretical Prerequisites diesbezüglich Folgendes ein:

Figurative language is generally ignored in current theories; at best it is handled by special, ad hoc descriptive devices. Yet it would be hard to find anything more pervasive and fundamental in language, even (I maintain) in the domain of grammatical structure; if figurative language were systematically eliminated from our data base, little if any data would remain. (Langacker 1987: 1)

Von Relevanz war ebenfalls der Verweis auf den kategorialen Charakter der metaphorischen Ausdrücke, die in den meisten Fällen nicht isoliert/zufällig vorkommen, sondern bestimmte Kategorien bilden. Dies hängt damit zusammen, dass die metaphorischen Ausdrücke als sprachliche Manifestationen einer konzeptuellen Metapher zu betrachten sind. So wird die konzeptuelle Metapher ZEIT IST GELD in sprachlichen, weitgehend konventionalisierten Ausdrücken wie Zeitverschwendung, Zeit sparen, dafür ist mir meine Zeit zu kostbar, keine Zeit verlieren, jmdm. die Zeit stehlen, eine Zeit raubende Arbeit sprachlich realisiert.

82 „Językoznawstwo kognitywne zrodziło się w opozycji do gramatyk generatywnych, które zdaniem kognitywistów osiągnęły taki stopień formalizacji i takie wyżyny abstrakcji, że trudno już im dostrzec żywy jezyk. Generatywistom zarzuca się, że potrafią opisać wyłącznie struktury prototypowe, które stanowią zaledwie kilka procent ogółu struktur językowych używanych w rzeczywistej komunikacji“ (Tabakowska 1990: 99). 
Die konzeptuelle Metapher wird somit als ein sich auf der konzeptuellen Ebene vollziehender Prozess/Mechanismus angesehen. Man definiert sie als Mapping zwischen zwei Domänen: einer source domain (Ausgangsdomäne) und einer target domain (Zieldomäne), wobei die zweitgenannte Domäne immer abstrakter als die Erstgenannte ist. Somit wird die Zieldomäne LOve u.a. ${ }^{83}$ auf der Folie der Ausgangsdomäne JOURNEY konzeptualisiert, was die konzeptuelle Metapher LOVE IS JOURNEY konstituiert und sich in zahlreichen sprachlichen Ausdrücken des Englischen, Deutschen und Polnischen manifestiert, z.B.:

LOVE IS JOURNEY/LIEBE IST EINE REISE/MIŁOŚĆ TO PODRÓŻ

Look, how far we have come. Schau doch, wie weit wir miteinander gekommen sind. Spójrz, jak daleko zaszliśmy.

Our relationship hit a dead-end street. Unsere Beziehung ist in einer Sackgasse. Nasz związek utknął w ślepym zaułku.

We are at a crossroad. Wir sind nun am Scheideweg. Jesteśmy na rozdrożu.

It has been a long, bumpy road. Das war ein langer, steiniger Weg. To była długa, wyboista droga.

The marriage is on the rocks. Unsere Ehe ist auf Grund gelaufen. Nasze małżeństwo ugrzęzło na mieliźnie. (Englische Belege von Lakoff 1993: 206, übers. von A. S.)

Lakoff und Johnson (2000 [1980] $]^{84}$ :22-45) teilen die konzeptuellen Metaphern in drei Typen ein:

Strukturmetaphern liegen vor, wenn ein Konzept von einem anderen Konzept her metaphorisch strukturiert wird. Bei diesen Metaphern liefert die Ausgangsdomäne eine relativ detaillierte Wissensstruktur (rich knowledge structure) für die Zieldomäne (Kövecses 2002: 33). Die bereits angeführte Metapher: LIEBE IST EINE REISE stellt ein Beispiel der Strukturmetapher dar.

Orientierungsmetaphern werden durch ein ganzes System von Konzepten, von denen die meisten mit der Orientierung im Raum zusammenhängen, in ihrer wechselseitigen Bezogenheit organisiert: z.B. oben-unten, innen-außen, vornehinten, dran-weg, tief-flach, zentral-peripher. Dadurch geben sie einem Konzept eine räumliche Beziehung an (Lakoff/Johnson 2000 [1980]: 22). Orientierungsmetaphern sind weitgehend durch die Beschaffenheit des menschlichen Körpers und die Umgebung, in der der Mensch lebt, bestimmt. Mit großer Wahrscheinlichkeit kann angenommen werden, dass die positive Einschätzung des Oben-Seins allen Kulturen gemeinsam ist: Der erwachsene Mensch bewegt sich in seinen besten Jahren in

83 Die Konzeptualisierungen der LIEBE wurden von Kövecses $(1986,1988)$ einer detaillierten Analyse unterzogen, die ergab, dass diesem Konzept ungefähr 20 konzeptuelle Metaphern zugrunde liegen.

84 Im Folgenden wird auf die 2. Auflage der deutschen Fassung des Werkes von Lakoff/ Johnson Bezug genommen, die aus dem Amerikanischen von A. Hildenbrand übersetzt im Jahre 2000 unter dem Titel: Leben in Metaphern: Konstruktion und Gebrauch von Sprachbildern erschien. 
der aufrechten Position, in der er fähig ist, schnell zu laufen, sich effektiv zu verteidigen, Überblick über die Umgebung zu behalten, andere zu kontrollieren. In der waagerechten Position, liegend, befinden sich die Menschen in den Zeiten, in denen sie - aus der biologisch-darwinistischen Perspektive des Überlebenskampfes - den äußeren Umständen schutzlos ausgeliefert sind: Neugeborene, Säuglinge sowie alte, kranke, durch physische oder psychische Erlebnisse geschwächte oder schlafende Menschen. Diese direkte physische Körpererfahrung, um kulturelle Vorgaben ${ }^{85}$ ergänzt, widerspiegelt sich dann in der übergeordneten konzeptuellen Orientierungsmetapher GUT IST OBEN, SCHLECHT IST UNTEN, die wiederum vielen Orientierungsmetaphern von einem niedrigeren Abstraktionsgrad zugrunde liegt, z.B.:

GLÜCKLICH SEIN IST OBEN; TRAURIG SEIN IST UNTEN

Ich fühle mich heute obenauf.

Das beflügelte meinen Geist.

Meine Stimmung stieg/sank.

Du bist in Hochstimmung.

Ich fühle mich niedergedrückt.

GESUND SEIN UND LEBEN SIND OBEN; KRANKHEIT UND TOD SIND UNTEN

Er hat eine hervorragende Gesundheit.

Lazarus erhob sich von den Toten.

Er ist in Höchstform.

Eine Erkältung hat ihn in die Knie gezwungen.

Er ist seiner schweren Krankheit erlegen.

Er fiel tot um.

KONTROLLE ODER MACHT AUSÜBEN IST OBEN; KONTROLLE ODER MACHT AUSGESETZT SEIN IST UNTEN

Ich habe die Kontrolle über sie.

Er ist auf der Höhe seiner Macht.

Er hat das Oberkommando.

Seine Macht stieg.

Er ist mir kräftemäßig überlegen.

Ich habe ihn unter Kontrolle.

HOHER STATUS IST OBEN; NIEDRIGER STATUS IST UNTEN

Er hat eine erhabene Position.

Sie wird bis zur Spitze aufsteigen.

Er ist auf dem Gipfel seiner Karriere.

Er klettert die Karriereleiter hoch.

85 Auch die kulturellen Begebenheiten werden durch so verstandene konzeptuelle Metaphern geprägt: Die Erhöhung eines Herrschers (Königs, Fürsten, Staatspräsidenten) bei allen wichtigen Gelegenheiten mittels eines Podests, Podiums, Throns kann als eine nicht-sprachliche Exemplifizierung der OBEN IST GUT-Metapher angesehen werden. 
Er ist am unteren Ende der gesellschaftlichen Hierarchie.

Ihr Ansehen sank. (Auswahl der Beispiele aus Lakoff/Johnson 2000 [1980]: 23-25)

Ontologische Metaphern basieren auf elementaren Erfahrungen des Menschen mit physischen Objekten sowie auf der Tatsache, dass die Menschen Wesen mit einer Physis sind, die durch die Hautoberfläche von der Welt getrennt ist. Aus diesem Grunde neigen wir dazu, die Dinge der umgebenden Welt als Einzelgebilde zu kategorisieren:

Wenn Dinge nicht eindeutig Einzelgebilde sind oder scharfe Grenzen haben, dann kategorisieren wir sie so, als ob sie diese Eigenschaften besäßen, z.B. Gebirge, Nachbarschaft, Hecke usw. Wir müssen physische Phänomene in dieser Weise sehen, damit wir bestimmte Ziele erreichen können: ein Gebirge lokalisieren, sich in der Nachbarschaft treffen, Hecken schneiden. Die vom Menschen gesetzten Ziele verlangen von uns bezeichnenderweise, dass wir künstliche Grenzen setzen, die physische Phänomene zu Einzelgebilden machen, wie wir das auch sind: Entitäten, die durch eine Oberfläche begrenzt sind. (Lakoff/Johnson 2000 [1980]: 35)

Dementsprechend werden die Dinge ohne Physis oder Abstrakta als Entitäten oder Materie konzeptualisiert, z.B.:

INFLATION IST EINE ENTITÄT

Die Inflation verringert unseren Lebensstandard.

Wir müssen die Inflation bekämpfen.

Die Inflation treibt uns in die Enge.

Die Inflation schlägt an der Kasse im Supermarkt und an der Tankstelle zu.

Immobilien zu kaufen ist die beste Art, der Inflation zu begegnen. (Lakoff/Johnson 2000 [1980]: 36)

DIE SEELE IST EIN ZERBRECHLICHES OBJEKT

Ihr Selbstwertgefühl ist sehr fragil.

Seit dem Tod seiner Frau muss man ihn vorsichtig anfassen.

Er brach unter dem Kreuzverhör zusammen.

Sie ist schnell niedergeschmettert.

Er ist an der Erfahrung zerbrochen. (Lakoff/Johnson 2000 [1980]: 38)

Besonders relevant und verbreitet unter den ontologischen Metaphern sind die GEFÄss-Metaphern, die der Konzeptualisierung von zahlreichen Ereignissen und Zuständen zugrunde liegen. Als eine Ausprägung der Gefäßmetapher kann z.B. die kognitive Metapher KATEgORIEN SIND BEHÄLTER (CATEGORIES ARE CONTAINERS) angesehen werden, die der Kategorisierung von abstrakten Begriffen wie Zeit, Zustand, oder Veränderung zugrunde liegt. Eine Entität ist dementsprechend in oder außerhalb einer Kategorie, kann in eine Kategorie gelegt oder aus ihr entfernt werden. Dies kommt deutlich im Gebrauch der Präpositionen zum Ausdruck:

Er ist in Liebe entbrannt.

Er ist aus dem Koma aufgewacht. 
Langsam komme ich in Form.

Er fiel in eine tiefe Depression.

Betonenswert ist dabei, dass die sprachlichen Ausdrücke eine wichtige, dennoch keinesfalls einzige Art und Weise, in der sich die konzeptuellen Metaphern manifestieren können, bilden. Konzeptuelle Metaphern werden als kognitiv-konzeptuelle (oder sogar neuronale ${ }^{86}$ ) Mechanismen aufgefasst und die Sprache stellt nur eins der vielen Ausdrucksmittel dar, in denen sie in Erscheinung treten. Kövecses (2002: 58-66) führt Beispiele aus den Bereichen u.a. der bildenden Kunst, Film- und Gebrauchskunst sowie der Mythologie für die nicht-linguistische Umsetzung der konzeptuellen Metapher.

A metaphorical mapping allows knowledge about the metaphor's source domain to be applied to the target in a way that fundamentally determines or influences the conceptualization of the target: metaphor is thus first and foremost a cognitive operation, and only derivately the name for a certain class of linguistic expressions. (Riemer 2003: 392)

Daraus ergibt sich die dritte These (außer den Annahmen von der Omnipräsenz und dem kategorialen Charakter der konzeptuellen Metaphern), nach der das Wesen der Metapher in den Mappings ${ }^{87}$, d.h. in den konzeptuellen Korrespondenzen (Projektionen) zwischen den Domänen liegt. Diese Mappings könnte man beispielshalber für die konzeptuelle Metapher LIFE Is A JOURNEY folgendermaßen beschreiben:

LIFE IS A JOURNEY

traveler $\rightarrow$ person leading a life

journey/motion (toward a destination) $\rightarrow$ leading a life (with a purpose)

destination $\rightarrow$ purpose of life

obstacles (in the way of motion) $\rightarrow$ difficulties (in life)

distance covered $\rightarrow$ progress made

path/way of the journey $\rightarrow$ the manner/way of living

choices about the path $\rightarrow$ choices in life. (Kövecses 2005: 14)

Es ist dabei von Bedeutung, dass die Mappings zwischen den Domänen nicht beliebig sind, sondern durch die Prinzipien der Unidirektionalität und der Invariabilität

86 Aus dieser Perspektive beschreibt die konzeptuelle Metapher Lakoff in der neuesten Version der CTM-Theorie (2008), in dessen Zentrum primary conceptual metaphors, die durch die unmittelbare Erfahrung gegründet sind, stehen. Nach Lakoff entstehen diese Metaphern durch die Mechanismen der Hebb'schen Lernregeln: what fires together, wires together, was heißt: Je häufiger ein Neuron gleichzeitig mit einem anderen Neuron aktiviert wird, desto bevorzugter werden die beiden Neuronen aufeinander reagieren.

87 Konzeptuelle Metapher ist „a cross-domain mapping in the conceptual system“ (Lakoff 1993: 203). 
eingeschränkt werden. Das Prinzip der Unidirektionalität (the unidirectionality principle) legt fest, dass die Mappings immer von der Ausgangs- in die Zieldomäne verlaufen; das Prinzip der Invariabilität (the invariance principle) hebt hervor, dass dabei die grundlegenden topologischen Korrespondenzen zwischen den Domänen aufrechterhalten werden müssen: „metaphorical mappings preserve the cognitive topology (...) of the source domain, in a way consistent with the current structure of the target domain" (Lakoff 1993: 215).

One should (...) think of the Invariance Principle in terms of constraints on fixed correspondences: If one looks at the existing correspondences, one will see that the Invariance Principle holds: source domain interiors correspond to target domain interiors; source domain exteriors correspond to target domain exteriors, and so forth. As a consequence it will turn out that the image-schematic structure of the target domain cannot be violated: One cannot find cases where a source domain interior is mapped onto a target domain exterior, or where a source domain exterior is mapped onto a target domain path. This simply does not happen. (Lakoff 1993: 215)

Gleichzeitig ist die metaphorische Strukturierung von einem partiellen Charakter: Nicht alle Bestandteile der Ausgangsdomäne müssen für das metaphorische Mapping von Belang sein. In der Metapher THEORIEN SIND GEBÄUdE spielen z.B. Fundamente und Außenwände aus der Ausgangsdomäne GEBÄUDE eine wichtige Rolle bei der metaphorischen Strukturierung des abstrakteren Konzeptes THEORIE (vgl. Eine Theorie hat ein solides Fundament. Der Aufbau der Theorie ist nicht überzeugend. Deine Theorie bricht auseinander), während Korridore, Zimmer und Treppenhäuser einen „unbenutzten“ Teil der Ausgangsdomäne ausmachen (Lakoff/Johnson 2000 [1980]: 66).

Die grundlegenden Unterschiede zwischen der traditionell aufgefassten (linguistischen) und der konzeptuellen Metapher bestehen also darin, dass die Erstgenannte auf der (oft ad hoc festgestellten) Ähnlichkeitsbeziehung aufbaut, wohingegen das Wesen der Zweitgenannten in den tiefen konzeptuellen Strukturen menschlicher Kognition platziert und in den (oft unbewussten) konzeptuellen Mappings von einem kategorialen Charakter etabliert ist.

Wesentlich weniger Aufmerksamkeit haben Lakoff und Johnson in Metaphors We Live By der Metonymie gewidmet. Die in der ursprünglichen Fassung vorgeschlagene Definition weist viele Ähnlichkeiten zu der traditionellen Auffassung der Metonymie auf, Lakoff und Johnson betonen die referentielle Funktion der Metonymie:

Hinter Metapher und Metonymie stehen unterschiedliche Konzeptionen: Die Metapher bietet vor allem die Möglichkeit, einen Sachverhalt im Lichte eines anderen Sachverhaltes zu betrachten; ihre wichtigste Aufgabe besteht darin, einen Sachverhalt verstehbar zu machen. Die Metonymie andererseits hat in erster Linie die Aufgabe, eine Beziehung herzustellen, so dass wir eine Entität benutzen können, damit diese für eine andere Entität steht. Doch die Metonymie hat nicht nur eine Beziehungsfunktion. Sie hat auch die Aufgabe, etwas verstehbar zu machen. (Lakoff/Johnson 2000 [1980]: 47) 
Seit der Veröffentlichung von Metaphors We Live By wurde die Rolle der Metonymie - vor allem unter dem Einfluss der empirischen Forschung - aufgewertet, sodass man heutzutage immer häufiger von der Theorie der kognitiven Metapher und Metonymie spricht (vgl. Barcelona 2000: 1).

\subsubsection{Kritik der konzeptuellen Metapherntheorie}

Auch wenn die Entdeckung der konzeptuellen Metaphern für die Auffassung dieses Sprachphänomens und die Entwicklung der kognitiv ausgerichteten Forschung als bahnbrechend angesehen wird, bestehen einige Kritikpunkte, die im Folgenden in Umrissen dargestellt werden:

(i) Kritisiert wird die von Lakoff/Johnson unterstellte Hypothese von der absoluten Omnipräsenz der konzeptuellen Metapher. Die Auffassung der konzeptuellen Metapher als eines Phänomens, das

... unser Alltagsleben durchdringt, und zwar nicht nur unsere Sprache, sondern auch unser Denken und Handeln. Unser alltägliches Konzeptsystem, nach dem wir sowohl denken als auch handeln, ist im Kern und grundsätzlich metaphorisch. (Lakoff/Johnson 2000 [1980]: 11)

scheint vielen Forschern übertrieben zu sein. Selbstverständlich existieren zahlreiche Ausdrücke, die unmetaphorisch-wörtlich sind, was die Gegenüberstellung von Jäkel (1998: 104-105) veranschaulicht (vgl. Tab. 4).

Tab. 4: Gegenüberstellung der wörtlichen und metaphorischen Ausdrücken von fäkel (1998: 104-105).

\begin{tabular}{ll}
\hline metaphernfrei, wörtlich & metaphorisch \\
\hline Wir sind hier in diesem Raum. & Wir sind hier in einer aussichtslosen Lage. \\
$\begin{array}{l}\text { Manche sitzen auf den wenigen Stühlen, } \\
\text { andere müssen stehen. }\end{array}$ & $\begin{array}{l}\text { Manche sitzen auf den wenigen gut } \\
\text { dotierten Stellen, andere stehen auf der }\end{array}$ \\
Ich habe mich eben an dem großen, & Straße. \\
schweren Tisch gestoßen. & Erscheinungsbild der Schule. \\
Hast du das gesehen? & Hast du das Problem gesehen? \\
Der Lehrer spricht zu leise. Ich höre nichts. & $\begin{array}{l}\text { Der Lehrer spricht in Rätseln. Ich höre } \\
\text { keinen Sinn heraus. }\end{array}$ \\
Bald gehe ich nach Hause. & Gleich gehe ich an die Decke. \\
\hline
\end{tabular}

Dies schmälert das Verdienst von Lakoff und Johnson nicht: In vielen metaphorischen Ausdrücken fallen die Übergänge zwischen dem Literalen und dem Metaphorischen erst bei genauerer Betrachtung auf, eine theoretische 
Gewichtsverschiebung der Metapher von einem Sonderfall hin zum Regelfall oder von der Ausnahmeerscheinung hin zum häufigen Phänomen ist vor diesem Hintergrund verständlich und begründet (Jäkel 1998: 102). Nichtsdestoweniger ist die Allgegenwärtigkeits-These nur in einer geschwächten Form akzeptabel: Konzeptuelle Metaphern liegen zahlreichen Konzeptualisierungen zugrunde, beeinflussen weitgehend menschliches Denken und menschliche Sprache, spielen eine wichtige Rolle bei der Konzeptualisierung abstrakter Begriffe, sind aber nicht omnipräsent.

(ii) Des Weiteren stellt Evans (2013: 74) die Annahme infrage, dass alle Metaphern durch konzeptuelles Metaphernsystem beeinflusst werden:

CTM provides an account of just one type of cognitive representation that must be in play in figurative language understanding. While conceptual metaphors may underpin certain types of figurative language, there are classes of linguistic metaphors that appear to be motivated in ways that are, at least in part, independent of conceptual metaphors. (Evans 2013: 74)

Am Beispiel eines Gedichtes Free Union von André Breton führt Evans vor Augen, dass zahlreiche Metaphern nicht auf den konzeptuellen Mappings (oder ontologischen Mappings im Sinne von Barcelona 2003), sondern auf der Ähnlichkeitsbeziehung, so wie sie in der klassischen Metapherntheorie angenommen wurde, beruhen:

My wife whose hair is brush fire

Whose thoughts are summer lightning

Whose waist is an hourglass

Whose waist is the waist of an otter caught in the teeth of a tiger

Whose mouth is a bright cackade with the fragrance of a star of the first magnitude

Whose teeth leave prints like the tracks of mice over snow

Whose tongue is made of amber and polished glass

Whose tongue is like a stabbed wafer. (André Breton, Free Union, 1931)

Diesen Mappings liegen keine festen, körperlich verankerten konzeptuellen Mappings zugrunde, sie werden aufgrund des epistemischen Wissens über die Welt, der äußerlichen Ähnlichkeitsbeziehung und auf Basis der Kooperation zwischen dem Sprachproduzenten und dem Sprachrezipienten vollzogen. ${ }^{88}$

88 In einem Artikel unter dem Titel Contemporary Theory of Metaphor nimmt Lakoff (1993) explizit Bezug auf diesen Metapherntyp, auch wenn er ihnen eine eher marginale Rolle zuweist, vgl. „A major difference between the contemporary theory and the classical one is based on the literal-figurative distinction. Given that distinction, one might think that one ,arrives at a metaphorical interpretation of a sentence by ,starting' with the literal meaning and applying some algorithmic process to it (...). Through there do exist cases where something like this happens, this is not in general how metaphor works" (Lakoff 1993: 205). 
(iii) Kontrovers diskutiert wird ebenfalls Lakoffs These, dass abstrakte Konzepte wie Zeit, Quantität, Zustand u.a. via konzeptuelle Metapher (Lakoff 1993: 212) verstanden werden. Barsalou (1999: 600) zieht die Annahme, dass konzeptuelle Metaphern selbstständig ein abstraktes Konzept wie LIEBE oder ÄRGER konstituieren können, mit guten Argumenten in Zweifel:

Knowing only that anger is like liquid exploding from a container hardly constitutes an adequate concept. If it is all that people know, they are far from having an adequate understanding of anger. Second, a direct representation of an abstract domain is necessary to guide the mapping of a concrete domain into it. A concrete domain cannot be mapped systematically into an abstract domain that has no content. (Barsalou 1999: 600)

Konzeptuelle Metaphern tragen demnach zur Etablierung eines abstrakten Konzeptes bei (Barsalou 1999: 600) oder können seine bestimmten Aspekte hervorheben (Barsalou/Wiemer-Hastings 2005: 133), für die mentale Repräsentation eines abstrakten Konzeptes sind sie aber alleine nicht ausreichend.

(iv) Darüber hinaus wird darauf verwiesen, dass man das Verstehen von zahlreichen metaphorischen Ausdrücken nicht nur mit der automatischen Aktivierung der konzeptuellen Projektionen erklären kann. Glucksberg/Keysar/McGlone (1992) greifen auf die konzeptuelle Metapher LOVE IS JOURNEY und ihre sprachliche Exemplifizierung: Our marriage is a roller coaster ride (Unsere Ehe ist eine Achterbahnfahrt) zurück, um dies zu veranschaulichen. Das metaphorische Modell mit seinen regulären Projektionen (Reisende $\rightarrow$ Liebhaber, Hindernisse auf dem Weg $\rightarrow$ Schwierigkeiten im Leben, der zurückgelegte Weg $\rightarrow$ das gemeinsam verbrachte Leben u.a.) mag einen Ausgangspunkt für die Konzeptualisierung bieten, ist aber für die Interpretation der Metapher keinesfalls ausreichend. Wie die Befragung der Probanden ergab, ist für die Auslegung der Metapher in dieser Äußerung das Wissen von den aufregenden, emotional beanspruchenden psychologischen Höhen und Tiefen des Zusammenseins hier wichtiger als Kategorie des Reisens. Die konzeptuellen Metaphern, die als feste, statische mentale Repräsentationen aufgefasst werden, erklären die Kontextsensibilität der sprachlichen Äußerungen nicht.

The results do not, in any way, cast doubt on the possibility that concepts in semantic memory may be organized by metaphor. What we do question is whether such metaphorical structures play a role in any given context. The development or more incisive, on-line measures of comprehension and production processes will ultimately shed more light on this issue of accessibility. (Glucksberg/Keysar/McGlone 1992: 579)

(v) Verwirrungsstiftend und nicht immer nachvollziehbar ist die Terminologie, mit der die Autoren die sie interessierenden Bereiche des metaphorischen Konzeptsystems abzugrenzen versuchen: Im Fokus der Aufmerksamkeit liegen die Metaphern, in denen wir leben, „metaphors we live by“, die sie als live metaphors bezeichnen. In ihrer Eingliederung nehmen Lakoff und Johnson (1980: 53-56, dt. Aufl. 2000: 66-68) eine terminologische Verschiebung vor, die auf begründete 
Kritik (vgl. Jäkel 1998, 2003: 42-55, Handl 2011, Pawelec 2005, 2006) stieß: Sie sprechen nämlich einerseits von den literalen und non-literalen (imaginativen) Metaphern, andererseits von toten (dead), lebenden (live) und innovativen (novel) Metaphern:

Tab. 5: Einteilung der Metaphern nach dem Konventionalitätsgrad in der traditionellen Linguistik und der CTM-Theorie (Romero/Soria 2005: 6).

\begin{tabular}{llll}
\hline Traditional terminology & \multicolumn{2}{c}{ CTM } \\
\hline $\begin{array}{l}\text { dead metaphors, conventional } \\
\text { metaphors }\end{array}$ & literal metaphors & dead metaphors \\
\cline { 1 - 1 } live metaphors, novel metaphors & $\begin{array}{l}\text { imaginative or novel } \\
\text { metaphors } \\
\text { (non-literal metaphors) }\end{array}$ & & live metaphors \\
\cline { 5 - 5 } & & & novel metaphors \\
\hline
\end{tabular}

Alltägliche, lebende Metaphern - „metaphors we live by“ - werden mit der literalen Sprache gleichgesetzt: Unter Verweis auf die konzeptuelle Metapher ARGUMENTIEREN IST KRIEG schreiben Lakoff und Johnson beispielsweise: „The language of argument is not poetic, fanciful, or rhetorical; it is literal“ (1980: 5). Die Begründer der CTM-Theorie wollen damit wahrscheinlich zum Ausdruck bringen, dass viele auf konzeptuellen Metaphern beruhende sprachliche Manifestationen so weitgehend konventionalisiert sind, eine so übliche Art und Weise darstellen, in der über abstrakte Konzepte gesprochen wird, dass man sie nicht mehr als Metaphern ansieht. Die Kollokationen eine Theorie konstruieren, das Fundament einer Theorie stellen ein Beispiel für den in der Alltagssprache so oft benutzten Teil der Metapher THEORIEN SIND GEBÄUDE, dass sie nicht mehr als übertragen, metaphorisch empfunden werden. Die für solche Phänomene vorgeschlagene Bezeichnung literal metaphors ist dennoch ein contradictio in adiectio: Erstens lässt sich der Begriff ,Metapher ohne Bezug auf das Literale kaum definieren, zweitens können die Kriterien der Literalität (Wörtlichkeit) und Konventionalität nicht als identisch angesehen werden: Es handelt sich hier eindeutig um zwei unterschiedliche Aspekte, auch wenn im Falle der konventionalisierten konzeptuellen Metaphern und der metaphorischen Ausdrücke ihre Metaphorizität nicht so offensichtlich wie bei innovativen, imaginativen (in der deutschen Ausgabe als ,bildhaft' bezeichneten) Metaphern ist.

Nicht immer nachvollziehbar sind des Weiteren die Beschreibungen der vorgeschlagenen Einteilung der Metaphern sowie die angeführten Beispiele. So werden beispielshalber die imaginativen Metaphern (non-literal, novel, imaginative metaphors), denen die konzeptuelle Metapher THEORIEN SIND GEBÄUDE zugrunde liegt, in drei Subtypen unterteilt (Lakoff/Johnson 2000 [1980]: 67): 
(a) Erweiterungen auf den unbenutzten Teil einer Metapher, z.B. Diese Daten sind die Ziegelsteine und der Mörtel meiner Theorie;

(b) Beispiele für den unbenutzten Teil der wörtlich zu nehmenden Metapher, z.B. Seine Theorie hat tausend Kämmerchen und lange, labyrinthische Flure;

(c) Beispiele für eine unkonventionelle Metapher, d.h. eine Metapher, die nicht benutzt wird, um einen Teil unseres normalen Konzeptsystems zu strukturieren, sondern die eine neue Art des Denkens über ein Phänomen darstellt, z.B. Klassische Theorien sind wie Patriarchen, die viele Kinder zeugen, von denen sich die meisten unablässig streiten.

Ob man das Beispiel (c) tatsächlich auf die konzeptuelle Metapher THEORIEN SIND GEBÄUDE zurückführen kann, scheint zweifelhaft. Lakoff und Johnson versuchen an dieser Stelle krampfhaft die innovativen, schaffenden Metaphern ${ }^{89}$ in das Raster ihrer Theorie aufzuzwingen. Diese Versuche sind allerdings, wie Pawelec (2006: 44) zu Recht bemerkt, paradox, zumal die beiden Autoren an anderen Stellen mehrmals die Relevanz von imaginativen Strukturen unterstreichen.

Wie ersichtlich, entstehen infolge der Fusion der beiden Kriterien (der Kriterien übrigens, die selbst ein Kontinuum bilden und keine scharfen Grenzen haben): literal-figurativ sowie konventionalisiert-innovativ zahlreiche terminologische Schwierigkeiten. Lakoffs und Johnsons Formulierungen wie ,literal metaphor (Lakoff/Johnson 2000 [1980]: 53) führen zur Begriffskonfusion. Die durch derartige Termini angedeutete Aufhebung der Grenze zwischen dem Wörtlichen und dem Metaphorischen führt dazu, „dass jeder sinnvolle Metaphernbegriff zusammenbricht" (Jäkel 1998: 103).

(vi) Kontrovers diskutiert wird ebenfalls das Prinzip der Unidirektionalität, das besagt, dass die Mappings immer von der Ausgangs- in die Zieldomäne gerichtet sind. Kiklewicz (2006: 267) führt anschauliche Beispiele für die Konversion der Ausgangs- und Zieldomäne in slawischen Sprachen an, die sich übrigens auch im Deutschen bewährt, vgl. die konzeptuellen Metaphern ARgumentieren (DiskUsSION) IST KRIEG SOWIe KRIEG IST EINE DISKUSSION:

ARGUMENTIEREN (DISKUSSION) IST KRIEG

Ihre Behauptungen sind unhaltbar.

Er griff jeden Schwachpunkt in meiner Argumentation an.

Seine Kritik traf ins Schwarze.

Ich schmetterte sein Argument $a b$.

Ich habe noch nie eine Auseinandersetzung mit ihm gewonnen.

Sie sind anderer Meinung? Nun, schießen Sie los!

89 In einer 1989 veröffentlichten, der poetischen Metapher gewidmeten Publikation führten Lakoff/Turner auch die sog. one-shot metaphor ein, die auf dem Mapping von einem Vorstellungsschema auf ein anderes Vorstellungsschema beruht (Lakoff/ Turner 1989: 89). 
Wenn du nach dieser Strategie vorgehst, wird er dich vernichten. (Lakoff/Johnson 2000 [1980]: 12)

KRIEG IST EINE DISKUSSION

Der Feind hat mit Maschinengewehrschüssen geantwortet.

Die Kanonen haben geschwiegen.

die Gesetzesübertretung verantworten

Kanonenstimmen ${ }^{90}$

Das Prinzip der Unidirektionalität wird des Weiteren vor dem Hintergrund der Theorie von mentalen Räumen sowie der Blending-Theorie von Fauconnier/Turner (1998, 2002), Turner/Fauconnier (2003) relativiert. Laut der Blending-Theorie konstituiert sich die Bedeutung in einem Rückkopplungsgefüge von vier mentalen Räumen: der Ausgangs- und Zieldomäne sowie des generischen und des Blending-Raumes (Näheres in Libura 2010). Die Blending-Theorie steht zwar in keinem Widerspruch zu der CTM-Theorie und ihrer zentralen Annahme von der Ausgangs- und Zieldomäne: „Although projections go from both inputs to the blend, the principal inferences project from the blend to the target, not to the source" (Barcelona 2003: 218), sie schwächt dennoch das Unidirektionalitätsprinzip ab.

Generell lässt sich feststellen, dass die CTM als Sprachtheorie einen fest etablierten Platz in der Kognitiven Lingustik hat. Die Entdeckung der fest verankerten konzeptuellen Mappings, die ein konzeptuelles System bilden, zahlreichen kognitiven Strukturen zugrunde liegen und sich sprachlich manifestieren können, bildet die Basis für die moderne Auffassung von Metapher und Metonymie. Das, was auf Kritik stößt, ist nicht die Theorie selbst, sondern einige terminologische Unklarheiten sowie die Tatsache, dass ihr explanatorischer Skopus manchmal von den Autoren überschätzt wurde.

Aus diesem Grunde werden im Folgenden die neueren Entwicklungen der Metapher- und Metonymietheorie dargestellt, in denen die Rolle der Metonymie hervorgehoben und mehreren Metapherntypen Rechnung getragen wird. Dabei werden immer häufiger die Interaktionen zwischen der Metapher und der Metonymie ins Zentrum der Aufmerksamkeit gerückt.

\subsubsection{Moderne Auffassung der Metapher und der Metonymie - Update}

Trotz der erwähnten Kritikpunkte wird der fundamentale Beitrag der CTM-Theorie zu der Kognitiven Linguistik im Allgemeinen und insbesondere zu der modernen Auffassung von Metapher und Metonymie kaum infrage gestellt. Metapher und Metonymie gehören zu den zentralen Begriffen der kognitiv ausgerichteten

90 WOJNA/KONFLIKT TO ROZMOWA/KOMUNIKACJA: Wróg odpowiedział strzałami karabinów maszynowych, odpowiadać za łamanie przepisów, działa milczaty, głosy dział (Kiklewicz 2006: 267). 
Forschung und werden als kognitive Mechanismen aufgefasst, die sich auf der konzeptuellen Ebene vollziehen und auf der sprachlichen Ebene manifestieren können. Die Existenz der konzeptuellen Metaphern, die nicht nur das sprachliche, sondern auch das konzeptuelle System beeinflussen, wird allgemein anerkannt, der kognitiv ausgerichtete Zugang zu den beiden Phänomenen darf dennoch nicht ausschließlich mit der CTM-Theorie gleichgesetzt werden. In der Fachliteratur werden heutzutage, fast 40 Jahre nach der Veröffentlichung des Werkes von Lakoff und Johnson, zum Teil andere Aspekte der beiden Mechanismen in den Fokus des Interesses gerückt, die sich in drei Punkten zusammenfassen lassen:

(i) Zum Ersten wird hervorgehoben, dass die CTM zwar einen wichtigen Ansatz zur Klärung der Metapherngenese darstellt (Stöckl 2004: 207), sich aber nicht immer und nicht alleine zur Klärung der metaphorischen Bedeutungskonstituierungsprozesse im authentischen Usus eignet. Nicht alle Metaphern können als feste mentale Mappings aufgefasst werden, nicht alle Metaphern bauen auf der körperlich verankerten Erfahrung auf und haben einen universellen Charakter. Konzeptuelle Metaphern sind des Weiteren als feste mentale Repräsentationen auf ko- und kontextuelle Bedingungen unempfindlich ${ }^{91}$. Aus diesem Grunde tauchen in der Forschung Modelle auf, die unmittelbar auf das Verstehen der Metapher, die Bedeutungskonstituierungsprozesse unter bestimmten kontextuellen Bedingungen eingehen. Als Beispiel für solche Ansätze wird im Folgenden das property attribution model des kanadischen Psycholinguisten Sam Glucksberg (2002) herangeführt.

(ii) Zum Zweiten wird anerkannt, dass Metaphern ein sehr komplexes Phänomen darstellen und nach etlichen Kriterien eingeteilt werden können. Eine für die weiteren Erörterungen wichtige Unterscheidung bezieht sich auf die Art der Mappings: Anhand dieses Kriteriums werden die konzeptuellen (in Barcelonas Terminologie ,ontologischen') von den epistemischen Metaphern abgegrenzt. Ein anderes, für Phraseologie relevantes Einteilungskriterium des metaphorischen Bereiches stellt ihr Konventionalitätsgrad dar (Kövecses 2002: 29-32). Die weiteren Klassifikationen hängen mit der Weiterentwicklung der CTM-Theorie zusammen: So setzt die von Kövecses (2002) vorgeschlagene Klassifikation der Metaphern nach ihrer Natur in die knowledge- und image-Metaphern die Kenntnis der von Johnson (1987) und Lakoff

91 Vgl. dazu Spieß/Köpcke (2015: 4): „Aus unserer Sicht sind gegenwärtig Ansätze vielversprechend, die unterschiedliche Perspektiven und die genannten Aspekte von Metaphorik (Metonymie) zu verknüpfen suchen und damit zur Ausdifferenzierung der Metaphern- und Metonymieforschung beitragen. Vor dem Hintergrund dieser integrativen Ansätze werden Metaphern und Metonymien nicht mehr unter kognitiven Aspekten betrachtet, vielmehr werden verschiedene Dimensionen, insbesondere Kognition, Semantik und Pragmatik miteinander verknüpft (...). Damit hätte sich die Analyse von Metaphern und Metonymien in ihren Verwendungszusammenhängen durchgesetzt." 
(1987) beschriebenen image schemas voraus. Die Differenzierung nach den Generalitätsstufen (levels of generality) zwischen der specific- und generic-level metaphors ist auf Lakoff und Turner (1989) zurückzuführen. Erwähnenswert ist ebenfalls eine korpusgestützte strukturbezogene Klassifikation der konzeptuellen Metaphern von Baldauf (1997).

(iii) Zum Dritten wird in den letzten Jahrzehnten viel mehr Aufmerksamkeit der Metonymie gewidmet, die als ein genauso wichtiger ${ }^{92}$ kognitiver Mechanismus wie Metapher angesehen wird. Man verweist dabei auf die Verflochtenheit der beiden Mechanismen, die ein Kontinuum bilden, wobei hybride Phänomene, wie Metaphtonimien, angenommen werden. Eng damit verbunden ist die Diskussion über die literale und figurative Sprache.

\subsubsection{Property attribution model von Glucksberg}

Wie erwähnt, lassen sich nicht alle für die Rezipienten durchaus motivierten und nachvollziehbaren Metaphern durch die konzeptuellen Mappings im Sinne von CTM-Theorie erklären. Dies veranschaulicht überzeugend Glucksberg (2001: 56) an folgenden Beispielen:

(i) Some roads are snakes.

(ii) Some lawyers are snakes.

In beiden Metaphern werden sehr unterschiedliche Aspekte der „Schlangenhaftigkeit" in den Vordergrund gerückt: Während es in (i) die äußere Gestalt einer Schlange ist, wird in (ii) die im abendländischen Kulturkreis diesen Tieren zugeschriebene Boshaftigkeit betont. Die Mappings, die die beiden Domänen verbinden, sind nicht konzeptuell im Sinne von CTM-Theorie: Es handelt sich hier nicht um die grundlegenden, körperlich verankerten, festen Mappings, die die Zieldomänen strukturieren ${ }^{93}$, sondern eher um das dynamische In-Beziehung-Setzen von zwei Konzepten: des vehicle/Ausgangsbereiches (Schlange) und des topic/Zielbereiches (der Straße im Beispiel (i), des Juristen im Beispiel (ii)). Glucksberg versteht unter Metaphern einen Prozess und betont seinen interaktiven Charakter: „Metaphors work via an interaction between the metaphor vehicle and the metaphor topic" (Glucksberg 2001: 52); sie beruhen auf der Übertragung von Attributen oder Merkmalen - sog. vehicle properties des vehicles (Ausgangsbereiches) - auf den Zielbereich, den topic (ebd., 53). Dabei spielen die vehicles und topics unterschiedliche

92 In der neueren Forschung verweist man darauf, dass Metonymie sogar fundamentaler als Metapher sein könnte, vgl. „Another, and perhaps even more fundamental trope than metaphor, which has seen a renaissance in cognitive linguistics, is metonymy“ (Panther 2011: 22).

93 Es ist somit auch eher unwahrscheinlich, dass die Tatsache, dass sich die Straßen schlängeln können, zur Struktur des Konzeptes STRASSE einen wesentlichen Beitrag leistet. 
Rollen im interaktiven Prozess der Metaphernkonstruktion. Der Zielbereich (topic) eröffnet eine topic dimension for attribution: Er bildet einen Rahmen, in den semantische Merkmale eingefügt werden können, wobei die Gewichtung der Merkmale je nach dem topic unterschiedlich sein kann und weitgehend durch den Kontext bestimmt wird:

When the topic is road, for example, dimensions such as shape (e.g. straight, curved, twisting), surface (smooth or bumpy), and width (narrow or wide), safety, and speed are meaningful and relevant in most context in which roads are discussed. Dimensions such as costs (cheap, expensive) and color (black, white, gray) can be meaningful but are irrelevant in most contexts in which roads are discussed. Still other dimensions, such as emotional arousal (calm, neutral, excited) are not normally applicable to roads, and consequently characterizations on these dimensions would usually be meaningless (although twisting mountain roads can be exhilarating). (Glucksberg 2001: 53)

Der Bildspenderbereich (vehicle) - in dem besprochenen Beispiel die Schlange liefert dagegen die zu übertragenden Merkmale (vehicle properties). In dem Zusammenspiel der in einer Beziehung eingefügten Konzepte entsteht eine emergente metaphorische Projektion:

Our interactive property attribution view of metaphor comprehension thus makes two independent claims. The first claim is that metaphor vehicles and topics play different but interactive roles. A metaphor topic provides dimensions for attribution, while a metaphor vehicle provides properties to be attributed to the topic. (...) The second claim is that the vehicle term can be used to refer at either of two levels of abstraction. When used in the metaphor form $X$ is a $Y$, than it is understood as referring at a higher level of abstraction than the topic term. When a term such as dagger [in the metaphor her letter was a dagger in his heart, A. S.] is used as a vehicle, it is understood as referring to a superordinate category that includes the topic and the term's literal referent as members. When a vehicle is used in smile form, $X$ is like $a Y$, than it is understood as referring to subordinate, literal referent. (Glucksberg 2001: 52-53)

Der interaktive Prozess der Merkmalsübertragungen wird dabei weitgehend durch den Kontext bestimmt:

For example, the metaphoric expression $A$ lifetime is a day may be interpreted as meaning either (a) life is short, or (b) the dawn of life is birth, high noon is maturity, and night is death. The knowledge schema that motivate each of these interpretations may be available in semantic memory, but only one (or neither) may be accessible in a given context. (Glucksberg/McGlone/Keysar 1992: 578)

Das property-attribution-Modell ist einleuchtend und lässt sich problemlos mit der Kognitiven Grammatik Langackers integrieren. Es trägt dem interaktiven Charakter der Metaphern Rechnung: Die sich konstituierenden metaphorischen Bedeutungen sind dynamisch, emergent, sie entstehen on-line und sind weitgehend durch 
den Ko- und Kontext bedingt. Die Tatsache, dass Metaphern durch das interaktive und spontane In-Beziehung-Setzen von zwei Konzepten gebildet werden können, schließt den Einfluss der konzeptuellen Metaphern auf die Konzeptualisierungen nicht aus: Die beiden Metapherntypen treten öfters zusammen auf, Glucksberg und Mitarbeiter bestreiten dennoch, dass die Aktivierung von konzeptuellen Metaphern automatisch ist und unbewusst geschieht:

We did (and still do) acknowledge the potential role of conventional metaphors in the generation of ad hoc attributive metaphor categories. We did, however, also argue that such conventional metaphoric mappings need not be accessed or used in the production and comprehension processes. (Glucksberg/McGlone/Keysar 1992: 578)

Glucksbergs Modell wird auch als linguistisches Modell bezeichnet (vgl. Stöckl

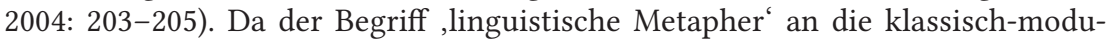
laren Theorien anknüpft und Glucksbergs Metaphernverständnis eine weite, holistische Auffassung der Sprache zugrunde liegt, wird im Weiteren für die Bezeichnung dieses Metapherntyps nach Barcelona der Terminus ,epistemische Metapher` eingesetzt.

\subsubsection{Klassifikationen der Metaphern}

Die Vielfalt der Herangehensweisen zum Phänomen ,Metapher ${ }^{6}$ widerspiegelt sich in der Anzahl ihrer Klassifikationen. Einige, für spätere Erwägungen relevante Einteilungen werden im Folgenden aufgegriffen: So richtet sich die Differenzierung zwischen konzeptuellen und epistemischen Metaphern nach der Art und Festigkeit von Mappings. Als Hauptkriterium der Einteilung in innovative und konventionalisierte Metaphern gilt ihr Konventionalitäts- und Lexikalisierungsgrad. In Hinsicht auf mentale Repräsentationsmodalität wird zwischen propositionalen und bildbasierten Metaphern unterschieden. Die Einteilung nach dem Generalitätsgrad nimmt Bezug auf die hierarchischen Rangordnungen zwischen den Metaphern. Die letzte strukturbezogene Klassifikation von Baldauf umfasst ausschließlich konzeptuelle Metaphern und stellt einen alternativen Vorschlag zu der ursprünglichen, von Lakoff/Johnson vorgeschlagenen Einteilung der konzeptuellen Metaphern in ontologische, Orientierungs- und Strukturmetaphern. Hervorzuheben bleibt dabei, dass keine der vorgenommenen Differenzierungen einen absoluten, dichotomischen Charakter hat: Die für viele Bereiche der Kognitiven Linguistik charakteristischen Verzahnungen, Wechselwirkungen, fließende Übergänge kommen auch im metaphorischen Bereich zur Geltung.

\subsection{Konzeptuelle und epistemische Metaphern}

In seiner - terminologisch leider vorbelasteten Metapherneinteilung - differenziert Barcelona (2003: 212-213) zwischen zwei relevanten Arten von Korrespondenzen (Mappings): Es sind zum einen die ontologischen Korrespondenzen (ontological correspondences), die sich im Zentrum der ursprünglichen Version der CTM-Theorie befinden und in den konzeptuellen Metaphern zum Ausdruck kommen. Zum 
anderen werden die auf dem allgemeinen Weltwissen aufbauenden epistemischen Korrespondenzen (knowledge/epistemic correspondences) anerkannt, die entweder die Metapher alleine konstituieren oder die ontologischen Korrespondenzen näher beschreiben. Barcelona (ebd.) veranschaulicht dies am folgenden Beispiel. Der Sprachäußerung:

The candidate's speech was not really transparent enough. There were many dark points in it. So we couldn't understand all of it.

liegen zwei Arten von Mappings zugrunde. Die ontologischen Mappings sind auf die konzeptuelle Metapher UNDERSTANDING IS SEEING zurückzuführen und lassen sich folgendermaßen umschreiben:

UNDERSTANDING IS SEEING

The act of seeing corresponds to the act of understanding.

The person that sees is the person that understands.

Impediments to seeing correspond to impediments to understand.

Außer den ontologischen Korrespondenzen wird die Rezeption der angeführten Sprachäußerung ebenfalls durch das allgemeine Erfahrungswissen beeinflusst: Wenn ein Objekt nicht durchsichtig ist, wenn es mit dunklen Flächen bedeckt wird, dann wird einem der Einblick in das Innere verwehrt. Dark points präzisieren, wie die allgemeinen Hindernisse (impediments) aus der konzeptuellen Metapher IMPEDIMENTs TO SEEING ARE IMPEDIMENTS TO UNDERSTAND aussehen könnten. Das Verständnis der Sprachäußerung ergibt sich aus der Aktivierung beider Korrespondenzarten.

Diese einleuchtende Klassifikation ist - insbesondere in Bezug auf den ersten Begriff - mit terminologischen Schwierigkeiten verbunden. Unter ontologischen Mappings versteht Barcelona die Mappings, die in den konzeptuellen Metaphern, so wie sie in der CTM-Theorie von Lakoff und Johnson (1980) verstanden werden, vorkommen. Er bezieht sich damit auf die metaphorischen Mappings, die fest in dem konzeptuellen System etabliert, embodied sind. Diese Mappings, wie VERSTEHEN IST SEHEN oder LEBEN IST EINE REISE, manifestieren sich dann in zahlreichen Konzeptualisierungen und sprachlichen Ausdrücken, womit sie Anspruch auf eine gewisse Universalität, wenigstens innerhalb einer Kultur, beanspruchen können. Lakoff und Johnson nennen die Metaphern, die auf Barcelona's ontologischen Mappings aufbauen, die konzeptuellen Metaphern, als ontologische Metaphern bezeichnen sie dafür nur einen nach der kognitiven Funktion abgesonderten Typ der konzeptuellen Metaphern (vgl. Lakoffs und Johnsons Einteilung in die Struktur-, Orientierungs- und ontologische Metaphern, Kap. 2.3.2). Dabei ist das Adjektiv ,konzeptuell“ aus der kognitiven Perspektive auch irreführend, da alle Metaphern - als Mappings zwischen zwei Domänen verstanden - konzeptueller Natur sind. Da aber der Terminus ,konzeptuelle Metapher' aufgrund der Popularität der CTM-Theorie in der Fachliteratur weit verbreitet und gut etabliert ist, wird im Weiteren dieser Begriff für die Bezeichnung der auf ontologischen Mappings aufbauenden Metaphern herangezogen.

Somit werden im Folgenden als konzeptuelle Metaphern die Metaphern angesehen, die durch einen Set von festen konzeptuellen Korrespondenzen gebildet 
sind. Konzeptuelle Metaphern weisen einen kategorialen Charakter auf: Es sind systematische kognitive Metaphernmodelle, im konzeptuellen System etablierte Strukturen. Die konzeptuellen Metaphern konstituieren sich nicht in der realen Sprechzeit, jedes Mal ad hoc bei der Verarbeitung einer Sprachäußerung durch die Gründung von Korrespondenzen zwischen zwei Erfahrungsbereichen, sondern sie werden als eine stabile, in weit gefasster körperlicher, kultureller und sozialer Erfahrung verankerte Strukturierungsart unserer Kognition verstanden. Viele konzeptuelle Metaphern sind embodied, körperlich verankert. Die Ausgangsdomänen der mächtigen konzeptuellen Metaphern von einem hohen Generalitätsgrad wie GUT IST OBEN, SCHLECHT IST UNTEN; LICHT IST GUT, DUNKELHEIT IST SCHLECHT; LEBEN IST EIN WEG sind durch die Beschaffenheit des menschlichen Körpers motiviert und finden ihre Grundlagen in den frühkindlich-alltäglichen Körpererfahrungen: LEBEN IST WEG-Metapher bilden möglicherweise nur Wesen heraus, die sich progressiv vorwärtsbewegen können, die Metapher LICHT IST GUT, DUNKELHEIT IST SCHLECHT wäre nicht nachvollziehbar, falls Menschen wie Nachttiere nur nachts aktiv wären, auf die körperliche Motivierung der Orientierungsmetapher GUT IST OBEN, SCHLECHT IST UNTEN und ihre Ausprägungen wurde bereits ausführlich eingegangen (vgl. Kap. 2.3.2). Von Belang ist aber auch die kulturelle und soziale Erfahrung: So wird für die abenländische, ziel- und leistungsorientierte Gesellschaft die konzeptuelle Metapher ZIELE IM LEBEN ERREICHEN IST ZU DEN ZIELEN ZU FUSS GEHEN richtungsweisend, während in ostasiatischen Kulturen die Konzeptualisierung des Lebens weitgehend durch die konzeptuelle Metapher ZIELE IM LEBEN ERREICHEN IST SICH ZU DEN ZIELEN TREIBEN LASSEN (vgl. z.B. das daoistische $\mathrm{Wu}$ Wei-Prinzip) bestimmt ist. In der linguistischen Praxis kann man konzeptuelle Metaphern daran erkennen, dass sie zahlreiche sprachliche Manifestationen haben: Je mächtiger die Metapher, desto mehr Exemplifizierungen lassen sich ermitteln. Die erwähnte konzeptuelle Metapher versTEHEN IST SEHEN manifestiert sich u.a. in folgenden sprachlichen Ausdrücken:

VERSTEHEN IST SEHEN

nicht vorausschauend, uneinsichtig sein

geistig unterbelichtet, umnachtet sein

Tomaten vor den Augen haben

nicht über seine Nasenspitze hinaussehen/hinausdenken (können)

nicht gerade eine/keine (große) Leuchte sein

jmdm. die Augen für etw. öffnen

einen engen Horizont haben

beschränkt, vernagelt, unaufgeklärt sein

den Durchblick haben/verlieren

jmdm. schleierhaft sein

einsichtsfähig sein

etw. durchblicken lassen

das Wesen, den Kern einer Sache sehen (DUW online, Zugriff am 17.01.2018)

die Ursachen sind in mysteriöses Dunkel gehüllt (DUW online, Zugriff am 17.01.2018) 


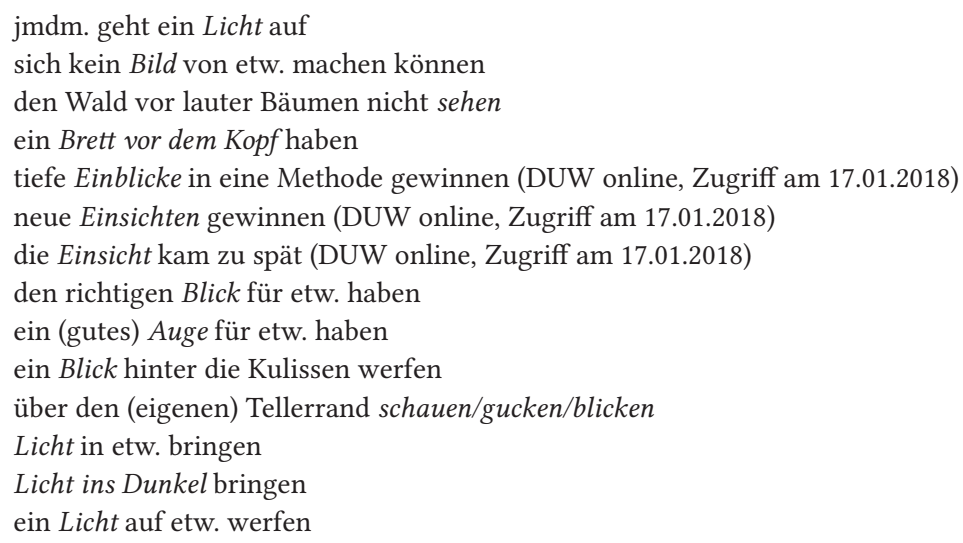

Von Belang ist dabei die Tatsache, dass das abstrakte Konzept des Verstehens, Begreifens, geistigen Erfassens teilweise über den Rückgriff auf das weniger abstrakte, optisch-perzeptive Sehen strukturiert wird.

Den anderen Typ der konzeptuellen Mappings zwischen den Domänen bilden die epistemischen Korrespondenzen (knowledge/epistemic correspondences, vgl. Barcelona 2003: 21). Diese Mappings entstehen oft ${ }^{94}$ ad hoc, indem sie - so wie in Glucksbergs property attribution model - zwei Domänen auf der Basis des allgemeinen Weltwissens verbinden. Demnach sind die metaphorischen Korrespondenzen, die der Rezeption von Bretons bereits zitiertem Gedicht (vgl. Kap. 2.3.3 Pkt. ii) zugrunde liegen, epistemischer Natur. Es lassen sich keine Strukturen höherer Ordnung herausfinden, die die metaphorischen Mappings zwischen Haaren einer Frau und Buschfeuer im Vers My wife whose hair is brush fire motivieren würden. Die Herstellung der Mappings erfolgt spontan, unter Rückgriff auf kontextuelle Begebenheiten, wobei mehrere Wege eingeschlagen werden können. Demnach können sich die Korrespondenzen auf die Haarfarbe (Die Haare einer Frau sind so intensiv rot wie loderndes Feuer) oder auf die Haarbeschaffenheit beziehen (Das Haar ist so voll, dick, bzw. kraus, dass es sich - so wie ein lichterloh flammender Busch - schwer bändigen lässt). Da die Frau im Gedicht angebetet wird, neigt der Rezipient dazu, ihrer Haarpracht keine negativen Attribute wie: strohig, zottelig, widerspenstig abstehend, zerzaust zuzuschreiben, auch wenn dies möglich wäre: Das Buschfeuer ist unkontrolliert, verheerend, Angst einflößend.

Auf epistemische Korrespondenzen greift man auch bei der Rezeption zahlreicher konventionalisierter/lexikalisierter Wortverbindungen zurück: Das Idiom

94 Epistemische Mappings können allerdings lexikalisiert sein, so wie im Idiom: (aussehen) wie Milch und Blut ,frisch und jung aussehen' (DUW). Dieses Idiom ist durch das allgemeine Weltwissen motiviert, dass die Blässe der Haut und das Rot der Lippen lange Zeit als ein Sinnbild der weiblichen Schönheit galten und in manchen Regionen (z.B. in Asien) immer noch gelten. 
nicht auf Rosen gebettet sein, nicht in guten Verhältnissen leben, es nicht gut und leicht haben im Leben' (DUW) ist vor dem Hintergrund der kulturellen Wissensbestände über Rosen als Symbole der Schönheit, Liebe, Jugendfrische, Freude, die in der Literatur (vgl. Märchen, Legenden) oder Architektur (Rosette) verherrlicht wurden, in seiner Motiviertheit nachvollziehbar. Epistemische Korrespondenzen liegen ebenfalls dem idiomatischen Vergleich $j d$. windet sich wie ein Aal zugrunde: Die Motiviertheit des letztgenannten Idioms ist für die meisten Sprecher aufgrund des Erfahrungs- oder Bildungswissens über die Aale, ihre schlangenförmige Körpergestalt, den durch schlüpfrigen Schleim bedeckten Körper, ihre Beweglichkeit und menschliches Verhalten in einer unangenehmen Situation leicht nachvollziehbar.

Unter epistemischen Metaphern werden im Folgenden also die Metaphern aufgefasst, deren Domänen durch epistemische, d.h. auf dem allgemeinen Weltwissen basierenden Korrespondenzen beruhen. Im Gegensatz zu den konzeptuellen Metaphern können die epistemischen Metaphern nicht als a set of fixed conceptual correspondences (Barcelona 2003: 212), die auf dem Embodiment und weit gefasster kultureller Erfahrung basieren, angesehen werden. Epistemische Metaphern sind ko- und kontextsensitiv, emergent, treten in vereinzelten sprachlichen Ausdrücken auf. Sie sind nicht auf das ausgebaute System der etablierten konzeptuellen Mappings zurückzuführen, können dennoch die richtungsgebenden konzeptuellen Metaphern präzisieren und ergänzen. Der grundlegende Unterschied zwischen den konzeptuellen und epistemischen Metaphern liegt demnach in ihrem Skopus: Während die erstgenannten Metaphern die ganzen Erfahrungsbereiche strukturieren und sich in zahlreichen sprachlichen Ausdrücken manifestieren, sind die epistemischen Mappings auf einen Ausdruck eingeschränkt.

\subsection{Innovative und konventionalisierte Metaphern}

Ein von der Art der Mappings unabhängiges, dennoch wichtiges und hilfreiches Kriterium bei der Klassifikation der als Metapher bezeichneten Phänomene stellt das Kriterium der Konventionalität ${ }^{95}$ dar: Die Metaphern kann man dementsprechend

95 In der polnischen Forschung spielt die Einteilung der Metaphern nach dem Grad ihrer Konventionalität eine relevante Rolle. Infolgedessen gibt es Versuche, die Metaphern nach diesem Kriterium detaillierter einzuteilen. Pawelec (2006: 39-42) unterscheidet beispielsweise zwischen drei Metapherntypen: (i) Abgedroschene Metaphern (Phraseologismen) haben konventionalisierte Bedeutungen. (ii) Metaphorische Erweiterungen besitzen Bedeutungen, die in einem Kontext offensichtlich sind und leicht konventionalisiert werden. Die Maus kann also metaphorisch sowohl ein Eingabegerät bei Computern, als auch ein bescheidenes, unauffälliges Mädchen bezeichnen. (iii) Die Bedeutungen von innovativen, schaffenden Metaphern sind nicht durchsichtig, sie sind mit der Einnahme einer besonderen Perspektive gebunden. Ob diese Dreiteilung aber alle Phänomene auf der Skala der wachsenden Konventionalität erfassen kann, bleibt fraglich. 
nach dem Grad ihrer Konventionalität/Lexikalisierung ${ }^{96}$ auf einer Skala ansiedeln, deren Pole völlig innovative Metaphern einerseits und völlig konventionalisierte Metaphern andererseits bilden: In der traditionellen Terminologie spricht man in diesem Kontext von konventionellen oder toten Metaphern (Leech 1969), denen man innovative (novel), poetische Metaphern gegenüberstellt.

Ein überzeugendes Beispiel für eine innovative Metapher führt Gibbs (1994: 261, zit. nach Kövecses 2002: 49) heran, indem er einen Satz von Gabriel García Márquez zitiert:

Once he tasted some chamomile tea and sent it back, saying only, „This stuff tastes of window.“

Während der Vergleich des Kammilienteegeschmacks zu dem Geschmack des Fensters absolut einmalig und innovativ ist, weisen andere Metaphern einen wesentlich höheren Konventionalitätsgrad.

So ist das Adjektiv ,schwarz' in den Ausdrücken: der schwärzeste Tag in meinem Leben; sie können warten, bis sie schwarz werden; etw. schwarz kaufen, schwarz über die Grenze gehen metaphorisch gebraucht: Die negativen Konnotationen der Farbe ,schwarz" - sie wird mit Unheil, Boshaftigkeit (der schwärzeste Tag in meinem Leben), Tod, Trauer, Verwesung (sie können warten, bis sie schwarz werden), Gesetzwidrigkeit (etw. schwarz kaufen, schwarz über die Grenze gehen) assoziiert - sind in kulturellen und körperlichen Erfahrungen des Menschen verankert und lassen sich auf den symbolischen Wert der Farbe ,schwarz' im abendländischen Kulturkreis einerseits und auf die konzeptuellen Metaphern: LICHT IST GUT, DUNKELHEIT IST SCHLECHT; HELL IST GUT, DUNKEL IST SCHLECHT (vgl. Attributsmetaphern von Baldauf 1997) andererseits zurückführen. Diese metaphorischen Übertragungen sind lexikalisiert ${ }^{97}$ und im Deutschen auch in weiteren Ausdrücken so weit

96 Bąk (2007: 48-49) differenziert zwischen lexikalisierten (usuellen, erloschenen, verblassten, im Lexikon der Sprache verfestigten) und konventionellen (in der literarischen Tradition eines Kulturraumes, einer Epoche verankerten) Metaphern. Diese für die Kultur- und Übersetzungsstudien relevante Unterscheidung wird in der vorliegenden phraseologisch ausgerichteten Arbeit aufgegeben.

97 Vgl. die Teilbedeutungen 5 und 6 in der lexikographischen Beschreibung des Lemmas ,schwarz in DUW online (Zugriff am 14.08.2018):

1. von der dunkelsten Färbung, die alle Lichtstrahlen absorbiert, kein Licht reflektiert

2. a. von sehr dunklem Aussehen

b. (auch Eigenbezeichnung) von [sehr] dunkler Hautfarbe

3. (umgangssprachlich) von Schmutz dunkel

4. a. (umgangssprachlich, oft abwertend) vom Katholizismus geprägt; eine überwiegend katholische Bevölkerung habend

b. (Politikjargon) christdemokratisch, konservativ [geprägt, regiert o. Ä.]

5. a. unheilvoll, düster

b. böse; niederträchtig

6. (umgangssprachlich) illegal; ohne behördliche Genehmigung, ohne Berechtigung 
verbreitet $^{98}$, dass sie von manchen Sprachteilhabern in einem unreflektierten Sprachgebrauch möglicherweise nicht mehr als metaphorisch empfunden werden. Die genannten Wortverbindungen befinden sich im Mittelfeld zwischen den Polen des Innovativen und des Konventionalisierten.

In der Sprache findet man des Weiteren Metaphern, die völlig konventionalisiert/lexikalisiert sind, von den Sprachteilhabern spontan überhaupt nicht als metaphorisch wahrgenommen werden und sich nur in einer vertieften linguistischen Reflexion als Metaphern entpuppen lassen, wie z.B. Tischbein, Buchrücken, überflüssig. Diese Metaphern machen das andere Extrem der Konventionalitätsskala aus.

Dabei ist anzunehmen, dass das Kriterium der Konventionalität ebenfalls auf konzeptuelle (auf ontologischen Mappings beruhende) Metaphern zutrifft und ein Kontinuum bildet. Konzeptuelle Metaphern können zu einem unterschiedlichen Grad konventionalisiert werden. Wie Lakoff und Turner (1989) schreiben:

(...) at the conceptual level, a metaphor is conventional to the extent that is automatic, effortless, and generally established as a mode of thought among members of a linguistic community. For example, DEATH IS A DEPARTURE is deeply conventionalized at the conceptual level, we probably all have it (...). (Lakoff/Turner 1989: 50)

Die Einteilungen nach der Art von metaphorischen Mappings (konzeptuelle und epistemische Metaphern) und nach der Konventionalität (innovative und konventionelle Metaphern) verzahnen sich an vielen Stellen und es ist nicht immer leicht, sie auseinanderzuhalten. Es sind allerdings zwei abzugrenzende Aspekte des als ,Metapher ' bekannten Phänomens: Das Kriterium der Konventionalität bezieht sich auf die Verfestigung einer Metapher in der Sprache; die Einteilung in konzeptuelle und epistemische Metaphern fokussiert den kategorialen Charakter der erstgenannten Metaphern, die Tatsache, dass sie im konzeptuellen System verankert sind und zahlreiche sprachliche Manifestationen generieren können.

\subsection{Propositionale und bildbasierte Metaphern}

Eine andere, für die weiteren Erörterungen wichtige Differenzierung bezieht sich auf die Natur der mentalen Repräsentationen, die den Ausgangspunkt der Konzeptualisierung bilden, Kövecses spricht hier von der Metaphernnatur (2002: 36-38). Die zu mappenden Wissensstrukturen können propositional oder bildbasiert (analog) sein, dementsprechend wird zwischen propositionalen, image schemas- und rich image-Metaphern differenziert (ebd.).

98 Vgl. z.B. weitere Verben und Wortverbindungen, in denen die metaphorische Projektion schwarz $\rightarrow$ illegal auftritt: schwarzarbeiten, schwarzfahren, schwarzgehen, schwarzhören, schwarzkopieren, schwarzschlachten, Waren schwarz exportieren, schwarz verkaufen, schwarz kaufen. 
In propositionalen Metaphern werden Wissenselemente einer Ausgangsdomäne auf die Wissenselemente einer Zieldomäne gemappt. So ist die Metapher LEBEN IST EINE REISE durch die systematischen propositionalen Mappings zwischen den Elementen der beiden Domänen (der Lebende $\rightarrow$ der Reisende; das Leben $\rightarrow$ der Weg; Schwierigkeiten im Leben $\rightarrow$ Hindernisse auf dem Weg; Partner, Freude und Bekannte $\rightarrow$ Reisegefährte usw.) konstituiert, die Konzepte LEBEN und REISE sind möglicherweise zu abstrakt, als dass man sie sich bildhaft vorstellen könnte.

Außer der propositionalen können die Metaphern auch auf bildbasierten Wissensstrukturen von verschiedenem Schematizitätsgrad aufbauen. Von einemäußerst skizzenhaften, analogen Charakter sind sog. image schemas-Metaphern: Baldauf (1997: 123) spricht in diesem Sinne von bildschematischen Metaphern. Der Begriff image-schemas hängt, wie bereits angemerkt, mit der Embodiment-These zusammen und bezeichnet tief in der frühkindlichen Erfahrung verankerte räumlich-analoge Konzeptualisierungsschemata. Diese Strukturen stellen dann eine Grundlage für zahlreiche konzeptuelle Metaphern dar. Image schemas-Metaphern sind skelettartig, weisen eine äußerst allgemeine schematische Struktur auf: „these metaphors map relatively little from source to target“ (Kövecses 2002: 37), öfters bilden sie dennoch den Ausgangspunkt für weitere, detailliertere Metaphern.

Einen anderen Typ der bildbasierten Metaphern bilden die rich image-Metaphern, die im Gegensatz zu den image schemas-Metaphern aufgrund des mentalen Bildes (rich image) durch zahlreiche Beziehungen zwischen der Ausgangs- und der Zieldomäne gekennzeichnet sind. Kövecses (2002: 38) führt an dieser Stelle folgendes umgangssprachliches Beispiel heran:

A. What'you doin'? B. Watering the plants.

und verweist auf die Korrespondenzen zwischen den beiden Domänen:

Both sentences utilize image metaphors that map a detailed set of images from the source to the target (...). In the sentences, the person watering the plants is the person urinating, the water is the urine, the watering can is the penis, the intended goal of the action of watering is the ground where the urine is directed. Notice, that there is no general structural metaphor involved in this mapping. The mapping is of the oneshot kind that is generated by two images that are brought into correspondence by the superimposition of one image onto the other. These are one shot image metaphors. (Kövecses 2002: 38)

Die Rolle der rich image-Metaphern ist in der Phraseologie kaum zu überschätzen: Die wörtliche Bedeutung zahlreicher Phraseologismen wird durch die Begriffe der Basisebene (im Sinne von Rosch 1975, Rosch u.a. 1976, Näheres im Unterkap. 2.2.3) konstituiert, die die mentalen Bilder evozieren können. Darauf ist die phraseologische Bildhaftigkeit zurückzuführen, deren Einfluss auf die phraseologische Bedeutung von Dobrovol'skij/Piirainen (2005) in der Theorie des Bildlichen Lexikons zur Sprache gebracht wird. 


\subsection{Die Einteilung nach dem Generalitätsgrad}

Konzeptuelle Metaphern umfassen tief liegende, durch Embodiment und fundamentale sozial-kulturelle Erfahrung weitgehend beeinflusste Strukturen von verschiedenem Generalitätsgrad: Sie bilden hierarchische Strukturen, in denen die Metaphern des niedrigeren Grades die Mapping-Struktur der Metaphern des höheren Grades übernehmen. Die hierarchischen Beziehungen zwischen den Metaphern veranschaulicht Lakoff (1993: 219-225) am Beispiel der EVENT STRUCTURE Metapher und der ihr untergeordneten Metaphern:

Level 1: THE EVENT STRUCTURE METAPHOR

Level 2: A PURPOSEFUL LIFE IS A JOURNEY

Level 3: LOVE IS A JOURNEY; A CAREER IS A JOURNEY

In der EVENT STRUCTURE Metapher korrespondieren metaphorisch die Zustände, Veränderungen, Prozesse, Aktionen, Gründe, Ziele, Mittel und Wege mit den grundsätzlichen physischen Entitäten wie Raum, Bewegung und Kraft. Die EvenT STRUCTURE Metapher wird durch folgende Mappings gekennzeichnet:

Generalitätsstufe 1: EVENT STRUCTURE Metapher

States are locations.

Changes are movements (into or out of bounded regions).

Causes are forces.

Purposes are destinations.

Means are paths (to destinations).

Difficulties are impediments to motion.

Expected progress is a travel schedule; a schedule is a virtual traveler, who reaches prearranged destinations at prearranged times.

External events are large, moving objects.

Long term, purposeful activities are journeys. (Lakoff 1993: 220)

Die auf der höchsten Ebene angesiedelten Mappings der event structure Metapher finden dann ihre Widerspiegelung in Metaphern von einem niedrigeren Generalitätsgrad. Da in unserer Kultur erwartet wird, dass man sich im Leben Ziele setzt und sie dann verfolgt, entstehen auf der Folie der EVENT STRUCTURE Metapher weitere metaphorische Mappings von einem niedrigeren Generalitätsgrad:

Generalitätsstufe 2: A PURPOSEFUL LIFE IS A JOURNEY

The person leading a life corresponds to a traveler.

Life goals correspond to destinations.

Difficulties in life correspond to the difficulties in the way.

Path/way of the journey corresponds to the way of living.

Destination corresponds to the purpose of life. (vgl. Lakoff 1993: 223)

Auf der dritten Generalitätsstufe kann das zielgerichtete Leben durch einzelne Lebensbereiche wie beispielshalber Karriere oder Beziehungen/Liebe ersetzt 
werden. Die konzeptuellen Metaphern love is A JOURNEY, CAREER IS A JOURNEY werden ebenfalls durch die genannten metaphorischen Korrespondenzen mitgestaltet, z.B.:

Generalitätsstufe 3: LOVE IS A JOURNEY

The lovers correspond to travelers.

The lovers' common goals correspond to their common destinations on the journey.

Difficulties in the relationships correspond to impediments to travel.

The love relationship corresponds to the vehicle. (vgl. Lakoff 1993: 224)

Auf den hierarchischen Aufbau des metaphorischen Systems wird ebenfalls in dem Kap. 4.2.1 eingegangen, wo die konzeptuelle Metapher Difficulties ARE IMPEDIMENTS TO MOTION und ihre sprachlichen Manifestationen genauer dargestellt werden.

\subsection{Strukturbezogene Klassifikation der konzeptuellen Metaphern}

Zum Schluss wird Baldaufs Klassifikation herangeführt, die sich ausschließlich auf konzeptuelle Metaphern bezieht und an einer korpusgestützten Analyse von Pressetexten ausgeführt wurde. Das leitende Kriterium von Baldaufs Einteilung richtet sich nach dem „Kriterium der Konzeptstruktur des jeweiligen Konzeptbereichs“ (Baldauf 1997: 82). Anders gesagt orientiert sich die Forscherin qualitativ-quantitativ daran, inwieweit die jeweiligen Herkunftsbereiche Struktur in die Zielbereiche hineintragen. Demnach wird „nach Maß und Art“ (Baldauf 1997: 83) der in den Zielbereich importierten Struktur zwischen vier Gruppen der konzeptuellen Metaphern unterschieden: Attributsmetaphern, ontologischen Metaphern, bildschematischen Metaphern und Konstellationsmetaphern (Baldauf 1997: 83-245).

Die schwächste Form der Strukturübertragung liegt in den Attributsmetaphern vor. Attributsmetaphern beruhen auf der Projektion von wertenden Eigenschaften auf Personen, Objekte oder Sachverhalte. Kennzeichnend für Attributsmetaphern ist, dass sie nicht wie die übrigen konzeptuellen Metaphern einem Zielbereich in seiner Ganzheit die Struktur des Ausgangsbereiches verleihen, sondern dem jeweiligen Zielbereich eine metaphorische Eigenschaft zusprechen, die es erlaubt, auf eine abstrakte Eigenschaft des Zielbereiches Bezug zu nehmen (Baldauf 1997: 97-98). Mittels metaphorischer Attribuierung werden vage, schwer fassbare Zielbereiche mit einfacheren, aus unmittelbarer Wahrnehmung hervorgehenden Eigenschaften ausgedrückt. Attributsmetaphern kommen oft in Gegensatzpaaren vor: dunkel-hell, warm-kalt, stark-schwach, leicht-schwer u.a. Für die Attributsmetapher NEGATIV IST DUNKEL führt Baldauf folgende sprachliche Manifestationen heran: düstere Gedanken, Nietzsches düstere Vision, Schwarzmaler, ihr Erscheinungsbild trübt sich erneut ein, in den dunklen Jahren der NS-Diktatur.

Die Gruppe der ontologischen Metaphern wird im Vergleich zu der ursprünglichen Klassifikation von Lakoff/Johnson (1980) reduziert und umfasst lediglich zwei Ausgangsbereiche: Objekte und Substanzen. Die unmittelbaren 
und elementaren Erfahrungen greifbarer Objekte und Substanzen im Umfeld des Menschen ermöglichen in ihrer metaphorischen Nutzung die Indentifizierbarkeit, Quantifizierbarkeit, Lokalisierbarkeit von schwer fassbaren und damit schwer thematisierbaren Zielbereichen. Die konzeptuelle Metapher ABSTRAKTA SIND objeKte/substanzen ist somit in der Sprache weit verbreitet. Die Folge der an Allgegenwart grenzenden Häufigkeit der ontologischen Metaphern ist eine Verschleierung der Grenze zwischen Konkreta und Abstrakta: „Metaphorische Ontologisierung ist derart routiniert, daß sie beginnt, für den Menschen Realität zu konstituieren“" (Baldauf 1997: 122).

Bildschematische Metaphern beruhen auf der Projektion gestalthafter, bildschematischer Struktur im Sinne von image schemas von Johnson (1987, vgl. auch Kap. 2.2.4) in abstrakte Bereiche. In ihrer strukturellen Komplexität sind sie zwischen den relativ einfachen ontologischen Metaphern und zusammengesetzten Konstellationsmetaphern anzusiedeln. In diese Gruppe wird die BEHÄLTERMetapher verschoben (bei Lakoff/Johnson als ontologische Metapher eingestuft), hier findet man auch weitere metaphorische Projektionen aus den Bereichen unserer unmittelbaren Raumerfahrung, die mit den Bildschemata WEG, SKALA, DISTANZ, GLEICHGEWICHT zusammenhängen.

Den höchsten Komplexitätsgrad weisen Konstellationsmetaphern auf. Bei den als Herkunftsbereich dienenden Ausgangsbereichen handelt es sich um rekurrente, aus mehreren Elementen bestehende Gestalten, die als Repräsentationen prototypischer, komplexer Alltagssituationen anzusehen sind (Baldauf 1997: 178). Relevant ist ebenfalls der epistemische Status der Ausgangsbereiche:

Während sich die bereits dargestellten Metapherntypen auf unmittelbare physische Erfahrung präkonzeptuell gegebener Strukturen der Realität stützen, sind zahlreiche Konstellationsmetaphern in kultureller Erfahrung begründet. Die als Herkunftsbereich belegte Theater-Konstellation, Handels-Konstellation oder Kriegs-Konstellation unterscheiden sich von physischer Temperaturerfahrung, Objekterfahrung oder Behältererfahrung in ihrer kulturellen Bedingtheit. (Baldauf 1997: 179)

Infolge der größeren Komplexität der Ausgangsbereiche werden größere Informationsmengen in den abstrakten Zielbereich übertragen. Daraus ergibt sich die Selektivität des Mappings: Zahlreiche Aspekte des Zielbereiches können zugunsten der oft fragwürdigen Logik der jeweils zur Konzeptualisierung genutzten Metapher in den toten Winkel gerückt werden (Baldauf 1997: 244, vgl. dazu auch hiding und highlighting von Lakoff/Johnson 1980).

Baldaufs Klassifikation der konzeptuellen Metaphern ist einleuchtend, stellt einen wesentlichen Fortschritt zu der relativ vagen Klassifikation von Lakoff/ Johnson aus dem Jahre 1980 dar (auf die beide Forscher übrigens in keinem ihrer weiteren Werken wieder Bezug nehmen), setzt allerdings Vernetzungen, Überlagerungen, Inklusionsverhältnisse und komplexe Interdependenzen voraus, auf die die Forscherin selbst verweist (vgl. z.B. Baldauf 105-106, 175, 245). Aus diesem Grunde - der Transparenz der weiteren Ausführungen halber - werden im 
Folgenden die weiteren Differenzierungen innerhalb der Gruppe der konzeptuellen Metaphern generell aufgegeben.

\subsubsection{Metonymie}

Einen wichtigen Beitrag zur Revidierung der CTM hat ebenfalls die eingehendere Befassung mit Metonymie geleistet. Metonymie, der Lakoff und Johnson in Metaphors We Live By lediglich ein kurzes Kapitel (2000 [1980]: 46-52) gewidmet haben, hat sich beim genaueren Hinsehen als wichtiger Mechanismus der Bedeutungskonstituierung erwiesen.

Die neueren Definitionsversuche zum Begriff der Metonymie werden in erster Linie durch den intra-domain-Ansatz gekennzeichnet. Die meisten Autoren sind sich darin einig, dass sich die Metaphern auf den inter-domain-, die Metonymien auf den intra-domain-Transfer beziehen (Turner 1987: 21, Lakoff 1987: 288, Goosens 2003: 351-352). Lakoff und Turner (1989: 103) bringen dies explizit zum Ausdruck: Die Metonymie „involves only one conceptual domain. A metonymic mapping occurs within a single domain, not across domains". Dabei werden unter der Domäne strukturierte Wissensbereiche verstanden, die entweder die Form von Langackers Domänen (vgl. z.B. Barcelona 2003, Croft 2003), von Fillmores Frames (vgl. z.B. Dancygier/Sweetster 2014, Panther 2015) oder von Lakoffs ICMs (vgl. z.B. Lakoff 1987, Radden/Kövecses 1999, Kövecses 2002) annehmen können, vgl. z.B.:

Metonymy is a cognitive process in which one conceptual entity, the vehicle, provides mental access to another conceptual entity, the target, within the same domain, or idealized cognitive model (ICM). (Radden/Kövecses 1999: 21, Kövecses 2002: 145) Metonymy is a cognitive mechanism whereby one experiential domain is partially understood in terms of another experiential domain included in the same common experiential domain. (Barcelona 2003: 215)

Als Metonymie wird (...) eine konzeptuelle Beziehung zwischen einem Quellkonzept (kurz: Quelle) und einem Zielkonzept (kurz: Ziel) innerhalb desselben konzeptuellen Rahmens (frame) verstanden. (Panther 2015: 208)

(...) the essence of metonymy resides in the possibility of establishing connections between entities which co-occur within a given conceptual structure. (Taylor 2003: 325)

Bei der näheren Betrachtung zieht die Auffassung der Metonymie als Mapping innerhalb einer Domäne zahlreiche Schwierigkeiten mit sich. Das Problem liegt vor allem in der Bestimmung, was durch Mappings verbunden wird, welche Entitäten hier gemeint sind. Es verdient Erwähnung, dass nicht alle Verschiebungen innerhalb eines zusammenhängenden Wissensbereiches als Metonymie angesehen werden. Croft (2003: 178-179) veranschaulicht dies an folgenden Beispielsätzen:

1.a. Proust spent most of his time in bed.

1.b. Proust is tough to read.

2.a. This book is heavy.

2.b. This book is history of Iraq. 
In allen beiden Satzpaaren kann man von einem ambiguen Gebrauch von Proust und book sprechen, auch wenn nur in dem ersten Satzpaar eine metonymische Bedeutungsverschiebung vorliegt. Im Satz (1.a) wird PROUsT als Mensch, Lebewesen profiliert, im (1.b)-Satz referiert PROUST auf sein literarisches Schaffen, auf seine Werke. In diesem Satz wird Proust als Metonymie betrachtet (Proust steht hier für seine Werke).

Verschiedene Wissensinhalte aus einem zusammenhängenden Bereich werden ebenfalls in den Sätzen (2.a) und (2.b) profiliert. Das BUCH referiert im Satz (2.a) auf ein physisches Objekt, im (2.b) referiert es auf den Inhalt. Bezeichnenderweise wäre die Annahme, dass in diesen Fällen eine Metonymie vorliegt, für die meisten Menschen kontraintuitiv: Der Gebrauch von BUCH wird in diesen Sätzen als ambigue, aber nicht als metonymisch angesehen.

Eine überzeugende und wenigstens zum Teil ordnende Lösung dieses Problems bietet Croft (2003) an. In Anlehnung an die Kognitive Grammatik von Langacker macht er darauf aufmerksam, dass nur ganz wenige Konzepte mithilfe einer einzigen Domäne konzeptualisiert werden. Die Basis für das Verständnis von den meisten Konzepten bilden mehrere Domänen. Selbst die auf den ersten Blick einfachen Konzepte wie der Buchstabe , $\mathrm{T}^{\prime}$ können nur vor dem Hintergrund von mehreren Domänen konzeptualisiert werden. Der genannte Buchstabe setzt die ALPHABET-Domäne voraus, der wiederum die FORM- und die schriftsystem-Domänen zugrunde liegen, von denen die Zweitgenannte sehr komplex ist und weitere Domänen evoziert: die Domänen SCHRIFT, KOMMUNikAtion, MENSChEn, LEBEWEsen u.a. (Croft 2003: 169-170). Die konzeptuelle Grundlage für das Verständnis von den meisten sprachlichen Einheiten bilden also nicht die einzelnen Domänen, sondern die aus mehreren Domänen zusammengesetzten Strukturen, die Langacker $(1987,2008)$ als Domänenmatrix bezeichnet.

Innerhalb einer Domänenmatrix weisen nicht alle Domänen den gleichen Status auf: Manche Domänen sind für das Verständnis eines Begriffes zentraler (Langacker bedient sich des Begriffes intrinsic ,immanent, innewohnend') als die anderen. (Die Prototypikalitätseffekte setzt übrigens ebenfalls Lakoff für seine ICMs voraus, vgl. ICM von mother im Unterkap. 2.1.3). Und eben diese Zentralität (intrinsicness) ist entscheidend für Metonymie. Das literarische Schaffen stellt eine wichtige Domäne innerhalb der Domänenmatrix von Proust, dieses Wissen ist dennoch nicht so zentral wie das enzyklopädische Wissen, dass Proust ein Mensch war. Im Gegensatz dazu stellen die Domänen: ,physisches Objekt' und ,semantischer Inhalt 'zwei primäre Domänen von vergleichbarer Relevanz für das Konzept BUCH dar. In diesem Sinne definiert Croft (2003: 179) die Metonymie als domain highlighting (die Hervorhebung/Profilierung einer Domäne in der Domänenmartix). Der konzeptuelle Effekt beruht hier hauptsächlich darauf, dass in der Metonymie eine Domäne innerhalb der Domänenmatrix primär gemacht wird - in der literalen Bedeutung kommt ihr indes der Status einer sekundären Domäne $\mathrm{zu}$ : „the metonymy makes primary a domain that is secondary in the literal 
meaning“ (ebd.) ${ }^{99}$. Bemerkenswert ist an dieser Stelle, dass diese Auffassung nicht zwingend an die Kognitive Grammatik von Langacker (samt ihren zentralen Begriffen wie z.B. Domänenmatrix) gebunden ist: Highlighting kann als mentale Aktivierung einer Domäne durch eine andere zusammenhängende Domäne innerhalb eines gemeinsam strukturierten Wissensbereiches von einem höheren Generalitätsgrad verstanden werden; dies schließt weder die Existenz von Mappings (als Korrespondenzen von beiden Domänen), noch die anderen Modelle zur Strukturierung des konzeptuellen Poles einer sprachlichen Einheit (wie ICMs oder Frames) aus.

Der Faktor der semantischen Fokussierung eines bestimmten semantischen Aspektes stellt eine wichtige Eigenschaft der Metonymien dar: Ihr Zielkonzept wird als Ergebnis des metonymischen Transfers hervorgehoben, während das Quellkonzept zwar präsent bleibt, aber kognitiv in den Hintergrund rückt (Panther 2015: 209). Es ist des Weiteren erwähnenswert, dass die Metonymie als Inferenzschema charakterisiert werden kann, mittels dessen Sprachteilnehmer ohne großen kognitiven Aufwand spontan von einem Quellkonzept auf ein Zielkonzept schließen: Mercier/Sperber (2009) unterscheiden zwischen intuitivem und reflektivem Schließen, Metonymie gehört zu der ersten Kategorie - der Kategorie des schnellen und spontanen assoziativen Denkens (Panther 2015: 208-209).

Die Metonymien haben meistens keinen zufälligen, rein sprachlichen Charakter, sondern weisen - so wie konzeptuelle Metaphern - eine innere Systematik auf. Parallel zu konzeptuellen Metaphern sind ebenfalls konzeptuelle Metonymien durch sprachliche Ausdrücke spezifiziert. Lakoff und Johnson führen folgende Beispiele für die konzeptuelle Metonymie heran:

DER TEIL STEHT FÜR DAS GANZE

Schieb deinen Hintern hierüber!

Der Fuß des Tages gehört Frank Stürmer.

Ich habe einen neuen Achtzylinder.

DER ERZEUGER STEHT FÜR DAS PRODUKT

Ich hätte gern ein Löwenbräu.

Er kaufte sich einen Ford.

Er hat einen Picasso in seiner Bude hängen.

99 Crofts Definition bietet die notwendige Präzisierung des Metonymiebegriffs. Allerdings bestehen auch bei dieser Definition Zweifelsfälle. Die Bestimmung, welche Domänen für ein Konzept primär/zentral, und welche sekundär/peripher sind, ist beispielshalber im folgenden Satz von Lakoff (1987: 76) disputabel: He's looking for a girlfriend who'll be a mother to him. Die Geburtsdomäne trägt zur Bedeutungskonstitutierung in diesem Satz nicht bei, profiliert wird dafür die Domäne der Großziehung und Pflege. Metonymische Verschiebung würde in diesem Fall voraussetzen, dass die Geburtsdomäne primär und die Domäne des Großziehens sekundär ist - eine Annahme, die kontrovers diskutiert werden kann und viele umstrittene Fragen (wie: Ist die Leihmutter eine Mutter und Pflegemutter keine Mutter?) nahe legt. 
DAS OBJEKT STEHT FÜR DEN BENUTZER

Das Saxophon hat heute die Grippe.

Das Schnitzel bringt kaum Trinkgeld mit.

Das Gewehr, das er anheuert, wollte fünfzig Riesen. (...)

DIE INSTITUTION STEHT FÜR DIE ENTSCHEIDUNGSTRÄGER

Esso hat schon wieder die Benzinpreise erhöht.

Du wirst die Universität nie dazu kriegen, dem zuzustimmen.

Das Verteidigungsministerium möchte den Grundwehrdienst verkürzen.

Der amerikanische Senat hält die Abtreibung für unmoralisch. (...) (Lakoff/Johnson

2000 [1980]: 49)

Zahlreiche von diesen Metonymien sind weitgehend konventionalisiert, obgleich neue, produktive Metonymien jederzeit entstehen. Betonenswert ist dabei, dass die referenzielle Funktion nicht völlig produktiv ist: Während Picasso für seine Werke stehen kann, ist die metonymische Bedeutungsverschiebung in dem Satz:

Mary was delicious.

in dem Mary für ihren Kuchen steht, kaum akzeptabel (Taylor 2003: 324).

Radden und Kövecses (1999: 30-43) stellen - von den ICMs als grundlegenden, enzyklopädisches Wissen ordnenden Strukturen ausgehend - eine Liste der möglichen metonymischen Verschiebungen, die im Allgemeinen auf zwei konzeptuelle Konfigurationen zurückzuführen sind: das ganze ICM und seine Teile sowie Teile von einem ICM (vgl. Tab. 6).

Tab. 6: Liste der konzeptuellen Metonymien nach Radden/Kövecses (1999: 30-43).

\section{Whole ICM and its parts}

(i) Thing-and-Parts ICM WHOLE THING FOR A PART OF THE THING

America for ,United States'

PART OF THE THING FOR THE

WHOLE THING

England for ,Great Britain

(ii) Scale ICM

WHOLE SCALE FOR UPPER END

OF THE SCALE

Henry is going too fast

UPPER END OF THE SCALE FOR

WHOLE SCALE

How old are you?

(iii) Constitution ICM

\section{Parts of an ICM}

(i) Action ICM

AGENT FOR ACTION

to author a new book

to butcher the cow

ACTION FOR AGENT

Writer, driver

INSTRUMENT FOR ACTION

to ski, to hammer

ACTION FOR INSTRUMENT

pencil sharpener, screwdriver

OBJECT FOR ACTION

to dust the room

ACTION FOR OBJECT

the best bites, the flight is waiting to

depart 
Tab. 6: Continued

\begin{tabular}{l}
\hline Whole ICM and its parts \\
\hline OBJECT FOR MATERIAL \\
CONSTITUTING THE OBJECT \\
I smell skunk \\
MATERIAL CONSTITUTING AN \\
OBJECT FOR OBJECT \\
wood for ,forest \\
(iv) event ICM \\
WHOLE EVENT FOR SUBEVENT \\
Bill smoked marihuana \\
SUBEVENT FOR WHOLE EVENT \\
Mary speaks Spanish \\
(v) Category-and-Member ICM \\
CATEGORY FOR A MEMBER OF \\
THE CATEGORY \\
The pill for ,a birth control pill \\
MEMBER OF A CATEGORY FOR \\
THE CATEGORY \\
Aspirin for any ,pain relieving tablet \\
GENERIC FOR SPECIFIC
\end{tabular}

Boys don't cry.

SPECIFIC FOR GENERIC

The/A spider has eight legs.

(vi) Category-and-Property ICM

CATEGORY FOR DEFINING

PROPERTY

Jerk for ,stupidity

DEFINING PROPERTY FOR

CATEGORY

Blacks for ,black people

(vii) Reduction ICM

PART OF A FORM FOR THE

WHOLE FORM

Crude for ,crude oil ${ }^{\star}$

\section{Parts of an ICM}

RESULT FOR ACTION

to landscape the garden

ACTION FOR RESULT

the production, the product

MANNER FOR ACTION

to tiptoe into the room

MEANS FOR ACTION

He sneezed the tissue off the table

TIME FOR ACTION

to summer in Paris

DESTINATION FOR MOTION

to porch the newspaper

INSTRUMENT FOR AGENT

the pen for , writer

(ii) Perception ICM

THING PERCEIVED FOR PERCEPTION

There goes my knee for ,there goes the pain

in my knee

PERCEPTION FOR THING PERCEIVED

Sight for ,thing seen ${ }^{6}$

(iii) Causation ICM

CAUSE FOR EFFECT

Healthy complexion for ,the good state of health bringing about the effect of healthy complexion' EFFECT FOR CAUSE

Slow road for ,slow traffic resulting from the poor state oft he road".

STATE/EVENT FOR THING/PERSON/STATE

\section{CAUSING IT}

She was my ruin

EMOTION FOR CAUSE OF EMOTION

She is my joy

MENTAL/PHYSICAL STATE FOR

OBJECT/PERSON CAUSING IT

You are a pain in the neck, you give me pain

PHYSICAL/BEHAVIORAL EFFECT FOR

EMOTION CAUSING IT

She was upset for ,something made her upset

SOUND FOR EVENT CAUSING IT

The car scratches to a halt

SEEING SOMETHING DONE FOR

MAKING SURE THAT IT IS DONE

See that he gets his money

ACT OF FORMING A PERCEPT FOR PERCEPT 


\begin{tabular}{|c|c|}
\hline Whole ICM and its parts & Parts of an ICM \\
\hline & 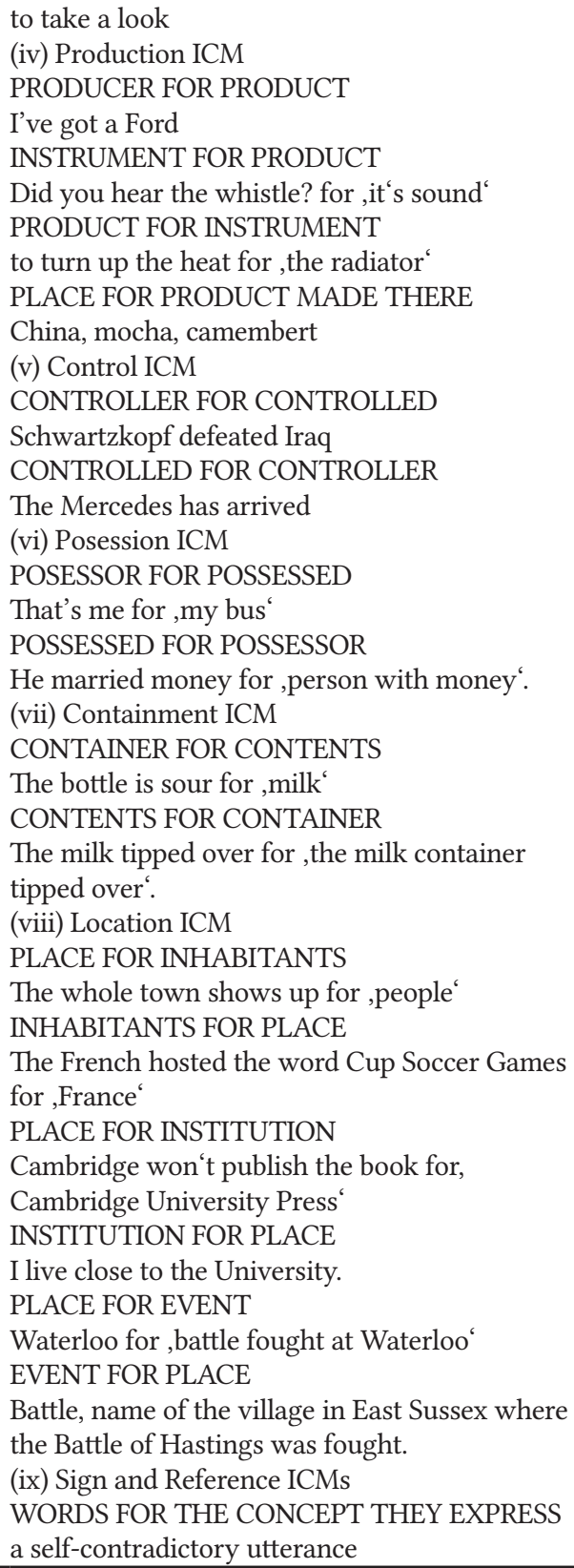 \\
\hline
\end{tabular}


In der neueren Forschung zeichnet sich die Tendenz ab, die Metonymien aus einer weiteren, die Semantik überlagernden Perspektive zu betrachten. So unterscheidet z.B. Panther (2015: 210-213) zwischen referenziellen, prädikativen und illokutiven Metonymien - analog zu den von Searle (1969) in der Sprechakttheorie vorgeschlagenen Akten des Referierens, des Prädizierens und des Vollziehens illokutiver Handlungen.

Referenzielle Metonymien operieren auf Denotata von nominalen Ausdrücken, als Beispiele können hier die von Lakoff und Johnson bereits angeführten konzeptuellen Metonymien dienen.

Eine wichtige Rolle bei der Erschließung von impliziten Bedeutungen kommt den prädikativen und illokutiven Metonymien zu, die an der Grenze zwischen Grammatik, Pragmatik und Semantik liegen. Prädikative Metonymien operieren auf Verbalphrasen oder verbalen Elementen. Als produktive prädikative Metonymien werden für das Deutsche und Englische die Metonymien obLIGATION $\rightarrow$ AKTUALITÄT SOWie POTENTIALITÄT $\longrightarrow$ AKTUALITÄT angesehen.

OBLIGATION $\longrightarrow$ AKTUALITÄT

1.a Die Autofabrik musste gestern die Produktion einstellen.

1.b Die Autofabrik stellte gestern die Produktion ein.

POTENTIALITÄT $\longrightarrow$ AKTUALITÄT

2.a Das Werk konnte gestern die Produktion wieder aufnehmen.

2.b Das Werk nahm gestern die Produktion wieder auf.

Die Äußerung (1.a) evoziert metonymisch die Wahrheit von (1.b), obgleich eine Obligation nicht unbedingt impliziert, dass eine Handlung tatsächlich vollzogen wird. Dasselbe bezieht sich auf das zweite Paar: Die Potenzialität, die durch das Modalverb können ausgedrückt wird, tritt in der Auslegung des Satzes in den Hintergrund: Durch das Vergangenheitstempus und die Zeitangabe gestern werden die Äußerungen (1.a) und (1.b) als aktuell verstanden.

Die illokutive Metonymie veranschaulicht Panther am Beispiel der Äußerung:

Du kannst mal eben den Müll entsorgen.

Mit dieser Äußerung wird eine konventionelle Aufforderung vollzogen (Ziel), obwohl der Sprecher mit dem Modalverb können lediglich die Fähigkeit des Hörers zur Ausführung einer Tätigkeit feststellt.

\subsubsection{Zur Abgrenzung von Metapher und Metonymie}

Die neueren detaillierten Analysen verweisen darauf, dass die eindeutigen Abgrenzungen zwischen der Metapher und der Metonymie nicht immer ausführbar sind. Dies hängt einerseits mit der Unmöglichkeit einer präzisen und intersubjektiven Bestimmung zusammen, was unter einer „Domäne“ zu verstehen ist (Croft 2003, Taylor 2003): Da sich die Domänen als in ontologischer Entwicklung des Menschen erworbene allgemeine Wissensstrukturen bilden und die alltäglichen 
Kategorisierungen widerspiegeln, lassen sie sich nicht immer nach strikten wissenschaftlichen Kriterien eindeutig einteilen. Andererseits wird immer häufiger darauf verwiesen, dass Metapher und Metonymie in manchen Ausdrücken interagieren, metaphorisch-metonymische Ketten bilden, in denen die Übergänge fließend, die Grenzen verschwommen und von der subjektiven Beurteilung abhängig sind. Der erste Aspekt wird im Folgenden in Anlehnung an einen Artikel von Barcelona (2003) zum aktuellen Forschungsstand diskutiert, der zweite nimmt auf den von Goosens (2003) eingeführten Terminus ,Metaphtonymy` Bezug, unter dem die Interaktion von Metapher und Metonymie subsumiert wird.

\subsection{Metapher und Metonymie vor dem Hintergrund des Domänenbegriffes}

Unabhängig davon, ob man grundlegende, strukturierte, auf der Erfahrung basierende Wissensbereiche als Domänen (Langacker 1987, 2008), ICMs (Lakoff 1987) oder Frames (Fillmore 1982, Fillmore/Baker 2009, Ziem 2008) bezeichnet, muss der enzyklopädische Charakter von diesen Strukturen, der u.a. ihre offenen, verschwommenen Grenzen, ihre Flexibilität, Veränderbarkeit sowie eine bestimmte Subjektivität impliziert, berücksichtigt werden. Diese Strukturen existieren des Weiteren nicht unabhängig voneinander, sondern bilden ein komplexes System, in dem eine Domäne eine andere Domäne voraussetzt. Aus diesen definitorischen Unzulänglichkeiten ergeben sich viele Umstrittigkeiten bezüglich der Abgrenzung von Metapher und Metonymie.

Definiert man die Metapher als Mappings zwischen zwei Domänen und Metonymie als Mappings/Highlighting innerhalb einer Domäne/Domänenmatrix, so könnte man selbst das Paradebeispiel für Metapher: fohn is a lion infrage stellen: $\mathrm{Zu}$ Recht verweist Barcelona (2003: 236-237) darauf, dass sowohl fohn als auch lion der übergeordneten Domäne LIVING BEINGs zuzurechen sind, also - völlig kontraintuitiv - als Metonymie angesehen werden könnten: Die Ausgangs- und die Zieldomäne können nämlich als Bestandteile einer übergeordneten Domäne angesehen werden.

Barcelona (2003: 233-235) führt des Weiteren Beispiele für Metaphern heran, deren Ausgangsdomänen anscheinend in den Zieldomänen liegen. Zur Konzeptualisierung von TRAUER leistet die konzeptuelle Metonymie: DROOPING BODILY POSTURE (EFFECT) STANDS FOR SADNESS (CAUSE) einen wichtigen Beitrag:

EFFECT STANDS FOR CAUSE

DROOPING BODILY POSTURE STANDS FOR SADNESS

Mary has a long face.

John drooped his head (sadly).

She walked with drooping shoulders/downcast eyes after the news of her child's death.

(Barcelona 2003: 234)

Die Domäne der Trauer setzt also die Domäne der Vertikalität, die wiederum nur vor dem Hintergrund der Domäne des Raumes betrachtet werden kann. Dies würde bedeuten, dass die Domänen der Vertikalität und des Raumes als Bestandteil der 
Domäne der TRAUER angesehen werden könnten ${ }^{100}$. Dieser Logik folgend müsste man ebenfalls die Aussagen:

She is in the pits.

Mike is in low spirits.

I am prostrate.

Mary is down in the dumps.

Her spirits drooped. (Barcelona 2003: 234)

als Manifestationen einer konzeptuellen Metonymie DOWn (verticality) FoR SADNESS und nicht der konzeptuellen Metapher SADNESS IS DOwN betrachten. Solche Schlussfolgerungen sind aber kaum akzeptabel: „(...) no native speaker of English (or, for that matter, Spanish, Italian, or other European languages) is likely to categorise verticality (or space) consciously as a subdomain of sadness" (Barcelona 2003: 235).

Aus diesen Gründen wird heutzutage Jakobsons Gedanke (vgl. Unterkap. 2.1.3) wieder aufgegriffen, dass Metonymie und Metapher ein Kontinuum mit graduellen, oft schwer zu definierenden Übergängen bilden. Radden (2003) veranschaulicht dies (Abb. 15) am Beispiel des Adjektives high in englischen Wortverbindungen und Kollokationen.
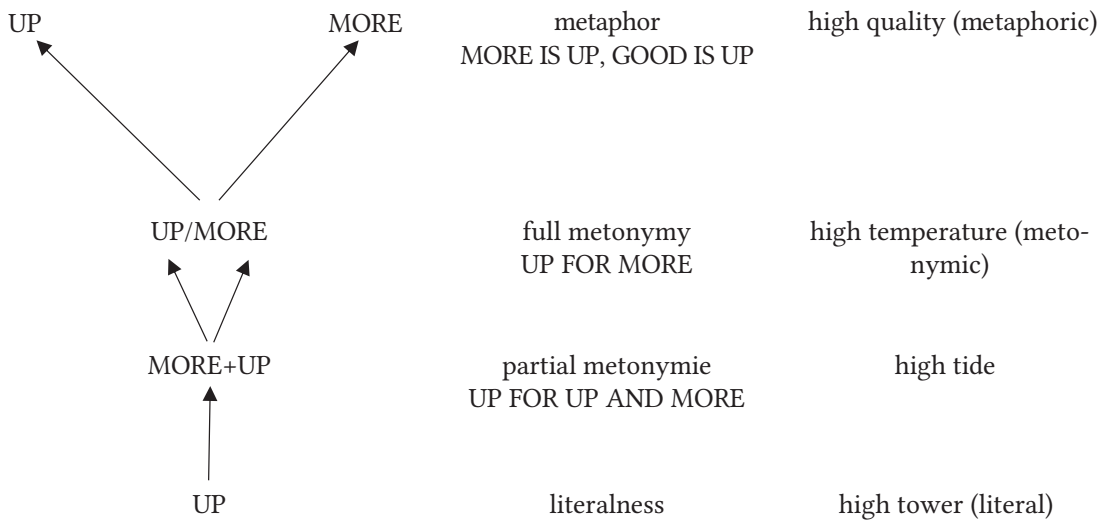

Abb. 15: Metapher und Metonymie als Kontinuum (nach Radden 2003: 409-410).

100 Möglicherweise wäre es an dieser Stelle angebrachter, nach Langacker (2008) und Croft (2003) von einer Domänenmatrix zu sprechen. Die Domänen der Vertikalität und des Raumes bilden demnach keinen Bestandteil der Domäne der Trauer, gehören dennoch zu der Domänenmatrix, die den Konzeptualisierungen von TRAUER zugrunde liegt. 
Das Adjektiv high bezieht sich in der Wortverbindung high tower ausschließlich auf das Kriterium der Vertikalität: Es wird literal gebraucht. In high tide ,Flut bezieht sich high sowohl auf die Vertikalität als auch auf die Quantität, in high temperature ist es (nach Radden, ebd.) vor allem die Quantität (UP FOR MORE). In high quality referiert high auf eine Einschätzungsskala (scale of evaluation) mit den höchsten Werten, die als good bezeichnet werden, hier liegt schon eine Metapher vor: „We cannot think of evaluation and verticality as belonging to the same conceptual domain; hence this situation is seen purely metaphorically as GOOD IS UP" (Radden 2003: 410).

\subsection{Metaphtonymie}

Die neueren detaillierten Analysen verweisen des Weiteren darauf, dass Metapher und Metonymie in den sprachlichen Äußerungen interagieren können, sodass man beide Mechanismen nicht eindeutig abgrenzen kann. Interessanterweise scheinen derartige Interaktionen eher als Regel denn als Ausnahme zu gelten. Goosens (2003) liefert beispielshalber mit der Untersuchung des semantischen Feldes linguistic interaction empirische Evidenz dafür, dass die Interaktionsfälle (mixed cases), in denen sich die Metapher und die Metonymie verzahnen, mehr als die Hälfte des untersuchten Korpus ausmachen. Als plakatives Beispiel dieser Interaktion gilt folgender Satz (Goosens 2003: 356):

„Oh dear," she giggled, „'d quite forgotten.“

Das Verb giggle ,kichern' kann in diesem Satz auf zwei Weisen interpretiert werden: Die erste Auslegung setzt voraus, dass eine Person weiblichen Geschlechts eine Aussage kichernd zum Ausdruck brachte. In diesem Fall liegt die Metonymie (genauer gesagt Synekdoche: Teil für Ganzes) vor. In der anderen Interpretation ist anzunehmen, dass eine Frau etwas sagte, was wie Kichern anmutete: KICHERN referiert in dieser Auslegung auf eine unbeschwerte, sorglose bzw. etwas alberne Sprechweise. Da man hier von zwei Domänen ausgehen müsste (Ausgangsdomäne: Töne, Geräusche, Laute, die von Menschen hervorgebracht werden z.B. keuchen, kichern, klatschen; Zieldomäne: linguistische Interaktion), spricht man in dieser Interpretation von einer Metapher aus Metonymie (metaphor from metonymy). Es bestehen also zwei Interpretationen des zitierten Satzes: Metapher aus Metonymie oder Metonymie. Die Auslegung dieser Sprachäußerung ist von Natur aus „unentschieden“" (undecided, Goosens 2003: 357).

Die Interaktion zwischen Metapher und Metonymie kann ebenfalls in entgegengesetzter Richtung erfolgen. Im metaphorischen Idiom to bite one's tongue off (,sich in die Zunge beißen'):

I should/could bite my tongue off.

liegt eindeutig eine metaphorische Übertragung zwischen zwei Domänen vor. Dabei ist die zUNGE auch metonymisch gebraucht: ZUNGE steht hier für Sprachfähigkeit. Derselbe Interaktionstyp (metonymy within metaphor) gilt für andere 
Idiome mit Körperteilen als Bedeutungskonstituenten: to catch someone's ear, to shoot one's mouth off. ${ }^{101}$

Goosens schlägt für derartige Spracheinheiten von einem hybriden Charakter den Terminus metaphtonymy (Metaphtonimie) vor. Dieser Terminus wird im Weiteren für die Bezeichnung der Grenzphänomene verwendet, die sowohl als Metonymie als auch als Metapher aufgefasst werden könnten.

Die besprochenen Probleme bei der Abgrenzung zwischen Metapher und Metonymie sind auch in der Phraseologie präsent. Der Bedeutungskonstituierung von zahlreichen Phraseologismen liegen metonymisch-metaphorische Derivationsketten mit flüssigen Übergängen und möglichen Interaktionen zugrunde. Für die Bedeutung des Idioms seinen Hut nehmen sind beispielshalber zwei Schritte konstitutiv. Im Ersteren handelt es sich um eine Metonymie: Die ritualisierte soziale Handlung des Sich-Verabschiedens besteht aus mehreren Handlungen (die Abschiednehmensabsicht äußern, sich aufheben und in Richtung Ausgangstür bewegen, insbesondere in den kalten Monaten sich anziehen, darunter seinen Hut nehmen, die Hand reichen und Hoffnung auf das Wiedersehen äußern usw.). Die Teilhandlung seinen Hut nehmen steht hier metonymisch für einen - bei näherer Betrachtung - zusammengesetzten Prozess. Der Teil steht für das Ganze.

Im zweiten Schritt unterliegt das Abschiednehmen einer weiteren Bedeutungsderivation. Das Idiom seinen Hut nehmen referiert nämlich nicht auf jeden Abschied, sondern auf den beruflichen Abschied, auf den Rücktritt. Je nach der Auslegung könnte man hier also von einer Pars-pro-toto Metonymie (sich verabschieden im Sinne einer sozialen Handlung macht nur einen Teil einer Rücktrittsprozedur aus), oder von einer Metapher sprechen. Hier liegen nämlich zwei (sich z.T. auch verzahnenden) Domänen, RITUALISIERTE SOZIALHANDLUNGEN sowie ARBEIT, vor. Aus diesem Grunde dürfte im zweiten Schritt eine Metaphtonymie angenommen werden. Eindeutige Abgrenzung zwischen Metapher und Metonymie ist hier nicht möglich (vgl. Abb. 16).

seinen Hut nehmen

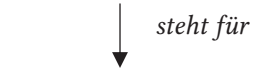

sich verabschieden

$\downarrow \begin{aligned} & \text { steht für/wird übertragen auf die } \\ & \text { berufliche Domäne }\end{aligned}$

seine Stelle aufgeben, zurücktreten

\section{metonymische Verschiebung (TEIL STEHT FÜR DAS GANZE)}

metaphtonymische Verschiebung

Abb. 16: Metonymie und Metaphtonymie als Mechanismen der
Bedeutungskonstituierung am Beispiel des Idioms seinen Hut nehmen.

101 Die beiden Interaktionstypen (metaphor from metonymy, metonymy within metaphor) sind in Goosens Untersuchungskorpus am häufigsten, als andere Interaktionstypen hat Goosens demetonymysation inside a metaphor, metaphor within metonymy ermittelt. 
Metaphorisch-metonymischen Bedeutungsverschiebungen können ebenfalls einzelne Idiomkonstituenten unterzogen werden (vgl. Abb. 17):

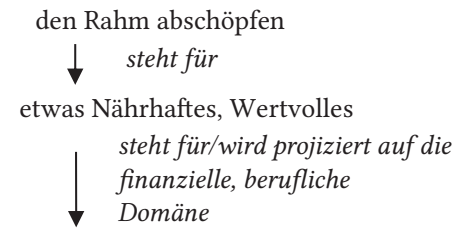

etwas Ertragreiches, Begehrtes

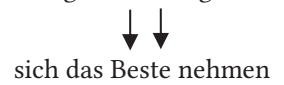

\author{
metonymische Verschie- \\ bung einer Idiomkonstituente \\ metaphtonymymische Ver- \\ schiebung einer Idiomkonsti- \\ tuente \\ metaphorische Verschiebung \\ der ganzen Wortverbindung
}

\begin{abstract}
Abb. 17: Metonymie, Metapher und Metaphtonymie als Mechanismen der Bedeutungskonstituierung am Beispiel des Idioms den Rahm abschöpfen.
\end{abstract}

Weitere Belege, die die kontiunuierlichen Übergänge zwischen Metonymie und Metapher illustrieren, werden im empirischen Teil des vorliegenden Buches präsentiert (vgl. z.B. Kap. 4.2.2.1.1.2.3).

\title{
2.3.5 Die literale, non-literale und figurative Sprache
}

Die Kontinuum-Annahme gilt nicht nur für das Begriffspaar ,Metonymie - ,Metapher', sondern auch für das Begriffspaar, literale Sprache - , figurative Sprache‘. Die angesprochene Problematik wird in der sprachphilosophischen und sprachwissenschaftlichen Fachliteratur unter dem Stichwort: literale - non-literale figurative (metaphorische) Sprache diskutiert (Ariel 2002, Burger 2007b, Cacciari 1993, Dirven 2002, Dancygier/Sweetster 2014, Dobrovol'skij/Piirainen 2005, Lakoff 1986). Die axiomatische Annahme $\mathrm{e}^{102}$ der literalen Sprache muss relativiert werden, sobald man die Bedeutung eines sprachlichen Zeichens nicht auf der statistischen Language-Ebene ansiedelt, so wie es im Strukturalismus der Fall war, sondern aus pragmatischer und kognitiver Perspektive als einen dynamischen, eine Interaktion zwischen einem Produzenten und einem Rezipienten voraussetzenden Bedeutungsgenerierungsprozess betrachtet:

102 Als das größte Problem stellt sich die Definierung, was unter der literalen Sprache zu verstehen ist, heraus. Die herkömmlichen Definitionen leisten hier wegen ihrer Zirkularität keine Hilfe: z.B. „Those concepts that are not comprehended via conceptual metaphor might be called literal“ (Lakoff 1993: 205) oder „figurative means, that a usage is motivated by a metaphoric or metonymic relationship to some other usage, a usage which may be labeled literal. And literal does not mean ,everyday, normal usage' but a meaning which is not dependent on a figurative extension from another meaning." (Dancygier/Sweetster 2014: 4) 
...mythical view of literal meaning as being well specified and easily identifiable in thought and language is incorrect. It is, in fact, quite difficult to specify the literal definitions of concepts and the words that refer to these concepts. (Gibbs 1994: 25)

Traditionell wird die literale Sprache als „direct, grammatically specified, sentencial, context-free“ (Katz 1977, zit. nach Ariel 2002: 362), „determinated, explicit, and fully compositional“ (Matthews 1997: 211, zit. nach Ariel 2002: 362) definiert. Die non-literale Sprache gilt dagegen in der traditionellen Auffassung als pragmatisch, an die Sprachäußerung und den Sprecher gebunden, nicht konventionell und nicht kompositionell (ebd.). Ariel führt auch weitere traditionell angenommene Charakteristika der literalen und non-literalen Lesart heran:

While not part of the classical definition, other properties are commonly associated with literal and nonliteral meanings. Literal meaning is automatic and obligatory, whereas nonliteral meaning is nonautomatic and optional (Grice 1975). Literal meaning is the unmarked meaning, or the norm (...), and it is the meaning frequently used (Rumelhart 1979). This was also the view endorsed by philosophers of law and judges (see Bowers, 1989: 115). Nonliteral meaning is generated only when the default literal meaning is implausible; it is therefore marked and relatively rare. (Ariel 2002: 363)

Diese Definitionen müssen selbstverständlich vor dem Hintergrund der kognitiven Forschungsergebnisse einer Revision unterzogen werden: Zum einen wird in den letzten Jahren kontrovers diskutiert (vgl. Kap. 2.1.4), inwieweit die Annahme der kompositionellen Bedeutung von Syntagmen der Sprachwirklichkeit entspricht. Zum anderen scheint auch der Pol der figurativen Sprache keinesfalls einheitlich zu sein, sondern umfasst sprachliche Äußerungen, die sich auf einer Skala zwischen der non-literalen und figurativen Bedeutung befinden. Einen wichtigen Beitrag zur Aufweichung der Grenzen zwischen dem Literalen und dem Figurativen hat die konzeptuelle Metapher- und Metonymie-Theorie geleistet: Der Einbezug der konzeptuellen Metaphern und Metonymien als einer weitverbreiteten konzeptuellen Grundlage der figurativen Sprache lässt die Grenze zwischen dem Literalen und dem Übertragenen verschwommener erscheinen. Wie bereits verwiesen, sind die metaphorisch gebrauchten Sprachausdrücke: solide Fundamente einer Theorie, eine Theorie konstruieren sowohl frequent als auch von den Laien als unmarkiert empfunden.

Lakoff (1986: 2) macht darauf aufmerksam, dass die literale Sprache aus wenigstens vier Perspektiven beschrieben werden kann:

(i) Literal kann sich auf den Kontrast zwischen der alltäglichen konventionellen Sprache und der poetischen Sprache beziehen.

(ii) Unter subject matter literality versteht Lakoff die Sprache, die man üblicherweise zum Sprechen über bestimmte Domänen gebraucht.

(iii) Die non-metaphorische Wörtlichkeit (nonmetaphorical literality) bezieht sich auf die direkt bedeutungsvolle Sprache, deren Verstehen auch ohne Zugriff auf konzeptuelle Metaphern und Metonymien möglich ist („not language that is understood, even partly, in terms of something else“, Lakoff 1986: 2). 
(iv) Als truth-conditional literality bezeichnet Lakoff eine Sprache, die der Wirklichkeit/Realität entspricht und objektiv als wahr oder falsch gelten kann („Language capable of ,fitting the world', that is, of referring to objectively existing objects or of being objectively true or false“, Lakoff 1986: 2).

Somit hängt die Bestimmung der literalen Sprachebene weitgehend von dem Betrachtungswinkel und der Sprachtheorie ab. Als Autor der CTM-Theorie räumt Lakoff selbstverständlich der dritten Literalitätsauffassung einen besonderen Stellenwert ein: Ein sprachlicher Ausdruck ist literal, wenn er autonom ist, d.h. es muss zu seinem Verständnis auf keine konzeptuellen Strukturen von der höheren Generalität (konzeptuelle Metaphern und Metonymien) zugegriffen werden.

Umstritten und uneinheitlich ist ebenfalls der der literalen Sprache entgegengesetzte Pol der figurativen (übertragenen) Sprache. Der Übergang von einer literalen bis zur figurativen Sprache scheint nämlich einen kontinuierlichen Charakter zu haben, was Radden (2003) am Beispiel des Adjektivs high in den Wortverbindungen: high tower, high tide, high temperature, high quality überzeugend veranschaulicht (Kap. 2.3.4.4.1). Eine ähnliche Studie legt Dirven (2002: 338-339) mit Bedeutungserweiterungen des Adjektivs sweet vor. In der literalen Basisbedeutung tritt das Adjektiv in der Syntagma sweet apple auf: sweet bezieht sich hier auf die perzeptuelle Geschmackserfahrung. Auf perzeptuelle Wahrnehmungen wird auch in den erweiterten Bedeutungen Bezug genommen: sweet water, sweet milk stellen Beispiele für polarisierende Bedeutungen (sweet water $\leftrightarrow$ salty water, sweet milk $\leftrightarrow$ sour milk) dar. Das Adjektiv ist hier non-literal, aber auch non-figurativ gebraucht. In den Syntagmen: sweet music oder sweet smell ist die Bedeutung von sweet schon figurativ: Hier liegt nach Dirven synästhetische Metapher vor. Es wird nämlich eine Verbindung zwischen zwei Domänen (Geschmack und Gehör) hergestellt, die dennoch eng aneinander liegen:

The lower figurativity of the synaesthetic meaning extensions may reside precisely in the very close presence of the donor domain and the receiver domain: we remain there in the word or domain of the sensory impressions and only witness a transfer from one subdomain to another subdomain. (Dirven 2002: 339)

Der deutliche metaphorische Übergang von einer Domäne der perzeptuellen Erfahrung in die psychologische Domäne der Emotionen findet erst in der Bedeutung sweet child statt, die eindeutig als figurativ bezeichnet werden kann. Die Differenzierung zwischen der literalen und der figurativen Bedeutung hat nach Dirven also einen kontinuierlichen Charakter und wird von dem konzeptuellen Abstand zwischen zwei Domänen abgeleitet:

The greater the contrast between the two elements, the greater also the degree of figurativity, or in its higher realisation, the higher the degree of the metaphoricity.

(Dirven 2002: 341)

2003 stellte Dirven eine erweiterte Version des Kontinuums zwischen der literalen und der figurativen Bedeutung anhand des folgenden Schemas (Abb. 18) dar: 


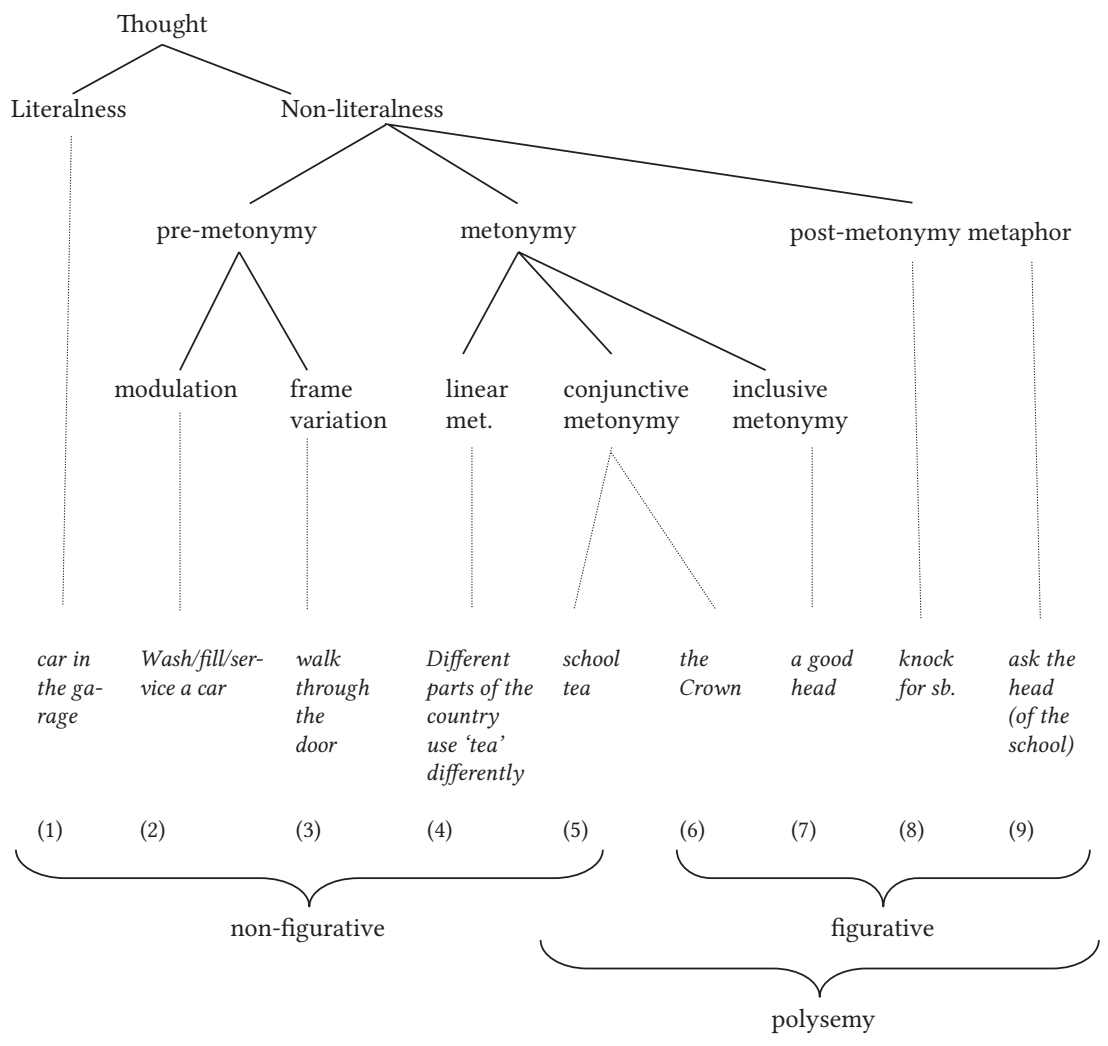

Abb. 18: Das Kontinuum zwischen der literalen und der figurativen Bedeutung (Dirven 2003b: 107).

Dobrovol'skij und Piirainen (2005) versuchten die Abgrenzung der non-literalen von der figurativen Sprache anhand zweier Kriterien zu parametrisieren. Das erste Kriterium macht die bildliche Komponente (image requirement) aus - eine spezifische konzeptuelle Struktur, die zwischen der lexikalen und der aktuellen Bedeutung übermittelt (vgl. Kap. 3.4.4.3). Das andere Kriterium wird als additional naming bezeichnet: Als figurativ gelten nur diese Spracheinheiten, die eine zusätzliche Bezeichnung eines Denotats darstellen. Auch hier tauchen dennoch die Grenzfälle auf, die von dem allgemeinen Wissen und der Sprachintuition des jeweiligen Benutzers abhängig sind: Das Lexem Seepferdchen zur Bezeichnung eines kleinen, in aufrechter Haltung schwimmenden Fisches kann dementsprechend als figurativ oder non-figurativ bezeichnet werden, je nachdem, ob dem Benutzer der andere Name Hippocampus bekannt ist (ebd., 18). 
Resümierend lässt sich feststellen, dass die alten Definitionen der literalen und figurativen Sprache vor dem Hintergrund der neueren Forschungsrichtungen nicht mehr zufriedenstellend sind. Die Formulierung von neuen Definitionen ist dennoch umstritten und problematisch (vgl. die Disskussion in Ariel 2002; Gibbs 1994). Keinem Zweifel unterliegt dennoch, dass sich die literale und die figurative Sprache nicht strikt abgrenzen lassen, die Übergänge fließend und verschwommen sind, während die Konstrukte des Literalen und des Figurativen lediglich als ein die Diskussion erleichterndes theoretisches Modell aufgefasst werden müssen.

\subsubsection{Zusammenfassung und Ausblick}

Metapher, Metonymie und die dazwischen liegende Metaphtonymie sind als die wichtigsten Mechanismen anzusehen, die der Ausweitung der ursprünglichen, literalen Bedeutung auf die weiteren, abgeleiteten Bedeutungen dienen. Ihre Relevanz für die Phraseologie ist damit offensichtlich. Der vorliegenden Arbeit liegt ein Domänen-Ansatz zugrunde, dessen Grundprämissen sich folgendermaßen zusammenfassen lassen:

(i) Metapher und Metonymie stellen mentale Mechanismen dar, d.h., sie vollziehen sich grundsätzlich auf der mentalen, konzeptuellen Ebene: „Metaphor and metonymy are mental mechanisms, not to be confused with their expression, linguistic or otherwise“ (Barcelona 2003: 216). Hervorgehoben wird also der Relation-Charakter einer Metapher und einer Metonymie: Ihr Wesen liegt in den Beziehungen, Projektionen, Mappings zwischen zwei Entitäten, worauf u.a. Rothkegel aufmerksam macht:

Terminologische Schwierigkeiten hängen u.a. damit zusammen, dass einer sprachlichen Einheit metaphorische Qualität zugesprochen wird anstelle der metaphorischen Relation, an der zwei Einheiten beteiligt sind. So wird z.B. als Metapher bezeichnet der ,bildgebende“ sprachliche Ausdruck (Liebert 1992: 5 „Lexemmetapher“, z.B. Fluss), eine zugehörige Generalisierung als Wortfeldname (z.B. WASSER), der ,bildempfangende“ Ausdruck (z.B. DYNAMIK, bei Liebert „Konzeptmetapher“). Eine zentrale Rolle spielt im Weiteren die Bestimmung der Analogierelation selbst. Die aus der rhetorischen Tradition stammende Auffassung von der ,Übertragung (...) stützt ebenfalls eine Sicht auf die beteiligten Einheiten als solche anstatt auf die Relation zwischen den Einheiten. In einer interaktionistischen Auffassung geht man dagegen davon aus, dass beide Einheiten aufeinander Einfluss nehmen (...) und dass im gegenseitigen Bezug etwas Neues entsteht (ein ,metaphorischer Mehrwert'). (Rothkegel 2004: 394)

Unter Metapher und Metonymie werden folglich konzeptuelle Mappings verstanden, die sich innerhalb der einen oder zwischen mehreren Domänen (strukturierten Erfahrungsbereichen) vollziehen. Sprachliche Manifestationen von Metapher und Metonymie haben in diesem Sinne einen sekundären Charakter. 
(ii) Die Metapher wird als kognitiver Mechanismus aufgefasst, in dem eine Erfahrungsdomäne (im Sinne von Langacker 1987, 2008) - als Ausgangsdomäne bezeichnet - mit einer anderen Erfahrungsdomäne (der Zieldomäne) durch konzeptuelle Mappings verbunden wird, wobei beide Domänen in verschiedenen Erfahrungsbereichen liegen. Wichtig ist dabei der kognitive Status der Domänen: Die Ausgangsdomäne liegt meistens im Bereich der direkten, sensuellen Erfahrung, die Zieldomäne bezieht sich auf abstraktere experienzielle Bereiche. Der kognitive Vorteil der Metapher beruht darauf, dass die abstraktere Zieldomäne mithilfe der auf der Wahrnehmung basierenden Ausgangsdomäne leichter konzeptualisiert, verstanden wird.

(iii) So weit verstandene Metapher umfasst mehrere Metapherntypen, die nach verschiedenen Kriterien voneinander abgegrenzt werden können. Die für die weiteren Ausführungen wichtigste Differenzierung bezieht sich auf den Typ der metaphorischen Mappings, nach dem man zwischen den konzeptuellen und den epistemischen Metaphern unterscheidet:

Die konzeptuellen Metaphern werden als Teil eines unsere Kognition strukturierenden konzeptuellen Systems angesehen. Es handelt sich um feste, oft in der frühesten Erfahrung verankerten Strukturen, die die komplexen, abstrakten Begriffe z.T. mitgestalten können. So beeinflussen die konzeptuellen Metaphern VeRSTEHEN IST SEHEN (mir leuchetet etw. ein, Einsehen haben, durchblicken, durchschauen, klar werden) und VERSTEHEN IST FASSEN (begreifen, auffassen, nachvollziehen) bis zu einem bestimmten Grad die Art und Weise, wie wir das Verstehen konzeptualisieren. Charakteristisch für konzeptuelle Metaphern ist die Tatsache, dass sie sich in zahlreichen sprachlichen Ausdrücken manifestieren.

Die epistemischen Mappings bilden keinen fest etablierten Teil des konzeptuellen Systems: Es sind einmalige Korrespondenzen zwischen zwei Domänen, die durch die allgemeinen Weltwissensinformationen motiviert sind. Die epistemischen Mappings entstehen oft ad hoc, sie sind emergent und an einen Ko- und Kontext gebunden, so wie es Glucksberg (2001: 56) überzeugend an Beispielen: Some roads are snakes und Some lawyers are snakes veranschaulicht (Kap. 2.3.4.1, Kap. 3.4.4.2). Manche epistemische Mappings können allerdings durch den Usus konventionalisiert werden: Falls eine okkasionelle Ausdrucksweise eines Sprachteilhabers von der Sprachgemeinschaft als treffend, anschaulich, die Situation gut widerspiegelnd empfunden wird, unterliegt sie dem Prozess der Konventionalisierung. Die Motiviertheit der usualisierten Wortverbindung nicht über seinen eigenen Schatten springen können, nicht anders handeln können, als es dem eigenen Wesen oder der eigenen Gewohnheit entspricht' (DUW) ist bei den meisten Menschen auf das allgemeine Weltwissen zurückzuführen, dass man den Schatten von dem Körper nicht lösen kann, der Sprung über den eigenen Schatten ist somit aus physikalischen Gründen unmöglich.

Die beschriebene Einteilung in die epistemischen und konzeptuellen Metaphern verzahnt sich teilweise mit der von Kövecses vorgenommen Einteilung nach der Metaphernnatur (dem Repräsenationsmodus der Wissensstrukturen) in die 
propositionalen, image schemas- und rich image-Metaphern. Zahlreichen konzeptuellen Metaphern liegt ein image schema zugrunde (vgl. image schema PATH und die konzeptuellen Metaphern LEBEN IST EINE REISE, LIEBE IST EINE REISE, KARRIERE IST EINE REISE). Die epistemischen Mappings sind dagegen oft an das rich image (das mentale Bild) gebunden, das durch die literale Lesart einer Wortverbindung evoziert wird;

(iv) Die Metaphorizität einer Wortverbindung konstituiert sich auf zwei Ebenen. Auf der ersten Ebene kann sie durch die konzeptuellen Metaphern von verschiedenem Generalitätsgrad beeinflusst werden, die die Konzeptualisierung in eine Richtung weisen. Auf der zweiten Ebene ergeben sich die metaphorischen Mappings aus den emergenten und oft kontextsensitiven Verbindungen von Wissensdomänen, die die semantischen Pole der sprachlichen Einheit konstituieren. Auf dem semantischen Pol sind zahlreiche Wissensstrukturen in verschiedenen Modalitäten gesammelt, die Aktivierungen von mentalen Bildern, Emotionen, mentalen Repräsentationen von sensorischen Empfindungen sind dadurch absolut möglich und vollziehen sich ständig. Die beiden Metapherntypen können unabhängig voneinander vorkommen oder - wie in Barcelonas Beispiel (vgl. 2.3.4.2.1) gleichzeitig zur Bedeutungskonstituierung beitragen.

(v) Grundlegend für das Zustandekommen der Metonymie ist die Tatsache, dass zwei durch metonymische Beziehung verbundene Inhalte etwas „miteinander zu tun haben“, dass sie assoziationspsychologisch aufeinander bezogen werden. Die in der klassischen Auffassung hervorgehobene Kontiguitätsbeziehung wird in dem Zwei-Domänen-Ansatz als konzeptuelle Verbindung von zwei Inhalten innerhalb einer Domäne/einer Domänenmatrix definiert. Da die Inhalte in einem strukturierten Erfahrungsbereich liegen, ist die Beziehung zwischen ihnen durch eine konzeptuelle Nähe gekennzeichnet. In dem Satz:

Ich habe einen Diesel gekauft.

ist die Verbindung zwischen einem Auto und seiner Antriebsart offensichtlich: Die Antriebsart bildet einen Teil der Wissensdomäne ,Auto'.

(vi) Da die Domänengrenzen von Natur aus verschwommen sind, ist es nicht immer leicht festzustellen, ob bestimmte Inhalte periphäre Bereiche einer Domäne oder einen integralen Teil einer anderen Domäne bilden. Daraus ergeben sich Schwierigkeiten bei der Bestimmung, ob in einem bestimmten Fall eine Metonymie oder eine Metapher vorliegt. Metonymie und Metapher werden in der modernen Forschung als ein Kontinuum betrachtet. Hybride Phänomene, die je nach Auslegung als Metonymien oder Metaphern interpretiert werden können, sind akzeptiert und als Metaphtonymien bezeichnet. 



\title{
3. Semantische Besonderheiten der Idiome aus kognitiver Perspektive
}

\author{
If natural language had been designed by a logician, \\ idioms would not exist.
}

(Johnson-Laird 1993: VII)

Seit der Entstehung der modernen Sprachwissenschaft gilt das Streben nach einer Sprachbeschreibung in Anlehnung an die naturwissenschaftlich-logischen Kriterien als Ideal der wissenschaftlichen Forschung. Auf der Suche nach intersubjektiven Beschreibungsgrößen und einem klaren Untersuchungsgegenstand wird die Sprache in den strukturalistisch und generativistisch ausgerichteten Ansätzen von anderen kognitiven Fähigkeiten des Menschen abgegrenzt und als unabhängiges Modul beschrieben. Phraseologie und insbesondere Idiomatik, die mit ihren inhärenten Merkmalen wie Idiomatizität, Motiviertheit oder Bildlichkeit/Bildhaftigkeit von Natur aus am Schnittpunkt zwischen dem Sprach- und Weltwissen liegen müssen, werden deswegen als problematische Ausnahme angesehen, die man als Randerscheinung abzutun versucht. ${ }^{103}$ Erst aus der Perspektive des holistischen Ansatzes der Kognitiven Linguistik (vgl. z.B. Lakoff/Johnson 1980, Langacker 1982, 2007, Lakoff 1987) lassen sich die intuitiv unwiderlegbaren, objektiv aber schwer fassbaren Konstrukte der Motiviertheit, Bildhaftigkeit und Idiomatizität näher beleuchten. Da dabei alle genannten Merkmale mit der Doppelbödigkeit des Inhaltsplans der Idiome, d.h., mit dem Zusammenspiel zwischen der literalen und der phraseologischen Lesart aufs Engste verbunden sind, wird zuerst auf die Rolle der beiden Lesarten bei der Konstituierung der Idiom-Bedeutung eingegangen.

\subsection{Literale und phraseologisierte Lesart von Idiomen}

Phraseologismen im engeren Sinne werden traditionell als besondere Sprachzeichen aufgefasst, weil sie Einheiten des sekundären semiotischen Systems

103 Vgl. dazu Keil (1997: 81-82): „Innerhalb der generativen Grammatiktheorien hat der Begriff der Idiomatizität bzw. Nicht-Kompositionalität dazu geführt, daß idiomatische Phraseologismen per Definition als ,semantische Ausnahmen` betrachtet werden. An die an der Wendung beteiligten Konstituenten wird keine semantische Information gebunden und dem zwar syntaktisch strukturieren Phraseologismus wird daher die Bedeutung als semantischer Bedeutungskomplex im Lexikon zugeordnet." 
darstellen (Burger 2010: 82). Dies bedeutet, dass ihnen aus semiotischer Perspektive ein besonderer Status zukommt, der sich aus der Koexistenz von zwei Lesarten in dem Inhaltsplan: der literalen und der lexikalisierten Lesart ergibt. Auf das Zusammenspiel der beiden Lesarten bei der Konstituierung der aktuellen Bedeutung sind die semantische Komplexität der Idiome und ihr semantischer Mehrwert zurückzuführen.

In der Literatur werden die beiden Lesarten auch als ,literale', ,wörtliche‘ sowie ,phraseologisierte', ,idiomatische', ,lexikalisierte', ,übertragene', ,figurative' Lesart bezeichnet. Während die Adjektive ,literal' und ,wörtlich` im Weiteren synonym gebraucht werden, scheinen die Begriffe ,phraseologisiert', ,idiomatisch', ,lexikalisiert' einerseits und ,übertragen', ,figurativ' andererseits doch der Abgrenzung bedürftig zu sein. Burgers Argumente für die Differenzierung zwischen den Begriffen: ,phraseological', ,derived' and ,figurative' sind einleuchtend:

„Phraseological meaning" has the advantage of denoting no more and no less than "the meaning of phrasem", whereas both "derived" and "figurative" already suggest a certain kind of (historical) derivation or a specific connection with the literal meaning. (Burger 2007b: 90)

Alle Idiome haben demnach eine phraseologisierte, idiomatische, lexikalisierte Bedeutung bzw. Lesart, wobei die Begriffe jeweils verschiedene Aspekte dieser Lesart hervorheben: ,Lexikalisiert' profiliert die Festigkeit der Idiome, den Lexikalisierungsprozess, ihre Stabilität, Sprachüblichkeit, Konventionalität. ,Phraseologisiert' und ,idiomatisch' beziehen sich eher auf den semantischen Faktor der Idiomatizität: Phraseologisierte Lesart haben demnach alle Phraseologismen, die idiomatische Lesart nur die Phraseologismen im engeren Sinne. Von einer ,figurativen ' bzw. ,übertragenen` Lesart darf dagegen nur bei denjenigen Idiomen gesprochen werden, in denen mittels Metapher oder Metonymie auf ein anderes Denotat referiert wird, als es in dem üblichen, literalen Gebrauch der Fall ist. Die feste Mehrwortverbindung nicht [so] ohne sein hat demnach eine phraseologisierte Lesart: ,ugs.: nicht so harmlos, sondern stärker, bedeutender sein als gedacht' (DUW), ist aber nicht figurativ, sondern elliptisch. Ebenfalls indexal motivierte Idiome wie Und ich bin der Kaiser von China! ,Das ist äußerst unglaubwürdig!' haben eine phraseologisierte/lexikalisierte Lesart, die nicht figurativ ist, sondern durch pragmatische Aspekte des Sprachgebrauchs bedingt wird. Somit sind aus theoretischer Sicht die Begriffe ,phraseologisierte` sowie , lexikalisierte Lesart weiter als Begriffe ,figurative und ,übertragene` Lesart. Die Tatsache, dass die Termini: ,phraseologisiert', ,lexikalisiert' sowie ,figurativ' im Weiteren austauschbar gebraucht werden, ergibt sich aus der Spezifik des zu untersuchenden Korpus, in dem sich die phraseologisierten Lesarten der meisten Idiome infolge der metaphorischen Derivationen oder metonymisch-metaphorischen Derivationsketten konstituieren.

Die Doppelbödigkeit der semantischen Struktur der Phraseologismen liegt einer Reihe der viel diskutierten Phänomene zugrunde, die als konstitutive Merkmale der Phraseologismen im engeren Sinne betrachtet werden. Idiomatizität, Motiviertheit/Motivierbarkeit und Bildlichkeit/Bildhaftigkeit können in ihrer 
Vielfalt erst vor dem Hintergrund der beiden Lesarten und den zwischen ihnen festzustellenden Beziehungen beschrieben werden, auch wenn diese Beschreibung aus unterschiedlichen Blickpunkten erfolgt und verschiedene Aspekte der semantischen Komplexität der Idiome profiliert. Aus diesem Grunde scheint es begründet zu sein, den Forschungsstand zur Problematik der Lesarten zu beleuchten, bevor auf die durch die Beziehung der literalen und der phraseologischen (lexikalisierten) Lesart hervorgerufenen sekundären semantischen Phänomene der Idiomatizität, der Motiviertheit und der Bildhaftigkeit eingegangen wird.

\subsubsection{Semiotische Perspektive}

Idiome genießen aus semiotischer Perspektive einen besonderen Status der Superzeichen. Unter diesem ursprünglich aus dem Bereich der Informationstheorie und Kybernetik stammenden Begriff wird eine normierte Zusammensetzung aus mehreren Zeichen verstanden, die als Einheit [...] zum Zeichenvorrat der Kommunikationspartner gehört (Moles 1977: 70, zit. nach Grzybek 2007: 192). Grzybek (2007: 192-193) verweist dabei auf den Bezug eines so aufgefassten Superzeichens zum Ehrenfels'chen gestaltpsychologischen Prinzip der Übersummativität: Superzeichen sind solche Zeichen, die entstehen, wenn eine Menge von einzelnen Zeichen sich zu einer ,Gestalt', einer 'Struktur" oder einer ,Konfiguration', also zu einer neuen Einheit zusammenschließt. Das Phänomen der ,Übersummativität' der phraseologischen Bedeutung wurde bereits von den Begründern der europäischen (Ch. Bally und V. Vinogradov), darunter der deutschen (Černyševa 1980: 44) Phraseologie wahrgenommen und ist in der einschlägigen Literatur als ,semantischer Mehrwert' (Gréciano 1982, Kühn 1985), ,konnotativer Mehrwert' (Burger 2003: 78) oder ,semantische Potenzen' (Palm 1989, Burger 2010) der idiomatischen Phraseologismen bezeichnet. Damit ist in der Terminologie der Sem-Analyse gemeint, dass der Phraseologismus neben dem semantischen Kern über mehr differenzierende und konkretisierende Seme als ein (semantisch vergleichbares) Einwortlexem verfügt (Burger 2010: 78), wobei es sich teilweise um latente Eigenschaften handelt, die sich erst im Sprachgebrauch entfalten.

\subsubsection{Psycholinguistisch-kognitive Perspektive}

Die Doppelbödigkeit der phraseologischen Bedeutung wurde relativ schnell in den Fokus der Aufmerksamkeit der psycholinguistisch und kognitiv ausgerichteten Phraseologieforschung gerückt, wo sie bis heute einen prominenten Platz einnimmt. Den beiden linguistischen Teildisziplinen ist großes Interesse an den rezeptiven Aspekten der Idiomverarbeitung sowie der Speicherung der Idiome gemeinsam (Dobrovol'skij 1997: 12-18, Cacciari/Tabossi 1998, Folkersma 2010: 49-50). Die Unterschiede zwischen kognitiver und psycholinguistischer Beschreibung dieser Phänomene sind vor allem methodologischer Natur: Die Kognitive Linguistik ist viel stärker modellbildend (Häcki Buhofer 2004: 148) als die eher empirisch geprägte Psycholinguistik: 
(...) the psycholinguistic approach has a systematic empirical part in addition to theoretical part, whereas the linguistic branch of cognitive approach aims mainly at the theoretical modelling of the phraseological lexicon. (...). Psycholinguistics is concerned with the mechanisms of language comprehension and production in a way as close to empiricism as possible, and its aim is the construction of cognitive models for mechanisms of processing and acquisition as well as for storage. (Häcki Buhofer 2007: 837)

Bezüglich der Frage nach der zeitlichen Abfolge der mentalen Aufschlüsselungsprozesse bei der Rezeption der Phraseologismen werden folgende Hypothesen vertreten:

(i) Die chronologisch älteste literal-first Hypothese geht von der Annahme aus, dass bei der Verarbeitung phraseologischer Einheiten immer zuerst auf die literale Bedeutung zurückgegriffen wird (Bobrow/Bell 1973). Erst wenn diese literale Interpretation den gegebenen kontextuellen Bedingungen nicht gerecht wird, greift man auf die lexikalisierte Lesart zurück. Dobrovol'skij (1997: 13) verweist darauf, dass dieses Verarbeitungsmodell im Einklang mit dem sog. Standard Pragmatic Model steht, d.h., auf eine vom Standard abweichende Bedeutung nur in dem Fall zugegriffen wird, wo die standardmäßige literale Bedeutung nicht zutrifft: „When sentence meaning is defective, look for a speaker meaning that differs from sentence meaning“ (Searle 1979: 114, zit. nach Dobrovol'skij 1997: 13).

(ii) Den Ausgangspunkt zur Formulierung der direct-access/figurative-first Hypothese (Gibbs 1980, 1986) bildete die empirische Evidenz dafür, dass die Idiome in psycholinguistischen Experimenten nicht länger (und in manchen Fällen sogar schneller) als freie Wortverbindungen verarbeitet werden. Dies stand in einem direkten Widerspruch zu der literal-first Hypothese: Sollten die Idiome tatsächlich jeweils zuerst in der literalen, dann in der lexikalisierten Lesart verarbeitet werden, dann müsste dieser Prozess mehr Zeit in Anspruch nehmen als die Verarbeitung übriger Wortverbindungen. Deswegen nahm man an, dass Idiome als Ganzheiten reproduziert und direkt in der phraseologisierten Lesart aus dem mentalen Lexikon abgerufen werden. Da die Reproduktion einer Wortverbindung kürzer als ihre Generierung unter Einbezug morphologisch-syntaktischer Regeln dauert, können Idiome unter Umständen sogar schneller als freie Wortverbindungen verarbeitet werden.

Die neueren, genaueren empirischen Untersuchungen $\mathrm{zu}$ diesem Thema bringen uneinheitliche Ergebnisse (Schweigert 1986, Cacciari/Tabossi 1988, Tabossi/Zardon 1993), die nicht zuletzt auf die pauschalierende, die Heterogenität der Phraseologismen außer Acht lassende Auswahl des Untersuchungsstoffes zurückzuführen sind.

(iii) Die dritte Hypothese - das Modell der simultanen Verarbeitung - geht davon aus, dass beide Lesarten gleichzeitig aus dem Gedächtnis abberufen und auf ihre Einsetzbarkeit in einem gegebenen Kontext hin überprüft werden. Wenn sich unter bestimmten Kontextbedingungen nur eine Lesart als 
kompatibel erweist, wird automatisch auf sie zugegriffen. Wenn dennoch beide Lesarten als sinnvoll erscheinen, stellt sich ein double-take effect ein. Die literale und die phraseologisierte Lesart stehen dann in Konkurrenz zueinander und weitere Verarbeitung des Idioms hängt von zahlreichen Faktoren (Frequenz und Geläufigkeit des PHs, der Beschaffenheit der literalen Lesart, der Position der Schlüsselkonstituente, der Dekompositionalität des Idioms u.a.) ab.

Die neueren Erklärungen zur Repräsentation und Rezeption der Idiome stellen eine balancierte Synthese der unterschiedlichen Zugänge: der direct-look-up Hypothese und der kompositionellen Strategien (Stöckl 2004: 186) dar. Die Verarbeitung der Idiome ist durch zahlreiche Faktoren bedingt, von denen sich manche kaum intersubjektiv erfassen lassen. Einen wichtigen Faktor der Verarbeitung von Idiomen macht beispielshalber die individuelle Geläufigkeit der Phraseologismen aus, die aus psycholinguistischer Perspektive problematisch ist: Menschen weisen nämlich deutliche Unterschiede in ihrem idiolektalen Gebrauch von Idiomen auf.

Parallel zu den in groben Umrissen dargestellten Theorien zur zeitlichen Interaktion der literalen und lexikalisierten Lesart haben sich die psycholinguistischen Theorien zum Speicherungsmodus der Phraseologismen entwickelt:

(i) Als Theorien der lexikalischen Repräsentation wird eine Gruppe der früheren Hypothesen bezeichnet, die von der Annahme ausgehen, dass Phraseologismen wie unteilbare Einheiten, sog. long words im Langzeitgedächtnis gespeichert werden. Gemeinsam ist diesen Theorien die Voraussetzung, dass die Idiome mit anderen Lexikoneinheiten gleichzusetzen sind. Im mentalen Lexikon existiere demnach ein separates Modul, in dem eine Liste mit Phraseologismen aufgeführt wird. Diese Theorie hat bei einer eingeschränkten Gruppe der unteilbaren und opaken Idiome ihre Daseinsberechtigung. Sie trägt dennoch der phraseologischen Flexibilität und Produktivität (semantische und formale Modifikationen), die zahlreiche Phraseologismen im Gebrauch kennzeichnet, kaum Rechnung.

(ii) Im Gegensatz zur Theorie der lexikalischen Repräsentation liegt der Konfigurationshypothese die Annahme zugrunde, dass Idiome als Kombinationen von Elementen gespeichert werden (Cacciari/Tabossi 1988). Demnach bestehen hinsichtlich des Speicherungsmodus keine Unterschiede zwischen den freien und den phraseologischen Mehrwortverbindungen. Bei der rezeptiven Verarbeitung der Idiome spielen die keywords eine besondere Rolle: Die Idiome werden so wie freie Wortverbindungen verarbeitet und in der literalen Lesart ausgelegt, bis der Rezipient das Schlüsselwort wahrnimmt. Dieses Schlüsselwort markiert eine qualitative Grenze in der Verarbeitung der Idiome: Es aktiviert die lexikalisierte Bedeutung und lenkt die Verarbeitung in eine bestimmte Richtung. Mit der Annahme relativer Unabhängigkeit der einzelnen Idiom-Konstituenten liefert die Konfigurationshypothese ein geeignetes Instrument zur Erklärung des diskursiven 
Verhaltens von vielen Idiomen, ihrer syntaktischen Durchlässigkeit und semantischer Produktivität.

(iii) Die Dekompositionshypothese, die vor allem in späteren Arbeiten von Gibbs u.a. (1989) vorgeschlagen wurde, verweist darauf, dass sich unter den als Phraseologismen bezeichneten Sprachphänomenen sowohl decomposable als auch non-decomposable Mehrworteinheiten befinden. Dementsprechend lassen sich viele Idiome nach einem semantisch-syntaktischen Kriterium in teilbare und nicht-teilbare Idiome einteilen. Teilbar sind Idiome, deren Konstituenten bzw. Konstituentengruppen (d.h. Mehrwort-Segmente wie grünes Licht ,Erlaubnis` im Idiom jmdm. grünes Licht geben) als Träger selbstständiger Bedeutungen empfunden werden: Die semantische Struktur dieser Idiome lässt sich in der Weise zergliedern, dass einzelne Konstituenten mit bestimmten Teilen der semantischen Struktur korrespondieren (Dobrovol'skij/Piirainen 2009: 46). Den Idiomkonstituenten: jmdm. einen Bären aufbinden könnte man eine unter syntaktisch-semantischer Hinsicht entsprechende Paraphrase: ,jmdm. eine Lügengeschichte erzählen` zuordnen. Eine Isomorphie zwischen der Form- und der Bedeutungsseite liegt vor (Burger 2010: 68). Keine derartige Isomorphie lässt sich dafür bei den Idiomen kick the bucket und ins Gras beißen ,sterben`erkennen.

Die Dekompositionshypothese wird zurzeit kontrovers diskutiert: Burger (2007b: 94-95) macht z.B. darauf aufmerksam, dass diese Theorie zum großen Teil von einer im Grunde genommen beliebigen und subjektiven Paraphrasierung abhängt. Manche Phraseologismen werden intuitiv als teilbar eingeschätzt (z.B. jmdm. eine Pistole an die Brust setzen ,jmdn. unter Drohungen zu etw. zwingen' $)^{104}$, obgleich die in grammatisch-semantischer Hinsicht entsprechende Bedeutungsparaphrase nicht zu finden ist. Auf der anderen Seite machen Dobrovol'skij/Piirainen (2009: 52-59) darauf aufmerksam, dass ein geeignetes Instrument zur Erklärung der syntaktischen Flexibilität und des semantisch-pragmatischen Verhaltens von teilbaren Idiomen in Aussicht steht, sobald man die Kompositionalität/Teilbarkeit nicht auf der oberflächlichen semantisch-syntaktischer Ebene, sondern auf der konzeptuellen Ebene untersucht. Grundlegend für das Phänomen der Teilbarkeit der Idiome ist die Erkenntnis, dass sich die Korrespondenzen nicht auf die lexikalische Struktur (d.h. den Konstituentenbestand) und die lexikalisierte Bedeutung, sondern auf zwei konzeptuelle Strukturen beziehen: die Ausgangs- und die Zieldomäne (source und target frame).

104 Im angeführten Idiom kommt semantische Autonomie nur einer nominalen Idiomkonstituente - Pistole - zu, während die Brust nicht als semantisch autonom empfunden wird. Aus dieser semantischen Erkenntnis ergeben sich syntaktische Konsequenzen, z.B. in der Passivbildung, Fokussierungsmöglichkeiten durch Fragesatzumformung (Was für eine Pistole wurde ihm auf die Brust gesetzt?) oder Demonstrativpronomen (Diese Pistole hat man ihm auf die Brust gesetzt). Dobrovol'skij/Piirainen (2009: 51) stellen dazu fest: Transformationsmöglichkeiten der Idiome sind grundsätzlich syntaktische Reflexe semantischer Gegebenheiten. 
Im Idiom die Katze aus dem Sack lassen ,seine wahre Absicht zu erkennen geben wären dementsprechend zwischen der Ausgangs- und der Zieldomäne die folgenden konzeptuellen Verbindungen möglich (vgl. Tab. 7):

Tab. 7: Die konzeptuellen Korrespondenzen zwischen der Ausgangs- und Zieldomäne für das Idiom die Katze aus dem Sack lassen.

\begin{tabular}{ll}
\hline Ausgangsdomäne (source frame) & Zieldomäne (target frame) \\
\hline $\begin{array}{l}\text { Agens: die Person, die die Katze } \\
\text { aus dem Sack lässt }\end{array}$ & $\begin{array}{l}\text { Agens: die Person, die das Geheimnis } \\
\text { offenbart }\end{array}$ \\
\hline Patiens: die Katze & $\begin{array}{l}\text { Thema: die Informationen, die bis zu einem } \\
\text { gewissen Moment vor den anderen geheim } \\
\text { gehalten wurden }\end{array}$ \\
\hline Container: der Sack & Experiencer: die anderen \\
\hline
\end{tabular}

Beim Mapping ergeben sich bestimmte Korrespondenzen: Das Agens des source frames korrespondiert mit dem Agens des target frames, das Patiens mit dem Thema, zwischen dem Container und dem Experiencer besteht dennoch keine Korrelation. Das ist der Grund, warum das Idiom die Katze aus dem Sack lassen keine Adressatenvalenz aufweist und der Sack semantisch nicht autonom ist.

Die kognitiv ausgerichtete Sicht auf die Kompositionalität der Idiomatik ist vielversprechend, dennoch neu, weswegen sie weiterer Forschung bedarf. Zu den relevanten und unwiderlegbaren Erkenntnissen der Dekompositionalitätshypothese gehören dennoch die Anerkennung der Heterogenität des idiomatischen Bereiches und die Konzeption der Idiomatik als Kontinuums: von unteilbaren Idiomen, die sich wie long words verhalten bis hin zu den teilbaren, leicht modifizierbaren, nur relativ festen Wortverbindungen. Als empirisch gut fundiert kann ebenfalls die Korrelation zwischen der Teilbarkeit der Idiome und ihrer syntaktischen Durchlässigkeit und Akzeptabilität der Modifikationen gelten: „Speakers will tend to be significantly more creative in their use of semantically analysable idioms both in terms of their syntactic productivity and their lexical flexibility" (Gibbs 1990: 426).

Für die weiteren Überlegungen ist die Annahme grundlegend, dass die phraseologisierte Bedeutung eines Idioms nicht nur durch den Bedeutungstransfer der ganzen Wortverbindung, sondern auch durch den Bedeutungstransfer einzelner Idiom-Konstituenten beeinflusst werden kann, wobei sich beide Prozesse oft gleichzeitig verzahnen.

\subsubsection{Zwischenbilanz}

Zusammenfassend lässt sich feststellen, dass sowohl die auf empirischen Untersuchungen basierende Psycholinguistik (Cacciari/Tabossi 1998, Dobrovol'skij 1997, 
Gibbs 1984) als auch die kognitiv ausgerichtete Forschung (Dirven 2003b, Dobrovol'skij 2009, Lakoff/Johnson 1980, Langacker 2008, vgl. auch Kap. 2.3.5) Evidenz dafür liefern, dass es keine strikt getrennten Speicher für die literale und die figurative Sprache gibt. Vielmehr muss von kontinuierlichen Übergängen, fließenden Grenzen, möglichen Verzahnungen ausgegangen werden. Auf die Phraseologie übertragen relativieren diese Erkenntnisse die traditionelle Differenzierung zwischen der literalen und der phraseologisierten Lesart. Die literale Lesart ergibt sich nicht immer direkt aus der Addition der Grundbedeutungen von einzelnen Konstituenten (vgl. Kap. 2.1.4). In manchen Fällen ist die Bestimmung der Lesart erst unter Einbezug der kontextuellen Faktoren möglich (vgl. das Idiom jmdm. eine Falle stellen). Trotz dieser Relativität stellen die Termini der literalen und der phraseologisierten (lexikalisierten) Lesart aus methodologischer Perspektive relevante theoretische Konstrukte dar, die die wissenschaftliche Diskussion auf dem Gebiet der Idiomatik wesentlich erleichtern, indem sie den Skopus der jeweiligen Theorie auf einen bestimmten Bereich einschränken.

Die zahlreichen Umstrittigkeiten in der phraseologischen Forschungsliteratur der wissenschaftlichen Anfangsphase sind nämlich darauf zurückzuführen, dass die Anzahl und die Art der Beziehungen zwischen der literalen und der lexikalisierten Lesart und die sich daraus ergebende Heterogenität der Phraseologismen im engeren Sinne nicht genügend berücksichtigt worden sind. Demgegenüber liefert die neuere Forschung Evidenz dafür, dass bei Speicherungs- und Verarbeitungsprozessen von Idiomen wesentliche Unterschiede vorkommen: Während manche idiomatische Einheiten tatsächlich wie long words gespeichert und verarbeitet werden (z.B. gang und gäbe), kann die Verarbeitung von anderen (z.B. $j m d n$. in die Zange nehmen, jmdm. Steine in den Weg legen) aufgrund ihrer ausgeprägten Metaphorizität bis zu einem gewissen Grade wie bei Ad-hoc-Metaphern verlaufen. Die Quantität der festzustellenden Lesarten und die Beschaffenheit der Beziehungen zwischen ihnen übt einen wesentlichen Einfluss auf die semantischen Begebenheiten innerhalb der Idiomatik aus. Aus diesem Grunde scheint die von Burger (2010: 62-65) vorgeschlagene Eingliederung des Gesamtbereiches der Phraseologie nach der Anzahl der Lesarten in vier Bereiche einen guten Ausgangspunkt zur Festlegung der Erklärungsreichweite jeder einzelnen Theorie zu sein:

(i) Die erste Gruppe bilden die Phraseologismen, die nur eine Lesart aufweisen, und deswegen auf zwei Polen der Idiomatizitätsachse liegen. Über nur eine Lesart verfügen einerseits Phraseologismen, die nicht idiomatisch sind (Dank sagen, blondes Haar, den Tisch decken), andererseits gehören zu dieser Gruppe unmotivierte Idiome mit unikalen Komponenten, wie z.B. sich mausig machen, gang und gäbe, klipp und klar, Maulaffen feilhalten, etw. auf dem Kerbholz haben. Unter Einbezug der etymologischen Perspektive konstituieren diese Gruppe also die Idiome, bei denen (noch) keine Idiomatisierung stattgefunden hat, sowie die Idiome, bei denen die ursprünglich einmal da gewesene wörtliche Bedeutung verloren gegangen ist. 
(ii) Die umfangreichste Gruppe der Phraseologismen im engeren Sinne (Idiome) bilden die Phraseologismen mit zwei Lesarten, die sich disjunktiv zueinander verhalten. Mit disjunktiv meint Burger (2010: 63), dass die beiden Lesarten in der Regel nicht in den gleichen Kontexten vorkommen können. Diese Gruppe ist heterogen: Hierher gehören metaphorische Idiome, bei denen sowohl die literale als auch die phraseologisierte Lesart in einem Text vorkommen können (jmdm. Steine in den Weg legen, seinen Hut nehmen, das Handtuch werfen), Idiome mit zwei Lesarten, deren literale Lesart dennoch äußerst unwahrscheinlich (jmdm. eine Laus hinters Ohr setzen) oder in der realen Welt unmöglich ist (an jmdm. einen Narren gefressen haben, jmdm. das Herz ausschütten, jmdm. auf der Nase tanzen) sowie die Idiome, deren Lesarten aus synchroner Perspektive als Homonyme betrachtet werden können (jmdm. einen Korb geben).

(iii) $\mathrm{Zu}$ der dritten Gruppe gehören Kinegramme: die Phraseologismen mit zwei Lesarten, die simultan realisiert werden (können). Bei diesen Mehrworteinheiten handelt es sich um ein nonverbales Verhalten, das ausgeführt werden kann und seine sprachliche Kodierung (die Achseln zucken, die Stirn runzeln, den Kopf schütteln, mit der Faust auf den Tisch schlagen).

(iv) Gemischter Typ umfasst teil-idiomatische Phraseologismen: Manche Konstituenten kommen in der phraseologisierten, manche in der literalen Lesart vor. Beim Idiom aus vollem Halse lachen tritt lachen in der literalen, aus vollem Halse in der phraseologisierten Lesart auf.

Von dieser Einteilung ausgehend wird an dieser Stelle die Erklärungsreichweite der vorliegenden Arbeit abgegrenzt: Da die Phraseologismen in dem zusammengestellten Korpus zwei Lesarten aufweisen, die sich generell disjunktiv zueinander verhalten, wird die zweite Gruppe in den Fokus der Aufmerksamkeit gerückt. Die synchron feststellbare Koexistenz der literalen und phraseologisierten Lesart in dieser Idiom-Gruppe wird schematisch in Abb. 19 dargestellt.

Das Schema kann aus diachroner und aus synchroner Perspektive interpretiert werden. Primär ist jeweils die Verbindung vom Konzept ${ }_{1}$ zum Konzept $_{2}$, die meistens aufgrund der metaphorischen, metonymischen oder metaphtonymischen Derivationen zwischen dem Ausgangs- und Zielbereich und/oder durch die Einbeziehung einer symbolischen Komponente entsteht. Aus diachroner Perspektive ist davon auszugehen, dass auch opake Idiome wie z.B. den Löffel abgeben, kick the bucket oder nie zasypiać gruszek w popiele in der Vergangenheit eine (metaphorisch, metonymisch, intertextuell oder/und symbolisch) motivierte Verbindung zwischen der literalen und der phraseologisierten Lesart aufgewiesen haben, die heutzutage für die durchschnittlichen Sprecher nicht mehr nachvollziehbar ist. Dabei können die beiden Konzepte in einem Rückkopplungsgefüge stehen: Ein geläufiges, oft gebrauchtes Idiom trägt zur Bedeutungserweiterung seiner Konstituente(n) bei. Als Beispiel könnte an dieser Stelle die im Kap. 2.3.4.2.2 bereits erwähnte Bedeutungserweiterung des Adjektivs ,schwarz' angeführt werden, dessen metaphorische Teilbedeutung, illegal; ohne behördliche Genehmigung, ohne Berechtigung، 


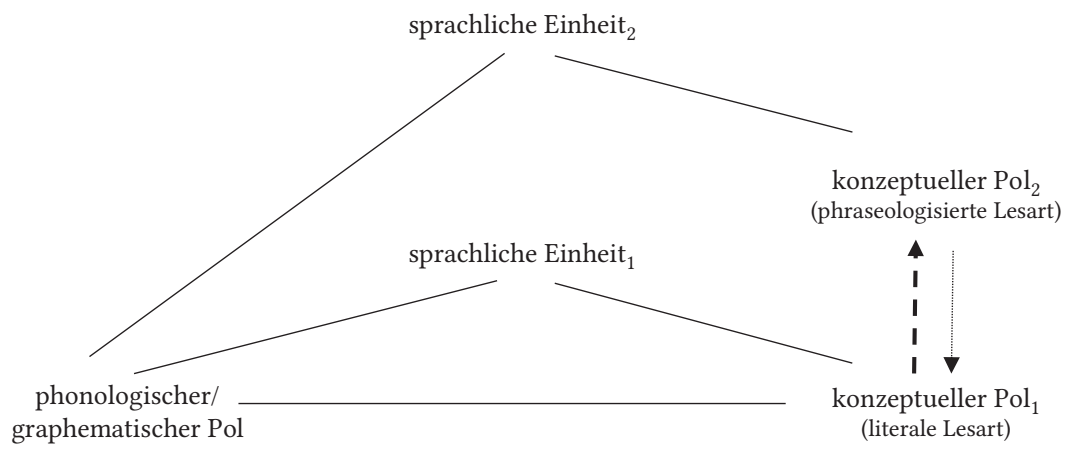

Abb. 19: Schematische Darstellung der Doppelbödigkeit der phraseologisierten Bedeutung.

(DUW online, Zugriff am 25.04.2017) möglicherweise durch Teilidiome: schwarze Geschäfte, etwas schwarz kaufen, schwarz über die Grenze gehen beeinflusst wird.

Im Laufe der Zeit kann es auch dazu kommen, dass die idiomatische Bedeutung die wörtliche Bedeutung verdrängt, so wie es z.B. bei der nominalen Konstituente der Idiome jmdn. in die Patsche reiten, in der Patsche sitzen, jmdm. aus der Patsche helfen der Fall ist. Die idiomatische Bedeutung der ,Patsche hat die wörtliche Bedeutung ersetzt, was sich in der lexikographischen Auffassung des Lexems ,Patsche ${ }^{\text {widerspiegelt }}{ }^{105}$ (andere Beispiele für die sog. Reidiomatisierung findet man bei Fleischer 1982: 39-41).

Aus synchroner Perspektive - und diese wird im Folgenden ins Zentrum des Interesses gerückt - bildet die mit Pfeilen gezeichnete Beziehung zwischen der literalen und der phraseologisierten Lesart, das Spannungsfeld zwischen dem Kon-

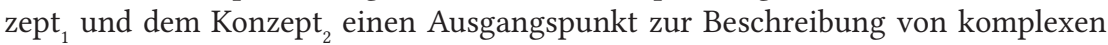
Phänomenen der Idiomatizität, Motiviertheit und Bildhaftigkeit, denen die folgenden Abschnitte gewidmet sind.

\subsection{Idiomatizität}

Traditionell wird die Idiomatizität mit Phraseologie in Verbindung gebracht und als „Asymmetrie zwischen Bezeichnetem und Bezeichnendem“ (Hessky 1992b: 82), „irreguläres Verhältnis“ (Fleischer 1997: 30), „Diskrepanz zwischen der phraseologischen Bedeutung und der wörtlichen Bedeutung des ganzen

105 Vgl. DUW 2007: Pạt|sche, die; -, -n [4: eigtl. = Matsch, aufgeweichte Straße] (ugs.): 1. Hand, 2. Feuerpatsche, 3. Patsch $\uparrow, 4 .<\mathrm{Pl}$. selten> unangenehme, schwierige Lage, Bedrängnis: jmdm. aus der P. helfen; in der P. sitzen. 
Ausdrucks" (Burger 2003: 31) definiert, die darauf beruht, dass sich die Bedeutung einer Mehrwortverbindung nicht aus den Bedeutungen ihrer Konstituenten zusammensetzt/ableiten lässt. In den letzten Jahrzehnten wurde das Idiomatizitätskonzept unter dem Einfluss der Pragmatik und der Kognitiven Linguistik dennoch deutlich erweitert: Heutzutage koexistieren in der Sprachwissenschaft mehrere Auffassungen der Idiomatizität, die diesem Phänomen z.T. extrem unterschiedliche Rollen in der Sprache zuschreiben: von einer Anomalie (die strukturelle Perspektive) bis hin zu einer übergreifenden, für ausgedehnte Sprachbereiche konstitutiven Regel (vgl. z.B. Taylor 2002: 669, Fillmore/ Kay/O’Connor 1988).

\subsubsection{Idiomatizität aus struktureller, pragmatischer und konstruktionsgrammatischer Perspektive}

Aus der strukturellen Perspektive hängt die Idiomatizität mit struktureller Festigkeit eines polylexikalen Ausdrucks zusammen und kommt in erster Linie in grammatischen Anomalien und transformationellen Defekten zum Vorschein (vgl. z.B. die Verstöße gegen die morphologisch-syntaktischen Regeln seinen Mann stehen, aller guter Dinge sind drei, poln. wyjść za kogoś za maż). So verstandene Idiomatizität ist relativ leicht operationalisierbar und kann mithilfe von z.B. Eliminierungs-, Substitutions- oder Permutationstests erfasst werden (vgl. Stöckl 2004: 171, Burger 2010: 28-29, vgl. auch Regularität vs. Defektivität des Paradigmas bei Dobrovol'skij, 1995a: 39, Kap. 3.2.2).

Eine wesentlich größere Rolle spielt die Idiomatizität in der pragmatisch ausgerichteten Sprachtheorie. Hier wird sie als Gebrauchsphänomen aufgefasst, das der Sprache als Ganzem zukommt: Es muss „zwangsläufig zu nicht voll motivierten Bedeutungen sowie zu semantischen Transformationen, Anomalien und Irregularitäten kommen, wenn sich polylexikale Ausdrücke in ihrer Verwendung verfestigen" (Stöckl 2004: 173), wobei sich der Festigungsprozess keinesfalls nur auf die Mehrwortverbindungen einschränkt. Feilke (1998: 74) verweist darauf, dass sich die Idiomatizität ebenfalls in Komposita manifestiert: Die Tatsache, dass unter dem Straßenhändler der Mann verstanden wird, der auf der Straße und nicht mit den Straßen Handel betreibt, lässt sich aus den kompositionellen Bedeutungen von Straße und Händler nicht ableiten; Ölverschmutzung kann sich auf die Verschmutzung von Öl oder durch Öl beziehen, die präferierte zweite Auslegung ist nur auf die Gebrauchsnorm zurückzuführen (Stöckl 2004: 174); als Wohnungstür wird die Eingangstür und nicht die - sich auch innerhalb der Wohnung befindende - Zimmertür bezeichnet. Zahlreiche sprachliche Ausdrücke sind in diesem Sinne idiomatisch geprägt (zum Begriff der ,idiomatischen Prägung vgl. Feilke 1998 sowie Kap. 1.2.1.3). Aus pragmatischer Perspektive wird die Idiomatizität also sehr weit als im usualisierten Gebrauch entstehende Verwendungsrestriktionen und Konnotationsspezifika aufgefasst (Stöckl 2004: 171-172). Dieser Ansicht schließt sich in Bezug auf die Phraseologismen auch Munske an, der behauptet: 
Meines Erachtens gibt es in strengem Sinne keine nicht-idiomatischen Phraseologismen, da diese im Zuge ihrer Phraseologisierung und Usualisierung stets idiomatische Züge annehmen. (Munske 2015 [1993]: 101)

Idiomatizität spielt ebenfalls eine grundlegende Rolle in der sich seit über 25 Jahren $^{106}$ intensiv entwickelnden, kognitiv ausgerichteten Konstruktionsgrammatik. Den Ausgangspunkt der Konstruktionsgrammatik ${ }^{107}$ bildet die Annahme, dass „Konstruktionen das Format sind, in dem Sprachwissen abgespeichert ist“ (Ziem/ Lasch 2013: 28) - der Schwerpunkt der Theorie liegt also auf der Ummodellierung der Auffassung von Grammatik sowie der Beziehung zwischen Grammatik und Lexikon. Unter Konstruktionen versteht Goldberg, eine der Begründer(innen) der Konstruktionsgrammatik, sehr weit sprachliche Einheiten verschiedenen Abstraktionsgrades, in denen sich ein Aspekt ihrer Form- und Inhaltsseite nicht kompositionell ermitteln lässt:

According to Construction Grammar, a distinct construction is defined to exist if one or more of its properties are not strictly predictable from knowledge or other constructions existing in the grammar: $\mathrm{C}$ is a construction if $\mathrm{C}$ is a form-meaning pair $<\mathrm{F}_{\mathrm{i}}$, $\mathrm{S}_{\mathrm{i}}>$ such that some aspect of $\mathrm{F}_{\mathrm{i}}$ or some aspects of $\mathrm{S}_{\mathrm{i}}$ is not strictly predictable from C's component parts or from other previously established constructions. (Goldberg 1995: 4)

Idiome, als nicht kompositionelle Wortverbindungen, stellen also Beispiele der Konstruktionen par excellence dar, als Konstruktionen gelten dennoch auch die nicht völlig kompositionellen Wortverbindungen, wie die bereits beschriebene Struktur der Ball unter dem Tisch sowie Derivations- und Flexionsmorpheme (-er in [groß-er], -ung in [Trau-ung]), Wörter, feste Mehrwortverbindungen (Guten Tag!), grammatische Phraseologismen (geschweige denn), schematische Idiome (Was macht $x y$ ? [Was macht die Fliege in meiner Suppe?]), Vergleichssätze (je x-er desto $y$-er) u.a. (vgl. Ziem/Lasch 2013: 19). Aus konstruktionsgrammatischer Perspektive wird die Idiomatiziät also sehr weit aufgefasst, was folgende Worte von Fillmore/ Kay/O'Connor veranschaulichen:

We think of a locution or manner of speaking as idiomatic if it is assigned an interpretation in the speech community but if somebody who merely knew the grammar and the vocabulary of a language could not, by virtue of that knowledge alone, know (i) how to say it, or (ii) what it means, or (iii) whether it is a conventional way to say. Put differently, an idiomatic expression or construction is something a

106 Als richtungsweisende Publikation, mit der die konstruktionsgrammatische Theoriebildung angefangen hatte, wird der 1988 veröffentlichte Artikel von Fillmore/ Kay/O'Connor zur englischen let-alone-Konstruktion angesehen.

107 Einen Überblick über den Forschungsstand sowie Beschreibung der einzelnen konstruktionsgrammatischen Ansätze findet man in Ziem/Lasch 2013, vgl. auch das Kap. 2.1.4. 
language user could fail to know while knowing everything else in the language. (Fillmore/Kay/O’Connor 1988: 506, Hervorhebungen von A. S.)

Eine derart weite Auffassung der Idiomatizität stellt eine vielversprechende Forschungsrichtung dar: Je intensiver und eingehender die Sprache im Gebrauch untersucht wird, desto deutlicher wird sichtbar, dass sich zahlreiche Konstruktionen nicht ausschließlich aus den Kernregeln der Grammatik ableiten lassen und die Sprache in wesentlich größerem Ausmaß aus vorgeformten, usualisierten Ausdrücken und Schablonen zusammengebaut ist, als man früher angenommen hat (Jackendoff 1997, Stein 1995, Stubbs 2002, Taylor 2007). Da die so weit verstandene Idiomatizität die Grenzen der Phraseologie enorm erweitern und den Rahmen dieser Untersuchung sprengen würde, werden im Folgenden diejenigen Wortverbindungen in den Fokus der Aufmerksamkeit gerückt, die man traditionellerweise als Idiome bezeichnet, also feste, polylexikale Wortverbindungen, deren Bedeutungen sich nicht von ihren Komponenten ableiten lassen.

\subsubsection{Idiomatizität in der Phraseologie - Versuche der Parametrisierung}

Idiomatizität stellt in der Phraseologie ein Kriterium dar, das sich von dem intuitiven, impliziten Wissen ausgehend leicht einsetzen lässt, aus der wissenschaftlichen Perspektive dennoch schwer operationalisierbar ist. Dementsprechend können kompetente Sprachteilhaber problemlos entscheiden, ob eine Wortverbindung idiomatisch ist, die Zusammenstellung einer vollständigen Parameterliste, mit denen man den Idiomatizitätsgrad einer Mehrwortverbindung intersubjektiv auffassen könnte, ist aber trotz der intensiven Beschäftigung mit dem Thema insbesondere in der sog. wissenschaftlichen Anfangsphase der phraseologischen Forschung (vgl. Kühn 2007, vgl. Kap. 1.1) nicht gelungen. Deswegen wird die Idiomatizität in der Phraseologie als ein Bündel klassenbildender Eigenschaften definiert, die man sehr weit als (i) Irregularität (Burger/Buhofer/Sialm 1982: 1, Burger 2007a, 2010: 29; Fleischer 1982: 35; Lewicki/Pajdzińska 2001: 315) und/oder (ii) Non-Kompositionalität der Bedeutung (Böhmer 1997: 1, Palm 1997: 8, Roos 2001: 9) erfasst.

Erwähnungswerte Versuche, die Irregularität der Idiome durch die Festlegung von intersubjektiv gültigen Parametern eindeutiger zu beschreiben, haben Dobrovol'skij (1995a: 27-45) und Lewicki (2003) vorgenommen.

Lewicki (2003) versucht, dem Terminus ,Idiomatizität' genauere Konturen angedeihen zu lassen, indem er die Idiomatizität nicht nur als Irregularität, sondern auch als Unkategorialität der Bedeutung definiert. Unter Regularität versteht Lewicki die Situation, in der die Bedeutung einer Wortverbindung sich aus der Verbindung der Bedeutungen ihrer Komponenten ergibt: der hölzerne Tisch ist dementsprechend im Gegenteil zu dem Runden Tisch (als Bezeichnung der gleichberechtigten Sitzordnung bei einer Konferenz und insbesondere als Bezeichnung für die 1989 stattgefundenen Gespräche zwischen den Vertretern der Polnischen 
Vereinigten Arbeiterpartei (PZPN), der oppositionellen Gewerkschaft Solidarność und der katholischen Kirche, die zum friedlichen Übergang vom Sozialismus zur Demokratie in Polen geführt haben) regulär. Einen anderen Indikator der Idiomatizität macht für Lewicki die sog. Kategorialität (poln. kategorialnośc) aus, d.h. solche Übereinstimmung einer Wortverbindung mit dem Sprachsystem, dass jede Komponente in derselben Bedeutung in anderen sinnvollen Wortverbindungen gebraucht werden kann, während die Wortverbindung den sprachlichen Regeln entspricht $^{108}$. Die Wortverbindung eine wilde Gegend ${ }^{109}$ ist somit kategorial, weil man beide Komponenten in den Bedeutungen: wild ,nicht kultiviert, im natürlichen Zustand befindlich'; Gegend ,ein Gebiet' auch in anderen Wortverbindungen gebrauchen kann, z.B.: ein wildes Tier, eine vornehme Gegend. Demgegenüber weist die Wortverbindung wilde Ehe keine Kategorialität auf, weil die Komponente wild in der Bedeutung ,nicht standesamtlich oder kirchlich getraut" nur in dieser Wortverbindung auftritt.

Die Kategorialität trägt in manchen Fällen zur Präzisierung des Idiomatizitätsbegriffes bei, nichtsdestoweniger muss hervorgehoben werden, dass sie als Kriterium der Phraseologizität umstritten ist ${ }^{110}$. Kategorialität stellt ein relatives Kriterium dar: Es sind zahlreiche Mehrwortverbindungen anzutreffen, in denen eine phraseologische Komponente ihre wendungsspezifische figurative Bedeutung mit anderen Komposita oder Mehrwortverbindungen teilt. Den festen Mehrwortverbindungen: schwarze Geschäfte ,illegale Geschäfte', etw. schwarz kaufen ,etw. auf dem Schwarzmarkt kaufen, illegal kaufen', etw. schwarz tun, etw. ohne Genehmigung tun' käme dann solange der Status von Idiomen zu, wie lange man die Bedeutung von schwarz als ,illegal' nicht als übertragene Bedeutungserweiterung des Adjektivs schwarz anerkennt. Die Übergänge zwischen dem Literalen und dem Übertragenen sind dennoch - wie bereits in den Kapiteln 2.3.4.4, 2.3.5 erörtert - fließend; diese Entscheidung ist deswegen wenigstens teilweise idiosynkratisch und beruht auf individueller Spracherfahrung und der Geläufigkeit der angeführten Wortverbindungen. Wie Dobrovol'skij bemerkt: „Je größer das

108 „Kategorialność: taka zgodność z systemem językowym, że każdy z komponentów może być w tym samym znaczeniu użyty w innych sensownych połączeniach, a samo połączenie jest zgodne z regułami języka" [Kategorialität: solche Übereinstimmung mit dem Sprachsystem, dass jede Komponente in derselben Bedeutung in anderen sinnvollen Wortverbindungen gebraucht werden kann und die Verbindung selbst mit den Sprachregeln im Einklang steht]. (Lewicki 2003: 160, übers. von A. S.)

109 Im Original bedient sich Lewicki bei der Darstellung der Nicht-Kategorialität eines Phraseologismus der Wortverbindung złodziej kieszonkowy (dt. ,Taschendieb'), die die fürs Polnische größte Gruppe der sog. hyperonymischen Phraseologismen repräsentiert. Da das deutsche Äquivalent Taschendieb als Kompositum nicht zum Bereich der Phraseologie gerechnet wird, wird das Merkmal der Nichtkategorialität mit dem teilidiomatischen Phraseologismus wilde Ehe veranschaulicht.

110 Vgl. die Diskussion von Fleischers (1982: 38) Beispiel blinder Passagier in Munske (2015 [1993]: 99). 
Lexikon, je mehr Elemente mit metaphorischer, bildlicher, abgeleiteter Bedeutung es enthält, desto seltener entsteht die Notwendigkeit, die Kombinationen dieser Elemente als irregulär und idiomatisch zu beschreiben" (Dobrovol'skij 1995a: 28).

Die von Dobrovol'skij (1995a) zusammengestellte Liste umfasst 12 Irregularitätsmerkmale und gibt somit einen Überblick über die Vielfalt der Faktoren, die Idiomatizität in der Phraseologie konstituieren. Der Autor unterstreicht dabei nachdrücklich, dass auch so eingehende Zusammenstellung keinen Anspruch auf Vollständigkeit erhebt. Dobrovol'skij strebt mit seinen Parametern keine binären Oppositionen zwischen den Idiomen und Nicht-Idiomen an, er setzt ein graduelles Verhältnis vom Typus: „gutes Idiom“- „weniger gutes Idiom“ - „noch schlechteres Idiom“ - „immer noch Idiom“ - „eher fast nicht mehr Idiom“ voraus:

Man kann von einer stärkeren bzw. schwächeren Irregularität der Phraseologismen sprechen und dementsprechend von einer stärkeren bzw. schwächeren Legitimation ihrer Zuordnung zur Kategorie der Idiome. Das basiert auf dem universellen Prinzip der Strukturierung sprachlicher Kategorien, die dadurch bedingt ist, dass die Sprache die indiskrete Welt mit diskreten Mitteln beschreibt. Das Graduierungsprinzip der kategorialen Mitgliedschaft bezieht sich also nicht nur auf die Idiomatik, sondern auch auf die Organisation des mentalen Lexikons. (Dobrovol'skij 1995a: 28)

Die von Dobrovol'skij unterschiedenen Irregularitätsmerkmale könnte man zur besseren Veranschaulichung als entgegengesetzte Pole auf einer Achse anordnen (vgl. Abb. 20). Die links platzierten Merkmale verweisen generell auf die "schwächere“ Irregularität als Merkmale, die auf dem rechten Pol der Achse angesiedelt sind:

Irregularitätsachse

kompositionell
Isomorphie zw. formaler und semantischer
Struktur
komplex
durchlässig
Variabilität des Konstituentenbestandes
konnotativ-pragmatisch neutral
formal neutral
konventionelle Konstituenten
reguläres Paradigma
semantisch kompatibel
zwei Lesarten
motiviert

nicht-kompositionell Allomorphie simplex undurchlässig Fixiertheit des Konstituentenbestandes konnotativ-pragmatisch markiert formal markiert (z.B. Stabreime) unikale Konstituenten defektes Paradigma semantisch inkompatibel eine Lesart opak

Abb. 20: Liste der Irregularitätsmerkmale nach Dobrovol'skij 1995a (zusammengestellt und bearbeitet von A. S.).

Die ersten vier Parameter sind eng miteinander verbunden und hängen mit der Dekompositionalitätshypothese zusammen: 
(i) Kompositionalität vs. Nonkompositionalität der Bedeutung

Dieser bereits an mehreren Stellen erwähnte Parameter repräsentiert ein Basismerkmal der Idiomatizität, das von der Seite der Sprachproduktion beschrieben wird. Generell lässt sich feststellen, dass die Einheiten, die zum non-kompositionellen Pol der Irregularitätsachse tendieren wie z.B. ins Gras beißen, bessere Vertreter der Kategorie der Idiome sind, als mehr oder weniger kompositionellen Einheiten (z.B. einen Haken haben, keinen Bock auf etw. haben).

(ii) Isomorphie vs. Allomorphie zwischen der formalen und der semantischen Struktur

Im Gegensatz zu dem Parameterpaar Kompositionalität vs. Nichtkompositionalität der Bedeutung werden bei den Parametern Isomorphie vs. Allomorphie zwischen der formalen und semantischen Struktur rezeptive, in der Dekompositionalitätshypothese zur Sprache gebrachten Aspekte in den Mittelpunkt der Aufmerksamkeit gerückt. Hier handelt es sich nicht um die Frage, ob Idiome auf die Weise wie Lexeme aus dem mentalen Lexikon abgerufen werden, sondern darum, ob sie rezeptiv als teilbar (composable) oder unteilbar (decomposable) empfunden werden. Die formal-semantische Gliederung des Idioms: den Wald vor lauter Bäumen nicht sehen ist möglich, nachträglich kann den einzelnen Konstituenten auch eine isomorphe Bedeutungsbeschreibung zugewiesen werden: den Wald (,das große Ganze') vor lauter Bäumen (,vor lauter Einzelheiten') nicht sehen (,nicht erkennen'). Dementsprechend weist dieses Idiom einen schwächeren Idiomatizitätsgrad auf als das nicht teilbare Idiom Haare spalten, dem keine isomorphe Bedeutungsparaphrase entspricht.

(iii) Semantische Komplexität vs. semantische Simplizität

Dieses Kriterium geht auf die von Cruse vorgeschlagene Definition zurück: „An idiom may be briefly characterized as a lexical complex which is semantically simplex" (1986: 37). Dementsprechend sind die Idiome, die man anhand eines EinWort-Identifikators paraphrasieren kann, z.B. jmdn. übers Ohr hauen ,betrügen“, den Löffel abgeben ,sterben' bessere Vertreter der Kategorie als Idiome, die derartige Bedeutungsbeschreibung nicht zulassen, z.B. jmdm. fällt die Decke auf den Kopf ,jd. langweilt sich zu Hause', zwei Fliegen mit einer Klappe schlagen ,einen doppelten Zweck auf einmal erreichen'. Dobrovol'skij präzisiert dieses Kriterium, indem er als Simplizia ausschließlich diejenigen Lexikoneinheiten qualifiziert, deren semantische Struktur sich auf ein Konzept der Basisebene (im Sinne von Rosch 1973, 1975, vgl. auch das Kap. 3.4) reduzieren lässt.

(iv) Syntaktische Durchlässigkeit vs. Undurchlässigkeit

Semantische Gegebenheiten üben einen wesentlichen Einfluss auf das syntaktische Verhalten von Idiomen aus: Non-kompositionale, unteilbare Idiome mit einer kompakten semantischen Struktur wie den Löffel abgeben oder ins Gras beißen lassen keine Einschübe wie *den alten Löffel abgeben oder *ins frische Gras beißen zu. 
Im Gegensatz dazu sind bei teilbaren, kompositionellen Idiomen generell Negationen, Qualifizierungen, Quantifizierungen von ihren Konstituenten möglich, vgl.:

Einen kleinen Haken hat die Untersuchungsmethode. Die Zeit, 19.04.2012 (DWDS, Zugriff am 15.03.2016)

Man könnte sich über diese Absicht noch mehr freuen, wenn die Sache nicht einen erheblichen Haken hätte. Die Zeit, 19.08.1948 (DWDS, Zugriff am 15.03.2016)

Syntaktisch undurchlässige Idiome sind damit irregulärer und weisen höhere Idiomatizität als syntaktisch „poröse“ Phraseologismen im engeren Sinne auf.

(v) Variabilität vs. Fixiertheit des Konstituentenbestandes

Als Varianten definiert Dobrovol'skij (1995a: 34) alle Idiome, die nach dem strukturellen und lexikalischen Aspekt einander völlig oder teilweise gleichen und dabei eine gleiche bildliche Grundlage haben. Zu den Idiom-Varianten zählen die Modifikationen desselben Idioms (Formenbildung) als auch verschiedene Idiome, die nach der Struktur, dem lexikalischen Bestand und der Bedeutung zusammenfallen bzw. korrelieren und die gleiche bildliche Grundlage haben (phraseologische Derivation).

Der idiomatischen Variabilität liegt eine Reihe der Operationen zugrunde, z.B.: Modifikationen in der Aktionsart bzw. Transitivität: auf dem Spiel stehen etw. aufs Spiel setzen; Antonyme: gute Karten haben - schlechte Karten haben; Synonyme mit unterschiedlichen pragmatischen Parametern: jmdm. in den Hintern kriechen - jmdm. in den Arm kriechen. Nach Dobrovol'skij schwächen die Varianten die Stabilität und dadurch die Idiomatizität ab: Je mehr Varianten ein Idiom aufweist, desto weniger idiomatisch ist es (ebd.).

(vi) Konnotativ-pragmatische Extension der Idiom-Bedeutung

Unter konnotativ-pragmatischer Extension der Idiom-Bedeutung versteht Dobrovol'skij (1995a: 35) „ein Zusammenspiel expressiver Charakteristika, die den Idiomen traditionell als immanente Merkmale zugeschrieben werden“. Die Idiomatizität geht oft - im Gegensatz zur normalen Ausdrucksweise - mit Bildhaftigkeit, Emotivität und stilistischer Markiertheit einher, die als starkes und kognitiv reales Irregularitätsmerkmal angesehen werden können. Phraseologismen: eine Rolle spielen, etw. in Kauf nehmen sind somit regelmäßiger als expressiv stark ausgeprägte Idiome wie jmdm. in den Arsch kriechen, sich die Füße nach etw. wund laufen.

(vii) Formale Spezifikation: neutral vs. markiert

Dieser Idiomatizitätsparameter bezieht sich auf die von Jakobson postulierte poetische Funktion der Sprache. Die ästhetische Markiertheit ist besonders gut bei den Zwillingsformeln sichtbar, die man traditionell aufgrund ihrer rhetorisch-ästhetischen Merkmale, die mittels z.B. End- oder Stabreimes: (mit) Sack und Pack; (unter) Dach und Fach, mit Ach und Krach, außer Rand und Band, poln. chtopek roztropek (vgl. Rytel 1988: 178) oder der Alliteration: mit allem Drum und Dran, auf Biegen und Brechen erzielt werden, als Idiome qualifiziert. 
(viii) Konstituentenbestand: konventionelle Lexikoneinheiten vs. unikale Konstituenten

Als starkes Irregularitätsmerkmal wird ebenfalls das Vorkommen von unikalen Konstituenten - auch fossile Lexeme (Roos 2001), erstarrte Komponenten (Schippan 1975), Nekrotismen (Telija 1975, Pociask 2007) genannt - angesehen. Aus der sprachökonomischen Perspektive ist es nämlich effizienter, die Einheiten wie: bei $j m d m$. ins Fettnäpfchen treten, jmdm. Paroli bieten, im Handumdrehen als Ganzes zu speichern, was die Irregularität der Konstruktion erhöht. Die Anwesenheit einer unikalen Komponente stellt dennoch kein notwendiges oder ausreichendes Merkmal der Zugehörigkeit einer Einheit zur Kategorie der Idiome, weil es auch nicht idiomatische Phraseologismen mit unikalen Komponenten gibt, vgl. in Anbetracht, mit Betreff, nach meinem Dafürhalten (Dobrovol'skij 1995a: 37).

(ix) Regularität vs. Defektivität des Paradigmas (vgl. die strukturelle Idiomatizität)

Zahlreiche Idiome sind durch ein defektes Paradigma gekennzeichnet, was bedeutet, dass sie Restriktionen in der Bildung mancher grammatischen Kategorien aufweisen, z.B.:

Restriktionen in der Bildung der Tempora:

jmdm. den Kopf waschen

Er hat ihm den Kopf gewaschen

*Er wäscht ihm den Kopf (Präsens in der phraseologisierten Lesart unmöglich)

Poln. spadać $z$ byka

$Z$ byka spadłeś (Vergangenheitsform)

Z byka spadasz (Präsens in der phraseologisierten Lesart unmöglich) (vgl. Lewicki 2003).

Restriktionen in der Passivbildung:

Engl. She lost her head.

${ }^{*}$ Her head was lost.

Restriktionen in der Bildung der Pluralform:

etw. ist kalter Kaffee

Das ist kalter Kaffee.

*Das sind kalte Kaffees. (Burger 2010: 21-22)

Die Defektivität eines Paradigmas zwingt den Sprachbenutzer dazu, sich die zulässigen Formen zu merken, und stellt damit ein zusätzliches Irregularitätsmerkmal auf: Je mehr Restriktionen ein Idiom aufweist, desto stärker irregulär ist es (Dobrovol'skij 1995a: 39).

(x) Semantische Kompatibilität vs. Inkompatibilität der Konstituenten

Dieses Kriterium bezieht sich auf die Kompatibilität der Konstituenten in der literalen Lesart. Bei manchen Idiomen, wie bei dem bereits erwähnten Idiom jmdm. den Kopf waschen vertragen sich die Komponenten semantisch gut. Die literalen Lesarten 
anderer Idiome, z.B. Haare auf den Zähnen haben, Ich fresse einen Besen, wenn ..., poln. nie zasypiać gruszek $w$ popiele stellen dagegen normwidrige Wortverbindungen dar und können als semantische Anomalien betrachtet werden. Die semantische Inkompatibilität der Konstituenten steigert die Absurdität des evozierten mentalen Bildes, den expressiven Wert sowie die Irregularität einer Wortverbindung.

(xi) Semantische Ambiguität: eine Lesart vs. zwei Lesarten

Der zu besprechende Parameter ist aufs Engste mit der semantischen Kompatibilität vs. Inkompatibilität der Konstituenten in der literalen Lesart verbunden, die Notwendigkeit der Auseinanderhaltung beider Kriterien begründet Dobrovol'skij (1995a: 40) folgendermaßen:

Der Unterschied zwischen ihnen besteht darin, dass die semantische Ambiguität des Idioms aufgrund der Referenzregeln und des Usus bestimmt wird, während die semantische Kompatibilität von den Produktionsregeln von syntagmatischen Ketten abhängt und somit schon auf der Ebene der Oberflächenstruktur in Erscheinung tritt. (Dobrovol'skij 1995a: 140)

Auch wenn diese Begründung diskutabel scheint ${ }^{111}$, so ist doch Dobrovol'skij zuzustimmen, dass die Idiome, die nur die idiomatische (phraseologisierte) Lesart zulassen, wie z.B. zwei linke Hände haben, jmdm. einen Bären aufbinden, auf der faulen Haut liegen, eine höhere Irregularität aufweisen als Idiome, die sowohl literal als auch figurativ interpretiert werden können, z.B. ins Wasser fallen, den Gürtel enger schnallen (müssen).

(xii) Motiviertheit vs. Opakheit

Das letzte, sehr relevante Kriterium ist eng an die phraseologische Motiviertheit/ Motivierbarkeit gebunden, auf die noch detailliert eingegangen wird. Als opake Idiome werden feste Mehrwortverbindungen bezeichnet, deren innere Logik für einen Sprecher nicht nachvollziehbar ist. Mit großer Wahrscheinlichkeit werden die Idiome: engl. by and large, dt. den Löffel abgeben, poln. kopnąć w kalendarz von den meisten Sprachbenutzern als opak empfunden. Im Gegensatz dazu sind motivierte Idiome für einen Sprecher nachträglich interpretierbar, d.h., eine mehr oder weniger plausible Erklärung, warum dem Idiom eine bestimmte Bedeutung zugewiesen wird, liegt nahe. Somit ist die Differenzierung zwischen den motivierten und opaken Idiomen subjektiv und von dem jeweiligen Alltags- und Bildungswissen abhängig. Dessen ungeachtet kann man doch die Opakheit als einen

111 Das Idiom: Ich fresse einen Besen, wenn... führt Dobrovol'skij als ein Beispiel für die Inkompatibilität, das Idiom: auf glühenden Kohlen sitzen als ein Beispiel für die semantische Ambiguität heran. Wo der Usus die semantische Kompatibilität bestimmt und wo es die Produktionsregeln sind, scheint vor diesem Hintergrund nicht klar zu sein. Im Lichte des stark ausgeprägten Interaktionismus im holistischen Ansatz der Kognitiven Linguistik müsste man des Weiteren fragen, ob solche Differenzierung im Allgemeinen legitimiert ist. 
Irregularitätsfaktor qualifizieren: Wenn man eine Wortverbindung nicht erklären kann, speichert man sie als Ganzheit; wenn man dagegen die innere Logik der Wortverbindung nachvollziehen kann, empfindet man sie als eine mehr oder weniger reguläre Kombination von Wörtern (Dobrovol'skij 1995a: 44-45).

Dobrovol'skijs Parameterliste veranschaulicht zweifelsohne die Komplexität der phraseologischen Idiomatizität und die Vielfalt der Perspektiven, aus denen sie erfasst werden kann. Ob man mit ihrer Hilfe intersubjektiv und präzise festlegen kann, welche feste Mehrwortverbindungen idiomatischer als die anderen sind, bleibt dennoch fraglich.

\subsubsection{Zwischenbilanz}

Das Idiomatizitätskonzept ist sehr facettenreich und kann unter Einbezug vieler Parameter gedeutet werden. In grober Vereinfachung kann die Idiomatizität auf zwei Weisen aufgefasst werden:

Zum einen wird darunter sehr weit Irregularität in der Sprache aufgefasst, d.h. syntaktische, semantische und pragmatische Abweichungen, die sich mit den grammatischen Regeln und semantischen Grundvoraussetzungen (Homogenitätsprämisse und Kompositionalitätsthese ${ }^{112}$ der Satzsemantik) nicht erklären lassen. Die Untersuchung der Irregularität bedarf immer eines Bezugspunktes: Um festlegen zu können, dass etwas irregulär ist, muss man über einen regulären Ausgangspunkt verfügen. Da die Omnipräsenz des Regulären in der Sprache seitens kognitiver und pragmalinguistischer Ansätze in den letzten Jahrzehnten stark relativiert wird, wird der Idiomatizität ein immer größerer Stellenwert eingeräumt, was den traditionellen Objektbereich der Phraseologie sehr wesentlich aufweicht.

Zum anderen kann die Idiomatizität auf syntaktische (z.B. na chybit trafit, auf gut Glück) oder semantische Eigenschaft der Phraseologismen eingeengt werden, wo man sie als Irregularität und Non-Kompositionalität der Bedeutung von Mehrwortausdrücken (aus synchroner Perspektive) begreift. Diese Auffassung der Idiomatizität ist in der Phraseologie weit verbreitet (Palm 1997: 8, Roos 2001: 9, Burger 2015: 14-15) und wird von Böhmer explizit wie folgt definiert:

Der Ausdruck ist idiomatisch, d.h. er bezieht sich unmittelbar auf eine Bedeutung, die sich nicht aus den Wörtern, aus denen er besteht, aufgrund der Hierarchie der grammatischen Beziehungen dieser Wörter zueinander konstituieren lässt (Nicht-Kompositionalität), sondern dem Ausdruck nur als ganzem zukommt. (Böhmer 1997: 1)

112 Als zwei grundlegende Annahmen der klassischen Bedeutungslehre gelten: die Homogenitätsprämisse, laut derer mit „Bedeutung“ überall da, wo man diesen Begriff anwendet, dasselbe gemeint wäre und die Kompositionalitätsthese, der die Annahme zugrunde liegt, dass das Verstehen einer Satzbedeutung auf dem Verstehen aller Bedeutungen der einzelnen Wörter beruht (Busse 2009: 111-112, zur Kompositionalität vgl. auch Kap. 2.1.4). 
Auch diese auf semantische Aspekte fokussierte Auffassung müsste man dennoch relativieren: Erstens gilt die erwähnte Abschwächung der Rolle des Fregeschen Kompositionalitätsprinzips als allgemeingültigen Sprachprinzips unter dem Einfluss pragmatischer, kognitiver und konstruktionsgrammatischer Forschung auch für literale Lesart der Phraseologismen. Zweitens stellen die korpusbasierten Untersuchungen die vorausgesetzte Festigkeit der Idiome und somit den Terminus der Global- oder Gesamtbedeutung teilweise infrage:

Corpora (...) show overwhelming evidence of the instability of the forms of phrasal lexemes, and the frequent indeterminacy of their lexical elements. (Moon 1998b: 92)

Viele Phraseologismen im engeren Sinne sind weder bezüglich ihrer Struktur noch bezüglich der daran gebundenen Gesamtbedeutung so monolithisch und unveränderbar, wie man es früher anzunehmen pflegte: Im Sprachgebrauch werden Idiome verhältnismäßig oft erweitert, gekürzt oder modifiziert, flexibel und kreativ verwendet, sodass man annehmen dürfte, dass sie wenigstens zum Teil auf manipulierbaren kognitiven Strukturen basieren und nicht als starre long words betrachtet werden können (Błachut 2004, Pociask 2007, Ptashnyk 2009, Sabban 2014). Drittens, und diese Erkenntnis ist an dieser Stelle betonenswert, steht die Idiomatizität als semantische Non-Kompositionalität idiomatischer Einheiten in ihrer starken Ausprägung im Widerspruch zur idiomatischen Motiviertheit. Die Anzahl der Idiome, auf die die Definition von Cruse (1986: 37) „an expression whose meaning cannot be inferred from the meanings of its parts" bedingungslos zutrifft, ist im Grunde genommen klein und auf opake Idiome eingeschränkt. Bei den meisten - vor allem metaphorisch und metonymisch motivierten - Idiomen haben die kompetenten Sprachteilhaber eine mehr oder weniger einleuchtende Ahnung, was ein Idiom bedeuten könnte und sind imstande, diese Bedeutung selbst bei unbekannten Idiomen unter Einbezug der ko- und kontextuellen Gegebenheiten zu konstruieren.

Idiomatizität stellt somit ein Bündel von Eigenschaften dar, die sich in unterschiedlicher Ausprägung und in unterschiedlichen Kombinationen manifestieren können: Dieser Begriff ist auch in der engeren, für die Phraseologie üblichen Auffassung immer noch diffus und „schillernd” (vgl. Munske 2015 [1993]: 93). Er stellt fest, dass einer Wortverbindung aus semantischer Perspektive ein besonderer Status im Lexikon zukommt, dass sie etwas Besonderes darstellt, ohne dennoch Näheres zu dieser Spezifik zu sagen. Obwohl dies die Aussagekraft der Idiomatizität als Klassifikationskriteriums abmindert, so ist es hervorzuheben, dass in einem so heterogenen Bereich wie die Phraseologie auch derart generelle und dadurch vage Begriffe vom theoretischen Wert sind, weil sie den Forschungsgegenstand wenigstens annährend konturieren lassen. Bereits 1982 bemerkt Fleischer zu Recht:

Alle noch so objektiv erscheinenden Klassifikationskriterien verlangen bei ihrer Anwendung auf das Material der Sprache Entscheidungen, die an bestimmten Stellen nicht eindeutig zugunsten des einen oder anderen Faktors getroffen werden können (Fleischer 1982: 41). „Das bedeutet nicht Ungenauigkeit des Resultats, 
sondern adäquate Beschreibung der Zwischenstellung “ eben der betreffenden sprachlichen Erscheinungen. (Fix 1974-76, 306, zit. nach Fleischer 1982: 41)

\subsection{Motiviertheit der Idiome}

Motivation weist in der Sprachwissenschaft verschiedene Bedeutungen auf, je nachdem, ob man sie der Arbitrarität oder der Idiomatizität gegenüberstellt. Setzt man sie in Opposition zu der Arbitrarität im Sinne von de Saussure, dann wird sie als Beziehung zwischen Inhalts- und Ausdrucksseite sprachlicher Zeichen verstanden, so wie sie beispielshalber in den Onomatopoetika zur Geltung kommt. Wird sie in Opposition zur Idiomatizität betrachtet, dann stellen Idiomatizität (verstanden als Unableitbarkeit der Bedeutung eines Idioms aus den Bedeutungen seiner Konstituenten) und Motivation/Motiviertheit/Motivierbarkeit zwei komplementäre Erscheinungen dar, die sich gegenseitig bedingen. Im Folgenden wird ausschließlich auf die zweite phraseologierelevante Perspektive eingegangen: Motivation in erster Bedeutung tritt in der Phraseologie nur bei der sog. indexalen Motiviertheit auf und bezieht sich auf wenige Idiome, vgl. die Typologie der phraseologischen Motiviertheit von Dobrovol'skij (2001, 2007) und Dobrovol'skij/Piirainen (2009).

Die traditionelle Auffassung, die auch heutzutage als ein angesichts der Komplexität und Vielfalt der als Idiome bezeichneten Phänomene notwendiger Konsens akzeptiert wird (Burger/Dobrovol'skij/Kühn/Norrick 2007), erkennt die Polylexikalität, Stabilität und Idiomatizität als primäre Eigenschaften der Phraseologismen im engeren Sinne an, während die Motiviertheit/Motivierbarkeit, Bildhaftigkeit und Expressivität als intersubjektiv schwer fassbare Phänomene ${ }^{113}$ für sekundäre Indikatoren der Phraseologizität gehalten werden (vgl. Fleischer 1982: 72, Worbs 1998: 261, Ptashnyk 2009: 19-29). Diese Auffassung lässt außer Acht, dass die absolute Idiomatizität - als Unableitbarkeit der Gesamtbedeutung einer Wortverbindung aus den Bedeutungen ihrer Konstituenten verstanden - in der reinen Form selten vorkommt. Sogar hinsichtlich ihres Realitätsbezugs grotesk und skurril anmutende Phraseologismen erscheinen häufig aus einer volksetymologischen ${ }^{114}$ bzw. individuellen

113 Zahlreiche Linguisten (Häusermann 1977: 22, Gläser 1986: 168-169, Rothkegel 1973: 45) lehnen die Motivation/die Motiviertheit als ein Klassifikationskriterium wegen der Subjektivität ab (vgl. auch die Diskussion in Chrissou 2000: 24-25). Auf der anderen Seite ist es anzumerken, dass die Motivation das Hauptkriterium der Idiom-Klassifikation von Vinogradov - einem der Begründer der europäischen Phraseologie bildete. Vinogradov (1947, zit. nach Roos 2001: 23-24) teilte die phraseologischen Einheiten in drei Klassen ein: völlig demotivierte phraseologische Zusammenbildungen (vollidiomatische Wortverbindungen wie red tape ,Bürokratismus'), motivierte phraseologische Einheiten (z.B. den Gürtel enger schnallen, sich einschränken, sparen'), sowie feste, dennoch kaum idiomatische phraseologische Verbindungen (z.B. to take a liking to $s b$, ,jmdn. gern mögen').

114 Unter Volksetymologie versteht man eine „volkstümliche Verdeutlichung eines nicht [mehr] verstandenen Wortes oder Wortteiles durch lautliche Umgestaltung unter 
Perspektive nicht gänzlich unmotiviert (Chrissou 2000: 24). Bei den meisten Idiomen besteht zwischen der literalen und der phraseologisierten Lesart eine für den Sprachrezipienten mehr oder weniger nachvollziehbare Verbindung.

Motivation means that this connection is not entirely arbitrary and conventional, but that the native speaker can see a direct connection between the structure of the lexical unit and its meaning. (Coates 1964: 1048)

Diese Verbindung - als Motivation, Motiviertheit oder Motivierbarkeit bezeichnet - bildet einen Gegenpol zur Idiomatizität, die beiden Kriterien ergänzen sich komplementär, sie sind „umgekehrt proportional“ (Gläser 1980: 164): Je größer die Motiviertheit, desto weniger idiomatisch ist ein Idiom, was das folgende Schema (Abb. 21) veranschaulicht:
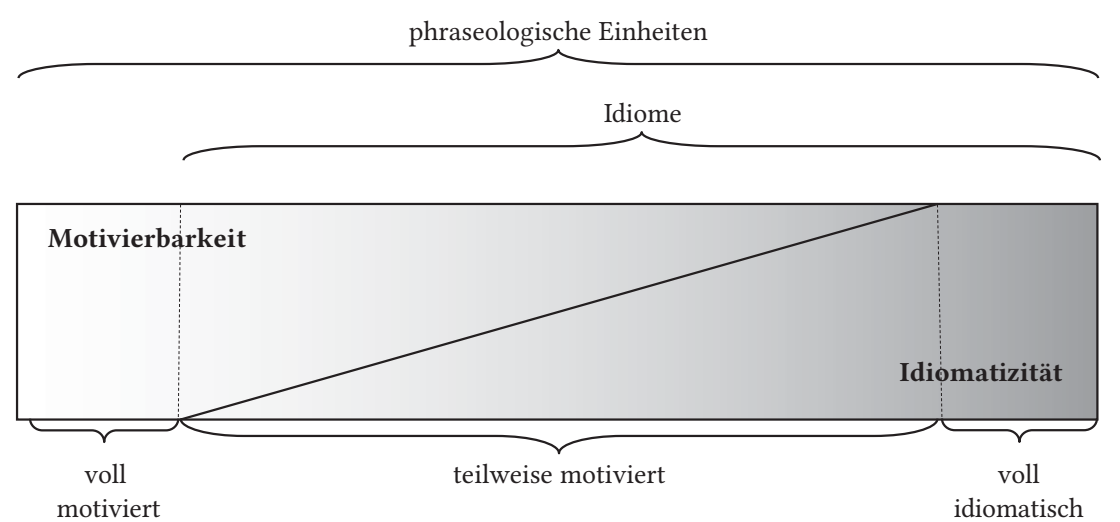

Abb. 21: Das komplementäre Verhältnis zwischen der Motiviertheit und Idiomatizität (Roos 2001: 156).

(etymologisch falscher) Anlehnung an ein ähnlich klingendes Wort" (DUW online, Zugriff am 14.07.2018). In der Phraseologie wird darunter eine sekundäre Remotivierung einer Metapher aufgefasst, die für die Sprachbenutzer undurchsichtig geworden ist. Die Neigung zur Erfindung einer neuen Ausgangsdomäne für metaphorische Wortverbindungen ist in der Phraseologie weit verbreitet: „Für die Phraseologie ist die Gefahr der Volksetymologie bedeutend größer als für die Lexikologie. Zugleich ist diese Volksetymologie - vom sozial- und psycholinguistischen Standpunkt aus betrachtet - eine normale Erscheinung, da eine, Wiederaufnahme der Aktualität der inneren Form nicht selten zu einer Lebensverlängerung eines Phrasems beiträgt. Die semantische,Wiederaufnahme' ist überhaupt eine der wichtigsten spezifischen Besonderheiten der Phraseologie in Verbindung mit ihrer kategorialen Expressivität“ (Mokienko 2007: 1138). 
Hervorzuheben ist an dieser Stelle, dass die beiden Lesarten nicht gleichberechtigt sind: Anders als bei der Interpretation von innovativen Metaphern, vollzieht sich die motivierende Verknüpfung der literalen und der phraseologisierten (meistens figurativen) Lesart in der Phraseologie vor dem Hintergrund der phraseologisierten Idiombedeutung. Es ist jeweils die phraseologisierte/lexikalisierte Lesart, die einen Spielraum eröffnet, innerhalb dessen der Sprachteilhaber aufgrund seines Welt- und Sprachwissens eine - mehr oder weniger plausible - Erklärung zwischen der literalen und der figurativen Ebene suchen kann, sie konturiert den Bereich, in dem diese Suche überhaupt möglich ist. Das Idiom: Öl ins Feuer gießen könnte demnach aufgrund der zugrunde liegenden Metapher mehrere Bedeutungen aufweisen (vgl. Sulikowska 2015b: 172), z.B.:

(i) ,einen Bummelanten zur Eile drängen';

(ii) ,jmdm. [durch Hinweise, Zureden, finanzielle Mittel o. Ä.] bei der Durchsetzung seiner Ziele helfen';

(iii) ,eine Sache, ein Projekt vorantreiben; beschleunigen';

(iv) ,einen oder mehrere Schnäpse oder alkoholhaltige Getränke zu sich nehmen';

(v) ,provozieren; einen Streit entfachen; einen schwelenden Konflikt zum Ausbruch bringen'.

Die Tatsache, dass ausgerechnet die letzte Bedeutung lexikalisiert wird, ist auf die Konvention zurückzuführen. Nur innerhalb dieser lexikalisierten Bedeutung wird ein kompetenter Sprachteilhaber nach einer motivierenden Verknüpfung zwischen der literalen und der phraseologisierten Lesart suchen: Ob er dabei auf das Alltagswissen, dass Öl beim Brennen eine sehr hohe Temperatur entwickelt und im Falle der Löschversuche mit Wasser zur gefährlichen Explosion führen kann (Volksetymologie) oder auf das intertextuelle Wissen über die Satire von Horaz ${ }^{115}$ (etymologische, intertextuelle Motivation) zurückgreift, hängt ausschließlich von seinen Wissensbeständen und seiner Erfahrung ab. Die Motiviertheit eines Idioms lässt sich somit nur auf der Folie seiner phraseologisierten Lesart, retrospektiv, post factum erkennen. Idiome sind damit „arbiträr und nichtarbiträr zugleich: arbiträr im Sinne der Imprediktabilität und nichtarbiträr im Sinne der nachträglichen Interpretierbarkeit relevanter Phänomene" (Dobrovol'skij 1995a: 90).

\subsubsection{Motivation, Motivierbarkeit und Motiviertheit}

In der Fachliteratur sind in Bezug auf das Phänomen der nachträglichen Verstehbarkeit der Idiome drei Termini gebräuchlich: Motivation, Motiviertheit und Motivierbarkeit (Munske 2015 [1993]: 94).

115 Horaz („Satiren“, Liber 2, Satira 3, V. 321) mit der lateinischen Formel „oleum addere camino" (redensarten-index, Zugriff am 21.09.2014). 
Den Begriff der Motiviertheit hat Häusermann (1977: 22) als Alternative zum älteren Begriff der Motivation vorgeschlagen, weil er der Dynamik des Prozesses sowie seinem individuellen Charakter besser Rechnung trägt.

Die weiteren Abgrenzungen zwischen der Motiviertheit und der Motivierbarkeit wurden beispielshalber von Munske (1993) und Burger (2007a, 2010, 2015) postuliert, allerdings unter Einbezug verschiedener Perspektiven:

Munske differenziert zwischen der Motiviertheit und der Motivierbarkeit anhand des synchronisch-diachronischen Kriteriums. Die Motivierbarkeit eines komplexen Ausdrucks bezieht sich auf seine aktuelle semantische Deutbarkeit aus den einzelnen Komponenten, die Motiviertheit ist historisch und bezieht sich auf den Zeitpunkt der Bildung eines komplexen Ausdrucks:

Beides kann identisch sein, wenn die ursprüngliche Motiviertheit bis heute bewahrt blieb (z.B. in den sauren Apfel beißen müssen, schon bei Luther belegt, Röhrich I, S. 92). Dagegen ist die Wendung etw. für einen Apfel und ein Ei bekommen heute nicht mehr gleichermaßen motiviert wie im Mittelalter, als Äpfel und Eier als ein anschauliches Synonym für nichts gelten konnten; offensichtlich ist die abhanden gekommene Motivation in Kind und Kegel oder jmdn. ins Bockshorn jagen. (Munske 2015 [1993]: 94)

Burger (2007a: 69-70; 2010: 68-74, 2015: 67-69) versucht dagegen mit der Differenzierung zwischen der Motivierbarkeit und der Motiviertheit individuell-situative und semantische Aspekte abzugrenzen. Unter der Motivierbarkeit subsumiert er folgende Aspekte:

(i) psycholinguistischer Aspekt: Der Phraseologismus ist für bestimmte Sprecher „verstehbar“, weil ihnen die Bildlichkeit „einleuchtet“ oder weil sie Assoziationen zu einzelnen konkreten Komponenten bilden;

(ii) textlinguistischer Aspekt: Der Phraseologismus wird in einem Text durch Kontextarrangements als metaphorisch erkennbar und „verstehbar“ gemacht;

(iii) historischer Aspekt: Der Phraseologismus ist für manche Sprecher in seiner Genese nachvollziehbar, da sie seine Etymologie kennen.

Motiviertheit schränkt Burger auf die semantische Relation ein. Als motiviert gelten für Burger nur diese Idiome, die über die sogenannte semantische Basis verfügen. Hier handelt es sich um den Anteil,

(...) den jeweils die wörtliche Bedeutung der ganzen Wortverbindung oder einer Komponente am (synchronen) Zustandekommen und damit an der „Verstehbarkeit“ der phraseologischen Bedeutung hat. Wir bezeichnen diejenigen Wörter oder Wortkomplexe, die in ihrer freien Bedeutung am Zustandekommen der phraseologischen Bedeutung beteiligt sind, als die semantische Basis des Phrasems. (Burger 2015: 67)

Die Motiviertheit basiert, so Burger, auf semantischen Relationen, den Relationen also 
die dem System der Sprache zuzusprechen sind, die von durchschnittlichen muttersprachlichen Sprechern jederzeit nachvollziehbar sind, die also nicht nur (wie in Fällen 1 bis 3) unter individuellen situativen oder kontextuellen Bedingungen eine Rolle spielen. (Burger 2015: 67-68)

Motivierbar sind also fast alle Phraseologismen im engeren Sinne, motiviert dagegen nur (i) die nicht-idiomatischen Phraseologismen, da dort die semantische Basis identisch mit der phraseologischen Bedeutung ist, sowie (ii) die metaphorischen Idiome (Burger 2010: 70; 2015: 68).

Obwohl Burgers Differenzierung theoretisch einsichtig zu sein scheint, so lässt sie sich doch, sobald man sie auf den empirischen Untersuchungsstoff übertragen hat, in zahlreichen Punkten schwer nachvollziehen.

Das erste Problem bildet der Begriff der semantischen Basis, mit dem Burger die modulare Sicht auf die Sprache aufrechtzuerhalten versucht. Kann man die Motiviertheit unter Ausschluss des individuellen psycholinguistischen, kulturellen und historischen Aspektes analysieren? Existieren semantische Relationen zwischen der literalen und der phraseologisierten Lesart, die man ausschließlich „dem System der Sprache“ zuschreiben könnte? Was ist unter dem „System der Sprache“ zu verstehen? Bezeichnenderweise führt Burger (im Gegensatz zu anderen Kapiteln seiner mit zahlreichen Beispielen veranschaulichten Phraseologie. Eine Einführung am Beispiel des Deutschen) ausgerechnet an dieser Stelle keine Beispiele für motivierte und motivierbare Idiome heran. Möglicherweise hängt dies damit zusammen, dass das Nachvollziehen der Verbindungen zwischen den Lesarten weitgehend individuell ist und aufs Engste mit dem allgemeinen (sprachlichen, kulturellen, bildungsbedingten) Wissen des Rezipienten, seinem Alter, dem Umfang seines mentalen Lexikons, seiner Vorstellungskraft und Lebenserfahrung zusammenhängt. Das bereits erwähnte Idiom Öl ins Feuer gießen kann, je nachdem, ob der Sprachteilhaber über das entsprechende Wissen im Bereich der Naturwissenschaften oder auch Geschichte bzw. Literatur verfügt - als motiviert, motivierbar oder nicht motivierbar gelten. Dasselbe bezieht sich auf zahlreiche andere Idiome: z.B. die Segel streichen ,den Kampf, den Widerstand aufgeben' (Verstehbarkeitsgrundlage bildet hier entweder das Wissen von Segelschiffen: Die eingeholten Segel bieten dem Wind keine Angriffsfläche an, oder historisches Bildungswissen: in früherer Zeit war es ein Zeichen der Kapitulation, wenn ein Segelschiff vor dem Feind die Segel einholte, vgl. DUW), ein heißes Eisen anpacken ,ein heikles, verfängliches, brisantes Thema ansprechen' (das Idiom ist aufgrund des allgemeinen Wissens von der hohen Temperatur des erhitzten Eisens und der davon ausgehenden Gefahr oder durch das historische Wissen von der sog. Eisenprobe, dem mittelalterlichen Rechtsbrauch motiviert, vgl. redensarten-index, Zugriff am 19.10.2016), den Ball flach halten, vorsichtig sein, sich zurückhalten' (wer im Fußball den Ball flachhält, der kann ihn besser kontrollieren, vgl. redensarten-index, Zugriff am 13.05.2016). Zwar existieren in jeder Sprache auch Idiome, denen - als musterhaften Manifestationen der konzeptuellen Metaphern und Metonymien - von durchschnittlichen Sprachteilhabern wahrscheinlich sehr ähnliche, motivierende Verbindungen 
zwischen den beiden Lesarten zugewiesen werden könnten, diese Mappings sind aber nicht auf der sprachlichen, sondern auf der konzeptuellen Ebene angesiedelt $^{116}$. Demnach mag die Motiviertheit der Idiome: jmdm. Steine in den Weg legen, jmdm. Hindernisse in den Weg legen, jmdm. in die Quere kommen aufgrund der weitverbreiteten konzeptuellen Metaphern: LEBEN IST EINE REISE, SCHWIERIGKEITEN SIND HINDERNISSE AUF DEM WEG für Sprecher und Rezipienten einleuchtend sein. Ähnliches gilt für die wegen des Embodiments (der Verankerung in der körperlichen Erfahrung) motivierten Idiome, mit denen Emotionen ausgedrückt werden: ÄRGER wird bekanntlich als FLÜSSIGKEIT IN EINEM BEHÄLTER konzeptualisiert, ANGST als KÄLTE, FEINDLICHES WESEN; LIEBE Und LEIDENSCHAFT als HITZE (Dobrovol'skij 1997, Folkersma 2010): Auch wenn diese motivierenden Verbindungen universelle Züge aufweisen, so steht ihre Platzierung auf der Ebene der semantischen Relationen, den Relationen also „die dem System der Sprache zuzusprechen sind“ (Burger 2015: 67) im krassen Widerspruch zu den Grundannahmen der kognitiven Theorie der Metapher und Metonymie. Ausgerechnet in Bezug auf das Phänomen der Motiviertheit, das von Natur aus auf dem Schnittpunkt zwischen der Sprache, dem Weltwissen und der Lebenserfahrung liegen muss, scheint die modulare Sicht auf die Sprache unhaltbar zu sein: Eine weite kognitive Perspektive ist hier erforderlich.

Zum anderen weckt die Einschränkung der Motiviertheit auf die metaphorischen Idiome Zweifel: Metonymische Idiome (ein kluger Kopf, ein intelligenter Mensch') werden natürlich auch als motiviert betrachtet. Darüber hinaus ist in der neueren Forschung die Tendenz erkennbar, ins Zentrum des Interesses außer Metapher auch Metonymie und Symbol zu rücken (vgl. u.a. Feyaerts 1999, Dirven 2003a, 2003b, Dobrovol'skij/Piraiinen 2005, 2009, Radden 2003, Taylor 2003, Tóth 2011). Die Motiviertheitsmechanismen sind bei zahlreichen Idiomen mehrschrittig, überlagern sich in mehreren Schichten und beruhen auf der Interaktion.

Aus diesen Gründen wird in den nachfolgenden Ausführungen die Differenzierung zwischen der Motiviertheit und der Motivierbarkeit aufgegeben und in Bezug auf die nachträgliche Interpretierbarkeit der Idiome ausschließlich der Begriff ,Motiviertheit' verwendet.

\subsubsection{Typen der Motiviertheit}

Ähnlich wie die Idiomatizität stellt auch die Motiviertheit ein facettenreiches, komplexes Phänomen dar, das aus mehreren Perspektiven beleuchtet werden kann. Der nachträglichen Verstehbarkeit der idiomatischen Bedeutung können nämlich mehrere Mechanismen zugrunde liegen, nicht auszuschließen ist dabei, dass sich diese Mechanismen überlagern oder in Konkurrenz zueinander stehen. Munske (1993) analysiert in seinem Artikel Wie entstehen Phraseologismen? die Motiviertheit aus einer diachron-synchronen Perspektive. Eine ausführliche Darstellung der

116 „Metaphors are conceptual, not lingustic“ (Johnson/Lakoff 2002: 253). 
unterschiedlichen Motiviertheitstypen von Idiomen (Phraseologismen im engeren Sinne) aus synchroner Sicht haben Dobrovol'skij (2001, 2007) sowie Dobrovol'skij/ Piirainen (2009) vorgeschlagen. Burgers (2007b) Typologie rückt die wichtigsten kognitiven Mechanismen der figurativen Bedeutungserweiterung in den Vordergrund: Metapher, Metonymie, Synekdoche sowie Symbol.

\subsubsection{Motivertheitstypologie von Munske}

Munskes Typologie der Motivation ist umfassend, da er seine Aufmerksamkeit auf die Phraseologismen im weiteren Sinne richtet. Damit bezieht sie sich - im Gegensatz zu den beiden anderen Typologien - nicht ausschließlich auf Idiome (die er als figurative Phraseologismen bezeichnet), sondern schließt ebenfalls feste Mehrwortverbindungen wie z.B. Nominationsstereotypen, onymische Phraseologismen ein. Munskes Beitrag ist zwar hauptsächlich auf diachrone Aspekte der Phraseologiebildung ausgerichtet, die Parallelen zwischen den Mechanismen der Phraseologiebildung und der späteren Motiviertheit der Phraseologismen sind dennoch offensichtlich und werden mehrmals zur Sprache gebracht. Aus dieser Perspektive unterscheidet Munske (2015 [1993]: 95-122) zuerst zwischen einer historischen Motiviertheit (Primärmotivation, Motivation) und aktueller Motivierbarkeit der Idiome.

Die historische Motiviertheit (Motivation) lässt sich in folgende Typen untergliedern:

(i) Die morphologisch-semantische Motiviertheit umfasst zum Zeitpunkt ihrer Bildung alle Phraseologismen (im weiteren Sinne), da ihre Bedeutung aus der Bedeutung ihrer Komponenten erwachsen ist bzw. figurativ darauf Bezug nimmt. Diese Gruppe umfasst heterogene Phraseologismen - Munske nennt sie unspezifische Phraseologismen - darunter onymische Phraseologismen, Phraseoschablonen, kommunikative Formeln u.a. Als Beispiel der morphologisch-semantischen Motivation können die Mehrwortverbindungen: die neuen Bundesländer, die alten Bundesländer dienen, mit denen in den 90er Jahren des 20. Jh. der Bezeichnungsnotstand bezüglich der neuen politischen Realität neutral ausgeräumt wurde.

(ii) Die figurative Motiviertheit beruht darauf, dass manche Phraseologismen darüber hinaus auf der Folie der morphologisch-semantischen Motivation einer bestimmten Kollokation eine zusätzliche übertragene Bedeutung verleihen (ebd., 95). Unter der figurativen Phraseologiebildung werden drei Mechanismen aufgefasst: die metaphorische, metonymische und synekdochische Phraseologiebildung. Die metaphorische Phraseologiebildung definiert Munske als Durchbrechen des thematischen Verwendungsbereiches: Im Akt der metaphorischen Nomination steckt zugleich eine Prädikation, indem ein Sachverhalt aufgrund von Ähnlichkeitsbeziehungen mit Ausdrücken eines anderen thematischen Bereichs benannt wird und eine spezifische Motivationsbedeutung erhält (ebd. 109). Der Raum der Ähnlichkeitsbeziehungen (das tertium comparationis) wird nicht explizit genannt, weswegen metaphorischer Gebrauch einen breiten interpretativen Spielraum 
eröffnet. Auf diesen Spielraum ist die sog. weite Bedeutung der metaphorischen Phraseologismen zurückzuführen:

Es ist deshalb auch recht schwierig, für metaphorische Phraseologismen eindeutige lexikographische Interpretamente zu bestimmen. Je nach Kontext können oft verschiedene Motivationsbedeutungen aktualisiert werden. Erst wenn der interpretative Bezug zur literalen Basis nicht mehr möglich ist, oder wenn eine weitgehende denotatsbezogene Idiomatisierung erreicht ist, haben auch metaphorische Phraseologismen eine enge Bedeutung. (Munske 2015 [1993]: 110)

Bei der metonymischen Phraseologiebildung handelt es sich um geringfügige Sinnverschiebungen (ebd., 111), Sinnberührung (im Sinne von Ullmann 1972), Übertragungen innerhalb thematischer Zusammenhänge, die man mit Termini der KI-Forschung als ,Frame‘ oder ,Szene“ bezeichnet (ebd.). Munske verweist darauf, dass in der germanistischen Phraseologieforschung keine nähere Beschäftigung mit Metonymien erfolgte, und führt eine Liste phraseologischer Einheiten mit der Komponente Gesicht an, die metonymisch motiviert sind, vgl. u.a.:

Gesicht steht für ,Miene, Gesichtsausdruck': ein freundliches/trauriges Gesicht machen, ein langes Gesicht machen/ziehen

Gesicht steht für ,Ansehen, Einschätzung durch andere': das Gesicht wahren/ verlieren

Gesicht steht für ,Charakter': sein wahres Gesicht zeigen

Auch wenn Munskes Einschätzung der Lage zweifelsohne richtig ist, so bleibt zu bemerken, dass einige der angeführten Bedeutungsverschiebungen nicht eindeutig als Metonymien eingestuft werden können, sondern durch Metonymien und Metaphern konstituiert sind, weil ein Durchbruch thematischer Zusammenhänge erkennbar ist, z.B. sein Gesicht wahren/verlieren (Abb. 22):

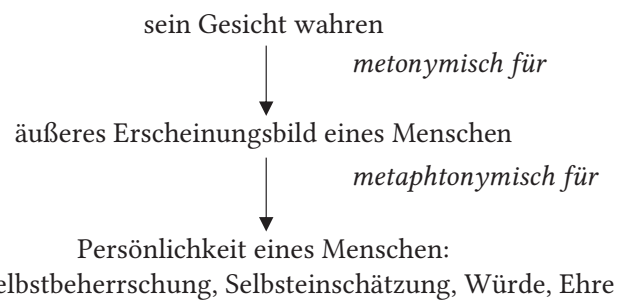

\begin{abstract}
Abb. 22: Metonymie und Metaphtonymie als Mechanismen der Bedeutungskonstituierung am Beispiel des Idioms sein Gesicht wahren.
\end{abstract}

Als dritter Typ der figurativen Motiviertheit gilt Synekdoche. Synekdoche wird als eine Spielart der Metonymie angesehen, die sich auf zwei Relationen einschränkt: die Teil-Ganzes-Relation sowie die Genus-Spezies-Relation (ebd., 114). 
Von Relevanz ist die Synekdoche für die einfachen Lexeme und Komposita: Die Genus-Spezies-Relation entspricht dem Verhältnis von Hyperonymie und Hyponymie (semantische Über- und Unterordnung); die Teil-Ganzes-Relation ist semantisch nicht fassbar, sondern nur aus dem Weltwissen über die Objekte abzuleiten (ebd., 114-115). In der Phraseologiebildung spielt die Synekdoche eine untergeordnete Rolle (ebd., 115).

(iii) Situativ motiviert sind Phraseologismen, die unter der Voraussetzung bestimmter situativer, nicht versprachlichter Gegebenheiten zustande kommen. Die Kenntnis der Situation ist dabei die Voraussetzung eines motivierten Verständnisses eines Idioms (ebd., 96). Als Beispiel können hier die elliptischen Phraseologismen wie großer Bahnhof für großer Empfang am Bahnhof dienen. Die Ellipse beruht auf der „Aussparung von sprachlichen Elementen, die aufgrund von syntaktischen Regeln oder lexikalischen Eigenschaften notwendig sind" (Bußmann 1990: 207). Sie ist damit ein Parole-Phänomen. Im Falle einer Lexikalisierung wird sie aber als Form der Bedeutungsbildung angesehen.

Viele elliptische Phraseologismen haben euphemistischen Charakter: ein Verhältnis mit jmdm. haben, oben ohne, du kannst mich mal! Besonders oft treten elliptische Idiome in situativ gebundenen kommunikativen Formeln, z.B. Der wird nicht mehr! ,Der wird nicht mehr gesund' auf (Munske 2015 [1993]: 116-117).

(iv) Die Zeichenfeldmotivation kommt in den Beschränkungen möglicher Modifikationen von Phraseologismen zum Ausdruck. Hier handelt es sich um unterschiedliche Formen sekundärer Phraseologiebildung ${ }^{117}$ : Einzelne Komponenten der Typen 1-3 sind ausgetauscht oder erweitert, die Gesamtbedeutung ist jedoch der ursprünglichen gleich oder ähnlich. Der Austausch oder die Erweiterung erfolgen im Rahmen eines Zeichenfeldes, um einzelne Kernwörter bilden sich phraseologische Nester (Häusermann 1977: 71, zit. nach Munske 2015 [1993]: 118). Sie lassen bestimmte Typen der Modifikation ${ }^{118}$ erkennen (Munske 2015 [1993]: 118):

(a) komplementäre Modifikation: leichten/schweren Herzens, von/ohne Belang sein, das will etwas/nichts heißen, zu etwas/nichts kommen,

117 Unter sekundärer Metaphorisierung versteht Černyševa (1986) die Veränderungen der bereits existierenden festen Wortverbindungen auf der syntaktischen und/oder lexematischen Ebene, z.B. Stille Wasser sind tief $\rightarrow j d$. ist stilles Wasser.

118 An dieser Stelle ist es anzumerken, dass die von Munske angeführten Modifikationen heutzutage eher als phraseologische Varianten bezeichnet werden. In der neueren Forschung hat sich die Abgrenzung zwischen den okkasionellen, textgebundenen Modifikationen und usuellen (lexikographisch allerdings nicht immer konsequent kodifizierten) Varianten durchgesetzt (vgl. Burger 2015: 22-25, Fleischer 1997a: 263, Ptashnyk 2009: 62-65). Selbstverständlich sind auch hier die Übergänge fließend: Der Gebrauch stellt keine Konstante dar, die Sprache ändert sich ständig. 
(b) konverse Modifikation: etwas zu Gesicht bekommen/etwas aus dem Gesicht verlieren, das Heft in die Hand nehmen/aus der Hand geben, auf der Bildfläche erscheinen/von der Bildfläche verschwinden,

(c) aktionale Modifikation: ( $\mathrm{I}=$ Inchoativ, $\mathrm{D}=$ Durativ, $\mathrm{K}=$ Kausativ): auf den Hund kommen (I)/auf dem Hund sein (D)/jmdn. auf den Hund bringen (K), aus dem Konzept kommen (I)/jmdn. aus dem Konzept bringen $(K) /$ sich nicht aus dem Konzept bringen lassen (K-Passiv), in die Jahre kommen (I)/in den besten Jahren $\operatorname{sein}(D)$.

Am Rande erwähnt Munske auch einen Typus der Motivation, der auf der Wiederherstellung der verloren gegangenen Motivation beruht: Die einzelnen, nicht mehr verstandenen Komponenten werden umgedeutet, wodurch Anschlüsse an den gegenwärtigen Wortschatz erreicht werden, ohne dass eine wirkliche Neumotivation erfolgt. Ein polnisches Beispiel für die sich vollziehende Remotivation ist das Idiom nie zasypiać gruszek w popiele [wörtl. 'die Birnen in der Asche nicht einschlafen'] ,die Gelegenheit nicht unbenutzt lassen', das oft inkorrekt in der Form nie zasypywać gruszek $w$ popiele [wörtl. 'die Birnen in der Asche nicht zuschütten'] gebraucht wird (https://sjp.pwn.pl/poradnia/haslo/nie-zasypiac-gruszek-w-popiele;2980.html, Zugriff am 02.12.2016). Die Etymologie dieses Idioms ist auf die alte Gepflogenheit zurückzuführen, nach dem Brotbacken die Birnen in der Asche zu dörren. Falls sie dabei nicht aufmerksam bewacht wurden (weil man beispielsweise am Ofen eingeschlafen war), waren sie verbrannt ${ }^{119}$. Da das Verb zasypiać ,einschlafen' den gegenwärtigen Sprachteilhabern als semantisch inkompatibel und grammatisch normwidrig (zasypiać wird heutzutage nur intransitiv gebraucht) erscheint, ersetzen sie es durch das mit dem mentalen Bild kompatible Verb zasypywać.

Nicht klar als Typ der phraseologischen Motiviertheit, dennoch als Modell der Phraseologismenbildung werden von Munske auch die Entlehnungen und Lehnbildungen angesehen. Die Entlehnungen, die die fremdsprachliche Orthographie und Aussprache beibehalten (take it easy, keep smiling, dolce vita, ad hoc, c'est la vie), bilden dabei „nur die Spitze des Eisbergs lexikalischen Lehnguts“ (ebd., 121). Die Mehrheit des Lehnguts bilden Lehnbildungen, zu denen Lehnübersetzungen und Lehnübertragungen gehören. Unter Lehnübersetzungen werden lexikalisch und syntaktisch genaue Übersetzungen verstanden, in denen die Gesamtbedeutung des quellsprachigen Ausdrucks auf das Übersetzungsäquivalent übertragen wird, z.B. stehende Ovationen aus engl. standing ovations, sein Gesicht wahren aus engl. to save one's face, der springende Punkt aus lateinisch punctum saliens. Lehnübertragungen weisen lexikalische, morphologische oder syntaktische Modifikationen auf, ihr Nachweis ist dennoch schwierig, denn die Wörterbücher führen meistens nur parallele Bildungen (ins Gras beißen, fr. mordre la poussière) auf (ebd., 121).

119 Głowińska (2012): Słownik frazeologiczny. IBIS, Poznań. 
Die Mechanismen, die zur Entstehung der Phraseologismen führen und dann zu ihrer nachträglichen Verstehbarkeit beitragen, veranschaulicht Munske zusammenfassend anhand des folgenden Schemas (Abb. 23):

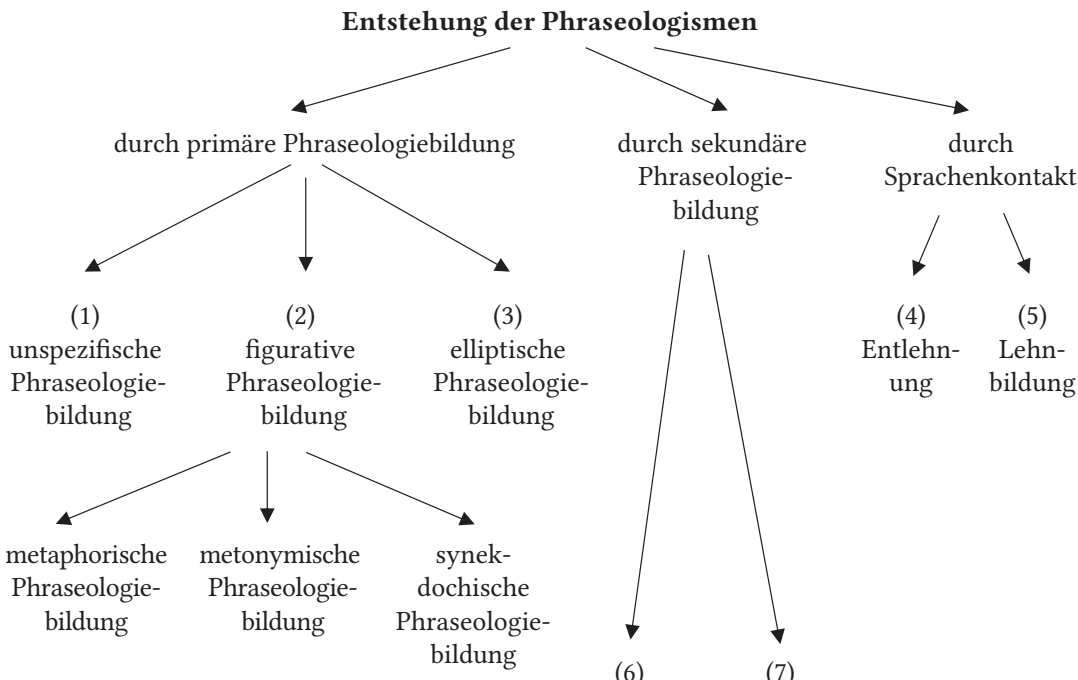

$\begin{array}{cc}\text { Modi- } & \text { remoti- } \\ \text { fikation von } & \text { vierende } \\ \text { PH } & \text { Umdeut- } \\ (1)-(5) & \text { ung aus }\end{array}$

(1)-(5)

Abb. 23: Modelle der Phraseologismenbildung nach Munske (2015 [1993]: 124).

\subsubsection{Motiviertheitstypologie von Dobrovol'skij/Piirainen}

Terminologisch knüpft die von Dobrovol'skij und Piirainen vorgeschlagene Klassifikation der Motiviertheit ${ }^{120}$ an die von Peirce (1960: 247-249) eingeführte semiotische Trichotomie: Ikon, Index und Symbol an, es werden aber auch die Termini der Kognitiven Linguistik einbezogen und berücksichtigt. Die Typologie wurde einigen Revisionen unterzogen und ausgebaut, die neueste Version aus dem Jahre 2009 lässt sich mithilfe des folgenden Schemas (Abb. 24) veranschaulichen:

120 Dobrovol'skij und Piirainen verweisen (2009: 18) auf die Koexistenz mehrerer Termini (Motiviertheit, Motivierbarkeit sowie Transparenz) bedienen sich aber „der Einfachheit halber" des Begriffes der Motivation. 


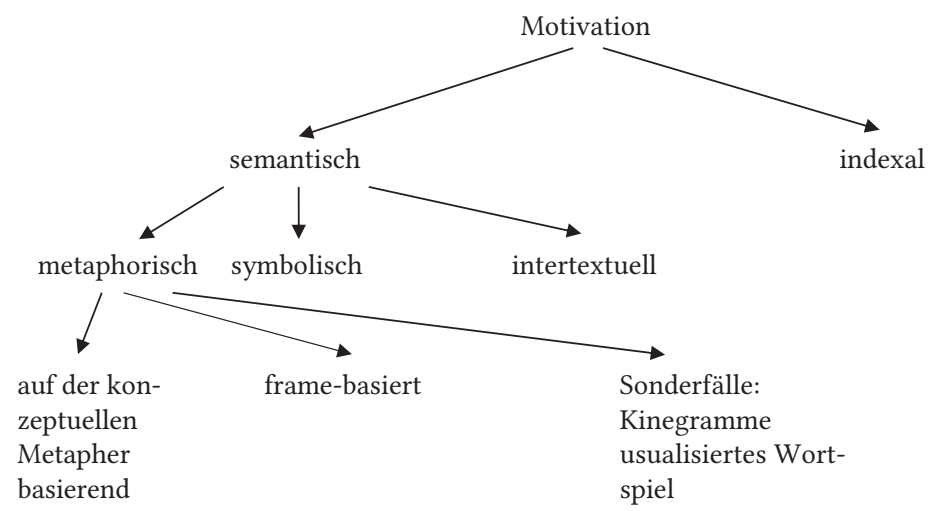

Abb. 24: Schematische Darstellung der Motivationstypen anhand der Typologie von Dobrovol'skij/Piirainen (2009: 17-41).

Im ersten Schritt gliedern Dobrovol'skij/Piirainen (2009) die Motivation der Idiome in die semantische und indexale Motivation auf.

Die meisten Idiome sind semantisch motiviert. Unter der semantischen Motivation von Idiomen wird die intuitiv nachvollziehbare Zuordnung der Form (der lexikalisierten Struktur) eines Idioms zu seiner lexikalisierten Bedeutung (seiner konzeptuellen Repräsentation im Lexikon) aufgefasst (Dobrovol'skij/Piiraninen 2009: 17). Die Verbindungen zwischen den beiden Ebenen können dabei vielfältiger Art sein, eine gewisse (vom individuellen Kenntnisstand abhängige) Subjektivität der Motiviertheit ist nicht auszuschließen (ebd., 18). Die semantische Motiviertheit zerfällt dabei in drei Haupttypen: die metaphorische, die symbolische und die intertextuelle Motiviertheit.

Bei der metaphorischen Motiviertheit handelt es sich um den großen Komplex konventionalisierter Metaphern. Generell entsteht sie durch die Mappings, die zwei Konzepte (das Ausgangs- und das Zielkonzept) miteinander verbinden. Der metaphorischen Motiviertheit liegen zwei konstitutive kognitive Mechanismen zugrunde. Die motivierenden Mappings können auf der übergeordneten, abstrakten Ebene der konzeptuellen Metapher (die auf der konzeptuellen Metapher basierende Motivation) oder auf einer konkreteren Ebene, bei der die individuellen Eigenschaften der betreffenden bildlichen Einheit im Mittelpunkt stehen (frame-basierte Motivation) angesiedelt werden (ebd., 20). Bei der Beschreibung des erstgenannten Metapherntypes greifen die Autoren auf die Pionierleistungen der CTM-Theorie zurück: Dementsprechend liegt die konzeptuelle Metapher WISSEN IST LICHT zahlreichen Idiomen des Deutschen und anderer Sprachen als Motiviertheitsbasis zugrunde und lässt sie zu Clustern gruppieren: Licht in etw. bringen ,eine undurchsichtige Angelegenheit aufklären', sein Licht leuchten lassen ,sein Wissen zur Geltung bringen', mit Blindheit geschlagen sein ,etw. Wichtiges 
nicht erkennen', im Dunkeln tappen ,in einer aufzuklärenden Sache noch keinen Anhaltspunkt haben', jmdm. geht ein Licht auf ,jd. versteht plötzlich etw.' (ebd., 21), etw. ans (Tages-)Licht bringen/ziehen/zerren ,etw. an die Öffentlichkeit bringen", ans (Tages-)Licht kommen ,bekannt werden, offenbar werden'. Die Einsetzbarkeit der CTM bei der Untersuchung der Phraseologie charakterisieren die Autoren wie folgt:

Wenn die KTM [= Kognitive Metapherntheorie, A. S.] als Analyseapparat angewendet wird, so lassen sich metaphorisch motivierte bildliche Lexikoneinheiten nach ihrer Motivationsbasis zu Clustern zusammenfassen. Solch eine Gruppierung kann zu nichttrivialen Ergebnissen führen. Erstens kann dies als ein Mittel genutzt werden, um reguläre, systematische Eigenschaften der bildlichen Sprache aufzudecken. Die Hypothese, dass eine relativ geringe Anzahl von Metaphernmodellen einer großen Anzahl von bildlichen Ausdrücken vieler Sprachen zugrunde liegt, hat einige Wahrscheinlichkeit für sich. Zweitens kann das - nach den zugrunde liegenden Metaphernmodellen gruppierte - Inventar bildlicher Ausdrücke empirische Evidenz zur Überprüfung bestimmter Hypothesen über die Beschaffenheit des mentalen Lexikons liefern. Es gehört jedoch nicht zu den Zielsetzungen der Kognitiven Metapherntheorie, ein Mittel zur umfassenden Beschreibung eines jeden bildlichen Ausdrucks zur Verfügung zu stellen. Deshalb kann sie kein universelles Instrument zur Erforschung der bildlichen Sprache sein. Ihre Leistung besteht nicht darin, die Motivation eines jeden bildlichen Ausdruck zu erklären oder Auskunft über die Beschaffenheit eines jeden einzelnen Ausdrucks zu geben. (...) Nicht alle bildlichen Ausdrücke, nicht einmal alle bildlichen Lexikoneinheiten, die auf einer metaphorischen Basis motiviert sind, können mit Hilfe von Metaphernmodellen der KTM zu Clustern gruppiert werden. Die KTM kann also, ebenso wenig wie andere Theorien, das semantische Resultat vorhersagen. (Dobrovol'skij/Piirainen 2009: 23)

Den anderen Typ der metaphorischen Motivation bilden die framebasierten Metaphern. Als frames definiert Dobrovol'skij (2007: 791) nach Minsky (1995): „a structure of data (or a conceptual structure, in other terms) designed to represent a stereotypical situation“. Im Jahr 2009 führen Dobrovol'skij und Piirainen eine erweiterte Definition von Fillmore/Ch. Johnson /Pertuck (2003: 235) heran: Frames sind „schematic representations of the conceptual structures and pattern of beliefs, practices, institutions, images etc. that provide a foundation for meaningful interaction in a given speech community". Die framebasierten Metaphern sind weniger abstrakt als konzeptuelle Metaphern, bei ihrer Herausbildung stehen die individuellen Eigenschaften der bildlichen Einheit im Mittelpunkt (Dobrovol'skij/Piirainen 2009: 20). So ist das Wissen über die stereotype Situation unerlässlich, um zahlreiche Idiome interpretieren zu können. Ohne grundsätzliches Szenario des Boxkampfes (z.B. Boxen ist ein Kampfsport, wird in mehreren Runden ausgetragen, zwischen denen Pausen angelegt werden; in den Pausen erholen sich die Gegner in den Ecken, dort werden sie ärztlich versorgt, wobei das Handtuch zum Abtrocknen und Wasser zum Mundspülen zu typischen Utensilien gehören; falls die Gesundheit eines Boxers infolge einer im Kampf davongetragenen Verletzung gefährdet 
ist, wird der Kampf unterbrochen u.a.) wäre die Motivation des Idioms das Handtuch werfen ,aufgeben' für die Sprecher nicht nachvollziehbar. Ähnliches gilt für andere Idiome, deren Motivation das Evozieren von zusammengesetzten, kulturellbedingten Wissensstrukturen voraussetzt: seinen Hut nehmen , aus dem Amt scheiden, zurücktreten', wie ein rotes Tuch auf jmdn. wirken, durch sein Vorhandensein jmds. Widerwillen, Zorn hervorrufen'.

Als Sonderfälle der metaphorischen Motivation werden Kinegramme und usualisiertes Wortspiel betrachtet (Dobrovol'skij/Piirainen 2009: 27-29):

Kinegramme (z.B. die Achseln zucken, ratlos sein, etw. nicht genau wissen, jmdm. gleichgültig sein', die Nase über jmdn./etw. rümpfen ,jmdn./etw. gering schätzen, seinen Unmut über jmdn. etw. kundtun') beruhen auf nonverbalen Verhaltensweisen wie Gesten, Gebärden oder Mimik als Metaphern. Die literale und die figurative Lesart sind bei den Kinegrammen soweit integriert, dass man die Geste oder Mimik auch ohne verbale Äußerung in der konventionalisierten Bedeutung interpretiert: Gesten stellen somit kulturspezifische Artefakte mit einer konventionalisierten Bedeutung dar.

Teilweise metaphorisch sind ebenfalls Mechanismen, die usualisiertes Wortspiel motivieren. Das Idiom etw. aus der Armenkasse kriegen ,Prügel bekommen“ ist durch das phonische Wortspiel der lexikalischen Komponente Armen- (als Teil des zusammengesetzten Nomens Armenkasse) und der Pluralform des Substantivs Arm - Arme, mit denen verprügelt wird, motiviert (ebd., 29). Um das Idiom metaphorisch interpretieren zu können, muss es zuerst linguistisch reinterpretiert werden. Als andere Beispiele führen die Autoren die Idiome: am Sankt-Nimmerleins-Tag ,niemals'; Kotzebues Werke studieren ,sich erbrechen'; vom Stamme Nimm sein ,geldgierig, habgierig sein“.

Den zweiten Typ der semantischen Motivation bildet die symbolische Motivation. Im Gegensatz zu der metaphorischen Motivation erstreckt sie sich nicht auf die ganze Wortverbindung, sondern auf eine Idiomkonstituente. So sind in den Idiomen: eine schwarze Seele haben ,böse sein, einen schlechten Charakter haben", ein goldenes Herz haben, einen guten Charakter haben, sehr freundlich und hilfsbereit sein' die adjektivischen Konstituenten: SCHWARZ, GOLD symbolisch motiviert. Die Verbindung zwischen den beiden Lesarten des Idioms kommt durch die Kohärenz zwischen symbolischen Konzepten, die in der Sprache existieren und entsprechenden symbolischen Phänomenen im kulturellen Kode zustande. Somit ist GOLD nicht a priori besser als andere Metalle, sondern erhält seinen besonderen Wert aufgrund kultureller Semiotisierungen. Zu anderen im christlich-abendländischen Kulturraum weitverbreiteten Kultursymbolen gehört beispielshalber BROT, vgl. anderer Leute Brot essen ,von anderen Leuten finanziell abhängig sein', sein eigen Brot essen ,beruflich selbstständig sein', ein hartes/schweres Brot ,schwere Arbeit, mühevoller Gelderwerb', überall sein Brot finden ,geschickt, fleißig, anstellig sein, sodass man überall seinen Lebensunterhalt finden kann', während im asiatischen Kulturkreis an dieser Stelle REIS fungiert: jap. Tanin no meshi wo kuu [wörtl. 'gekochten Reis fremder Leute fressen'] ,von anderen Menschen finanziell abhängig sein'. Symbolisch motiviert sind auch Idiome mit den Zahlen: z.B. sIEBEN (auf 
der Wolke sieben schweben, überglücklich, in Hochstimmung sein'), Farben: z.B. scHWARz (schwarzes Schaf, jd., der in einer Gemeinschaft unangenehm auffällt'), Tieren: z.B. HUND (wie ein Hund leben, ärmlich, elend leben', jmdn. wie einen Hund behandeln ,jmdn. sehr schlecht, menschenunwürdig behandeln', unter dem/allem Hund sein ,miserabel, unter aller Kritik sein').

Im Gegensatz zu der metaphorischen Motivation, die weitgehend auf die Ähnlichkeitsbeziehung zurückzuführen ist, kann die symbolische Motivation erst im Rahmen der Kultursemiotik adäquat beschrieben werden (Dobrovol'skij/Piirainen 2009: 31). Für die Explikation der konzeptuell-semantischen Beziehung zwischen der literalen und der phraseologisierten Lesart ist die Aktivierung spezifischen Kulturwissens notwendig, das aus der Perspektive der Mitglieder der Sprach- und Kulturgemeinschaft zwar trivial erscheint, aus der Sicht „von außen“ aber deutliche kulturspezifische Züge trägt (Dobrovol'skij 2007: 91). Die Beziehungen beruhen auf bestimmten Konventionen, die in der jeweiligen Kultur tradiert werden und ohne Rückgriff auf bestimmte kultursemiotische Wissensstrukturen nicht als Motivationsbasis der phraseologisierten Bedeutung erläutert werden können (vgl. Dobrovol'skij/Piirainen 2009: 30-31).

Den letzten Typ der semantischen Motivation der Idiome macht die intertextuelle Motivation aus. Sie bezieht sich auf Idiome, deren lexikalische Struktur auf einen bereits existierenden Text zurückführt (2009: 32). Die intertextuelle Motivation ist an das sog. Bildungswissen gekoppelt: Die Motiviertheit des Phraseologismus der Groll frisst jmdm. an der Leber ist für die Sprecher, deren Bildungshintergrund sich bis hin zum Prometheus-Mythos erstreckt, besser nachvollziehbar als für diejenigen Sprecher, die über entsprechendes Wissen nicht verfügen (Folkersma 2010: 53). Dieser Motivationstyp kommt dennoch selten in reiner Form vor: Dementsprechend ist das Idiom gegen/mit Windmühlen kämpfen, einen sinnlosen, von vornherein aussichtslosen Kampf führen (gegen eingebildete Gegner) ' für diejenigen Sprecher, die Cervantes' Roman „Don Quixote“ (1605) kennen, intertextuell motiviert, während andere Sprecher diesem Idiom eine metaphorische Motivation zuweisen würden. Ähnliches gilt für jmdm. einen Bärendienst erweisen ,in guter Absicht etwas tun, was dem anderen, zu dessen Nutzen es gedacht war, schadet, als wäre es der Bär in der Fabel, der in guter Absicht die Fliege im Gesicht des Gärtners tötet und ihn selbst dabei erschlägt', dessen Etymologie auf eine Fabel von Jean de La Fontaine zurückzuführen ist (Dobrovol'skij/Piirainen 2009: 35).

Die intertextuelle Motivation kommt in zwei Typen vor: Zum einen treten Idiome auf, die bis in den Wortlaut hinein mit einer Textquelle identisch sind, oft handelt es sich hier um Zitate, bei denen das Zitatenbewusstsein verloren gegangen ist. Zum anderen existieren Idiome, die auf eine gesamte Textpassage zurückgehen und deren Pointe kurz resümieren (ebd., 32-33).

Nicht-semantisch ist der letzte von Dobrovol'skij/Piirainen vorgeschlagene Motivationstyp. Bei der indexalen Motivation handelt es sich um einen in der Form des Idioms angelegten Verweis auf seine aktuelle (phraseologisierte) Bedeutung (Dobrovol'skij 2001: 95). So wie Indizes an sich keine Bedeutung tragen, sondern die Aufmerksamkeit in eine Richtung lenken, so kommen auch Idiome vor, 
deren phonische oder konzeptuelle Form als Symptom der aktuellen Bedeutung gedeutet wird. Innerhalb der indexalen Motivation werden zwei Typen unterschieden: Es kann sich um phonische und pragmatische Verweise (Indizes) handeln (Dobrovol'skij/Piirainen 2009: 36-38).

Bei der phonischen Indexierung verweisen bestimmte Merkmale der Lautstruktur des Idioms auf die korrespondierenden Merkmale der lexikalisierten Idiombedeutung. Im Idiom: den heiligen Ulrich anrufen, sich erbrechen' verweist der Name Ulrich als onomatopoetische Nachahmung des beim Sich-Übergeben entstehenden Geräusches auf die phraseologisierte Bedeutung des Idioms (Dobrovol'skij 2001: 95).

Im Falle der pragmatischen Indexierung ergibt sich die lexikalisierte Bedeutung aus der Absurdität, die der Wortkette in der wörtlichen Lesart zugrunde liegt (ebd., 96), vgl. Ist der Papst katholisch? ,die Antwort auf diese Frage versteht sich von selbst', Und ich bin der Kaiser von China ,das ist äußerst unglaubwürdig, was du da sagst".

Die indexale Motivation stellt einen separaten Motivationstyp dar und lässt sich mit dem Beschreibungsapparat der Kognitiven Linguistik nur bedingt erfassen. Die Parallelität der wörtlichen Lesart zum situativen Kontext und die sich daraus ergebenden pragmatischen Implikaturen sind zur Erklärung der Motiviertheit unabdingbar. Die Idiomatizität von indexal motivierten Wortverbindungen ist nicht semantischer Natur (ergibt sich nicht aus der Non-Kompositionalität der Bedeutung), sondern pragmatischer Natur. Der indexalen Motivation kommt in der europäischen Phraseologie eine eher marginale Stellung zu, wesentlich häufiger liegt den Idiomen die semantische, insbesondere die metaphorische Motivation zugrunde.

Abschließend bleibt zu bemerken, dass die genannten Motivationstypen gleichzeitig auftreten können, was Dobrovol'skij/Piirainen (2009: 39-40) als Blending verschiedener Motivationstypen bezeichnen und als Interaktion verschiedener Motivationen in ein und derselben idiomatischen Lexikoneinheit definieren. So wird das Idiom im siebten Himmel sein/sich wie im siebten Himmel fühlen ,sich in einer überaus glücklichen Stimmungslage befinden' durch konzeptuelle Metaphern GUT IST OBEN, SCHLECHT IST UNTEN, durch frame-ähnliche, z.T. religös- und kulturbedingte Strukturen von dem Konzept HIMMEL, den symbolischen Wert der Zahl SIEBEN sowie - bei vertieftem etymologischem Wissen auch intertextuell (Schöpfungsgeschichte in der Bibel, babylonische und griechische Mythologie, Sonderstellung der Zahl sieBen in Judentum, Christentum und in der antiken Kosmogonie) motiviert.

\subsubsection{Motiviertheitstypologie von Burger}

Trotz der an einer anderen Stelle (Burger 2007a, 2010, 2015) vorgeschlagenen Abgrenzung der Termini: Motivation, Motiviertheit und Motivierbarkeit bedient sich Burger in seinem Beitrag zu Phraseologie/Phraseology ausschließlich des Begriffs motivation, was wahrscheinlich auf die Sprachfassung (Englisch) 
zurückzuführen ist. Burgers Motivationstypologie (2007b: 98-101) knüpft an die in der Phraseologie verbreitete Ansicht an, dass die „Vergleichsrelation der Metapher und die Ersatzrelation der Metonymie die zwei wichtigsten Motivationen " sind (Palm 1995: 14). Während die Typologien von Munske und Dobrovol'skij/Piirainen sich zum Ziel setzen, so viele Aspekte der nachträglichen Verstehbarkeit der Idiome wie möglich zu ermitteln, konzentriert sich Burger auf die Beschreibung der wichtigsten bekannten Mechanismen des Bedeutungswandels.

Terminologisch basiert diese Motivationstypologie auf drei Tropen der klassischen Rhetorik: Metapher, Metonymie und Synekdoche, die um das Symbol (symbolische Motivation) erweitert werden.

Die Auffassung symbolischer Motivation von Burger basiert weitgehend auf der Definition von Dobrovol'skij/Piirainen (1996): Als Symbole werden kulturell vermittelte Konzepte angesehen, die auf der Konvention basieren und ohne entsprechendes Wissen nicht verständlich sind (Burger 2007b: 98). „Contrary to metaphors and metonymies, in my opinion, no basic cognitive operations but only cultural knowledge is needed to understand symbols" (ebd.). Zugleich verweist Burger dennoch darauf, dass Symbole in Idiomen mit Metaphern und Metonymien zusammenspielen können: Gold in der Kehle haben ist zugleich symbolisch (die Komponente ,Gold‘ als Symbol für etwas Schönes, Wertvolles) und metonymisch (Kehle steht für Gesang) motiviert.

Näherer Beschreibung erfordern dagegen die rhetorischen Figuren als Basis semantischer Motivation idiomatischer Wortverbindungen.

Metapher und Metonymie werden als Motivationsmechanismen von Burger in einem Punkt behandelt, wobei er die beiden Mechanismen aus zwei Perspektiven diskutiert: aus der traditionellen und aus der kognitiven Perspektive.

Bei der Darstellung der kognitiven Metapher und Metonymieauffassung greift Burger auf den bereits beschriebenen und diskutierten Zwei-Domänen-Ansatz zurück. Metapher wird demnach als mentale Operation aufgefasst, die zwei distinkte konzeptuelle Domänen aufgrund einer bestimmten Projektionsrelation (conceptual mapping) verbindet: Sie projiziert die Ursprungsdomäne auf die Zieldomäne, wobei die Domänen nicht durch eine pragmatische Funktion verbunden sind. Eine Metonymie stellt dagegen „a mapping of a conceptual domain, the source, onto another conceptual domain, the target" (ebd.), die Domänen sind dennoch durch eine pragmatische Funktion verbunden. Unter pragmatischer Funktion wird die Zugehörigkeit zu einer funktionalen Erfahrungsdomäne verstanden (Barcelona 2003: 237). Auf die Unzulänglichkeiten dieser Definition wurde bereits im Kap. 2.3.4.4.1 verwiesen: Aus der Grenzenverschwommenheit der Domänen resultieren schwerwiegende Probleme in der Abgrenzung der beiden Mechanismen.

Aus diesem Grunde führt Burger unter Verweis auf die Untersuchungen von Feyaerts (1999) auch die klassische Definition der beiden Mechanismen von Jakobson heran, der Metonymie als eine Kontiguitätsbeziehung, Metapher als eine Ähnlichkeitsbeziehung zwischen zwei Entitäten (Bedeutungen, Konzepten) beschreibt. Wegen mangelnder Präzision lehnt Feyaerts die kognitive Definition 
ab, Burger bemerkt aber zu Recht, dass ebenfalls die Definition von Jakobson eine gewisse Interpretationsbeliebigkeit aufweist: „neither similarity nor contiguity exist ,objectively', but are a construct of the particular language or speaker" (2007b: 99).

Demzufolge schließt sich Burger der neuesten Auffassung der beiden Mechanismen an, nach der Metonymie und Metapher zwei Pole einer Achse sind, die sich in dem Grad der Transformation von Bedeutung unterscheiden (vgl. z.B. Radden 2003: 408).

Da die metaphorischen Transformationen von Natur aus stärker ausgeprägt und auffallender sind, ist der Metapher - als einem Derivations- und zugleich Motivationsmechanismus - in der Phraseologie schon seit Jahren großes Interesse zuteil gekommen, was sich u.a. in der Terminologie widerspiegelt (vgl. z.B. die Motviertheitsklassifikation von Dobrovol'skij/Piirainen 2009, in der nur metaphorische Motiviertheit vorkommt). Dies ist übrigens auch im Hinblick auf die große Anzahl der metaphorisch motivierten Idiome nicht verwunderlich. Wesentlich schwieriger ist es, Idiome zu finden, deren Motivation ausschließlich auf metonymische Bedeutungsverschiebungen zurückzuführen ist - als Beispiel könnte hier das Idiom den Kopf verlieren dienen. Allerdings verweisen die neueren Untersuchungen (Folkersma 2010, Tóth 2011, Geeraerts 2003) darauf, dass beide Mechanismen sich oft verzahnen: Burger spricht hier von „numerous interconnections in particular cases“ (2007b: 99). Eine wichtige und viel diskutierte Studie zur Rolle der Metonymie in der Phraseologie hat Feyaerts (1999) veröffentlicht, der das semantische Feld der „Dummheit“ einer semantischen Analyse unterzieht und am empirischen Material die grundlegende Rolle metonymischer Verschiebungen in der Konstituierung der Idiombedeutung veranschaulicht.

Als den dritten Motivationstyp führt Burger die rhetorische Figur der Synekdoche $^{121}$ an. Die Synekdoche im engeren Sinne bezieht sich auf zwei Relationstypen: die pars-pro-toto-Relation (z.B. pro Nase ,pro Kopf', seine (eigene) Haut retten ,sich retten') und die genus-species-Relation (z.B. seine Brötchen verdienen, seinen Lebensunterhalt verdienen'), die in der deutschen Phraseologie ohnehin selten allein vorkommt (Burger 2007b: 100). Von manchen Forschern wird die Synekdoche als spezielle Subklasse der Metonymie aufgefasst, andere weisen ihr einen autonomen Status zu: Dietz (1999: 33, zit. nach Burger 2007b: 100) argumentiert z.B., dass man die eher quantitative Beziehung (Synekdoche) von der eher qualitativen Beziehung (Metonymie) abgrenzen soll.

121 Angesichts der Tatsache, dass die Metapher und Metonymie in einem Punkt behandelt wurden, mag die Zuweisung eines separaten Punktes der Synekdoche etwas überraschend sein, zumal ihre Abgrenzung von der Metonymie problematisch ist und in der kognitiv ausgerichteten Forschung (vgl. den Sammelband von Dirven/ Pörings 2003), auf die Burger doch Bezug nimmt, aufgegeben wird. 


\subsubsection{Zwischenbilanz}

Ähnlich komplex wie die Idiomatizität ist auch der Begriff der Motiviertheit, unter der eine für den Rezipienten wenigstens teilweise transparente Beziehung zwischen der literalen und der phraseologisierten Lesart verstanden wird. So aufgefasste Motiviertheit stellt einen Gegenpol zur Idiomatizität dar. Je höher der Grad der Idiomatizität ist, desto niedriger ist der Grad der Motiviertheit und umgekehrt: Motivierte, auf ausgeprägten konzeptuellen Metaphern von hohem Generalitätsgrad aufbauende Idiome (jmdm./einer Sache den Weg ebnen, sich jmdm./einer Sache in den Weg stellen) werden als weniger idiomatisch als Mehrwortverbindungen empfunden, die sich aus synchroner Perspektive schwer erklären lassen $(D a$ ist Holland in Not). Phraseologische Motiviertheit ist weitgehend subjektiv und individuell: Da sich die Menschen in ihren Wissensbeständen sowie im Umfang ihres Lexikons unterscheiden, können Idiome bezüglich ihrer Motiviertheit von Sprecher zu Sprecher diametral anders wahrgenommen werden.

Wie die Übersicht einiger Motiviertheitstypologien ergab, werden unter der nachträglichen Verstehbarkeit der Idiome z.T. unterschiedliche Aspekte aufgefasst. Im Folgenden wird versucht, die Motiviertheitstypen zusammenzustellen und zu vereinheitlichen, um einen Rahmen für den empirischen Teil der vorliegenden Arbeit abzustecken. Hervorzuheben ist dabei, dass diese Eingliederung keinen Anspruch auf die Vollständigkeit erhebt. Es wird generell auch davon ausgegangen, dass die Blendings von verschiedenen Motiviertheitstypen nicht nur möglich, sondern gar üblich sind.

(i) Figurativer Motiviertheit liegen die wichtigsten Mechanismen der Bedeutungserweiterung zugrunde: die Metapher, die Metonymie (samt Synekdoche) und die dazwischen liegende Metaphtonymie. Da die genannten Mechanismen sowie ihre Typen bereits an einer anderen Stelle des vorliegenden Buches definiert und detailliert beschrieben sind (vgl. Kap. 2.3), wird im Folgenden darauf rekurriert. Der kognitiven Auffassung folgend, wird im Weiteren ebenfalls das oft schwer nachvollziehbare und für die Phraseologie irrelevante Auseinanderhalten der Metonymie und der Synekdoche aufgegeben: Die Synekdoche wird der Übersichtlichkeit halber als Ausprägung der Metonymie schlechthin betrachtet. Figurativ motiviert sind die meisten Idiome des Deutschen, darunter auch alle Idiome der schwierigen Lage, diesem Motiviertheitstyp kommt die wichtigste Rolle in der Phraseologie zu (Palm 1995: 14, Burger 2007b).

(ii) Symbolisch motiviert sind einzelne Konstituenten der Idiome. Die Auffassung des Symbols ist so wie bei Dobrovol'skij/Piirainen und Burger: Symbole sind motiviert aufgrund des dahinter stehenden semiotischen Wissens über ihre Bedeutung in kulturellen Kenntnissystemen außerhalb der Sprache (Dobrovol'skij/Piirainen 2009: 30-31, Burger 2007: 98). Symbolischer Motiviertheit liegen weder die vorwiegend in den körperlichen Erfahrungen verankerten konzeptuellen Metaphern noch die auf dem Allgemeinwissen beruhenden Ähnlichkeits- oder Kontiguitätsbeziehungen zugrunde, sondern lediglich kulturspezifische Wissensinhalte, obgleich sich die Letzteren oft auf große kulturelle Gemeinschaften erstrecken. So 
ist das Symbol des Herzens als Sitz der Gefühle und der Lebenskraft in den meisten europäischen Sprachen etabliert und kommt in zahlreichen Phraseologismen zum Ausdruck: Herz haben, poln. mieć serce, engl. to have a heart (for sth.); das Herz erweichen, poln. zmiękczyć czyjes serce, engl. to melt sb's heart; jmdm. das Herz brechen, poln. złamać komuś serce, engl. to break sb's heart, während in der japanischen Kultur eine ähnliche Rolle dem Bauch zukommt (Trautmann-Voigt/ Voigt 2012: 33).

(iii) Idiome können auch inter- und intralingual motiviert sein.

Die intralinguale Motiviertheit deckt sich teilweise mit der Zeichenfeldmotivation aus der angeführten Motiviertheitstypologie von Munske, auch wenn Munske - im Gegensatz zu Burger (2003), Hessky (1992b), Palm (1995), Ptashnyk (2009) u.a. - keine Differenzierung zwischen den usuellen Idiomvarianten und okkasionellen Modifikationen vornimmt. Bei der intralingualen Motiviertheit handelt es sich um strukturelle und semantische Modifikationen der Phraseologismen, die die Verstehbarkeitsgrundlage für die neuen, zuerst meist idiosynkratisch (okkasionell) gebrauchten, dann ggf. lexikalisierten Wortverbindungen bilden. Die korpusbezogenen Untersuchungen liefern Evidenz für derartige Prozesse: Das Idiom ein heißes Eisen, eine bedenkliche, heikle Sache, ein unbeliebtes Thema' (DUW) unterliegt beispielshalber in dem folgenden Beleg einer semantischen Kontamination mit dem Sprichwort man muss das Eisen schmieden, solange es heiß ist ,man muss den rechten Augenblick nutzen' (DUW):

Den „Pfeilern“ nicht genau zugeordnet werden können die „institutionellen Reformen“, die die EU plant (...). Sie sind das heißeste Eisen, das in Amsterdam zu schmieden ist. Berliner Zeitung, 17.06.1997 (DWDS, Zugriff am 15.05.2016)

Die Motiviertheit der aktuellen Bedeutung ergibt sich hier aus dem Zusammenspiel der kognitiven Mechanismen, die zur Bedeutungskonstituierung der beiden Phraseologismen beitragen.

Da der Umfang phraseologischer Modifikationen im authentischen Sprachgebrauch bedeutend ist, spielt die intralinguale Motiviertheit eine relativ große Rolle, insbesondere, wenn sich der singuläre, okkasionelle Gebrauch lexikalisiert:

Die Abwandlung von Phraseologismen im Sprachgebrauch erscheint dem heutigen Betrachter zunächst als ein textuelles Spiel mit den semantischen Potenzen der Phraseologismen - zum Beispiel, wenn ein Fernsehspiel über eine Drogengeschichte in der Kritik als „Goldener Schuß in den Ofen“ (FAZ vom 26.7.01) charakterisiert wird; doch liegt in allen textuellen Abwandlungen die Quelle eines künftigen Wandels. (Munske 2015 [1993]: 87)

Die interlinguale Motiviertheit ist auf die Phänomene zurückzuführen, die Munske als Sprachkontakte bezeichnet. Die jeweiligen Linguae francae hatten wahrscheinlich immer einen Einfluss auf den phraseologischen Bestand einer Sprache, in Zeiten der Globalisierung und des Bedarfs an internationaler Zusammenarbeit ist dieser Einfluss allerdings besonders gravierend. Da in der Phraseologie Expressivität und stilistische Markiertheit schwer ins Gewicht fallen, ist 
heutzutage der Umfang des aus dem Englischen stammenden phraseologischen Lehnguts im Deutschen außerordentlich groß:

Mit dem Streben nach Prestige eng verbunden ist als ein häufig anzutreffendes Motiv für die Verwendung von Anglizismen der Wunsch nach Expressivität zu berücksichtigen. Das kann vor dem Hintergrund der positiven Konnotation des Englischen Intentionen einschließen wie modern auf der Höhe der Zeit sein zu wollen, als gebildet zu gelten oder seine Gruppenzugehörigkeit unter Beweis stellen zu wollen. Fremde Lexik wirkt innovativ, sie kann für kreative Zwecke (z.B. Sprachspiele) genutzt werden. (Fiedler 2014: 4)

Phraseologisches Lehngut lässt sich je nach dem Grad seiner Anpassung an das Deutsche in folgende Gruppen einteilen (Fiedler 2014: 42, Munske 2015 [1993]: 120-121):

(a) direkte Entlehnungen, die meist sofort durch die befremdende Form auffallen (Fiedler 2014: 42), z.B: fishing for compliments, learning by doing, forget it, common sense;

(b) hybride Bildungen, bei denen eine Teilsubstitution vorliegt. Die Gruppe der Mischformen ist relativ klein, manchmal konkurrieren hybride Bildungen (fair genug) und direkte Entlehnungen (fair enough) miteinander. Als Beispiele führt Fiedler (ebd.) folgende Wortverbindungen heran: den Turnaround schaffen, Speed machen, ein Statement abgeben, etwas in der Pipeline haben, eine Deadline setzen;

(c) Die Mehrheit des Lehngutes machen Lehnübersetzungen (calques) aus. Fiedler verweist darauf, dass die Lehnübersetzungen, die ca. $70 \%$ des gesammelten Materials ausmachen, englischer Herkunft sind. Vgl. z.B. folgende Phraseologismen: netter Versuch engl. nice try, aus dem Blauen heraus engl. out of the blue. Munske (2015 [1993]: 121) differenziert an dieser Stelle zwischen Lehnbildungen (als einem übergeordneten Begriff), Lehnübersetzungen (lexikalisch und syntaktisch genaue Übersetzungen, in denen die Gesamtbedeutung des quellsprachigen Ausdrucks auf das Übersetzungsäquivalent übertragen wird) und Lehnübertragungen (in denen kleine lexikalische, morphologische oder syntaktische Modifikationen der fremdsprachigen Wortverbindung akzeptiert werden). Beide Autoren verweisen auf die Schwierigkeit in der Festlegung, wo es sich um tatsächliche Lehnübersetzungen und wo um parallele Entwicklungen in zwei oder mehreren Sprachen handelt.

(iv) Die intertextuelle Motiviertheit wird im Folgenden nach Dobrovol'skij/ Piirainen (2009: 33) als Rückgriff auf eine textuelle Vorgabe, auf einen existierenden Text (Bibel, Schriften antiker Autoren, literarische Werke, Aussagen bekannter Persönlichkeiten) aufgefasst. Hier handelt es sich um Aphorismen, Sentenzen, geflügelte Worte, Zitate, die sich in der Sprache verfestigt haben und den Status der Phraseologismen genießen, wie z.B. Wer zu spät kommt, den bestraft das Leben (diesen Satz soll Michail Gorbatschow, der letzte Generalsekretär des Zentralkomitees 
der Kommunistischen Partei der Sowjetunion, am 6. Oktober 1989 in einem VierAugen-Gespräch zu Honecker gesagt haben ${ }^{122}$ ), das ist des Pudels Kern ,das ist der wahre, eigentliche Sachverhalt, des Rätsels Lösung“ (ein Zitat aus Goethes „Faust“). Da die Bekanntheit der Etymologie von intertextuell motivierten Idiomen unterschiedlich ist und mit dem allgemeinen Bildungswissen des Rezipienten aufs Engste verbunden ist, ist ihre Motiviertheit graduell.

(v) Den letzten Motiviertheitstyp macht die indexale Motiviertheit aus, so wie sie von Dobrovol'skij/Piirainen (2009: 36-38) definiert und beschrieben wird. Die Verbindung zwischen der literalen und der phraseologisierten Lesart eines Idioms ist indexal (verweisend), weil sie nicht auf semantisch-konzeptueller Beziehung aufbaut, sondern darauf, dass in der Form des Idioms ein angelegter Verweis auf seine lexikalisierte Bedeutung enthalten ist: So wie der Rauch einen Verweis darauf darstellt, dass es in der Nähe Feuer gibt (Index bei Peirce 1993: 65), so verweist die phonische Form des Idioms: den heiligen Ulrich anrufen onomatopoetisch auf die Bedeutung des Idioms ,sich übergeben'. Die indexale Motiviertheit ist selten, kommt in der dieser Arbeit vorliegenden Phraseologismensammlung nicht vor und wird deswegen nur am Rande, der Vollständigkeit halber, behandelt.

Schematisch lassen sich die besprochenen Motiviertheitstypen wie folgt darstellen (Abb. 25):

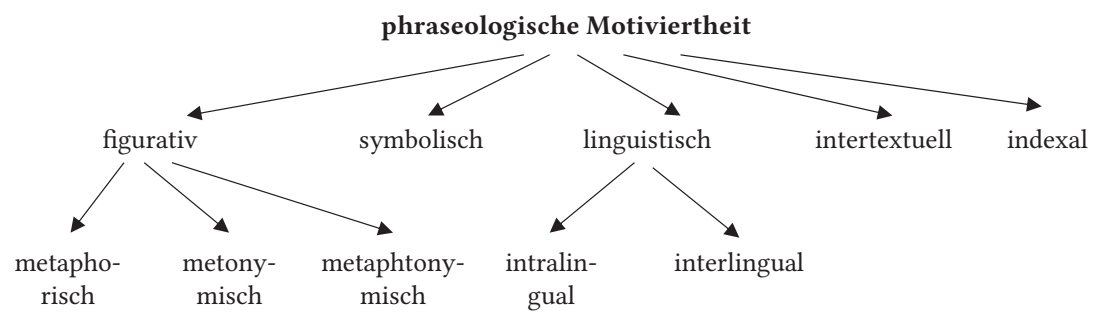

Abb. 25: Die Motiviertheitstypen der Phraseologismen.

\subsection{Bildlichkeit und Bildhaftigkeit der Idiome}

Die Fähigkeit der Idiome, mentale Bilder zu evozieren, wurde in der Phraseologie schnell erkannt: Auf die die Expressivität beeinflussende Bildhaftigkeit sprachlicher Einheiten, darunter Einzellexeme und Idiome, verweist bereits Ch. Bally (Bally 1905: 101-112, zit. nach Thun 1978: 137). Als Phraseologizitätsindikator wird die Bildhaftigkeit auch in Definitionen der Phraseologismen im engeren

122 Vgl. auch: https://www.welt.de/geschichte/article132968291/Gorbatschow-hat-denberuehmten-Satz-nie-gesagt.html/ (Zugriff am 03.12.2016). 
Sinne relativ früh angeführt (vgl. Burger/Buhofer/Sialm 1982, Ehegötz 1990: 499). Gleichzeitig stellt sie aber einen bis heute problematischen und verhältnismäßig selten berührten ${ }^{123}$ Aspekt der Phraseologismen dar, was auf mehrere Umstände zurückzuführen ist.

Zuallererst muss auf die Diskussion über mentale Repräsentationen verwiesen werden. Wie bereits erwähnt, haben die Verfechter eines propositional basierten Denkens in der Linguistik jahrelang die Oberhand behalten. Die strukturalistisch und generativistisch geprägten Sprachtheorien gingen von der Annahme aus, dass die semantischen Pole der sprachlichen Einheiten generell propositional strukturiert seien. Die einzelnen Theorien (vgl. z.B. Paivio 1971, 1986, Kosslyn 1980), die dem Anschaulichen, den Vorstellungsbildern einen gewissen Stellenwert eingeräumt hatten, wurden zwar zur Kenntnis genommen, dennoch fanden sie keinen Eingang in die linguistischen Theorien:

Diese kritische Distanz hängt zum einen mit dem über Jahrhunderte in kommunikativen wie wissenschaftlichen Praktiken eingeübten Logozentrismus zusammen. Sprache und Schrift gelten danach dem Bild als überlegen - sind dem die Dinge „durchschauenden“ Logos verpflichtet, der uns zu homo loquens macht. Bilder hingegen werden mit dem oberflächlichen Blick auf den Schein der Dinge und mit emotionalen Effekten und mythisch-rituellen Handlungen in Verbindung gebracht. (Stöckl 2004: 6-7)

Dabei kann die Skepsis, die den mentalen Bildern entgegengebracht wird, auf die methodologischen Schwierigkeiten ihrer Erforschung zurückgeführt werden, denn das Problem des Zugangs zu mentalen Bildern bleibt nach wie vor ungelöst: Die mentalen Bilder, die bei der Verarbeitung natürlicher Sprachen erschlossen werden, haben nämlich unter normalen Umständen eine äußerst ephemere Natur, sie entstehen an der Bewusstseinsschwelle.

In dem Moment, in dem die Vp [Versuchsperson, A. S.] beginnt, über ihre Bilder zu berichten, unternimmt sie zusätzliche mentale Operationen, die bei der normalen Rezeption des Idioms nicht unbedingt vorausgesetzt sind. Die Bilder, die die Vp wahrscheinlich auch wirklich in dem Moment sieht, in dem sie über sie nachzudenken beginnt, brauchen nicht identisch zu sein mit den Bildern, die bei ihr möglicherweise während des Rezipierens des Idioms in der Kommunikation evoziert werden. Wenn die Vp ihre Empfindungen dann außerdem verbalisieren muß, d.h. durch den Filter der Sprache hindurchschickt, muß sie sie nolens volens ordnen und verändern. Darum sollte man den Aussagen der Vpn über ihre Bilder nicht unbedingt Glauben schenken.

123 Abgesehen von einigen Beiträgen von Häcki-Buhofer (1989) und Rothkegel (2004, 2014) ist der Bildhaftigkeit in der Phraseologie wenig Aufmerksamkeit zugekommen. Wesentlich umfangreichere Literatur liegt zum Thema Bildlichkeit vor (Dobrovol'skij/Piirainen 2005, 2009; Rothkegel 2004). Im Fokus der Aufmerksamkeit von Stöckls Monographie (2004) Die Sprache im Bild, das Bild in der Sprache liegen die Beziehungen zwischen Bild und Text. Den Phraseologismen als sprachlichen Bildern werden zwei Kapitel $(3,4)$ gewidmet. 
Es ist bekannt, dass bei einer diskursiv kanalisierten Entfaltung von prinzipiell reduzierten, zusammengefalteten Strukturen immer eine Um- bzw. Dazu-Interpretation vor sich geht, vgl. z.B. die Wiedergabe der Trauminhalte. (Dobrovol'skij 1997: 46)

Hervorgehoben wird die subjektive Natur der mentalen Bilder: Das mentale Vorstellungsbild des Hundes wird maßgeblich dadurch beeinflusst, welchen Hund man besitzt oder besessen hat: Solche durch die individuelle Erfahrung geprägten Bilder sind intersubjektiv schwer fassbar und für die wissenschaftliche Behandlung äußerst problematisch. Darüber hinaus können sich die Menschen in der Quantität und Qualität ihrer mentalen Vorstellungsbilder wesentlich unterscheiden. Dies hat bereits 1883 Sir Francis Galton entdeckt, als er 100 Menschen, darunter prominente Wissenschaftler, um die Formung eines mentalen Bildes von dem am Morgen verzehrten Frühstück gebeten hat: Während manche Probanden über detaillierte mentale Bilder berichten konnten, waren die anderen nicht imstande, ein mentales Bild zu evozieren (vgl. http://www.intropsych.com/ch07_cognition/mental_imagery.html, Zugriff am 21.12.2016).

Das mangelnde Interesse an der Beschäftigung mit mentalen und sprachlichen Bildern in der Sprachwissenschaft ist möglicherweise darauf zurückzuführen, dass man analoge und propositionale Repräsentationsformate jahrelang in Konkurrenz zueinander setzte (vgl. die Beschreibung der einzelnen Positionen bei Schwarz 1992: 92-93). Erst mit der kognitiven Wende und der Entwicklung der Embodied/ Grounded Cognition sowie der Bild- und Medienlinguistik wird die Skepsis, die man bisher der multimodalen Natur der menschlichen Repräsentation entgegenbrachte, schrittweise überwunden. Die analogen und propositionalen Repräsentationsformate schließen sich nämlich nicht aus: Der konzeptuelle (semantische) Pol einer sprachlichen Einheit ist multimodal und wird als eine Kombination von ganzheitlichen (darunter analogen) und propositionalen Strukturen verstanden. Diese multimodale Struktur macht die „Übersetzungstheorien“ zu Repräsentationsformaten entbehrlich. Bemerkenswert ist dabei das Primat des Sehens (des analogen Repräsentationsformats) sowie die Tatsache, dass unter dem ganzheitlichen Format ebenfalls das Auditive, Olfaktorische, Taktile, Gustatorische verstanden wird. Die Prominenz des Bildes ist zweifelsohne darauf zurückzuführen, dass sich die meisten Menschen als „Augentiere“ betrachten und die Rolle der visuellen Wahrnehmung sehr hoch veranschlagen, was u.a. in Spruchweisheiten: seeing is believing, ein Bild sagt mehr als tausend Worte zum Ausdruck kommt (Stöckl 2004: 4). Festzuhalten bleibt auf jeden Fall:

Eine starke Fraktion innerhalb der kognitiven Psychologie hält die Existenz mentaler Bilder mittlerweile für erwiesen und betont deren zentrale Rolle in kognitiven Operationen, vornehmlich auch in mentalen Problemlösungsprozessen. Dieses durch Bilder initiierte anschauliche Denken bietet gegenüber einem symbolmanipulierenden Denken eine Reihe von Vorzügen. Wie beide kognitiven Modalitäten, die eine bildvermittelt, die andere sprachvermittelt, miteinander interagieren, bleibt eine der zentralen Fragen innerhalb der kognitiven Psychologie. Hiermit in engem Zusammenhang 
stehen die Unterschiede in den jeweiligen Repräsentationen sowie deren wechselseitige Aktivierbarkeit und Koppelung. (Stöckl 2004: 56)

\subsubsection{Materielles, mentales und sprachliches Bild}

Bezüglich der Bilder sind zahlreiche philosophische (z.B. Scholz 1991), psychologische (z.B. Oestermeier 1998), kunstwissenschaftliche (z.B. Bryson/Holly/Moxey 1991) Theorien entstanden ${ }^{124}$. Da ihre Beschreibung den Rahmen der folgenden Arbeit sprengen würde, wird im Folgenden ausschließlich auf die von Stöckl (2004) und Burger (2010: 96, 2015: 91-95) angeführte und für weitere Ausführungen relevante Einteilung in die materiellen, mentalen und sprachlichen Bilder eingegangen.

Bei materiellen Bildern handelt es sich - im Gegensatz zu den immateriellen, d.h. in der Sprache oder Kognition existierenden Bildern - um physisch wahrnehmbare Bilder (Burger 2010: 96). Den Ausgangspunkt bildet dabei die Ikonizitätstheorie, die besagt, dass das Bild grundsätzlich dem Gegenstand bzw. dem Sachverhalt, den es abbildet, ähnlich ist. Unter einem materiellen Bild versteht Stöckl das Bild und seine Beziehung zu dem abgebildeten Gegenstand. Als materielle Bilder fungieren also Photos, Gemälde u.Ä.

Materielle Bilder weisen zwei Leistungen auf: Sie können als Zeichen oder als optische Ereignisse funktionieren (Rothkegel 2004: 391). Als Zeichen haben sie eine den sprachlichen Zeichen analoge Bedeutung: Als Beispiel führt hier Rothkegel die sprachunabhängigen Gebrauchsanleitungen von IKEA, die komplizierte Inhalte übermitteln können. Als optisches Ereignis hat das Bild eine „Gestalt" im Hinblick auf die Form, Farbe, Dynamik, aber keine referentielle Bedeutung:

So ist es einsichtig, dass wir an den mittelalterlichen Geschichten-Bildern unsere Freude haben, sie ästhetisch genießen, auch wenn uns die dargestellten Inhalte nicht interessieren. Bei den IKEA-Instruktionsgraphiken ist es umgekehrt. Hier interessiert uns der Inhalt, aber nicht ein ästhetischer Wert. Kurz, mit Sprache vermitteln wir kognitive Inhalte: also Konzepte als begriffliche Einordnungen oder als Referenz auf Nicht-Sprachliches - Denkbares. Mit Bildern vermitteln wir ebenfalls kognitive Inhalte, aber auch Inhaltsfreies: Sichtbares, sinnlich-optische Erlebnisse. (Rothkegel 2004: 391)

Die analogen Repräsentationsformate weisen einige Charakteristika auf, die die kognitive Verarbeitung der Informationen wesentlich begünstigen. Die empirischen Befunde der kognitiven Psychologie, die kommunikativen Vorteile des Einsatzes der Bilder, fasst Stöckl in folgenden Punkten zusammen:

124 Einen Überblick über diese Theorien bietet Stöckl (2004: 47-86) sowie Kubaszczyk (2011: 29-39). 
i. das überlegene Gedächtnis für Bilder (picture superiority effect);

ii. die schnelle Wahrnehmung und Verarbeitung von Bildern;

iii. die effektive Aufmerksamkeitslenkung durch Bilder;

iv. die räumliche Grammatik des Bildes und ihr unmittelbarer Zugriff auf „Realität";

v. die emotionale Beteiligung und Beeinflussung durch visuelle Kommunikation sowie die Unterschwelligkeit bildlicher Botschaften;

vi. die größere Garantie, doppelt (d.h. zugleich sprachlich-kategoriell und bildlich) kodiert zu werden (Stöckl 2004: 9-10).

Mentale Bilder definiert Podding als „konsistente mentale Abbildungen der externen Informationsbasis" (Podding 1995: 176, zit. nach Stöckl 2004: 56). Ihr Status ist, wie Kubaszczyk (2011) zu Recht betont, nicht unumstritten: Während manche Forscher propositionale Repräsentation visueller Wahrnehmungen voraussetzen und mentale Bilder höchstens als subjektives Epiphänomen betrachten (Theoriebildung in Nachfolge von Fodor 1975 und Pylyshyn 1973), vertreten andere die Ansicht, dass als Ergebnis von visuellen Perzeptionen ein funktionsanaloges mentales Bild entsteht (Kubaszczyk 2011: 35). In der neueren Forschung ist die Tendenz erkennbar, einen integrativen Erklärungsansatz, nach dem die kognitiven Strukturen im Langzeitgedächtnis sowohl modalitätsspezifisch als auch modalitätsunspezifisch repräsentiert sind, anzustreben (Schwarz 2008: 126, vgl. auch Kap. 2.2 über modalitätsspezifische Repräsentationsformate und Grounded Cognition).

Ursprünglich bezog sich der Terminus, mentales Bild' ausschließlich auf die analogen Repräsentationen von dreidimensionalen Objekten, so wie sie beispielshalber in den Experimenten mit mentalen Rotationen von Shepard/Metzler (1971) eingesetzt wurden. ${ }^{125}$ In der modernen Auffassung werden als mentale Bilder allerdings nicht nur mentale Strukturen analogen Charakters angesehen, die für die Speicherung visuell-räumlicher Informationen geeignet sind. Der Terminus rich image schränkt sich nicht auf die visuellen Reize ein, Lakoff spricht ebenfalls von „auditory images, olfactory images, and images of how forces act upon us" (1987: 444). Die mentalen Bilder weisen somit die Züge der mentalen Modelle von Johnson-Laird (1983) auf:

Mentale Modelle werden prinzipiell als Kombinationen von ganzheitlichen, analogen und propositionalen, symbolmanipulierenden (digitalen) Repräsentationen verstanden. Der funktionsanaloge Charakter mentaler Modelle scheint allerdings besonders wichtig. So gelten sie vor allem als „hypothetische interne Quasi-Objekte, deren Eigenschaften denen des zu repräsentierenden Sachverhalts analog sind" (Schnotz 1994: 168). In ihre Konstruktion können jedoch propositionale Repräsentationen eingehen, die die analog gespeicherten Informationen ergänzen und ausdifferenzieren.

125 Shepard \& Metzler (1971) führten Experimente durch, die unter Beweis stellten, dass Menschen die wahrgenommenen Objekte mental präzise abbilden und sogar manipulieren können. 
Auch im Bereich der mentalen Zeichenprozesse also scheint eine Symbiose aus sprachnahen, symbolisch organisierten Repräsentationen und ikonisch, ganzheitlich bewerkstelligten Repräsentationen eine effektive Form der Informationsverarbeitung zu garantieren. (Stöckl 2004: 56)

Betonenswert ist dabei, dass die mentalen Bilder als mentale Repräsentationen der Wirklichkeit einen konstruktivistischen Charakter haben. Die wahrgenommenen Reize werden nicht in einem 1:1-Verhältnis abgebildet, man konstruiert sie eher neu auf der Folie der bisherigen Erfahrungen, Wissensbestände, Schemata und vor allem - unter dem lenkenden Einfluss der selektiven Aufmerksamkeit. Mentale Bilder stellen kein Abbild, sondern eine Repräsentation der Wirklichkeit dar; es sind mentale Konstrukte, die infolge der kognitiven Aktivität eines Menschen entstehen und in diesem Sinne können sie auch produktiv sein (vgl. das Beispiel der Cheshire-Katze von Barsalou, Kap. 2.2.2.3): Der visuelle Anreiz ist nicht notwendig, um die imaginierten, inneren Bilder zu erzeugen, mentale Vorstellungsbilder können sich auch ohne unmittelbare visuelle Wahrnehmung herausbilden (Kubaszczyk 2011: 36). Demzufolge ist auch ihre Wirklichkeitstreue unterschiedlich:

It is important at the outset to distinguish mental images from perceptions. A perception of a scene is rich in detail; every part of the visual field is filled. And one can focus on details that are very small and intricate. Moreover, since our eyes are constantly scanning different parts of the visual field, the details focused on are continually changing (...). Mental images have a different character. They are not nearly as detailed as perceptions, and they do not allow anything like the full range of perceived colors. People who see in color can have mental images in black and white. Not all of the field of mental vision is filled (...). Construction of an image and keeping it in mind is an effortful activity. Moreover, we can form images of things we can't see. (Lakoff 1987: 444)

Sprachliche Bilder kommen dann zustande, wenn ein eher abstrakter Sachverhalt durch einen konkreteren (ein „Bild“) konzeptualisiert wird (Stöckl 2004: 201202). Eine besondere Rolle bei der Konstituierung sprachlicher Bilder kommt der Metapher zu, deren Wesen darin liegt, dass sie assoziative Brücken zu perzeptuellen Systemen wie Sehen, Hören, Riechen, Schmecken und Fühlen schlägt (ebd., 210). Dementsprechend integriert ein weit gefasster psychologischer Begriff des sprachlichen Bildes neben typischen Wahrnehmungen des Sehens wie Form, Farbe und Verortung der Objekte im Raum auch die sensorischen Modalitäten des Olfaktorischen, Gustativen, Kinetischen, Taktilen, Auditiven etc. und erlaubt daher auch Synästhesien (ebd., 213).

Da Metaphern zwei Bereiche verbinden, den Bereich des Konkreten (Ausgangsbereich) und den Bereich des Abstrakten (Zielbereich), müssen die auf sensorischer Wahrnehmung aufbauenden ganzheitlichen Repräsentationen des Ausgangsbereiches als Erfahrungsgrundlage von Natur aus in den Konstruktionsprozess der metaphorischen Mappings kommen. Charakteristisch sind in diesem Sinne die traditionellen Bezeichnungen der Ausgangs- und Zieldomäne, die man 
als Bildspender- und Bildempfängerbereiche bezeichnet (vgl. Weinreich 1976, Burger 2010). Die Position der sprachlichen Bilder beschreibt Rothkegel wie folgt:

In der Diskussion zur Relation von Sprache und Bild nimmt das sprachliche Bild eine Zwischenposition ein. Dem Zeichensystem Sprache zugehörig, bringt es Eigenschaften ein, die Bildern zugesprochen werden. Beiden Ebenen gemeinsam ist die Funktion der Bedeutungsbildung und -vermittlung sowie der formalen Gestaltung in Bezug auf Fläche und Raum. Während - in kognitiver Sicht - sprachliche Mittel immer als Kode fungieren (geregelte Zuordnung von Ausdruck und Inhalt/Funktion), d.h. als Übersetzung von Information, operieren bildliche Mittel analog, d.h. als Abbildung von Information. Phraseme, die sprachliche Bilder repräsentieren wie das Herz höher schlagen lassen, sich über Wasser halten, auf die Palme bringen haben Anteil an beiden Ebenen. (Rothkegel 2004: 392)

\subsubsection{Bildlichkeit und Bildhaftigkeit}

Viele Parallelen zu der Einteilung in die mentalen und sprachlichen Bilder weist die in der Phraseologie und Stilistik übliche Differenzierung zwischen der Bildhaftigkeit und der Bildlichkeit auf.

Ursprünglich wurden die Termini Bildlichkeit und Bildhaftigkeit gleichgesetzt. So definieren Burger/Buhofer/Sialm (1982) die phraseologische Bildlichkeit als Eigenschaft der Phraseologismen, die darin besteht, dass die meisten (wenn auch nicht alle) Phraseologismen, unabhängig von der semantischen Unmotiviertheit durch ihre wörtliche Bedeutung eine anschauliche, analoge Vorstellung zu evozieren vermögen, selbst dann, wenn sich keinerlei Verhältnis zwischen dem Bild und der phraseologischen Bedeutung feststellen lässt.

In der neueren Forschung besteht dennoch die Tendenz, die Bildlichkeit von der Bildhaftigkeit abzugrenzen (Burger 1989, 2007a, 2010, 2015, Häcki-Buhofer 1989, Kapuścińska 2014, Rothkegel 2004, Stöckl 2004, Topczewska 2004). Als aufschlussreich erwies sich hier vor allem die von Burger vorgenommene Neudefinierung der beiden Begriffe: In Anlehnung an die Stilistik führt Burger (1989: 28) nach E. Riesel folgende Definitionen der beiden Begriffe heran:

Bildhaft (synonym zu anschaulich, sinnfällig) sind Wörter und Wendungen, die zwangsläufig mit einer konkreten, klaren Situation, mit einem leicht erfaßbaren Wirklichkeitszusammenhang assoziiert werden.

Bildlich nennen wir Wörter und Wendungen auf Grund von Vergleich, Tropen, metaphorischen und metonymischen Periphrasen, metaphorischen Beiwörtern sowie expressiver Phraseologie. (Riesel 1970: 310)

Bezogen auf die Phraseologie interpretiert Burger die Termini folgendermaBen: Bildhaft sind die Phraseologismen, die eine wörtliche Lesart haben, die konkret vorstellbar ist.

Insofern kann man sagen, dass Wörter wie $\dot{O} l$ und Feuer bildhaft sind, weil man sich unter $\dot{O} l$ und Feuer etwas Visuell-Konkretes (eventuell verbunden mit weiteren 
Sinnesausdrücken) vorstellen kann, und man kann sagen, dass die wörtliche Bedeutung des Idioms Öl ins Feuer gießen bildhaft ist, wie auch der ganze Vorgang als visuell-konkret vorstellbar ist. (Burger 2010: 97)

Bildlich sind dagegen die Phraseologismen, die einen Zusammenhang zwischen der wörtlichen und der phraseologischen Lesart haben, der für den muttersprachlichen Sprecher/Hörer nachvollziehbar ist, d.h. der Sprecher „muss die wörtliche Lesart als ein >>natürliches $<<$, einleuchtendes Modell für die phraseologische Lesart empfinden" (Burger 1989: 26). Bildhaftigkeit ist somit an die konkret-anschauliche, literale Lesart gebunden, Bildlichkeit hängt dagegen mit der Metaphorizität (ev. Metonymisierung und Symbolisierung) zusammen. Die phraseologische Bedeutung des Idioms Öl ins Feuer gießen ist „bildlich“, insofern sie durch einen metaphorischen Prozess zustande kommt. Hier meint Bild nur etwas ganz anderes, nämlich die metaphorische Konzeptualisierung eines abstrakten Vorgangs durch einen konkreten (Burger 2010: 97). Aus psycholinguistischer Perspektive beschreibt Häcki-Buhofer die beiden Phänomene wie folgt:

Bildhaftigkeit meint eine Eigenschaft der Sprache, die auch einfachen Wörtern zugeschrieben werden kann, bei der es darum geht, wie gut man sich visuell etwas dazu vorstellen kann. Bildhaftigkeit vereinfacht. Übertragenheit dagegen betrifft Metaphern und Phraseologismen und meint eine Komplikation, eine kognitiv zu lösende Schwierigkeit gegenüber wörtlich verstehbaren Ausdrucksweisen, dass man nämlich einen Ausdruck nicht wörtlich verstehen kann, sondern als Bild für etwas Gemeintes verstehen muss, wobei man das Gemeinte - wenn man nicht konventionalisiert versteht - erst noch erschließen muss. Übertragenheit verkompliziert. (Häcki-Buhofer 1989: 165$)^{126}$

Den Versuch, die Begriffe der Bildlichkeit und Bildhaftigkeit genauer zu konturieren, nimmt Burger (2007a) vor. Parallel zu der Unterscheidung zwischen der Motiviertheit und Motivierbarkeit formuliert er vier Bedingungen, die ein Idiom erfüllen muss, um als bildhaft zu gelten:

Damit ein bildhaftes Idiom vorliegt, müssen folgende Bedingungen gegeben sein:

1. Der Phraseologismus muss eine wörtliche Lesart haben, die als konkrete vorstellbar ist (das ist die „Bildhaftigkeit“ des Phraseologismus oder - wie man einfacher sagen könnte - das idiomatische Bild).

126 Diese Schlussfolgerung ist im Kontext der Diskussion über die Bildlichkeit und Bildhaftigkeit vielleicht nachvollziehbar, in anderen Kontexten dennoch höchst umstritten. Die Metapher hat schließlich die Funktion, die komplizierten, abstrakten Inhalte durch den Bezug auf die Sphäre der täglichen Erfahrung sinnbildlich, vereinfachend darzustellen. Im Weiteren wird auch dafür argumentiert, dass man zwischen bildhaften, bildlichen sowie bildhaft-bildlichen Idiomen differenzieren kann. 
2. Der Zusammenhang zwischen der wörtlichen und der phraseologischen Lesart muss für den muttersprachlichen Sprecher/Hörer nachvollziehbar sein, d.h. er muss die wörtliche Lesart als ein „natürliches“, „einleuchtendes“ Modell für die phraseologische Lesart empfinden. (...) Mögliche Zusammenhänge können als metaphorische, metonymische, symbolische usw. Relationen beschrieben werden.

3. Der Zusammenhang muss kollektiv (konventionell) sein, d.h. für die ganze Sprachgemeinschaft oder Teile davon Geltung haben.

4. Der Zusammenhang muss lexikalisiert sein, d.h. die metaphorische Übertragung ist auf eine Interpretation festgelegt. Man könnte sagen: Die phraseologische Lesart determiniert die wörtliche Lesart als den Bildspender genau dieser Metapher und sie interpretiert das Bild in einer bestimmten (arbiträren) Weise. (Burger 2007a: 101)

In dieser Definition setzt die Bildhaftigkeit die Bildlichkeit voraus, was meiner Ansicht nach nicht nachvollziehbar ist. Bildhaftigkeit ist nämlich nicht an die metaphorischen, metonymischen oder symbolischen Derivationen gebunden, sondern kommt als Eigenschaft ebenfalls zahlreichen literalen Ausdrücken zu, die konkret-anschauliche Bildvorstellungen auslösen, vgl. die Äußerungen:

Das Kind spielte mit einem Auto.

Im Flur lag ein großer Hund.

Nicht überzeugend ist ebenfalls die Annahme, dass die Bildhaftigkeit an die Motiviertheit gebunden ist (Punkt 2). Manche opake Idiome (ins Gras beißen, kick the bucket) sind für die meisten Sprachteilhaber bildhaft ${ }^{127}$, auch wenn ihre Motiviertheit aus synchroner Perspektive nicht für alle verständlich ist. Selbst Idiome mit unikalen Komponenten (am Hungertuch nagen, in der Tretmühle sein) können mentale Bilder evozieren. Somit sind die Bildlichkeit und Bildhaftigkeit als zwei getrennte Phänomene zu fassen, die zwar oft zusammen auftreten, wohl aber in keiner Wechselrelation stehen.

\subsubsection{Das mentale und das idiomatische Bild}

In den neueren Auflagen der Phraseologie. Eine Einführung am Beispiel des Deutschen unternimmt Burger (2010: 96-100, 2015: 91-95) einen weiteren Versuch, die terminologische Verwirrung aufzulösen, indem er den Terminus des idiomatischen Bildes einführt und definiert. Burger unterscheidet zwischen bildhaften Idiomen und den Idiomen mit einem idiomatischen Bild. Drei Bedingungen müssen erfüllt sein, damit man von einem idiomatischen Bild sprechen kann.

127 Vorsichtige Bemerkungen zu intersubjektiven Aspekten der Bildhaftigkeit erlaubt die Überprüfung der Wortverbindungen auf www.google.grafika. Manche Idiome sind mit zahlreichen Zeichnungen, Skizzen, Fotos, Bildern aus verschiedenen Quellen veranschaulicht (z.B. ins Gras beißen), zu anderen (z.B. jmdn. im Stich lassen) findet man keine passenden materiellen Bilder. 
1. Das Idiom muss eine wörtliche Lesart haben, die als konkrete vorstellbar ist. (Das ist die „Bildhaftigkeit“ des Idioms.)

2. Der Zusammenhang zwischen der wörtlichen und der phraseologischen Lesart muss für den muttersprachlichen Sprecher/Hörer nachvollziehbar sein, d.h. er muss die wörtliche Lesart als ein „natürliches“, „einleuchtendes“ Modell für die phraseologische Lesart empfinden, anders gesagt: Er muss das Idiom als motiviert auffassen. Mögliche Zusammenhänge können als metaphorische, metonymische, symbolische usw. Relationen beschrieben werden.

3. Der Zusammenhang muss lexikalisiert sein, d.h. die metaphorische Übertragung ist auf eine Interpretation festgelegt. Man könnte sagen: Die phraseologische Lesart determiniert die wörtliche Lesart als den Bildspender genau dieser Metapher und sie interpretiert das Bild in einer bestimmten (arbiträren) Weise. Das Bild ist integraler Bestandteil des Idioms als Zeichen. (Burger 2010: 99; 2015: 92)

Bildhaft sind somit zahlreiche Idiome. Als Idiome mit einem idiomatischen Bild können dagegen nur diejenigen bezeichnet werden, die zusätzlich die Bedingungen 2 und 3 erfüllen, d.h. phraseologisch motiviert sind. So ist z.B. das Idiom jmdm. einen Korb geben ,einen Heiratsantrag ablehnen' aufgrund seiner Visualisierbarkeit bildhaft, da es aber für die meisten Sprecher synchron nicht motiviert ist, besitzt es kein idiomatisches Bild (ebd.).

Diese Unterscheidung ist nachvollziehbar und für die Theorie der Phraseologie wichtig. Welcher Status dem idiomatischen Bild dennoch aus der psycholinguistisch-kognitiven Perspektive zukommt und ob das mentale Bild und das idiomatische Bild im Falle der motivierten Idiome identisch sind, d.h. ob das idiomatische Bild auch psychologisch real ist, scheint allerdings erklärungsbedürftig zu sein.

Der Terminus des idiomatischen Bildes hat nämlich einen engen Bezug zu dem Begriff der Motiviertheit, die Burger wiederum mit der semantischen Basis in Beziehung setzt. Wenn die Motiviertheit eines Idioms tatsächlich für alle Sprecher einer Gemeinschaft gleich ist, dann muss auch das idiomatische Bild wahrscheinlich gemeinsame Züge aufweisen. Die Motiviertheit ist aber - worauf bereits verwiesen wurde - ein graduelles Kriterium. Die meisten Idiome erwerben die Menschen nicht durch den bewussten Lernprozess, in dem sie ihre Motiviertheit und Etymologie explizit erörtern und sich merken, sondern sie erschließen sie aus den Sprachgebrauchsereignissen, in denen die idiomatischen Wortverbindungen in ambiguen Kontexten verwendet werden.

So könnte das Idiom die Flinte ins Korn werfen, ugs. vorschnell aufgeben, versagen' (DUW) für manche Sprecher motiviert, für andere als in seiner Motiviertheit nicht nachvollziehbar betrachtet werden. Dabei evoziert das Idiom wenigstens zwei mentale Vorstellungsbilder:

In dem ersten Bild kann man sich das Korn als einen Haufen Getreidekorn z.B. in einer Scheune vorstellen, auf den man eine Flinte wirft. In diesem Fall wäre es möglich, dass manche Sprachteilhaber Probleme mit der Herausfindung der 
Korrespondenzen zwischen der literalen und der phraseologisierten Lesart hätten. Das Idiom würde dann für sie als unmotiviert - also bildhaft, aber ohne idiomatisches Bild - gelten.

Ein anderes potenziell mögliches Bild beschreibt Rothkegel (2014: 279): Das Korn referiert hier nicht auf das Samenkorn, das Getreide, sondern auf ein Kornfeld, in das man das Gewehr wirft.

Bei 1 [dem Idiom die Flinte ins Korn werfen, A. S.] können wir - unabhängig von der Etymologie (Bezug auf Deserteure im 30jährigen Krieg) - uns ein (hoch stehendes) Kornfeld sowie eine Flinte (Gewehr) auf der Basis unseres Erfahrungswissens (erlebt oder vermittelt) vorstellen und auch, wie eine Person den Gegenstand in das Feld wirft, um (a) ihn dort den Blicken anderer, insbesondere der Vorgesetzten zu entziehen, und (b) sich damit seines professionellen Werkzeugs entledigt. Die Vorstellung von (b) gestattet schließlich die gegenwärtige Bedeutung „resignieren“. (Rothkegel 2014: 279)

Dieses Bild ist durch die wahre Etymologie ${ }^{128}$ beeinflusst, die einer Phraseologieforscherin bekannt, einem durchschnittlichen Sprachteilhaber aber nicht unbedingt geläufig ist. Ob unsere Zeitgenossen, mehrheitlich doch Stadtmenschen und im Falle der jüngeren Generation auch „Computermenschen“ tatsächlich ausnahmslos eine assoziative Verbindung zwischen der sequenziellen Vorstellung der Entledigung einer Flinte im Korn und dem Resignieren herstellen, dürfte nicht mit Sicherheit vorausgesetzt werden. Bei positiver Antwort käme der Wortverbindung der Status eines Idioms mit einem idiomatischen Bild, bei negativer Antwort wäre das Idiom nur bildhaft.

Einleuchtende Beispiele für die individuelle Prägung der Bildlichkeit und Bildhaftigkeit dürfte die Übersicht der materiellen Bilder zu den Idiomen auf den Internetseiten der www.google.grafika geben. Zwar können die materiellen, in vielen Fällen sorgfältig ausgearbeiteten Graphiken oder kunstvoll komponierten Fotos keinesfalls mit flüchtigen mentalen Bildern gleichgesetzt werden, die während der spontanen Sprachverarbeitung auftauchen, nichtsdestotrotz gewähren sie

128 Interessanterweise sind diese Darstellungen durch das etymologische Wissen geprägt: Die Herkunft des Idioms die Flinte ins Korn werfen wird nämlich auf zwei potenzielle Quellen zurückgeführt: Noch bis in den Dreißigjährigen Krieg (16181648) hinein wurden Handfeuerwaffen mit Radschloss und Lunte gebraucht, die angezündet werden musste. Um 1630 erfand man in Frankreich eine selbstzündende, mit einem Feuerstein ausgestattete Waffe. Althochdeutsch „flins“ (Feuerstein, verwandt mit „Fliese“) gab dieser Flintbüchse den Namen. „Flinte“ und „Büchse“ sind heute die jägersprachlichen Ausdrücke für das Gewehr. Die Redensart „die Flinte ins Korn werfen" wird allgemein auf die Flucht des Soldaten zurückbezogen, der die hinderliche Waffe wegwirft, um schneller voranzukommen. Seiler dagegen vermutet den Ursprung in der Jägersprache: „Der Jäger wirft aus Wut darüber, daß er nicht getroffen hat, die Flinte auf die Erde" (Deutsche Sprichwörterkunde, 1922: 253) (vgl. redensarten-index, Zugriff am 11.01.2016). 
Einblicke in die Vielfalt der subjektiven Assoziationen zu einzelnen Idiomen. So sieht man auf den Bildern/Fotos zum Idiom ins Gras beißen (i) eine Nahaufnahme eines Mundes mit einigen Grashalmen zwischen den Zähnen, (ii) einen Fußballspieler, der mit wutverzerrtem Gesicht in den Rasen beißt, (iii) einen auf dem Gras eines Schlachtfeldes liegenden Ritter, (iv) ein aus der Vogelperspektive aufgenommenes Foto eines bäuchlings auf dem Rasen eines gepflegten Gartens liegenden jungen Mannes, um den herum unordentlich Gartenutensilien und abgebrochene Äste liegen, was auf einen tragischen Unfall oder Mord schlussfolgern lässt. Die Fotos (i), (ii) liefern eine bildhafte Darstellung des Idioms ins Gras beißen, in der Zeichnung (iii) und auf dem Foto (iv) besteht eine deutliche Verbindung zwischen der literalen und der phraseologisierten Bedeutung ,plötzlich sterben'. In diesen Fällen kann man aus linguistischer Perspektive von Bildlichkeit der Darstellung/ einem idiomatischen Bild sprechen.

Demnach bereitet die Erfassung der subtilen und weitgehend individuellen Phänomene der Bildhaftigkeit und der Bildlichkeit zahlreiche Schwierigkeiten. $\mathrm{Ob}$ die von Menschen evozierten mentalen Bilder generell gut etabliert und durch die phraseologisierte Lesart beeinflusst sind (also als idiomatische Bilder im Sinne von Burger fungieren), oder eher als flüchtige, punktuelle Vorstellungen von einem analogen Charakter zu den einzelnen Idiomkonstituenten aufzufassen sind, ist umstritten, was ebenfalls in den unten dargestellten Theorien zum Ausdruck kommt.

\subsubsection{Mentale Bilder und die Konstituierung idiomatischer Bedeutung - Hypothesen}

Die Schwierigkeiten in der Erfassung der flüchtigen Natur der mentalen Bilder sind in den Theorien sichtbar, die die mentalen Bilder und ihren Einfluss auf die Bedeutung der Phraseologismen zu erforschen suchen: Während sich Gibbs und Mitarbeiter hauptsächlich auf den Einfluss der konzeptuellen Metaphern auf die mentalen Bilder konzentrieren, verweisen Cacciari und Glucksberg (1995) auf die grundlegende Rolle der literalen Lesart. Dobrovol'skij und Piirainen rücken die semantische Perspektive in den Vordergrund der Aufmerksamkeit. Sie bedienen sich der Termini ,bildliche Komponente' sowie ,innere Form', um das Zusammenspiel zwischen der literalen und der phraseologisierten Lesart darzustellen.

\subsubsection{Mentale Bilder und konzeptuelle Metaphern: die kognitiv- konzeptuelle Hypothese von Gibbs/O’Brien}

Auf große Resonanz in der kognitiv ausgerichteten Phraseologie stoßen die Untersuchungen zu mentalen Bildern von Gibbs und O’Brien (1990), die in psycholinguistisch ausgerichteten Experimenten die mit englischen Idiomen assoziierten mentalen Bilder erforschen. Der Untersuchungsstoff umfasst fünf thematische Gruppen, in denen jeweils fünf idiomatische Einheiten aufgeführt werden, z.B.: 
Anger
Blow your stack
Hit the ceiling
Lose your control
Foam at the mouth
Flip your lip
Revelation
Spill the beans
Let the cat out of the bag
Blow the whistle
Blow the lid off
Loose lips. (Gibbs/O'Brien 1990: 41)

Die Aufgabe der Probanden liegt darin, die von Idiomen evozierten mentalen Bilder zu beschreiben und detaillierte Fragen bezüglich der Kausalität, Intentionalität, der Art und Weise der Durchführung und der Folgen von verschiedenen Ereignissen und Handlungen zu beantworten. So müssen sie beispielshalber herausfinden, ob die Bohnen in dem Idiom spill the beans vor dem Verschütten gekocht oder ungekocht, nach dem Verschütten mit oder ohne Schmutzbeimischung, schwer oder leicht einzusammeln waren. Dabei stellte sich heraus, dass die meisten Menschen auf derartige Fragen problemlos antworten konnten:

Most speaker can form mental images for idioms like spill the beans and answer these questions about their mental images without difficulty. Even people without a conscious image of this phrase can answer these questions. Although there is some variation in people's images for spill the beans, speakers generally report that the container for the beans is about the size of a human head, the spilling appears to be accidental, the spilled beans are rarely in a neat pile, and are not easy to retrieve. (Gibbs/O'Brien 1990: 37)

Die Regularität und Kohärenz der mentalen Bilder erklären Gibbs und O’Brien mit dem Einfluss der konzeptuellen Metaphern: Die mentalen Bilder, die mit dem Idiom spill the beans assoziiert werden, sind durch die conDuIT (Kanal)-Metapher (Reddy 1979, Lakoff/Johnson 1980) motiviert:

This metaphor specifies the conceptual mapping that THE MIND IS A CONTAINER, and IDEAS ARE PHYSICAL ENTITIES which are communicated by taking ideas out of the mind, putting them into words, and sending them to other people. We understand the mind (the target domain) as being like a container (the source domain) and ideas (the target domain) as being like different physical entities (the source domain) such as food, plants, or money. (...). Most of the conventional images for spill the beans correspond to the information or ideas which are supposed to be kept in the container, but which are accidentally let out through spilling. (Gibbs/ O’Brien 1990: 38) 
Ähnliche Resultate erzielen sie im Hinblick auf die Ärger-Idiome, z.B. flip your lid, hit the ceiling. Auch wenn die Deckel und Decken auf unterschiedliche Art und Weise geworfen oder gestoßen werden können, beruhen die mentalen Bilder der Probanden generell auf der Vorstellung eines unter Druck stehenden Behälters. Die Probanden wissen, wie Druck (z.B. Stress oder Frustration) die Aktion auslöst, dass das Individuum keine oder nur kleine Kontrolle über die Handlung hat, dass die gewaltsame Freilassung unwillkürlich geschieht und nicht rückläufig gemacht werden kann. Der Einfluss der konzeptuellen Metaphern: KÖRPER IST BEHÄLTER, ÄRGER IST DRUCK IN DEM BEHÄLTER ist in den mentalen Bildern unverkennbar: „subject's protocols revealed little variation in the general events that took place in their images for idioms with similar meanings" (ebd., 43). Die häufigsten Antworten der Probanden werden unten angeführt:

Anger
General Image:
Causation
Intentionality
Manner
Consequences
Negative consequen
Reversibility
Revelation
General Image:
Causation
Intentionality
Manner
Consequences

Negative consequences

Reversibility
Some force causes a container to release pressure violently

Stress/anger/frustration

Action is not intentional

Action is performed with force

Anger/pressure is released

Build-up of pressure, explosion

The action is difficult to reverse

Some container is opened or tipped over and its contents are forcefully revealed

Pressure or a pressureful situation

Action is intentional

Action is performed with force

Substance that should be contained is released or revealed

Substance remain contained

The action is difficult to reverse

Auf der Grundlage dieser Experimente wird eine Hypothese formuliert, die als ,konzeptuell-metaphorisch (Dobrovol'skij 1997: 43) oder ,kognitiv ' (Stöckl 2004: 205) bezeichnet wird. Die Grundannahme dieser Hypothese lässt sich wie folgt zusammenfassen:

People have very consistent mental images for idioms and their knowledge of these images suggest the active role of conceptual metaphors in motivation the figurative meanings of idioms. People tacitly know that certain idioms have the meanings they do because of the continuing influence that conceptual metaphors have on their mental images for these expressions. And it is these conceptual metaphors that 
motivate the links between idioms and their nonliteral meanings. (Gibbs/O'Brien 1990: 49)

Dementsprechend sind die mentalen Bilder durch die konzeptuellen Metaphern beeinflusst, die unbewusst, automatisch bei der Idiom-Rezeption aktiviert werden. Auch wenn Elemente des mentalen Bildes durch die konkret-anschauliche literale Lesart evoziert sind (Bohnen, verschütten), so ist ihre räumliche Anordnung durch die phraseologisierte Lesart restringiert, die wiederum durch die konzeptuellen Metaphern (MIND IS A CONTAINER, IDEAS ARE ENTITIES) geprägt wird: Der Behälter hat die Größe des menschlichen Kopfes, die Bohnen sind ursprünglich in dem Behälter, das Verschütten ist unbeabsichtigt, die Bohnen sind danach schwer einzusammeln (ebd., 37).

Diese Forschungsergebnisse und die darauf fußende Hypothese werden dann dennoch einer Revision unterzogen. Kritisiert wird u.a. die Methodik gezielter Fragen über die mentalen Bilder, die als suggestiv angesehen wird (Häcki-Buhofer 1993: 152, Dobrovol'skij 1997: 46-47):

Wenn die Vpn z.B. gefragt werden, ob man die verschütteten Bohnen wieder einsammeln kann, werden sie schon durch die Form einer Entscheidungsfrage vor eine Alternative gestellt. Indem sie zur Entscheidung kommen, befragen sie höchstwahrscheinlich nicht nur ihre visuellen Bilder (vielleicht haben sie gar keine Bilder gesehen), sondern auch ihre Kenntnis der aktuellen Bedeutung des Idioms spill the beans. Da man weiß, dass die erzählten Inhalte nicht unerzählt gemacht werden können, wird über die Bohnen ausgesagt, dass sie nicht mehr in den Topf zurück können. (Dobrovol'skij 1997: 46-47)

Wie erwähnt, ist es des Weiteren anzunehmen, dass die bewusst elaborierten mentalen Bilder, über die befragten Probanden nachträglich verbal zu reflektieren hatten, nicht unbedingt identisch mit den flüchtigen mentalen Bildern sein müssen, die unter authentischen Bedingungen entstehen (vgl. Kap. 3.4).

\subsubsection{Mentale Bilder und literale Lesart: property-attribute model von Glucksberg u.a.}

Im Gegensatz zu der dargestellten kognitiv-konzeptuellen Hypothese, die von Gibbs/Colston (2007), Gibbs/O'Brien und Gibbs (1993, 1994) in mehreren Veröffentlichungen vertreten wird, verweisen Cacciari/Gluckberg (1995) sowie Glucksberg/McGlone/Keysar (1992) im Rahmen des sogenannten property-attribute-Modells auf die grundlegende Rolle der literalen Lesart bei der Herausbildung des mentalen Bildes. In ähnlich wie bei Gibbs konzipierten psycholinguistischen Experimenten werden die Probanden gebeten, ihre mentalen Bilder zu den in vier Gruppen eingeteilten Idiomen (geläufige und transparente, nicht-geläufige und transparente, geläufige und opake, nicht-geläufige und opake Idiome) möglichst genau zu beschreiben. Die weitaus überwiegende Mehrheit der Probanden war imstande, die mentalen Bilder zu evozieren (nur 
in 4 der insgesamt 340 durchgeführten Umfragen hatten die Probanden kein mentales Bild evoziert). Interessanterweise sind die meisten (78,8\%) mentalen Bilder ausschließlich durch die literale Lesart beeinflusst (Cacciari/Gluckberg 1995: 290). Selbst bei geläufigen und usualisierten Idiomen, bei denen die phraseologisierte Lesart als dominant angesehen werden kann, sind die mentalen Bilder hauptsächlich an die literale Lesart gebunden. So berichten die meisten Probanden zu dem Idiom break the ice von den Vorstellungsbildern wie „ein Eskimo mit Hammer und Meißel, der das Eis um sich herum zerschlägt" oder „das Eis in einer Küchenmaschine zerbröckeln, damit man damit das Essen abkühlt" (ebd.). Die durch die phraseologisierte Lesart des Idioms beeinflussten mentalen Bilder (wie z.B. „ein großer Eisklotz, der von beiden Seiten von Menschen mit Meißeln wie Berliner Mauer zerschlagen wird“) sind wesentlich seltener (ebd., 290-291).

Die von Cacciari/Glucksberg erzielten Untersuchungsergebnisse widersprechen zwar der potenziellen Möglichkeit der Beeinflussung von mentalen Bildern durch die konzeptuelle Metapher nicht ganz, sie verweisen aber darauf, dass ihr Einfluss wesentlich geringer ist, als von Gibbs angenommen wird. Dazu schreibt Glucksberg u.a.:

We did (and still do) acknowledge the potential role of conventional metaphors in the generation of ad hoc attributive metaphor categories. We did, however, also argue that such conventional metaphoric mappings need not be accessed or used in the production and comprehension processes. The issue then is not how many (very few, some, many, or, as Gibbs argues, the vast majority of) metaphorical expressions are understood by accessing prestored conventional metaphoric mappings, but rather under which circumstances (if any) such mappings come into play. Conventional metaphorical mappings, as well as other types of conceptual schema, can be available yet not accessible in given contexts (...). (Glucksberg/McGlone/Keysar 1992: 578)

Wie daraus erhellt, bringt die Psycholinguistik keine eindeutigen Antworten zur Natur der mentalen Bilder. Die empirische Evidenz lässt schlussfolgern, dass mentale Bilder hauptsächlich durch literale Lesart eines Idioms evoziert und beeinflusst werden. Der Beitrag der phraseologisierten Lesart und konzeptueller Metaphern zur Konstituierung von mentalen Bildern ist dabei möglich, scheint dennoch weniger ausgeprägt zu sein.

\subsubsection{Die Theorie des bildlichen Lexikons von Dobrovol'skij/Piirainen}

Der Frage nach der Natur der semantisch relevanten analogen Komponente gehen in ihrer Conventional Figurative Language Theory (= CFLT) Dobrovol'skij/Piirainen $(2005,2009)$ nach. Zentral für die Theorie des bildlichen Lexikons ist die Annahme einer spezifischen konzeptuellen Struktur, die zwischen der literalen und der phraseologisierten Lesart vermittelt. Diese konzeptuelle Struktur - als 
bildliche Bedeutungskomponente, Bildkomponente bzw. innere Form ${ }^{129}$ bezeichnet - wird durch das der literalen Lesart zugrunde liegende mentale Bild evoziert. Der Inhaltsplan der Idiome besteht somit aus zwei Makrokomponenten: (1) aus der lexikalisierten Bedeutung und (2) aus dem mentalen Bild, das durch die lexikalische, wörtliche Struktur evoziert wird (Dobrovol'skij/Piirainen 2009: 12).

The underlying mental image, which is in general an individual psychological phenomenon, possesses certain elements that are more or less stable and intersubjective in the sense that they leaves traces in the lexicalised figurative meaning of a CFU [conventional figurative unit, A. S.] (i.e. in its actual meaning) or elements of the mental image make up the image component of a CFU. The image component provides motivating links: conceptual links between the literal reading and the actual meaning constitute the image component. (Dobrovol'skij/Piirainen 2005: 354)

Im Gegensatz zu der traditionellen Phraseologie, die davon ausgeht, dass zwischen den beiden Ebenen keine Beziehungen bestünden ${ }^{130}$, wird in der Theorie des bildlichen Lexikons die Ansicht vertreten, dass in der lexikalisierten Bedeutung oft bestimmte Spuren des mentalen Bildes zu finden sind, das durch die literale Lesart evoziert wurde (Dobrovol'skij/Piirainen 2009: 12-13). Aus dieser zentralen Annahme ergeben sich folgende Postulate für die Theorie des bildlichen Lexikons (Dobrovol'skij/Piirainen 2005: 354-355), dessen relevanten Bestandteil Idiome ausmachen:

(i) Zahlreiche relevante Usus-Restriktionen von Idiomen sind auf die Spezifik der Bildkomponente zurückzuführen.

(ii) Semantische und pragmatische Differenzen zwischen Idiomen mit ähnlicher lexikalisierter Bedeutung lassen sich von der Bildkomponente ableiten.

(iii) Quasi-äquivalente Idiome aus verschiedenen Sprachen sind sich nie in ihren semantischen und pragmatischen Eigenschaften identisch, wenn zwischen ihren Bildkomponenten wesentliche Unterschiede bestehen.

(iv) Auch wenn die Bildkomponente den Gebrauch eines Idioms nicht direkt beeinflusst, macht sie doch einen Teil seines Inhaltsplans, der in spezifischen, z.B. wortspielerischen Kontexten aktiviert werden kann.

(v) Da manche spezifischen Eigenschaften der Bildkomponente historisch begründet sind (d.h. die Bildkomponente erhält Wissensstrukturen aus der Entstehungszeit einer figürlichen Spracheinheit), können bestimmte

129 Der Terminus, innere Form ' ist von Dobrovol'skij/Piirainen anders aufgefasst als in der neuromantischen Sprachtheorie von L. Weisgerber. Weisgerber versteht unter innerer Sprachform das, „was in dem begrifflichen Aufbau des Wortschatzes und Inhalt der syntaktischen Formen einer Sprache an gestalteter Erkenntnis niedergelegt ist" (Weisgerber, 1929: 86, zit. nach Helbig 1989: 121). Zu Weisgerbers Sprachtheorie vgl. auch Andrzejewski (1983).

130 Dies ergibt sich auch aus der Definition der Idiomatizität, nach der sich die Bedeutung einer idiomatischen Einheit nicht aus den Bedeutungen ihrer Konstituenten ergibt. 
Elemente des etymologischen Wissens die semantischen und pragmatischen Eigenschaften der Idiome beeinflussen.

(vi) Die spezifischen Eigenschaften der Bildkonstituente können auch kulturell begründet sein, weswegen die Eigentümlichkeiten einer gegebenen Kultur ebenfalls Einfluss auf die figürlichen Spracheinheiten haben. Dabei manifestiert sich die Relevanz der kulturellen Phänomene nicht ausschließlich in dem kombinatorischen oder diskursiven Verhalten von konventionalisierten figürlichen Spracheinheiten, sondern auch in zwischensprachlichen Differenzen, die nur vor dem kulturellen Hintergrund erklärt werden können.

2016 grenzt Dobrovol'skij die theoretischen Konstrukte der ,inneren Form' und der ,Bildkomponente/der bildlichen Komponente“ doch ab und verweist darauf, dass sich die beiden Begriffe oft verzahnen, dennoch nicht als synonym betrachtet werden können.

Mit dem Begriff der inneren Form knüpft Dobrovol'skij an die russische Sprachphilosophie des 19. Jh. an. Potebnja (1892) definiert die innere Form als ,the ratio of the content of thought to consciousness" (Dobrovol'skij 2016: 21). In Anlehnung an diese vage und schwer operationalisierbare Definition schlägt der Forscher folgende Definition der inneren Form in der Phraseologie vor:

(...) the inner form of a lexical unit (word or idiom) can be defined as a kind of semantic paradigmatic relations between the target lexeme and the meanings associated with its constituent parts and/or the underlying mental image. In other words, the inner form of a lexical item is the image fixed in its content plane as well as the motivation of its lexicalized meaning, which the speakers derive from the meaning of its constituents (morphemes or words). (Dobrovol'skij 2016: 23)

Unter dem image component versteht er dagegen:

(...) the linguistically relevant traces of the mental image underlying its semantics. It provides a semantic bridge between two levels of the figurative unit's conceptual structure, i.e. between its meaning proper and the literal interpretation of the underlying lexical structure which triggers the corresponding mental image. (Dobrovol'skij 2016: 23)

Die bildliche Komponente weist also viele Parallelen zu Burgers idiomatischem Bild auf, was Dobrovol'skijs Erklärungen am Beispiel des Idioms to take a sledgehammer to crack a nut nahe legen:

The image component provides conceptual material that is used in constructing the actual meaning, namely the idea that the means is fully inappropriate for achieving a given goal (to crack a nut), in that it is too powerful. Using a sledgehammer requires effort, much more that is needed to crack a nut, so that the subject of this action is wasting energy. Even if the intended result is achieved (the nut is cracked) it is so significant when compared to the wasted effort that the whole action has been inefficient. Thus traces of the underlying image can be found in all parts of the semantic definition. An important feature of this metalanguage is that it does not point to all 
details of the „rich image“ but exploits only those traces of the source concept that are relevant for the actual meaning. Another feature of the metalanguage (connected with the first one) is that it often uses formulations of a relatively high level of abstraction. This enables us to concentrate on the conceptual structures which are immediately relevant for constructing the actual meaning and which provide the semantic bridge between source and target concepts. (Dobrovol'skij 2016: 25)

Ebenfalls hier handelt es sich um eine konzeptuelle Struktur, die zwar von dem an die literale Lesart gebundenen mentalen Bild ausgeht, dennoch durch die motivierenden Beziehungen zwischen den beiden Lesarten stark beeinflusst wird. Hervorgehoben werden nur diejenigen Aspekte des mentalen Bildes, die für die Konstituierung der Bedeutung von Relevanz sind.

Die innere Form stelle demnach einen weiteren Terminus als die bildliche Komponente dar: Während die bildliche Komponente nur ausgewählte Aspekte herausgreift, die für die phraseologisierte Bedeutung eines Idioms von Relevanz sind, bezieht sich der Begriff der inneren Form ebenfalls auf die Inhalte, die zwar nicht als motivierende Verbindungen zwischen den beiden Lesarten in der konventionellen Bedeutung gelten können, aber doch einen potentiellen Bestandteil der Semantik von einem Idiom bilden, der in bestimmten Kontexten zur Geltung kommen kann:

The motivational basis of an idiom consists, first of all, of linguistically relevant traces of the underlying image. This kind of image trace makes up the so-called image component of idiom semantics, and in this sense, it is part of the content plane of the idiom. However, other parts of the image which do not necessarily influence the idiom's lexicalized semantic also play a certain role in its cognitive processing. The parts of the image that do not immediately construct the motivational link between the literal reading and the lexicalized meaning of an idiom can, nevertheless, be activated in non-standard contexts. The conceptual details of the image that do not provide the motivating link can, nevertheless, evoke certain stylistic properties of figurative lexical units. In this sense, the image basis of every figurative lexical unit (one-word metaphor or idiom), taken as a whole, is psychologically real. All these „additional“ conceptual features along with the image component are subsumed under the term inner form. (Dobrovol'skij 2016: 32-33)

Die Differenzen zwischen der inneren Form und der bildlichen Komponente versuche ich an einem Beispiel zu veranschaulichen: Für das Idiom eine harte Nuss, eine schwierige Aufgabe' kann das Wissen als Motivationsbasis gelten, dass die Nüsse eine harte Schale haben, die schwer zu knacken ist. Wahrscheinlich stellen sich auch die meisten Menschen unter einer harten Nuss eher eine Walnuss bzw. Haselnuss als eine Erdnuss mit einer papierartigen Schale vor. Die bildliche Komponente dieses Idioms umfasst also ein mentales Bild einer Walnuss/Haselnuss sowie die dahinter stehenden epistemischen Strukturen. Profiliert wird die Beschaffenheit der Schale sowie möglicherweise der hohe Nährwert des Kerns. 
Sobald aber der authentische Sprachgebrauch in den Fokus der Aufmerksamkeit gerückt wird, lassen sich zahlreiche Belege finden, wo zusätzliche Aspekte der Nuss einen wichtigen Bestandteil des Bedeutungskonstituierungsprozesses ausmachen: Der sprachspielerische Effekt in dem folgenden Sprachbeleg beruht darauf, dass die rundliche Form der Walnuss/Haselnuss mitprofiliert wird und eine metaphorische Verbindung zu der gedrungenen Körperform eines Mannes bildet.

Seit dem legendären ȮTV-Chef Heinz Klunker, Gott hab ihn selig, hat es keinen Arbeiterführer mehr gegeben, der die proletarischen Massen so richtig auf die Barrikaden treiben konnte. Wenn Klunker rief, standen alle Räder still und die Löhne wurden zweistellig erhöht. Für den nordrhein-westfälischen Ministerpräsidenten Jürgen Rüttgers könnte das im kommenden Jahr noch eine richtig neue Herausforderung werden. Den Lafontaine macht er schon gelegentlich, wenn es um populistische Stimmenmaximierung geht. Auch mit dem langjährigen sozialdemokratischen Landesvater Johannes Rau hat er sich schon versöhnt. Heinz Klunker wäre eine harte Nuss, nicht wegen dessen Bauchumfanges. Aber wenn es dem Christdemokraten Rüttgers tatsächlich gelänge, in dessen Fußstapfen zu treten, dann ist ihm die Macht an Rhein und Ruhr wohl auf ewig sicher. Die Zeit, 29.12.2008 (DWDS, Zugriff am 16.03.2017)

Die latente Fähigkeit der Idiome, derartige metaphorische Mappings herzustellen, ist auf ihre innere Form zurückzuführen.

\subsubsection{Zwischenbilanz}

Bei der Besprechung der Bildhaftigkeit und Bildlichkeit der Idiome muss auf zwei Perspektiven eingegangen werden.

Die erste Betrachtungsweise ist theoretischer Natur und für die Theorie der Phraseologie von Bedeutung. Hier scheint die Abgrenzung der Begriffe Bildhaftigkeit und Bildlichkeit von Relevanz zu sein:

Die Bildhaftigkeit wird somit als eine allgemeine Eigenschaft von einer Klasse variabler Ausdrücke wie einfache Lexeme, Komposita, (mehr oder weniger feste) Wortverbindungen und nicht zuletzt ganze Texte und Äußerungen angesehen. Sie beruht darauf, dass manche sprachlichen Einheiten aufgrund ihrer Konkretheit visuelle Vorstellungen, sog. mentale Bilder, evozieren können. Wie die neueren kognitiven Ansätze der Embodied/Grounded Cognition beweisen, ist der semantische (konzeptuelle) Pol einer sprachlichen Einheit durch verschiedene Repräsentationsmodi vertreten. Bildhaft sind generell die Begriffe der Basisebene, so wie sie von Rosch (vgl. Kap. 2.2.3) definiert wurden: Es liegt nämlich experimentelle Evidenz dafür vor, dass im Spracherwerb und im spontanen Sprachgebrauch eine mittlere Ebene zwischen sehr allgemeiner und sehr spezialisierter Kategorisierung bevorzugt wird (vgl. Apfel als Begriff der Basiskategorie vs. Frucht und fonagold). Charakteristisch ist die privilegierte Stellung der Begriffe der Basisebene anderen Begriffen gegenüber: Sie weisen eine hohe Frequenz auf, sind schnell verarbeitet, der semantische Pol ist sehr ausgebaut, darüber hinaus ist es die höchste 
Kategorieebene, für die ein gemeinsames mentales Bild existiert. So evozieren die Begriffe der Basisebene: Apfel, Hund, Haus bei der Sprachrezeption bei den meisten Menschen mentale Bilder, was bei der hierarchiehöheren Ebene (Frucht, Tier, Gebäude) bzw. bei einer hierarchieniedrigeren (Rotkehlchen, Zwergspitz) nicht immer der Fall ist.

Die Bildlichkeit steht dagegen mit einer figurativen Bedeutung einer Wortverbindung im Zusammenhang: Bildlich sind die Ausdrücke, die aufgrund einer metaphorischen (seltener: metonymischen oder symbolischen) Bedeutungsderivation ein direktes Verhältnis zwischen dem versprachlichten Bild und dem Gemeinten als Bildempfänger aufweisen (Sowinski 1978: 259). Bildlichkeit geht oft mit der Bildhaftigkeit einher, sie ist dennoch nicht unbedingt an die analoge Repräsentation des Wissens gebunden und durch die multimodale Struktur mentaler Repräsentationen zahlreicher Konzepte im Langzeitgedächtnis erklärbar. Inwieweit die mentalen Bilder, die bei der natürlichen Sprachverarbeitung ausgelöst werden, bildlich sind, d.h. inwieweit sie von den metonymischen und metaphorischen Mappings zwischen der literalen und der phraseologisierten Lesart des Idioms beeinflusst werden, lässt sich beim heutigen Wissensstand nicht eindeutig ermitteln. Viele Phraseologismen sind gleichzeitig bildhaft und bildlich:

jmdn. in die Zange nehmen ,1. ugs. jmdn. hart unter Druck setzen, ihm mit Fragen zusetzen. 2. Fußball; einen gegnerischen Spieler von zwei Seiten her so bedrängen, dass er erheblich behindert wird' (DUW) eine Kröte schlucken ,ugs. etwas Unangenehmes [stillschweigend] hinnehmen; sich mit einer lästigen Sache [ohne Sträuben] abfinden: sie hat in ihrem Berufsleben viele Kröten schlucken müssen' (DUW)

an der Quelle sitzen, ugs. gute Verbindung zu jmdm. haben und daher zu besonders günstigen Bedingungen in den Besitz von etw. gelangen ' (DUW)

Die Verbindung einer konkret-anschaulichen, in der täglichen Erfahrung liegenden Ausgangsdomäne mit einer abstrakteren Zieldomäne durch die konzeptuellen Mappings gehört zu den ausgeprägten Eigenschaften der Metapher, deren Funktion eben in der Veranschaulichung des schwer Fassbaren liegt. Auf der anderen Seite ist dennoch hervorzuheben, dass Idiome bildlich sein können, ohne Bildhaftigkeit aufzuweisen:

jmdn. im Stich lassen 1. ,sich um jmdn., der in eine Notlage geraten ist, sich in einer kritischen Situation befindet, nicht mehr kümmern' 2. ,jmdn., mit dem man verbunden war, verlassen '3. ugs. ,jmdm. den Dienst versagen' (DUW)

$j m d n$. kalt erwischen, unangenehm überrascht werden; unerwartet kommen, ohne Vorwarnung betroffen sein ' (redensarten-index, Zugriff am 06.12.2017)

Die Bildhaftigkeit stellt somit - so wie die Motiviertheit - eine graduelle und individuelle Eigenschaft dar: Manche Idiome evozieren ein gut ausgeprägtes, deutliches mentales Bild (ein heißes Eisen anpacken, ein glattes Parkett), das explizit in Einzelheiten beschrieben werden könnte, bei anderen (sich in seiner Haut wohl fühlen) kann man höchstens von einem schematischen Bild sprechen. 
Hervorzuheben ist noch die Tatsache, dass die Bildhaftigkeit die Bildlichkeit von festen Wortverbindungen steigern kann. Ihr Einfluss auf die Verarbeitung eines Phraseologismus ist bei denjenigen Idiomen am größten, die einem Sprachteilhaber unbekannt oder wenig bekannt sind: Dann geht er vom mentalen Bild aus und sucht - ähnlich wie bei der Verarbeitung von innovativen Metaphern und unter Einbezug der ko- und kontextuellen Begebenheiten - nach motivierenden Verbindungen, die eine Wortverbindung verstehbar machen könnten. Auch bei geläufigen Idiomen, bei denen die phraseologisierte Bedeutung gut bekannt und schnell abgerufen wird, trägt die idiomatische Bildhaftigkeit zur Aktivierung und Vergegenwärtigung der literalen Lesart bei, eröffnet den Spielraum der möglichen Interpretationen und ermöglicht den modifizierten Gebrauch der Idiome. Der sprachspielerische Gebrauch, der u.a. durch den Ausbau des Szenarios um das mentale Bild herum erfolgen kann und zu der bewussten Ambiguierung der Bedeutung führt, kommt bei manchen Idiomen in einer nennenswerten Anzahl der Belege vor (beim Idiom ein glattes Parkett sind es über $20 \%$ der Belege), vgl. folgende Gebrauchsbelege:

Allerdings sei es nicht die Macht der Banken, derentwegen ein raider um sein Gebiß fürchten müsse, sondern das Aktienrecht: „Aufgrund der Zweigleisigkeit von Aufsichtsrat und Vorstand ist der deutsche Markt eine harte Nuß." Allerdings ist es eine Nuß mit verlockendem Inhalt. Die Zeit, 25.03.1988 (DWDS, Zugriff am 15.03.2016)

Der „Regierende“ hat zweifellos seine Fehler, manchmal bewegt er sich nicht ganz stilsicher auf dem glatten Parkett der Diplomatie und Business-World - aber er ist doch ein richtiger Mensch mit seinen Fehlern und Vorzügen, kein perfekter Plastikautomat, in den man oben Geld einwirft, und unten kommt ein McDonald'sHamburger heraus! Wenn er strauchelt, steht er wieder auf; und wenn er auf die Schnauze fällt, schüttelt er sich, grinst und rappelt sich. Berliner Zeitung, 29.12.2004 (DWDS, Zugriff am 15.03.2016)

Damit leistet die phraseologische Bildhaftigkeit einen wichtigen Beitrag zum sog. phraseologischen Mehrwert (Kühn 1985): So wie die materiellen Bilder von Natur aus mehrdeutig und polyvalent sind und ihre Deutung hochgradig kontextabhängig ist (Stöckl 2004: 151), so erweitern auch die mentalen Bilder die Interpretationsmöglichkeiten der idiomatischen Bedeutung und verursachen, dass ihre Modellierung komplex und vielschichtig ist.

Die andere Perspektive, aus der mentale Bilder beschrieben werden können, bezieht sich auf die Natur der mentalen Bilder und ihren Einfluss auf die kognitive Verarbeitung der Idiome. Die Tatsache, dass viele metaphorische Idiome zugleich bildhaft und bildlich sein können, sagt uns nur wenig über die psychologische Realität der mentalen Bilder und ihren Beitrag zur Bedeutungskonstituierung im natürlichen Sprachgebrauch: Die theoretischen Erwägungen der Sprachwissenschaftler müssen sich nicht unbedingt in den Köpfen der Sprechenden widerspiegeln.

Zur psycholinguistischen Realität und der Gestaltung der mentalen Bilder liegen viele Fragen nahe, auf die beim heutigen Forschungsstand keine eindeutigen 
Antworten bestehen: Sind die mentalen Bilder, die durch die literale Lesart evoziert werden, in Form von gut und in Einzelheiten ausgearbeiteten Szenen mental präsent oder handelt es sich eher um punktuelle, anschauliche Vorstellungen von einzelnen Konstituenten? D.h. haben die Menschen, die das Idiom eine Flinte ins Korn werfen wahrnehmen, ein in Einzelheiten elaboriertes Vorstellungsbild, oder eher eine flüchtige Vorstellung einer Flinte mental vor Augen? Sind diese Vorstellungen oder Szenen bei allen Menschen ähnlich? Sind die mentalen Bilder, mit denen wir in der natürlichen Kommunikation zu tun haben, mit den idiomatischen Bildern identisch oder ihnen wenigstens ähnlich? In anderen Worten: Fließen die Elemente der phraseologisierten Lesart in das mentale Bild hinein (indem das Getreide, das phraseologisierte Korn, beispielsweise genügend dicht gesät ist, um die Flinte zu verbergen)? Welchen Einfluss hat die Geläufigkeit des Idioms auf das mentale Bild? Besitzen die Idiome, die man häufig gebraucht, ein besser ausgeprägtes, elaboriertes mentales Bild als die Idiome, die man selten verwendet? Verfügen die Idiome, die man sich bewusst angeeignet oder über deren Bedeutung man reflektiert hat, über mehr ausgebaute, vielleicht sogar etymologisch motivierte mentale Bilder? Am oben besprochenen Beispiel: Evozieren die Sprachteilhaber, die mal eine materielle Illustration des Idioms die Flinte ins Korn werfen ${ }^{131}$ gesehen haben und seine Etymologie kennen, das mentale Bild eines fliehenden, desertierenden Soldaten? Übt der Kontext Einfluss auf die Beschaffenheit der mentalen Bilder aus? Sind die mentalen Bilder von einer punktuellen (bild- oder fotoähnlichen) oder von einer sequenziellen (sich wie ein Film abspielender) Natur? Betonenswert ist der weitgehend individuelle und subjektive Charakter der mentalen Bilder. ${ }^{132}$ Der erschwerte Zugang zu den in der spontanen Sprachverarbeitung generierten und evozierten mentalen Bildern ${ }^{133}$ hat zur Folge, dass auch die Ergebnisse der empirisch ausgerichteten psycholinguistischen Untersuchungen in diesem Bereich inkonsistent sind. Aus diesem Grunde werden in den folgenden Erörterungen die mentalen

131 Das Idiom die Flinte ins Korn werfen wird relativ oft zu didaktischen Zwecken illustriert (vgl. Google grafika https://www.google.pl/search?q=die+Flinte+ins+Korn+werfen\&client, Deutsche Phraseologismen). Manche Idiome werden auch künstlerisch dargestellt. Als eine weltbekannte Illustration der niederländischen Sprichwörter und Phraseologismen gilt das Ölgemälde Die flämischen Sprichwörter von Pieter Bruegel dem Älteren (1559).

132 Als Beispiele der nicht-bildhaften Phraseologismen führt Burger (2015: 91) eine Kollokation ein Paket packen, ein Idiom keinen Hehl aus etw. machen, ein Sprichwort Aus Schaden wird man klug und ein Gemeinplatz Was sein muss, muss sein an. Während die drei letztgenannten Phraseologismen aufgrund der Abstraktheit der Konstituenten als nicht-bildhaft einzustufen sind, evoziert die Kollokation ein Paket packen bei der Autorin des vorliegenden Buches ein kohärentes mentales Bild und ist eindeutig bildhaft.

133 Wie Dobrovol'skij (1997: 46) zu Recht bemerkt, müssen die nachträglich versprachlichten mentalen Bilder keinesfalls mit denen identisch sein, die uns bei der Sprachverarbeitung als mentale Vorstellungen rasch vorübergehend erscheinen. 
Bilder allgemein aufgefasst, ihre psychologische Realität und der Einfluss auf die Konzeptualisierungen von Idiomen stehen außer Zweifel, Versuche, über ihre Natur und Detailliertheit zu entscheiden, werden dennoch nicht vorgenommen.

\subsection{Zusammenfassung}

Diese Zusammenfassung bildet einen Übergang zwischen den theoretischen Überlegungen zur Phraseologie, Sprache, Auffassung der Bedeutung, Metapher, Metonymie sowie der phraseologischen Bildhaftigkeit und Motiviertheit aus kognitiver Sicht und den empirisch ausgerichteten korpusbasierten Untersuchungen zur Semantik der einzelnen Phraseologismen. Aus der Vielfalt der dargestellten Theorien und Hypothesen werden diejenigen Leitgedanken und Termini resümierend herausgegriffen, die für die weiteren Erörterungen von besonderer Relevanz sind. Hervorzuheben ist an dieser Stelle, dass diese Auswahl keinesfalls wertend ist: Beispielshalber ergibt sich die Tatsache, dass Symbole und symbolische Motiviertheit eine relativ untergeordnete Rolle in der vorliegenden Arbeit spielen, aus der Spezifik des zu untersuchenden Diskursbereiches der Schwierigkeit/der schwierigen Lage und darf nicht als eine für die Phraseologie allgemeingültige Regel interpretiert werden.

Den theoretischen Rahmen für die vorliegende Arbeit macht der holistische Ansatz der Kognitiven Linguistik aus. Grundsätzlich werden die sich aus der Annahme von trennscharfen Grenzen zwischen einzelnen Kognitionsebenen und Phänomenen ergebenden Dichotomien (z.B. zwischen dem Körper und dem Geist; der Sprache und anderen kognitiven Fähigkeiten; Perzeption, Kognition und Emotion; der literalen, nicht-literalen und figurativen Sprache; Metapher und Metonymie) zugunsten eines ganzheitlichen Bildes von kognitiven Fähigkeiten eines Menschen aufgegeben. Kognitive Linguistik ist mentalistisch: Sprachliche Zeichen beziehen sich nicht auf außersprachliche Entitäten, sondern auf mentale Konstrukte von diesen Entitäten, nicht auf die wirkliche, sondern auf die projizierte Welt. Das konzeptuelle System eines Menschen wird durch Erfahrung konstruiert, es wird eine gemäßigt empirische Weltsicht vertreten: Die fundamentale Stellung der Erfahrung wird zwar anerkannt, zugleich lässt man aber bestimmte genetische Einschränkungen, die z.T. durch die Beschaffenheit des menschlichen Körpers auferlegt werden, zu. Elementare Operationen wie Kategorisierung oder Schematisierung können z.B. in ihren Grundzügen durch genetische Faktoren bedingt werden. Mentale Repräsentationen sind dabei multimodal: Sie umfassen Reize in allen möglichen Sinnesmodalitäten, auch Emotionen, Interozeption und Prioprozeption werden mental gespeichert.

In diesem komplexen, durch zusammengesetzte Wechselbeziehungen gekennzeichneten System funktioniert die Sprache. Eine sprachliche Einheit besteht aus einem phonologischen und aus einem konzeptuellen Pol, die durch eine symbolische Beziehung verbunden werden. Der konzeptuelle Pol einer sprachlichen Einheit greift dabei auf die Gesamtheit des mental repräsentierten Wissens, auf ein individuelles kultur-, alters- und erfahrungsbedingtes Wissensgefüge zurück. Die 
sprachlichen Bedeutungen sind somit enzyklopädisch: Es gibt keine Abgrenzung zwischen sprachrelevanten oder sprachirrelevanten Wissensinhalten. Die Annahme eines Sprachmoduls mit einem abgesonderten mentalen Lexikon wird abgewiesen: Weder die Sprache noch sprachliche Bedeutungen können als stabile, statische, von anderen kognitiven Fähigkeiten abgegrenzte Größen angesehen werden. Es handelt sich eher um Phänomene in statu nascendi, dynamische Prozesse. Sprache konstituiert sich durch den interaktiven Sprachgebrauch: Konzeptähnliche Strukturen werden als kognitive Routinen, aktuelle Bedeutungen als Konzeptualisierungen aufgefasst.

Phraseologismen im engeren Sinne (im Folgenden auch als Idiome und idiomatische Einheiten bezeichnet) umfassen sehr heterogene Gruppen der festen Wortverbindungen. In den Fokus der Aufmerksamkeit der vorliegenden Arbeit wird die größte Gruppe - Idiome mit zwei disjunktiven Lesarten gerückt. Der Prozess der Konstituierung der aktuellen Bedeutung eines Idioms weist viele Parallelen zur Bedeutungskonstituierung von Einzellexemen auf: Er ist dynamisch, interaktiv, vom Kontext abhängig, es wird auf enzyklopädische Wissensstrukturen von multimodaler Repräsentationsart zurückgegriffen. Die Besonderheit der Idiome mit zwei disjunktiven Lesarten als sprachlicher Einheiten liegt darin, (i) dass sich ihre Bedeutungen auf mehreren Ebenen herausbilden können (d.h. durch die Derivationsprozesse auf der Ebene der ganzen Wortverbindung sowie auf der Ebene der einzelnen Idiom-Konstituenten), (ii) dass sie bei gleicher Ausdrucksseite auf der Inhaltsseite zwei Lesarten: die literale und die phraseologisierte Lesart aufweisen (vgl. Abb. 17). Die Bedeutung von Idiomen mit zwei disjunktiven Lesarten konstituiert sich in einem Spannungsfeld zwischen der literalen und der phraseologisierten Lesart. Aus dem Zusammenspiel der beiden Lesarten ergibt sich die Motiviertheit der Phraseologismen, ihre semantische Ambiguität und Vagheit, ihr semantischer Mehrwert und Affinität zum sprachspielerischen Gebrauch.

Als wichtigste Mechanismen der Bedeutungskonstituierung, die in dem Spielraum zwischen der literalen und der phraseologisierten Lesart tätig sind, gelten konzeptuelle und epistemische Metaphern, Metonymie, Metaphtonymie, metonymisch-metaphorische Ketten sowie mentale Bilder. Als Metaphern werden die konzeptuellen Mappings zwischen zwei distinkten Domänen (d.h. Erfahrungsbereichen) verstanden, wobei eine Ausgangsdomäne, die meistens im Bereich der direkten, alltäglichen Erfahrung liegt, in eine abstraktere Domäne projiziert wird und sie auf diese Art und Weise verständlicher macht. Von grundlegender Bedeutung für die weiteren Erörterungen im phraseologischen Bereich ist die von Barcelona (2003) vorgeschlagene Einteilung nach der Natur der metaphorischen Mappings: Die metaphorischen Korrespondenzen zwischen der Ausgangs- und Zieldomäne können demnach ontologischer oder epistemischer Natur sein und entsprechend konzeptuelle und epistemische Metaphern konstituieren. Ontologische Mappings kommen in den konzeptuellen Metaphern vor, so wie sie von Lakoff/ Johnson (1980) in der CTM-Theorie beschrieben werden. Konzeptuelle Metaphern werden als verfestigte kognitive Strukturen von einem hohen Abstraktionsgrad aufgefasst. Die Ausgangsdomänen, die den konzeptuellen Metaphern zugrunde 
liegen, erstrecken sich von den absolut elementaren Domänen wie die Körperund Raumerfahrung (z.B. die GEFÄss-Metapher), bis hin zu den Erfahrungsbereichen, die den kulturellen Einflüssen unterliegen und keinen kulturübergreifenden, universalen Charakter haben (vgl. z.B. die konzeptuelle Metapher DER GEIST IST EINE MASCHINE). Prinzipiell sind sie also „grounded in the body and in everyday experience and knowledge" (Lakoff 1993: 39). Als grundlegende kognitive Mechanismen beeinflussen die konzeptuellen Metaphern unser Denken, Handeln und die Sprache, allerdings werden sie vor allem aus den der Untersuchung direkt zugänglichen sprachlichen Ausdrücken eruiert: Das methodologische Hauptverfahren bei der Ermittlung der konzeptuellen Metaphern liegt nämlich darin, dass man sie aus ihren sprachlichen Manifestationen erschließt, d.h., von einer konzeptuellen Metapher spricht man dann, wenn man die Existenz von einer genügenden Anzahl der sprachlichen Exemplifizierungen, in denen diese Metapher zur Geltung kommt, nachweisen kann. Idiome als konventionalisierte, weitgehend von den Sprachgemeinschaften akzeptierte und gebrauchte Einheiten der figurativen Sprache sind aus diesem Grund zur Erforschung der Reichweite der CTM-Theorie von Natur aus par excellence geeignet.

Im Gegensatz zu den ontologischen Mappings, die als „a set of fixed conceptual correspondences" (Barcelona 2003: 212) angesehen werden, fest verankert sind und großen konzeptuellen Bereichen eine Struktur auferlegen, sind die epistemischen Korrespondenzen (knowledge/epistemic correspondences, vgl. Barcelona 2003: 212) an konkrete sprachliche Äußerungen gebunden. Epistemische Metaphern entstehen, indem sie zwei Domänen auf der Basis des allgemeinen Weltwissens verbinden. Demnach sind die metaphorischen Korrespondenzen, die den metaphorischen Komposita Apfelfigur ,eine weibliche Figur, die durch schlanke Beine und fülligen Rumpf gekennzeichnet ist ' oder Sanduhrfigur ,Körperbau einer Frau, für den volle Brüste, schmale Taille, ausladende Hüfte charakteristisch sind" vor dem Hintergrund des allgemeinen Wissens über die räumliche Form eines Apfels und einer Sanduhr und den unterschiedlichen Körperbautypen von Frauen leicht nachvollziehbar. Unter epistemischen Metaphern werden in der vorliegenden Arbeit also die Metaphern, deren Domänen durch epistemische, d.h. auf dem allgemeinen Weltwissen basierende Korrespondenzen verbunden sind, aufgefasst. Die epistemischen Metaphern haben im Vergleich zu den konzeptuellen Metaphern einen wesentlich kleineren Wirkungsskopus: Während die auf ontologischen Mappings aufbauenden konzeptuellen Metaphern große Erfahrungsbereiche strukturieren und sich demnächst in zahlreichen sprachlichen Ausdrücken manifestieren, beziehen sich die epistemischen Metaphern auf einzelne Konzepte, die aufgrund des Weltwissens miteinander in Beziehung gesetzt werden. Hervorzuheben bleibt an dieser Stelle, dass beide Metapherntypen konzeptuell sind: Die Mappings zwischen den Domänen vollziehen sich in beiden Metapherntypen auf der konzeptuellen Ebene. Die Beibehaltung des Terminus konzeptuelle Metapher für die Bezeichnung der auf ontologischen Korrespondenzen beruhenden Metapher ist darauf zurückzuführen, dass dieser Begriff seit der für die moderne Metaphernauffassung 
bahnbrechenden Veröffentlichung von Lakoff/Johnson (1980) in der kognitiv ausgerichteten Forschung gut etabliert ist.

Unter Metonymie wird ein kognitiver Mechanismus bezeichnet, in dem eine (Sub-)Domäne teilweise unter Einbezug einer anderen (Sub-)Domäne verstanden wird, wobei die beiden Domänen innerhalb einer übergeordneten Domäne (oder Domänenmatrix) liegen (Barcelona 2003: 215). Croft (2003) und Lakoff (1987: 78-80) sprechen in diesem Kontext von domain highlighting. Der Unterschied zwischen Metapher und Metonymie liegt also zum einen in der Anzahl der involvierten Domänen, zum anderen in der Spezifik des Projektionsprozesses: Die Metapher verbindet zwei unterschiedliche Wissens- und Erfahrungsbereiche (Domänen), in der Metonymie erfolgt die Projektion innerhalb eines Erfahrungsbereiches, wobei jeweils ein Teil der Domäne auf einen anderen Teil derselben Domäne projiziert wird, z.B. (PART FOR WHOLE, ACTION FOR AGENT, AUTHOR FOR WORK, vgl. Barcelona 2003: 226-231). Da sich die Metonymie durch die ,konzeptuelle Nähe` (ein Begriff von Dirven 2003: 92) auszeichnet und deswegen im Sprachgebrauch nicht so auffällt, ist ihr in der bisherigen Forschung wesentlich weniger Aufmerksamkeit als der Metapher geschenkt worden. In den letzten Jahren wird in der Kognitiven Linguistik dennoch immer häufiger die Meinung vertreten, dass die Metonymie möglicherweise „even more basic than metaphor in language and cognition“ ist (Barcelona 2003: 215). In der Phraseologie bildet die Metonymie oft den Ausgangspunkt zur Herausbildung der Metapher.

Die neueren detaillierten Analysen der Metapher und Metonymie im authentischen Sprachgebrauch verweisen des Weiteren darauf, dass strikte Abgrenzungen der beiden kognitiven Prozesse nicht immer ausführbar sind. Dies hängt einerseits mit der Unmöglichkeit einer präzisen und intersubjektiven Bestimmung zusammen, was unter einer „Domäne“ zu verstehen ist (Croft 2003, Taylor 2003), andererseits lässt die Analyse des authentischen Sprachgebrauchs in zahlreichen Fällen schlussfolgern, dass Metapher und Metonymie in sprachlichen Äußerungen interagieren können. Goosens (2003) schlägt für derartige Spracheinheiten vom hybriden Charakter (Metapher aus Metonymie, Metonymie in der Metapher) den Terminus Metaphtonymie (metaphtonymy) vor; mit diesem Terminus sind im Weiteren die Grenzphänomene bezeichnet, die sowohl als Metonymie als auch als Metapher aufgefasst werden können.

Eine wichtige Rolle bei den Konstituierungsprozessen der Idiom-Bedeutungen kommt bei vielen idiomatischen Einheiten den sog. mentalen Bildern (rich images) zu: Zahlreiche Idiome sind dadurch gekennzeichnet, dass sie mentale Bilder evozieren können. Mentale Bilder werden wahrscheinlich vorwiegend durch die literale Lesart eines Idioms ausgelöst und liegen dem Phänomen der phraseologischen Bildhaftigkeit zugrunde. Über die psycholinguistische Natur der mentalen Bilder bestehen beim heutigen Wissensstand mehr Fragen als Antworten: Es handelt sich hier um weitgehend individuelle und subjektive Phänomene. Menschen unterscheiden sich in der Fähigkeit, mentale Bilder zu evozieren, sowie in der Konsistenz und Detailliertheit ihrer mentalen Bilder. Umstritten ist beispielsweise, inwieweit die mentalen Vorstellungsbilder durch die phraseologisierte 
Lesart eines Idioms beeinflusst werden. Aus diesem Grunde werden im Folgenden die Differenzierungen zwischen dem mentalen und dem idiomatischen Bild, der Bildlichkeit und Bildhaftigkeit der Idiome aufgegeben. Unter mentalen Bildern werden (meist flüchtige) mentale, interne, analoge Abbildungen der externen Informationen verstanden, die bei der Verarbeitung der Idiome vorkommen und zu der Bedeutungskonstituierung ihren Beitrag leisten (können).

Betonenswert ist der dynamische, prozessuale Charakter der Bedeutungskonstituierung von Idiomen. Die konventionellen Bedeutungen von Idiomen bilden sich auf der Grundlage rekurrenter Sprachgebrauchsereignisse heraus (Ziem 2008: 138, Langacker 2008). Den Ausgangspunkt zur Untersuchung der Semantik der sprachlichen Einheiten bilden die jeweiligen Konzeptualisierungen: „Knowledge of language emerges of language use" (Croft/Cruse 2004: 1). Zur Erfassung der Dynamik und Emergenz der Bedeutungskonstituierungsprozesse ist der Rückgriff auf authentische Sprachbelege erforderlich, die Korpora zur Verfügung stellen. Dem empirischen Teil der vorliegenden Arbeit wird deswegen ein Exkurs vorangestellt, in dem kurz auf die Korpuslinguistik und ihre Rolle in der Phraseologie eingegangen wird.

\section{EXKURS: Korpuslinguistik}

Den grundsätzlichen Leitfaden der folgenden Erörterungen bildet die Annahme, dass sich die Bedeutungen von Idiomen in rekurrenten Sprachgebrauchsereignissen durch den Prozess der Schematisierung, Kategorisierung und Automatisierung herausbilden und etablieren. Die idiomatischen Bedeutungen sind demnach nicht als stabile mentale Entitäten, sondern eher als kognitive Verfestigungen, kognitive Routinen aufzufassen, die sich aus dynamischen, emergenten Konzeptualisierungen herauskristallisieren. Eine fundamentale Rolle bei der Untersuchung der Semantik von sprachlichen Einheiten kommt in diesem Sinne der Untersuchung des Sprachgebrauchs zu: einer Aufgabe, bei der die Leistungen des neuen Zweiges der sprachwissenschaftlichen Forschung der Korpuslinguistik - kaum zu unterschätzen sind. Aus diesem Grunde wird im folgenden Exkurs kurz auf den theoretischen Hintergrund der korpuslinguistischen Forschung, ihre Einsatzbereiche und Grundverfahren eingegangen.

Die Entstehung der Korpuslinguistik ist an die Entwicklung von elektronischen Datenbanken und dem Internet gebunden, in denen große Textsammlungen samt geeigneten Suchmaschinen aufgesammelt sind. Mit diesen Datenbanken wurde der Linguistik ein nützliches Werkzeug zur Verfügung gestellt, mit dem authentische Sprachdaten in den bisher nicht zugänglichen Mengen für die linguistischen Fragestellungen und Analysen bereitstehen. In diesem Sinne ist der Beitrag der Korpuslinguistik zu sprachwissenschaftlicher Methodologie revolutionär: An die Stelle der introspektiven Untersuchung bzw. der Analyse einzelner willkürlich ausgesuchter Beispiele tritt die Möglichkeit der Recherche in einer großen Menge der einschlägigen Belege im Korpus, wodurch Zusammenhänge sichtbar werden, die man früher höchstens zufällig entdecken konnte (Teubert 2006: 49).

Als theoretischer Hintergrund der korpuslinguistischen Forschung wird der Kontextualismus angesehen, so wie er einst von John Rupert Firth entworfen 
wurde. Das Forschungsziel des Kontextualismus liegt darin, sprachliche Äußerungen und deren verschiedene linguistische Aspekte als Funktionen des sprachlichen und nicht-sprachlichen Kontextes zu erklären, in dem diese Äußerungen stehen (Lemnitzer/Zinsmeister 2010: 28) ${ }^{134}$. Die Bedeutung einer sprachlichen Einheit wird nicht als mentale Disposition von Sprechern, die unabhängig vom Gebrauch existiert, aufgefasst (ebd., 30). Der Kontextualismus ist eine Gebrauchstheorie der Bedeutung im Sinne von Wittgensteins Formel (1967: 43): „Die Bedeutung eines Wortes ist sein Gebrauch in der Sprache“, die ebenfalls den Anfang der Pragmatik akzentuiert.

In diesem Punkt verzahnen sich also die Grundprämissen des Kontextualismus und der Kognitiven Linguistik: Die grundsätzliche Dichotomie zwischen langue und parole (Strukturalismus), oder anders der Sprachkompetenz und Sprachperformanz, der e-Sprache und i-Sprache (Generativismus) wird aufgehoben. Bedeutung und Gebrauch sind aufs Engste aufeinander bezogen, indem sich die Bedeutungen im Sprachgebrauch konstituieren und im Sprachgebrauch immer neu verhandelt werden:

Discourse is the use of language. Conversely, a language resides in conventional patterns of usage. These patterns, learned from countless instances of use in discourse contexts, are subsequently applied in producing and understanding further discourse. It is the old, familiar story of the chicken and the egg. (Langacker 2008: 457)

Die Korpuslinguistik kann in diesem Sinne sowohl als eine Methode, als auch als ein an der Erforschung der Sprache im Gebrauch orientierter Zweig der Sprachwissenschaft angesehen werden. Steyer (2013: 69) hebt hervor, dass es die Korpuslinguistik an sich nicht gebe. Der Terminus ,Korpuslinguistik' stelle vielmehr einen Oberbegriff für eine Vielzahl heterogener Strömungen und Methoden dar, die eigentlich nur eins miteinander verbinde: die Nutzung elektronisch aufbereiteter sprachlicher Messdaten als empirische Basis und elaborierter Methoden, diese automatisch auszuwerten (ebd.). Gemeinsam ist diesen unterschiedlichen Zugangsweisen das Korpus, das folgendermaßen definiert wird:

Ein Korpus ist eine Sammlung schriftlicher oder gesprochener Äußerungen in einer oder mehreren Sprachen. Die Daten des Korpus sind digitalisiert, d.h. auf Rechnern

134 Firth (1991: 182, zit. nach Lemnitzer/Zinsmeister 2010: 29) unterscheidet dabei zwischen dem sprachlichen und nicht sprachlichen Kontext, die er als ,Kotext ' bzw. „Kontext ' bezeichnet. Der Kotext einer linguistischen Einheit ist die Menge der linguistischen Einheiten, die im gleichen Text verwendet wurden. Diese linguistischen Einheiten determinieren die Funktion und die Bedeutung der untersuchten Einheit. Unter dem Kontext dagegen wird Summe der unmittelbaren Rahmenbedingungen einer Sprachhandlung verstanden, die als das Bezugssystem fungiert, innerhalb dessen einer Äußerung eine Funktion zukommt. Dabei bildet der kulturelle Kontext das Bezugssystem für eine Sprache und steuert die Art und Weise, wie Sprecher sprachliche Handlungen wahrnehmen. Der situative Kontext determiniert die Funktion einer konkreten sprachlichen Handlung (Lemnitzer/Zinsmeister 2010: 29). 
gespeichert und maschinenlesbar. Die Bestandteile des Korpus, die Texte oder Äußerungsfolgen, bestehen aus den Daten selber sowie möglicherweise aus Metadaten, die diese Daten beschreiben, und aus linguistischen Annotationen, die diesen Daten zugeordnet sind. (Lemnitzer/Zinsmeister 2010: 40)

Die Korpora unterscheiden sich in einer Menge der Eigenschaften. Als wichtige Kriterien der Korpustypologie können die Funktionalität (Zweck, zu dem das Korpus erstellt wurde), Sprachenauswahl (mono-, bi- und multilingual), Medium (gesprochen, geschrieben, multimodal), Größe, Annotation (keine oder Morphosyntax, Syntax, Pragmatik, Semantik usw.), Persistenz (Monitorkorpus ${ }^{135}$ oder statisch), Sprachbezug (Referenzkorpus oder Spezialkorpus) und Verfügbarkeit angesehen werden (Lemnitzer/Zinsmeister 2010: 103).

Das Spektrum der Einsatzmöglichkeiten der Korpora ist in der Sprachwissenschaft beinahe unbegrenzt und reicht von statistischer Sprachmodellierung über die Lexikographie und Übersetzungswissenschaft bis zu der theoretischen Linguistik $^{136}$. Traditionell wird von zwei grundsätzlichen Herangehensweisen ausgegangen, die in Form von Oppositionspaaren: Deduktion-Induktion, bzw. top down- und bottom up-Verfahren zur Sprache gebracht werden. Auf Korpuslinguistik übertragen kann das Korpus dazu dienen, eine aufgestellte Hypothese oder These am empirischen Material zu revidieren (deduktives Verfahren, das von $a$ priori Annahmen hinausgeht) oder man kann, die Korpusdaten als Ausgangspunkt nehmend, explorativ nach den Regularitäten in der Sprache suchen, z.B. statistisch die Kookurrenzrelationen zwischen den Wörtern berechnen (induktives Verfahren, das a posteriori ausgerichtet ist). Möglich ist auch die Mischlösung: Man geht zwar von einem induktiven, quantitativen Verfahren aus, die gewonnenen Daten werden dennoch annotiert und interpretiert (das sog. quantitativ-qualitative Verfahren).

Dementsprechend spricht man in der Korpuslinguistik von drei Korpusparadigmen (Ansätzen der Korpusanalyse) mit verschiedenen Einsatzbereichen (vgl. Lemnitzer/Zinsmeister 2010: 32-38):

(i) In dem korpusbasierten, quantitativen Ansatz werden aus dem Korpus „rohe“ quantitative Daten extrahiert. Diese Daten dienen in der ersten Linie

135 Die meisten Korpora sind Monitorkorpora, d.h. die Größe des Korpus ändert sich in der Zeit. Der Grund für die Größenänderung kann darin liegen, dass das Korpus kontinuierlich wächst, indem beispielshalber neue Ausgaben einer Tageszeitung ergänzt werden. Der Nachteil eines Monitorkorpus liegt darin, dass die Ergebnisse einer Untersuchung nicht (oder nur bedingt) am gleichen Material wiederholt werden können (Lemnitzer/Zinsmeister 2010: 106).

136 Eine kurze Übersicht über die Einsatzmöglichkeiten von Korpora in Orthographie, Wortbildung, Syntax, Computerlinguistik, Lexikologie und Lexikographie, Partikelforschung, Fremdsprachenerwerb und Fremdsprachenvermittlung findet man im Kapitel Korpuslinguistik in der Praxis bei Lemnitzer/Zinsmeister (2010: 124-168). 
statistischen Zwecken. Es kann beispielshalber bestimmt werden, mit welcher Häufigkeit eine bestimmte Zeichenkette in einem Korpus vorkommt, welchen Rangplatz diese Zeichenkette aufgrund ihrer Häufigkeit annimmt, wie die Distribution eines Wortes ist (gemessen als Häufigkeit des Vorkommens dividiert durch die Zahl der Texte, in denen das Wort vorkommt). Anhand des korpusbasierten quantitativen Verfahrens werden auch n-Gramme ${ }^{137}$ ermittelt, mit deren Hilfe Suchmaschinen die zu einem Thema passenden Texte finden können, selbst dann, wenn das in die Suchmaschine eingegebene Wort nicht im Text vorkommt (vgl. Lemnitzer/Zinsmeister 2010: 35).

(ii) Der korpusbasierte, qualitativ-quantitative Ansatz geht ebenfalls von der exhaustiven Analyse der Korpusdaten aus und schließt andere Methoden wie Experimente oder Befragungen der Informanten aus. Im Gegensatz zu dem korpusbasierten quantitativen Ansatz werden die Korpusdaten dennoch einer weiteren linguistischen Analyse unterzogen. Aufgrund der Generalisierung der Beobachtungsdaten können dann Aussagen über das Sprachsystem gemacht werden. Dieser Ansatz wird in der Lexikographie, Übersetzungswissenschaft, Sprachdidaktik und Sprachkritik erfolgreich eingesetzt.

(iii) In einem korpusgestützten Ansatz werden die Korpusdaten als zusätzliche Quelle der Evidenz herangeführt. So können die Korpora nach bestimmten grammatischen Konstruktionen durchsucht werden, die eine aufgestellte These bestätigen.

\section{Zur Rolle der Korpora in der phraseologischen Forschung}

Einer der wichtigsten Bereiche, in denen die Korpuslinguistik die Anwendung fand, war von Anfang an die Untersuchung des Vorgeprägten in der Sprache, der sprachlichen Patterns (Moon 2007: 1046). In diesem Sinne wurde der Phraseologie relativ schnell ein wichtiger Stellenwert in der Korpuslinguistik eingeräumt, andererseits übt auch die Korpuslinguistik einen Einfluss auf die Phraseologie: Auf die Aufweichung der Grenzen von Phraseologie und Neudefinierung ihrer zentralen Begriffe wurde im Vorangehenden bereits eingegangen (vgl. Kap. 1.1).

Nichtsdestotrotz werden die Phraseologie und insbesondere semantische Aspekte der Idiome immer noch als sprachwissenschaftlicher Bereich angesehen, in dem die engere Integration der digital-empirischen Analyseverfahren in die

137 Unter n-Grammen linguistischer Einheiten werden Bruchteile von Wörtern, Sätzen oder Texten verstanden, die zu statistischen Zwecken erstellt sind. Lemnitzer und Zinsmeister (2010: 35) illustrieren die Einsatzmöglichkeiten von n-Grammen am folgenden Beispiel: Wenn in einem Text Operationen am offenen Herzen vorkommen und in der Suchanfrage Herzoperation angegeben wird, dann wird in einer einfachen Suche das Dokument mit Operationen am offenen Herzen nicht gefunden. Falls der Text dennoch in n-Gramme geteilt wird, dann haben beide Zeichenketten 8 Trigramme gemeinsam:_He, Her, erz, per, era, ati, tio, ion. Trotz unterschiedlicher Schreibvarianten kann man dann zu den gesuchten sprachlichen Einheiten gelangen. 
theoretische Forschung ein wichtiges Desiderat bildet (vgl. u.a. Dräger/Juska-Bacher 2010, Bubenhofer/Ptashnyk 2010, Dobrovol'skij 2016, Steyer 2009, 2013). Die Signifikanz der engen Einbindung der Korpora in die phraseologische und phraseographische Praxis ist auf mehrere Gründe zurückzuführen:

(i) Trotz der Vielfalt der Forschungsschwerpunkte in der Phraseologie wurde sehr lange, wie Dobrovol'skij (2002: 429) zu Recht bemerkt, ihre wichtigste Aufgabe - eine systematische Beschreibung der Phraseologismen aller Klassen in allen möglichen Sprachen - vernachlässigt. Die Phraseologie hat sich bis zu der Jahrtausendwende kaum ernsthaft und eingehend mit Bedeutungsexplikationen der einzelnen Phraseologismen befasst. Die in den letzten 15 Jahren eingeleiteten Projekte ${ }^{138}$ und Publikationen (vgl. z.B. Dräger/JuskaBacher 2010, Fellbaum/Kramer/Neumann 2006, Quasthoff/Schmidt/Hallsteinsdóttir 2010, Steyer 2009, 2013, 2016) stellen einen relevanten Fortschritt in dieser Hinsicht dar, von einer zufriedenstellenden Datenbank, in der die meisten Phraseologismen erfasst und in ihrer semantischen, pragmatischen und grammatischen Komplexität beschrieben würden, sind wir aber noch weit entfernt. Dabei bildet die Erstellung von theoretischen und praktischen

138 Als Beispiele können hier große korpusgestützte phraseographische Projekte dienen, infolge deren Printwörterbücher erschienen sind oder vorbereitet werden: (1) Wörterbuch der Kollokationen im Deutschen von Uwe Quasthoff (2011) wird als die erste empirisch fundierte Sammlung deutscher Kollokationen angesehen. Anhand einer zuerst strikt korpusgesteuerten Untersuchung der Nachbarschaftskookkurrenzen im Korpus Deutscher Wortschatz (www.wortschatz.uni-leipzig.de) wurde eine Liste der Kollokationskandidaten erstellt, die man demnächst einer linguistischen Untersuchung unterzog. Das Printwörterbuch enthält über 3200 Stichwörter, zu denen fast 200000 Kollokatoren angegeben werden. (2) Das Projekt Das Kollokationenwörterbuch. Feste Wortverbindungen des Deutschen. Kollokationen für den Alltag wurde von Annelies Häcki Buhofer, Harald Burger, Hans Bickel und Brigit Eriksson geleitet. Auch in diesem Projekt wird von der Kookkurrenzanalyse ausgegangen, wobei die Daten aus mehreren Korpora: DWDS, Schweizer Korpus, Korpus C4 sowie dem Deutschen Referenzkorpus DeReKo und dem Korpus Wortschatz-Leipzig stammen (nähere Informationen unter http://kollokationenwoerterbuch.ch/web/projekt/ korpus, Zugriff am 21.05.2017). Das Printwörterbuch Feste Wortverbindungen des Deutschen. Kollokationenwörterbuch für den Alltag ist 2014 erschienen. (3) Das Projekt Moderne deutsch-russische Idiomatik: Ein Korpus-Wörterbuch wird unter der Leitung von Dmitrij Dobrovol'skij, Artem Šarandin und Tat'jana Filipenko entwickelt und von der Russischen Akademie der Wissenschaften in Moskau und der Österreichischen Akademie der Wissenschaften in Wien befördert. Ausgewählte Artikel sind über die Plattform Wortverbindungen online (http://wvonline.ids-mannheim. de/idiome_russ/index.htm, Zugriff am 21.05.2017) zugänglich. (4) Auf die Projekte von Kathrin Steyer (Usuelle Wortverbindungen) und von Christiane Fellbaum et al. (Kollokationen im Wörterbuch), infolge derer digitalisierte Datenbanken entstanden sind, wird im Haupttext kurz eingegangen. 
Regeln zur Ermittlung von phraseologischen Bedeutungen ausgerechnet in der Phraseologie und Idiomatik - aufgrund der Vielschichtigkeit der semantischen Struktur der Phraseologismen im engeren Sinne und ihres semantischen Mehrwerts - ein wichtiges Forschungsdesiderat.

(ii) Dieses Desiderat ist desto gültiger, als die Beschreibung der Semantik und Pragmatik von Phraseologismen aus der lexikographischen Perspektive einen Bereich darstellt, in dem ein Nachholbedarf und Verbesserungen am ehesten notwendig sind (Burger 2009: 23, Dobrovol'skij/Piirainen 2009: 158, Dräger/Juska-Bacher 2010: 172-174). Metalexikographie verweist auf zahlreiche Unzulänglichkeiten in Hinsicht auf die Behandlung der Phraseologismen in allgemeinen (vgl. u.a. Burger 2009, Hallsteinsdóttir 2006, Jesenšek 2008, Lisiecka-Czop/Misiek 2011, Müller/Kunkel-Razum 2007, Nerlicki 2011, Stantcheva 2003, Wiktorowicz 2011) und in phraseologischen (vgl. u.a. Mellado-Blanco 2009b, Müller/Kunkel-Razum 2007, Szczęk 2010) Wörterbüchern. Weder einsprachige noch bilinguale Nachschlagewerke, die bisher veröffentlicht worden sind, entsprechen den Benutzererwartungen insbesondere hinsichtlich ihrer Brauchbarkeit in der Textproduktion (Dobrovol'skij 2002: 429). Bei manchen Phraseologismen mögen die aufgeführten Bedeutungserläuterungen bzw. Äquivalente sogar in der Textrezeption irreführend sein (vgl. z.B. Sulikowska 2013). Die Beschreibung der semantischen Eigenschaften eines Lexems oder eines Phrasems bleibt deswegen nach wie vor nicht nur die Hauptaufgabe, sondern mit Abstand auch die schwierigste Aufgabe der lexikographischen Praxis (Mellado Blanco 2009: 8).

(iii) Diese Unzulänglichkeiten mögen darauf zurückzuführen sein, dass als primäres Verfahren in der lexikographischen Praxis immer noch Introspektion (evtl. gestützt auf einzelne Gebrauchsbelege) zum Einsatz kommt. Die Wichtigkeit der Autorenintuition bei der Wörterbuchverfassung liegt möglicherweise nicht in den expliziten Ansichten der Lexikographen und ihrer Abneigung der Korpusrecherche gegenüber, sondern eher in der Tatsache, dass zahlreiche Wörterbücher (darunter die umfassendsten und bekanntesten wie DUW oder WAHRIG) für Neuauflagen nicht neu geschrieben, sondern nur überarbeitet werden ${ }^{139}$ (Dräger/Juska-Bacher 2010: 172, Juska-Bacher 2006: 71, Müller/Kunkel-Razum 2007: 944). Es wird also auf Vorgängerwerke zurückgegriffen, was des Öfteren zur Folge hat, dass die Lemmaauswahl als antiquiert empfunden wird, die vor Jahren formulierten Bedeutungsparaphrasen dem heutigen Sprachgebrauch nicht oder nicht ganz gerecht werden, phraseologische Neologismen, Bedeutungserweiterungen oder -verschiebungen oder areale Aspekte nicht erfasst werden.

139 Dräger und Juska-Bacher (2010: 172) sprechen von drei „klassischen“ Quellen, auf die Lexikographen bei der Erstellung ihrer Werke traditionellerweise zurückgegriffen haben: Autorenintuition, Vorgängerwerke, Beiträger. 
Aus diesem Grunde wird der verstärkte Einsatz der Korpora in den Untersuchungen zur Semantik der Phraseologismen postuliert (Bubenhofer/Ptashnyk 2010, Dobrovol'skij 2016: 879, Dräger/Juska-Bacher 2010: 172-174, Jesenšek 2009: 65). Die elektronischen Sprachkorpora können bestehende Defizite an der Datenerhebung weitgehend eliminieren, indem sie als Quelle leicht zugänglicher Sprachbelege dienen, mit deren Hilfe das vorhandene Wissen über die Bedeutung von Phraseologismen ausgewertet, erweitert oder revidiert werden kann. In der Lexikographie und Phraseographie spricht man inzwischen von corpus revolution (Hanks 2012) und der pre-corpus era (Dobrovolskij 2016: 867). Moons Worte über die Rolle der Korpora in der lexikologischen und lexikographischen Forschung sind aus heutiger Sicht programmatisch:

I take it as axiomatic that effective and robust descriptions of any kind of lexical item must be based on evidence, not intuition, and that corpora provide evidence of a suitable type and quality. (Moon 1998: 44)

\section{Korpusaufbau und Grundverfahren der Korpusuntersuchung in der Phra- seologie}

Ausschlaggebend für die phraseologische Forschung sind bezüglich des Aufbaus des Korpus drei Kriterien: die Korpusgröße, seine Zusammensetzung sowie die zugänglichen Suchmaschinen (vgl. size, composition, tools, vgl. Moon 2007: 1045).

Die Wichtigkeit der Korpusgröße ist für phraseologische Untersuchungen offensichtlich: Die Idiome gehören generell zu wenig frequenten sprachlichen Einheiten (Cowie 2003: 48, Juska-Bacher 2006: 71-72, Moon 2007: 1050, Quasthoff/Schmidt/Hallsteinsdóttir 2010: 37), für die Exzerpierung einer für adäquate Beschreibung ausreichenden Menge der Sprachbelege sind infolgedessen große Korpora erforderlich ${ }^{140}$ :

Corpus size is important for research into phraseology because large amount of data are needed in order to produce robust results. Statistics derived from a small corpus may just record idiosyncrasies with no real implications for a description of the phraseological patterning of English, and most idioms and proverbs are relatively infrequent, so that it is entirely a matter of chance whether or not they occur in a small corpus. (Moon 2007: 1045)

Einen weiteren sehr wichtigen Punkt für phraseologische Korpusuntersuchungen macht die Zusammensetzung eines Korpus aus. Es ist allgemein bekannt, dass die Phraseologismen in ihrer Distribution in verschiedenen Textsorten gravierende Unterschiede aufweisen (Moon 2007: 1049-1051, Stein 2007: 220). Je heterogener ein Korpus ist, d.h. je mehr Quellen zu der Datenbeschaffung herangezogen werden, desto umfangreicher sind seine Einsatzmöglichkeiten und zuverlässiger die Schlussfolgerungen. Der Aspekt der Ausgewogenheit ist für die Reliabilität der Ergebnisse von größter Relevanz, in der Praxis treten aber bei

140 Moon (2007: 1050) verweist darauf, dass im Englischen $86 \%$ der Phraseologismen nicht häufiger als einmal pro eine Million der Wörter vorkommen. 
der Zusammenstellung eines Korpus Schwierigkeiten auf, weil viele Daten der Forschung wegen Copyright-Beschränkungen nicht zur Verfügung stehen. Die meisten Korpora beruhen deswegen auf weitgehend opportunistischen Datenzusammenstellungen, d.h. sie bestehen größtenteils aus Texten, deren Autorenrechte verfallen sind und die unentgeltlich (und am besten gleich in digitalisierter Form) zur Verfügung stehen (Lemnitzer/Zinsmeister 2010: 106). Wahrscheinlich auf diese technologischen Gründe ist die deutliche Überzahl der geschriebenen Texte in großen Korpora des Deutschen zurückzuführen: Selbst bei den als ausgewogen geltenden Korpora wie DWDS-Kernkorpus (s.u.) macht die gesprochene Sprache wegen der zeit- und arbeitsaufwendigen Transkription nur einige Prozent des Gesamtkorpus aus. Die Unausgewogenheit des Verhältnisses zwischen der gesprochenen und der geschriebenen Sprache stellt für semantisch ausgerichtete phraseologische Fragestellungen ein Problem dar: Ausgerechnet in diesem Bereich sind die Unterschiede zwischen der geschriebenen und der gesprochenen Sprache prägnant. Darüber hinaus wird in der Phraseologie davon ausgegangen, dass Phraseologismen in der gesprochenen Sprache wesentlich häufiger auftreten, als es in geschriebenen Texten der Fall ist (Stein 2007: 220). Leider liegen heutzutage noch keine genügend großen Korpora gesprochener Sprache vor, um empirisch basierte Vergleiche zwischen der mündlichen und der schriftlichen Phraseologie vorzunehmen (Quasthoff/Schmidt/Hallsteinsdóttir 2010: 38), die Aussagekraft der Forschungsergebnisse zur Semantik und Pragmatik der Phraseologismen muss deswegen in Hinsicht auf Unausgewogenheit der Korpora relativiert werden.

Die ausgebaute Infrastruktur eines Korpus (tools) erweitert seine Einsatzmöglichkeiten und ist besonders in a posteriori ausgerichteter Forschung hilfreich. So sind z.B. erweiterte Funktionen der Suchmaschinen von besonderer Relevanz in den Untersuchungen, die - den neueren Desiderata der Phraseologie folgend sich auf die Suche nach den vorgeformten Mustern, usuellen Wortverbindungen konzentrieren. Eine große Herausforderung an die technische Seite der Korpora stellt z.B. maschinelle Identifikation von Phraseologismen oder Phraseoschablonen ${ }^{141}$ - grammatischen Konstruktionen mit festgelegter Bedeutung, aber paradigmatisch austauschbaren lexikalischen Elementen vom Typ: $X$ ist $X$ (Hin ist hin, vorbei ist vorbei), von $X z u X$ (von Schritt zu Schritt, von Tag zu Tag), es ist zum $X$ (es ist zum Kotzen, Lachen, Wahnsinnigwerden), Ich (und) mir Sorgen machen? dar (das letzte Beispiel von Sailer 2007: 1069). Steyer (2013: 74) zufolge gibt es zurzeit sehr wenige Tools, die geronnene syntagmatische Strukturen berechnen und abbilden können. Ebenfalls zu den Studien zu phraseologischen Variationen und Modifikationen leisten ausgebaute Suchmaschinen einen wesentlichen Beitrag.

141 Phraseoschablone definiert Wolfgang Fleischer als syntaktische Strukturen - und zwar sowohl nichtprädikative Wortverbindungen als auch Satzstrukturen, deren lexikalische Füllung variabel ist, die aber eine Art syntaktischer Idiomatizität aufweisen (1982: 135). 
Hinsichtlich des Einbezugs der Korpora in die phraseologische Forschung wurden zwei Grundverfahren herausgearbeitet (Sailer 2007: 1064-1067, Steyer 2009: 119). Diese Grundverfahren verzahnen sich inhaltlich selbstverständlich mit den von Lemnitzer/Zinsmeister (2010) beschriebenen Korpusparadigmen, hinzuweisen sei an dieser Stelle auf die terminologischen Unterschiede, insbesondere bei dem Gebrauch des Terminus ,korpusbasiert ${ }^{6}{ }^{142}$ Als die wichtigsten methodologischen Herangehensweisen, die vorerst die Richtungen abstecken, in die sich korpuslinguistische Phraseologieforschung bewegt, gelten demnach das Konsultations- (consultation paradigm) und das Analyseparadigma (analysis paradigm).

Das Konsultationsparadigma, von Steyer (2009: 119-120) als korpusbasiertes Herangehen bezeichnet, beruht auf einer systematischen, korpusbasierten Untersuchung von sprachlichen Einheiten. Die Hypothesen und Fragen an das Korpus sind dabei von vornherein gestellt, während das Vorgehen primär der Überprüfung, Revidierung, Ausdifferenzierung und Erweiterung bereits vorhandenen Wissens über den sprachlichen Gebrauch dient (Steyer 2009: 119). Auf diese Art und Weise werden verbale Idiome beispielshalber in einem von Christiane Fellbaum ${ }^{143}$ geleiteten Projekt Kollokationen im Wörterbuch erforscht und in einer digitalisierten Datenbank beschrieben (http://kollokationen.bbaw.de, Zugriff am 16.05.2016). Die Analysen basieren auf den Daten aus dem DWDS-Korpus, werden eingehend und unter Rückgriff auf Korpusbelege bezüglich ihrer Nennform, Morphologie, Syntax und Semantik manuell annotiert. Herangeführt und mit Korpusbelegen veranschaulicht wird ebenfalls der sprachspielerische und fehlerhafte Gebrauch der Idiome. Solche Aufarbeitung der Phraseologismen stellt einen deutlichen Mehrwert gegenüber den traditionellen lexikographischen Methoden dar, ist aber aufgrund der Fülle der anzugebenden Informationen äußerst zeitund arbeitsaufwendig: Lexikographische Aufarbeitung von Phrasemen ist um ein Vielfaches umfassender und aufwendiger als es bei Einwortlexemen der Fall ist ${ }^{144}$

142 Das terminologische Wirrwarr mag auf die unterschiedlichen Übersetzungen der englischen Begriffe: corpus-based, corpus-driven (Sinclair 1991) zurückzuführen sein.

143 Die Beschreibung des durch den Wolfgang Paul-Preis der Alexander von HumboldtStiftung geförderten Projektes „Kollokationen im Wörterbuch“ unter Leitung der Preisträgerin Christiane Fellbaum findet man auf http://www.bbaw.de/forschung/ kollokationen/projektdarstellung (Zugriff am 25.05.2017).

144 Vgl. dazu Dräger/Juska-Bacher (2010: 166): „Den einschlägigen Veröffentlichungen zum Thema folgend (u.a. Kempcke 1986, Pilz 2002, Schemann 1989, Steffens 1989) sollte ein solider phraseographischer Artikel folgende Informationen zu einem Phrasem liefern: Angabe einer gebräuchlichen Nennform und von Varianten, Bedeutungsangabe, Hinweise zu möglichen Restriktionen sowie pragmatische Angaben. Je nach Fachausrichtung und Interessenlage können hierzu etymologische Erklärungen (Mokienko 2002), Angaben zur arealen Verteilung (Piirainen 2001, Schmidlin 2001), zum Bekannheitsgrad respektive der Verwendungshäufigkeit (wichtig u.a. für Phraseodidaktik, siehe Arbeiten zur Erstellung sog. phraseologischer Minima oder Optima von Grzybek 1991, Durčo 2001, Hallsteinsdóttir/Šajánková/Quasthoff 
(Dräger/Juska-Bacher 2010: 175, Fellbaum/Kramer/Neumann 2006: 43, Schmidlin 2001: 108).

Das Analyseparadigma, von Steyer als korpusgesteuertes (2009: 119) oder korpusanalytisches (2013: 70-73) Herangehen bezeichnet, ist induktiv und versucht, das Wissen aus den beobachteten Sprachdaten zu generieren und Generalisierungen a posteriori vorzunehmen. Die korpusgesteuerten Recherchen stellen eine Herausforderung in technischer Hinsicht dar, erfordern ggf. vertiefte EDVKenntnisse (Quasthoff/Schmidt/Hallsteinsdóttir 2010: 51), führen aber zu vielversprechenden Ergebnissen. Dieses Paradigma liegt beispielsweise den von Steyer (2013) geleiteten Projekten zu den sog. usuellen Wortverbindungen - festen und/ oder relativ festen Wortkombinationen, die Bausteine des Sprachgebrauchs darstellen - zugrunde. Ausgegangen wird von einer großen Sammlung von Texten aus den IDS-Sprachkorpora, in denen mithilfe einer Suchmaschine nach Kookurrenzen - frequent miteinander vorkommenden Wörtern - gesucht wird. Auf diese Art und Weise werden aus einer großen Datenbank induktiv statistisch signifikante Kookkurrenzen extrahiert, die man als Kandidaten für usuelle Wortverbindungen betrachtet ${ }^{145}$. Im zweiten Schritt werden die Elemente des Konsultationsparadigmas zurate gezogen: Diese extrahierten Lexemkombinationen unterzieht man nämlich einer eingehenden linguistischen Analyse. ${ }^{146}$

Steyer verweist auf den zweifelsohne innovativen und gewinnbringenden Beitrag der korpusanalytischen/korpusgesteuerten Herangehensweise zur Phraseologie:

Arbeitet man als Linguist konsequent korpusgesteuert, wird man mit neuen Fragen und aber auch neuen Problemen der phraseologischen Beschreibung konfrontiert. Neue interpretative Herausforderungen entstehen z.B. durch die Quantität und die Heterogenität der beobachteten Sprachdaten. Man sieht nicht nur einfach mehr als früher. Man hat auch eine andere Sicht auf die Dinge und erkennt neue Zusammenhänge, Vernetzungen, Hierarchien. So können sich beispielsweise bisher als prominent und daher als lexikographisch beschreibungswürdig angesehene Wortverbindungen als weniger relevant erweisen. Es kann dagegen andere Kandidaten geben,

2006), zu Textsortenpräferenzen (Kühn 1994) und einige andere Detailinformationen kommen."

145 Mittlerweile hat Steyer ihren Forschungsbereich auf Wortverbindungsmuster ausgeweitet, vgl. Steyer/Hein (2016).

146 Im Resultat der Korpusrecherche entstehen Listen von Phraseologismus-Kandidaten, die dann interpretiert werden müssen. Ihre Auslegung und Erstellung der Kriterien, die das Schon-Phraseologische von dem Noch-nicht-Phraseologischen abgrenzen würden, kann dennoch vom Experten zu Experten variieren. Endlich müsste man hier komplexe Fragen beantworten: Ab wann kann eine sprachliche Einheit als lexikalisiert betrachtet werden? Welche Frequenz muss ein Phraseologismus-Kandidat aufweisen, um in den Status einer festen Mehrwortverbindung erhoben zu werden? Aus wie vielen Quellen müssten dann die Belege stammen? 
die sich durch eine viel größere Auffälligkeit auszeichnen, als bis dato zu erkennen war. (Steyer 2009: 120-121)

hebt aber zugleich die Notwendigkeit der Verflechtung beider Paradigmen hervor:

Die terminologische Unterscheidung korpusanalytischer Herangehensweisen war in der programmatischen Phase der Entwicklung der Korpuslinguistik in dieser Radikalität durchaus sinnvoll. Aber die Erfahrungen der empirischen Praxis haben mittlerweile gezeigt, dass es sich bei diesen Zugängen nicht um sich gegenseitig ausschließende Paradigmen handelt. Vielmehr muss man von einem graduellen Einfluss korpusanalytischer Befunde auf die linguistische Interpretation sprechen: von der reinen Suche nach Belegen als Beweis oder Widerlegung von A-priori-Annahmen über eine Zugrundelegung von Korpusdaten als empirische Ausgangsbasis bis hin zu einer hart an den Daten orientierten iterativen Vorgehensweise. (Steyer 2013: 72) Beide methodischen Wege haben ihre Berechtigung. Kein Paradigma kann derzeit den Alleinvertretungsanspruch erheben und wird es vielleicht auch nie können. (Steyer 2009: 120)

Der große Wert des Einsatzes von empirisch-digitalen Methoden für die theoretische und praktische Phraseologie wird kaum in Zweifel gezogen, auch wenn es einige Herausforderungen mit sich bringt:

In der Theorie der Phraseologie führt die korpuslinguistische Forschung dazu, dass sich der Bereich des Phraseologischen immer mehr ausweitet: Die Phraseologie wird von dem traditionellen lexikalischen Bereich immer mehr zum Schnittpunkt zwischen Lexik und Syntax verschoben ${ }^{147}$. Einige Grundbegriffe - wie etwa die Auffassung der phraseologischen Festigkeit - werden umgedacht, von manchen Forschern werden neue, korpuslinguistisch basierte Definitionen vorgeschlagen $^{148}$. Die Kriterien der Phraseologizität werden nicht mehr als absolut, sondern als skalar betrachtet. Verwies man schon früher auf die Heterogenität des phraseologischen Gegenstandes, so gewährt uns die Korpuslinguistik schon beim heutigen Forschungsstand den Einblick in die kaum übersehbare Fülle des Formelhaften, Vorgeprägten und Idiomatischen in der Sprache.

Auch in der phraseologischen Praxis bringt die Korpuslinguistik Herausforderungen mit sich. Als ungelöstes Problem wird die Beziehung zwischen der Frequenz einer Wendung im Korpus und der sprachlichen Norm betrachtet (Eismann 2018). Viele erfahrene Korpuslinguisten verweisen des Weiteren darauf, dass die erhoffte und am Anfang bejubelte Erleichterung der empirischen Alltagsarbeit sich

147 „Ob die Öffnung der Phraseologie den neuen Methoden gegenüber dazu führt, dass sich die Phraseologie einen engeren, deutlich abgesteckten Untersuchungsgegenstand reserviert, oder dass an der Schnittstelle traditioneller Phraseologie und Syntax sich ein neues linguistisches Teilgebiet behauptet, wird die künftige Forschung zeigen" (Bubenhofer/Ptashnyk 2010: 18-19).

148 So schlägt z.B. Colson (2010) eine Neudefinierung der Kollokationen, die auf statistisch operationalisierbaren Korpusdaten basiert (vgl. auch das erste Kapitel). 
nicht in allen Bereichen einstellt. Die vom Korpus gewonnenen Daten machen lediglich den Ausgangspunkt in einem Forschungsvorhaben aus, der - die Komplexität des tatsächlichen Sprachgebrauchs vor Augen führend - nicht immer die Arbeit abnimmt, sondern öfters neue Fragen aufwirft, traditionelle Grenzen aufweicht, etablierte Termini infrage stellt.

Datenmengen anzusammeln und sie mittels statistischer Verfahren zu strukturieren, ist eben nur das eine. Es muss aber dann auch die Interpreten geben, die diese quantitative Dimension adäquat in linguistische Beschreibungen überführen und den Transfer dieser Ergebnisse in praxisnahe Anwendungsgebiete ermöglichen. Adäquat bedeutet, eine qualitative Auswertung der Sprachdaten ohne die Quantität dann im Nachhinein wieder zu nivellieren. Die Quantität nivellieren bedeutet, sich doch wieder auf Einzelfallstudien zu konzentrieren, nach a priori wohl ausgesuchten Fragestellungen und Kriterien. (Steyer 2013: 69) 



\section{Mechanismen der Bedeutungskonstituierung von Idiomen}

Das Ziel des empirischen Teils der vorliegenden Arbeit liegt in der Veranschaulichung der Komplexität der Bedeutungskonstituierungsprozesse von Idiomen mit zwei disjunktiven Lesarten. Es wird an authentischen Sprachgebrauchsbelegen erläutert, wie Metonymien, Metaphtonymien, epistemische und konzeptuelle Metaphern vom unterschiedlichen Generalitätsgrad, mentale Bilder, tief in der frühesten Körpererfahrung verankerten image schemas und relativ individuelle Weltwissensinhalte über Politik, Wirtschaft, Gesellschaft und Sprache in einem vielschichtigen, viele Aspekte umfassenden Zusammenspiel die Bedeutungen von Idiomen gestalten. In den Fokus der Aufmerksamkeit wird dabei ein kohärenter Erfahrungs- und Diskursbereich gerückt - das semantische Feld der Schwierigkeit/ der schwierigen Lage.

\subsection{Daten und Methoden}

Die folgenden empirischen Untersuchungen beruhen auf einer Kombinierung der onomasiologischen und semasiologischen Herangehensweise.

Unter Onomasiologie (zu griech. onoma ,Name ') versteht man in der Semantik und Lexikologie die Lehre von den Benennungen (Schmidt-Wiegand 2002: 738). Onomasiologie in einem weiteren Sinne erstreckt sich auf die (den Wortschatz unterschiedlicher Sprachen einbeziehenden) interlingualen und etymologischmorphologischen Studien: Sie versucht die Prozesse zu erklären, die zu einzelnen Bezeichnungen geführt haben. Die Onomasiologie im engeren Verständnis (auch als Onomasiographie bezeichnet) setzt sich zum Ziel, die Bezeichnungen, die zu einem bestimmten Begriff gehören, zu sammeln, zu klassifizieren und zu beschreiben, d.h. zeitlich und räumlich möglichst genau festzulegen (ebd., 740).

Während die Onomasiologie von einer Sache bzw. von einem Begriff ausgeht und nach den dazugehörigen Bezeichnungen fragt, hat die Semasiologie (zu griech. sema ,Zeichen') ihren Ausgangspunkt bei den Bezeichnungen und fragt nach deren Bedeutung(en). Dementsprechend wird die Onomasiologie auch als Bezeichnungslehre, Semasiologie als Lehre von Bedeutungen benannt ${ }^{149}$.

149 Beide Begriffe assoziiert man traditionellerweise mit dem Strukturalismus, onomasiologisch und semasiologisch ausgerichtete Verfahren werden dennoch erfolgreich auch in den kognitiven Studien eingesetzt. So bedienen sich z.B. Kövecses (1988, 1990, 2000), Lakoff/Kövecses (1987) sowie Lakoff (1987: 380-415) bei ihren Untersuchungen zur Konzeptualisierung der Emotionen (LIEBE, ÄRGER/WUT, ANGST, STOLZ) und den damit verbundenen konzeptuellen Metaphern onomasiologischer Herangehensweise. Jäkel (2003) untersucht unter Einbezug onomasiologischen Verfahrens 
Im empirischen Teil der vorliegenden Arbeit werden beide Herangehensweisen aneinandergestellt. Die Zusammenstellung des Untersuchungsmaterials erfolgt in einem onomasiologisch ausgerichteten Verfahren. Ausgehend von einem weit gefassten, relativ abstrakten Diskursbereich der Schwierigkeit/schwierigen Lage wird anhand der lexikographischen Werke nach den festen Wortverbindungen gesucht, die seiner Versprachlichung dienen. Die gesammelten Idiome werden dann einer weiteren Analyse unterzogen, die sich zum Ziel setzt, die das zu besprechende semantische Feld strukturierenden konzeptuellen Metaphern zu ermitteln.

Der von dem Umfang und der Relevanz her konstitutive Teil der empirischen Untersuchung ist semasiologisch ausgerichtet: Ausgewählte Idiome werden unter Rückgriff auf ein Sprachkorpus semantisch-kognitiv analysiert, um die Bedeutungen und Teilbedeutungen (Verwendungsprofile und Verwendungsmuster) der Phraseologismen aus dem authentischen Sprachgebrauch zu eruieren sowie die kognitiven Mechanismen darzustellen, die zur Konstituierung dieser Bedeutungen unter den jeweiligen kontextuellen Bedingungen führen. Die Analyse der authentischen Verwendung eines Phraseologismus bei der Untersuchung seiner Semantik ist aus zwei Gründen relevant: Zum einen weist die lexikographische Erfassung der Semantik von Idiomen öfters Unzulänglichkeiten auf, auf die vielerorts verwiesen wurde (vgl. dazu u.a. Bąba/Liberek 2011, Burger 2009, Dobrovol'skij 2002b, Dobrovol'skij/Piirainen 2009, Ettinger 2004, 2009, Filipenko 2009, Mellado-Blanco 2009b, Parina 2014, Sulikowska 2013, 2014a, 2015c, Szczęk 2011). Zum anderen werden in den meisten Nachschlagewerken die weniger frequenten Teilbedeutungen (Verwendungsmuster) außer Acht gelassen. Diese Teilbedeutungen, die zwar nicht durch die meisten Gebrauchsbelege vertreten sind, aber zugleich nicht (mehr) idiosynkratisch gebraucht werden, sind währenddessen aus der kognitiven Perspektive sehr interessant. Sie gewähren uns nämlich Einblick in die dynamischen metaphorisch-metonymischen Konstituierungsprozesse der Bedeutung von bestimmter Systematizität und weisen auf die potenziellen künftigen Richtungen der semantischen Entwicklung von idiomatischen Einheiten hin.

die Konzeptualisierungen in den Diskursbereichen: Wissenschaft, Wirtschaft, Geistestätigkeit und Religion, Ehrenmüller (2017) ermittelt konzeptuelle Metaphern, die dem SPIEL-Konzept Struktur verleihen. Als Beispiel einer onomasiologischen Studie in der kognitiv ausgerichteten Phraseologie kann der Beitrag von Dobrovol'skij (1995) zur Konzeptualisierung von ANGST herangeführt werden. Semasiologisches Verfahren kommt z.B. bei der semantischen Untersuchung von Präpositionen zum Tragen: Auf großes Interesse stieß z.B. Lakoffs (1987: 416-461) Analyse der Präposition on in der räumlichen Grundbedeutung und in übertragenen Bedeutungen. Kognitiv-semasiologische Analysen zu englischen Präpositionen wurden des Weiteren von Brugman (1989) und Rice (1992) durchgeführt, den Konzeptualisierungen von Finger in der phraseologisch gebundenen Bedeutung ist ein Beitrag von Staffeldt/ Ziem (2008) gewidmet. 


\subsubsection{Untersuchungsmaterial}

$\mathrm{Zu}$ den in der Phraseologie besonders gern behandelten Themenbereichen gehören zweifelsohne Somatismen, Emotionen, Tiere und Farben ${ }^{150}$. Die Popularität der phraseologischen Studien zu Tier- und Farbbezeichnungen ist auf ihre kulturelle Verankerung zurückzuführen. Somatismen und Emotionen wird dagegen vor allem in kognitiv ausgerichteter Phraseologieforschung eine wichtige Stellung eingeräumt: Sie eignen sich aufgrund ihrer Körpergebundenheit hervorragend dazu, den Einfluss von Embodiment und konzeptuellen Metaphern auf die Struktur komplexer abstrakter Konzepte und Konzeptualisierungen aufzuzeigen. Da in der vorliegenden Arbeit das Ziel anvisiert wird, ein möglichst großes Spektrum der Bedeutungskonstituierungsmechanismen zu erfassen, wird von diesen populären Forschungsbereichen abgesehen. Stattdessen steht ein relativ umfangreiches, breit gefächertes, nach dem Wissen der Autorin in der bisherigen Forschung noch nicht eingehend thematisiertes semantisches Feld der Schwierigkeit/der schwierigen Lage im Zentrum des Interesses.

Die Erstellung der Phraseologismensammlung, die zur Beschreibung der Notlage eines Menschen im Deutschen verwendet werden, erfolgt mithilfe von drei phraseographischen Nachschlagewerken:

(i) Deutsche Redewendungen. Ein ideographisch gegliedertes Wörter-, Übungs- und Lesebuch für Fortgeschrittene ist über die Seite www.ettinger-phraseologie.de (letzter Zugriff am 29.05.2017) zugänglich und basiert in der Auswahl der Lemmata auf dem 1997 veröffentlichten Lernerwörterbuch Deutsche Redewendungen von Ettinger/ Hessky. Aus Ettingers Nachschlagewerk werden ausgewählte Phraseologismen aus folgenden thematischen Bereichen:

F. 15. Schwierigkeiten haben - Schwierigkeiten machen

F. 16. Benachteiligung - Schaden

E. 9. Ablehnen - Verneinen

in die vorliegende Phraseologismensammlung übernommen;

(ii) Hans Schemanns Synonymwörterbuch der deutschen Redensarten ist als Printwörterbuch 1989 erschienen und umfasst ca. 20000 nach inhaltlichen Kriterien eingeteilten Lemmata. Im Folgenden wird auf die 2. erweiterte Auflage dieses Wörterbuches aus dem Jahre 2012 Bezug genommen. Schemanns Werk ist im Hinblick auf die onomasiologische Struktur detailliert ausgearbeitet. In die Sammlung werden Phraseologismen aus semantischen Kategorien:

$150 \mathrm{Zu}$ den Somatismen in der Phraseologie vgl. z.B. Guławska-Gawkowska 2013, Staffeldt/Ziem 2008; zu Emotionen vgl. u.a. Dobrovol'skij 1995, Gondek 2015, Pohl/Kaczmarek 2014, zu den Tierbezeichnungen vgl. u.a. Chrissou 2000, Schowalter 2010, Stypa 2015, Szczęk 2010c, zu den Farben vgl. z.B. Hofmannová 2004, Wanzeck 2003. 
Fa 20 zwingen, Druck ausüben

Fa 21 Zwang, Zwangslage: unter Druck stehen, wohl oder übel tun müssen

Ga 4 ernste Lage; Zwickmühle: in Schwulitäten

Hb 4 (ver-)hindern; jmdm. in die Quere kommen; jmdm. Knüppel zwischen die Beine werfen; jmdm. einen Strich durch die Rechnung machen (Auswahl)

Hb 5 schaden, schädigen: Schaden anrichten; jmdm. etw. einbrocken

Gb 1 Gefahr, gefährlich; seines Lebens nicht mehr sicher (Auswahl)

einbezogen;

(iii) Das elektronische Wörterbuch redensarten-index (www. redensarten-index. de) ist nur bedingt onomasiologisch: Die in die Eingabemaske eingefügten Stichwörter können zwar in Bedeutungsparaphrasen oder Beispielen gesucht werden, eine den vorangehenden Wörterbüchern zugrunde liegende reflektierte Zuweisung der Phraseologismen zu den einzelnen inhaltlichen Bereichen wird aber nicht vorgenommen. Deswegen spielt dieses Wörterbuch eine Behelfsrolle. Die Bedeutungen von den in die Sammlung aufgenommenen Phraseologismen wurden von der Autorin auf ihre Zugehörigkeit zum semantischen Feld der Schwierigkeit/der schwierigen Lage hin auch in anderen Nachschlagewerken (DUW online, Wahrig 2007) manuell überprüft.

Als Ergebnis entstand eine Liste von 250 konventionalisierten (Mehr-)Wortverbindungen. Da die Datengrundlage für weitere Untersuchungen semantisch motivierte Phraseologismen im engeren Sinne ausmachen, wird das Untersuchungsmaterial demnächst manuell untersucht und einem Reduktionsverfahren unterzogen. Einwortphraseologismen als Einheiten mit einem umstrittenen Status in der Phraseologie ${ }^{151}$ (sich festfahren, festsitzen, jmdm. dazwischenfunken, sich totlaufen, dazwischenkommen, etw. zunichtemachen), elliptische Phraseologismen (z.B. Da haben wir's!/habt ihr's/...), pragmatisch motivierte Phraseologismen (z.B. Da haben wir/habt ihr/... die Bescherung!), nicht-idiomatische und schwach-idiomatische Phraseologismen (z.B. in Gefahr sein, auf bessere Zeiten hoffen/warten, aufs/ auf das Äußerste/Ärgste gefasst sein (müssen), sich aufs/auf das Äußerste gefasst machen (müssen), in Schwierigkeiten geraten, in Todesgefahr schweben/sein, nicht an jmds. Stelle sein mögen, aufs/auf das Schlimmste gefasst sein (müssen), sich aufs/ auf das Schlimmste gefasst machen (müssen), mit dem Schlimmsten rechnen müssen, mit jmdm./etw. steht es nicht zum besten), aber auch Zwillingsformeln, die vor allem durch die ästhetische Funktion der Sprache motiviert sind ${ }^{152}$ (mit Ach und Krach, mit Müh und Not, mit Hängen und Würgen) werden aus der Untersuchung

151 Als Einwortlexeme erfüllen sie die Bedingung der Polylexikalität nicht. Da man sie dennoch als idiomatisch empfindet, werden sie öfters in phraseologische Nachschlagewerke aufgenommen (vgl. Kap. 1.2.2.1)

152 Es handelt sich hier um rhetorische Mittel, wie z.B. Alliteration oder Reimelemente, die in den Zwillingsformeln gehäuft auftreten. 
ausgeschlossen. Die verbleibende Menge von 206 idiomatischen Zieleinheiten bildet die Datengrundlage für eine semantisch-kognitiv ausgerichtete Analyse des semantischen Feldes der Schwierigkeit/der schwierigen Lage im Deutschen.

Die vollständige Phraseologismenliste befindet sich im Anhang (Tab. 44). Im Folgenden werden - unter Verweis auf die Quellen - 206 Phraseologismen angeführt, die die Datengrundlage für weitere Analysen aufmachen. Die Nennformen der Phraseologismen werden im Original angegeben, woraus sich Differenzen in der Behandlung der phraseologischen Varianten ergeben können:

Tab. 8: Die Phraseologismensammlung anhand lexikographischer Nachschlagewerke nach dem Reduktionsverfahren.

\begin{tabular}{llcl}
\hline Phraseologismen & \multicolumn{2}{c}{ Quellen } \\
\hline & $\begin{array}{l}\text { Ettinger- } \\
\text { phraseologie mann }\end{array}$ & $\begin{array}{l}\text { Sche- } \\
\text { arten- } \\
\text { index }\end{array}$ \\
\hline
\end{tabular}

sich wie ein Aal winden

F.15.

Cc 14

in den sauren Apfel beißen (müssen)

F.15.

jmdm. in den Arm fallen

$\mathrm{Hb} 4$

den Bach runtergehen

etw. an der Backe tragen

mit etw. auf den Bauch fallen

zwischen Baum und Borke geraten

Ga 4

zwischen Baum und Borke sein (selten)

Ga 4

Es brennt der Baum

in (große/arge/...) Bedrängnis kommen

in großer/arger ... Bedrängnis sein

Ga 4

Ga 4

sich in großer/arger ... Bedrängnis fühlen

Ga 4

jmdm. ein Bein stellen (ugs.)

F.15. $\quad \mathrm{Hb} 4$

jmdm. ein Beinchen stellen (ugs.)

$\mathrm{Hb} 4$

etw. am Bein haben

sich etw. ans Bein hängen/binden

mit jmdm. geht es bergab/bergauf

sich eine Blöße geben

Ga 4

(total/völlig) am Boden zerstört sein

jmdm. brennt der Boden unter den Füßen

jmdm. den Boden unter den Füßen heiß machen

jmdm. wird der Boden (unter den Füßen) zu heiß ja

ja

ja

ja

ja

ja

ja

ja

ja

ja

ja 
Tab. 8: Continued

\begin{tabular}{|c|c|c|}
\hline \multirow[t]{2}{*}{ Phraseologismen } & \multicolumn{2}{|l|}{ Quellen } \\
\hline & $\begin{array}{ll}\text { Ettinger- } & \text { Sche- } \\
\text { phraseologie } & \text { mann }\end{array}$ & $\begin{array}{l}\text { Redens- } \\
\text { arten- } \\
\text { index }\end{array}$ \\
\hline $\begin{array}{l}\text { sich auf schwankenden/unsicheren Boden begeben; } \\
\text { sich auf unsicherem/schwankendem Boden } \\
\text { bewegen/befinden }\end{array}$ & & ja \\
\hline jmdm. schwankt der Boden unter den Füßen & & ja \\
\hline jmdm. den Boden unter den Füßen wegziehen & & ja \\
\hline einer Sache den Boden entziehen & & ja \\
\hline den Boden unter den Füßen verlieren & & ja \\
\hline den festen Boden unter den Füßen gewinnen & & ja \\
\hline
\end{tabular}

$$
\text { in die Bredouille geraten (geh.) }
$$

Ga 4

jmdn. in die Bredouille bringen (geh.) Ga 4

in der Bredouille sein/(sitzen) (geh.) Ga 4

sich in die Brennnesseln/Nesseln setzen ja

ein harter/schwerer Brocken ja

ein dicker Brocken $\quad$ Ga 4

etw. ist ein hartes/schweres Brot

F.15.

(ganz schön/...) im Dreck sitzen/stecken (vulg.)

Ga 4

jmdn. in die Ecke drängen

ja

sich ein Eigentor schießen

sich auf dünnes Eis begeben/wagen; sich auf

dünnem Eis bewegen

ein heißes Eisen sein

Gb 1

ein heißes Eisen anpacken/anfassen $\quad$ Gb 1

jmdn. in die Enge treiben $\quad$ Fa 20

in gefährliches Fahrwasser geraten ja

zu Fall kommen ja

jmdn. in die/eine Falle locken; jmdm. eine Falle ja

stellen

jmdm. einen Fallstrick/Fallstricke legen

zwischen zwei Feuer geraten/kommen

ja

ja

sich die Finger an/bei etw. verbrennen 
Tab. 8: Continued

\begin{tabular}{llrl}
\hline Phraseologismen & \multicolumn{3}{c}{ Quellen } \\
\hline & $\begin{array}{l}\text { Ettinger- } \\
\text { phraseologie }\end{array}$ & $\begin{array}{l}\text { Sche- } \\
\text { mann }\end{array}$ & $\begin{array}{l}\text { Redens- } \\
\text { arten- } \\
\text { index }\end{array}$ \\
\hline
\end{tabular}

der Funke sein, der das Pulverfass zum Explodieren

Gb 1

bringt

Es knistert im Gebälk

Gb 1

ins Gedränge kommen

Ga 4

jmdn. ins Gedränge bringen

Ga 4

sich auf Glatteis bewegen

auf Glatteis geraten, sich aufs Glatteis begeben

jmdm. ins Gehege kommen

ja

[bei jmdm.] [mit etw.] auf Granit beißen

F.15. Ga 4

eine Sache hat einen Haken (ugs.)

F.15. Ga 4

jmdn./etw. am/auf dem Hals haben (ugs.)

F. $15 \quad$ Ga 4

jmdn./sich etw. an den Hals hängen/binden

den Hals in der Schlinge haben

den Hals/Kopf aus der Schlinge ziehen

zwischen Hammer und Amboss geraten (geh.).

Ga 4

zwischen Hammer und Amboss sein (geh.).

Ga 4

Hammer oder Amboss sein (geh.)

Ga 4

jmdm. die Hände binden

Fa 20

jmdm. ins Handwerk pfuschen

$\mathrm{Hb} 4$

jmds. Pläne über den Haufen werfen

$\mathrm{Hb} 4$

Da liegt der Hase im Pfeffer (ugs.)

Ga 4

nicht in jmds. Haut stecken mögen

$\mathrm{Hb} 4$

jmdm. einen Hemmschuh in den Weg legen

(selten)

jmdm. Hindernisse in den Weg legen

$\mathrm{Hb} 4$

bei jmdm. ist Holland in Not

Ga 4

Da liegt der Hund begraben (ugs.)

F.15.

Ga 4

eine Hürde nehmen

ja

Hürden/eine Hürde beseitigen

ja 
Tab. 8: Continued

\begin{tabular}{|c|c|c|c|}
\hline \multirow[t]{2}{*}{ Phraseologismen } & \multicolumn{3}{|c|}{ Quellen } \\
\hline & $\begin{array}{l}\text { Ettinger- } \\
\text { phraseologie }\end{array}$ & $\begin{array}{l}\text { Sche- } \\
\text { mann }\end{array}$ & $\begin{array}{l}\text { Redens- } \\
\text { arten- } \\
\text { index }\end{array}$ \\
\hline sich im Jammertal befinden & & & ja \\
\hline $\begin{array}{l}\text { jmdm. Knüppel/einen Knüppel zwischen die } \\
\text { Beine werfen (ugs.) }\end{array}$ & F. 16. & $\begin{array}{l}\mathrm{Ga} 4 \\
\mathrm{Hb} 4\end{array}$ & \\
\hline ein Kapitel für sich sein & E. 9. & $\mathrm{Ga} 4$ & \\
\hline $\begin{array}{l}\text { etw./den Karren/die Karre an/vor/gegen die Wand } \\
\text { fahren }\end{array}$ & & & ja \\
\hline Die Karre ist (gründlich) verfahren (ugs.) & & $\mathrm{Ga} 4$ & \\
\hline Der Karren ist (gründlich) verfahren (ugs.) & & $\mathrm{Ga} 4$ & \\
\hline Die Karre steckt/ist im Dreck (ugs.) & & $\mathrm{Ga} 4$ & \\
\hline Der Karren steckt/ist im Dreck (ugs.) & & $\mathrm{Ga} 4$ & \\
\hline Die Karre in den Dreck fahren (ugs.) & & $\mathrm{Ga} 4$ & \\
\hline Den Karren in den Dreck fahren (ugs.) & & $\mathrm{Ga} 4$ & \\
\hline an etw. zu kauen haben & & & ja \\
\hline etw. im Keim ersticken & & $\mathrm{Hb} 4$ & \\
\hline in die Klemme geraten & & $\mathrm{Ga} 4$ & \\
\hline (ganz schön/...) in der Klemme sitzen (ugs.) & & $\mathrm{Ga} 4$ & \\
\hline die Klippen umfahren/umschiffen & & & ja \\
\hline
\end{tabular}

jmdm. ein Klotz am Bein sein (ugs.)

F.15.

sich (Dativ) [mit jmdm./etw.] einen Klotz ans Bein F.15.

binden (ugs.)

jmdm. (einen) Knüppel zwischen die Beine werfen

wie ein Knüppel am Bein

jmdm. das/sein Konzept verderben (ugs.)

F.15.

etw. wächst jmdm. über den Kopf (ugs.)

F.15

aufs Kreuz fallen

ja

die Kuh vom Eis holen/ziehen/schieben/kriegen/

führen/bringen

mit seiner Kunst am Ende sein (ugs.)

Ga 4

jmdn./etw. in eine unangenehme/missliche/

Ga 4

verzwickte Lage bringen

in einer ausweglosen Lage (sein) 


\begin{tabular}{llrl}
\hline Phraseologismen & \multicolumn{3}{c}{ Quellen } \\
\hline & $\begin{array}{l}\text { Ettinger- } \\
\text { phraseologie mann }\end{array}$ & $\begin{array}{l}\text { Redens- } \\
\text { arten- } \\
\text { index }\end{array}$ \\
\hline
\end{tabular}

mit seinem Latein am Ende sein (ugs.)

Ga 4

jmdm. eine Laus in den Pelz setzen

$\mathrm{Hb} 5$

jmdm. eine Laus ins Fell setzen

$\mathrm{Hb} 5$

sich durchs Leben schlagen (ugs.)

jmdm. das Leben sauer machen

Licht am Ende des Tunnels sehen

jmdm. die Luft abdrehen

Die Luft wird dünn

die Lunte ans Pulverfass legen

Das Messer sitzt jmdm. an der Kehle

auf die Nase fallen/fliegen

eine harte Nuss [für jmdn.] sein (ugs.)

eine harte Nuss zu knacken haben (ugs.)

sich auf glattes Parkett wagen

in die Patsche geraten (ugs.)

F.15.

jmdn. in die Patsche reiten

in der Patsche sitzen (ugs.)

die Peitsche im Nacken spüren

jmdm. die Pistole, das Messer, den Dolch auf die

Brust/an die Gurgel, an die Kehle setzen

jmds. Pläne durchkreuzen

jmdm. den schwarzen Peter zuspielen

sich bei/an etw. die Pfoten verbrennen

Hier/da/in/... (wie) auf einem Pulverfass sitzen

jmdm. in die Quere kommen (seltener:) geraten/ laufen (ugs.) Schemann: laufen/rennen/kommen nicht auf Rosen gebettet sein (ugs.)

mit dem Rücken zur Wand stehen

Ruhe vor dem Sturm

ins Rutschen/Schlingern kommen/geraten

F.15.

F.15.

F.15.

Fa 21

$\mathrm{Gb} 1$

Ga 4

Ga 4

Ga 4

Fa 20

$\mathrm{Hb} 4$

$\mathrm{Hb} 4$

ja

Gb 1

F.15. $\quad \mathrm{Hb} 4$

ja

$$
\begin{aligned}
& \text { ja } \\
& \text { ja } \\
& \text { ja } \\
& \text { ja }
\end{aligned}
$$

Gb 1

Ga 4

ja

ja 
Tab. 8: Continued

\begin{tabular}{llrl}
\hline Phraseologismen & \multicolumn{3}{c}{ Quellen } \\
\hline & $\begin{array}{l}\text { Ettinger- } \\
\text { phraseologie }\end{array}$ & $\begin{array}{l}\text { Sche- } \\
\text { mann }\end{array}$ & $\begin{array}{l}\text { Redens- } \\
\text { arten- } \\
\text { index }\end{array}$ \\
\hline
\end{tabular}

in eine Sackgasse geraten

Ga 4

sich in eine Sackgasse verrennen $\quad$ Ga 4

in einer Sackgasse stecken

Ga 4

jmdn. im eigenen Saft schmoren lassen

F.15.

Sand ins Getriebe streuen

$\mathrm{Hb} 4$

Sand im Getriebe sein

$\mathrm{Hb} 4$

nicht über seinen (eigenen) Schatten springen

F.15.

können

in der Scheiße sitzen (vulg.)

Ga 4

jmdn./sich in die Scheiße reiten

bis zum Hals in der Scheiße stecken

jmdn. aus der Scheiße ziehen

(tief/knietief) in der Scheiße/Kacke sitzen/stecken

(ganz schön/...) im Schlamassel stecken/sitzen

Da haben wir/habt ihr/... den Schlamassel! (ugs.)

auf dem Schlauch stehen

die Schlinge zieht sich zu

mit etw. auf die Schnauze/Fresse fallen

nicht in jmds. Schuhen stecken mögen (selten)

ja

ja

ja

ja

Ga 4

Ga 4

(ständig/...) das Schwert des Damokles über sich haben/fühlen ... (geh.) (selten)

(ständig/...) ein/das Damoklesschwert über sich

haben/fühlen (geh.) (selten)

das Schwert des Damokles schwebt über jmdm.

(geh.) (selten)

in den Staub beißen

jmdm. einen (dicken) Strich durch die Rechnung

machen (ugs.)

die Suppe auslöffeln (müssen), die man sich (Dativ) F. 16.

eingebrockt hat (ugs.)

in Schwulitäten kommen/geraten (ugs.) 


\begin{tabular}{lll}
\hline Phraseologismen & \multicolumn{2}{c}{ Quellen } \\
\hline & $\begin{array}{l}\text { Ettinger- } \\
\text { phraseologie mann }\end{array}$ & $\begin{array}{l}\text { Redens- } \\
\text { arten- } \\
\text { index }\end{array}$ \\
\hline
\end{tabular}

jmdn. in Schwulitäten bringen (ugs.)

Ga 4

in Schwulitäten sein (ugs.)

Ga 4

in Schwulibus sein (veraltend)

Ga 4

zwischen Skylla/Scylla und Charybdis sein

jmdm. Steine in den Weg legen

F.15.

ja

Wenn ...dann/... kann sich jd. ja gleich/sofort einen

Strick kaufen/nehmen (und sich aufhängen) (ugs.)

sich an einen/letzten Strohhalm klammern (ugs.)

nach einem/letzten Strohhalm greifen (ugs.)

jmdm. (gehörig/...) die Suppe versalzen (ugs.)

jmdm. in die Suppe spucken (ugs.) (selten)

Suppe einbrocken; sich etw. einbrocken

auf Talfahrt sein

das Ende der Talsohle ist erreicht/die Talsohle ist durchschnitten

etw. ist ein (regelrechter/...) Tanz auf dem Vulkan (path.).

bei etw. hat der Teufel die/seine Hand im Spiel

F.15.

in Teufels Küche kommen/geraten (ugs.)

F.15.

Ga 4

in einem Tief stecken

(ganz schön/...) in der Tinte sitzen (ugs.)

F.15.

$\mathrm{Hb} 4$

Ga 4

Ga 4

Ga 4

$\mathrm{Hb} 4$

$\mathrm{Hb} 4$

sich aus der Tinte ziehen (ugs.)

jmdn. in die Tinte reiten

ins Trudeln kommen/geraten

auf einem Vulkan leben (path.)

auf einem Vulkan tanzen

jmdn. an die Wand drücken/spielen

jmdn./sich über Wasser halten, Schemann: sich (noch/noch so eben/...) über Wasser halten; den Kopf noch/noch so eben über Wasser halten 
Tab. 8: Continued

\begin{tabular}{llrl}
\hline Phraseologismen & \multicolumn{3}{c}{ Quellen } \\
\hline & $\begin{array}{l}\text { Ettinger- } \\
\text { phraseologie }\end{array}$ & $\begin{array}{l}\text { Sche- } \\
\text { mann }\end{array}$ & $\begin{array}{l}\text { Redens- } \\
\text { arten- } \\
\text { index }\end{array}$ \\
\hline
\end{tabular}

das Wasser steht/geht/reicht jmdm. (schon/...)

Ga 4

bis zum/(an den) Hals/bis hier (hin) (mit einer

Geste: Hand quer zum Kinn bzw. unter die Nase)

das Wasser steht/geht/reicht jmdm. (schon/...) bis

Ga 4

an die/(zur) Kehle

jmdm. in den Weg laufen

$\mathrm{Hb} 4$

jmdm. in den Weg kommen

$\mathrm{Hb} 4$

sich jmdm. in den Weg stellen (bei etw.)

$\mathrm{Hb} 4$

jmdm. in den Weg treten

$\mathrm{Hb} 4$

jmdm. den Weg versperren

$\mathrm{Hb} 4$

jmdm. den Weg vertreten (veraltet)

$\mathrm{Hb} 4$

jmdm. den Weg verlegen (veraltet)

$\mathrm{Hb} 4$

jmdm. im Weg(e) sein

$\mathrm{Hb} 4$

jmdm./einer Sache im Wege stehen (bei etw.)

$\mathrm{Hb} 4$

nicht mehr weiter wissen

Ga 4

nicht mehr ein noch aus/nicht mehr aus noch ein/

Ga 4

weder aus noch ein/weder ein noch aus wissen

nicht wissen, wie man aus etw./da herauskommen

soll

mit seiner Weisheit am Ende sein (ugs.)

Ga 4

Es ballen sich drohende Wolken über jmdm./einem

Gb 1

Land/... zusammen (path.).

von einer (dunklen) Wolke überschattet werden

Gb 1

(path.).

sich (Dativ) die Zähne an etw. ausbeißen

F.15.

die Zeitbombe tickt

Gb 1

jmdn. in die Zange nehmen

Fa 20

sich am eigenen Zopf/an den eigenen Haaren/am

eigenen Haar aus dem Sumpf ziehen

jmdn. (nicht) zum Zug(e) kommen lassen

$\mathrm{Hb} 4$

in einer (richtigen/...) Zwickmühle stecken

Ga 4

sich in einer richtigen Zwickmühle befinden (ugs.)

Ga 4 


\begin{tabular}{|c|c|c|c|}
\hline \multirow[t]{2}{*}{ Phraseologismen } & \multicolumn{3}{|c|}{ Quellen } \\
\hline & $\begin{array}{l}\text { Ettinger- } \\
\text { phraseologie }\end{array}$ & $\begin{array}{l}\text { Sche- } \\
\text { mann }\end{array}$ & $\begin{array}{l}\text { Redens- } \\
\text { arten- } \\
\text { index }\end{array}$ \\
\hline in eine Zwickmühle geraten (ugs.) & & Ga 4 & \\
\hline in einem Zwiespalt stecken & & Ga 4 & \\
\hline jmdn. in einen Zwiespalt bringen/stürzen & & Ga 4 & \\
\hline
\end{tabular}

\subsubsection{Methoden der Untersuchung}

Die Methodologie der vorliegenden Arbeit wird in zwei großen Themenblöcken behandelt: In dem ersten wird erklärt, nach welchem Verfahren die Strukturierung des gesamten phraseologischen Untersuchungsmaterials in dem zu besprechenden semantischen Feld der Schwierigkeit/der schwierigen Lage vorgenommen wird. Der Schwerpunkt des zweiten Themenblocks liegt dagegen auf der Beschreibung der Prozedur, nach der die 13 für eingehende Fallstudien ausgewählten Idiome zusammengestellt, in Anlehnung an Korpusbelege semantisch analysiert und dann in Bezug auf kognitive Bedeutungskonstituierungs- und Motiviertheitsmechanismen untersucht werden.

\subsubsection{Methoden der Eruierung von konzeptuellen Metaphern}

Die nach den im Unterkap. 4.1.1 beschriebenen Kriterien zusammengestellte Phraseologismen-Sammlung (Tab. 8) wird zuerst im Hinblick auf die sie strukturierenden konzeptuellen Metaphern untersucht. Es wird also der Frage nachgegangen, welche Ausgangsdomänen einen systematischen Beitrag dazu leisten, wie die abstrakte Zieldomäne der schwierigen Lage und ggf. der Schwierigkeit konzeptualisiert wird.

Der dieser Aufgabenstellung zugrunde liegende onomasiologische Analysevorgang ist in Anlehnung an Jäkel (2003: 142) entstanden, wird dennoch wesentlich modifiziert und an Bedürfnisse einer in der Phraseologie angesiedelten Recherche angepasst. Das Verfahren wird in vier Schritten ausgeführt:

(i) Anhand onomasiologischer Wörterbücher wird das Untersuchungsmaterial in Form von einer Idiom-Sammlung nach den bereits beschriebenen Regeln zusammengestellt. Die gesammelten Idiome werden als konventionalisierte, lexikalisierte Metaphern betrachtet.

(ii) Es wird analysiert, aus welchen Bereichen die Hauptkonstituenten der Idiome in ihrer literalen Bedeutung stammen. Diese Bereiche werden als potenzielle Ausgangsdomänen für die metaphorischen Mappings betrachtet.

(iii) Falls die Ausgangsdomänen mehrmals vorkommen und die metaphorischen Mappings eine gewisse Regelmäßigkeit aufweisen, wird angenommen, dass sie einen systematischen Charakter haben: Eine konzeptuelle Metapher wird formuliert. 
(iv) Die ermittelten konzeptuellen Metaphern werden analysiert, systematisiert und in Bezug auf die möglichen hierarchischen Beziehungen untersucht. Falls sich die einzelnen Metaphern in Hinsicht auf ihren Generalitätsgrad unterscheiden, werden hierarchische Strukturen angenommen.

Infolge einer so angelegten Vorgehensweise wird eine hierarchisch aufgebaute Liste der konzeptuellen Metaphern erstellt, die das semantische Feld der schwierigen Lage strukturieren. Diese Metaphern und ihre sprachlichen Manifestationen im phraseologischen Bereich werden detailliert im Kap. 4.2.1 behandelt.

\subsubsection{Methoden der semantisch-kognitiven Untersuchung am Korpusmaterial}

Den grundsätzlichen Teil der vorliegenden Arbeit bilden die semantisch-kognitiven Fallstudien zu Idiomen. Diese semasiologisch ausgerichteten Untersuchungen werden in drei Schritten ausgeführt:

(i) Da die semantisch-kognitiven Fallstudien zeit- und arbeitsaufwendig sind und dabei viel Platz in Anspruch nehmen, wird im ersten Schritt eine Auswahl der zu beschreibenden Idiome getroffen.

(ii) Im zweiten Schritt werden ausgewählte Idiome unter Rückgriff auf Sprachkorpora einer detaillierten semantischen Analyse unterzogen, die das Ziel anstrebt, die Bedeutungen und Teilbedeutungen (Verwendungsprofile und Verwendungsmuster) der Phraseologismen aus dem authentischen Sprachgebrauch zu ermitteln, Bedeutungsparaphrasen zu formulieren sowie Sprachbelege auszuwählen, mit denen diese Bedeutungen exemplarisch veranschaulicht werden.

(iii) Im dritten Schritt werden die kognitiven Mechanismen nachträglich erschlossen, schematisch dargestellt und eingehend beschrieben, die zur Konstituierung von diesen Verwendungsprofilen und Verwendungsmustern unter den jeweiligen kontextuellen Bedingungen führen.

\subsection{Die Auswahl der zu beschreibenden Idiome}

Da eine detaillierte semantisch-kognitive Untersuchung von über 200 in der Tabelle 8 aufgelisteten Idiome sehr umfangreich wäre und den Rahmen dieser Arbeit sprengen würde, muss im weiteren Verfahren eine Auswahl von Idiomen getroffen werden, die man anschließend einer eingehenden semantischen und kognitiven Analyse unterzieht.

Der Einfluss der konzeptuellen Metaphern auf die Strukturierung der ganzen Diskursbereiche und auf die Bedeutungen von einzelnen Idiomen gilt vor dem Hintergrund der bisherigen Forschung als gesichert (vgl. Dobrovol'skij 1995, Guławska-Gawkowska 2013, Staffeldt/Ziem 2008). In der vorliegenden Studie wird dennoch das Ziel angestrebt, möglichst viele kognitive Mechanismen der Bedeutungskonstituierung von Idiomen in ihrer ganzen Vielfalt und Komplexität 
zu ermitteln und aufzuzeigen. Aus diesem Grunde erfolgt die Auswahl von den zu beschreibenden Idiomen nach zwei Kriterien: Es werden einerseits Idiome untersucht, für die sich in der onomasiologischen Analyse des semantischen Feldes der schwierigen Lage unterschiedliche konzeptuelle Metaphern ermitteln lassen. Andererseits wird - zur Veranschaulichung der Relevanz von anderen kognitiven Mechanismen außer der konzeptuellen Metapher für die Konstituierung phraseologischer Bedeutung - jeweils auf zwei bis vier idiomatische Einheiten mit einer gemeinsamen konzeptuellen Metapher, dennoch unterschiedlicher Bildhaftigkeit zurückgegriffen. Demnach liegt z.B. den bedeutungsähnlichen Phraseologismen im engeren Sinne: schwankender Boden, glattes Parkett oder dünnes Eis zwar eine gemeinsame konzeptuelle Metapher: SICHERHEIT IST STABILER BODEN, SCHWIERIGE LAGE IST UNSICHERER/UNSTABILER BODEN zugrunde, zugleich unterscheiden sich aber die Idiome wesentlich in ihrem Konstituentenbestand und in ihrer Bildhaftigkeit. Mit dieser Vorgehensweise wird die Vielfältigkeit des Untersuchungsmaterials gewährleistet, die die Erfassung von einer möglichst großen Bandbreite divergenter Mechanismen von idiomatischer Bedeutungskonstituierung in Aussicht stellt.

\subsection{Methoden der semantischen Analyse von Idiomen}

Die Ausgangsbasis aller Aussagen, die in dem vorliegenden Arbeitsteil getroffen werden, bilden die Ergebnisse einer Analyse von Korpusbelegen von ausgewählten Idiomen. Unter dem Begriff ,Korpus` sind im Folgenden ausschließlich die elektronisch angelegten Korpora der deutschen (bzw. polnischen Sprache) zu verstehen: Als primäre Quelle der Korpusbelege dienen die DWDS-Korpora, gelegentlich, in den kontrastiv-interlingual ausgerichteten Erwägungen wird die Untersuchung um das Nationale Korpus der Polnischen Sprache erweitert.

Unter dem Namen Digitales Wörterbuch der Deutschen Sprache ${ }^{153}$ (DWDS) bezeichnet man Korpora, die an der Berlin-Brandenburgischer Akademie der Wissenschaften beheimatet sind und das Ziel verfolgen, ein „Digitales Lexikalisches System“ - ein umfassendes, jedem Benutzer über das Internet zugängliches Wortinformationssystem, das Auskunft über den deutschen Wortschatz in Vergangenheit und Gegenwart gibt - zu schaffen. 2018 umfasst das DWDS 13 Milliarden Textwörter, womit es - vom Umfang her - als zweitgrößtes Korpus der deutschen Sprache gilt.

DWDS stellt ein Beispiel eines Monitorkorpus dar: Es wird kontinuierlich ausgebaut. In der dritten Version, die seit August 2016 zur Verfügung steht, werden zahlreiche Lexeme um Angaben zur Form und zur Bedeutung, zur Etymologie sowie um Thesaurusinformationen, Verwendungsbeispiele aus Korpora und typische Wortverbindungen bereichert. Alle Informationstypen sind mit einer

153 Die folgende Beschreibung ist auf der Grundlage der Angaben aus https://www. dwds.de entstanden (Zugriff am 01.12.2018). 
Quellenangabe versehen, sodass jederzeit Herkunft sowie das Datum der Belege nachvollzogen werden können.

Das DWDS beinhaltet Referenz-, Zeitungs- und Spezialkorpora. Eine besondere Stellung kommt dabei dem DWDS-Kernkorpus zu, das als erstes, zeitlich und nach Textsorten ausgewogenes Referenzkorpus der deutschen Sprache des 20. Jh. betrachtet wird. Das DWDS-Kernkorpus enthält ungefähr 100 Millionen Textwörter, fünf Textsorten liegen dem Korpus zugrunde: Belletristik (27\%), journalistische Prosa (26\%), Fachtexte (22\%), Gebrauchstexte (20\%) und transkribierte Texte gesprochener Sprache (5\%). Außer dem DWDS-Kernkorpus gilt ebenfalls Deutsches Textarchiv als ein Referenzkorpus, da es sich aber auf die historischen Texte bezieht (1600-1900), ist seine Rolle in der vorliegenden, synchron ausgerichteten Untersuchung marginal.

Abgesehen von den zeitlich und hinsichtlich der Textsortenverteilung ausgewogenen Referenzkorpora werden weitere Korpora, sog. Ergänzungskorpora in die DWDS-Abfrageplattform eingebunden: Zeitungskorpora bestehen aus digitalisierten Texten der großen Tages- und Wochenzeitungen (Die Zeit, Berliner Zeitung, Der Tagesspiegel, bis 2016 ebenfalls Potsdamer Neueste Nachrichten), Spezialkorpora umfassen Blogs, Filmuntertitel, Polytechnisches Journal, die DDR-Sprache sowie das Korpus Gesprochene Sprache.

\subsection{Erstellung der Belegsammlung}

Zur genauen semantisch-kognitiven Analyse der ausgewählten Idiome wird für jede zu besprechende idiomatische Einheit eine Belegsammlung von 40 DWDSGebrauchsbelegen zusammengestellt. Es wird davon ausgegangen, dass 40 Belege eine genügende Menge darstellen, um bestimmte Schlussfolgerungen hinsichtlich der Semantik der Idiome zuzulassen und Verwendungsprofile ermitteln zu können. Die Belege werden den DWDS-Korpora nach folgenden Regeln entnommen:

Alle Belege entstammen dem DWDS-Kernkorpus sowie den DWDS-Zeitungskorpora. Der Grund für die Heranziehung der (von Natur aus textsortenspezifischen und nicht ausgewogenen) Zeitungskorpora ist praktischer Natur: Für keinen der zu beschreibenden Phraseologismen stehen in dem öffentlich zugänglichen ${ }^{154}$ DWDS-Kernkorpus genügend Belege zur Verfügung. Tabelle 9 gibt einen Überblick über die Distribution der zu erforschenden Wortverbindungen (hier stellvertretend: dünnes Eis, glattes Parkett und schwankender Boden) in unterschiedlichen Korpora.

154 Die neueste dritte Version des DWDS-Korpus ist im vollen Umfang nur für die Mitarbeiter der BBAW zugänglich. Offfentlich recherchierbar ist nur ein Teil des Korpus. $\mathrm{Zu}$ der älteren, bis August 2016 gültigen Version konnten sich alle Interessierten einen erweiterten Zugang über die Registrierung und Anmeldung verschaffen. Die in den Jahren 2014-2016 zusammengestellten Belege entstammen der erweiterten Korpusversion für registrierte Nutzer. 
Tab. 9: Die Distribution der Phraseologismen dünnes Eis, glattes Parkett und schwankender Boden in den DWDS-Korpora (https://www.dwds.de, Zugriff 19.05.2017).

\begin{tabular}{|c|c|c|}
\hline dünnes Eis & glattes Parkett & schwankender Boden \\
\hline $\begin{array}{l}\text { Referenzkorpora } \\
\text { - DWDS-Kernkorpus } \\
\text { (12) } \\
\text { - DWDS-Kernkorpus } 21 \\
\text { (2) } \\
\text { - Deutsches Textarchiv } \\
\text { (3) }\end{array}$ & $\begin{array}{l}\text { Referenzkorpora } \\
\text { - DWDS-Kernkorpus } \\
\text { (14) } \\
\text { - DWDS-Kernkorpus } 21 \\
\text { (7) } \\
\text { - Deutsches Textarchiv } \\
\text { (7) }\end{array}$ & $\begin{array}{l}\text { Referenzkorpora } \\
\text { - DWDS-Kernkorpus } \\
\text { (17) } \\
\text { - DWDS-Kernkorpus } 21 \\
\text { (1) } \\
\text { - Deutsches Textarchiv } \\
\text { (7) }\end{array}$ \\
\hline $\begin{array}{l}\text { Zeitungskorpora } \\
\text { - Berliner Zeitung (44) } \\
\text { - Tagesspiegel (27) } \\
\text { - Die Zeit (69) }\end{array}$ & $\begin{array}{l}\text { Zeitungskorpora } \\
\text { - Berliner Zeitung (109) } \\
\text { - Tagesspiegel (95) } \\
\text { - Die Zeit (273) }\end{array}$ & $\begin{array}{l}\text { Zeitungskorpora } \\
\text { - Berliner Zeitung (26) } \\
\text { - Tagesspiegel (13) } \\
\text { - Die Zeit (178) }\end{array}$ \\
\hline $\begin{array}{l}\text { Spezialkorpora } \\
\text { - Referenz- und } \\
\text { Zeitungskorpora (157) } \\
\text { - Blogs (1) } \\
\text { - Polytechnisches } \\
\text { Journal (0) } \\
\text { - Filmuntertitel (2) } \\
\text { - Gesprochene Sprache } \\
(0) \\
\text { - DDR (0) }\end{array}$ & $\begin{array}{l}\text { Spezialkorpora } \\
\text { - Referenz- und } \\
\text { Zeitungskorpora (505) } \\
\text { - Blogs (79) } \\
\text { - Polytechnisches } \\
\text { Journal (1) } \\
\text { - Filmuntertitel (35) } \\
\text { - Gesprochene Sprache } \\
\text { (0) } \\
\text { - DDR (3) }\end{array}$ & $\begin{array}{l}\text { Spezialkorpora } \\
\text { - Referenz- und } \\
\text { Zeitungskorpora (242) } \\
\text { - Blogs (4) } \\
\text { - Polytechnisches } \\
\text { Journal (3) } \\
\text { - Filmuntertitel (0) } \\
\text { - Gesprochene Sprache } \\
\text { (0) } \\
\text { - DDR (2) }\end{array}$ \\
\hline
\end{tabular}

Der Einsatz der Zeitungskorpora ist ebenfalls im Hinblick auf die Aktualität der Belege begründet: Die Ressourcen im DWDS-Kernkorpus beziehen sich auf den Zeitraum von 1900 bis heute (vorwiegend aber auf die Texte, deren Autorenrechte abgelaufen sind, d.h. auf die erste Hälfte des 20. Jh.), im Deutschen Textarchiv sind Texte aus den Jahren 1600-1900 gesammelt, in den Zeitungskorpora sind es vor allem neuere Texte: Das Korpus der Berliner Zeitung erhält alle Online-Veröffentlichungen aus der Zeit von Januar 1999 bis Dezember 2005, das Korpus Der Tagesspiegel umfasst die im Zeitraum 1996-2005 online veröffentlichten Artikel, das umfangreichste ZeitKorpus besteht aus allen Zeit-Ausgaben von 1946 bis heute, soweit diese in digitaler Form auf der Webseite www.zeit.de zur Verfügung stehen, sowie aus Artikeln, die nur online auf der Webseite www.zeit.de erschienen sind. Die am 23. August 2016 in Betrieb gesetzte dritte Version der DWDS-Korpora lässt die Nutzer zusätzlich in Spezialkorpora recherchieren, z.B. in Blogs oder dem Korpus der gesprochenen Sprache. Die Heranziehung der Belege aus diesen Korpora wäre für die folgende Untersuchung bestimmt interessant und wünschenswert, diese Korpora waren 
aber in der zweiten Version nicht vorhanden ${ }^{155}$. Da die dieser Arbeit zugrunde liegenden Belegsammlungen in den Jahren 2014-2017 zusammengestellt worden sind, wird - der Einheitlichkeit der jeweiligen Belegsammlung halber - konsequent nur auf dieselben Referenz- und Zeitungskorpora zurückgegriffen.

Der Anteil der einzelnen DWDS-Korpora an den zusammenzustellenden Belegsammlungen wird folgendermaßen bestimmt. Insgesamt sind für jedes Idiom 40 DWDS-Belege erforderlich, die den Teilkorpora: DWDS-Kernkorpus, Deutsches Textarchiv, Berliner Zeitung, Tagesspiegel, Die Zeit sowie Potsdamer Neuesten Nachrichten entnommen werden. Als generelle Regel gilt: Je mehr Belege in einem Teilkorpus angeführt werden, desto mehr Belege aus diesem Teilkorpus werden in die jeweilige Belegsammlung aufgenommen. In der Praxis entstammt etwa ein Viertel der Belege in der jeweiligen Belegsammlung dem größten Zeitungskorpus Die Zeit. Außer der Größe liegt ein weiterer Vorteil des Teilkorpus Die Zeit darin, dass es aus digitalisierten und im Internet leicht auffindbaren Texten besteht: Falls die maximale Kontextangabe im Korpus nicht ausreichend ist, um die aktuelle Bedeutung des Idioms zu eruieren, ist die Lektüre einer längeren Passage ohne zeitaufwendige Suche in den Printmedien möglich. Die übrigen Belege entstammen den kleineren Korpora, wobei die Anzahl der Belege aus dem jeweiligen Korpus im Vorhinein bestimmt wird. Das Zugriffsdatum, die Suchanfrage sowie die Anzahl der zu dieser Zeit in den DWDS-Korpora angeführten und in die Belegsammlung übernommenen Gebrauchsbelege werden bei jedem Idiom einzeln in der Fußnote angegeben.

Für die Sortierung der Korpustreffer wird in die Eingabemaske jeweils die zufällige Vorgehensweise eingegeben ${ }^{156}$, sodass die Belege aus unterschiedlichen Jahrzehnten des 20. und 21. Jh. stammen. Für semantische Studien ist es wichtig, dass der Textausschnitt um das Idiom herum als Exzerpt groß genug ist, damit kontextuelle Begebenheiten für den Rezipienten verständlich werden. Oft muss deswegen auf längere Sequenzen Bezug genommen werden, in manchen Fällen war die Lektüre eines großen Teils oder halt eines ganzen Artikels notwendig. Wo der maximale über Korpus zugängliche Kontext keine semantische Interpretation zulässt und der längere Kontext im Internet nicht zugänglich ist, wird der jeweilige Beleg gegen den nächsten aus demselben Teilkorpus getauscht.

\subsection{Ermittlung der Verwendungsprofile und Verwendungsmuster}

In der Regel bietet die semantische Analyse der Gebrauchsbelege ein wesentlich breiteres Spektrum der Bedeutungen, Teilbedeutungen, Bedeutungsnuancen,

155 Die ältere Version ist zum Teil noch abrufbar über http://eins.dwds.de (Zugriff am 19.05.2017).

156 Die anderen Möglichkeiten der Sortierung von Korpustreffern richten sich z.B. nach dem chronologischen Kriterium (Datum absteigend, Datum aufsteigend) oder nach der Belegelänge. 
als lexikographische Werke. ${ }^{157}$ Selbstverständlich kann anhand der Analyse von 40 Belegen nicht endgültig auf den lexikographischen Status der zu erfassenden Bedeutungen geschlussfolgert werden, zumal die auf die bereits beschriebene Art und Weise zusammengestellte Belegsammlung kein ausgewogenes Korpus bildet, das fundierte lexikographische Schlussfolgerungen zulassen würde. Erstens ist sie für den schriftlichen Sprachgebrauch repräsentativ, weil alle Gebrauchsbelege den literarischen und Pressetexten entstammen ${ }^{158}$. Zweitens werden im Folgenden zahlreiche lexikographisch relevante Informationen zur Grammatik, Frequenz/ Geläufigkeit oder Textsortenspezifik nicht (oder wenigstens nicht systematisch) erfasst. Drittens hängen in der Lexikographie semantisch relevante Grundfragen wie z.B.:

(i) Wie viele Korpusbelege deuten auf eine etablierte/sich etablierende feste Wortverbindung hin, die als ein phraseologischer Neologismus Eingang in lexikographische Werke finden soll? Wie vielfältig müssen die Fundstellen sein, damit man die Existenz eines phraseologischen Neologismus behaupten kann $^{159}$ ?

(ii) Welche Frequenz muss ein Idiom bzw. eine Teilbedeutung eines Idioms aufweisen, um lexikographisch erfasst zu werden?

(iii) Wie erfasst man die parallelen Metaphorisierungen (als Teilbedeutungen eines polysemen Idioms oder als Stichwörter)?

(iv) Wie detailliert sollten die einzelnen Bedeutungsaspekte dargestellt werden?

(v) Wie soll die Nennform formuliert werden?

157 Auf dieses Phänomen verweist u.a. Dobrovol'skij (2016: 4): „Although an analysis of examples of use clearly indicates that polysemy in phraseology is an extremely widespread phenomenon (for further details see Dobrovol'skij \& Filipenko 2009), traditional dictionaries rarely distinguish the different meanings of idioms, and seldom reflect the full diversity of variants actually represented in texts. Dictionaries often register only a single "canonized" form of an idiom that in many cases proves to be not the most frequent one".

158 In diesem Zusammenhang muss berücksichtigt werden, dass diese Textsorten einen reflektierten Sprachgebrauch vertreten: Sowohl Journalisten als auch Buchautoren werden als Menschen angesehen, die sich einen bewussten Umgang mit der Sprache zu einem Beruf gemacht haben. Somit ist die Anzahl der um das Idiom herum ausgebauten Szenarios sowie der Beispiele für den sprachspielerischen Gebrauch möglicherweise größer als im spontanen Redefluss eines durchschnittlichen Muttersprachlers.

159 Vgl. dazu das im Unterkap. 4.2.2.1.2.1 beschriebene Verwendungsprofil des Idioms einen Klotz am Bein sein, das eine relativ hohe Frequenz in den DWDS-Korpora aufweist, im Grunde genommen aber auf einem viel zitierten okkasionellen Gebrauch des Idioms beruht. Ob sich dieser Gebrauch durchsetzt und etabliert, bedarf weiterer Forschung. 
mit weiteren Faktoren: dem anvisierten Benutzerkreis, dem Wörterbuchtyp, seiner Funktion (aktives oder passives Wörterbuch) oder dem Wörterbuchmedium (Printwörterbücher oder elektronische Nachschlagewerke) zusammen, die für unsere Zielsetzung nicht relevant sind und an dieser Stelle nicht erörtert werden können.

Das primäre Ziel der vorliegenden Arbeit liegt nämlich nicht in der lexikographischen Aufbereitung der Idiom-Darstellung, sondern in der Veranschaulichung der potenziellen Komplexität der Mechanismen von der Bedeutungskonstituierung der Idiome aus kognitiver Perspektive. Aus diesem Grund wird im Weiteren nicht von den Teil-, Unter- oder Nebenbedeutungen, deren eindeutige Auseinanderhaltung sehr schwierig und nur unter Bezugnahme eines detaillierten lexikographischen Kriterienkatalogs möglich wäre, sondern allgemeiner von den Verwendungsprofilen und Verwendungsmuster gesprochen. Unter einem ,Verwendungsprofil' die Bezeichnung ${ }^{160}$ von Hümmer (2009: 65) - wird eine Bedeutung aufgefasst, die sich aus mehreren Korpusbelegen abstrahieren lässt. Über die Untersuchung von Gebrauchsbelegen werden also Verwendungsprofile eruiert, die die Aussagen über die sich vollziehenden Bedeutungskonstituierungsmechanismen auf der über den Idiolekt hinausgehenden Ebene erlauben. Die Verwendungsprofile sind manchmal hierarchisch aufgebaut: Die in der Hierarchie niedriger befindlichen Strukturen, in die Verwendungsprofile zerfallen, werden im Folgenden Verwendungsmuster genannt.

Der Einsatz der elektronischen Korpora erhöht den Intersubjektivitätsgrad der Analysen und trägt zur Reliabilität der Ergebnisse bei. Der entscheidende Schritt, in dem aus konkreten Korpusdaten Verwendungsprofile abstrahiert werden, ist dennoch weitgehend subjektiv und durch individuelle Auslegung geprägt. Dieses Problem ist allerdings allen semantischen Untersuchungen gemeinsam und beim heutigen Wissensstand wahrscheinlich unumgehbar, vgl. dazu Steyer:

Durch eine intelligente Vorstrukturierung kann der Linguist eine ungleich größere Menge sprachlicher Daten betrachten, als es ihm mit „bloßem Auge” auch nur irgendwie möglich wäre. Er kann so auf einer viel höheren analytischen Ebene ansetzen. Aber letztlich wird kein Linguist z.B. allein auf der Basis berechneter Kookkurrenzen Generalisierungen in Bezug auf das Kollokationsverhalten von Substantiven vornehmen können. Kein Lexikograph wird nur mit Hilfe von Listen oder Netzen ein Bedeutungswörterbuch fester Wortverbindungen erarbeiten, weil ab einem bestimmten Interpretationsschritt immer die usuellen, authentischen kontextuellen Umgebungen eines Analyseobjekts für den kontextuellen Hintergrund notwendig sind. An der grundlegenden Kulturtechnik, nämlich Texte zu lesen und

160 In der Fachliteratur werden die Verwendungsprofile auch als behavioural profile (Divjak 2004: 227), patterns of usage (Hanks 2004: 90), combinatorial profile (Dobrovol'skij 2004: 787), Wortprofile (Blumenthal/Diversy/Mielebacher 2005: 50) bzw. word sketch (Kilgarriff/Rychly/Smry 2004: 105) bezeichnet. 
zu interpretieren, hat denn auch die Korpuslinguistik meines Erachtens nichts geändert. (Steyer 2013: 73)

\subsection{Methoden der kognitiven Analyse von Idiomen}

Auf die semantische Analyse der eruierten Verwendungsprofile folgt die detaillierte Beschreibung der kognitiven Mechanismen, die diese Verwendungsprofile konstituieren. In einem introspektiven, durch die Recherche im Internet und in Nachschlagewerken unterstützten Verfahren wird nach konzeptuellen Metaphern von unterschiedlichem Generalitätsgrad, nach den Metonymien und Metaphtonymien gesucht, es werden metaphorisch-metonymische Ketten sowie die epistemischen Metaphern und die sie oft begleitenden mentalen Bilder geschildert.

Zur besseren Übersichtlichkeit der ermittelten Derivationsprozesse werden sie jeweils nach dem folgenden Muster (Abb. 26) schematisch veranschaulicht:

Ebene 1

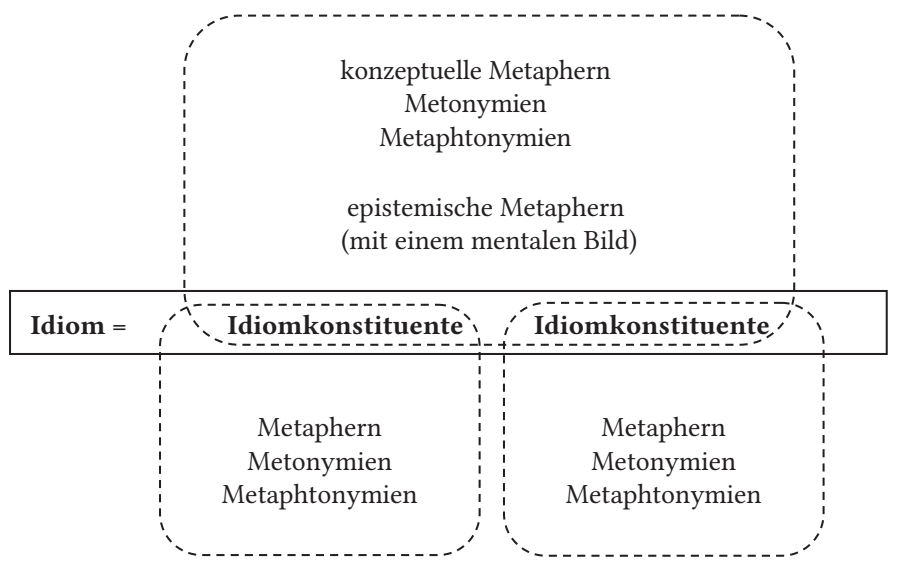

Abb. 26: Schablone einer schematischen Veranschaulichung von idiomatischen Bedeutungskonstituierungsprozessen.

Das Schema besteht aus zwei Ebenen: Die erste Ebene betrifft die Bedeutungsderivationen der ganzen Wortverbindung, auf der zweiten Ebene wird der eventuelle Beitrag der Derivationen von einzelnen Idiom-Komponenten berücksichtigt. Dies lässt die Derivationsmechanismen, auf die jeweils detailliert eingegangen wird, auf eine überblicksartige Art und Weise veranschaulichen.

Die zu ermittelnden Mechanismen der Bedeutungskonstituierung sind durch große Komplexität gekennzeichnet. Deswegen sind Idiome zu kleinen, 2-4 Idiome beinhaltenden Gruppen zusammengeschlossen. Die deskriptive 
Darstellung der Bedeutungskonstituierungsmechanismen von Idiomen wird in jeder Gruppe mit einer Zusammenfassung vervollständigt, die bestimmte kognitive Aspekte, die bei der Untersuchung besonders augenfällig waren, hervorhebt und näher beleuchtet. In den Fokus der Aufmerksamkeit werden dabei die kognitiven Mechanismen gerückt, denen in der bisherigen kognitiv-phraseologischen Forschung wenig Aufmerksamkeit zugekommen ist: die epistemischen Mappings, konzeptuelle Metonymien, mentale Bilder, ontologische Metaphern. In Unterkapiteln 4.2.2.1.1.1.4, 4.2.2.1.3.3, 4.2.2.2.5 wird zusätzlich auf die Fragenkomplexe der interlingualen Äquivalenz, ihrer lexikographischen Erfassung und des sprachspielerischen Gebrauchs der Phraseologismen vor dem kognitiven Hintergrund eingegangen. Die eruierten kognitiven Mechanismen, ihre Beschreibungen und angeschnittene Fragen erheben keinen Anspruch auf Vollständigkeit; möglicherweise lassen sich an weiteren Idiomen noch andere Bedeutungskonstituierungsmechanismen festlegen. Sie gewähren uns eher Einblicke in die komplexen Zusammenhänge der Bedeutungskonstituierungsprozesse.

\subsection{Analyse und Interpretation}

Im Mittelpunkt des folgenden Kapitels stehen die kognitiven Mechanismen der Bedeutungskonstituierung von idiomatischen Einheiten. Die Analyse dieser Mechanismen umfasst zwei Schritte: Im ersten wird das semantische Feld der Schwierigkeit/ der schwierigen Lage makrostrukturell in Bezug auf die es strukturierenden konzeptuellen Metaphern untersucht. Im zweiten Schritt wird eine korpusbasierte, ausführliche Analyse einiger Idiome durchgeführt, die die Motiviertheitsmechanismen und die Rolle der Bildhaftigkeit bei der Konstituierung der phraseologisierten Bedeutung darstellt.

\subsubsection{Konzeptuelle Metaphern als Strukturierungsprinzip des semantischen Feldes der Schwierigkeit/der schwierigen Lage}

Metaphern stellen sprachliche Phänomene dar, durch die Weltsichten, Weltanschauungen, Einstellungen gegenüber Sachverhalten und Ideologien in besonderer Weise zur Geltung kommen, durch die man Wissen perspektivistisch konstruiert, sedimentiert, verändert und vermittelt (Spieß 2017: 94) sowie neuartige Themen in ein bekanntes terminologisches Umfeld integriert und an vertraute Erfahrungskonzepte anschließt (Mikołajczyk 2002: 49). Den konzeptuellen Metaphern als systematischen und relativ festen Strukturprinzipien der menschlichen Kognition wird dabei von den Autoren der CTM-Theorie eine Erschließungsfunktion zugewiesen: Bestimmte Gegenstandsbereiche sind unserer Sprache und unserem Denken kaum anders als durch das Mittel der konzeptuellen Metapher zugänglich. Darauf, dass die sog. 
Notwendigkeitshypothese ${ }^{161}$ in ihrer strengen Form nicht uneingeschränkt gilt, wird zwar im Unterkap. 2.3.3 verwiesen, generell herrscht aber in der Fachliteratur Einigkeit darüber, dass konzeptuelle Metaphern viele abstrakte und komplexe Bereiche strukturieren und zu ihrer Versprachlichung einen wesentlichen Beitrag leisten.

Das semantische Feld der schwierigen Lage/Schwierigkeit bildet einen relativ abstrakten und komplexen Bereich menschlicher Wirklichkeit, deswegen kann man erwarten, dass er weitgehend metaphorisch strukturiert wird. Die konzeptuellen Metaphern, die dieses Feld gestalten, erfüllen dabei zwei wichtige Aufgaben, die ihnen von Lakoff/Johnson (1980) zugewiesen wurden:

(i) Da der Zielbereich der schwierigen Lage als abstrakt empfunden wird, dienen die konzeptuellen Metaphern dazu, die Vorgänge zu veranschaulichen. Die abstrakten Sachverhalte werden durch Rückgriff auf konkrete, sinnlicher Anschauung zugängliche Ursprungsbereiche verdeutlicht.

(ii) Da der Zielbereich komplex ist, üben die konzeptuellen Metaphern eine Fokkussierungsfunktion aus: Sie lassen uns die Situation aus einer bestimmten Perspektive betrachten. Dies ist in einem so mannigfaltigen Bereich wie die zu besprechende schwierige Lage gut sichtbar: Die konzeptuellen Metaphern richten die Aufmerksamkeit auf bestimmte Aspekte der Zwangslage, die durch verschiedene Faktoren, z.B. durch unsichere Grundlagen von vertretenen Ansichten, Annahmen, Thesen, Interpretationen (schwiERIGKeIten SIND UNSICHERER BODEN), durch den Zwang, der auf ein Patiens von zwei unabhängigen Quellen auferlegt wird (SCHWIERIGKEITEN SIND DRUCK AUS ZWEI SEITEN), oder durch zusätzliche, als Ballast empfundene Aufgaben und Personen (sCHWIERIGKEITEN SIND EINE LAST) verursacht werden kann. Bestimmte Bedeutungsaspekte werden hervorgehoben, andere verschiebt man in den Hintergrund. Pielenz (1993: 100) spricht in diesem Kontext von der Filterfunktion der Metapher, Spieß (2017: 99) betont, dass die Metaphern aufgrund der hiding und highlighting-Mechanismen persuasiv und wertend sind.

Die gravierende Rolle der konzeptuellen Metaphern als eines Motiviertheitsmechanismus in der Phraseologie ist allgemein anerkannt und mit mehreren empirischen Studien untermauert (vgl. Angst-Metaphorik bei Dobrovol'skij 1995, Weg-Metaphorik bei Mellado-Blanco 2014, Erfolg-, Fortschritt- und Niederlagemetaphorik bei Langlotz 2006). Die onomasiologisch-kognitive Analyse der Diskursbereiche hat sich als ein Werkzeug, das die Systematizität der metaphorischen Phänomene erfasst, bewährt. Auch das idiomatische Untersuchungsmaterial der vorliegenden Studie ist weitgehend durch die konzeptuellen

161 Die Notwendigkeits-Hypothese besagt, dass bestimmte Gegenstandsbereiche unserem Denken kaum anders zugänglich sind als durch das Mittel der konzeptuellen Metapher (Jäkel 2003: 41). 
Metaphern strukturiert. Die Analyse der Idiom-Sammlung (Tab. 8) nach der im Unterkap. 4.1.2.1 beschriebenen Vorgehensweise lässt ein hierarchisch gebautes System der konzeptuellen Metaphern aufstellen, die dem semantischen Feld der Schwierigkeit/der schwierigen Lage Struktur verleihen. Die eruierten konzeptuellen Metaphern stellt die folgende Abbildung dar:

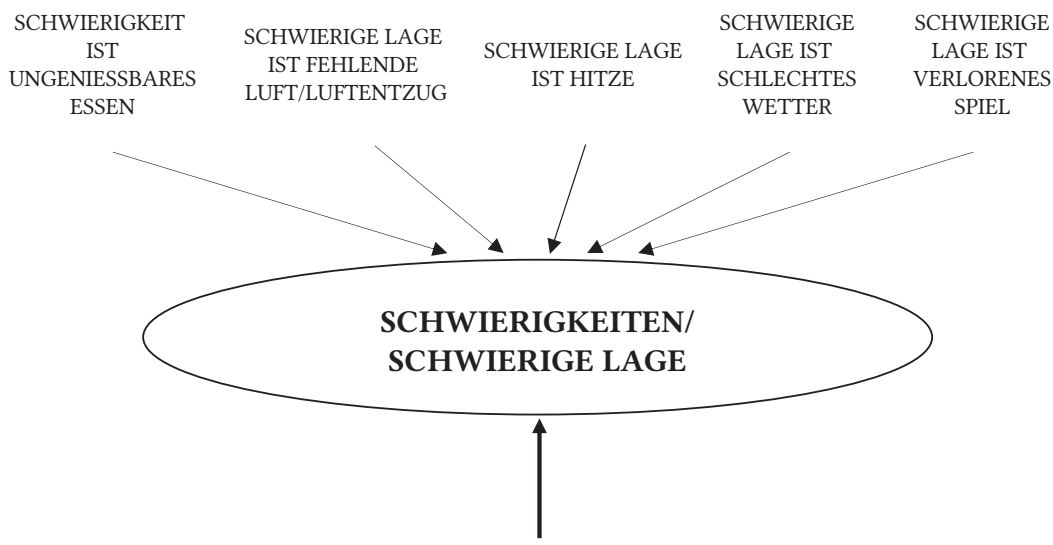

\section{SCHWIERIGKEITEN SIND VERHINDERUNGEN DER (VORWÄRTS) BEWEGUNG}

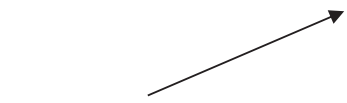

SCHWIERIGKEITEN SIND HINDERNISSE AUF DEM WEG

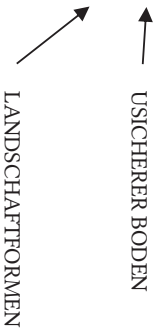

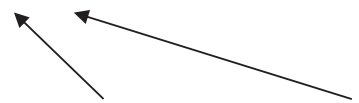

SCHWIERIGKEITEN SIND SCHWIERIGE LAGE IST BESCHRÄNKUNG EINE LAST

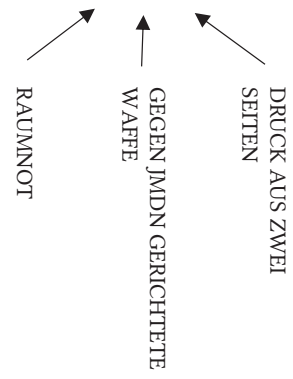

Abb. 27: Die konzeptuell-metaphorische Strukturierung des semantischen Feldes Schwierigkeit/schwierige Lage in der deutschen Phraseologie. 
Die Art und Weise, wie die schwierige Lage/Schwierigkeiten in der deutschen Phraseologie konzeptualisiert werden, ist durch mehrere konzeptuelle Metaphern beeinflusst. Schwierigkeiten werden unter Rückgriff auf unangenehme Körpererfahrungen, wie z.B. ungenießbares Essen, Luftentzug, Hitze oder schlechte Wetterbedingungen konzeptualisiert, ebenfalls die Spiel-Metaphorik trägt zu Konzeptualisierung der Schwierigkeit/der schwierigen Lage bei. Ein besonderer Stellenwert kommt dennoch der konzeptuellen Metapher vom mittleren Generalitätsgrad: SCHWIERIGKEITEN SIND VERHINDERUNGEN DER (VORWÄRTS-)BEWEGUNG $\mathrm{zu}$, die die meisten phraseologischen Einheiten motiviert und durch zahlreiche konzeptuelle Metaphern von einem kleineren Generalitätsgrad (scHWIERIGKEITEN SIND HINDERNISSE AUF DEM WEG $\rightarrow$ SCHWIERIGKEITEN SIND LANDSCHAFTSFORMEN, SCHWIERIGKEITEN SIND KLEBRIGE MASSE, SCHWIERIGKEITEN SIND UNSICHERER BODEN, SCHWIERIGKEITEN SIND SPERRUNGEN DES DURCHGANGS, SCHWIERIGKEITEN SIND HINDERNISSE, DIE EINEN ZU FALL BRINGEN; SCHWIERIGKEITEN SIND EINE LAST; SCHWIERIGE LAGE IST BESCHRÄNKUNG DER BEWEGUNGSFREIHEIT $\rightarrow$ SCHWIERIGE LAGE IST RAUMNOT, SCHWIERIGE LAGE IST GEGEN JMDN. GERICHTETE WAFFE, SCHWIERIGE LAGE IST DRUCK AUS ZWEI SEITEN) untermauert wird. Zugleich stellt die SCHWIERIGKEITEN ALS VERHINDERUNGEN DER VORWÄRTSBEWEGUNG-Metapher eine Ausprägung der konzeptuellen Metapher von einer großen Reichweite LEBEN IST EIN WEG/LEBEN IST EINE REISE dar. Der Darstellung der das zu erörternde semantische Feld strukturierenden konzeptuellen Metaphern wird deswegen eine skizzenhafte Beschreibung der LEBEN IST EIN WEG-Metapher angeschlossen.

\subsubsection{LEBEN IST EIN WEG, SCHWIERIGKEITEN SIND VERHINDERUNGEN DER (VORWÄRTS-) BEWEGUNG}

Die LEBEN IST EIN WEG-Metapher baut auf dem grundlegenden image schema (Vorstellungschema) auf, das von Johnson (1989) als PATH bezeichnet wird. Das Vorstellungsschema PATH ist für die Konzeptualisierung des Lebens, aber auch eines zielgerichteten Handelns grundlegend, was möglicherweise schon in der frühkindlichen Erfahrung verankert ist. Die ersten Schritte stellen nämlich in der Entwicklung des Kindes Meilenschritte dar, aus ontogenetischer Perspektive sind es die Schritte in Richtung der zielgerichteten Aktivität, Unabhängigkeit und Selbstbestimmung. Diese sensorische Erfahrung der Bewegung des Körpers im Raum, vom Punkt A bis zum Punkt B, bildet den Ausgangsbereich, der in viele abstraktere Zielbereiche (Politik, Wirtschaft, Religion) übertragen wird: Der A-Punkt macht den Startpunkt aus, der B-Punkt funktioniert als das Ziel, das schnelle Bewältigen der Strecke wird mit schnellem Fortschritt gleichgesetzt, in der Weite liegende Ziele oder labyrinthartige Wege dazu werden als schwierige, langwierige Aufgaben aufgefasst.

Zur Ubiquität der LEBEN IST EIN WEG-Metaphorik trägt zweifelsohne ihre Verbreitung im religiösen Bereich und in der Bibel bei: In vielen Religionen fungiert der Weg als ein Symbol für die Suche nach Gott, Erleuchtung, sich selbst. Im Christentum wird das irdische Leben als Reinigungsweg von der Sünde konzeptualisiert 
(vgl. z.B. Jesus Worte: „Ich bin der Weg, die Wahrheit und das Leben“ Joh. 14, 6). Die dichotomische Unterscheidung zwischen einem guten, moralisch gerechtfertigten und einem unmoralischen, verwerflichen Leben wird unter Rückgriff auf konzeptuelle Metaphern: LEADING A MORAL LIFE IS MAKING A JOURNEY ON GOD's WAY, GOD'S COMMANDMENTS ARE PATHS, SINNING IS DEVIATING/SWEARING FROM GOD'S WAY, REPENTING IS RETURNING, LEADING AN IMMORAL LIFE IS WALKING EVIL WAYS, MORAL CHOICE IS CHOICE OF PATH u.a. bestimmt (vgl. Jäkel 2003: 265-279).

Auch im profanen Bereich kommt der LEBEN IST EIN WEG-Metapher eine besondere Stellung zu: Die Weg-Metaphorik liegt beispielsweise nicht nur der Konzeptualisierung der menschlichen Onto- sondern auch der Phylogenese zugrunde, wovon populäre Schemata (Abb. 28, 29) zeugen.
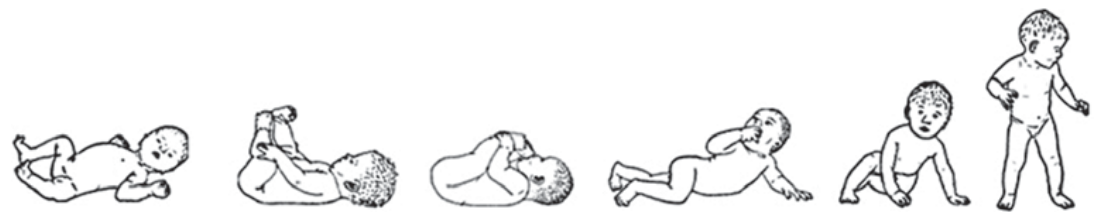

Abb. 28: Populäre Darstellung der Ontogenese https://www.logopaedie-in-bayreuth.de/ entwicklung-kinder-primitive-reflexe/ (Zugriff am 02.06.2017).

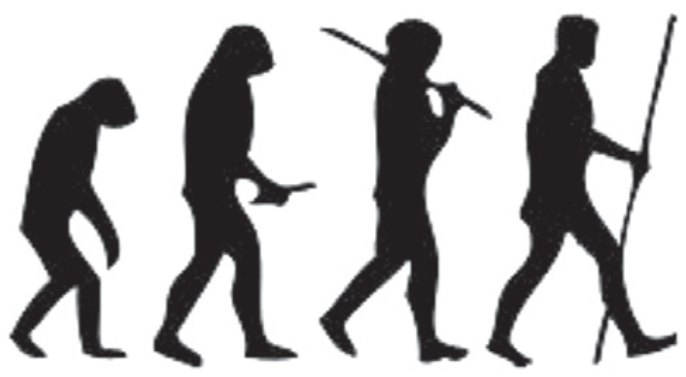

Abb. 29: Populäre Darstellung der Phylogenese https://de.wikipedia.org/wiki/Mensch (Zugriff am 02.06.2017).

In vielen Konzeptualisierungen verzahnt sich die LEBEN IST EIN WEG-Metapher mit der Orientierungsmetapher GUT IST OBEN, SCHLECHT IST UNTEN. In der Konzeptualisierung des menschlichen Lebens, aber auch des Lebenszyklus spielen die beiden Metaphern eine grundlegende Rolle: Das erfolgreiche, wertvolle Leben wird als die Vorwärtsbewegung nach oben, in den Himmel konzeptualisiert. Oben ist die Richtung entgegen der Schwerkraft, weswegen dieser Weg schwer und anstrengend ist, zugleich ist er aber der Mühe wert: Oben ist Himmel, Sonne, Geist, Licht, Übersicht, Macht, Erfolg, Kopf. Unten ist das Minderwertige, Verwerfliche, Animalische: die 
Hölle, die Materie, der Trieb- und Instinktbereich, Unterwerfung, Dunkelheit, Kontrollverlust, Chaos. In diese Vorstellung fügt sich die Lebenszyklus-Konzeptualisierung ein: Neugeborene beginnen ihr Leben unten, liegend, Jugend ist die Zeit des Wachstums, der Progression, der Erweiterung des Lebensraumes, als Erwachsene in der produktiven Berufslebens- und Familienphase sind wir körperlich und psychisch oben, das Alter bringt die Regression, den körperlichen (und heutzutage oft auch sozialen) Abstieg mit sich. Die Verbindung zwischen Progression und der Ausrichtung nach oben kommt auch in der Vorstellung der Phylo- und Ontogenese deutlich zum Ausdruck (vgl. Abb. 28, 29).

Vor dem Hintergrund der LEBEN ALS WEG-Metaphorik werden die Schwierigkeiten generell als weit verstandene Erschwerungen, Behinderungen der Fortbewegung konzeptualisiert. Interessanterweise sind diese Erschwerungen auf drei Obstruktionstypen zurückzuführen: Sie können mit der Beschaffenheit der Wegstrecke, mit der zusätzlichen Belastung des Wandernden oder mit der Einschränkung seiner Bewegungsfreiheit, der räumlichen Not zusammenhängen.

\subsection{SCHWIERIGKEITEN SIND HINDERNISSE AUF DEM WEG}

Inspiziert man genauer die Beschaffenheit der Wegstrecken, dann findet man detaillierte und lebhafte Bilder, die tief in der körperlichen Erfahrung verankert sind und auf dem Wissen fußen, dass uns manche Hindernisse auf dem Weg kurz- oder langfristig aufhalten können. So werden die Hindernisse als Landschaftsformen (z.B. in einem Tief stecken), unsicherer Boden (z.B. schwankender Boden, dünnes Eis), klebrige oder schmutzige Masse (z.B. in der Patsche sitzen), Blockierungen/Sperrungen des Durchgangs (z.B. Steine in den Weg legen) bzw. Hindernisse, die einen zu Fall bringen (z.B. Knüppel zwischen die Beine werfen) konzeptualisiert. Viele der genannten Konzeptualisierungen sind aufs Engste an die konzeptuelle Orientierungsmetapher von großem Generalitätsgrad: GUT IST OBEN, SCHLECHT IST UNTEN gebunden. Dies widerspiegelt sich in der Sprache: Schlechtes Befinden wird mit dem Verweilen in einer Geländesenke (z.B. sich in einem fammertal befinden, in einem Tief stecken, down sein, ganz unten sein), Verlust des Ansehens mit Abstieg (Absteiger, jmdn. heruntermachen), Fehler mit Sturz assoziiert (auf dem Bauch landen, Ausrutscher). Als hierarchieniedrigere Konkretisierungen der Metapher SCHWIERIGKEITEN SIND HINDERNISSE AUF DEM WEG lassen sich folgende konzeptuelle Metaphern anführen: SCHWIERIGKEITEN SIND DIE LANDSCHAFTSFORMEN, SCHWIERIGKEITEN SIND UNSICHERER BODEN, SCHWIERIGKEITEN SIND KLEBRIGE MASSE, SCHWIERIGKEITEN SIND SPERRUNGEN DES DURCHGANGS, SCHWIERIGKEITEN SIND HINDERNISSE, DIE EINEN ZUM FALL BRINGEN.

SCHWIERIGKEITEN SIND DIE LANDSCHAFTSFORMEN

Die konzeptuelle Metapher SCHWIERIGKEITEN SIND DIE LANDSCHAFTSFORMEN steht in engster Verbindung mit der Orientierungsmetapher GUT IST OBEN, SCHLECHT IST unTEN. Die Vorstellung des Weges und der progressiven Vorwärtswanderung als 
einer körperlich ausgeführten Tätigkeit bilden den Ausgangspunkt zur metaphorischen Konzeptualisierung der Bewältigung des Lebens, des Umgangs mit seinen Tiefen und Höhen. Dabei werden Berge und Hügel mit Positivem/Erhabenem verbunden: mit geistiger Entwicklung, Karriere, Ehrgeiz, Zielstrebigkeit, Dominanz, Progression. Eine Geländesenke/ein Tal fungiert als direkter Gegensatz zum Berg und steht für das Leiden und Regression. In Übereinstimmung mit dieser Konzeptualisierung wird der Abstieg, obwohl er in Richtung der Schwerkraft erfolgt, als unerwünschter als das Ersteigen eines Berges dargestellt: Auch wenn der Aufstieg mit Anstrengung und Mühe verbunden ist, wird er als eine positive Aufwärtsentwicklung angesehen, was sich sprachlich beispielshalber in Ausdrücken wie der Aufschwung der Wirtschaft, auf der Karriereleiter stehen, sich zu Höherem berufen fühlen, auf dem aufsteigenden Ast sein manifestiert.

\section{SCHWIERIGKEITEN SIND UNSICHERER BODEN}

Tief in der körperlichen Erfahrung und in der Kultur ist ebenfalls die konzeptuelle Metapher SCHWIERIGKEITEN SIND UNSICHERER BODEN verankert. Sie wurzelt in der unangenehmen und als gefährlich empfundenen Erfahrung, die mit der Bewegung auf dem schlammigen, morastigen Boden, einem Steinschlag, oder Wanderdünen in Verbindung gebracht wird (z.B. sich auf dem schwankenden/unsicheren Boden bewegen/befinden, jmdm. schwankt der Boden unter den Füßen). Steinschlag stellt in den Bergen ein erhebliches Risiko dar, im Schlamm oder Moor kann man in Extremfällen versinken, ohne dass die Leiche je gefunden wird. Daraus ergibt sich möglicherweise der symbolische Wert der moorartigen Gebiete, die mit Unheimlichem (Geistern, Dämonen, dem Teufel, Irrlichtern, Hexen und verirrten Seelen) assoziiert werden. Eine andere Gruppe der Phraseologismen hebt die Glitschigkeit, Schlüpfrigkeit des Bodens (dünnes Eis, Glatteis, glattes Parkett) hervor, die metaphorisch als Fehlerträchtigkeit einer Handlung gedeutet werden kann (FEHLER IST STURz). Zusätzlich wird bei Idiomen mit Eis-Konstituente die Gefahr des Einbruchs der Eisfläche unter dem Gewicht eines Menschen zum Ausdruck gebracht, was in die Domäne der Psyche (z.B. Nervenzusammenbruch) oder Gesundheit (z.B. Kollaps) übertragen wird. Eine aufgezwungene Vorwärtsbewegung auf einem wackeligen oder glitschigen Boden ist äußerst unangenehm: Der Boden ist ein menschlicher Wurzelgrund, die Menschen sind Erdenwesen: Auch wenn sie sich durch technische Mittel von dem Boden abheben, auf oder unter dem Wasser bewegen können, ist doch das feste Land ihre natürlichste Umgebung (vgl. z.B. jmdm. den Boden (unter den Füßen) wegziehen, den Boden unter den Füßen verlieren, den (festen) Boden unter den Füßen gewinnen).

\section{SCHWIERIGKEITEN SIND KLEBRIGE MASSE}

Als eine wesentliche Erschwerung wird ebenfalls die Bewegung in einer dicken, klebrigen Masse empfunden. Bei einem im Schlamm festgefahrenen Auto greifen die Räder nicht mehr, das Auto kommt nicht weiter, selbst wenn der Motor mit aller Kraft arbeitet. Die Elemente aus dieser Ausgangsdomäne können dann in die Zieldomäne übertragen werden und sich auf die Situation beziehen, in der man trotz der Anstrengung keine Fortschritte erzielt. Durch diese metaphorischen Mappings 
sind die Phraseologismen die Karre in den Dreck fahren, die Karre steckt im Dreck, der Karren steckt/ist im Dreck, den Karren in den Dreck fahren, die Karre/den Karren im Dreck stehen lassen motiviert. Die übrigen Phraseologismen beziehen sich auf einen Menschen: Ein durch dickflüssige, klebrige Substanzen beschmutzter Mensch strebt danach, sich so schnell wie möglich sauber zu machen und umzuziehen. Ein besonderer, symbolischer Status kommt dabei den Ausscheidungsprodukten (Scheiße, Kacke) zu: In den Mythen wird die Unterwelt, das Unwürdige mit Exkrementen assoziiert (z.B. Augias Stall), in der Kultur wird die Analität dem Animalischen, Primitiven, Unkontrollierten gleichgesetzt und tabuisiert. In der Phraseologie stehen Scheiße, Kacke in einer besonders derben Ausdrucksweise für Schwierigkeiten, Unsinn, Fehler, vgl. die Idiome: in der Scheiße sitzen, jmdn. aus der Scheiße ziehen, (tief/knietief) in der Scheiße/Kacke sitzen/stecken/sein, bis zum Hals in der Scheiße stecken, in die Scheiße greifen, Scheiße bauen.

SCHWIERIGKEITEN SIND SPERRUNGEN DES DURCHGANGS

Plakativ kommen die konzeptuellen Metaphern: LEBEN IST EIN WEG, SCHWIERIGKEITEN SIND HINDERNISSE AUF DEM WEG in einer ziemlich ausgebauten Phraseologismengruppe zum Ausdruck, in der die Schwierigkeiten als Sperrungen des Durchgangs, die bewältigt oder umgangen werden müssen, konzeptualisiert werden. In beiden Fällen wird der Schreitende auf seinem Weg zum Ziel abgelenkt, muss die wertvolle Zeit und Energie für die Überwindung der Schwierigkeiten verlieren. Die Erschwernisse auf dem Weg entstehen meistens aufgrund einer beabsichtigten Handlung eines feindlich eingestellten Agens, der einem Steine, Hindernisse, einen Hemmschuh in den Weg legt oder sich halt selbst in den Weg stellt und ihn versperrt.

SCHWIERIGKEITEN SIND HINDERNISSE, DIE EINEN ZUM FALL BRINGEN

Für die Konstituierung der hier gesammelten Phraseologismen ist außer den genannten Metaphern von großem Generalitätsgrad die konzeptuelle Metapher FEHLER IST STURZ relevant. Sturz oder Absturz werden aus der Domäne der körperlichen Erfahrung in den emotionalen Bereich übertragen: Sturz bedeutet Schmerz, Verlust der Kontrolle, Sicherheit und Orientierung. Er hält einen vom Erreichen der eigenen Ziele ab, ist unerwartet, ungeplant, unangenehm (in den Staub beißen), kann durch selbst verschuldete Fehleinschätzung der Situation, Überschätzung der eigenen Kräfte und Möglichkeiten verursacht oder durch Dritte (jmdm. ein Bein stellen, Knüppel zwischen die Beine werfen) herbeigeführt werden.

\subsection{SCHWIERIGKEITEN SIND EINE LAST}

Während die bisher besprochenen konzeptuellen Metaphern die Beschaffenheit des Weges fokussierten, rücken die Metaphern schWIERIGKEITEN SIND EINE LAST, SCHWIERIGE LAGE IST BESCHRÄNKUNG DER BEWEGUNGSFREIHEIT den einen Weg Beschreitenden in den Mittelpunkt des Interesses. Die erstgenannte Metapher baut auf der körperlichen Erfahrung auf, dass die Fortbewegung mit einer Belastung, mit einem schweren Gewicht langsam, kräfteraubend und mühsam 
ist. Als Erschwernis bei der Vorwärtsbewegung wird auch das Tragen oder Stützen eines Mitmenschen empfunden (jmdn. am Hals haben, jmdm. wie ein Mühlstein am Hals hängen). Möglicherweise greifen manche Sprachteilhaber auch auf das historisch-kulturelle Wissen zurück, dass Sträflingen früher ein eisernes Gewicht an die Beine angeschmiedet wurde, um sie an der potenziell möglichen Flucht zu hindern.

\subsection{SCHWIERIGE LAGE IST EINSCHRÄNKUNG DER}

\section{BEWEGUNGSFREIHEIT}

Aus offensichtlichen Gründen ist die Fortbewegung nicht möglich, falls das Agens seiner Bewegungsfreiheit unter einem größeren oder kleineren Gewalteinsatz beraubt ist. Anhand der gesammelten deutschen Phraseologismen ließen sich drei konzeptuelle Metaphern ermitteln, die diesen Konzeptualisierungen zugrunde liegen: SCHWIERIGE LAGE IST RAUMNOT (z.B. in die Enge treiben, ins Gedränge kommen), SCHWIERIGE LAGE IST EINE GEGEN JMDN. GERICHTETE WAFFE (z.B. jmdm. sitzt das Messer an der Kehle, jdm. die Pistole, das Messer, den Dolch auf die Brust/an die Gurgel, an die Kehle setzen, den Hals in der Schlinge haben) sowie SCHWIERIGE LAGE IST DRUCK AUS ZWEI SEITEN (z.B. jmdn. in die Zange nehmen/in der Zange haben, in die Klemme geraten, zwischen Hammer und Amboss geraten).

SCHWIERIGE LAGE IST RAUMNOT

Der LEBEN IST EIN WEG-Metapher kann ebenfalls die SCHWIERIGE LAGE IST RAUMNOT-Metapher zugeordnet werden. Der eingeengte, an die Wand gedrückte, ins Gedränge gebrachte, in der Zwickmühle steckende Mensch kann sich kaum gezielt bewegen, was aus der körperlichen in die psychologische Domäne der Einschränkung in den Entscheidungs- und Handlungsmöglichkeiten übertragen wird. Der Raum ist dabei zur Entfaltung eines Menschen unabdingbar (einem Gedanken/ einem Gefühl/einer Idee Raum geben, in Schwung kommen/sein), man braucht ihn, um bestimmte Zwecke zu erreichen (jmdm. Raum schaffen, Raum einnehmen), auf gutem Niveau zu leben (auf großem Fuß leben, in Saus und Braus leben). Im Allgemeinen wird der Raum also mit Positivem assoziiert: mit der Luft, dem Spielraum, dem Wirkungskreis, der Freiheit und Entwicklungsmöglichkeit. Die Einengung und Verschließung des Menschen sind für die Psyche belastend: Dies kommt z.B. in panikartiger Angst mancher Menschen vor geschlossenen, fensterlosen Räumen (Klaustrophobie) sowie in der Lästigkeit der Freiheitsstrafe zum Vorschein.

\section{SCHWIERIGE LAGE IST EINE GEGEN JMDN. GERICHTETE WAFFE}

In einer akuten Gefahrsituation befinden sich Menschen, gegen die eine Waffe gerichtet ist (Messer an der Kehle, Pistole, Dolch auf der Brust, das schwebende Schwert des Damokles). Messer, Dolche, Schwerte sind effektive Waffen im Nahkampf: Falls Gewalt mit diesen Waffen angedroht wird, ist für das Opfer nicht nur die Fortbewegung, sondern jegliche Bewegung äußerst gefährlich: Ein Messer- oder 
Dolchstich in die inneren Organe bzw. ein Schnitt in eine Hauptschlagader führen den Tod herbei. Dieses Wissen aus der Ausgangsdomäne einer unmittelbaren, gefährlichen Körperandrohung bildet den Ausgangspunkt für die metaphorischen Mappings in andere, sich auf die Zwangslage und den Zustand höchster Anspannung beziehenden Lebensbereiche der Politik, der Finanzen u.Ä.

SCHWIERIGE LAGE IST DRUCK AUS ZWEI SEITEN

Aspekte aus beiden oben genannten Metaphern kommen in der Vorstellung einer bedrängten Lage zum Ausdruck, in der auf das Agens Druck aus zwei Seiten ausgeübt wird. Die Wissensbestände aus der Ausgangsdomäne der körperlichen Erfahrung, die Vorstellung des Festhaltens, Quetschens, der Folter bilden die Basis für die Konzeptualisierung der Idiome: jmdn. in Zange nehmen, in die Klemme geraten/in der Klemme sitzen, zwischen Hammer und Amboss geraten. Von beiden Seiten in seinem Wirkungsfeld eingeschränkt und deswegen in einer äußerst misslichen Lage ist das Agens, das sich zwischen den zwei mythologischen Meeresungeheuern: Skylla und Charibdis befindet, vom Feuer umgeben wird (zwischen zwei Feuer geraten) oder im $Z$ wiespalt steckt. Auch wenn das letztgenannte Kompositum heutzutage ausschließlich in Bezug auf psychisches Befinden gebraucht ist, wird der Bedeutungsaspekt des Beengtseins durch die Konstituente Spalt ,einen Zwischenraum bildende schmale, längliche Öffnung' (DUW) wahrscheinlich immer noch wachgerufen.

Außer der geschilderten ausgebauten konzeptuellen Metapher SCHWIERIGKEITEN SIND VERHINDERUNGEN DER (VORWÄRTS-)BEWEGUNG werden die Konzeptualisierungen von Schwierigkeiten und der schwierigen Lage durch fünf weitere konzeptuelle Metaphern beeinflusst, die an biologisch-vegetative Grundvoraussetzungen des Lebens (Essen und Atmen), an die direkte Umgebung des Menschen (schlechtes Wetter), seine kulturellen Errungenschaften (Spiel), oder an körperliche Symptome des sich in einer schwierigen Lage befindenden Menschen (verspürte Hitze) anknüpfen.

\subsubsection{SCHWIERIGKEIT IST UNGENIESSBARES ESSEN}

Einverleiben von Nahrung sowie Koch-, Ess- und Tafelsitten stellen einen so zentralen Bestandteil der alltäglichen Erfahrung eines Menschen sowie der Kultur einer Gesellschaft dar, dass die Nahrungsaufnahme eine wichtige Ausgangsdomäne für viele konzeptuelle Mappings bildet. So wird auch der Diskursbereich der schwierigen Lage und der Schwierigkeit zum Teil durch die tägliche Erfahrung der Nahrungsaufnahme metaphorisch strukturiert. In diesem Bereich werden Schwierigkeiten mit unreifen (in den sauren Apfel beißen), nicht mehr genießbaren (ein hartes Brot), oder schwer zuzubereitenden Lebensmitteln (eine harte Nuss) assoziiert. Generell ist die Essen-Metaphorik weitgehend durch die historischen Begebenheiten bestimmt: Positiv konnotiert sind die Lebensmittel, die von der Mehrheit - den Bauern und Arbeitern - in kleinen Mengen verzehrt und vor allem den höheren Gesellschaftsklassen (Geistlichen, Rittern, Adeligen) vorenthalten wurden: weiche, 
fetthaltige und/oder süße Produkte (Sahne, Butter, Fett, Wurst, Speck, Rosinen), während der saure und salzige Geschmack sowie die harten Lebensmittel metaphorisch mit Schwierigkeiten assoziiert werden (das Leben sauer machen, jmdm. die Suppe versalzen, sich die Zähne an etw. ausbeißen, harte Nuss, hartes Brot).

\subsubsection{SCHWIERIGE LAGE IST FEHLENDE LUFT/LUFTENTZUG}

Die Wichtigkeit des Atmens als eines körperlichen Grundbedürfnisses wird den Menschen in den Momenten bewusst, in denen sie nicht mehr atmen können. Offensichtlich ist dabei die Lebensnotwendigkeit der Luft, ohne die man nur einige Minuten überleben kann. Der Luftentzug wird also als Ausgangsdomäne zur emotionsbeladenen metaphorischen Bezeichnung der besonders schwierigen Situationen herangezogen. Die Phraseologismen, die durch die konzeptuelle Metapher Schwierige LAgE IST FEHLENDE LUfTMetapher motiviert sind, verweisen dabei auf zwei Möglichkeiten des Luftentzugs: durch Ertrinken/Ertränken (das Wasser steht/geht/reicht jmdm. (schon/...) bis an die/(zur) Kehle, jmdn./sich über Wasser halten, den Kopf noch/noch so eben über Wasser halten) oder durch Erwürgen/Erhängen (den Hals in der Schlinge haben, die Schlinge zieht sich zu, den Kopf/Hals aus der Schlinge ziehen). Wahrscheinlich ist die metaphorische Übertragung in dem (sich allem Anschein nach erst konstituierenden) Idiom jmdm./einer Sache die Luft abdrehen durch die neueren Technologien und Hobbys (z.B. Tauchen und Tauchflaschen) bedingt.

\subsubsection{SCHWIERIGE LAGE IST HITZE}

Die nächste ermittelte Metapher ist z.T. an das religös-kulturelle Symbol der Hölle gebunden (jmdm. die Hölle heiß machen, die Hölle auf Erden haben, oder verhüllend Teufels Küche). Vorstellungen von einer Hölle im Sinne eines Ortes der Qual und der Verdammnis sind im Christentum mit extremer Hitze und Feuer assoziiert. Andererseits ist für diese konzeptuelle Metapher die körperliche Erfahrung konstitutiv, dass die Gefahr, Aufregung und Ärger mit dem körperlichen Symptom der innerlich gespürten Hitze einhergehen (EFFEKT FÜR URSACHE, FOLGE FÜR GRUND-Metonymie). Die Konzeptualisierungen von Wut und Aggression (vor Wut platzen/explodieren/kochen, Wut/Zorn flammen auf), aber auch von heiklen und/ oder gefährlichen Angelegenheiten (ein heißes Eisen sein, ein heißes Eisen anpacken/anfassen, sich die Finger/Pfoten an etw. verbrennen, es brennt an allen Ecken) werden also z.T. durch die HITZE-Metapher beeinflusst.

\subsubsection{SCHWIERIGE LAGE IST SCHLECHTES WETTER}

Der Mensch erlebt sich als ein Teil seiner Umgebung und bildet mit ihr eine Einheit. Die Begegnung mit der äußeren Natur kommt manchmal mit dem Erleben einher, sich der inneren menschlichen Natur anzunähern. Die Schilderung der seelischen Zustände unter Rückgriff auf die Wetterbeschreibung kommt in der 
Literatur öfters vor, auch in der Alltagssprache verzahnt sich der Wortschatz aus dem Wetter- und Personenbeschreibungsbereich an vielen Stellen (z.B. jd. ist heiter, stürmisch, glühend, jmds. Blick umwölkt sich). Es kann also nicht wundern, dass zur Konzeptualisierung der schwierigen Lage auch die Unwetter-Beschreibungen herangezogen werden (Es ballen sich drohende Wolken über jmdm./einem Land/... zusammen, von einer dunklen Wolke überschattet werden, Ruhe vor dem Sturm).

\subsubsection{SCHWIERIGE LAGE IST EIN VERLORENES SPIEL}

Für die Bedeutungskonstituierung von einigen Idiomen der schwierigen Lage ist die LEBEN IST SPIEL-Metapher richtungsweisend. Den Spielen kommt in der Kultur und in der Entwicklung des Menschen eine wichtige Rolle zu: Kinderspiele bilden eine unumgängliche Etappe des Reifeprozesses, in der sich das Kind mit wichtigen Themen und Verhaltensmustern der Erwachsenenwelt (den Höhen und Tiefen des Lebens, dem Schicksal, der Notwendigkeit der Überwindung von Hindernissen, dem Kräftemessen mit Gegnern) zum ersten Mal auf einer kleinen, übersichtlichen Skala auseinandersetzen kann. Die metaphorischen Mappings zwischen der Niederlage im Spiel und der Notlage im Leben liegen deswegen auf der Hand und kommen in den Idiomen jmdn. nicht zum Zuge kommen lassen, sich ein Eigentor schießen, jmdm. den Schwarzen Peter zuschieben/zuspielen, den Schwarzen Peter haben zum Ausdruck.

Die aufgelisteten konzeptuellen Metaphern, deren ausgewählte Aspekte skizzenhaft beschrieben wurden, verleihen dem Großteil des gesammelten phraseologischen Materials Struktur. Die meisten der in der Phraseologismensammlung zusammengestellten Idiome (vgl. Kap. 4.1.1, Tab. 8) lassen sich einer oder mehreren von diesen konzeptuellen Metaphern zuordnen. Manchmal kommt es zu Verzahnungen: $\mathrm{Zu}$ der Bedeutungskonstituierung des Idioms sich am eigenen Zopf/an den eigenen Haaren/am eigenen Haar aus dem Sumpf ziehen mag sowohl die konzeptuelle Metapher SCHWIERIGKEITEN SIND KLEBRIGE/sCHMUTZIGE MASSE als auch die Metapher SCHWIERIGE LAGE IST UNSICHERER BODEN beitragen. Ähnliches gilt für das Idiom jmdm. brennt der Boden unter den Füßen, das möglicherweise am Schnittpunkt zwischen den konzeptuellen Metaphern SCHWIERIGE LAGE IST UNSICHERER BODEN und SCHWIERIGE LAGE IST HITZE liegt. Diese Verzahnungen scheinen für die Phraseologie keinesfalls ungewöhnlich zu sein. Im Gegenteil: Die Bedeutungen von den meisten Idiomen sind von einer Vielzahl der metaphorischen und metonymischen Derivationen konstituiert, die zusammenspielen, sich gegenseitig ergänzen, gelegentlich aber auch konkurrieren, was im nächsten Kapitel veranschaulicht wird.

Die folgende Tabelle (Tab. 10) stellt eine um phraseologische Exemplifizierungen erweiterte Version der Zusammenstellung der konzeptuellen Metaphern, die das semantische Feld der Schwierigkeit/der schwierigen Lage strukturieren und motivieren. Die einzelnen Metaphern und ihre sprachlichen Exemplifizierungen aus dem phraseologischen Bereich (vgl. die in der Tab. 8 zusammengestellte Phraseologismensammlung) sind wie folgt klassifizierbar: 
Tab. 10: Die aus der Phraseologismensammlung eruierten konzeptuellen Metaphern des semantischen Feldes, schwierige Lage, Schwierigkeit' und ihre phraseologischen Exemplifizierungen.

\section{SCHWIERIGKEITEN SIND VERHINDERUNGEN DER (VORWÄRTS-)BEWEGUNG}

\subsection{SCHWIERIGKEITEN SIND HINDERNISSE AUF DEM WEG}

\subsubsection{SCHWIERIGKEITEN SIND DIE LANDSCHAFTSFORMEN}

in einem Tief stecken

das Ende der Talsohle ist erreicht

die Talsohle ist durchschritten

sich im Jammertal befinden

auf Talfahrt sein

den Bach runtergehen

Licht am Ende des Tunnels sehen

mit jmdm./etw. geht es bergab

mit jmdm. geht es (wieder) bergauf

jmdm./einer Sache die Bahn/den Boden ebnen

\subsubsection{SCHWIERIGE LAGE IST UNSICHERER BODEN}

sich auf den schwankenden Boden begeben, sich auf unsicheren Boden begeben, sich auf unsicherem/schwankendem Boden bewegen/befinden

jmdm. schwankt der Boden unter den Füßen

jmdm. den Boden unter den Füßen wegziehen, jmdm. (einer Sache) den Boden entziehen, den Boden unter den Füßen verlieren

den (festen) Boden unter den Füßen gewinnen

sich auf dünnes Eis begeben/wagen, sich auf dünnem Eis bewegen

sich auf glattes Parkett wagen

aufs Glatteis geraten, sich aufs Glatteis begeben, sich auf Glatteis bewegen

die Kuh vom Eis holen/ziehen/schieben/kriegen/führen/bringen

jmdm. brennt der Boden unter den Füßen

ins Rutschen/Schlingern kommen/geraten

sich an einen/letzten Strohhalm klammern

nach einem/letzten Strohhalm greifen

(in gefährliches Fahrwasser geraten)

\subsubsection{SCHWIERIGKEITEN SIND KLEBRIGE/SCHMUTZIGE MASSE}

die Karre in den Dreck fahren, die Karre steckt im Dreck, der Karren steckt/ ist im Dreck, den Karren in den Dreck fahren, die Karre/den Karren im Dreck stehen lassen

in die Patsche geraten, jmdn. in die Patsche reiten, in der Patsche sitzen in der Scheiße sitzen, jmdn. aus der Scheiße ziehen, (tief/knietief) in der Scheiße/ Kacke sitzen/stecken/sein, bis zum Hals in der Scheiße stecken 


\section{Tab. 10: Continued}

sich am eigenen Zopf/an den eigenen Haaren/am eigenen Haar aus dem Sumpf ziehen in die Bredouille geraten, jmdn. in die Bredouille bringen, in der Bredouille sein/ sitzen (Bredouille, fr. Dreck)

in der Tinte sitzen, sich aus der Tinte ziehen, jmdn. in die Tinte reiten

\subsubsection{SCHWIERIGKEITEN SIND BLOCKIERUNGEN, SPERRUNGEN DES DURCHGANGS}

jmdm. Steine in den Weg legen

eine Hürde nehmen

Hürden/eine Hürde beseitigen

jmdm. etw. aus dem Weg räumen/schaffen

jmdm. Hindernisse in den Weg legen

jmdm. einen Hemmschuh in den Weg legen

jmdm. in den Weg kommen, jmdm. in den Weg treten, sich jmdm. in den Weg

stellen

jmdm. den Weg versperren, jmdm. den Weg vertreten

jmdm im Weg(e) sein/stehen, einer Sache im Wege stehen (bei etw.)

jmdm. in den Weg laufen

jmdm./jmdm. in die Quere kommen/geraten/laufen/rennen

die Klippen umfahren/umschiffen

in eine Sackgasse geraten, sich in eine Sackgasse verrennen, in einer Sackgasse stecken

jmdn./etw. in ausweglose Lage bringen, in einer ausweglosen Lage sein

jmdm. ins Gehege kommen

nicht mehr weiterwissen, nicht mehr ein noch aus/nicht mehr aus noch ein/weder aus noch ein/weder ein noch aus wissen

mit seiner Kunst/seiner Weisheit/seinem Latein am Ende sein

am toten Punkt angelangt sein

sich durchs Leben schlagen

\subsubsection{SCHWIERIGKEIT IST EIN HINDERNIS AUF DEM WEG, DAS EINEN ZUM FALL BRINGT;} SCHEITERN/IN SCHWIERIGKEITEN GERATEN IST FALLEN

jmdm. ein Bein/ein Beinchen stellen

jmdm. Knüppel/einen Knüppel zwischen die Beine werfen

jmdn. in die/eine Falle locken, jmdm. eine Falle stellen

jmdm. einen Fallstrick legen, Fallstricke legen

in den Staub beißen

auf Kreuz fallen

auf die Nase fallen/fliegen

mit etw. auf den Bauch/auf die Schnauze/Fresse fallen

zu Fall kommen

mit etw. auf den Arsch/Hintern fallen 
Tab. 10: Continued

\subsection{SCHWIERIGKEITEN SIND EINE LAST}

jmdm. ein Klotz am Bein sein, sich (mit jmdm./etw.) einen Klotz ans Bein binden etw. noch am Bein haben, sich etw. ans Bein hängen/binden, jmdn./etw. am/auf dem Hals haben jmdn./sich etw. an den Hals hängen/binden jmdm. wie ein Mühlstein am Hals hängen etw. an der Backe tragen wie ein Knüppel am Bein

\subsection{SCHWIERIGE LAGE IST BESCHRÄNKUNG DER BEWEGUNGSFREIHEIT}

\subsubsection{SCHWIERIGE LAGE IST RAUMNOT}

jmdn. in die Enge treiben, in die Enge geraten ins Gedränge kommen, jmdn. ins Gedränge bringen jmdn. ins Bockhorn jagen in einer (richtigen/...) Zwickmühle stecken, sich in einer richtigen Zwickmühle befinden, in eine Zwickmühle geraten in eine Sackgasse geraten/sich in eine Sackgasse verrennen/in einer Sackgasse stecken jmdn. an die Wand drücken jmdn. an die Wand spielen mit dem Rücken zur/an der Wand stehen jmdn. in die Ecke drängen in (große/arge/...) Bedrängnis kommen, in großer/arger ... Bedrängnis sein, sich in großer/arger Bedrängnis fühlen jmdm. die Hände binden

\subsubsection{SCHWIERIGE LAGE IST EINE GEGEN JMDN. GERICHTETE WAFFE}

(Ständig/...) das Schwert des Damokles über sich haben/fühlen, (ständig/...) ein/ das Damoklesschwert über sich haben/fühlen das Schwert des Damokles schwebt über jmdm. jmdm. sitzt das Messer an der Kehle jmdm. die Pistole/das Messer/den Dolch auf die Brust/an die Gurgel/an die Kehle setzen den Hals in der Schlinge haben die Schlinge zieht sich zu den Kopf/Hals aus der Schlinge ziehen die Peitsche im Nacken spüren 


\title{
Tab. 10: Continued
}

\author{
1.3.3 SCHWIERIGE LAGE IST DRUCK AUS ZWEI SEITEN \\ jmdn. in die Zange nehmen/in der Zange haben \\ in die Klemme geraten; (ganz schön/...) in der Klemme sitzen \\ zwischen Baum und Borke geraten/sein \\ zwischen Hammer und Amboss geraten, zwischen Hammer und Amboss sein \\ zwischen zwei Feuer geraten/kommen \\ zwischen Scylla/Skylla und Charibdis sein \\ in einem Zwiespalt stecken, jmdn. in einen Zwiespalt bringen/stürzen \\ zwischen den/allen/zwei Stühlen sitzen
}

\section{SCHWIERIGKEIT IST UNGENIESSBARES ESSEN}

in den sauren Apfel beißen (müssen)

etw. ist ein hartes/schweres Brot

eine harte Nuss für jmdn. sein, eine harte Nuss zu knacken haben, manche/eine harte

Nuss zu knacken haben/bekommen

die Suppe auslöffeln (müssen), die man sich eingebrockt hat

jmdm. (gehörig/...) die Suppe versalzen

jmdm. in die Suppe spucken

Suppe einbrocken, sich etw. einbrocken

jmdm. das Leben sauer machen

sich (Dativ) die Zähne an etw. ausbeißen

an etw. zu kauen haben

(bei jmdm. mit etw. auf Granit beißen)

\section{SCHWIERIGE LAGE IST FEHLENDE LUFT/LUFTENTZUG}

das Wasser steht/geht/reicht jmdm. (schon/...) bis zum/(an den) Hals/bis hier (hin) (mit einer Geste: Hand quer zum Kinn bzw. unter die Nase)

das Wasser steht jmdm. bis bis zur Kehle/bis an die Kehle

jmdn./sich über Wasser halten

den Kopf noch/noch so eben über Wasser halten

den Hals in der Schlinge haben

die Schlinge zieht sich zu

den Kopf/Hals aus der Schlinge ziehen

Wenn ...dann/... kann sich jd. ja gleich/sofort einen Strick kaufen/nehmen (und sich aufhängen)

die Luft wird dünn

jmdm. die Luft abdrehen

etw. im Keim ersticken

sich an einen/letzten Strohhalm klammern

nach einem/letzten Strohhalm greifen 
Tab. 10: Continued

\section{SCHWIERIGE LAGE IST HITZE}

jmdm. die Hölle heiß machen

sich die Finger an etw. verbrennen

sich die Pfoten an etw. verbrennen

die Hölle auf Erden haben

in Teufels Küche kommen/geraten

es brennt an allen Ecken (und Enden)

etw. ist ein (regelrechter/...) Tanz auf dem Vulkan

ein heißes Eisen sein, ein heißes Eisen anpacken/anfassen

Es brennt der Baum

jmdm. brennt der Boden unter den Füßen

jmdm. den Boden unter den Füßen heiß machen

jmdm. wird der Boden (unter den Füßen) zu heiß

auf einem Vulkan leben/tanzen

jmdn. im eigenen Saft schmoren lassen

Hier/da/in/... (wie) auf einem Pulverfass sitzen

der Funke sein, der das Pulverfass zum Explodieren bringt

die Lunte ans Pulverfass legen

\section{SCHWIERIGE LAGE IST SCHLECHTES WETTER}

es ballen sich drohende Wolken über jmdm./einem Land/... zusammen

von einer (dunklen) Wolke überschattet werden (path.)

Ruhe vor dem Sturm

${ }^{*}$ Es knistert im Gebälk

\section{SCHWIERIGE LAGE IST VERLORENES SPIEL}

jmdm. den schwarzen Peter zuspielen/zuschieben

den schwarzen Peter haben

jmdn. (nicht) zum Zug(e) kommen lassen

sich ein Eigentor schießen

Den ermittelten konzeptuellen Metaphern lässt sich die Mehrheit der Idiome zuordnen. Allerdings passen 31 Idiome, darunter vier Idiome (samt ihrer Varianten) mit unikalen Komponenten, zu keiner der für dieses semantische Feld ermittelten Metapher:

Da liegt der Hase im Pfeffer

Da liegt der Hund begraben

nicht in jmds. Haut stecken mögen

nicht in jmds. Schuhen stecken mögen

in den Arm fallen 
jmds. Pläne über den Haufen werfen

jmds. Pläne durchkreuzen

jmdm. einen (dicken) Strich durch die Rechnung machen

sich eine Blöße geben

sich wie ein Aal winden

Die Sache hat einen Haken

(total/völlig) am Boden zerstört sein

bei jmdm. ist Holland in Not

ein Kapitel für sich sein

bei etw. hat der Teufel die/seine Hand im Spiel

etw. wächst jmdm. über den Kopf

nicht auf Rosen gebettet sein

auf dem Schlauch stehen

jmdm. das/sein Konzept verderben

jmdm. ins Handwerk pfuschen

die Zeitbombe tickt

ins Trudeln kommen/geraten

jmdm. eine Laus in den Pelz/ins Fell setzen

sich in die Brennnesseln/Nesseln setzen

Sand ins Getriebe streuen

Sand im Getriebe sein

nicht über seinen (eigenen) Schatten springen können

\section{Idiome mit unikalen Komponenten}

in Schwulitäten kommen/geraten, jmdn. in Schwulitäten bringen, in Schwulitäten sein (ursprünglich Studentensprache, vgl. DUW online, Zugriff am 06.05.2016)

in Schwulibus sein

(ganz schön/...) im Schlamassel stecken/sitzen, Da haben wir/habt ihr/... den Schlamassel! (jiddisch schlamassel = Unglück, Pech, zu schlimm und jiddisch massel, Massel, DUW online, Zugriff am 06.05.2016);

in Kalamitäten kommen/geraten (lateinisch calamitas = Schaden, Unglück, DUW online, Zugriff am 06.05.2016)

Diese Idiome von sehr unterschiedlicher Etymologie sind symbolisch (Rose als Symbol der Schönheit), durch epistemische Metaphern motiviert oder möglicherweise - so wie im Falle der Idiome mit unikalen Komponenten - für die meisten Sprecher aus synchroner Perspektive nicht motiviert. In ihrer Motiviertheit sind manche von ihnen stark situationsbezogen: Das Idiom auf dem Schlauch stehen ,etwas nicht verstehen; etwas nicht begreifen; nicht weiterkommen; mit widrigen Umständen kämpfen müssen; in eine ungünstige Lage geraten' (redensarten-index, Zugriff am 29.06.2017) leitet sich beispielsweise von der Vorstellung ab, dass Gedanken fließen. Wer also versehentlich auf dem Schlauch steht, stört seinen „Gedankenfluss“. Nach dem gleichen Bild kann auch der „Fluss“ des Arbeitsvorganges gestört sein, wenn etwas nicht richtig funktioniert (ebd.). Das Idiom (total/ 
völlig) am Boden zerstört sein ist dagegen auf eine Kriegsstrategie zurückzuführen. Falls man gegnerische Flugzeuge noch vor dem Einsatz zerstört, richtet man dem Feind erheblichen Schaden an, noch bevor man angegriffen wird (vgl. dazu auch Müller 2005: 68).

Die Tatsache, dass man unter den unklassifizierten Phraseologismen keine konzeptuellen Metaphern eruieren konnte, die das semantische Feld der schwierigen Lage strukturieren, bedeutet nicht, dass bei ihrer Konzeptualisierung keine konzeptuellen Metaphern zu Geltung kommen können. Der Konzeptualisierung des Idioms auf dem Schlauch stehen liegt beispielshalber die konzeptuelle KANALMetapher zugrunde, für die Bedeutungskonstituierung vom Idiom (total/völlig) am Boden zerstört sein ist u.a. die GUT IST OBEN, SCHLECHT IST UNTEN-Metapher richtungsweisend. Der Einfluss unterschiedlicher konzeptueller Metaphern auf die Bedeutungskonstituierung von diesen Idiomen ist durchaus möglich, da sie aber in dem untersuchten Diskursbereich nur vereinzelt vorkommen, können sie nicht als ein Strukturierungsprinzip des semantischen Feldes der Schwierigkeit/der schwierigen Lage angenommen werden.

\subsubsection{Mechanismen der Bedeutungskonstituierung von Idiomen}

Im vorangegangenen Kapitel wurde am Beispiel des semantischen Feldes der schwierigen Lage/der Schwierigkeit veranschaulicht, wie große Rolle die konzeptuellen Metaphern von unterschiedlichem Generalitätsgrad bei der Strukturierung des phraseologischen Materials spielen: Der überwiegenden Mehrheit der Idiome liegt eine relativ kleine Anzahl konzeptueller Metaphern als Motiviertheitsmechanismen zugrunde, die bildliche Sprache weist also bestimmte Regularitäten auf, die man systematisch erfassen kann. Die kognitive Metapherntheorie setzt sich zum Ziel, diese Regularitäten aufzudecken und zu beschreiben, wobei am interessantesten zweifelsohne diejenigen sind, die durch einen großen Generalitätsgrad gekennzeichnet sind. So sind beispielshalber die in der frühesten Körpererfahrung verankerten Vorstellungsschemata für menschliche Wahrnehmung und Verarbeitung der Welt von größter Relevanz: Es ist kaum vorstellbar, wie die Zivilisation aussehen würde, wenn sich die Menschen nicht als (von der Außenwelt strikt abgegrenzter) Behälter konzeptualisieren würden, die Dichotomie Ich-Außenwelt bzw. InnenweltAußenwelt ist für menschliche Perzeption und Kognition absolut grundlegend. So ausgerichtete Forschung ist für Linguistik und alle Kognitionswissenschaften vielversprechend: Die Aufdeckung der universalen Kategorisierungsregeln lässt uns Einblick nicht nur in die Natur der bildlichen, metaphorischen Sprache, sondern auch in das Wesen des menschlichen Geistes und seine z.T. körpergebundenen Grenzen gewähren.

Bei aller Wichtigkeit der konzeptuellen Metaphern und ihrem programmatischen Beitrag zu der Erforschung der bildlichen Sprache erweisen sie sich 
alleine für eine detaillierte semantische Beschreibung eines Idioms dennoch als nicht ausreichend. Zum einen lassen sich in dem zu besprechenden semantischen Feld nicht für alle idiomatischen Ausdrücke konzeptuelle Metaphern und Metonymien aufdecken. Zum anderen sind die Mechanismen der Bedeutungskonstituierung und der Motiviertheit von Idiomen im authentischen Sprachgebrauch höchst komplex und vielschichtig: Konzeptuelle Metaphern stellen einen richtungsweisenden Ausgangspunkt der Konzeptualisierungen aus, sind aber außerstande, die subtilen, jedoch deutlich spürbaren Bedeutungsunterschiede zwischen den durch dieselbe konzeptuelle Metapher motivierten Idiomen zu erklären. Die Vielfalt und Einzigartigkeit der kognitiven Mechanismen, die der phraseologischen Motiviertheit und dem Zustandekommen der Idiom-Bedeutung zugrunde liegen, wird im Folgenden anhand einer korpusgestützten Analyse ausgewählter Idiome aufgezeigt. In den Mittelpunkt des Interesses werden dabei - bis auf wenige Ausnahmen - nicht die einzelnen Konzeptualisierungen gerückt, sondern die aus dem Korpus eruierten Verwendungsprofile und Verwendungsmuster: Es wird auf diejenigen Mechanismen eingegangen, die nicht in einem einzigen Sprachgebrauchsereignis nachweisbar sind, sondern eine bestimmte Regularität aufweisen und darauf schlussfolgern lassen, dass sie bei mehreren Sprachteilhabern zu der Idiomproduktion (als Bedeutungskonstituierungsmechanismen) und Rezeption (als Motiviertheitsmechanismen) beitragen und Bedeutungen gestalten, die als lexikalisiert gelten oder eine Tendenz zur Lexikalisierung aufweisen. (Zu Methoden der Ermittlung von Verwendungsmustern und -profilen vgl. Unterkap. 4.1.2.2.2.2). Der idiosynkratische Gebrauch von Idiomen, darunter stark kontextgebundene Beispiele vom sprachspielerischen Idiomgebrauch, werden im Folgenden nur am Rande behandelt.

Um einen Überblick über mannigfaltige Bedeutungskonstituierungsmechanismen von Idiomen zu gewinnen, werden die Idiome in Gruppen eingeteilt. Den in die jeweilige Gruppe zugeordneten Idiomen liegen die gemeinsamen konzeptuellen Metaphern zugrunde (vgl. Tab. 10). So sind die Idiome ein dünnes Eis, ein glattes Parkett und ein schwankender Boden durch die konzeptuellen Metaphern: LEBEN IST EIN WEG $\rightarrow$ SCHWIERIGKEITEN SIND VERHINDERUNGEN DER (VORWÄRTS-)BEWEGUNG $\rightarrow$ SCHWIERIGKEITEN SIND HINDERNISSE AUF DEM WEG $\rightarrow$ SCHWIERIGE LAGE IST UNSICHERER BODEN motiviert, den Idiomen ein Bein stellen, Knüppel zwischen die Beine werfen liegen die Metaphern LEBEN IST EIN WEG $\rightarrow$ SCHWIERIGKEITEN SIND VERHINDERUNGEN DER (VORWÄRTS-)BEWEGUNG $\rightarrow$ SCHWIERIGKEITEN SIND HINDERNISSE AUF DEM WEG $\rightarrow$ SCHWIERIGKEITEN SIND HINDERNISSE, DIE EINEN ZUM FALL BRINGEN zugrunde, den Ausgangspunkt der Motiviertheitsmechanismen der Idiome in die Enge treiben und an die Wand rücken bilden die Metaphern LEBEN IST EIN WEG $\rightarrow$ SCHWIERIGKEITEN SIND VERHINDERUNGEN DER (VORWÄRTS-)BEWEGUNG $\rightarrow$ SCHWIERIGE LAGE IST RÄUMLICHE BESCHRÄNKTHEIT, Klotz am Bein sowie jmdn. am Hals haben sind vor dem Hintergrund der Metaphern LEBEN 
IST EIN WEG $\rightarrow$ SCHWIERIGKEITEN SIND VERHINDERUNGEN DER (VORWÄRTS-) BEWEGUNG $\rightarrow$ SCHWIERIGKEITEN SIND EINE LAST BEI BEWEGUNG verständlich. Anderer Provenienz sind die konzeptuellen Motiviertheitsmechanismen der Idiome: ein hartes Brot, eine harte Nuss, in den sauren Apfel beißen, bei deren Konzeptualisierung nicht auf die Weg-Metaphorik, sondern auf die konzeptuelle Metapher SCHWIERIGKEITEN SIND UNGENIESSBARES ESSEN zurückgegriffen wird. Die detaillierte Darstellung der Mechanismen der phraseologischen Bedeutungskonstituierung und Motiviertheit wird mit Idiom ein dicker Brocken abgeschlossen: Dank der Ambiguität der nominalen Konstituente Brocken in der literalen Lesart lässt sich hier der Einfluss des mentalen Bildes auf die Konzeptualisierungen überzeugend nachweisen. Jedes Kapitel wird mit einer Zusammenfassung abgeschlossen, in der bestimmte kognitive Aspekte der Bedeutungskonstituierung herausgegriffen und am Beispiel der besprochenen Idiome detaillierter beschrieben werden.

\subsubsection{Die Weg-Metaphorik im Deutschen: SCHWIERIGKEITEN SIND VERHINDERUNGEN DER VORWÄRTSBEWEGUNG}

Die auf dem Vorstellungsschema WEG (PATH) aufbauende konzeptuelle LEBEN IST EIN WEG-Metapher ist aufgrund ihrer Omnipräsenz in den einzelnen Sprachen, des sprachübergreifenden Charakters (wenigstens in dem abendländischen Kulturraum) sowie ihres Embodiments ein Beispiel par excellence für die konzeptuellen (in Barcelonas Terminologie: ontologischen) Mappings. Nach Jäkel (2003: 281) ist es eine der allergebräuchlichsten Metaphern; man spricht des Öfteren von der Weg-Metaphorik (Spieß 2017: 106, Mellado-Blanco 2014). Das Leben eines Menschen wird darin als ein Weg, eine Strecke dargestellt, die der Mensch von Geburt bis zu seinem Tode zurücklegt (vgl. auch weitere konzeptuelle Metaphern GEBURT IST ANKUNFT, TOD IST ABREISE, Kövecses 2005: 32). In den glücklichen Zeiten kann er die einzelnen Strecken schnell und in der aufrechten Position zurücklegen, in den schweren Zeiten wird er auf dem Weg aufgehalten, zu Fall gebracht (hier kommt zusätzlich die Orientierungsmetapher: GUT IST OBEN, SCHLECHT IST UNTEN zur Geltung). In der Wanderung durch das Leben verhalten sich Menschen also analog zum Beschreiten eines Weges, der glatt oder steinig, voll von Hindernissen, Umwegen, Abgründen, Sackgassen sein kann. Ab und zu werden sie vor Entscheidungen gestellt (Weggabelungen), oder begehen Fehler und kommen nicht voran (irren auf labyrinthartigen Wegen). Auf der Folie dieser Metapher konzeptualisiert man wichtige Ereignisse, Wendepunkte, Beziehungen: die Geburt (z.B. auf die Welt kommen), älter werden (in der Mitte des Lebens stehen), Tod (es geht mit jmdm. zu Ende, sich dem/seinem Ende zuneigen, die letzte Fahrt/Reise antreten, den Weg allen Fleisches gehen), Freundschaft und Ehe (durch dick und dünn mit jmdm. gehen, jds. Wege kreuzen sich), Trennung und Betrug (unsere Wege trennen sich, getrennte Wege gehen, einen Seitensprung machen), Arbeit und Karriere (es weit bringen, es zu nichts bringen) usw. Im Gegensatz zu der Sicherheit des von der Fläche her begrenzten 
Hauses sind die Menschen auf den Wegen stets Gefahren ausgesetzt, die Wege werden dennoch auch mit Positivem: der Erschließung der Außenwelt, Selbstverwirklichung assoziiert.

Da die konzeptuelle Metapher LEBEN IST EIN WEG und ihre Ausprägung sCHWIERIGKEITEN SIND VERHINDERUNGEN DER VORWÄRTSBEWEGUNG auch die mächtigsten der eruierten Metaphern des semantischen Feldes Schwierigkeit/schwierige Lage sind, beeinflussen sie die meisten (9 von 13) der zu besprechenden Idiome. Die beiden konzeptuellen Metaphern leisten einen grundsätzlichen Beitrag zu den Konzeptualisierungen von Idiomen: schwankender Boden, dünnes Eis, glattes Parkett, ein Bein stellen, Knüppel zwischen die Beine werfen, Klotz am Bein, etw. am Hals haben, in die Enge treiben und an die Wand drücken.

\subsection{SCHWIERIGKEITEN SIND HINDERNISSE AUF DEM WEG}

Die fünf zuerst der Untersuchung zu unterziehenden Idiome rücken die Wegbeschaffenheit und die auf dem Weg anzutreffenden Erschwerungen in den Fokus der Aufmerksamkeit und werden durch die konzeptuelle Metapher SCHWIERIGKEITEN SIND HINDERNISSE AUF DEM WEG beeinflusst.

Dabei liegt den Idiomen schwankender Boden, dünnes Eis, glattes Parkett die konzeptuelle Metapher SCHWIERIGE LAGE IST UNSICHERER BODEN zugrunde, bei den Idiomen ein Bein stellen, Knüppel zwischen die Beine werfen wird dagegen von dem grundsätzlichen Beitrag der konzeptuellen Metapher SCHWIERIGKEITEN SIND HINDERNISSE, DIE EINEN ZUM FALL BRINGEN ausgegangen.

\subsection{SCHWIERIGE LAGE IST UNSICHERER BODEN schwankender Boden, dünnes Eis, glattes Parkett}

Die drei zu besprechenden Phraseologismen weisen so große Variabilität auf, dass die Frage naheliegt, ob sie überhaupt als verbale Idiome eingestuft werden können. So scheinen die Verben in den lexikographisch erfassten Idiomen sich auf schwankenden/unsicheren Boden begeben, sich auf dünnes Eis begeben/wagen, glattes Parkett betreten, sich auf glattem Parkett bewegen relativ schwach verfestigt zu sein. Wegen der starken Affinität der genannten Phraseologismen zur Varianz und Modifikationen auf der formalen Seite sind in die Suchmaschine ausschließlich die nominalen Phrasen: dünnes Eis, schwankender Boden, glattes Parkett eingegeben worden.

\subsection{1 schwankender Boden}

Lexikographisch erfasste Varianten: sich auf schwankenden/unsicheren Boden begeben, sich auf unsicherem/schwankendem Boden bewegen/befinden

Modifikationen: auf dem schwankenden Boden stehen, überleben, auf schwankendem Boden mit einiger Stabilität weiter bestehen, etw. steht auf dem schwankenden Boden, etw. ist auf schwankendem Boden aufgebaut, den schwankenden Boden (der Exegese) für fest erklären 


\section{Darstellung in lexikographischen Nachschlagewerken ${ }^{162}$}

Tab. 11: Das Idiom ein schwankender Boden in allgemeinen und phraseologischen Wörterbüchern des Deutschen.

\begin{tabular}{|c|c|c|}
\hline $\begin{array}{l}\text { Wörter- } \\
\text { buchtyp }\end{array}$ & Wörterbuch & Lexikographische Darstellung \\
\hline \multirow[t]{3}{*}{ allgemein } & DUw 2006 & nicht verzeichnet \\
\hline & $\underline{\text { DUW ONLINE }}$ & nicht verzeichnet (letzter Zugriff am 26.10.2017) \\
\hline & WAHRIG 2007 & nicht verzeichnet \\
\hline \multirow[t]{5}{*}{$\begin{array}{l}\text { phraseo- } \\
\text { logisch }\end{array}$} & DUDEN 11 & $\begin{array}{l}\text { sich auf schwankenden/unsicheren Boden } \\
\text { begeben: (in seinen Betrachtungen, Argumentationen } \\
\text { o.Ä.) den Boden der Tatsachen, des Gesicherten verlassen, } \\
\text { unsichere Voraussetzungen einbeziehen: Mit diesen } \\
\text { Theorien begab er sich auf unsicheren Boden. (2011: 135) }\end{array}$ \\
\hline & $\begin{array}{l}\text { SCHEMANN } \\
2011^{163}\end{array}$ & $\begin{array}{l}\text { sich auf schwankenden/unsicheren Boden } \\
\text { begeben form } \\
\text { Er sollte zu diesem Thema schweigen, weil er nicht } \\
\text { informiert ist. Er begibt sich da auf schwankenden } \\
\text { Boden; mit jedem Wort, das er sagt, geht er ein Risiko } \\
\text { ein. (2011: 94) }\end{array}$ \\
\hline & & $\begin{array}{l}\text { sich auf unsicherem/schwankendem Boden } \\
\text { bewegen (mit etw.) form } \\
\text { Er bewegt sich da mit seinen Aufnahmen auf } \\
\text { schwankendem Boden. Er ist nicht ausreichend } \\
\text { informiert und sollte sich deshalb mit seiner Meinung } \\
\text { zurückhalten. (2011: 94) }\end{array}$ \\
\hline & $\begin{array}{l}\text { Redensarten- } \\
\text { index }\end{array}$ & $\begin{array}{l}\text { sich auf schwankenden/unsicheren Boden } \\
\text { begeben; sich auf unsicherem/schwankendem } \\
\text { Boden bewegen/befinden } \\
\text {,eine ungesicherte Meinung vertreten; eine riskante } \\
\text { Zusage machen; sich angreifbar machen; einer neuen/ } \\
\text { ungeschützten Situation ausgesetzt sein' }\end{array}$ \\
\hline & MÜLLER 2005 & nicht verzeichnet \\
\hline
\end{tabular}

162 Die originale Notationsweise der Wörterbuchartikel wird in den Tabellen, die die Erfassung der Idiome in lexikographischen Werken wiedergeben, beibehalten, woraus sich die Unterschiede in Abkürzungen, Markierungen, enzyklopädischen Angaben usw. ergeben. Nur die Hervorhebung aller Lemmata durch Fettdruck wurde von der Autorin der Einheitlichkeit und Übersichtlichkeit der Tabelle halber vorgenommen.

163 An dieser Stelle ist auf die besondere Bedeutung zu verweisen, die den Gebrauchsbelegen in SCHEMANNs $(1993,2011)$ phraseologischem Wörterbuch: Deutsche Idiomatik 


\section{Korpusgestützte Analyse anhand der DWDS-Korpora ${ }^{164}$}

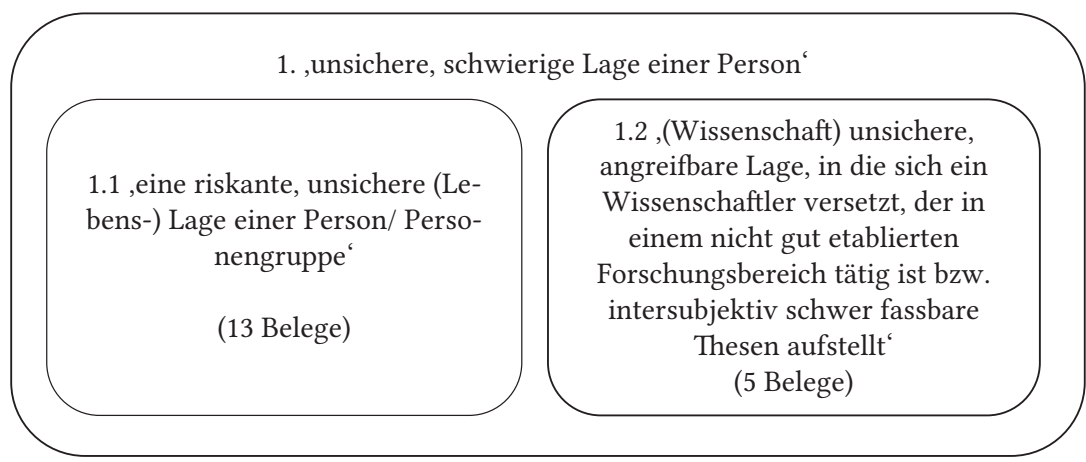

\section{schwankender Boden}

2. etw. steht auf dem schwankenden Boden ,etw. (eine Theorie, eine Argumentation, eine Anklage, die Wirtschaft) hat unsichere Grundlagen/ Fundamente (10 Belege)
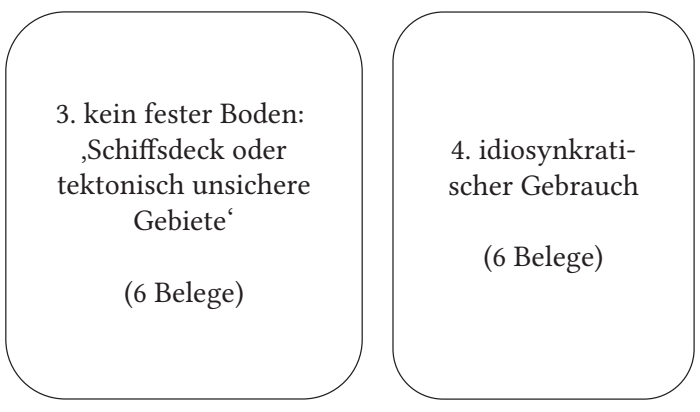

Abb. 30: Die Verwendungsprofile und-muster des Idioms ein schwankender Boden anhand der Analyse der Gebrauchsbelege im DWDS-Korpus.

zukommt. Statt Bedeutungserläuterungen werden hier repräsentative Kontexte aufgeführt, aus denen der Benutzer selbst die Bedeutung des Phraseologismus aufschlüsselt.

164 Zugriffsdatum: 25.02.2017, Suchanfrage: schwankender\&\&Boden. Der Anteil der einzelnen DWDS-Teilkorpora in der 40 Belege zählenden Belegsammlung: Deutsches Textarchiv: 0/7; Kernkorpus 2/17; Die Zeit: 24/178; Berliner Zeitung: 8/26; Der Tagesspiegel: 6/13. Die erste Zahl bezieht sich auf die Anzahl der in die Belegsammlung aufgenommenen Belege, die zweite auf die Anzahl der Belege, die zum Zeitpunkt der Stichprobeentnahme in dem jeweiligen DWDS-Korpus zur Verfügung standen. 
Das zu besprechende Idiom bezieht sich in den meisten Belegen auf eine schwierige, unsichere Lage eines Menschen. Die Ausgangsdomäne liegt in der verkörperten Erfahrung: Jeder hat wahrscheinlich Schwindelgefühle und die damit verbundenen Koordinationsstörungen, Gang- und Standunsicherheit, Fallangst und Benommenheit empfunden. Diese negativen Empfindungen werden in die abstrakteren Domänen übertragen. Schwankender Boden wird ebenfalls metonymisch für Plätze verwendet, die oft wacklig sind: Decke der Schiffe sowie tektonisch aktive Gebiete mit häufigen Erdbeben und Vulkanausbrüchen.

Verwendungsprofil 1: ,unsichere, schwierige Lage einer Person“ (18 Belege) Dem ersten Verwendungsprofil lassen sich 18 Belege zuordnen, in denen größtenteils Menschen in der Agensrolle auftreten. Der schwankende Boden bezieht sich auf eine heikle Lage einer Person unter den neuen Umständen sowie - in wissenschaftlichem Bereich - auf die unsichere Position eines Forschers, der sich mit seinen Hypothesen auf ein wissenschaftlich nicht gut etabliertes Terrain begibt. Treten in der Subjektrolle unbelebte Objekte (Theorien, Anklagen, Hypothesen u.Ä. sowie ihre Auslegungen) auf, dann werden die wackligen, schwachen, leicht widerlegbaren Grundlagen dieser Annahmen profiliert.

Verwendungsmuster 1.1: ,riskante, unsichere, schwierige (Lebens-)Lage eines Menschen' (13 Belege)

Stellvertretend für dieses Verwendungsmuster kann folgender Beleg angeführt werden, in dem um das Idiom herum ein Szenario ausgebaut wird: Die Gefangenen, die mal die Grenze des Rechts, des Anstands und der Moral überschritten haben, werden als „Gestrauchelten“, ihre schwierige Lage nach der Freilassung als schwankender Boden bezeichnet. Das ganze Bild fügt sich in die LEBEN ALS WEGMetaphorik ein:

(1) Lösch sagt, was ihm zunehmend klar geworden sei während der letzten Arbeitswochen, sei der schwankende Boden, auf dem diese Gestrauchelten stünden, die enorme Unsicherheit, was werden wird, was kommen wird. Wie im Roman von Döblin, wie bei Franz Biberkopf in Berlin der zwanziger Jahre. Und dieser schwankende Boden, den diese Leute besonders spüren, "hat viel mit unserer Zeit zu tun. Man kann hinschauen, wo man will, wer weiß schon, wie es weitergeht." Die Zeit, 10.12.2009165

In einer schwierigen Situation befindet sich ebenfalls ein heranwachsendes Mädchen, das unerwartet vor erwachsene Probleme gestellt wird:

165 Alle im Folgenden angeführten deutschsprachigen Gebrauchsbelege entstammen den DWDS-Korpora und wurden nach den im Unterkap. 4.1.2.2.2.1 beschriebenen Kriterien im Zeitraum 2014-2017 erhoben. 
(2) Sie ist hin- und hergerissen zwischen Schamgefühl und der Liebe zu ihrem Vater. Ihre bürgerliche Erziehung entpuppt sich als wertlos. „Sie hat kein Lebensrüstzeug, um auch auf schwankendem Boden überleben zu können“, so Sabine Becker. „Else erfährt ihre tiefe Einsamkeit und erlebt einen Reifungsprozess." Der Untertitel des Stückes könnte heißen: ,Der Tod der Träume? Die Geschichte einer Emanzipation;, so Regisseur Wilke. Der Einblick in die Denkweise des quirligen und auch eingebildeten jungen Mädchens lockert die Tragik des Stücks auf. Else ist selber geprägt von der verlogenen Gesellschaft, an der sie leidet. So schwankt der Zuschauer zwischen Schadenfreude und Mitleid. Berliner Zeitung, 07.03.1995

Im politischen Bereich bezieht sich der schwankende Boden auf die schwierige Lage eines Politikers, dem die politische Unterstützung in der Partei, im Parlament usw. entzogen wird:

(3) „Der Supreme Court hat Obamas illegalen Machtmissbrauch gestoppt. Er hat gezeigt, auf welch schwankendem Boden der Präsident jedes Mal steht, wenn er seine Politik gegen die Abgeordneten des Volkes machen will." Vom weltweiten Ausstoß von Treibhausgasen verursacht China vor allem wegen seines starken Wirtschaftswachstums fast ein Drittel. Die Zeit, 10.02.2016 (online)

Die Bedeutungskonstituierungsmechanismen sind auf zwei Ebenen angesiedelt: Auf der ersten Ebene unterliegt der Bedeutungsderivation die ganze Wortverbindung, auf der zweiten Ebene ist jeweils eine Idiom-Konstituente von der Bedeutungsverschiebung betroffen. Die konzeptuellen und epistemischen Metaphern der ersten Ebene werden in diesem Fall also durch die metonymisch-metaphorischen Derivationsketten auf der zweiten Ebene unterstützt (vgl. Abb. 31).

Den Konzeptualisierungen des schwankenden Bodens liegen in den angeführten Verwendungsbelegen mehrere konzeptuelle Metaphern zugrunde. Einen wichtigen Beitrag leisten hier die bereits besprochenen Metaphern LEBEN IST EIN WEG, SCHWIERIGKEITEN SIND HINDERNISSE AUF DEM WEG, von Relevanz sind allerdings auch weitere, z.T. auf image schemas aufbauenden Metaphern.

Die konzeptuellen Metaphern SICHERHEIT IST STABILER BODEN/SCHWIERIGE LAGE IST UNSICHERER BODEN sind stark embodied, wahrscheinlich schon in frühesten ontogenetischen Erfahrungen verkörpert. Sie bauen auf dem grundlegenden, an die Erfahrung der Schwerkraft gebundenen Vorstellungsschema (image schemas) GLEICHGEWICHT ${ }^{166}$ (BALANCE), zu dessen Allgegenwärtigkeit Johnson schreibt:

166 Das Vorstellungsschema GLEICHGEwicht ist - wie die Studie von Baldauf (1997: 177179) zeigt - ebenfalls für die Konzeptualisierung der Ausgewogenheit in den Diskursbereichen: Recht, psychische Verfassung und Macht ausschlaggebend. 
The experience of balance is so pervasive and absolutely basic for our coherent experience of our world, and for our survival in it, that we are seldom ever aware of its presence. We almost never reflect on the nature and meaning of balance, and yet without it our physical reality would be utterly chaotic, like the wildly spinning world of a very intoxicated person. The structure of balance is one of the key threads that holds our physical experience together as a relatively coherent and meaningful whole. (Johnson 1987: 74)

Ebene 1

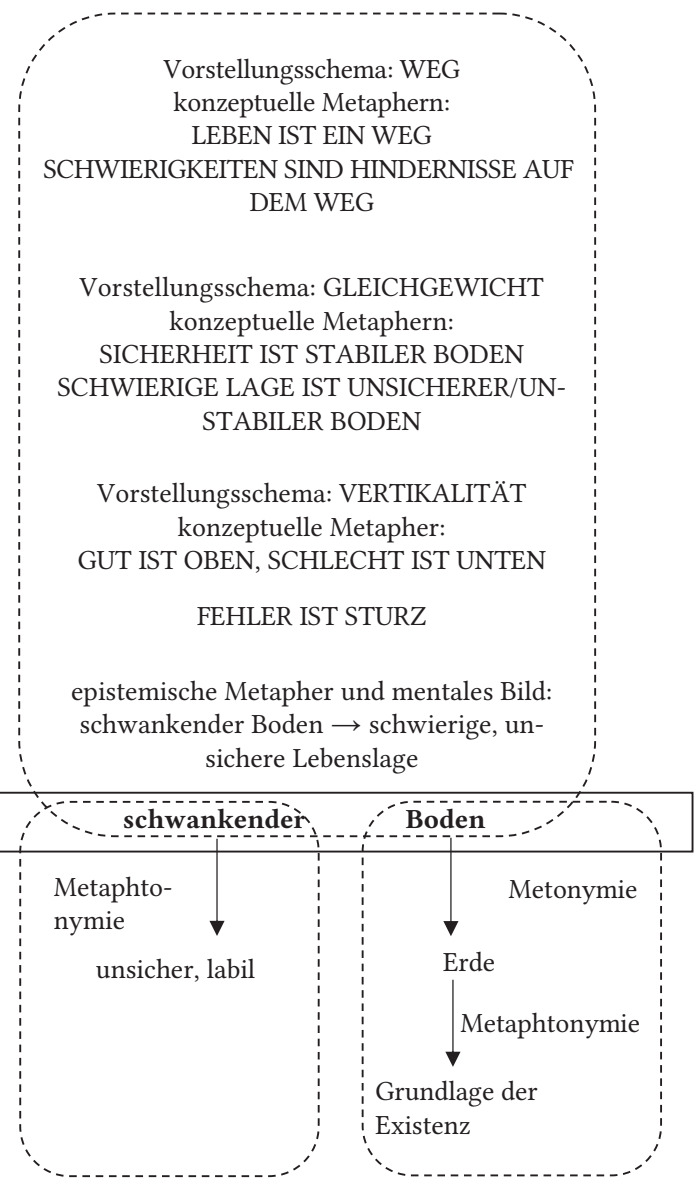

Abb. 31: Bedeutungskonstituierungsmechanismen für das Verwendungsmuster 1.1 , unsichere, schwierige (Lebens-)Lage eines Menschen: 
Das Halten des Gleichgewichts stellt eine der Grundfunktionen des menschlichen Organismus dar, die meistens unbewusst ist und erst in bestimmten Situationen: bei Schifffahrten, insbesondere bei starkem Wellengang, bei Schwindelgefühlen oder nach dem Karussellbesuch wahrgenommen wird. Da das Erfahren der Unstabilität von Boden verursacht, dass sich die Menschen verunsichert, nicht gut in der Welt verankert fühlen, wird der schwankende Boden mit der Gefahr, Bedrohung assoziiert. Das Metaphernpaar SICHERHEIT IST STABILER BODEN/SCHWIERIGE LAGE IST UNSICHERER BODEN weist, wenigstens in den europäischen Sprachen, eine gewisse Universalität auf und manifestiert sich sprachlich in zahlreichen festen Wortverbindungen, vgl. z.B. die deutschen, polnischen und englischen Idiome:

SICHERHEIT IST STABILER BODEN, SCHWIERIGE LAGE IST UNSICHERER BODEN jmdm. wird der Boden [unter den Füßen] zu heiß; jmdm. brennt der Boden unter den Füßen ,jmdm. wird es an seinem Aufenthaltsort zu gefährlich' (DUW online, Zugriff am 20.10.2017) ${ }^{167}$; poln. grunt się pali komuś pod nogami [wörtl. 'jmdm. brennt der Boden unter den Füßen']

festen Boden unter den Füßen haben, eine sichere wirtschaftliche Grundlage haben“ (DUW online, Zugriff am 20.10.2017), poln. stać na pewnym, twardym gruncie [wörtl. 'auf dem festen, sicheren Boden stehen']

jmdm. den Boden unter den Füßen wegziehen, jmdn. seiner [Existenz]grundlage berauben' (DUW online, Zugriff am 20.10.2017); engl. to cut the ground from under sb's feet den Boden unter den Füßen verlieren, die [Existenz]grundlage verlieren; haltlos werden' (DUW online, Zugriff am 20.10.2017); poln. ziemia usunęła się komuś spod nóg [wörtl. 'der Boden sank unter jmds. Füßen']

wie auf einem Vulkan leben ,sich in ständiger Gefahr befinden' (DUW online, Zugriff am 20.10.2017), engl. sit on a vulcano

ein Tanz auf dem Vulkan, eine unbekümmerte Lebensweise in gefährlichen Umständen, trotz Bedrohung feiern' (redensarten-index, Zugriff am 20.10.2017)

auf einem/dem Pulverfass sitzen, sich in einer spannungsreichen, gefährlichen Lage befinden' (DUW online, Zugriff am 20.10.2017), engl. sitting on a powder keg, poln. beczka prochu [wörtl. 'Pulverfass']

sich auf unsicheren/schwankenden Boden begeben, sich auf unsicherem/schwankendem Boden bewegen/befinden, poln. wchodzić na grząski grunt [wörtl. 'sich auf den morastigen Boden begeben'], engl. be on safe ground, be on dangerous ground.

167 Die sprachlichen Manifestationen zu den konzeptuellen Metaphern sowie die Bedeutungsparaphrasen von Phraseologismen bzw. übertragenen Lexem-Bedeutungen entstammen dem Universalwörterbuch DUDEN online (www.duden.de, im Weiteren als DUW online markiert), dem phraseologischen Internet-Wörterbuch redensarten-index (www.redensarten-index.de, im Weiteren als redensarten-index gekennzeichnet), dem lexikographischen Teil des DWDS, dem DWDS-Wörterbuch (dwds.de/wb, im Weiteren DWDS-Wörterbuch) sowie den Korpora des DWDS (im Weiteren als DWDS angeführt). Sie wurden in dem Zeitraum 03.10.2015-30.11.2017 erhoben. Nicht markierte Exemplifizierungen werden von der Autorin hinzugefügt. 
einen Seiltanz vollführen, eine unsichere Sache tun; vorsichtig sein; eine heikle/schwierige/gefährliche Sache bewältigen; Gegensätze ausgleichen müssen; zwischen zwei oder mehreren Extremen vermitteln müssen ' (redensarten-index, Zugriff am 20.10.2017) ein heißes Pflaster, eine gefährliche Umgebung ${ }^{\prime 168}$ (redensarten-index, Zugriff am 20.10.2017)

sich auf Glatteis bewegen ,in einer heiklen, unsicheren Lage sein; gefährdet sein“ (redensarten-index, Zugriff am 20.10.2017). engl. be skating on thin ice, on thin ice aufs Glatteis geraten, sich aufs Glatteis begeben, in eine unsichere Situation geraten; sich in eine heikle Lage manövrieren' (redensarten-index, Zugriff am 20.10.2017) sich auf glattes Parkett wagen ,sich in eine unsichere, heikle Lage manövrieren“ (redensarten-index, Zugriff am 20.10.2017)

Außer den bereits besprochenen konzeptuellen Metaphern: SICHERHEIT IST STABILER BODEN, SCHWIERIGE LAGE IST UNSICHERER BODEN kommt hier ebenfalls die STURZ-Metapher (FEHLER/SCHEITERN IST STURZ) zur Geltung, die sich sprachlich u.a. in folgenden Nomen, polysemen Bewegungsverben, Idiomen sowie Verb-Nomen-Verbindungen, die literal oder übertragen gebraucht werden können, manifestiert.

\section{FEHLER/SCHEITERN IST STURZ}

Durch den doppelten Ausrutscher bei den Schwaben rutschten die Kiezkicker wieder auf den letzten Tabellenplatz ab. Die Zeit, 27.04.2015 (DWDS, Zugriff am 27. 02. 2017) Dahler bezeichnete seine Entgleisung als „Reaktion auf eine persönliche Beleidigung“. Berliner Zeitung, 26.11.2005 (DWDS, Zugriff am 27. 02. 2017)

Die Mannschaft ist gegen einen Außenseiter gestrauchelt. (DUW online, Zugriff am 20.10.2017)

Mancher [dieser jungen Bürger] strauchelt und wird kriminell. Neue fustiz 1968 (DWDS, Zugriff am 20.10.2017)

Ihr erster Film floppte, und ihre Musik verkaufte sich nur noch mäßig. Die Welt, 27.12.2005 (DWDS, Zugriff am 20.10.2017)

Die Klinikleitung bringt sich durch Behauptungen ins Schleudern, die von Untersuchungen widerlegt werden. Die Zeit, 04.07.2015 (DWDS, Zugriff am 27. 02. 2017) Sie haben diesmal einen Fehltritt begangen.

„Spekulanten flogen mit Euro-Wetten auf die Nase“ (redensarten-index, Zugriff am 20.10.2017)

„Wer als Käufer mit seinem Darlehen nicht auf dem Bauch landen will, muss sich Fachwissen aneignen“. (redensarten-index, Zugriff am 20.10.2017)

durch einen Skandal zu Fall kommen, gestürzt werden, scheitern' (DUW online, Zugriff am 20.10.2017)

Sie ist durch die Prüfung gefallen.

168 In einer genaueren, korpusbasierten Analyse lassen sich auch andere Teilbedeutungen ermitteln, vgl. Sulikowska 2015b, 2015c. 
In beiden konzeptuellen Metaphern: SICHERHEIT IST STABILER BODEN, FEHLER IST STURZ ist der Einfluss der Orientierungsmetapher GUT IST OBEN, SCHLECHT IST UNTEN unverkennbar. Der bereits erwähnten Orientierungsmetapher (vgl. u.a. Kap. 2.3.2) liegt das Vorstellungsschema Verticality (VERTIKALITÄT) zugrunde. Die Polarität UnTEN-OBEN ist eines der Urgegensätze, die physisch in dem Körper, kulturell u.a. in der Mythologie, religiös in der Bibel verankert sind: Eine Aufspaltung zwischen der geistigen Lebenssphäre und der elementaren Bindung an die uns Nahrung liefernde Erde, der Sehnsucht, nach Sternen zu greifen und der täglichen Mühe der Existenzsicherung, den mentalen und den körperlichen Prozessen fühlen die meisten Menschen intuitiv. In der christlichabendländischen Kultur wird dem Kopf das Denken, dem Herzen das Fühlen, dem am niedrigsten liegenden Bauch die Triebzone sowie die niederen Affekte zugeordnet. In vielen Schöpfungsmythen beginnt die Welt mit der Aufteilung einer ursprünglichen Einheit in den oberen (geistigen) und unteren (materiellen, physischen) Bereich: Himmel und Erde, Seele und Körper. Das Materielle, Irdische, Fleischliche, Triebhafte wird mit dem Körper verbunden, es ist unten, auf der Erde. Der Mensch ist aus Erde und wird zu Erde („Denn du bist Erde und sollst zu Erde werden“ Genesis 3, 19). Unten, in der naiven Vorstellung unter der Erde, ist auch die (unerträglich heiße, vom Feuerfluss beherrschte) Hölle, der Ort der ewigen Verdammnis, sowie - in Mythen, Sagen und Märchen - Unterwelten, die von finsteren Mächten regiert sind, z.B. der Olymp und der Hades in der griechischen Mythologie. Den edlen Geist assoziieren wir dagegen mit Himmel, mit Positivem, die Berge werden in vielen Religionen und Mythologien als Orte aufgefasst, wo man dem Transzendentalen, dem Göttlichen, der Erleuchtung begegnen kann. Die Dichotomie oBEN-UnTEN widerspiegelt sich in der Sprache (z.B. oben sein, auf der Höhe sein, in Höchstform sein), aber auch in der weit gefassten Kultur (z.B. in der Architektur: hohe, in den Himmel ragende Kirchentürme). Im idiomatischen Bereich lässt sich die GUT IST OBEN, SCHLECHT IST UNTEN-Metapher u.a. durch folgende Phraseologismen aus dem elektronischen phraseologischen Wörterbuch redensarten-index (Zugriff am 25.02.2017) exemplifizieren:

GUT IST OBEN, SCHLECHT IST UNTEN

mit etw. eine Notlandung machen, scheitern“

auf die schiefe Bahn/Ebene geraten,moralisch oder wirtschaftlich absinken; kriminell werden; auf Abwege geraten'

jmdn. auf die schiefe Bahn bringen,jmdn. zu einer kriminellen Laufbahn führen; jmds. Irrwege verursachen"

auf Grund laufen ,1. mit dem Boot/Schiff auf dem Meeres-/See-/Flussboden aufsitzen und somit festsitzen; 2. scheitern'

auf die Schnauze/auf die Fresse/auf die Nase fallen ,scheitern

auf der Schnauze/Fresse/Nase liegen ,Pech haben, gescheitert sein“

im Aufwind sein,wachsenden Erfolg haben“

Kopf hoch ,Hab Mut!, Sei nicht traurig! 
den Kopf hängen lassen, deprimiert, traurig, resigniert, mutlos, enttäuscht sein die Oberhand gewinnen/haben/behalten ,der Stärkere sein, gewinnen“ (total/völlig) am Boden (zerstört) sein ,sich miserabel/schlecht/elend/erschöpft fühlen; deprimiert/besiegt sein'

mit den Nerven herunter/runter sein, geistig erschöpft/überlastet sein; deprimiert sein jmds. Stern ist im Aufgehen, jmds. Ruhm wächst; jd. hat Erfolg

den Mut sinken lassen, die Hoffnung aufgeben, keinen Ausweg sehen, keine Anzeichen für Besserung mehr sehen; mutlos/pessimistisch/deprimiert sein“

vgl. auch folgende Kollokationen und Verben:

die höheren Beamten

die hochgestellte Persönlichkeit

eine Sache auf höchster Ebene beraten

niedrig gesinnt sein

niedrige Triebe

den Aufstieg schaffen

jmdn. übertreffen, überbieten

emporkommen, emporsteigen

etw. toppen ,etw. überbieten, übertreffen' (redensarten-index, Zugriff am 20.10.2017)

Die dargestellten konzeptuellen Metaphern sind für die Konzeptualisierung richtungsweisend, von Relevanz sind aber ebenfalls epistemische Mappings, die bei den meisten Sprachteilhabern durch das mentale Bild eines schwankenden Bodens (eines Schiffes, eines Moors) untermauert sind. Die epistemischen Mappings könnten auf folgende Weltwissensinformationen zurückgreifen (Tab. 12):

Tab. 12: Die epistemischen Mappings für das Verwendungsprofil 1.1, unsichere, schwierige (Lebens-)Lage eines Menschen:

\section{schwankender Boden (Ausgangsdomäne)}

Unsicherer Boden, auf dem man keinen Halt mehr hat und leicht hinfallen kann.

Gleichgewichtssinn ist gestört, die Füße sind wacklig, die Umgebung sieht man verschwommen, man steht oder geht unsicher.

\section{unsichere, schwierige Lage eines Menschen (Zieldomäne)}

Schwierige Lage eines Menschen, in der man leicht einen Fehler begehen kann.

Die objektive Beurteilung der Lage kann schwer sein, man handelt (u.a. unter dem Einfluss der Emotionen) fehlerträchtig.

Die Empfindungen sind unangenehm, man Die Situation ist für den Betroffenen fühlt sich kraftlos, man fühlt die Übelkeit in unangenehm, schwierig, man leidet unter sich aufsteigen. Stresssymptomen. 
Auf der zweiten Ebene leisten die Bedeutungsderivationen der nominalen und der adjektivischen Komponente einen Beitrag zur Bedeutungskonstituierung bei. Der semantischen Derivation von Boden liegt eine metonymisch-metaphorische Kette zugrunde: Im ersten Schritt steht der Boden metonymisch für die Erde, diese metonymische Verschiebung ist konventionalisiert und lexikographisch ${ }^{169}$ erfasst. Im zweiten Schritt liegt eine Metaphtonymie vor: Der Boden/die Erde steht hier nämlich für die Grundlage der Existenz. Je nach der Auslegung könnte man an dieser Stelle von einer Metonymie oder einer Metapher sprechen. Die für die Metonymie charakteristische konzeptuelle Nähe zwischen dem Boden und der Existenzgrundlage aller auf festem Land lebenden Wesen ist hier offensichtlich. Andererseits beziehen sich die Existenzgrundlagen in den besprochenen Belegen nicht unbedingt auf die körperlichen Daseinsfundamente: Im Beleg (1) handelt es sich sowohl um die materielle Absicherung der freigelassenen Gefängnisinsassen (zwischen der körperlichen und der materiellen Existenzsicherung besteht hier konzeptuelle Nähe, die als die Zugehörigkeit zu einer Domäne ausgelegt werden dürfte), als auch um ihre psychische Durchhaltekraft, der Versuchung widerzustehen, sich mit den kriminellen Mitteln wieder einen schnellen und einträglichen Unterhalt zu sichern (in dieser Interpretation müssten zwei Domänen: die physische Domäne der Existenzgrundlage und die Domäne der psychologischen Konstitution eines Menschen angenommen werden). In weiteren Belegen liegt eher eine Metapher vor: Die nominale Konstituente im Gebrauchsbeleg (2) bezieht sich auf die harten Regeln, die in einer realen Welt herrschen und zu den bürgerlich-moralischen Werten, die einem verwöhnten jungen Mädchen beigebracht wurden, im krassen Widerspruch stehen. Im dritten Beleg ist die politische Basis eines Präsidenten, seine Position unter anderen Politikern gemeint. Dementsprechend dürfte in diesen Belegen von zwei unterschiedlichen Domänen ausgegangen werden, von denen die Ausgangsdomäne im Bereich der körperlichen Erfahrung, die Zieldomäne dagegen im abstrakteren Bereich des Lebensunterhalts, der Moral, der Politik liegt. Ähnliche fließende Übergänge zwischen der Domäne des Körperlichen und der Domäne des Abstrakteren kommen in weiteren sprachlichen Exemplifizierungen zum Vorschein:

BODEN/ERDE STEHT FÜR DIE GRUNDLAGE DER EXISTENZ//GRUNDLAGE DER EXISTENZ IST WIE BODEN/ERDE

(wieder) (festen) Boden unter den Füßen haben/spüren 1. ,wieder festes Land unter den Füßen haben' (DUW online, Zugriff am 10.03.2017), 2. ,(wieder) sicher/selbstsicher/ gestärkt/fundiert/gesichert sein; sich erholen; sich sicher fühlen' (redensarten-index, Zugriff am 10.03.2017)

den Boden für jmdn./etw. vorbereiten, günstige Bedingungen schaffen' (DUW online, Zugriff am 10.03.2017)

169 Vgl. DUW online: Boden: ,1. Erdreich, Erde; 2. Grundfläche im Freien oder in einem Innenraum; 3. Grundlage; 4. Gebiet; 5. unterste Fläche von etwas; 6. Kurzform für Tortenboden; Kurzform für Dachboden', Zugriff am 13.07.2017. 
günstigen, guten Boden für etw. finden, günstige, gute Voraussetzungen ' (DUW online, Zugriff am 10.03.2017)

einer Sache den Boden bereiten; den Boden bereiten für etw. ,Grundlage/günstige Bedingungen für etw. schaffen; etw. vorbereiten' (DUW online, Zugriff am 10.03.2017) einer Sache den Boden entziehen, einer Sache die Existenzgrundlage entziehen; dafür sorgen, dass eine Sache nicht mehr sachlich begründet werden kann' (DUW online, Zugriff am 10.03.2017)

Eine weitere Bedeutungsverschiebung lässt sich in Bezug auf die partizipiale Idiomkonstituente schwankend festlegen. Das Verb schwanken unterliegt auf Grund der verkörperten Erfahrung einer metonymischen oder metonymisch-metaphorischen Derivation und wird - mit Abstufungen - aus der Domäne des torkelnden Ganges, des entzogenen Halts, über die psychologischen Gemütszustände der verspürten Labilität in die abstrakten Domänen der unstabilen, unsicheren Lage z.B. auf dem Arbeitsmarkt übertragen. Davon, dass diese Mappings einen konzeptuellen Charakter haben, zeugen folgende sprachliche Exemplifizierungen:

SCHWANKEN STEHT FÜR UNSICHER SEIN/UNSICHER, LABIL SEIN IST SCHWANKEN auf der Kippe stehen ,1. zu kippen und herunterzustürzen, umzufallen drohen: die Tasse steht fast auf der Kippe. 2. gefährdet sein, sich in einer kritischen Lage, Situation befinden: drei Schüler der Klasse stehen auf der Kippe; der Kranke steht, mit dem Kranken steht es auf der Kippe. 3. noch unsicher, noch nicht entschieden sein: ob sie wiedergewählt wird/ihre Wiederwahl steht auf der Kippe‘ (DUW online, Zugriff am 21.03.2017)

Auf den ersten Metern fahre ich noch etwas unsicher, denn der BMW-Roller ist sehr kippelig. Bild, 29.05.1998 (DWDS, Zugriff am 04.10.2017)

Dabei ist Macht natürlich nicht greifbar, kein Ding, kein Ring, sondern ein höchst kippeliger Zustand. Die Zeit, 16.11.2006 (DWDS, Zugriff am 04.10.2017)

ein schwankender (,nicht in sich gefestigter') Charakter (DUW online, Zugriff am 21.03.2017)

nicht wanken und [nicht] weichen, nicht von der Stelle weichen' (DUW online, Zugriff am 20.10.2017)

sein Gesundheitszustand ist schwankend, eine schwankende Gesundheit (DUW online, Zugriff am 20.10.2017)

sich durch nichts in seinem Vorsatz schwankend machen lassen (DUW online, Zugriff am 21.03.2017)

die Monarchie, seine Stellung begann zu wanken (DUW online, Zugriff am 21.03.2017) in seinem Glauben, seinen Entschlüssen wanken, wankend werden (DUW online, Zugriff am 21.03.2017)

wackelige Arbeitsplätze (DUW online, Zugriff am 21.03.2017)

um die Firma steht es recht wackelig , sie ist vom Bankrott bedroht' (DUW online, Zugriff am 21.03.2017)

er steht in der Schule sehr wackelig, seine Versetzung ist gefährdet' (DUW online, Zugriff am 21.03.2017)

seine Stellung, sein Arbeitsplatz wackelt (DUW online, Zugriff am 21.03.2017) 
der Thron des Chefs wackelt, er droht seinen Posten zu verlieren` (DUW online, Zugriff am 21.03.2017)

jd. ist wankelmütig, haltlos

eine wackelige Angelegenheit, Argumentation, Finanzierung (DUW online, Zugriff am 21.03.2017)

Verwendungsmuster 1.2: (Forschung/Wissenschaft) ,unsichere, angreifbare Lage, in die sich ein Wissenschaftler versetzt, der in einem nicht gut etablierten Forschungsbereich tätig ist bzw. intersubjektiv schwer fassbare These aufstellt' (5 Belege)

In einer perfektiven (sich mit etw. auf den schwankenden Boden begeben) bzw. durativen Aktionsart (sich auf schwankendem Boden bewegen) tritt die idiomatische Wortverbindung in Belegen auf, die sich auf wissenschaftliche Tätigkeit beziehen. Hier werden als schwankender Boden diejenigen Forschungsbereiche bezeichnet, die mit objektiven Kriterien schwer fassbar sind, subjektive Forschungsmethoden voraussetzen und deswegen leicht widerlegt werden können:

(4) Leider hat er aber dazu die sichere Basis der meßbaren Hirnchemie verlassen und sich auf den schwankenden Boden psychischer Phänomene begeben müssen. Berliner Zeitung, 29.08.1998

(5) Wir dürfen wohl noch einen Schritt weitergehen und den Erklärern folgen, die annehmen oder nachgewiesen zu haben glauben, daß das Wort Snob an der Universität Cambridge entstand. Etwa so (jetzt bewegen wir uns freilich als Philologen auf schwankendem Boden): Die adeligen Studenten nannten zunächst den bürgerlichen Kommilitionen „sine nobilitate“ und kürzten das zu „snob“. Die Zeit, 02.11.1979

Die Bedeutungskonstituierungsmechanismen vollziehen sich auf zwei Ebenen: Die für die erste Ebene konstitutiven konzeptuellen Metaphern: SICHERHEIT IST STABILER BODEN; FEHLER IST STURZ; GUT IST OBEN, SCHLECHT IST UNTEN wurden im Vorangehenden erörtert und bedürfen an dieser Stelle keiner näheren Beschreibung. Viele Gemeinsamkeiten mit dem Verwendungsmuster 1.1 scheinen ebenfalls die epistemischen Mappings aufzuweisen (vgl. Tab. 12). Neu und konstitutiv für das $\mathrm{zu}$ besprechende Verwendungsmuster ist dafür die metonymisch-metaphorische Kette: Boden $\rightarrow$ Gebiet $\rightarrow$ Forschungsbereich.

Die metonymische Derivation Boden $\rightarrow$ Gebiet ist konventionalisiert, lexikographisch erfasst und im DUW online mit folgenden Beispielen veranschaulicht: heiliger Boden, den Boden seiner Heimat betreten (Zugriff am 11.03.2017). Die Bedeutungsverschiebung Boden $\rightarrow$ Gebiet manifestiert sich sprachlich auch in folgenden Idiomen, die zugleich den kontinuierlichen Übergang zwischen der Metonymie und Metapher vor Augen führen:

BODEN STEHT FÜR GEBIET

[an] Boden gewinnen, sich ausbreiten, zunehmen' (DUW online, Zugriff am 20.10.2017) Boden gutmachen, wettmachen, aufholen, Fortschritte machen' (DUW online, Zugriff am 20.10.2017)

[an] Boden verlieren ,Macht, Einfluss verlieren“ (DUW online, Zugriff am 20.10.2017) 
Konventionalisiert ist ebenfalls die Bedeutungsverschiebung Gebiet $\rightarrow$ Forschungsbereich, vgl. die Teilbedeutung 2 im DUW online (Zugriff am 11.03.2017):

1. unter bestimmten Gesichtspunkten in sich geschlossener räumlicher Bereich von größerer Ausdehnung

2. [Sach]bereich, Feld, Fach

Auch in diesem Fall ist die Entscheidung, ob in der zweiten Bedeutung eine Metonymie EIN GEBIET STEHT FÜR EINEN FORSCHUNGSBEREICH oder eine Metapher EIN FORSCHUNGSBEREICH IST (WIE) EIN GEBIET vorliegt, schwer. Da die Erfahrungsdomänen des Raumes sowie des in den Gebrauchsbelegen angesprochenen Forschungsbereiches konzeptuell entfernt sind, wird in diesem Fall eine metaphorische Bedeutungsverschiebung angenommen.

Von einem kleineren Einfluss auf die Konzeptualisierung scheint eine andere metonymisch-metaphorische Kette zu sein, die folgendermaßen dargestellt werden könnte:

$$
\text { Boden } \rightarrow \text { Erde } \rightarrow \text { Realitätssinn }
$$

Die metonymische Verschiebung Boden $\rightarrow$ Erde ist in dem Verwendungsprofil 1.1 bereits aufgetreten. Die metaphorischen Mappings zwischen der Erde und dem Realitätssinn, dem gesunden Menschenverstand manifestieren sich sprachlich in folgenden Ausdrücken:

REALITÄTSSINN IST AUF DER ERDE/AUF DEM BODEN BLEIBEN mit beiden Beinen/Füßen (fest) auf der Erde/im Leben/auf dem Boden stehen, lebenstüchtig sein; sicher im Leben zurechtkommen; keine Illusionen haben; normal bleiben; realistisch denken; pragmatisch/erfolgreich/solide/sicher sein' (redensartenindex, Zugriff am 14.03.2017)

auf der Erde/dem Boden bleiben ,sich keinen Illusionen hingeben; realistisch/pragmatisch denken; besonnen sein' (redensarten-index, Zugriff am 14.03.2017)

jd. ist hochfliegend, weltentrückt, weltfremd

in höheren Sphären schweben, seinen Träumen nachhängen; weltfremd/versponnen sein; Akademiker/Intellektueller sein, der nichts mehr vom wahren Leben mitbekommt' (redensarten-index, Zugriff am 14.03.2017)

jmdn. auf den Boden der Tatsachen zurückholen,jmdm. die Tatsachen bewusst machen/ die Sachlage erklären/die Realität klarmachen“

auf dem Boden der Tatsachen bleiben, die Wahrheit sagen, nicht hinzudichten' (redensarten-index, Zugriff am 14.03.2017)

auf festem Boden stehen, eine gesicherte Meinung haben; sicher sein' (redensartenindex, Zugriff am 14.03.2017)

sich auf sicherem Boden bewegen/befinden, eine gesicherte Meinung vertreten; sicher sein; gute Voraussetzungen haben' (redensarten-index, Zugriff am 14.03.2017)

Die Abbildung 32 stellt beide Ebenen von den Bedeutungskonstituierungsmechanismen des Verwendungsmusters 1.2 graphisch dar: 
Ebene 1

Ebene 2

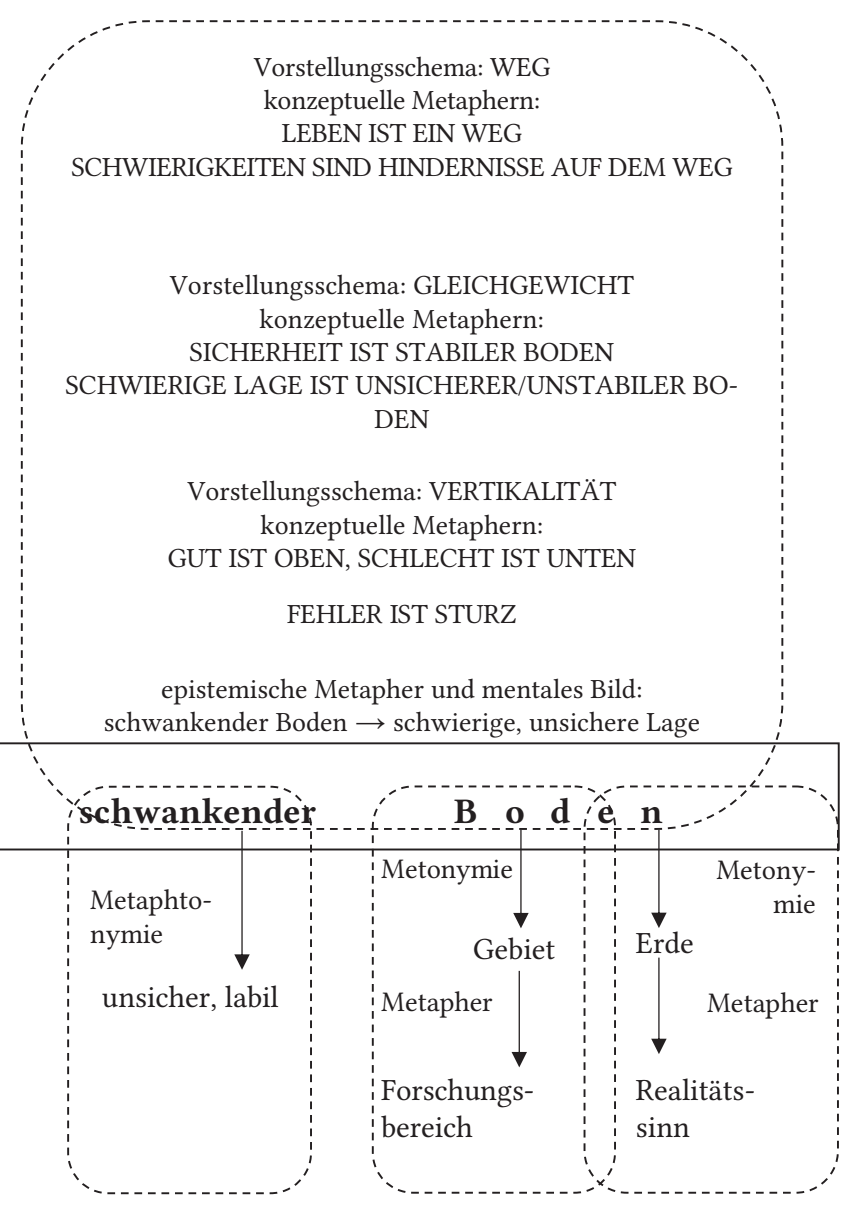

Abb. 32: Bedeutungskonstituierungsmechanismen für das Verwendungsmuster 1.2 , unsichere, angreifbare Lage, in die sich ein Wissenschaftler versetzt, der in einem nicht gut etablierten Forschungsbereich tätig ist bzw. intersubjektiv schwer fassbare These aufstellt:

Verwendungsprofil 2: ,unsichere Grundlagen/Fundamente einer Konstruktion des menschlichen Geistes (einer Theorie, einer Argumentation, einer Anklage, eines Wirtschaftsbereiches, einer bestimmten Politik) ${ }^{6}$ (10 Belege)

Im Gegensatz zu den Verwendungsmustern 1.1 und 1.2 treten in den folgenden Belegen in der Subjektposition unbelebte Objekte auf, bei denen es sich hauptsächlich 
um Konstruktionen des menschlichen Geistes: Anklagen, Hypothesen, Voraussagen, Interpretationen, Theorien u. ̈̈. handelt:

(6) Auch der renommierte Hamburger Kriminologe Professor Fritz Sack sieht eine Anklage, die hauptsächlich auf Tagebucheintragungen basiert, „auf schwankendem Boden“. Berliner Zeitung, 25.04.1997

(7) Die Voraussagen stehen nach Ansicht der Spitzenverbände vor allem deshalb auf schwankendem Boden, weil die von der Politik zugesagte deutliche Verbesserung der steuerlichen und sozialpolitischen Rahmenbedingungen nach wie vor zu wünschen übriglasse. Berliner Zeitung, 02.01.1997

In vier Belegen wird die Subjektposition durch einen Wirtschaftszweig (Filmwirtschaft, Ferienindustrie), einen Konzern bzw. die ostdeutsche Wirtschaft besetzt:

(8) Und auch Ägyptens Ferienindustrie steht auf schwankendem Boden. Die Zeit, 14.09.2015 (online)

Profiliert werden in diesen Belegen die schwachen, unsicheren Grundlagen einer Konstruktion, eines von Menschen aufgestellten Systems von Aussagen, Annahmen, Einrichtungen und Maßnahmen sowie ihr möglicher Zusammenbruch. Zur Bedeutungskonstituierung tragen zweifelsohne zwei konzeptuelle Metaphern bei: die bereits besprochene, auf dem Vorstellungsschema GLEICHGEWICHT aufbauende Metapher SICHERHEIT IST STABILER BODEN Sowie eine konzeptuelle Metapher THEORIEN (KONSTRUKTIONEN DES MENSCHLICHEN GEISTES) SIND GEBÄUDE mit der besonderen Profilierung der Fundamente: GUTE GRUNDVORAUSSETZUNGEN DIESER KONSTRUKTIONEN SIND SOLIDE FUNDAMENTE (vgl. Abb. 33).

Die konzeptuelle Metapher THEORIEN (UND ARGUMENTE) SIND GEBÄUdE wurde von Lakoff/Johnson ([1980] 2000) als Paradebeispiel einer Strukturmetapher angeführt und mit folgenden sprachlichen Konkretisierungen veranschaulicht:

THEORIEN (UND ARGUMENTE) SIND GEBÄUDE

GUTE GRUNDVORAUSSETZUNGEN EINER THEORIE SIND SOLIDE FUNDAMENTE EINES GEBÄUDES

Ist das das Fundament Ihrer Theorie?

Die Theorie muss besser untermauert werden.

Dieses Argument steht auf unsicherem Grund.

Wir brauchen weitere Fakten, damit diese Argumentation nicht in sich zusammenfällt.

Wir müssen dafür ein gutes Argument konstruieren.

Ich habe die Form meiner Argumentation noch nicht festgelegt.

Die Theorie stützt sich noch auf weitere Fakten.

Wir müssen die Theorie mit soliden Argumenten abstützen.

Die Theorie steht und fällt mit der Stärke dieses Arguments.

Die Argumentation fiel in sich zusammen.

Sie brachten seine jüngste Theorie $z$ u Fall. (Lakoff/Johnson 2000 [1980]: 59) 
Ebene 1

Vorstellungsschema: GLEICHGEWICHT konzeptuelle Metaphern

SICHERHEIT IST STABILER BODEN SCHWIERIGE LAGE IST UNSICHERER/UNSTABILER BODEN

\section{KONSTRUKTIONEN DES MENSCHLICHEN} GEISTES SIND EIN GEBÄUDE, GUTE GRUNDVORAUSSETZUNGEN DIESER KONSTRUKTIONEN SIND SOLIDE FUNDAMENTE EINES GEBÄUDES

epistemische Metapher und mentales Bild schwankender Boden $\rightarrow$ unsichere Fundamente einer Theorie

Ebene 2

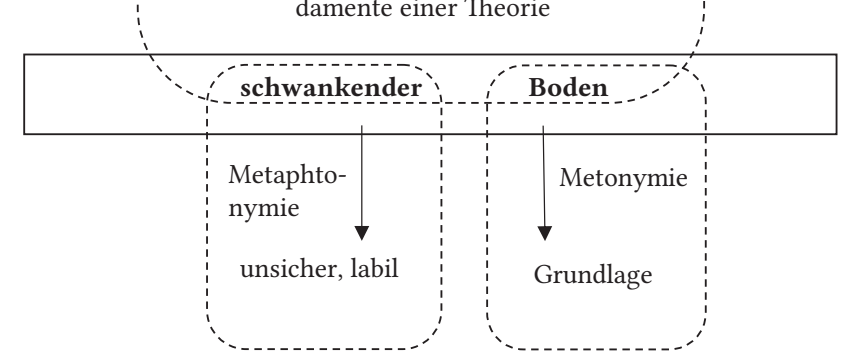

Abb. 33: Bedeutungskonstituierungsmechanismen für das Verwendungsprofil 2 ,etw. (eine Theorie, eine Argumentation, eine Anklage, die Wirtschaft) hat unsichere Grundlagen/Fundamente:

Lakoffs und Johnsons Liste kann man um weitere Idiome ergänzen, im Deutschen spricht man gelegentlich von der Bauwerk-Metaphorik ${ }^{170}$ :

THEORIEN (UND ARGUMENTE) SIND GEBÄUDE

Luftschlösser bauen ,optimistische, übermütige Pläne haben; unrealistische Träume haben' (redensarten-index, Zugriff am 20.10.2017)

auf Sand bauen ,zum Scheitern verurteilt sein; auf unsicherer Grundlage fußen; von falschen Voraussetzungen ausgehen; sich auf etwas Unsicheres verlassen' (redensarten-index, Zugriff am 20.10.2017)

aus den Fugen gehen/geraten zerbrechen, den inneren Zusammenhalt verlieren; zerfallen; durcheinander/in Unordnung geraten` (redensarten-index, Zugriff am 20.10.2017)

170 Vgl. z.B. http://www.redensarten-index.de/suche.php?suchbegriff=luftschl\%C3\% B6sser\&bool=relevanz\&gawoe $=$ an\&suchspalte[] =rart_ou (Zugriff am 18.04.2016) sowie Spieß (2011: 444-452) und Baldauf (1997: 196-202). 
der Grundstein für/zu etw. sein ,der entscheidende Ausgangspunkt/der Beginn sein“ (redensarten-index, Zugriff am 20.10.2017)

es blieb kein Stein auf dem anderen ,alles wurde komplett zerstört' (redensarten-index, Zugriff am 20.10.2017)

daran lässt sich nicht rütteln; daran ist nichts zu rütteln, das steht fest; das ist unumstößlich/unabänderlich' (redensarten-index, Zugriff am 20.10.2017)

Öde Kommentare sind wie Moder im Gebälk: leicht zu übersehen, nicht so spannend wie ein brennendes Haus, aber das Ergebnis ist dasselbe. Die Zeit, 14.04.2014 (DWDS, Zugriff am 14.03.2017)

Selbstverständlich gibt es Risse im Gebälk der iranischen Politik; seit Chomeinis Tod wogt ein untergründiger Machtkampf zwischen Reformern und Reaktionären. Die Zeit, 14.11.2013 (DWDS, Zugriff am 14.03.2017)

Außer der richtungsweisenden konzeptuellen Metapher SICHERHEIT IST STABILER BODEN sowie der mit der Bauwerk-Metaphorik verbundenen konzeptuellen Metaphern: KONSTRUKTIONEN DES MENSCHLICHEN GEISTES SIND EIN GEBÄUDE, GUTE GRUNDVORAUSSETZUNGEN DIESER KONSTRUKTIONEN SIND SOLIDE FUNDAMENTE EINES GEBÄUDES tragen zur Bedeutungskonstituierung ebenfalls das mentale Bild und die epistemischen Mappings bei (vgl. Tab. 13):

Tab. 13: Die epistemischen Mappings für das Verwendungsprofil 2 ,etw. (eine Theorie, eine Argumentation, eine Anklage, die Wirtschaft) hat unsichere Grundlagen/ Fundamente.

\section{schwankender Boden (Ausgangsdomäne)}

Schwankender Boden ist als Fundamentbasis nicht genug tragfähig, ungeeignet für die Fundamente.

\section{unsichere Fundamente/Grundlagen einer Theorie, Argumentation, eines Gesetzes (Zieldomäne)}

Eine Theorie, Argumentation, ein Gesetz, das man leicht zu Fall bringen kann; ihre Grundlagen sind nicht genug zuverlässig, sondern schlecht fundiert, durch Sachkenntnis nicht gesichert.

Argumente können jederzeit widerlegt werden, sie sind zu schwach, um verteidigt werden zu können.

Auf der zweiten Ebene unterliegt die nominale Konstituente einer metonymischen, konventionalisierten und lexikographisch erfassten Bedeutungsderivation Boden $\rightarrow$ Grundlage, vgl. DUW online (Zugriff am 14.03.2017).

BODEN STEHT FÜR DIE GRUNDLAGE

den Boden der Tatsachen verlassen

auf dem Boden der Verfassung stehen

sich auf den Boden der Wirklichkeit stellen 
Eine weitere Bedeutungsderivation vollzieht sich ebenfalls in Bezug auf die partizipiale Idiomkonstituente schwankend. Die Bedeutungsverschiebung ist durch die im Verwendungsmuster 1.1 bereits beschriebene Metaphtonymie UNSICHER SEIN IST SCHWANKEN beeinflusst.

\section{Verwendungsprofil 3: ,kein fester Boden: Schiffsdeck oder tektonisch aktive Gebiete' (6 Belege)}

In insgesamt sechs Gebrauchsbelegen referiert schwankender Boden auf Grundflächen, die unter bestimmten Umständen tatsächlich schwanken können, d.h. Schiffsdecke:

(9) Allein in Mitte haben sich im abgelaufenen Jahr 34 Paare auf schwankendem Boden trauen lassen. Berliner Zeitung, 15.01.2001

oder tektonisch unsichere Gebiete, auf denen Erdbeben und Vulkanausbrüche öfters vorkommen:

(10) Die Volkshochschule veranstaltet heute um 18.15 Uhr in der Bertolt-Brecht-Oberschule (Wilhelmstraße 10) einen kostenlosen Dia-Vortrag zum Thema „Japan - auf schwankendem Boden". Berliner Zeitung, 08.03.1995

(11) Das Geheimnis seines Fußballkönnens liegt vermutlich darin, dass der Isländer es gewohnt ist, auf schwankendem Boden zu leben und selbst im Taumeln noch den Ball $z u$ treffen. Er ist umgeben von 31 aktiven Vulkanen. Ausbrüche und Erdbeben sind für ihn so gewöhnlich wie für unsereins ein Gewitter. Gerade diese exotische, herzerfrischende Apartheit ist es, die ihm die Herzen aller zufliegen lässt. Endlich mal was anderes! Die Zeit, 07.07.2016

Die Bedeutungskonstituierungsmechanismen beruhen vor allem auf einer metonymischen Bedeutungsverschiebung: Der Aspekt einer gelegentlich wackligen, bebenden Grundfläche steht hier in einer pars-pro-toto-Metonymie stellvertretend für das ganze Land (Japan, Island) bzw. das Schiff (vgl. Abb. 34).

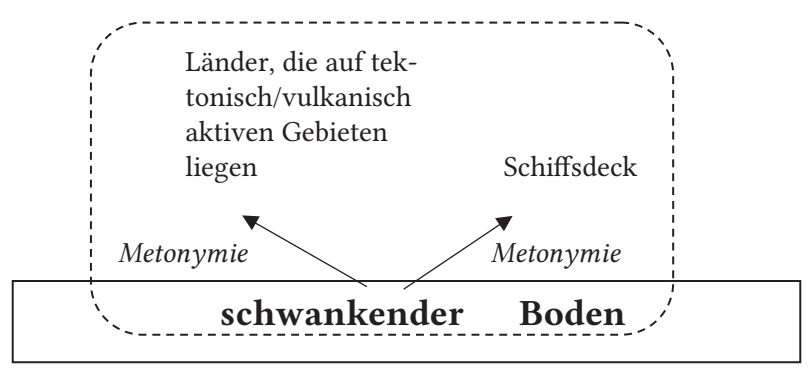

Abb. 34: Bedeutungskonstituierungsmechanismen für das Verwendungsprofil 3 , kein fester Boden: Schiffsdeck oder tektonisch aktive Gebiete: 


\subsection{2 dünnes Eis}

Lexikographisch erfasste Varianten: sich auf dünnes Eis begeben, sich auf dünnes Eis wagen, auf dünnem Eis stehen, sich auf dünnem Eis bewegen

Modifikationen: jd. wandelt auf bedenklich dünnem Eis, jd. geht auf dünnes Eis, jd. rettet sich auf das dünne Eis semantischer Spitzfindigkeiten, jd. wagt vom dünnen Eis weitere Schritte, jd. tanzt auf besonders dünnem Eis, etw. ist das dünne Eis, jd. spricht von dünnem Eis, jd. befindet sich auf dünnem Eis, auf dünnem Eis schleudern

\section{Darstellung in lexikographischen Nachschlagewerken}

Tab. 14: Das Idiom dünnes Eis in allgemeinen und phraseologischen Wörterbüchern des Deutschen.

\begin{tabular}{|c|c|c|}
\hline \multicolumn{2}{|c|}{ Wörterbuchtyp Wörterbuch } & \multirow{2}{*}{$\begin{array}{l}\text { Lexikographische Darstellung } \\
\text { nicht verzeichnet }\end{array}$} \\
\hline allgemein & DUW 2006 & \\
\hline & DUW ONLINE & $\begin{array}{l}\text { sich auf dünnes Eis begeben, wagen (sich in eine } \\
\text { unsichere, riskante Lage bringen) } \\
\text { auf dünnem Eis stehen, sich bewegen (sich in einer } \\
\text { unsicheren, riskanten Lage befinden) (letzter Zugriff } \\
\text { am 27.10.2017) }\end{array}$ \\
\hline & WAHRIG 2007 & $\begin{array}{l}\text { sich auf dünnes Eis begeben 〈fig.〉 sich einer } \\
\text { riskanten Situation aussetzen; sich auf dünnem } \\
\sim \text { bewegen }\langle\text { fig.〉 sich in einer riskanten Situation } \\
\text { befinden; keine gesicherte Grundlage haben }\end{array}$ \\
\hline \multirow[t]{4}{*}{ phraseologisch } & $\underline{\text { DUDEN } 11}$ & nicht verzeichnet \\
\hline & $\begin{array}{l}\text { SCHEMANN } \\
2011 \\
\end{array}$ & nicht verzeichnet \\
\hline & $\begin{array}{l}\text { REDENSARTEN- } \\
\text { INDEX }\end{array}$ & $\begin{array}{l}\text { sich auf dünnes Eis begeben/wagen; sich auf } \\
\text { dünnem Eis bewegen ,sich in eine riskante/kritische/ } \\
\text { unsichere Situation begeben; sich in einer gefährlichen } \\
\text { Lage befinden“ } \\
\text { Varianten der Redensart sind seit dem Mittelalter } \\
\text { geläufig. Ein Spruch aus dem 13. Jahrhundert } \\
\text { lautet: „Qui currit glaciem, se non monstrat sapientem“ } \\
\text { (= Wer auf das Eis läuft, zeigt sich nicht weise) (letzter } \\
\text { Zugriff am 27.10.2017) }\end{array}$ \\
\hline & MÜLLER 2005 & $\begin{array}{l}\text { sich auf dünnem Eis bewegen in gefährdeter und } \\
\text { unsicherer Lage sein [Gefährdung] } \\
\text { Varianten der Redensart sind seit dem Mittelalter } \\
\text { geläufig. Ein Spruch aus dem 13. Jahrhundert } \\
\text { lautet: „Qui currit glaciem, se non monstrat sapientem“ } \\
\text { „Mit dieser Theorie bewegst du dich aber auf dünnem } \\
\text { Eis! An deiner Stelle würde ich diese Prognose } \\
\text { empirisch überprüfen!“ (2005: 106) }\end{array}$ \\
\hline
\end{tabular}




\section{Korpusgestützte Analyse anhand der DWDS-Korpora ${ }^{171}$}
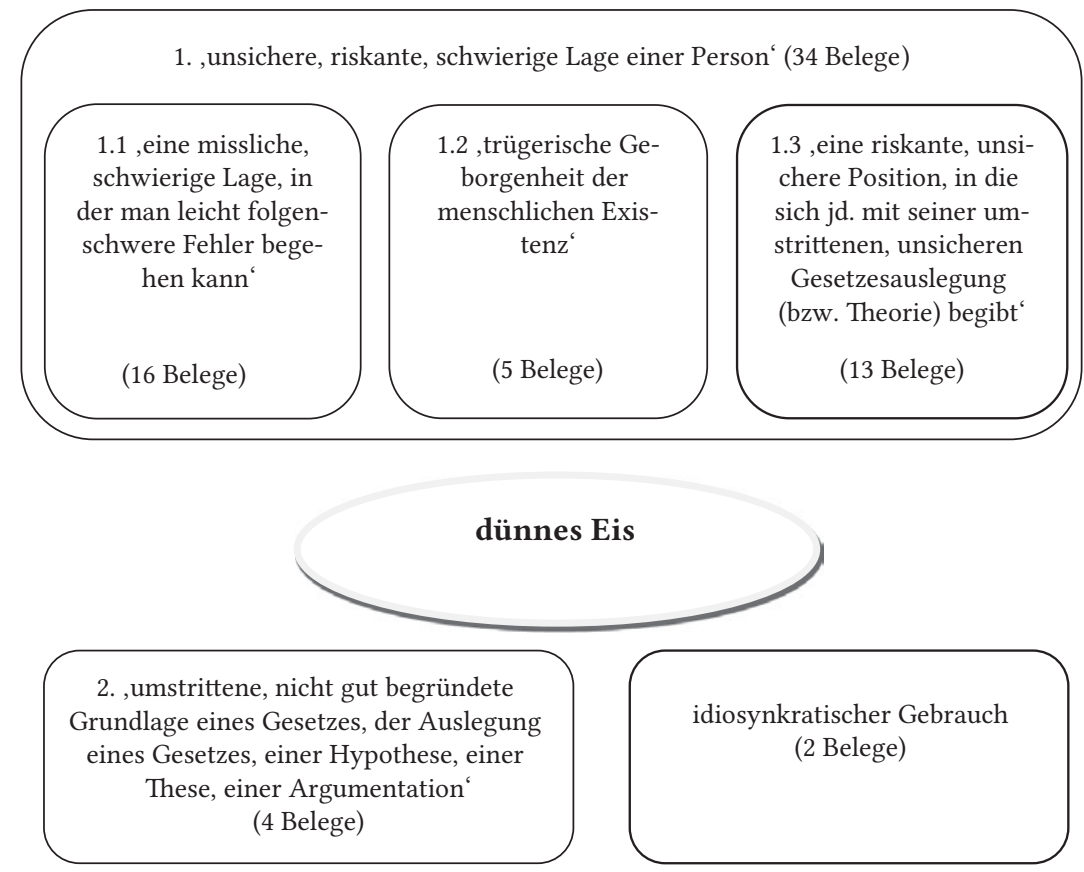

Abb. 35: Die Verwendungsprofile und-muster des Idioms ein dünnes Eis anhand der Analyse der Gebrauchsbelege im DWDS-Korpus.

Verwendungsprofil 1: ,unsichere, riskante, schwierige Lage einer Person‘ (34 Belege)

In den meisten Belegen lässt sich das Idiom mit der Bedeutungsparaphrase ,unsichere, riskante, schwierige Lage einer Person' beschreiben, wobei in der Subjektposition Menschen oder Menschengruppen auftreten. Drei Verwendungsmuster, die verschiedene Aspekte profilieren, können hier ermittelt werden:

171 Zugriffsdatum: 05.04.2016, Suchanfrage: dünnes \&\& Eis. Deutsches Textarchiv: 1/6; Kernkorpus: 1/3; Die Zeit: 15/257; Berliner Zeitung: 10/108; Der Tagesspiegel: 10/110; Potsdamer Neueste Nachrichten: 3/13. 


\section{Verwendungsmuster 1.1: ,eine missliche, schwierige Lage, in der man leicht folgenschwere Fehler begehen kann' (16 Belege)}

Das erste Verwendungsmuster bilden 16 Belege, in denen die verbale Komponente eine starke Affinität zur Varianz aufweist. Außer den lexikographisch erfassten Grundformen: $j d$. bewegt sich auf dünnem Eis, $j d$. begibt sich auf dünnes Eis, tritt das Idiom in zahlreichen phraseologischen Modifikationen auf: $j d$. wandelt auf bedenklich dünnem Eis, $j d$. geht auf dünnes Eis, $j d$. rettet sich auf das dünne Eis semantischer Spitzfindigkeiten, jd. wagt vom dünnen Eis weitere Schritte, jd. tanzt auf dünnem Eis. Die stabile nominale Komponente dünnes Eis lässt sich als eine missliche Lage interpretieren, in der man leicht einen (folgenschweren) Fehler begehen kann. In den meisten Fällen geht es um den Bereich einer beruflichen Tätigkeit, in dem die Aktanten in einer riskanten, angreifbaren Position sind. Einem großen Druck vonseiten der Öffentlichkeit waren beispielshalber die BBC-Journalisten vor dem Hintergrund des jahrelang im Geheimen gehaltenen sexuellen Missbrauchsskandals um den berühmten BBC-Moderator Jimmy Savile ausgesetzt:

(12) Wer derzeit versucht, mit BBC-Leuten zu reden, stößt auf eine Mauer des Schweigens. Ein Starmoderator sagt ein Gespräch erst zu und schickt dann die Nachricht: »Entschuldigen Sie, aber dies ist die Hölle.« Ein anderer aus der Chefetage schreibt: »Das ganze Ding ist extrem heiß und idiotisch gehandhabt... es ist alles verdammt schwierig, jeder bewegt sich auf dünnem Eis. « Meirion Jones selbst antwortet auf eine Anfrage: »Tut mir wirklich leid - würde liebend gerne reden, darf aber momentan keine Interviews geben.« »Aus Journalisten werden Geheimniskrämer und verängstigte Beamte, die bloß noch an ihre Jobs denken«, sagt Jenni Russel, die früher eine der wichtigsten Nachrichtensendungen im BBC-Radio geleitet hat. »In ihrem Inneren ist die BBC ein hierarchisches Monster, ineffizient wie ein gleichgeschalteter Staatsapparat.« Die Zeit, 08.11.2012

In einer schwierigen Lage befindet sich auch ein Politiker, der in einer heiklen, persönlichen Angelegenheit gelogen hat und sich jetzt öffentlich rechtfertigen muss:

(13) Dies wird überdeutlich in dem Interview, das sein politisches Überleben sichern soll und dann doch wieder im Meinungs-Fiasko endet. Der Mann, der eine Affäre mit der Verschwundenen erst bei der dritten Befragung durch die Polizei eingeräumt hat, gerät bei den bohrenden Fragen der TV-Reporterin schnell in die Defensive, vermeidet Klarstellungen und rettet sich auf das dünne Eis semantischer Spitzfindigkeiten, auf dem schon anerkannte Formulier-Weltmeister wie Bill Clinton ausrutschten. Der Tagesspiegel, 24.08.2001

sowie ein Politiker, dem die politische Basis in der eigenen Partei entzogen wird:

(14) Schröders größte Schwachstelle bleibt sein Verhältnis zur eigenen Partei; viele Sozialdemokraten sind überzeugt, dass die bisherigen Reformschritte sozial unausgewogen und ökonomisch bestenfalls unnnütz sind. Wie aber soll Politik die Wähler überzeugen, wenn nicht einmal die eigenen Leute daran glauben? Und wie könnte der Kanzler von so dünnem Eis aus weitere Schritte wagen? Dazu kommt die miserable 
Verfassung des Bundeskabinetts. Schröders Ministerriege ist verbraucht und unfähig zu großen Sprüngen. Berliner Zeitung, 26.03.2004

Zur Bedeutungskonstituierung tragen in diesen Gebrauchsbelegen mehrere Metaphern bei, der Bedeutungsderivation unterliegt die ganze Wortverbindung. Die Bedeutungskonstituierungsmechanismen stellt schematisch Abbildung 36 dar:

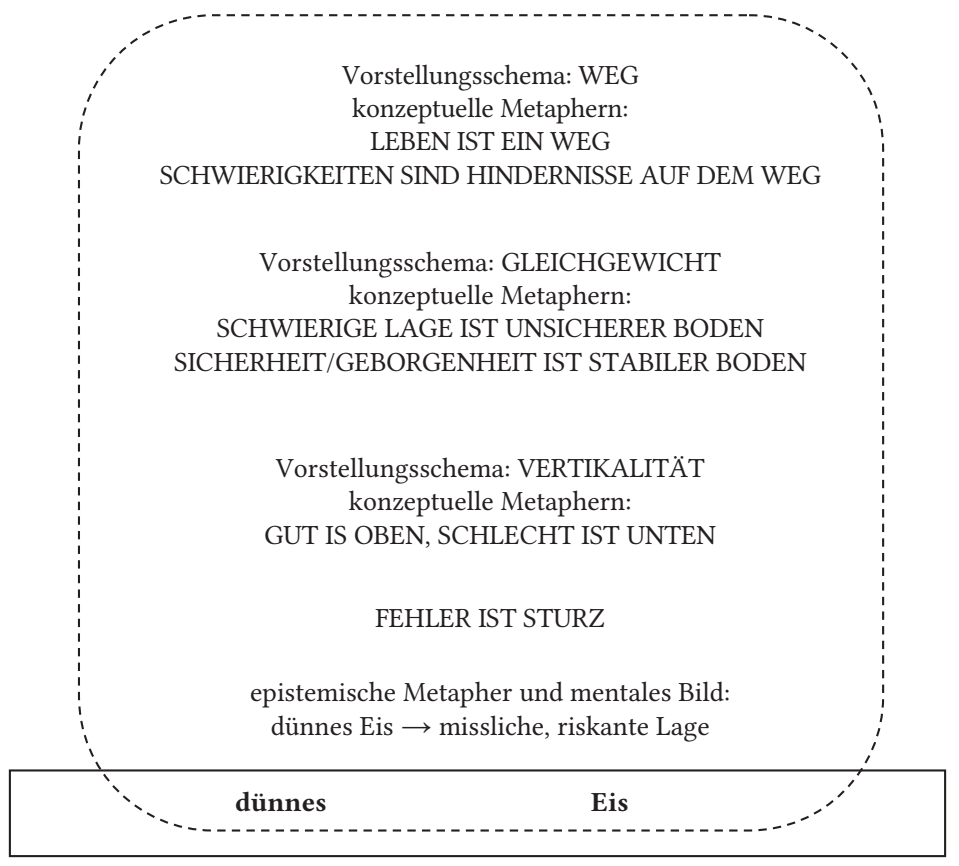

Abb. 36: Bedeutungskonstituierungsmechanismen für das Verwendungsmuster 1.1 , eine missliche, schwierige Lage, in der man leicht folgenschwere Fehler begehen kann:

Richtungsweisend für die Bedeutungskonstituierung des Idioms sind die bereits besprochenen konzeptuellen Metaphern LEBEN IST EIN WEG, SCHWIERIGKEITEN SIND HINDERNISSE AUF DEM WEG, SICHERHEIT IST STABILER BODEN SOWIe FEHLER IST STURZ, wobei die FEHLER IST STURZ-Metapher sowohl durch die Weg-Metaphorik als auch durch die Orientierungsmetapher von einem hohen Generalitätsgrad GUT IST OBEN, SCHLECHT IST UNTEN beeinflusst wird.

Von Relevanz für die Bedeutungskonstituierung sind ebenfalls epistemische Mappings. Die metaphorischen Korrespondenzen der konzeptuellen und epistemischen Natur verzahnen sich teilweise, in den epistemischen Metaphern sind sie dennoch - auch wegen des zugrunde liegenden mentalen Bildes - näher bestimmt (vgl. Tab. 15): 
Tab. 15: Die epistemischen Mappings zwischen der Ausgangs- und Zieldomäne für das Verwendungsmuster 1.1 , eine missliche, schwierige Lage, in der man leicht folgenschwere Fehler begehen kann:

dünnes Eis (Ausgangsdomäne) missliche, schwierige Lage (Zieldomäne)

Eis ist glitschig, man rutscht darauf leicht Die Situation ist sehr schwierig, gespannt, aus. emotionsbeladen. In solchen Situationen begeht man leicht einen Fehler.

Dünnes Eis kann jederzeit unter Gewicht Der Aktant kann jederzeit viel verlieren: einer Person zusammenbrechen. Seine Arbeitsstelle/Karriere ist bedroht.

Der Sturz ins kalte Wasser ist lebensgefährlich, Rettungschancen sind gering (Unterkühlung, schwer Die Situation ist sehr ernst, der Karrierebruch ist möglich.

rauszukommen).

Nicht auszuschließen ist auch die linguistische Motiviertheit des Idioms, sowohl in der intra- als auch in der interlingualen Ausprägung. Die intralinguale Motiviertheit hängt mit dem Sprichwort Wenn es dem Esel zu wohl wird, geht er auf Eis tanzen ,Wenn es jmdm. zu gut geht, wird er übermütig und bringt sich in Gefahr ${ }^{\text {' und }}$ dem davon abgeleiteten Phraseologismus auf Eis tanzen gehen , sich leichtsinnig in Gefahr bringen, im Übermut viel riskieren' (vgl. Duden 11, 2011: 191, 202) zusammen. Die interlinguale Motiviertheit ist auf den mittelalterlichen Spruch: Qui currit glaciem, se non monstrat sapientem ,Wer auf Eis läuft, zeigt sich nicht weise zurückzuführen (vgl. Müller 2005: 106). Falls einem Sprachteilhaber diese Phraseologismen geläufig sind, können sie zur Konzeptualisierung einen Beitrag leisten.

\section{Verwendungsmuster 1.2: ,trügerische Geborgenheit der menschlichen Exis- tenz' (5 Belege)}

In den folgenden Gebrauchsbelegen bezieht sich das Idiom auf die scheinbare Sicherheit der menschlichen Existenz. Profiliert wird die Zerbrechlichkeit dessen, worauf Menschen ihren Alltag aufbauen und was ihnen - solange keine Schicksalsschläge zustoßen - als selbstverständlich vorkommt. In drei der vier Belege handelt es sich dabei um die schmale Linie zwischen Leben und Tod:

(15) Man staunt, wenn die Kinder erzählen, was aus dem Paradies der frühen Jahre in Hermsdorf geworden ist. Alle Ehen in der Nachbarschaft wurden geschieden. Die Brüder des Vaters kamen bei Autounfällen ums Leben. Freunde, die das Haus mitgebaut hatten, starben bei einem Segelunfall im Mittelmeer. Alexander hatte selbst schwere Unfälle, wäre einmal fast nicht mehr aus dem Koma erwacht. Jederzeit kann das dünne Eis, auf dem man sich so sicher bewegt, brechen. Der Tagesspiegel 17.10.2003

In einem Beleg bezieht sich das Idiom auf die scheinbare Sicherheit eines erfolgreichen Großkonzernmanagers, der, sobald sich die hochgesteckten Erwartungen nicht erfüllt haben, einer gnadenlosen Kritik ausgesetzt wird: 
(16) Wenn du zum Verlierer, zum Looser abgestempelt bist, so hat es sich ihm dargestellt, „hast du im Grunde keine Chance, Autorität zu wahren“. Edzard Reuter erfuhr, auf wie dünnem Eis er brilliert hatte und wie wenig Solidarität er fand, nachdem sich als Folge eigener Fehler und veränderter Marktverhältnisse schwere Turbulenzen ankündigten. Scheinbar entfallen war den meisten Vorstandskollegen und Aufsichtsräten, daß sie alles treu und brav mitbeschlossen hatten, daß niemand beizeiten gefragt hatte, ob sich der Autobauer mit Dornier, AEG und MBB nicht vielleicht zuviel, in jedem Fall zuviel auf einmal, aufgehalst habe. Die Zeit, 29.01.1998

Die Bedeutungskonstituierungsmechanismen werden auf der Abbildung 37 veranschaulicht:

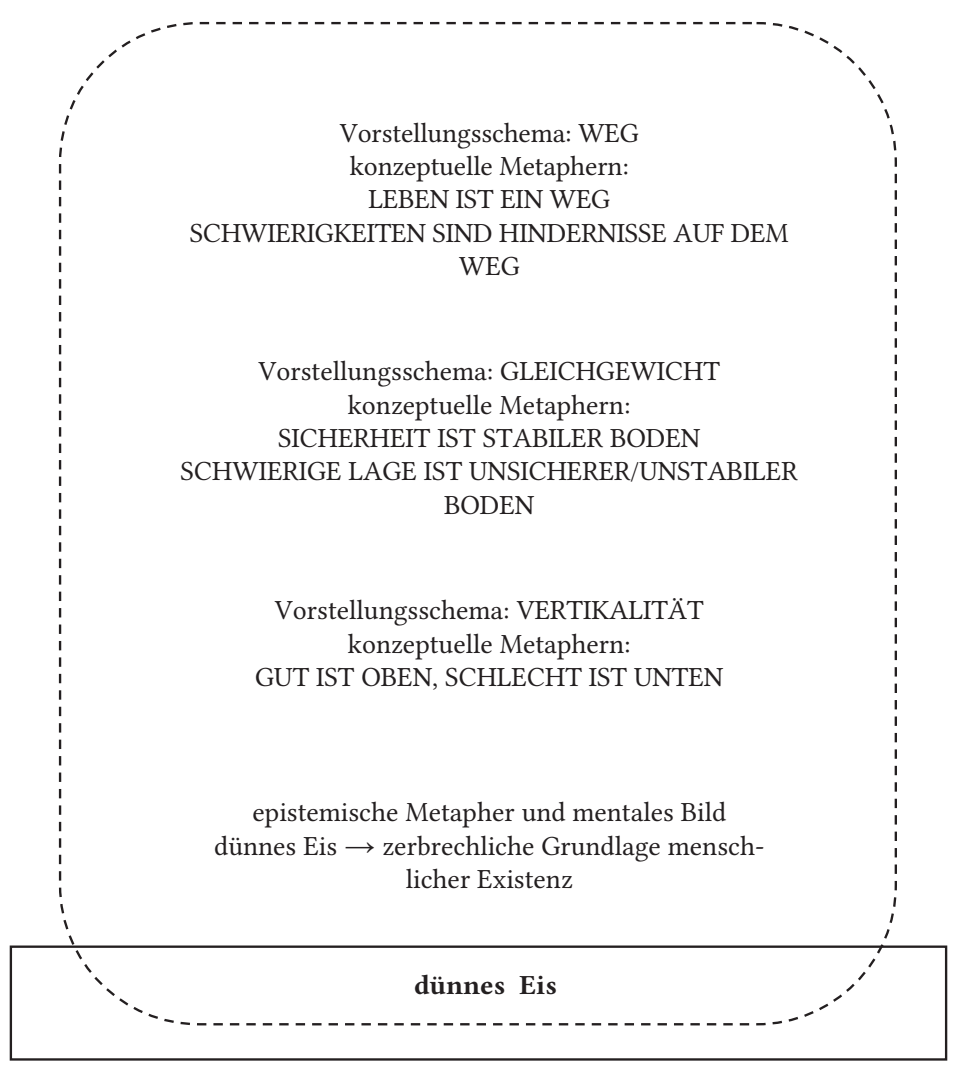

Abb. 37: Bedeutungskonstituierungsmechanismen für das Verwendungsmuster 1.2 ,trügerische Geborgenheit der menschlichen Existenz: 
Profiliert wird in diesen Gebrauchsbelegen die Zerbrechlichkeit der Grundlage, auf der Menschen ihre Existenz gestalten. Außer den konzeptuellen Metaphern: SCHWIERIGE LAGE IST UNSICHERER BODEN SOWIe SICHERHEIT/GEBORGENHEIT IST STABILER BODEN kommen noch zahlreiche epistemische Korrespondenzen zur Geltung, zumal das durch die wörtliche Lesart des Idioms evozierte mentale Bild sehr kohärent und deutlich ist (vgl. Tab. 16):

Tab. 16: Die epistemischen Mappings zwischen der Ausgangs- und Zieldomäne für das Verwendungsmuster 1.2 , trügerische Geborgenheit der menschlichen Existenz:

\begin{tabular}{ll}
\hline dünnes Eis (Ausgangsdomäne) & $\begin{array}{l}\text { trügerische Geborgenheit der } \\
\text { menschlichen Existenz (Zieldomäne) }\end{array}$ \\
\hline
\end{tabular}

Das Eis hat auf natürlichen Wasserbecken Menschen leben in einer trügerischen unterschiedliche Dicke, die von oben schwer einzuschätzen ist.

Geborgenheit. Sie wissen zwar, dass es im Leben nichts Sicheres gibt, die tägliche Routine vermittelt ihnen aber das Sicherheitsgefühl, sie vergegenwärtigen sich die lauernde Gefahr nicht.

Das Eis bricht schnell, unerwartet. Die Schicksalschläge kommen unerwartet, schnell.

Der Sturz ins kalte Wasser ist Extremsituationen und Schicksalschläge lebensgefährlich, Rettungschancen sind gering (Unterkühlung, schwer rauszukommen).

Verwendungsmuster 1.3: (vor allem juristisches Deutsch) ,eine riskante, unsichere Position, in die sich jd. mit seiner umstrittenen, unsicheren Gesetzesauslegung (bzw. Theorie) begibt' (13 Belege)

Die nachstehenden 13 Gebrauchsbelege stellen eine mehr oder weniger ausgeprägte Interaktion zwischen den Bedeutungskonstituierungsmechanismen, die in dem Verwendungsmuster 1.1 und dem Verwendungsprofil 2 (unten dargestellt) zur Geltung kommen: In eine riskante Position begibt sich zwar eine Person/eine Personengruppe ${ }^{172}$, das Risiko hängt dennoch jeweils mit einer umstrittenen Auslegung eines Gesetzes zusammen. Die Belege nehmen nämlich vorwiegend auf juristische Angelegenheiten Bezug (11 Belege), was in drei Kontexten durch die Modifikation der Phraseologismen durch ein adjektivisches Attribut rechtlich

172 Falls in der Subjektposition eine Stadt (Berlin), eine Institution (Staatsanwaltschaft) oder eine Partei (CSU) auftreten, handelt es sich eindeutig um metonymische Verschiebungen: Stadt steht für Stadtverwaltung, Institution bzw. Partei steht für die Menschen, die da tätig sind. 
hervorgehoben wird, vgl. z.B. einen Text über Besorgnisse des Managers vom FCKöln Jörg Schmadtke über Strafe, die dem Verein wegen Fans-Ausschreitungen auferlegt werden kann:

(17) Man müsse eine „Entsolidarisierung“ hinbekommen: „Auch wenn wir auf rechtlich dünnem Eis stehen, werden wir die Dinge durchstehen." Es habe bisher „relativ viel Zuspruch von Fans und Sponsoren" für diesen Kurs gegeben. Die Zeit, 19.02.2015

sowie einen weiteren Beleg für den Idiomgebrauch im Bereich der Rechtsprechung:

(18) Sie spricht von falschen und unerhörten Behauptungen. Wieland weiß genau, auf welch dünnem Eis er sich bewegt. Ohne Akten, die seine Argumente stützen, ist alles nur ein Verdacht, der schnell zur Rufschädigung werden kann. Berliner Zeitung, 03.02.2001

Die übrigen zwei Belege referieren nicht auf die Gesetzesinterpretation, sondern auf (nicht unbedingt wissenschaftlich fundierte) Theorien, die bestimmten Anschauungen zugrunde liegen, vgl. z.B.:

(19) Gerade Leute, die gutes und richtiges Deutsch dennoch von schlechtem und falschem unterscheiden wollen, sollten immer einmal wieder daran erinnert werden, auf wie dünnem Eis sie sich bewegen mit ihren Kriterien Erlernbarkeit, Vergleichbarkeit und Verständlichkeit. Reiners kommt dann zu dem für einen Autor wie ihn doch einigermaßen erstaunlichen Schluß, dem Kind zu sagen, „fragte“ sei vorzuziehen, weil die meisten der guten Schriftsteller von heute es dem "frug“ vorzögen. Die Zeit, 25.02.1983

Bezüglich der Bedeutungskonstituierungsmechanismen scheint es zur Interaktion zwischen mehreren konzeptuellen Metaphern zu kommen. Zweifelsohne wird die Gesamtbedeutung durch die konzeptuelle Metapher SICHERHEIT IST STABILER BODEN beeinflusst. Ansonsten scheint sich die Gesamtbedeutung im Spannungsfeld zwischen zwei Interpretationen und den dahinter stehenden Metaphern zu konstituieren: Einerseits wird in den Belegen hervorgehoben, dass sich eine Person/eine Personengruppe bewusst in eine riskante Position begibt, was als ein potenzieller Fehler ausgelegt wird. Diese Person steht dann auf dünnem Eis, d.h. ist in einer unsicheren Lage, den verbal-argumentatorischen Angriffen ausgeliefert, die ihr - mehr oder weniger - schaden können: Zum Vorschein kommen hier die metaphorischen Mappings, die das 1.1-Verwendungsmuster ,jd. ist in einer misslichen, schwierigen Lage, in der man leicht folgenschwere Fehler begehen kann' konstituiert haben. Andererseits wird in den Belegen explizit auf die kausal-instrumentalen Angaben eingegangen: Eine Person begibt sich mit einer Gesetzesauslegung/Theorie auf dünnes Eis bzw. bewegt sich wegen ihrer Gesetzesauslegung/Theorie auf dünnem Eis. Beachtenswert ist dabei, dass in den Gebrauchsbelegen des 1.3-Verwendungsmusters ausführlich auf die Schwäche der vertretenen Gesetzesauslegung oder Theorie, auf ihre ungenügende Begründung, fehlende Beweise, falsche Grundvoraussetzungen verwiesen wird, vgl. dazu auch den Beleg (20): 
(20) Brandenburgs CDU, namentlich ihr innenpolitischer Sprecher Sven Petke, begibt sich auf dünnes Eis. Zu dünnes Eis. Denn nicht ohne Grund wird im Bundesgesetz das Beschmieren von Gegenständen, Gebäuden und Anlagen nicht als Sachbeschädigung gewertet, wenn die Substanz nicht beschädigt wird. Denn dann kann auch keine Sachbeschädigung vorliegen - allenfalls eine Verunstaltung. Was die CDU nun plant, ist das Verdrehen von Tatsachen. Denn wer jemandem mit Absicht etwas auf den Anzug kippt, der kann mit zweierlei Folgen rechnen: Lässt sich der Weißwein auswaschen, muss er die Reinigung bezahlen. Geht aber der Rotwein nicht raus, hat er den Anzug beschädigt und kann wegen Sachbeschädigung belangt werden und muss den Anzug ersetzen. Genauso sieht es schon jetzt bei den Sprayern aus. Entweder die Farbe geht ab oder nicht. Danach richtet sich die Einstufung als Ordnungswidrigkeit bzw. Straftat und die Strafe. Und: Mit einem härteren Gesetz, einer härteren Strafe, wird kein Polizist auch nur einen Sprayer mehr fangen. Die Aufklärungsquote wird nicht steigen, die Hauswände werden nicht sauberer. Auch das Argument, die Strafen müssten abschrecken, geht ins Leere. Denn es gibt wohl kein Beispiel aus der Kriminalgeschichte, wo schärfere Strafen zu einem Rückgang der Taten geführt hätten. Wer eine Tat begeht, der tut dies ja nicht in dem Bewusstsein, eventuell bestraft zu werden, sondern eben in dem Glauben, nicht erwischt zu werden - egal, ob Sprayer,

Dieb, Räuber oder Raser. Potsdamer Neueste Nachrichten, 17.03.2005

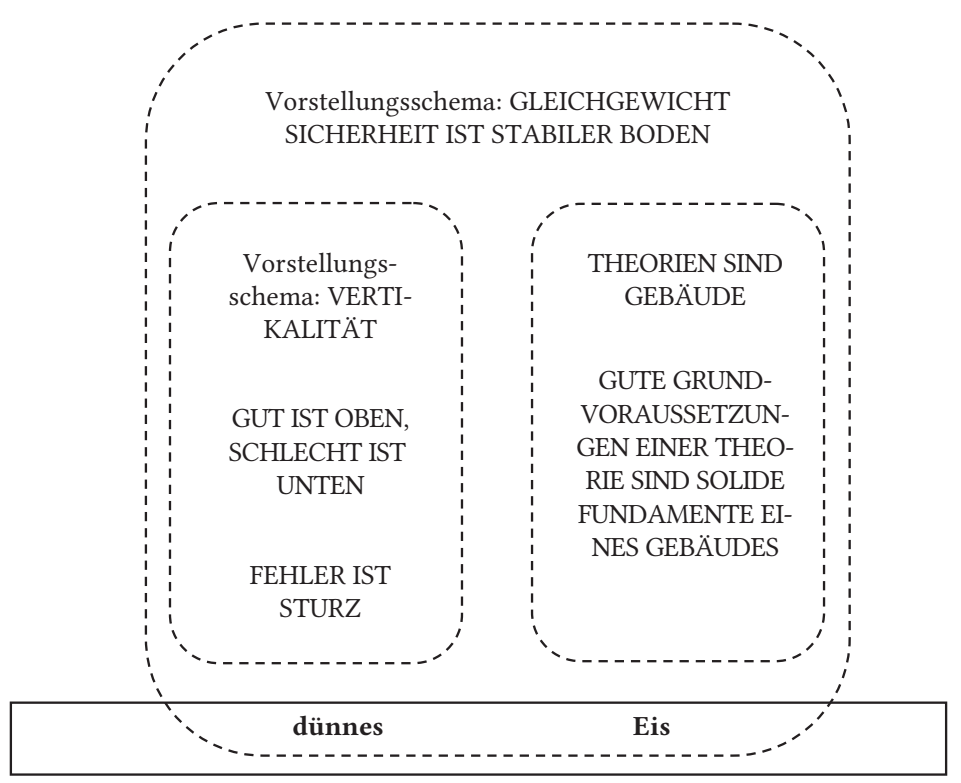

Abb. 38: Bedeutungskonstituierungsmechanismen für das Verwendungsmuster 1.3 , eine riskante, unsichere Position, in die sich jd. mit seiner umstrittenen, unsicheren Gesetzesauslegung (bzw. Theorie) begibt. 
Dementsprechend wird dieses Verwendungsmuster durch mehrere Metaphern mitkonstituiert. Die konzeptuelle Metapher SICHERHEIT IST STABLIER BODEN kommt in jeder Konzeptualisierung zur Geltung: Der Bedeutungsaspekt der riskanten Lage, der Unsicherheit ist die ganze Zeit vorhanden. Der Beitrag von zwei weiteren konzeptuellen Metaphern: FEHLER IST STURZ, THEORIEN SIND GEBÄUDE zur Bedeutung der idiomatischen Einheit dünnes Eis ändert sich im Textverlauf und kann je nach der Fokussierung als eine riskante Lage einer Person sowie als eine schlecht fundierte Hypothese/Gesetzesauslegung interpretiert werden (vgl. Abb. 38).

Verwendungsprofil 2: etw. steht auf dünnem Eis, umstrittene, nicht gut begründete Grundlage eines Gesetzes, der Auslegung eines Gesetzes, einer Hypothese, einer These, einer Argumentation' (4 Belege)

Dieses Verwendungsprofil wird lediglich mit 4 Belegen vertreten, die hier involvierten konzeptuellen Metaphern tragen dennoch zur Konstituierung des bereits beschriebenen Verwendungsmusters 1.3 bei. Nur in dieser Bedeutung ist das Subjekt unbelebt und abstrakt (ein Gesetz, eine Konstruktion, die durch Gesetze zur Gefahrenabwehr zugelassenen und von der Polizei eingesetzten Maßnahmen) und referiert auf Erfindungen menschlichen Geistes:

(21) Mit der 6. Novelle des Hochschulrahmengesetzes lösen SPD und Grüne kurz vor Ende der Legislaturperiode noch ein Wahlversprechen an die Studenten ein. Doch das Gesetz steht auf dünnem Eis: Die Union hat Verfassungsklage angekündigt, um darüber im Bundesrat zu entscheiden. Der Tagesspiegel, 26.04.2002

(22) Das wäre jedoch zu vernachlässigen, stünde nicht die gesamte Konstruktion auf etwas dünnem Eis. Dass sich beide Völker trotz 500-jähriger Trennung noch in einer gemeinsamen Sprache verständigen können, legt die Autorin auf der letzten Seite selber als unerklärliches Phänomen bloß. Der Tagesspiegel, 22.02.2004

Dünnes Eis bezieht sich in diesen Gebrauchsbelegen auf die schwachen, umstrittenen und nicht gut fundierten Grundlagen der Gesetze, Argumentationen, Theorien, die bei einer näheren Betrachtung oder im Falle eines (Rechts-)Streites leicht infrage gestellt und widerlegt werden können.

Die Bedeutungskonstituierungsmechanismen weisen viele Parallelen zu den Konstituierungsmechanismen auf, die für das zweite Verwendungsprofil des Idioms ein schwankender Boden konstitutiv waren. Die semantischen Derivationen auf der Ebene der ganzen Wortverbindung beruhen auf den konzeptuellen Metaphern SICHERHEIT IST STABILER BODEN; GUT IST OBEN, SCHLECHT IST UNTEN sowie der Bauwerk-Metaphorik, d.h. den konzeptuellen Strukturmetaphern THEORIEN SIND GEBÄUDE, GUTE GRUNDVORAUSSETZUNGEN EINER THEORIE SIND SOLIDE FUNDAMENTE EINES GEBÄUDES, die auf der konzeptuellen Ebene die konkretere Domäne des Gebäudes und abstraktere Domäne von Konstruktionen des menschlichen Geistes verbinden (vgl. Abb. 39). 


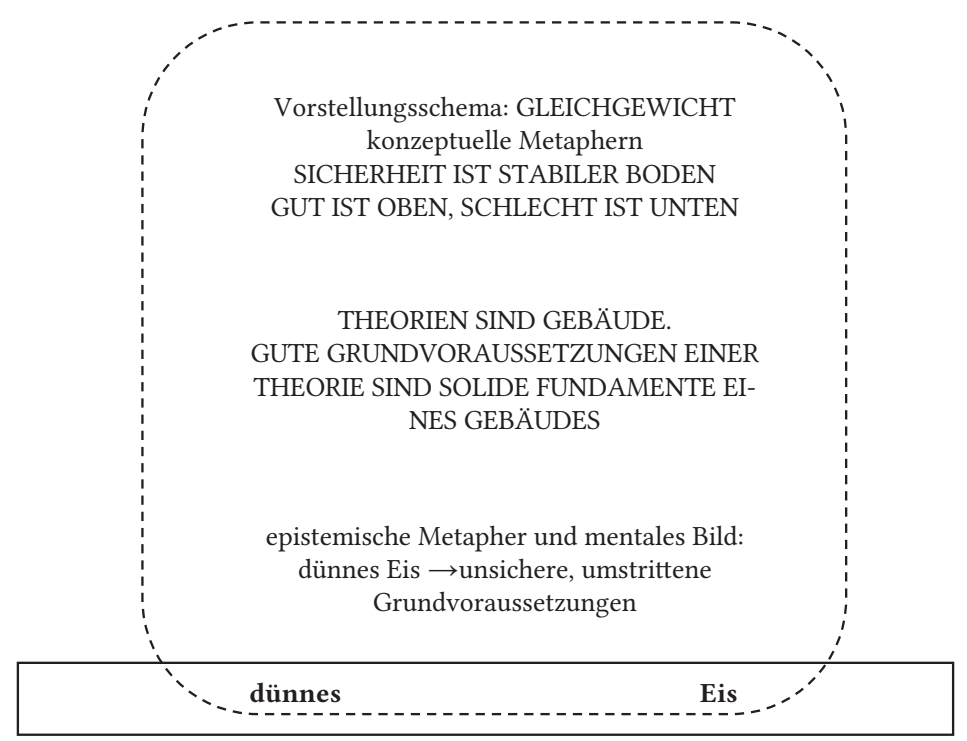

Abb. 39: Bedeutungskonstituierungsmechanismen für das Verwendungsprofil 2 ,umstrittene, nicht gut begründete Grundlage eines Gesetzes, der Auslegung eines Gesetzes, einer Hypothese, einer These, einer Argumentation:

Diese in der Kognition fest verankerten Mappings zwischen den Fundamenten und Grundlagen erhalten dann in den epistemischen, durch das mentale Bild unterstützten metaphorischen Mappings genauere Konturen. Das Eis stellt - wenigstens im abendländischen Kulturkreis und der diesem Kulturkreis entsprechenden Klimazone - eine von Natur aus äußerst ungeeignete und unsolide Basis für die Fundamente dar, das dünne Eis kann zusätzlich unter dem Gewicht der Konstruktion brechen. Die metaphorischen Korrespondenzen zwischen der Ausgangs- und der Zieldomäne gibt die Tabelle 17 wieder:

Tab. 17: Die epistemischen Mappings für das Verwendungsprofil 2 , umstrittene, nicht gut begründete Grundlage eines Gesetzes, der Auslegung eines Gesetzes, einer Hypothese, einer These, einer Argumentation:

\begin{tabular}{ll}
\hline dünnes Eis (Ausgangsdomäne) & $\begin{array}{l}\text { unsichere Grundlage einer Theorie, } \\
\text { Argumentation, eines Gesetzes (Zieldomäne) }\end{array}$ \\
\hline
\end{tabular}

Nicht genug tragfähig, ungeeignet für Eine Theorie, Argumentation, ein Gesetz, das die Fundamente. man leicht zu Fall bringen kann, deren/dessen Voraussetzungen von Grund auf falsch sein können. 
dünnes Eis (Ausgangsdomäne) unsichere Grundlage einer Theorie, Argumentation, eines Gesetzes (Zieldomäne)

Als Fundamentbasis ist dünnes Eis Die Grundlagen sind nicht genug zuverlässig, nicht widerstandsfähig, haftbar, dauerhaft. schlecht fundiert, durch Sachkenntnis nicht gesichert.

Dünnes Eis kann jederzeit unter Die Argumente/die aufgestellten Theorien können einem Gewicht zusammenbrechen. jederzeit widerlegt werden.

Wenn das dünne Eis zusammenbricht, Wenn jemand die Theorie, Argumentation, ist die darauf errichtete Konstruktion ein Gesetz infrage stellt. und ihre Schwächen nicht zu retten. offenbart, wird sie total zurückgewiesen.

\subsection{3 glattes Parkett}

Lexikographisch erfasste Varianten: glattes Parkett betreten, sich auf glattem Parket bewegen, sich auf glattes Parkett wagen

Modifikationen: auf dem glatten Parkett ausrutschen, auf glattem Parkett stehen, Vergnügen am glatten Parkett haben, glattes Parkett bleibt für jmdn. rutschfest, sich auf dem glatten Parkett einer Sache auskennen, sich auf dem angestrebten glatten Parkett bewegen, auf dem Boden des glatten Parketts hart aufschlagen, u.a.

\section{Darstellung in lexikographischen Nachschlagewerken}

Tab. 18: Das Idiom glattes Parkett in allgemeinen und phraseologischen Wörterbüchern des Deutschen.

\begin{tabular}{|c|c|c|}
\hline \multicolumn{2}{|c|}{ Wörterbuchtyp Wörterbuch } & \multirow{2}{*}{$\begin{array}{l}\text { Lexikographische Darstellung } \\
\text { nicht verzeichnet }\end{array}$} \\
\hline allgemein & DUw 2006 & \\
\hline & $\underline{\text { DUW ONLINE }}$ & nicht verzeichnet (letzter Zugriff am 27.10.2017) \\
\hline & WAHRIG 2007 & nicht verzeichnet \\
\hline \multirow[t]{4}{*}{ phraseologisch } & DUDEN 11 & $\begin{array}{l}\text { glattes Parkett betreten, sich auf glattem } \\
\text { Parkett bewegen: ein Risiko eingehen, etw. } \\
\text { Riskantes tun: Wer an die Börse geht, müsse } \\
\text { eben wissen, dass er glattes Parkett betrete (Zeit } \\
\text { 12.10.2000). Dafür verlässt der Evolutionsbiologe } \\
\text { mitunter auch schon einmal den festen Boden } \\
\text { der Naturwissenschaft und begibt sich immer } \\
\text { wieder aufs glatte Parkett der Philosophie, wo } \\
\text { er nicht immer eine so ganz überzeugende Figur } \\
\text { macht (Standard 20.01.2007, 41). (2011: 573) }\end{array}$ \\
\hline & SCHEMANN 2011 & nicht verzeichnet \\
\hline & $\begin{array}{l}\text { REDENSARTEN- } \\
\text { INDEX }\end{array}$ & $\begin{array}{l}\text { sich auf glattes Parkett wagen ,sich in eine } \\
\text { unsichere, heikle Lage manövrieren }\end{array}$ \\
\hline & MÜLLER 2005 & nicht verzeichnet \\
\hline
\end{tabular}




\section{Korpusgestützte Analyse anhand der DWDS-Korpora ${ }^{173}$}

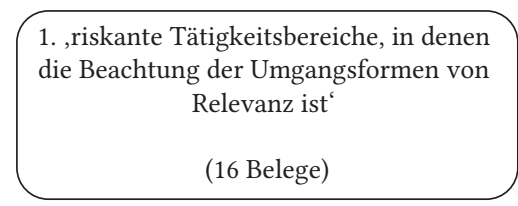

2. ,Börsenverkehr und die damit verbundenen finanziellen Risikos'

(11 Belege)

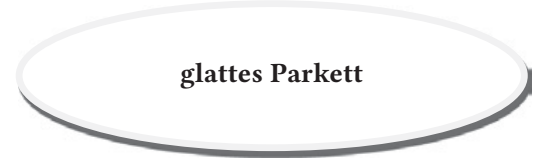

3. ,ein schwieriger Bereich, ein heikles Thema'

(4 Belege)
4. idiosynkratischer und sprachspielerischer Gebrauch

(9 Belege)

Abb. 40: Die Verwendungsprofile des Idioms glattes Parkett anhand der Analyse der Gebrauchsbelege im DWDS-Korpus.

Verwendungsprofil 1: ,riskante Tätigkeitsbereiche, in denen die Beachtung der Umgangsformen von Relevanz ist; schwierige, riskante Tätigkeitsbereiche, in denen man sich in einem gesellschaftlichen Rahmen, den Umgangsformen entsprechend, bewegen muss' (16 Belege)

Das erste, 16 Belege umfassende Verwendungsprofil kommt in mehreren Nuancen zum Vorschein, denen zwei latente Bedeutungsaspekte gemeinsam sind: Zum einen wird das Idiom in Bezug auf Tätigkeitsbereiche gebraucht, die von Natur aus fehlerträchtig, riskant sind, zumal alle Entgleisungen des Einzelnen gleich von größeren Menschengruppen wahrgenommen werden. Zum anderen handelt es sich hier um die Tätigkeitsbereiche (Politik, Diplomatie, höheres Management), in denen korrekte Umgangsformen und angemessenes Auftreten erwartet werden. Die einzelnen Belege lassen sich in vier Gruppen einteilen, in denen unterschiedliche metaphorische bzw. metonymische Korrespondenzen profiliert werden:

In der Politik (4 Belege) werden als glattes Parkett vor allem Tätigkeitsbereiche bezeichnet, die geschicktes, vorsichtiges, gut durchdachtes Vorgehen sowie Fähigkeit, Schwierigkeiten intelligent zu umgehen, voraussetzen. Die besonderen

173 Zugriffsdatum: 17.03.2016, Suchanfrage: glattes\&\&Parkett. Deutsches Textarchiv: 0; Kernkorpus 2/11; Die Zeit: 18/68; Berliner Zeitung: 11/ 45; Der Tagesspiegel: 8/30; Potsdamer Neueste Nachrichten: 1/1. 
Fähigkeiten eines Pressesprechers (rhetorisches Geschick), aber auch die hohen Risiken seiner Öffentlichkeitsarbeit (z.B. gravierende Fehler können die Stelle kosten, auch wenn sie nicht selbst verschuldet sind) werden im Beleg 23 zum Ausdruck gebracht:

(23) Und Butz gehört zu den Diepgen-Vertrauten mit der Gabe, den trockenen Ernst des Chefs mit einer heiteren Note aufzulockern. Er ist seit achteinhalb Jahren Diepgens Sprachrohr, vor allem Diepgens - ungewöhnlich lange, denn Regierungssprecher stehen immer auf sehr glattem Parkett. Der Tagesspiegel, 16.03.2000

In einem anderen Beleg wird das politische Geschick eines Bundesarbeitsministers hervorgehoben, der früher in dem Artikel als „Meister im Lavieren“ bezeichnet wurde:

(24) Katzer hat Krallen, aber er zeigt sie äußerst ungern. Dieser vielschichtige Mann hat Vergnügen am glatten Parkett, am Balancieren. Als die Gefahr drohte, daß der Bund in diesem Jahr 500 Millionen Mark bei den neun Milliarden Mark einsparen muß, die er den Sozialversicherungen zahlt, beließ es Katzer nicht beim Krallenzeigen, nicht beim harten Nein. Er schlug seinem Kabinettskollegen Strauß vielmehr eine Ersatzlösung vor, man möge doch die Heizölsteuer erhöhen und sich so die fehlenden Gelder beschaffen. Auf diese Weise könne gleich der ärgste Konkurrent der notleidenden Kohle getroffen werden und allen sei geholfen. Die Zeit, 20.01.1967

In der Diplomatie referiert glattes Parkett in erster Linie auf die Gefahren, die mit der Unkenntnis der korrekten Umgangsformen, der Unfähigkeit, die Nuancen und Stimmungen mit Fingerspitzengefühl zu erkennen und eventuell zu steuern, zusammenhängen:

(25) Der Diplomat soll glänzen, nicht auffallen. Nur dann bleibt für ihn glattes Parkett rutschfest. Der neue niederländische Botschafter in Bonn geriet gleich beim ersten Schritt ins Schleudern. Die Zeit, 04.06.1993

(26) Schwupps war Branoner auf dem glatten Parkett der Diplomatie ausgerutscht, ohne es je entschlossen betreten zu haben. Die Zeitungen freuen sich derweil über ein paar Meldungen. Berliner Zeitung, 06.07.1996

Im wirtschaftlichen Bereich wird nicht nur die Kenntnis der Umgangsformen, Verhaltensnormen und interkulturellen Begebenheiten in dem gesellschaftlichen Regelkanon, sondern ebenfalls ein ausgebautes Fachwissen sowie (potenzielle) gesellschaftliche Beziehungen zur notwendigen Bedingung gemacht, um den Gefahren des Missgeschicks oder falscher Entscheidungen zu entgehen und erfolgreich Geschäfte abschließen zu können:

(27) Es fehlen weltgewandte Vertriebsleute, die sich auf dem glatten Parkett der Weltmärkte auskennen. Opel bezieht beispielsweise seine Beleuchtungsteile für den Corsa aus Spanien, obwohl FER nur einen Steinwurf entfernt ist. Der Tagesspiegel, 18.08.1998

Am deutlichsten kommt der gesellschaftliche Aspekt in den vier Belegen zum Vorschein, in denen die korrekten Umgangsformen als identitätsstiftendes Zeichen der Zugehörigkeit zu einer gehobenen sozialen Gruppe interpretiert werden. Es handelt sich grundsätzlich um von klein auf anerzogene Umgangsformen, die einen dazu 
befähigen, sich in bestimmten gesellschaftlichen Kreisen ${ }^{174}$ situationsangemessen verhalten zu können. In diesen Belegen wird die metonymische Bedeutungsverschiebungskette:

Parkett $\rightarrow$ Fußbodenbeleg in Palästen u. Ä. $\rightarrow$ Plätze für gehobene Kreise profiliert:

(28) Die Gründe, warum Arbeitgeber den Bewerber nach dem Beruf von Eltern oder Geschwistern fragen, bleiben nicht unerwähnt. Der Karriere-Ingenieur muß offenbar den richtigen Stallgeruch haben: „Man will einfach sehen, ob seine Ansprüche an Laufbahn und vielleicht auch soziale Stellung, in dieser Familie üblich`sind, ob er sich also vermutlich auf dem angestrebten glatten Parkett mit der aus der Erziehung kommenden Sicherheit bewegt oder ob spezielle Probleme zu befürchten sind, vor die sich soziale Aufsteiger manchmal gestellt sehen." Die Zeit, 18.04.1986

(29) Dr. Natale Rusconi, im Hause nur il dottore genannt, wurde buchstäblich in ein Hotel hineingeboren, kam im Zimmer 28 des Mailänder Hotels „Argentina“ zur Welt, das seinem Großvater gehörte. Seinen Eltern zuliebe promovierte er in Philosophie und klassischen Sprachen. (...) Dieser sympathische, eher zurückhaltende, wie ein Gelehrter wirkende Mann, der vier Sprachen perfekt beherrscht und es gelernt hat, sich auf glattem Parkett zu bewegen, war genau der richtige Mann, um aus dem „Cipriani“ nun wirklich ein ganz großes Hotel zu machen. Die Zeit, 19.02.1988

Die kognitiven Mechanismen, die bei der Konstituierung des ersten Verwendungsprofils zur Geltung kommen, stellt vereinfachend Abbildung 41 dar.

Die Bedeutung der ganzen Wendung konstituiert sich auf zwei Ebenen: Semantische Derivation bezieht sich sowohl auf die ganze Wortverbindung als auch auf ihre nominale Konstituente. Auf der ersten Ebene lassen sich mehrere Metaphern eruieren:

Die konzeptuellen Metaphern SICHERHEIT IST STABILER BODEN, FEHLER IST STURZ, GUT IST OBEN, SCHLECHT IST UNTEN wurden im Vorangehenden geschildert und brauchen an dieser Stelle nicht wiederholt behandelt zu werden. Außer den beiden konzeptuellen Metaphern trägt ebenfalls eine epistemische Metapher mit einem ausgeprägten mentalen Bild zur Bedeutungskonstituierung der in dem ersten Verwendungsprofil zusammengestellten Belege bei (vgl. Tab. 19). Die Wissensdomänen, die das mentale Bild evozieren, sind sowohl aus der alltäglichen Erfahrung als auch aus dem Bildungswissen bekannt: Parkett gilt als ein repräsentativer, relativ pflegeaufwendiger und kostspieliger Fußbodenbelag, der nach dem

174 Vgl. Dazu etymologische Angaben in Müller (2005: 455) zum Idiom: sich auf diplomatischem/internationalem Parkett bewegen können, sich in einem bestimmten gesellschaftlichen Rahmen zu benehmen wissen ' [Etikette]: Parkett ist eine theatertechnische Bezeichnung für Sitze vor der Bühne (bzw. die dort sitzenden Zuschauer), aber auch ein Fachwort für holzgetäfelten Fußboden, wie er in aristokratischer Zeit den Schlössern und Wohnungen der reichen vorbehalten war. Das Parkett konnte so zum Kennzeichen für eine ranghohe Gesellschaftszugehörigkeit werden. 
Ebene 1

Ebene 2

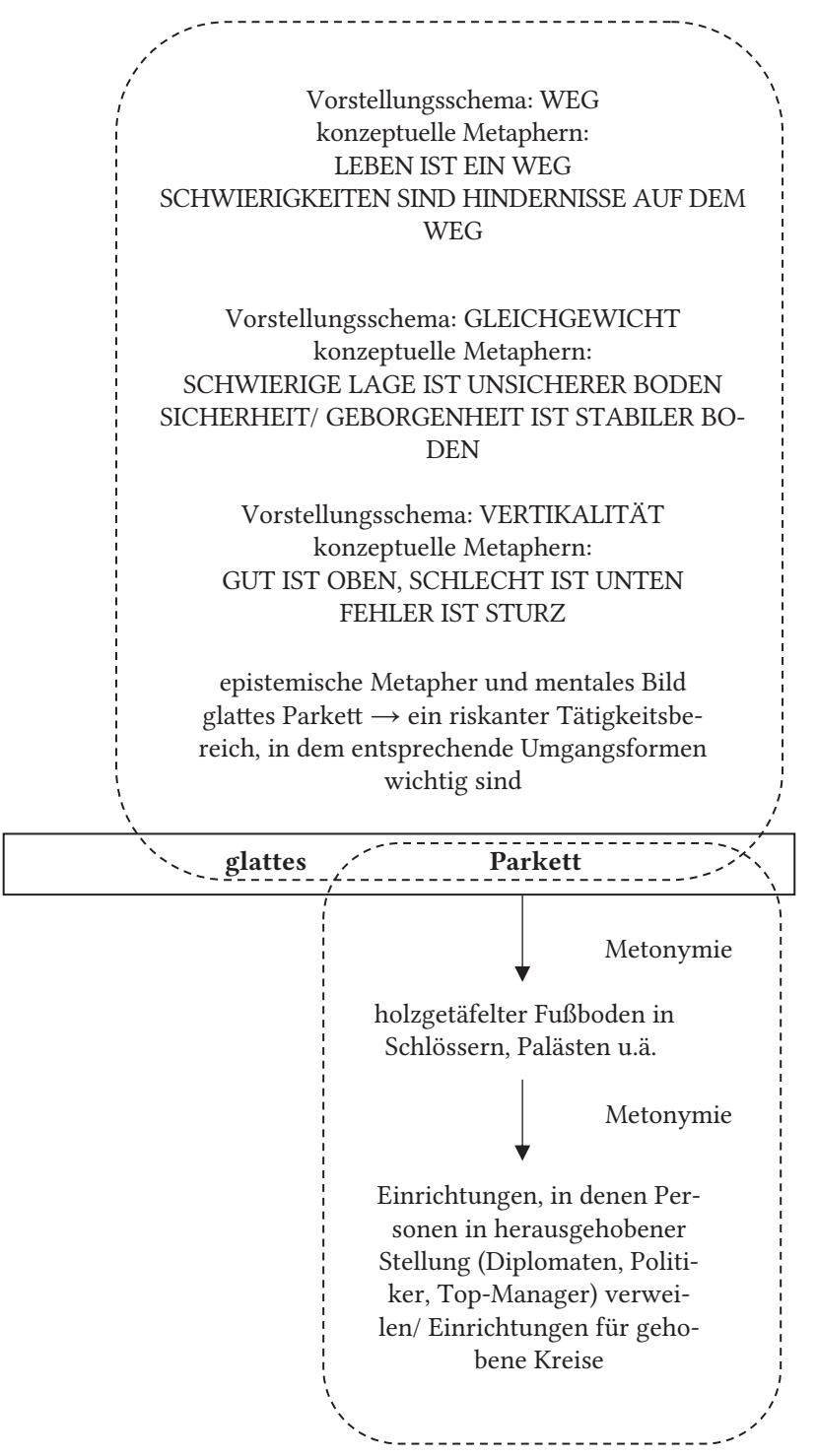

Abb. 41: Bedeutungskonstituierungsmechanismen für das Verwendungsprofil 1 , riskante Tätigkeitsbereiche, in denen die Beachtung der Umgangsformen von Relevanz ist . 
Bohnern glitschig ist. Dieses Hintergrundwissen aus der Ausgangsdomäne findet Widerspiegelung in der Zieldomäne, die sich auf die Tätigkeitsbereiche von eher überdurchschnittlich qualifizierten Personen bezieht.

Tab. 19: Die epistemischen Mappings für das Verwendungsprofil 1 , riskante Tätigkeitsbereiche, in denen die Beachtung der Umgangsformen von Relevanz ist.

\begin{tabular}{ll}
\hline glattes Parkett (Ausgangsdomäne) & $\begin{array}{l}\text { ein Tätigkeitsbereich, in dem man } \\
\text { leicht einen Fehler begehen kann } \\
\text { (Zieldomäne) }\end{array}$ \\
\hline
\end{tabular}

Das Parkett wurde als Fußbodenbelag in Repräsentative Tätigkeitsbereiche, in denen traditionellen Bürgerhäusern, Palästen, man die Interessen von Menschengruppen Schlössern in zentralen Räumen verlegt, oder Organisationen vertritt: Politik, in denen man die Gäste empfing. Eher Diplomatie, höhere Managementstufen. nicht geeignet ist das Parkett für die „schmutzigen Bereiche“ wie Küche, Bad u.ä.

Ein frisch gebohnertes Parkett ist glitschig, es ist leicht, beim Gehen auszurutschen.

Das Rutschen passiert vor Augen aller Gäste.

Das Bewegen auf dem gebohnerten Parkett kann man lernen, man kann sich daran gewöhnen: Je länger man auf einem Parkett geht, desto geschickter bewegt man sich darauf.
In diesen Tätigkeitsbereichen ist es leicht, einen Fehler zu begehen.
Die potenziellen Fehler fallen gleich auf.

Das stilsichere Verhalten in den ehobenen Kreisen kann man lernen: Je mehr Erfahrung man hat, desto stilsicherer sind die Auftritte.

Der Aspekt der Zugehörigkeit zu den ranghohen Gesellschaftskreisen kommt ebenfalls auf der zweiten Ebene zum Vorschein, in deren Mittelpunkt sich die semantische Derivation des Nomens Parkett befindet. Hinter der metonymischen Bedeutungsverschiebung:

$$
\text { Parkett } \underset{\text { Metonymie }}{\stackrel{\text { [steht für }]}{\longrightarrow}} \text { den Schössern, Palästen } \stackrel{\text { Fußbodenbelag in }}{\stackrel{[\text { steht für] }]}{\text { Metonymie }}} \begin{aligned}
& \text { Einrichtungen für } \\
& \text { Personen in einer } \\
& \text { herausgehobenen } \\
& \text { Stellung/für } \\
& \text { gehobene Kreise }
\end{aligned}
$$

Abb. 42: Bedeutungsverschiebungskette der nominalen Konstituente im Idiom ein glattes Parkett. 
steckt das historisch-gesellschaftliche Wissen darüber, dass das Parkett lange Zeit vor allem der wohlhabenden Oberschicht vorbehalten war (vgl. Abb. 42). Erst in den letzten Jahrzehnten fand das Parkett Einzug in die Häuser der „Normalbürger“, wo es immer noch den Status eines der hochwertigsten Bodenbeläge genießt. Dieses assoziative Wissen macht einen wichtigen Bestandteil der hinter dem Konzept stehenden epistemischen Strukturen: In der Subjektposition treten ausschließlich überdurchschnittlich qualifizierte, einflussreiche oder Macht ausübende Personen/ Personengruppen bzw. Anwärter auf, die einen sozialen und/oder beruflichen Aufstieg anstreben.

Die genannten Metaphern und Metonymien kommen - mehr oder weniger explizit - in allen Belegen des ersten Verwendungsprofils zur Geltung, es gibt dennoch Unterschiede in ihrer Profilierung in den einzelnen Bedeutungsnuancen. In dem Beleg (27) sind beispielshalber die konzeptuellen Metaphern sicHERHEIT IST STABILER BODEN, FEHLER IST STURZ sowie die epistemische Metapher und das mentale Bild von besonderer Relevanz für die Konstituierung der aktuellen Bedeutung. Der von einem Hotelmanager aus einer Hotelbesitzerfamilie mit einer langen Tradition handelnde Beleg (29) profiliert die metonymische Verschiebung Parkett $\rightarrow$ Plätze für gehobene Kreise sowie das letztgenannte Mapping der epistemischen Metapher: Die gesellschaftlichen Aspekte der sozialen Herkunft, des familiären Hintergrundes stehen hier im Zentrum der Aufmerksamkeit.

\section{Verwendungsprofil 2: das glatte Parkett (der Börse) ,Börsenverkehr und die damit verbundenen finanziellen Risikos' (11 Belege)}

In dem zweiten Verwendungsprofil steht glattes Parkett metonymisch für die Börse und die damit zusammenhängenden Risiken für Investoren.

Die metonymische Bedeutungsverschiebungskette:

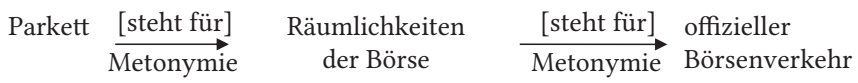

Abb. 43: Bedeutungsverschiebungskette der nominalen Konstituente im Idiom das glatte Parkett (der Börse).

kann wahrscheinlich als lexikalisiert angesehen werden, was u.a. in lexikographischen Nachschlagewerken ihren Niederschlag findet, vgl. DUW online (Zugriff am 01.02.2017):

Parkett:

1. Fußboden aus schmalen, kurzen Holzbrettern, die in einem bestimmten Muster zusammengesetzt sind

2. zu ebener Erde liegender [vorderer] Teil eines Zuschauerraumes

3. offizieller Börsenverkehr [Hervorhebung von A. S.] 
Interessanterweise veranschaulichen Gebrauchsbelege deutlich, dass beide Schritte aus der metonymischen Bedeutungsverschiebungskette bei der Konzeptualisierung zur Geltung kommen können. Im Beleg (30) referiert das glatte Parkett auf die Räumlichkeiten der Börse (Synekdoche, pars pro toto-Metonymie), in denen Makler ihre Geschäfte in persona abschließen:

(30) Der Schutz der Anleger werde dadurch gewährleistet, daß aus der größten Zahl der bei ihnen eingehenden Angebote und Nachfragen der Kurs festgestellt wird. Ob die Makler dieser Aufgabe auf dem glatten Parkett oder elektronisch nachkämen, sei dabei nicht so wichtig, meint Heinemann. Über Xetra werden mittlerweile die meisten Umsätze in Dax-Werten abgewickelt. Berliner Zeitung, 07.04.1999

In den übrig gebliebenen Belegen referiert das Idiom das glatte Parkett auf den weit verstandenen, offiziellen Börsenverkehr: Diese Interpretation wird durch das Wissen untermauert, dass Anleger, insbesondere Kleinanleger, ihre Geschäfte nicht persönlich, sondern über berechtigte Personen (Makler, Broker) abwickeln dürfen. Oft wird das Idiom markiert gebraucht: Die Textproduzenten knüpfen bewusst an die Zwischenstufe in der metonymischen Bedeutungsverschiebungskette (Räumlichkeiten der Börse) an und bauen durch entsprechende Redemittel (für die ersten Schritte, ins Rutschen kommen, den Gang wagen) das durch das mentale Bild evozierte Szenario aus.

(31) Die Deutschen kaufen wieder Aktien. Mitten in der tiefsten Vertrauenskrise, die die Börse seit Jahrzehnten erlebt, wagen die früheren Sparbuchbesitzer den Gang aufs glatte Parkett der Kapitalmärkte. Der Tagesspiegel, 15.01.2003

(32) Zusammen mit drei Freunden gründete er im November 1996 einen Börsenclub. Für die ersten Schritte auf dem glatten Parkett investierte jeder 2500 Mark. Die erste Order von Telekomaktien entpuppte sich gleich als Erfolg. Der Tagesspiegel, 22.05.1998 (33) Das angebliche „Leasing-Modell“ umwehte ein Zauber wundersamer Geldvermehrung, der schon im Börsenboom der späten 90er Jahre die halbe Nation in den Bann gezogen hatte, bis die meisten Anleger auf dem Boden des glatten Parketts hart aufschlugen. Der Tagesspiegel, 07.06.2003

Dieses Verfahren dient der Versinnbildlichung, Veranschaulichung des abstrakten, für die meisten Menschen undurchsichtigen und als kompliziert empfundenen Börsenhandels: Durch die Verbindung des Abstrakten mit dem Konkreten werden komplexe Zusammenhänge in einer vereinfachten, selbst für einen uneingeweihten Leser verständlichen Form dargestellt. Bemerkenswert ist auch, dass in insgesamt 5 von 11 Belegen nach dem glatten Parkett ein Genitivattribut (das glatte Parkett der Börse/der Kapitalmärkte/des kapitalistischen Finanzwesens) steht (vgl. die Belege 31, 34):

(34) Vor wenigen Jahren noch hätten bei Bulle und Bär die meisten Menschen an den Zoo gedacht, niemals aber an das glatte Parkett der Börse, auf dem schon mancher böse ins Rutschen kam. Beide Tiere stehen dort für das Wechselspiel von Hausse und Baisse, wobei der Bulle die optimistische Risikofreude, der Bär hingegen die pessimistische Vorsicht verkörpert. Berliner Zeitung, 13.01.2001 
Außer der metonymischen Bedeutungsverschiebungskette:

Parkett $\rightarrow$ Räumlichkeiten der Börse $\rightarrow$ Börsenverkehr

leistet noch die adjektivische Idiomkonstituente glatt einen modifizierenden Beitrag zu der Bedeutungskonstituierung der ganzen Wortverbindung. Auf der ersten Ebene tragen die bereits besprochenen konzeptuellen Metaphern: SCHWIERIGE LAGE IST UNSICHERER BODEN, SICHERHEIT/GEBORGENHEIT IST STABILER BODEN; GUT IST OBEN, SCHLECHT IST UNTEN, FEHLER IST STURZ zur Bedeutungskonstituierung bei, sodass in allen Konzeptualisierungen die Aspekte des Risikos, der Verlustgefahr, der Ungewissheit über die Rentabilität der abgeschlossenen Geschäfte zum Ausdruck gebracht werden. Schematisch werden die Bedeutungskonstituierungsmechanismen in der Abbildung 44 geschildert:

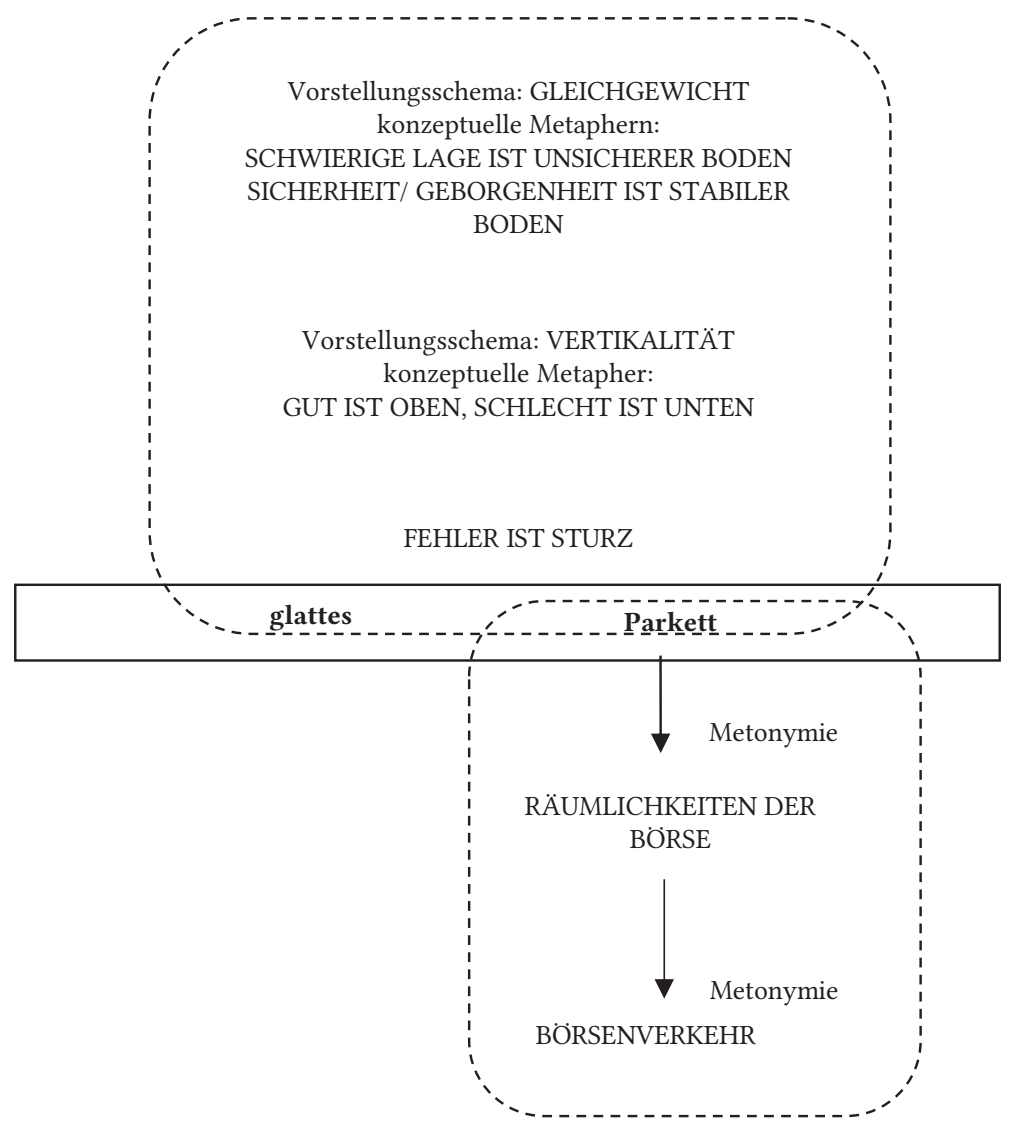

Abb. 44: Bedeutungskonstituierungsmechanismen für das Verwendungsprofil 2 ,Börsenverkehr und die damit verbundenen finanziellen Risikos: 
Verwendungsprofil 3: ,ein schwieriger Bereich, ein heikles Thema' (4 Belege) Das dritte, durch vier Belege vertretene Verwendungsprofil weist viele Parallelen $\mathrm{zu}$ anderen Idiomen des semantischen Feldes der ,schwierigen Lage' auf: Glattes Parkett bezieht sich hier auf eine verfängliche, heikle Lage der Aktanten, die in ihren Handlungen durch äußere Umstände eingeschränkt sind. Dies kommt deutlich im folgenden Gebrauchsbeleg zum Ausdruck:

(35) Letztendlich wußte niemand der Damen und Herren zu sagen, wie das heikle Datum - 50 Jahre Kriegsende, 50 Jahre Nürnberger Prozesse, 60 Jahre Verkündigung der Nürnberger Rassengesetze - denn zu begehen sei. Also übte man sich allseits in Vorsicht - nur ja keinen Fehler machen auf diesem glatten Parkett! - und zerpflückte ersatzweise die Vorlage der Verwaltung. „Weniger wäre mehr gewesen, kam die Klage aus den Reihen der CSU, am Ende werde das Überangebot an kollektiver Trauerarbeit noch zu einer Übersättigung in der Bevölkerung führen. Die Zeit, 04.11.1994

Auf die verwickelte Lage, in der politische Fehler mit weitreichenden Konsequenzen möglich sind, wird ebenfalls im Gebrauchsbeleg (36) verwiesen: In einem der Entspannungspolitik zwischen der DDR und der BRD gewidmeten Artikel ergeben sich die potenziellen Schwierigkeiten aus den internationalen Begebenheiten der durch Eisernen Vorhang geteilten Welt:

(36) Beide Seiten bewegen sich also auf glattem Parkett. Es scheint, als wolle die DDR den geringen Spielraum, den sie im Ostblock hat, bis zum äußersten nutzen. (...). In ganz ähnlicher Lage befindet sich die Bundesregierung. Zwar haben die Amerikaner versichert, daß von Handelsbeschränkungen und Boykottmaßnahmen nur die Sowjetunion, nicht aber die übrigen Ostblockländer betroffen sein sollten. Aber eine demonstrative Ausweitung der Wirtschaftsbeziehungen zwischen beiden deutschen Staaten würde zumindest in der amerikanischen Öffentlichkeit nicht gut ankommen.

Die Zeit, 18.04.1980

Die Bedeutung dieser Belege wird vor allem auf der Ebene konstituiert, auf der die ganze Wortverbindung einer semantischen Derivation unterzogen wird. Das kulturell-gesellschaftliche Wissen vom Parkett und die sich daraus ergebenden metonymischen Verschiebungen, die in den Verwendungsprofilen 1 und 2 von Relevanz waren, spielen hier eine eher untergeordnete Rolle. Von Relevanz ist der unsichere Boden in der Ausangsdomäne, auf dem jeder einzelne Schritt mit größter Vorsicht zu stellen ist. Als die wichtigsten Bedeutungskonstituierungsmechanismen sind demnach die konzeptuellen Metaphern anzusehen (vgl. Abb. 45): 


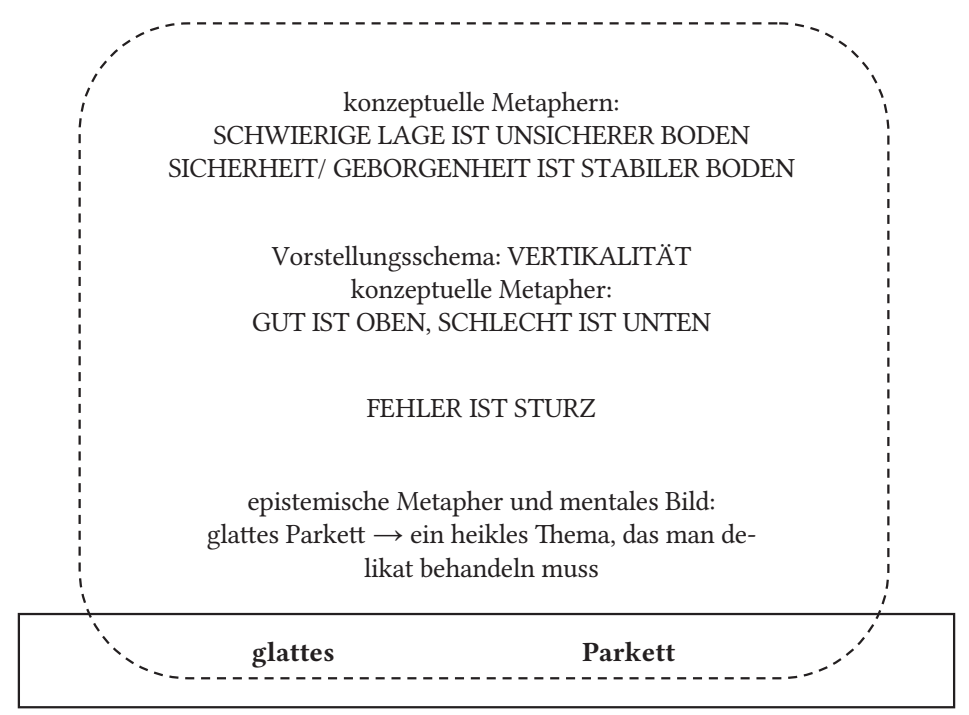

Abb. 45: Bedeutungskonstituierungsmechanismen für das Verwendungsprofil 3 ,ein heikles Thema, ein schwieriger Bereich!

\subsection{4 Resümee mit Schwerpunkt: Epistemische Metaphern und Konstituierung der Idiom-Bedeutung}

Die detaillierte Analyse des authentischen Usus von den besprochenen drei Idiomen führt die Vielfalt der Verwendungsprofile und Verwendungsmuster vor Augen. Zwar lassen sich in der Mehrheit der Gebrauchsbelege die zu besprechenden Phraseologismen pauschal mit der Bedeutungsparaphrase ,eine riskante, unsichere, schwierige Lage' umschreiben, dennoch werden bei näherer Betrachtung subtile Bedeutungsunterschiede ersichtlich. Die aus dem Sprachgebrauch eruierten Verwendungsprofile sind zur Veranschaulichung in der Tab. 20 zusammengestellt.

Aus semantischer Perspektive eignen sich diese Idiome hervorragend zur Veranschaulichung der Rolle der epistemischen Mappings und des mentalen Bildes bei der Konstituierung der Idiom-Bedeutung. Bis auf eine ausschließlich metonymische Bedeutungsverschiebung im dritten Verwendungsprofil des Idioms schwankender Boden (vgl. Belege 9,10,11) sind nämlich allen übrigen Verwendungsprofilen und -mustern dieselben konzeptuellen Metaphern SCHWIERIGE LAGE IST UNSICHERER BODEN, SICHERHEIT/GEBORGENHEIT IST STABILER BODEN gemeinsam. Den meisten Verwendungsprofilen liegen des Weiteren die konzeptuellen Metaphern GUT IST OBEN, SCHLECHT IST UNTEN SOwie FEHLER IST STURZ zugrunde. Nichtsdestotrotz weisen die Idiome aufgrund der unterschiedlichen mentalen Bilder und der dahinter stehenden, auf dem Weltwissen beruhenden epistemischen 
Mappings subtile Bedeutungs- und Verwendungspräferenzen auf. Der Einfluss der epistemischen Mappings auf die Konstituierung der phraseologisierten Bedeutung lässt sich dabei auf wenigstens drei Ebenen feststellen: (i) er kommt in den spezifischen Gebrauchspräferenzen und Bedeutungsaspekten zum Vorschein, die nur in einem der drei Idiome vorkommen, (ii) er wird in den Substitutionsproben ersichtlich, die man an weitgehend synonymen Verwendungsprofilen durchführt, (iii) er entfaltet sich in dem sprachspielerischen Gebrauch der Phraseologismen.

Tab. 20: Zusammenstellung der ermittelten Verwendungsprofile für Idiome: dünnes Eis, schwankender Boden, glattes Parkett.

\begin{tabular}{|c|c|c|}
\hline dünnes Eis & schwankender Boden & glattes Parkett \\
\hline $\begin{array}{l}\text { 1. unsichere, riskante, } \\
\text { schwierige Lage } \\
\text { einer Person } \\
\text { 2. eine umstrittene, nicht } \\
\text { gut begründete Grundlage } \\
\text { eines Gesetzes oder der } \\
\text { Auslegung eines Gesetzes, } \\
\text { einer Hypothese, These, } \\
\text { einer Argumentation } \\
\text { 3. ambiguer und } \\
\text { idosynkratischer } \\
\text { Gebrauch }\end{array}$ & $\begin{array}{l}\text { 1. unsichere, schwierige Lage } \\
\text { einer Person } \\
\text { 2. etw. eine Theorie, eine } \\
\text { Argumentation, eine } \\
\text { Anklage, die Wirtschaft } \\
\text { hat unsichere, umstrittene } \\
\text { Grundlagen } \\
\text { 3. kein fester Boden: } \\
\text { Schiffsdeck oder tektonisch } \\
\text { unsichere Gebiete } \\
\text { 4. literaler oder } \\
\text { idiosynkratischer } \\
\text { Gebrauch }\end{array}$ & $\begin{array}{l}\text { 1. unsichere, riskante Lage } \\
\text { einer Person, die in einem } \\
\text { Tätigkeitsbereich aktiv } \\
\text { ist, in dem die Beachtung } \\
\text { der Umgangsformen von } \\
\text { Relevanz ist } \\
\text { 2. Börsenverkehr und die } \\
\text { damit verbundenen } \\
\text { finanziellen Risikos } \\
\text { 3. ein schwieriger Bereich, } \\
\text { ein heikles Thema } \\
\text { 4. ambiguer und } \\
\text { idosynkratischer Gebrauch }\end{array}$ \\
\hline
\end{tabular}

(i) Jedes der drei Idiome weist Verwendungsprofile und Verwendungsmuster auf, die spezifische, eigenartige Bedeutungsaspekte zum Ausdruck bringen. Diese Bedeutungsaspekte sind auf die epistemischen Mappings zwischen der literalen und der phraseologisierten Lesart zurückzuführen.

Demnach tritt der Bedeutungsaspekt der anerzogenen Umgangsformen, der Kultiviertheit und der damit verbundenen sozialen Zugehörigkeit ausschließlich im Idiom ein glattes Parkett auf, was vor dem Hintergrund des kulturell-historischen Weltwissens von dem Parkett als einem Fußboden in Prachtbauten, sowie des alltäglichen Wissens vom Parkett als einem relativ teuren, pflegeaufwendigen Bodenbelag in repräsentativen Räumlichkeiten zurückzuführen ist. Wer des Parketts gewohnt ist, zeichnet sich durch ein in bestimmten Milieus erwünschtes Sozialverhalten aus. Derartige Assoziation vom Boden über eine ästhetisch ansprechende Behausung zu den gepflegten Umgangsformen kommt in Idiomen mit nominalen Konstituenten: Eis, Boden nicht vor.

Bei diesen Idiomen spielt dagegen die Bauwerk-Metaphorik und die konzeptuelle Metapher EINE THEORIE/EINE KONSTRUKTION DES MENSCHLICHEN GEISTES IST 
EIN GEBÄUDE eine nicht zu unterschätzende Rolle. Ein schwankender Boden und ein dünnes Eis gelten bekanntermaßen als für Fundamente ungeeignete, nicht genug tragfähige Flächen. Die Verwendungsprofile, in denen ungeeignete Bauflächen mit schwachen, nicht genügend begründeten Grundlagen von Theorien, Argumentationen, Thesen, Anklagen verbunden werden, lassen sich nur für diese Idiome ermitteln. Da kein Gebäude innerhalb eines bereits existierenden Gebäudes entstehen kann, ist diese Metapher beim Idiom ein glattes Parkett nicht nachvollziehbar.

Einen erwähnenswerten Beitrag zur Spezifizierung der phraseologisierten Bedeutungen leisten auch andere metonymische bzw. metaphtonymische Derivationen der nominalen Konstituenten: Boden, Parkett. Die Bedeutungsverschiebungen: (a) Parkett $\rightarrow$ Börsenräumlichkeiten $\rightarrow$ Börsenverkehr, (b) Boden $\rightarrow$ Erde $\rightarrow$ Realitätssinn, (c) Boden $\rightarrow$ Grundlage sind beispielshalber vor dem Hintergrund des alltäglichen Weltwissens nur in den Idiomen ein glattes Parkett (a) und ein schwankender Boden (b, c) möglich.

(ii) Eine weitere Möglichkeit der Untersuchung des Einflusses von epistemischen Mappings auf die Konzeptualisierungen bieten die Substituierungsproben. Ersetzt man das in einem Korpusbeleg verwendete Idiom durch andere (quasi-synonyme) Idiome, dann treten die latenten Bedeutungsaspekte deutlicher hervor. Im Folgenden werden Substituierungsproben in dem ersten Verwendungsprofil aller Idiome vorgenommen, das auf eine schwierige, riskante Lage einer Person referiert.

Trotz der gemeinsamen Bedeutungsparaphrase lassen sich die Idiome dünnes Eis und schwankender Boden in den Verwendungsmustern 1.1 nur bedingt ersetzen. Die subtilen Bedeutungsnuancen kommen beispielshalber bei der Zusammenstellung des Gebrauchbelegs (37) und seiner substituierten Form zum Ausdruck:

(37) Lohnverhandlungen waren für die Teilnehmer auf beiden Seiten sicherlich selten ein reines Vergnügen. Aber auf so dünnem Eis wie in diesem Jahr haben sich Arbeitgeber und Gewerkschaften wohl noch nie bewegt - zumindest war ihnen das noch nie so bewußt. Und sie waren dabei auch noch nie so einsam. Die Zeit, 25.01.1980

(?) Lohnverhandlungen waren für die Teilnehmer auf beiden Seiten sicherlich selten ein reines Vergnügen. Aber auf so schwankendem Boden wie in diesem Jahr haben sich Arbeitgeber und Gewerkschaften wohl noch nie bewegt - zumindest war ihnen das noch nie so bewußt. Und sie waren dabei auch noch nie so einsam. Die Zeit, 25.01.1980

Im konnotativen Bereich sind nämlich diskrete Bedeutungsunterschiede spürbar, die auf das epistemische Wissen zurückzuführen sind. Das Bewegen auf dem schwankenden Boden ist zwar unangenehm, kann Schwindelgefühle hervorrufen und mit einem Sturz enden, ist aber bei Weitem nicht so gefährlich, wie es im Falle vom dünnen Eis ist, bei dessen Einbruch die Rettungschancen wegen der Unterkühlung im Eiswasser und erschwerten Zugangs zu dem eingebrochenen Ertrinkenden gering sind.

Die besprochenen Bedeutungsaspekte der Existenzbedrohung, Lebensgefahr werden besonders deutlich auch in dem folgenden Gebrauchsbeleg des Idioms 
dünnes Eis, der vom Schicksal eines zufällig angeschossenen Tischlers erzählt, der am Tatort auf ein Ausschreibungsergebnis wartete:

(38) „Ab nach Sedan“, sagt der Chef der Tischlerei, bevor man sich zur Ausschreibungs-Entscheidung ins Schöneberger Rathaus begibt. Da sind Sätze und Sequenzen hängengeblieben, die den Fernseh-Sonntagabend überdauern. Warum? Deshalb, weil hier deutlich wurde, auf welch dünnem Eis wir uns im Alltag bewegen. Die Zeit, 02.07.1971

Die Ersetzung des Phraseologismus durch die beiden Idiome ist möglich, bringt dennoch neue Bedeutungsnuancen zum Ausdruck:

$(\approx)$ „Ab nach Sedan“, sagt der Chef der Tischlerei, bevor man sich zur Ausschreibungs-Entscheidung ins Schöneberger Rathaus begibt. Da sind Sätze und Sequenzen hängengeblieben, die den Fernseh-Sonntagabend überdauern. Warum? Deshalb, weil hier deutlich wurde, auf welch schwankendem Boden wir uns im Alltag bewegen. Die Zeit, 02.07.1971

$(\approx)$ „Ab nach Sedan“, sagt der Chef der Tischlerei, bevor man sich zur Ausschreibungs-Entscheidung ins Schöneberger Rathaus begibt. Da sind Sätze und Sequenzen hängengeblieben, die den Fernseh-Sonntagabend überdauern. Warum? Deshalb, weil hier deutlich wurde, auf welch glattem Parkett wir uns im Alltag bewegen. Die Zeit, 02.07.1971

Kein anderes Idiom bringt so explizit das Schicksalhafte, das Unerwartete, die Irreversibilität im menschlichen Leben wie dünnes Eis zum Ausdruck. So wie die Dicke der Eisdecke auf zugefrorenen Seen an unterschiedlichen Stellen verschieden sein kann, ihr Betreten lebensgefährlich, das Einbrechen von Eis unerwartet und unumkehrbar ist, so ist auch die Geborgenheit, mit der wir den Alltag erleben, trügerisch, die Schicksalschläge sind ungeahnt und nicht rückgängig zu machen. Diese Dramatik ist den übrigen Idiomen nicht eigen, auf dem schwankenden Boden oder glattem Parkett kann man zwar stürzen, aber nicht so unerwartet nach unten gehen.

(iii) Besonders deutlich werden das mentale Bild und die epistemischen Mappings in den Belegen, in denen Idiome markiert gebraucht werden. Ausgebaute Weltwissensstrukturen sind notwendig, um sprachspielerische Effekte entschlüsseln zu können. Auffälliger, ambiguer, sprachspielerischer Gebrauch tritt in jedem der besprochenen Idiome vor: 2 Gebrauchsbelege beim Idiom dünnes Eis, 6 Belege beim Idiom schwankender Boden und 9 Belege beim Idiom glattes Parkett sind markiert gebraucht. Die Komplexität der Bedeutungskonstituierungsmechanismen und der wesentliche Beitrag der epistemischen Mappings zu der jeweiligen aktuellen Bedeutung werden im Folgenden an ausgewählten Gebrauchsbelegen geschildert.

Wahrscheinlich auf den Status eines Neologismus und den damit verbundenen hohen affektiven Wert ist die Tatsache zurückzuführen, dass in fast einem Viertel (9 von 40) der Korpusbelege das Idiom ein glattes Parkett markiert gebraucht wird. 
In insgesamt 8 Verwendungsbelegen ist das Idiom bewusst ambiguiert. Dementsprechend ist der Text vom Verfasser mit Absicht so arrangiert, dass beide Lesarten aktiviert werden und dann aktiv bleiben müssen, während der Rezipient mal auf die literale, mal auf die phraseologische Bedeutungsebene zurückgreift:

(39) Neuer Vertrag für Theater- und Orchesterverbund

Ansonsten bewegt sie sich sicher selbst auf glattestem Parkett. Politisch und körperlich. Doch diesmal wäre Brandenburgs Kulturministerin Johanna Wanka fast tatsächlich auf dem blank gewienerten Bühnenboden des Kleist Forum in Frankfurt (Oder) ausgeglitten - weil sie zu eilig dem Rednerpult zustrebte, an dem sie vor der öffentlichen Vertragsunterzeichnung zum Theater- und Orchesterverbundes des Landes Brandenburg gestern in der Oderstadt den Anwesenden hoffnungsvoll stimmende Worte mit auf den gemeinsam geplanten und nunmehr auch gesicherten Weg gab. Potsdamer Neueste Nachrichten, 13.08.2004

Ein ähnliches Verfahren, allerdings mit einer sequenziellen Reihenfolge (zuerst wird die literale, dann die phraseologisierte Bedeutung aktiviert), liegt in einem Konferenzbericht der Literaten vor, die über den Stand der gegenwärtigen Literatur im vornehmen Ambiente eines Schlosses diskutieren:

(40) Ein glattes Parkett, nicht das in diesen wundersamen Sälen des Schlosses Eu, sondern das der Diskussion über Form und Inhalt des Gegenwartsromans, brachte so manchen zu Fall. Etwa Robbe-Grillet, „Salz“ der Versammlung, als er mit der Behauptung gegen Toynbee junior aufstand: „Moral ist kein Thema des Romans mehr, sie ist Sache der Moralisten. Ich habe eine Welt ohne Werturteile im Kopf." Darauf Toynbee: „In Ihrem Buch ,Le Voyeur' behandeln Sie Menschen und Gegenstände auf der gleichen Ebene, geben den Algen die gleiche Wichtigkeit wie den Menschen“. Robbe-Grillet: „Mensch oder Algen, es ist das gleiche“. Die Zeit, 02.08.1956

Nicht immer wird auf die Zweideutigkeit des Idioms im Text so explizit verwiesen. In dem nachstehenden Beleg (41) werden zwar durch das Genitivattribut das glatte Parkett der Gerichtssäle beide Lesarten aktiviert, die Auslegung des Spannungsverhältnisses zwischen der wörtlichen und der phraseologischen Lesart wird aber dem Leser überlassen:

(41) Auf dem glatten Parkett der Gerichtssäle kennt er sich aus, mit den Sorgen der Schweriner mußte er sich erst vertraut machen. Doch was zum Himmel stinkt, roch er natürlich auch - und packte es an. Wie die Müllberge, -ecken und -tümpel in Schwerin. Die Zeit, 27.03.1992

Die literale Interpretation des Idioms ist in diesem Fall möglich, obwohl es aufgrund des Weltwissens einleuchtend ist, dass sich der Verfasser nicht auf die körperliche Sturzgefahr, sondern auf die Tücken der langwierigen, teuren und schwer zu prognostizierenden Gerichtsprozesse bezieht, die die Rechtsanwälte mit dem Spruch Vor Gericht und auf hoher See ist man in Gottes Hand auf den Punkt bringen. 
Bei der Konstituierung der aktuellen Bedeutung der Idiome in den Belegen (39)-(41) kommen also beide Lesarten zum Zuge. Für die phraseologische Bedeutung scheinen vor allem die Metaphern SICHERHEIT IST STABILER BODEN; GUT IST OBEN, SCHLECHT IST UNTEN; FEHLER IST STURZ von Relevanz zu sein, in der literalen Lesart wird das Wissen von der Sturzgefahr auf einem gewienerten Parkett profiliert. Beide Lesarten werden aktiviert und in der Sprachverarbeitung ,umgeschaltet', was auf der Abbildung 46 schematisch durch Pfeile dargestellt wird.

phraseologische Lesart

Vorstellungsschema: WEG

konzeptuelle Metaphern:

SCHWIERIGE LAGE IST UNSICHERER BODEN

SICHERHEIT/ GEBORGENHEIT IST STABILER BODEN

Vorstellungsschema: VERTIKALITÄT

konzeptuelle Metaphern:

GUT IST OBEN, SCHLECHT IST UNTEN

FEHLER IST STURZ wörtliche Lesart glattes Parkett

(literal: ein Fußbodenbeleg aus Massivholz, der - frisch gebohnert - glitschig ist)

Abb. 46: Bedeutungskonstituierungsmechanismen für Gebrauchsbelege (39)-(41).

Im Beleg (42) ist die Ambiguierung der Bedeutung zusätzlich dadurch gesteigert, dass man der phraseologischen Lesart unterschiedliche Interpretationen zuweisen kann:

(42) Immer ausgerutscht wären die Leute, die in der Reichskanzlei an der Voßstraße über die endlos lange Marmorgalerie zu ihm vordringen wollten. Leibarchitekt Albert Speer empfahl, einen Teppich zu verlegen, sein Führer konterte mit platter Überheblichkeit: „Wer zu mir will, soll spüren, daß er sich auf glattes Parkett begibt.“ Berliner Zeitung, 24.06.1999

Hitlers Widerwille gegen die Verlegung der Teppiche ist auf zwei Weisen interpretierbar. Glattes Parkett in seiner Äußerung kann sowohl als ,eine riskante, potenziell gefährliche Situation einer Person, die der Gunst oder Missgunst eines

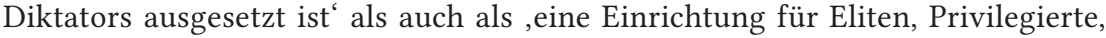
ranghohe Gesellschaftsgruppen' interpretiert werden. Bei der Konzeptualisierung der ersten Interpretation kommen die bereits besprochenen Metaphern SCHWIERIGE LAGE IST UNSICHERER BODEN; SICHERHEIT/GEBORGENHEIT IST STABILER BODEN; GUT IST OBEN, SCHLECHT IST UNTEN; FEHLER IST STURZ (vgl. 
Bedeutungskonstituierungsprozesse im ersten Verwendungsprofil) zur Geltung. In der zweiten Auslegung, die vor dem Hintergrund des Wissens von der nationalsozialistischen Rassenpolitik und dem offensichtlichen Streben nach der Gründung einer neuen Gesellschaftsordnung wahrscheinlich ist, spielt - außer den erwähnten Metaphern - ebenfalls die bereits erwähnte metonymisch-metaphorische Bedeutungsverschiebungskette (vgl. Abb. 42) eine wichtige Rolle bei der Konzeptualisierung. Beide Interpretationen können zusätzlich miteinander in der phraseologischen Lesart interagieren, durch die Kontextarrangements bleibt aber auch die literale Bedeutungsebene aktiv (vgl. Abb. 47).

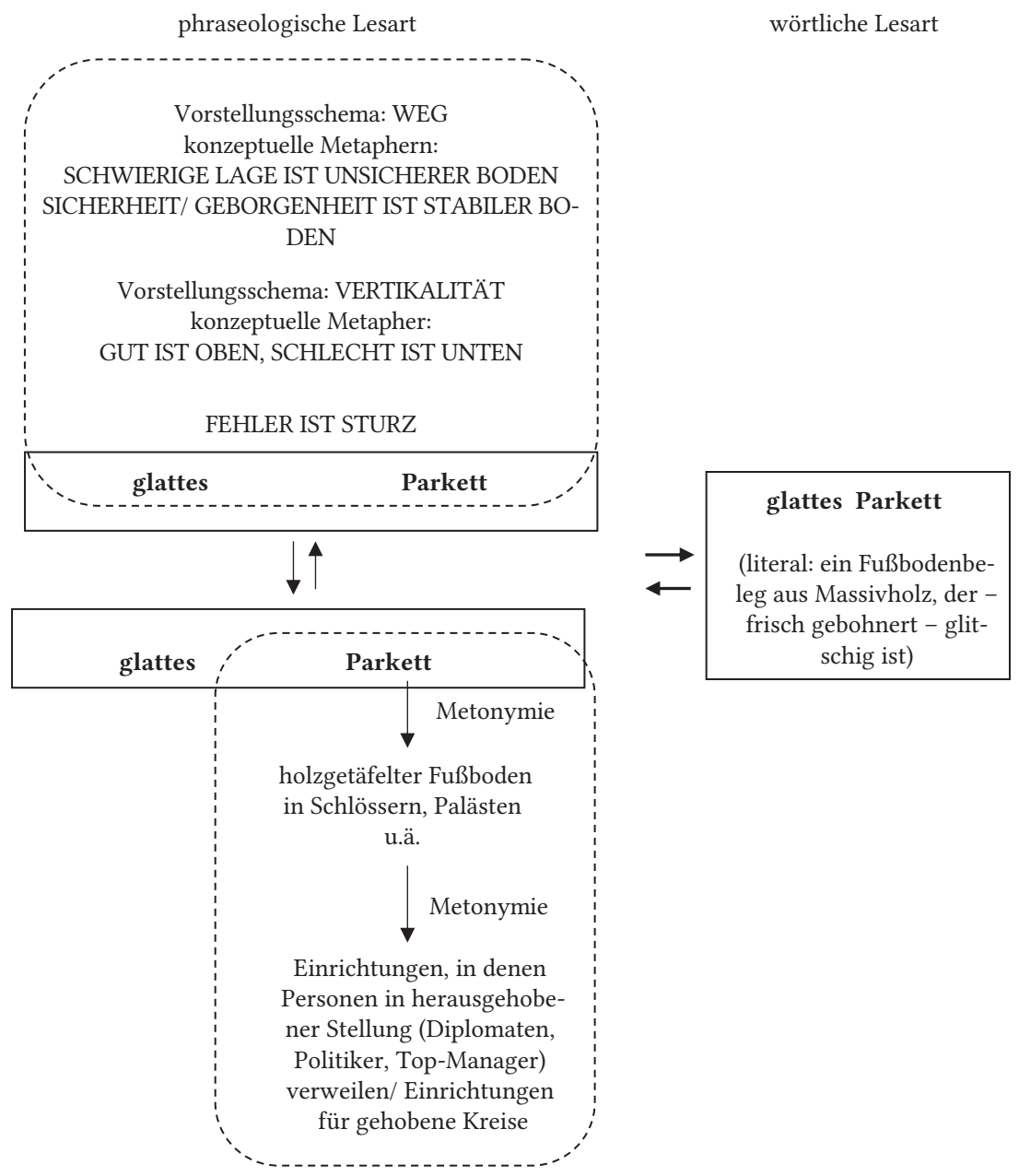

Abb. 47: Bedeutungskonstituierungsmechanismen für den Gebrauchbeleg (42). 
In allen besprochenen Belegen werden die Rezipienten also dazu aufgefordert, unter Einbeziehung zahlreicher epistemischer Wissensstrukturen eine plausible Interpretation zu erstellen, wobei sie im Verlauf des Textes mal auf die literale, mal auf die phraseologisierte Bedeutung zurückgreifen müssen.

Das Idiom ein glattes Parkett tritt überdurchschnittlich oft im idiosynkratischen, markierten Gebrauch vor, Beispiele für derartigen Sprachgebrauch lassen sich aber auch für die übrigen Idiome finden. Ein interessantes Exempel für den ambiguen, auf dem Sprachspiel beruhenden Gebrauch liefert beispielshalber das Idiom dünnes Eis:

(43) Deutsche Politiker lassen sich kaum blicken. Dafür veranstaltet Audi auf dem zugefrorenen Wolfgangsee Kurse über das, was in der bundesrepublikanischen Politik derzeit hochaktuelle Mode ist: Schleudern auf dünnem Eis. Die Zeit, 17.07.2003

Die aktuelle Bedeutung konstituiert sich im Beleg (43) durch die gleichzeitige Aktivierung der literalen und der phraseologisierten Bedeutung, so wie sie in dem Verwendungsmuster ,eine missliche, schwierige Lage, in der man leicht folgenschwere Fehler begehen kann' vorgekommen ist. Das Dynamik und Risiko ausdrückende nominalisierte Verb schleudern profiliert in beiden Bedeutungen den Aspekt des Kontrollverlustes. Die Idiombedeutung konstituiert sich im Spannungsfeld zwischen der literalen und der phraseologisierten Auslegung, die gleichzeitig evoziert werden und von vergleichbarer kognitiver Relevanz sind (vgl. Abb. 48):

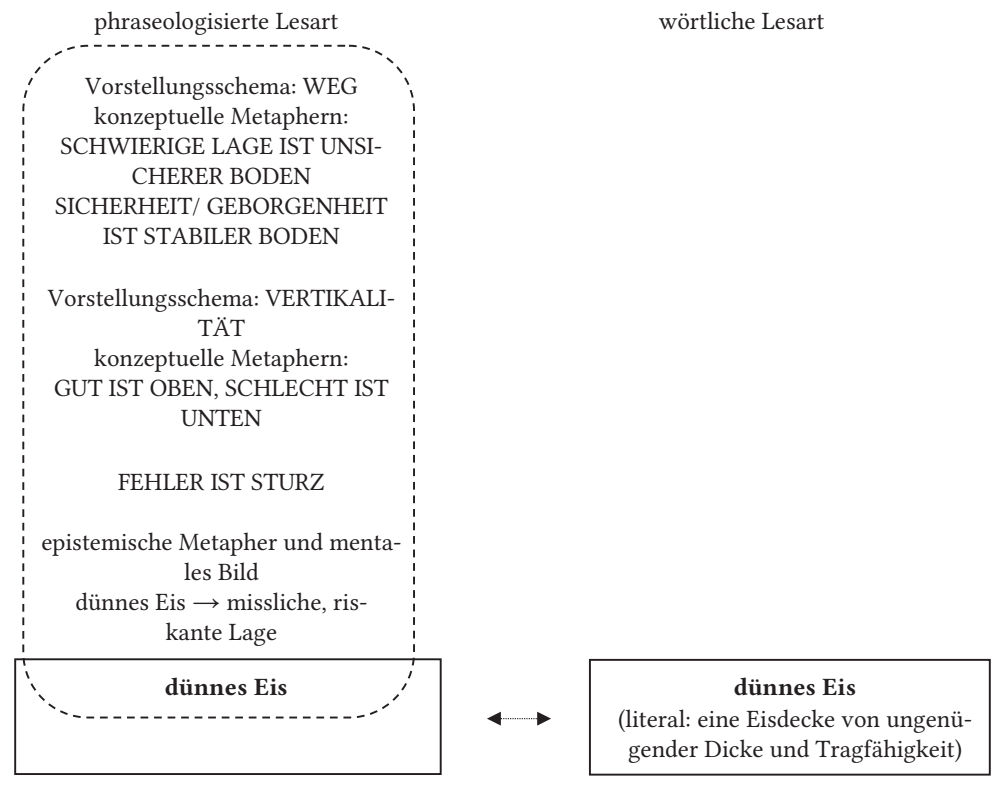

Abb. 48: Bedeutungskonstituierungsmechanismen für den sprachspielerischen Idiomgebrauch im Beleg (43). 


\subsection{SCHWIERIGKEITEN SIND HINDERNISSE, DIE EINEN ZU FALL BRINGEN}

jmdm. ein Bein stellen, Knüppel zwischen die Beine werfen

Der Weg-Metaphorik lassen sich ebenfalls zwei kausative Idiome zuordnen, deren syntaktische Form sich auf die Formel cause (y, BEcome (schwierige Lage(x))) zurückführen lässt. Im Gegensatz zu den bereits besprochenen Idiomen, in denen sich jemand in der schwierigen Situation stativ befindet (schwierige Lage (x)) oder sich in eine schwierige Lage inchoativ begibt BECOME (schwierige Lage (x)), existiert bei den zu besprechenden Idiomen ein Agens, das das Patiens meistens intentional in eine schwierige Lage bringt.

\subsection{1 ein Bein stellen}

Lexikographisch erfasste Varianten: jmdm. ein/(schweiz.) das Bein stellen Modifikationen: jmdm. kein Bein stellen, sich selbst ein Bein stellen

\section{Darstellung in lexikographischen Nachschlagewerken}

Tab. 21: Das Idiom ein Bein stellen in allgemeinen und phraseologischen Wörterbüchern des Deutschen.

\begin{tabular}{|c|c|c|}
\hline Wörterbuchtyp & Wörterbuch & Lexikographische Darstellung \\
\hline \multirow[t]{3}{*}{ allgemein } & DUw 2006 & $\begin{array}{l}\text { jmdm. ein Bein stellen (1. jmdn. durch Vorstellen } \\
\text { eines Beines zum Stolpern bringen. } 2 \text {. jmdm. } \\
\text { durch eine bestimmte Handlung Schaden zufügen; } \\
\text { jemanden hereinlegen.) }\end{array}$ \\
\hline & DUW ONLINE & $\begin{array}{l}\text { jemandem ein Bein stellen (1. jemanden durch } \\
\text { Vorstellen eines Beines zum Stolpern bringen. } \\
\text { 2. jemandem durch eine bestimmte Handlung } \\
\text { Schaden zufügen; jemanden hereinlegen.) } \\
\text { (letzter Zugriff am 27.10.2017) }\end{array}$ \\
\hline & WAHRIG 2007 & $\begin{array}{l}\text { jmdm. ein Bein stellen versuchen, ihn zu Fall zu } \\
\text { bringen; 〈a. fig.〉ihm absichtl. Schaden zufügen }\end{array}$ \\
\hline phraseologisch & DUDEN 11 & $\begin{array}{l}\text { jmdm. ein/(schweiz.) das Bein stellen: } \\
\text { 1. jmdn. durch Vorstellen eines Beins zum Stolpern } \\
\text { bringen: Jemand hat mir das Bein gestellt (Frisch, } \\
\text { Andorra 117). Wenn ich erwischt werde, hau ich } \\
\text { ab, und du stellst denen, die mir nachlaufen, ein } \\
\text { Bein (Roehler, Würde 55). 2. (ugs.) jmdm. hinterlistig } \\
\text { Schaden zufügen, jmdn. hereinlegen: Wenn Sie nicht } \\
\text { aufpassen, stolpern Sie ... über ein Bein, das Ihnen ein } \\
\text {... Kollege gestellt hat (Erne, Fahrgäste } 317) .(2011: 103)\end{array}$ \\
\hline
\end{tabular}


Tab. 20: Continued

\begin{tabular}{|c|c|c|}
\hline Wörterbuchtyp & Wörterbuch & Lexikographische Darstellung \\
\hline & $\begin{array}{l}\text { SCHEMANN } \\
2011\end{array}$ & $\begin{array}{l}\text { jm. (ein) Bein stellen } \rightarrow \text { jm. (ein) Beinchen } \\
\text { stellen ugs. } \\
\text { 1. Hast du gesehen, wie der Oswald dem Hansi schon } \\
\text { zum dritten Mal (ein) Beinchen gestellt hat? Und der } \\
\text { Schiedsrichter sieht das nicht? Warum, meint der } \\
\text { wohl, stolpert und fällt der Hansi dauernd? } \\
\text { 2. Pass auf, dass dir der Obermaier kein } \\
\text { Beinchen stellt! -Warum? - Der will mit allen } \\
\text { Mitteln verhindern, dass deine Position in der } \\
\text { Geschäftsleitung noch stärker wird, und wartet nur } \\
\text { auf eine günstige Gelegenheit, um dir eine Falle zu } \\
\text { stellen oder dich sonstwie reinzulegen. (2011: 65) }\end{array}$ \\
\hline & $\begin{array}{l}\text { REDENSARTEN- } \\
\text { index }\end{array}$ & $\begin{array}{l}\text { jemandem ein Bein stellen ,das eigene Bein nach } \\
\text { vorne strecken, damit der andere darüber stolpert; } \\
\text { im erweiterten Sinne: jemandem absichtlich schaden; } \\
\text { jemanden hereinlegen' (letzter Zugriff am 27.10.2017) }\end{array}$ \\
\hline & MÜLLER 2005 & $\begin{array}{l}\text { jmdm. ein Bein stellen (umg.) jmdm. absichtlich } \\
\text { schaden [Schädigung] „Wenn dir niemand ein } \\
\text { Bein stellt, kannst du in diesem Betrieb eine gute } \\
\text { Karriere machen.“ (2005: 52) }\end{array}$ \\
\hline
\end{tabular}

\section{Korpusgestützte Analyse anhand der DWDS-Korpora ${ }^{175}$}

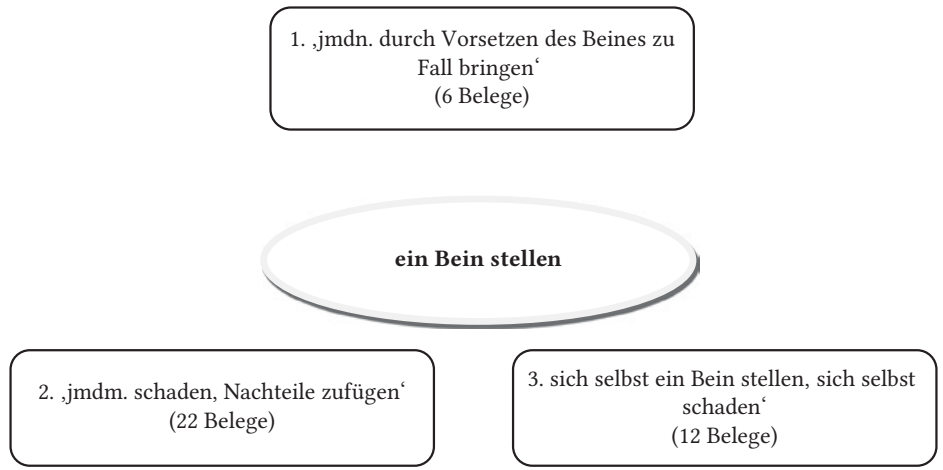

Abb. 49: Die Verwendungsprofile des Idioms ein Bein stellen anhand der Analyse der Gebrauchsbelege im DWDS-Korpus.

175 Zugriffsdatum: 24.11.2014, Suchanfrage: @Bein\&\&stellen. Kernkorpus 10/84; Die Zeit: 10/276; Berliner Zeitung: 8/197; Der Tagesspiegel: 9/88; Potsdamer Neueste Nachrichten 3/18. 


\section{Verwendungsprofil 1: ,jmdn. durch Vorsetzen eines Beines hinfallen las-} sen, jmdn. zu Fall bringen' (6 Belege)

Die zu besprechenden sechs Belege mögen auf den ersten Blick nicht idiomatisch erscheinen, bei näherer Betrachtung stellen sie doch ein Beispiel einer metonymischen Bedeutungsverschiebung dar, der konzeptuelle Metonymien TEIL STEHT FÜR DAS GANZE SOWie GRUND FÜR FOLGE zugrunde liegen:

(44) Als die drei daraufhin die Flucht ergriffen, hatte der 12-jährige Stephen Kariuki seine Chance, den Helden zu spielen: Er stellte einem der Davonlaufenden ein Bein, die anderen warfen sich auf ihn. Mittlerweile waren Menschen zusammengelaufen, und dann folgte eine der rüden Szenen, die sich meist abspielen, wenn ein Dieb oder Räuber von der Menge gestellt wird. Der Tagesspiegel, 24.06.1998

(45) Mein Freund lachte und lachte. Wütend stellte ich ihm ein Bein und fotografierte ihn, wie er so da lag und sich den Ellenbogen rieb. Dann drehte ich mich um und stapfte durch den blinkenden Schnee nach Hause. Berliner Zeitung, 05.03.2005

In diesen Belegen, von denen zwei stellvertretend angeführt werden, referiert das Idiom nämlich nicht ausschließlich auf die Teilhandlung des Bein-Stellens, sondern ebenfalls auf ihre Konsequenz - das Hinfallen des Patiens. Der Bedeutungskonstituierung liegen zwei konzeptuelle Metonymien: TEILHANDLUNG STEHT FÜR HANDLUNG (eine Ausprägung der TEIL FÜR GANZES-Metonymie) sowie GRUND FÜR FOLGE (CAUSE FOR EFFECT)-Metonymie zugrunde. Interessanterweise sind die metonymischen Mappings so tief verankert, dass die für das Verstehen notwendigen Inferenzen quasi automatisch ablaufen und die Figurativität der phraseologisierten Bedeutung kaum wahrgenommen wird: In beiden angeführten Belegen wird die Tatsache, dass das Patiens gestürzt ist, als offensichtlich eingestuft und übersprungen, versprachlicht werden erst die darauf folgenden Tätigkeiten: des Fotografierens und des Sich-Werfens. Die metonymische Bedeutungsverschiebungskette wird in Abbildung 50 geschildert.

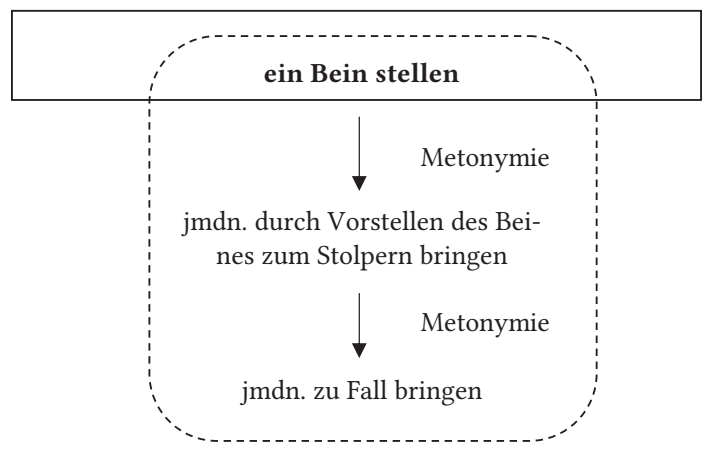

Abb. 50: Bedeutungskonstituierungsmechanismen für das Verwendungsprofil 1 ,jmdn. durch Vorsetzen eines Beines hinfallen lassen, zu Fall bringen: 


\section{Verwendungsprofil 2: ,jmdm. Schaden/Nachteile zufügen' (22 Belege)}

In dem mit den meisten Belegen vertretenen Verwendungsprofil ,jmdm. Schaden/ Nachteile zufügen' bezieht sich das Idiom auf Situationen, in denen ein Agens dem Patiens intentional (infolge des Konkurrenzkampfes oder aus Schadenfreude, Eifersucht, Rache u.Ä.) zu schaden versucht.

(46) Max Webers Unterscheidung zwischen Gesinnungsethik und Verantwortungsethik zielt auf das gleiche Problem, und sie hat einige Verwirrung in den Köpfen angerichtet. Der Vorwurf der Gesinnungsethik ist üblich geworden, wenn es gilt, unbequeme Meinungen zu diffamieren; und Verantwortungsethik nimmt jeder Kreistagsabgeordnete für sich in Anspruch, der seinen Konkurrenten ein Bein stellt. So leicht sollte man die Politiker nicht davonkommen lassen. Die Zeit, 20.06.1975

(47) Zudem betonen sie die präfeministischen Ansätze der scheinbar hausbackenen, konservativen Day-Hudson-Komödien: hier die tapfere Frau, die im Beruf ernst genommen werden will, dort der miese Chauvi, der ihr ein Bein stellt. Als Wiedergeburt von Doris Day schreibt Barbara Novak (Renée Zellweger) ein Buch über Frauen, die der romantischen Liebe adieu sagen. Der Tagesspiegel, 24.12.2003

In einigen Belegen treten in der Rolle des Patiens Abstrakta auf:

(48) Peinlich? Gewiß, aber nicht, weil hier dem Geschmack ein Bein gestellt und das Schamgefühl verletzt wird, sondern peinlich wegen der Dummheit und Primitivität, die solchen Szenen anhängt. Pikant sollten sie sein, und statt dessen verspritzen sie nur Reeperbahn-Erotik. Die Zeit, 06.06.1957

In insgesamt 7 Belegen aus dem thematischen Bereich Sport könnte man die vorgeschlagene Bedeutungsparaphrase um ,den Gegner schlagen, besiegen, ihm eine Niederlage bereiten' erweitern.

(49) "Wir fahren als krasser Außenseiter zu diesem Spiel", bleibt Trainer Thomas Leek deshalb auch Realist. Es sieht zur Zeit überhaupt nicht danach aus, als könne man solch starken Mannschaften ein Bein stellen. Selbst eine Wiederholung des 0:0 vom Vorjahr dürfte schwer fallen. Potsdamer Neueste Nachrichten, 28.11.2003

(50) Die Regionalliga-Volleyballerinnen, die mit dem Ziel des Meisterschaftssieges die Saison begannen, treffen am Sonnabend auf den Tabellenzweiten Rudow. Dort kann die Mannschaft um Trainer Morten Gronwaldt einem potenziellen Aufstiegskandidaten ein Bein stellen, bevor eine Woche später das Duell gegen Tabellennachbar Staßfurt ansteht. Potsdamer Neueste Nachrichten, 20.11.2003

Die Bedeutung des Idioms konstituiert sich in diesen Belegen in zwei Schritten. Den ersten Schritt macht die bereits geschilderte metonymische Bedeutungsverschiebungskette aus, die für die erste Bedeutung konstitutiv war: Die Handlung des Beinstellens steht hier metonymisch für die Handlung des Zu-Fall-Bringens. Dem Derivationsmechanismus liegen die konzeptuellen Metonymien: GRUND STEHT FÜR FOLGE, TEIL STEHT FÜR DAS GANZE, d.h. DIE TEILHANDLUNG (ein Bein 
stellen) STEHT FÜR DIE HANDLUNG (zu Fall bringen). Im zweiten Schritt erfolgt eine metaphorische Verschiebung aus dem Bereich des Körperlichen in den Bereich des Abstrakteren: Die metaphorischen Mappings verbinden dann den körperlichen Sturz mit den Domänen des Schadenzufügens im Beruf und in der Politik, des Misserfolgs im Sport (vgl. Abb. 52).

Konstitutiv für die Idiom-Bedeutung der beiden in diesem Kapitel zu behandelnden Phraseologismen ist die FEHLER als sturz-Metapher, die in folgenden Ausprägungen: SCHWIERIGKEITEN SIND HINDERNISSE, DIE EINEN ZUM FALL BRINGEN; FALLEN IST IN SCHWIERIGKEITEN GERATEN; JMDN. ZU FALL BRINGEN IST JMDM. SCHADEN/JMDN. IN SCHWIERIGKEITEN BRINGEN zur Geltung kommt. Unverkennbar ist ebenfalls der Einfluss von zwei potenten bildschematischen konzeptuellen Metaphern auf die Konzeptualisierungen: der auf dem image schema PATH basierenden Metapher von einem großen Generalitätsgrad LEBEN IST EIN WEG (und ihrer Ausprägung SCHWIERIGKEITEN SIND HINDERNISSE AUF DEM WEG), sowie der weitverbreiteten konzeptuellen Orientierungsmetapher GUT IST OBEN, SCHLECHT IST UNTEN, der das image schema VERTIKALITÄT zugrunde liegt.

Auf die Weg-Metaphorik wurde im Vorangehenden bereits eingegangen, an dieser Stelle werden drei Spezifizierungen der LEBEN IST EIN WEG-Metapher behandelt, die bisher nicht zur Sprache gebracht worden sind. Die erste Strukturmetapher ZIELE IM LEBEN ANSTREBEN IST ZU DEN ZIELEN ZU FUSS GEHEN rückt die einzelnen zu bewältigenden Strecken des Ausgangsbereiches in den Fokus der Aufmerksamkeit und lässt sie in der Zieldomäne als Schritte zu Lebenszielen konzeptualisieren. Sprachlich manifestiert sich diese Strukturmetapher u.a. in folgenden Ausdrücken:

ZIELE IM LEBEN ANSTREBEN IST ZU DEN ZIELEN ZU FUSS GEHEN

Fortschritt, Aufwärtsbewegung, Aufwärtsentwicklung

wenn du dich nicht anstrengst, wirst du nie zu etwas kommen

sie hat es weit gebracht

vorankommen, keinen Schritt vorankommen

ein Schritt vorwärts, ein Fortschritt, ein Erfolg' (redensarten-index, Zugriff am 20.10.2017)

mit jmdm. Schritt halten, die gleiche Leistung bringen, ebenbürtig sein“ (redensartenindex, Zugriff am 20.10.2017)

etw. auf die Beine stellen, etw. in bewundernswerter Weise zustande bringen' (DUW online, Zugriff am 20.10.2017)

die neue Stelle bedeutet für sie einen großen Sprung nach vorn, eine große Verbesserung ' (DUW online, Zugriff am 20.10.2017)

sich kein Bein ausreißen, sich [bei der Arbeit] nicht besonders anstrengen' (DUW online, Zugriff am 20.10.2017) 


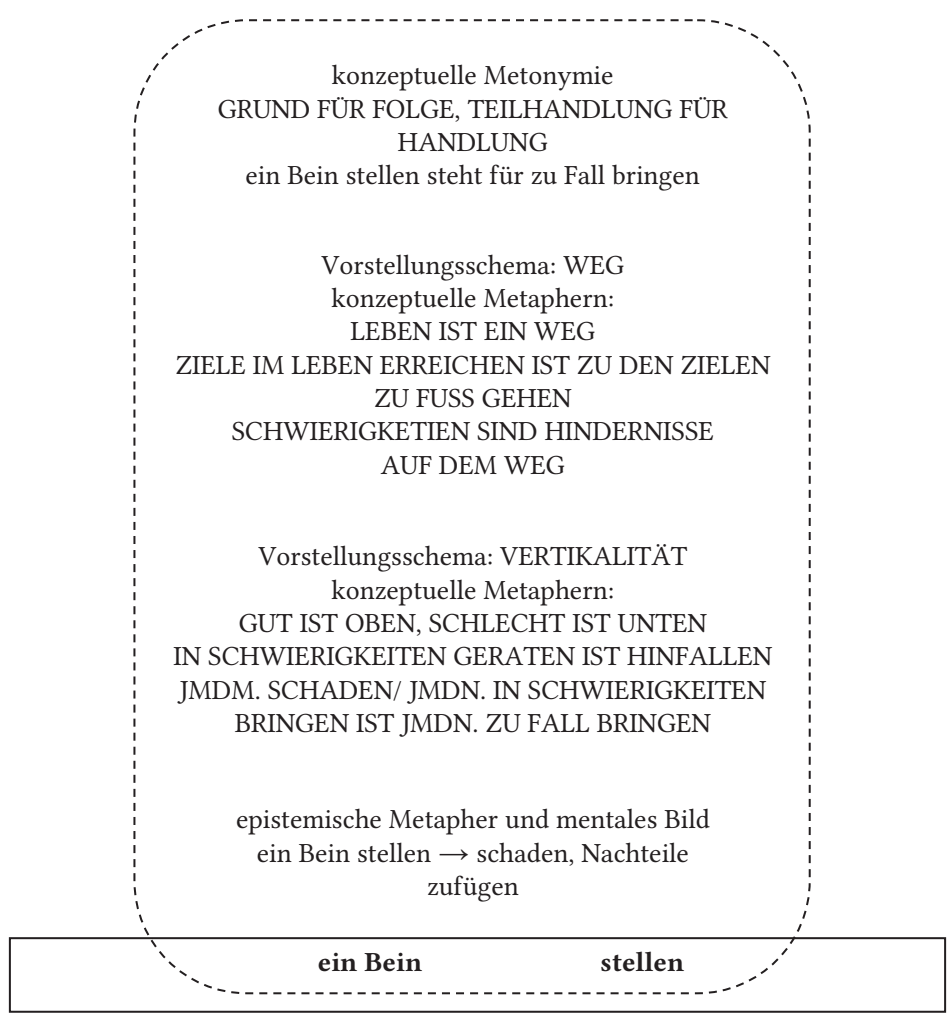

Abb. 51: Bedeutungskonstituierungsmechanismen für das Verwendungsprofil 2 ,jmdm. Schaden/Nachteile zufügen:

Zwei weitere konzeptuelle Metaphern SCHEITERN/IN SCHWIERIGKEITEN GERATEN IST HINFALLEN SOWIe JMDM. SCHADEN/JMDN. IN SCHWIERIGKEITEN BRINGEN IST JMDN. ZU FALL BRINGEN können als Spezifizierungen der FEHLER/SCHEITERN IST STURZ-Metapher betrachtet werden. Die FEHLER IST STURZ-Metapher wurde im Vorangehenden bei dem Idiom ein schwankender Boden besprochen, im Folgenden werden sprachliche Manifestationen für SCHEITERN/IN SCHWIERIGKEITEN GERATEN IST HINFALLEN Und JMDM. SCHADEN/JMDN. IN SCHWIERIGKEITEN BRINGEN IST JMDN. ZU FALL BRINGEN angeführt: 
SCHEITERN/IN SCHWIERIGKEITEN GERATEN IST HINFALLEN

auf Kreuz fallen, einen Misserfolg erleiden ' (redensarten-index, Zugriff am 01.11.2016) in den Staub beißen, die eigene Unterlegenheit spüren müssen, sterben' (redensartenindex, Zugriff am 01.11.2016)

auf die Nase fallen ,kein Glück haben; scheitern; einen Misserfolg haben' (redensarten-index, Zugriff am 01.11.2016)

mit etw. auf den Bauch/auf die Schnauze/Fresse fallen, scheitern, einen Misserfolg erleiden' (redensarten-index, Zugriff am 01.11.2016)

auf die Nase fallen ,kein Glück haben, scheitern, einen Misserfolg haben' (redensarten-index, Zugriff am 01.11.2016)

auf die Nase fliegen ,1. hinfallen, stürzen 2. scheitern' (redensarten-index, Zugriff am 01.11.2016)

zu Fall kommen ,1. hinfallen; stürzen 2. scheitern; niedergehen; ruiniert werden“ (redensarten-index, Zugriff am 01.11.2016)

über eine Affäre, einen Paragrafen stolpern ,an etw. scheitern' (DUW online, Zugriff am 18.10.2017)

die Mannschaft ist in der ersten Runde gestolpert , hat eine Niederlage erlitten' (DUW online, Zugriff am 18.10.2017)

der Stolperstein ,Schwierigkeit, an der etw./jd. leicht scheitern kann' (DUW online, Zugriff am 18.10.2017)

etw. fällt ins Wasser ,etw. zerschlägt sich“ (DWDS-Wörterbuch, Zugriff am 20.10.2017) das Vorhaben, der Plan, Ausflug ist ins Wasser gefallen (DWDS-Wörterbuch, Zugriff am 20.10.2017)

ein tief gefallener Mensch ,ein gestrauchelter Mensch` (DWDS-Wörterbuch, Zugriff am 20.10.2017)

ein gefallenes Mädchen ,Frau, die vor-, außereheliche Beziehungen gehabt hat (DWDS-Wörterbuch, Zugriff am 20.10.2017)

die belagerte Festung, Stadt fällt ,wird erobert' (DWDS-Wörterbuch, Zugriff am 20.10.2017)

der Minister, die Regierung fällt, wird gestürzt‘ (DWDS-Wörterbuch, Zugriff am 20.10.2017)

ein Vorschlag, Antrag fällt ,wird abgelehnt' (DWDS-Wörterbuch, Zugriff am 20.10.2017)

Dieses Netz an Vorschriften klingt dicht genug, und doch sind viele Stolperfallen im Detail versteckt. (DWDS, Die Zeit, 06.04.1979, Zugriff 20.10.2017)

SCHWIERIGKEITEN SIND HINDERNISSE, DIE EINEN ZU FALL BRINGEN

JMDM. SCHADEN/JMDN. IN SCHWIERIGKEITEN BRINGEN IST JMDN. ZU FALL BRINGEN jmdm. Knüppel/einen Knüppel zwischen die Beine werfen jmdn. in die/eine Falle locken; jmdm. eine Falle stellen jmdm. Fallstricke legen 
Außer den konzeptuellen Metaphern wird die aktuelle Bedeutung in den angeführten Belegen ebenfalls durch die epistemischen Mappings mitkonstituiert. In zahlreichen Belegen $(46,49,50)$ kommt beispielshalber der Bedeutungsaspekt des Konkurrenzkampfes ${ }^{176}$ zur Geltung, das Szenario des Wettrennens wird evoziert. Die epistemischen Mappings in diesen Belegen stellt Tabelle 22 dar:

Tab. 22: Die epistemischen Mappings für das Verwendungsprofil 2 ,jmdm. Schaden/Nachteile zufügen:

\begin{tabular}{ll}
\hline $\begin{array}{l}\text { jmdm. ein Bein stellen } \\
\text { (Ausgangsdomäne) }\end{array}$ & $\begin{array}{l}\text { jmdm. Schaden/Nachteile zufügen } \\
\text { (Zieldomäne) }\end{array}$ \\
\hline $\begin{array}{l}\text { Das Vorsetzen des Beines ist intentional } \\
\text { und bewusst. }\end{array}$ & Das Agens handelt intentional. \\
\hline $\begin{array}{l}\text { Das Agens ist in nahem körperlichem } \\
\text { Kontakt zu dem Patiens. }\end{array}$ & $\begin{array}{l}\text { Das Agens ist in jedem Beleg bekannt, man } \\
\text { weiß, wer für die Tat verantwortlich ist. }\end{array}$ \\
$\begin{array}{l}\text { Wenn man hinfällt, verliert man Zeit, } \\
\text { gefährdet Gesundheit. Das Aufrichten } \\
\text { und eventuelles Auskurieren kann } \\
\text { aufwendig sein. }\end{array}$ & $\begin{array}{l}\text { In zahlreichen Belegen stehen das Agens und } \\
\text { das Patiens im Konkurrenzkampf: Wenn man } \\
\text { den Gegner hinstürzen lässt, dann wachsen } \\
\text { die eigenen Siegeschancen. }\end{array}$ \\
\hline
\end{tabular}

Verwendungsprofil 3: sich selbst ein Bein stellen, sich selbst (unwillentlich, durch eine Handlung, Aussage, Bestimmung) Schaden hinzufügen' (12 Belege)

Interessanterweise wird das Idiom in 12 Belegen in Bezug auf das Agens gebraucht. Dabei vollzieht das Agens eine undurchführbare Handlung, indem es sich selbst ein Bein vorstellt. Der innere Widerspruch in der literalen Lesart - in der Realität kann man höchstens über den eigenen Fuß stolpern, sich aber unmöglich ein Bein vorsetzen - steigert den emotionalen Wert des Phraseologismus:

(51) Offensichtlich krankt das bayerische Schulwesen allen Beteuerungen zum Trotz an der gleichen Misere wie die Schulen überall in der Republik. Die bayerischen Schulerneuerer stellen sich jedoch selbst ein Bein, wenn sie unverändert an dem Irrglauben festhalten, nur das traditionelle dreigliedrige deutsche Schulsystem könne

176 In diesen Belegen werden die Bedeutungskonstituierungsprozesse auch durch die konzeptuellen Metaphern: KONKURRENZKAMPF IST EIN WETTLAUF, ÜBERLEGENHEIT IST RÄUMLICHER VORSPRUNG beeinflusst, die auf dem Vorstellungsschema wEG basieren und für die Konzeptualisierung des Konkurrenzkampfes grundlegend sind. In der Sprache manifestieren sich diese Metaphern beispielsweise in den Ausdrücken: Vorsprung, Rückstand, Rückschritt, Abstand zu den Konkurrenten vergrößern, etw. nachholen, jmdn. aufholen, voraus sein, auf der Strecke bleiben. 
gute Schulleistungen garantieren. Leistung durch Auslese heißt die Grundidee, die von den Reformern nun rigoroser denn je verfolgt wird. Die Zeit, 08.04.1998

(52) Es ist immer wieder interessant, zu beobachten, wie die Musikindustrie sich vor lauter Vorsicht selbst ein Bein stellt. Jüngstes Bruchlandungsopfer ist der gute alte Westbam, dessen neues Album „Do You Believe In The Westworld“ vorab nur in einer sehr stark gekürzten Form an Journalisten ausgeliefert wurde; dazu wurde informiert, dass es den bekannten Techno-DJ zukünftig mit Band auf die Bühne drängen wird. Berliner Zeitung, 08.09.2005

(53) Für Lothar Späth ist sonnenklar: er ist über eine Intrige gestolpert. Der Gedanke, daß er sich selbst ein Bein gestellt hat, scheint ihn nicht zu quälen. Sein Amtsverständnis als oberster Handelsvertreter des Südwest-Staates, als Topmanager der Baden-Württemberg GmbH, hinterfragt Lothar Späth nicht. Die Zeit, 18.01.1991

Die konzeptuellen Metonymien und Metaphern, die zur Bedeutungskonstituierung des Idioms sich selbst ein Bein stellen beitragen, ähneln weitgehend den in Abb. 51 (Verwendungsprofil 2) aufgelisteten Mechanismen. Die destruktive Handlung des $\mathrm{Zu}$-Fall-Bringens in der Ausgangsdomäne sowie des Schadens in der Zieldomäne ist reflexiv auf das Agens der Handlung gerichtet (vgl. Abb. 52):

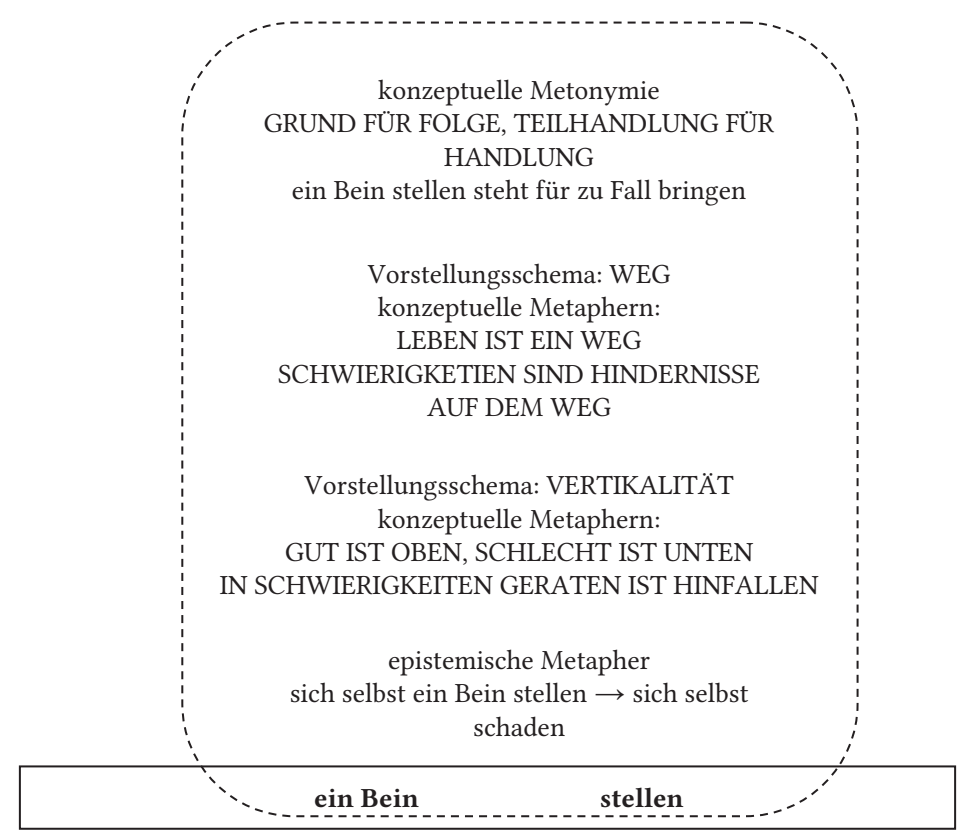

Abb. 52: Bedeutungskonstituierungsmechanismen für das Verwendungsprofil 3 sich selbst ein Bein stellen , sich selbst (unwillentlich, durch eine Handlung, Aussage, Bestimmung) Schaden hinzufügen: 
Auf der Grundlage des allgemeinen Weltwissens können folgende epistemische Mappings konstruiert werden und zur Herausbildung aktueller Bedeutungen beitragen (vgl. Tab. 23):

Tab. 23: Die epistemischen Mappings für das Verwendungsprofil sich selbst ein Bein stellen ,sich selbst (unwillentlich, durch eine Handlung, Aussage, Bestimmung) Schaden hinzufügen:

sich selbst ein Bein stellen (Ausgangsdomäne)

Das Vorsetzen des Beines ist nicht intentional.

Niemand will unter normalen Umständen hinfallen.

Wenn man hinfällt, kann man eine (u.U. schwere) Körperverletzung davontragen, Stürzen ist schmerzhaft.

Das Aufstehen und Genesen kostet Zeit, Mühe, Geld. sich selbst schaden/Nachteile zufügen (Zieldomäne)

Das Agens handelt in gutem Glauben, ist von der Richtigkeit seines Handelns überzeugt.

Niemand handelt unter normalen

Umständen autodestruktiv, selbstzerstörerisch.

Durch den Fehler entsteht ein Schaden, das Agens verliert Prestige, finanzielle Mittel, Glaubwürdigkeit u.Ä.

Die Wiedergutmachung des Fehlers kann zeitaufwendig und kostspielig sein.

\subsection{2 Knüppel $z$ wischen die Beine werfen}

Lexikographisch erfasste Varianten: jmdm. einen Knüppel zwischen die Beine werfen, jmdm. Knüppel zwischen die Beine werfen

Modifikationen: stärkere Knüppel zwischen die Beine werfen, einige/zahllose/ allerlei Knüppel zwischen die Beine werfen, immer wieder/ständig/nicht ständig Knüppel zwischen die Beine werfen, Knüppel zwischen die Beine geworfen bekommen, die meisten Knüppel zwischen die Beine werfen, einen Knüppel nach dem anderen zwischen die Beine werfen, diplomatische Knüppel zwischen die Beine werfen, mit Schwung Knüppel zwischen die Beine werfen, Knüppel zwischen die Beine werfen, wo es nur geht 


\section{Darstellung in lexikographischen Nachschlagewerken}

Tab. 24: Das Idiom Knüppel zwischen die Beine werfen in allgemeinen und phraseologischen Wörterbüchern des Deutschen.

\begin{tabular}{|c|c|c|}
\hline Wörterbuchtyp & Wörterbuch & Lexikographische Darstellung \\
\hline \multirow[t]{3}{*}{ allgemein } & DUW 2006 & $\begin{array}{l}\text { jmdm. [einen] K. zwischen die Beine werfen (ugs.; } \\
\text { jmdm. Schwierigkeiten bereiten) }\end{array}$ \\
\hline & DUW ONLINE & $\begin{array}{l}\text { jemandem Knüppel/einen Knüppel zwischen } \\
\text { die Beine werfen (umgangssprachlich: jemandem } \\
\text { Schwierigkeiten bereiten.) (letzter Zugriff am 27.10.2017) }\end{array}$ \\
\hline & WAHRIG 2007 & $\begin{array}{l}\text { jmdm. einen Knüppel zwischen die Beine werfen } \\
\langle\text { fig. }\rangle \text { ihm Hindernisse in den Weg stellen, Schwierigkeiten } \\
\text { machen [<ostmdt. im 15. Jh. für mhd. knüpfel, eigtl. } \\
\text { „Knottenstock“; zu Knopf „Knorren an Gewächsen“] }\end{array}$ \\
\hline \multirow[t]{4}{*}{ phraseologisch } & DUDEN 11 & $\begin{array}{l}\text { jmdm. Knüppel/einen Knüppel zwischen } \\
\text { die Beine werfen (ugs.): jmdm. Schwierigkeiten } \\
\text { machen: Der hatte, nur um ihm den Knüppel zwischen } \\
\text { die Beine zu werfen, alle diese frechen, höllisch } \\
\text { schlauen Klauseln und Erschwernisse ausgeheckt } \\
\text { (Feuchtwanger, Herzogin 100) (2011: 429) }\end{array}$ \\
\hline & $\begin{array}{l}\text { SCHEMANN } \\
2011\end{array}$ & $\begin{array}{l}\text { jm Knüppel/(einen Knüppel) zwischen die Beine } \\
\text { werfen/schmeißen ugs. } \\
\text { 1. Wir verstehen überhaupt nicht, warum der Klaus } \\
\text { Kiebert unserem Willy immer Knüppel zwischen } \\
\text { die Beine werfen muß! - Wieso? - Es ist jetzt schon } \\
\text { das dritte oder vierte Mal, daß er mit irgendwelchen } \\
\text { unfairen Mitteln zu verhindern sucht, daß der Willy } \\
\text { Abteilungsleiter wird. } \\
\text { 2. Vgl. in den Arm fallen (2) } \\
\text { Es gibt Leute, die können einfach nicht sehen, wenn } \\
\text { andere konstruktiv arbeiten. Die müssen beständig } \\
\text { jemandem Hindernisse in den Weg legen, Knüppel } \\
\text { zwischen die Beine werfen. Es ist ihnen einfach nicht } \\
\text { leicht gegeben, irgendjemanden etwas ausführen zu } \\
\text { lassen, ohne (zu versuchen,) ihm in den Arm zu fallen. } \\
\text { Geborene Saboteure. (2011: } 421 \text { ) }\end{array}$ \\
\hline & $\begin{array}{l}\text { REDENSARTEN- } \\
\text { INDEX }\end{array}$ & $\begin{array}{l}\text { jemandem (einen) Knüppel zwischen die Beine } \\
\text { werfen ,jemanden absichtlich behindern' (letzter } \\
\text { Zugriff am 27.10.2017) }\end{array}$ \\
\hline & MÜLLER 2005 & $\begin{array}{l}\text { jmdm. Knüppel zwischen die Beine werfen (umg.) } \\
\text { jmdn. absichtlich (beruflich) behindern [Behinderung] } \\
\text { „Wenn Sie zu einer anderen Firma wechseln wollen, } \\
\text { werden wir Ihnen keine Knüppel zwischen die Beine } \\
\text { werfen und einer Kündigung des Arbeitsvertrages } \\
\text { zustimmen.” (2005: 324) }\end{array}$ \\
\hline
\end{tabular}




\section{Korpusgestützte Analyse anhand der DWDS-Korpora ${ }^{177}$}

,jmdn. in seinen Absichten, seiner Funktion behindern, jmdn. bei etw. stören, jmdm. schaden bzw. zu schaden versuchen`

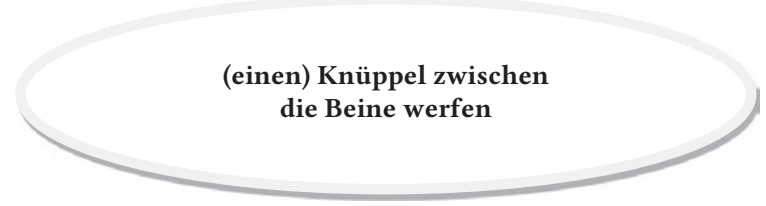

Abb. 53: Das Verwendungsprofil des Idioms Knüppel zwischen die Beine werfen anhand der Analyse der Gebrauchsbelege im DWDS-Korpus.

Das zu besprechende Idiom weist bezüglich der Nennform zahlreiche Modifikationen auf, die generell von der Pluralform des Nomens Knüppel ausgehen. Dementsprechend hat die Handlung auch einen wiederholten, rekurrenten Charakter, was gelegentlich durch Pronomina und Zahlwörter (z.B. einige, zahllose) bzw. Adverbien (z.B. immer wieder, ständig) unterstrichen wird. Nur in einem der 40 in der Belegsammlung zusammengestellten Belege wird das Substantiv Knüppel im Singular gebraucht:

(54) In einer zunehmend globalisierten Wirtschaft könnten die Behörden aber auch deutschen Firmen, die in Amerika investieren wollen, künftig einen Knüppel zwischen die Beine werfen. Berliner Zeitung, 14.10.1999

In semantischer Hinsicht ist das Idiom relativ einheitlich und lässt sich mit der Bedeutungsparaphrase, jmdn. in seiner Handlung, seiner Funktion behindern, jmdn. bei etw. stören' umschreiben. Bezeichnenderweise wird in allen Verwendungsbelegen detailliert auf die kausalen Hintergründe des Agensverhaltens eingegangen. Dementsprechend unterscheiden sich die aktuellen Bedeutungen des Idioms in der Intentionalität der Handlung, wobei sich die meisten Belege eindeutig auf ein absichtliches, geplantes, des Offteren heimtückisches Verhalten des Agens beziehen, das aus Eifersucht, aus persönlicher Abneigung, für Gewinn u.Ä. einem Patiens, oft dem Konkurrenten, zu schaden versucht. Nur in insgesamt 6 Belegen referiert das Idiom auf die Situationen, in denen eine Handlung nicht unbedingt durch Boshaftigkeit und bewussten Willen, dem Patiens zu schaden, gekennzeichnet ist. Da

177 Zugriffsdatum: 23.05.2014, Suchanfrage: Knüppel\&\&zwischen\&\&Beine. Deutsches Textarchiv: 0; Kernkorpus 4/13 (anzeigbar: 9); Die Zeit: 13/163; Berliner Zeitung: 10/48; Der Tagesspiegel: 12/55; Potsdamer Neueste Nachrichten: 1/4. 
die Übergänge zwischen den beiden Bedeutungsnuancen fließend und die Beweggründe und Absichten des Agens meistens komplex sind, wird im Folgenden die Abgrenzung der Verwendungsmuster aufgegeben.

Verwendungsprofil: ,jmdn. in seinen Absichten, seiner Funktion behindern, jmdn. bei etw. stören, jmdm. schaden bzw. zu schaden versuchen'

In den meisten Gebrauchsbelegen stehen das Agens und das Patiens in Konkurrenz zueinander, sie vertreten unterschiedliche Interessen, das Agens kann Vorteile aus der Beeinträchtigung des Patiens ziehen, weswegen es das Patiens mit unterschiedlichen, nicht immer rechtmäßigen und fairen Mitteln unter Druck zu setzen versucht:

(55) »Sachte, sachte, liebe Genossin, « wehrte er ab. »Im Augenblick sind uns stärkere Knüppel zwischen die Beine geworfen worden, als Ihre hilfsbereiten Damen aufheben können. Wenn England die deutsche Konfektion boykottiert, so können wir einpacken.« Braun, Lily, Memoiren einer Sozialistin, München: Langen 1911, S. 10070

(56) Dorn im Auge von HDW ist, dass die Thyssen-Werft in Emden entgegen der Absprache die U-Boot-Kapazitäten aufgestockt hat. Außerdem werfe der mögliche zukünftige Partner HDW bei der internationalen Vermarktung der von der schwedischen HDW-Tochter Kockums gebauten Korvette Knüppel zwischen die Beine. Hierüber gebe es unterschiedliche Interpretationen bei beiden Gruppen, räumt Thyssen-Sprecherin Andrea Wessel ein. Der Tagesspiegel, 27.01.2002

In zahlreichen Belegen wird zusätzlich die Boshaftigkeit des Agens, sein heimtückisches Handeln hervorgehoben. Oft kommen dabei persönliche Animositäten zum Ausdruck:

(57) Wolfgang Schäuble und Oskar Lafontaine verwenden einen beträchtlichen Teil ihrer Energien darauf, dem jeweils anderen Knüppel zwischen die Beine zu werfen, ohne sich dabei erwischen zu lassen. Sie bedienen sich der Parteifreunde aus der zweiten Reihe, um publikumswirksame Streitereien anzuzetteln. Berliner Zeitung, 26.09.1998 (58) Und sie verweisen darauf, daß der Außenminister in den zurückliegenden Monaten keine Gelegenheit habe verstreichen lassen, dem Verteidigungsminister Knüppel zwischen die Beine zu werfen und bei Präsident Ford anzuschwärzen. Die Zeit, 14.11.1975 (59) Daß er Politik in ausgefahrenen Bahnen betreibe, wirft ihm allen voran Philippe Séguin vor, der selber gerne Premierminister geworden wäre. Nun bleibt er Präsident der Nationalversammlung und darf von seinem Hochsitz aus Juppé Knüppel zwischen die Beine werfen. Beide sehen weniger den Premierministerposten als den großen Preis, für den sich jede Schlacht lohnt, als vielmehr den Thron im Elysée. Beide gebärden sich seit Jahren als eifersüchtige Zöglinge Chiracs, und beide sind finster entschlossen, diesen im Jahr 2002 zu beerben. Schon 1979, als sie zum ersten Mal aufeinandertrafen, hat Philippe Séguin im „Chez Edgard“, wo die politische Klasse gern speist, prophetisch ausgerufen: „Irgendwann wird es heißen: er oder ich.“ Die Zeit, 22.05.1995

In einigen Belegen ergibt sich die angespannte Beziehung zwischen dem Agens und dem Patiens nicht aus der gegenseitigen Konkurrenz, sondern aus der Natur 
der Aktanten. Der Generationskonflikt zwischen Kindern und Erwachsenen stellt ein typisches Beispiel für ein derartiges Spannungsverhältnis dar, ahnungslose Erwachsene, denen die Welt der Kinder verschlossen bleibt, bereiten ihren Schützlingen unbeabsichtigt Schwierigkeiten:

(60) Oder ein Portal, durch das Voldemort Einfluss auf seine Gedanken, Träume, ja eventuell gar nächtliche Handlungen nehmen kann? Diese unheimliche Präsenz des Dunklen Lords, kombiniert mit den zahllosen Knüppeln, die übelmeinende oder bloß ahnungslose Erwachsene den kindlichen Helden zwischen die Beine werfen, reicht für viele Stationen einer verwickelten Handlung ein ausgedehntes Finale inklusive. Der Tagesspiegel, 24.06.2003

In 5 Belegen wird die Position des Agens durch bürokratische Behörden (oder metonymisch Bürokratie) eingenommen. Zur Natur des Bürokratismus gehört das Handeln nach einem vorgefertigten Schema, was einerseits eine Rationalisierung und Gerechtigkeit zur Folge hat, andererseits den Besonderheiten von Einzelangelegenheiten oft nicht gerecht wird. In der Folge sind bürokratische Entscheidungen der an Vorschriften gebundenen Behörden als kleinlich, kurzsichtig und zerstörerisch empfunden:

(61) „Ich war entsetzt, wie sich hier alles verändert hat“, sagt Ernst Schliemann: „Als wir das Land Mitte der 90er Jahre verließen, da hatten die Leute noch Mut und Ideen. Jetzt erleben wir nur noch Resignation und Hilflosigkeit. Wenn jemand was versucht, wirft ihm die deutsche Bürokratie Knüppel zwischen die Beine." Dann erzählt er die Geschichte eines Investors, der eine Strandgaststätte mit Biergarten aufbaute. Dem wurde in einem vierseitigen Brief mitgeteilt, dass er seinen Biergarten nicht Biergarten nennen dürfe, weil er runde Tische habe. In deutschen Biergärten müssten aber eckige Tische stehen. Potsdamer Neueste Nachrichten, 23.07.2004

In Extremfällen kann die überkorrekte Einhaltung der Vorschriften zu menschlichen Tragödien führen: So tötet eine verzweifelte Mutter ihren schwerbehinderten Sohn und versucht, Selbstmord zu begehen, nachdem ihre Hilfegesuche von den Behörden abgeschlagen worden sind:

(62) Die Frau war an ihre Grenzen gelangt, weil ihr von verschiedenen Ämtern immer wieder „Knüppel zwischen die Beine geworfen worden sind“, glaubt Beatrice Huber von der Lumia-Stiftung. Sie berichtet, dass Brigitte R. seit Juli 2003 versuchte, eine neue Wohnmöglichkeit und einen Platz in einer Tagesförderwerkstatt für ihren Sohn zu bekommen. Ricco R. hatte nach seinem Motorradunfall vor etwa zehn Jahren ein Schädelhirntrauma erlitten. Seither war er schwerbehindert und saß als Wachkomapatient im Rollstuhl. Um eine bessere Betreuungsmöglichkeit zu finden, sei Brigitte R. vor rund vier Jahren aus Forst (Brandenburg) nach Berlin gezogen, sagt Huber. Der Tagesspiegel, 17.12.2004

Inwieweit die Beschlüsse der Behörden auf die Routinisierung, inwieweit auf die Herzlosigkeit und bösen Willen der einzelnen Beamten zurückzuführen sind, lässt sich an dieser Stelle nicht eindeutig festlegen. 
Die Bedeutungskonstituierungsmechanismen für das Idiom jmdm. Knüppel $z$ wischen die Beine werfen weisen viele Parallelen zu den Mechanismen auf, die das Idiom jmdm. ein Bein stellen in dem zweiten Verwendungsprofil gestaltet haben. Richtungsweisend für beide Idiome sind auf der ersten Ebene dieselben konzeptuellen Metaphern und Metonymien, die den körperlichen Sturz mit Schwierigkeiten im persönlichen, beruflichen und wirtschaftlichen Bereich verbinden (Abb. 54):

Ebene 1

konzeptuelle Metonymie

GRUND FÜR FOLGE, TEILHANDLUNG FÜR HANDLUNG

Knüppel zwischen die Beine werfen steht für zu Fall bringen

\section{Vorstellungsschema: WEG \\ konzeptuelle Metaphern: \\ LEBEN IST EIN WEG}

ZIELE IM LEBEN ANSTREBEN IST ZU DEN ZIELEN ZU FUSS GEHEN SCHWIERIGKETIEN SIND HINDERNISSE AUF DEM WEG

Vorstellungsschema: VERTIKALITÄT

konzeptuelle Metaphern:

GUT IST OBEN, SCHLECHT IST UNTEN

IN SCHWIERIGKEITEN GERATEN IST HINFALLEN JMDM. SCHADEN/ JMDN. IN SCHWIERIGKEITEN BRINGEN IST JMDN. ZU FALL BRINGEN

epistemische Metapher:

jmdm. Knüppel zwischen die Beine werfen $\rightarrow$ jmdn. behindern

Ebene 2

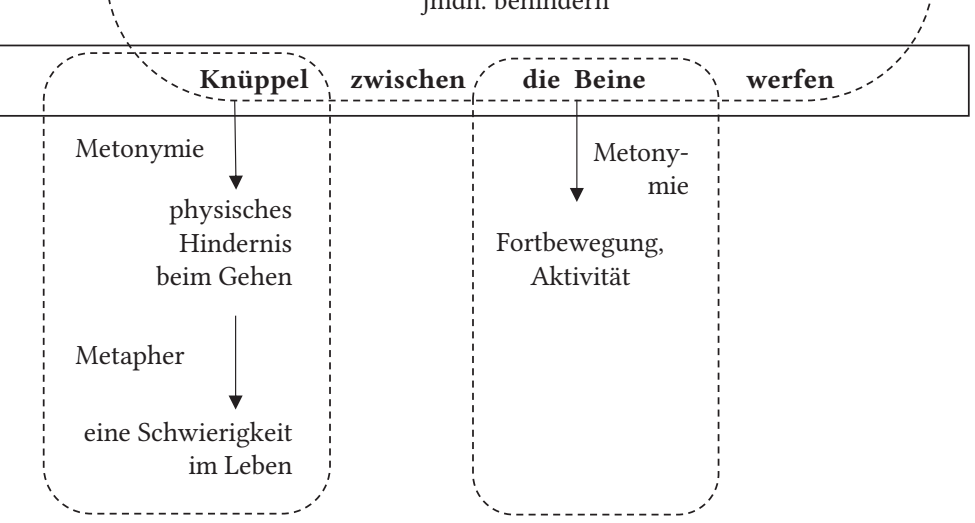

Abb. 54: Bedeutungskonstituierungsmechanismen für das Verwendungsprofil ,jmdn. in seinen Absichten, seiner Funktion behindern, jmdn. bei etw. stören, jmdm. schaden bzw. zu schaden versuchen: 
Aufgrund der Differenzen im lexikalischen Bestand und der sich daraus ergebenden unterschiedlichen mentalen Bilder sind die epistemischen Mappings, die der Bedeutungsderivation der ganzen Wortverbindung zugrunde liegen, dennoch andersartig, was in der Tabelle 25 veranschaulicht wird.

Tab. 25: Die epistemischen Mappings für das Verwendungsprofil ,jmdn. in seinen Absichten, seiner Funktion behindern, jmdn. bei etw. stören, jmdm. schaden bzw. zu schaden versuchen:

\section{jmdm. Knüppel zwischen die Beine werfen (Ausgangsdomäne).}

jmdn. in seinen Absichten/seiner Funktion behindern, jmdn. bei etw. stören, jmdm. schaden bzw. zu schaden versuchen (Zieldomäne).

Das Agens handelt absichtlich, oft hinterhältig. Er will dem Patiens vorsätzlich schaden.

Das Werfen des Knüppels ist absichtlich und bewusst. Um jemandem Knüppel zwischen die Beine werfen zu können, muss man die Knüppel bereithaben.

Das Agens handelt mit Vorbedacht. Gegenstände kann man aus größerer Entfernung werfen, es gibt keinen direkten körperlichen Kontakt zwischen dem werfenden Agens und dem betroffenen Patiens.
Verborgenes, hinterhältiges Handeln ist möglich.
Man muss manchmal mehrere Knüppel werfen, bevor man den Betroffenen zum Sturz bringt.
Es handelt sich meistens um eine Reihe von Hindernissen, Gehässigkeiten, gegen das Patiens ausgerichteten Taten, die ihm Schaden zufügen sollen.

Wenn das Patiens hinfällt, verliert es. Das In zahlreichen Belegen konkurrieren die Agens zieht aus dieser Niederlage Nutzen. beiden Aktanten. Wenn man den Gegner hinstürzen lässt, wachsen die eigenen Siegeschancen.

Zu der Bedeutung des Idioms leisten ebenfalls die Bedeutungsderivationen der nominalen Idiom-Konstituenten ihren Beitrag, die mit der Weg-Metaphorik eng zusammenhängen. So können für das Substantiv Knüppel folgende metonymisch-metaphorische Derivationen angenommen werden (vgl. Abb. 55):

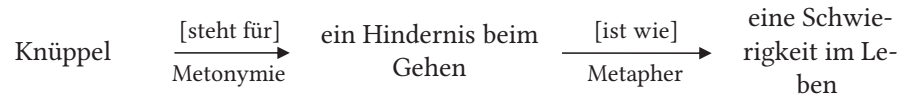

Abb. 55: Bedeutungsverschiebungskette der nominalen Konstituente ,Knüppel ' im Idiom jmdm. Knüppel zwischen die Beine werfen. 
Möglicherweise ist die Gesamtbedeutung ebenfalls durch die Bedeutungsverschiebung vom Nomen Bein beeinflusst. Bein steht hier zuerst metonymisch für die Fortbewegung (HANDLUNGSMITTEL FÜR HANDLUNG, MEANS FOR ACTION) und allgemeiner für Aktivität (vgl. Abb. 56). Die Fortbewegung, Aktivität werden dabei vor dem Hintergrund der Weg-Metaphorik und der konzeptuellen Metapher ZIELE IM LEBEN ERREICHEN IST ZU DEN ZIELEN (ZU FUSS) GEHEN mit Fortschritt, Fortentwicklung assoziiert. Die positive, mit Aktivität verbundene Konnotation des Beines ist in vielen deutschen Phraseologismen erkennbar und wird im Exkurs Somatismen in der Phraseologie und in der Kognitiven Linguistik thematisiert.

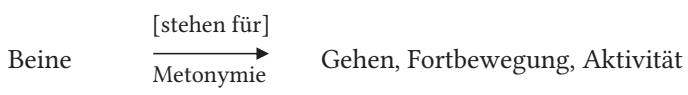

Abb. 56: Metonymische Bedeutungsverschiebung der nominalen Konstituente ,Beine im Idiom jmdm. Knüppel zwischen die Beine werfen.

\subsection{Resümee mit Schwerpunkt: Konzeptuelle Metonymien und Konstituierung der Idiom-Bedeutung}

Auf die Relevanz der epistemischen Mappings, die die konzeptuellen Metaphern ergänzen und die Konzeptualisierungen um zahlreiche Details bereichern, wurde bereits im Unterkap. 4.2.2.1.1.1.4 eingegangen. Selbstverständlich wird ebenfalls hier der Einfluss der epistemischen Mappings insbesondere dann ersichtlich, wenn man die Verwendungsprofile der Idiome ein Bein stellen, Knüppel zwischen die Beine werfen vergleicht oder Substitutionsproben in einzelnen Gebrauchsbelegen vornimmt.

So bezieht sich das Idiom ein Bein stellen auf eine Tätigkeit, bei der der Täter bekannt ist und dem Patiens intentional und offen schaden will. Diese Bedeutungsaspekte sind durch das mentale Bild und die epistemischen Mappings motiviert. Die Handlung des Bein-Stellens erfordert einen direkten körperlichen Kontakt und wird von beiden involvierten Seiten, dem Täter und dem Betroffenen, bewusst wahrgenommen. Knüppel kann man dagegen auch aus einer bestimmten Entfernung werfen, das heimtückische Handeln ist hier durchaus möglich und diese Bedeutungsnuance kommt in zahlreichen Belegen (vgl. die Verwendungsbelege 57, 58) deutlich zum Vorschein. Auf die epistemischen Mappings und das mentale Bild ist ebenfalls zurückzuführen, dass das Idiom Knüppel zwischen die Beine werfen auf eine Situation referiert, in der das Patiens mehrmals gestört wird/werden kann, während beim Idiom ein Bein stellen eine einmalige, aber wirksame boshafte Handlung vorliegt.

Am Beispiel der in diesem Kapitel besprochenen Idiome wird aber nicht erneut auf die Rolle der epistemischen Metaphern eingegangen, sondern die konzeptuellen Metonymien und ihr Einfluss auf die Bedeutungskonstituierungsprozesse 
werden in den Fokus der Aufmerksamkeit gerückt. Insbesondere das Idiom ein Bein stellen eignet sich dazu hervorragend, da hier die aufmerksamkeitssteuernde und sprachökonomische Funktion der konzeptuellen Metonymien sowie ihre Produktivität besonders deutlich ersichtlich werden.

Wegen der konzeptuellen Nähe zwischen den Entitäten, die durch metonymische Projektionsprozesse verbunden sind, sind die Metonymien prosaischer (Jakobson 2003: 47), weniger auffallend als Metaphern. Aus diesem Grunde führten sie auch lange ein Schattendasein, sowohl in der klassischen Auffassung als Tropen (vgl. Aristoteles in der Ars Poetica, nach Folkersma 2010: 100), als auch in der neueren kognitiven Auffassung (vgl. Kap. 2.3). Erst zur Jahrtausendwende, 20 Jahre nach der Veröffentlichung von Metaphors We Live By wurde wahrgenommen, dass

metonymische Phänomene und Prozesse - vor allem im Vergleich mit bevorzugter Metaphorik - wesentlich grundlegender für Sprache und Denken [sind, A. S.], als bisher angenommen wurde, da gerade die Metonymie durch ihren Wirkzusammenhang der Kontiguität viel tiefer in den semantisch-kognitiven Strukturen verankert ist als die Metaphorik. (Drößiger 2007: 153, zit. nach Folkersma 2010: 99)

Der besondere Status der Metaphern als Forschungsobjekte gilt auch für die Phraseologie. Dies widerspiegelt sich bereits in der Terminologie: Burger (2007: 63, 2010: 63, 88) spricht bei der Diskussion der Idiome mit zwei Lesarten, die sich disjunktiv zueinander verhalten, verallgemeinernd von metaphorischen Phraseologismen, Rothkegel (2004, 2014) von Metaphernphrasemen. Viele Forscher sehen den Reiz der Phraseologie darin begründet, dass an dieser Stelle die Metaphernforschung und Forschung lexikalisierter Sprache zusammenfallen:

Was Ausdrücke wie Sturm im Wasserglas, in die Höhle des Löwen gehen oder den Kopf unter dem Arm tragen u.a. so interessant macht, ist die Tatsache, dass hier zwei autonome Phänomene mit den entsprechenden Forschungsrichtungen zusammengebracht werden. Einerseits kommen die spezifischen Eigenschaften von Phrasemen zum Tragen, andererseits die Eigenschaften von Metaphern. (Rohtkegel 2004: 275)

Außer Acht wird dabei gelassen, dass viele Metaphern auf konzeptuellen Metonymien aufbauen, von denen die Metonymien GRUND FÜR FOLGE, TEIL FÜR DAS GANZE besonders produktiv und wichtig zu sein scheinen.

Die TEIL STEHT FÜR DAS GANZE-Metonymie ist in der Phraseologie weit verbreitet. Im nominalen Bereich ist sie u.a. durch die KÖRPERTEIL STEHT FÜR DEN MENscHeN-Metonymie spezifiziert. So referieren flinke Finger auf Profis an der Tastatur oder Pianisten, goldene Hände auf begabte Handwerker, kluge Köpfe auf intelligente Menschen ${ }^{178}$. Im verbalen Bereich ist die TEIL STEHT FÜR DAS GANZE-Metonymie

178 Vgl. z.B. folgende Internetbelege: Flinke Finger für die Kundenbetreuung in Berlin gesucht. https://www.ebay-kleinanzeigen.de/s-kundenservice-callcenter/mitte/ c10513518?origin= DELETED_AD, (Zugriff am 26.07.2017). Henryk hatte früher Arbeit genug, konnte alles reparieren, besaß eine »goldene Hand «. Die Zeit, 03.02.2005, Nr. 06. Wir möchten, daß kluge Köpfe auch ohne dickes Konto ein Risiko übernehmen - die Sicherheit, die wir garantieren, macht das möglich. Die Zeit, 21.02.1999, Nr. 4 
u.a. in vielen Idiomen in Form von TEILHANDLUNG FÜR HANDLUNG-Metonymie in lexikalisierter Form präsent. Sehr oft deckt sich dabei die TEILHANDLUNG FÜR HANDLUNG-Metonymie mit der GRUND FÜR FOLGE-Metonymie.

So wird im ersten Verwendungsprofil des Idioms jmdm. ein Bein stellen in keinem der 6 Belege explizit darauf verwiesen, dass das Patiens gestürzt ist, dies ist aufgrund der Inferenzen aus dem Kontext erschließbar (vgl. Belege 44, 45 sowie den Beleg 63):

(63) Sie störte ständig den Unterricht durch kuriose Geräusche und beschoß mich mit Papierkugeln, auf die Herzchen und Liebesschwüre gekritzelt waren. Sie stellte mir in der Pause ein Bein, setzte sich auf meinen Rücken und steckte mir so lange ihren Bleistift ins Ohr, bis ich versprach, sie zu heiraten. Dagegen unternehmen konnte ich nichts, denn Fredda hatte die Kraft von zehn Berggorillas, die Reflexe eines Pumas und die Ausdauer eines Delphins. Moers, Walter, Die 13 1/2 Leben des Käpt'n Blaubär, Frankfurt a. M.: Eichborn 1999, S. 130.

Dem Verstehen der Sprachäußerung liegt die konzeptuelle Metonymie zugrunde, das Vorstellen eines Beines stellt ein Paradebeispiel der Art dar, in der man einen Menschen umwerfen kann, eine Teilhandlung steht in diesem Sinne für die ganze Handlung. Bemerkenswert sind an dieser Stelle die sprachlich-kognitiven Leistungen der Metonymie. Eine metonymisch ausgedrückte Teilhandlung wird konzeptuell hervorgehoben und dient als ein salient example für die ganze Handlung. Das Hintergrundwissen wird aktiviert: Das ahnungslos gehende Patiens wird durch eine intentional ausgeführte, böswillige Handlung des Agens unerwartet und abrupt zu Fall gebracht, was schmerzhaft, erniedrigend, demütigend, u.U. sogar gefährlich sein kann. Eine kurze, einfache Paraphrasierung (z.B. jmdn. zu Fall bringen) ist ohne semantischen Verlust kaum möglich, die Metonymien leisten also einen sehr relevanten Beitrag zu der Sprachökonomie.

Die metonymische Derivation ist für die Rezeption der Belege (44), (45), (63) ausreichend, in anderen angeführten Belegen sowie im Beleg (64) kommt in einem weiteren Schritt ein metaphorischer Projektionsprozess hinzu:

(64) Für vorgeschoben hielt ich das Argument mangelnder journalistischer Erfahrung; es wurde in einer Ecke vorgebracht, in der man sich darauf verstand, publizistischen Gegenwind zu erzeugen, ohne viel nach dem politischen Gegner zu fragen. $\mathrm{Da} ß$ an einigen Stellen die Gelegenheit gesehen und genutzt wurde, mir ein Bein zu stellen, war leicht zu erkennen und noch leichter zu verschmerzen. Getroffen hat mich allerdings, daß sich fremdenfeindliche Briefe - auch aus der eigenen Partei und deren Umfeld - auf meinem Schreibtisch häuften; dabei hat man mir nicht einmal alle gezeigt. Brandt, Willy, Erinnerungen, Frankfurt a. M.: Propyläen 1989, S. 326.

Die Handlung wird infolgedessen aus dem körperlichen in einen abstrakteren politischen Erfahrungsbereich übertragen, was sich schematisch folgendermaßen darstellen lässt: 


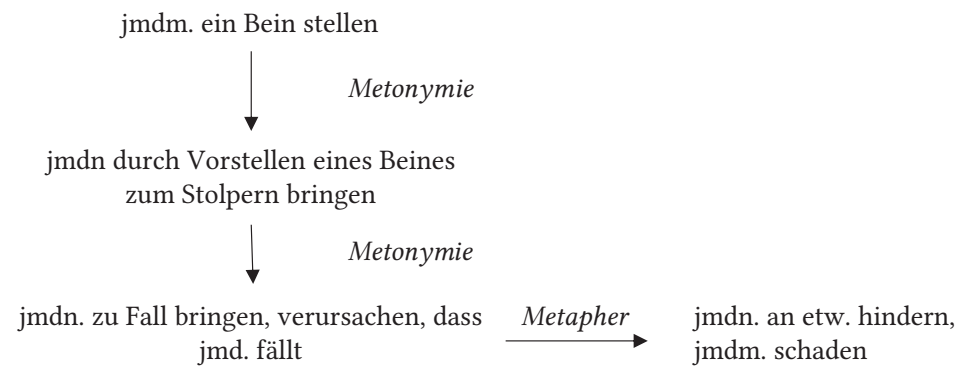

Abb. 57: Metonymisch-metaphorische Bedeutungsverschiebungen im Idiom jmdm. ein Bein stellen.

Derartige Projektionsprozesse sind in der Phraseologie im Allgemeinen sowie in dem untersuchten Diskursbereich im Besonderen weit verbreitet. Das geschilderte Schema wiederholt sich im Idiom jmdm. Knüppel zwischen die Beine werfen:

jmdm. Knüppel zwischen die Beine werfen

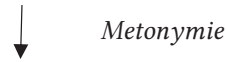

jmdm. ständig am Gehen hindern, ihn zu stolpern bringen

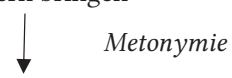

jmdm. Schwierigkeiten auf dem Weg bereiten, ihm die Bewältigung einer Strecke unangenehm/unmöglich ma$\stackrel{\text { Metapher } \longrightarrow \quad \begin{array}{l}\text { jmdn. an der Realisierung seiner } \\ \text { Pläne, Verfolgung seiner Ziele } \\ \text { hindern, jmdm. absichtlich } \\ \text { Schwierigkeiten bereiten }\end{array}}{ }$ chen

Abb. 58: Metonymisch-metaphorische Bedeutungsverschiebungen im Idiom jmdm. Knüppel zwischen die Beine werfen.

Ähnliche metonymisch-metaphorische Ketten liegen als Derivationsmechanismen auch anderen Idiomen des zu untersuchenden semantischen Feldes der Schwierigkeit/der schwierigen Lage zugrunde: 
jmdm. Steine in den Weg legen

$$
\downarrow \quad \text { Metonymie }
$$

jmdm. Hindernisse in den Weg legen

$$
\downarrow \text { Metonymie }
$$

jmdm. das Weitergehen unmöglich machen, jmdn. auf dem Weg hindern, dazu zwingen, die Hindernisse umzugehen o-

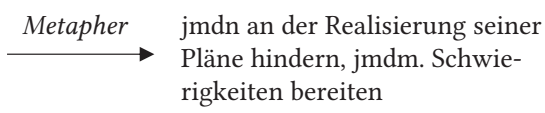
der aus dem Weg zu räumen

Abb. 59: Metonymisch-metaphorische Bedeutungsverschiebungen im Idiom jmdm. Steine in den Weg legen.

sich die Finger verbrennen

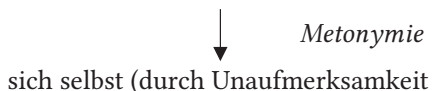

u.a.) verwunden

$$
\downarrow \quad \text { Metonymie }
$$

Schmerzliche Erfahrungen machen

(im körperlichen Bereich)

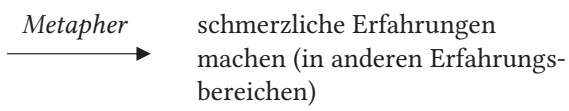

Abb. 60: Metonymisch-metaphorische Bedeutungsverschiebungen im Idiom sich die Finger verbrennen.

in eine Sackgasse geraten

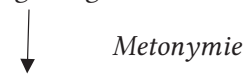

keine Durchfahrt, keinen Durchgang ha-

ben, nicht fortfahren können

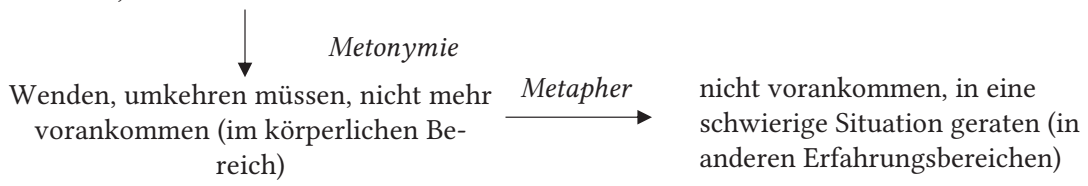

Abb. 61: Metonymisch-metaphorische Bedeutungsverschiebungen im Idiom in eine Sackgasse geraten. 
Als weitere Beispiele für Idiome, in denen konzeptuelle Metonymien auf ähnliche Art und Weise zur Bedeutungskonstituierung beitragen, können idiomatische Wortverbindungen aus der Phraseologismensammlung angeführt werden: auf Kreuz fallen, auf die Nase fallen/fliegen, mit etwas auf den Bauch/auf die Schnauze/Fresse fallen, mit etwas auf den Arsch/Hintern fallen, jmdm. (gehörig/...) die Suppe versalzen, jmdm. in die Suppe spucken, sich (Dativ) die Zähne an etwas ausbeißen, den Kopf noch/noch so eben über Wasser halten, den Hals in der Schlinge haben, jmdm. sitzt das Messer an der Kehle, jmdm. die Pistole/das Messer/ den Dolch auf die Brust/an die Gurgel/an die Kehle setzen, jmdm. brennt der Boden unter den Füßen, jmdm. den Boden unter den Füßen heiß machen, zwischen zwei Feuer geraten/kommen.

\subsection{SCHWIERIGKEITEN SIND EINE LAST}

Klotz am Bein, jmdn./etw. am Hals/auf dem Hals haben

An die Weg-Metaphorik sind ebenfalls die Phraseologismen im engeren Sinne: Klotz am Bein, jmdn./etw. am/auf dem Hals haben gebunden. Im Gegensatz $\mathrm{zu}$ den bisher besprochenen Idiomen werden dennoch nicht der Weg, seine Beschaffenheit, Passierbarkeit und die eventuellen Hindernisse profiliert, sondern der Reisende. Beiden Idiomen liegt die Erfahrung als Motiviertheitsmechanismus zugrunde, dass eine Last, die zum Tragen aufgeladen wird, dem Gehenden hinderlich ist, weswegen ein schwere Sachen tragender Mensch die eingeplante Strecke langsam, mühevoll und ohne Freude bewältigt. Diese verkörperte Erfahrung wird metaphorisch in abstraktere Domänen übertragen, wo die materielle Belastung als Schwieriges/Unerträgliches/Störendes in anderen Erfahrungssphären konzeptualisiert wird.

\subsection{Klotz am Bein}

Lexikographisch erfasste Varianten: jmdm. ein Klotz am Bein sein, einen Klotz am Bein haben, sich mit jmdm./etw. einen Klotz ans Bein binden/hängen.

Modifikationen: etw. hängt jmdm. wie ein Klotz am Bein, marschieren, als ob man einen Klotz am Bein hätte, sich als Klotz am Bein erweisen, jmdn. als Klotz am Bein bezeichnen, der größte Klotz am Bein sein, der defizitäre Klotz am Bein ist weg, etw. wird als schwerer Klotz am Bein empfunden, jmdm. wie ein Klotz am Bein hängen, zum Klotz am Bein werden, Wettbewerb mit einem Klotz am Bein, etw. wie einen Klotz am Bein mit sich herumschleppen, sich als ein Klotz am Bein erweisen. 


\section{Darstellung in lexikographischen Nachschlagewerken}

Tab. 26: Das Idiom Klotz am Bein in allgemeinen und phraseologischen Wörterbüchern des Deutschen.

\begin{tabular}{|c|c|c|}
\hline Wörterbuchtyp & Wörterbuch & Lexikographische Darstellung \\
\hline \multirow[t]{3}{*}{ allgemein } & DUW 2006 & $\begin{array}{l}\text { [in den folgenden Wendungen ist wahrscheinlich } \\
\text { an den Klotz gedacht, der Tieren auf der Weide ans } \\
\text { Bein gebunden wurde, damit sie nicht weglaufen } \\
\text { können] } \\
\text { jmdm. ein K. am Bein sein (ugs.; jmdm. hinderlich, } \\
\text { für jmdn. eine Last sein: er ist ihr nur noch ein Klotz } \\
\text { am Bein) } \\
\text { sich <Dativ> mit jmdm., etw. einen K. ans } \\
\text { Bein binden/hängen (ugs.; sich mit jmdm., etw. } \\
\text { belasten) } \\
\text { einen K. am Bein haben (ugs.; eine Last zu tragen } \\
\text { haben) }\end{array}$ \\
\hline & DUW ONLINE & $\begin{array}{l}\text { [in den folgenden Wendungen ist wahrscheinlich } \\
\text { an den Klotz gedacht, der Tieren auf der Weide ans } \\
\text { Bein gebunden wurde, damit sie nicht weglaufen } \\
\text { können] } \\
\text { jemandem ein Klotz am Bein sein } \\
\text { (umgangssprachlich: jemandem hinderlich, für } \\
\text { jemanden eine Last sein: er ist ihr nur noch ein Klotz } \\
\text { am Bein) } \\
\text { sich <Dativ> mit jemandem, etwas einen Klotz ans } \\
\text { Bein binden/hängen (umgangssprachlich: sich mit } \\
\text { jemandem, etwas belasten) } \\
\text { einen Klotz am Bein haben } \\
\text { (umgangssprachlich: eine Last zu tragen haben) (letzter } \\
\text { Zugriff am 27.10.2017) }\end{array}$ \\
\hline & WAHRIG 2007 & $\begin{array}{l}\text { sich einen Klotz ans Bein binden }\langle\text { fig. }\rangle \text { sich mit } \\
\text { etwas belasten } u \text {. sich dadurch am Vorwärtskommen } \\
\text { hindern; } \rightarrow \text { a. Keil }[<\text { mhd. klotz „Klumpen, Kugel, } \\
\text { Baumstumpf, Kloben“; } \rightarrow \text { Kloß] }\end{array}$ \\
\hline
\end{tabular}


Tab. 26: Continued

\begin{tabular}{lll}
\hline Wörterbuchtyp Wörterbuch & Lexikographische Darstellung \\
\hline phraseologisch & DUDEN 11 & jmdm. ein Klotz am Bein sein (ugs.) eine Last, ein \\
& $(2011)$ & Hemmnis für jmdn. sein: Das Mädchen lasse ich doch \\
& & hier. Sie wäre mir in der ersten Zeit nur ein Klotz am \\
& Bein. (Brecht, Mensch 72) \\
& sich <Dativ> einen Klotz ans Bein binden/hängen
\end{tabular}

(ugs.): sich etw. aufbürden: Ich habe nicht geahnt, was ich mir mit dieser ehrenamtlichen Tätigkeit für einen Klotz ans Bein binden würde.

einen Klotz am Bein haben (ugs.): eine Verpflichtung übernommen haben und dadurch in seiner Bewegungsund Handlungsfreiheit spürbar eingeengt, belastet sein: ... zumal den tschechischen Politikern sicherlich bewusst ist, dass sie mit ihren Entscheidungen in Bezug auf EU-Osterweiterung einen Klotz am Bein haben (www. parinkom.gv.at.) (2011: 424)

SCHEMANN (für jmdn.) (wie) ein Klotz am Bein sein sal

2011 1. Diese alte Tante Berti ist für die Erika (wie) ein Klotz am Bein. Sie kann sozusagen nicht mehr ausgehen; ihr ganzer Tagesablauf ist auf die alte Tante ausgerichtet. 2. Man merkt ihm an, daß er sich nicht so frei bewegen kann, wie er will; dieses Amt ist für ihn ein Klotz am Bein. Seltener (2011: 417)

REDENSARTEN- einen Klotz am Bein haben ,einer Belastung INDEX ausgesetzt sein; durch etwas in seiner Bewegungsfreiheit eingeschränkt sein; mit etwas nur Arbeit (und keinen Nutzen) haben"

(jemandem) ein Klotz am Bein sein ,(jemandem) eine Last sein umgangssprachlich; Der Klotz am Bein dieser Redensart ist ursprünglich das (eiserne) Gewicht, an das früher Sträflinge angeschmiedet wurden, um sie an schneller Flucht zu hindern'

sich einen Klotz ans Bein binden ,eine lästige Verpflichtung übernehmen umgangssprachlich` (letzter Zugriff am 27.10.2017)

MÜLLER 2005 ein Klotz am Bein sein (umg.) für andere eine Belastung sein [Belastung] „Unsere Großmutter meint immer, sie sei uns ein Klotz am Bein. Dabei haben wir sie nach dem Tode ihres Mannes gerne bei uns aufgenommen." Der Klotz am Bein dieser Redensart ist ursprünglich das (eiserne) Gewicht, an das früher Sträflinge angeschmiedet wurden, um sie an schneller Flucht zu hindern. (2005: 320) 


\section{Korpusgestützte Analyse anhand der DWDS-Korpora ${ }^{179}$}

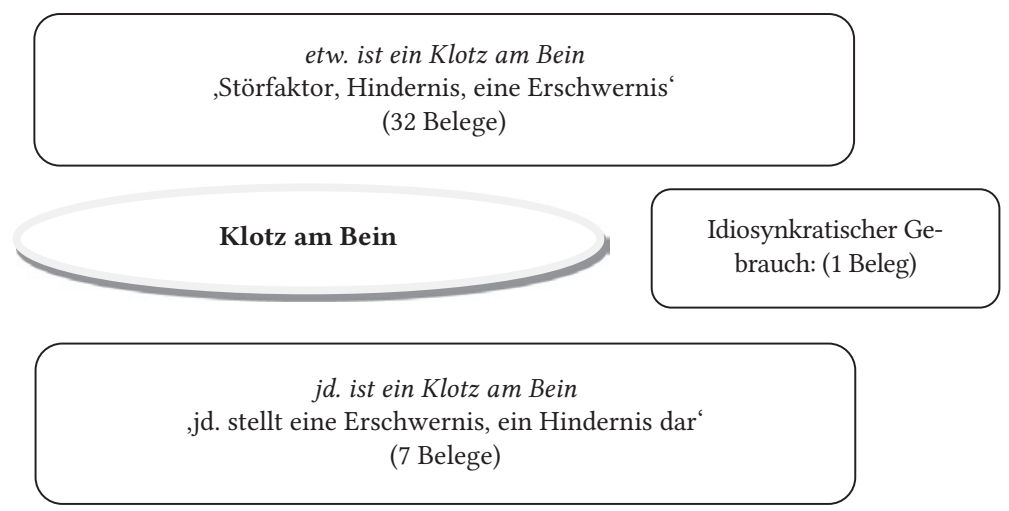

Abb. 62: Die Verwendungsprofile des Idioms Klotz am Bein anhand der Analyse der Gebrauchsbelege im DWDS-Korpus.

Verwendungsprofil 1: etw. ist ein Klotz am Bein ,etw. ist ein Hindernis, ein Störfaktor' (32 Belege)

Aus den untersuchten 40 Gebrauchsbelegen lässt sich für 32 eine Bedeutung ermitteln, in der der Klotz am Bein als ein Störfaktor, ein Hindernis bei der Bewältigung der Aufgaben, beim Erreichen der Ziele konzeptualisiert wird. Möglicherweise nehmen die Sprachteilhaber bei der Konzeptualisierung auf die Etymologie des Idioms Bezug, die auf zwei bildliche Quellen zurückgeführt werden kann. So wird dem Vieh auf einer nicht eingezäunten Weide ein Holzklotz an die Beine gebunden, um es in seiner Bewegungsfreiheit einzuschränken (vgl. Duden 11 2011: 242). Darüber hinaus kettete man in den früheren Zeiten Gefangene an einen Klotz, damit sie nicht flüchten können (ebd., Müller 2005: 320). Interessanterweise deuten die Veranschaulichungen des Idioms, die mittels der Google-Suchmaschine unter Graphiken aufgefunden werden können (https://www.google.pl/search?client=firefox$\& \mathrm{dcr}=0 \& \mathrm{biw}=1147 \& \mathrm{bih}=533 \& \mathrm{tbm}=\mathrm{isch} \& \mathrm{sa}=1 \& \mathrm{q}=\mathrm{klotz}+\mathrm{am}+$ Bein\&oq=klotz $+\mathrm{am}+$ Bein\&gs, Zugriff am 05.09.2017) darauf, dass man sich unter dem idiomatischen Klotz nicht (mehr?) einen Holzklotz, sondern vorwiegend eine eiserne Kugel, die einem mit einer Kette an das Bein angeschmiedet wird, vorstellt. Die Motiviertheit der idiomatischen Einheit ist dennoch klar: Mit einer an das Bein angebundenen

179 Zugriffsdatum: 22.04.2017, Suchanfrage: Klotz \&\&@am\&\&Bein. DWDS-Kernkorpus 21: 2/2 (anzeigbar 2); Deutsches Textarchiv: 1/1; Die Zeit: 18/201; Berliner Zeitung: 12/87; Der Tagesspiegel: 7/59. 
Last geht man nicht schnell vorwärts (Ausgangsdomäne), was in den Zieldomänen als eine Einschränkung der Arbeitseffizienz bzw. Beeinträchtigung in einer eventuellen Konkurrenz interpretierbar ist. Zwei Bedeutungsnuancen lassen sich dabei festlegen. In der ersten referiert der Klotz am Bein auf einen politischen oder gesellschaftlichen Störfaktor, eine einengende politische oder gesellschaftliche Verpflichtung, die die erwünschte Entwicklung verhindert (17 Belege):

(65) Erst 1929 kehrte das Papsttum auf die weltpolitische Bühne zurück, als es sich in den Lateran-Verträgen mit dem italienischen Staat aussöhnte und dafür von ihm den souveränen Vatikanstaat eingeräumt bekam, mit einer Fläche von 44 Hektar kein irdischer Klotz am Bein, wie es der alte Kirchenstaat gewesen war, und doch groß genug, um mit den Mächtigen der Erde diplomatisch von Gleich zu Gleich zu verkehren. Welche Stellung nimmt der Papst heute, nimmt dieser Papst ein? Berliner Zeitung, 13.05.2000

(66) In Polen schreibt die Literaturpäpstin Maria Janion in einem furiosen Essay von einem „Abschied von Polen“, von den traditionellen, romantisch-larmoyanten polnischen nationalen Mythen und Selbstbildern, die bei der Modernisierung des Landes zunehmend ein Klotz am Bein seien. Und - noch vor kurzem ein Sakrileg für das polnische Selbstverständnis - sie sagt prompt, dass die traditionelle polnische Kultur postkolonial sei, von denselben Komplexen und Verdrängungen geprägt, wie sie Edward Said im Orient festgemacht hat. Der Tagesspiegel, 27.06.2004

In insgesamt 14 Belegen bezieht sich der Klotz am Bein auf eine finanzielle Belastung, die man nicht/oder nur schwer loswerden kann:

(67) Wie der Trainer erzählte, müssen immer noch Altkredite abbezahlt werden, so dass Finanzen für die von ihm gewünschten Verstärkungen fehlen. «Das teure Stadion ist wie ein Klotz am Bein. Das ist ein Problem», erläuterte der Stuttgarter Meistermacher von 2007. Die Zeit, 24.04.2012

(68) Kein angenehmes Erbe hat der letzte Zar Nikolai Romanow da seinen „Untertanen“ hinterlassen. Auslandsschulden Rußlands aus der Kaiserzeit hängen den Nachfolgern wie ein Klotz am Bein: 30 Milliarden Dollar nannte der private russische Fernsehsender NTV als Gesamtsumme, von Schätzungen auf bis zu 200 Milliarden Dollar sprechen Quellen in Westeuropa. Berliner Zeitung, 28.11.1996

Selbstverständlich lässt sich ein erwähnenswerter Überlappungsbereich festlegen, die Verbindungen zwischen Finanzen und Politik sind nicht leicht abzugrenzen:

(69) „Es ist fraglich, ob wir überhaupt einen Hammerschlag tun dürfen“, sagt Kerstin Maria Kunitz, Sprecherin der Wohnungsbaugesellschaft Prenzlauer Berg (WIP), die mit rund 5500 notverwalteten Wohnungen den größten Klotz am Bein hat. Berliner Zeitung, 07.04.1995

Den allmählichen Übergang zwischen der literalen und der phraseologisierten Bedeutung veranschaulicht der folgende Beleg, in dem das Idiom als ein irrealer Vergleich funktioniert: 
(70) Solange das Land offen vor uns lag, mußten wir nach Möglichkeit eilen. Saumseligkeit konnte gefährlich werden, die Paks marschierten aber, als ob sie einen Klotz am Bein hätten! Im Selin-do sahen wir keine Zelte, in der Dämmerung aber kam Namgjal mit zwei Tibetern, die er in einem Quertal getroffen hatte, angewandert. Weigeldt, Paul: Lektüre zur Erdkunde. Leipzig, 1912.

Die Bedeutungskonstituierungsprozesse verlaufen auf zwei Ebenen (vgl. Abb. 63):

Ebene 1

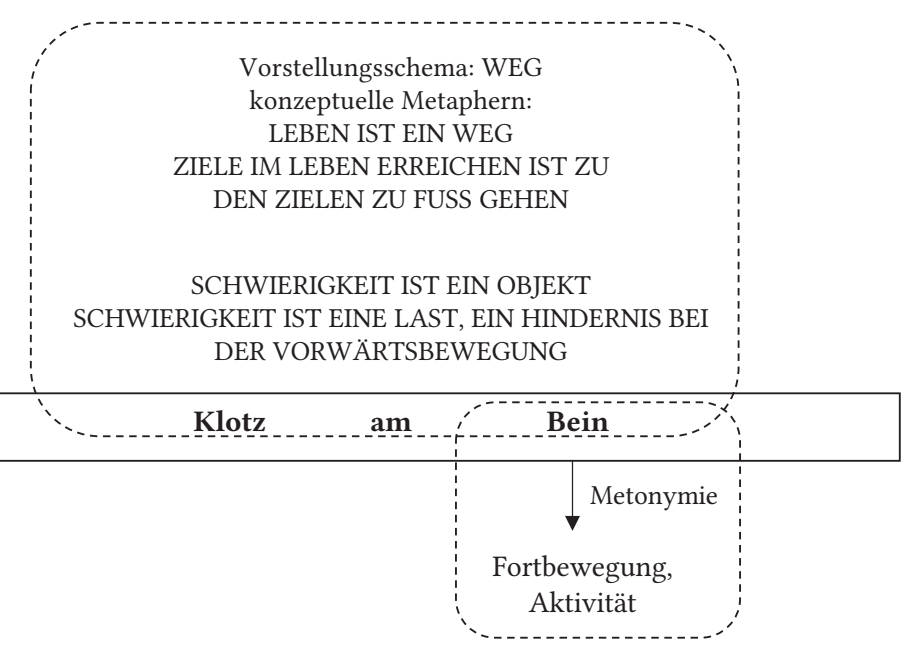

Abb. 63: Bedeutungskonstituierungsmechanismen für das Verwendungsprofil 1 , etw. ist ein Hindernis, ein Störfaktor.

Auf der ersten Ebene wird die phraseologisierte Bedeutung durch die im Vorangehenden bereits besprochene LEBEN IST EIN wEG-Metapher und ihre Spezifizierung ZIELE IM LEBEN ERREICHEN IST ZU DEN ZIELEN ZU FUSS GEHEN beeinflusst. Profiliert wird dabei der belastete Wanderer, der die Strecke langsam und unter großem Krafteinsatz bewältigt. Die verkörperte Erfahrung, wie man sich mit einer großen, von dem Tragenden als drückend empfundenen Belastung bewegt, wird aus der körperlichen Ausgangsdomäne in die abstrakteren Domänen der Politik, Wirtschaft, Finanzen projiziert, wo sie auf Verpflichtungen, Aufgaben, Erschwernisse, Probleme referiert, die einem Menschen aufgebürdet werden oder die er auf sich nimmt.

Die konzeptuelle Metapher SCHWIERIGKEIT IST EINE LAST widerspiegelt sich selbst in der Etymologie des Nomens Schwierigkeit: Auf die etymologische Bindung zwischen schwer und schwierig im Neuhochdeutschen verweist z.B. DUW online: ,mittelhochdeutsch swiric, sweric = voll Schwären, eitrig, zu schwären; 
neuhochdeutsch an schwer angelehnt ${ }^{6}$ (Zugriff am 06.09.2017) ${ }^{180}$. Schwierigkeiten werden folglich unter anderem einer Bürde, Erschwernis gleichgesetzt, als bedeutungsähnliche Nomen werden Ballast, Belastung, Ladung, Beschwerlichkeit, Zentnerlast angegeben. Als sprachliche Exemplifizierungen der Metapher können folgende Ausdrücke angeführt werden:

SCHWIERIGKEIT IST EIN OBJEKT

SCHWIERIGKEIT IST EINE LAST

ich bin dir dabei nur ein Ballast (DWDS-Wörterbuch, Zugriff am 06.09.2017)

Erschwernisse in Kauf nehmen, beseitigen (DWDS-Wörterbuch, Zugriff am 06.09.2017) die Bürde des Alters (DUW online, Zugriff am 06.09.2017)

sie hatte zeitlebens eine schwere Bürde zu tragen (DUW online, Zugriff am 06.09.2017) dass er neben seinem Studium noch beruflich tätig sein muss, bedeutet für ihn eine (zusätzliche) Erschwernis (DWDS-Wörterbuch, Zugriff am 06.09.2017)

die schrecklichen Vorstellungen, die Vorwürfe sind für ihn eine ständige, unerträgliche, große Belastung (DWDS-Wörterbuch, Zugriff am 06.09.2017)

die Last auf sich nehmen, auf andere abwälzen (DUW online, Zugriff am 06.09.2017)

unter der Last der Anforderungen zusammenbrechen (DUW online, Zugriff am 06.09.2017)

ein schweres, drückendes foch zu tragen haben (DUW online, Zugriff am 20.10.2017)

jmdm. ein schweres foch auferlegen (DUW online, Zugriff am 06.09.2017)

jeder hat sein Bündel zu tragen, jeder hat seine Sorgen' (DUW online, Zugriff am 06.09.2017)

sein Päckchen zu tragen haben, seine Sorgen, seine Bürde zu tragen haben' (DUW online, Zugriff am 20.10.2017)

sein Kreuz auf sich nehmen, geduldig tragen (DUW online, Zugriff am 06.09.2017)

mit jmdm./etw. sein Kreuz haben ,mit jmdm./etw. große Last, Mühe haben, schwer fertigwerden' (DUW online, Zugriff am 06.09.2017)

180 Vgl. auch die Angaben zu schwierig im Digitalen Wörterbuch der Deutschen Sprache: schwierig Adj. 'kompliziert, schwer zu behandeln', frühnhd. swiric, sweric, auch suerecht 'schwärend, eitrig' (15. Jh.) ist abgeleitet vom Substantiv mhd. swer(e) 'leiblicher Schmerz, Krankheit, bes. Geschwulst, Geschwür', nhd. Schwäre (s. \schwären), wird heute allerdings als zu schwer gehörend empfunden. Die alte Bedeutung ist bis ins 18. Jh. bewahrt, vgl. ein schwüriger ('schwärender') Finger (Adelung). Daneben entwickelt sich vom 16. Jh. an auf innere Stimmung und Haltung bezogener übertragener Gebrauch im Sinne von 'reizbar, unzufrieden, aufrührerisch' sowie 'leicht aufgebracht, empfindlich, schwer zu behandeln', der seit dem 17. Jh. in erweiterter Anwendung auch auf Verhältnisse und allgemeine Zustände ausgedehnt wird (vgl. schwürige Zeiten, 1660). Schwierigkeit f. "komplizierte Lage, Situation, Mühsal, Kummer' (18. Jh.), frühnhd. Schwirikait 'Eiterung' (1572), Schwürigkeit 'Tumult' (1660); dann (in etymologischer Unsicherheit in Verbindung gebracht mit mhd. swærecheit 'Schwere, Hindernis', zu mhd. swære, nhd. schwer) Schwürigkeit oder Schwerigkeit 'Beschwernis' (1664). (www.dwds.de/wb/ Schwierigkeit\#et-1, Zugriff am 05.09.2017). 
jmdn./etw. am/auf dem Hals haben (s.u.)

jmdm. wie ein Mühlstein am Hals hängen, eine große Belastung sein, Grund für jmds. Ärger/Mühe sein' (redensarten-index, Zugriff am 21.10.2017)

etw. an der Backe tragen, eine Last/Bürde tragen; verpflichtet/eingebunden sein; etwas Unangenehmes ertragen müssen' (redensarten-index, Zugriff am 21.10.2017) die ganze Verantwortung liegt, lastet auf seinen Schultern (DUW online, Zugriff am 20.10.2017)

jmdm. Verantwortung, eine schwere Arbeit aufbuckeln, aufbürden, aufhalsen

Auf der zweiten Ebene trägt die metonymische Bedeutungsverschiebung der nominalen Idiom-Konstituente zur Bedeutungskonstituierung bei: Das Bein steht hier metonymisch für die Fortbewegung, das Gehen, der Derivation liegt die konzeptuelle Metonymie (HANDLUNGS-)MITTEL STEHT FÜR HANDLUNG (MEANS FOR ACTION) zugrunde. Die Beschreibung dieser funktionalen metonymischen Derivation wurde bei der Analyse des Idioms Knüppel zwischen die Beine werfen kurz angesprochen (vgl. Unterkap. 4.2.2.1.1.2.2), im folgenden, den Somatismen gewidmeten Exkurs wird näher darauf eingegangen.

\section{Verwendungsprofil 2: jd. ist ein Klotz am Bein, jd. stellt eine Erschwernis, eine Belastung dar' (7 Belege)}

In übrig gebliebenen Gebrauchsbelegen referiert das zu besprechende Idiom auf eine Person:

(71) Und um so plausibler werden sie das bei einem behinderten Neffen finden. Du warst deinen Eltern ein Klotz am Bein, sie blamierten sich, wollten dich loswerden, schickten dich zu deinem komischen Onkel. Man wird dich in keinem Verein vermissen, Behinderte brauchen sie nicht. Koneffke, Jan: Paul Schatz im Uhrenkasten, Köln: DuMont Buchverlag 2000, S. 172

Bezeichnenderweise wird in 5 der 7 Belege auf einen FDP-Politiker und Außenminister - Guido Westerwelle - Bezug genommen, der vor den Landtagswahlen von einem Parteikollegen Herbert Mertin als Klotz am Bein bezeichnet wurde:

(72) Ebenso wurde registriert, dass sich der einflussreichste Liberale in Rheinland-Pfalz mit keiner Silbe von der Ausladung des Parteivorsitzenden aus dem Wahlkampf distanzierte. Der Vorwurf, Westerwelle sei ein „Klotz am Bein“ steht weiter im Raum. Selbst wenn Westerwelle das Dreikönigstreffen politisch überlebt, wird seine Zukunft dann vom Ausgang der Wahl in Baden-Württemberg bestimmt. Die Zeit, 16.12.2010, Nr. 51

Die Anhäufung der Zitierungen schwächt selbstverständlich die quantitative Aussagekraft der in diesem Verwendungsprofil gesammelten Belege. Wahrscheinlich nimmt das Idiom in seinen verschiedenen Varianten doch vor allem auf unbelebte Objekte Bezug, Menschen werden viel seltener als Klotz am Bein bezeichnet. Die Bedeutungskonstituierungsprozesse verlaufen analog $\mathrm{zu}$ dem ersten Verwendungsprofil. 


\subsection{2 am Hals haben}

Lexikographisch erfasste Varianten: jmdn./etw. am/auf dem Hals/Halse haben Modifikationen: mit etw. am Hals, als ob jd. nicht schon genug (Krisen, Probleme) am Hals hätte, mit etw. schon genug am Hals haben.

\section{Darstellung in lexikographischen Nachschlagewerken}

Tab. 27: Das Idiom am/auf dem Hals haben in allgemeinen und phraseologischen Wörterbüchern des Deutschen.

\begin{tabular}{|c|c|c|}
\hline Wörterbuchtyp & Wörterbuch & Lexikographische Darstellung \\
\hline \multirow[t]{3}{*}{ allgemein } & DUW 2006 & $\begin{array}{l}\text { jmdn./etw. am/auf dem Hals haben (ugs. mit jmdm., } \\
\text { etw. belastet sein; viel Mühe oder Ärger mit jmdm., etw. } \\
\text { haben): sie hat immer ziemlich viel am Hals. }\end{array}$ \\
\hline & DUW ONLINE & $\begin{array}{l}\text { jemanden, etwas am/auf dem Hals haben } \\
\text { (umgangssprachlich: mit jemandem, etwas belastet } \\
\text { sein; viel Mühe oder Ärger mit jemandem, etwas } \\
\text { haben: sie hat immer ziemlich viel am Hals) (letzter } \\
\text { Zugriff am 27.10.2017) }\end{array}$ \\
\hline & WAHRIG 2007 & $\begin{array}{l}\text { jmdn. od. etwas am od. auf dem Hals(e) haben } \\
\text { 〈fig.; umg.〉 sich um jmdn. od. etwas kümmern müssen, } \\
\text { der od. das einem lästig ist }\end{array}$ \\
\hline \multirow[t]{2}{*}{ phraseologisch } & DUDEN 11 & $\begin{array}{l}\text { jmdn., etw. am/auf dem Hals haben (ugs.): sehr } \\
\text { viel Mühe, Arger mit jmdm., etw. haben; mit jmdm., etw. } \\
\text { belastet sein: ... hoffentlich kommt er nicht auf die Idee, } \\
\text { sich allein davonzuschleichen. Dann hab ich sie auf dem } \\
\text { Hals (Kronauer, Bogenschütze 301).... er hatte Verfahren } \\
\text { wegen unberechtigter Führung akademischer Titel ... am } \\
\text { Hals (Spiegel 49, 1966, 44). (2011: 318) }\end{array}$ \\
\hline & $\begin{array}{l}\text { SCHEMANN } \\
2011\end{array}$ & $\begin{array}{l}\text { jmdn./etw. am Hals haben sal } \\
\text { 1. Bisher hatte er schon für sieben Personen zu sorgen. } \\
\text { Und jetzt hat er noch die Tochter seines Cousins am } \\
\text { Hals. Auch für die muß er jetzt noch aufkommen. } \\
\text { 2. Schon der Betriebsrat hängt mir dauernd in } \\
\text { den Ohren, ich soll den Kollenheim rausscheißen! } \\
\text { Und jetzt kommt der Personalleiter mit derselben } \\
\text { Geschichte! Jetzt hab` ich den auch noch am Hals! } \\
\text { 3. Er hat viel Arbeit mit seiner Praxis. - Wenn es nur } \\
\text { das wäre! Daneben hat er noch die Vertretung der } \\
\text { Ärzteschaft gegenüber den Gewerkschaften am Hals. } \\
\text { Das ist eine sehr große Belastung für ihn. }\end{array}$ \\
\hline
\end{tabular}




\begin{tabular}{|c|c|c|}
\hline Wörterbuchtyp & Wörterbuch & Lexikographische Darstellung \\
\hline & & $\begin{array}{l}\text { 4. >> Wir leben schon in einem komischen Land! }><\text {, } \\
\text { meinte mein Bruder nachdenklich. }>>\text { Wenn du } \\
\text { einen Polizisten duzt, hast du sofort ein Verfahren } \\
\text { wegen Beleidigung am Hals. Wenn ein Polizist } \\
\text { einen Unschuldigen plattschießt, dann hat er mit } \\
\text { schönster Regelmäßigkeit in ,vermeintlicher Notwehr } \\
\text { gehandelt }<<.(2011: 300)\end{array}$ \\
\hline & \multicolumn{2}{|c|}{$\begin{array}{l}\text { REDENSARTEN- } \text { etwas/jemanden am/auf dem Hals/Halse haben } \\
\text { INDEX }\end{array}$} \\
\hline & MÜLLER 2005 & $\begin{array}{l}\text { jmdn./etwas auf dem/am Hals(e) haben (umg.) } \\
\text { 1) für einen Menschen sorgen müssen [Verpflichtung] } \\
\text { 2) Arbeit/Sorgen zu tragen haben [Belastung] } \\
\text { 1) „Seit dem Tod ihres Mannes habe ich meine } \\
\text { Schwiegermutter auf dem Hals. Sie wohnt bei uns, ich } \\
\text { muß für sie waschen und kochen und so weiter. Lang } \\
\text { halte ich das nicht durch!“ } \\
\text { 2) „So geht's nicht! Der halbe Betrieb fährt in Urlaub, } \\
\text { und ich habe die ganze Arbeit am Hals!“ } \\
\text { Die Redensarten aus dem Bereich der Fürsorge, } \\
\text { der Verpflichtung und der Belastung beziehen } \\
\text { ihren Ursprung aus der Sorge für das auf dem Arm } \\
\text { getragene Kleinkind oder aus dem Joch, das der Ochse } \\
\text { bei der Feldarbeit tragen mußte. Beide Bildfelder } \\
\text { überlagern sich, so daß meist keine eindeutige } \\
\text { Zuordnung möglich ist. Zudem gibt es in diesem } \\
\text { Bereich eine Fülle von Varianten. (2005: 216-217) }\end{array}$ \\
\hline
\end{tabular}

\section{Korpusgestützte Analyse anhand der DWDS-Korpora ${ }^{181}$}

Das Idiom tritt in 2 Varianten mit unterschiedlichen Präpositionen auf: auf dem Hals/am Hals haben. Die anschließende semantische Analyse bezieht sich auf die häufiger auftretende Variante mit der Präposition an und ergibt folgende Verwendungsprofile und -muster:

181 Zugriffsdatum: 22.04.2017, Suchanfrage: am Hals haben. Deutsches Textarchiv: 0/29 (Belege vorwiegend aus dem 17. Jh.); DWDS-Kernkorpus 21: 2/7; Die Zeit: 26/73; Berliner Zeitung: 6/37; Der Tagesspiegel: 6/35. 
1. etw. am Hals haben juristische, finanzielle u.Ä. Schwierigkeiten, Ärger, Probleme haben, die bewältigt werden müssen

(30 Belege)

1.1 , (unverschuldet, oft wegen eines bekleideten Amtes, einer ausgeübten Funktion) Schwierigkeiten, Konflikte, Krisen zu bewältigen haben`

(17 Belege)

\section{2 Ärger,} Schwierigkeiten mit einem Prozess, einem selbstverschuldeten Strafverfahren haben ${ }^{\circ}$

(10 Belege)
1.3 ,finanzielle Schwierigkeiten, Belastungen haben

(3 Belege)

am Hals haben

2. jmdn. am Hals haben ,mit sorgepflichtigen Personen belastet sein (7 Belege)
3. literaler und sprachspielerischer

Gebrauch

(3 Belege)

Abb. 64: Die Verwendungsprofile und -muster des Idioms am Hals haben anhand der Analyse der Gebrauchsbelege im DWDS-Korpus.

Etymologisch wird auf zwei mögliche Motiviertheitsquellen verwiesen (vgl. redensarten.index, Zugriff am 06.09.2017): Die erste Quelle stellt der Bereich der Fürsorge, der Verpflichtung und Belastung dar, die mit dem mentalen Bild eines auf dem Arm getragenen Kleinkindes zusammenhängt. Den anderen Bereich stellt das historische Wissen über die Landwirtschaft und das Joch, das die Zugtiere bei der Feldarbeit tragen mussten (vgl. auch Duden 11, Müller 2005). Beide Bereiche scheinen bei synchroner Motiviertheit ihren Anteil zu haben, wobei die zweite, landwirtschaftlich geprägte Motivierungsquelle mutmaßlich Oberhand gewinnt.

Verwendungsprofil 1: etw. am Hals haben,Schwierigkeiten, Ärger, Probleme mit etw. haben' (30 Belege)

In der überwiegenden Anzahl der Belege ist die schwierige Lage des Patients durch unbelebte Verhinderungen und Belastungen bedingt. Dabei lassen sich drei Verwendungsmuster ermitteln:

Verwendungsmuster 1.1: ,Schwierigkeiten, Probleme, die von einem unverschuldet sind und mit objektiven Begebenheiten, äußeren Umständen zusammenhängen' (17 Belege)

In den meisten Belegen sind die Schwierigkeiten, Konflikte und Krisen, die die Betroffenen zu bewältigen haben, unverschuldet und hängen beispielsweise mit 
dem bekleideten Amt, der ausgeübten Funktion, den von ihnen unabhängigen Begebenheiten zusammen:

(73) Es gab schon einfachere Brüsseler Spitzentreffen, zumal die «Chefs» seit vergangenem Sonntag noch einen weiteren Notfall am Hals haben: Italien. Beim Vor-Gipfel forderten Frankreich und Deutschland den italienischen Regierungschef Silvio Berlusconi ungewöhnlich deutlich und völlig undiplomatisch auf, doch bitte den Schuldenabbau zu verstärken und mehr für das Wachstum zu tun. Die Zeit, 25.10.2011

(74) Die Türkei will es nicht, weil sie sonst ein noch größeres Kurdenproblem am Hals hätte; Iran will es nicht, weil es sich nicht noch tiefer in den innerirakischen Krieg hineinziehen lassen möchte und ohnehin über genügend Einfluss im Irak verfügt. Ein Irak, der sich in Chaos auflöst, ist für Teheran, Ankara und auch für das saudische Königshaus ein Albtraum. Die Zeit, 18.12.2007

Zur Bedeutungskonstituierung tragen zweifelsohne die bereits besprochenen konzeptuellen Metaphern: LEBEN IST EIN WEG; SCHWIERIGKEIT IST EINE LAST; GUT IST OBEN, SCHLEChT IST UNTEN bei, wobei die letztgenannte Orientierungsmetapher mit der Körperstellung eines am Hals belasteten und deswegen gebeugten, den Kopf senkenden Menschen in Verbindung gebracht werden kann (vgl. Abb. 65):

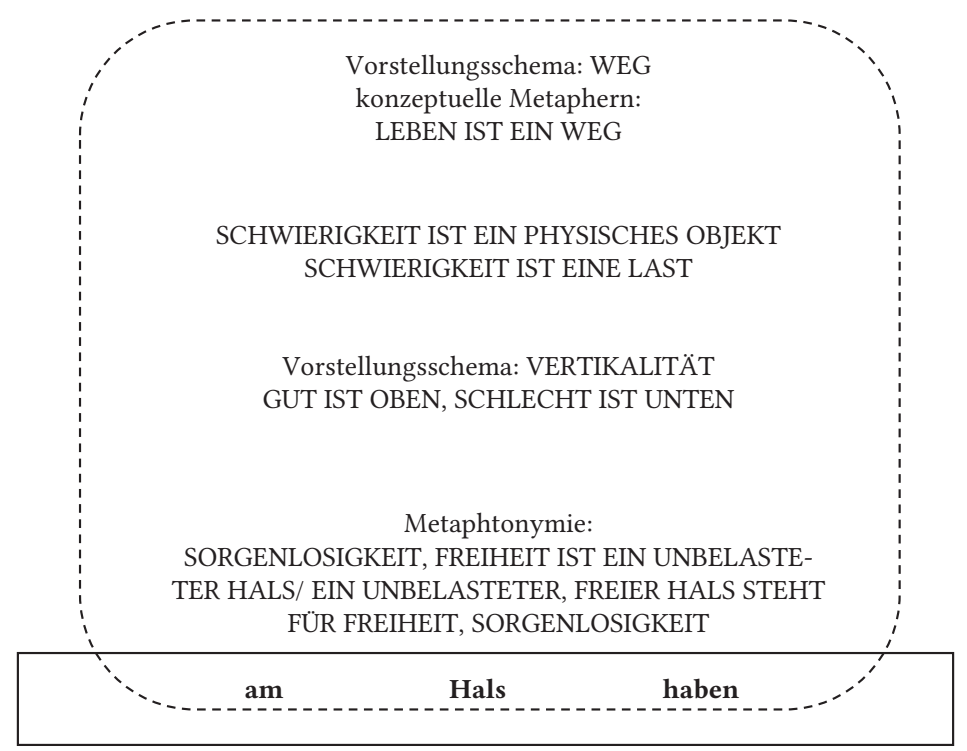

Abb. 65: Bedeutungskonstituierungsmechanismen für das Verwendungsmuster $1.1, j d$. hat Schwierigkeiten, Ärger, Probleme, die von ihm unverschuldet sind und mit objektiven Begebenheiten, äußeren Umständen zusammenhängen! 
Von Belang für die Konzeptualisierung ist ebenfalls biologisch-allgemeines, historisch-kulturelles und verkörpertes Weltwissen über die Empfindlichkeit und Wichtigkeit des Halses als eines Körperteils. Der Hals verbindet den Kopf mit dem Rumpf, was eine eigenständige Bewegung des Kopfes gegen den Rumpf ermöglicht. Der Kopf wird mit Denken, Sprechen, Sehen und Verstehen assoziiert, da sind die wichtigsten Sinnesorgane platziert, die Relevanz des Halses, seine Nähe zu den Sinnesorganen spielt deswegen in der Konzeptualisierung eine bestimmte Rolle. Für Lastentragen ist der Hals - der engste Teil des menschlichen Körpers ungeeignet, weswegen seine Belastung als besonders behindernd, unangenehm beanspruchend, beschwerlich empfunden wird, die Position erzwingt, in der Kopf nach unten gerichtet ist und das Patiens in der Fähigkeit einschränkt, sich umzusehen und die Lage objektiv zu beurteilen. Erwähnenswert ist ebenfalls historischkulturelles Wissen vom Hals. Zum einen wird der Hals als ein gut sichtbarer, am Gesicht liegender Körperteil auf eine besondere, oft auf den Status, soziale Stellung und Gruppenzugehörigkeit hinweisende Art geschmückt: Halsketten und Kragenformen verweisen auf den Beruf (Amtsketten, Priesterkragen), Rang (Fürsten und Könige), Zugehörigkeit zu einer sozialen (Goldketten der Rapper) oder religiösen Gruppe. Zum anderen wurden in den früheren Zeiten Unterwerfung, Unterjochung, Unterordnung durch das Setzen des Fußes auf einen Teil des Halses - den Nacken - symbolisiert. Von diesem Brauch zeugen z.B. folgende Bibelstellen:

Wie glücklich bist du, Israel! Wer ist dir gleich, du Volk, gerettet durch den Herrn, den Schild, der dir hilft, deine Hoheit, wenn das Schwert kommt? Deine Feinde werden sich vor dir erniedrigen und du setzt deinen Fuß auf ihre Nacken. (5. Mose 33,29). Man wälzte die Steine beiseite und brachte die Könige von Jerusalem, von Hebron, von Jarmut, von Lachisch und von Eglon heraus. Als sie vor Josua standen, rief dieser alle Männer Israels herbei und sagte zu den Anführern des Heeres: ,Kommt her und setzt euren Fuß auf den Nacken dieser Könige!' (Josua 10,23 f.) (zit. nach redensartenindex, Zugriff am 14.09.2017, Lemma: den Fuss in den Nacken setzen).

Dieses teilweise kulturell bedingte Wissen findet Widerspiegelung in der Phraseologie: Die metaphorischen Mappings zwischen dem Ausgangsbereich der körperlichen Belastung des Halses, Nackens durch ein Joch, Tragejoch, ein Paket, ein auf den Schultern/huckepack getragenes Kind und der psychischen Domäne, in der Aufgaben, Verpflichtungen, problematische Personen als eine Erschwernis, Beeinträchtigung in der Arbeit, Funktionsweise oder sogar Existenz empfunden werden, wiederholt sich regelmäßig in zahlreichen deutschen Phraseologismen mit Hals-, Genick- oder Nackenkonstituente. Die metaphorischen Mappings basieren dabei offensichtlich auf der Metonymie. Die Übergänge zwischen der Metonymie und der Metapher sind fließend, weswegen die Beziehungen zwischen den beiden Domänen als metaphtonymisch angesehen werden: 
EIN UNBELASTETER HALS STEHT FÜR FREIHEIT, SORGENLOSIGKEIT/SORGENLOSIGKEIT, FREIHEIT IST EIN UNBELASTETER HALS

sich jmdn. auf den Hals laden ugs. ,sich mit jmdm., etw. belasten und dadurch viel Arbeit und Verantwortung auf sich nehmen' (DUW online, Zugriff am 15.09.2017)

jmdm. mit etw. vom Hals[e] bleiben ugs. ,jmdn. mit etw. nicht belästigen“ (DUW online, Zugriff am 15.09.2017)

sich jmdn./etw. etw. vom Hals[e] halten ugs. ,sich mit jmdm., auf etw. nicht einlassen“ (DUW online, Zugriff am 15.09.2017)

sich jmdn./etw. vom Hals[e] schaffen ugs. ,sich von jmdm./etw. befreien; jmdn., der, etwas, was einem lästig ist, abschütteln“ (DUW online, Zugriff am 15.09.2017)

jmdm. im Nacken sitzen ,1. jmdn. verfolgen, dicht hinter jmdm. her sein; 2. jmdn. stark bedrängen, jmdm. zusetzen; 3. jmdn. erfüllen, beherrschen: die Angst saß ihm im Nacken' (DUW online, Zugriff am 15.09.2017)

jmdn. im Nacken haben, von jmdm. verfolgt und bedrängt werden' (DUW online, Zugriff am 15.09.2017)

jmdm. im Genick sitzen, ugs. jmdn. bedrängen, dass er eine bestimmte Arbeit schnell erledigt‘ (DUW online, Zugriff am 15.09.2017)

jmdm. jmdn. auf den Hals schicken/hetzen ugs. ,jmdn., der unerwünscht ist, zu jmdm. schicken' (DUW online, Zugriff am 15.09.2017)

sich jmdm. an den Hals werfen ugs. ,sich jmdm. aufdrängen' (DUW online, Zugriff am 15.09.2017)

jmdn./etw. an den Hals bekommen ,mit jmdm./etw. in unerwünschter Weise zu tun haben' (DWDS, Zugriff am 16.09.2017)

jmdm. etw. an den Hals hängen, jmdn. beschuldigen, jmdn. anzeigen' (DUW online, Zugriff am 15.09.2017)

jmdm. zu viel Arbeit, zu viel Verantwortung aufhalsen

Verwendungsmuster 1.2: ,mit etw. (einem Prozess, einem Strafverfahren, einem juristischen Verfahren wegen Gesetzesbrüche u. ̈.) viel Ärger, viele Schwierigkeiten haben, die man selbst verschuldet hat' (10 Belege)

In zehn folgenden Belegen sind die Schwierigkeiten in ihrer Gestalt näher präzisiert und auf einen juristisch-strafrechtlichen Bereich eingeschränkt:

(75) Die Durchsetzung von Grillos Forderung, dass Abgeordnete, die einen Prozess am Hals haben, ihr Amt bis zur Klärung der Angelegenheit niederlegen müssen, würde zum sofortigen Auszug von mindestens 100 italienischen Abgeordneten führen. Ebenso populär sind die Vorschläge der M5S, die Besoldung von Politikern radikal zu reduzieren. Die Zeit, 12.09.2013

(76) Spannend wurde es erst zur Halbzeit der Sendung, als Affären und Skandale der Beteiligten auf den Tisch kamen. Hier litt Sarkozy, der mehr als ein juristisches Verfahren wegen Gesetzesbrüchen in seiner Amtszeit am Hals hat. Plötzlich lag seine Sprechzeit, die eine Stoppuhr sekundengenau festhielt, weit vor der seiner Konkurrenten. Die Zeit, 14.10.2016 
Die Bedeutung des Idioms konstituiert sich auf einer Ebene, der Derivation unterliegt die ganze Wortverbindung (vgl. Abb. 66). Als kognitive Mechanismen wiederholen sich hier die konzeptuellen Metaphern LEBEN IST EIN WEG, SCHWIERIGKEIT IST EINE LAST, GUT IST OBEN, SCHLEChT IST UNTEN, die das erste Verwendungsprofil mitgestaltet haben:

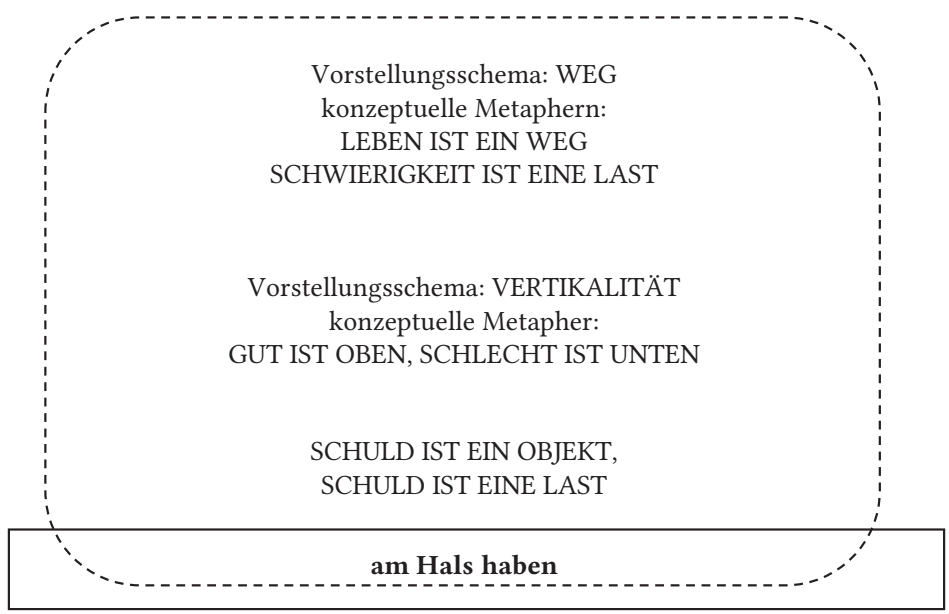

Abb. 66: Bedeutungskonstituierungsmechanismen für das Verwendungsmuster 1.2 ,mit etw. viel Ärger, viele Schwierigkeiten haben, die man selbst verschuldet hat'.

Neu sind als Bedeutungskonstituierungsmechanismen konzeptuelle Metaphern, die abstrakte Konzepte als ein physisches Objekt konzeptualisieren lassen.

Das unanschauliche, wenig klar umrissene Konzept der Schuld als einer (moralischen) Verfehlung, eines Fehltrittes und der damit verbundenen Gewissensbisse, wird im Deutschen wesentlich durch die konzeptuellen Metaphern SCHULD IST EINE LAST konstituiert. Der Beitrag dieser Metapher zur Konzeptualisierung der Schuld ist sehr wesentlich. Geläufige sprachliche Ausdrucksmittel, die in diesem Diskursbereich gebraucht werden, sind auf diese konzeptuelle Metapher zurückzuführen:

SCHULD IST EIN OBJEKT

SCHULD IST EINE LAST

jmdm. etw. zur Last legen

eine Last auf sich nehmen (DUW online, Zugriff am 15.09.2017)

das Gefühl der Schuld bedrückte ihn (DWDS-Wörterbuch, Zugriff am 20.10.2017)

große Schuld lastet auf ihm (DWDS-Wörterbuch, Zugriff am 20.10.2017)

die Schuld auf jmdn. abwälzen (DUW online, Zugriff am 15.09.2017)

Es ist aber wichtig, die Schuld nicht nur auf ihn abzuschieben. Weizsäcker, Carl Friedrich von: Bewußtseinswandel, München: Hanser 1988, S. 287 (DWDS, Zugriff am 15.09.2017) 
etw. auf seine eigene Kappe nehmen ,für eventuelle negative Folgen von etw. die Verantwortung übernehmen; wahrscheinlich zurückgehend auf die Bedeutung der Kappe als Teil der Amtstracht, z.B. des Richters' (DUW online, Zugriff am 15.09.2017) auf jmds. Schultern ruhen/lasten, etwas leisten müssen; eine Aufgabe übernehmen müssen' (redensarten-index, Zugriff am 20.10.2105)

eine Belastung aus der Vergangenheit haben

eine Schuld auf sich geladen haben

ein schuldbeladener Missetäter

jmdn./etw. auf dem Gewissen haben

\section{Verwendungsmuster 1.3: ,finanziell belastet sein' (3 Belege)}

Die konzeptuelle Metapher SCHULD IST EINE LAST ist richtungsweisend ebenfalls für die Konzeptualisierung der zu erstattenden Schulden als Geldbeträge, finanzieller Verbindlichkeiten:

(77) Erst nach Abschluss des Schiedsverfahrens wird sich zeigen, wer zu hoch gepokert hat. Hinzu kommt, dass Daimler wie Telekom neben den drohenden Zahlungen aus Schadenersatzforderungen weitere Sonderaufwendungen am Hals haben, weil das Maut-System mit großer Verspätung erst im Januar 2005 starten soll. Bis dahin müssen sie noch viel Geld investieren - mindestens 700 Millionen Euro hat Toll Collect bereits verschlungen. Der Tagesspiegel, 04.03.2004

(78) Freunde brachten den 29-jährigen Gastronomen Ernst auf die Idee, Schiffseigner zu werden. „Ich weiß nicht, ob ich ihnen dafür dankbar sein soll“, sagt Ernst, der 1995 gemeinsam mit vier Partnern das Schiff kaufte und plötzlich nicht nur ein neues Spielzeug in der Hand, sondern vor allem Kosten und Bürokratie am Hals hatte. Die schwimmende Location musste zunächst auf Vordermann gebracht werden. Berliner Zeitung, 27.09.1999

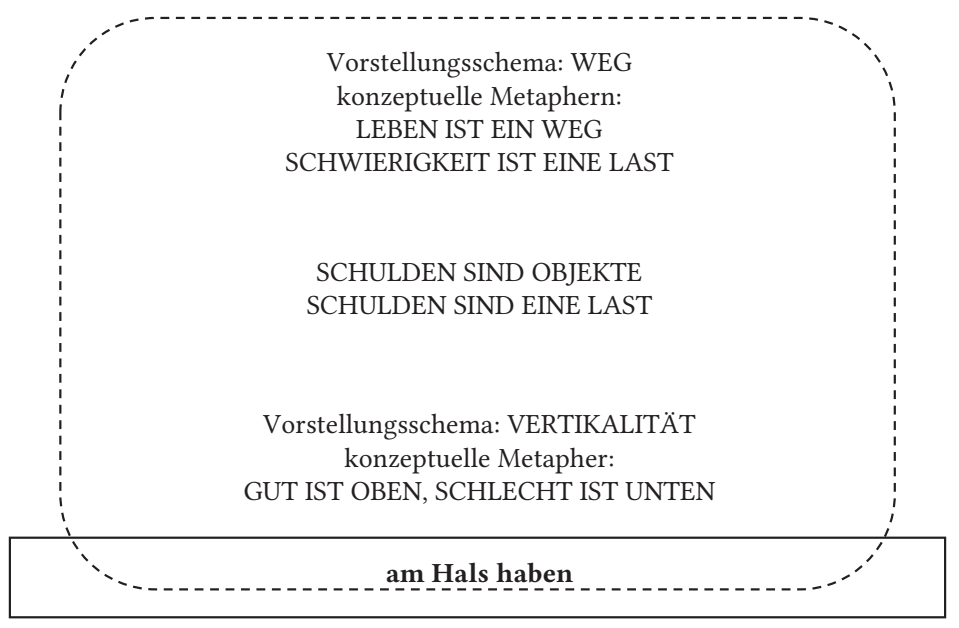

Abb. 67: Bedeutungskonstituierungsmechanismen für das Verwendungsmuster 1.3 ,finanziell belastet sein'. 
Die Konzeptualisierung der Schulden, des Solls als einer Belastung ist in der Sprache, ebenfalls in der Fachsprache, weit verbreitet, wovon folgende Beispiele zeugen:

SCHULDEN SIND EINE LAST

lastenfrei, nicht mit Schulden belastet sein

drückende Schulden

(Geldwesen) unbelastet

Grundstückbelastung

Schulden massen (beim Konkurs)

Die Schulden nicht mehr schultern können

mit einer Hypothek belasten

\section{Verwendungsprofil 2: jmdn. am Hals haben, mit sorgepflichtigen Personen belastet sein' (7 Belege)}

In insgesamt sieben Belegen treten Menschen, vorwiegend als lästig empfundene Kinder in der Rolle der Obstruktion auf:

(79) Sie spielt die Mutter von Joachim Król, und Joachim Król spielt einen Scheidungsanwalt, und Franziska Herr-Gross (Veronica Ferres), die Frau des furchtbaren Will, ist sein neunhundertvierundzwanzigster Fall. Der Furchtbare war auch fruchtbar, weshalb sein Weib zwei lärmende Kleinkinder am Hals hat; dergleichen hemmt die Kreativität (freilich nicht bei Frau Lind, die während ihrer drei Schwangerschaften ebenso viele Erfolgsbücher schrieb). Doch nun die Wendung! Die Zeit, 08.03.1996

(80) Nach dem ebenso kurzen wie heftigen Flirt mit einem Eishockey-Star bekommt die Detektivin Vic (Kathleen Turner, Foto) mächtig Ärger, weil der Sportsmann eines Tages ermordet aufgefunden hat und sie nun seine Tochter am Hals hat. Jeff Kanew realisierte diesen satirischen Thriller nach einem Roman von Sara Paretzky. Berliner Zeitung, 24.08.1996

(81) „Ich habe meine Zweifel, ob Du bei der Leitung eines Hotels besser wegkämest. Du würdest auf einmal lauter mittellose, schwangere, unverheiratete Frauen am Hals haben, die Du mitsamt ihren Kindern für den Rest ihres natürlichen Lebens ernähren müßtest. Du fändest dann wohl, daß so etwas kaum einträglicher ist als die Leitung einer modernen Schule." Die Zeit, 28.08.1970

Die Bedeutungskonstituierungsmechanismen ähneln generell denjenigen, die im ersten Verwendungsprofil bereits beschrieben wurden, die meisten konzeptuellen Metaphern und Metaphtonymien wiederholen sich, weil die Kleinkinder oder mittellose Frauen in der ersten Linie als lästige Pflichten, die das Patiens in der Verwirklichung seiner Pläne verhindern, betrachtet werden. Nicht auszuschließen ist dennoch der Beitrag des Fürsorgeaspektes zu der sich konstituierenden Bedeutung: Aus denselben Gründen, aus denen der Hals als Lastenträger ungeeignet ist (der engste, hoch gelegene Körperteil, Nähe zum Gesicht), dient er auch als prototypischer Körperteil, um den die Kleinkinder ihre Arme schlingen. Diese Geste drückt Zuneigung aus, wird aber auch als Suche nach Geborgenheit und Fürsorge interpretiert: 
KÖRPERLICHE NÄHE STEHT FÜR ZUNEIGUNG, FÜRSORGE

an jmds. Hals liegen (DWDS-Wörterbuch, Zugriff am 27.10.2017)

das Kind hängt am Hals der Mutter (DWDS-Wörterbuch, Zugriff am 27.10.2017)

jmdm./einander (vor Freude) um den Hals fallen (DWDS-Wörterbuch, Zugriff am 27.10.2017)

jmdm. den Arm um den Hals legen (DWDS-Wörterbuch, Zugriff am 27.10.2017)

die Arme um jmds. Hals schlingen (DWDS-Wörterbuch, Zugriff am 27.10.2017)

sie warf sich dem ersten besten an den Hals ,sich jmdm. aufdrängen' (DUW online,

Zugriff am 25.10.2017)

jd. ist anhänglich

jd. ist zurückhaltend, unzugänglich

Die Aspekte der verärgernden Belastung, Einschränkung in der Freiheit und Handlungsmöglichkeiten sowie der Fürsorge, der Barmherzigkeit und Zuneigung mögen sich in der Konzeptualisierung verzahnen: In der Subjektposition treten nur bestimmte Menschengruppen auf. Die Bedeutungskonstituierungsmechanismen werden in der Abbildung 68 veranschaulicht.

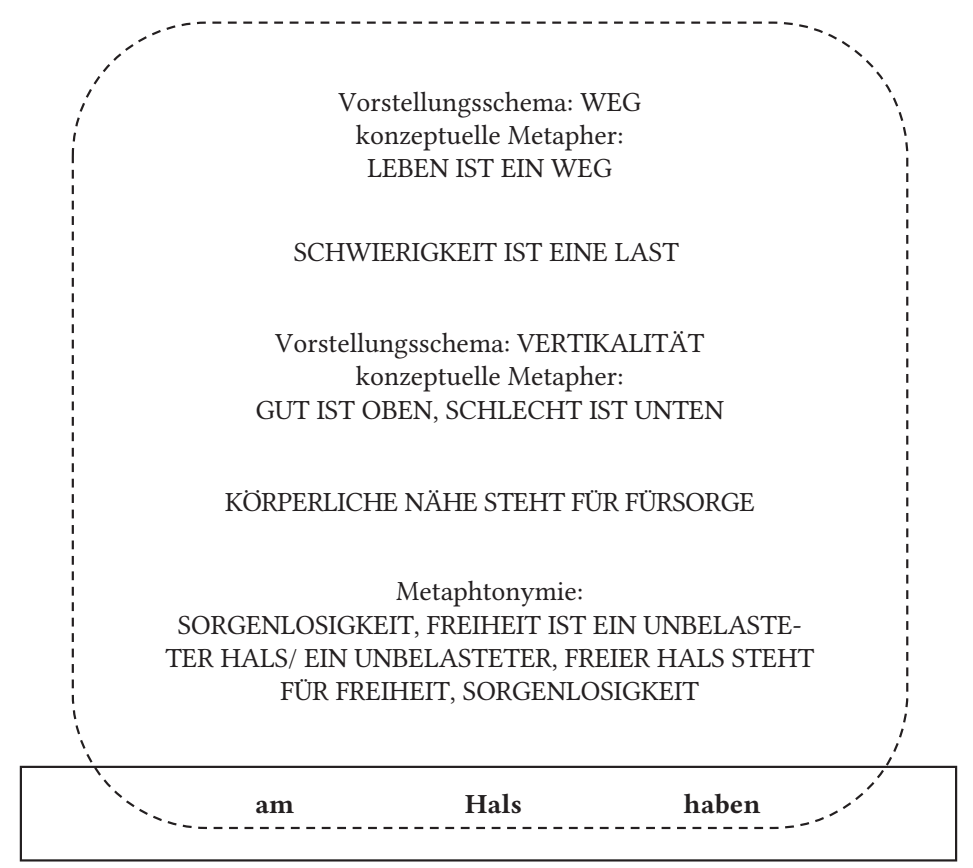

Abb. 68: Bedeutungskonstituierungsmechanismen für das Verwendungsprofil 2 , mit sorgepflichtigen Personen belastet sein: 


\subsection{Resümee mit Schwerpunkt: Ontologische Metaphern, Embodiment und Bedeutung von Phraseologismen}

Am Beispiel der besprochenen Idiome werden an dieser Stelle zwei Aspekte zur Sprache gebracht: Zum einen wird zusammenfassend auf den Einfluss mächtiger ontologischer Metaphern auf die Konzeptualisierungen von komplexen Zuständen verwiesen. Zum anderen stellen beide Idiome musterhafte Somatismen dar: Da den Idiomen mit einer Körperteil-Konstituente wegen der hohen Frequenz und der körperlichen Verankerung ein besonderer Stellenwert in der Phraseologie zukommt, wird das Unterkapitel mit einem Exkurs abgeschlossen, in dem eine exemplarische Untersuchung zu Konzeptualisierungen vom Körperteil Bein dargestellt wird.

Als grundlegende konzeptuelle Metapher, die den Idiomen einen Klotz am Bein haben, etw. am Bein haben zugrunde liegt und den Diskursbereich der Schwierigkeit/der schwierigen Lage mitgestaltet, wird die SCHWIERIGKEIT IST EINE LAST-Metapher angesehen. Als eine Strukturmetapher fügt sich diese Metapher in die LEBEN IST EIN WEG-Metaphorik ein, eine Abstraktionsstufe höher fußt sie aber zugleich auf der Metapher schwiERIGKeIT IST EIN OBJEKT. Beide konzeptuellen Metaphern können als Spezifizierung einer weitverbreiteten und einflussreichen ontologischen Metapher ABSTRAKTES IST EIN OBJEKT betrachtet werden, die die abstrakten, sinnlich nicht wahrnehmbaren und oft zusammengesetzten Konzepte ohne scharfe Grenzen wie z.B. Inflation (Beispiel von Lakoff/Johnson 2000: 35) oder eben Schwierigkeiten über den Rückgriff auf unsere Erfahrung mit materiellen Entitäten greifbar macht und konzeptualisieren hilft. Die Art und Weise, wie wir die Schwierigkeiten und andere abstrakte Begriffe konzeptualisieren, ist nämlich in vielen Fällen durch alltägliche, bereits in den ersten Lebensmonaten gemachte Erfahrung geprägt, die mit der Hantierung mit Gegenständen zusammenhängt. So wie Gegenstände können die Schwierigkeiten also in etwas liegen, weggeräumt, beseitigt, umgangen werden; groß oder klein sein, sie können einem gehören (meine, deine Schwierigkeiten), sind lokalisierbar (das Problem liegt darin, dass ...) und quantifizierbar (viele, einige Schwierigkeiten), vgl. auch die typischen Verwendungsbeispiele:

SCHWIERIGKEIT IST EIN MATERIELLES OBJEKT

jmdm. Schwierigkeiten bereiten, machen, in den Weg legen (DWDS-Wörterbuch ${ }^{182}$, Zugriff am 22.09.2017)

Schwierigkeiten beseitigen, umgehen, vermeiden, aus dem Weg räumen (DWDS-Wörterbuch, Zugriff am 22.09.2017)

ich sehe darin keine Schwierigkeit (DWDS-Wörterbuch, Zugriff am 22.09.2017)

es gab Schwierigkeiten mit der Behörde (DUW online, Zugriff am 19.10.2017)

daraus können uns Schwierigkeiten erwachsen (DWDS-Wörterbuch, Zugriff am 22.09.2017)

182 Dieser Beleg ist nicht den DWDS-Korpora, sondern dem lexikographisch erarbeiteten Wortauskunftssystem zur Deutschen Sprache der Geschichte und Gegenwart des DWDS entnommen. Im Weiteren werden die Verwendungsbeispiele aus dem Wörterbuchteil des DWDS als DWDS-Wörterbuch gekennzeichnet. 
da werden wir wohl Schwierigkeiten bekommen (DWDS-Wörterbuch, Zugriff am 22.09.2017)

er geht jeder Schwierigkeit aus dem Weg (DWDS-Wörterbuch, Zugriff am 22.09.2017) die Schwierigkeit liegt darin, dass ... (DWDS-Wörterbuch, Zugriff am 22.09.2017) dabei sind große, ernste, unnötige Schwierigkeiten aufgetreten (DWDS-Wörterbuch, Zugriff am 22.09.2017)

Dementsprechend werden auch abstrakte Begriffe wie z.B. der alte große Kirchenstaat (vgl. Beleg 65), Modernisierung des Landes (66), die Verschuldung eines Sportvereins durch ein neues, kostspieliges Stadion (67), alte Auslandsschulden (68), politische Notfälle $(73,74)$, die von Natur aus eine komplexe, vielschichtige Struktur und keine scharfen Grenzen haben, als körperlich greifbare Objekte, die man tragen, aufbürden, auf sich nehmen, als Belastung empfinden kann, konzeptualisiert.

Die Tendenz, komplexe und abstrakte Angelegenheiten als hantierbare Objekte zu konzeptualisieren, ist für die menschliche Kognition kennzeichnend. Unterzieht man typische Wortverbindungen, in denen schwierige Fachbegriffe vorkommen, einer eingehenden Untersuchung, dann sind zahlreiche Belege für ihre Vergegenständlichung auffindbar. Das Wirtschaftswachstum kann beispielshalber so wie eine rollende Maschine verlangsamt, angekurbelt, angehalten, gebremst, beschleunigt werden:

WIRTSCHAFTSWACHSTUM IST EIN OBJEKT

WIRTSCHAFTSWACHSTUM IST EINE MASCHINE

Die schwache Konjunktur in Europa hat das deutsche Wirtschaftswachstum gebremst. (DWDS-Wörterbuch, Zugriff am 22.09.2017)

In der zweiten Jahreshälfte 2011 habe sich das Wirtschaftswachstum verlangsamt. (DWDS-Wörterbuch, Zugriff am 22.09.2017)

ein robustes Wirtschaftswachstum (DWDS-Wörterbuch, Zugriff am 22.09.2017)

ein langsameres Wirtschaftswachstum macht den Aktienmarkt anfälliger (DWDS, Zugriff am 22.09.2017)

Klar ist, dass ein Börsenkrach das Wirtschaftswachstum schwächt. (DWDS, Zugriff am 22.09.2017)

Gleichzeitig wurden Vorräte abgebaut, was mit minus 0,3 Prozentpunkten das Wirtschaftswachstum dämpfte. (DWDS, Zugriff am 22.09.2017)

Doch langsam drohen die hohen Preise, auf das Wirtschaftswachstum zu drücken.

(DWDS, Zugriff am 22.09.2017)

Als physische Objekte werden auch mentale Zustände konzeptualisiert, so wie es bei Schuld der Fall ist. Schuld stellt in ihrem Wesen ein sehr komplexes Konzept, das viele Aspekte: Verantwortung, moralische und sittliche Gebote, Pflichtbewusstsein, Erkenntnis, einen Fehler begangen zu haben, Gewissensbisse, Reue umfasst. Das Konzept hat viele Facetten und keine scharfen Grenzen, seine Versprachlichung über die SCHULD IST EIN OBJEKT-Metapher ist so allgegenwärtig, dass die folgenden sprachlichen Manifestationen von den meisten Sprachteilhabern auf den ersten Blick wahrscheinlich gar nicht als metaphorisch empfunden werden: 
SCHULD IST EIN OBJEKT

die Schuld liegt bei mir (DWDS-Wörterbuch, Zugriff am 18.10.2017)

er hat, trägt die Schuld an dem Unfall (DWDS-Wörterbuch, Zugriff am 18.10.2017)

sie trifft keine Schuld (DWDS-Wörterbuch, Zugriff am 18.10.2017)

wenig, viel Schuld haben (DWDS-Wörterbuch, Zugriff am 18.10.2017)

jmdm. die Schuld [an etw.] geben, zuschreiben (DWDS-Wörterbuch, Zugriff am 18.10.2017)

die Schuld auf sich nehmen (DWDS-Wörterbuch, Zugriff am 18.10.2017)

jmdm. die Schuld in die Schuhe schieben (DWDS-Wörterbuch, Zugriff am 18.10.2017)

die Schuld auf jmdn. abwälzen (DWDS-Wörterbuch, Zugriff am 18.10.2017)

Ebenfalls Vorgänge, Verfahren, Prozesse wie beispielshalber Gerichtsverfahren konzeptualisieren wir unter Rückgriff auf die ABSTRAKTES ALS OBJEKT-Metapher.

EIN VORGANG/EIN PROZESS/EIN EREIGNIS IST EIN OBJEKT

ein Verfahren anwenden (DWDS-Wörterbuch, Zugriff am 18.10.2017)

ein Verfahren erproben (DWDS-Wörterbuch, Zugriff am 18.10.2017)

den Prozess beschleunigen, hemmen, beobachten (DWDS-Wörterbuch, Zugriff am 18.10.2017)

ein leichter, schwerer Verlauf (einer Krankheit) (DWDS-Wörterbuch, Zugriff am 18.10.2017)

große, künftige Ereignisse werfen ihre Schatten voraus (Sprichwort: ,Große Ereignisse sind an besonderen Anzeichen vorzeitig zu erkennen') (DWDS-Wörterbuch, Zugriff am 18.10.2017)

einen guten, glatten Verlauf nehmen (DWDS-Wörterbuch, Zugriff am 18.10.2017)

EIN GERICHTSVERFAHREN, EIN RECHTSSTREIT IST EIN OBJEKT

eine drohende Gerichtsverhandlung vermeiden (DWDS-Wörterbuch, Zugriff am 18.10.2017)

ein schwerer Prozess (DWDS-Wörterbuch, Zugriff am 18.10.2017)

einen Prozess verlieren (DWDS-Wörterbuch, Zugriff am 18.10.2017)

ein kostspieliger, langwieriger, teurer Gerichtsprozess (DWDS-Wörterbuch, Zugriff am 18.10.2017)

Zahlreiche strukturelle Metaphern fußen also auf ontologischen Metaphern, während ontologische Metaphern und image schemas eine relevante Prämisse des holistischen Ansatzes der Kognitiven Linguistik - die Bedeutung ist embodied - vor Augen führen. Das konzeptuelle System, das für den konzeptuellen Pol einer sprachlichen Einheit eine integrale Basis darstellt, ist in der sehr weit gefassten körperlichen Erfahrung verankert und durch die Beschaffenheit unseres Körpers bedingt. Die ontologische ABSTRAKTES ALS OBJEKT-Metapher bilden möglicherweise nur Wesen heraus, die Objekte hantieren können (z.B. Gliedmaßen haben), die körperliche Gebundenheit von images schemas beschreiben Johnson und Lakoff (2002) wie folgt:

... it is hard to imagine any creature with a body similar to ours, located within a gravitational field like the one we inhabit, that would not have some form of verticality schema, some form of balance schema, and some shared schemas of forceful interaction. (Johnson/Lakoff 2002: 251) 
Damit sind die Bedeutungen in der tief liegenden Sphäre der sensomotorischen Erfahrung verankert, während konzeptuelle Metaphern, Metonymien, Metaphtonymien und Blendings auf diesen sensomotorischen Erfahrungen basieren und sie erweitern: Auf dem BALANCE-image schema baut beispielsweise das Konzept der Gerechtigkeit auf, das Vorstellungsschema verTICALITy liegt der an zahlreichen Stellen dieses Bandes beschriebenen Orientierungsmetapher GUT IST OBEN, SCHLECht IST UNTEN zugrunde. Das begriffliche Denken beginnt mit körperlicher Erfahrung, bezieht seine Bedeutungen aus körperlicher Erfahrung und ist wenigstens teilweise - an die körperliche Erfahrung gebunden.

There is a level of physical interaction in the world at which we have evolved to function very successfully, and an important part of our conceptual system is attuned to such functioning. (Lakoff/Johnson 1999: 90)

Es besteht somit keine strikte Abgrenzung zwischen dem Körper und der Kognition: „we are always ,in touch " with our world through our embodied acts and experience“ (Johnson/Lakoff 2002: 245).

Da der Körper und die verkörperte Erfahrung so relevante Rolle bei dem Zustandekommen von Bedeutungen spielen, kann es nicht wundern, dass somatische Phraseologismen - als lexikalisierte Metonymien und Metaphern mit einer Körperteilkonstituente - auf besonderes Interesse in der kognitiv ausgerichteten Forschung gestoßen sind. Im folgenden Exkurs werden skizzenhaft die Hauptrichtungen der phraseologischen Somatismen-Forschung dargestellt, danach wird in einer Pilotstudie aufgezeigt, wie das Bein in den phraseologisch gebundenen Bedeutungen konzeptualisiert wird.

\section{EXKURS: Somatismen in der Phraseologie und in der Kognitiven Linguistik}

Die Idiome: etw. am Hals haben, einen Klotz am Bein haben, jmdm. ein Bein stellen, Knüppel zwischen die Beine werfen stellen plakative Beispiele für eine viel diskutierte Gruppe der Phraseologismen - sog. Somatismen dar. Die Somatismen, d.h. Idiome mit wenigstens einer Körperteil-Konstituente (Burger 2015: 88), bilden seit Jahren einen der beliebtesten Forschungsbereiche innerhalb der Phraseologie und der Kognitiven Linguistik, was auf mehrere Gründe zurückzuführen ist:

Zum einen weisen Somatismen in der Phraseologie eine hohe Frequenz auf. Auf die starke Affinität der Körperbezeichnungen zur Verwendung als phraseologische Komponente machen sowohl Phraseologen (z.B. Fleischer 1982: 177) als auch Lexikographen (vgl. Schemann 1993: CIII) aufmerksam. In der bereits erwähnten Studie (Quasthoff/Schmidt/Hallsteinsdóttir 2010: 39-42) zu den häufigsten Substantiven in den Phraseologismen haben 21 Körperbezeichnungen und eine Körperflüssigkeit Blut in die Liste der 50 häufigsten Nomen geschafft: Auge $(16)^{183}$,

183 Die in Klammern angegebenen Zahlen beziehen sich auf den Rang eines Somatismus auf der Liste. 
Augen (4), Beine (35), Blut (30), Finger (23), Fuß (36), Füßen (37), Gesicht (41), Hals (18), Hand (2), Hände (24), Händen (46), Haut (44), Herz (11), Herzen (45), Kopf (1), Mund (9), Nase (7), Ohr (33), Ohren (5), Rücken (32), Zunge (22).

Andersherum ist es anzumerken, dass Körperteile in der Alltagssprache relativ oft phraseologisch gebraucht werden: So stellen Staffeldt/Ziem (2010: 477) in einer repräsentativen Korpusuntersuchung (am Korpus COSMAS II) fest, dass es sich in $46 \%$ des Finger-Vorkommens um einen phraseologischen Gebrauch handelt: In den untersuchten 921 Belegen ist die Körperbezeichnung Finger in 421 Belegen in Phraseologismen, in 446 Belegen frei, in 54 Belegen in Bezug auf die Musikinstrumente (seine Finger glitten über die Tasten, wirbelten über die Saiten, tanzten auf dem Klavier u.Ä.) verwendet. Der hohe Stellenwert der Somatismen in der phraseologischen und lexikographischen Forschung ist damit aus quantitativer Sicht begründet.

Zum anderen kommt den Somatismen auch in der kognitiv ausgerichteten IdiomForschung eine besondere Rolle zu, da hier der Zusammenhang zwischen Körper und Sprache evident wird. Idiome entstehen, um Benennungslücken zu ergänzen, wobei sprachliche Analogien zu Alltagsgegenständen, -erfahrungen und -begebenheiten gezogen werden. Auch wenn sich in diesem Alltag viele Körpererfahrungen der bewussten Reflexion entziehen, so ist die besondere Stellung des menschlichen Körpers als Ausgangs- und Bezugspunktes jeder Erfahrung offensichtlich: Der eigene Körper ist das uns vertrauteste Objekt, mit dem wir propriozeptisch im ständigen Kontakt bleiben und durch den wir die Umwelt bekunden: Alle äußeren Reize gelangen über den Körper in die Kognition, werden durch das Sieb der Sinnesorgane gefiltert.

Die zentrale Rolle des Körpers manifestiert sich in der Sprache: Zahlreiche abstrakte Zustände, Emotionen, Gefühle werden unter Rückgriff auf den Körper konzeptualisiert und versprachlicht. Wie Pajdzińska (1990: 61) feststellt, ist für einen durchschnittlichen Menschen der Mensch das Zentrum und das Maß aller Dinge, der phraseologische Bestand des Polnischen (auch des Deutschen, A. S.) ist durch den weitgehenden Anthropozentrismus gekennzeichnet. Die Annahme, dass sich körperliche und sensomotorische Erfahrungen in konzeptuellen Metaphern sedimentiert haben und figurative Bedeutungsverschiebungen maßgeblich durch körperliche Erfahrungen motiviert sind, ist für die Embodiment-Prämisse grundlegend. Kognition setzt physikalische Interaktion voraus. Zahlreiche abstrakte Konzepte sind in Körpererfahrungen verankert und ihre sprachlichen Manifestationen an die Körpererfahrungen gebunden: Die Phraseologismen als lexikalisierte, frequente und geläufige Metonymien und Metaphern eignen sich dabei zur Untersuchung der Verbindung Körper-Sprache hervorragend.

Die kognitiv ausgerichteten Untersuchungen zur Rolle einzelner Körperbezeichnungen in Phraseologismen erfolgen dabei in zwei Richtungen: Einerseits wird von einem abstrakten Konzept ausgegangen und gefragt, auf welche Art und Weise es in der Sprache konzeptualisiert wird. Hier findet man insbesondere in den Studien zur Konzeptualisierung der Emotionen (vgl. z.B. Bergerová 2011, Dobrovol'skij 1995b, Kövecses 1986, 1988, 1990, Pohl/Kaczmarek 2014, Ziem 2016) eine Anhäufung der Somatismen, zumal die Basisemotionen wie LIEBE, ANGST, wUT, TRAUER weitgehend über die Beschreibung ihrer körperlichen Symptome zum 
Ausdruck gebracht werden. So steht z.B. in Idiomen etw. schnürt einem die Gurgel $z u$, jmds. Gurgel schnürt sich zusammen, eine Gänsehaut bekommen, in den Knien weich werden oder unter Zähneklappern ein Symptom, ein körperliches Erscheinungsbild einer Emotion ANGST pars pro toto für die Emotion.

In anderen Studien wird semasiologisch vorgegangen, indem gefragt wird, welchen Referenzbereich eine Körperbezeichnung abdeckt. So untersuchen Kövecses und Szabó (1996) die sprachliche Einheit Hand im Englischen, Staffeldt und Ziem (2010) den Finger im Deutschen, Yu (2000, zit. nach Staffeldt/Ziem, 2010) die Hand im Chinesischen und Englischen. Die bisherigen Untersuchungen lassen schlussfolgern, dass die Bedeutungsverschiebungen einen systematischen Charakter haben.

Im Folgenden wird ein Versuch vorgenommen, in einer exemplarischen Studie festzulegen, wofür die sprachliche Einheit Bein in der phraseologisch gebundenen Bedeutung steht. Die Wahl dieser nominalen Konstituente für die Untersuchung ergibt sich aus einer relativ hohen Frequenz dieses Substantivs in der Phraseologismensammlung zu dem Diskursbereich der Schwierigkeit/der schwierigen Lage: Bein tritt beispielsweise in drei im Vorangehenden der detaillierten Analyse unterzogenen Phraseologismen: ein Bein stellen, Knüppel zwischen die Beine werfen, Klotz am Bein auf. Die empirische Grundlage der Untersuchung bilden 40 Phraseologismen mit Bein-Konstituente, die im DUW online (Zugriff 20.09.2017) unter dem Lemma Bein abrufbar sind. Das Ziel der Recherche liegt darin, das Bedeutungspotenzial der Konstituente Bein in diesen Phraseologismen herauszufinden, wobei in den Fokus des Interesses metonymische und metaphorische Derivationen von einer bestimmten Regelmäßigkeit gerückt werden. Die ermittelten Metonymien und Metaphern von einem systematischen, übergreifenden Charakter stellt die Tabelle 28 dar:

Tab. 28: Phraseologismen mit Bein-Konstituente und die konstituierenden und motivierenden konzeptuellen Metonymien und Metaphern.

\section{BEIN STEHT FÜR AKTIVITÄT}

\subsection{BEIN STEHT FÜR BEWEGUNG}

sich die Beine vertreten ,nach langem Sitzen ein wenig hin und her gehen ${ }^{184^{\circ}}$ viel auf den Beinen sein, viel unterwegs sein; [in einer Tätigkeit mit Stehen oder Umherlaufen] sehr beschäftigt sein

sich die Beine nach etw. ablaufen, abrennen, wund laufen/wundlaufen, in dauerndem Bemühen hinter einer Sache her sein, viele Gänge wegen etw. machen' sich die Beine abstehen; sich die Beine in den Leib/Bauch stehen, lange stehen und auf etw. warten müssen

jüngere Beine haben ,besser als eine ältere Person laufen können`

184 Alle Bedeutungsparaphrasen entstammen, falls nicht anders vermerkt, dem DUW online (Zugriff am 20.09.2017). 
Tab. 28: Continued

in die Beine gehen ,1. die Beine schwer machen, belasten; die Beweglichkeit der Beine hemmen, 2. zum rhythmischen [Sich]bewegen, zum Tanzen anregen ${ }^{6}$ von einem Bein aufs andere treten ,ungeduldig warten müssen

1.2 BEIN STEHT FÜR FLUCHT

jmdm. [lange] Beine machen ,1. jmdn. fortjagen. 2. jmdn. antreiben, sich schneller zu bewegen"

die Beine in die Hand/unter die Arme nehmen, ganz schnell [weg]laufen“

1.3 AUF DEN BEINEN SEIN STEHT FÜR AKTIV/IN GUTER FORM SEIN

1.3.1 AUF DEN BEINEN SEIN STEHT FÜR GESUND, FIT SEIN/GESUND, FIT SEIN IST AUF DEN BEINEN SEIN

wieder auf den Beinen sein ,wieder [ganz] gesund sein“

schwach auf den Beinen, 1. nicht gesund, von (schwerer) Krankheit geschwächt. 2. unbewiesen, ungesichert

sich nicht [mehr]/kaum [noch] auf den Beinen halten können, vor

Müdigkeit, Schwäche dem Umfallen nahe sein ${ }^{\prime}$

[wieder] auf die Beine kommen ,1. sich aufrichten, aufstehen. 2. [wieder]

gesund werden. 3. wirtschaftlich wieder hochkommen, festen Fuß

fassen'

jmdm. auf die Beine helfen, 1. einer gestürzten Person wieder aufhelfen.

2. jmdm. helfen, eine Schwäche oder Krankheit zu überwinden.

3. jmdm. finanziell helfen, damit er wieder wirtschaftlich vorankommt ${ }^{\star}$ jmdn. sich [wieder] auf die Beine bringen/stellen ,1. jmdn. sich [wieder]

aufrichten: ich stellte mich mühsam auf die Beine. 2. jmdn. sich

[innerlich] stärken, wieder aufrichten`

auf schwachen Beinen stehen ,schwach, unsicher sein'

* immer wieder auf die Beine fallen, aus allen Schwierigkeiten immer wieder ohne Schaden hervorgehen; nach der Beobachtung, dass Katzen bei einem Sturz meist auf die Beine fallen und sich deshalb nur selten Schäden zuziehen`

1.3.2 AUF DEN BEINEN SEIN STEHT FÜR BETRIEBSAM SEIN/BETRIEBSAM SEIN IST AUF DEN BEINEN SEIN

viel auf den Beinen sein, viel unterwegs sein; [in einer Tätigkeit mit Stehen oder Umherlaufen] sehr beschäftigt sein“

auf den Beinen sein ,draußen, auf der Straße sein' redensartenindex: den ganzen Tag/schon lange auf den Beinen sein ,schon lange unterwegs, wach sein' (Zugriff am 19.10.2017)

jmdn. auf die Beine bringen,jmdn. herauslocken, zusammenbringen ‘ Wahrig: ,10.000 Mann auf die Beine bringen', redensarten-index: viele Leute auf die Beine bringen, viele Leute aufbieten, mobilisieren' (Zugriff am 19.10.2017) 
1.3.3 AUF DEN BEINEN SEIN STEHT FÜR ERFOLGREICH, FINANZIELL UNABHÄNGIG SEIN/ ERFOLGREICH, FINANZIELL UNABHÄNGIG SEIN IST AUF DEN BEINEN SEIN [wieder] auf die Beine kommen (s.o.)

die Beine unter jmds. Tisch strecken ,sich von jmdm. ernähren lassen; von jmdm. versorgt werden

jmdm. auf die Beine helfen (s.o.)

auf eigenen Beinen stehen ,selbstständig, unabhängig sein ‘

etw. [wieder] auf die Beine bringen, etw. [wieder] in einen guten Zustand bringen'

etw. auf die Beine stellen, etw. in bewundernswerter Weise zustande bringen

\subsection{BELASTETES BEIN STEHT FÜR HEMMUNG/SCHWIERIGKEITEN, VERBINDLICHKEITEN} SIND BELASTETES BEIN

etw. noch am Bein haben, etw. noch bezahlen müssen, als Verpflichtung haben; nach dem früheren Brauch, sich kleine Lasten am Bein festzubinden jmdm./sich etw. ans Bein hängen/binden,jmdm./sich etw. aufbürden und ihn, sie, sich dadurch in der Aktivität hemmen“

etw. ans Bein binden, etw. darangeben, einbüßen; die Wendung meint eigentlich, dass etw., was man sich ans Bein bindet, nicht bis zum Herzen dringen kann, dass man sich also etw. nicht zu Herzen gehen lässt und es leicht verschmerzt

\section{EIN BEIN STEHT FÜR EIN HINDERNIS}

jmdm. ein Bein stellen ,1. jmdn. durch Vorstellen eines Beines zum Stolpern bringen.

2. jmdm. durch eine bestimmte Handlung Schaden zufügen; jmdn. hereinlegen ein langes Bein machen ,Fußball: den ballführenden Gegner durch einen Spreizoder Grätschschritt vom Ball zu trennen suchen“

ein/das Bein stehen lassen ,Fußball: den ballführenden Gegner über ein Bein fallen lassen"

\section{ZWEI BEINE STEHEN FÜR DEN GANZEN MENSCHEN, DIE VOLLSTÄNDIGKEIT}

EIN BEIN STEHT FÜR ZERRISSENHEIT, ZWIESPALT

mit beiden Beinen im Leben/[fest] auf der Erde stehen ,Realist[in], Praktiker[in] sein; sich in jeder Lage zurechtfinden"

auf einem Bein kann man nicht stehen, ein Glas Alkohol genügt nicht; bei der Aufforderung oder dem Wunsch, ein zweites Glas zu trinken`

mit einem Bein im Gefängnis stehen,1. etw., was hart an der Grenze des Erlaubten ist, getan haben. 2. einen risikoreichen Beruf haben, bei dem eine Unachtsamkeit o. Ä. schwerwiegende Folgen hat, die einem eine Gefängnisstrafe einbringen kann`

mit einem Bein im Grab[e] stehen ,schwer krank oder in großer Gefahr sein`

4. EIN BEIN STEHT FÜR EINEN MENSCHEN

kein Bein ,kein Mensch“

alles, was Beine hat, alle, die laufen können` 
Die zu untersuchenden Phraseologismen mit Bein-Konstituente sind durch metonymische und metaphorische Bedeutungsverschiebungen motiviert, wobei die Ausgangsdomäne in dem verkörperten Wissen über das Bein, die mit dem Bein verbundenen Wahrnehmungen und seine Funktionen liegt.

1. Einen besonders relevanten Stellenwert für die Konzeptualisierung des Beines in der deutschen Phraseologie scheint der funktionale Aspekt zu haben. Bein steht hier für Aktivität und - in weiteren metaphorischen Bedeutungserweiterungen im Rahmen der Weg-Metaphorik (LEBEN IST EIN WEG, DIE ZIELE IM LEBEN ERREICHEN IST ZU DEN ZIELEN GEHEN) - für zielgerichtetes Handeln. Die verkörperte Erfahrung, die der Metonymie BEIN STEHT FÜR AKTIVITÄT zugrunde liegt, ist bei näherer Betrachtung offensichtlich: Im Gegensatz zu vielen Körperteilen und Sinnesorganen, die Wahrnehmungen passiv aufnehmen (Augen nehmen unwillkürlich wahr, was sich im Blickfeld befindet, Ohren leiten Geräusche ins Gehirn, die es in der Umgebung gibt usw.), charakterisieren sich die Gliedmaßen wie Beine und Hände durch Beweglichkeit und willkürliche Steuerung. Der umfassendsten Gruppe der Idiome mit Bein-Konstituente liegt folglich die BEIN STEHT FÜR DIE AKTIVITÄT-Metonymie mit verschiedenen Ausprägungen zugrunde:

1.1, 1.2 In Phraseologismengruppen 1.1 und 1.2 werden die körperlichen Aspekte in den Fokus der Aufmerksamkeit gerückt: Sowohl die Ausgangs- als auch die Zieldomäne liegen im körperlichen Bereich, hervorgehoben wird die Funktion der Beine, die hauptsächlich für das Gehen und Laufen stehen, der Einfluss der konzeptuellen Metonymie: MITTEL FÜR HANDLUNG (MEANS FOR ACTION) ist hier evident. Beachtenswert ist, insbesondere bei den Phraseologismen der Flucht: lange Beine machen, die Beine unter die Arme nehmen, der Beitrag des mentalen Bildes zu der Konzeptualisierung: Je schneller ein Mensch läuft, desto mehr muss er die Beine in die Höhe reißen und ausstrecken; die Kurzstreckenläufer machen tatsächlich den Eindruck, als ob sie die Beine/Füße unter die Arme nähmen.

1.3 Metonymisch-metaphorische Derivationen konstituieren die phraseologischen Bedeutungen in der Gruppe 1.3: AUF DEN BEINEN SEIN STEHT FÜR AKTIV/IN GUTER FORM SEIN. Die Untergruppen, die hier ermittelt werden konnten, unterscheiden sich in dem Zielbereich, der in der ersten Untergruppe AUF DEN BEINEN SEIN IST GESUND/FIT SEIN in der Domäne der Gesundheit, in der zweiten Untergruppe AUF DEN BEINEN SEIN IST BETRIEBSAM SEIN in der Domäne der Bereitschaft und Betriebsamkeit, in der dritten, durch die Metapher AUF DEN BEINEN SEIN IST ERFOLGREICH/ FINANZIELL UNABHÄNGIG SEIN geprägten Gruppe in der Domäne des finanziellen Erfolgs liegt. Beachtenswert ist die positive Konnotation des Beines, das für die Fortbewegung und Aktivität steht, die in unserem kulturellen Kreis mit Fortschritt, Energie, Tatkraft, Zielstrebigkeit assoziiert und als wünschenswert betrachtet werden, während man Passivität: Laufen- und Geschehen-Lassen, Teilnahmslosigkeit, Apathie eher negativ bewertet (vgl. folgende sprachliche Exemplifizierungen: Trägheit, Stockung, Stagnation, passive Handelsbilanz, Übergewicht der Einfuhr über die Ausfuhr', Leergang, Passiv wird bei Genera verbi anders als Leideform bezeichnet). 
Einen Beitrag zu Konzeptualisierungen leistet hier ebenfalls die konzeptuelle Orientierungsmetapher: GUT IST OBEN, SCHLECHT IST UNTEN und verkörperte Erfahrung: Kranke, Schwache, wehrlose Menschen: Kleinkinder, Schlafende usw. sind nicht imstande, die stehende Position zu halten, die positive Wertung der mit Aktivität, Bereitschaft, Gesundheit, psychischer Stabilität und Erfolg assoziierten Aufrechtposition ergibt sich aus menschlicher Physiognomie.

Bei vielen Idiomen dieser Gruppe ist die Kontinuierlichkeit der Übergänge zwischen metaphorischen und metonymischen Verschiebungen gut ersichtlich. So weisen beispielshalber die Idiome wieder auf die Beine kommen, jmdm. auf die Beine helfen drei Teilbedeutungen auf, die als lexikalisierte Schritte einer metonymisch-metaphorischen Kette betrachtet werden können:

DUW: [wieder] auf die Beine kommen ,1. sich aufrichten, aufstehen. 2. [wieder] gesund werden. 3. wirtschaftlich wieder hochkommen, festen Fuß fassen

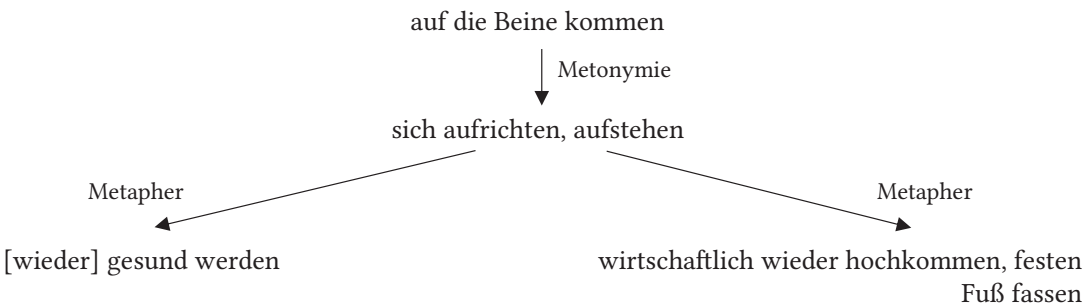

Abb. 69: Teilbedeutungen des Idioms auf die Beine kommen als lexikalisierte Metaphern und Metonymien.

DUW: jmdm. auf die Beine helfen ,1. einer gestürzten Person wieder aufhelfen. 2. jmdm. helfen, eine Schwäche oder Krankheit zu überwinden. 3. jmdm. finanziell helfen, damit er wieder wirtschaftlich vorankommt

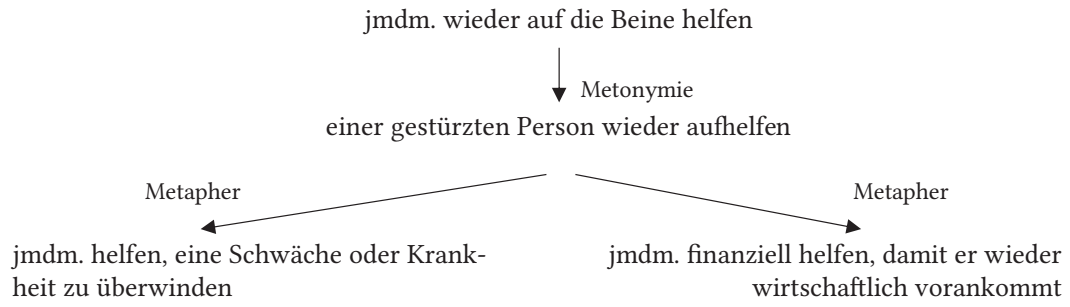

Abb. 70: Teilbedeutungen des Idioms jmdm. wieder auf die Beine helfen als lexikalisierte Metaphern und Metonymien. 
1.4 An die BeIN STeHt FÜR AKTIVItÄT-Metonymie knüpfen ebenfalls die Phraseologismen der Gruppe 1.4 an, in denen das Bein als ein ungeeigneter Lastenträger konzeptualisiert wird. Der Motiviertheit der Idiome: etw. noch am Bein haben, sich/jmdm. etw. ans Bein binden/hängen liegen ähnliche kognitive Mechanismen zugrunde, die bei der Analyse des Idioms: Klotz am Bein ${ }^{185}$ im Vorangehenden beschrieben wurden: Bein steht hier für die Fortbewegung, Fortbewegung steht für Aktivität und Fortschritt; ein belastetes Bein steht also für Hemmung/Hindernis bei der Fortbewegung, Hemmung steht für (hauptsächlich finanzielle) Schwierigkeiten. Beachtenswert sind hier die fließenden Übergänge zwischen dem Literalen und dem Übertragenen, der Metonymie und der Metapher. Während BEIN STEHT FÜR DIE FORTBEWEGUNG wegen der konzeptuellen Nähe zwischen dem Körperteil und seiner Funktion als eine Metonymie betrachtet werden kann, ist die darauf aufbauende Derivation je nach dem konzeptuellen Abstand zwischen der Ausgangs- und der Zieldomäne sowohl als Metonymie: BEWEGUNG STEHT FÜR AKTIVITÄT UND FORTSCHRITT, als auch als Metapher AKTIVITÄT UND FORTSCHRITT SIND EINE (VORWÄRTS-)BEWEGUNG auslegbar.

FORTBEWEGUNG STEHT FÜR AKTIVITÄT UND FORTSCHRITT

die Schlange der Wartenden rückt nur langsam vor (DWDS-Wörterbuch, Zugriff am 18.10.2017)

die Zeiger der Uhr rücken immer weiter vor (DWDS-Wörterbuch, Zugriff am 18.10.2017)

die Truppen sind im Vormarsch (DWDS-Wörterbuch, Zugriff am 18.10.2017)

AKTIVITÄT UND FORTSCHRITT SIND BEWEGUNG NACH VORNE/VORWÄRTSBEWEGUNG

eine weit vorangeschrittene Wissenschaft (DWDS-Wörterbuch, Zugriff am 18.10.2017)

der Bau des Hauses schritt schnell fort (DWDS-Wörterbuch, Zugriff am 18.10.2017)

in diesen Verhandlungen sind wir ein gutes Stück vorangekommen (DWDS-Wörterbuch, Zugriff am 18.10.2017)

er wollte in seinem Beruf, im Leben vorankommen (DWDS-Wörterbuch, Zugriff am 18.10.2017)

Seit der Bau unter Dach war, schritt er nur langsam voran (DWDS-Wörterbuch, Zugriff am 18.10.2017)

die Untersuchungen, Bauarbeiten gehen rasch, zügig, schleppend voran (DWDS-Wörterbuch, Zugriff am 18.10.2017)

Seit 1949 im Deutschen Bundestag, war ich auch in die vordere Linie der deutschen Politik vorgerückt. Brandt, Willy: Erinnerungen, Berlin: Ullstein 1997 [1989], S. 11 (DWDS, Zugriff am 26.10.2017)

Der Gedanke des sozialen Friedens ist wieder im Vormarsch (DWDS-Wörterbuch, Zugriff am 18.10.2017)

185 Dieser Phraseologismus wird dennoch nicht in die vorliegende Untersuchung aufgenommen, da es im DUW online (Zugriff 26.09.2017) makrostrukturell dem Lemma ,Klotz‘ eingeordnet wird. 
2. Die BEIN STEHT FÜR AKTIVITÄT-Metonymie mit allen weiteren Ausprägungen motiviert über die Hälfte der Phraseologismen mit der Bein-Konstituente. Die weiteren Gruppen sind durch wesentlich kleinere Anzahl der Phraseologismen vertreten. So umfasst die zu besprechende zweite Gruppe EIN BEIN STEHT FÜR EIN HINDERNIs lediglich drei idiomatische Einheiten. Die hier gesammelten Phraseologismen: das einer Analyse unterzogene Idiom jmdm. ein Bein stellen, sowie zwei Idiome aus der Fußball-Fachsprache: ein langes Bein machen, ein/das Bein stehen lassen heben andere Wissensaspekte hervor. Das Bein selbst stellt hier nämlich das Hindernis dar, das einem anderen Menschen - mehr oder weniger absichtlich vorgehalten werden kann (zu weiteren Motiviertheitsmechanismen vgl. das Kap. 4.2.2.1.1.2.1).

3. Grundlegend für die dritte Phraseologismengruppe ist das Wissen, das ein Mensch ein zweibeiniges Wesen ist und beide Beine zum richtigen Funktionieren braucht. Dieses Wissen ist selbstverständlich embodied: Wenn man auf beiden Beinen steht, steht man sicher, erschütterungsfest, stabil, das Stehen auf einem Bein erfordert Konzentration, ist naturwidrig, das Sturzrisiko ist groß. Dementsprechend wird die Wortverbindung mit beiden Beinen als ,vollständig, gut etabliert' konzeptualisiert, mit einem Bein bringt dagegen eine innere Aufspaltung, Zerrissenheit zum Ausdruck. Beachtenswert ist dabei, dass die Phraseologismen mit einem Bein im Gefängnis stehen, mit einem Bein im Grab[e] stehen einen konstruktiven Charakter haben: Die kurze Übersicht der DWDS-Belege lässt schlussfolgern, dass Grab und Gefängnis/Knast als Idiom-Konstituenten in synchronem Gebrauch keinesfalls stabil sind. Mit einem Bein kann man demzufolge beispielsweise auch im Berufsleben, im Mittelalter, im vorigen fahrhundert, im fazz der Bebop-Ära, auf der Seite des Leidens, im Osten, auf der Straße stehen. An dieser Stelle kann man also von einem phraseologischen Muster/einer Modellbildung sprechen (Burger 2015: 54), oder - aus konstruktionsgrammatischer Sicht - von einer Konstruktion.

4. In der letzten, zwei Phraseologismen umfassenden Gruppe ist die phraseologische Lesart durch die Spezifizierung der konzeptuellen pars-pro-toto-Metonymie: EIN BEIN STEHT FÜR EINEN MENSCHEN motiviert.

Die übrig gebliebenen sechs Phraseologismen aus der dieser Untersuchung zugrunde liegenden Zusammenstellung weisen keine übergreifenden Gemeinsamkeiten auf. Das metonymisch motivierte (TEILHANDLUNG STEHT FÜR DIE HANDLUNG) Idiom die Beine breit machen ,salopp: [von Frauen] Geschlechtsverkehr ausüben' ist euphemistisch; im spezialisierten und auf den Fußball eingeschränkten Phraseologismus [nur] ein linkes, rechtes Bein haben, nur mit dem linken, rechten Bein richtig schießen können' steht das Bein metonymisch für Schusskraft, Beine bekommen/gekriegt haben, ugs. plötzlich abhandengekommen oder gestohlen worden sein' ist durch einen ironischen Gebrauch einer anthropomorphen Metapher motiviert, in der einem Gegenstand menschliche Attribute zugeschrieben werden. Das Idiom: mit dem linken Bein zuerst aufgestanden sein, schlechter Laune sein, an 
allem etwas auszusetzen haben' ist durch die symbolische Bedeutung des Adjektivs ,links' und der ,linken Seite' im abendländischen Kulturkreis motiviert. Das Idiom sich kein Bein ausreißen, ugs. sich [bei der Arbeit] nicht besonders anstrengen' stellt ein Beispiel einer Hyperbel dar: Der Beitrag der BEIN STEHT FÜR AKTIVITÄт-Metonymie ist hier nicht auszuschließen, den ermittelten systematischen Ausprägungen dieser Metonymie in vorliegender Zusammenstellung lässt sich das Idiom aber nicht zuordnen.

\subsection{SCHWIERIGE LAGE IST RÄUMLICHE BESCHRÄNKTHEIT}

jmdn. in die Enge treiben, jmdn. an die Wand drücken

Die zu besprechenden Idiome lassen sich im Allgemeinen der Weg-Metaphorik mit leitenden konzeptuellen Metaphern: LEBEN IST EIN WEG, SCHWIERIGKEITEN SIND VERHINDERUNGEN DER (VORWÄRTS-)BEWEGUNG zuordnen. Während aber den bisherigen Idiomen als Ausgangspunkt der Konzeptualisierung die konzeptuellen Metaphern: SCHWIERIGKEITEN SIND HINDERNISSE AUF DEM WEG (UNSICHERER BODEN, HINDERNISSE, DIE EINEN ZUM FALL BRINGEN) zugrunde liegen, ist bei Idiomen jmdn. in die Enge treiben, jmdn. an die Wand drücken die konzeptuelle Metapher: SCHWIERIGE LAGE IST RÄUMLICHE BESCHRÄNKTHEIT richtungsweisend, auch wenn Interaktionen mit anderen konzeptuellen Metaphern keinesfalls ausgeschlossen sind.

Möglicherweise haben die Idiome jmdn. in die Enge treiben, jmdn. an die Wand drücken eine gemeinsame Motiviertheitsbasis, die auf eine Jagd, Schlacht bzw. ein Duell zurückzuführen ist: Eine der bewährtesten Strategien im Zweikampf liegt nämlich darin, dass man den Gegner in einen seitlich eingeschränkten Raum (in eine Ecke, in einen Kessel) hineintreibt, von wo her er nicht mehr fliehen kann. Das Gefühl des Eingeschlossenseins hat weitreichende Folgen für die Psyche des Betroffenen, weswegen das Idiom aufgrund der körperlichen Verankerung ebenfalls synchron nachvollziehbar ist. Das Wort Enge löst in erster Linie negative Assoziationen aus, wovon z.B. die frequentesten computergenerierten typischen Verbindungen $\mathrm{zu}$ diesem Nomen zeugen: bedrückende, beklemmende, drangvolle, klaustrophobische, kleinbürgerliche, provinzielle, qualvolle, räumliche [Enge], [der Enge] entfliehen, [in die Enge] treiben (DWDS, Zugriff am 07.04.2017).

\subsection{1 in die Enge treiben}

Lexikographisch erfasste Varianten:-

Modifikationen: sich in die Enge getrieben fühlen, sich in die Enge getrieben finden 


\section{Darstellung in lexikographischen Nachschlagewerken}

Tab. 29: Das Idiom in die Enge treiben in allgemeinen und phraseologischen Wörterbüchern des Deutschen.

\begin{tabular}{|c|c|c|}
\hline Wörterbuchtyp & Wörterbuch & Lexikographische Darstellung \\
\hline \multirow[t]{3}{*}{ allgemein } & DUw 2006 & $\begin{array}{l}\text { jmdn. in die Enge treiben (durch Fragen, Drohungen } \\
\text { o. A. in Bedrängnis bringen) }\end{array}$ \\
\hline & DUW ONLINE & $\begin{array}{l}\text { jemanden in die Enge treiben (durch Fragen, } \\
\text { Drohungen o.Ä. in Bedrängnis bringen) (letzter Zugriff } \\
\text { am 31.03.2017) }\end{array}$ \\
\hline & WAHRIG 2007 & $\begin{array}{l}\text { jmdn. in die Enge treiben jmdm. alle Auswege } \\
\text { versperren; 〈fig.〉 alle Ausflüchte, jegliche Ausreden } \\
\text { widerlegen }\end{array}$ \\
\hline \multirow[t]{4}{*}{ phraseologisch } & DUDEN 11 & $\begin{array}{l}\text { jmdn. in die Enge treiben: jmdn durch Fragen, } \\
\text { Drohungen o.Ä. in Bedrängnis bringen: Der Staatsanwalt } \\
\text { trieb den Angeklagten in die Enge. Die Lehrerin geriet } \\
\text { in Verlegenheit, als sei sie in die Enge getrieben und } \\
\text { müsse sich herausreden (Th. Mann, Zauberberg 192) } \\
\text { • Die Wendung bezieht sich in ihrer Bildlichkeit } \\
\text { darauf, dass man früher beim Kampf den Gegner gegen } \\
\text { die Wand oder in die Ecke zu treiben versuchte, um } \\
\text { seine Bewegungsfreiheit einzuschränken und ihm die } \\
\text { Möglichkeit zur Flucht zu nehmen. (2011: 196) }\end{array}$ \\
\hline & $\begin{array}{l}\text { SCHEMANN } \\
2011\end{array}$ & $\begin{array}{l}\text { jmdn. in die Enge treiben } \\
\text { Er behauptete immer wieder, er sei unschuldig. Doch } \\
\text { als ihn der Anwalt der Gegenseite mit gezielten } \\
\text { Fangfragen in die Enge trieb, blieb ihm nichts anderes } \\
\text { üblich als zuzugeben, dass er den Diebstahl begangen } \\
\text { hatte. }(2011: 162)\end{array}$ \\
\hline & $\begin{array}{l}\text { REDENSARTEN- } \\
\text { INDEX }\end{array}$ & $\begin{array}{l}\text { jemanden in die Enge treiben ,jemanden } \\
\text { einschüchtern/in Bedrängnis/Verlegenheit bringen“ } \\
\text { Die „Enge“ ist eine Falle, in die das Wild bei der Jagd } \\
\text { getrieben wurde, um es leichter zu erlegen (letzter } \\
\text { Zugriff am 31.03.2017) }\end{array}$ \\
\hline & MÜLLER 2005 & $\begin{array}{l}\text { jmdn. in die Enge treiben jmdn. einschüchtern, jmdn. } \\
\text { in eine wehrlose Lage bringen [Einschüchterung] } \\
\text { „Laß dich nicht von deinem Bruder so in die Enge } \\
\text { treiben! Schließlich habt ihr beide Anspruch an diese } \\
\text { Erbschaft!“ } \\
\text { Die „Enge“ ist eine Falle, in die das Wild bei der Jagd } \\
\text { getrieben wurde, um es leichter zu erlegen. Vgl.: jmdn. } \\
\text { ins Bockshorn jagen. (2005: } 110)\end{array}$ \\
\hline
\end{tabular}




\section{Korpusgestützte Analyse anhand der DWDS-Korpora ${ }^{186}$}

1. ,jmdn. in seiner Bewegungs- und Handlungsfreiheit beschränken, in eine ausweglose Lage bringen, unter Druck setzen“

(23 Belege)

\section{in die Enge treiben}

2. in einer verbal-argumentatorischen Auseinandersetzung: ,jmdm.mit gezielt gestellten Fragen zusetzen, jmdn. mit Argumenten und Fragen in eine schwierige, ausweglose Situation bringen, in der er die Überlegenheit des Gesprächspartners anerkennen muss'

(17 Belege)

Abb. 71: Die Verwendungsprofile des Idioms in die Enge treiben anhand der Analyse der Gebrauchsbelege im DWDS-Korpus.

Das Idiom in die Enge treiben wird vorwiegend in Passiv bzw. passivähnlichen Konstruktionen verwendet, im Mittelpunkt der Aufmerksamkeit befindet sich somit nicht das Agens und seine potenziellen Bewegungsgründe, sondern der Zustand des Betroffenen. Das Agens tritt in den meisten Gebrauchsbelegen in den Hintergrund und wird explizit nicht genannt. Die Bedeutung des Idioms jmdn. in die Enge treiben lässt sich pauschal mit der Bedeutungsparaphrase ,jmdn. in eine schwierige, ausweglose Lage bringen“ umschreiben. Diese Bedeutungsparaphrase deckt das semantische Spektrum aller Belege ab, die zwei Verwendungsprofile, die aus der Analyse der einzelnen Belege ermittelt wurden, differieren in Bezug auf den üblichen Verwendungsbereich. Während die Enge in dem ersten Verwendungsprofil auf eine weit gefasste Beschränkung der Bewegungs-, Entscheidungs- und Handlungsfreiheit, auf eine schwierige Lebenslage referiert, bezieht sich die zweite Teilbedeutung auf eine Spezifizierung dieser allgemeinen Situation - die Notlage eines Gesprächspartners in einer verbalen Auseinandersetzung. Die korpusbasierte semantische Analyse lässt dabei auf einen sich vollziehenden Bedeutungserweiterungsprozess schlussfolgern: Der in den lexikographischen Nachschlagewerken (vgl. DUW online, Duden 11, Wahrig 2007) vorausgesetzte und mit den Ergänzungen ,durch Fragen,

186 Zugriffsdatum: 20.05.2014, Suchanfrage: in\&\&@die\&\&@Enge\&\&treiben. Deutsches Textarchiv: 5/73; Kernkorpus: 10/108 (anzeigbar 78); Die Zeit: 10/555; Berliner Zeitung: 7/191; Der Tagesspiegel: 7/156; Potsdamer Neueste Nachrichten: 1/6. 
Drohungen' zum Ausdruck gebrachte verbal-argumentative Verwendungsbereich kommt in 17 von 40 Gebrauchsbelegen vor, in den übrig gebliebenen 23 Kontexten werden die Verwendungsmöglichkeiten des Idioms auf andere Bereiche erweitert.

\section{Verwendungsprofil 1: ,jmdn. in seiner Bewegungs- und Handlungsfreiheit beschränken, in eine ausweglose Lage bringen, in der er sich unter Druck gesetzt fühlt' (23 Belege)}

Das mit den meisten Belegen vertretene Verwendungsprofil referiert auf die Beschränkung des Patiens in seiner Bewegungs-, Entscheidungs- und/oder Handlungsfreiheit. Im erstgenannten, insgesamt vier Belege umfassenden Fall wird unter der Enge vor allem die räumliche Beschränkung verstanden. Die Belege beziehen sich auf die bedrängte Lage der Tiere, der Truppen oder einer Schachfigur, vgl. z.B.:

(82) Richtig gefährlich sind die Tiere nur bis zu sechs Wochen nach dem Wurf von Frischlingen, die im November/Dezember gezeugt werden und genau drei Monate, drei Wochen und drei Tage später zur Welt kommen. „Aber wenn sie sich in die Enge getrieben fühlen, können auch Keiler schon mal in die menschliche Wade beißen", warnt Wehner. Gefährlicher sei aber die Bache. Berliner Zeitung, 13.07.1999

In weiteren Gebrauchskontexten liegt eine metaphorische Verschiebung vor. Die Enge bezieht sich hier eher auf den psychologischen Bereich, die Einschränkung des Patiens in seiner Handlungsfreiheit. Dabei sind die Grenzen zwischen dem konkreten Bereich der tatsächlichen oder gespürten körperlichen Einsperrung und dem abstrakteren Bereich des eingeschränkten Entscheidungs- und Handlungsspielraums und der dabei empfundenen Beklemmung verschwommen. So kann das zu besprechende Idiom im folgenden Gebrauchsbeleg sowohl als tatsächlicher Mangel am Platz auf Gehwegen, als auch als psychische Empfindung einer durch Bedrängnis hervorgerufenen Verunsicherung, einer Bedrohung ausgelegt werden:

(83) Vielen Radfahrern ist es auf der Straße zu unsicher. Deshalb weichen sie auf Gehwege aus. Da sind sie unangreifbar, und das merkt man ihnen an. Immer häufiger fühlen sich Fußgänger von rücksichtslosen Raser-Radlern genötigt und in die Enge getrieben. Immer mehr werden auch verletzt. Der Tagesspiegel, 03.04.2005

Fließende Übergänge sind ebenfalls in den folgenden Belegen feststellbar, die sich auf den psychischen Zustand eines - körperlich in seiner Bewegungs- und Handlungsfreiheit eingeschränkten - Menschen beziehen, dem alle Fluchtwege versperrt worden sind:

(84) Das Tatmotiv werde weiter im Umfeld des Mannes ermittelt, hieß es. Die Ermittler gehen davon aus, dass der psychisch labile Michael Berger sich in der Polizeikontrolle in die Enge getrieben fühlte und durchdrehte. Nach den Todesschüssen auf die Polizisten in Dortmund und Waltrop richtete sich der 31-Jährige am Mittwoch selbst. Berliner Zeitung, 17.06.2000

(85) Hitlers maßloser Argwohn, seine niedere Rachsucht, sein ungehemmter Haß, seine kaltherzige Menschenverachtung brachen in einem einzigartigen Wutanfall 
hervor, der seinen eigenen Bankrott, sein eigenes Versagen nur schlecht verhehlen konnte. In die Enge getrieben, wählte Hitler den Freitod, den er Tage zuvor noch als verantwortungslos gebrandmarkt hatte. Er war entschlossen, sich dem Zugriff seiner Feinde und seinen irdischen Richtern zu entziehen. Die Zeit, 26.07.1968

(86) Jetzt ist der mutmaßliche Mörder des italienischen Modeschöpfers Gianni Versace, der 27-jährige Andrew Cunanan, tot. Er hat sich wahrscheinlich selbst erschossen, als er in die Enge getrieben wurde. Seine Leiche wurde in einem Hausboot in Miami Beach gefunden, das dem Deutschen Torsten Reineck gehört. Der Tagesspiegel, 25.07.1997

Eine deutliche metaphorische Übertragung aus dem körperlichen in einen abstrakten Bereich liegt in den Belegen vor, die auf wirtschaftliche Lage eines Unternehmers oder Unternehmens referieren und als deutliche Einschränkung der Handlungsfreiheit interpretiert werden können:

(87) „Es wird für ein solches Projekt keine Mittel von unserer Zentrale in Frankfurt geben. Seit die Bahn eine Aktiengesellschaft geworden ist, werden wir wirtschaftlich noch mehr in die Enge getrieben“, machte Wilfried Kuhl, verantwortlich für den Bereich Elektrotechnik in Berlin, vor dem Umweltausschuß klar. Das Geld müsse von der Bundesregierung kommen. Berliner Zeitung, 18.01.1995

(88) Das Wort vom unabwendbaren Konkurs des Vereins schwebt ständig über dem kickenden Personal. Immer neue Zahlungsforderungen zahlreicher Gläubiger, die auch dem Vertragspartner und Sponsor Nike bei dessen Engagementbeginn im Frühjahr 1997 bei Union nicht vollständig bekannt waren, treiben Union in die Enge „So kann ich nicht weiterarbeiten“, klagt Heine, „ich fordere jeden Tag von meinen Spielern, daß sie alles für den Verein geben sollen, daß sie die Sorgen hintenanstellen“. Berliner Zeitung, 20.09.1997

Die Bedeutungskonstituierungsmechanismen lassen sich auf zwei Ebenen ansiedeln (Abb. 72).

Die erste Ebene wird grundsätzlich durch zwei Gruppen der konzeptuellen Metaphern konstituiert, die sich dennoch an vielen Punkten verzahnen. Richtungsweisend für die Konzeptualisierungen sind einerseits die bereits diskutierten konzeptuellen Metaphern LEBEN IST EIN WEG, SCHWIERIGKEITEN SIND VERHINDERUNGEN DER BEWEGUNG, andererseits taucht eine neue Metapher RAUM IST GUT, ENGE IST SCHLECHT auf. Die konzeptuelle Metapher von niedrigerem Generalitätsgrad: SCHWIERIGE LAGE IST RÄUMLICHE BEGRENZTHEIT liegt auf dem Schnittpunkt zwischen den beiden Metaphern.

Die RAUM IST GUT, ENGE IST SCHLECHT-Metapher ist in der Sprache weitverbreitet. Die Weite und Größe haben die Menschen seit Urzeiten beeindruckt, darüber hinaus brauchen alle Lebewesen (Menschen, Pflanzen, Tiere) Raum, um sich entfalten zu können. Raum wird also mit Luft, Entwicklung, Möglichkeiten assoziiert: 
Ebene 1

Vorstellungsschema: WEG

konzeptuelle Metaphern:

LEBEN IST EIN WEG

SCHWIERIGKEITEN SIND HINDERNISSE

AUF DEM WEG

RAUM IST GUT, ENGE IST SCHLECHT

SCHWIERIGE LAGE/ SCHWIERIGKEIT IST RÄUMLI-

CHE BESCHRÄNKTHEIT

Metaphtonymie

BEWEGUNGSEINSCHRÄNKUNG STEHT FÜR/ IST HANDLUNGSEINSCHRÄNKUNG

Ebene 2

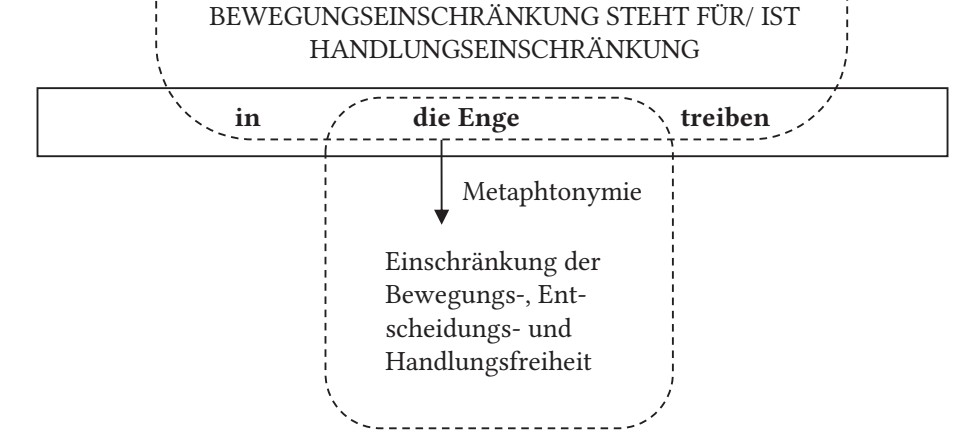

Abb. 72: Bedeutungskonstituierungsmechanismen für das Verwendungsprofil 1 ,jmdn. in seiner Bewegungs- und Handlungsfreiheit beschränken, in eine ausweglose Lage bringen, in der er sich unter Druck gesetzt fühlt:

RAUM IST GUT, ENGE IST SCHLECHT

engstirnig, schmalspurig, kleindenkend sein

(an) Boden gewinnen ,sich ausbreiten, zunehmen' (DUW online, Zugriff am 26.10.2017)

(an) Boden verlieren ,Macht, Einfluss verlieren' (DUW online, Zugriff am 26.10.2017)

eine weitblickende Entscheidung, eine künftige Notwendigkeiten einkalkulierende

Entscheidung، (DWDS-Wörterbuch, Zugriff am 26.10.2017)

unter Druck stehen (DUW online, Zugriff am 26.10.2017)

jmdn. unter Druck setzen ,bedrängen“ (DUW online, Zugriff am 26.10.2017)

mit etw. in Druck (,Bedrängnis') kommen, geraten (DUW online, Zugriff am 26.10.2017)

einer Sache Raum geben ,etw. sich entfalten, sich entwickeln lassen' (DUW online, Zugriff am 26.10.2017)

einen engen/weiten Horizont haben (DWDS-Wörterbuch, Zugriff am 26.10.2017)

das Lesen von Büchern erweitert den Horizont (DWDS-Wörterbuch, Zugriff am 26.10.2017) das geht über seinen Horizont, übersteigt seine intellektuelle Kraft, sein Verständnis‘ (DUW online, Zugriff am 29.07.2017) 
seine gedankliche Weite, sein vieles umfassendes Denken' (DWDS-Wörterbuch, Zugriff am 26.10.2017)

Entscheidungsspielraum, Ermessensspielraum, Handlungsspielraum

sich etwas Luft verschaffen ,Bewegungsfreiheit für seine Handlungen“ (DUW online, Zugriff am 29.07.2017)

in etw. ist noch Luft [ drin] ,bei etw. gibt es noch einen Spielraum zum Manövrieren, noch eine bestimmte Handlungsfreiheit o. A.' (DUW online, Zugriff am 29.07.2017) der Spielraum verengte sich, verringerte sich ' für sie (DUW online, Zugriff am 28.07.2017) alle anderen in den Kasten stecken, alle andere übertreffen, überbieten' (redensartenindex, Zugriff am 20.10.2017)

Leicht ausfindig sind, ebenfalls im phraseologischen und Wortbildungsbereich, die sprachlichen Exemplifizierungen der Metapher SCHWIERIGE LAGE/SCHWIERIGKEIT IST RÄUMLICHE BESCHRÄNKTHEIT:

SCHWIERIGE LAGE/SCHWIERIGKEIT IST RÄUMLICHE BESCHRÄNKTHEIT Engpässe in einigen Teilen der Wirtschaft (DWDS-Wörterbuch, Zugriff am 06.04.2017) Man versucht, durch gegenseitige Unterstützung durch das Nadelöhr zu gelangen. Die Zeit, 13.08.2003 (DWDS, Zugriff am 06.04.2017)

Die Hardware wird immer schneller, und das ist schön, aber der eigentliche Flaschenhals ist die Software. $C^{\prime} t$, 1996, Nr. 11 (DWDS, Zugriff am 06.04.2017)

Geldströme sind das nicht, sie müssen immer durch leicht beherrschbare Engstellen. Die Zeit, 14.08.2013 (DWDS, Zugriff am 06.04.2017)

Dieses Projekt musste schon in den Anfängen steckenbleiben (= aufgegeben werden) (DWDS-Wörterbuch, Zugriff am 06.04.2017)

Er befand sich (wirtschaftlich) in arger Bedrängnis, er lebt in großer (innerer) Bedrängnis, in der Bedrängnis seines Herzens bat er sie um Rat (DWDS-Wörterbuch, Zugriff am 06.04.2017)

Tiefe Beklemmung beschlich uns (DWDS-Wörterbuch, Zugriff am 06.04.2017) von einem Albdruck befreit sein (DWDS-Wörterbuch, Zugriff am 06.04.2017) ins Gedränge kommen, jmdn. ins Gedränge bringen

[mit etw.] ins Gedränge kommen/geraten ([mit etw.] in [zeitliche] Schwierigkeiten, in Bedrängnis kommen; ursprünglich vom Gedränge im Kampf' (DUW online, Zugriff am 25.10.2017)

jmdn. ins Bockhorn jagen, sich [nicht] ins Bockshorn jagen lassen, (umgangssprachlich: sich [keine] Angst machen lassen, sich durch Täuschung o. Ä. [nicht] erschrecken und verwirren lassen“ (DUW online, Zugriff am 25.10.2017)

in einer (richtigen/...) Zwickmühle stecken; sich in einer richtigen Zwickmühle befinden; in eine Zwickmühle geraten ,schwierige, verzwickte Lage, aus der es keinen Ausweg zu geben scheint' (DUW online, Zugriff am 25.10.2017)

in eine Sackgasse geraten/sich in eine Sackgasse verrennen/in einer Sackgasse stecken ,nicht mehr zurückkönnen; keinen Ausweg mehr haben' (redensarten-index, Zugriff am 25.10.2017)

mit dem Rücken zur Wand stehen, in einer äußerst schwierigen Situation sein, in einer Lage, in der sich jd. energisch wehren, verteidigen muss' (DUW online, Zugriff am 29.07.2017) 
Den kontinuierlichen Übergängen aus dem Bereich der körperlichen Einengung in den Bereich der in der Wirklichkeit vorhandenen oder subjektiv empfundenen Beraubung von Entscheidungs- und Handlungsfreiheit liegt die in der körperlichen Erfahrung des Menschen tief verankerte konzeptuelle Metaphtonymie BEWEGUNGSEINSCHRÄNKUNG STEHT FÜR HANDLUNGSEINSCHRÄNKUNG/HANDLUNGSEINSCHRÄNKUNG IST BEWEGUNGSEINSCHRÄNKUNG zugrunde. An dieser Stelle wird eine Metaphtonymie angenommen, weil der konzeptuelle Abstand zwischen den beiden Erfahrungsbereichen: der Domäne der Einschränkung der körperlichen Bewegung und der Domäne der weit verstandenen Handlungseinschränkung in den einzelnen Kontexten sehr unterschiedlich sein kann. Wie die Belege (83)-(88) veranschaulichen, sind hier vielfältige Verzahnungen möglich. Als weitere sprachliche Manifestationen können folgende Ausdrücke angeführt werden:

BEWEGUNGSEINSCHRÄNKUNG STEHT FÜR HANDLUNGSEINSCHRÄNKUNG/

HANDLUNGSEINSCHRÄNKUNG IST BEWEGUNGSEINSCHRÄNKUNG

jmdm. sind die Hände gebunden, jd. kann nicht so handeln oder entscheiden, wie er möchte, weil seine Handlungs-, Entscheidungsfreiheit durch bestimmte äußere Umstände entscheidend eingeengt ist' (DUW online, Zugriff am 05.10.2017)

jmdm. in den Arm fallen ,jmdn. an etw. hindern' (DUW online, Zugriff am 05.10.2017) freie Hand haben ,tun können, was man will' (DUW online, Zugriff am 05.10.2017) jmdm. freie Hand geben, es jmdm. erlauben, nach eigenem Ermessen zu handeln“ (redensarten-index, Zugriff am 25.10.2017)

sich/jmdm. etw. ans Bein binden, sich/jmdm. etw. (z.B. Arbeit) aufhalsen; sich etw. aufbürden; auf jmdn. Arbeit/Verantwortung/Schuld abwälzen`

etw. am Bein haben, verpflichtet/eingebunden sein' (redensarten-index, Zugriff am 09.04.2017)

ich sitze mit diesem Problem fest, finde keine Lösung، (übertragen von das Schiff saß auf der Sandbank fest) (DUW online, Zugriff am 09.04.2017)

Bei der Bedeutungskonstituierung vieler Gebrauchsbelege hat ebenfalls die metaphorische Verschiebung der nominalen Konstituente Enge auf der zweiten Ebene ihren Anteil. Die ursprüngliche Bedeutung des Platzmangels, der Raumnot wird in abstraktere Domänen der psychischen Empfindung von Beengtheit übertragen. Die Übergänge zwischen dem Bereich des Körperlichen und dem Bereich des Psychischen sind dabei kontinuierlich: Sowohl die Tiere aus dem Beleg (82) als auch der von der Polizei kontrollierte Mann aus dem Beleg (84) sind gleichzeitig in der Bewegungsfreiheit eingeschränkt und - in ihrer subjektiven, nicht unbedingt den Tatsachen entsprechenden Empfindung - gefährdet, ihrer Freiheit, Eigenständigkeit, Selbstbestimmung beraubt. Die negativen Assoziationen zur Enge sind embodied, tief in der körperlichen Erfahrung verankert und beziehen sich zugleich auf die äußeren Umstände und die inneren Empfindungen: Einerseits lösen enge Räume bei vielen Menschen Klaustrophobie und Angst vor Ersticken aus, andererseits verspürt man in extremen Stresssituationen, unter psychischen Belastungen krampfhafte Verspannungen der Muskeln, die zur Luftknappheit führen und sich wie ein enger Panzer um 
die Brust legen (vgl. jmdm. die Kehle zuschnüren). Angst vor Beengtwerden, Luftnot und Ersticken werden dann auf politische, wirtschaftliche u.Ä. Situationen projiziert.

Verwendungsprofil 2: (in einer verbal-argumentatorischen Auseinandersetzung): ,jmdm. mit gezielt gestellten Fragen zusetzen, jmdn. mit Argumenten und Fragen in eine schwierige, ausweglose Situation bringen, in der er die Überlegenheit des Interlokutors anerkennen muss' (17 Belege)

Das zweite Verwendungsprofil stellt eine Spezialisierung der bereits besprochenen Bedeutung dar und lässt sich mit ähnlicher Bedeutungsparaphrase ,jmdn. in seiner Freiheit beschränken, in eine ausweglose Lage bringen, in der er sich nicht verteidigen kann, unter Druck gesetzt wird“ umschreiben. Der grundlegende Unterschied liegt dennoch darin, dass sich diese Bedeutung ausschließlich auf verbale Auseinandersetzungen, Diskussionen oder Debatten bezieht. Auf diesen spezialisierten Verwendungsbereich wird in manchen Belegen explizit hingewiesen:

(89) Die Absicht Jesu bei Vorlegung dieser Frage war, den Pharisäern zu zeigen, dass auch er, was sie früher gegen ihn versucht hatten, im Stande sei, sie durch verfängliche Fragen in die Enge zu treiben, und zwar mit besserem Erfolg als sie. Strauß, David Friedrich: Das Leben Jesu, kritisch bearbeitet. Bd. 1. Tübingen, 1835.

(90) Damit war meine gestrige Gesellschaft durchaus nicht einverstanden, und man versuchte mich mit vielen Fragen in die Enge zu treiben. Aber dann mache ich mir's bequem und verstumme. Reventlow, Franziska Gräfin zu, Von Paul zu Pedro, in: Deutsche Literatur von Frauen, Berlin: Directmedia Publ. 2001.

(91) Die Briten sehen in ihm den harten Mann, dem Kritik und Spott näher liegen als die Entwicklung von Zukunftsvisionen, die Blair so gern und farbenfroh ausmalt. Wieder und wieder treibt Howard im parlamentarischen Zweikampf seinen Gegner mit messerscharfer Logik, triumphierender Stimme und höhnischem Gesichtsausdruck in die Enge. In der öffentlichen Wahrnehmung gereicht ihm das nicht gerade zum Vorteil. Der Tagesspiegel, 01.05.2005

oder ist aus dem allgemeinen Wissen inferierbar:

(92) Beim letzten Prozeßtermin mußte Dat noch ohne den Beistand seiner Rechtsanwältin auskommen. Prompt hatte Hans-Joachim Henschke, Verteidiger eines der Polizisten, den Vietnamesen in die Enge getrieben. Zum gestrigen zweiten Prozeßtag brachte Dat nun gleich zwei Anwälte mit. Berliner Zeitung, 25.11.1994

Die Bedeutungskonstituierungsmechanismen ähneln dementsprechend der bereits besprochenen Bedeutung, die erste Ebene wird durch die genannten konzeptuellen Metaphern und Metaphtonymien mitgestaltet. Neu ist allerdings die konzeptuelle Metapher ARgumentIEREN IST KRIEG, die sich - von Lakoffs/Johnsons (2000 [1980]: 12, vgl. Kap. 2.3.3) Exemplifizierungen abegesehen - in folgenden Ausdrücken niederschlägt:

ARGUMENTIEREN IST KRIEG

Gegenargumente

der parlamentarische Zweikampf (vgl. Gebrauchsbeleg 91) 


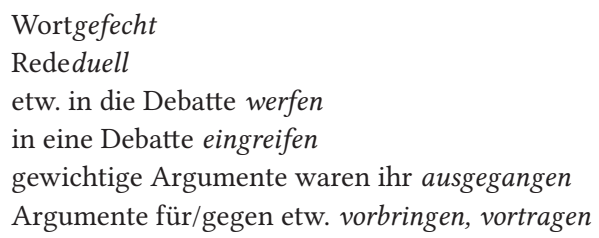

Auf der zweiten Ebene referiert die Enge auf eine bestimmte Art der Beschränkung von Entscheidungs- und Handlungsfreiheit, die als ,argumentative Verunsicherung in einem Gespräch` bezeichnet werden kann.

Ebene 1

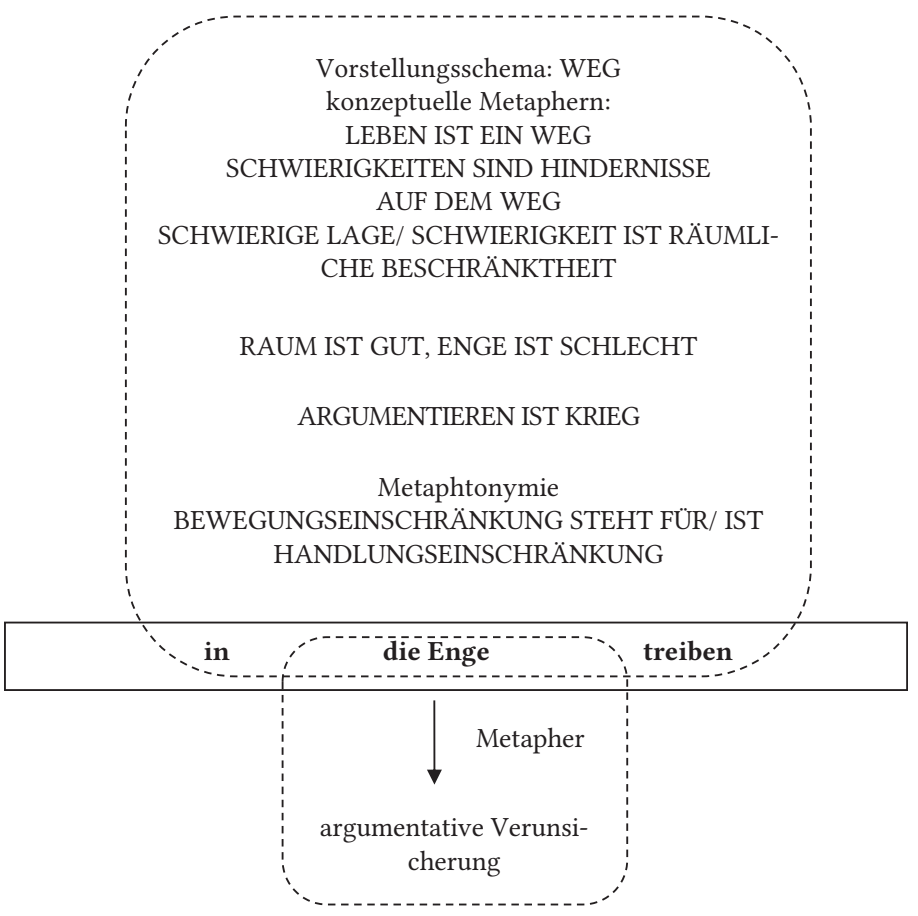

RAUM IST GUT, ENGE IST SCHLECHT

ARGUMENTIEREN IST KRIEG

Metaphtonymie

BEWEGUNGSEINSCHRÄNKUNG STEHT FÜR/ IST

HANDLUNGSEINSCHRÄNKUNG

Ebene 2

Abb. 73: Bedeutungskonstituierungsmechanismen für das Verwendungsprofil 2 ,jmdm. mit gezielt gestellten Fragen zusetzen, jmdn. mit Argumenten und Fragen in eine schwierige, ausweglose Situation bringen, in der er die Überlegenheit des Gesprächspartners anerkennen muss.

\subsection{2 jmdn. an die Wand drücken}

Lexikographisch erfasste Varianten: jmdn. an die Wand drängen, jmdn. gegen die Wand drücken, jmdn. an die Wand spielen 
Modifikationen: sich an die Wand drücken lassen, sich an die Wand gedrückt fühlen, sich an die Wand gedrückt sehen

\section{Darstellung in lexikographischen Nachschlagewerken}

Tab. 30: Das Idiom an die Wand drücken in allgemeinen und phraseologischen Wörterbüchern des Deutschen.

\begin{tabular}{|c|c|c|}
\hline Wörterbuchtyp & Wörterbuch & Lexikographische Darstellung \\
\hline \multirow[t]{3}{*}{ allgemein } & DUW 2006 & $\begin{array}{l}\text { jmdn. an die Wand drücken (ugs.; einen } \\
\text { Konkurrenten o.Ä. rücksichtslos beiseite-, in den } \\
\text { Hintergrund drängen) }\end{array}$ \\
\hline & DUW ONLINE & $\begin{array}{l}\text { jemanden an die Wand drücken } \\
\text { (umgangssprachlich: einen Konkurrenten o.Ä. } \\
\text { rücksichtslos beiseite-, in den Hintergrund drängen) } \\
\text { (letzter Zugriff am 27.10.2017) }\end{array}$ \\
\hline & WAHRIG 2007 & $\begin{array}{l}\text { jmdn. an die Wand drücken }\langle\text { fig. }\rangle \text { jmdn. in seinem } \\
\text { Wirken behindern, nicht zu Wort kommen lassen, indem } \\
\text { man sich selbst hervortut }\end{array}$ \\
\hline \multirow[t]{4}{*}{ phraseologisch } & DUDEN 11 & $\begin{array}{l}\text { jmdn. an/gegen die Wand drücken (ugs.): jmdn. } \\
\text { in den Hintergrund drängen: Sie war eine Regisseurin, } \\
\text { die sich von keinem Intendanten gegen die Wand } \\
\text { drücken ließ. Den steckte er, was politisches Wissen } \\
\text { betraf, in die Tasche; den drückte er auch als Redner } \\
\text { glatt an die Wand (Bredel, Väter } 89) .(2011: 842)\end{array}$ \\
\hline & $\begin{array}{l}\text { SCHEMANN } \\
2011\end{array}$ & $\begin{array}{l}\text { jmdn. an die Wand drücken/(drängen) ugs - path } \\
\text { 1. Der Erich Kaufmann kann sich überhaupt gar } \\
\text { nicht einordnen! Er versucht ständig, die anderen an } \\
\text { die Wand zu drücken. Nur er zählt, sonst keiner! - } \\
\text { Starallüren! Solche Leute wie er vertragen niemanden } \\
\text { neben sich; für sie bilden andere nur die Kulisse ... } \\
\text { 2. Vgl. - jmdn./etw. in den Hintergrund drängen (1) } \\
\text { Im vergangenen Jahr sah es so aus, als ob der Kahl } \\
\text { Kanzlerkandidat würde; aber inzwischen hat ihn der } \\
\text { Stross völlig in den Hintergrund gedrängt. Von dem } \\
\text { Kahl redet kein Mensch mehr. (2011: 936) }\end{array}$ \\
\hline & $\begin{array}{l}\text { REDENSARTEN- } \\
\text { INDEX }\end{array}$ & $\begin{array}{l}\text { jemanden an die Wand drücken/spielen } \\
\text { jemanden verdrängen/ausschalten; überlegen sein; } \\
\text { gewinnen; siegen (letzter Zugriff am 27.10.2017) }\end{array}$ \\
\hline & MÜLLER 2005 & $\begin{array}{l}\text { jmdn. an die Wand drücken jmdn. so verdrängen, } \\
\text { daß man davon profitiert [Bedrängung] } \\
\text { „Mit diesem neuen Produkt drängen wir die } \\
\text { Konkurrenz an die Wand!“ (2005: 648) }\end{array}$ \\
\hline
\end{tabular}




\section{Korpusgestützte Analyse anhand der DWDS-Korpora ${ }^{187}$}

Das zu besprechende Idiom kann in eine Reihe fester Wortverbindungen mit der Komponente Wand eingeordnet werden, in denen die Wand negativ konnotiert ist. So wird das Idiom jmdn. an die Wand spielen im DUW online (Zugriff am 19.04.2017) mit Bedeutungsparaphrasen: ,1. jmdn. durch größeres Können [besonders als Schauspieler, Sportler] überflügeln, 2. jmdn. durch geschickte Manöver ausschalten' versehen. Der Phraseologismus jmdn. an die Wand stellen steht metonymisch für ,jmdn. (standrechtlich) erschießen` (ebd.). Wer mit dem Rücken an der/zur Wand steht befindet sich, in einer äußerst schwierigen Situation, in einer Lage, in der er sich energisch wehren, verteidigen muss' (ebd.). Aus dieser Vielfalt der Idiome, in denen an der Wand sein metaphorisch als eine Not- und Zwangslage konzeptualisiert wird, ergeben sich Assoziationen, die zur potenziellen Bedeutungserweiterung des Idioms jmdn. an die Wand drücken führen.

Aus grammatischer Perspektive ist das zu besprechende Idiom jmdn. an die Wand drücken durch eine deutliche Tendenz zum Gebrauch im Passiv, oder in passivähnlichen Konstruktionen gekennzeichnet (vgl. sich an die Wand drücken lassen, sich an die Wand gedrückt fühlen, sich an die Wand gedrückt sehen). Lediglich in 11 von 40 zusammengestellten Belegen wird das Idiom im Aktiv verwendet. Im Vergleich zu dem wegen der Abstraktheit der literalen Lesart weniger bildhaften Idiom: jmdn. in die Enge treiben lassen sich für die Mehrwortverbindung jmdn. an die Wand drücken mehr Verwendungsprofile ermitteln. Die konzeptuellen Mechanismen ihrer Bedeutungskonstituierung sind dennoch ähnlich und divergieren vor allem in der Profilierung und in thematischem Verwendungsbereich. Zudem weisen manche Gebrauchskontexte semantische Aspekte mehrerer Verwendungsprofile auf: Als Sammelbecken verschiedener Bedeutungsaspekte werden sie in der Abbildung 74 schematisch als Übergangsbereiche gekennzeichnet.

187 Zugriffsdatum: 10.04.2017, Suchanfrage: an die Wand drücken. DWDS-Kernkorpus 4/36; Die Zeit: 22/187; Berliner Zeitung: 8/54; Der Tagesspiegel: 6/33. 


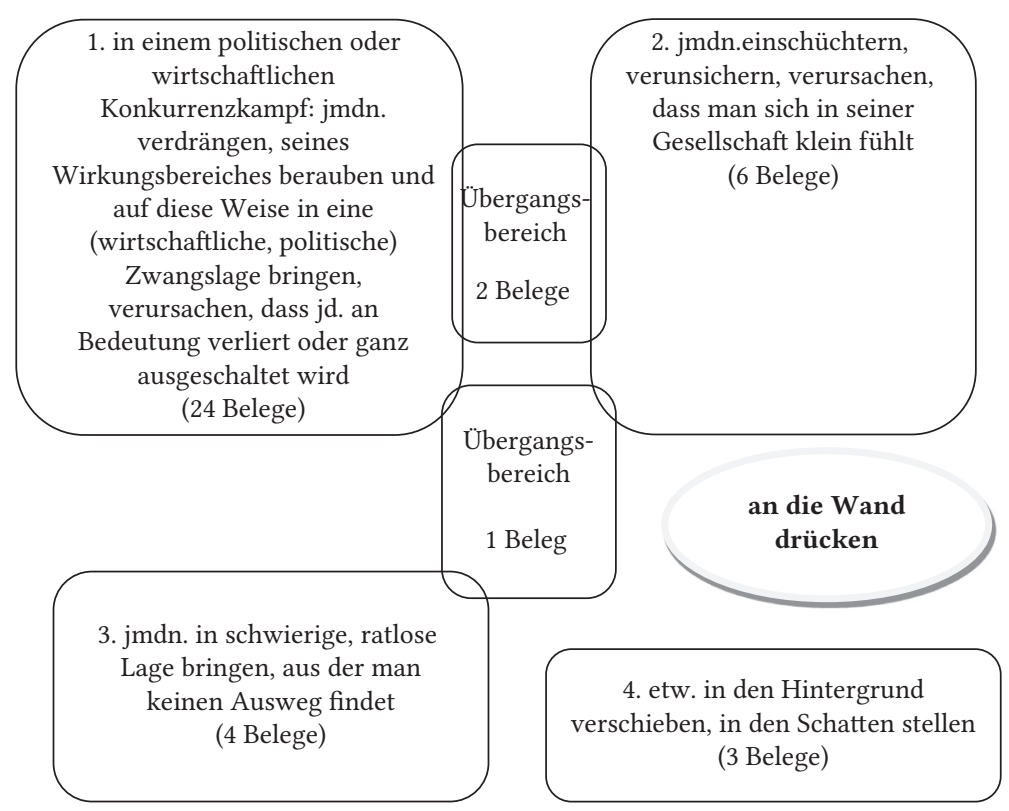

Abb. 74: Die Verwendungsprofile des Idioms an die Wand drücken anhand der Analyse der Gebrauchsbelege im DWDS-Korpus.

Verwendungsprofil 1: (in einem politischen oder wirtschaftlichen Konkurrenzkampf) ,jmdn. verdrängen, seines Einflusses und Wirkungsbereiches berauben und ihn auf diese Weise in (wirtschaftliche, politische) Zwangslage bringen; verursachen, dass $\mathrm{jd}$. an Bedeutung verliert bzw. ganz ausgeschaltet wird' (24 Belege)

Das erste, mit 24 Belegen vertretene Verwendungsprofil tritt in 18 Verwendungskontexten im Passiv oder in passivähnlichen Konstruktionen auf: jd. wird an die Wand gedrückt, jd. lässt sich (nicht) an die Wand drücken, jd. sieht sich an die Wand gedrückt. In allen besprochenen Belegen handelt es sich um einen Wettkampf im wirtschaftlichen oder im politischen Bereich, an dem meistens zwei Aktanten beteiligt sind:

(93) Doch er schaffte es nicht, über ein erfolgreiches Engagement in den USA die in seiner Branche notwendige weltweite Präsenz zu erringen. Von der fernöstlichen Industrie an die Wand gedrückt, musste der permanent mit Managementproblemen kämpfende Patriarch schließlich 1984 sein Lebenswerk in die unternehmerische Obhut des niederländischen Multikonzerns Philips legen. Die Zeit, 11.04.2002

(94) In wenigen Jahren hatte er mit dem Blatt genug Geld gemacht, um Sidneys „Daily Mirror“ aufzukaufen. Er verwandelte die sich bis dahin um Seriosität mühende 
Zeitung in einen mit Mord und Totschlag gespickten Busen-Bilderbogen, der bald die Konkurrenz an die Wand drückte. Die Zeit, 04.02.1977

(95) Die Union für die Präsidentenmehrheit (UMP) und die Sozialistische Partei haben alle anderen Parteien an die Wand gedrückt. Aber die Klarheit, die mit der Polarisierung durch zwei Parteien einhergeht, könnte sich als Täuschung erweisen. Der Tagesspiegel, 20.06.2002

(96) Immerhin hat sich die FDP unter der cleveren Regie von Karry bis zum Schluß des Wahlfeldzuges nicht an die Wand drücken lassen. Sie hat versucht, ihre Erfolge darzustellen, zum Beispiel bei der Verwaltungsreform, mit der 2700 hessische Gemeinden zu knapp 500 neuen, lebensfähigen Kommunaleinheiten verschmolzen wurden. Die Zeit, 25.10.1974

Die kognitiven Mechanismen, die zur Bedeutungskonstituierung beitragen, verzahnen sich teilweise mit den aus der Beschreibung des Idioms in die Enge treiben bereits bekannten Bedeutungsverschiebungsmechanismen (vgl. Abb. 75).

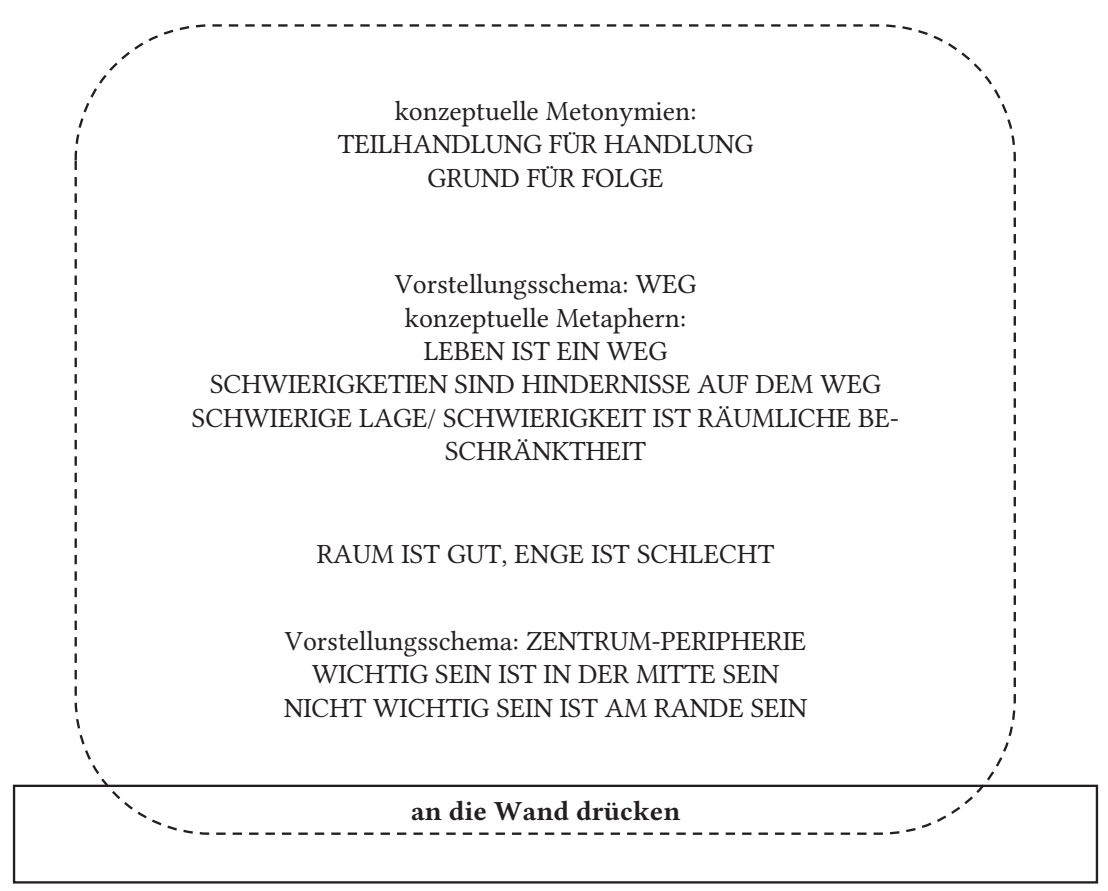

Abb. 75: Bedeutungskonstituierungsmechanismen für das Verwendungsprofil 1 ,jmdn. verdrängen, seines Einflusses und Wirkungsbereiches berauben und ihn auf diese Weise in (wirtschaftliche, politische) Zwangslage bringen; verursachen, dass jd. an Bedeutung verliert bzw. ganz ausgeschaltet wird: 
So leisten die konzeptuellen Metonymien TEILHANDLUNG STEHT FÜR HANDLUNG, GRUND STEHT FÜR FOLGE sowie die Metaphern von einem absteigenden Generalitätsgrad: LEBEN IST EIN WEG $\rightarrow$ SCHWIERIGKETIEN SIND HINDERNISSE AUF DEM WEG $\rightarrow$ SCHWIERIGE LAGE/SCHWIERIGKEIT IST RÄUMLICHE BESCHRÄNKTHEIT und die Metapher RAUM IST GUT, ENGE IST SCHLECHT einen wichtigen Beitrag zur Konzeptualisierung des ersten Verwendungsprofils. Hervorzuheben ist an dieser Stelle die Tatsache, dass die Zieldomänen im Falle des zu besprechenden Idioms deutlich im abstrakten Bereich liegen: Die fließenden Übergänge zwischen dem körperlichen und dem psychologischen Bereich, Schwingungen zwischen der literalen und der phraseologisierten Lesart, die für das Idiom jmdn. in die Enge treiben charakteristisch sind, treten hier nicht zutage.

Zusätzlich scheint die Konzeptualisierung durch ein neues, bisher noch nicht aufgetauchtes Paar von konzeptuellen Metaphern wiCHTIG SEIN IST IN DER MITTE SEIN, NICHT WICHTIG SEIN IST AM RANDE SEIN beeinflusst zu werden, das auf dem image schema zenTRUM-PERIPHERIE aufbaut. Die Quellen dieses Vorstellungsschemas liegen in der Wahrnehmung des Körpers selbst: Zentral liegende Organe sind lebenswichtiger als Extremitäten, vgl. Herz versus Finger, Leber versus Zehen. Die mittlere Position des Wichtigen ist möglicherweise kulturübergreifend: Kulturelle und religiöse Artefakte - Kultgegenstände, Altare, (in der katholischen Kirche) Tabernakel werden üblicherweise in der Raummitte aufgestellt. Im Mittelpunkt der Gesellschaft befinden sich ebenfalls die einflussreichen Menschen, die das Sagen haben (vgl. z.B. die Stellung des Throns, die Sitzordnung im Gericht, in der Diplomatie, in Konferenzen, Treffen, Dinner, Hochzeiten), um sie herum sammeln sich die anderen. An die Seite geschoben zu werden interpretiert man als Verlust des Ranges und Einflusses. Diese konzeptuelle Metapher findet sprachliche Exemplifizierungen in zahlreichen mehr oder weniger festen Mehrwortverbindungen:

WICHTIG SEIN IST IN DER MITTE SEIN

NICHT WICHTIG SEIN IST AM RANDE SEIN

im Zentrum des Interesses stehen, sein

im Mittelpunkt stehen, sein

jmdn. an die Seite drängen

jmdn. beiseite schieben

der Nabel der Welt, das Wichtigste, der Mittelpunkt, um den sich alles dreht' (DUW online, Zugriff am 19.10.2017)

es dreht sich alles um ihn,er steht bei allen Überlegungen im Vordergrund" (DUW online, Zugriff am 19.10.2017)

Dreh- und Angelpunkt ,zentraler Punkt, um den sich alles dreht` (DUW online, Zugriff am 19.10.2017)

aufs Abstellgleis geschoben werden, seiner Bedeutung/seines Einflusses beraubt werden' (redensarten-index, Zugriff am 20.10.2017) 
aufs tote Gleis/Abstellgleis geraten, in eine Position geraten, in der man keinen Einfluss hat; abgesetzt/eingestellt/niedergelegt/beseitigt/ausgeschlossen werden/nicht mehr weitergeführt werden' (redensarten-index, Zugriff am 20.10.2017) auf dem toten Gleis/Abstellgleis sein/stehen, in einer Position sein, in der man keinen Einfluss hat, abgesetzt/eingestellt/niedergelegt/beseitigt/zurückgedrängt/ausgeschlossen wird' (redensarten-index, Zugriff am 20.10.2017)

Verwendungsprofil 2: ,jmdn. einschüchtern, verunsichern, entmutigen; verursachen, dass man sich in seiner Gesellschaft klein fühlt' (6 Belege) Das zweite, mit sechs Belegen vertretene Verwendungsprofil bezieht sich hauptsächlich auf den Bereich der psychischen Empfindungen eines Menschen, der sich von einem anderen eingeschüchtert, bevormundet, mürbegemacht fühlt:

(97) Sie sprach lebhaft und gut, und diese jeden Hamburger bewegenden Erinnerungen lenkten ganz von Allert und seinen Sorgen ab. Sophie, die sich in Gegenwart der Senatorin immer an die Wand gedrückt fühlte, ohne dadurch im mindesten verletzt zu sein, denn es war unwillkürlich und entsprach dem Wesen beider, Sophie hätte zu gern nachgefragt. Aber sie wollte nicht unhöflich sein. Boy-Ed, Ida: Vor der Ehe. In: Deutsche Literatur von Frauen, Berlin: Directmedia Publ. 2001 [1915], S. 8206

(98) Der alte Harry und der neue lebten bald im bittern Streit, bald im Frieden miteinander. Der alte Harry schien manchmal ganz und gar tot zu sein, gestorben und begraben, und plötzlich stand er dann wieder da, befahl und tyrannisierte und wußte alles besser, und der neue, kleine, junge Harry schämte sich, schwieg und ließ sich an die Wand drücken. $\mathrm{Zu}$ anderen Stunden nahm der junge Harry den alten an der Kehle und drückte wacker zu, es gab viel Gestöhne, viel Todeskampf, viel Gedanken an das Rasiermesser. Hesse, Hermann: Der Steppenwolf, Frankfurt a. M.: Suhrkamp 1955 [1927], S. 139

(99) Sie will das Kind unbedingt, während er mit irritierten Satzfetzen seine Ratlosigkeit offenbart. Remi fühlt sich überfordert von der Situation, wird von ihrer provozierenden Direktheit an die Wand gedrückt. Wenig später beginnt Valeries erster Arbeitstag als Zimmerkellnerin in einem Pariser Hotel. Berliner Zeitung, 22.05.1997

Im Fokus der Aufmerksamkeit steht hier die Wand als eine seitliche Begrenzungsfläche eines Gebäudes, Zimmers, Raumes bzw. eine Felswand. Von Relevanz für die Konzeptualisierung scheint hier eine konzeptuelle Metapher SCHWIERIGE LAGE/SCHWIERIGKEIT IST RÄUMLICHE BESCHRÄNKTHEIT zu sein, die die körperliche Ausgangsdomäne der Freizügigkeit, Bewegungsfreiheit in einem Raum mit der abstrakteren, psychologischen Zieldomäne der Ungezwungenheit im Verhalten verbindet. Zugleich wird die dominante Persönlichkeit des Agens (der Senatorin, des alten Harrys) zum Ausdruck gebracht, die das Patiens einschüchtert, entmutigt, in Entfaltungsmöglichkeiten einschränkt. Für die Konzeptualisierungen der starken und schwächeren Persönlichkeiten sind die konzeptuellen Metaphern: STARKE 
PERSÖNLICHKEIT IST PERSÖNLICHKEIT, DIE VIEL RAUM IN ANSPRUCH NIMMT; SCHWACHE PERSÖNLICHKEIT IST DIE PERSÖNLICHKEIT, DIE SICH KLEIN MACHT richtungSweisend, der Beitrag von RAUM IST GUT, ENGE IST SCHLECHT-Metapher (vgl. das erste Verwendungsprofil des Idioms in die Enge treiben) sowie des Vorstellungsschemas ZENTRUM-PERIPHERIE ist an dieser Stelle eklatant:

STARKE PERSÖNLICHKEIT IST PERSÖNLICHKEIT, DIE VIEL RAUM IN ANSPRUCH NIMMT SCHWACHE PERSÖNLICHKEIT IST DIE PERSÖNLICHKEIT, DIE SICH KLEIN MACHT

nicht kleinzukriegen sein

sich breit/dick machen

ein dicker/großer Fisch

sich klein machen/kleinmachen

(den) Kopf einziehen

er hat Format ,er ist eine Persönlichkeit' (DWDS-Wörterbuch, Zugriff am 20.10.2017)

ein Mann größten, seltenen Formats (DWDS-Wörterbuch, Zugriff am 20.10.2017)

ein Wissenschaftler, Künstler von internationalem Format (DWDS-Wörterbuch, Zugriff am 20.10.2017)

eine Frau, Persönlichkeit von ungewöhnlichem Format (DWDS-Wörterbuch, Zugriff am 20.10.2017)

die Rübe einziehen ,sich ducken' (redensarten-index, Zugriff am 20.10.2017)

den Schwanz einziehen, einkneifen, zwischen die Beine nehmen, hängen lassen, den Widerstand aufgeben, nach-, klein beigeben' (DWDS-Wörterbuch, Zugriff am 20.10.2017)

klein beigeben ,seinen Widerstand aufgeben, sich schließlich fügen; kleinlaut nachgeben; eigentlich = beim Kartenspiel dem Mitspieler nur Karten von kleinem Wert zuspielen, weil man keine besseren hat' (DUW online, Zugriff 20.10.2017)

sich fügen ,sich einer oft unpersönlichen Gewalt [aus Einsicht] unterordnen, sich in gegebene Verhältnisse einordnen' (DUW online, Zugriff 20.10.2017)

sich ducken ,sich aus Angst, Unterwürfigkeit, Berechnung o.Ä. demütigen, ergeben zeigen; es nicht wagen, aufzubegehren' (DUW online, Zugriff 20.10.2017)

Duckmäuser ,jd., der seine Meinung nicht zu sagen wagt, sie nicht einer entgegengesetzten entgegenzustellen wagt' (DUW online, Zugriff 20.10.2017)

jmdn. in die Tasche stecken (können) ,jmdm. überlegen sein' (redensarten-index, Zugriff am 20.10.2017)

jmdn. in der Tasche haben ,jmdm. überlegen sein, jmdn. unter Kontrolle haben“ (redensarten-index, Zugriff am 20.10.2017)

alle anderen in den Kasten stecken ,alle andere übertreffen, überbieten' (redensartenindex, Zugriff am 20.10.2017)

jmdn. in den Sack stecken ,besser sein, als der andere, jmdm. überlegen sein' (redensarten-index, Zugriff am 20.10.2017)

Da knickte Zillich ein (= da gab Zillich widerwillig nach) und gab zu, daß er die ... Äußerung allerdings gehört habe H. Mann Untertan 4, 207 (DWDS, Zugriff am 18.04.2017)

Die Bedeutungskonstituierungsmechanismen stellt schematisch die Abbildung 76 dar: 


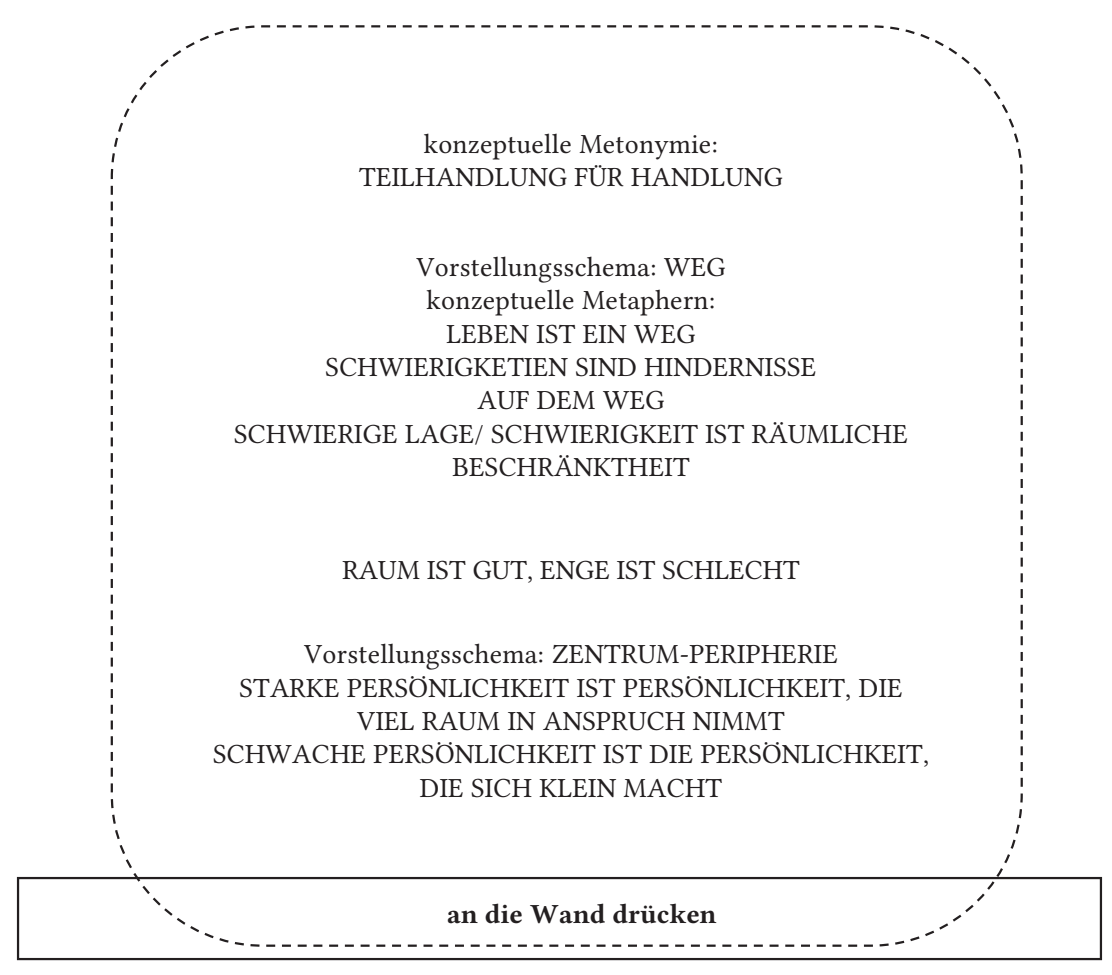

Abb. 76: Bedeutungskonstituierungsmechanismen für das Verwendungsprofil 2 ,jmdn. einschüchtern, verunsichern, entmutigen, verursachen, dass man sich in seiner Gesellschaft klein fühlt'.

Verwendungsprofil 3: ,jmdn. in eine aussichtslose Lage bringen, in der er ratlos ist' (4 Belege)

In den folgenden Belegen wird die Ratlosigkeit des Patiens, Ausweglosigkeit seiner Situation zum Ausdruck gebracht:

(100) Nur 27 Cent bekommen Bauern noch für den Liter, die Produktion aber kostet 30 Cent. Viele haben nun Angst, bei den jetzt laufenden Preisverhandlungen zwischen Discountern und Molkereien endgültig an die Wand gedrückt zu werden. Zu Recht. Die Zeit, 01.04.2004

(101) Martin Walser geht auf keine Kuhhaut, schon gar nicht auf die der literarischen Fünf-Uhr-Causerie. Seine Kritiker machen nicht selten einen zerrauften Eindruck. Redakteure und Buchbinder wissen kaum, wohin mit ihm. Selbst ergraute Sechs-Tage-Rezensenten sehen sich an die Wand gedrückt. Auch seine Leser wissen ein Lied davon zu singen, daß Walser nicht im Rahmen bleibt; er sprengt ihn. Die Zeit, 29.09.1961 
Dementsprechend liegen im Fokus des Interesses die konzeptuellen Metaphern und Metonymien, die die konzeptuellen Mappings zwischen dem Bereich der Bewegungseinschränkung und dem Bereich der Handlungseinschränkung herstellen (vgl. Abb. 77):

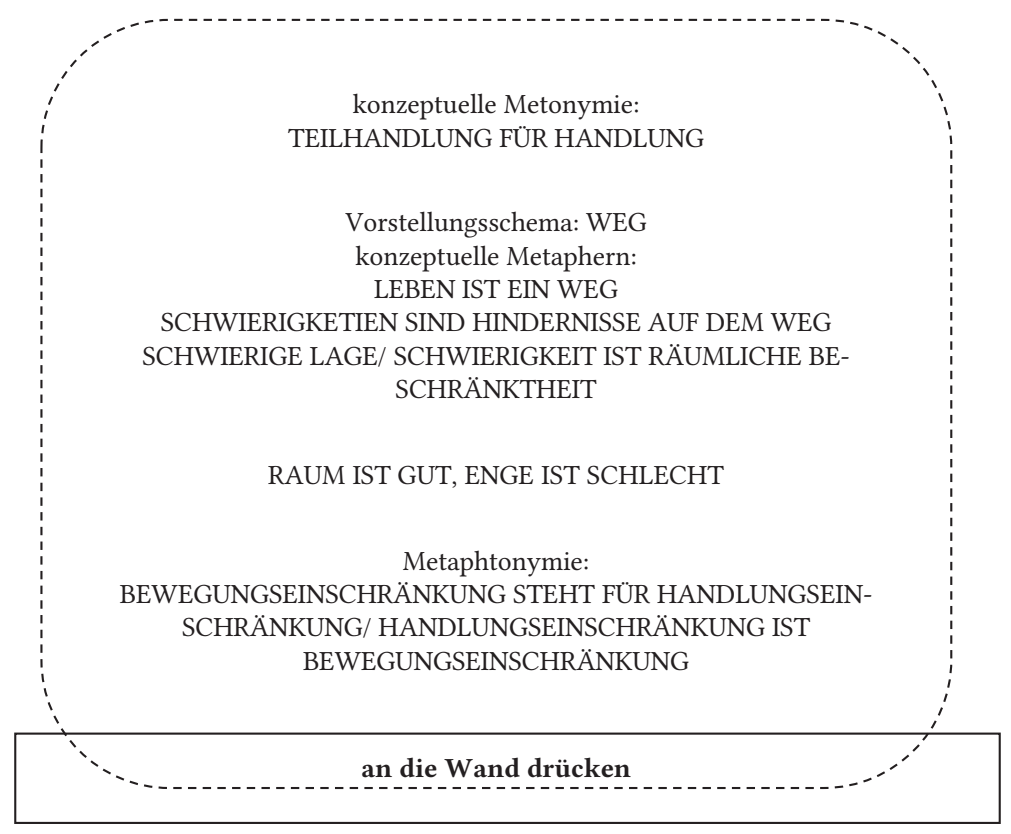

Abb. 77: Bedeutungskonstituierungsmechanismen für das Verwendungsprofil 3 ,jmdn. in eine aussichtslose Lage bringen, in der er ratlos ist:

\section{Verwendungsprofil 4: ,etw. in den Hintergrund verschieben, in den Schatten} stellen, jmdm./etw. überlegen sein' (3 Belege)

Die dieses Verwendungsprofil vertretenden drei Belege werden ausschließlich im Aktiv gebraucht. Zwei Entitäten werden verglichen, von denen die eine die andere in der Qualität, Leistung o. ̈̈. übertrifft:

(102) Die kindliche, textkritische Potter-Gemeinde protestiert flüsternd auf dem Nebensitz, die erwachsenen Rowling-Schriftgelehrten werden ins Detail gehen und beide glücklicherweise in der Unendlichkeit des Internets verschwinden. Dem Durchschnitts-Potter-Leser bleiben zwei große Momente, in denen der Film das Buch überschreitet, die Gewalt der Bilder das sprachliche Talent der Autorin an die Wand drückt. Da rasen zum einen in schwindelerregender Höhe die Quidditch-Spieler auf ihren Besen durch die Lüfte, versuchen einander in die Tiefe zu stürzen, wird das Unbarmherzige des gerühmten englischen Sportgeistes spürbar. Die Zeit, 22.11.2001 
(103) Nämlich jenes nunmehr sacht anlaufende, bald alles überflutende gigantische Mittwintersaisongeschäft, dessen Konjunktur sich aus allerlei alten heidnischen Bräuchen entwickelt hat und das seit langem und immer mehr das gleichzeitige Christgeburtsfest an die Wand drückt. Zwar schmückt es sich selber mit christlichen Emblemen. Die Zeit, 21.11.1957

Konstitutiv für die Bedeutungskonstituierung sind die konzeptuellen Metaphern: RAUM IST GUT, ENGE IST SCHLECHT SOwie WICHTIG SEIN IST IN DER MITTE SEIN, NICHT WICHTIG SEIN IST AM RANDE SEIN (vgl. Abb. 78). Die metaphorischen Mappings verbinden die Domäne der physischen Räumung eines Gegenstandes, indem er aus der Mitte zur Seite geschoben wird, mit der abstrakteren Domäne des Verdrängens von einer weniger geschätzten Entität (das schriftstellerische Talent einer Autorin, ein kirchliches Fest) durch etwas Neues, neu Erschienenes (die Anschaulichkeit des Filmes, den Konsum).

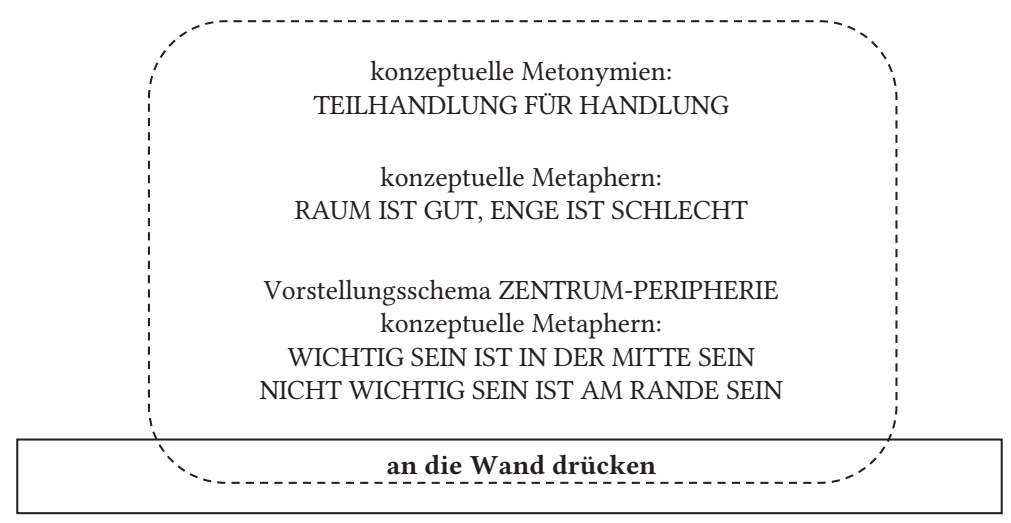

Abb. 78: Bedeutungskonstituierungsmechanismen für das Verwendungsprofil 4 ,etw. in den Hintergrund verschieben, in den Schatten stellen, jmdm. überlegen sein:

Abschließend wird auf zwei Belege verwiesen, die den Übergangsbereichen zugeordnet sind, d.h. die semantischen Bedeutungsnuancen aus mehreren Verwendungsprofilen vereinbaren. So kommen im Beleg (104) die semantischen Aspekte des ersten ,jmdn. verdrängen, seines Einflusses und Wirkungsbereiches berauben und ihn auf diese Weise in (wirtschaftliche, politische) Zwangslage bringen; verursachen, dass jd. an Bedeutung verliert bzw. ganz ausgeschaltet wird" und des zweiten Verwendungsprofils,jmdn. einschüchtern, verunsichern, entmutigen, verursachen, dass man sich in seiner Gesellschaft klein fühlt' gleichzeitig zur Geltung:

(104) Winfried Hermann ist dennoch nicht überzeugt. „Ich lasse mich durch die Vertrauensfrage vom Bundeskanzler nicht an die Wand drücken“, sagt der Pazifist nach der Sitzung und macht klar, dass er den Bundeswehreinsatz am Freitag ablehnen wird. 
Von den meisten anderen Abweichlern hingegen wird erzählt, sie wollten die Entscheidung über die Koalitionsfrage dem Parteitag überlassen und deshalb dem Antrag zustimmen. Berliner Zeitung, 14.11.2001

Sehr interessant ist ebenfalls der Gebrauch des Idioms im folgenden Verwendungsbeleg:

(105) Bautz: Viele Staaten haben Massenvernichtungswaffen. Wenn die USA losschlagen und Saddam sich an die Wand gedrückt fühlt, besteht viel eher die Gefahr, dass er sie einsetzt. Natürlich hat Saddam schon Massenvernichtungswaffen eingesetzt, aber doch nur in der Zeit, als er politisch und logistisch von den USA unterstützt wurde. Der Tagesspiegel, 15.02.2003

In dieser Bedeutung verzahnen sich die semantischen Aspekte des ersten, zweiten und dritten Verwendungsprofils. Von Wichtigkeit für die Bedeutungskonstituierung ist sowohl die Konkurrenz, die dem Wettrüsten zweifelsohne innewohnt, als auch die subjektiven Gefühle der Ausweglosigkeit und des Sich-Wehren-Müssens, die zu unvorhersehbaren Reaktionen des Patiens führen können. Alle genannten Bedeutungsnuancen schwingen in diesem Beleg mit, ihre Profilierung wird dem Rezipienten überlassen.

\subsection{Resümee mit Schwerpunkt: Interlinguale Äquivalenz, Arbitrarität und Motiviertheit von Phraseologismen aus kognitiver Perspektive}

Aus grammatischer Perspektive weisen die Idiome jmdn. in die Enge treiben und jmdn. an die Wand drücken viele Parallelen auf: Beiden Phraseologismen liegt ein gemeinsames Paradigma CAUSE (y, BECOME (schwierige Lage(x)) ) zugrunde, in beiden Fällen ist das Agens der Handlung in den Gebrauchsbelegen nur implizit vorhanden, aus dem weiteren Kontext erschließbar, da die Idiome im authentischen Gebrauch vorwiegend im Passiv oder passivähnlichen Strukturen verwendet werden.

Auf die durchsichtige Metaphorizität der zu besprechenden Phraseologismen ist eine einheitliche Grundbedeutung zurückzuführen, die sich in allen Gebrauchsbelegen mit der Paraphrase ,jmdn. in eine schwierige, ausweglose Lage bringen umschreiben lässt. Für alle Verwendungsprofile beider Phraseologismen sind die in der körperlichen Erfahrung verankerten konzeptuellen Metaphern: RAUM IST GUT, ENGE IST SCHLECHT; SCHWIERIGE LAGE/SCHWIERIGKEIT IST RÄUMLICHE BESCHRÄNKTHEIT konstitutiv. Die grundlegenden kognitiven Mechanismen sind damit gleich, es lassen sich allerdings auch konzeptuelle Metaphern ermitteln, die nur in einem der Phraseologismen vorkommen. So tritt die konzeptuelle Metapher ARGUMENTIEREN IST KRIEG ausschließlich in einem der Verwendungsprofile des Idioms jmdn. in die Enge treiben auf, die Metaphern: WICHTIG SEIN IST IN DER MITTE SEIN, NICHT WICHTIG SEIN IST AM RANDE SEIN können dagegen nur aus den Gebrauchsbelegen des Idioms jmdn. an die Wand drücken eruiert werden. Auf die komplizierte Natur der phraseologischen Motiviertheit, die einerseits durch den grundlegenden, universalen Charakter der konzeptuellen Metonymien und Metaphern bestimmt, andererseits in 
gewissen Grenzen willkürlich ist, wird im Folgenden aus einer interlingualen Perspektive anhand des Idioms jmdn. an die Wand drücken und seines polnischen Äquivalents przycisnąć kogoś do muru/ściany eingegangen.

Die bisherigen Untersuchungen dürften die Vermutung nahe legen, dass die Motiviertheitsmechanismen der Idiome vorhersehbar, nahezu zwingend sind, was auf zwei Gründe zurückzuführen ist:

(i) Die semantischen Analysen bestätigen, dass Bedeutungskonstituierungs- und Motiviertheitsmechanismen weitgehend durch konzeptuelle Metonymien und Metaphern bedingt sind, die zu einer gewissen Universalität prätendieren. Insbesondere die konzeptuellen Metonymien und Metaphern von einem großen Generalitätsgrad wie z.B. LEBEN IST EIN WEG-, FEHLER IST STURZ-, SCHWIERIGKEITEN SIND HINDERNISSE AUF DEM WEG-Metaphern oder GRUND FÜR FOLGE-, TEILHANDLUNG FÜR HANDLUNG-Metonymien fußen auf grundlegenden sensomotorischen, körperlichen Erfahrungen, die wohl allen Menschen gemeinsam sind. Da sie in der kognitiven Metonymie- und Metapherntheorie als tief verankerte kognitive Denkmodi, die unsere Kognition und Sprache strukturieren, aufgefasst werden, dürften sie als Motiviertheitsmechanismen für die übertragene Sprache unabdingbar sein und bei ihrer Verarbeitung quasi reflexartig eingeschaltet werden.

(ii) Auch die Weltwissensstrukturen, die den epistemischen Mappings zugrunde liegen, werden innerhalb eines Kulturkreises von vielen Sprachteilhabern geteilt. Bei einem interlingualen deutsch-polnischen Vergleich zeigen sich unvermeidlich viele Parallelen auf:

Eine ähnliche historische Entwicklung und Zugehörigkeit zu demselben oder verwandten Kulturkreis setzen bei den Sprechern der beiden Sprachgemeinschaften dieselbe/eine identische Vorstellungskraft voraus, an die die Metaphern kognitiv appellieren. (Mikołajczyk 2002: 52)

Selbstverständlich sind epistemische Metaphern z.T. auch alters-, bildungs- und interessenbestimmt. Gewisses Weltwissen, beispielshalber über die vom dünnen Eis ausgehende Gefahr, wird aber wohl von allen mitteleuropäischen, in ähnlichem Klima lebenden Sprechern geteilt.

Dieser Denkweise folgend, insbesondere den Gedanken von der automatischen Einschaltung der konzeptuellen Metaphern und Metonymien als festgeprägten und universalen Denkmodi berücksichtigend (Universalitäts- und Notwendigkeitsthese in der CTM-Theorie), sollten die aus ähnlichen Konstituenten aufgebauten Idiome im Deutschen und im Polnischen in ihrer Motiviertheit deckungsgleich sein. Davon, dass diese Annahme nicht ohne Weiteres akzeptierbar ist, zeugt der interlinguale Vergleich des Idioms an die Wand drücken mit seinem polnischen Quasi-Äquivalent przyprzeć/przypierać/przyciskać do muru ${ }^{188} /$ ściany ${ }^{189}$ [wörtl. 'an die Mauer/Wand drücken/drängen'].

188 Narodowy Korpus Języka Polskiego, Suchanfrage: do muru, Zugriff am 26.07.2017. 189 Narodowy Korpus Języka Polskiego, Suchanfrage: do ściany, Zugriff am 26.07.2017. 
Das deutsche und das polnische Idiom haben ähnliche Konstituenten und versprachlichen das mentale Bild, in dem ein Agens durch aggressives verbales oder brachiales Verhalten ein Patiens Schritt für Schritt zurückdrängt, sodass das Patiens endlich eine Wand erreicht und keine Flucht mehr ergreifen kann. In der klassischen Nennform ${ }^{190}$ des polnischen Idioms fungiert als die nominale Konstituente mur 'Mauer', in der Umgangssprache sowie im Nationalkorpus der Polnischen Sprache sind allerdings die Sprachbelege für die idiomatische Verwendung der Wortverbindung przypierać/przycisnać do ściany 'an die Wand drücken' problemlos auffindbar:

Rubaszewska to sie oczywista od razu musiała mądrzyć, że zna kuzyna tego Shakspira, ale jak ją przycisnęłam do ściany, to się okazało, że ten kuzyn to się nazywa Szepir albo jakoś tak, a nie Shakspir. Christian Skrzyposzek, W.A.B., Wolna Trybuna, 1985 (Rubaszewska musste selbstverständlich klugreden, dass sie einen Cousin von diesem Shakspire kennt, aber als ich sie 'an die Wand drückte' [wörtl.], stellte sich heraus, dass dieser Cousin Szepir und nicht Shakspir heißt. Christian Skrzyposzek, W.A.B., Wolna Trybuna, 1985, übers. von A. S.)

Natychmiast zamilkła, bo zrozumiała, że powiedziała zbyt dużo. Ale oni zasypali ją pytaniami. Milczała, przyciśnięta do ściany. Andrzej Zbych (Andrzej Szypulski, Zbigniew Safjan), Stawka większa niż życie, Anta, 1967 (Sofort verstummte sie, da ihr klargeworden ist, dass sie zuviel gesagt hatte. Aber sie überschütteten sie mit Fragen. 'An die Wand gedrückt' [wörtl.], schwieg sie. Andrzej Zbych (Andrzej Szypulski, Zbigniew Safjan), Stawka większa niż życie, Anta, 1967, übers. von A. S.)

Die nach bisheriger Methode (vgl. Unterkap. 4.1.2.2.2.2) durchgeführte Untersuchung von 40 Gebrauchsbelegen aus dem Nationalen Korpus der Polnischen Sprache lässt schlussfolgern, dass das polnische Äquivalent przyprzeć/przypierać/ przyciskać do muru/ściany zwei Verwendungsprofile ${ }^{191}$ aufweist.

Die ermittelten Verwendungsprofile sowie die sie konstituierenden Bedeutungsprozesse stellt Abb. 79 dar:

190 Vgl. PWN, Wielki słownik frazeologiczny z przysłowiami (2005): przycisnąć, przyprzeć kogoś do muru «postawić kogoś w sytuacji przymusowej, zmusić kogoś do zrobienia lub powiedzenia czegoś, czego nie chce zrobić lub powiedzieć»: Wypierat się $w \dot{z} y w e$ oczy albo o niczym nie wiedziat. A może za wcześnie zacząłem i się spłoszyt. Nie należato przyciskać go do muru. S. Mrożek, Opowiadania II. Przyparta do muru dziewczyna wyznała, iż podstuchała rozmowę (...). Z. Kossak, Wina.

191 Vgl. Narodowy Korpus Języka Polskiego, http://www.nkjp.uni. lodz.pl, Suchanfrage do muru, Zugriff am 26.07.2017. 
1. in einer verbal-argumentatorischen Auseinandersetzung: ,jmdn. mit gezielt gestellten Fragen zu einem Geständnis zwingen

(25 Belege)

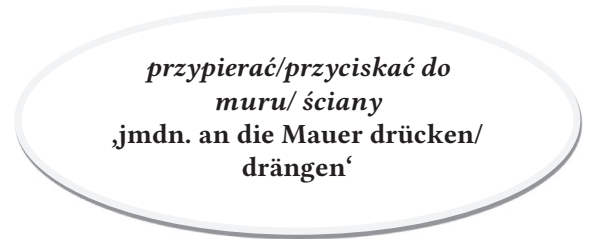

2. ,jmdn. in eine ausweglose Lage bringen, unter Druck setzen, so dass er etwas (für ihn Unerwünschtes) machen muss ‘

(15 Belege)

Abb. 79: Die Verwendungsprofile des Idioms przypierać/przyciskać do muru anhand der Analyse der Gebrauchsbelege im Nationalen Korpus der Polnischen Sprache.

\section{Verwendungsprofil 1: ,in einer verbal-argumentatorischen Auseinander- setzung jmdn. mit gezielt gestellten Fragen zu einem Geständnis zwingen‘ (25 Belege)}

Die überwiegende Mehrheit der Belege bezieht sich auf eine verbale Auseinandersetzung, in der das Patiens zu einer von ihm unerwünschten Stellungnahme, Erklärung oder einem unangenehmen Geständnis gezwungen wird und durch direkte Fragen keine Ausflüchte oder Ausreden vorbringen kann:

Ale bezpośrednio, wprost, nigdy nic takiego nie powiedziałem i przyparty do muru na pewno nie wydobyłbym z siebie jawnego fałszerstwa. Gazeta jednak musi podawać wiadomości mogące liczyć na uwagę czytelnika. Stawomir Mrożek, Opowiadania 1974-1979, Noir sur Blanc, 1979 (Aber direkt, unmittelbar, habe ich so etwas nie gesagt und 'an die Wand gedrückt' [wörtl. 'an die Mauer gedrückt'] hätte ich bestimmt keine offensichtliche Fälschung hervorgebracht. Eine Zeitung muss doch Nachrichten übermitteln, die Aufmerksamkeit der Leser auf sich ziehen. Stawomir Mrożek, Opowiadania 1974-1979, Noir sur Blanc, 1979, übers. von A. S.)

Indagowany o przyszłość Kacperczak nie potrafił dać konkretnej odpowiedzi. Kiedy Marta przyparła go do muru, oznajmił, że maszyny chyba zgromadzi się gdzieś i w miarę potrzeb będzie wypożyczać za opłatą. Teresa Bojarska, Świtanie, przemijanie, Trio, 1996 (Über die Zukunft ausgefragter Kacperczak konnte keine genaue Antwort geben. Als ihn Marta 'an die Wand drückte' [wörtl. 'an die Mauer drückte'], teilte er mit, dass man die Maschinen irgendwo anhäuft und bei Bedarf gegen Bezahlung vermieten wird. Teresa Bojarska, Świtanie, przemijanie, Trio, 1996, übers. von A. S.). 
Die Bedeutungskonstituierungsmechanismen werden durch die bereits bekannten konzeptuellen Metaphern und eine Metaphtonymie beeinflusst (vgl. Abb. 80):

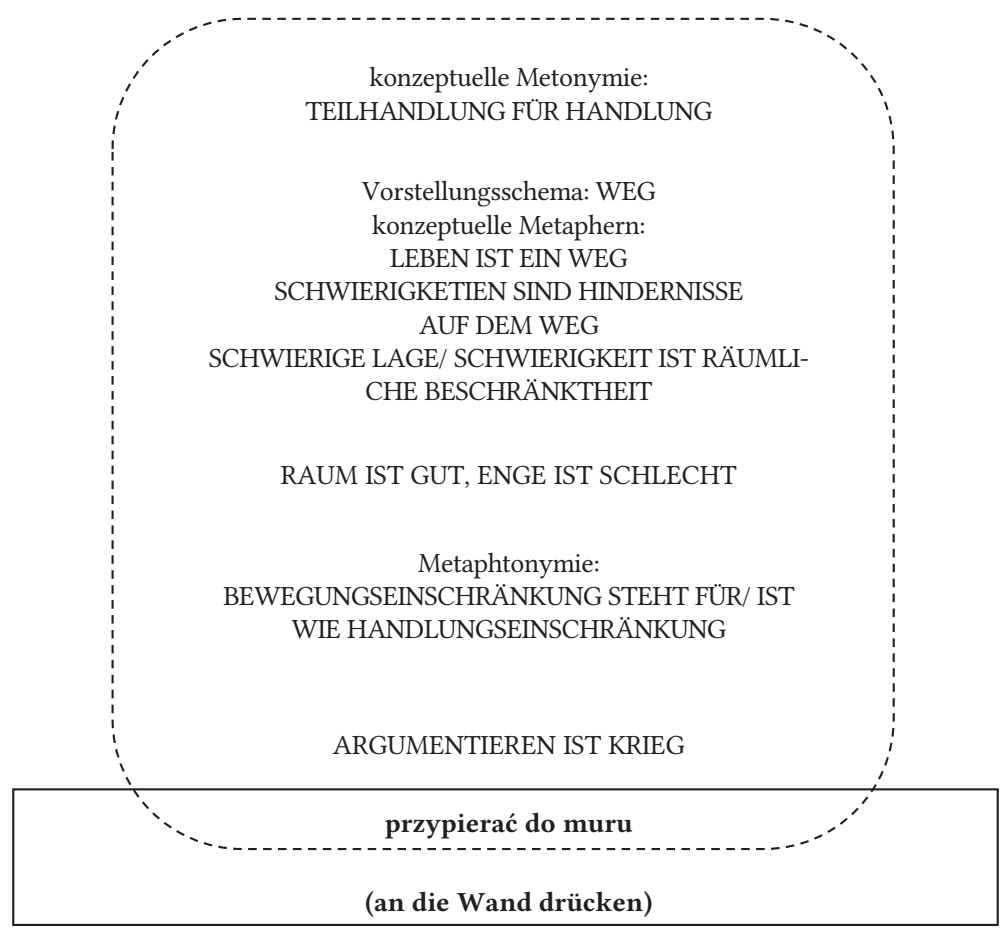

Abb. 80: Bedeutungskonstituierungsmechanismen für das Verwendungsprofil 1 ,(in einer verbal-argumentatorischen Auseinandersetzung) jmdn. mit gezielt gestellten Fragen zu einem Geständnis zwingen:

Verwendungsprofil 2: ,jmdn. in eine ausweglose Lage bringen, in der er ratlos ist und sich dem Agens fügen muss' (15 Belege)

In insgesamt 15 Belegen wird die ausweglose Lage eines Patiens hervorgehoben, der - einem großen Druck ausgesetzt - verzweifelte Schritte vornehmen kann:

Dlaczego Husajn właśnie teraz doprowadził do zaostrzenia sytuacji? - Bo nie chce doprowadzić do zniszczenia swej broni masowego rażenia. Liczy, że w przyszłości może mu być potrzebna przeciw wewnętrznym buntownikom czy przeciw Iranowi, Kuwejtowi, Izraelowi... Teraz został przyciśnięty do muru przez ONZ i Amerykanów, więc się broni. Czy to jedyna gra Husajna? Gazeta Wyborcza, 1997-11-05 (Warum hat Husajn ausgerechnet jetzt zu einer Situationsverschärfung geführt? - Weil er es nicht zulassen will, dass seine Massenvernichtungswaffe zugrunde gerichtet wird. Er nimmt an, dass sie in Zukunft zum Einsatz gegen interne Aufrührer, den Iran, Kuwait, 
Israel notwendig sein kann.... Jetzt wurde er von UNO und Amerikanern an die Wand gedrückt [wörtl. 'an die Mauer gedrückt'], also wehrt er sich. Ist das das einzige Spiel von Husajn? Gazeta Wyborcza, 1997-11-05, übers. von A. S.)

- Eksmisje będą masowe szczególnie tam, gdzie mieszkania można zamienić na lokale użytkowe dla biznesu - zapowiada prezes Olszewska. Jej zdaniem ustawa o najmie lokali nieuchronnie spowoduje konflikty. - Nie wiadomo, co się stanie, bo lokatorzy przyciśnięci do muru mogą pójść do przodu - ostrzega Olszewska. Wydaje się, że obawy krakowskich lokatorów są jednak przesadzone. Wprawdzie ustawa dopuszcza eksmisje na bruk, ale bać się ich powinni jedynie ci lokatorzy, którzy dewastują mieszkanie i zakłócają spokój innym. Gazeta Wyborcza, 1994-10-22 (Zwangsräumungen werden massenhaft insbesondere dort, wo man die Wohnungen in Gewerberäume verwandeln kann - kündigt Vorsitzende Olszewska an. Ihrer Meinung nach wird das Vermittlungsgesetz unvermeindlich Konflikte auslösen. - Es ist schwer zu sagen, was passiert, weil die an die Wand gedrückten [wörtl. 'an die Mauer gedrückten'] Bewohner Flucht nach vorne antreten können - warnt Olszewska. Die Befürchtungen der Krakauer Bewohner scheinen dennoch übertrieben zu sein. Zwar lässt das neue Gesetz die Zwangsräumungen auf die Straße zu, Angst davor sollten aber nur diejenigen Bewohner haben, die Wohnungen verwüsten und die Hausruhe stören. Gazeta Wyborcza, 1994-10-22 übers. von A. S.)

Die Bedeutungskonstituierungsmechanismen veranschaulicht schematisch Abb. 81:

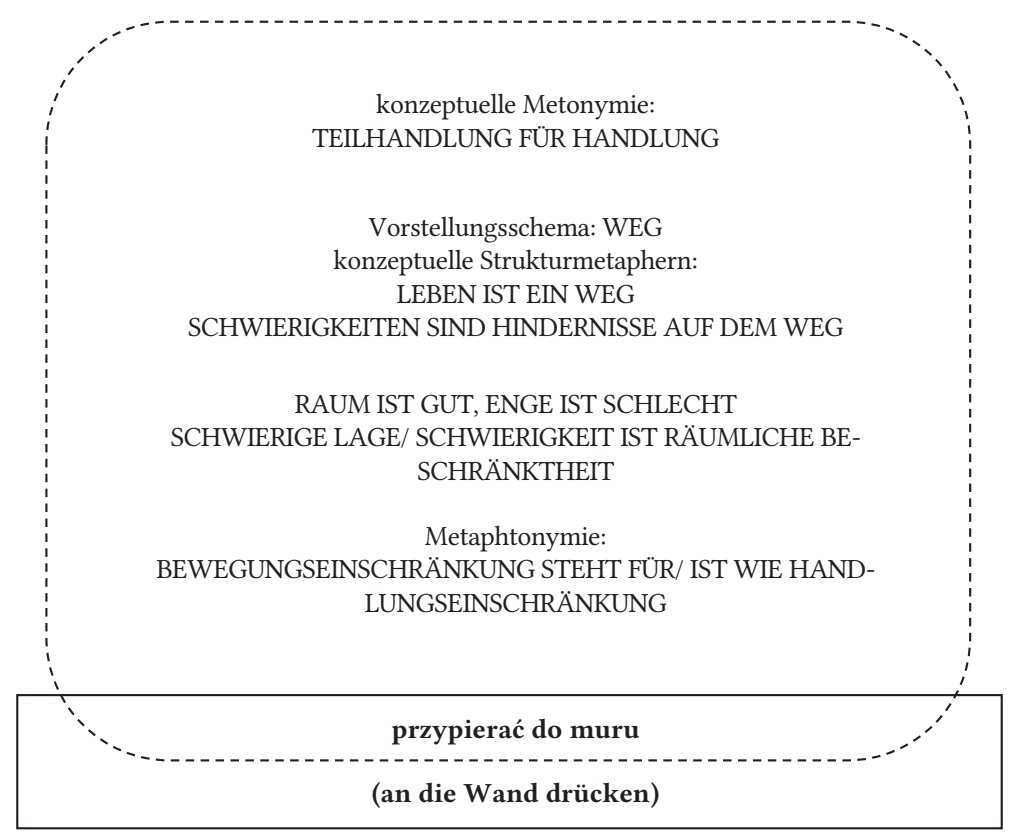

Abb. 81: Bedeutungskonstituierungsmechanismen für das Verwendungsprofil 2 ,jmdn. in eine aussichtslose Lage bringen, in der er ratlos ist und sich dem Agens fügen muss. 
Vergleicht man das deutsche Idiom mit seinem polnischen Quasi-Äquivalent, dann fallen einige semantische Unterschiede auf:

(i) Das deutsche Idiom hat eine komplexere semantische Struktur als sein polnisches Äquivalent. Für die Wortverbindung an die Wand drücken lassen sich vier Verwendungsprofile ermitteln, für przypierać do muru/ściany zwei. Bemerkenswert ist dabei, dass das Idiom przyciskać/przypierać do muru/ ściany semantisch mehr Parallelen zu dem deutschen Phraseologismus in die Enge treiben aufweist, als zu dem bezüglich des Komponentenbestandes sehr ähnlichen Idiom an die Wand drücken.

(ii) Deutliche Differenzen treten in den wichtigsten, lexikalisierten Verwendungsprofilen auf, die mit mehr als der Hälfte der Gebrauchsbelege vertreten sind. Für das Deutsche ist das das Verwendungsprofil: ,jmdn. verdrängen, seines Wirkungsbereiches berauben und auf diese Weise in eine (wirtschaftliche, politische) Zwangslage bringen; verursachen, dass jd. an Bedeutung verliert oder ganz ausgeschaltet wird‘ (24 Belege), für das Polnische: ,jmdn. mit gezielt gestellten Fragen zu einer Erklärung, Stellungnahme, zu einem Geständnis zwingen' (25 Belege). Beide Idiome referieren zwar auf eine Notlage, in der ein Patiens zur Ausführung einer Handlung gezwungen wird, sie werden dennoch in anderen Diskursbereichen verwendet. Przypierać do muru gebraucht man hauptsächlich in Bezug auf eine Zwangslage eines Interlokutors in einem Gespräch/einer Diskussion, an die Wand drücken bezieht sich auf eine schwierige Situation des Patiens in einem Konkurrenzkampf.

(iii) Ebenfalls in anderen Verwendungsprofilen sind Bedeutungsunterschiede ersichtlich: Zwar ist der Kern ,die schwierige Situation des Patiens, seine Notlage ' allen deutschen und polnischen Verwendungsbelegen gemeinsam, das polnische Idiom hebt dennoch mehr die Ausweglosigkeit der Zwangslage, das deutsche Idiom mehr den Bedeutungsaspekt des In-den-HintergrundDrängens (vgl. Verwendungsprofile 1, 2, 4) hervor. Die ermittelten Differenzen zwischen den beiden Idiomen sind auf die unterschiedlichen Metaphern zurückzuführen, die den Verwendungsprofilen zugrunde liegen. Auch wenn sich das deutsche und das polnische Idiom zahlreiche konzeptuelle Mechanismen teilen (vgl. konzeptuelle Metonymie: TEILHANDLUNG FÜR HANDLUNG, konzeptuelle Metaphern: LEBEN IST EIN WEG, SCHWIERIGKEITEN SIND HINDERNISSE AUF DEM WEG, RAUM IST GUT, ENGE IST SCHLECHT, SCHWIERIGE LAGE/SCHWIERIGKEIT IST RÄUMLICHE BESCHRÄNKTHEIT, Metaphtonymie: BEWEGUNGSEINSCHRÄNKUNG STEHT FÜR/IST WIE HANDLUNGSEINSCHRÄNKUNG), so werden die Bedeutungen der Idiome doch z.T. auch durch unterschiedliche konzeptuelle Metaphern mitgestaltet: Im deutschen Idiom treten in den Verwendungsprofilen die Metaphern: WICHTIG SEIN IST IN DER MITTE SEIN, NICHT WICHTIG SEIN IST AM RANDE SEIN; STARKE PERSÖNLICHKEIT IST DIE PERSÖNLICHKEIT, DIE VIEL RAUM IN ANSPRUCH NIMMT, SCHWACHE PERSÖNLICHKEIT IST DIE PERSÖNLICHKEIT, DIE SICH KLEIN MACHT auf, das polnische Idiom wird in seinem ersten Verwendungsprofil durch die konzeptuelle Metapher ARGUMENTIEREN IST 
KRIEG mitgestaltet. Die Bedeutungskonstituierungsmechanismen für das deutsche und das polnische Idiom werden in der Tab. 31 zusammengestellt, die fett gedruckten Metaphern sind für das jeweilige Idiom spezifisch.

Tab. 31: Die kognitiven Mechanismen der Bedeutungskonstituierung für das Idiom an die Wand drücken und sein polnisches Äquivalent przypierać do muru/ściany.

\begin{tabular}{ll}
\hline an die Wand drücken & przypierać/przyciskać do muru \\
\hline Verwendungsprofil 1: & Verwendungsprofil 1: \\
GRUND FÜR FOLGE & GRUND \\
LEBEN IST EIN WEG & LEBEN IST EIN WEG \\
SCHWIERIGKETIEN SIND HINDERNISSE & SCHWIERIGKETIEN SIND HINDERNISSE \\
AUF DEM WEG & AUF DEM WEG \\
RAUM IST GUT, ENGE IST SCHLECHT & RAUM IST GUT, ENGE IST SCHLECHT \\
SCHWIERIGE LAGE/SCHWIERIGKEIT IST & SCHWIERIGE LAGE/SCHWIERIGKEIT IST \\
RÄUMLICHE BESCHRÄNKTHEIT & RÄUMLICHE BESCHRÄNKTHEIT \\
WICHTIG SEIN IST IN DER MITTE SEIN & BEWEGUNGSEINSCHRÄNKUNG STEHT FÜR/ \\
NICHT WICHTIG SEIN IST AM RANDE SEIN & IST WIE HANDLUNGSEINSCHRÄNKUNG \\
& ARGUMENTIEREN IST KRIEG \\
\hline VerWEndUngSPROfil 2: & VerWENdUngSPROfil 2: \\
LEBEN IST EIN WEG & LEBEN IST EIN WEG \\
SCHWIERIGKETIEN SIND HINDERNISSE & SCHWIERIGKETIEN SIND HINDERNISSE AUF \\
AUF DEM WEG & DEM WEG \\
SCHWIERIGE LAGE/SCHWIERIGKEIT IST & SCHWIERIGE LAGE/SCHWIERIGKEIT IST \\
RÄUMLICHE BESCHRÄNKTHEIT & RÄUMLICHE BESCHRÄNKTHEIT \\
RAUM IST GUT, ENGE IST SCHLECHT & RAUM IST GUT, ENGE IST SCHLECHT \\
STARKE PERSONLICHKEIT IST PERSÖNLICHKEIT, & BEWEGUNGSEINSCHRÄNKUNG STEHT FÜR/ \\
DIE VIEL RAUM IN ANSPRUCH NIMMT & IST WIE HANDLUNGSEINSCHRÄNKUNG \\
SCHWACHE PERSÖNLICHKEIT IST & \\
PERSÖNLICHKEIT, DIE SICH KLEIN MACHT & \\
\hline
\end{tabular}

Verwendungsprofil 3:

LEBEN IST EIN WEG

SCHWIERIGKEITEN SIND HINDERNISSE AUF

DEM WEG

SCHWIERIGE LAGE/SCHWIERIGKEIT IST

RÄUMLICHE BESCHRÄNKTHEIT

BEWEGUNGSEINSCHRÄNKUNG STEHT FÜR/

IST WIE HANDLUNGSEINSCHRÄNKUNG

Verwendungsprofil 4:

TEILHANDLUNG FÜR HANDLUNG

RAUM IST GUT, ENGE IST SCHLECHT

WICHTIG SEIN IST IN DER MITTE SEIN,

NICHT WICHTIG SEIN IST AM RANDE SEIN 
Auf die Differenzen in den Bedeutungskonstituierungsmechanismen ist die Teiläquivalenz des polnischen Pendants zurückzuführen. Da die Bedeutung des polnischen Idioms durch die konzeptuelle Metapher ARGUMENTIEREN IST KRIEG mitkonstituiert wird, lässt sich der folgende Beleg nur bedingt durch das Idiom an die Wand drücken übersetzen. Der Aspekt der argumentativen Auseinandersetzung, der Zwangslage des Patiens, die durch Drohungen, bohrende Fragen verursacht wird, geht verloren, vgl. z.B.:

Ale bezpośrednio, wprost, nigdy nic takiego nie powiedziałem i przyparty do muru na pewno nie wydobyłbym z siebie jawnego fałszerstwa. Gazeta jednak musi podawać wiadomości mogące liczyć na uwagę czytelnika. Sławomir Mrożek, Opowiadania 1974-1979, Noir sur Blanc, 1979

(?) Aber direkt, unmittelbar, habe ich so etwas nie gesagt und an die Wand gedrückt [wörtl. 'an die Mauer gedrückt'] hätte ich bestimmt keine offensichtliche Fälschung hervorgebracht. Eine Zeitung muss doch Nachrichten übermitteln, die Aufmerksamkeit der Leser auf sich ziehen.

An dieser Stelle scheint das Idiom in die Enge treiben, dessen Bedeutungskonstituierungsmechanismen in dem zweiten Verwendungsprofil mehr Parallelen zu dem polnischen Pendant aufweisen, geeigneter zu sein:

$\approx$ Aber direkt, unmittelbar, habe ich so etwas nie gesagt und in die Enge getrieben hätte ich bestimmt keine offensichtliche Fälschung hervorgebracht. Eine Zeitung muss doch Nachrichten übermitteln, die Aufmerksamkeit der Leser auf sich ziehen.

Problematisch sind ebenfalls die Übersetzungen aus dem Deutschen ins Polnische. Nehmen wir als Beispiel den Gebrauchsbeleg (102):

Die kindliche, textkritische Potter-Gemeinde protestiert flüsternd auf dem Nebensitz, die erwachsenen Rowling-Schriftgelehrten werden ins Detail gehen und beide glücklicherweise in der Unendlichkeit des Internets verschwinden. Dem DurchschnittsPotter-Leser bleiben zwei große Momente, in denen der Film das Buch überschreitet, die Gewalt der Bilder das sprachliche Talent der Autorin an die Wand drückt. Da rasen zum einen in schwindelerregender Höhe die Quidditch-Spieler auf ihren Besen durch die Lüfte, versuchen einander in die Tiefe zu stürzen, wird das Unbarmherzige des gerühmten englischen Sportgeistes spürbar. Die Zeit, 22.11.2001, Nr. 48

(?) Grupka dziecięcych wielbicieli Harrego Pottera szeptem protestuje na fotelu obok, dorośli krytycy prozy Rowling wdadzą się w szczegóły, obie grupy znikną na szczęście gdzieś w otchłaniach internetu. Przeciętnemu czytelnikowi Harrego Pottera pozostaną w pamięci dwa momenty, w których film przebija książkę, a potęga obrazu przypiera talent autorki do muru. Oto gracze w quidditch pędzą z zawrotną prędkością wysoko w chmurach na swoich miotłach i próbują strącić się w dół, bezduszność sławnego angielskiego ducha rywalizacji jest wyraźnie wyczuwalna.

Die wörtliche Übersetzung des Idioms an die Wand drücken ist in diesem Kontext in diesem Sinne verständlich, dass ein kompetenter Sprachrezipient spontan die notwendigen motivierenden Mappings herstellen kann. Die Wortverbindung przypierać 
do muru funktioniert hier dennoch eher als eine Ad-hoc-Metapher, als Idiom ist sie verfremdend, da die Bedeutungsaspekte ,jmdn./etw. in den Schatten stellen, jmdm./ etw. überlegen sein, besser als jd./etw. sein', denen die konzeptuellen Metaphern WICHTIG SEIN IST IN DER MITTE SEIN, NICHT WICHTIG SEIN IST AM RANDE SEIN zugrunde liegen, im Polnischen nicht lexikalisiert sind. Geeigneter als Äquivalente sind an dieser Stelle die Verben przyćmiewać [wörtl. 'abblenden, abdunkeln', übertragen: ,in den Schatten stellen'], przewyższać [wörtl. 'größer sein', übertragen: ,übertreffen'], akzeptabel wären auch die Idiome: brać nad kimś górę (,die Oberhand gewinnen') und spychać na drugi plan (,in den Hintergrund drängen').

$\approx$ Grupka dziecięcych wielbicieli Harrego Pottera cicho protestuje na fotelu obok, dorośli krytycy prozy Rowling wdadzą się w szczegóły, obie grupy znikną na szczęście gdzieś w otchłaniach internetu. Przeciętnemu czytelnikowi Harrego Pottera pozostaną w pamięci dwa momenty, w których film przebija książkę, a potęga obrazu przyćmiewa/przewyższa talent autorki ( $\approx$ bierze górę nad talentem autorki/ spycha talent autorki na drugi plan). Oto gracze w quidditch pędzą z zawrotną prędkością wysoko w chmurach na swoich miotłach i próbują strącić się w dół, bezduszność sławnego angielskiego ducha rywalizacji jest wyraźnie wyczuwalna.

Die Schwierigkeiten in der Auffassung der Idiombedeutung im interlingualen Vergleich widerspiegeln sich auch in lexikographischen Nachschlagewerken: Die vorgeschlagenen Äquivalente unterscheiden sich in dem deutsch-polnischen und polnisch-deutschen Teil der Großwörterbücher PONS online und des PWN Wörterbuches von Wiktorowicz/Frączek, kein Äquivalentenpaar kommt dennoch der semantischen Komplexität der Bedeutungen und Teilbedeutungen (Verwendungsprofilen und Verwendungsmustern) gerecht:

Tab. 32: Idiome: an die Wand drücken und przypierać/przyciskać do muru in bilingualen Großwörterbüchern.

\begin{tabular}{|c|c|c|}
\hline Wörterbuchtyp & Wörterbuch & Lexikographische Darstellung \\
\hline \multirow[t]{2}{*}{$\begin{array}{l}\text { zweisprachig: } \\
\text { polnisch-deutsch }\end{array}$} & $\begin{array}{l}\text { PONS (Stichwort: } \\
\text { mur) Zugriff am } \\
\text { 25.07.2017 }\end{array}$ & $\begin{array}{l}\text { przypierać do ściany - jmdn. an die Wand } \\
\text { drücken } \\
\text { przyprzeć do muru - jmdn. in die Enge treiben }\end{array}$ \\
\hline & $\begin{array}{l}\text { PWN } \\
\text { (Stichwort: mur) }\end{array}$ & $\begin{array}{l}\text { być przypartym a. przyciśniętym do muru - an } \\
\text { die Wand gedrückt werden pot.; mit dem Rücken } \\
\text { an der Wand stehen; przyprzeć a. przycisnąć } \\
\text { kogoś do muru - jmdn. an die Wand drücken }\end{array}$ \\
\hline \multirow[t]{2}{*}{$\begin{array}{l}\text { zweisprachig: } \\
\text { deutsch-polnisch }\end{array}$} & $\begin{array}{l}\text { PONs (Stichwort: } \\
\text { Wand, Zugriff am } \\
\text { 25.07.2017) }\end{array}$ & $\begin{array}{l}\text { jmdn. an die Wand drücken - wyeliminować } \\
\text { kogoś jako konkurenta }\end{array}$ \\
\hline & $\begin{array}{l}\text { PWN (Stichwort: } \\
\text { Wand) }\end{array}$ & $\begin{array}{l}\text { jmdn. an die Wand drücken - pot. usunąć kogoś } \\
\text { na dalszy plan }\end{array}$ \\
\hline
\end{tabular}


Auf die interlingualen Äquivalenzbeziehungen wird wegen der Komplexität des Themas im Folgenden nicht näher eingegangen, das Problem der Übersetzbarkeit der Phraseologismen steht im Mittelpunkt des Interesses der bilingualen Lexikologie und Lexikographie sowie der kontrastiven Phraseologie (vgl. dazu u.a. Burger 2009, Chrissou 2000, Dobrovol'skij 1999, 2009, Jesenšek 2008, Korhonen 2007, Mellado-Blanco 2009). Es sei bemerkt, dass die interlinguale vollständige Äquivalenz zweier Begriffe sogar in Bezug auf Einwortlemmata selten ist (Lipczuk 2004: 834). Diese Annahmen bestätigen die auf Phraseologie bezogenen Studien von Laskowski (2003) und Chrissou (2000, 2018). Laskowskis Untersuchung von 400 Zwillingsformeln und 1000 idiomatischen Wendungen ergibt, dass Nulläquivalenz in der deutsch-polnischen Phraseologie am häufigsten vorkommt (2003: 130). Auch Chrissou $(2000,2018)$ stellt eine geringe Affinität der phraseologischen Systeme im deutsch-griechischen Vergleich fest und verweist auf eine größere Anzahl der interlingual divergenten als konvergenten Äquivalentpaare. Die Bedeutungsbeschreibung von Phraseologismen in Wörterbüchern ist dabei besonders schwierig:

Der Übersetzer hat die Möglichkeit, ein Zuwenig an Information auf der Wort- bzw. syntagmatischen Ebene auf der makrostrukturellen Ebene auszugleichen, der Lexikograph muss dies im Mikrotext eines Wörterbuchartikels tun. (Worbs 1997: 502)

Die Schwierigkeiten in der lexikographischen Erfassung der Idiome sind vor dem Hintergrund der kognitiven, die Komplexität und Dynamik der Bedeutungskonstituierungsmechanismen aufzeigenden Analysen leicht nachvollziehbar und völlig verständlich: Die Bedeutung von Idiomen ist in den meisten Fällen zu vielschichtig, reichhaltig und vage, um in einer einzelnen Paraphrase aufzugehen. Vielversprechend sind aus diesem Grund die neueren Entwicklungstendenzen in der Lexikographie: Zum einen lässt der verstärkte Einsatz der korpusbasierten und korpusgesteuerten Untersuchungen in der monolingualen und bilingualen Phraseographie viele bisherigen Unzulänglichkeiten in der Makro- und Mikrostruktur der Nachschlagewerke beseitigen, die genaueren kognitiven Analysen zur Semantik einzelner Idiome könnten dabei zur akkuraten Erfassung der Bedeutungen und Teilbedeutungen einen nicht zu unterschätzbaren Beitrag leisten. Zum anderen hebt die sich anbahnende Wende von gedruckten zu elektronischen Nachschlagewerken viele Einschränkungen der traditionellen Lexikographie auf und ermöglicht eine detaillierte und trotzdem benutzerfreundliche und übersichtliche Darstellung der Lemmata.

Aus der kognitiven Perspektive verweist der Vergleich der Phraseologismen an die Wand drücken und przypierać/przyciskać do muru/śsiany auf den komplexen Charakter der phraseologischen Motiviertheit. Der Konstituentenbestand und mentales Bild sind in beiden Phraseologismen sehr ähnlich, die Vorstellungswelt, auf die Metaphern Bezug nehmen, weist aufgrund der offensichtlichen kulturellen Nähe der beiden Sprachen, die sich aus der Zusammengehörigkeit zu demselben Kulturkreis ergibt, viele Parallelen auf. Beiden Idiomen liegen z.T. auch dieselben konzeptuellen Metaphern zugrunde. Nichtsdestotrotz lässt sowohl das deutsche als auch das polnische Idiom bestimmte Bedeutungsaspekte erkennen, die einzigartig sind und sich auf spezifische metaphorische Mappings zurückführen lassen, die lexikalisiert wurden. 
Die phraseologische Motiviertheit ist also einerseits offen, willkürlich, lässt die individuellen Assoziationen der Sprachteilhaber zu, die sich im Laufe der Zeit verfestigen können: Dies erklärt den semantischen Mehrwert der Idiome, ihre Ambiguität, oft anzutreffende Vielfalt der Bedeutungen und Teilbedeutungen sowie Affinität zum sprachspielerischen Gebrauch. Andererseits ist die Motiviertheit an die Lexikalisierung gebunden und durch Lexikalisierung beschränkt - die lexikalisierte Bedeutung eröffnet den Spielraum, in dem die motivierenden metonymischen und metaphorischen Mappings möglich sind. Die konzeptuelle Metapher ARGUMENTIEREN IST KRIEG wurde nur im polnischen Idiom lexikalisiert, die Metaphern WICHTIG SEIN IST IN DER MITTE SEIN, NICHT WICHTIG SEIN IST AM RANDE SEIN, STARKE PERSÖNLICHKEIT IST PERSÖNLICHKEIT, DIE VIEL RAUM IN ANSPRUCH NIMMT kommen ausschließlich im deutschen Idiom zum Vorschein. Die Bedeutungen der Phraseologismen im engeren Sinne konstituieren sich folglich in einem Raum, der zwar groß ist und eine gewisse Bewegungsfreiheit gestattet, gleichzeitig aber durch die Wände der Lexikalisierung abgesteckt wird. Diese Wände sind zwar elastisch, in vielen Fällen dünn, sodass Breschen in die Mauer geschlagen werden können: Die phraseologischen Bedeutungen vieler Idiome unterliegen nämlich öfters den Bedeutungsverschiebungs-, Bedeutungserweiterungs- oder Bedeutungsverengungsprozessen. Andererseits lässt sich nicht von vornherein prognostizieren, welche metaphorischen oder metonymischen Projektionen sich in der Sprache verfestigen und reproduzierbar werden, auf die Raum-Metaphorik zurückgreifend, auf welche Wand Druck ausgeübt wird und welche Form dieser Raum zu einem gewissen Zeitpunkt annimmt. In diesem komplexen Zusammenspiel zwischen dem Verfestigten und sich Verfestigenden, dem bereits in kommunikativen Prozessen Ausgehandelten und dem neu Auszuhandelnden konstituiert sich das, was man vergegenständlichend als lexikalische Bedeutung bezeichnet, auf dieses Zusammenspiel sind interlinguale Differenzen in Idiomen mit ähnlichem Konstituentenbestand zurückzuführen.

\subsubsection{SCHWIERIGKEITEN SIND UNGENIESSBARES ESSEN}

ein hartes Brot, eine harte Nuss, in den sauren Apfel beißen, ein dicker Brocken ${ }^{192}$

Stellvertretend für die kleineren Phraseologismengruppen, die nicht mit der reichlich vertretenen Weg-Metaphorik zusammenhängen und doch zu der Konzeptualisierung der Schwierigkeiten im Deutschen herangezogen werden können, werden in diesem Kapitel die Idiome untersucht, deren Ausgangsdomäne im weit gefassten Erfahrungsbereich der Ernährung liegt. Die Relevanz der Domänen: Essen, Nahrungszubereitung, Tafelsitten ist in der Phraseologie vor dem Hintergrund der Tatsache, dass Mahlzeiten zu bereiten, verzehren und genießen ein tägliches, notwendiges,

192 Dieses Unterkapitel stützt sich z.T. auf korpusbasierte Analysen der Idiome ein hartes Brot, eine harte Nuss, ein dicker Brocken, die bereits in Artikeln und Beiträgen mit unterschiedlichen Schwerpunkten veröffentlicht wurden: vgl. Sulikowska 2016a, 2016b, 2017. 
mehrmals wiederholtes, kulturell-ritualisiertes soziales Ereignis ist, verständlich. Die Aufnahme der Lebensmittel ist für die Erhaltung des Körpers und das Wohlbefinden des Menschen unabdingbar, der Prozess der Verwandlung der materialen Erdfrüchte in die Lebensenergie und Körperkraft existenziell, dementsprechend werden auch abstraktere kognitive und emotionale Vorgänge des Öfteren unter Rückgriff auf die lebensnahen und täglich erfahrenen Konzepte der Essenaufnahme, des Schluckens, der Verdauung konzeptualisiert, wobei man sich bekömmliche Lebensmittel als Vorteile, ungenießbare oder schwer zubereitende Nahrung als Schwierigkeiten vorstellt.

\subsubsection{1 ein hartes Brot}

Lexikographisch erfasste Varianten: ein hartes/schweres/saures Brot

Modifikationen: hartes Brot, ganz schön hartes Brot, ein sehr hartes Brot, das harte Brot (+ Gen): das harte Brot der Opposition (3 Belege), das harte Brot der Identitätssuche, das harte Brot jedes Essenliebhabers, das harte Brot der Kunst, dasselbe harte Brot

\section{Darstellung in lexikographischen Nachschlagewerken}

Tab. 33: Das Idiom ein hartes Brot in allgemeinen und phraseologischen Wörterbüchern des Deutschen.

\begin{tabular}{|c|c|c|}
\hline Wörterbuchtyp & Wörterbuch & Lexikographische Darstellung \\
\hline \multirow[t]{3}{*}{ allgemein } & DUW 2006 & $\begin{array}{l}\text { ein hartes/schweres B. (schwere Arbeit, } \\
\text { mühevoller Gelderwerb) }\end{array}$ \\
\hline & DUW ONLINE & $\begin{array}{l}\text { ein hartes/schweres Brot (schwere Arbeit, } \\
\text { mühevoller Gelderwerb) }\end{array}$ \\
\hline & WAHRIG 2007 & $\begin{array}{l}\text { das ist ein hartes, saures Brot }\langle\text { fig. }\rangle \text { schwere, } \\
\text { mühsame Arbeit }\end{array}$ \\
\hline \multirow[t]{4}{*}{ phraseologisch } & DUDEN 11 & $\begin{array}{l}\text { ein hartes/schweres Brot sein: ein mühevoller } \\
\text { Gelderwerb sein: Er brummelte ... das könnte doch } \\
\text { nie gut gehen - Vertreter, Reisender, das sei ein } \\
\text { hartes Brot (Richartz, Büroroman 100). (2011: 142) }\end{array}$ \\
\hline & SCHEMANN 2011 & $\begin{array}{l}\text { ein hartes/schweres/saures Brot (für jn.) sein/ } \\
\text { (etw. zu tun/zu sein) path veraltend selten } \\
\text { So Jahr um Jahr unter der Erde die Kohle } \\
\text { losschlagen - das ist schon ein hartes Bort. - } \\
\text { Obwohl ich es einige Male mit großem Interesse } \\
\text { mitgemacht habe, würde ich auch nicht gern } \\
\text { ständig ,unter Tage' oder ,vor Ort' arbeiten, wie } \\
\text { man sagt. Das Geld ist sauer verdient. (2011: 104) }\end{array}$ \\
\hline & $\begin{array}{l}\text { REDENSARTEN- } \\
\text { INDEX }\end{array}$ & $\begin{array}{l}\text { ein hartes/schweres Brot ,mühevoll; mühselig; } \\
\text { beschwerlich; schwer verdient }\end{array}$ \\
\hline & MÜLLER 2005 & nicht verzeichnet \\
\hline
\end{tabular}




\section{Korpusgestützte Analyse anhand der DWDS-Korpora ${ }^{193}$}

1. ,eine schwere Arbeit, die mit der Sicherung der materiellen Lebensgrundlage verbunden ist ${ }^{\prime}$

(21 Belege)

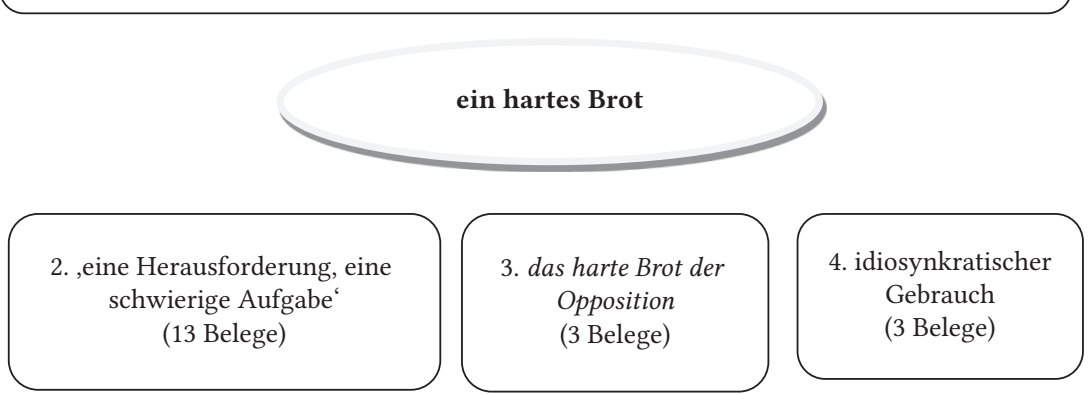

Abb. 82: Die Verwendungsprofile des Idioms ein hartes Brot anhand der Analyse der Gebrauchsbelege im DWDS-Korpus.

Verwendungsprofil 1: ,eine schwere Arbeit, die zur Existenzsicherung notwendig ist, ein mühevoller Gelderwerb' (21 Belege)

Das frequenteste Verwendungsprofil des Idioms bezieht sich auf die mit Gelderwerb und mit Sicherung der materiellen Lebensgrundlage verbundene Arbeit und kann mit der Bedeutungsparaphrase: ,eine schwere Arbeit, die zur Existenzsicherung notwendig ist, ein mühevoller Gelderwerb“ umschrieben werden. In 21 Gebrauchsbelegen wird der unangenehme Aspekt dieser Tätigkeit profiliert, der beispielsweise:

in einer großen körperlichen Anstrengung:

(106) Drei Dinge braucht der Erntehelfer: ein Spargelmesser, eine Kelle, um die Sandhügel wieder in Form zu bringen, und ein gutes Auge. Für Urlauber ist es ein Spaß, für die Arbeiter hartes Brot. Sie beginnen in der Morgendämmerung und arbeiten den lieben langen Tag gebückt, was für den Rücken alles andere als gut ist. Der Tagesspiegel, 21.03.1998

(107) Der Hof wurde vom Vater an den Sohn übergeben, solange er es zurückverfolgen kann. Die Schafzucht ist ein hartes Brot, kaum Freizeit, wenig Einnahmen.

193 Zugriffsdatum: 25.10.2015, Suchanfrage: hartes\&\&Brot. Deutsches Textarchiv: 0/12; Kernkorpus 3/58 (anzeigbar 37); Die Zeit: 13/171; Berliner Zeitung: 10/60; Der Tagesspiegel: 10/56; Potsdamer Neueste Nachrichten: 4/6. 
Doch: „Solange die Schafe satt werden, habe ich genug zu essen.“ Der Tagesspiegel, 17.04.2005

in einem übermäßigen Kraftaufwand, der (vergleichsweise) wenig Ertrag mit sich bringt:

(108) Schauen Sie sich an, was Fußballer verdienen und wofür. Biathlon, das sei richtig „hartes Brot“. Der Tagesspiegel, 29.12.2002

in den gespannten zwischenmenschlichen Beziehungen, die (wahrscheinlich wegen der großen Konkurrenz) auf dem Arbeitsplatz herrschen:

(109) Taxifahren ist ein hartes Brot in Berlin. „Zur Zeit ist es besonders schlimm“, sagt Manfred Q. „Du stehst am Stand brav in der Schlange“. Gestern stand der 38-jährige Taxifahrer Kai S. vor dem Amtsrichter. Er hatte sich am Flughafen Tegel vorgedrängelt. „Eine bodenlose Frechheit“, sagt Manfred Q. Berliner Zeitung, 06.02.1998

oder in den besonders hohen Ansprüchen, die einem an dem Arbeitsplatz gestellt werden, liegt:

(110) „Auch wenn nicht alle Überstunden generell abgeschafft werden können, sind die täglich geleisteten Überstunden größtenteils vorhersehbar und könnten zugunsten von Neueinstellungen umverteilt werden“, schreibt die Ärztekammer-Zeitschrift „Berliner Ärzte“. Möglich, dass vor allem fertig ausgebildete Ärztinnen, die das harte Brot der Kliniklaufbahn dem Familienleben geopfert haben, durch kalkulierbarere und damit familienfreundlichere Arbeitszeiten zur Rückkehr bewegt werden könnten. Der Tagesspiegel, 16.11.2001

Generalisierend ist anzunehmen, dass dieses Verwendungsprofil durch die in Abb. 83 dargestellten Metonymien, Metaphtonymien und Metaphern mitkonstituiert wird, die sich auf zwei Ebenen: der Ebene der Bedeutungsderivation von der ganzen Wortverbindung sowie der Ebene der semantischen Verschiebung von der nominalen Konstituente vollziehen.

Grundlegend für die Bedeutungskonstituierung ist auf der ersten Ebene die konzeptuelle Metapher SCHWIERIGKEITEN SIND UNGENIESSBARES [SCHLECHT SCHMECKEndes] ESSEN. Für diese konzeptuelle Metapher lassen sich zahlreiche sprachliche Exemplifizierungen finden, ebenfalls im phraseologischen Bereich:

SCHWIERIGKEITEN SIND UNGENIESSBARES [SCHLECHT SCHMECKENDES] ESSEN eine harte Nuss für jmdn. sein ,[für jmdn.] eine schwierige Aufgabe, ein großes Problem darstellen)' (DUW online, Zugriff am 22.10.2017)

manche, eine harte Nuss zu knacken haben, bekommen, ugs.; eine schwierige Aufgabe, ein schweres Problem zu bewältigen haben“ (DUW online, Zugriff am 22.10.2017)

die Suppe auslöffeln (müssen), die man sich eingebrockt hat, die Folgen eines Tuns tragen' (DUW online, Zugriff am 22.10.2017)

jmdm. die Suppe versalzen ,jmdm. etw. verderben/verleiden/madig machen; jmdm. schaden, jmds. Pläne vereiteln` (redensarten-index, Zugriff am 20.03.3017) 
jmdm./sich eine schöne Suppe einbrocken,jmdn./sich in eine unangenehme Lage bringen' (DUW online, Zugriff am 22.10.2017)

jmdm. das Leben sauer machen, jmdm. das Leben schwer, unangenehm machen, jmdm. Schwierigkeiten bereiten' (redensarten-index, Zugriff am 20.03.2017) sich (Dativ) die Zähne an etw. ausbeißen ,ugs.: an einer schwierigen Aufgabe trotz größter Anstrengungen scheitern' (DUW online, Zugriff am 22.10.2017) in den sauren Apfel beißen (müssen) ,etw. Unangenehmes notgedrungen tun' (DUW online, Zugriff am 22.10.2017) ${ }^{194}$.

Ebene 1

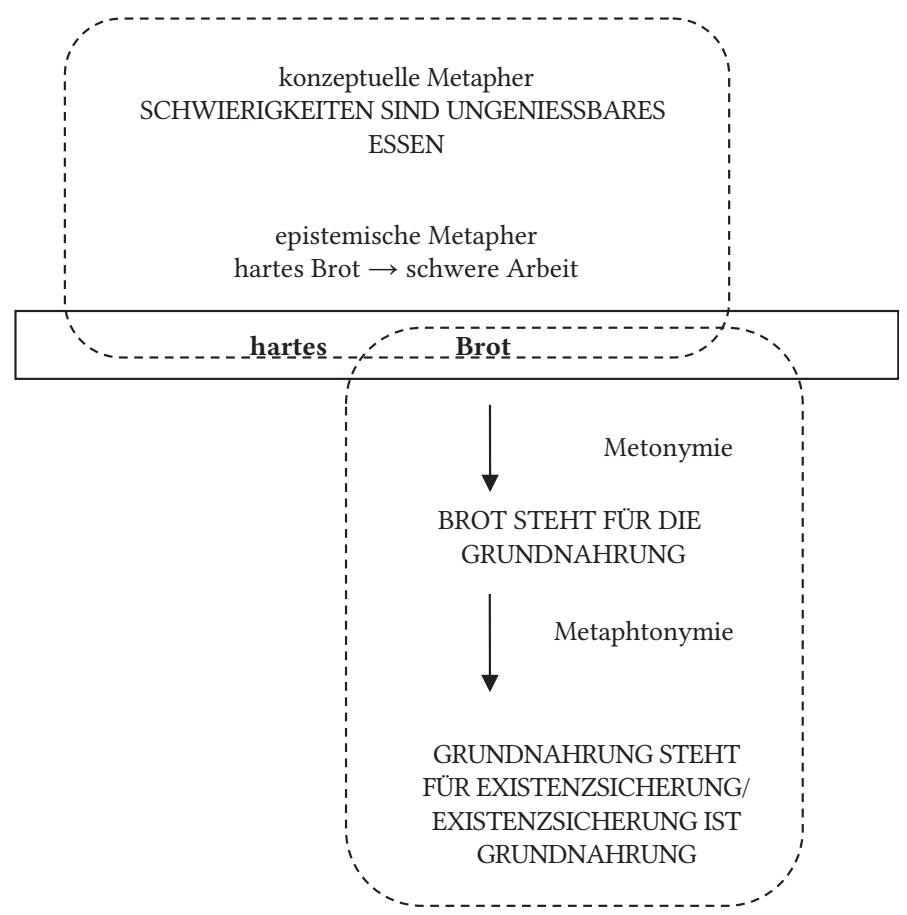

Abb. 83: Bedeutungskonstituierungsmechanismen für das Verwendungsprofil 1 , eine schwere Arbeit, die zur Existenzsicherung notwendig ist, ein mühevoller Gelderwerb:

Während die konzeptuelle Metapher SCHWIERIGKEITEN SIND UNGENIESSBARES/SCHLECHT SCHMECKENDES ESSEN den Konzeptualisierungen eine bestimmte

194 In einer loseren Beziehung dazu steht das Idiom bei jmdm. mit etw. auf Granit bei$ß e n$,bei jmdm. mit einem Bestreben, einer Forderung o. $\ddot{\text {. }}$ auf unüberwindlichen Widerstand stoßen' (DUW). 
Richtung gibt, trägt die epistemische Metapher und das mentale Bild zur Präzisierung der Bedeutung wesentlich bei. Die Wortverbindung ein hartes Brot in der literalen Lesart ruft nämlich ein mentales Bild hervor und aktiviert die epistemischen Strukturen: Ein durchschnittlicher Mensch hat eine genaue Vorstellung, wie ein hartes Brot aussieht, wie es schmeckt, wie es sich anfühlt und wie es verzehrt wird. Diese Informationen werden aus der Ausgangsdomäne des EsSENS auf die Zieldomäne der ARBEIT projiziert, was folgende Korrespondenzen (Tab. 34) ergibt:

Tab. 34: Die epistemischen Mappings zwischen der Ausgangs- und Zieldomäne für das Verwendungsprofil ,eine schwere Arbeit, die zur Existenzsicherung notwendig ist, ein mühevoller Gelderwerb؛

\begin{tabular}{ll}
\hline hartes Brot (Ausgangsdomäne) & schwere Arbeit (Zieldomäne) \\
\hline schwer zu knabbern & $\begin{array}{l}\text { eine Arbeit, die nur in kleinen Schritten } \\
\text { ausgeführt werden kann }\end{array}$ \\
langes Kauen & viel Anstrengung notwendig, mühselig \\
schmeckt nicht gut & unangenehme Arbeit \\
billig, günstiger als frisches Brot; & finanziell nicht befriedigende Arbeit \\
Armenkost & \\
nicht so begehrt wie frisches Brot & eine Arbeit, die für viele unattraktiv ist \\
\hline
\end{tabular}

Selbstverständlich werden nicht in jedem Gebrauchsbeleg alle Mappings fokussiert: Durch den Gebrauch der Metaphern können bestimmte Bedeutungsaspekte in den Vordergrund geschoben werden, während man andere in den Schatten stellt. So sind beispielshalber für den Beleg (110) vor allem die ersten zwei Korrespondenzen bedeutungskonstitutiv, während im Beleg (108) das vierte, den finanziellen Aspekt hervorhebende Mapping in den Fokus der Aufmerksamkeit geschoben wird.

Außer den metaphorischen Bedeutungsverschiebungen auf der Ebene der ganzen Wortverbindung lässt sich ebenfalls eine kulturell bedingte Bedeutungserweiterungsrelation zwischen der Idiomkonstituente Brot in der literalen Lesart und ,Existenzsicherung', ,Arbeit' in der phraseologisierten Lesart festlegen. Die in diesem Kontext oft angenommene symbolische Motivation (Dobrovol'skij/Piirainen 2009: 30-31) beruht im Grunde genommen auf einer metaphorisch-metonymischen Kette:

$$
\text { Brot } \stackrel{\text { [steht für] }}{\longrightarrow} \text { Grundnahrung } \stackrel{\text { [steht für/ist wie] }}{\longrightarrow} \text { Existenzsicherung }
$$

Abb. 84: Bedeutungsverschiebungskette der nominalen Konstituente im Idiom ein hartes Brot. 
Das Brot steht hier zuerst - pars pro toto -für die Grundnahrungslebensmittel: Da beide Konzepte innerhalb einer Wissensdomäne liegen, wird eine metonymische Verbindung angenommen. Weniger eindeutig lässt sich die nächste Bedeutungsverschiebung bestimmen: Der Aspekt der Existenzsicherung, der Lebensgrundlage kann sowohl als Teil der Domäne ESSEN als auch der Domäne ARBEIT angesehen werden. Im erstgenannten Fall müsste eine metonymische Bedeutungsverschiebung innerhalb der Domäne ESSEN angenommen werden (Grundnahrung steht für materielle Existenzsicherung), im zweitgenannten Fall hätten wir mit einer metaphorischen Verbindung zwischen zwei Domänen (ESSEN und ARBEIT) zu tun. Da sich die Mechanismen nicht eindeutig auseinander halten lassen und zwischen den beiden Domänen zahlreiche Übergangsbereiche bestehen, wird in diesem Fall eine Metaphtonymie angenommen. Anzumerken ist dabei, dass diese Metaphtonymie lexikalisiert ist:

GRUNDNAHRUNG (BROT) STEHT FÜR EXISTENZSICHERUNG/EXISTENZSICHERUNG IST GRUNDNAHRUNG (вROT)

jmdn. um sein Brot/um Lohn und Brot bringen ,jmdn. brotlos machen' (DWDS-Wörterbuch, Zugriff am 20.10.2017)

sein Brot verdienen ,seinen Lebensunterhalt bestreiten ' (redensarten-index, Zugriff am 20.10.2017)

in Lohn und Brot stehen/sein, eine feste Arbeit haben (und damit seinen Lebensunterhalt verdienen' (redensarten-index, Zugriff am 20.10.2017)

jmdn. um Lohn und Brot bringen ,jmdm. die Arbeit nehmen' (redensarten-index, Zugriff am 20.10.2017)

nach Brot gehen müssen, für einen Lohn arbeiten müssen' (redensarten-index, Zugriff am 20.10.2017)

überall sein Brot finden, geschickt, fleißig, anstellig sein, sodass man überall seinen Lebensunterhalt finden kann' (DUW online, Zugriff am 20.10.2017)

das Brot und Buttergeschäft ,die Haupteinnahmequelle, der Kernbereich/das Kerngeschäft eines Unternehmens' (redensarten-index, Zugriff am 20.10.2017)

die Kunst geht nach Brot ,der Künstler muss Geld verdienen` (DWDS-Wörterbuch, Zugriff am 20.10.2017)

wieder in Arbeit und Brot kommen, wieder eingestellt sein' (DWDS-Wörterbuch, Zugriff am 20.10.2017)

jmdn. in Arbeit und Brot bringen ,jmdm. eine Arbeit verschaffen' (DWDS-Wörterbuch, Zugriff am 20.10.2017)

der fugendliche isst schon sein eigenes Brot ,verdient sich seinen Unterhalt selbst (DWDS-Wörterbuch, Zugriff am 20.10.2017)

sich sein Brot mit Zeitungsaustragen [mühsam, sauer] verdienen (DUW online, Zugriff am 20.10.2017)

Der Mensch lebt nicht vom Brot allein ,Es gibt noch andere Dinge im Leben als Essen, die wichtig sind; Die Befriedigung materieller Bedürfnisse allein reicht nicht aus, um glücklich zu leben' (redensarten-index, Zugriff am 20.10.2017) 


\section{Verwendungsprofil 2: ,eine schwierige Aufgabe, eine Herausforderung، (13 Belege)}

Interessanterweise lässt die Analyse der Korpusbelege darauf schließen, dass die lexikographisch erfasste Bedeutung ,eine schwere Arbeit, ein mühevoller Gelderwerb ' zwar die frequenteste, dennoch keinesfalls die Einzige ist. In insgesamt 13 Belegen tritt der Faktor der finanziellen Existenzsicherung nicht zutage, das Idiom bezieht sich dafür auf schwere, herausfordernde Aufgaben/Probleme, die vor einen gestellt werden. In typischen Beispielen beziehen sich die Herausforderungen:

im politischen Bereich auf die wegen der Komplexität des Themas schwer durchzuführenden Reformen (3 Belege):

(111) Die Kosten laufen davon, der durchschnittliche Beitragssatz liegt nun bei etwa 14,5 Prozent. Der CSU-Politiker Horst Seehofer weiß, was für ein hartes Brot Reformen im Gesundheitswesen sind. „Die Politik repariert seit 25 Jahren erfolglos am Gesundheitssystem herum - einschließlich Seehofer und der anderen“(...). Der Tagesspiegel, 13.01.2003

im Sport auf die wegen eines anspruchsvollen Gegners schwierigen Wettkämpfe (3 Belege), z.B.:

(112) Das ergab die Auslosung beim Deutschen Fußball-Bund (DFB) in Frankfurt/ Main am Montag. „Wir hätten uns einen leichteren Gegner gewünscht, das wird ein hartes Brot", so Turbine-Coach Bernd Schröder. Pokalfinalist und Bundesliga-Spitzenreiter 1. FFC Frankfurt empfängt Bundesliga-Aufsteiger SG Essen- Schönebeck. Potsdamer Neueste Nachrichten, 16.11.2004

in anderen Kontexten auf bevorstehende Aufgaben, die viel Zeit, Ausdauer, Geduld und Disziplin erfordern, wie beispielshalber eine freiwillige Zusammenarbeit von sechs (sich früher nicht bekannten) Personen an einem gemeinsamen Drehbuch:

(113) Ein „unglaublich hartes Brot“ sei die gemeinsame Arbeit am Drehbuch, sagt Heidrun Jänchen, die gewissermaßen vom Fach ist. Denn die 38-jährige Physikerin arbeitet bei Zeiss Geräte-Entwicklung in Jena an Rückprojektionsfernsehern. Gerne hätte sie der Frau des Staatsanwaltes eine stärkere Persönlichkeit verliehen, doch „das war nicht zu machen“, weiß sie jetzt. Neben den anderen Autoren wachten natürlich wie üblich auch Redaktion und Produktion über die Buch-Entwicklung. Der Tagesspiegel, 18.10.2003

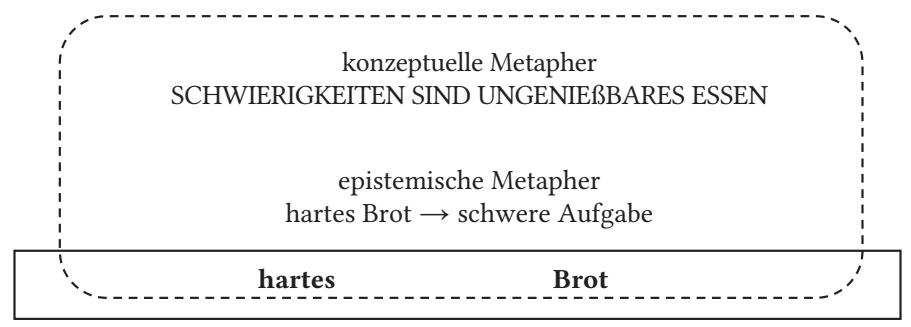

Abb. 85: Bedeutungskonstituierungsmechanismen für das Verwendungsprofil 2 , eine schwierige Aufgabe, eine Herausforderung. 
Die Prozesse der Bedeutungskonstituierung werden schematisch in der Abbildung 85 dargestellt.

Im Gegensatz zu dem ersten Verwendungsprofil wird die Bedeutung der vorliegenden Belege ausschließlich auf der Ebene der ganzen Wortverbindung konstruiert. Der richtungsweisende Beitrag der konzeptuellen Metapher SCHWIERIGKEITEN SIND UNGENIESSBARES ESSEN kommt ebenfalls hier zur Geltung. Erst durch das evozierte mentale Bild und die dahinter stehenden Wissensstrukturen erhält die Metapher dennoch deutlichere Konturen. Die Mappings zwischen der Ausgangs- und der Zieldomäne dürften den bereits beschriebenen ähnlich sein, in einigen Punkten werden dennoch andere Aspekte der Ausgangsdomäne profiliert (vgl. Tab. 35):

Tab. 35: Die metaphorischen Mappings zwischen der Ausgang- und Zieldomäne in dem Verwendungsprofil , eine schwierige Aufgabe, eine Herausforderung.

\begin{tabular}{ll}
\hline hartes Brot (Ausgangsdomäne) & $\begin{array}{l}\text { schwere, herausfordernde Aufgabe } \\
\text { (Zieldomäne) }\end{array}$ \\
\hline schwer zu knabbern & $\begin{array}{l}\text { eine Aufgabe, die in kleinen Schritten ausgeführt } \\
\text { wird, die Mühe, Zeit und Geduld in Anspruch nimmt }\end{array}$ \\
$\begin{array}{l}\text { langes Kauen } \\
\text { schmeckt nicht gut }\end{array}$ & $\begin{array}{l}\text { unangenehme Aufgabe } \\
\text { nicht so begehrt wie frisches Brot } \\
\text { gefährlich für das Gebiss }\end{array}$ \\
\hline
\end{tabular}

\section{3. das harte Brot der Opposition (3 Belege)}

Ein interessantes Beispiel für einen Übergangsbereich zwischen einer phraseologischen Modifikation und einem sich etablierenden Phraseologismus bildet die sich konventionalisierende Wortverbindung das harte Brot der Opposition, die in der Belegsammlung mit 3 Belegen vertreten ist (7,5\% der Belegsammlung $\left.{ }^{195}\right)$. In diesen Belegen tritt das Lexem Opposition als Genitivattribut auf, vgl. die Belege (114), (115):

(114) Die Sorge, doch noch das harte Brot der Opposition essen und vielleicht sich auch noch einem Volksentscheid beugen zu müssen, bewog die CDU, in der Schulfrage der SPD das zu gewähren, was sie der FDP vorenthielt. Archiv der Gegenwart, 36, 1966 (115) Es gibt, so sagt ein CDU-Mann, der es wissen muß, „ein eindrucksvolles Potential" für einen Hauch Reaganscher Politik in der Partei. Der Respekt, den die Leute der neuen amerikanischen Regierung der CDU sozusagen von gleich zu gleich entgegenbringen, schmeichelt zudem manchem Politiker, der des harten Brots der Opposition müde ist. Die Zeit, 18.09.1981

195 Die Recherche mit der Google-Suchmaschine ergibt zahlreiche weitere Treffer für die Wortverbindung das harte Brot der Opposition (Zugriff 26.03.2017). 
Die Bedeutung der idiomatischen Modifikation das harte Brot der Opposition oszilliert - je nach der individuellen Auslegung durch den Sprachrezipienten - zwischen dem ersten ,eine schwere Arbeit, die zur Existenzsicherung notwendig ist ${ }^{\circ}$ und dem zweiten Verwendungsprofil ,eine schwierige Aufgabe, eine Herausforderung' (vgl. Abb. 86). Der Bedeutungsaspekt der materiellen Lebensgrundlage aus dem ersten Verwendungsprofil dürfte hier für manche Sprachteilhaber mitschwingen: Da die politische Tätigkeit von den meisten Politikern als Beruf ausgeübt wird, geht es den Politikern der Opposition wahrscheinlich materiell (etwas) schlechter als den Politikern der Regierungspartei.

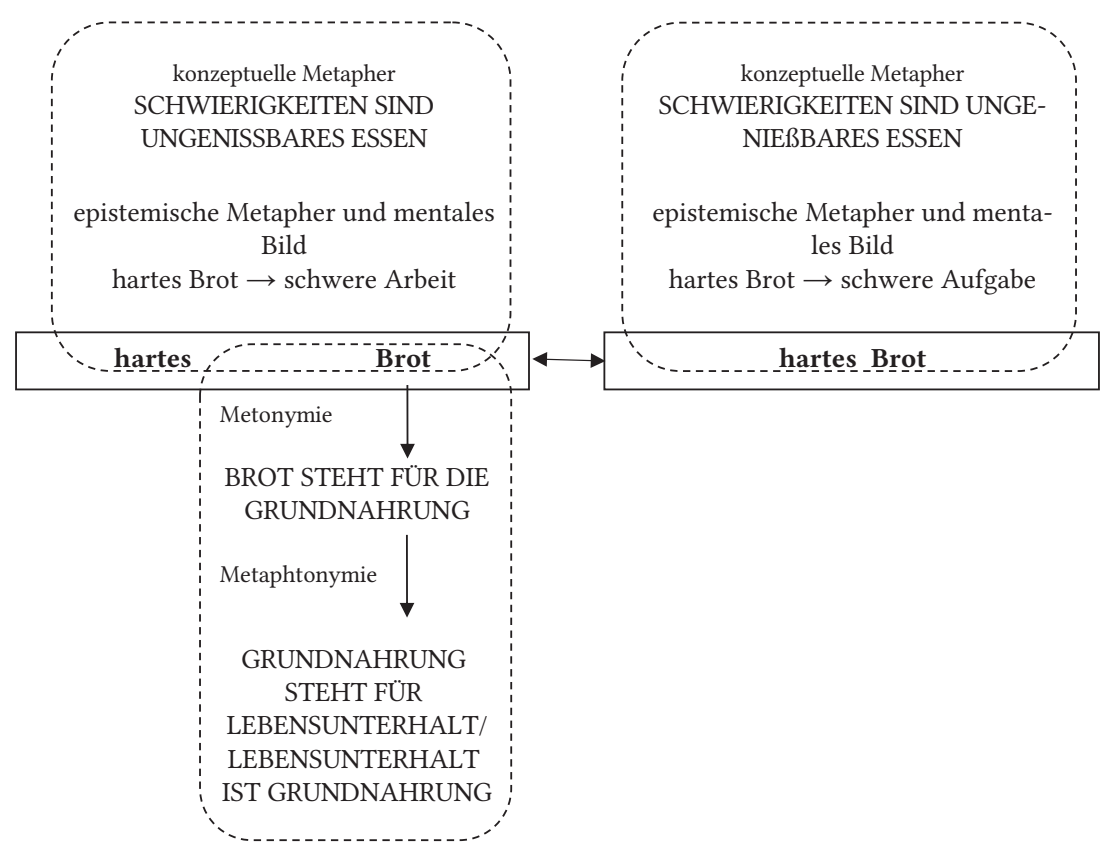

Abb. 86: Bedeutungskonstituierungsmechanismen für die sich etablierende Wortverbindung das harte Brot der Opposition.

Bezeichnenderweise kommt im Korpusbeleg (14) ein Phänomen zum Vorschein, den Sabban (2015: 104, 114) als „Aufbau und Ausgestaltung eines Szenarios“ bezeichnet: Die Bildbasis oder das einer etablierten Metapher zugrunde liegende Szenario wird durch die Nennung weiterer Handlungsschritte fortentwickelt oder um Details angereichert und ausgestaltet, was in dem besprochenen Text durch das Lexem: essen gewährleistet wird. Der Beitrag des mentalen Bildes zur Konstituierung der Bedeutungen von Idiomen wird im Unterkap. 4.2.2.2.5 behandelt. 


\subsubsection{2 eine harte Nuss}

Lexikographisch erfasste Varianten: eine harte Nuss (für jmdn. sein)

Modifikationen: alles harte Nüsse, eine richtig harte Nuss, eine besonders harte Nuss, eine ähnlich harte Nuss wie ..., eine härtere Nuss als ... (2 Belege), eine vielleicht noch härtere Nuss, die härteste Nuss, eine $z u$ harte Nuss

\section{Darstellung in lexikographischen Nachschlagewerken}

Tab. 36: Das Idiom eine harte Nuss in allgemeinen und phraseologischen Wörterbüchern des Deutschen.

\begin{tabular}{|c|c|c|}
\hline Wörterbuchtyp & Wörterbuch & Lexikographische Darstellung \\
\hline \multirow[t]{3}{*}{ allgemein } & Duw 2006 & $\begin{array}{l}\text { [für jmdn.] eine harte Nuss sein (ugs.: [für jmdn.] } \\
\text { eine schwierige Aufgabe, ein großes Problem } \\
\text { darstellen) }\end{array}$ \\
\hline & DUW ONLINE & $\begin{array}{l}\text { [für jemanden] eine harte Nuss sein } \\
\text { (umgangssprachlich: [für jemanden] eine schwierige } \\
\text { Aufgabe, ein großes Problem darstellen) (letzter } \\
\text { Zugriff am 27.10.2017) }\end{array}$ \\
\hline & WAHRIG 2007 & eine harte Nuss $\langle$ fig.; umg. $\rangle$ schwierige Aufgabe \\
\hline \multirow[t]{2}{*}{ phraseologisch } & DUDEN 11 & $\begin{array}{l}\text { eine harte Nuss [für jmdn.] sein (ugs.): ein } \\
\text { schwieriges Problem, eine unangenehme Aufgabe } \\
\text { [für jmdn.] sein: Die letzte Frage im Radioquiz war } \\
\text { wirklich eine harte Nuss. Er sollte jemanden ausfindig } \\
\text { machen, der vor fünfzehn Jahren nach Südamerika } \\
\text { ausgewandert war, das war auch für einen guten } \\
\text { Detektiv eine harte Nuss! } \\
\text { jmdm. eine harte Nuss zu knacken geben } \\
\text { (ugs.): jmdm. eine schwierige Aufgabe, ein schweres } \\
\text { Problem zu bewältigen geben: Mit diesem Auto und } \\
\text { seinem Preis gibt Ford dem Wolfsburger Konkurrenten } \\
\text { eine harte Nuss zu knacken (rp-online.de). } \\
\text { eine harte Nuss zu knacken haben (ugs.): eine } \\
\text { schwierige Aufgabe zu lösen, ein schweres Problem zu } \\
\text { bewältigen haben: Der Untersuchungsausschuss wird } \\
\text { eine harte Nuss zu knacken haben, wenn er diesem } \\
\text { Herrn unlautere Manipulationen nachweisen will. } \\
\text { (2011: 557-558) }\end{array}$ \\
\hline & $\begin{array}{l}\text { SCHEMANN } \\
2011\end{array}$ & $\begin{array}{l}\text { eine harte Nuss sein ugs. } \\
\text { Was bin ich froh, dass ich diese Aufgabe gelöst habe! } \\
\text { Das war eine harte Nuss! Selten habe ich ein so } \\
\text { schweres Problem zu lösen gehabt! (2011: 589) }\end{array}$ \\
\hline
\end{tabular}


Tab. 36: Continued

\begin{tabular}{|c|c|c|}
\hline Wörterbuchtyp & Wörterbuch & Lexikographische Darstellung \\
\hline & $\begin{array}{l}\text { REDENSAR- } \\
\text { TEN-INDEX }\end{array}$ & $\begin{array}{l}\text { eine harte Nuss ,eine schwierige Aufgabe } \\
\text { eine harte Nuss zu knacken haben ,eine } \\
\text { schwierige Aufgabe zu bewältigen haben' } \\
\text { jemandem eine harte Nuss zu knacken geben } \\
\text {,jemanden vor eine schwierige Aufgabe stellen` } \\
\text { (letzter Zugriff am 27.10.2017) }\end{array}$ \\
\hline & MÜLLER 2005 & $\begin{array}{l}\text { eine harte Nuß (umg.) eine schwierige/unangenehme } \\
\text { Sache [Schwierigkeit] } \\
\text { „Die Zwischenprüfung war leider mal eine harte Nuß. } \\
\text { Fast die Hälfte der Kandidaten war durchgefallen!“ } \\
\text { Die harte Schale der meisten Nußarten hat vielen } \\
\text { Sprichwörtern und Redensarten als Vorbild gedient. } \\
\text { (2005: 442-443) }\end{array}$ \\
\hline
\end{tabular}

\section{Korpusgestützte Analyse anhand der DWDS-Korpora ${ }^{196}$}

1. etw. ist eine harte Nuss: ,etw. stellt eine schwierige Aufgabe/ eine Herausforderung dar, etw. ist eine Herausforderung' (28 Belege)

2. jd. ist eine harte Nuss: ,jd. (eine Gruppe von Menschen) ist unnachgiebig, widerstandsfähig‘

(12 Belege)

eine harte Nuss

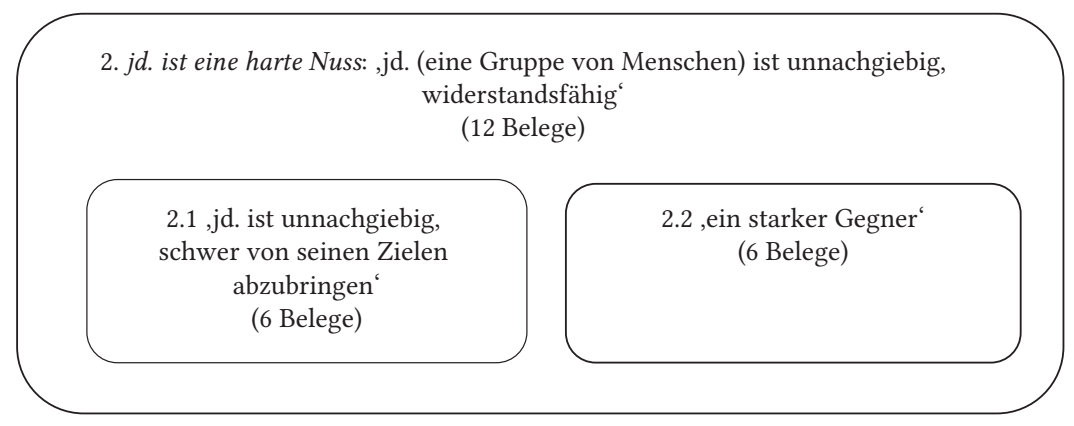

Abb. 87: Die Verwendungsprofile und -muster des Idioms eine harte Nuss anhand der Analyse der Gebrauchsbelege im DWDS-Korpus.

196 Zugriffsdatum: 11.11.2015, Suchanfrage: harte\&\&Nuss. Deutsches Textarchiv: 3/42; Kernkorpus: 0/1; Die Zeit: 18/152; Berliner Zeitung: 5/16; Der Tagesspiegel: 11/36; Potsdamer Neueste Nachrichten: 3/5. 
Die Untersuchung der Korpusbelege hat ergeben, dass das Idiom eine harte Nuss zwei Verwendungsprofile aufweist. Die meisten Belege beziehen sich auf die lexikographisch erfasste Bedeutung etw. ist eine harte Nuss, etw. stellt eine schwierige Aufgabe dar'. In insgesamt 12 Belegen ist das Subjekt allerdings belebt: Hier tritt eine Person oder eine Gruppe von Menschen in der Subjektposition auf.

Verwendungsprofil 1: etw. ist eine harte Nuss, etw. stellt eine schwierige Aufgabe, eine Herausforderung dar' (28 Belege)

In den meisten Belegen referiert eine harte Nuss auf schwierige Aufgaben, wobei das Herausfordernde an diesen Aufgaben mit mehreren Aspekten im Zusammenhang stehen kann:

Im Beruf und in der Wissenschaft ist es die Einzigartigkeit und Unkonventionalität der Aufgaben, die vor einen gestellt werden und hohe Ansprüche an seine Kreativität stellen:

(116) An den Seiten des Saales gibt es Echokammern, die je nach Auffassung des Dirigenten wie Scharniere auf die klanglichen Eigenarten einer Komposition hin geöffnet oder geschlossen werden können, wie die Kiemen beim Fisch. Alles harte Nüsse für einen Architekten, der die Poesie in der Gestalt und nicht in den Tönen sucht. Die Zeit, 24.08.1998

(117) Entzündungen, die dann auftreten, sind Folge und nicht Ursache der Krankheit. Es scheint so, als sei Rheuma für die forschenden Mediziner eine ähnlich harte Nuß wie Krebs. Das ist wenig tröstlich für Patienten, die schmerzgeplagt und oft lebenslang verkrüppelt mit ihren entzündeten Gelenken leben müssen. Die Zeit, 14.10.1983

In der Wirtschaft, Politik oder Gesellschaft wird dagegen eher das Problemhafte hervorgehoben:

(118) Für die Energie-Versorgungsunternehmen dürfte das Programm allerdings eine harte Nuß bedeuten: Gebremster Ausbau der bisherigen Zentralisierung in der Elektrizitätsversorgung durch Großkraftwerke, Ergänzung der Großkraftwerke durch eine große Anzahl sogenannter Energieboxen direkt beim Verbraucher. Die Zeit, 06.07.1979

(119) „Der Telekommunikationsmarkt wird nach dem WTO-Beitritt ganz anders aussehen", sagt Jürgen Oberg, der bei Siemens für das China-Geschäft zuständig ist. Die Öffnung ist eine harte Nuss für die chinesischen Machthaber. Sie sind es gewohnt, im Lande relativ abgeschottet handeln zu können. Der Tagesspiegel, 03.02.2001 (120) „Wenn es nötig sein sollte, die Armee einzusetzen, um Teile Londons zu schützen, werden wir davor nicht zurückschrecken", sagte er. Vor einem Jahr wurden nach einem Terroralarm Panzerwagen und Soldaten am Flughafen Heathrow eingesetzt - eine Maßnahme, die laut Stevens eine gute Wirkung hatte: „Wir wissen, dass gewisse Terroristengruppen sich Heathrow angesehen haben, aber eine zu harte Nuss fanden. Sie kamen, sahen sich um und gingen wieder. Der Tagesspiegel, 16.03.2004

Nicht zuletzt referiert eine harte Nuss auf die Herausforderungen, die einen zum Umdenken zwingen, gegen die bisherigen Weltanschauungen verstoßen: 
(121) Süffig zu lesen, aber eine harte Nuss für alle, die glauben, der Mann sei immer schon Versorger und Chef gewesen. Nein, die Steinzeitfrau saß nicht kümmerlich am Feuer und wartete auf den Beschützer und Fleischbringer, sie sammelte sich ihr Essen selbst. Ehe? Gab's nicht. Wie sich das änderte und was daraus für heute folgt, erzählt Marie-Luise Schwarz-Schilling in ihrem Ritt durch die Geschichte. Der Tagesspiegel, 16.12.2004

Die Bedeutungskonstituierungsprozesse vollziehen sich auf der Ebene der ganzen Wortverbindung (vgl. Abb. 88) und werden durch die konzeptuelle Metapher SCHWIERIGKEITEN SIND UNGENIESSBARES ESSEN sowie die epistemischen Mappings (Tab. 37) mitgestaltet:

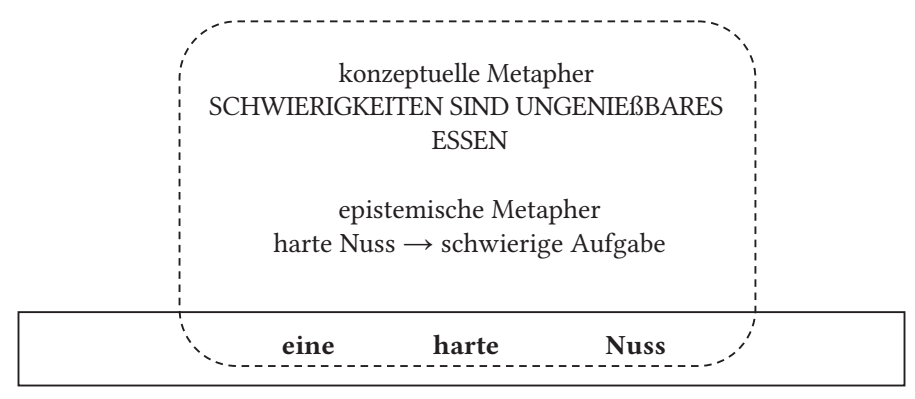

Abb. 88: Bedeutungskonstituierungsmechanismen für das Verwendungsprofil 1 ,unsichere, schwierige (Lebens-)Lage eines Menschen'.

Tab. 37: Die epistemischen Mappings für das Verwendungsprofil 1 , unsichere, schwierige (Lebens-)Lage eines Menschen'.

\begin{tabular}{ll}
\hline harte Nuss (Ausgangsdomäne) & $\begin{array}{l}\text { eine schwierige, herausfordernde } \\
\text { Aufgabe (Zieldomäne) }\end{array}$ \\
\hline Eine harte Schale. & $\begin{array}{l}\text { Eine schwierige Aufgabe, die mit } \\
\text { konventionellen Mitteln nicht zu knacken ist. }\end{array}$ \\
\hline Der Kern ist nahrhaft, fett. & $\begin{array}{l}\text { Das Ziel ist der Mühe wert, das Erreichen des } \\
\text { Ziels bringt Befriedigung, soziales Ansehen, } \\
\text { Ruhm, Durchbruch in der Forschung, } \\
\text { materiellen Wohlstand u.ä. mit sich. }\end{array}$
\end{tabular}

Wenn man die Schale knackt, gibt sie den Wenn man die Schwierigkeiten überwindet, Kern frei. erreicht man das Ziel.

Die harte Schale knackt man leichter, indem man die Nuss an bestimmten Stellen zusammenpresst.

Eine schwierige, herausfordernde Aufgabe löst man oft durch die Trial-and-ErrorMethode.

Das Knacken/ Zusammenpressen kann viel Viel Anstrengung/Zeit ist notwendig. Zeit kosten, spezielles Werkzeug ist nötig. 
Verwendungsprofil 2: jd. ist eine harte Nuss, jd. ist unnachgiebig, ausdauernd, zielstrebig, schwer von eigenen Zielen abzubringen' (12 Belege)

Das zweite Verwendungsprofil weist zwei Verwendungsmuster auf, die in den Bedeutungskonstituierungs- und Motiviertheitsmechanismen leicht divergieren.

Verwendungsmuster 2.1: eine Person ist eine harte Nuss, eine Person ist unnachgiebig, robust, schwer von eigenen Zielen abzubringen' (6 Belege)

Bei den einzelnen Personen, die als eine harte Nuss bezeichnet werden, handelt es sich um einflussreiche Menschen in höheren Positionen, die an ihrem Arbeitsplatz ein großes Maß an Macht und Respekt genießen. Ihre Erfolge sind auf einen unnachgiebigen, beharrlich ausdauernden Charakter sowie die Fähigkeit, ihre Weltansichten/Überzeugungen/Ziele unerschütterlich zu verteidigen, zurückzuführen (im Polnischen gibt es ein nominales Idiom twarda sztuka [wörtl. ,ein hartes Stück' $\approx$,ein zäher Typ']). Diese Belege sind überwiegend in den thematischen Bereichen Politik und Wirtschaft angesiedelt, zwei werden im Folgenden zitiert:

(122) Marjorie Scardino dürfte dem zustimmen. Aber sie ist zu klug, um sich zwei Monate vor ihrem Antritt in der Führungsetage in die Karten blicken zu lassen. Sie habe „keine strategischen Vorurteile“, sagt sie und gibt zu erkennen, daß sie willens ist, auch heilige Kühe zu schlachten. Die sie kennen, zweifeln nicht eine Sekunde daran, daß sie sehr genau weiß, wohin die Reise geht. Beim Economist nennt man sie bewundernd a tough cookie, eine harte Nuß. Die Zeit, 28.10.1996

(123) Stiftungsrecht, Erbschaftssteuer, Neubewertung von Grundbesitz - die Formulierungen bleiben allgemein. Für die konkrete Ausformulierung ist das Bundesministerium für Finanzen zuständig. Mit anderen Worten: Hans Eichel. Was für eine harte Nuss ${ }^{197}$ der ist, hat die Debatte über die Reform des Stiftungsrechts gezeigt. Er möchte nicht zu viele Einnahmen verlieren. Gegen seinen Widerstand wurde die Formulierung im Antrag durchgesetzt, dass nicht nur Kultur und Bildung, sondern auch Stiftungen für Kirche und Sport zu den Begünstigten gehören sollen. Aber Eichel gibt nicht auf. Er will nun dafür sorgen, dass die Steuerersparnis für Sport-Stiftungen geringer ausfällt als solche für kulturelle Zwecke. Der Tagesspiegel, 03.12.1999

Die Bedeutungskonstituierungsmechanismen sind in diesem Fall komplexer als in dem ersten Verwendungsprofil und können auf mehreren Ebenen untersucht werden: Semantischer Derivation wird sowohl die ganze Wortverbindung eine harte Nuss in der literalen Lesart, als auch die nominale Konstituente Nuss unterzogen (vgl. Abb. 89):

197 Bemerkenswert ist an dieser Stelle, dass die Zusammenstellung des Namens Eichel mit dem Idiom eine harte Nuss möglicherweise einem vom Sprecher intendierten sprachspielerischen Effekt dient. 


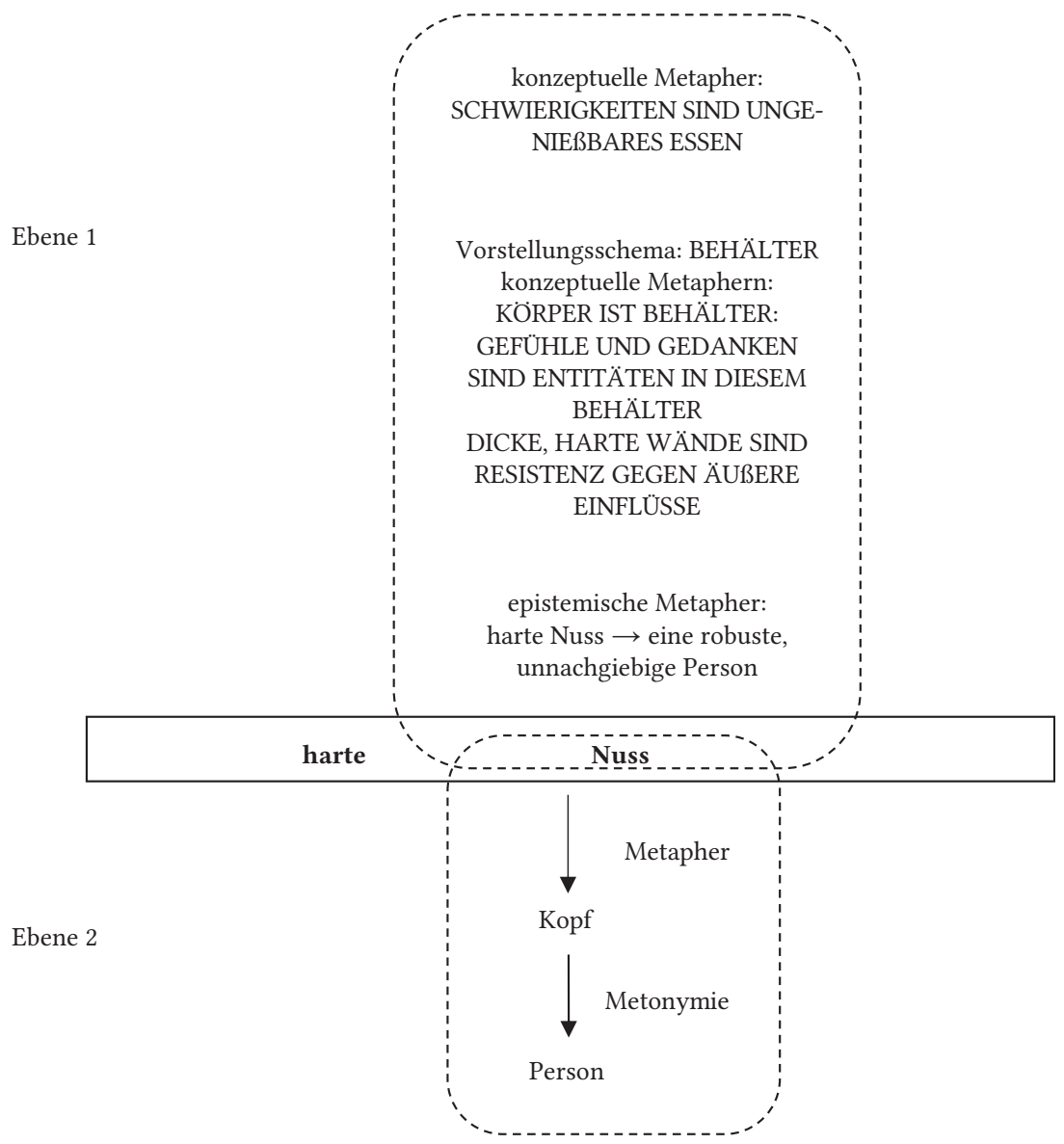

Abb. 89: Bedeutungskonstituierungsmechanismen für das Verwendungsmuster 2.1 , eine Person ist unnachgiebig, robust, schwer von eigenen Zielen abzubringen!

Von größter Relevanz scheint die metaphorische Übertragung der ganzen Wortverbindung zu sein (Ebene 1), die durch mehrere Metaphern von verschiedenem Generalitätsgrad aufgebaut wird. Zum ersten wird die Beziehung zwischen der literalen und der phraseologisierten Bedeutung der ganzen Wortverbindung durch die konzeptuelle Metapher scHWIERIGKEITEN SIND UNGENIESSBARES ESSEN mitgestaltet, die Konzeptualisierungen in eine bestimmte Richtung weist: In allen genannten Belegen handelt es sich um Personen, die aufgrund 
ihrer Persönlichkeits- oder Charakterzüge bestimmten, andere Interessen vertretenden Menschen(-gruppen) Schwierigkeiten bereiten können. Zum zweiten tragen ontologische Metaphern von einem sehr hohen Generalitätsgrad: KÖRPER IST BEHÄLTER, GEFÜHLE UND GEDANKEN SIND ENTITÄTEN IN DIESEM BEHÄLTER sowie die sich aus den genannten Metaphern ergebenden metaphorischen Korrespondenzen: DICKE WÄNDE DES BEHÄLTERS SIND RESISTENZ GEGEN ÄUSSERE EINFLÜSSE, DÜNNE WÄNDE DES BEHÄLTERS SIND EMPFINDLICHKEIT zur Konzeptualisierung der harten Nuss bei. Die genannten ontologischen Metaphern basieren auf elementaren Erfahrungen des Menschen mit physischen Objekten sowie auf der Tatsache, dass die Menschen Wesen mit einer Physis sind, die durch die Hautoberfläche von der Welt getrennt ist. Und diese Hautoberfläche, d.h. die Wände des Behälters, wird in den besprochenen Gebrauchsbelegen profiliert. Die Wände, die - so wie eine Wal-, Hasel-, Nussschale - dick, robust und widerstandsfähig sind, sorgen für die Unabhängigkeit des Inneren von dem Äußeren, seine Widerstandskraft, Unempfindlichkeit und Resistenz, dünne Wände ziehen die (körperliche und psychische) Empfindlichkeit gegen die Umwelteinflüsse mit sich. Diese konzeptuellen Metaphern kommen in mehreren Phraseologismen und Komposita des Deutschen zum Vorschein:

KÖRPER IST BEHÄLTER

DICKE WÄNDE DES BEHÄLTERS SIND RESISTENZ GEGEN ÄUSSERE EINFLÜSSE DÜNNE WÄNDE DES BEHÄLTERS SIND EMPFINDLICHKEIT

jd. hat/bekommt ein dickes Fell/eine dicke Haut , unempfindlich sein, werden' (redensarten-index, Zugriff am 25.10.2017)

jd. ist dickfellig ,gleichgültig, unempfindlich gegenüber Aufforderung, Missbilligung‘ (DUW online, Zugriff am 25.10.2017)

jmdn. wie ein rohes Ei behandeln ,etw./jmdn. sehr behutsam, pfleglich, vorsichtig behandeln' (redensarten-index, Zugriff am 25.10.2017)

Dickkopf/Dickschädel ,jd., der eigensinnig, stur, beharrlich ist ' (redensarten-index, Zugriff am 25.10.2017)

jmdn. in Watte packen, etw./jmdn. sehr behutsam, pfleglich, vorsichtig behandeln“ (redensarten-index, Zugriff am 25.10.2017)

seinen Dickkopf aufsetzen, trotzig sein' (DUW online, Zugriff am 25.10.2017)

einen harten Schädel haben, hartnäckig, willensstark, eigensinnig, unnachgiebig sein (redensarten-index, Zugriff am 25.10.2017)

jd. ist dünnhäutig ,sehr empfindsam, überempfindlich sein' (redensarten-index, Zugriff am 25.10.2017)

jd. ist unerschütterlich, sich durch nichts erschüttern lassend; von großer, gleichbleibender Festigkeit, Beständigkeit' (DUW online, Zugriff am 25.10.2017)

einen weichen Kern in einer harten/rauen Schale haben; harte/raue Schale, weicher Kern ,sich abgebrüht und hart geben, aber im Grunde gutmütig sein' (redensarten-index, Zugriff am 25.10.2017)

ein weiches Herz in einer rauen Schale haben, sich abgebrüht und hart geben, aber im Grunde gutmütig sein' (redensarten-index, Zugriff am 25.10.2017) 
jmdn. mit Samthandschuhen/Glacéhandschuhen/seidenen Handschuhen anfassen,jmdn. rücksichtsvoll, sanft, behutsam, vorsichtig behandeln' (redensarten-index, Zugriff am 25.10.2017)

Außer den aufgelisteten konzeptuellen Metaphern, die für die Bedeutungskonzeptualisierung relevant sind, wird die Bedeutung durch die auf dem mentalen Bild basierenden epistemischen Mappings beeinflusst. Das mentale Bild einer harten Nuss in der literalen Bedeutung aktiviert die Wissensbestände, die dann auf eine Person und ihre Eigenschaften übertragen werden könnten und die erwähnten ontologischen Metaphern präziser beschreiben. Die konzeptuellen Mappings zwischen den beiden Domänen dürften die in der Tab. 38 dargestellte Form annehmen.

Tab. 38: Die epistemischen Mappings für das Verwendungsmuster 2.1 , eine Person ist unnachgiebig, robust, schwer von eigenen Zielen abzubringen'.

harte Nuss (Ausgangsdomäne) ein unnachgiebiger, zielorientierter
Mensch (Zieldomäne)

Eine harte Schale.

Ein robuster, unzugänglicher Mensch.

Der Kern ist nahrhaft, fett.

Der Mensch ist einflussreich, wichtig.

Den Kern kann man essen, erst wenn man die Schale geknackt hat.

Mit dem Menschen kann man verhandeln, erst nachdem man ihn zu sich überzeugt hat, der Mensch lässt sich nicht leicht von seinen Überzeugungen/Zielen abbringen.

Das Zusammenpressen kann viel Zeit und Viel Anstrengung ist notwendig. Mühe in Anspruch nehmen.

Wenn man die Schale knackt, gibt sie den Wenn man jmdn. für eine Sache gewinnt, Kern frei. erreicht man das Ziel.

Einen Einfluss auf die Bedeutungskonstituierung des Idioms übt die auf der zweiten Ebene angesiedelte Beziehung zwischen der Idiomkomponente Nuss in der literalen und in der phraseologisierten Bedeutung aus. Die Bedeutungsverschiebung Nuss $\rightarrow$ Mensch beruht auf einer metaphorisch-metonymischen Kette (Abb. 90):

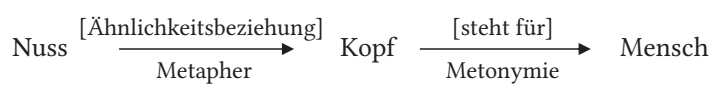

Abb. 90: Bedeutungsverschiebungskette der nominalen Konstituente im Idiom eine harte Nuss. 
Die metaphorische Verbindung baut auf der visuellen Ähnlichkeit beider Entitäten auf: Menschlicher Schädel ist wie Schale einer Walnuss, Gehirn (mit Furchen und Windungen) ist wie ein Nusskern (und genauer Nusskernhälfte). In der Phraseologie existieren wenigstens zwei Idiome, denen diese Metapher zugrunde liegt: eins auf die Nuss kriegen, einen Schlag auf den Kopf bekommen', jmdm./einer Sache eins auf die Nuss geben, jmdm. einen Schlag auf den Kopf verpassen' (redensarten-index, Zugriff am 22.10.2017).

Fest etabliert ist die metonymische Bedeutungsverschiebung KOPF STEHT FÜR EINEN MENSCHEN (TEIL FÜR DAS GANZE):

KOPF STEHT FÜR EINEN MENSCHEN

pro Kopf

sie ist ein kluger Kopf

der Kopf des Unternehmens

Kopf an Kopf stehen

Interessanterweise scheinen die metonymische Bedeutungsverschiebung Kopf $\rightarrow$ Mensch sowie die metaphorisch-metonymische Bedeutungsderivation Nuss $\rightarrow$ Mensch einem Lexikalisierungsprozess zu unterliegen. Die Allgemeinwörterbücher des Deutschen weisen beiden Derivationen den Status einer Teilbedeutung zu, vgl. die Teilbedeutungen 7.1, 7.2 in Wahrig 2007, Lemma Nuss:

1. $\langle$ Bot. $\rangle$

$1.1\langle i . w . S$.$\rangle trockene pflanzl. Schließfrucht, die mithilfe eines Trennungsgewebes als$ Ganzes abfällt (Hasel )

$1.2\langle$ i.e.S.〉 essbarer Kern von Schalenobstarten (Wal , Kokos $\sim)$

2. nussförmiges Stück (z.B. Kohle)

3. $\langle$ Kochk. $\rangle=$ Kugel (4)

4. 〈Jägerspr.〉äußeres Geschlechtsteil (von Wölfin, Füchsin, Hündin)

5. 〈Tech.〉 auswechselbarer Kopf eines Steckschlüssels

6. 〈Waffenk.〉 Teil des Schlosses am Gewehr

7. 〈umg. $\rangle$

$7.1 \mathrm{Kopf}$

7.2Person

8. 〈meist Pl.; derb〉 Hoden

sowie die Teilbedeutung 2 im DUW online (Zugriff am 22.10.2017):

1. a. (Botanik) rundliche Frucht mit harter, holziger Schale, die einen ölhaltigen, meist essbaren Kern umschließt

b. Kurzform für: Walnuss

c. essbarer Kern einer Nuss

2. (Schimpfwort) Mensch

3. (landschaftlich) Kopfnuss

4. (Kochkunst) rundes Fleischstück aus der Keule von bestimmten Schlachttieren

5. (Jägersprache) (vom Hund, Fuchs, Wolf o.Ä.) weibliches Geschlechtsteil 
6. (Technik) auswechselbarer Kopf eines Steckschlüssels

7. in »jemandem eins auf die Nuss geben«

In der Umgangssprache liegen drei Wortverbindungen mit einer lexikalisierten Verschiebung Nuss $\rightarrow$ Mensch vor: eine feige Nuss, ein feiger Mensch', eine taube Nuss, ein Versager, ein Nichtskönner" und eine dumme Nuss, ein dummer Mensch (redensarten-index, Zugriff am 22.10.2017).

Dem Verwendungsmuster ,eine unnachgiebige, robuste Person, die sich schwer von ihren Zielen abbringen lässt ' wird ebenfalls der folgende Beleg zugeordnet, der aus der kognitiven Perspektive allerdings besonderer Aufmerksamkeit wert ist:

(124) Der 59-Jährige ist alles andere als ein deutscher 007, er ist kein Draufgänger, keiner, der bewusst das Risiko und den Nervenkitzel sucht. Uhrlau ist eher ein vorsichtiger Typ, immer abwägend und von bedächtiger Natur. Wahrscheinlich aber macht ihn gerade das besonders geeignet, eine Behörde mit Tausenden von Geheimdienstlern zu leiten, von denen mancher im Schatten der großen Weltpolitik bisweilen ein gefährliches Eigenleben führt. Ernst Uhrlau fällt mitten im Gespräch bisweilen in minutenlanges Schweigen, was entweder seiner vorherigen Aussage Nachdruck verleihen soll oder dem Gesprächspartner demonstriert, dass er auf die Frage einfach nicht antworten will. Geheimnisse sind bei ihm gut aufgehoben, für neugierige Journalisten ist er eine harte Nuss. Die Zeit, 01.12.2005

In diesem Gebrauchsbeleg scheint die Auslegung der aktuellen Bedeutung des Idioms zwischen mehreren Auslegungsmöglichkeiten zu schwanken.

Das idiomatische Prädikativ eine harte Nuss kann zum ersten auf eine vorsichtige, beherrschte und dadurch als unzugänglich, Abstand haltend empfundene Verhaltensweise eines hochgestellten Beamten verweisen. Zur Bedeutungskonstituierung tragen also die metaphorischen Mappings des Verwendungsmusters 2.1 bei, die die harte Nussschale mit der Unnachgiebigkeit und Willensstärke von Uhrlau verbinden und diese Beziehung im Rahmen der konzeptuellen Metaphern: KÖRPER IST BEHÄLTER, DICKE WÄNDE DES BEHÄLTERS SIND RESISTENZ GEGEN ÄUSSERE EINFLÜSSE profilieren.

Von Relevanz für die Konzeptualisierung des Idioms ist ebenfalls das Wissen, dass Uhrlau in zahlreiche, für Journalisten äußerst interessante Staatsangelegenheiten eingeweiht ist, über die er ein absolutes Stillschweigen gegenüber Dritten bewahrt. In den Fokus der Aufmerksamkeit wird demnach nicht nur die Beschaffenheit, sondern auch der Inhalt des Behälters gerückt. Die konzeptuelle Metapher KÖRPER IST BEHÄLTER scheint in diesem Kontext die Gedanken, Informationen, darunter Geheimnisse hervorzuheben. Die konzeptuelle Metapher GEDANkEN/ INFORMATIONEN/GEHEIMNISSE SIND ENTITÄTEN IN EINEM BEHÄLTER manifestiert sich sprachlich in den üblichen Ausdrücken des Wissenserwerbs, der Informationsaufbewahrung, der Geheimnishütung, vgl. u.a. 
GEDANKEN/INFORMATIONEN/GEHEIMNISSE SIND ENTITÄTEN IN EINEM BEHÄLTER Flausen/Flusen im Kopf haben, unrealistische Pläne schmieden; verrückte, sinnlose Ideen haben; Unsinn machen' (redensarten-index, Zugriff am 22.10.2017)

Motten im Kopf haben ,merkwürdige, sonderbare Gedanken haben' (redensarten-index, Zugriff am 22.10.2017)

sich etw. aneignen, sich etw. zu eigen machen, etw. lernen' (DUW online, Zugriff am 22.10.2017)

etw. wie mit dem Nürnberger Trichter eingeben/eingießen, etw. mühelos lernen ' (redensarten-index, Zugriff am 22.10.2017)

jmdm. nicht aus dem Kopf gehen/wollen ,jmdn. ständig beschäftigen“ (DUW online, Zugriff am 22.10.2017)

jmdm. die Würmer aus der Nase ziehen, jmdn. mühsam zum Reden bringen, jmdm. (z.B. ein Geheimnis oder Geständnis) entlocken; jmdn. aushorchen, ausfragen ‘ (redensarten-index, Zugriff am 22.10.2017)

jmdm. alles/jedes Wort einzeln aus der Nase ziehen (müssen), jmdn. mühsam zum sprechen bringen (müssen), jmdn. durch geschicktes Fragen aushorchen' (redensartenindex, Zugriff am 22.10.2017)

jmdm. die Seele aus dem Leib fragen ,jmdn. penetrant/hartnäckig ausfragen' (redensarten-index, Zugriff am 22.10.2017)

jmdn. ausquetschen ,jmdn. genauestens ausfragen, jmdn. verhören' (redensarten-index, Zugriff am 22.10.2017)

jmdn. Löcher/ein Loch in den Bauch fragen ,jmdn. intensiv ausfragen; jmdn. durch dauernde Fragen belästigen' (redensarten-index, Zugriff am 22.10.2017)

sich etw. aus dem Kopf schlagen, einen Plan o. ̈̈. aufgeben' (DUW online, Zugriff am 22.10.2017)

sich etw. in den Kopf setzen ,fest entschlossen sein, etw. zu tun' (redensarten-index, Zugriff am 20.10.2017)

jmdm. nicht in den Kopf [hinein]gehen/[hinein]wollen ,jmdm. unverständlich, unbegreiflich sein: ihr will nicht in den Kopf, dass er nur so wenig verdient' (DUW online, Zugriff am 22.10.2017)

Rosinen im Kopf haben, optimistische Pläne haben, unrealistische Träume haben“ (redensarten-index, Zugriff am 22.10.2017)

Aus einer anderen Perspektive betrachtet, stellt ein in zahlreiche interessante Staatsangelegenheiten eingeweihter Beamter durch seine Vorsicht, Beherrschtheit, Schweigsamkeit eine Herausforderung, eine schwierige Aufgabe für die neugierigen Journalisten dar. Diese Auslegung aktiviert die kognitiven Mechanismen des ersten Verwendungsprofils. Die Interpretation dürfte vom Sprecher zu Sprecher variieren, wahrscheinlich oszilliert die aktuelle Bedeutung zwischen den beiden Möglichkeiten, ohne sich auf eine festzulegen. Diesen Sachverhalt stellt graphisch Abbildung 91 dar: 


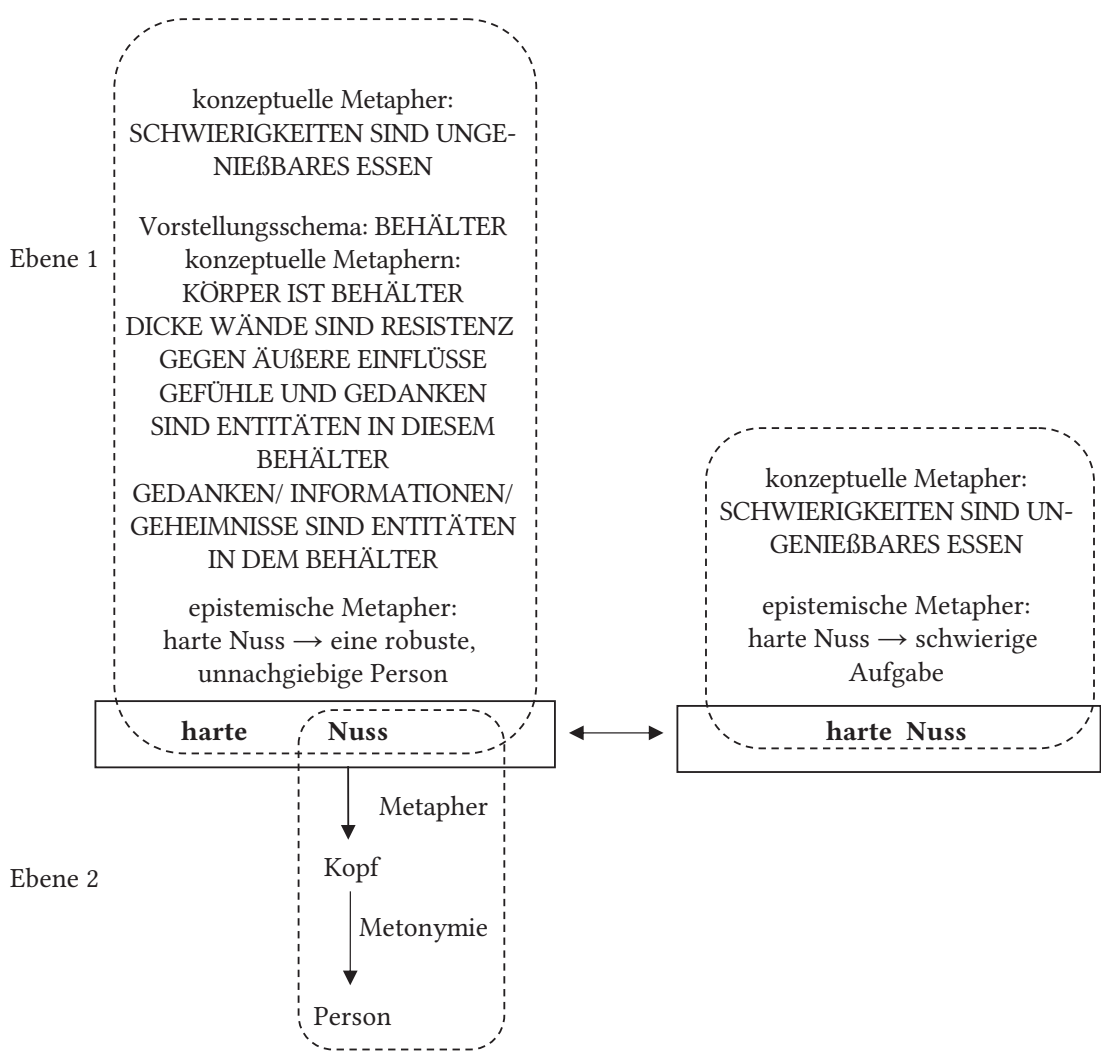

Abb. 91: Konstituierung der aktuellen Bedeutung für den Beleg (124). Der Pfeil stellt symbolisch die Bedeutungsoszillation zwischen dem ersten Verwendungsprofil und dem Verwendungsmuster 2.1 dar.

Auf ähnliche Art und Weise oszilliert die aktuelle Bedeutung in den sechs Belegen, die sich hauptsächlich auf einen starken Gegner beziehen.

Verwendungsmuster 2.2: eine organisierte Gruppe von Menschen ist eine harte Nuss - ,ein starker Gegner, gegen den man sich schwer bewähren kann' (6 Belege)

Die letzten sechs Belege (fünf aus dem Themenbereich Sport, ein Beleg bezieht sich auf eine islamische Terroristengruppe) referieren auf eine Mannschaft, die für den Sprecher einen herausfordernden Gegner darstellt:

(125) Aus München wurde zumindest rhetorisch Respekt bekundet. „Das ist sicherlich eine ganz harte Nuss“, sagte Bayerns Kotrainer Michael Henke, „Aachen spielt 
sehr stark. Gegen eine Spitzenmannschaft der Zweiten Liga, die Heimvorteil hat, verschwimmt der Klassenunterschied". Der Tagesspiegel, 08.12.2003

(126) Die neuen Entführungen seien eine willkommene Gelegenheit für die philippinische Armee, die Zusammenarbeit mit dem US-Militär zu rechtfertigen, sagt PolitikProfessor Renato Cruz de Castro von der De-La-Salle-Universität in Manila. Unter Einheimischen wird die Allianz bislang heftig kritisiert, obwohl Präsidentin Gloria Arroyo nicht müde wird zu betonen, ohne US-Unterstützung werde das Land der islamistischen Extremisten nie Herr. Castro glaubt, dass die nächste Offensive gegen die Rebellen länger dauern wird: „Die Abu-Sayyaf-Gruppe auf Jolo ist eine härtere Nuss als die auf Basilan." Der Tagesspiegel, 23.08.2002

Auch wenn in diesen Belegen als Subjekt Menschen(-gruppen) mit bestimmten, im Sport hochgeschätzten Eigenschaften wie Resistenz, Leistungsfähigkeit, Widerstandsfähigkeit auftreten, scheinen nicht alle konzeptuellen Metaphern aus dem Verwendungsmuster 2.1 von Relevanz zu sein: Die konzeptuellen Mappings, die sich aus der ontologischen Metapher KÖRPER IST BEHÄLTER ergeben (GEFÜHLE UND GEDANKEN SIND ENTITÄTEN IN DIESEM BEHÄLTER, DICKE WÄNDE SIND RESISTENZ GEGEN ÄUSSERE EINFLÜSSE), sind beispielshalber in dem Fall, in dem das nominale Idiom nicht auf einen Menschen, sondern auf eine Gruppe von Menschen/ eine Mannschaft referiert, von eher marginaler Bedeutung. Andere Aspekte des zugänglichen enzyklopädischen Wissens werden teilweise auch durch die epistemischen Mappings profiliert (vgl. Tab. 39):

Tab. 39: Die epistemischen Mappings für das Verwendungsmuster 2.2 ,ein starker Gegner, gegen den man sich schwer bewähren kann:

\begin{tabular}{ll}
\hline harte Nuss (Ausgangsdomäne) & ein starker Gegner (Zieldomäne) \\
\hline Eine harte Schale. & Ein leistungsfähiger, robuster, starker \\
& Gegner. \\
\hline Man will die Schale knacken, damit sie den & Man will den Gegner besiegen, schwache \\
Kern freigibt. & $\begin{array}{l}\text { Punkte des Gegners finden, damit man das } \\
\text { Spiel gewinnt. }\end{array}$ \\
\hline $\begin{array}{ll}\text { Das Zusammenpressen, das Knacken kann } \\
\text { viel Zeit und Mühe in Anspruch nehmen. }\end{array}$ & Viel Anstrengung ist notwendig. \\
\hline
\end{tabular}

Auch in diesen Belegen oszilliert die aktuelle Bedeutung zwischen dem ersten Verwendungsprofil und dem Verwendungsmuster 2.1 und kann sowohl als ,eine schwierige Aufgabe, eine Herausforderung' als auch als eine Gruppe von ,unnachgiebigen, ausdauernden, zielstrebigen Menschen, die schwer von ihrem Ziel 
abzubringen sind' ausgelegt werden. Die Bestimmung, ob sich das Idiom auf das menschliche Subjekt oder auf die herausfordernde Aufgabe bezieht, die die Zusammenarbeit mit diesem Menschen darstellt, hängt von einer subjektiven Auslegung ab und bleibt unentschlossen. Schematisch kann man die Bedeutungskonstituierung folgendermaßen darstellen (Abb. 92):
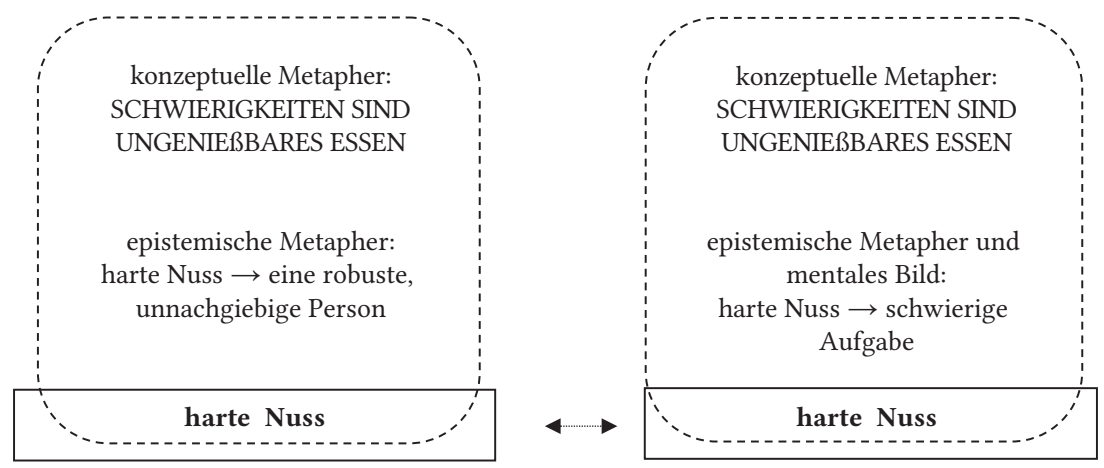

Abb. 92: Bedeutungskonstituierungsmechanismen für das Verwendungsmuster 2.2 ,ein starker Gegner, gegen den man sich schwer bewähren kann:

\subsubsection{3 in den sauren Apfel beißen}

Lexikographisch erfasste Varianten: in den sauren Apfel beißen, in den sauren Apfel beißen (müssen)

Modifikationen: etw. ist ein mächtig saurer Apfel; in den größten sauren Apfel beißen; in den sauren Apfel (+ Gen.) hoher Effektenabschreibungen, der Gegebenheiten beißen; das war der saure Apfel, in den wir beißen mussten; ein Biss in den sauren Apfel 


\section{Darstellung in lexikographischen Nachschlagewerken}

Tab. 40: Das Idiom in den sauren Apfel beißen in allgemeinen und phraseologischen Wörterbüchern des Deutschen.

\begin{tabular}{|c|c|c|}
\hline Wörterbuchtyp & Wörterbuch & Lexikographische Darstellung \\
\hline \multirow[t]{3}{*}{ allgemein } & DUW 2006 & $\begin{array}{l}\text { in den sauren Apfel beißen (ugs.; etwas } \\
\text { Unangenehmes notgedrungen tun) }\end{array}$ \\
\hline & DUW ONLINE & $\begin{array}{l}\text { in den sauren Apfel beißen } \\
\text { (umgangssprachlich: etwas Unangenehmes } \\
\text { notgedrungen tun) (Zugriff: } 25.03 .2017 \text { ) }\end{array}$ \\
\hline & WAHRIG 2007 & $\begin{array}{l}\text { in den sauren Apfel beißen }\langle\text { fig.〉 etwas } \\
\text { Unangenehmes auf sich nehmen, sich ins } \\
\text { Unvermeidliche fügen }\end{array}$ \\
\hline \multirow[t]{4}{*}{ phraseologisch } & DUDEN 11 & $\begin{array}{l}\text { in den sauren Apfel beißen (ugs.): etwas } \\
\text { Unangenehmes notgedrungen tun: Wenn sich } \\
\text { alle drum drücken, muss ich wohl in den } \\
\text { sauren Apfel beißen und den Wochenputz mal } \\
\text { wieder alleine machen. (2011: } 55)\end{array}$ \\
\hline & SCHEMANN 2011 & $\begin{array}{l}\text { (wohl oder übel) in den sauren Apfel } \\
\text { beißen müssen } \\
\text { Wer soll nun diese schwierigen } \\
\text { Verhandlungen führen? - Nun, Herr Kollege, } \\
\text { es ist keiner in die Materie so eingearbeitet } \\
\text { wie Sie. Ich fürchte, Sie werden in den sauern } \\
\text { Apfel beißen müssen. Ich bin überzeugt, } \\
\text { Sie werden sich der Aufgabe mit Anstand } \\
\text { entledigen. (2011:28) }\end{array}$ \\
\hline & $\begin{array}{l}\text { REDENSARTEN- } \\
\text { INDEX }\end{array}$ & $\begin{array}{l}\text { in den sauren Apfel beißen (müssen) } \\
\text {,etwas Unangenehmes, aber oft Notwendiges } \\
\text { tun; sich überwinden (müssen); ein } \\
\text { notwendiges Übel akzeptieren (müssen) }\end{array}$ \\
\hline & MÜLLER 2005 & $\begin{array}{l}\text { in den sauren Apfel beißen (müssen) } \\
\text { (umg.) etwas Unagenehmes tun müssen } \\
\text { [Zwang] } \\
\text { „Wenn die Schmerzen zunehmen, werde ich } \\
\text { wohl in den sauren Apfel beißen müssen und } \\
\text { statt mit dir ins Kino lieber zum Zahnarzt } \\
\text { gehen." } \\
\text { Das Bild von saurem Apfel findet sich erstmals } \\
\text { bei Luther, ist aber sicher älter. (2005: } 28)\end{array}$ \\
\hline
\end{tabular}




\section{Korpusgestützte Analyse anhand der DWDS-Korpora ${ }^{198}$}

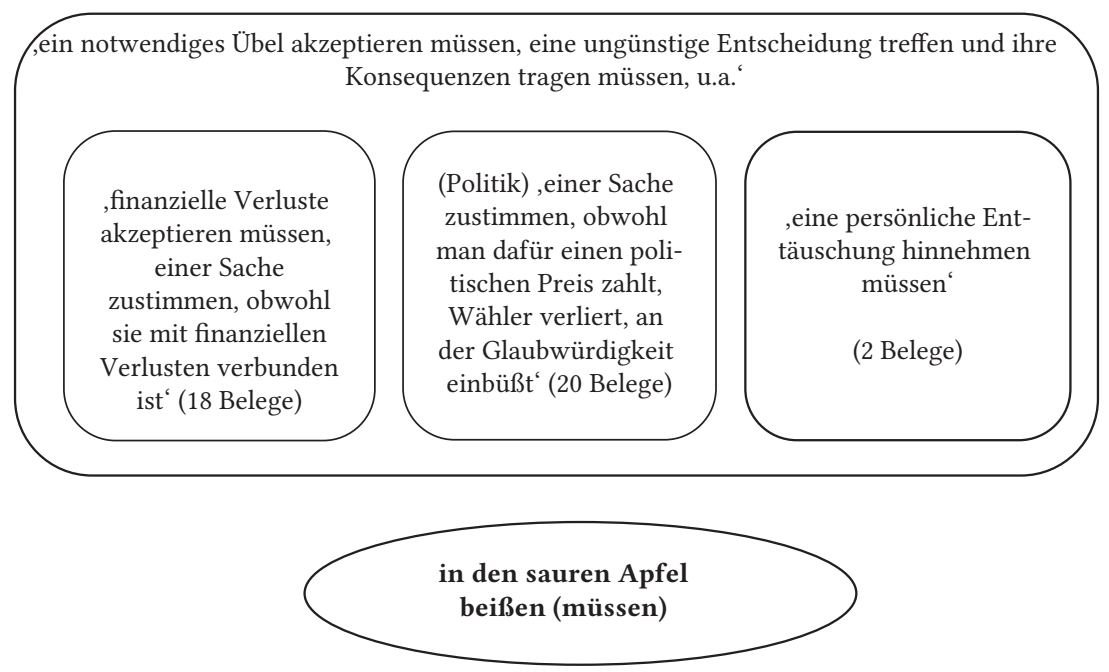

Abb. 93: Das Verwendungsprofil und die Verwendungsmuster des Idioms in den sauren Apfel beißen anhand der Analyse der Gebrauchsbelege im DWDS-Korpus.

Die semantische Struktur des vorliegenden Idioms ist einheitlich und lässt sich mit der Bedeutungsparaphrase: ,(in einer schwierigen Situation) ein notwendiges Übel akzeptieren müssen, eine (für sich) ungünstige Entscheidung treffen und ihre Konsequenzen tragen müssen' beschreiben. Unter dem notwendigen Übel sind in den Belegen beispielshalber die finanziellen Verluste der Anfangsphase verstanden, die man in Kauf nehmen muss, falls man eine innovative Dienstleistung auf den Markt bringt bzw. neue Märkte zu erschließen versucht:

(127) Handel: Online-Supermärkte bauen auf klickfreudige Kunden

„Man muss einfach in den sauren Apfel beißen und den schwierigsten Part übernehmen", sagte der Gründer und Geschäftsführer von food.de, Karsten Schaal, im Juni auf einem EHI-Kongress in Köln. Der Anfang liege vielleicht in einer Lieferung im fünften Stock, irgendwann sei man auch in der ersten Etage, weil Anwohner auf den Lieferservice aufmerksam werden. Die Zeit, 12.07.2013

(128) Um neue Märkte beispielsweise in China zu erschließen, verzichten die Vermarkter aus strategischen Gründen zunächst auf Geld. „Für das langfristige Wachstum des

198 Zugriffsdatum: 18.03.2016, Suchanfrage: sauren\&\&Apfel. Deutsches Textarchiv: 1/147; Kernkorpus 2/29; Die Zeit: 20/150; Berliner Zeitung: 8/56; Der Tagesspiegel: 8/48; Potsdamer Neueste Nachrichten: 1/4. 
Produkts in China werden wir wohl in den sauren Apfel beißen und die Konditionen von China Central Television (CCTV) akzeptieren“, sagte Schmidt: „Eine Zusammenarbeit mit dem Staatssender ist wichtig. Daher sind wir bereit, in diesem Fall auf viel Geld zu verzichten." Die Zeit, 13.05.2015

oder die finanziellen Auflagen, die als kleineres Übel, etwas Unangenehmes aber Unumgängliches empfunden werden:

(129) Für Zuschüsse entschied sich jüngst auch die hannoversche Stadtverwaltung. Im April 1984 war mit sechs kleineren Altpapierhändlern eine Vereinbarung abgeschlossen worden; für die Stadt zunächst kostenfrei. Jede Woche werden seitdem die Zeitungsbündel abgefahren. Abnehmer ist der hannoversche Großhändler Franz Holler, der mit einem Monatsumatz von 25000 Tonnen bundesweit zu den Größten der Branche zählt. Im September muckten die Händler auf: Durch die niedrigen Preise könnten sie noch nicht einmal mehr ihre Benzinkosten bezahlen. „Da haben wir in den sauren Apfel gebissen. Sonst wäre ein verheerender Schaden für das Umweltbewußtsein entstanden“, erklärt Hannovers Stadtdirektor Peter Halm. Die Zeit, 14.11.1986

Im politischen Bereich bezieht sich das Idiom auf Situationen, in denen man schmerzhafte Kompromisse hinnehmen muss:

(130) Nach dem ersten großen Koalitionsstreit seit der Bundestagswahl sehen sich die Grünen als Verlierer, auch wenn dies niemand offen zugeben mag. Man habe „in den sauren Apfel beißen müssen", nur so viel wollte die Arbeitsmarkt-Politikerin Thea Dückert einräumen. Intern hieß es aber in der Grünen-Fraktion am Dienstag, die Entscheidung zur Erhöhung des Rentenbeitrags auf 19,5 Prozent sei eine „politische Katastrophe“. Berliner Zeitung, 06.11.2002

Im Privatleben sind darunter Enttäuschungen, peinliche Situationen, aufgezwungene Aufgaben verstanden:

(131) Povero Silvio! Vier Jahre Kittchen wegen Steuerbetrugs, sieben Jahre für bezahlten Sex mit Ruby, ein Jahr für die Veröffentlichung eines illegal abgehörten Telefonats plus zwei weitere Verfahren wegen Bestechung und Amtsmissbrauch - das macht locker 20 Jährchen. (...) In den größten sauren Apfel freilich hat der Ex-Premier von selber gebissen: Seine Verlobte Francesca P., 28, von der er sich unlängst noch „einen Hauch Jugend“ versprach, soll zu Hause nicht nur ein scharfes Regiment führen, sondern auch noch lesbisch sein. Die Zeit, 31.10.2013

Die Bedeutungskonstituierungsmechanismen lassen sich in einem erheblichen Maß auf die bereits beschriebenen Metonymien und Metaphern zurückführen. Abgesehen von der für das ganze Unterkapitel fundamentalen konzeptuellen Metapher scHWIERIGKEITEN SIND UNGENIESSBARES ESSEN kommt hier - insbesondere in den sich auf Vergangenheit beziehenden Belegen - die konzeptuelle Metonymie TEILHANDLUNG STEHT FÜR HANDLUNG zum Tragen. An diese Metonymie ist die konzeptuelle Metapher ETW. HINNEHMEN IST ETW. SCHLUCKEN, VERDAUEN angekoppelt. Der Biss in den - mangels anderer - sauren Apfel, als unangenehm empfundene Erfahrung wird in abstrakteren Domänen der Wirtschaft und Politik als eine ungünstige, dennoch notwendige Entscheidung ausgelegt. 
Nicht nur das Beißen ist für die Konzeptualisierung von Relevanz (auch wenn sich die Geschmacksrezeptoren auf der Zunge befinden und der Biss besonders unangenehm ist), sondern auch das Hinunterschlucken (in der Zieldomäne: das Hinnehmen) und Verdauen (in der Zieldomäne: das Verarbeiten) von einem unschmackhaften Happen (in der Zieldomäne: einer finanziell abträglichen, schmerzhaften oder politisch ungünstigen Angelegenheit). Die konzeptuelle Metapher ETw. HINNEHMEN IST ETW. SCHLUCKEN/ VERDAUEN ist auf einer abstrakteren Ebene durch das image schema BEHÄLTER und die ontologische (bei Baldauf 1997 bildschematische) Metapher KÖRPER IST BEHÄLTER motiviert, sprachlich manifestiert sie sich in den folgenden Ausdrücken:

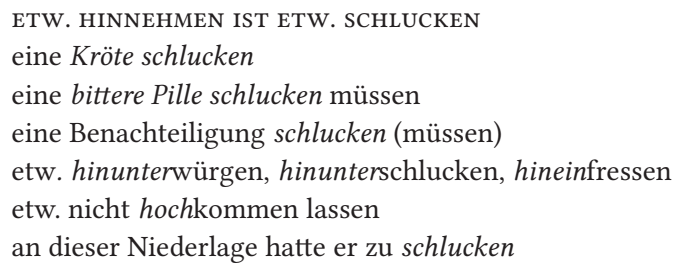

Die Bedeutungskonstituierungsmechanismen für das Idiom in den sauren Apfel beißen stellt Abb. 94 dar:

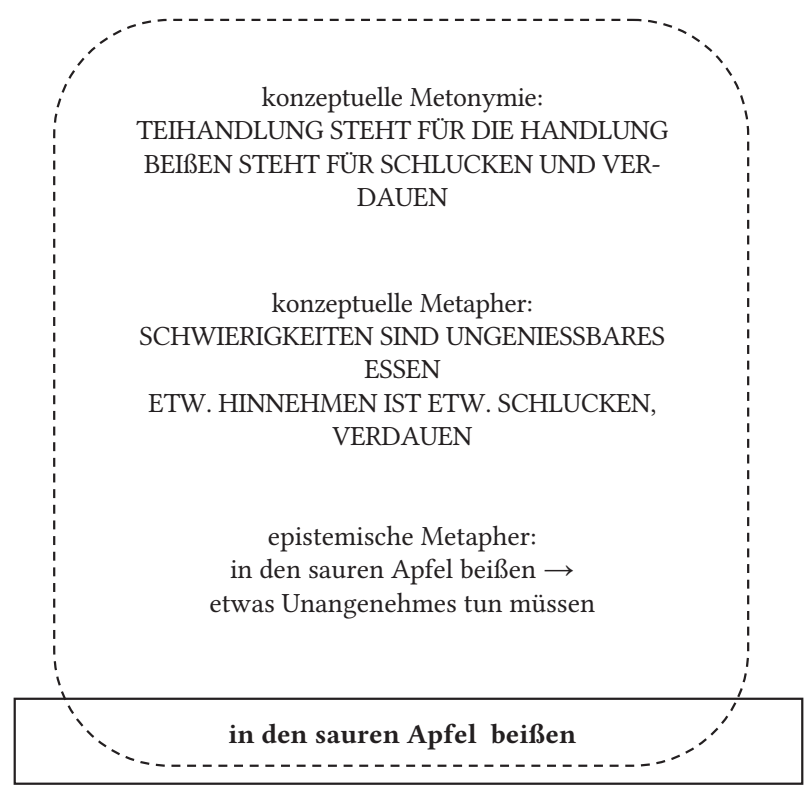

Abb. 94: Bedeutungskonstituierungsmechanismen für das Verwendungsprofil ,ein notwendiges Übel akzeptieren müssen, eine für sich ungünstige Entscheidung treffen und ihre Konsequenzen tragen müssen: 


\subsubsection{4 ein dicker Brocken}

\section{Lexikographisch erfasste Varianten:-}

Modifikationen: dickster Brocken, der dickste Brocken, mit den ganz dicken Brocken, einige dicke Brocken

\section{Darstellung in lexikographischen Nachschlagewerken}

Tab. 41: Das Idiom ein dicker Brocken in allgemeinen und phraseologischen Wörterbüchern des Deutschen.

\begin{tabular}{|c|c|c|}
\hline Wörterbuchtyp & Wörterbuch & Lexikographische Darstellung \\
\hline \multirow[t]{3}{*}{ allgemein } & DUw 2006 & nicht verzeichnet \\
\hline & DUW ONLINE & nicht verzeichnet (letzter Zugriff am 25.10.2017) \\
\hline & WAHRIG 2007 & nicht verzeichnet \\
\hline \multirow[t]{4}{*}{ phraseologisch } & $\begin{array}{l}\text { DUDEN } 11 \\
(2011)\end{array}$ & nicht verzeichnet \\
\hline & $\begin{array}{l}\text { SCHEMANN } \\
2011\end{array}$ & $\begin{array}{l}\text { ein dicker Brocken ugs } \\
\text { 1. Mensch, ist das ein dicker Brocken geworden! - } \\
\text { Wieviel wiegt er denn jetzt? - So um die } 85 \text { Kilo. Und } \\
\text { das bei 1,65. } \\
\text { 2. An sich war das Examen nicht zu schwer. Nur die } \\
\text { Übersetzung, das war ein dicker Brocken (2011: 103) }\end{array}$ \\
\hline & $\begin{array}{l}\text { REDENSARTEN- } \\
\text { INDEX }\end{array}$ & nicht verzeichnet (letzter Zugriff am 25.10.2017) \\
\hline & MÜLLER 2005 & nicht verzeichnet \\
\hline
\end{tabular}




\section{Korpusgestützte Analyse anhand der DWDS-Korpora ${ }^{199}$}
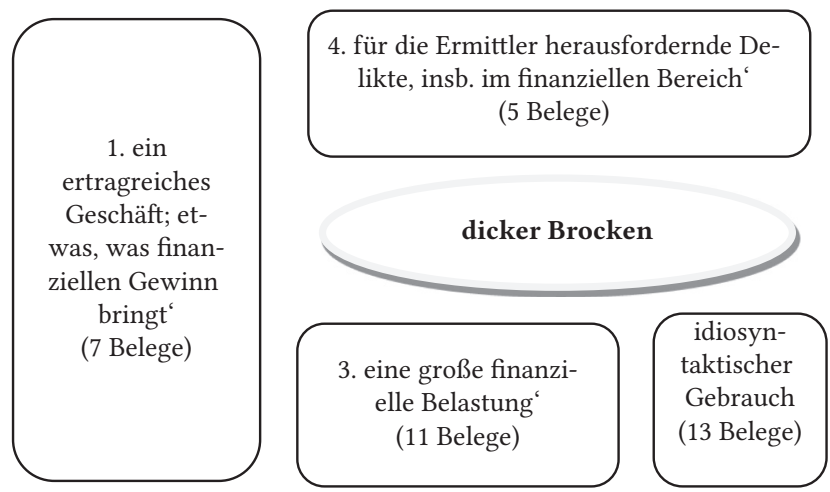

2. ein Hindernis, eine Schwierigkeit, eine HerausForderung ${ }^{6}$ (2 Belege); ,ein herausfordernder Gegner"

(2 Belege)

Abb. 95: Die Verwendungsprofile des Idioms ein dicker Brocken anhand der Analyse der Gebrauchsbelege im DWDS-Korpus.

Dem Idiom ein dicker Brocken kann der Status eines phraseologischen Neologismus zugewiesen werden, da die genannte Wortverbindung eine relativ hohe Frequenz in dem DWDS-Korpus aufweist und gleichzeitig kaum in die allgemeinen und phraseologischen Wörterbücher des Deutschen Eingang gefunden hat ${ }^{200}$.

Die semantische Struktur des Idioms ist komplex, wozu zweifelsohne die Ambiguität der beiden Idiom-Konstituenten in der wörtlichen Lesart beiträgt. Diese Ambiguität, insbesondere im Bezug auf die nominale Konstituente, macht das Idiom auf besondere Art und Weise dafür geeignet, die Rolle des mentalen Bildes zu veranschaulichen. Den Brocken, den DUW online als ,unregelmäßig geformtes, von etwas abgebrochenes Stück' definiert, kann man sich nämlich zweierlei vorstellen: Das Nomen referiert sowohl auf einen ,Happen, Bissen' als auch auf einen ,Block, Klotz, Klumpen'. Beide Vorstellungen sind in Form von materiellen Bildern in Google-Grafik (Zugriff am 25.10.2017) zu finden:

199 Zugriffsdatum: 05.11.2015, Suchanfrage: dicker\&\&Brocken. Deutsches Textarchiv: 0/2; Kernkorpus 3/18 (anzeigbar 13); Die Zeit: 17/317; Berliner Zeitung: 8/91; Der Tagesspiegel: 10/126; Potsdamer Neueste Nachrichten: 2/9.

200 Interessanterweise hat das zu untersuchende Idiom ein dicker Brocken eine höhere Frequenz (in den Zeitungs- und Referenzkorpora aggregiert 559 Verwendungsbelege, Zugriff am 25.10.2017) als beispielshalber der Phraseologismus: ein harter Brocken (in den Zeitungs- und Referenzkorpora aggregiert 349 Belege, Zugriff am 25.10.2017), der in die lexikographischen Werke (DUW 2006, DUW online Zugriff am 25.10.2017, Wahrig 2007, PWN 2010, redensarten-index Zugriff am 25.10.2017) aufgenommen worden ist. 


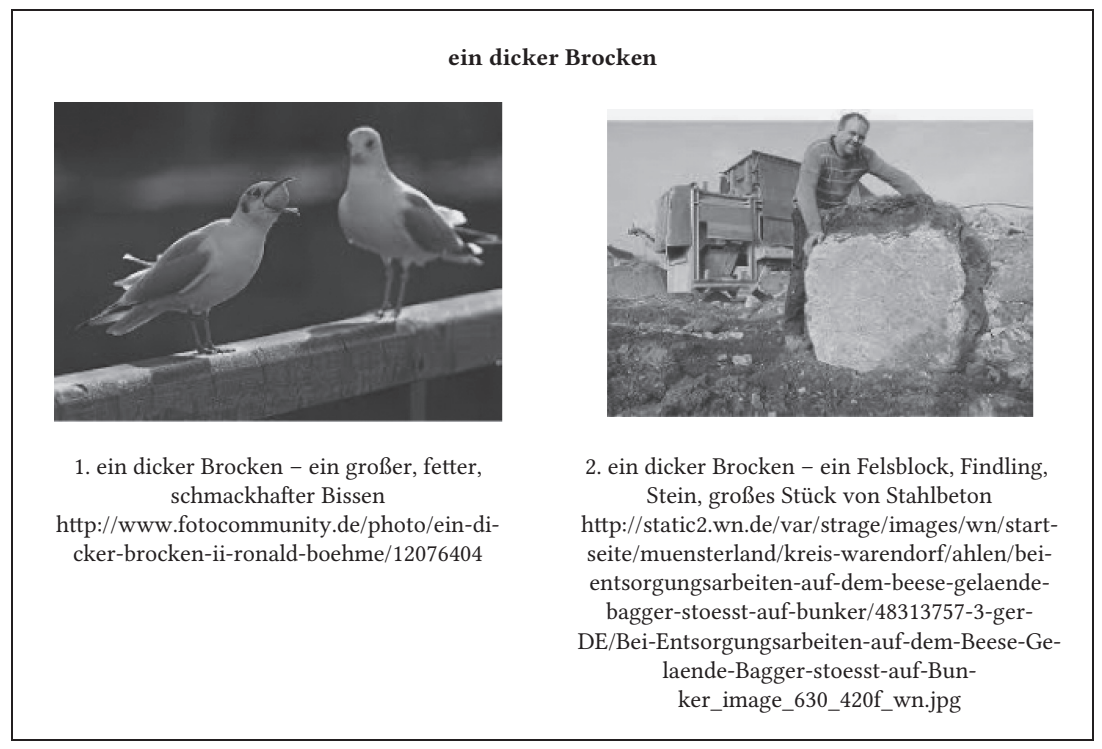

Abb. 96: Die bildhaften Veranschaulichungen der Wortverbindung ein dicker Brocken.

Wie ersichtlich, üben die mentalen Bilder einen entscheidenden Einfluss auf die Konzeptualisierung des dicken Brockens, der entweder positiv, als etwas Ertragreiches, ein hoher Gewinn oder als etwas Störendes, ein Hindernis konzeptualisiert wird. Viele Belege liegen im Zwischenbereich und können auf zwei Weisen ausgelegt werden.

\section{Verwendungsprofil 1: ,ein ertragreiches Geschäft; etwas, was finanziellen Gewinn bringt' (7 Belege)}

Dieses Verwendungsprofil lässt sich exemplarisch mit folgenden Gebrauchsbelegen veranschaulichen:

(132) Untereinander gönnen sich die Anwälte der Insolvenzzunft nichts. Zwar steigt die Zahl der Pleiten im Osten von einem Rekordwert zum nächsten, aber die dicken Brocken, an denen es viel zu verdienen gibt, sind fast alle weg. Sket ist einer der letzten. Berliner Zeitung, 28.10.1996

(133) Zuletzt hatte der Reifenkonzern Continental die Emotionen hochgehen lassen, als er die Produktion des vor zehn Jahren übernommenen Reifenherstellers Semperit halbierte und nach Tschechien auslagerte. Den dicksten Brocken schnappte sich im Sommer der Kölner Rewe-Konzern mit dem Kauf des größten österreichischen Einzelhändlers Billa für angeblich 15 Milliarden Schilling (2,1 Milliarden Mark). Für viele schmerzhaft war auch der Verkauf der Möbelmanufaktur Thonet an den deutschen Geschäftsmann Wolfgang Mellinghoff. Berliner Zeitung, 31.12.1996 
Das vorliegende Verwendungsprofil wird durch die in Abbildung 97 dargestellten Mechanismen der Bedeutungskonstituierung gestaltet:

Ebene 1

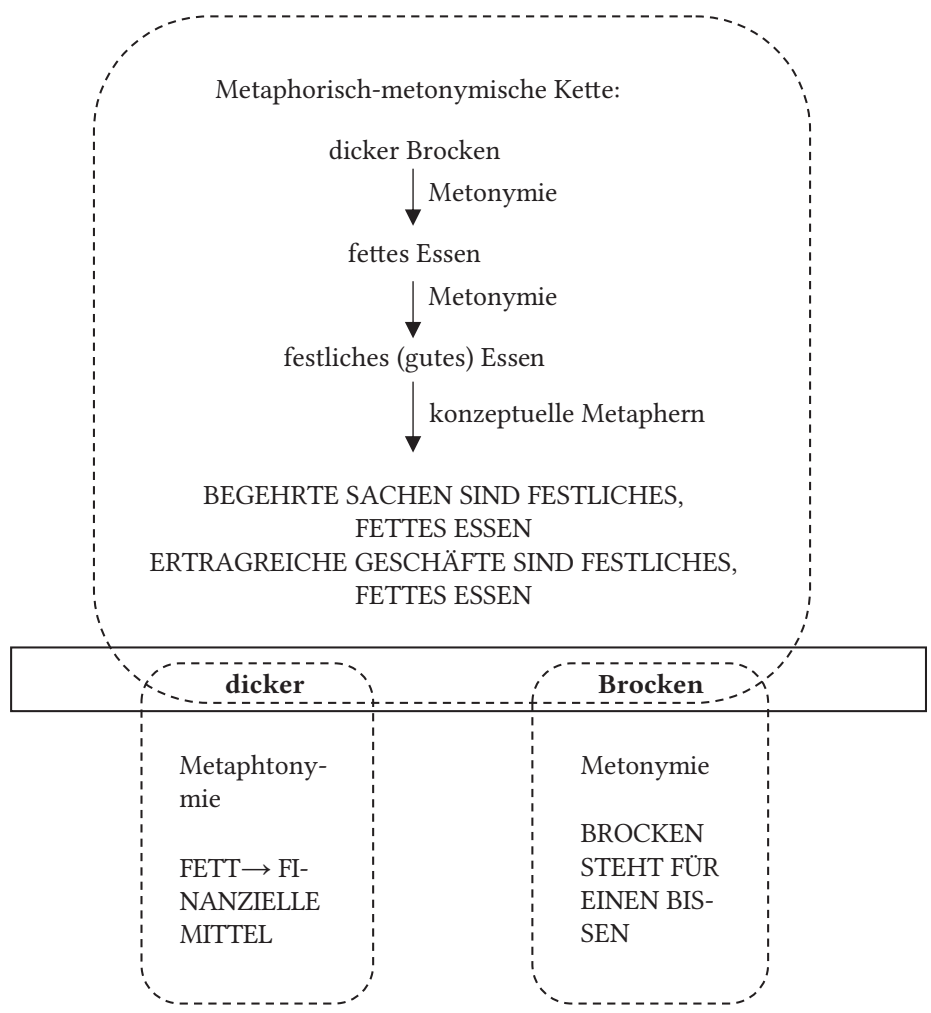

Abb. 97: Die Bedeutungskonstituierungsmechanismen für das Verwendungsprofil 1 , ein ertragreiches Geschäft.

Somit konstituiert sich die aktuelle Bedeutung des Phraseologismus auf zwei Ebenen: Auf der ersten Ebene wird eine metonymisch-metaphorische Bedeutungsverschiebungskette angenommen, die von einem dicken Brocken über fettes, festliches Essen zu den konzeptuellen Metaphern BEGEHRTE SACHEN SIND EIN FESTLICHES, FETTES ESSEN/ERTRAGREICHE GESCHÄFTE SIND FESTLICHES, FETTES ESSEN führt. Diese Metaphern fußen auf dem alltäglichen und dem historischen Wissen. Zum einen sind viele Gaumengenüsse, denen man nur schwer widerstehen kann, fetthaltig, cholesterinreich, weswegen sie nur aus besonderen Anlässen verzehrt werden. Zum anderen mögen für die Konzeptualisierung des dicken Brockens in diesem Verwendungsprofil auch historisch-kulturelle Wissensbestände 
von Relevanz sein: Jahrhundertelang bildeten Getreidegrützen, -breie, Brot sowie einige tierische Erzeugnisse wie Milch oder Eier für die überwiegende Mehrheit der Gesellschaft die wichtigsten Grundnahrungsmittel. Der Verzehr von Fleisch und Fett war aus religiösen (die Anzahl der Fastentage belief sich im Mittelalter bis auf zu 150 Tage $^{201}$ ) und/oder ökonomischen Gründen mit Feiertagen verbunden. In den Zeiten, in denen Missernten, Kriege, Plünderungen oft zu Hungerkatastrophen führten, assoziierte man nahrhaftes Fett, fettes Essen und Fettleibigkeit mit positiven Werten: Üppigkeit, Sättigungsgefühl, Vorräten, Reichtum und hohem Rang, das Magere und Magerheit brachte man dagegen mit einem Mangel an Vitalität, Lebenskraft, Armut in Verbindung. Die aus heutiger Perspektive einer überernährten Gesellschaft nicht immer nachvollziehbare positive Konnotierung fetthaltiger Lebensmittel (Butter, Sahne, Speck) kommt in vielen Phraseologismen und Komposita zum Ausdruck, denen die konzeptuelle Metapher attraktive/BegeHrTe SACHEN SIND FESTLICHES, FETTES ESSEN, sowie ihre Spezialisierung ERTRAGREICHE GESCHÄFTE SIND FESTLICHES, FETTES ESSEN zugrunde liegen:

ATTRAKTIVE/BEGEHRTE SACHEN SIND FESTLICHES, FETTES ESSEN

etw. ist [aller]erste Sahne ,erstklassig, von hervorragender Güte sein' (DUW online, Zugriff am 25.10.2017)

etw. ist ein (sportlicher, technischer, touristischer) Leckerbissen (DUW online, Zugriff am 25.10.2017)

das Konzert war ein köstlicher Leckerbissen ,Genuss' für uns (DWDS-Wörterbuch, Zugriff am 25.10.2017)

die Goldmedaille war das Sahnehäubchen „Krönung“ ihrer Karriere (DUW online, Zugriff am 25.10.2017)

den Rahm abschöpfen ,sich selbst den größten Vorteil, das Beste verschaffen“ (DUW online, Zugriff am 25.10.2017)

mit Speck fängt man Mäuse, mit einem verlockenden Angebot kann man jmdn. dazu bewegen, etw. zu tun, auf etw. einzugehen' (DUW online, Zugriff am 25.10.2017)

fette (große) Beute machen (DUW online, Zugriff am 25.10.2017)

er ließ sich die Butter nicht vom Brot nehmen, sich nichts gefallen lassen, sich nicht benachteiligen lassen' (DUW online, Zugriff am 25.10.2017)

jmdm. nicht die Butter auf dem Brot gönnen, jmdm. gegenüber missgünstig sein ' (DUW online, Zugriff am 25.10.2017)

es ist alles in [bester] Butter, es ist alles in Ordnung' (DUW online, Zugriff am 25.10.2017)

die Butterseite ,die vorteilhafte Seite (DWDS-Wörterbuch, Zugriff am 25.10.2017): Sie wohnen in traumhafter Lage, der Butterseite der Elbchaussee, im Treppenviertel und auf dem Süllberg. (Die Welt 2001, DWDS, Zugriff am 25.10.2017)

das macht den Kohl [auch] nicht fett, das nützt auch nichts, macht etw. nicht besser (DUW online, Zugriff am 25.10.2017)

201 Vgl. https://de.wikipedia.org/wiki/Esskultur_im_Mittelalter (Zugriff am 18.07.2016). 
ERTRAGREICHE GESCHÄFTE SIND FESTLICHES, FETTES ESSEN

das ist ein fetter Happen, ein großer Gewinn, ein einträgliches Geschäft' (DUW online, Zugriff am 25.10.2017)

diesen [fetten] Happen, dieses einträgliche Geschäft ' will er sich nicht entgehen lassen (DUW online, Zugriff am 25.10.2017)

davon wirst du/wird man nicht fett , das bringt nicht viel ein, rentiert sich nicht (DUW online, Zugriff am 25.10.2017)

jmdn. wie eine Weihnachtsgans ausnehmen, sich in schamloser Weise an jmdm. bereichern, jmdn. schamlos ausbeuten, ausnutzen' (DUW online, Zugriff am 25.10.2017)

ein dickes Gehalt/Honorar ,ein hohes Gehalt, Honorar' (DUW online, Zugriff am 25.10.2017)

ein dicker Auftrag ,ein großer Auftrag، (DWDS-Wörterbuch, Zugriff am 25.10.2017)

das ist ein fetter Posten, fettes Amt ,sehr einträglich, gewinnbringend' (DWDS-Wörterbuch, Zugriff am 25.10.2017)

jd. hat eine fette Stelle, Pfründe ,sehr einträglich, gewinnbringend' (DWDS-Wörterbuch, Zugriff am 25.10.2017)

ein fetter Gewinn (DWDS-Wörterbuch, Zugriff am 25.10.2017)

eine fette Erbschaft antreten, machen (DWDS-Wörterbuch, Zugriff am 25.10.2017)

fette Dividenden, Prozente abschöpfen (DWDS-Wörterbuch, Zugriff am 25.10.2017)

ein fettes Stipendium einheimsen (DWDS-Wörterbuch, Zugriff am 25.10.2017)

jmdm. einen fetten ,sehr einträglichen, gewinnbringenden“ Braten, Brocken, Bissen wegschnappen (DWDS-Wörterbuch, Zugriff am 25.10.2017)

das ist eine fette Beute ,sehr einträglich, gewinnbringend' (DWDS-Wörterbuch, Zugriff am 25.10.2017)

ein fetter Braten, ein großer Gewinn, ein guter Fang' (DUW online, Zugriff am 25.10.2017)

Die konzeptuellen Metaphern der ersten Ebene stehen im Zusammenhang mit der konzeptuellen Metaphtonymie FETT STEHT FÜR FINANZIELLE MITTEL/WOHLSTAND, FINANZIELLE MITTEL/WOHLSTAND SIND (WIE) FETT, die auf der zweiten Ebene angesiedelt ist. Beachtenswert ist an dieser Stelle der umstrittene kognitive Status der Bedeutungsverschiebung Fett $\rightarrow$ Wohlstand. Insbesondere aus historischer Perspektive besteht nämlich eine Beziehung zwischen bestimmten, fetthaltigen Nahrungsmitteln (z.B. Butter, Speck, Wurst, Sahne) und dem Reichtum/ Wohlstand. Wohlstand bildet somit einen zwar peripheren, dennoch für manche Produkte zu berücksichtigenden Bestandteil der Domäne EsSEN. In diesem Sinne kann man von einer Kontiguitätsbeziehung sprechen: Bestimmte Aspekte innerhalb einer Domäne werden hervorgehoben. Andererseits macht Wohlstand einen integralen Bestandteil der Wissensdomäne: LEBENSSTANDARD, SOZIALER STATUS aus. Die Korrespondenzen beziehen sich damit auf zwei unterschiedliche Wissens- und Erfahrungsdomänen, weswegen die Annahme einer Metapher ebenfalls begründet ist. Dementsprechend handelt es sich hier um eine Metaphtonymie, die übrigens mehreren Sprachausdrücken zugrunde liegt: 
FETT STEHT FÜR FINANZIELLE MITTEL/WOHLSTAND

FINANZIELLE MITTEL/WOHLSTAND SIND WIE FETT

es nicht so dick haben ,nicht über so viel Geld verfügen' (DUW online, Zugriff am 25.10.2017)

seine Verwandten sind dicke, reiche‘ Bauern (DUW online, Zugriff am 25.10.2017)

wie die Made im Speck leben ,sehr behaglich, gut, in Wohlstand, im Überfluss leben“ (redensarten-index, Zugriff am 25.10.2017)

im Fett sitzen/schwimmen ,im Wohlstand leben“ (DUW online, Zugriff am 25.10.2017) die Fleischtöpfe Ägyptens ,das Leben im Wohlstand, nach Mose 16, 3‘ (DUW online, Zugriff am 25.10.2017)

Fettlebe machen ,gut und üppig essen, leben“ (DUW online, Zugriff am 25.10.2017)

ein dickes Auto ,großes, teures Auto' (DUW online, Zugriff am 25.10.2017)

den Gürtel enger schnallen ,sich einschränken, zurücknehmen, kürzer treten; sparen (redensarten-index, Zugriff am 25.10.2017)

fette Jahre, magere Jahre (DUW online, Zugriff am 25.10.2017)

fett leben (DUW online, Zugriff am 25.10.2017)

mit jmdm. durch dick und dünn gehen ,jmdm. in allen Lebenslagen beistehen' (DUW online, Zugriff am 25.10.2017)

Die Bedeutungsverschiebung der nominalen Komponente scheint dagegen einfacher zu sein: Der Brocken steht hier metonymisch für einen Bissen, einen Happen.

Verwendungsprofil 2: ,ein Hindernis, eine Schwierigkeit, eine Herausforderung, ein schwieriger Gegner' (2 Belege)

Das zweite, eine Tendenz zu Lexikalisierung aufweisende Verwendungsprofil, das sich mit der Bedeutungsparaphrase ,ein Hindernis, eine Schwierigkeit, eine Herausforderung" umschreiben lässt, kommt exemplarisch in folgenden Verwendungsbelegen zum Vorschein:

(134) Pianisten sind sich meist einig in der Beurteilung des zweiten Klavierkonzerts von Johannes Brahms. Ein dicker Brocken ist es, ein konditionsraubendes Ungetüm, das, wenn man nicht aufpaßt, Krämpfe oder steife Finger verursacht. Berliner Zeitung, 08.04.1997

(135) Dieser Ausbau der Wannseebahn ist dringend notwendig, weil die Strecke ab Anfang Januar als Ausweichroute bei der Sanierung der Stadtbahn vorgesehen ist. Denn das ist der nächste dicke Brocken für „Max den Maulwurf“, das S-Bahn-eigene Bau-und-Buddel-Maskottchen zum Trösten der Fahrgäste. Ab dem 6. Januar 2003 rollen auf dem Abschnitt Zoo-Charlottenburg keine S-Bahnen - und zwar ein ganzes Jahr lang. Fahrgäste können auch in die Regionalexpresszüge der Linien RE 1 und 3 umsteigen, der dann zusätzlich in Charlottenburg halten wird. Der Tagesspiegel, 10.10.2002

Aus kognitiver Sicht kann diese Bedeutung auf unterschiedlichen Metaphern und Metonymien beruhen, die wahrscheinlich durch unterschiedliche mentale Bilder evoziert werden: Der Brocken kann hier nämlich sowohl auf einen (a) ,Bissen als auch auf einen (b) ,(Fels-)Block, Klotz, Klumpen' referieren. In beiden Fällen 
evoziert das mentale Bild Entitäten, die bezüglich der Größe, Beschaffenheit, Umfang sowie Funktionen von Grund auf unterschiedlich sind. Ebenfalls in diesem Verwendungsprofil sind die Bedeutungskonstituierungsprozesse auf zwei Ebenen angesiedelt (vgl. Abb. 98):

(a)

Eb.1

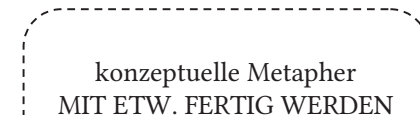

IST ETW. AUFESSEN

Eb. 2 (b)

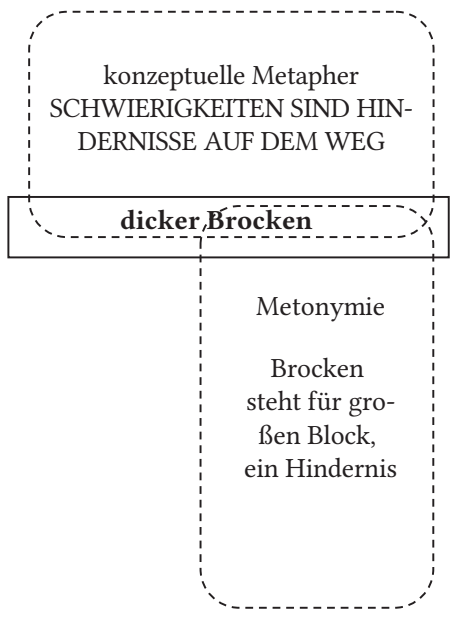

Abb. 98: Die Bedeutungskonstituierungsmechanismen für das Verwendungsprofil 2 ,ein Hindernis, eine Schwierigkeit, eine Herausforderung, ein schwieriger Gegner.

Die erste Interpretation (a) wird auf der Ebene der ganzen Wortverbindung durch konzeptuelle Metapher MIT ETW. FERTIG WERDEN IST ETW. AUFESSEN mitgestaltet. Den konzeptuellen Status dieser Metapher stellen folgende sprachliche Manifestationen unter Beweis:

MIT ETW. FERTIG WERDEN IST ETW. AUFESSEN

an etw. zu knabbern haben ,1. sich mit etw. lange und schwer plagen, sich anstrengen müssen. 2. unter den Folgen von etw. leiden müssen` (DUW online, Zugriff am 26.10.2017)

an den Folgen dieser Maßnahme wird er noch lange zu schlucken haben (DWDS-Wörterbuch, Zugriff am 25.10.2017)

ihr fresst es nie ,begreift es nie‘ (DWDS-Wörterbuch, Zugriff am 25.10.2017)

etw. gefressen haben ,etw. verstanden haben' (DUW online, Zugriff am 26.10.2017) wie es kommt, so wird es gefressen, was einem auch immer bevorsteht, man muß damit fertig werden' (DWDS-Wörterbuch, Zugriff am 25.10.2017)

Eindrücke, Erlebnisse, einen Schicksalsschlag, Schock verdauen ,geistig, psychisch verarbeiten, bewältigen` (DWDS-Wörterbuch, Zugriff am 25.10.2017) 
etw. in den falschen Hals bekommen ,etw. missverstehen und ärgerlich werden, sich angegriffen fühlen' (DWDS-Wörterbuch, Zugriff am 25.10.2017)

sich neue Wissensschätze, Erkenntnisse einverleiben ,erwerben' (DWDS-Wörterbuch, Zugriff am 25.10.2017)

Da der Brocken hier metonymisch für einen großen Bissen steht, liegt nahe, dass ein vom Umfang her großer Happen nicht leicht zu schlucken und folglich zu verdauen ist. Daraus ergeben sich auch die epistemischen Korrespondenzen (vgl. Tab. 42), die die konzeptuelle Metapher präzisieren und ergänzen.

Tab. 42: Die epistemischen Mappings für das Verwendungsprofil ,ein Hindernis, eine Schwierigkeit, eine Herausforderung:

\begin{tabular}{ll}
\hline ein dicker Brocken (Ausgangsdomäne) & $\begin{array}{l}\text { ein Hindernis, eine Schwierigkeit, eine } \\
\text { Herausforderung (Zieldomäne) }\end{array}$ \\
\hline Schwer zu knabbern. & $\begin{array}{l}\text { Eine Aufgabe, die in kleinen Schritten } \\
\text { ausgeführt wird, die Mühe, Zeit und } \\
\text { Geduld in Anspruch nimmt. }\end{array}$ \\
\hline Langes Kauen. & Viel Anstrengung notwendig, mühselig. \\
\hline
\end{tabular}

Falls nicht genügend zerkleinert, kann im Riskant, Misserfolg möglich.

Hals stecken bleiben.

Für die zweite mögliche Auslegung (b) scheint außer der metonymischen Bedeutungsverschiebung ,Brocken steht für einen großen Block' die weitverbreitete und zahlreichen Phraseologismen zugrunde liegende konzeptuelle Metapher schwIERIGKEITEN SIND HINDERNISSE AUF DEM WEG richtungsweisend zu sein.

Dieselbe Metapher liegt auch den zwei markiert gebrauchten Belegen zugrunde, in denen sich der dicke Brocken auf einen starken Gegner bezieht:

(136) „Für uns zählt seit Beginn der Qualifikation nur der Gruppensieg, alles andere kann für uns nicht der Anspruch sein. Platz eins ist auch im Hinblick auf die Auslosung der Vorrundengruppen für die EM im kommenden Jahr wichtig, weil man damit einigen dicken Brocken schon einmal aus dem Weg gehen kann", sagte er. Die Zeit, 19.08.2014 (137) Deutschland war bei der Auslosung, die weltweit 500 Millionen Menschen verfolgten, aufgrund seiner Platzierung in der Weltrangliste (3) in Lostopf 1 gesetzt. Dadurch war ein Kräftemessen mit den ganz dicken Brocken wie Welt- und Europameister Spanien (Weltranglistenplatz 1) oder Vize-Weltmeister Niederlande (Platz 2) von vornherein ausgeschlossen. Die Zeit, 30.07.2011

In allen beiden Belegen wird der Brocken als ein Fels, ein Hindernis, das man auf dem Weg zum Ziel wegschaffen/umgehen muss, konzeptualisiert, worauf kontextuelle Verweise: dicken Brocken aus dem Weg gehen, Kräftemessen mit dicken Brocken, schlussfolgern lassen. 


\section{Verwendungsprofil 3: ,große finanzielle Belastung innerhalb eines Systems' (11 Belege)}

Für die mit meisten Belegen vertretene Bedeutung ist die metonymische Bedeutungsverschiebung ,Brocken steht für ein großes Stück von etw.' richtungsweisend. In der Konzeptualisierung schwingen die finanziellen Aspekte, die das erste Verwendungsprofil hervorhebt, sowie die für das zweite Verwendungsprofil konstitutiven Aspekte der Herausforderung, Schwierigkeit. In den meisten im Superlativ formulierten Gebrauchsbelegen wird als der dickste Brocken nämlich die größte, $\mathrm{zu}$ reduzierende finanzielle Belastung innerhalb eines Systems bezeichnet, eine Belastung, die ein Problem darstellt und als ein Problem empfunden wird:

(138) Bei einer Abschaffung der EU-Regionalförderung betrage das Einsparvolumen sogar 51 Milliarden Euro im Jahr. Der Personalbestand im öffentlichen Dienst müsse als „dickster Brocken“ auf der Ausgabenseite „auf allen Ebenen über die bisherigen Planungen hinaus zusätzlich um ein Prozent verringert werden“, verlangte Däke. Allein hier könnten jährlich 19 Milliarden Euro gespart werden. Der Tagesspiegel, 27.02.2003

(139) Würden aber alle nach Leitlinien therapiert, ergebe sich allein bei sieben ausgewählten Krankheiten und „bei vorsichtigster Berechnungsweise“ ein Mehrbedarf von 2,24 Milliarden Euro. Der dickste Brocken sind koronare Herzkrankheiten, laut Hansen der häufigste Grund für Frühverrentung: Für die derzeit 3,3 Millionen Patienten fehlten 864 Millionen Euro. Der Tagesspiegel, 11.08.2004

(a)

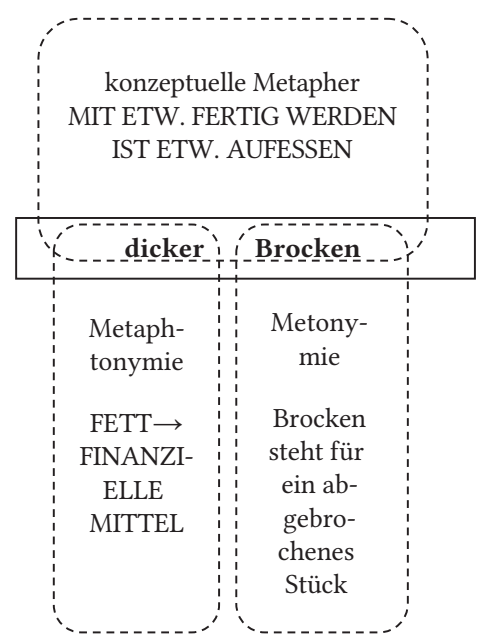

(b)

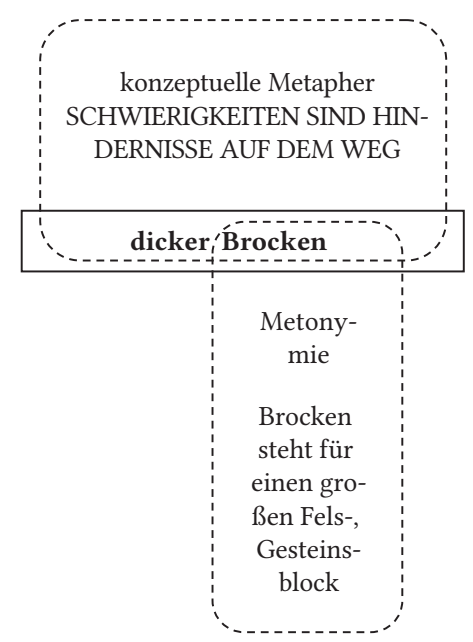

Abb. 99: Die Bedeutungskonstituierungsmechanismen für das Verwendungsprofil 3 ,große finanzielle Belastung innerhalb eines Systems. 
Ebenfalls hier dürften die Konzeptualisierungen zwischen zwei unterschiedlichen mentalen Bildern und den dahinter stehenden epistemischen Mappings schwanken (vgl. Abb. 99): Wegen einer Assoziation mit einem Torten- oder Kuchendiagramm, weil die Metaphtomymie ,Fett $\rightarrow$ finanzielle Mittel' in allen elf Belegen zur Geltung kommt und eher mit einem Brocken als einem ,Happen, Bissen' kompatibel ist, scheint die Interpretation (a) plausibler zu sein.

\section{Verwendungsprofil 4: Juristisches Deutsch: ,die für Ermittler herausfor- dernden Delikte, insbesondere im finanziellen Bereich (Betrug, Korruption, Wettbewerbsdelikte, Monopole)' (5 Belege)}

Ein interessantes Zusammenspiel mehrerer besprochener Bedeutungsaspekte kommt ebenfalls in fünf, auf juristische Angelegenheiten Bezug nehmenden Belegen zum Vorschein. Hier handelt es sich um schwerwiegende Delikte, Rechtsverstöße von einem großen finanziellen Wert, die als große Herausforderungen für Ermittler, Staatsanwälte, Rechtsanwälte angesehen werden. Besonders gut sichtbar sind diese Aspekte im Gebrauchsbeleg (140), in dem ein Staatsanwalt der versuchten und vollendeten Strafvereitelung angeklagt wurde, weil er sich nur spektakulärer, schwieriger Fälle angenommen hatte und die leichteren, langweiligen Delikte unerledigt ließ, so dass sie endlich verjährt waren. Im Beleg (141) werden dagegen die finanziellen Aspekte mitprofiliert:

(140) Doch das, was schon die Fernsehkrimis nur am Rande zeigen, weil's langweilig ist, nahm auch Godow als bald weniger wichtig: die Schreibtischroutine, die Erledigung von "Vorgängen“ - das eigentliche, harte Brot der Justizbeamten. Als er seinen Chef vorsichtig darauf ansprach, daß er den Aktenberg nicht mehr bewältigen könne, stieß er auf wenig Verständnis. Nun war auch Godow nicht mehr pingelig, er nahm sich nur noch die „ganz dicken Brocken“ vor. Die Zeit, 28.05.1976

(141) Zunächst sollen die „leichteren“ Fälle geprüft werden, so die Zündholzmonopole in Frankreich, Italien und Deutschland, und die Monopole für Kali in Frankreich und für Salz in Italien. Dann will man sich die dickeren Brocken vornehmen - die Tabakmonopole in Italien und Frankreich und das französische Erdölmonopol. Die Zeit, 29.04.1966

Die Bedeutungskonstituierungsprozesse vollziehen sich sowohl auf der Ebene der ganzen Wortverbindung als auch auf der Ebene der einzelnen Konstituenten der Wortverbindung (vgl. Abb. 100). Interessanterweise hängt auch hier die Auslegung weitgehend von dem mentalen Bild ab, das durch die Wortverbindung in der literalen Lesart evoziert wird. Der ersten Interpretation liegt das Bild eines schmackhaften, großen Happens zugrunde. Der dicke Brocken wird als eine spektakuläre, karrierefördernde, über den alltäglichen Kleinkram hinausgehende Aufgabe für die Ermittler ausgelegt. Eine wichtige Rolle bei der Bedeutungskonstituierung spielt hier die metonymisch-metaphorische Kette, die zu der konzeptuellen Metapher BEGEHRTE SACHEN SIND FETTES, FESTLICHES ESSEN führt. Gleichzeitig kommt aber auch die Komplexität der Aufgabe, ihre überdurchschnittliche Relevanz, die Herausforderung, die diese Aufgabe darstellt, zum Ausdruck. Dieser Interpretation 
liegt die Metonymie: Brocken steht hier für ein großes Stück sowie eine metonymisch-metaphorische Kette zugrunde, an deren Ende sich die konzeptuelle Metapher MIT ETW. FERTIG WERDEN IST ETW. SCHLUCKEN/verdAUEN befindet. Profiliert wird dabei die Korrespondenz großer Happen - Verschluckungsgefahr. Da der finanzielle Aspekt in den Belegen eine Rolle spielt (auch im Beleg 140 handelt es sich hauptsächlich um Raub- sowie Bankkriminalität), trägt wahrscheinlich ebenfalls die Metaphtonymie: Fett $\rightarrow$ finanzielle Mittel zur Bedeutungskonstituierung des dicken Brockens bei.

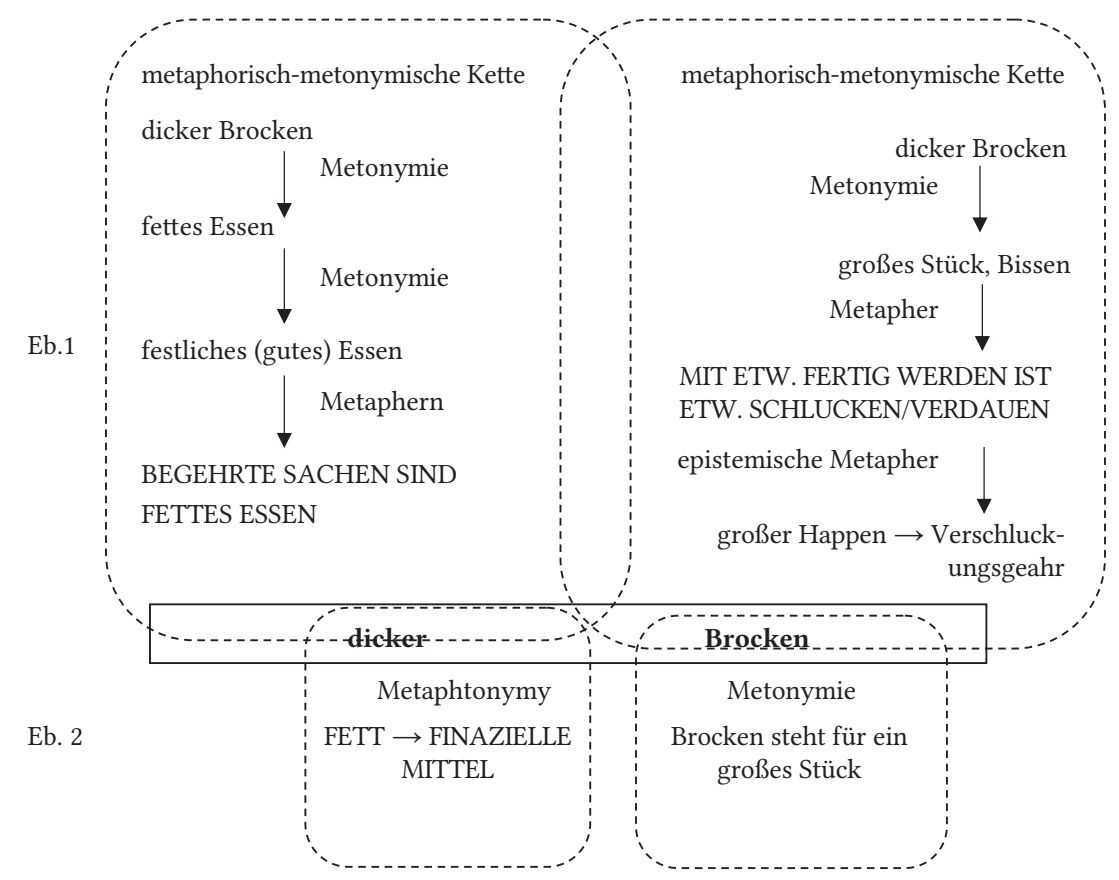

Abb. 100: Die Bedeutungskonstituierungsmechanismen für das Verwendungsprofil 4 , die für Ermittler herausfordernden Delikte, insbesondere im finanziellen Bereich.

Nicht auszuschließen ist dennoch, dass man bei der Interpretation des Idioms auf ein anderes mentales Bild zurückgreift: auf das Bild eines Felsbrockens von einem beträchtlichen Umfang, der einem den Weg versperrt oder Erdarbeiten verhindert. In diesem Fall wird der große Schwierigkeitsgrad der vorliegenden bzw. bevorstehenden Aufgaben profiliert. Die Bedeutungskonstituierungsprozesse würden dann wie in Abbildung 98b verlaufen. 


\subsection{Resümee mit Schwerpunkt: Mentales Bild und die Konstituierung der phraseologisierten Bedeutung}

An zahlreichen Stellen der bisherigen Idiom-Analysen wurde der Einfluss der epistemischen Mappings und des mentalen Bildes auf Konzeptualisierungen ersichtlich. Beide Strukturen - auch wenn sie unterschiedliche Modalitäten aufweisen - sind nach den neueren holistischen Ansätzen der Kognitiven Linguistik und der Grounded Cognition in dem konzeptuellen System angesiedelt, aus dem der semantische Pol einer sprachlichen Einheit Inhalte für die Konzeptualisierungen bezieht. Sowohl mentale Bilder als auch epistemische Metaphern sind dabei eng an die literale Lesart des Idioms gebunden: Die mentalen Bilder werden durch die literale Lesart evoziert, die zugleich auch den Quellenbereich (source) darstellt, aus dem die epistemischen Projektionen in andere, öfters abstraktere Bereiche ausgeführt werden. Auf die Rolle der epistemischen Mappings wurde explizit im Unterkap. 4.2.2.1.1.1.4 eingegangen, im Folgenden wird das umstrittene Konstrukt des mentalen Bildes in den Fokus der Aufmerksamkeit gerückt.

Die Rolle, die die mentalen Bilder bei der Konstituierung der Bedeutungen spielen, ist umstritten, was zweifelsohne mit den individuellen Differenzen in der Anschaulichkeit, Kohärenz, Einprägsamkeit der mentalen Bilder bei unterschiedlichen Sprachteilhabern, ihrem flüchtigen Charakter und methodologischen Schwierigkeiten bei ihrer Erforschung zusammenhängt. Möglicherweise denken manche Menschen bildhafter als andere, Meinungsunterscheide zur Rolle dieses Phänomens sind deswegen unvermeidlich. Nichtsdestotrotz sind die mentalen Bilder psychologisch real und spielen bei der Konstituierung und Etablierung der Idiom-Bedeutung eine nicht zu unterschätzende Rolle, in vereinzelten Fällen - so wie es bei dem Idiom ein dicker Brocken veranschaulicht wird - ist ihr Einfluss auf die Konzeptualisierungen beinahe konstitutiv.

Das mentale Bild stellt nämlich in diesem Idiom einen Ausgangspunkt für weitere kognitive Prozesse der Bedeutungskonstituierung eines sich etablierenden phraseologischen Neologismus dar. Aufgrund der Ambiguität des Brockens in der literalen Lesart ist dies bei Idiom ein dicker Brocken besonders gut ersichtlich. Je nachdem, was man sich unter einem Brocken vorstellt, ob er sich auf einen Bissen oder ein Bruchstück bezieht, sind die weiteren metonymischen und metaphorischen Derivationen anders und profilieren andere Bedeutungsaspekte ${ }^{202}$.

202 In der per Zufallsgenerator zusammengestellten Belegsammlung findet man - möglicherweise aufgrund einer relativ kleinen, 40 Verwendungsbelege enthaltenden Stichprobeentnahme - nur vereinzelte Belege, die den richtungsweisenden Einfluss des mentalen Bildes mittels eines ausgebauten Szenarios explizit vor Augen führen (vgl. Belege 136, 137), unter den über 500 Belegen der DWDS-Korpora sind solche Belege dennoch problemlos auffindbar, z.B.:

Doch dann kommt sie wieder: Natascha, die einfältige Lieder mit noch einfältigeren Gedichten unterbieten kann. Weil sie jeweils den nächsten Gang ankündigt, muss man immer erst sie, als dicksten Brocken des Abends, schlucken, bevor 
Das Idiom ein dicker Brocken bildet wegen der Ambiguität der nominalen Komponenten sowie des Status eines Neologismus eine Besonderheit. Der wesentliche Beitrag des mentalen Bildes zu der Bedeutungskonstituierung ist dennoch im sprachspielerischen Gebrauch vieler Idiome ersichtlich. Wegen der Doppelbödigkeit ihrer semantischen Struktur eignen sich Idiome hervorragend dazu, bildhafte Formulierungen zu bilden, „mit denen der Sprachproduzent die ausgetretenen Pfade seiner Sprache verlassen kann" (Sabban 2014: 100). Grundlegend für dieses Formulieren ist die Hervorhebung der literalen Lesart und die damit einhergehende Anknüpfung an das mentale Bild. ${ }^{203}$ Dies ist im vom Sprachproduzenten intendierten, bewussten, markierten Gebrauch der Idiome der Fall, auf dessen zwei Strategien - die Ambiguierung der Bedeutung sowie den Ausbau des Szenarios am Beispiel der Idiome ein hartes Brot, eine harte Nuss - näher eingegangen wird.

Die Verwendung der Idiome in einem Text kann nach Sabban (2007b: 240-241) unauffällig (unmarkiert) oder markiert sein. Eine unauffällige Verwendung liegt vor, wenn man einen Phraseologismus nur in seiner phraseologischen Bedeutung, in einem typischen thematischen oder situativen Kontext gebraucht. In einem auffälligen Gebrauch wird der Phraseologismus nicht oder nicht ausschließlich als Träger einer phraseologisierten Bedeutung verwendet oder wird in einen untypischen thematischen oder situativen Zusammenhang versetzt. Als eine markierte Verwendung gelten auch die Fälle, in denen Phraseologismen oder Verwendungsweisen von Phraseologismen gehäuft auftreten.

Der markierte Gebrauch von Idiomen hat seine Grundlage im Spannungsverhältnis zwischen der literalen und der phraseologisierten Lesart. Die Ambiguierung der phraseologischen Bedeutung beruht darauf, dass der Sprachproduzent seine Sprachäußerung bewusst so arrangiert, dass die literale und phraseologisierte Lesart zugleich aktiviert werden und keine eine deutliche Oberhand gewinnt. Ein Beispiel für den ambiguen Gebrauch des Phraseologismus liegt im folgenden Beleg vor:

es dann wahlweise zum Timbale von Flusskrebsen auf Meerrettichmousse, zum Supreme vom Steinbutt mit Tomatenkruste, zum Filet vom Milchkalb auf Wirsinggemüse oder zum Délice aus Schokolade mit eingelegten Bananen übergeht. Berliner Zeitung, 27.10.2003

Und Magath ist optimistisch, dass sein Team Individualisten wie den Argentinier Crespo in beiden Spielen neutralisieren kann: Chelsea ist ein dicker Brocken, aber ein Brocken, den man auch zur Seite räumen kann. Berliner Zeitung, 13.12.2003

203 Erwähnenswert ist dabei die Text bildende Rolle der Phraseologismen: Idiomatische Einheiten werden in den Fokus der Aufmerksamkeit gerückt, indem aus einem Phraseologismus ganze Textabschnitte oder gar abgeschlossene Texte entwickelt werden (Burger/Buhofer/Silam 1982: 90). Dem Begriff und der systematischen Erforschung der Text bildenden Potenzen der Phraseologismen sowie der Erforschung der Phraseologismen zu verschiedenen Textdimensionen wurden mehrere Publikationen gewidmet (vgl. Sabban 2004, 2007b, Dobrovol'skij 1980, 1987). 
(142) Eine Sonderbehandlung gibt es für die gewalttätigen Störenfriede nicht. Sie erwartet dasselbe harte Brot wie alle anderen Inhaftierten. Die engen Zellen, in denen nur spärlich das Tageslicht eindringt, bieten gerade Platz für ein schmales Eisenbett, Waschbecken und Toilette, Stuhl, Tisch und Schrank. Berliner Zeitung, 21.06.1996

Auffällig ist in diesem Gebrauch die gleichzeitige Aktivierung der literalen und der phraseologisierten Lesart. Demzufolge kann die Wortverbindung ,dasselbe harte Brot' im Beleg (142) auf mehreren Stufen der metaphorisch-metonymischen Bedeutungsderivation ausgelegt werden: in der literalen Bedeutung, in der metonymischen Bedeutungserweiterung ,ein einfaches, nicht raffiniertes Essen' sowie in der metaphtonymischen Derivation ,schwere, nicht komfortable Haftbedingungen'. Von Relevanz für die verspürte konzeptuelle Nähe zwischen der literalen und der metaphorischen Bedeutung ist zweifelsohne die Tatsache, dass das harte Brot als ,ein einfaches, nicht raffiniertes Essen' einen wichtigen Bestandteil der GEFÄNGNIs-Domäne ausmacht (vgl. bei Brot und Wasser sitzen ,im Gefängnis sitzen').

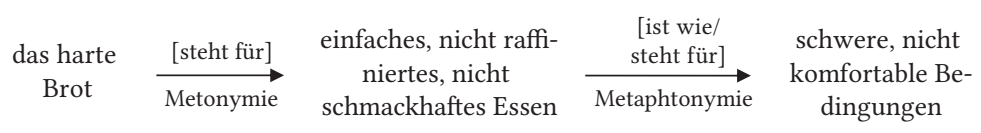

Abb. 101: Metonymisch-metaphtonymische Bedeutungsverschiebungen im Idiom ein hartes Brot (Beleg 142).

Ein ambiguer Gebrauch des Idioms liegt ebenfalls im Beleg (143) vor, hier kommt allerdings zusätzlich eine weitere Strategie des bildhaften Formulierens - der sog. Ausbau des Szenarios (vgl. Sabban 2014: 104) - zum Vorschein:

(143) Es ist klar, daß das Volk der Magazineure von vornherein verdächtigt wird. Leute ohne rechte Ambitionen auf die Sprossenleiter des beruflichen Aufstiegs, stille Verzichter und an diesen Strand Verschlagene, die nur das Einmaleins der Kataloge beherrschen wollten, sich mit hartem Brot und dünnem Tee begnügten, in ihren Bücherkammern wie in Waben saßen. So lassen sie die Reihe der Verdächtigen für ein erstes leichtes Verhör einer nach dem andern in das Zimmer treten, das ihnen die Direktion freundlicherweise zur Verfügung gestellt hat. Fries, Fritz Rudolf: Der Weg nach Oobliadooh, Frankfurt a. M.: Suhrkamp 1966, S. 184

Das Idiom ein hartes Brot funktioniert hier als ein Wendepunkt in der Konzeptualisierung, der zwischen der phraseologisierten und der literalen Lesart schlagartig „umschaltet“. Der Anfang der Äußerung, der minimale berufliche Ambitionen der Magazineure und ihre bescheidenen Ansprüche an das Leben, eine schlecht bezahlte, nur zur Befriedigung der Grundbedürfnisse dienende und über das Minimum der Existenzsicherung nicht hinausgehende Arbeit thematisiert, profiliert 
die phraseologisierte Lesart des Idioms ein hartes Brot (vgl. Verwendungsprofil 1). Mit dem Ausbau des Szenarios durch das Hinzufügen von dünnem Tee wird abrupt die literale Lesart des harten Brotes in den Fokus der Aufmerksamkeit gerückt, die Fortsetzung der Äußerung in ihren Büchernkammern wie in Waben saßen lässt das mentale Bild eines Menschen in niedrigrangiger beruflicher Position, der in einer kleinen Kammer seine bescheidene Mahlzeit zu sich nimmt, detailliert und präzise aufkommen. Bei der Rezeption der Äußerung stellt sich also ein plötzlicher Perspektivenwechsel ein, das evozierte Bild bleibt dennoch schlüssig und widerspruchslos.

Besonders gut ausgebaut und bildhaft ist das Szenario im folgenden Beleg mit idiomatischer Einheit eine harte Nuss:

(144) Die Abneigung gegen take-overs im Inland begründet die Börsenabteilung der Dresdner Bank in Frankfurt so: „Auch ohne Übernahmegebote sind in der Bundesrepublik immer sinnvolle unternehmerische Lösungen zustande gekommen. Bei uns würden sich die raiders so manchen Zahn ausbeißen." Allerdings sei es nicht die Macht der Banken, derentwegen ein raider um sein Gebiß fürchten müsse, sondern das Aktienrecht: „Aufgrund der Zweigleisigkeit von Aufsichtsrat und Vorstand ist der deutsche Markt eine harte Nuß." Allerdings ist es eine Nuß mit verlockendem Inhalt. Denn schließlich erwarten nicht nur die Deutschen selber, daß ihre Unternehmen am stärksten vom großen Binnenmarkt profitieren werden. Die Zeit, 25.03.1988

Als raiders werden die Unternehmensjäger bezeichnet, die aus der Differenz zwischen dem inneren Wert eines Unternehmers und seinem niedrigen Börsenwert durch verschiedene Kauf-, Verkauf-, Spekulationsgeschäfte große finanzielle Gewinne zu erzielen versuchen. Das Idiom eine harte Nuss referiert hier auf eine Herausforderung, die der deutsche Markt wegen der internen Regelungen für raiders darstellt, und wird durch die im ersten Verwendungsprofil ermittelten Bedeutungsderivationen konstruiert. Der sprachspielerische Effekt wird dadurch erzielt, dass der umliegende Text gezielt an das mentale Bild des Idioms anknüpft und es durch die okkasionellen metaphorischen Bedeutungserweiterungen von anderen Spracheinheiten in den Fokus der Aufmerksamkeit rückt. Dadurch entsteht der Eindruck, dass sich die ganze Äußerung um das mentale Bild dreht, in einem schwierigen Fachtext wird ein scherzhafter Auflockerungseffekt erzielt. Das ausgebaute Szenario ist dabei kohärent und stimmt mit der lexikalisierten Bedeutung überein: Nicht die einzelnen Bedeutungsaspekte kommen in die aktuelle Bedeutung hinein, sondern das ganze Bild und die dahinter stehenden Wissensinhalte werden aus einer konkreten ESSEN-Domäne in eine abstrakte MARKT-Domäne projiziert. Eine harte Nuss, die man mit den Zähnen zu knacken versucht, stellt für das Gebiss eine Gefahr dar, da man sich daran die Zähne ausbeißen kann. Auf dieses schmerzhafte und kostspielige Risiko gehen manche Nascher dennoch ein, um an den fetten Nusskern zu kommen. Analog verhält es sich mit Unternehmensjägern, für die der deutsche Markt aufgrund juristischer Angelegenheiten mit finanziellem Risiko verbunden ist, andererseits aber auch lukrative Geschäfte in Aussicht stellt, die waghalsige Handlungen rechtfertigen (vgl. Tab. 43): 
Tab. 43: Die epistemischen Mappings für den Verwendungsbeleg (148).

\begin{tabular}{ll}
\hline harte Nuss (Ausgangsdomäne) & $\begin{array}{l}\text { Herausforderung, die die Übernahme von } \\
\text { deutschen Unternehmen in Deutschland } \\
\text { darstellt (Zieldomäne) }\end{array}$ \\
\hline Eine harte Schale. & $\begin{array}{l}\text { Eine aufgrund der juristischen Regelungen } \\
\text { (Aktienrecht) schwierige Aufgabe. }\end{array}$ \\
\hline Der Kern ist nahrhaft, fett. & $\begin{array}{l}\text { Es handelt sich um die Unternehmen von einem } \\
\text { großen finanziellen Wert. Der Gewinn, den die } \\
\text { eventuelle Übernahme erbringen könnte, ist der } \\
\text { Mühe wert, begehrenswert. }\end{array}$ \\
\hline $\begin{array}{l}\text { Das Knacken mit den Zähnen } \\
\text { ist für das Gebiss gefährlich, } \\
\text { kann anhaltende, schmerzhafte } \\
\text { und kostspielige Konsequenzen } \\
\text { hinterlassen (abgebrochene Zähne). }\end{array}$ & $\begin{array}{l}\text { Beim derzeitigen Rechtsstand sind die } \\
\text { der beträchtlichen Summen, die zu investieren } \\
\text { sind, wären die finanziellen Konsequenzen einer } \\
\text { misslungenen Übernahme für einen raider ernst } \\
\text { und kostspielig. }\end{array}$ \\
\hline
\end{tabular}

Im Verwendungsbeleg (145) ergibt sich die Bedeutung der Äußerung aus dem Spannungsverhältnis zwischen der phraseologisierten Lesart und einer flüchtigen metonymischen Kette, die auf der literalen Lesart aufbaut.

(145) Bern ist nicht das harte Brot jedes Essliebhabers, Bern ist nicht einmal das. Es ist ein Nicht-Ort, um den man wohlweislich einen Bogen macht, so auch Wolfram Siebeck, der deutsche Doyen der Esskritik, während seiner jüngsten Schweizreise für die ZEIT. Darum muss ich mich über diesen Blechnapf beugen, in dem es ja durchaus einiges auszutupfen gibt. Die Zeit, 06.12.2010

Der Sprachproduzent knüpft in diesem gastronomiekritischen Artikel intentional an das durch die literale Lesart evozierte mentale Bild und hebt es durch das Hinzufügen von jedes Essliebhabers hervor. Bei der Auslegung des Idioms stehen dem Sprachrezipienten mehrere Wege zur Verfügung:

Das harte Brot kann an dieser Stelle als ,eine schwierige Aufgabe, eine Herausforderung' interpretiert werden. Der Bedeutungsderivation liegen dann zwei Metaphern: die konzeptuelle Metapher SCHWIERIGKEITEN SIND UNGENIESSBARES ESSEN und die epistemische Metapher hartes Brot $\rightarrow$ Herausforderung zugrunde, so wie sie in dem zweiten Verwendungsprofil des Idioms ein hartes Brot zur Geltung kamen:

$$
\text { das harte Brot } \underset{\text { Metapher }}{\longrightarrow} \begin{aligned}
& \text { eine Herausforderung, } \\
& \text { eine schwierige Aufgabe }
\end{aligned}
$$

Abb. 102: Metaphorische Bedeutungsverschiebung im Idiom ein hartes Brot (Beleg 145). 
Nicht auszuschließen ist zugleich der Beitrag einer flüchtigen, einmaligen metonymischen Kette zur Konzeptualisierung. Die Äußerung: Bern ist ein hartes Brot jedes Essliebhabers kann nämlich auch als ,Bern ist ein Ort, an dem man nicht gut essen kann` ausgelegt werden. Die Bedeutung konstituiert sich dann infolge einer flüchtigen metonymischen Kette:

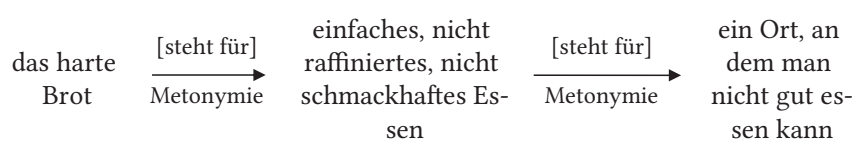

Abb. 103: Metonymische Bedeutungsverschiebung im Idiom ein hartes Brot (Beleg 145).

Der Sprachproduzent knüpft hier bewusst an das mentale Bild an, das durch die literale Bedeutung hervorgerufen wird, um die intendierten Inhalte auf eine stilistisch auffallende Art und Weise mitzuteilen. Die erste metonymische Verschiebung ist z.T. lexikalisiert und trägt zur Bedeutungskonstituierung des ersten Verwendungsprofils bei (Brot $\rightarrow$ Grundnahrungsmittel), auch wenn hier andere Aspekte hervorgehoben werden: Im ersten, durch Belege (106-110) vertretenen Verwendungsprofil wurde Brot als ein einfaches, alltägliches Lebensmittel, das die Grundlage der Existenzsicherung bildet, profiliert. Diese Bedeutungsaspekte werden im zu besprechenden Beleg (145) in den Hintergrund verschoben, ausschlaggebend für diese Konzeptualisierung ist das Wissen, dass das harte Brot keinen Gaumengenuss für Feinschmecker darstellt, was im weiteren metonymischen Schritt auf den Ort, an dem man nicht gut essen kann, erweitert wird. Die metonymische Derivationskette hat einen flüchtigen, einmaligen Charakter, die Bedeutungskonstituierung beruht hier so, wie bei einer innovativen Ad-hoc-Metapher, auf einer Zusammenarbeit zwischen dem Sprachproduzenten und dem Sprachrezipienten. Die aktuelle Bedeutung schwankt zwischen beiden Interpretationen, von denen die erste lexikalisiert, die zweite flüchtig und innovativ ist.

Wesentlich komplexer sind die kognitiven Mechanismen, die der Bedeutungskonstituierung und Motiviertheit des Idioms im Beleg (146) zugrunde liegen.

(146) Seit dem legendären ÖTV-Chef Heinz Klunker, Gott hab ihn selig, hat es keinen Arbeiterführer mehr gegeben, der die proletarischen Massen so richtig auf die Barrikaden treiben konnte. Wenn Klunker rief, standen alle Räder still und die Löhne wurden zweistellig erhöht. Für den nordrhein-westfälischen Ministerpräsidenten Jürgen Rüttgers könnte das im kommenden Jahr noch eine richtig neue Herausforderung werden. Den Lafontaine macht er schon gelegentlich, wenn es um populistische Stimmenmaximierung geht. Auch mit dem langjährigen sozialdemokratischen Landesvater Johannes Rau hat er sich schon versöhnt. Heinz Klunker wäre eine harte Nuss, nicht wegen dessen Bauchumfanges. Aber wenn es dem Christdemokraten 
Rüttgers tatsächlich gelänge, in dessen Fußstapfen zu treten, dann ist ihm die Macht an Rhein und Ruhr wohl auf ewig sicher. Die Zeit, 29.12.2008

Zum einen referiert hier eine harte Nuss auf einen Politiker. Zur Geltung kommen hier also die zusammengesetzten kognitiven Mechanismen, die im Verwendungsmuster 2.1 beschrieben wurden: die konzeptuellen Metaphern SCHWIERIGKEITEN SIND UNGENIESSBARES ESSEN, KÖRPER IST BEHÄLTER; DICKE, HARTE WÄNDE SIND RESISTENZ GEGEN ÄUSSERE EINFLÜSSE, die epistemischen Mappings: harte Nuss $\rightarrow$ eine robuste, unnachgiebige Person, sowie die metaphorisch-metonymische Kette Nuss $\rightarrow$ Kopf $\rightarrow$ Person, die für die Bedeutungsderivation der nominalen Konstituente zuständig ist. Zum anderen ist das vertiefte Weltwissen unabdingbar, um sprachspielerische Intention des Sprachproduzenten entziffern zu können. Der in den 80er Jahren verstorbene, als harte Nuss bezeichnete Gewerkschaftler Heinz Klunker war für seine unnachgiebige Tarifpolitik, energische und effiziente Vertretung der Arbeiterinteressen bekannt, was ihm den Ruf des mächtigsten Gewerkschaftsführers Deutschlands einbrachte. Äußerlich fiel er zugleich durch mächtige Postur auf. In einem Nachruf hieß es:

„Von guten Freunden und Kritikern gleichermaßen aufgrund seines Umfangs stets „der Dicke“ genannt, galt er als der mächtigste Gewerkschaftsführer Deutschlands, wozu seine dröhnende Stimme nur allzugut passte. Für viele Wirtschaftsbosse war er oftmals der Buhmann der Nation." (www. wikipedia.de, Zugriff am 07.10.2017)

Die phraseologisierte Bedeutung ,jd. ist unnachgiebig, ausdauernd, zielstrebig, schwer von eigenen Zielen abzubringen' kommt hier also zweifelsohne zur Geltung. Die Durchsetzung der Lohnerhöhung um 11 \% gegen den Willen des Bundeskanzlers Willi Brandts hat Schlagzeilen gemacht, die Bewunderung für Klunkers Willensstärke und Charisma schwingt deutlich im Text mit. In der Äußerung Heinz Klunker wäre eine harte Nuss, nicht wegen dessen Bauchumfanges wird der sprachspielerische Effekt jedoch nicht durch die Anknüpfung an die lexikalisierte Bedeutung erzielt, sondern durch die Profilierung einer nicht lexikalisierten Eigenschaft des mentalen Bildes und ihre okkasionelle, innovative Metaphorisierung: In den Mittelpunkt der Konzeptualisierung wird nämlich die runde Form einer Walnuss geschoben, mit der der umfangreiche Bauch eines Mannes verglichen wird. Diese innovative Metapher beruht auf der Ähnlichkeitsbeziehung, die übrigens nicht besonders konsistent ist: Der Bauch - insbesondere ein sich vorwölbender Bauch eines beleibten Menschen - stellt bekanntermaßen einen der weichsten und empfindlichsten Körperteile dar, die Reminiszenz zu einer Walnuss bezieht sich also ausschließlich auf seine visuelle (und nicht z.B. taktile) Eigenschaft. Möglicherweise fällt die Inkohärenz des mentalen Bildes dennoch beim natürlichen, unreflektierten Sprachgebrauch gar nicht auf: Zu der Konstituierung der metaphorischen Bedeutung werden nur diese Inhalte herangezogen, die zu der Konzeptualisierung passen, alle anderen werden ausgeblendet. Dabei wird auf eine Strategie des bildhaften Formulierens zurückgegriffen, die oft in Sprachwitzen vorkommt: 
Es gibt keine fließenden Übergänge zwischen den Bedeutungen, sondern einen Aspektenwechsel, der sich plötzlich und oft überraschend einstellt. Daher rührt die Möglichkeit des Wortwitzes, der von Ambiguität lebt; er suggeriert dem Hörer ein Ausdruck sei klar in einer bestimmten Bedeutung verwendet, und deckt dann schlagartig - in der Pointe - die Ambiguität auf. (H.-J. Heringer, Die Unentscheidbarkeit der Ambiguität, In: D. Wolf, H. Geckeler (Hg.), Logos Semantikos. Studia Linguistica in Honorem Eugenio Coseriu, Berlin 1981, S. 95, zit. nach Urban 2009: 420)

Die besprochenen Belege führen vor Augen, wie sich mentale Bilder von idiomatischen Einheiten an dem Zustandekommen neuartiger, bildhafter, sprachspielerischer Formulierungen beteiligen können. Sie veranschaulichen aber auch die Vielfältigkeit und Komplexität dieses Einsatzes: Die aktuellen Bedeutungen der Äußerungen kommen nämlich in unterschiedlichen Verfahren zustande:

(i) Der Text ist so arrangiert, dass eine Wortverbindung in der literalen, in einer metonymischen oder in einer metaphtonymischen Bedeutung interpretiert werden kann, so wie es im Beleg (142) der Fall ist und als Ambiguierung der Bedeutung bezeichnet wird.

(ii) Der Text knüpft an das mentale Bild explizit an, indem um das Idiom herum ein Szenario ausgebaut wird. Im Beleg (143) wird dies durch das Hinzufügen von dünnem Tee gewährleistet. Die durch das mentale Bild evozierte literale Lesart wird schlagartig aufgegriffen und weitergeführt. Die Wortverbindung mit hartem Brot wird zuerst in der phraseologisierten Lesart ,eine finanziell nicht befriedigende Arbeit' ausgelegt, um dann plötzlich durch die Kontextarrangements in die literale Lesart umzuschlagen: Leute ohne rechte Ambitionen auf die Sprossenleiter des beruflichen Aufstiegs, stille Verzichter und an diesen Strand Verschlagene, die nur das Einmaleins der Kataloge beherrschen wollten, sich mit hartem Brot und dünnem Tee begnügten, in ihren Bücherkammern wie in Waben saßen. Das mentale Bild stellt einen Impuls für eine Assoziation dar, die versprachlicht wird.

(iii) Das durch die literale Lesart evozierte mentale Bild ist für einen längeren Abschnitt konstitutiv, indem die wörtliche Lesart des Idioms aufgegriffen wird und der Sprecher seine Äußerung im gleichen Szenario weiter formuliert (vgl. Beleg 144). Auf diese Art und Weise entsteht eine ausgebaute Metapher, mit der komplizierte Vorgänge vermittelt und bildlich veranschaulicht werden können.

(iv) Die durch das mentale Bild evozierte literale Lesart unterliegt weiterer Metonymisierung, so wie es im Verwendungsbeleg (145) der Fall war. Die aktuelle Bedeutung gestaltet sich im Spannungsraum zwischen der phraseologisierten Lesart und einer idiosynkratischen, einmaligen, innovativen Derivationskette.

(v) Durch den Ausbau des Szenarios kann ebenfalls eine innovative Metapher, die neue Aspekte des mentalen Bildes fokussiert, an die bereits lexikalisierte Bedeutung angekoppelt werden (Nuss $\rightarrow$ runder Bauch, rundliche Gestalt eines Menschen im Beleg 146). Eine gewisse Verdichtung der Informationen 
wird dadurch erzielt: In einer kurzen Äußerung: jd. ist eine harte Nuss, nicht wegen dessen Bauchumfanges werden zahlreiche Informationen über das Aussehen und Charakter eines Menschen in einer komprimierten Form vermittelt: Mit einem geringen kommunikativen Aufwand wird ein großer kommunikativer Effekt erzielt (Spieß/Köpcke 2015: 9).

In jedem Fall wird dadurch eine Originalität der Äußerung, ihre Vagheit und semantischer Mehrwert erreicht: So wie die materiellen Bilder viele Interpretationsmöglichkeiten zulassen, so eröffnen auch die mentalen Bilder, falls sie bewusst in den Fokus der Aufmerksamkeit verschoben werden, neue Spielräume der Bedeutungskonstituierung. 



\section{Resümierende Schlussbemerkungen}

Die Bedeutungen - als mentale Konstrukte aufgefasst - sind weder unmittelbar wahrnehmbar noch greifbar, weder fest, deutlich abgegrenzt, stabil, noch bei allen Sprachteilhabern in allen Einzelheiten identisch. In ihrer neuronal-mentalen Natur weisen sie einen prozessualen und konstruktiven Charakter auf: Sie tauchen in der Kommunikation als Konzeptualisierungen auf, nehmen eine emergente, durch Kound Kontext weitgehend beeinflusste Gestalt an und gehen unter. Wiederholt sich dieser Prozess mehrmals und wird jedes Mal auf dieselben Entitäten der äußeren Welt referiert, verfestigen sie sich und werden zu mehr oder weniger stabilen kognitiven Routinen mit mehr oder weniger scharfen Grenzen.

Die Bedeutungen kann man also nicht ausschneiden, auf eine Laborschale legen, von allen Seiten betrachten und beschreiben. Man kommt ihnen über die Analyse des Sprachgebrauchs näher, indem man ihr Vorkommen in Ko- und Kontexten untersucht und durch den Abgleich von vielen Sprachgebrauchsbelegen die ihnen gemeinsamen Züge zu erfassen versucht. Die deskriptiven Produkte einer derartigen Analyse sind immer annähernd und eigentlich schon zu dem Zeitpunkt ihrer Entstehung veraltet: Sie sind approximativ, weil niemand imstande ist, alle in einer Sprachgemeinschaft vorgekommenen und vorkommenden Sprachgebrauchsereignisse, in denen eine sprachliche Einheit aufgetreten ist, aufzuzeichnen und zu untersuchen. Sie sind nur über kurze Zeit gültig, weil die Sprache lebt, die Bedeutungen von den Sprachteilhabern ständig konstruiert und rekonstruiert, in kommunikativen Akten neu ausgehandelt und somit Erweiterungen, Verengungen, Verschiebungen unterzogen werden.

Dieses kognitiv-gebrauchstheoretische Axiom liegt der vorliegenden Arbeit zugrunde, deren Hauptanliegen in der Beschreibung von den Prozessen der Bedeutungskonstituierung anhand des authentischen Sprachgebrauchs liegt. In diesem Sinne schließt sich das Buch an die gegenwärtige korpuslinguistische Forschung an, das angewendete Verfahren ist dabei korpusbasiert und semantisch-qualitativ. Die Korpusbelege stellen das empirische Fundament der Analysen dar, aus den authentischen Sprachgebrauchsbelegen werden die jeweiligen Konzeptualisierungen ermittelt, auf die Gemeinsamkeiten untersucht und auf der Basis der abstrahierten Parallelen zu Verwendungsprofilen und Verwendungsmustern zusammengestellt. Selbstverständlich lassen die durchgeführten Untersuchungen aufgrund der relativ kleinen Anzahl der analysierten Korpusbelege keine weitreichenden phraseographischen Schlussfolgerungen ${ }^{204} \mathrm{zu}$ : Dementsprechend wurden auch die üblichen Termini: ,Bedeutungen' und ,Teil- bzw. Unterbedeutungen

204 Korpuslinguistisch-kognitive Studien, die zugleich erfolgreich in der Phraseographie eingesetzt werden können, sind allerdings schon vorhanden, vgl. Staffeldt/ Ziem (2008). 
durch ,Verwendungsprofile‘ und ,Verwendungsmuster ersetzt. Einige Bemerkungen zur semantischen Analyse der Idiome und den festzustellenden Differenzen zwischen der korpusbasierten Analyse und der lexikographischen Auffassung der Idiome können allerdings auf der Basis der semantischen Analyse von ausgewählten Idiomen formuliert und zusammenfassend angeführt werden:

1. Generell ist die Verwendungsbreite und Variabilität der Phraseologismen, auf die man anhand der Untersuchung von authentischen Sprachbelegen schließen kann, bei untersuchten Idiomen größer als in lexikographischen Werken. (Eine überblicksartige Zusammenstellung der Duden-Bedeutungsparaphrasen, der in Korpusbelegen festzustellenden Modifikationen und der eruierten Verwendungsprofile und Verwendungsmuster bietet die Tabelle 2 im Anhang).

2. Idiome weisen große Variabilität und Modifizierbarkeit auf dem phonologischen Pol (der Formseite des Idioms) auf, in manchen Fällen ist die Anzahl der ermittelten Varianten so erheblich, dass die Festigkeit der verbalen Idiom-Komponente infrage gestellt werden muss. Beispielshalber sind die Verben in Idiomen: schwankender Boden, dünnes Eis, glattes Parkett, Klotz am Bein so schwach verfestigt, dass der semantischen Analyse ausschließlich die nominale Phrase unterzogen werden konnte. Auch bei anderen Idiomen lassen sich zahlreiche Modifikationen feststellen. $\mathrm{Zu}$ den häufigsten Modifikationen gehören: Erweiterungen durch ein Adjektivattribut (z.B. in den größten sauren Apfel beißen, stärkere Knüppel zwischen die Beine werfen, einige/zahllose/allerlei/diplomatische Knüppel zwischen die Beine werfen, der größte Klotz am Bein sein, der defizitäre Klotz am Bein, einige dicke Brocken); Erweiterungen durch eine Adverbialbestimmung (z.B. eine besonders harte Nuss, eine richtig harte Nuss, mit etw. schon genug am Hals haben, immer wieder/ständig/nicht ständig Knüppel zwischen die Beine werfen, mit Schwung Knüppel zwischen die Beine werfen); Erweiterungen durch ein Genitivattribut (z.B. das dünne Eis semantischer Spitzfindigkeiten, das harte Brot der Opposition [3 Belege], das harte Brot der Identitätssuche, in den sauren Apfel hoher Effektenabschreibungen/der Gegebenheiten beißen, sich auf dem glatten Parkett einer Sache auskennen); Erweiterungen durch einen Relativsatz (z.B. das war der saure Apfel, in den wir beißen mussten); Nominalisierungen von verbalen Phraseologismen (z.B. ein Biss in den sauren Apfel); verbale Erweiterungen mit gleichzeitiger Änderung der Aktionsart: (z.B. sich an die Wand drücken lassen, sich an die Wand gedrückt fühlen, sich an die Wand gedrückt sehen, Knüppel zwischen die Beine geworfen bekommen, sich in die Enge getrieben fühlen, sich in die Enge getrieben finden). Hervorzuheben ist dabei, dass die festgelegten Varianten und Modifikationen nur zufällige Funde darstellen: Wegen der semantisch-kognitiven Zielsetzung der vorliegenden Arbeit waren die Korpusanfragen in den einzelnen Fallstudien in ihrer Formulierung keinesfalls auf die Suche nach Modifikationen ausgerichtet. Die Anzahl und Vielfalt der festzustellenden Veränderungen auf der formalen Seite von Idiomen lässt dennoch die phraseologische Stabilität in einem anderen Licht erscheinen und macht die Formulierung der Zitierform in der Phraseographie zu einer Herausforderung. 
3. Aus semantischer Perspektive bieten die eruierten Verwendungsprofile und Verwendungsmuster ein breiteres Spektrum der Bedeutungen und Bedeutungsnuancen als lexikographische Werke an. Dies hängt z.T. mit der Granularität der Bedeutungsbeschreibung zusammen, die in korpuslinguistischen Studien generell detaillierter als in (insbesondere gedruckten) Nachschlagewerken ist. Unterzieht man die lexikographisch erfassten Bedeutungsparaphrasen und die eruierten Verwendungsprofile einer vergleichenden Analyse, dann lassen sich einige Tendenzen festlegen, die im Folgenden - ohne Anspruch auf lexikographische Postulate - an ausgewählten Idiomen resümierend dargelegt werden:

(i) Bei einigen Idiomen sind die Abwandlungen in der Valenz feststellbar: Außer den lexikographisch verzeichneten belebten Subjekten/Objekten treten im Usus auch unbelebte Subjekte/Objekte auf. Dies ist beispielshalber bei Idiomen schwankender Boden und dünnes Eis der Fall: Das durch das reflexive Verb angedeutete belebte, menschliche Subjekt wird in manchen Verwendungsprofilen durch unbelebte Abstrakta: leicht anfechtbare Argumentation, Theorie, umstrittene Gesetzesauslegung u.Ä. ersetzt.

(ii) Viele Idiome weisen eine weitere Bedeutung auf als es lexikographisch vorgeschrieben ist. So referiert das Idiom schwankender Boden (Duden 11: sich auf schwankenden/unsicheren Boden begeben: in seinen Betrachtungen, Argumentationen o. ̈̈. den Boden der Tatsachen, des Gesicherten verlassen, unsichere Voraussetzungen einbeziehen) in fünf Belegen tatsächlich auf eine unsichere, angreifbare Lage, in die sich ein Wissenschaftler versetzt, der in einem nicht gut etablierten Forschungsbereich tätig ist bzw. intersubjektiv schwer fassbare Thesen aufstellt, in 13 Belegen lässt es sich allerdings mit einer allgemeineren Bedeutungsparaphrase ,eine schwierige, riskante (Lebens-)Lage einer Person' beschreiben, die mit den vertretenen Ansichten oder gezielten Handlungen in keinem Zusammenhang steht. Beachtenswert ist ebenfalls das zweite Verwendungsprofil des Idioms ein hartes/schweres Brot. In einer nennenswerten Anzahl der Belege (13) ist der in den lexikographischen Werken hervorgehobene Bedeutungsaspekt des finanziellen Lebensunterhalts, des Gelderwerbs nicht vorhanden. Das Idiom referiert auf eine herausfordernde und schwierige Aufgabe. Vor dem Hintergrund des authentischen Usus können ebenfalls die im Duden 11 angebrachten Zusatzinformationen (durch Fragen, Bedrohungen) in der Bedeutungsparaphrase des Idioms in die Enge treiben irreführend sein: Die Bedeutungsnuance einer verbalen Auseinandersetzung ist 17 Belegen eigen, in 23 Gebrauchsbelegen kommt sie aber nicht in Erscheinung.

(iii) Unter den untersuchten Idiomen findet man ebenfalls Beispiele für eine gegensätzliche Tendenz - die Bedeutungsverengung (Spezialisierung). Vor dem Hintergrund des empirischen Materials scheint die Bedeutungsparaphrase des Idioms glattes Parkett betreten, sich auf glattes Parkett wagen: ,ein Risiko eingehen, etw. Riskantes tun' (Duden 11) zu allgemein zu sein. Die Korpusbelege 
verweisen auf zwei Diskursbereiche, in denen das Idiom verwendet wird: ,riskante Tätigkeitsbereiche (höheres Management, Diplomatie, Politik), die geschliffene Umgangsformen voraussetzen“ sowie ,Börsenverkehr'. Die Substitutionsproben führen deutlich vor Augen, dass dieses Idiom gegen andere Idiome der ,schwierigen Lage' nicht ohne Bedeutungsverlust ersetzbar ist (vgl. Unterkap. 4.2.2.1.1.1.4).

(iv) Charakteristisch für manche Idiome ist eine relativ hohe Anzahl der Belege, die keinem der eruierten Verwendungsprofile/Verwendungsmuster zuordenbar waren und als idiosynkratischer bzw. sprachspielerischer Gebrauch klassifiziert werden (vgl. die Idiome schwankender Boden, glattes Parkett, an die Wand drücken, ein hartes Brot, dicker Brocken). Diese Belege unterstreichen den prozessualen Charakter der Bedeutungskonstituierung, das kreative Potenzial der Idiomatik, wo der Rückgriff des Sprachproduzenten auf alle zugänglichen Wissensressourcen immer möglich ist: Die Motiviertheit der Idiome ist in diesen Gebrauchsbelegen des Öfteren situativ, die Inferenzen strikt kontextgebunden, spezialisiertes Weltwissen wird vorausgesetzt. Wegen der Komplexität und Einmaligkeit der Inferenzen sowie situativer Gebundenheit sind die in diesen Belegen ermittelten Bedeutungen lexikographisch nicht erfassbar.

Der Hauptertrag der vorliegenden Arbeit liegt aber nicht in der semantischen Bedeutungsanalyse der Korpusbelege, sondern in der kognitiv ausgerichteten Untersuchung der Mechanismen, die zur Konstituierung der Bedeutungen von Idiomen führen. Die Mannigfaltigkeit der als Idiome bezeichneten sprachlichen Phänomene, ihre semantischen Potenzen, darunter ihre Inklination zu sekundären und parallelen Metaphorisierungen und Metonymisierungen sowie Affinität zum sprachspielerischen Gebrauch, stellen seit Langem eine Herausforderung für die Phraseologie dar, vgl.:

The multifaceted nature of idioms has, among its consequences, the fact that it is virtually impossible for any current knowledge or methodology to fully capture it. Moreover, our current knowledge of these expressions is such, that the picture that emerges from their study is still rather fragmentary. (Cacciari/Tabossi 1993: XIII)

Die facettenreiche Natur der Idiome und ihrer Bedeutungen wurde im Vorangehenden nachdrücklich unterstrichen und empirische Studien des vierten Kapitels leisten noch einen Beitrag zu ihrer Bestätigung. Der innovative Wert des vorliegenden Buches mag aber darin liegen, dass ein Verfahren herausgearbeitet wurde, mit dem viele semantische Aspekte der Idiome einheitlich, d.h. anhand eines kongruenten methodischen Instrumentariums und unter gemeinsamen theoretischen Prämissen in einer übereinstimmenden Terminologie erläutert werden können. Die Grundvoraussetzungen, die diesem Verfahren zugrunde liegen, lassen sich in folgenden Punkten zusammenfassen: 
1. Der besondere semantische Status der Phraseologismen im engeren Sinne (= Idiome) unter anderen sprachlichen Zeichen ist auf zwei Faktoren: die Doppelbödigkeit ihrer Bedeutung und ihre Polylexikalität zurückzuführen.

2. Die meisten Idiome sind doppelbödig, weil sie zwei Lesarten: eine wörtliche (= literale) und eine phraseologische (= phraseologisierte, idiomatische, übertragene) Lesart aufweisen. Die Bedeutungen der Idiome konstituieren sich im Spannungsfeld zwischen den beiden Lesarten, in einem Prozess der semantischen Schwankung zwischen den Polen des Literalen und des Nicht-Literalen. Sie werden also nicht als ,long words' aus dem Langzeitgedächtnis abgerufen, so wie dies die traditionelle Definition der Idiomatizität nahe legt, sondern jeweils unter bestimmten ko- und kontextuellen Bedingungen und mit Rückgriff auf zugängliche Wissensstrukturen konstruiert. Der Unterschied zwischen Idiomen und freien figurativen Wortverbindungen (z.B. innovativen Metaphern) liegt darin, das bei den Erstgenannten die Grenzen der potenziell möglichen Konzeptualisierungen durch die phraseologisierte Lesart abgesteckt sind.

3. Im Spannungsfeld zwischen den beiden Lesarten konstituieren sich die Bedeutungen von Idiomen weitgehend durch Projektionsprozesse. Als wichtigste Mechanismen der Bedeutungskonstituierung von Idiomen aus der Perspektive des Sprachproduzenten und der idiomatischen Motiviertheit aus der Perspektive des Sprachrezipienten werden Metapher, Metonymie, Metaphtonymie angesehen.

Die relevante Rolle der Metapher in der kognitiv ausgerichteten Phraseologie gilt als gesichert, besonders viel Aufmerksamkeit wurde bis dato den konzeptuellen Metaphern im Sinne der kognitiven Metapherntheorie von Lakoff/Johnson gewidmet. Die im Kap. 4.2.1 durchgeführte Studie am phraseologischen Material der Schwierigkeit/der schwierigen Lage liefert eindeutig Evidenz dafür, dass konzeptuelle Metaphern dieses semantische Feld zu einem erheblichen Grad strukturieren: Die überwiegende Mehrheit $(85 \%)$ der anhand der lexikographischen Nachschlagewerke zusammengestellten idiomatischen Einheiten lässt sich zu konzeptuell-metaphorisch bedingten Clustern gruppieren, was die leitende These der Lakoff'schen Metapherntheorie vom Einfluss der konzeptuellen Metaphern auf die Konzeptualisierung abstrakter Begriffe weitgehend untermauert.

Richtet man allerdings die Aufmerksamkeit auf den authentischen Sprachgebrauch und versucht die kognitiven Mechanismen nachzuvollziehen, die unter bestimmten ko- und kontextuellen Bedingungen zur Geltung kommen und die Bedeutungskonstituierungsprozesse der Sprache im Gebrauch beeinflussen, dann stellt sich das Erklärungspotenzial der kognitiven Metapherntheorie als unzureichend aus. Idiome, denen dieselben konzeptuellen Metaphern zugrunde liegen, weisen nämlich deutliche Bedeutungsunterschiede auf, die in eruierten Verwendungsprofilen und -mustern erkennbar werden und durch Substitutionsproben besonders deutlich zur Geltung kommen: Bedeutungsähnliche, durch dieselbe konzeptuelle Metapher motivierten Idiome lassen sich in einzelnen Korpusbelegen kaum ohne Bedeutungsverlust bzw. -verschiebung gegeneinander tauschen. 
Zur Bedeutungskonstituierung tragen demnach auch die an konkrete sprachliche Äußerungen gebundenen epistemischen Metaphern bei, die zwei Domänen auf der Basis des allgemeinen Weltwissens verbinden.

Die konzeptuellen und die epistemischen Metaphern schließen sich als Motiviertheitsmechanismen in der Phraseologie keineswegs aus: Es gibt Idiome, deren metaphorische Motiviertheit auf epistemischen Mappings beruht und für die sich keine konzeptuellen Metaphern ermitteln lassen, sowie Idiome, in denen die konzeptuellen Metaphern par excellence zur Geltung kommen. In den meisten Fällen interagieren beide Metapherntypen: Die konzeptuellen Mappings stellen eine interpretative Basis dar und vergeben den Konzeptualisierungen eine bestimmte Richtung, die epistemischen Mappings liefern eine detaillierte, an ein bestimmtes mentales Bild, sowie den Ko- und Kontext gebundene Erklärungsvariante der Metapher. Selbstverständlich bilden die Metapherntypen theoretische Konstrukte: So wie sich die konzeptuellen Wissenssysteme nicht trennscharf auseinanderhalten lassen, so kommt es unausweichlich zu Verzahnungen zwischen den konzeptuellen und epistemischen Metaphern.

Den zweiten grundlegenden Bedeutungskonstituierungs- und Motiviertheitsmechanismus stellt innerhalb der Phraseologie die Metonymie dar. Die traditionelle Auffassung der Metonymie als einer reinen Ersatzrelation (A STEHT FÜR B) wird in der neueren Forschung um die Hervorhebung ihres semantischen Mehrwerts erweitert. Metonymie eröffnet einen mentalen Zugang zu einer konzeptuellen Einheit über eine andere konzeptuelle Einheit. Die konzeptuellen Metonymien TEILHANDLUNG STEHT FÜR HANDLUNG, GRUND FÜR FOLGE stellen den Ausgangspunkt für die Konzeptualisierungen von zahlreichen verbalen Idiomen des untersuchten semantischen Feldes dar, nominale Idiome bzw. nominale Konstituenten von Idiomen werden oft durch die TEIL FÜR GANZES-Metonymie beeinflusst.

Die kognitiv ausgerichteten Definitionen der Metapher und der Metonymie sind an den Begriff der ,Domäne - einer geordneten Repräsentationsstruktur für unterschiedliche Wissens- und Erfahrungsbereiche gebunden: Die Metaphern werden als Projektionen zwischen distinkten Domänen, Metonymien als Projektionen innerhalb eines strukturierten Wissensbereiches definiert. Das menschliche Wissen lässt sich aber in seiner Komplexität und Vielfalt nicht immer eindeutig in einzelne Bereiche einordnen. Viele Bedeutungsverschiebungen lassen sich wegen der mangelnden Trennschärfe und der Affinität zu Mehrfachzuordnungen weder als Metonymie noch als Metapher identifizieren: Metaphtonymische Bedeutungsverschiebungen bilden den dritten Hauptmechanismus der Konstituierung von idiomatischer Bedeutung.

Aus detaillierten empirischen Analysen der metonymischen, metaphorischen und metaphtonymischen Projektionsprozesse in der Idiomatik lassen sich zwei generelle Schlussfolgerungen ziehen: Zum einen sind die Idiome nur selten in ihrer Motiviertheit auf einen einzigen kognitiven Mechanismus zurückzuführen. Die Bedeutungen von Idiomen konstituieren sich in einem zusammengesetzten Geflecht von Metonymien, Metaphern, Metaphtonymien, oft bilden sich metonymisch-metaphorischen Ketten heraus. Es kommt auch vor, dass mehrere 
konkurrierende Mechanismen zugleich evoziert werden und im Spannungsverhältnis stehen, sodass der Rezipient zwischen Auslegungen schwankt bzw. mehrere Aspekte in einer Konzeptualisierung mitschwingen lässt. Zum anderen werden durch die metonymischen, metaphorischen und metaphtonymischen Projektionen kognitive Bereiche nicht einfach in Verbindung gebracht, sondern durch das Zusammenfallen von zwei (konzeptuell mehr oder weniger entfernter) Bereiche tauchen neue Bedeutungen mit einem semantischen Mehrwert auf. Die metaphorischen und metonymischen Mappings erbringen aus sprachökologischer Sicht eine besondere kognitive Leistung: Sie eröffnen Auslegungsspielräume, lassen schwer zu nennende, komplexe Sachverhalte komprimiert, verdichtet auf den Punkt bringen. So nimmt die lexikalisierte Metonymie das Weiße Haus je nach dem Kontext auf den US-Präsidenten, seine Entscheidungen, seinen Mitarbeiterstab, den Regierungssitz in Washington, die US-Regierung sowie die Innen- und Außenpolitik der Vereinigten Staaten von Amerika Bezug. Ähnliche Funktionen üben die Metonymien und Metaphern in der Idiomatik aus: Daraus resultiert semantischer Mehrwert der Idiome, ihre semantische Indeterminiertheit, Flimmrigkeit, ihr kreatives Potenzial.

Die angeführten Projektionsprozesse bilden die relevantesten Mechanismen der Konstituierung von Idiom-Bedeutungen, damit wird allerdings nicht behauptet, dass man mittels der Metonymie, Metapher, Metaphtonymie und der mentalen Bilder alle Faktoren der Bedeutungskonstituierung und Motiviertheit von Idiomen auffasst. Charakteristisch für Idiomatik ist es, dass Forschungsergebnisse in diesem Bereich möglicherweise wenigstens zum Teil materialgeleitet sind, d.h. manche Diskursbereiche eignen sich besser zur Auffassung von bestimmten sprachlichen Phänomenen als andere. So bilden die Zahlen beispielshalber einen exzellenten Bereich zur Erfassung kultureller Divergenzen zwischen den Sprachen, während in den Untersuchungen zu Emotionen wiederum zahlreiche sprachübergreifende Charakteristika, universale Züge feststellbar sind. Da in dieser Arbeit nur ein kleiner Ausschnitt des idiomatischen Bestandes des Deutschen einer eingehenden Analyse unterzogen wurde, sind die Schlussfolgerungen auf das analysierte Material eingeschränkt. Demzufolge werden beispielshalber Ironie und Hyperbel als Mechanismen der Bedeutungsgestaltung nicht berücksichtigt, weil sie in der für die Bedürfnisse der Untersuchung zusammengestellten Phraseologismensammlung nicht auftreten. Auch wenn weitere bedeutungskonstituierende Operationen nicht auszuschließen sind und weiterer Forschung bedürfen, scheinen die metonymischen, metaphorischen und metaphtonymischen Projektionsprozesse doch die verbreitetsten Bedeutungskonstituierungsmechanismen im idiomatischen Bereich darzustellen.

4. Einen wichtigen Beitrag zur Erzeugung des semantischen Mehrwerts leisten des Weiteren die sog. mentalen Bilder, rich images. Zahlreiche Metaphern und Metonymien sind dadurch gekennzeichnet, dass sie mentale Bilder evozieren können. Mentale Bilder werden vorwiegend durch die literale Lesart eines Idioms ausgelöst und liegen dem Phänomen der phraseologischen Bildhaftigkeit zugrunde. Als 
kognitive Phänomene sind sie umstritten: Menschen differieren interindividuell in Bildhaftigkeit ihrer Gedanken, was möglicherweise mit den - in der kognitiven Psychologie gut bekannten - Unterschieden in der Wahrnehmung und Verarbeitung der Informationen zusammenhängt. Auch wenn die Fähigkeit der Individuen zur Evozierung mentaler Bilder individuelle Züge aufweist, liefern die detaillierten Analysen des sprachspielerischen Gebrauchs der Idiome (vgl. Kap. 4.2.2.2.5) sowie die Bedeutungskonstituierungsprozesse eines Idioms mit ambiguer nominaler Konstituente (ein dicker Brocken, vgl. Kap. 4.2.2.2.4) empirische Evidenz für den Einfluss mentaler Bilder auf die Konstituierung idiomatischer Bedeutungen.

5. Zur semantisch-kognitiver Komplexität der Idiom-Bedeutungen trägt des Weiteren ihre Polylexikalität bei: Einerseits stellen die Idiome polylexikale reproduzierbare Spracheinheiten dar: Ihre Bedeutungen konstituieren sich durch semantische Derivationen der ganzen Wortverbindung. Andererseits werden in vielen Verwendungsprofilen und -mustern auch die einzelnen (vorwiegend nominalen) Konstituenten metonymisch-metaphorischen Bedeutungsverschiebungen unterzogen. Demnach sind in den Beschreibungen zwei Ebenen der Bedeutungskonstituierungsprozesse anzunehmen, die potenziell koexistieren können: die Ebene der Bedeutungsverschiebungen von der ganzen Wortverbindung sowie die Ebene der Bedeutungsverschiebungen von einzelnen Idiom-Konstituenten.

6. Die Bedeutungen von idiomatischen Einheiten, aber auch die Phraseologie und Idiomatik im Allgemeinen müssten also als Phänomene in statu nascendi aufgefasst werden. Phraseologie wird als ein Teil des Lexikons erachtet, der sich dynamischer als andere Lexikonteile entwickelt (Lewiński/Pajdzińska/Rejakowa 1987: 40, Worbs 1998: 262). Dies mag einerseits auf die Tatsache zurückzuführen sein, dass der figurative Gebrauch von Wörtern, Ausdrücken und Sätzen eins der kreativen Verfahren der Nomination ist, von dem jeder Sprechende und Schreibende ständig Gebrauch macht und die jeder Hörende und Schreibende in der Regel aufgrund bestimmter Ähnlichkeit- und Kontiguitätsbeziehungen versteht (Munske 2015 [1993]: 104). Werden okkasionell gebrauchte Mehrwortverbindungen als treffend, auffallend, attraktiv und situationsangemessen empfunden und häufig gebraucht, dann erwächst aus dem Usus eine lexikalisierte Bedeutung einer Wortverbindung.

Andererseits unterliegen die bereits bestehenden Phraseologismen möglicherweise häufiger als Einwortlexeme den Bedeutungsverschiebungsprozessen. Die Metaphern und Metonymien, die den Phraseologismen zugrunde liegen, bleiben relativ lange lebendig und eröffnen - wenigstens potenziell - einen interpretativen Spielraum: Auch wenn sich nur manche konzeptuelle Mappings lexikalisieren, so können doch bei Bedarf neue, kreative Korrespondenzen gegründet werden, die man aufgrund der universalen Fähigkeit, Ähnlichkeits- und/oder Kontiguitätsbeziehungen zu erkennen, versteht. Diese Mechanismen bilden eine Basis für phraseologische Variationen und Modifikationen, die keinesfalls zu unterschätzen sind: Es sind die potenziellen Quellen des künftigen Bedeutungswandels, der sich im Wechselspiel zwischen Lexikalisierung und Modifizierung, Idiomatisierung 
und Demotivation vollzieht (Munske 2015 [1993]: 87). Obwohl sich die vorliegende Arbeit grundsätzlich auf die synchrone Betrachtung der phraseologischen Einheiten konzentriert, bleibt es dennoch zu betonen, dass sich die synchronen und diachronen Aspekte in vielen Fällen nicht klar abgrenzen lassen und ein Beispiel für das Leben der Sprache, ein Leben, das aus dem Sprachgebrauch erwächst und durch den Sprachgebrauch bedingt ist, darstellen.

Die semantisch-kognitiven Untersuchungen zu Bedeutungen der Idiome bewegen sich also auf einem weiten Forschungsfeld, der sich zwischen den Landmarken: Produziertes und Reproduziertes, Literales und Nicht-Literales, Metonymisches und Metaphorisches, Verfestigtes und Innovatives, Idiomatisches und Motiviertes, Idiosynkratisches und Konventionalisiertes erstreckt. Dieses Feld zu bebauen, ist ein wahrlich hartes Brot, oft begibt man sich auf den schwankenden Boden der intersubjektiven Interpretationen, das dünne Eis individueller Inferenzen, schwer zu erfassender kognitiver Phänomene. Strebt man allerdings eine wirklichkeitstreue Beschreibung der Bedeutungen im Gebrauch, muss man die entbehrende strenge Formalisierung in Kauf nehmen:

(Linguistic meaning) ... is vague and does not allow one to draw a line in any particular place, even for specific examples. But I consider it appropriate. I prefer a realistic notion of linguistic meaning that is only fuzzily delimited and partially compositional, as opposed to one that (by definition) is precisely and fully compositional, but whose cognitive status is quite dubious. (Langacker 2008: 42-43) 



\section{Anhang}

Tab. 44: 250 deutsche Phraseologismen der Schwierigkeit/der schwierigen Lage anhand lexikographischer Werke.

\begin{tabular}{|c|c|c|c|c|}
\hline \multirow[t]{2}{*}{ Phraseologismen } & \multicolumn{3}{|c|}{ Quellen } & \multirow[t]{2}{*}{ Ausschluss } \\
\hline & $\begin{array}{l}\text { Ettinger- } \\
\text { Phraseologie }\end{array}$ & $\begin{array}{l}\text { Sche- } \\
\text { mann }\end{array}$ & $\begin{array}{l}\text { Redens- } \\
\text { arten- } \\
\text { index }\end{array}$ & \\
\hline sich wie ein Aal winden & F.15. & Cc 14 & & \\
\hline${ }^{*}$ mit Ach und Krach (ugs.) & F.15. & & & ja \\
\hline $\begin{array}{l}\text { in den sauren Apfel beißen } \\
\text { (müssen) }\end{array}$ & F.15. & & & \\
\hline jmdm. in den Arm fallen & & $\mathrm{Hb} 4$ & & \\
\hline $\begin{array}{l}\text { *aufs/auf das Äußerste gefasst sein } \\
\text { (müssen) }\end{array}$ & & $\mathrm{Ga} 4$ & & ja \\
\hline $\begin{array}{l}\text { *aufs/auf das Ärgste gefasst sein } \\
\text { (müssen) }\end{array}$ & & $\mathrm{Ga} 4$ & & ja \\
\hline $\begin{array}{l}\text { *sich aufs/auf das Äußerste gefasst } \\
\text { machen (müssen) }\end{array}$ & & Ga 4 & & ja \\
\hline den Bach runtergehen & & & ja & \\
\hline etw. an der Backe tragen & & & ja & \\
\hline mit etw. auf den Bauch fallen & & & ja & \\
\hline zwischen Baum und Borke geraten & & $\mathrm{Ga} 4$ & & \\
\hline $\begin{array}{l}\text { zwischen Baum und Borke sein } \\
\text { selten }\end{array}$ & & Ga 4 & & \\
\hline Es brennt der Baum & & & ja & \\
\hline $\begin{array}{l}\text { in (große/arge/...) Bedrängnis } \\
\text { kommen }\end{array}$ & & $\mathrm{Ga} 4$ & & \\
\hline in großer/arger ... Bedrängnis sein & & $\mathrm{Ga} 4$ & & \\
\hline $\begin{array}{l}\text { sich in großer/arger ... Bedrängnis } \\
\text { fühlen }\end{array}$ & & $\mathrm{Ga} 4$ & & \\
\hline jmdm. ein Bein stellen (ugs.) & F.15. & $\mathrm{Hb} 4$ & & \\
\hline jmdm. ein Beinchen stellen (ugs.) & & $\mathrm{Hb} 4$ & & \\
\hline etw. am Bein haben & & & ja & \\
\hline sich etw. ans Bein hängen/binden & & & ja & \\
\hline mit jmdm. geht es bergab/bergauf & & & ja & \\
\hline
\end{tabular}


Tab. 44: Continued

\begin{tabular}{lll}
\hline Phraseologismen & \multicolumn{2}{c}{ Quellen } \\
\cline { 2 - 3 } & $\begin{array}{l}\text { Ettinger- Sche- Redens- } \\
\text { Phraseologie mann } \\
\text { arten- } \\
\text { index }\end{array}$ \\
\hline
\end{tabular}

*um jmdn./etw. ist es nicht gut bestellt

Ga 4

ja

*mit jmdm./etw. steht es nicht zum

Ga 4

Ausschluss

besten

*mit seiner Gesundheit/

Leistungskraft/...ist es schlecht/

miserabel... beschaffen (selten)

*Da haben wir/habt ihr/... die

Ga 4

ja

Bescherung!

${ }^{*}$ Da hilft/half nur noch/nichts als

beten (ugs.)

Ga 4

ja

sich eine Blöße geben

Ga 4

(total /völlig) am Boden zerstört

Ga 4

ja

sein

jmdm. brennt der Boden unter den

Füßen

jmdm. den Boden unter den Füßen

heiß machen

jmdm. wird der Boden (unter den

Füßen) zu heiß

sich auf schwankenden/unsicheren

Boden begeben; sich auf

unsicherem/schwankendem Boden

bewegen/befinden

jmdm. schwankt der Boden unter

den Füßen

jmdm. den Boden unter den Füßen

wegziehen

einer Sache den Boden entziehen

den Boden unter den Füßen

verlieren

den festen Boden unter den Füßen

gewinnen

in die Bredouille geraten (geh.)

ja

ja

ja

ja

ja

ja

ja

ja

ja

ja

Ga 4 
Tab. 44: Continued

\begin{tabular}{lll}
\hline Phraseologismen & \multicolumn{2}{c}{ Quellen } \\
\cline { 2 - 3 } & $\begin{array}{l}\text { Ettinger- } \\
\text { Phraseologie mann }\end{array}$ & $\begin{array}{l}\text { Redens- } \\
\text { arten- } \\
\text { index }\end{array}$ \\
\hline
\end{tabular}

jmdn. in die Bredouille bringen (geh.)

in der Bredouille sein/(sitzen)

(geh.)

sich in die Brennnesseln/Nesseln

setzen

ein harter/schwerer Brocken

ein dicker Brocken

etw. ist ein hartes/schweres Brot

*es kommt jmdm. etw./einiges/..

dazwischen

*jmdm. dazwischenfunken (ugs.).

* gut/schlecht ...dran sein

(ganz schön/...) im Dreck sitzen/

stecken vulg.

jmdn. in die Ecke drängen

sich ein Eigentor schießen

sich auf dünnes Eis begeben/wagen;

sich auf dünnem Eis bewegen

ein heißes Eisen sein

ein heißes Eisen anpacken/anfassen

jmdn. in die Enge treiben

in gefährliches Fahrwasser geraten

zu Fall kommen

jmdn. in die/eine Falle locken;

jmdm. eine Falle stellen

jmdm. einen Fallstrick/Fallstricke

legen

zwischen zwei Feuer geraten/

kommen

*sich festfahren
Gb 1

Ga 4

$\mathrm{Ga} 4$

$$
\begin{aligned}
& \text { ja } \\
& \text { ja } \\
& \text { ja }
\end{aligned}
$$

Ga 4

F.15.

$\mathrm{Hb} 4 \quad$ ja

$\mathrm{Hb} 4 \quad$ ja

Ga $4 \quad$ ja

Ga 4

$$
\begin{aligned}
& \text { ja } \\
& \text { ja } \\
& \text { ja }
\end{aligned}
$$

Gb 1

Fa 20

$$
\begin{aligned}
& \text { ja } \\
& \text { ja } \\
& \text { ja } \\
& \text { ja }
\end{aligned}
$$

Ga 4

Ga 4

ja 
Tab. 44: Continued

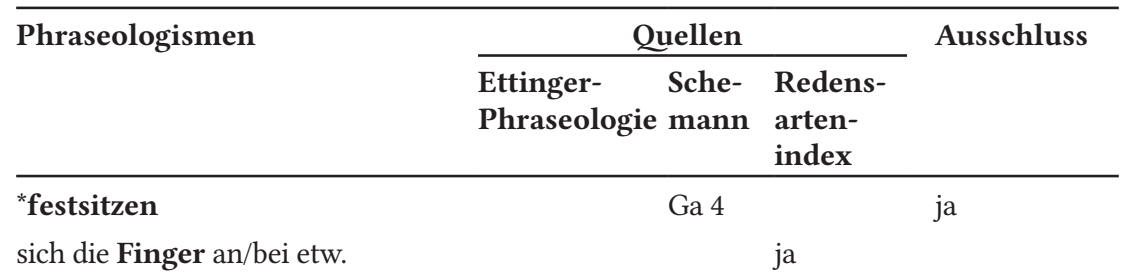

verbrennen

der Funke sein, der das Pulverfass

Gb 1

zum Explodieren bringt

Es knistert im Gebälk

Gb 1

*jmdn./etw. in Gefahr bringen

Gb 1

ja

* sich einer Gefahr aussetzen form

Gb 1

ja

*in Gefahr sein

Gb 1

ja

ins Gedränge kommen

Ga 4

jmdn. ins Gedränge bringen

Ga 4

sich auf Glatteis bewegen

auf Glatteis geraten, sich aufs

Glatteis begeben

*sich auf etw. gefasst machen

Ga 4

ja

(müssen)

jmdm. ins Gehege kommen

$\mathrm{Hb} 4$

[bei jmdm.] [mit etw.] auf Granit beißen

F.15. Ga 4

*Da haben wir's!/habt ihr's/... usg.

Ga 4

ja

*Da hast du's/habt ihr's/... (ugs.)

Ga 4

ja

eine Sache hat einen Haken (ugs.)

F.15.

Ga 4

jmdn./etw. am/auf dem Hals haben

F.15

(ugs.)

Ga 4

jmdn./sich etw. an den Hals hängen

/binden

den Hals in der Schlinge haben

ja

ja

den Hals/Kopf aus der Schlinge

ziehen

zwischen Hammer und Amboss

Ga 4

geraten (geh.). 


\begin{tabular}{|c|c|c|c|}
\hline \multirow[t]{2}{*}{ Phraseologismen } & \multicolumn{2}{|l|}{ Quellen } & \multirow[t]{2}{*}{ Ausschluss } \\
\hline & $\begin{array}{l}\text { Ettinger- Sche- } \\
\text { Phraseologie mann }\end{array}$ & $\begin{array}{l}\text { Redens- } \\
\text { arten- } \\
\text { index }\end{array}$ & \\
\hline
\end{tabular}

zwischen Hammer und Amboss

Ga 4

sein (geh.).

Hammer oder Amboss sein (geh.)

Ga 4

jmdm. die Hände binden

Fa 20

jmdm. ins Handwerk pfuschen

F.15. $\quad \mathrm{Hb} 4$

*mit Hängen und Würgen (ugs.)

F.15.

ja

jmds. Pläne über den Haufen

werfen

Da liegt der Hase im Pfeffer (ugs.)

F.15.

nicht in jmds. Haut stecken mögen

Ga 4

jmdm. einen Hemmschuh in den

Weg legen selten

*aus etw./da nicht (mehr)

herauskommen

${ }^{*}$ Sieh $\mathrm{zu} / .$. , wie du/... da

herauskommst!

jmdm. Hindernisse in den Weg

legen

bei jmdm. ist Holland in Not

$\mathrm{Hb} 4$

Ga 4

ja

Da liegt der Hund begraben (ugs.)

F.15.

Ga 4

ja

eine Hürde nehmen

Hürden/eine Hürde beseitigen

sich im Jammertal befinden

jmdm. Knüppel/einen Knüppel

zwischen die Beine werfen (ugs.)

F.16. $\quad$ Ga 4

$\mathrm{Hb} 4$

ein Kapitel für sich sein

E.9.

$\mathrm{Hb} 4$

etw./den Karren/die Karre an/vor/

Ga 4

gegen die Wand fahren

Die Karre ist (gründlich) verfahren (ugs.) 
Tab. 44: Continued

\begin{tabular}{lll}
\hline Phraseologismen & \multicolumn{2}{c}{ Quellen } \\
\cline { 2 - 3 } & $\begin{array}{l}\text { Ettinger- } \\
\text { Phraseologie mann }\end{array}$ & $\begin{array}{l}\text { Redens- } \\
\text { arten- } \\
\text { index }\end{array}$ \\
\hline
\end{tabular}

Der Karren ist (gründlich)

Ga 4

verfahren (ugs.)

Die Karre steckt/ist im Dreck (ugs.)

Ga 4

Der Karren steckt/ist im Dreck

Ga 4

(ugs.)

Die Karre in den Dreck fahren

Ga 4

(ugs.)

Den Karren in den Dreck fahren

Ga 4

(ugs.)

an etw. zu kauen haben

ja

etw. im Keim ersticken

$\mathrm{Hb} 4$

in die Klemme geraten

Ga 4

(ganz schön/...) in der Klemme

Ga 4

sitzen (ugs.)

die Klippen umfahren/umschiffen

ja

jmdm. ein Klotz am Bein sein (ugs.) F.15.

sich (Dativ) [mit jmdm./etw.] einen F.15.

Klotz ans Bein binden (ugs.)

jmdm. (einen) Knüppel zwischen

die Beine werfen

wie ein Knüppel am Bein

*/etw. nicht/nicht erst/.../dazu

kommen lassen

*es/etw. nicht/nicht erst/gar nicht

erst/... so weit kommen lassen

jmdm. das/sein Konzept verderben F.15.

(ugs.)

etw. wächst jmdm. über den Kopf F.15.

(ugs.)

aufs Kreuz fallen

ja

die Kuh vom Eis holen/ziehen/

ja

schieben/kriegen/führen/bringen

$\mathrm{Hb} 4 \quad$ ja

$\mathrm{Hb} 4 \quad$ ja 


\begin{tabular}{|c|c|c|c|}
\hline \multirow[t]{2}{*}{ Phraseologismen } & \multicolumn{2}{|l|}{ Quellen } & \multirow[t]{2}{*}{ Ausschluss } \\
\hline & $\begin{array}{l}\text { Ettinger- Sche- } \\
\text { Phraseologie mann }\end{array}$ & $\begin{array}{l}\text { Redens- } \\
\text { arten- } \\
\text { index }\end{array}$ & \\
\hline
\end{tabular}

mit seiner Kunst am Ende sein

(ugs.)

jmdn./etw. in eine unangenehme/

Ga 4

missliche/verzwickte Lage bringen

in einer ausweglosen Lage (sein)

Ga 4

*nicht in jmds. Lage sein mögen

Ga 4

mit seinem Latein am Ende sein

Ga 4

ja

(ugs.)

jmdm. eine Laus in den Pelz setzen

Ga 4

jmdm. eine Laus ins Fell setzen

$\mathrm{Hb} 5$

sich durchs Leben schlagen (ugs.)

$\mathrm{Hb} 5$

jmdm. das Leben sauer machen

Licht am Ende des Tunnels sehen

jmdm. die Luft abdrehen

Die Luft wird dünn

die Lunte ans Pulverfass legen

F.15.

Das Messer sitzt jmdm. an der

Kehle

*mit (knapper) Müh und Not

F.15.

ja

auf die Nase fallen/fliegen

ja

*in tausend Nöten sein (path.).

Ga 4

$$
\begin{aligned}
& \text { ja } \\
& \text { ja } \\
& \text { ja } \\
& \text { ja }
\end{aligned}
$$

Gb 1

Ga 4

eine harte Nuss [für jmdn.] sein

(ugs.)

eine harte Nuss zu knacken haben

(ugs.)

sich auf glattes Parkett wagen

ja

in die Patsche geraten (ugs.)

Ga 4

jmdn. in die Patsche reiten

Ga 4

in der Patsche sitzen (ugs.)

Ga 4

die Peitsche im Nacken spüren

F.15.

F.15. ja 
Tab. 44: Continued

\begin{tabular}{lll}
\hline Phraseologismen & \multicolumn{2}{c}{ Quellen } \\
\cline { 2 - 3 } & $\begin{array}{l}\text { Ettinger- } \\
\text { Phraseologie mann }\end{array}$ & $\begin{array}{l}\text { Redens- } \\
\text { arten- } \\
\text { index }\end{array}$ \\
\hline
\end{tabular}

jmdm. die Pistole, das Messer, den

Fa.20

Dolch auf die Brust/an die Gurgel, an die Kehle setzen

jmds. Pläne durchkreuzen

$\mathrm{Hb} 4$

jmdm. den schwarzen Peter

$\mathrm{Hb} 4$

zuspielen

sich bei/an etw. die Pfoten

ja

verbrennen

Hier/da/in/... (wie) auf einem

Gb 1

Pulverfass sitzen

jmdm. in die Quere kommen

F.15. $\quad \mathrm{Hb} 4$

(seltener:) geraten/laufen (ugs.),

laufen/rennen/kommen (Schemann)

nicht auf Rosen gebettet sein (ugs.) F.15.

mit dem Rücken zur Wand stehen

Fa 21

Ruhe vor dem Sturm

Gb 1

ins Rutschen/Schlingern

kommen/geraten

in eine Sackgasse geraten

$\mathrm{Ga} 4$

sich in eine Sackgasse verrennen

Ga 4

in einer Sackgasse stecken

Ga 4

jmdn. im eigenen Saft schmoren

lassen

Sand ins Getriebe streuen

$\mathrm{Hb} 4$

Sand im Getriebe sein

$\mathrm{Hb} 4$

nicht über seinen (eigenen)

F.15.

Schatten springen können

in der Scheiße sitzen vulg.

Ga 4

jmdn./sich in die Scheiße reiten

bis zum Hals in der Scheiße stecken

jmdn. aus der Scheiße ziehen

F.15.

ja

ja
ja
ja 


\begin{tabular}{|c|c|c|c|}
\hline \multirow[t]{2}{*}{ Phraseologismen } & \multicolumn{2}{|l|}{ Quellen } & \multirow[t]{2}{*}{ Ausschluss } \\
\hline & $\begin{array}{l}\text { Ettinger- Sche- } \\
\text { Phraseologie mann }\end{array}$ & $\begin{array}{l}\text { Redens- } \\
\text { arten- } \\
\text { index }\end{array}$ & \\
\hline $\begin{array}{l}\text { (tief/knietief) in der Scheiße/Kacke } \\
\text { sitzen/stecken }\end{array}$ & & ja & \\
\hline $\begin{array}{l}\text { (ganz schön/...) im Schlamassel } \\
\text { stecken/sitzen }\end{array}$ & $\mathrm{Ga} 4$ & & \\
\hline $\begin{array}{l}\text { Da haben wir/habt ihr/... den } \\
\text { Schlamassel! (ugs.) }\end{array}$ & Ga 4 & & \\
\hline auf dem Schlauch stehen & & ja & \\
\hline $\begin{array}{l}\text { *aufs/auf das Schlimmste gefasst } \\
\text { sein (müssen) }\end{array}$ & Ga 4 & & ja \\
\hline $\begin{array}{l}\text { *sich aufs/auf das Schlimmste } \\
\text { gefasst machen (müssen) }\end{array}$ & $\mathrm{Ga} 4$ & & ja \\
\hline $\begin{array}{l}{ }^{*} \text { mit dem Schlimmsten rechnen } \\
\text { müssen }\end{array}$ & $\mathrm{Ga} 4$ & & ja \\
\hline die Schlinge zieht sich zu & & ja & \\
\hline mit etw. auf die Schnauze/Fresse & & ja & \\
\hline
\end{tabular}

nicht in jmds. Schuhen stecken Ga 4

mögen selten

(ständig/...) das Schwert des

$\mathrm{Gb} 1$

Damokles über sich haben/fühlen

... (geh.) selten

(ständig/...) ein/das

Damoklesschwert über sich

haben/fühlen (geh.) selten

das Schwert des Damokles

schwebt über jmdm. (geh.) selten

*in Schwierigkeiten geraten

*es steht schlecht/nicht gut/... um

jmdn./etw.

in den Staub beißen

jmdm. einen (dicken) Strich durch

die Rechnung machen (ugs.)

F.16. $\quad \mathrm{Hb} 4$
Gb 1

Gb 1

Ga 4

ja

Ga 4

ja ja 
Tab. 44: Continued

\begin{tabular}{|c|c|c|c|}
\hline \multirow[t]{2}{*}{ Phraseologismen } & \multicolumn{2}{|l|}{ Quellen } & \multirow[t]{2}{*}{ Ausschluss } \\
\hline & $\begin{array}{l}\text { Ettinger- Sche- } \\
\text { Phraseologie mann }\end{array}$ & $\begin{array}{l}\text { Redens- } \\
\text { arten- } \\
\text { index }\end{array}$ & \\
\hline
\end{tabular}

die Suppe auslöffeln (müssen),

F.16.

die man sich (Dativ) eingebrockt

hat (ugs.)

in Schwulitäten kommen/geraten

(ugs.)

jmdn. in Schwulitäten bringen

Ga 4

(ugs.)

in Schwulitäten sein (ugs.)

Ga 4

in Schwulibus sein (veraltend)

Ga 4

zwischen Skylla/Scylla und

Charybdis sein

jmdm. Steine in den Weg legen

F.15.

Ga 4

*nicht an jmds. Stelle sein mögen

Wenn ...dann/... kann sich jd. ja

gleich/sofort einen Strick kaufen/

nehmen (und sich aufhängen) (ugs.)

sich an einen/letzten Strohhalm

klammern (ugs.)

nach einem/letzten Strohhalm

greifen (ugs.)

jmdm. (gehörig/...) die Suppe

versalzen (ugs.)

jmdm. in die Suppe spucken (ugs.)

selten

Suppe einbrocken; sich etw.

einbrocken

auf Talfahrt sein

das Ende der Talsohle ist erreicht/

die Talsohle ist durchschnitten

etw. ist ein (regelrechter/...) Tanz

auf dem Vulkan (path.).

Ga 4

$\mathrm{Hb} 4$

Ga $4 \quad$ ja

Ga 4

Ga 4

$\mathrm{Hb} 4$

$\mathrm{Hb} 4$

bei etw. hat der Teufel die/seine

F.15.

Hand im Spiel

ja

ja

ja

Gb 1 
Phraseologismen

\begin{tabular}{lll}
\multicolumn{3}{c}{ Quellen } \\
\hline $\begin{array}{l}\text { Ettinger- } \\
\text { Sche- }\end{array}$ & $\begin{array}{l}\text { Redens- } \\
\text { Phraseologie mann } \\
\text { arten- } \\
\text { index }\end{array}$
\end{tabular}

Ausschluss

Ga 4

in Teufels Küche kommen/geraten F.15.

(ugs.)

in einem Tief stecken

ja

(ganz schön/...) in der Tinte sitzen (ugs.)

F.15.

Ga 4

sich aus der Tinte ziehen (ugs.) ja

jmdn. in die Tinte reiten

ja

*in Todesgefahr schweben/sein

* sich totlaufen

*etw./die Sache hat sich totgelaufen

ins Trudeln kommen/geraten

*die Sache/Situation/Geschichte/

Verhandlungen/... ist/sind

gründlich/rettungslos/völlig/...

verfahren

*in die Verlegenheit kommen

(können), etw. zu tun

*jmdn. (arg/sehr/ziemlich ...) in

Verlegenheit bringen/(setzen)

*etw./die Sache/der Fall ist/liegt/...

sehr verwickelt

auf einem Vulkan leben (path.)

Ga 4

ja

Ga $4 \quad$ ja

auf einem Vulkan tanzen

Gb 1

Ga $4 \quad$ ja

Ga $4 \quad$ ja

Ga $4 \quad$ ja

jmdn. an die Wand drücken /

spielen

jmdn./sich über Wasser halten,

Schemann: sich (noch/noch so eben/...) über Wasser halten; den

Kopf noch/noch so eben über

Wasser halten 
Tab. 44: Continued

\begin{tabular}{lll}
\hline Phraseologismen & \multicolumn{2}{c}{ Quellen } \\
\cline { 2 - 3 } & $\begin{array}{l}\text { Ettinger- } \\
\text { Phraseologie mann }\end{array}$ & $\begin{array}{l}\text { Redens- } \\
\text { arten- } \\
\text { index }\end{array}$ \\
\hline
\end{tabular}

das Wasser steht/geht/reicht jmdm.

Ga 4

(schon/...) bis zum/(an den) Hals/

bis hier (hin) (mit einer Geste: Hand

quer zum Kinn bzw. unter die Nase)

das Wasser steht/geht/reicht jmdm.

Ga 4

(schon/...) bis an die/(zur) Kehle

jmdm. in den Weg laufen

$\mathrm{Hb} 4$

jmdm. in den Weg kommen

$\mathrm{Hb} 4$

sich jmdm. in den Weg stellen (bei

$\mathrm{Hb} 4$

etw.)

jmdm. in den Weg treten

$\mathrm{Hb} 4$

jmdm. den Weg versperren

$\mathrm{Hb} 4$

jmdm. den Weg vertreten (veraltet)

$\mathrm{Hb} 4$

jmdm. den Weg verlegen (veraltet)

$\mathrm{Hb} 4$

jmdm. im Weg(e) sein

$\mathrm{Hb} 4$

jmdm./einer Sache im Wege stehen

$\mathrm{Hb} 4$

(bei etw.)

nicht mehr weiter wissen

Ga 4

nicht mehr ein noch aus/nicht mehr

Ga 4

aus noch ein/weder aus noch ein/

weder ein noch aus wissen

nicht wissen, wie man aus etw./da

Ga 4

herauskommen soll

mit seiner Weisheit am Ende sein

Ga 4

(ugs.)

Es ballen sich drohende Wolken

Gb 1

über jmdm./einem Land/...

zusammen (path.).

von einer (dunklen) Wolke

Gb 1

überschattet werden (path.).

sich (Dativ) die Zähne an etw.

F.15.

ausbeißen

die Zeitbombe tickt

Gb 1 


\begin{tabular}{|c|c|c|c|}
\hline \multirow[t]{2}{*}{ Phraseologismen } & \multicolumn{2}{|l|}{ Quellen } & \multirow[t]{2}{*}{ Ausschluss } \\
\hline & $\begin{array}{l}\text { Ettinger- Sche- } \\
\text { Phraseologie mann }\end{array}$ & $\begin{array}{l}\text { Redens- } \\
\text { arten- } \\
\text { index }\end{array}$ & \\
\hline *auf bessere Zeiten hoffen & $\mathrm{Ga} 4$ & & ja \\
\hline *auf bessere Zeiten warten & $\mathrm{Ga} 4$ & & ja \\
\hline jmdn. in die Zange nehmen & Fa 20 & & \\
\hline $\begin{array}{l}\text { sich am eigenen Zopf/an den } \\
\text { eigenen Haaren/am eigenen Haar } \\
\text { aus dem Sumpf ziehen }\end{array}$ & & ja & \\
\hline $\begin{array}{l}\text { jmdn. (nicht) zum Zug(e) kommen } \\
\text { lassen }\end{array}$ & $\mathrm{Hb} 4$ & & \\
\hline $\begin{array}{l}\text { *Pläne/Hoffnungen } \\
\text { zunichtemachen }\end{array}$ & $\mathrm{Hb} 4$ & & ja \\
\hline $\begin{array}{l}\text { in einer (richtigen/...) Zwickmühle } \\
\text { stecken }\end{array}$ & Ga 4 & & \\
\hline $\begin{array}{l}\text { sich in einer richtigen Zwickmühle } \\
\text { befinden (ugs.) }\end{array}$ & Ga 4 & & \\
\hline in eine Zwickmühle geraten (ugs.) & $\mathrm{Ga} 4$ & & \\
\hline in einem Zwiespalt stecken & $\mathrm{Ga} 4$ & & \\
\hline $\begin{array}{l}\text { jmdn. in einen Zwiespalt bringen/ } \\
\text { stürzen }\end{array}$ & $\mathrm{Ga} 4$ & & \\
\hline
\end{tabular}


Tab. 45: Zusammenstellung der Zitierform und Bedeutungsparaphrasen aus dem Wörterbuch Duden 11 (bzw. DUW online) und den aus den Belegesammlungen ermittelten Varianten/Modifikationen sowie Verwendungsprofilen/Verwendungsmustern der untersuchten Idiome.

\begin{tabular}{ll}
\hline DUDEN 11 (2011) & $\begin{array}{l}\text { Die ermittelten Varianten/ } \\
\text { Modifikationen }\end{array}$ \\
\hline $\begin{array}{l}\text { sich auf schwankenden/ } \\
\text { unsicheren Boden }\end{array}$ & $\begin{array}{l}\text { auf dem schwankenden } \\
\text { Boden stehen, überleben, } \\
\text { begeben: (in seinen }\end{array}$ \\
$\begin{array}{l}\text { auf schwankendem Boden } \\
\text { mit einiger Stabilität }\end{array}$ \\
$\begin{array}{l}\text { Argumentationen o.A.) } \\
\text { den Boden der Tatsachen, }\end{array}$ & $\begin{array}{l}\text { weiterbestehen, etw. steht auf } \\
\text { dem schwankenden Boden, }\end{array}$ \\
$\begin{array}{l}\text { es Gesicherten verlassen, } \\
\text { unsichere Voraussetzungen }\end{array}$ & $\begin{array}{l}\text { Boden auf } \text { augebaut, den } \\
\text { einbeziehen: Mit diesen }\end{array}$ \\
Theorien begab er sich auf & schwankenden Boden (der \\
\end{tabular}

unsicheren Boden.

Die ermittelten Verwendungsprofile und Verwendungsmuster

schwankender Boden

1. jd. steht auf einem schwankenden Boden - jd. ist in einer schwierigen, unsicheren Lage

(18 Belege)

1.1 ,eine riskante, unsichere (Lebens-) Lage einer Person/Personengruppe

(13 Belege)

1.2 ,(Wissenschaft) unsichere, angreifbare Lage, in die sich ein Wissenschaftler versetzt, der in einem nicht gut etablierten Forschungsbereich tätig ist bzw. intersubjektiv schwer fassbare Thesen aufstellt (5 Belege)

2. etw. steht auf dem schwankenden Boden ,etw. (eine Theorie, eine Argumentation, eine Anklage, die Wirtschaft) hat unsichere Grundlagen/ Fundamente

(10 Belege)

3. kein fester Boden: ,Schiffsdeck oder tektonisch unsichere Gebiete

(6 Belege)

idiosynkratischer Gebrauch

(6 Belege)

Im Duden 11 nicht

verzeichnet

sich auf dünnes Eis

begeben, wagen (sich in

eine unsichere, riskante Lage bringen)

auf dünnem Eis stehen, sich bewegen (sich in einer unsicheren, riskanten Lage befinden)

jd. wandelt auf bedenklich dünnem Eis, jd. geht auf dünnes Eis

1. ,unsichere, riskante, schwierige Lage einer dünnes Eis, jd. rettet sich auf Person" das dünne Eis semantischer (34 Belege)

Spitzfindigkeiten, jd. wagt vom 1.1. ,eine missliche, schwierige Lage, in der man dünnen Eis weitere Schritte, jd. leicht folgenschwere Fehler begehen kann tanzt auf besonders dünnem (16 Belege)

Eis, etw. ist das dünne Eis, jd. 1.2. ,trügerische Geborgenheit der menschlichen spricht von dünnem Eis, jd. Existenz ${ }^{6}$ befindet sich auf dünnem Eis, (5 Belege) (DUW online, letzter Zugriff auf dünnem Eis schleudern. am 27.10.2017)
1.3 ,eine riskante, unsichere Position, in die sich jd. mit seiner umstrittenen, unsicheren Gesetzesauslegung bzw. Theorie begibt ${ }^{\star}$

(13 Belege)

2. ,umstrittene, nicht gut begründete Grundlage eines Gesetzes, der Auslegung eines Gesetzes, einer Hypothese, einer These, einer Argumentation (4 Belege) idiosynkratischer Gebrauch (2 Belege) 


\begin{tabular}{|c|c|c|}
\hline DUDEN 11 (2011) & $\begin{array}{l}\text { Die ermittelten Varianten/ } \\
\text { Modifikationen }\end{array}$ & $\begin{array}{l}\text { Die ermittelten Verwendungsprofile und } \\
\text { Verwendungsmuster }\end{array}$ \\
\hline $\begin{array}{l}\text { glattes Parkett betreten, } \\
\text { sich auf glattem Parkett } \\
\text { bewegen ein Risiko } \\
\text { eingehen, etw. Riskantes } \\
\text { tun: Wer an die Börse geht, } \\
\text { müsse eben wissen, dass er } \\
\text { glattes Parkett betrete (Zeit } \\
\text { 12.10.2000). Dafür verlässt der } \\
\text { Evolutionsbiologe mitunter } \\
\text { auch schon einmal den festen } \\
\text { Boden der Naturwissenschaft } \\
\text { und begibt sich immer } \\
\text { wieder aufs glatte Parkett } \\
\text { der Philosophie, wo er } \\
\text { nicht immer eine so ganz } \\
\text { überzeugende Figur macht } \\
\text { (Standard 20.01.2007, } 41 \text { ). }\end{array}$ & $\begin{array}{l}\text { auf dem glatten Parkett } \\
\text { ausrutschen, auf glattem } \\
\text { Parkett stehen, Vergnügen } \\
\text { am glatten Parkett haben, } \\
\text { glattes Parkett bleibt für } \\
\text { jmdn. rutschfest, sich auf dem } \\
\text { glatten Parkett einer Sache } \\
\text { auskennen, sich auf dem } \\
\text { angestrebten glatten Parkett } \\
\text { bewegen, auf dem Boden } \\
\text { des glatten Parketts hart } \\
\text { aufschlagen, u.a. }\end{array}$ & $\begin{array}{l}\text { glattes Parkett } \\
\text { 1. ,riskante Tätigkeitsbereiche, in denen die } \\
\text { Beachtung der Umgangsformen von Relevanz ist‘ } \\
\text { (16 Belege) } \\
\text { 2. ,Börsenverkehr und die damit verbundenen } \\
\text { finanziellen Risikos' } \\
\text { (11 Belege) } \\
\text { 3. ,ein schwieriger Bereich, ein heikles Thema‘ } \\
\text { (4 Belege) } \\
\text { idiosynkratischer und sprachspielerischer } \\
\text { Gebrauch } \\
\text { (9 Belege) }\end{array}$ \\
\hline $\begin{array}{l}\text { jmdm. ein/(schweiz.) das } \\
\text { Bein stellen: 1. jmdn. durch } \\
\text { Vorstellen eines Beins zum } \\
\text { Stolpern bringen: Jemand hat } \\
\text { mir das Bein gestellt (Frisch, } \\
\text { Andorra 117). Wenn ich } \\
\text { erwischt werde, hau ich ab, } \\
\text { und du stellst denen, die mir } \\
\text { nachlaufen, ein Bein (Roehler, } \\
\text { Würde 55). 2. (ugs.) jmdm. } \\
\text { hinterlistig Schaden zufügen, } \\
\text { jmdn. hereinlegen: Wenn Sie } \\
\text { nicht aufpassen, stolpern Sie } \\
\text {... über ein Bein, das Ihnen ein } \\
\text {... Kollege gestellt hat (Erne, } \\
\text { Fahrgäste } 317) .\end{array}$ & $\begin{array}{l}\text { jmdm. kein Bein stellen, sich } \\
\text { selbst ein Bein stellen }\end{array}$ & $\begin{array}{l}\text { 1. ,jmdn. durch Vorsetzen des Beines zu Fall } \\
\text { bringen` } \\
\text { (6 Belege) } \\
\text { 2. ,jmdm. schaden, Nachteile zufügen' } \\
\text { (22 Belege) } \\
\text { 3. sich selbst ein Bein stellen ,sich selbst schaden } \\
\text { (12 Belege) }\end{array}$ \\
\hline
\end{tabular}


Tab. 45: Continued

\begin{tabular}{ll}
\hline DUDEN 11 (2011) & $\begin{array}{l}\text { Die ermittelten Varianten/ } \\
\text { Modifikationen }\end{array}$ \\
\hline Knüppel zwischen die & stärkere Knüppel zwischen \\
Beine werfen jmdm. & die Beine werfen, einige/ \\
Schwierigkeiten machen: & zahllose/allerlei Knüppel \\
Der hatte, nur um ihm & zwischen die Beine werfen, \\
den Knüppel zwischen die & immer wieder/ständig/nicht \\
Beine zu werfen, alle diese & ständig Knüppel zwischen \\
frechen, höllisch schlauen & die Beine werfen, Knüppel \\
Klauseln und Erschwernisse & zwischen die Beine geworfen \\
ausgeheckt (Feuchtwanger, & bekommen, die meisten \\
Herzogin 100). & Knüppel zwischen die Beine \\
& werfen, einen Knüppel nach \\
& dem anderen zwischen die \\
& Beine werfen, diplomatische \\
& Knüppel zwischen die Beine \\
& werfen, mit Schwung Knüppel \\
& zwischen die Beine werfen, \\
& Knüppel zwischen die Beine \\
& werfen, wo es nur geht. \\
\hline
\end{tabular}

Klotz am Bein jmdm. ein Klotz am Bein sein (ugs.) eine Last, ein Hemmnis für jmdn. sein: Das Mädchen lasse ich doch hier. Sie wäre mir in der ersten Zeit nur ein Klotz am Bein. (Brecht, Mensch 72)

sich $<$ Dativ $>$ einen Klotz ans Bein binden/hängen (ugs.): sich etw. aufbürden: Ich habe nicht geahnt, was ich mir mit dieser ehrenamtlichen Tätigkeit für einen Klotz ans Bein binden würde. etw. hängt jmdm. wie ein Klotz am Bein, marschieren, als $o b$ man einen Klotz am Bein hätte, sich als Klotz am Bein erweisen, jmdn. als Klotz am Bein bezeichnen, der größte Klotz am Bein sein, der defizitäre Klotz am Bein ist weg, etw. wird als schwerer Klotz am Bein empfunden, jmdm. wie ein Klotz am Bein hängen, zum Klotz am Bein werden, Wettbewerb mit einem Klotz am Bein, etw. wie einen Klotz am Bein mit sich einen Klotz am Bein haben herumschleppen, sich als ein (ugs.): eine Verpflichtung Klotz am Bein erweisen. etw. ist ein Klotz am Bein

,Störfaktor, Hindernis, eine Erschwernis`

(32 Belege)

jd. ist ein Klotz am Bein

,jd. stellt eine Erschwernis, ein Hindernis dar

(7 Belege)

übernommen haben und

dadurch in seiner Bewegungs-

und Handlungsfreiheit spürbar

eingeengt, belastet sein: ...

zumal den tschechischen

Politikern sicherlich bewusst

ist, dass sie mit ihren

Entscheidungen in Bezug auf

EU-Osterweiterung einen

Klotz am Bein haben (www.

parinkom.gv.at.) (2011: 424) 


\begin{tabular}{|c|c|c|}
\hline DUDEN 11 (2011) & $\begin{array}{l}\text { Die ermittelten Varianten/ } \\
\text { Modifikationen }\end{array}$ & $\begin{array}{l}\text { Die ermittelten Verwendungsprofile und } \\
\text { Verwendungsmuster }\end{array}$ \\
\hline $\begin{array}{l}\text { jmdn., etw. am/auf dem } \\
\text { Hals haben (ugs.): sehr viel } \\
\text { Mühe, Ärger mit jmdm., etw. } \\
\text { haben; mit jmdm., etw. belastet } \\
\text { sein: ... hoffentlich kommt er } \\
\text { nicht auf die Idee, sich allein } \\
\text { davonzuschleichen. Dann } \\
\text { hab ich sie auf dem Hals } \\
\text { (Kronauer, Bogenschütze 301). } \\
\text {... er hatte Verfahren wegen } \\
\text { unberechtigter Führung } \\
\text { akademischer Titel ... am Hals } \\
\text { (Spiegel } 49,1966,44 \text { ). }\end{array}$ & $\begin{array}{l}\text { mit etw. am Hals, als ob jd. } \\
\text { nicht schon genug (Krisen, } \\
\text { Probleme) am Hals hätte, } \\
\text { mit etw. schon genug am Hals } \\
\text { haben. }\end{array}$ & 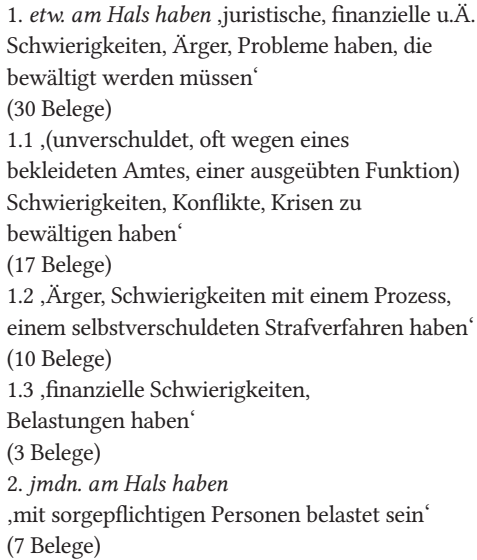 \\
\hline
\end{tabular}

\section{jmdn. in die Enge}

treiben: jmdn durch Fragen, Drohungen o. Ä. in Bedrängnis bringen: Der Staatsanwalt trieb den Angeklagten in die Enge. Die Lehrerin geriet in Verlegenheit, als sei sie in die Enge getrieben und müsse sich herausreden (Th. Mann, Zauberberg 192)

- Die Wendung bezieht sich in ihrer Bildlichkeit darauf, dass man früher beim Kampf den Gegner gegen die Wand oder in die Ecke zu treiben versuchte, um seine Bewegungsfreiheit einzuschränken und ihm die Möglichkeit zur Flucht zu nehmen. sich in die Enge getrieben fühlen, sich in die Enge getrieben finden

1. ,jmdn. in seiner Bewegungs- und Handlungsfreiheit beschränken, in eine ausweglose Lage bringen, unter Druck setzen (23 Belege)

2. in einer verbal-argumentatorischen Auseinandersetzung: ,jmdm. mit gezielt gestellten Fragen zusetzen, jmdn. mit Argumenten und Fragen in eine schwierige, ausweglose Situation bringen, in der er die Überlegenheit des Gesprächspartners anerkennen muss (17 Belege) 
Tab. 45: Continued

\begin{tabular}{|c|c|c|}
\hline DUDEN 11 (2011) & $\begin{array}{l}\text { Die ermittelten Varianten/ } \\
\text { Modifikationen }\end{array}$ & $\begin{array}{l}\text { Die ermittelten Verwendungsprofile und } \\
\text { Verwendungsmuster }\end{array}$ \\
\hline $\begin{array}{l}\text { jmdn. an/gegen die Wand } \\
\text { drücken (ugs.): jmdn. in den } \\
\text { Hintergrund drängen: Sie war } \\
\text { eine Regisseurin, die sich von } \\
\text { keinem Intendanten gegen } \\
\text { die Wand drücken ließ. Den } \\
\text { steckte er, was politisches } \\
\text { Wissen betraf, in die Tasche; } \\
\text { den drückte er auch als } \\
\text { Redner glatt an die Wand } \\
\text { (Bredel, Väter } 89 \text { ). }\end{array}$ & $\begin{array}{l}\text { sich an die Wand drücken } \\
\text { lassen, sich an die Wand } \\
\text { gedrückt fühlen, sich an die } \\
\text { Wand gedrückt sehen }\end{array}$ & $\begin{array}{l}\text { 1. in einem politischen oder wirtschaftlichen } \\
\text { Konkurrenzkampf: ,jmdn. verdrängen, seines } \\
\text { Wirkungsbereiches berauben und auf diese Weise } \\
\text { in eine (wirtschaftliche, politische) Zwangslage } \\
\text { bringen, verursachen, dass jd. an Bedeutung } \\
\text { verliert oder ganz ausgeschaltet wird‘ } \\
\text { ( } 24 \text { Belege) } \\
\text { 2. ,jmdn. einschüchtern, verunsichern, verursachen, } \\
\text { dass man sich in seiner Gesellschaft klein fühlt' } \\
\text { (6 Belege) } \\
\text { 3. ,jmdn. in schwierige, ratlose Lage bringen, aus } \\
\text { der man keinen Ausweg findet } \\
\text { (4 Belege) } \\
4 . \text {,etw. in den Hintergrund verschieben, in den } \\
\text { Schatten stellen } \\
\text { ( } 3 \text { Belege) }\end{array}$ \\
\hline
\end{tabular}

ein hartes/schweres

Brot sein: ein mühevoller Gelderwerb sein: Er brummelte ... das könnte doch nie gut gehen - Vertreter, Reisender, das sei ein hartes Brot (Richartz, Büroroman 100). hartes Brot, ganz schön hartes 1. ,eine schwere Arbeit, die mit der Sicherung der Brot, ein sehr hartes Brot, materiellen Lebensgrundlage verbunden ist (21 Belege)

2. ,eine Herausforderung, eine schwierige Aufgabe (13 Belege) harte Brot der Opposition (3 Belege), das harte Brot der Identitätssuche, das harte Brot 3. das harte Brot der Opposition jedes Essenliebhabers, das (3 Belege) harte Brot der Kunst, dasselbe harte Brot eine harte Nuss [für jmdn.] alles harte Nüsse, eine richtig sein (ugs.): ein schwieriges Problem, eine unangenehme Aufgabe [für jmdn.] sein harte Nuss, eine besonders
1. etw. ist eine harte Nuss: ,etw. stellt eine schwierige Aufgabe/eine Herausforderung dar, harte Nuss, eine ähnlich harte etw. ist eine Herausforderung Nuss wie ..., eine härtere Nuss (28 Belege) als ... (2 Belege), eine vielleicht 2. jd. ist eine harte Nuss: ,jd. (eine Gruppe von noch härtere Nuss, die härteste Menschen) ist unnachgiebig, widerstandsfähig Nuss, eine $z u$ harte Nuss
(12 Belege)

2.1 ,jd. ist unnachgiebig, schwer von seinen Zielen abzubringen'

(6 Belege)

2.2 ,ein starker Gegner

(6 Belege) 


\begin{tabular}{|c|c|c|}
\hline DUDEN 11 (2011) & $\begin{array}{l}\text { Die ermittelten Varianten/ } \\
\text { Modifikationen }\end{array}$ & $\begin{array}{l}\text { Die ermittelten Verwendungsprofile und } \\
\text { Verwendungsmuster }\end{array}$ \\
\hline $\begin{array}{l}\text { in den sauren Apfel beißen } \\
\text { (ugs.): etw. Unangenehmes } \\
\text { notgedrungen tun: Wenn sich } \\
\text { alle drum drücken, muss ich } \\
\text { wohl in den sauren Apfel } \\
\text { beißen und den Wochenputz } \\
\text { mal wieder alleine machen. }\end{array}$ & $\begin{array}{l}\text { etw. ist ein mächtig saurer } \\
\text { Apfel; in den größten } \\
\text { sauren Apfel beißen; in den } \\
\text { sauren Apfel (+ Gen.) hoher } \\
\text { Effektenabschreibungen, der } \\
\text { Gegebenheiten beißen; das war } \\
\text { der saure Apfel, in den wir } \\
\text { beißen mussten; ein Biss in } \\
\text { den sauren Apfel }\end{array}$ & $\begin{array}{l}\text { 1. ,ein notwendiges Übel akzeptieren müssen, } \\
\text { eine ungünstige Entscheidung treffen und ihre } \\
\text { Konsequenzen tragen müssen` }\end{array}$ \\
\hline $\begin{array}{l}\text { ein dicker Brocken } \\
\text { (im Duden } 11 \text { und DUW } \\
\text { online nicht verzeichnet) }\end{array}$ & $\begin{array}{l}\text { dickster Brocken, der dickste } \\
\text { Brocken, mit den ganz } \\
\text { dicken Brocken, einige dicke } \\
\text { Brocken, }\end{array}$ & $\begin{array}{l}\text { 1. ,ein ertragreiches Geschäft; etw., was } \\
\text { finanziellen Gewinn bringt‘ } \\
\text { ( } 7 \text { Belege) } \\
\text { 2. ,für die Ermittler herausfordernde Delikte, insb. } \\
\text { im finanziellen Bereich` } \\
\text { (5 Belege) } \\
\text { 3. ,ein Hindernis, eine Schwierigkeit, eine } \\
\text { Herausforderung' } \\
\text { (2 Belege); } \\
\text {,ein herausfordernder Gegner } \\
\text { (2 Belege) } \\
\text { 4. ,eine große finanzielle Belastung } \\
\text { (11 Belege) }\end{array}$ \\
\hline
\end{tabular}





\section{Abbildungsverzeichnis}

Abb. 1: $\quad$ Klassifikation der Phraseologismen nach Burger (2010). ............... 44

Abb. 2: $\quad$ Der Ball unter dem Tisch - die erste Interpretation. ...................... 72

Abb. 3: $\quad$ Der Ball unter dem Tisch - die zweite Interpretation. .................... 72

Abb. 4: $\quad$ Der Ball unter dem Tisch - die dritte Interpretation. ...................... 73

Abb. 5: Die Darstellung von (a) moon [[MOON]/[moon]], (b) moonless

$[[[\mathrm{MOON}] /[\mathrm{moon}]]--[[\mathrm{LESS}] /[$ less $]]]$, (c) moonless

night $[[[[\mathrm{MOON}] /[\mathrm{moon}]]-[[\mathrm{LESS}] /[\mathrm{less}]]]-[[\mathrm{NIGHT}] /$

[night]]] als symbolische Strukturen: $\mathrm{S}$ bezieht sich auf den semantischen Pol, $\mathrm{P}$ auf den phonologischen Pol, mit $\Sigma$ wird die symbolische Struktur dargestellt (Langacker 2008: 15).

Abb. 6: Konstruktion als Form-Inhaltspaar (Ziem 2008: 185 in Anlehnung an Croft 2001: 18).

Abb. 7: Konzeptualisierung in der Kognitiven Grammatik (Langacker 2008: 39).

Abb. 8: Konzeptueller Inhalt (conceptual content) und Interpretation (construal) (Langacker 2008: 44).

Abb. 9: $\quad$ Schema und Konkretisierungen nach Taylor (2007: 148). .............. 88

Abb. 10: Die Grundannahmen der amodalen Repräsentationsysteme (Barsalou 1999: 579).

Abb. 11: Schematische Darstellung der dualen Repräsentationstheorie mit repräsentationalen, referentiellen und assoziativen Beziehungen zwischen dem System der logogene und der imagene nach Paivio (vereinfacht nach Paivio 1986: 67, übers. von A. S.).

Abb. 12: Die Grundannahmen der Perceptual-Symbol-Theorie nach Barsalou (1999: 578).

Abb. 13: Die Konstituierung eines Frames für ein Auto nach Barsalou (1999: 590). (A) Ein Beispiel für die Errichtung eines Anfangsframes nach der ersten Wahrnehmung eines Autoexemplars. (B) Evaluierung des Frames nach der Bearbeitung des zweiten Exemplars. (C) Konstruktion von einer Simulation von dem zweiten Exemplar aus dem Frame in Abb. 13B.

Abb. 14: Metapher und Metonymie auf der paradigmatischen und syntagmatischen Achse (Dirven 2003b: 77).

Abb. 15: Metapher und Metonymie als Kontinuum (nach Radden 2003: 409-410).

Abb. 16: Metonymie und Metaphtonymie als Mechanismen der Bedeutungskonstituierung am Beispiel des Idioms seinen Hut nehmen. 
Abb. 17: Metonymie, Metapher und Metaphtonymie als Mechanismen der Bedeutungskonstituierung am Beispiel des Idioms den Rahm abschöpfen.

Abb. 18: Das Kontituum zwischen der literalen und der figurativen Bedeutung (Dirven 2003b: 107). 166

Abb. 19: Schematische Darstellung der Doppelbödigkeit der phraseologisierten Bedeutung.

Abb. 20: Liste der Irregularitätsmerkmale nach Doborolskij 1995a (zusammengestellt und bearbeitet von A. S.).

Abb. 21: Das komplementäre Verhältnis zwischen der Motiviertheit und Idiomatizität (Roos 2001: 156).

Abb. 22: Metonymie und Metaphtonymie als Mechanismen der Bedeutungskonstituierung am Beispiel des Idioms sein Gesicht wahren.

Abb. 23: Modelle der Phraseologismenbildung nach Munske (2015 [1993]: 124).

Abb. 24: Schematische Darstellung der Motivationstypen anhand der Typologie von Dobrovol'skij/Piirainen (2009: 17-41).

Abb. 25: Die Motiviertheitstypen der Phraseologismen. 213

Abb. 26: Schablone einer schematischen Veranschaulichung von idiomatischen Bedeutungskonstituierungsprozessen.

Abb. 27: Die konzeptuell-metaphorische Strukturierung des semantischen Feldes Schwierigkeit/schwierige Lage in der deutschen Phraseologie.

Abb. 28: Populäre Darstellung der Ontogenese https://www. logopaedie-in-bayreuth.de/entwicklung-kinder-primitivereflexe/ (Zugriff am 02.06.2017). 278

Abb. 29: Populäre Darstellung der Phylogenese https://de.wikipedia. org/wiki/Mensch (Zugriff am 02.06.2017). 278

Abb. 30: Die Verwendungsprofile und -muster des Idioms ein schwankender Boden anhand der Analyse der Gebrauchsbelege im DWDS-Korpus.

Abb. 31: Bedeutungskonstituierungsmechanismen für das Verwendungsmuster 1.1 , unsichere, schwierige (Lebens-)Lage eines Menschen`.

Abb. 32: Bedeutungskonstituierungsmechanismen für das Verwendungsmuster 1.2 , unsichere, angreifbare Lage, in die sich ein Wissenschaftler versetzt, der in einem nicht gut etablierten Forschungsbereich tätig ist bzw. intersubjektiv schwer fassbare These aufstellt'. 309

Abb. 33: Bedeutungskonstituierungsmechanismen für das Verwendungsprofil 2 ,etw. (eine Theorie, eine Argumentation, eine Anklage, die Wirtschaft) hat unsichere Grundlagen/ Fundamente؛ 
Abb. 34: Bedeutungskonstituierungsmechanismen für das

Verwendungsprofil 3 ,kein fester Boden: Schiffsdeck oder tektonisch aktive Gebiete.

Abb. 35: Die Verwendungsprofile und -muster des Idioms ein dünnes

Eis anhand der Analyse der Gebrauchsbelege im DWDS-Korpus. 315

Abb. 36: Bedeutungskonstituierungsmechanismen für das

Verwendungsmuster 1.1 ,eine missliche, schwierige Lage, in der man leicht folgenschwere Fehler begehen kann'.

Abb. 37: Bedeutungskonstituierungsmechanismen für das

Verwendungsmuster 1.2 , trügerische Geborgenheit der menschlichen Existenz:

Abb. 38: Bedeutungskonstituierungsmechanismen für das Verwendungsmuster 1.3 ,eine riskante, unsichere Position, in die sich jd. mit seiner umstrittenen, unsicheren Gesetzesauslegung (bzw. Theorie) begibt". 322

Abb. 39: Bedeutungskonstituierungsmechanismen für das Verwendungsprofil 2 , umstrittene, nicht gut begründete Grundlage eines Gesetzes, der Auslegung eines Gesetzes, einer Hypothese, einer These, einer Argumentation".

Abb. 40: Die Verwendungsprofile des Idioms glattes Parkett anhand der Analyse der Gebrauchsbelege im DWDS-Korpus

Abb. 41: Bedeutungskonstituierungsmechanismen für das Verwendungsprofil 1 , riskante Tätigkeitsbereiche, in denen die Beachtung der Umgangsformen von Relevanz ist. .

Abb. 42: Bedeutungsverschiebungskette der nominalen Konstituente im Idiom ein glattes Parkett.

Abb. 43: Bedeutungsverschiebungskette der nominalen Konstituente im Idiom das glatte Parkett (der Börse).

Abb. 44: Bedeutungskonstituierungsmechanismen für das Verwendungsprofil 2 ,Börsenverkehr und die damit verbundenen finanziellen Risikos'.

Abb. 45: Bedeutungskonstituierungsmechanismen für das Verwendungsprofil 3 ,ein heikles Thema, ein schwieriger Bereich'.

Abb. 46: Bedeutungskonstituierungsmechanismen für Gebrauchsbelege (39)-(41).

Abb. 47: Bedeutungskonstituierungsmechanismen für den Gebrauchbeleg (42).

Abb. 48: Bedeutungskonstituierungsmechanismen für den sprachspielerischen Idiomgebrauch im Beleg (43).

Abb. 49: Die Verwendungsprofile des Idioms ein Bein stellen anhand der Analyse der Gebrauchsbelege im DWDS-Korpus. 
Abb. 50: Bedeutungskonstituierungsmechanismen für das

Verwendungsprofil 1 ,jmdn. durch Vorsetzen eines Beines

hinfallen lassen, zu Fall bringen'.

Abb. 51: Bedeutungskonstituierungsmechanismen für das

Verwendungsprofil 2 ,jmdm. Schaden/Nachteile zufügen“.

Abb. 52: Bedeutungskonstituierungsmechanismen für das

Verwendungsprofil 3: sich selbst ein Bein stellen, sich selbst

(unwillentlich, durch eine Handlung, Aussage, Bestimmung)

Schaden hinzufügen".

Abb. 53: Das Verwendungsprofil des Idioms Knüppel zwischen die Beine werfen anhand der Analyse der Gebrauchsbelege im DWDS-

Korpus.

Abb. 54: Bedeutungskonstituierungsmechanismen für das

Verwendungsprofil ,jmdn. in seinen Absichten, seiner

Funktion behindern, jmdn. bei etw. stören, jmdm. schaden bzw. zu schaden versuchen'.

Abb. 55: Bedeutungsverschiebungskette der nominalen Konstituente

„Knüppel' im Idiom jmdm. Knüppel zwischen die Beine werfen. ..... 358

Abb. 56: Metonymische Bedeutungsverschiebung der nominalen

Konstituente ,Beine' im Idiom jmdm. Knüppel zwischen die

Beine werfen.

Abb. 57: Metonymisch-metaphorische Bedeutungsverschiebungen im Idiom jmdm. ein Bein stellen.

Abb. 58: Metonymisch-metaphorische Bedeutungsverschiebungen im Idiom jmdm. Knüppel zwischen die Beine werfen.

Abb. 59: Metonymisch-metaphorische Bedeutungsverschiebungen im Idiom jmdm. Steine in den Weg legen.

Abb. 60: Metonymisch-metaphorische Bedeutungsverschiebungen im Idiom sich die Finger verbrennen.

Abb. 61: Metonymisch-metaphorische Bedeutungsverschiebungen im Idiom in eine Sackgasse geraten.

Abb. 62: Die Verwendungsprofile des Idioms Klotz am Bein anhand der Analyse der Gebrauchsbelege im DWDS-Korpus.

Abb. 63: Bedeutungskonstituierungsmechanismen für das

Verwendungsprofil 1 ,etw. ist ein Hindernis, ein Störfaktor .

Abb. 64: Die Verwendungsprofile und -muster des Idioms am Hals haben anhand der Analyse der Gebrauchsbelege im DWDSKorpus.

Abb. 65: Bedeutungskonstituierungmechanismen für das

Verwendungsmuster 1.1 ,jd. hat Schwierigkeiten, Ärger, Probleme, die von ihm unverschuldet sind und mit objektiven Begebenheiten, äußeren Umständen zusammenhängen‘. 
Abb. 66: Bedeutungskonstituierungsmechanismen für das

Verwendungsmuster 1.2 , mit etw. viel Ärger, viele

Schwierigkeiten haben, die man selbst verschuldet hat'.

Abb. 67: Bedeutungskonstituierungsmechanismen für das

Verwendungsmuster 1.3 ,finanziell belastet sein'.

Abb. 68: Bedeutungskonstituierungsmechanismen für das

Verwendungsprofil 2 , mit sorgepflichtigen Personen belastet

sein'

Abb. 69: Teilbedeutungen des Idioms auf die Beine kommen als

lexikalisierte Metaphern und Metonymien.

Abb. 70: Teilbedeutungen des Idioms $j m d m$. wieder auf die Beine helfen als lexikalisierte Metaphern und Metonymien.

Abb. 71: Die Verwendungsprofile des Idioms in die Enge treiben anhand der Analyse der Gebrauchsbelege im DWDS-Korpus.

Abb. 72: Bedeutungskonstituierungsmechanismen für das Verwendungsprofil 1 ,jmdn. in seiner Bewegungs- und Handlungsfreiheit beschränken, in eine ausweglose Lage bringen, in der er sich unter Druck gesetzt fühlt'.

Abb. 73: Bedeutungskonstituierungsmechanismen für das Verwendungsprofil 2 ,jmdm. mit gezielt gestellten Fragen zusetzen, jmdn. mit Argumenten und Fragen in eine schwierige, ausweglose Situation bringen, in der er die Überlegenheit des Gesprächspartners anerkennen muss'. 403

Abb. 74: Die Verwendungsprofile des Idioms an die Wand drücken anhand der Analyse der Gebrauchsbelege im DWDS-Korpus. 406

Abb. 75: Bedeutungskonstituierungsmechanismen für das Verwendungsprofil 1 ,jmdn. verdrängen, seines Einflusses und Wirkungsbereiches berauben und ihn auf diese Weise in (wirtschaftliche, politische) Zwangslage bringen; verursachen, dass jd. an Bedeutung verliert bzw. ganz ausgeschaltet wird".

Abb. 76: Bedeutungskonstituierungsmechanismen für das Verwendungsprofil 2 ,jmdn. einschüchtern, verunsichern, entmutigen, verursachen, dass man sich in seiner Gesellschaft klein fühlt'.

Abb. 77: Bedeutungskonstituierungsmechanismen für das

Verwendungsprofil 3 ,jmdn. in eine aussichtslose Lage

bringen, in der er ratlos ist ${ }^{\prime}$.

Abb. 78: Bedeutungskonstituierungsmechanismen für das

Verwendungsprofil 4 ,etw. in den Hintergrund verschieben, in den Schatten stellen, jmdm. überlegen sein'.

Abb. 79: Die Verwendungsprofile des Idioms przypierać/przyciskać do muru anhand der Analyse der Gebrauchsbelege im Nationalen Korpus der Polnischen Sprache. 
Abb. 80: Bedeutungskonstituierungsmechanismen für das

Verwendungsprofil 1 , (in einer verbal-argumentatorischen

Auseinandersetzung) jmdn. mit gezielt gestellten Fragen zu

einem Geständnis zwingen`.

Abb. 81: Bedeutungskonstituierungsmechanismen für das

Verwendungsprofil 2 ,jmdn. in eine aussichtslose Lage

bringen, in der er ratlos ist und sich dem Agens fügen muss'.

Abb. 82: Die Verwendungsprofile des Idioms ein hartes Brot anhand der Analyse der Gebrauchsbelege im DWDS-Korpus.

Abb. 83: Bedeutungskonstituierungsmechanismen für das Verwendungsprofil 1 , eine schwere Arbeit, die zur

Existenzsicherung notwendig ist, ein mühevoller Gelderwerb‘. ... 429

Abb. 84: Bedeutungsverschiebungskette der nominalen Konstituente im Idiom ein hartes Brot.

Abb. 85: Bedeutungskonstituierungsmechanismen für das

Verwendungsprofil ,eine schwierige Aufgabe, eine

Herausforderung'.

Abb. 86: Bedeutungskonstituierungsmechanismen für die sich etablierende Wortverbindung das harte Brot der Opposition.

Abb. 87: Die Verwendungsprofile und -muster des Idioms eine harte Nuss anhand der Analyse der Gebrauchsbelege im DWDSKorpus.

Abb. 88: Bedeutungskonstituierungsmechanismen für das

Verwendungsprofil 1 , unsichere, schwierige (Lebens-)Lage eines Menschen“.

Abb. 89: Bedeutungskonstituierungsmechanismen für das

Verwendungsmuster 2.1 ,eine Person ist unnachgiebig, robust, schwer von eigenen Zielen abzubringen".

Abb. 90: Bedeutungsverschiebungskette der nominalen Konstituente im Idiom eine harte Nuss.

Abb. 91: Konstituierung der aktuellen Bedeutung für den Beleg (124). Der Pfeil stellt symbolisch die Bedeutungsoszillation zwischen dem ersten Verwendungsprofil und dem Verwendungsmuster 2.1 dar. 446

Abb. 92: Bedeutungskonstituierungsmechanismen für das Verwendungsmuster 2.2 , ein starker Gegner, gegen den man sich schwer bewähren kann'.

Abb. 93: Das Verwendungsprofil und die Verwendungsmuster des Idioms in den sauren Apfel beißen anhand der Analyse der Gebrauchsbelege im DWDS-Korpus.

Abb. 94: Bedeutungskonstituierungsmechanismen für das Verwendungsprofil ,ein notwendiges Übel akzeptieren müssen, eine für sich ungünstige Entscheidung treffen und ihre Konsequenzen tragen müssen'. 
Abb. 95: Die Verwendungsprofile des Idioms ein dicker Brocken anhand der Analyse der Gebrauchsbelege im DWDS-Korpus. 454

Abb. 96: Die bildhaften Veranschaulichungen der Wortverbindung ein dicker Brocken. 455

Abb. 97: Die Bedeutungskonstituierungsmechanismen für das Verwendungsprofil 1 , ein ertragreiches Geschäft'. 456

Abb. 98: Die Bedeutungskonstituierungsmechanismen für das Verwendungsprofil 2 ,ein Hindernis, eine Schwierigkeit, eine Herausforderung, ein schwieriger Gegner'.

Abb. 99: Die Bedeutungskonstituierungsmechanismen für das Verwendungsprofil 3 ,finanzielle Belastung innerhalb eines Systems'.

Abb. 100: Die Bedeutungskonstituierungsmechanismen für das Verwendungsprofil 4 , die für Ermittler herausfordernden Delikte, insbesondere im finanziellen Bereich: 464

Abb. 101: Metonymisch-metaphtonymische Bedeutungsverschiebungen im Idiom ein hartes Brot (Beleg 142).

Abb. 102: Metaphorische Bedeutungsverschiebung im Idiom ein hartes Brot (Beleg 145).

Abb. 103: Metonymische Bedeutungsverschiebung im Idiom ein hartes Brot (Beleg 145). 



\section{Tabellenverzeichnis}

Tab. 1: Die Ausweitung des phraseologischen Begriffsverständnisses und Gegenstandes nach Stein (1995: 25).

Tab. 2: Die Beschreibung des Konzeptes HUND als Merkmalsbündels (Sulikowska 2014c: 58).

Tab. 3: Taxonomie der Kategorien nach Rosch et al. 1976: 388 (übers. und gekürzt von A. S.).

Tab. 4: Gegenüberstellung der wörtlichen und metaphorischen Ausdrücken von Jäkel (1998: 104-105).

Tab. 5: $\quad$ Einteilung der Metaphern nach dem Konventionalitätsgrad in der traditionellen Linguistik und der Theorie der konzeptuellen Metaphern (Romero/Soria 2005: 6).

Tab. 6: Liste der konzeptuellen Metonymien nach Radden/Kövecses (1999: 30-43).

Tab. 7: Die konzeptuellen Korrespondenzen zwischen der Ausgangsund Zieldomäne für das Idiom die Katze aus dem Sack lassen.

Tab. 8: Die Phraseologismensammlung anhand lexikographischer Nachschlagewerke nach dem Reduktionsverfahren.

Tab. 9: Die Distribution der Phraseologismen dünnes Eis, glattes Parkett und schwankender Boden in den DWDS-Korpora (https://www.dwds.de, Zugriff 19.05.2017).

Tab. 10: Die aus der Phraseologismensammlung eruierten konzeptuellen Metaphern des semantischen Feldes ,schwierige Lage, Schwierigkeit' und ihre phraseologischen Exemplifizierungen. 286

Tab. 11: Das Idiom ein schwankender Boden in allgemeinen und phraseologischen Wörterbüchern des Deutschen.

Tab. 12: Die epistemischen Mappings für das Verwendungsprofil 1.1 ,unsichere, schwierige (Lebens-)Lage eines Menschen'. 304

Tab. 13: Die epistemischen Mappings für das Verwendungsprofil 2 ,etw. (eine Theorie, eine Argumentation, eine Anklage, die Wirtschaft) hat unsichere Grundlagen/Fundamente'.

Tab. 14: Das Idiom dünnes Eis in allgemeinen und phraseologischen Wörterbüchern des Deutschen.

Tab. 15: Die epistemischen Mappings zwischen der Ausgangs- und Zieldomäne für das Verwendungsmuster 1.1 ,eine missliche, schwierige Lage, in der man leicht folgenschwere Fehler begehen kann`. 
Tab. 16: Die epistemischen Mappings zwischen der Ausgangs- und Zieldomäne für das Verwendungsmuster 1.2 ,trügerische Geborgenheit der menschlichen Existenz .

Tab. 17: Die epistemischen Mappings für das Verwendungsprofil 2 ,umstrittene, nicht gut begründete Grundlage eines Gesetzes, der Auslegung eines Gesetzes, einer Hypothese, einer These, einer Argumentation'.

Tab. 18: Das Idiom glattes Parkett in allgemeinen und phraseologischen Wörterbüchern des Deutschen.

Tab. 19: Die epistemischen Mappings für das Verwendungsprofil 1 ,riskante Tätigkeitsbereiche, in denen die Beachtung der Umgangsformen von Relevanz ist'.

Tab. 20: Zusammenstellung der ermittelten Verwendungsprofile für Idiome: dünnes Eis, schwankender Boden, glattes Parkett.

Tab. 21: Das Idiom ein Bein stellen in allgemeinen und phraseologischen Wörterbüchern des Deutschen.

Tab. 22: Die epistemischen Mappings für das Verwendungsprofil 2 ,jmdm. Schaden/Nachteile zufügen'.

Tab. 23: Die epistemischen Mappings für das Verwendungsprofil sich selbst ein Bein stellen, sich selbst (unwillentlich, durch eine Handlung, Aussage, Bestimmung) Schaden hinzufügen'.

Tab. 24: Das Idiom Knüppel zwischen die Beine werfen in allgemeinen und phraseologischen Wörterbüchern des Deutschen.

Tab. 25: Die epistemischen Mappings für das Verwendungsprofil ,jmdn. in seinen Absichten, seiner Funktion behindern, jmdn. bei etw. stören, jmdm. schaden bzw. zu schaden versuchen'.

Tab. 26: Das Idiom Klotz am Bein in allgemeinen und phraseologischen Wörterbüchern des Deutschen.

Tab. 27: Das Idiom am/auf dem Hals haben in allgemeinen und phraseologischen Wörterbüchern des Deutschen.

Tab. 28: Phraseologismen mit Bein-Konstituente und die konstituierenden und motivierenden konzeptuellen Metonymien und Metaphern.

Tab. 29: Das Idiom in die Enge treiben in allgemeinen und phraseologischen Wörterbüchern des Deutschen.

Tab. 30: Das Idiom an die Wand drücken in allgemeinen und phraseologischen Wörterbüchern des Deutschen.

Tab. 31: Die kognitiven Mechanismen der Bedeutungskonstituierung für das Idiom an die Wand drücken und sein polnisches Äquivalent przypierać do muru/ściany.

Tab. 32: Idiome: an die Wand drücken und przypierać/przyciskać do muru in bilingualen Großwörterbüchern. 
Tab. 33: Das Idiom ein hartes Brot in allgemeinen und phraseologischen Wörterbüchern des Deutschen. 426

Tab. 34: Die epistemischen Mappings zwischen der Ausgangs- und Zieldomäne für das Verwendungsprofil ,eine schwere Arbeit, die zur Existenzsicherung notwendig ist, ein mühevoller Gelderwerb: 430

Tab. 35: Die metaphorischen Mappings zwischen der Ausgang- und Zieldomäne in dem Verwendungsprofil ,eine schwierige Aufgabe, eine Herausforderung.

Tab. 36: Das Idiom eine harte Nuss in allgemeinen und phraseologischen Wörterbüchern des Deutschen.

Tab. 37: Die epistemischen Mappings für das Verwendungsprofil 1 ,unsichere, schwierige (Lebens-)Lage eines Menschen'.

Tab. 38: Die epistemischen Mappings für das Verwendungsmuster 2.1 ,eine Person ist unnachgiebig, robust, schwer von eigenen Zielen abzubringen'.

Tab. 39: Die epistemischen Mappings für das Verwendungsmuster 2.2 ,ein starker Gegner, gegen den man sich schwer bewähren kann'.

Tab. 40: Das Idiom in den sauren Apfel beißen in allgemeinen und phraseologischen Wörterbüchern des Deutschen.

Tab. 41: Das Idiom ein dicker Brocken in allgemeinen und phraseologischen Wörterbüchern des Deutschen. 453

Tab. 42: Die epistemischen Mappings für das Verwendungsprofil ,ein Hindernis, eine Schwierigkeit, eine Herausforderung. 461

Tab. 43: Die epistemischen Mappings für den Verwendungsbeleg (148). ... 469

Tab. 44: 250 deutsche Phraseologismen der Schwierigkeit/der schwierigen Lage anhand lexikographischer Werke. 485

Tab. 45: Zusammenstellung der Zitierform und Bedeutungsparaphrasen aus dem Wörterbuch Duden 11 (bzw. DUW online) und den aus den Belegesammlungen ermittelten Varianten/Modifikationen sowie Verwendungsprofilen/ Verwendungsmustern der untersuchten Idiome. 498 



\section{Literatur}

Agricola, Erhard (1977): Wörter und Wendungen. Wörterbuch zum deutschen Sprachgebrauch. VEB Bibliographisches Institut, Leipzig.

Ajdukiewicz, Kazimierz (2004 [1949]): Zagadnienia i kierunki filozofii. Teoria poznania. Metafizyka. Wydawnictwo Antyk - Fundacja Aletheia, Kęty Warszawa.

Anderson, John Robert (1976): Language, Memory, and Thought. Erlbaum, Hillsdale - New York.

Anderson, John Robert (1988): Kognitive Psychologie. Eine Einführung. Spektrum der Wissenschaft, Heidelberg.

Anderson, John Robert (1996): The Architecture of Cognition. Psychology Press, Taylor and Francis Group, New York - London.

Andrzejewski, Bolesław (1983): Leo Weisgerbera relatywistyczna koncepcja języka. Studia metodologiczne 22, 137-153.

Ariel, Mira (2002): Introduction. In: Ariel, Mira (Hg.): Literal, minimal and salient meanings. Fournal of Pragmatics 34/4 (special issue), Elsevier, 345-348.

Aristoteles (1982): Poetik. Griechisch-Deutsch. (hg. und übersetzt von Manfred Fuhrmann). Reclam Universal-Bibliothek, Stuttgart.

Bąba, Stanisław/Liberek, Jarosława (2011): O zwrocie odrodzić się//odradzać się/powstać //powstawać jak/niczym Feniks z popiołów. In: Afeltowicz, Beata/Ignatowicz-Skowrońska, Jolanta/Wojdak, Piotr (Hg.): In silva verborum. Prace dedykowane Profesor Ewie Pajewskiej z okazji 30-lecia pracy zawodowej. Volumina, Szczecin, 35-45.

Baddeley, Allan (1998): Pamięć. Poradnik użytkownika. Prószyński i S-ka. Warszawa.

Baker, Collin F./Fillmore, Charles J./Lowe, John B. (1998): The Berkeleys FrameNet project. Proceedings of the 17th international conference on Computational Linguistics. Vol. I. [http://aclweb.org/anthology/P/P98/P98-1013.pdf, Zugriff am 11.11.2017].

Baldauf, Christa (1997): Metapher und Kognition. Grundlagen einer neuen Theorie der Alltagsmetapher. Peter Lang, Frankfurt am Main.

Bally, Charles (1905): Précis de stylistique: esquisse d'une methode fondée sur l'étude du français moderne. A. Eggimann, Genève.

Baran, Anneli (2013): On the role of visualization in understanding phraseologisms on the example of commercials. Folklore 4, 47-72.

Baranov, Anatolij (2007): The problem of the metalanguage. In: Burger, Harald/Dobrovol'skij, Dmitrij/Kühn, Peter/Norrick, Neal R. 
(Hg.): Phraseologie - Phraseology. Ein internationales Handbuch der zeitgenössischen Forschung. Bd. 1. Walter de Gruyter, Berlin - New York, 77-90.

Barcelona, Antonio (2000): On the plausibility of claiming a metonymic motivation for conceptual metaphor. In: Barcelona, Antonio (Hg.): Metaphor and Metonymy at the Crossroads. Mouton de Gruyter, Berlin - New York, 31-58.

Barcelona, Antonio (2003): Clarifying and applying the notions of metaphor and metonymy within cognitive linguistics: An update. In: Dirven, René/Pörings, Ralf (Hg.): Metaphor and Metonymy in Comparison and Contrast. Mouton de Gruyter, Berlin - New York, 207-278.

Barsalou, Lawrence W. (1999): Perceptual symbol systems. Behavioral and brain sciences 22, 577-660.

Barsalou, Lawrence W. (2008): Grounded Cognition. Annual Review of Psychology 59, 617-645.

Barsalou, Lawrence W. (2010): Grounded Cognition: Past, Present, and Future. Topics in Cognitive Science 2, 716-724.

Barsalou, Lawrence W. (2012): The Human Conceptual System. In: Spivey, Michael J./McRae, Ken/Joanisse, Marc F. (Hg.): The Cambridge Handbook of Psycholinguistics. Cambridge University Press, Cambridge, 239-258.

Barsalou, Lawrence W. (2016): Situated Conceptualization: Theory and applications. In: Coello, Yann/Fischer, Martin H. (Hg.): Foundations of embodied cognition. Psychology Press, East Sussex, 12-37.

Barsalou Lawrence W./Hale, Christopher R. (1993): Components of conceptual representation: from feature lists to recursive frames. In: Van Mechelen, Iven/Hampton, James/Michalski, Ryszard/Theuns, Peter (Hg.): Categories and Concepts: Theoretical Views and Inductive Data Analysis. Academic Press, London - San Diego - New York, 97-144.

Barsalou, Lawrence W./Wiemer-Hasting, Katja (2005): Situating Abstract Concepts. In: Pecher, Diane/Zwaan, Rolf A. (Hg.): Grounded Cognition. The Role of Perception and Action in Memory, Language and Thought. Cambridge University Press, New York, 129-163.

Bartlett, Frederic C. (1932): Remembering: A Study in Experimental and Social Psychology. Cambridge University Press, New York - London.

Bartmiński, Jerzy (1988): Definicja kognitywna jako narzędzie opisu konotacji stowa. In: Bartmiński, Jerzy (Hg.): Konotacja. Wydawnictwo UMCS, Lublin, 169-183.

Bartmiński, Jerzy (2006): Językowe podstawy obrazu świata. Wydawnictwo UMCS, Lublin.

Bartmiński, Jerzy/Żuk, Grzegorz (2009): Pojęcie równości i jego profilowanie we współczesnym języku polskim. Etnolingwistyka 21, 47-67. 
Bartsch, Renate (2003): Genereting polysemy: Metaphor and metonymy. In: Dirven, René/Pörings, Ralf (Hg.): Metaphor and Metonymy in Comparison and Contrast. Mouton de Gruyter, Berlin - New York, 49-74.

Barz, Irmhild (1992): Phraseologische Varianten: Begriff und Probleme. In: Földes, Csaba (Hg.): Deutsche Phraseologie in Sprachsystem und Sprachverwendung. Ed. Preasens, Wien, 25-47.

Baur, Rupprecht S./Chlosta, Christoph (1996): „Welche Übung macht den Meister?". Von der Sprichwortforschung zur Sprichwortdidaktik. Fremdsprache Deutsch 15: Redewendungen und Sprichwörter, 17-24.

Bąk, Paweł (2007): Die Metapher in der Übersetzung. Studien zum Transfer der Aphorismen von Stanislaw Jerzy Lec und der Gedichte von Wislawa Szymborska. Peter Lang, Frankfurt am Main u.a.

Bebermeyer, Gustav/Bebermeyer, Renate (1977): Abgewandelte Formen sprachlicher Ausdruck unserer Zeit. Muttersprache 87, 1-42.

Berdychowska, Zofia/Schatte, Czesława (2017): Phraseologie - Fragen der Abgrenzungen und Zugänge. In: Berdychowska, Zofia/Lüger, HeinzHelmut/Schatte, Czesława/Zenderowska-Korpus, Grażyna (Hg.): Phraseologie als Schnittstelle zwischen Sprache und Kultur I. Abgrenzungen - sprach- und textvergleichende Zugänge. Peter Lang, Frankfurt am Main, 7-17.

Bergenholtz, Hennig (2005): Lemmaselektion in deutschen und deutsch-finnischen Wörterbüchern. In: Barz, Irmhild/Bergenholtz, Hennig/Korhonen, Jarmo (Hg.): Schreiben, Verstehen, Übersetzen, Lernen. Zu ein- und zweisprachigen Wörterbüchern mit Deutsch. Peter Lang, Frankfurt am Main u.a., 146-163.

Bergernholtz, Hennig (2006): Idiomwörterbücher und ihre Benutzer. In: Breuer, Ulrich/Hyvärinen, Irma (Hg.): Wörter - Verbindungen. Festschrift für Jarmo Korhonen zum 60. Geburtstag. Peter Lang, Frankfurt am Main u.a., 17-30.

Bergenholtz, Hennig/Tarp, Sven (2005): Wörterbuchfunktionen. In: Barz, Irmhild/Bergenholtz, Hennig/Korhonen, Jarmo (Hg.): Schreiben, Verstehen, Übersetzen, Lernen. Zu ein- und zweisprachigen Wörterbüchern mit Deutsch. Peter Lang, Frankfurt am Main u.a., 11-25.

Bergerová, Hana (2011): Emotionen im Spiegel bildlicher Sprache. Fallbeispiel: Ärger. Acta Facultatis Philosophicae Universitatis Ostraviensis. Studia Germanistica 8, 5-19.

Bierwisch, Manfred/Lang, Ewald (1987): Grammatische und konzeptuelle Aspekte von Dimensionsadjektiven. Akademie-Verlag, Berlin.

Blumenthal, Peter/Diwersy, Sascha/Mielebacher, Jörg (2005): Kombinatorische Wortprofile und Profilkontraste. Berechnungsverfahren und Anwendungen. Zeitschrift für romanische Philologie 121/1, 49-83.

Błachut, Edyta (2004): Sprachspielerische Modifikationen formelhafter Wendungen: Untersuchungen anhand deutscher und polnischer Belege. Oficyna Wydawnicza Atut, Wrocław. 
Bobrow, Samuel A./Bell, Susan M. (1973): On catching on to idiomatic expressions. Memory and Cognition 1, 343-346.

Bogusławski, Andrzej (1989): Uwagi o pracy nad frazeologia. In: Saloni, Zygmunt (Hg.): Studia z polskiej leksykografii współczesnej III. Dział Wydawnictw Filii Uniwersytetu Warszawskiego, Białystok, 13-30.

Böhmer, Heiner (1997): Ist Phraseologie heute noch als einheitliches Gebiet haltbar? In: Sabban, Annette (Hg.): Phraseme im Text. Beiträge aus romanistischer Sicht. Brockmeyer, Bochum, 1-28.

Borghi, Anna M./Pecher, Diane (2011): Introduction to the special topic Embodied and Grounded Cognition. In: Borghi, Anna M./Pecher, Diane (Hg.): Embodied and Grounded Cognition. Frontiers in Psychology 2 (special issue), Frontiers Media SA, 5-6.

Bowers, Frederick (1989): Linguistic aspects of legislative expression. University of British Columbia Press, Vancouver.

Brugman, Claudia (1989): The Story of 'Over': Polysemy, Semantics, and the Structure of the Lexicon. Garland, New York.

Bubenhofer, Noah/Ptashnyk, Stefaniya (2010): Korpora, Datenbanken und das Web: State of the Art computergestützter Forschung in der Phraseologie und Lexikographie. In: Ptashnyk, Stefaniya/Hallsteinsdóttir, Erla/Bubenhofer, Noah (Hg.): Korpora, Web und Datenbanken. Computergestützte Methoden in der modernen Phraseologie und Lexikographie. Schneider Verlag Hohengehren, Baltmannsweiler, 7-19.

Burger, Harald (1973): Idiomatik des Deutschen. Germanistische Arbeitshefte 16. Niemeyer, Tübingen.

Burger, Harald (1989): „Bildhaft, übertragen, metaphorisch ... “ Zur Konfusion um die semantischen Merkmale von Phraseologismen. In: Gréciano, Gertrud (Hg.): EUROPHRAS 88: phraséologie contrastive. Actes du Colloque International. Klingenthal, Strasbourg, 12-16 mai 1988. Strasbourg, 17-30.

Burger, Harald (1992): Phraseologie im Wörterbuch. Überlegungen aus germanistischer Perspektive. In: Eismann, Wolfgang/Petermann, Jürgen (Hg.): Studia phraseologica et alia. Festschrift für Josip Matešic zum 65. Geburtstag. Otto Sagner, München, 33-51.

Burger, Harald (1999): Phraseologie in Fernsehnachrichten. In: Baur, Rupprecht S./Chlosta, Christoph/Piirainen, Elisabeth (Hg.): Wörter in Bildern - Bilder in Wörtern. Beiträge zur Phraseologie und Sprichwortforschung aus dem Westfälischen Arbeitskreis. Schneider Verlag Hohengehren, Baltmannsweiler, 71-106.

Burger, Harald (2001): Phraseologie. Eine Einführung am Beispiel des Deutschen. Erich Schmidt, Berlin.

Burger, Harald (2002a): Die Charakteristika phraseologischer Einheiten: Ein Überblick. In: Cruse, Alan D./Hundsnurscher, Franz/Job, Michael/Lutzeier, 
Peter Rolf (Hg.): Lexikologie - Lexikology. Ein internationales Handbuch zur Natur und Struktur von Wörtern und Wortschätzen. Bd. 1. Walter de Gruyter, Berlin - New York, 392-401.

Burger, Harald (2002b): Dialektale Phraseologie am Beispiel des

Schweizerdeutschen. In: Piirainen, Elisbeth/Piirainen, Ilpo T. (Hg.): Phraseologie in Raum und Zeit. Akten der 10. Tagung des Westphälischen Arbeitskreises „Phraseologie/Parömiologie“" (Münster 2001). Schneider Verlag Hohengehren, Baltmannsweiler, 11-29.

Burger, Harald (2003): Phraseologie. Eine Einführung am Beispiel des Deutschen. Erich Schmidt, Berlin.

Burger, Harald (2006): Zur Phraseologie des Wetters. In: Breuer, Ulrich/Hyvärinen, Irma (Hg.): Wörter - Verbindungen. Festschrift für Jarmo Korhonen zum 60. Geburtstag. Peter Lang, Frankfurt am Main u.a., 136-151.

Burger, Harald (2007a): Phraseologie. Eine Einführung am Beispiel des Deutschen. Erich Schmidt, Berlin.

Burger, Harald (2007b): Semantic aspects of phrasemes. In: Burger, Harald/Dobrovol'skij, Dmitrij/Kühn, Peter/Norrick, Neal R.

(Hg.): Phraseologie - Phraseology. Ein internationales Handbuch der zeitgenössischen Forschung. Bd. 1. Walter de Gruyter, Berlin - New York, 90-110.

Burger, Harald (2009): Semantische Aspekte der deutschen Phraseologie: die aktuelle Praxis - allgemeine und phraseologische Wörterbücher im Vergleich. In: Mellado Blanco, Carmen (Hg.): Theorie und Praxis der idiomatischen Wörterbücher. Niemeyer, Tübingen, 23-44.

Burger, Harald (2010): Phraseologie. Eine Einführung am Beispiel des Deutschen. 4., neu bearbeitete Aufl. Erich Schmidt Verlag, Berlin.

Burger, Harald (2015): Phraseologie. Eine Einführung am Beispiel des Deutschen. 5., neu bearbeitete Aufl. Erich Schmidt Verlag, Berlin.

Burger, Harald /Dobrovol'skij, Dmitrij /Kühn, Peter/Norrick, Neal R. (2007a) (Hg.): Phraseologie - Phraseology. Ein internationales Handbuch der zeitgenössischen Forschung. Bd. 1. Walter de Gruyter, Berlin - New York.

Burger, Harald/Dobrovol'skij, Dmitrij/Kühn, Peter/Norrick, Neal R. (2007b): Einführung/Subject area, terminology and research topics. In: Burger, Harald/Dobrovol'skij, Dmitrij/Kühn, Peter/Norrick, Neal R. (Hg.): Phraseologie - Phraseology. Ein internationales Handbuch der zeitgenössischen Forschung. Bd. 1. Walter de Gruyter, Berlin New York, 1-10.

Burger, Harald/Häcki Buhofer, Annelies/Silam, Ambros/Eriksson, Brigit (1982) (Hg.): Handbuch der Phraseologie. Walter de Gruyter, Berlin.

Busse, Dietrich (1987): Historische Semantik. Analyse eines Programms. KlettCotta, Stuttgart. 
Busse, Dietrich (2009): Semantik. W. Fink, UTB, Paderborn.

Bußmann, Hadumod (1990): Lexikon der Sprachwissenschaft. Kröner, Stuttgart.

Cacciari, Cristina (1993): The Place of Idioms in a Literal and Metaphorical World.

In: Cacciari, Cristina/Tabossi, Patrizia (Hg.): Idioms: Processing, Structure, and Interpretation. Psychology Press, New York - London, 27-55.

Cacciari, Cristina/Glucksberg, Sam (1995): Understanding idioms: Do visual images reflect figurative meanings? European fournal of Cognitive Psychology 7/3, 283-305

Cacciari, Cristina/Tabossi, Patrizia (1988): The comprehension of idioms. fournal of Memory and Language 27, 668-683.

Černyševa, Irina (1970): Frazeologija sovremennogo nemeckogo jazyka. Vysšaja škola, Moskau.

Černyševa, Irina (1975): Phraseologie. In: Stepanova, Maria D./Černyševa, Irina (Hg.): Lexikologie der deutschen Gegenwartssprache. Vysšaja škola, Moskau, 198-261.

Černyševa, Irina (1980): Feste Wortkomplexe des Deutschen in Sprache und Rede. Vysšaja škola, Moskau.

Černyševa, Irina (1984): Aktuelle Probleme der deutschen Phraseologie. Deutsch als Fremdsprache 21/1, 17-22.

Chrissou, Marios (2000): Kontrastive Untersuchungen zu deutschen und neugriechischen Phraseologismen mit animalistischer Lexik. Clemon, Essen.

Chrissou, Marios (2018): Interlinguale Aspekte zur Bestimmung des Lernschwierigkeitsgrads von Phrasemen für DaF-Lernende mit Griechisch als Muttersprache. In: Burger, Harald/Buhofer Häcki, Annelies/Sabban, Annette/Steyer, Kathrin (Hg.): Yearbook of Phraseology 9. De Gruyter Mouton, Berlin - Boston, 111-136.

Chlebda, Wojciech (2003): Elementy frazematyki: Wprowadzenie do frazeologii nadawcy. Oficyna Wydawnicza Leksem, Lask.

Chlebda, Wojciech (2005): Szkice o skrzydlatych stowach. Interpretacje lingwistyczne. Uniwersytet Opolski, Opole.

Chlewiński, Zdzisław/Hankała, Andrzej/Jagodzińska, Maria/Mazurek, Beata (1997): Psychologia pamięci. Wiedza Powszechna, Warszawa.

Chomsky, Noam (1959): Review of Skinner's >>Verbal Behaviour $<<$. Language 35, 26-58.

Chomsky, Noam (1986): Changing Perspectives on Knowledge and Use of Knowledge. Leuvense Bijdragen 75, 1-71.

Clark, Andy (1998): Embodied, situated, and distributed cognition. In: Bechtel, William/Graham, George (Hg.): A companion to cognitive science. Wiley Blackwell, Maden, 506-517. 
Clausner, Timothy C./Croft, William (1999): Domains and image schemas. Cognitive Linguistics 10, 1-31.

Coates, William A. (1964): Meaning in morphems and compound lexical units. In: Lunt, Horace G. (Hg.): Proceedings of the $9^{\text {th }}$ International Congress of Linguistics. Cambridge, Mass., August 27-31, 1962. Mouton, The Hague, 1046-1052.

Colson, Jean-Pierre (2010): The Contribution of Web-based Corpus Linguistics to a Global Theory of Phraseology. In: Ptashnyk, Stefaniya/Hallsteinsdóttir, Erla/Bubenhofer, Noah (Hg.): Korpora, Web und Datenbanken. Computergestützte Methoden in der modernen Phraseologie und Lexikographie. Schneider Verlag Hohengehren, Baltmannsweiler, 23-35.

Coulmas, Florian (1981): Routine im Gespräch. Zur pragmatischen Fundierung der Idiomatik. Akademische Verlagsgesellschaft Athenaion, Düsseldorf.

Cowie, Anthony P. (2003): Exploring native-speaker knowledge of phraseology: informant testing or corpus research? In: Burger, Harald/Häcki Buhofer, Annelies/Gréciano, Gertrud (Hg.): Flut von Texten - Vielfalt der Kulturen. Ascona 2001. Zur Methodologie und Kulturspezifik der Phraseologie. Schneider Verlag Hohengehren, Baltmannsweiler, 73-81.

Croft, William (2001): Radical Construction Grammar. Syntactic Theory in Typological Perspective. Oxford University Press, Oxford.

Croft, William (2003): The role of domains in the interpretation of metaphors and metonymies. In: Dirven, René/Pörings, Ralf (Hg.): Metaphor and Metonymy in Comparison and Contrast. Mouton de Gruyter, Berlin - New York, 161-206.

Croft, William/Cruse, Allan D. (2004): Cognitive Linguistics. Cambridge University Press, Cambridge.

Czarnecka, Małgorzata (2010): Die Rolle formelhafter Sequenzen im Zweitsprachenerwerb. Studia Germanica Gedanensia 23, 59-70.

Damasio, Antonio R./Damasio, Hanna (1994): Cortical systems for retrieval of concrete knowledge: The convergence zone framework. In: Koch, Christof/Davis, Joel L. (Hg.): Large-scale neuronal theories of the brain. MIT Press, Cambridge - Massachussets - London, 61-74.

Dancygier, Barbara/Sweetster, Eve (2014): Figurative Language. Cambridge University Press, Cambridge.

Dausendschön-Gay, Ulrich/Gülich, Elisabeth/Krafft, Ulrich (2007): Phraseologische/formelhafte Texte. In: Burger, Harald/Dobrovol'skij, Dmitrij/Kühn, Peter/Norrick, Neal R. (Hg.): Phraseologie - Phraseology. Ein internationales Handbuch der zeitgenössischen Forschung. Bd. 1. Walter de Gruyter, Berlin - New York, 468-481. 
Dewey, John (1925): Experience and nature. In: Boydston, Jo Ann (Hg.) (1981): John Dewey: Later works 1925-1953. Southern Illnois University Press, Carbondale.

Diekmannshenke, Hajo (2008): Text-Bild-Kommunikation am Beispiel der Postkarte. In: Pohl, Inge (Hg.): Semantik und Pragmatik - Schnittstellen. Peter Lang, Frankfurt am Main u.a., 85-107.

Dietz, Hans-Ulrich (1999): Rethorik in der Phraseologie. Zur Bedeutung rhetorischer Stilelemente im idiomatischen Wortschatz des Deutschen. Niemeyer, Tübingen.

Dirven, René (2002): Structuring of word meaning III: Figurative use of language. In: Cruse, Alan D./Hundsnurscher, Franz/Job, Michael/Lutzeier Peter R. (Hg.): Lexikologie/Lexicology. Ein internationales Handbuch zur Natur und Struktur von Wörtern und Wortschätzen. Walter de Gruyter, Berlin New York, 337-341.

Dirven, René (2003a): Introduction. In: Dirven, René/Pörings, Ralf (Hg.): Metaphor and Metonymy in Comparison and Contrast. Mouton de Gruyter, Berlin New York, 1-38.

Dirven, René (2003b): Different mental strategies of conceptualization. In: Dirven, René/Pörings, Ralf (Hg.): Metaphor and Metonymy in Comparison and Contrast. Mouton de Gruyter, Berlin - New York, 75-112.

Divjak, Dagmar (2004): Degrees of Verb Integation. Conceptualizing and Categorizing Events in Russian. Katholieke Universiteit Leuven. Department Oosterse en Slavische Studies. Dissertation, Lueven.

Dobrovol'skij, Dmitrij (1980): Zur Dialektik des Begriffs der textbildenden Potenzen der Phraseologismen. Zeitschrift für Phonetik, Sprachwissenschaft und Kommunikationsforschung 33, 690-700.

Dobrovol'skij, Dmitrij (1987): Textbildende Potenzen von Phraseologismen. Linguistische Studien ZISW/A 164, 69-85.

Dobrovol'skij, Dmitrij (1995a): Kognitive Aspekte der Idiom-Semantik. Studien zum Thesaurus der Idiom-Semantik. Narr, Tübingen.

Dobrovol'skij, Dmitrij (1995b): Schiß und Espenlaub. Idiome der Angst. Folia Linguistica XXIX/3-4, 317-346.

Dobrovol'skij, Dmitrij (1997a): Idiome im mentalen Lexikon: Ziele und Methoden der kognitivbasierten Phraseologieforschung. Wissenschaftlicher Verlag, Trier.

Dobrovol'skij, Dmitrij (1997b): Kontrastive Idiomatik Deutsch-Russisch: Zur lexikographischen Konzeption. In: Gréciano, Gertrud/Rothkegel, Annely (Hg.): Phraseme in Kontext und Kontrast. Brockmeyer, Bochum, 45-59.

Dobrovol'skij, Dmitrij (1999): Kontrastive Phraseologie in Theorie und Praxis. In: Baur, Rupprecht S./Chlosta, Christoph/Piirainen, Elisabeth (Hg.): Wörter in Bildern - Bilder in Wörtern. Beiträge zur Phraseologie und 
Sprichwortforschung aus dem Westfälischen Arbeitskreis. Schneider Verlag Hohengehren, Baltmannsweiler, 107-122.

Dobrovol'skij, Dmitrij (2001): Zur Motivation in der Idiomatik. In: Häcki Buhofer, Annelies/Burger, Harald/Gautier, Laurent (Hg.): Phraseologiae Amor.

Aspekte europäischer Phraseologie. Festschrift für Gertrud Gréciano zum 60.

Geburtstag. Schneider Verlag Hohengehren, Baltmannsweiler, 89-98.

Dobrovol'skij, Dmitrij (2002a): Grammatik der Idiome. In: Hartmann,

Dietrich/Wirrer, Jan (Hg.): Wer A sägt, muss auch B sägen. Beiträge zur

Phraseologie und Sprichwortsammlung aus dem Westphälischen Arbeitskreis.

Schneider Verlag Hohengehren, Baltmannsweiler, 56-74.

Dobrovol'skij, Dmitrij (2002b): Phraseologie als Datenbank. In: Hartmann,

Dietrich/Wirrer, Jan (Hg.): Wer A sägt, muss auch B sägen. Beiträge zur

Phraseologie und Sprichwortsammlung aus dem Westphälischen Arbeitskreis.

Schneider Verlag Hohengehren, Baltmannsweiler, 429-432.

Dobrovol'skij, Dmitrij (2004): Lexical Semantics and Combinatorial Profile: A

Corpus-Based Approach. In: Proceedings of the $11^{\text {th }}$ EURALEX International

Congress. Lorient, 787-796. [www.euralex.org/elx_proceedings/Euralex2004, Zugriff am 18.05.2017].

Dobrovol'skij, Dmitrij (2006): Zur kontrastiven Analyse kulturspezifischer

Konzepte. In: Breuer, Ulrich/Hyvärinen, Irma (Hg.): Wörter - Verbindungen.

Festschrift für Jarmo Korhonen zum 60. Geburtstag. Peter Lang, Frankfurt am Main u.a., 31-45.

Dobrovol'skij, Dmitrij (2007): Cognitive approaches to idiom analysis.

In: Burger, Harald/Dobrovol'skij, Dmitrij/Kühn, Peter/Norrick, Neal R. (Hg.): Phraseologie - Phraseology. Ein internationales Handbuch der zeitgenössischen Forschung. Bd. 2. Walter de Gruyter, Berlin - New York, 789-818.

Dobrovol'skij, Dmitrij (2009): Zur lexikographischen Repräsentation der Phraseme (mit Schwerpunkt auf zweisprachigen Wörterbüchern). In: Mellado Blanco, Carmen (Hg.): Theorie und Praxis der idiomatischen Wörterbücher. Niemeyer, Tübingen, 149-168.

Dobrovol'skij, Dmitrij (2016a): The notion of 'inner form' and idiom semantics. Études et travaux d'Eur'ORBEM, 21-36.

Dobrovol'skij, Dmitrij (2016b): The Use of Corpora in the Bilingual Phraseography. Proceedings of the XVI EURALEX International Congress: The User in Focus, 867-884. [http://www.euralex.org/elx_proceedings/Euralex2014/ euralex_2014_066_p_867.pdf, Zugriff am 21.05. 2017].

Dobrovol'skij, Dmitrij/Filipenko, Tatjana (2007): Russian phraseology. In: Burger, Harald/Dobrovol'skij, Dmitrij/Kühn, Peter/Norrick, Neal R. (Hg.): Phraseologie - Phraseology. Ein internationales Handbuch der 
zeitgenössischen Forschung. Bd. 2. Walter de Gruyter, Berlin - New York, $714-727$.

Dobrovol'skij, Dmitrij/Piirainen, Elisabeth (1997): Symbole in Sprache und Kultur: Studien aus kultursemiotischer Perspektive. Brockmeyer, Bochum.

Dobrovol'skij, Dmitrij /Piirainen, Elisabeth (2005): Figurative Language: Crosscultural and Cross-linguistic Perspective. Elsevier, Amsterdam.

Dobrovol'skij, Dmitrij/Piirainen, Elisabeth (2009): Zur Theorie der Phraseologie. Kognitive und kulturelle Aspekte. Stauffenburg Linguistik, Tübingen.

Dobrzyńska, Teresa (1992): Metafora w przektadzie. In: Nowakowska-Kempna, Iwona (Hg.): Język a kultura. Podstawy metodologiczne semantyki współczesnej. Wydawnictwo Uniwersytetu Wrocławskiego, Wrocław, 231-250.

Dölling, Johannes (2001): Systematische Bedeutungsvariationen: Semantische Form und kontextuelle Variation. Linguistische Arbeitsberichte 78. Universität Leipzig, Leipzig.

Donalies, Elke (1994): Idiom, Phraseologismus oder Phrasem? Zum Oberbegriff eines Bereichs der Linguistik. Zeitschrift für germanistische Linguistik 22, 334-339.

Dönninghaus, Sabine (2002): Das lexikalisch-semantische Feld der Täuschung in Phraseologismen des Tschechischen. In: Hartmann, Dietrich/Wirrer, Jan (Hg.): Wer A sägt, muss auch B sägen. Beiträge zur Phraseologie und Sprichwortsammlung aus dem Westphälischen Arbeitskreis. Schneider Verlag Hohengehren, Baltmannsweiler, 75-81.

Dräger, Marcel/Juska-Bacher, Britta (2010): Online-Datenerhebungen im Dienste der Phraseographie. In: Ptashnyk, Stefaniya/Hallsteinsdóttir, Erla/Bubenhofer, Noah (Hg.): Korpora, Web und Datenbanken. Computergestützte Methoden in der modernen Phraseologie und Lexikographie. Schneider Verlag Hohengehren, Baltmannsweiler, 165-179.

Drößiger, Hans-Harry (2007): Metaphorik und Metonymie im Deutschen. Untersuchungen zum Diskurpotenzial semantisch-kognitiver Räume. Dr. Kovač, Hamburg.

Drumm, Daniela (2004): Semantischer Mehrwert von Phraseologismen in der englischsprachigen Anzeigewerbung. Wissenschaftliche Arbeit zur Erlangung des Doktorgrades im Fach Anglistik. [webdoc.sub.gwdg.de/ebook/dissts/Trier/ Drumm2005.pdf, Zugriff am 01.02.2017]

Duhme, Michael (1991): Phraseologie der deutschen Wirtschaftssprache. Eine empirische Untersuchung zur Verwendung von Phraseologismen in journalisitschen Texten. Blaue Eule, Essen.

Duhme, Michael (1995): Lauschangriff und Rollkommando „Einwortphraseologismen” in der Pressesprache am Beispiel des Nachrichtenmagazin FOCUS. In: Baur, Rupprecht S./Chlosta, Christoph 
(Hg.): Von der Einwortmetapher zur Satzmetapher. Akten des Westfälischen Arbeitskreises Phraseologie /Parömiologie. Brockmeyer, Bochum, 83-93.

Edelmann, Walter (1996): Lernpsychologie. 5. Aufl. Beltz PVU, Weinheim.

Edelmann, Walter (2000): Lernpsychologie. 6. vollst. überarb. Aufl. Beltz PVU, Weinheim.

Ehegötz, Erika (1986): Zur Darstellung des phraseologischen Materials im allgemeinsprachlichen Übersetzungswörterbuch. In: Beiträge zur Lexikographie slawischer Sprachen. Linguistische Studien. Reihe A. Arbeitsberichte 147, Berlin, 132-140. [http://www.fb06.uni-mainz.de/inst/is/polnisch/texte/ phrasmat.pdf, Zugriff am 10.09.2010].

Ehegötz, Erika (1990): Versuch einer Typologie von Entsprechungen im zweisprachigen phraseologischen Wörterbuch. Zeitschrift für Slawistik 35, 499-504.

Ehrenfels, Christian v. (1890): Über Gestaltqualitäten. Vierteljahrsschrift für wissenschaftliche Philosophie 15, 285-347.

Ehrenmüller, Jürgen (2017): Idiomatische Phraseologismen aus der Domäne ,Spiel'. In: Berdychowska, Zofia/Lüger, Heinz-Helmut/Schatte, Czesława/Zenderowska-Korpus, Grażyna (Hg.): Phraseologie als Schnittstelle zwischen Sprache und Kultur II. Öffentlicher Raum - Medien Phraseodidaktik. Peter Lang, Frankfurt am Main, 73-86.

Ehrhardt, Claus (2007): Phraseme in der fugendsprache. In: Burger, Harald/Dobrovol'skij, Dmitrij/Kühn, Peter/Norrick, Neal R. (Hg.): Phraseologie - Phraseology. Ein internationales Handbuch der zeitgenössischen Forschung. Bd. 1. Walter de Gruyter, Berlin - New York, $253-264$.

Eismann, Wolfgang (1989): Zum Problem der Äquivalenz von Phraseologismen. In: Gréciano, Gertrud (Hg.): EUROPHRAS 88: phraséologie contrastive. Actes du Colloque International. Klingenthal, Strasbourg, 12-16 mai 1988. Strasbourg, 83-93.

Eismann, Wolfgang (2007): Phraseme in literarischen Texten. In: Burger, Harald/Dobrovol'skij, Dmitrij/Kühn, Peter/Norrick, Neal R. (Hg.): Phraseologie - Phraseology. Ein internationales Handbuch der zeitgenössischen Forschung. Bd. 1. Walter de Gruyter, Berlin - New York, 316-329.

Eismann, Wolfgang (2018): Phraseologie, Korpus und Norm. In: Gondek, Anna/Jurasz, Alina/Szczęk, Joanna (Hg.): Einblicke und Rückblicke. Beiträge zur deutschen Phraseologie und Parömiologie aus intra- und interlingualer Sicht. Bd. 1. Schneider Verlag Hohengehren, Baltmannsweiler, 45-58.

Elspaß, Stephan (2007): Phrasems in political speech. In: Burger, Harald/Dobrovol'skij, Dmitrij/Kühn, Peter/Norrick, Neal R. (Hg.): Phraseologie - Phraseology. Ein internationales Handbuch der 
zeitgenössischen Forschung. Bd. 1. Walter de Gruyter, Berlin - New York, 284-292.

Ernst, Peter (2011): Gibt es eine österreichische Phraseologie? In: Lipczuk, Ryszard/Lisiecka-Czop, Magdalena/Misiek, Dorota (Hg.): Phraseologismen in deutsch-polnischen und polnisch-deutschen Wörterbüchern. Theoretische und praktische Aspekte der Phraseologie und Lexikographie. Dr. Kovač, Hamburg, 177-190.

Ettinger, Stefan (1989): Einige Probleme der lexikographischen Darstellung idiomatischer Einheiten. In: Gréciano, Gertrud (Hg.): EUROPHRAS 88: phraséologie contrastive. Actes du Colloque International. Klingenthal, Strasbourg, 12-16 mai 1988. Strasbourg, 95-115.

Ettinger, Stefan (2004): ,Zeig Pelz die kalte Schulter': Phraseographie und Sprachwirklichkeit. In: Brdar-Szabó, Rita/Knipf-Komlósi, Elisabeth (Hg.): Lexikalische Semantik, Phraseologie und Lexikographie. Abgründe und Brücken. Festgabe fur Regina Hessky. Peter Lang, Frankfurt am Main u.a., 315-329.

Ettinger, Stefan (2007): Phraseme im Fremdsprachenunterricht. In: Burger, Harald/Dobrovol'skij, Dmitrij/Kühn, Peter/Norrick, Neal R. (Hg.): Phraseologie - Phraseology. Ein internationales Handbuch der zeitgenössischen Forschung. Bd. 1. Walter de Gruyter, Berlin - New York, 893-908.

Ettinger, Stefan (2009): ,Haben die Männer am Grill die Hosen an?’Phraseographie und Sprachwirklichkeit. In: Mellado Blanco, Carmen (Hg.): Theorie und Praxis der idiomatischen Wörterbücher. Niemeyer, Tübingen, 45-64.

Ettinger, Stefan (2011): Einige kritische Fragen zum gegenwärtigen Forschungsstand der Phraseodidaktik. In: Schäfer, Patrick/Schowalter, Christine (Hg.): In mediam linguam. Mediensprache - Redewendungen - Sprachvermittlung. Festschrift für Heinz Helmut Lüger. Verlag Empirische Pädagogik, Landau, 231-250.

Evans, Vyvyan (2013): Metaphor, Lexical Concepts, and Figurative Meaning Construction. Journal of Cognitive Semiotics V/1-2, 73-107.

Evans, Vyvyan/Green, Melanie (2006): Cognitive Lingusitics: An Introduction. Edinburgh University Press, Edinburgh.

Ewald, Petra (2002): Zur Ausprägung graphischer Phraseologisierungsindikatoren. In: Pohl, Inge (Hg.): Prozesse der Bedeutungskonstruktion. Peter Lang, Frankfurt am Main u.a., 147-163.

Fabiszak, Małgorzata/Konat, Barbara (2013): Zastosowanie korpusów językowych w językoznawstwie kognitywnym. In: Stalmaszczyk, Piotr (Hg.): Metodologie językoznawstwa. Ewolucja języka. Ewolucja teorii językoznawczych.

Wydawnictwo Uniwersytetu Łódzkiego, Łódź, 131-142.

Fauconnier, Gilles (1985): Mental Spaces: Aspects of Meaning Construction in Natural Language. Bradford, London. 
Fauconnier, Gilles (1997): Mappings in Thought and Language. Cambridge University Press, Cambridge.

Fauconnier, Gilles/Turner, Mark (1998): Conceptual Integration Network. Cognitive Science 22/1, 133-187.

Fauconnier, Gilles/Turner, Mark (2002): The Way We Think. Conceptual Blendings and The Mind's Hidden Complexities. New York, Basic Books.

Feilke, Helmuth (1994): Common sense-Kompetenz. Überlegungen zu einer Theorie des 'sympatischen' und 'natürlichen' Meinens und Verstehens. Suhrkamp, Frankfurt am Main.

Feilke, Helmuth (1996): Sprache als soziale Gestalt. Ausdruck, Prägung und die Ordnung der sprachlichen Typik. Suhrkamp, Frankfurt am Main.

Feilke, Helmuth (1998): Idiomatische Prägung. In: Barz, Irmhild/Öhlschläger, Günther (Hg.): Zwischen Grammatik und Lexikon. Forschungen zu einem Grenzbereich. Niemeyer, Tübingen, 69-81.

Feilke, Helmuth (2004): Kontext - Zeichen - Kompetenz. Wortverbindungen unter sprachtheoretischem Aspekt. In: Steyer, Kathrin (Hg.): Wortverbindungen mehr oder weniger fest. Walter de Gruyter, Berlin, 41-64.

Feilke, Helmuth (2007): Syntaktische Aspekte der Phraseologie III: Construction Grammar und verwandte Ansätze. In: Burger, Harald/Dobrovol'skij, Dmitrij/Kühn, Peter/Norrick, Neal R. (Hg.): Phraseologie - Phraseology. Ein internationales Handbuch der zeitgenössischen Forschung. Bd. 1. Walter de Gruyter, Berlin - New York, 63-76.

Fellbaum, Christiane/Kramer, Undine/Neumann, Gerald (2006): Corpusbasierte lexikographische Erfassung und linguistische Analyse deutscher Idiome.

In: Häcki-Buhofer, Annelies/Burger, Harald (Hg.): Phraseology in Motion. Proceedings of Europhras Basel 2004. Schneider Verlag Hohengehren, Baltmannsweiler, 43-56.

Feyaerts, Kurt (1999): Die Metonymie als konzeptuelles Strukturprinzip: eine kognitiv-semantische Analyse deutscher Dummheitsausdrücke. In: Baur, Rupprecht S./Chlosta, Christoph/Piirainen, Elisabeth (Hg.): Wörter in Bildern - Bilder in Wörtern. Beiträge zur Phraseologie und Sprichwortforschung aus dem Westfälischen Arbeitskreis. Schneider Verlag Hohengehren, Baltmannsweiler, 139-176.

Fiedler, Sabine (2014): „Gläserne Decke” und „Elefant im Raum“: Phraseologische Anglizismen im Deutschen. Logos Verlag, Berlin.

Filatkina, Natalia (2007): Pragmatische Beschreibungsansätze. In: Burger, Harald/Dobrovol'skij, Dmitrij/Kühn, Peter/Norrick, Neal R.

(Hg.): Phraseologie - Phraseology. Ein internationales Handbuch der zeitgenössischen Forschung. Bd. 1. Walter de Gruyter, Berlin - New York, $132-158$. 
Filipenko, Tat'jana (2009): Darstellung von deutschen und russischen Idiomen in zweisprachigen Wörterbüchern. In: Mellado Blanco, Carmen (Hg.): Theorie und Praxis der idiomatischen Wörterbücher. Niemeyer, Tübingen, 169-187.

Fillmore, Charles J. (1975): An Alternative to Checklist Theories of Meaning. In: Cogen, Cathy (Hg.): Proceedings of the First Annual Meeting of the Berkeley Linguistics Society. Berkeley Linguistics Society, Berkeley, 123-131.

Fillmore, Charles J. (1982): Frame Semantics. In: The Linguistic Society of Korea (Hg.): Lingustics in the Morning Calm. Selected Papers from SICOL-1981. Hanshin Publishing Company, Seoul, 111-137.

Fillmore, Charles J. (1988): The mechanisms of Construction Grammar. In: Axmaker, Sheeely/Jaisser, Annie/Singmaster, Helen (Hg.): Proceedings of the Fourteenth Annual Meeting of the Berkeley Lingustistics Society. Berkeley Linguistics Society, Berkeley, 35-55.

Fillmore, Charles J. (1992): “Corpus Linguistics" or "Computer-aided Armchair Linguistics". In: Svartvik, Jan (Hg.): Directions in Corpus Linguistics: Proceedings of Nobel Symposium 82, Stockholm, 4-8. August 1991. Mouton de Gruyter, Berlin - New York, 35-60.

Fillmore, Charles J./Atkins, Beryl T. S. (1992): Towards a Frame-based organisation of the lexicon: the semantics of RISK and its neighbors. In: Lehrer, Adrienne/Kittay, Eva (Hg.): Frames, Fields, and Contrasts: New Essays in Semantics and Lexicon Organisation. Lawrence Erlbaum, Hillsdale, 75-102.

Fillmore, Charles J./Baker, Collin (2009): A frames approach to semantic analysis. In: Heine, Bernd/Narrog, Heiko (Hg.): The Oxford Handbook of Semantic Analysis. Oxford Univeristy Press, New York, 313-339.

Fillmore, Charles J./Johnson, Christopher R./Pertuck, Miriam R.L. (2003): Background to FrameNet. International Journal of Lexicography 16/3, 235-250.

Fillmore, Charles J./Kay, Paul/O'Connor, Mary Catherine (1988): Regularity and Idiomacity in Grammatical Constructions: The case of let alone. Language 64/3, 501-538.

Firth, John Rupert (1991): Personality and Language in Society. In: Papers in Linguistics 1934-1951 herausgegeben von Firth, John Rupert, London, 177-189.

Fix, Ulla (1971): Das Verhältnis von Syntax und Semantik im Wortgruppenlexem. Versuch einer objektivierten Klassifizierung und Definition des Wortgruppenlexems. Karl-Marx-Universität, Leipzig.

Fix, Ulla (1974): Zum Verhältnis von Syntax und Semantik im Wortgruppenlexem. Beiträge zur Geschichte der deutschen Sprache und Literatur 95, 214-318.

Fix, Ulla (2002): Anschauliche Wörter? Wörter im Dienste der Bildhaftigkeit, Bildlichkeit, Bildkräftigkeit, Sinnlichkeit, Lebendigkeit, Gegenständlichkeit von 
Texten. In: Barz, Irmhild/Fix, Ulla/Lerchner, Gotthard (Hg.): Das Wort in Text und Wörterbuch. Hirzer, Stuttgart - Leipzig, 9-22.

Fix, Ulla (2007): Der Spruch - Slogan und andere Spruchtextsorten.

In: Burger, Harald/Dobrovol'skij, Dmitrij/Kühn, Peter/Norrick, Neal R. (Hg.): Phraseologie - Phraseology. Ein internationales Handbuch der zeitgenössischen Forschung. Bd. 1. Walter de Gruyter, Berlin - New York, 459-468.

Fleischer, Wolfgang (1982): Phraseologie der deutschen Gegenwartssprache. VEB Bibliographisches Institut, Leipzig.

Fleischer, Wolfgang (1983): Phraseologie. In: Fleischer, Wolfgang (Hg.): Kleine Enzyklopädie Deutsche Sprache. Peter Lang, Leipzig, 307-321.

Fleischer, Wolfgang (1996): Zum Verhältnis von Wortbildung und Phraseologie im Deutschen. In: Korhonen, Jarmo (Hg.): Studien zur Phraseologie des Deutschen und des Finnischen. Teil 2. Brockmeyer, Bochum, 333-344.

Fleischer, Wolfgang (1997): Phraseologie der deutschen Gegenwartssprache. Niemeyer, Tübingen.

Fleischer, Wolfgang/Michel, Georg/Starke, Günter (1993): Stilistik der deutschen Gegenwartssprache. Peter Lang, Frankfurt am Main.

Fodor, Jerry A. (1975): The Language of Thought. Crowell, New York.

Földes, Csaba (1996): Deutsche Phraseologie kontrastiv. Intra- und interlinguale Zugänge. Julius Groos Verlag, Heidelberg.

Földes, Csaba (2007): Phraseme mit spezifischer Struktur. In: Burger, Harald/Dobrovol'skij, Dmitrij/Kühn, Peter/Norrick, Neal R.

(Hg.): Phraseologie - Phraseology. Ein internationales Handbuch der zeitgenössischen Forschung. Bd. 1. Walter de Gruyter, Berlin - New York, 425-436.

Folkersma, Petra (2010): Emotionen im Spannungsfeld zwischen Körper und Kultur. Peter Lang, Frankfurt am Main u.a.

Fortmüller, Richard (1991): Lernpsychologie. Grundkonzeptionen, Theorien, Forschungsergebnisse. Manz Verlags- und Universitätsbuchhandlung, Wien.

Fraas, Claudia (2002): Wissen als kognitives und als sozial bestimmtes Phänomen - Zur sprachlichen Manifestation von Bedeutungswissen. In: Pohl, Inge (Hg.): Prozesse der Bedeutungskonstruktion. Peter Lang, Frankfurt am Main u.a., 39-58.

Gainotti, Guido/Silveri, Maria C./Daniele, Antonio/Giustolisi, Laura (1995): Neuroanatomical correlates of category-specific semantic disorders: A critical survey. Memory 3, 247-264.

Gallese, Vittorio/Lakoff, George (2005): The Brain's Concepts: The Role of the sensory-motor system in conceptual knowledge. Cognitive Neuropsychology $21,1-26$. 
Gazzaniga, Michael.S./Ivry, Richard B./Mangun, George R. (2009): Cognitive Neuroscience. The Biology of the Mind. Norton \& Company, New York London.

Geeraerts, Dirk (2003): The interaction of metaphor and metonymy in composite expression. In: Dirven, René/Pörings, Ralf (Hg.): Metaphor and Metonymy in Comparison and Contrast. Mouton de Gruyter, Berlin - New York, 435-467.

Gibbs, Raymond W (1984): Literal meaning and psychological theory. Cognitive Psychology 8, 191-219.

Gibbs, Raymond W. (1990): Psycholinguistic studies on the conceptual basis of idiomaticity. Cognitive Linguistics 1-4, 417-451.

Gibbs, Raymond W. (1993): Why Idioms Are Not Dead Metaphors. In: Cacciari, Cristina/Tabossi, Patrizia (Hg.): Idioms: Processing, Structure, and Interpretation. Psychology Press, New York - London, 57-78.

Gibbs, Raymond W. (1994): The Poetics of Mind. Figurative Thought, Language, and Understanding. Cambridge University Press, Cambridge.

Gibbs, Raymond W./Colston, Herbert L. (2007): Psycholinguistic aspects of phraseology: American tradition. In: Burger, Harald/Dobrovol'skij, Dmitrij/Kühn, Peter/Norrick, Neal R. (Hg.): Phraseologie - Phraseology. Ein internationales Handbuch der zeitgenössischen Forschung. Bd. 2. Walter de Gruyter, Berlin - New York, 819-836.

Gibbs, Raymond W./O’Brien, Jennifer E. (1990): Idioms and mental imagery: The metaphorical motivation for idiomatic meaning. Cognition 36, 35-68.

Gläser, Rosemarie (1980): Idiomatik und Sprachvergleich. Sprache und Literatur 56, 67-73.

Gläser, Rosemarie (1986): A Plea for Phraseo-Stylistics. In: Kastovsky, Dieter/Szwedek, Aleksander (Hg.): Linguistics Across Historical and Geographical Boundaries: In Honour of Jacek Fisiak on the Occasion of his 50. Birthday. Mouton de Gruyter, Berlin - New York - Amsterdam, 41-52.

Gläser, Rosemarie (2007): Fachphraseologie. In: Burger, Harald/Dobrovol'skij, Dmitrij/Kühn, Peter/Norrick, Neal R. (Hg.): Phraseologie - Phraseology. Ein internationales Handbuch der zeitgenössischen Forschung. Bd. 1. Walter de Gruyter, Berlin - New York, 482-505.

Głaz, Adam (2010): Czym jest (językowy) obraz świata - powrót do źródeł. Etnolingwistyka 22, 211-215.

Glucksberg, Sam (1993): Idiom Meanings and Allusional Content. In: Cacciari, Cristina/Tabossi, Patrizia (Hg.): Idioms: Processing, Structure, and Interpretation. Psychology Press, New York - London, 3-26.

Glucksberg, Sam (2001): Understandig Figurative Language. From Metaphor to Idioms. Oxford University Press, New York. 
Glucksberg, Sam/McGlone, Matthiew S./Keysar, Boaz (1992): Metaphor Understanding and Accessing Conceptual Schema: Reply to Gibbs (1992). Psychological Review 99/3, 578-581.

Goldberg, Adele (1995): Constructions. A Construction Grammar Approach to Argument Structure. Chicago University Press, Chicago.

Gondek, Anna (2015): Konzeptualisierung der Emotionen auf der Mikrotextebene (am Beispiel von Sprichwörtern mit der Komponente Zorn). Linguistik online 74. [https://bop.unibe.ch/linguistik-online/article/view/2229, Zugriff am 30.03.2017].

Goosens, Louis (2003): Metaphtonymy: The interaction of metaphor and metonymy in expressions for linguistic action. In: Dirven, René/Pörings, Ralf (Hg.): Metaphor and Metonymy in Comparison and Contrast. Mouton de Gruyter, Berlin - New York, 349-378.

Grabowska, Anna (2000): Percepcja wzrokowa i jej analogie do innych form percepcji. In: Górska, Teresa/Grabowska, Anna/Zagrodzka, Jolanta (Hg.): Mózg a zachowanie. Wydawnictwo Naukowe PWN, Warszawa, 147-183.

Grady, Jospeh E. (2005): Image schemas and perception: Refining a definition. In: Hampe, Beate (Hg.): From Perception to Meaning. Image Schemas in Cognitive Linguistics. Mouton de Gruyter, Berlin - New York, 35-56.

Gréciano, Gertrud (1982): Zur Semantik der deutschen Idiomatik. Zeitschrift für germanistische Linguistik 10, 295-316.

Gréciano, Gertrud (1983): Forschungen zur Phraseologie. Zeitschrift für Germanistische Linguistik 11, 232-241.

Gréciano, Gertrud (2007): Phraseme in medizinischen Texten. In: Burger, Harald/Dobrovol'skij, Dmitrij/Kühn, Peter/Norrick, Neal R. (Hg.): Phraseologie - Phraseology. Ein internationales Handbuch der zeitgenössischen Forschung. Bd. 1. Walter de Gruyter, Berlin - New York, 516-529.

Grice, Paul H. (1975): Logic and conversation. In: Cole, Peter/Morgan, Jerry L. (Hg.): Syntax and semantics 3: Speech acts. Academic Press, New York, 41-58.

Grucza, Franciszek (1983): Zagadnienia metalingwistyki. Lingwistyka - jej przedmiot, lingwistyka stosowana. PWN, Warszawa.

Grucza, Franciszek (1993a): Język, ludzkie właściwości językowe, językowa zdolność ludzi. In: Piontek, Janusz/Wiercińska, Alina (Hg.): Człowiek w perspektywie ujęć biokulturowych. Uniwersytet im. Adama Mickiewicza, Poznań, 151-174.

Grucza, Franciszek (1993b): Zagadnienia ontologii lingwistycznej: O językach $i$ ich (rzeczywistym) istnieniu. In: Barmiński, Jerzy (Hg.): Opuscula Logopaedica. In honorem Leonis Kaczmarek. Wydawnictwo Uniwersytetu Marii CurieSkłodowskiej, Lublin, 25-47. 
Grucza, Franciszek (1997a): Problemy historii i genezy języków ludzkich. In: Dębski, Antoni (Hg.): Plus ratio quam vis. Festschrift für Aleksander Szulc zum 70. Geburtstag. Wydawnictwo Uniwersytetu Jagiellońskiego, Kraków, 7799.

Grucza, Franciszek (1997b): Języki ludzkie a wyrażenie językowe, wiedza a informacja, mózg a umyst ludzki. In: Grucza, Franciszek/Dakowska, Maria (Hg.): Podejścia kognitywne w lingwistyce, translatoryce i glottodydaktyce. Wydawnictwo Uniwersytetu Warszawskiego, Warszawa, 7-21.

Grucza, Sambor (2010): Główne tezy antropocentrycznej teorii języków. Lingwistyka Stosowana 2, 41-68.

Grucza, Sambor (2012): Fachsprachenlinguistik. Warschauer Studien zur Germanistik und zur Angewandten Linguistik. Peter Lang, Frankfurt am Main u.a.

Grzegorczykowa, Renata (1992): Kognitywne ujęcie znaczenia a problem realizmu filozoficznego. In: Nowakowska-Kempna, Iwona (Hg.): Język a kultura. Podstawy metodologiczne semantyki współczesnej. Bd. 8, Wiedza o kulturze, Wrocław, 37-42.

Grzegorczykowa, Renata (1999): Pojęcie językowego obrazu świata $i$ sposoby jego rekonstrukcji. In: Bartmiński, Jerzy (Hg.): Językowy obraz świata. Wydawnictwo Uniwersytetu Marii Curie-Skłodowskiej, Lublin, 39-46.

Grzegorczykowa, Renata (2009): Punkty dyskusyjne w rozumieniu pojęcia językowego obrazu świata - widziane z perspektywy badań porównawczych. Etnolingwistyka 21, 15-29.

Grzegorczykowa, Renata (2011): Wprowadzenie do semantyki językoznawczej. PWN, Warszawa.

Grzybek, Peter (1991): Sinkendes Kulturgut? Eine empirische Pilotstudie zur Bekanntheit deutscher Sprichwörter. Wirkendes Wort 2, 239-264.

Grzybek, Peter (2007): Semiotik und Phraseologie. In: Burger, Harald/Dobrovol'skij, Dmitrij/Kühn, Peter/Norrick, Neal R. (Hg.): Phraseologie - Phraseology. Ein internationales Handbuch der zeitgenössischen Forschung. Bd. 1. Walter de Gruyter, Berlin - New York, 188-208.

Guławska-Gawkowska, Małgorzata (2012): Semantische Aspekte im Vergleich von deutschen und polnischen Phraseologismen. Zeitschrift des Verbandes der Polnischen Germanisten 2, 74-88.

Guławska-Gawkowska, Małgorzata (2013): Somatische und emotionale Konzepte in der deutschen und polnischen Phraseologie. Ein lexikographischer Ansatz zum phraseologischen Übersetzungswörterbuch. Peter Lang, Franfurt am Main.

Häcki Buhofer, Annelies (1989): Psycholinguistische Aspekte in der Bildhaftigkeit der Phraseologismen. In: Gréciano, Gertrud (Hg.): EUROPHRAS 88: phraséologie contrastive. Actes du Colloque International. Klingenthal, Strasbourg, 12-16 mai 1988. Strasbourg, 165-175. 
Häcki Buhofer, Annelies (1993): Psycholinguistik der Phraseologie. Zum Stand der Forschung. In: Durčo, Peter/Kroslakowa, Emma (Hg.): Papers for the $2^{\text {nd }}$ International Conference on Phraseology: „Phraseology in Education, Culture and Science" in Nitra, 14-16 September 1992. Nitra, 148-160.

Häcki Buhofer, Annelies (1996): Theorie und Methodologie der psycholinguistisch basierten Bedeutungsbeschreibung: Zur Bandbreite phraseologischer Bedeutungen. In: Weigand, Edda/Hundsnurscher, Franz (Hg.): Lexical structures and language use. Max Niemeyer, Tübingen, 387-398.

Häcki Buhofer, Annelies (2004): Spielräume des Sprachverstehens. Psycholinguistische Zugänge zum individuellen Umgang mit Phraseologismen. In: Steyer, Kathrin (Hg.): Wortverbindungen - mehr oder weniger fest. Walter de Gruyter, Berlin, 144-164.

Häcki Buhofer, Annelies (2007a): Phraseme im Erstspracherwerb. In: Burger, Harald/Dobrovol'skij, Dmitrij/Kühn, Peter/Norrick, Neal R. (Hg.): Phraseologie - Phraseology. Ein internationales Handbuch der zeitgenössischen Forschung. Bd. 2. Walter de Gruyter, Berlin - New York, 854-869.

Häcki Buhofer, Annelies (2007b): Psycholinguistic aspects of phraseology: European tradition. In: Burger, Harald/Dobrovol'skij, Dmitrij/Kühn, Peter/Norrick, Neal R. (Hg.): Phraseologie - Phraseology. Ein internationales Handbuch der zeitgenössischen Forschung. Bd. 2. Walter de Gruyter, Berlin - New York, 836-853.

Häcki Buhofer, Annelies (Hg.) (2009): Fortschritte in Sprach- und Textkorpusdesign und linguistischer Korpusanalyse I. Proceedings in language and text corpus design and linguistic corpus analysis I. Linguisitk online 3 [http://www.linguistik-online.de/38_09/index.pdf, Zugriff am 17.06.2017].

Hahn, Marion (2006): Kommunikative Routineformeln in lexikographischer Hinsicht. In: Breuer, Ulrich/Hyvärinen, Irma (Hg.): Wörter - Verbindungen. Festschrift für Jarmo Korhonen zum 60. Geburtstag. Peter Lang, Frankfurt am Main u.a., 153-164.

Hallsteinsdóttir, Erla (2001): Das Verstehen idiomatischer Phraseologismen in der Fremdsprache Deutsch. Dr. Kovač, Hamburg.

Hallsteinsdóttir, Erla (2005): Vom Wörterbuch zum Text zum Lexikon. In: Fix, Ulla/Lerchner, Gotthard/Schröder, Marianne/Wellmann, Hans (Hg.): Zwischen Lexikon und Text - lexikalische, stilistische und textlinguistische Aspekte. Hirzer, Leipzig, 325-337.

Hallsteinsdóttir, Erla (2006a): Phraseographie. Hermes - fournal of Language and Communication Studies 36, 91-128.

Hallsteinsdóttir, Erla (2006b): Konzeption und Erstellung einer computergestützten zweisprachigen Phraseologiesammlung Isländisch - Deutsch. In: Häcki Buhofer, Annelies/Burger, Harald (Hg.): Phraseology in Motion. Proceedings of 
Europhras Basel 2004. Schneider Verlag Hohengehren, Baltmannsweiler, 211-222.

Hallsteinsdóttir, Erla (2007): A bilingual electronic dictionary of idioms.

In: Gottlieb, Henrik/Mogensen, Jens Erik (Hg.): Dictionaries visions, Research and Practise: Selected papers from the $12^{\text {th }}$ International Symposium on Lexicography, Copenhagen 2004. John Benjamins, Amsterdam, 97-106.

Hallsteinsdóttir, Erla (2009): Zweisprachige Lernerphraseographie aus funktionaler Sicht. In: Mellado Blanco, Carmen (Hg.): Theorie und Praxis der idiomatischen Wörterbücher. Niemeyer, Tübingen, 209-231.

Hallsteinsdóttir, Erla/Šajánková, Monika/Quasthoff, Uwe (2006): Phraseologisches Optimum für Deutsch als Fremdsprache. Ein Vorschlag auf der Basis von Frequenz- und Geläufigkeitsuntersuchungen. Linguistik online 27/2 [http:// www.linguistik-online.de/27_06/hallsteinsdottir_et_al.html, Zugriff am 14.04.2014].

Hampe, Beate (2005): Image Schemas in Cognitive Linguistics: Introduction. In: Hampe, Beate (Hg.): From Perception to Meaning: Image Schemas in Cognitive Linguistics. Mouton de Gruyter. Berlin - New York, 1-12.

Hampton, James A. (1989): Review: "Woman, fire and dangerous things" by George Lakoff. Mind and Language 4, 130-137.

Handl, Sandra (2011): The Conventionality of Figurative Language: A Usage-based Study. Narr Verlag, Tübingen.

Hanks, Patrick (2004): Corpus Pattern Analysis. In: Proceedings of the $11^{\text {th }}$ EURALEX International Congress. Lorient, 87-98. [http://www.euralex.org/ elx_proceedings/Euralex2004, Zugriff am 18.05.2017]

Hanks, Patrick (2012): The corpus revolution in lexicography. International Fournal of Lexicography 25/4, 398-436.

Hartmann, Dietrich (1998): Lexikalische Felder als Untersuchungsrahmen für Phraseologismen und deren Leistungen für den Wortschatz. In: Hartmann, Dietrich (Hg.): „Das geht auf keine Kuhhaut“ - Arbeitsfelder der Phraseologie. Akten des Westfälischen Arbeitskreises Phraseologie/Parömiologie 1996, Bochum, 127-147.

Hartmann, Dietrich (1999): Zur Phraseologiebildung mittels metonymischer Prozesse aus der Sicht der kognitiven Linguistik. In: Baur, Rupprecht S./Chlosta, Christoph/Piirainen, Elisabeth (Hg.): Wörter in Bildern - Bilder in Wörtern. Beiträge zur Phraseologie und Sprichwortforschung aus dem Westfälischen Arbeitskreis. Schneider Verlag Hohengehren, Baltmannsweiler, 218-238.

Hartmann, Dietrich (2002): Ein Plädoyer für lexikographische Struktur und Lexikographie phraseologischer Wortschätze. In: Hartmann, Dietrich/Wirrer, Jan (Hg.): Wer A sägt, muss auch B sägen. Beiträge zur Phraseologie und Sprichwortforschung aus dem Westfälischen Arbeitskreis. Schneider Verlag Hohengehren, Baltmannsweiler, 433-437. 
Hausmann, Franz Josef (1984): Wortschatzlernen ist Kollokationslernen. Zum Lehren und Lernen französischer Wortverbindungen. Praxis des neusprachlichen Unterrichts 31, 385-406.

Häusermann, Jürg (1977): Phraseologie. Hauptprobleme der deutschen Phraseologie auf der Basis sowjetischer Forschungsergebnisse. Niemeyer, Tübingen.

Hein, Katrin (2012): Zugang zu Sprichwortbedeutung und-gebrauch mit Hilfe von Korpora. In: Steyer, Kathrin (Hg.): Sprichwörter multilingual. Theoretische, empirische und angewandte Aspekte der modernen Parömiologie. Narr, Tübingen, 315-340.

Heine, Antje (2010): Wie viel Polylexikalität braucht ein Phraseologismus? In: Korhonen, Jarmo/Mieder, Wolfgang/Piirainen, Elisabeth/Piňel, Rosa (Hg.): EUROPHRAS 2008. Beiträge zur internationalen Phraseologiekonferenz vom 13.-16. 08. 2008 in Helsinki. Universität Helsinki, Institut für Moderne Sprache, Helsinki, 11-18.

Heringer, Hans-Jürgen (1981): Die Unentscheidbarkeit der Ambiguität. In: Wolf, Dietrich/Geckeler, Horst (Hg.): Logos Semanticos. Studia Linguistica in Honorem Eugenio Coseriu. Bd. 3, Berlin - New York - Madrid, 93-126.

Hessky, Regina (1992a): Aspekte der Verwendung von Phraseologismen im Unterricht Deutsch als Fremdsprache. Fremdsprachen Lehren und Lernen 21, 159-168.

Hessky, Regina (1992b): Grundfragen der Phraseologie. In: Ágel, Vilmos/Hessky, Regina (Hg.): Offene Fragen, offene Antworten in der Sprachgermanistik. Niemeyer, Tübingen, 77-94.

Hessky, Regina (1992c): Phraseolexeme als harte Nuß für die zweisprachige Lexikographie. In: Földes, Csaba (Hg.): Deutsche Phraseologie in Sprachsystem und Sprachverwendung. Ed. Praesens, Wien, 107-123.

Hessky, Regina (1997): Feste Wendungen - ein heißes Eisen? Einige phraseodidaktische Überlegungen für den DaF-Unterricht. Deutsch als Fremdsprache 3, 139-143.

Hessky, Regina (1999): Phraseologie: Vermittlungsinstanz zwischen Sprachsystem und Sprachverwendung. In: Fernandes Bravo, Nicole/Behr, Irmtraud/Rozier, Claire (Hg.): Phraseme und typisierte Rede. Stauffenburg Verlag, Tübingen, 233-240.

Hessky, Regina (2000): Entwicklungen der Phraseologie seit Mitte des 20. Fahrhunderts. In: Bensch, Werner (Hg.): Sprachgeschichte. Ein Handbuch zur Geschichte der deutschen Sprache und ihrer Erforschung. Bd. 2. Walter de Gruyter, Berlin - New York, 2101-2106.

Hoffmann, Lothar (1984): Fachwortschatz - Grundwortschatz - Minimum. Deutsch als Fremdsprache 21, 4, 224-228.

Hofmannová, Jana (2004): Farbbezeichnungen als phraseologische Komponenten im Deutschen und im Tschechischen. Sbornik praci filozoficke fakulty brnenske studia minora facultatis philosphicae Universitatis Brunensis 9, 163-177. 
Hümmer, Christiane (2006): Semantische Besonderheiten phraseologischer Ausdrücke - korpusbasierte Analyse. Linguistik online 27/2 [http://www. linguistik-online.de/27_06/huemmer.html, Zugriff am 17.06.2014].

Hümmer, Christiane (2009): Synonymie bei phraseologischen Einheiten. Eine korpusbasierte Untersuchung. Peter Lang, Frankfurt am Main u.a.

Hyvärinen, Irma (2011): Zur Abgrenzung und Typologie pragmatischer Phraseologismen - Forschungsüberblick und offene Fragen. In: Hyvärinen, Irma/Liimatainen, Annikki (Hg.): Beiträge zur pragmatischen Phraseologie. Peter Lang, Frankfurt am Main u.a., 9-43.

Ignatowicz-Skowrońska, Jolanta/Sulikowska, Anna (2015): Zur Entwicklung und zum Gegenstandbereich der deutschen und der polnischen Phraseologie. Linguistik online 74 [https://bop.unibe.ch/linguistik-online/article/view/2224, Zugriff am 14.09.2017].

Jackendoff, Ray S. (1983): Semantics and Cognition. MIT, Cambridge - London. Jackendoff, Ray (1987): The status of thematic relations in linguistic theory. Linguistic Inquiry 18, 369-411.

Jackendoff, Ray (1997): The architecture of the language faculty. MIT Press, Cambridge.

Jakobson, Roman (2003 [1956]): The metaphoric and metonymic poles. In: Dirven, René/Pörings, Ralf (Hg.): Metaphor and Metonymy in Comparison and Contrast. Mouton de Gruyter, Berlin - New York, 41-48.

Jäkel, Olaf (1998): Diachronie und Wörtlichkeit: Problembereiche der kognitiven Metapherntheorie. In: Ungerer, Friedrich (Hg.): Kognitive Lexikologie und Syntax (RBS - Rostocker Beiträge zur Sprachwissenschaft 5/1998). Philosophische Fakultät, Universität Rostock, 99-117.

Jäkel, Olaf (2003): Wie Metaphern Wissen schaffen. Die kognitive Metapherntheorie und ihre Anwendung in Modell-Analysen der Diskursbereichen Geistestätigkeit, Wirtschaft, Wissenschaft und Religion. Dr. Kovač, Hamburg.

Jaksche, Harald/Sialm, Ambros/Burger Harald (1981): Reader zur sowjetischen Phraseologie. Walter de Gruyter, Berlin.

James, William (1900): Psychology. Henry Holt and Company, New York. Janyan, Armina/Andonova, Elena (2000): The Role of Mental Imaginery in Understanding Unknown Idioms. In: Gleitman, Lila R./Joshi, Aravind K. (Hg.): Proceedings of the Twenty-Second Annual Conference of the Cognitive Science Society. Lawrence Erlbau Associaters, New Yersey - London, 693-695.

Jesenšek, Vida (2006): Phraseologie und Fremdsprachenlernen. Zur Problematik einer angemessenen phraseodidaktischen Umsetzung. Linguistik online 27/2 [http://www.linguistik-online.de/27_06/jesensek.html, Zugriff am 12.03.2014]. 
Jesenšek, Vida (2008): Phraseologie im zweisprachigen Wörterbuch. Eine Herausforderung für Lexikographen und Übersetzer. Germanistische Linguistik 195/196, 387-404.

Jesenšek, Vida (2009): Phraseologische Wörterbücher auf dem Weg zu Phraseologiedatenbanken. In: Mellado Blanco, Carmen (Hg.): Theorie und Praxis der idiomatischen Wörterbücher. Niemeyer, Tübingen, 65-81.

Johnson, Christopher R./Fillmore, Charles J./Wood, Esther J./Rupperhofer, Joseph/Urban, Margaret/Petruck, Miriam R. L./Baker, Collin F. (2001): The FrameNet Project: Tools for Lexicon Building. [http://citeseerx.ist.psu.edu/ viewdoc/download?doi=10.1.1.129.9667 \&rep=rep1\&type=pdf, Zugriff am 04.06.2016].

Johnson, Mark (1987): The Body in the Mind: The Bodily Basis of Meaning, Imagination, and Reason. University of Chicago Press, Chicago.

Johnson, Mark/Lakoff, George (2002): Why Cognitive Linguistics Require Embodied Realism. Cognitive Linguistics 13/3, 245-263.

Johnson, Mark/Rohrer, Tim (2007): We are Live Creatures: Embodiment, American Pragmatism, and the Cognitive Organism. In: Ziemke, Tom/Zlatev, Jordan/Frank, Roslyn M. (Hg.): Body, Language and Mind. Mouton de Gruyter, Berlin, 17-53. [http://www.neurohumanitiestudies.eu/archivio/ blmjohnsonrohrerdraft.pdf, Zugriff am 21.10.2016].

Johnson-Laird, Philip N. (1993): Foreword. In: Cacciari, Cristina/Tabossi, Patrizia (Hg.): Idioms: Processing, Structure, and Interpretation. Psychology Press, New York - London, vii-x.

Juska-Bacher, Britta (2006): Empirisch-kontrastive Phraseologie. Am Beispiel der Bekanntheit der niederländischen Sprichwörter im Niederländischen, Deutschen und Schwedischen. Schneider Verlag Hohengehren, Baltmannsweiler.

Kan, Irene P./Barsalou, Lawrence W./Olseth Solomon, Karen/Minor, Jeris K./Thompson-Schill, Sharon L. (2003): Role of mental imaginery in the property verification task: fMRI evidence for perceptual representations of conceptual knowledge. Cognitive Neuropsychology 20, 525-540.

Kania, Stanisław/Tokarski, Jan (1984): Zarys leksykologii i leksykografii polskiej. Wydawnictwa Szkolne i Pedagogiczne, Warszawa.

Kapuścińska, Anna (2014): Bildhaft oder bildlich? Kleiner Unterschied mit großer Wirkung. In: Kaczmarek, Dorota/Makowski, Jacek/Michoń, Maciej/Weigt, Zenon (Hg.): Felder der Sprache. Felder der Forschung. Primum Verbum, Łódź, 33-40.

Kardela, Henryk (1992): Gramatyka kognitywna jako globalna teoria języka. In: Nowakowska-Kempna, Iwona (Hg.): Język a kultura. Podstawy metodologiczne semantyki współczesnej. Wydawnictwo Uniwersytetu Wrocławskiego, Wrocław, 9-22. [http://docslide.pl/documents/01henryk-kardelagramatyka-kognitywna-jako-globalna-teoria-jezyka.html, Zugriff am 13.11.2015]. 
Kardela, Henryk (2006): Metodologia językoznawstwa kognitywnego.

In: Stalmaszczyk, Piotr (Hg.): Metodologie językoznawstwa ogólnego.

Podstawy teoretyczne. Wydawnictwo Uniwersytetu Łódzkiego, Łódź, 196-233.

Kątny, Andrzej (2011): Zu Phraseologismen im zweisprachigen Wörterbuch Wielki stownik niemiecko-polski von PONS. In: Lipczuk, Ryszard/Lisiecka-Czop, Magdalena/Misiek, Dorota (Hg.): Phraseologismen in deutsch-polnischen und polnisch-deutschen Wörterbüchern. Theoretische und praktische Aspekte der Phraseologie und Lexikographie. Dr. Kovač, Hamburg, 55-64.

Katz, Jerrod J./Fodor, Jerry A. (1963): The Structure of a Semantic Theory. Language 39, 170-210.

Katz, Jerrold J. (1977): Propositional structure and illocutionary force. Thomas Y. Crowell, New York.

Kay, Paul/Fillmore, Charles J. (1999): Grammatical constructions and lingustic generalizations: The What's X is doing Y? constructions. Language 75/1, 1-33.

Keil, Martina (1997): Wort für Wort. Repräsentation und Verarbeitung verbaler Phraseologismen (Phraseo-Lex). Max Niemeyer, Tübingen.

Kiklewicz, Aleksander (2006): Język. Komunikacja. Wiedza. VTAA Prawa i Ekanomika, Mińsk.

Kilgarriff, Adam/Rychly, Pavel/Smrz, Pavel/Tugwell, David (2004): The Sketch Engine. In: Proceedings of the $11^{\text {th }}$ EURALEX International Congress. Lorient, 105-116 [http://www.euralex.org/elx_proceedings/Euralex2004, Zugriff am 18.05.2017].

Kispál, Tamás (2011): Die kognitiv-metaphorische Motiviertheit beim Erlernen von Idiomen am Beispiel eines Aufgabenblattes. Linguistik online 47/3 [https:// bop.unibe.ch/linguistik-online/article/view/366, Zugriff am 18.05.2016].

Kleiber, Georges (1983): Prototypensemantik. Eine Einführung. Günter Narr, Tübingen.

Koller, Werner (2007): Probleme der Übersetzung von Phrasemen.

In: Burger, Harald/Dobrovol'skij, Dmitrij/Kühn, Peter/Norrick, Neal R. (Hg.): Phraseologie - Phraseology. Ein internationales Handbuch der zeitgenössischen Forschung. Bd. 1. Walter de Gruyter, Berlin - New York, 605-613.

Komenda-Earle, Barbara (2015): Sprachhistorische Entwicklungsprozesse der Idiomatik. An Beispielen von realhistorisch motivierten verbalen Idiomen des Deutschen. Schneider Verlag Hohengehren, Baltmannsweiler.

Komenda-Earle, Barbara/Staffeldt, Sven (2009): Deutsch-polnische Fingerübungen. Methode und Praxis vergleichender Bedeutungsbeschreibung von Phraseologismen. In: Lipczuk, Ryszard/Jackowski, Przemysław (Hg.): Sprachkontakte - Sprachstruktur. Entlehnungen - Phraseologismen. Dr. Kovač, Hamburg, 151-178. 
Komorowska, Ewa (2011): Das deutsch-polnische Wörterbuch der biblischen Phraseologie mit historisch-etymologischen Kommentaren - ausgewählte Probleme. In: Lipczuk, Ryszard/Lisiecka-Czop, Magdalena/Misiek, Dorota (Hg.): Phraseologismen in deutsch-polnischen und polnisch-deutschen Wörterbüchern. Theoretische und praktische Aspekte der Phraseologie und Lexikographie. Dr. Kovač, Hamburg, 217-225.

Korhonen, Jarmo (1992a): Idiome als Lexikoneinheiten. Eine Auswahl von Beschreibungsproblemen. In: Korhonen, Jarmo (Hg.): Phraseologie und Wortbildung - Aspekte der Lexikonerweiterung. Finnisch-deutsche sprachwissenschaftliche Konferenz, 5-6. Dezember 1990 in Berlin. Tübingen, 1-20.

Korhonen, Jarmo (1992b): Morphosyntaktische Variabilität der Phraseologismen. In: Földes, Csaba (Hg.): Deutsche Phraseologie in Sprachsystem und Sprachverwendung. Ed. Preasens, Wien, 49-87.

Korhonen, Jarmo (2002): Typologien von Phraseologismen. Ein Überblick. In: Cruse, Alan D./Hundsnurscher, Franz/Job, Michael/Lutzeier Peter R. (Hg.): Lexikologie/Lexicology. Ein internationales Handbuch zur Natur und Struktur von Wörtern und Wortschätzen. Walter de Gruyter, Berlin New York, 402-408.

Korhonen, Jarmo (2007): Probleme der kontrastiven Phraseologie.

In: Burger, Harald/Dobrovol'skij, Dmitrij/Kühn, Peter/Norrick, Neal R. (Hg.): Phraseologie - Phraseology. Ein internationales Handbuch der zeitgenössischen Forschung. Bd. 1. Walter de Gruyter, Berlin - New York, 574-589.

Kosslyn, Stephen M. (1980): Image and Mind. Harvard University Press, Cambridge.

Köster, Lutz (2007): Phraseme in audiovisuellen Medien. In: Burger, Harald/Dobrovol'skij, Dmitrij/Kühn, Peter/Norrick, Neal R. (Hg.): Phraseologie - Phraseology. Ein internationales Handbuch der zeitgenössischen Forschung. Bd. 1. Walter de Gruyter, Berlin - New York, $275-284$.

Kövecses, Zoltan (1986): Metaphors of anger, pride and love: a lexical approach to the structure of concepts. John Benjamins, Amsterdam - Philadelphia.

Kövecses, Zoltan (1988): The Language of Love: The Semantics of Passion in conversational English. Bucknell University Press, Lewisburg - London - Toronto.

Kövecses, Zoltan (1990): Emotion concepts. Springer, New York.

Kövecses, Zoltan (2000): Metaphor and emotion. Language, culture and body in human feeling. Cambridge University Press, Cambridge.

Kövecses, Zoltan (2002): Metaphor. A practical introduction. Oxford University Press, New York. 
Kövecses, Zoltan (2005): Metaphor and metonymy in cognitive linguistics. In: Turewicz, Kamila (Hg.): Cognitive Linguistics: A user-friendly Approach. Wydawnictwo Naukowe Uniwersytetu Szczecińskiego, Szczecin, 13-38.

Kövecses, Zoltan/Palmer, Gary B./Dirven, René (2003): Language and emotion: The interplay of conceptualisation with physiology and culture. In: Dirven, René/Pörings, Ralf (Hg.): Metaphor and Metonymy in Comparison and Contrast. Mouton de Gruyter, Berlin - New York, 133-160.

Kövecses, Zoltan/Szabó, Péter (1996): Idioms: A View from Cognitive Semantics. Applied Linguistics 17/3, 326-355.

Krawczyk, Izabela (2006): Wendungsinterne Modifikationen von Phraseologismen am Beispiel der zeitgenössischen Berichterstattung. Lublin Studies in Modern Languages and Literature 29/30. [http://www.lsmss.umcs.lublin.pl, Zugriff am 25.05.2016].

Krzeszowski, Tomasz (2006): Czy istnieja niemożliwe metafory? - kilka uwag o ograniczeniach metaforyzacji. In: Hebrajska, Grażyna/Ślósarska, Joanna (Hg.): Kognitywizm w poetyce i stylistyce. Universitas, Kraków, 36-45.

Kubaszczyk, Joanna (2011): Wortbilder und Übersetzungsbilder. Eine Untersuchung zur Wortbildung als Bildbildung im Kontext der Übersetzungswissenschaft. Wydawnictwo Naukowe UAM, Poznań.

Kühn, Peter (1985): Phraseologismen und ihr semantischer Mehrwert: Jemandem auf die Finger gucken in einer Bundestagsrede. Sprache und Literatur in Wissenschaft und Unterricht 16/56, 37-46.

Kühn, Peter (1987): Phraseologismen: Sprachhandlungstheoretische Einordnung und Beschreibung. In: Burger, Harald/Zett, Robert (Hg.): Aktuelle Probleme der Phraseologie. Peter Lang, Bern, 121-137.

Kühn, Peter (1992): Phraseodidaktik, Entwicklungen, Probleme und Überlegungen für den Muttersprachenunterricht und den Unterricht DaF. Fremdsprachen Lehren und Lernen 21, 169-189.

Kühn, Peter (1994): Pragmatische Phraseologie: Konsequenzen für die Phraseographie und Phraseodidaktik. In: Sandig, Barbara (Hg.): Europhras 92. Tendenzen der Phraseologieforschung. Brockmeyer, Bochum, 411-428.

Kühn, Peter (2007): Phraseologie des Deutschen: Zur Forschungsgeschichte. In: Burger, Harald/Dobrovol'skij, Dmitrij/Kühn, Peter/Norrick, Neal R. (Hg.): Phraseologie - Phraseology. Ein internationales Handbuch der zeitgenössischen Forschung. Bd. 2. Walter de Gruyter, Berlin - New York, 619-644.

Kunkel-Razum, Kathrin (2007): Phraseme in populärwissenschaftlichen Texten. In: Burger, Harald/Dobrovol'skij, Dmitrij/Kühn, Peter/Norrick, Neal R. (Hg.): Phraseologie - Phraseology. Ein internationales Handbuch der zeitgenössischen Forschung. Bd. 1. Walter de Gruyter, Berlin - New York, 312-315. 
Łabno-Falęcka, Ewa (1995): Phraseologie und Übersetzen. Eine Untersuchung der Übersetzbarkeit kreativ-innovativ gebrauchter wiederholter Rede anhand von Beispielen aus der polnischen und deutscher Gegenwartsliteratur. Peter Lang, Frankfurt am Main.

Labov, William (1973): The Boundaries of Words and their Meanings. In: Bailey, Charles-James/Shuy, Roger W. (Hg.): New Ways of Analysing Variation in English. Georgetown University Press, Washington, 340-373.

Lakoff, George (1986): A Figure of Thought. Metaphor and Symbolic Activity 1, 215-225.

Lakoff, George (1987): Woman, Fire, and Dangerous Things. What Categories Reveal about the Mind. The University of Chicago Press, Chicago - London.

Lakoff, George (1990): The Invariance Hypothesis: Is Abstract Reason Based on Image-Schemas? Cognitive Lingusitics I/1, 39-74.

Lakoff, George (1993): The Contemporary Theory of Metaphor. In: Ortony, Andrew (Hg.): Metaphor and Thought. Cambridge University Press, Cambridge New York, 202-251.

Lakoff, George/Johnson, Mark (2000 [1980]): Metaphors We Live By. University of Chicago Press, Chicago. Deutsche Ausgabe (2000): Leben in Metaphern: Konstruktion und Gebrauch von Sprachbildern. Aus dem Amerikanischen übersetzt von A. Hildenbrand. 2. korrigierte Aufl. Kösel, Kempten.

Lakoff, George/Johnson, Mark (1999): Philosophy in the flesh: The embodied mind and its challenge to western thought. Basic Books, New York.

Lakoff, George/Kövecses, Zoltan (1987): The cognitive model of anger inherent in American English. In: Holland, Dorothy/Quinn, Naomi (Hg.): Cultural Models in Language and Thought. Cambridge University Press, Cambridge New York, 195-221.

Lakoff, George/Turner, Mark (1989): More than Cool Reason. University of Chicago Press, Chicago.

Langacker, Ronald W. (1982): Space Grammar, Analysability, and the English Passive. Language 58/1, 22-80.

Langacker, Ronald (1986): An Introduction to Cognitive Grammar. Cognitive Science 10, 1-40.

Langacker, Ronald W. (1987): Foundations of Cognitive Grammar. Vol. I. Theoretical Prerequisites. Stanford University Press, Stanford.

Langacker, Ronald W. (1988): A view of linguistic semantics. In: RudzkaOstyn, Brygida (Hg.): Topics in Cognitive Linguistics. John Benjamins, Amsterdam, 49-90.

Langacker, Ronald W. (1991a): Foundations of Cognitive Grammar. Vol. II. Descriptive Application. Stanford University Press, Stanford. 
Langacker, Ronald W. (1991b): Concept, Image, and Symbol. The Cognitive Basis of Grammar. Mouton de Gruyter, Berlin.

Langacker, Ronald W. (2008): Cognitive Grammar. A Basic Introduction. Oxford University Press, Oxford. Polnische Ausgabe (2009): Gramatyka kognitywna. Wprowadzenie. (Aus dem Englischen übersetzt von E. Tabakowska, M. Buchta, H. Kardela u.a.), Universitas, Kraków.

Langacker, Ronald W. (2009): A Dynamic View of Usage and Language Acquisition. Cognitive Linguistics 20/3, 627-640.

Langlotz, Andreas (2006): Idiomatic Creativity. A cognitive-linguistic model of idiom-representation and idiom-variation in English. John Benjamins, Amsterdam.

Laskowski, Marek (2003): Semantische und pragmatische Aspekte der deutschen und polnischen Phraseologie. Oficyna Wydawnicza Uniwersytetu Zielonogórskiego, Zielona Góra.

Leech, Geoffrey N. (1969): A Linguistic Guide to English Poetry. Longman, London.

Lemnitzer, Lothar/Zinsmeister, Heike (2010): Korpuslinguistik. Eine Einführung. Gunter Narr, Tübingen.

Levin-Steinmann, Anke (2007): Orthographie und Phraseologie.

In: Burger, Harald/Dobrovol'skij, Dmitrij/Kühn, Peter/Norrick, Neal R. (Hg.): Phraseologie - Phraseology. Ein internationales Handbuch der zeitgenössischen Forschung. Bd. 1. Walter de Gruyter, Berlin - New York, $36-41$.

Levorato, Chiara M. (1993): The Acquisition of Idioms and the Development of Figurative Competence. In: Cacciari, Cristina/Tabossi, Patrizia (Hg.): Idioms: Processing, Structure, and Interpretation. Psychology Press, New York - London, 101-128.

Lewicki, Andrzej M. (2003): Studia z frazeologii. Oficyna Wydawnicza Leksem, Łask.

Lewicki, Andrzej M./Pajdzińska, Anna (2001): Frazeologia. In: Bartmiński, Jerzy (Hg.): Wspótczesny język polski. Wydawnictwo UMCS, Lublin.

Lewicki, Andrzej M./Pajdzińska, Anna/Rejakowa, Bożena (1987): Z zagadnień frazeologii. Problemy leksykograficzne. PWN, Warszawa.

Lewkowicz, David J. (2011): The Biological Implausibility of the Nature-Nurture Dichotomy and What It means for the Study of Infancy. Infancy 16/4, 331-367.

Libura, Agnieszka (2010): Teoria przestrzeni mentalnych i integracji pojęciowej. Struktura modelu i jego funkcjonalność. Wydawnictwo Uniwersytetu Wrocławskiego, Wrocław.

Liebert, Wolf-Andreas (1992): Metaphernbereiche der deutschen Alltagssprache. Kognitive Linguistik und die Perspektiven einer Kognitiven Lexikographie. Peter Lang, Frankfurt am Main. 
Lipczuk, Ryszard (2004): Zum Problem der Äquivalente in zweisprachigen Wörterbüchern. Studien zur Deutschkunde XXVIII, 833-843.

Lipczuk, Ryszard (2011a): Eine Biographie zur Phraseologie und Phraseographie.

In: Lipczuk, Ryszard/Lisiecka-Czop, Magdalena/Misiek, Dorota

(Hg.): Phraseologismen in deutsch-polnischen und polnisch-deutschen

Wörterbüchern. Theoretische und praktische Aspekte der Phraseologie und

Lexikographie. Dr. Kovač, Hamburg, 13-41.

Lipczuk, Ryszard (2011b): Ein Überblick über die Forschungen zum Thema

Phraseologismen in der polnischen Germanistik. In: Lipczuk, Ryszard/Lisiecka-

Czop, Magdalena/Misiek, Dorota (Hg.): Phraseologismen in deutsch-polnischen und polnisch-deutschen Wörterbüchern. Theoretische und praktische Aspekte der Phraseologie und Lexikographie. Dr. Kovač, Hamburg, 43-52.

Lipczuk, Ryszard/Lisiecka-Czop, Magdalena/Misiek, Dorota (Hg.)

(2011): Phraseologismen in deutsch-polnischen und polnisch-deutschen

Wörterbüchern. Theoretische und praktische Aspekte der Phraseologie und Lexikographie. Dr. Kovač, Hamburg.

Lisiecka-Czop, Magdalena/Misiek, Dorota (2011): Phraseologismen und ihre Präsentationsformen in ausgewählten deutsch-polnischen und polnisch-deutschen Lernerwörterbüchern. In: Lipczuk, Ryszard/Lisiecka-Czop, Magdalena/Misiek, Dorota (Hg.): Phraseologismen in deutsch-polnischen und polnisch-deutschen Wörterbüchern. Theoretische und praktische Aspekte der Phraseologie und Lexikographie. Dr. Kovač, Hamburg, 103-117.

Löbner, Sebastian (2003): Semantik. Eine Einführung. Walter de Gruyter, Berlin New York.

Löbner, Sebastian (2010): Prototypensemantik. In: Hoffmann, Ludger

(Hg.): Sprachwissenschaft. Ein Reader. 3. aktualisierte und erweiterte Aufl., De Gruyter, Berlin - New York, 850-870.

Loppe, Tim (2010): Bedeutungswissen und Wortgebrauch. Entwurf einer Semantik in Anschluss an Wittgenstein und Putnam. Narr, Tübingen.

Mandl, Heinz F./Friedrich, Helmut (1992): Lern- und Denkstrategien. Analyse und Intervention. Verlag für Psychologie Hoegrefe, Göttingen.

Mandler, Jean M. (2005): How to build a baby. Image schemas and the transition to verbal thought. In: Hampe, Beate (Hg.): From Perception to Meaning. Image Schemas in Cognitive Linguistics. Mouton de Gruyter, Berlin - New York, 137-164.

Martin, Alex (2007): The Representation of Object Concepts in the Brain. The Annual Review of Psychology 58, 25-45.

Matthews, Peter H. (1997): The Concise Oxford Dictionary of Linguistics. Oxford University Press, Oxford.

Mazurkiewicz-Sokołowska, Jolanta (2010): Lingwistyka mentalna w zarysie. O zdolności językowej w ujęciu integrującym. Universitas, Kraków. 
Mazurkiewicz-Sokołowska, Jolanta (2014): Emotionen in Konzeptualisierungen und ihren Versprachlichungen. In: Mazurkiewicz-Sokołowska, Jolanta/Sulikowska, Anna/Westphal, Werner (Hg.): Konzeptualisierung, Sprache und Diskurs. Dr. Kovač, Hamburg, 35-54.

Mazurkiewicz-Sokołowska, Jolanta (2015): Zur individuell-subjektiven Prägung der Bedeutung am Beispiel ausgewählter Ess- und Trinkwaren. Peter Lang, Frankfurt am Main u.a.

Mazurkiewicz-Sokołowska, Jolanta (2016): Zur prozessualen Veränderlichkeit der Bedeutung am Beispiel komplexer Ausdrücke mit dem Verb ,spielen 'Versuch einer generalisierenden Auffassung. In: Mazurkiewicz-Sokołowska, Jolanta/Sulikowska, Anna/Westphal, Werner (Hg.): Chancen und Perspektiven einer Emotionslinguistik. Dr. Kovač, Hamburg, 153-169.

Mazurkiewicz-Sokołowska, Jolanta (2017a): Ausgewählte sprachwissenschaftliche Fachausdrücke im Fokus einer kognitionslinguistisch orientierten Bedeutungsanalyse. In: Lipczuk, Ryszard/Lisiecka-Czop, Magdalena/Ramers, Karl Heinz (Hg.): Sprache und Wörterbücher in Theorie und Praxis. Dr. Kovač, Hamburg, 125-142.

Mazurkiewicz-Sokołowska, Jolanta (2017b): Konzeptualisierungen und Bedeutungen als ,mentale Erkenntnisprozesse' in der Verarbeitung von deutschen und polnischen Phraseologismen. Glottodidactica XLIV/1, 97-117.

Mellado Blanco, Carmen (Hg.) (2009a): Theorie und Praxis der idiomatischen Wörterbücher. Niemeyer, Tübingen.

Mellado Blanco, Carmen (2009b): Einführung. Idiomatische Wörterbücher und Metaphraseographie: zwei Realitäten, eine Herausforderung. In: Mellado Blanco, Carmen (Hg.): Theorie und Praxis der idiomatischen Wörterbücher. Niemeyer, Tübingen. 1-20.

Mellado Blanco, Carmen (2014): Die WEG-Metaphorik in der deutschen Phraseologie: ein Typologisierungsversuch. In: Dalmas, Martine/Piirainen, Elisabeth (Hg.): Figurative Sprache - Figurative Language - Langage figuré. Festgabe für Dmitrij O. Dobrovol'skij. Stauffenburg, Tübingen, 59-78.

Mercier, Hugo/Sperber, Dan (2009): Intuitive and reflective interferences. In: Evans, Jonathan St. B. T./Frankish, Keith (Hg.): In Two Minds: Dual Processes and Beyond. Oxford University Press, Oxford, 149-170.

Mieder, Wolfgang (1992): Sprichwort-Wahlwort!? Studien zur Geschichte, Bedeutung und Funktion deutscher Sprichwörter. Peter Lang, Frankfurt am Main u.a.

Mieder, Wolfgang (1995): Deutsche Redensarten, Sprichwörter und Zitate: Studien zu ihrer Herkunft, Überlieferung und Verwendung. Edition Praesens, Wien.

Mieder, Wolfgang (2007): Proverbs as cultural units or items of folklore. In: Burger, Harald/Dobrovol'skij, Dmitrij/Kühn, Peter/Norrick, Neal R. (Hg.): Phraseologie - Phraseology. Ein internationales Handbuch der 
zeitgenössischen Forschung. Bd. 1. Walter de Gruyter, Berlin - New York, 394-414.

Mikołajczyk, Beata (2002): Zur Übersetzbarkeit der Metapher. Studia Germania Posnanesnsia XXVIII, 49-60.

Milczarek, Mariusz (2009): Meilensteine in der Entwicklung der deutschsprachigen Phrasologieforschung. Acta Universitatis Lodziensis, Folia Germanica 5, 61-68.

Minsky, Marvin (1975): A framework for representing knowledge. In: Winston, Patrick (Hg.): Thinking. Reading in Cognitive Science. Cambridge University Press, Cambridge, 355-367.

Minsky, Marvin (1995 [1974]): A framework for representing knowledge. In: Luger, George F. (Hg.): Computation and Intelligence: Collected Readings. The Mitt Press, Menlo Park, 163-189.

Miodunka, Władysław (1989): Podstawy leksykologii i leksykografii. PWN, Warszawa.

Misiek, Dorota (2011): Bemerkungen zur Stabilität der Phraseologismen und ihrer externen Valenz in der lexikographischen Praxis. Colloquia Germanica Stetinensia 19, 159-169.

Mokienko, Valerij M. (2002): Prinzipien einer historisch-etymologischen Analyse der Phraseologie. In: Hartmann, Dietrich/Wirrer, Jan (Hg.): Wer A sägt, muss auch B sägen. Beiträge zur Phraseologie und Sprichwortforschung aus dem Westfälischen Arbeitskreis. Schneider Verlag Hohengehren, Baltmannsweiler, 231-254.

Mokienko, Valerij M. (2007): Historische Phraseologie der slavischen Sprachen. In: Burger, Harald/Dobrovol'skij, Dmitrij/Kühn, Peter/Norrick, Neal R. (Hg.): Phraseologie - Phraseology. Ein internationales Handbuch der zeitgenössischen Forschung. Bd. 2. Walter de Gruyter, Berlin - New York, 1136-1145.

Moles, Abraham A. (1977): Superzeichenbildung und Problemlösung in der künstlerischen Kommunikation. In: Posner, Roland/Reinecker, Hans-Peter (Hg.): Zeichenprozesse: semiotische Forschung in den Einzelwissenschaften. Athenaion, Wiesbaden, 69-72.

Moon, Rosamund (1998): Fixed expressions and idioms in English. Clarendon Press, Oxford.

Moon, Rosamund (2007): Corpus linguistic approaches with English corpora. In: Burger, Harald/Dobrovol'skij, Dmitrij/Kühn, Peter/Norrick, Neal R. (Hg.): Phraseologie - Phraseology. Ein internationales Handbuch der zeitgenössischen Forschung. Bd. 2. Walter de Gruyter, Berlin - New York, 1046-1059.

Müller, Peter O./Kunkel-Razum, Kathrin (2007): Phraseographie des Deutschen. In: Burger, Harald/Dobrovol'skij, Dmitrij/Kühn, Peter/Norrick, Neal R. 
(Hg.): Phraseologie - Phraseology. Ein internationales Handbuch der zeitgenössischen Forschung. Bd. 2. Walter de Gruyter, Berlin - New York, 939-949.

Munske, Horst Haider (2015 [1993]): Wie entstehen Phraseologismen? In: Linheen Lee (Hg.): Horst Haider Munske. Ausgewählte sprachwissenschaftliche Schriften 1970-2015. FAU University Press, Erlangen 2015, 83-134, ursprünglich veröffentlicht in: Mattheier, Klaus J./Wegera, KlausPeter/Hoffman, Walter/Macha, Jürgen/Solms, Hans-Joachim (Hg.): Vielfalt des Deutschen. Festschrift für Werner Besch. Peter Lang, Frankfurt am Main, 481-515.

Nerlicki, Krzysztof (2011): Glossierung der Phraseologismen in einem zweisprachigen Wörterbuch: Vor- und Nachteile für die Benutzer. In: Lipczuk, Ryszard/Lisiecka-Czop, Magdalena/Misiek, Dorota (Hg.): Phraseologismen in deutsch-polnischen und polnisch-deutschen Wörterbüchern. Theoretische und praktische Aspekte der Phraseologie und Lexikographie. Dr. Kovač, Hamburg, 139-150.

Newell, Allen/Simon, Herbert (1972): Human Problem Solving. Pretince Hall, Engelwood Cliffs.

Omazić, Marija (2005): Cognitive linguistic theories in phraseology. Jezikoslovije 6, 37-56.

Osmańska-Lipka, Iwona (2012): Elements of Gestalt Psychology in American Cognitive Linguistics. Annales Universitatis Mariae Curie-Skłodowska Lublin Polonia XXX/2, 47-72.

Paivio, Allan (1971): Imagery and verbal processes. Holt, Rinehard \& Winston, New York.

Paivio, Allan (1986): Mental representations. A dual coding approach. Oxford University Press, New York.

Pajdzińska, Anna (1990): Antropocentryzm frazeologii potocznej. Etnolingwistyka 3, 59-68.

Pajdzińska, Anna (1991): Językowe granice metafory. Pamiętnik Literacki czasopismo kwartalne poświęcone historii i krytyce literatury polskiej 82/1, 131-143.

Pajdzińska, Anna (2001): My, to znaczy ...: z badań językowego obrazu świata. Teksty Drugie: teoria literatury, krytyka, interpretacja 66/1,33-53.

Pajdzińska, Anna/Tokarski, Ryszard (1996): Językowy obraz świata - konwencja i kreacja. Pamiętnik Literacki: czasopismo kwartalne poświęcone historii i krytyce literatury polskiej 87/4, 143-158.

Palm, Christiane (1989): Die konnotative Potenz usueller und okkasioneller Phraseologismen und anderer festgeprägter Konstruktionen in Christa Wolfs Roman Kindheitsmuster. In: Gréciano, Gertrud (Hg.): EUROPHRAS 
88: phraséologie contrastive. Actes du Colloque International. Klingenthal, Strasbourg, 12-16 mai 1988. Strasbourg, 313-326.

Palm, Christine (1995): Phraseologie. Eine Einführung. Gunter Narr, Tübingen.

Palm, Christine (1997): Phraseologie. Eine Einführung. 2. durchgesehene Aufl. Gunter Narr, Tübingen.

Panther, Klaus-Uwe/Radden, Günter (1999): Introduction. In: Panther, KlausUwe/Günter Radden (Hg.): Metonymy in Language and Thought. John Benjamins, Amsterdam - Philadelphia, 1-14.

Panther, Klaus-Uwe (2011): Taking stock of figurative language and grammar: Results and prospects. In: metaphorik.de [http://www.metaphorik. de/en/journal/21/taking-stock-figurative-language-and-grammar-results-andprospects.html, Zugriff am 21.07.2017].

Panther, Klaus-Uwe (2015): Metonymien im Sprachvergleich. In: Spieß, Constanze/Köpcke, Klaus-Michael (Hg.): Metapher und Metonymie. Theoretische, methodische und empirische Zugänge. De Gruyter, Berlin u.a., 207-226.

Parina, Irina (2014): Ein Gentleman vom Scheitel bis zur Sohle: Korpusbasierte Untersuchung und lexikographische Beschreibung der phraseologischen Synonyme. In: Dalmas, Martine/Piirainen, Elisabeth (Hg.): Figurative Sprache Figurative Language - Langage figuré. Festgabe für Dmitrij O. Dobrovol'skij. Stauffenburg, Tübingen, 161-172.

Pawelec, Andrzej (2005): Znaczenie ucieleśnione: propozycje kręgu Lakoffa. Universitas, Kraków.

Pawelec, Andrzej (2006): Metafora pojęciowa a tradycja. Universitas, Kraków.

Pecher, Diane/Zwaan, Rolf A. (2005): Grounding Cognition. The Role of Perception and Action in Memory, Language and Thinking. University Press, Cambridge.

Pecher, Diane/Zwaan, Rolf A. (2009): Introduction to Grounded Cognition. The Role of Perception and Action in Memory, Language and Thinking. Cambridge University Press [http://www.cogsci.ucsd.edu/ coulson/203/pecher-zwaan.pdf, Zugriff am 02.01.2017].

Peirce, Charles S. (1960): Collected Papers of Charles Sanders Peirce. Vol. II: Elements of Logic. Cambridge.

Peirce, Charles S. (1993): Phänomen und Logik der Zeichen. 2. Aufl. Suhrkamp, Frankfurt am Main.

Petruck, Miriam (2003): Frame Semantics. [https://www.princeton.edu/ adele/ LIN_106:_UCB_files/Miriam-Petruck-frames.pdf, Zugriff am 06.06.2016].

Pielenz, Michael (1993): Argumentation und Metapher. Gunter Narr, Tübingen. Piirainen, Elisabeth (2001): Phraseologie und Arealität. Deutsch als Fremdsprache 4, 240-243. 
Piirainen, Elisabeth (2004): Falsche Freunde in der Phraseologie des Slowakischen und anderer Sprachen. In: Piirainen, Ilpo T./Meier, Jörg (Hg.): Deutsche Sprache in der Slowakei. Geschichte, Gegenwart und Didaktik. Edition Praesens, Wien, 151-162.

Piirainen, Elisabeth (2007): Phrasems from a cultural semiotic perspective. In: Burger, Harald/Dobrovol'skij, Dmitrij/Kühn, Peter/Norrick, Neal R. (Hg.): Phraseologie - Phraseology. Ein internationales Handbuch der zeitgenössischen Forschung. Bd. 1. Walter de Gruyter, Berlin - New York, 208-219.

Pilz, Klaus-Dieter (1978): Phraseologie. Versuch einer interdisziplinären Abgrenzung, Begriffsbestimmung und Systematisierung unter besonderer Berücksichtigung der deutschen Gegenwartssprache. Kümmerle, Göppingen.

Pilz, Klaus-Dieter (1981): Phraseologie. Redensartenforschung. Metzler, Stuttgart.

Pilz, Klaus-Dieter (1987): Allgemeine und phraseologische Wörterbücher. Brauchen wir überhaupt phraseologische Wörterbücher? In: Korhonen, Jarmo (Hg.): Beiträge zur allgemeinen und germanistischen Phraseologieforschung. Internationales Symposium in Oulu 13.-15. Juni 1986. Oulu, 129-153.

Pilz, Klaus-Dieter (2002): Vorschläge für ein Phraseolexikon der deutschen Sprache. Oder: Vorschläge für ein Lexikon der deutschen Phraseme/Phraseologismen. In: Hartmann, Dietrich/Wirrer, Jan (Hg.): Wer A sägt, muss auch B sägen. Beiträge zur Phraseologie und Sprichwortforschung aus dem Westfälischen Arbeitskreis. Schneider Verlag Hohengehren, Baltmannsweiler, 299-311.

Piotrowska, Agnieszka Ewa (2012): Rozwój semantyczny wyrazu godność (od staropolszczyzny do wspótczesności). In: Mikołajczuk, Agnieszka/Waszakowa, Krystyna (Hg.): Odkrywanie znaczeń w języku. Wydawnictwo Uniwersytetu Warszawskiego, Warszawa, 30-48.

Pociask, Janusz (2007): Zu Status und Funktion der idiomatischen Einheit in Pressetexten. Dargestellt an den Beispielen aus der Neuen Züricher Zeitung. Peter Lang, Frankfurt am Main u.a.

Poddig, Frank (1995): Die Enkodierung und Dekodierung piktorieller Werbebotschaften: ein semiotisch-kognitiver Ansatz. Deutscher Universitätsverlag DUV, Wiesbaden.

Pohl, Inge/Kaczmarek, Hanna (2014): Kontrastive Analyse des phraseologischen Vokabulars zur Emotion Angst im Deutschen und Polnischen. Prace Naukowe Akademii im. Jana Dtugosza w Częstochowie X, 145-171.

Ptashnyk, Stefaniya (2009): Phraseologische Modifikationen und ihre Funktionen im Text. Eine Studie am Beispiel deutschsprachiger Presse. Schneider Verlag Hohengehren, Baltmannsweiler.

Pulvermüller, Friedemann (1999): Words in the brain's language. Behavioral and Brain Sciences 22/2, 253-336. 
Pylyshyn, Zenon W. (1973): What The Mind's Eye tells the Mind's Brain.

A Critique of Mental Imagery. Psychological Bulletin 80, 1-24.

Pylyshyn, Zenon W. (1984): Computation and Cognition. MIT Press, Cambridge.

Quasthoff, Uwe/Schmidt, Fabian/Hallsteinsdóttir, Erla (2010): Häufigkeit und

Struktur von Phraseologismen. In: Ptashnyk, Stefaniya/Hallsteinsdóttir,

Erla/Bubenhofer, Noah (Hg.): Korpora, Web und Datenbanken.

Computergestützte Methoden in der modernen Phraseologie und

Lexikographie. Schneider Verlag Hohengehren, Baltmannsweiler, 37-54.

Radden, Günter (2003): How metonymic are metaphors? In: Dirven, René/Pörings, Ralf (Hg.): Metaphor and Metonymy in Comparison and Contrast. Mouton de Gruyter, Berlin - New York, 407-434.

Radden, Günter/Kövecses, Zoltán (1999): Towards a Theory of Metonymy.

In: Panther, Klaus-Uwe/Radden, Günter (Hg.): Metonymy in Language and

Thought. John Benjamins, Amsterdam - Philadelphia, 18-59.

Reddy, Michael J. (1979). The conduit metaphor: A case of frame conflict in our language about language. In: Ortony, Andrew (Hg.): Metaphor and Thought.

Cambridge University Press, Cambridge, 284-310.

Regier, Terry (1996): The Human Semantic Potential: Spatial Language and Constrained Connectionism. MIT Press, Cambridge.

Reichmann, Oskar (1976): Germanistische Lexikologie. Metzler, Stuttgart.

Reichstein, Aleksandr D. (1973): Zur Analyse der festgeprägten Sätze im

Deutschen. Deutsch als Fremdsprache 4, 321-331.

Rentel, Nadine (2017): Die kognitive Abwandlung von Phraseologismen in

Artikelüberschriften. In: Berdychowska, Zofia/Lüger, Heinz-Helmut/Schatte,

Czesława/Zenderowska-Korpus, Grażyna (Hg.): Phraseologie als

Schnittstelle zwischen Sprache und Kultur II. Öffentlicher Raum - Medien Phraseodidaktik. Peter Lang, Frankfurt am Main, 97-113.

Rice, Sally (1992): Polysemy and Lexical Representation: The Case of Three English Prepositions. In: Proceedings of the Fourteenth Annual Conference of the Cognitive Science Society. New Jersey, 89-94.

Rickheit, Gert/Weiss, Sabine/Eikmeyer, Hans-Jürgen (2010): Kognitive Linguistik. Theorien, Modelle, Methoden. A. Francke, Tübingen - Basel.

Riemer, Nick (2003): When is a metonymy no longer a metonymy? In: Dirven, René/Pörings, Ralf (Hg.): Metaphor and Metonymy in Comparison and Contrast. Mouton de Gruyter, Berlin - New York, 379-406.

Riesel, Elise (1970): Der Stil der deutschen Alltagsrede. Reclam, Leipzig.

Rohrer, Tim (2005): Image schemata in the brain. In: Hampe, Beate (Hg.): From Perception to Meaning. Image Schemas in Cognitive Linguistics. Mouton de Gruyter, Berlin - New York, 165-193. 
Romero, Esther/Soria, Belén (2005): Cognitive Theory of Metaphor Revisited. Journal of Literary Semantics 34, 1-20. [http://www.ugr.es/ bsoria/papers/ Cognitive\%20metaphor \%20theory\%20revisited, Zugriff am 18.02.2017].

Roos, Eckhard (1979): Semantische Aspekte englischer Idioms. Anglistik und Englischunterricht 8, 117-130.

Roos, Eckhard (1992): Lehrmaterialien zur englischen Idiomatik. Eine kritische Analyse. Fremdsprachen Lehren und Lernen 21, 190-201.

Roos, Eckhard (2001): Idiom und Idiomatik: Ein sprachliches Phänomen im Lichte der kognitiven Linguistik und Gestalttheorie. Shaker, Aachen.

Rorty, Richard (1979): Philosophy and the Mirror of Nature. Princeton University Press, Princeton.

Rosch, Eleanor (1973): Natural Categories. Cognitive Psychology 4/3, 328-350.

Rosch, Eleanor (1975): Cognitive Representations of Semantic Categories. Journal of Experimental Psychology 104/3, 192-233.

Rosch, Eleanor/Merrvis, Carolyn/Gray, Wayne/Johnson, David/Boyes-Braem, Penny (1976): Basic Objects in Natural Categories. Cognitive Psychology 8, 382-439.

Rothkegel, Annely (1973): Feste Syntagmen. Grundlagen, Strukturbeschreibung und automatische Analyse. Niemeyer, Tübingen.

Rothkegel, Annely (2004): Bild und/oder Konzept - sprachliche Visualisierung durch Phraseme im Text. In: Palm-Meister, Christine (Hg.): EUROPHRAS 2000. Stauffenburg, Tübingen, 391-400.

Rothkegel, Annely (2014): Sprachliche Bilder und Modelle: Bedeutungskonstruktion abstrakter Begriffe durch Metaphernphraseme (Beispiele GESUNDHEIT und RISIKO). Germanica Wratislaviensia 139, 275-289.

Rumelhart, David E. (1979): Some problems with the notion of literal meaning. In: Ortony, Andrew (Hg.): Metaphor and thought. Cambridge University Press, Cambridge, 78-90.

Russell, Bertrand (1911): Knowledge by Acquaintance and Knowledge by Description. Proceedings of the Aristotelian Society XI (1910-1911), 108-128.

Sabban, Anette (2004): Zur Rolle der Phraseme für die Konstitution und Funktion des Textes. Ein Beitrag zum Konzept der textbildenden Potenzen. In: Steyer, Kathrin (Hg.): Wortverbindungen - mehr oder weniger fest. De Gruyter, Berlin, 238-261.

Sabban, Annette (2006): Zur textbildenden Rolle von Phrasemen - mit einer Analyse von Musik-Moderationen und Kulturnachrichten im Hörfunk. In: Breuer, Ulrich/Hyvärinen, Irma (Hg.): Wörter - Verbindungen. Festschrift für Jarmo Korhonen, Peter Lang, Frankfurt am Main u.a., 275-290.

Sabban, Annette (2007a): Culture-boundness and problems of cross-cultural phraseology. In: Burger, Harald/Dobrovol'skij, Dmitrij/Kühn, Peter/Norrick, 
Neal R. (Hg.): Phraseologie - Phraseology. Ein internationales Handbuch der zeitgenössischen Forschung. Bd. 1. Walter de Gruyter, Berlin - New York, 590-605.

Sabban, Annette (2007b): Textbildende Potenzen von Phrasemen. In: Burger, Harald/Dobrovol'skij, Dmitrij/Kühn, Peter/Norrick, Neal R. (Hg.): Phraseologie Phraseology. Ein internationales Handbuch der zeitgenössischen Forschung. Bd. 1. Walter de Gruyter, Berlin - New York, 237-253.

Sabban, Annette (2014): Flüchtige Figuriertheit: Ressourcen für kreatives bildhaftes Formulieren. In: Dalmas, Martine/Piirainen, Elisabeth (Hg.): Figurative Sprache - Figurative Language - Langage figuré. Festgabe für Dmitrij O. Dobrovol'skij. Stauffenburg, Tübingen, 101-116.

Sadziński, Roman (2012): Zum Prinzip der Sachsteuerung im Deutschen. In: Grzywka, Katarzyna/Filipowicz, Małgorzata (Hg.): Kultur - Literatur Sprache. Gebiete der Komparatistik. Festschrift für Herrn Professor Lech Kolago zum 70. Geburtstag. Bd. 2. Instytut Germanistyki Uniwersytetu Warszawskiego, Warszawa, 1305-1311.

Sadziński, Roman (2018): Transsemische Idiosynkrasie. In: Gondek, Anna/Jurasz, Alina/Szczęk, Joanna (Hg.): Einblicke und Rückblicke. Beiträge zur deutschen Phraseologie und Parömiologie aus intra- und interlingualer Sicht. Bd. 2. Schneider Verlag Hohengehren, Baltmannsweiler, 59-73.

Sailer, Manfred (2007): Corpus linguistic approaches with German corpora. In: Burger, Harald/Dobrovol'skij, Dmitrij/Kühn, Peter/Norrick, Neal R. (Hg.): Phraseologie - Phraseology. Ein internationales Handbuch der zeitgenössischen Forschung. Bd. 2. Walter de Gruyter, Berlin - New York, 1060-1071.

Sandig, Barbara (2007): Stilistische Funktionen von Phrasemen. In: Burger, Harald/Dobrovol'skij, Dmitrij/Kühn, Peter/Norrick, Neal R. (Hg.): Phraseologie - Phraseology. Ein internationales Handbuch der zeitgenössischen Forschung. Bd. 1. Walter de Gruyter, Berlin - New York, 158-174.

Schack, Thomas (2010): Die kognitive Architektur menschlicher Bewegungen. Innovative Zugänge für Psychologie, Sportwissenschaft und Robotik. Meyer\&Meyer Verlag, Aachen.

Schatte, Czesława (1993): Zwroty językowe w nauczaniu języków obcych na przykładzie języka niemieckiego. Przegląd Glottodydaktyczny 12, 47-55.

Schatte, Czesława (1995): Kriterien für die Auswahl von Phraseologismen für den Unterricht Deutsch als Fremdsprache. In: Iluk, Jan (Hg.): Aspekte der Wortschatzbeschreibung für Zwecke des Fremdsprachenunterrichts. Wydawnictwo Uniwersytetu Śląskiego, Katowice, 93-105.

Schatte, Czesława (2008a): Zum Sprichwort-Minimum des Deutschen vor dem Hintergrund deutsch-polnischer Sprichwörterbücher. In: Kątny, Andrzej (Hg.) 
Kontakty językowe i kulturowe w Europie/Sprach- und Kulturkontakte in Europa. Wydawnictwo Uniwersytetu Gdańskiego, Gdańsk, 177-185.

Schatte, Czesława (2008b): Zum Sprichwortminimum im Unterricht Deutsch als Fremdsprache. In: Myczko, Kazimiera/Skowronek, Barbara/Zabrocki, Władysław (Hg.): Perspektywy Glottodydaktyki i Językoznawstwa. Wydawnictwo Naukowe UAM, Poznań, 91-105.

Schemann, Hans (1989): Das phraseologische Wörterbuch. In: Hausmann, Franz J./Reichmann, Oskar/Wiegand, Herbert E./Zgusta, Ladislav (Hg.): Wörterbücher. Dictionaries. Dictionnaires. Ein internationales Handbuch der Lexikographie. Mouton de Gruyter, Berlin-New York, 1019-1032.

Schemann, Hans (1993): Wissenschaftliche Einführung. In: Schemann, Hans: Deutsche Idiomatik. Die deutschen Redewendungen im Kontext. 1. Aufl. Ernst Klett Verlag für Wissen und Bildung, Stuttgart - Dresden.

Schippan, Thea (1975): Einführung in die Semasiologie. VEB Bibliographisches Institut, Leipzig.

Schmale, Günter (2009): Phraseologische Ausdrücke als Bestandteil des Fremdsprachenerwerbs. Überlegungen zur Phraseodidaktik auf der Grundlage einer korpusbasierten Analyse deutscher Talkshows. Beiträge zur Fremdsprachenvermittlung 48, 149-179.

Schmale, Günter (2017): Von der Routineformel zur Konstruktion - Präformierte Konstruktionseinheiten als polyfaktorielles Phänomen. In: Berdychowska, Zofia/Lüger, Heinz-Helmut/Schatte, Czesława/Zenderowska-Korpus, Grażyna (Hg.): Phraseologie als Schnittstelle zwischen Sprache und Kultur I. Abgrenzungen - sprach- und textvergleichende Zugänge. Peter Lang, Frankfurt am Main, 41-59.

Schmidlin, Regula (2001): Lexikographische Probleme bei phraseologischen Varianten. In: Piirainen, Elisabeth (Hg.): Phraseologie im Raum und Zeit. Akten der 10. Tagung des Westphälischen Arbeitskreises „Phraseologie/ Parömiologie“ (Münster 2001). Baltmannsweiler, 377-391.

Schmidt-Wiegand, Ruth (2002): Die onomasiologische Sichtweise auf den Wortschatz. In: Cruse, Alan D./Hundsnurscher, Franz/Job, Michael/Lutzeier Peter R. (Hg.): Lexikologie/Lexicology. Ein internationales Handbuch zur Natur und Struktur von Wörtern und Wortschätzen. Walter de Gruyter, Berlin - New York, 738-752.

Schnotz, Wolfgang (1994): Aufbau von Wissensstrukturen. Untersuchungen zur Kohärenzbildung bei Wissenserwerb mit Texten. Beltz, Weinheim.

Schowalter, Christine (2010): „Ein Geier kommt selten allein“- Tiermetaphern in phraseologisch gestützten Alltagsargumentationen. Eine kontrastive Studie zur internationalen Wirtschaftsberichterstattung. In: Korhonen, Jarmo/Mieder, Wolfgang/Piirainen, Elisabeth/Piňel, Rosa (Hg.): EUROPHRAS 2008. Beiträge 
zur internationalen Phraseologiekonferenz vom 13.-16. 08. 2008 in Helsinki. Universität Helsinki, Institut für Moderne Sprache, Helsinki, 262-272.

Schrader, Herman (1894): Der Bilderschmuck der Deutschen Sprache. Einblick in den unerschöpflichen Bilderreichtum unserer Sprache und ein Versuch wissenschaftlicher Deutung dunkler Redensarten und sprachlicher Räthsel. $\mathrm{H}$. Dolfuss, Berlin.

Schwarz, Monika (1992): Einführung in die Kognitive Linguistik. 1. Aufl., A. Francke, Tübingen.

Schwarz, Monika (2008): Einführung in die Kognitive Linguistik. 3. überarbeitetete und erweiterte Aufl., A. Francke, Tübingen - Basel.

Schwarz-Friesel, Monika (2007): Sprache und Emotion. A. Francke, Tübingen.

Schwarz-Friesel, Monika (2008): Sprache, Kognition und Emotion: Neue Wege in der Kognitionswissenschaft. In: Kämper, Heidrun/Eichinger, Ludwig (Hg.): Sprache - Kognition - Kultur. De Gruyter, Berlin - New York, 277-301.

Schwarz, Monika/Chur, Jeannette (2007): Semantik. Ein Arbeitsbuch. Narr, Tübingen.

Schweigert, Wendy A. (1986): The comprehension of familiar and less familiar idioms. Journal of Psycholingustic Research 20, 305-314.

Searle, John R. (1969): Speech Acts: An Essay in the Philosophy of Language. Cambridge University Press, Cambridge.

Searle, John R. (1979): Metaphor. In: Ortony, Andrew (Hg.): Metaphor and Thought. Cambridge University Press, Cambridge, 92-132.

Searle, John (2010): Making the Social Word. The Structure of Human Civilisation. Oxford University Press, Oxford.

Shepard, Roger N./Metzler Jacqueline (1971): Mental rotation of threedimensional objects. Science 171, 701-703.

Simmons, Willam K./Barsalou, Lawrence W. (2003): The similarity-intopography principle: reconciling theories of conceptual deficits. Cognitive Neuropsychology 20, 451-486.

Sowinski, Bernhardt (1978): Deutsche Stilistik. Fischer, Frankfurt am Main.

Spieß, Constanze (2011): Diskurshandlungen: Theorie und Methode der Diskursanalyse am Beispiel der Bioethikdebatte. De Gruyter, Berlin-Boston.

Spieß, Constanze (2017): Metaphern. In: Roth, Kersten Sven/Wengeler, Martin/Ziem, Alexander (Hg.): Handbuch Sprache in Politik und Gesellschaft. De Gruyter, Berlin -München - Boston, 94-115.

Spieß, Constanze/Köpcke, Klaus-Michael (2015): Metonymie und Metapher Theoretische, methodische und empirische Zugänge. Eine Einführung in den Sammelband. In: Spieß, Constanze/Köpcke, Klaus-Michael (Hg.): Metapher und Metonymie. De Gruyter, Berlin -München - Boston, 1-21. 
Staffeldt, Sven/Ziem, Alexander (2008): Körper-Sprache: Zur Motiviertheit von Körperbezeichnungen in Phraseologismen. Sprachwissenschaft 33, 455-499.

Stantcheva, Diana (2003): Phraseologismen in deutschen Wörterbüchern. Ein Beitrag zur Geschichte der lexikographischen Behandlung von Phraseologismen im allgemeinen einsprachigen Wörterbuch von Adelung bis zur Gegenwart. Dr. Kovač, Hamburg.

Stathi, Katerina (2006): Korpusbasierte Analyse der Semantik von Idiomen. Linguistik online 27/2. [http://www.linguistik-online.de/27_06/stathi.html, Zugriff 03.09.3014].

Steffens, Doris (1989): Untersuchung zur Phraseologie der deutschen Gegenwartssprache unter lexikographischem Aspekt. Beiträge zur Erforschung der deutschen Sprache 9, 79-93.

Stein, Stephan (1995): Formelhafte Sprache. Peter Lang, Frankfurt am Main u.a.

Stein, Stephan (2001): Formelhafte Sprache. Untersuchungen zu ihren pragmatischen und kognitiven Funktionen im gegenwärtigen Deutsch. Peter Lang, Frankfurt am Main.

Stein, Stephan (2007): Mündlichkeit und Schriftlichkeit aus phraseologischer Perspektive. In: Burger, Harald/Dobrovol'skij, Dmitrij/Kühn, Peter/Norrick, Neal R. (Hg.): Phraseologie - Phraseology. Ein internationales Handbuch der zeitgenössischen Forschung. Bd. 1. Walter de Gruyter, Berlin - New York, 220-236.

Stein, Stephan (2011): Formelhafte Texte oder textwertige Phraseologismen? Kontroverse Positionen, empirische Beobachtungen, offene Fragen. In: Schäfer, Patrick/Schowalter, Christine (Hg.): In mediam linguam. Mediensprache Redewendungen - Sprachvermittlung. Empirische Pädagogik, Landau, 161-176.

Steyer, Kathrin (2009): Zwischen theoretischer Modellierung und praxisnaher Anwendung. Zur korpusgesteuerten Beschreibung usueller Wortverbindungen. In: Mellado Blanco, Carmen (Hg.): Theorie und Praxis der idiomatischen Wörterbücher. Niemeyer, Tübingen, 119-145.

Steyer, Kathrin (2012): Sprichwortstatus, Frequenz, Musterbildung. Parömiologische Fragen im Lichte korpusmethodischer Empirie. In: Steyer, Kathrin (Hg.): Sprichwörter multilingual. Theoretische, empirische und angewandte Aspekte der modernen Parömiologie. Narr, Tübingen.

Steyer, Kathrin (2013). Usuelle Wortverbindungen. Zentrale Muster des Sprachgebrauchs aus korpusanalytischer Sicht. Narr, Tübingen.

Steyer, Kathrin/Hein, Katrin (2016): Nach Belieben kombinieren? Korpusbasierte Beschreibung präpositionaler Mehrworteinheiten im Sprachvergleich. In: Margalitadze, Tinatin/Meladze, George (Hg.): Proceedings of the XVII EURALEX International Congress, Lexicography and Linguistic Diversity, 402-408. 
Stöckl, Hartmut (2004): Die Sprache im Bild - Das Bild in der Sprache. Zur Verfassung von Sprache und Bild im massmedialen Text. Konzepte, Theorien, Analysemethoden. Walter de Gruyter, Berlin - New York.

Stubbs, Michael (2002): Words and Phrases. Corpus Studies of Lexical Semantics. Blackwell, Malden u.a.

Stumpf, Sören (2015): Formelhafte (Ir-)Regularitäten. Korpuslinguistische Befunde und sprachtheoretische Überlegungen. Peter Lang, Frankfurt am Main u.a.

Stypa, Hanna (2009): Von alten Hasen, weißen Mäusen und Katzen, die man im Sack kauft. Zu Phraseologismen als Trägern der Kulturtraditionen. Studien zur Deutschkunde XLIII, 413-419.

Stypa, Hanna (2015): Äquivalenzbeziehungen und Divergenz am Beispiel von deutschen Phraseologismen mit Tierbezeichnungen im Komponentenbestand und ihren polnischen Entsprechungen. Linguistik online 74. [https://bop.unibe. ch/linguistik-online/article/view/2229, Zugriff am 30.03.3017].

Sulikowska, Anna (2013): Kalt erwischt! Zwischen Phraseographie und Sprachgebrauch. Einige Anmerkungen zur Rolle der Korpusuntersuchungen in der lexikographischen Praxis. Colloquia Germanica Stetinensia 22, 265-279.

Sulikowska, Anna (2014a): Das Idiom in Watte packen in der Phraseographie und im Sprachgebrauch. Colloquia Germanica Stetinensia 23, 241-256.

Sulikowska, Anna (2014b): Konzept- und Spracherwerb als kognitive Prozesse. In: Mazurkiewicz-Sokołowska, Jolanta/Sulikowska, Anna/Westphal, Werner (Hg.): Konzeptualisierung, Sprache und Diskurs. Dr. Kovač, Hamburg, 79-108.

Sulikowska, Anna (2014c): Zur Einwirkung der Konzeptualisierungen auf die Elastizität der Bedeutung am Beispiel des Konzeptes Hund. In: Mazurkiewicz-Sokołowska, Jolanta/Sulikowska, Anna/Westphal, Werner (Hg.): Konzeptualisierung, Sprache und Diskurs. Dr. Kovač, Hamburg, 55-78.

Sulikowska, Anna (2015a): Zwischen der wörtlichen und phraseologischen Bedeutung - Zur Semantik der metaphorisch motivierten Idiome aus der Perspektive der Kognitiven Grammatik. Linguistik online 74. [https://bop. unibe.ch/linguistik-online/article/view/2229, Zugriff am 14.09.2016].

Sulikowska, Anna (2015b): Zur Motiviertheit der Idiome am Beispiel des Phraseologismus ,ein heißes Pflaster. Colloquia Germanica Stetinensia 24, 171-189.

Sulikowska, Anna (2015c): Zwischen Phraseographie und Sprachgebrauch. Das Idiom „ein heißes Pflaster“ im Wörterbuch und im Usus. Germanica Wratislaviensia 140, 271-286.

Sulikowska, Anna (2016a): Wie entsteht die Bedeutung von phraseologischen Neologismen? Eine korpusgestützte Untersuchung der kognitiven Bedeutungskonstituierungsprozesse am Beispiel des Idioms ,ein dicker Brocken'. Studien zur Deutschkunde LVIII, 469-486. 
Sulikowska, Anna (2016b): Semantische Besonderheiten der Phraseologismen am Beispiel der Idioms, ein hartes Brot'. In: Bartoszewicz, Iwona/Szczęk, Joanna/Tworek, Artur (Hg.): Linguistische Treffen in Wroclaw 12. Phrasenstrukturen und Interpretationen im Gebrauch. Atut, WrocławDresden, 229-252.

Sulikowska, Anna (2017): Zur Konstituierung der phraseologischen Bedeutung aus der Perspektive der Kognitiven Linguistik - eine Fallstudie. In: Lipczuk, Ryszard/Lisiecka-Czop, Magdalena/Ramers, Karl Heinz (Hg.): Sprache und Wörterbücher in Theorie und Praxis. Dr. Kovač, Hamburg, 193-212.

Szczęk, Joanna (2010a): Auf der Suche nach phraseologischer Motiviertheit im Deutschen (am lexikographischen Material). Atut-Neisse Verlag, Dresden Wrocław.

Szczęk, Joanna (2010b): Die deutschen und polnischen Phraseologismen in der deutsch-polnischen phraseographischen Praxis. Studia Germanica Gedanensia 23, 257-267.

Szczęk, Joanna (2010c): Eine kleine Schweinerei gefällig? Zum sprachlichen Bild des Schweins in der deutschen und polnischen Phraseologie (am lexikografischen Material). In: Korhonen, Jarmo/Mieder, Wolfgang/Piirainen, Elisabeth/Piňel, Rosa (Hg.): EUROPHRAS 2008. Beiträge zur internationalen Phraseologiekonferenz vom 13.-16.08.2008 in Helsinki. Universität Helsinki, Institut für Moderne Sprache, Helsinki. [https://homepage.univie.ac.at/beata. trawinski/publications/europhras_08.pdf, Zugriff am 14.09.2016]

Szczęk, Joanna (2011): „Falsche Freunde des Übersetzers“-Zur Analyse der phraseologischen Entsprechungen in den deutsch-polnischen Nachschlagewerken. In: Lipczuk, Ryszard/Lisiecka-Czop, Magdalena/Misiek, Dorota (Hg.): Phraseologismen in deutsch-polnischen und polnisch-deutschen Wörterbüchern. Theoretische und praktische Aspekte der Phraseologie und Lexikographie. Dr. Kovač, Hamburg, 271-280.

Szczęk, Joanna (2013): Einblicke in die deutsche Kultur durch die Sprache zur Motiviertheit in der Phraseologie. Zeitschrift des Verbandes Polnischer Germanisten 2/1, 81-92.

Szulc, Aleksander (1981): Kontrastivität und Lernersprache. In: Brückner, Heidrun (Hg.): Lehrer und Lernende im Deutschunterricht. Langenscheidt, Berlin, 67-74.

Szulc, Aleksander (1982): Pragmatische Linguistik und konfrontativ orientierte Fremdsprachendidaktik. Zeitschrift für Germanistik 3, 402-411.

Tabakowska, Elżbieta (1990): Językoznawstwo kognitywne a poetyka przekładu. Teksty Drugie: teoria literatury, krytyka, interpretacja 3, 97-114.

Tabakowska, Elżbieta (1995): Gramatyka i obrazowanie. Wprowadzenie do jezzykoznawstwa kognitywnego. Polska Akademia Nauk, Kraków. 
Tabakowska, Elżbieta (2005): Komunikowanie i poznawanie w językoznawstwie. Teksty Drugie: teoria literatury, krytyka, interpretacja 1-2, 50-59.

Taborek, Janusz (2011): Korpusbasierte Analyse der Phraseologismen. Dargestellt am Beispiel von ausgewählten verbalen Phraseologismen mit Komponenten aus dem Bereich Fussball. In: Lipczuk, Ryszard/Lisiecka-Czop, Magdalena/Misiek, Dorota (Hg.): Phraseologismen in deutsch-polnischen und polnisch-deutschen Wörterbüchern. Theoretische und praktische Aspekte der Phraseologie und Lexikographie. Dr. Kovač, Hamburg, 73-82.

Tabossi, Patrizia/Zardon, Francesco (1993): The Activation of Idiomatic Meaning in Spoken Language Comprehension. In: Cacciari, Cristina/Tabossi, Patrizia (Hg.): Idioms: Processing, Structure, and Interpretation. Psychology Press, New York - London, 145-162.

Talmy, Leonard (2000): Toward a Cognitive Semantics. MIT Press, Cambridge.

Taylor, John R. (2002): Cognitive Grammar. Oxford University Press, Oxford.

Taylor, John R. (2003): Category extension by metaphor and metonymy. In: Dirven, René/Pörings, Ralf (Hg.): Metaphor and Metonymy in Comparison and Contrast. Mouton de Gruyter, Berlin - New York, 323-349.

Taylor, John R. (2007): Gramatyka kognitywna. (Aus dem Englischen übersetzt von M. Buchta, Ł. Wiraszka). Universitas, Kraków.

Telija, Veronika N. (1975): Die Phraseologie. In: Serebrennikow, Boris A. (Hg.): Allgemeine Sprachwissenschaft. Bd. 2. Akademie Verlag, Berlin, 374-429.

Teubert, Wolfgang (2006): Korpuslinguistik, Hermeneutik und die soziale Konstruktion der Wirklichkeit. In: Näff, Anton/Duffner, Rolf (Hg.): Korpuslinguistik im Zeitalter der Textdatenbanken. Linguistik online 28. [http://linguistik-online.de/28_06/index.html, Zugriff am 01.05.2017].

Thun, Harald (1978): Probleme der Phraseologie. Untersuchungen zur wiederholten Rede. Max Niemeyer, Tübingen.

Tokarski, Ryszard (1989): Zagadki: metafory: gry językowe. Język Artystyczny 6, 16-31.

Tokarski, Ryszard (1991): Wartościowanie człowieka w metaforach językowych. Pamiętnik Literacki: czasopismo kwartalne poświęcone historii i krytyce literatury polskiej 82/1, 144-157.

Topczewska, Urszula (2004): Phraseolexeme in Paulusbriefen und ihre Widergabe im Deutschen und im Polnischen anhand ausgewählter Bibelübersetzungen. Wissenschaftlicher Verlag, Trier.

Topczewska, Urszula (2017): Der Gegenstandsbereich der Phraseologie. Ein Diskussionbeitrag zu ausgewählten Problemen. In: Berdychowska, Zofia/Lüger, Heinz-Helmut/Schatte, Czesława/Zenderowska-Korpus, Grażyna (Hg.): Phraseologie als Schnittstelle zwischen Sprache und Kultur 
I. Abgrenzungen - sprach- und textvergleichende Zugänge. Peter Lang, Frankfurt am Main, 21-39.

Tóth, Máté (2011): Das Problem der Abgrenzung der Metonymie von der Metapher. Sprachtheorie und germanistische Linguistik 21.1, 25-53.

Trautmann-Voigt, Sabine/Voigt, Bernd (2012): Grammatik der Körpersprache: ein integratives Lehr- und Arbeitsbuch zum Embodiment. Schattauer, Stuttgart.

Turner, Mark (1987): Death is the Mother of Beauty. University of Chicago Press, Chicago.

Turner, Mark/Fauconnier, Gilles (2003): Metaphor, metonymy, and binding. In: Dirven, René/Pörings, Ralf (Hg.): Metaphor and Metonymy in Comparison and Contrast. Mouton de Gruyter, Berlin - New York, 469-488.

Ullmann, Stephen (1972): Grundzüge der Semantik. Die Bedeutung aus sprachwissenschaftlicher Sicht. De Gruyter, Berlin - New York.

Urban, Anna (2009): Zur ambiguen Verwendung von Phraseologismen anhand von Belegen aus der FAZ. Orbis Linguarum 35, 419-427.

Vega-Moreno, Rosa E. (2001): Representing and processing idioms. [www.ucl. ac.uk/pals/research/linguistics/publications/wpl/01papers/vega, Zugriff am 20.04.2015].

Vinogradov, Viktor V. (1947): Russkij jazyk: Grammaticheskoe uchenie o slove. Uchpedgiz, Moscow, 3-11.

Wanzeck, Christiane (2003): Zur Etymologie lexikalisierter Farbwortverbindungen. Untersuchungen anhand der Farben Rot, Gelb, Grün und Blau. Amsterdamer Publikationen zur Sprache und Literatur. Rodopi, Amsterdam - New York.

Waszakowa, Krystyna (2012): Ztożony charakter procesów włączania elementów obcych do języka polskiego (na przykładzie zapożyczenia celebryta).

In: Mikołajczuk, Agnieszka/Waszakowa, Krystyna (Hg.): Odkrywanie znaczeń w języku. Wydawnictwo Uniwersytetu Warszawskiego, Warszawa, 290-306.

Weber, Hannelore (1994): Ärger. Psychologie einer Alltagsemotion. Juventa, Weinheim - München.

Weinreich, Harald (1976): Sprache in Texten. Klett, Stuttgart.

Wierzbicka, Anna (1980): The semantics of natural language. Academic Press, Sydney - New York.

Wierzbicka, Anna (1999): Język - umyst - kultura: wybór prac. PWN, Warszawa.

Wiktorowicz, Józef (2011): Zur lexikographischen Erfassung der Phraseologismen im deutsch-polnischen Wörterbuch von Piperk/Ippoldt. In: Lipczuk, Ryszard/Lisiecka-Czop, Magdalena/Misiek, Dorota (Hg.): Phraseologismen in deutsch-polnischen und polnisch-deutschen Wörterbüchern. Theoretische und praktische Aspekte der Phraseologie und Lexikographie. Dr. Kovač, Hamburg, 83-91. 
Wildgen, Wolfgang (2008): Kognitive Grammatik. Klassische Paradigmen und neue Perspektiven. De Gruyter, Berlin.

Wittgenstein, Ludwig (2010 [1958]): Philosophische Untersuchungen. In: Hoffmann, Ludger (Hg.): Sprachwissenschaft. Ein Reader. De Gruyter, Berlin - New York, 110-111.

Worbs, Erika (1994): Theorie und Praxis der slawisch-deutschen Phraseographie. Liber, Mainz.

Worbs, Erika, (1997): Plädoyer für das zweisprachige Wörterbuch als Hilfsmittel des Translators. In: Drescher, Horst W. (Hg.): Transfer. Übersetzen - Dolmetschen Interkulturalität. Peter Lang, Frankfurt am Main u.a., 497-510. [http://www. fb06.uni-mainz.de/inst/is/polnisch/texte/plaedoyer.pdf, Zugriff am 14.04.2014].

Worbs, Erika (1998): Phraseologismen, Zitate, geflügelte Worte. In: Huber, Dieter/Worbs, Erika (Hg.): Ars transferendi. Sprache - Übersetzung Interkulturalität. Peter Lang, Frankfurt am Main u.a., 261-272.

Wotjak, Barbara (1992): Verbale Phraseolexeme in System und Text. Niemeyer, Tübingen.

Wotjak, Barbara (1994): Fuchs, du hast sie ganz gestohlen: Zu auffälligen Vernetzungen von Phraseologismen in der Textsorte Anekdote. In: Sandig, Barbara (Hg.): Europhras 92. Tendenzen der Phraseologieforschung. Brockmeyer, Bochum, 619-650.

Wotjak, Barbara (2005): Routineformeln im Lernerwörterbuch. In: Barz, Irmhild/Bergenholtz, Hennig/Korhonen, Jarmo (Hg.): Schreiben, Verstehen, Übersetzen, Lernen. Zu ein- und zweisprachigen Wörterbüchern mit Deutsch. Peter Lang, Frankfurt am Main u.a., 371-387.

Wray, Alison (2007): Set phrases in second language acquisition.

In: Burger, Harald/Dobrovol'skij, Dmitrij/Kühn, Peter/Norrick, Neal R. (Hg.): Phraseologie - Phraseology. Ein internationales Handbuch der zeitgenössischen Forschung. Bd. 1. Walter de Gruyter, Berlin - New York, 870-881.

Wunderlich, Gottlob (1886): Deutsche Redensarten: Zur Pflege vaterländischer Sprachkenntnis in der Volksschule. 2. Aufl. Gressler, Langensalza.

Yu, Ning (2000): Figurative Uses of Finger and Palm in Chinese and English. Metaphor and Symbol 15, 159-175.

Zenderowska-Korpus, Grażyna (2017): Phraseologie und Kommunikation aus didaktischer Sicht. In: Berdychowska, Zofia/Lüger, Heinz-Helmut/Schatte, Czesława/Zenderowska-Korpus, Grażyna (Hg.): Phraseologie als Schnittstelle zwischen Sprache und Kultur II. Offfentlicher Raum - Medien Phraseodidaktik. Peter Lang, Frankfurt am Main, 151-169.

Ziem, Alexander (2005): Frame-Semantik und Diskursanalyse. Zur Verwandschaft zweier Wissensanalysen. Paper für die Konferenz Diskursanalyse in Deutschland 
und Frankreich. Aktuelle Tendenzen in den Sozial- und Sprachwissenschaften. 30. Juni - 2. Juli 2005, Paris, Université Val-de-Marne. [http://www.univ/paris12. $\mathrm{fr} / \mathrm{www} / \mathrm{labos} / \mathrm{ceditec} / \mathrm{colloqueADFA.html,} \mathrm{Zugriff} \mathrm{am} \mathrm{04.06.2016].}$

Ziem, Alexander (2008): Frames und sprachliches Wissen. Walter de Gruyter, Berlin - New York.

Ziem, Alexander (2014a): Kognitive Linguistik heute - Überblick über zentrale Positionen und Konzepte. [https://www.phil-fak.uni-duesseldorf.de/fileadmin/ Redakton/Institute/Germanistik/AbteilungI/Mitarbeiter/ziem/Ziem _ KognitiveLinguistikHeute.pdf, Zugriff am 02.03.2014].

Ziem, Alexander (2014b): Metaphern für Fremdsprachenlerner. In: Dalmas, Martine/Piirainen, Elisabeth (Hg.): Figurative Sprache - Figurative Language Langage figuré. Festgabe für Dmitrij O. Dobrovol'skij. Stauffenburg, Tübingen, 201-220.

Ziem, Alexander (2016): Embodied emotions: Trauer im Spannungsfeld von Sprache und Kognition. In: Mazurkiewicz-Sokołowska, Jolanta/Sulikowska, Anna/Westphal, Werner (Hg.): Chancen und Perspektiven einer Emotionslinguistik. Dr. Kovač, Hamburg, 13-36.

Ziem, Alexander/Lasch, Alexander (2013): Konstruktionsgrammatik: Konzepte und Grundlagen gebrauchsbasierter Ansätze. Germanistische Arbeitshefte, Bd. 44. Walter de Gruyter, Berlin - Boston.

Zürrer, Peter (2007): Phraseme aus germanistisch-dialektologischer Sicht. In: Burger, Harald/Dobrovol'skij, Dmitrij/Kühn, Peter/Norrick, Neal R. (Hg.): Phraseologie - Phraseology. Ein internationales Handbuch der zeitgenössischen Forschung. Bd. 1. Walter de Gruyter, Berlin - New York, 540-551.

Zwaan, Rolf A./Stanfield, Robert A./Yaxley, Richard H. (2002): Research report: Language comprehenders mentaly represent the shapes of objects. Psychological science 13/2, 168-171.

Żuk, Grzegorz (2010): Jezykowy obraz świata w polskiej lingwistyce przetomu wieków. In: Karwatowska, Małgorzata/Siwiec, Adam (Hg.): Przeobrażenia w języku i komunikacji medialnej na przełomie XX i XXI wieku. Best Print, Chełm, 239-257.

\section{Nachschlagewerke:}

Duden 11 = Duden Band 11 Redewendungen. Wörterbuch der deutschen Idiomatik (2011). Mannheim.

Duw 2006 = Duden Universalwörterbuch digital (2006). Mannheim.

Duw ONLINE = Duden online. [https://www.duden.de].

DWDS = Das digitale Wörterbuch der deutschen Sprache. [http://www.dwds.de]. 
GW PWN = Wiktorowicz, Józef; Frączek, Agnieszka (Hg.)

(2010): Großwörterbuch PWN deutsch-polnisch. Warszawa.

Häcki Buhofer, Annelies/Dräger, Marcel/Meier, Stefanie/Roth, Tobias (2014): Feste Wortverbindungen des Deutschen. Kollokationenwörterbuch für den Alltag. Francke, Tübingen.

Hessky Regina/Ettinger, Stefan (1997): Deutsche Redewendungen. Ein Wörterund Übungsbuch für Fortgeschrittene. Gunter Narr, Tübingen.

Głowińska, Katarzyna (2012): Słownik frazeologiczny. Ibis, Poznań.

Ettinger-Phraseologie $=$ Ettinger, Stefan: Phraseographie und Phraseodidaktik. [http://www.ettinger-phraseologie.de/].

MÜLLER 2005 = Müller, Klaus (Hg.): Lexikon der Redensarten. Herkunft und Bedeutung deutscher Redewendungen. Bassermann, München.

Narodowy Korpus Języka Polskiego, (Nationales Korpus der Polnischen Sprache) [http://www.nkjp.uni. lodz.pl].

PONS = Pons.eu. Słownik internetowy. Stuttgart 2001-2013, [http://www.pons. eu.].

Quasthoff, Uwe (2011): Wörterbuch der Kollokationen im Deutschen. De Gruyter, Berlin - New York.

REDENSARTEN-INDEX = www.redensarten-index.de. [https://www.redensartenindex.de/]

Schemann 1993 = Schemann, Hans (1993): Deutsche Idiomatik. Die deutschen Redewendungen im Kontext. 1. Aufl. Ernst Klett Verlag für Wissen und Bildung, Stuttgart - Dresden.

Schemann 2011 = Schemann, Hans (2011): Deutsche Idiomatik. Wörterbuch der deutschen Redewendungen im Kontext. 2. Aufl. Walter de Gruyter, Berlin Boston.

SchemANn 2012 = Schemann, Hans (2012): Synonymwörterbuch der deutschen Redensarten. 2. Aufl. Walter de Gruyter, Berlin - Boston.

Stankiewicz, Anna (2005): Wielki słownik frazeologiczny PWN z przysłowiami. Państwowe Wydawnictwo Naukowe, Warszawa.

WAHRIG 2007 = Wahrig Deutsches Wörterbuch digital (2007). Gütersloh München. 



\section{Index}

A

Ambiguierung 234, 340, 466, 472

Ambiguität 66, 189, 237, 294, 425, 454, 465, 466, 472, 536

analoge Repräsentation 52, 63, 82, 94-97, 99-101, 103, 105, 107, 109, 111, $113,115,117,119,120,215-217,233$

Analyseparadigma 248, 249 anthropozentrische Linguistik 50 Äquivalenz 245, 274, 414, 422, 424, 424, 526, 555

Attributsmetapher 146, 150

Ausbau des Szenarios 234, 466, 467, 468, 472

Ausgangsdomäne 127, 131, 143, 159, $161,168,177,193,233,237,265$, $280,283,298,304,305,312,318$, $320,325,330,350,351,352,358$, $368,369,390,425,430,433,439$, $442,447,461,469$

aussagenartige Repräsentation 96, 97

Automatisierung 50, 76, 240

B

Basisbegriff 113, 114

Basisdomäne 83,84

Basisebene 94, 96, 114, 115, 120, 121, $148,186,232,233$

Bauwerk-Metaphorik 311, 312, 323, 336

Bedeutungswandel 208, 483

bildbasierte Metapher 10, 141, 147, 148

Bildhaftigkeit 17-19, 21, 23, 29, 38, $40,41,47,52,63,81,95,96,118$, $119,121,148,171-173,180,187,192$, 213-215, 217, 219, 220-225, 227, 229, 231-236, 239, 240, 267, 274, 482, 530, 534 image component

(Bildkomponente) 229, 230, 231

Bildlichkeit 19, 21, 29, 35, 38, 40, 41, 43, 47, 171, 172, 195, 213-215, 217, 219-221, 223-225, 227, 229, 231-235, $240,395,501,530$

C

Conceptual Metaphor Theory (CTMTheorie) 20, 52, 80, 109, 125, 130, 133, 135, 137-139, 141, 142, 165, 203, 204, 228, 237, 238, 274, 415, 518

Conventional Figurative Language Theory $(=$ CFLT) $123,228,229,535$

D

Defektivität des Paradigmas 188

Dekompositionshypothese 176

Demotivation 483 direct-access-Hypothese 174 figurativ-first-Hypothese 174 domain highlighting 153, 239

Domäne 16, 52, 56, 58, 69, 76, 77, 79$84,86,89,93,94,122,127,130,131$, 136, 137, 139, 142-145, 148, 152-154, 158-165, 167-169, 176, 177, 193, 208, 218, 233, 237-239, 265, 280-284, 298, 304-306, 308, 312, 318, 320, 323-325, $328,330,334,347,348,350-352,358$, $364,368,369,376,376,390,392$, 401, 407, 409, 413, 425, 430, 431. $433,439,442,447,451,452,458$, 461, 467-469, 480, 513-515, 526

Domänenmatrix 83, 84, 86, 153, 154, $159,160,169,239$

Drei-Ebenen-Modell 89, 90 duale Repräsentationstheorie 98, 100, 101, 505 durchsichtige Metaphorisierung 37 
E

Ein-Ebenen-Semantik 90

Ein-Wort-Phraseologismus 29

Embodiment 52, 58, 61, 62, 116, 145, 148, 149, 197, 255, 294, 382, 386, 538, 558

epistemische Metapher 20, 138, 141, 145, 147, 168, 237, 238, 253, 273, 291, 300, 304, 309, 311, 317, 319, 324, 328, $329,331,335,343,348,352,357,359$, $415,429,430,432,434,438,440,446$, 448, 452, 464, 465, 469, 480,

experiential realism

(Erfahrungsrealismus) 51, 54, $56,57,62$

Expressivität 18, 34, 38, 42, 43, 47, 192, 193, 211-213

F

feste Phrase 15, 23-25, 28-31, 33, 38, 44, 63, 172, 182-184, 192, 198, 234, 237, 249, 271, 301, 405, 561

Festigkeit 23, 25, 28, 29, 31-36, 38, 47, $121,141,172,191,250,441,476$

figurative Motiviertheit 198, 199, 210

figurative-first- Hypothese 174

formelhafte Texte 26, 31, 32, 46, 523, 555

formelhafte Wendungen 31, 32, 519

Frame 52, 56, 77-81, 99, 104-109, 112, 152, 154, 159, 166, 176, 177, 199, 203, 207, 505, 518, 529, 550, 560

Frame-Semantik 51, 80, 560

G

geflügelte Worte 26, 31, 45, 47, 212, 559

Grounded Cognition 52, 54, 58, 61-63, 96, 98, 101, 102, 120, 215, 217, 232, $465,518,520,548$

H

handlungsmäßige Repräsentation 98
Holismus 49, 51, 53, 82

Homogenitätsprämisse 71,190

I

ICM 52, 69, 77, 79-81, 152-157, 159

Idiom 15-42, 44-47, 51, 52, 63, 66, 74, 81, 121, 144, 145, 161-163, 171-240, 242-248, 250, 253, 254, 256, 257, 258, 260, 262, 264-268, 270-276, 278, 280-286, 288, 290-304, 306-308, 310318, 320-326, 328, 330-354, 356-368, 370-374, 376-378, 380, 382, 384-388, 390-398, 400, 402, 404-410, 412, 414418, 420-430, 432, 434-440, 442-444, 446-448, 450-454, 456, 458, 460, 462, 464-470, 472, 476-483, 498, 505-511, 513-515, 519-529, 531-535, 537-541, 543, 545, 546, 549-551, 553-558

idiomatisches Bild 222

Idiomatizität 18, 19, 21, 23, 26, 28, 29, 35-40, 44, 47, 171, 172, 178, 180-183, 185-193, 197, 207, 210, 229, 247, 479, 506

Idiomspeicherung 38, 173, 175, 178

Idiomverarbeitung 173

illokutive Metonymie 158

image component 229-231

image schemas

(Vorstellungsschemata) 20, 57-59, 80, 83, 101, 103, 116-118, 120, 138, 147, 148, 151, 169, 253, 299, 384, 408, 522, 532, 535, 542, 544, 550 image schemas-Metaphern (bildschematische Metapher) 118, 148, 151, 347, 452

Imagene 100, 101, 505

indexale Motiviertheit 192, 203, 206, 207, 213

Inkompatibilität der Idiom-

Konstituenten 188, 189

innere Form 193, 224, 228-232

innovative Metapher 135, 136, 141, 145-147, 194, 234, 470-472, 479 
konventionalisierte Metaphern 20, 126, 135, 141, 145-147, 203, 205, 238, 265

Interaktionismus 86, 189

interlinguale Motiviertheit 211, 274, $318,414,415,424$

intertextuelle Motivation 194, 203, 206 intralinguale Motiviertheit 211, 318 Invariabilität 130, 131

Irregularität der Bedeutung 36, 181, 183, 186-190, 506

K

Kategorialität der Bedeutung 183, 184 Kategorisierung 25, 50, 52, 64, 65, 68-70, 76, 77, 87-89, 93, 103, 105, $109,110,113-115,129,159,232,236$, 240, 292

Kinegramm 45, 179, 203, 205

Kognitive Grammatik 28, 51, 52, 70, 71, 74, 76, 78-82, 85, 87, 89, 90, 94, $103,118,140,153,154,182,505$, 556, 559

kognitive Routine 87-89, 91, 93, 237, 240

Kollokation 26, 41, 44, 46, 47, 76, 135 , $160,198,235,244,248,250,272$, 304, 536, 561

komparative Phraseologismen 45

Kompatibilität der IdiomKonstituenten 188, 189

Kompositionalitätsprämisse 71

Konfigurationshypothese 155, 173

Konstellationsmetapher 150, 151

Konstruktion 16, 30, 41, 75, 76, 78, 85, $86,104,107,110,118,119,121,127$, 182, 188, 217, 218, 243, 247, 310-312, $322,323,325,336,393,396,405$, 505, 542, 547, 553

Konstruktionsgrammatik 28, 35, 37, 75, 76, 78, 79, 181, 182, 191, 560

Konsultationsparadigma 248

Kontextualismus 240, 241 konventionalisierte Metapher 20, 126, 135, 141, 145-147, 203, 205, 238, 265

Konzeptualisierung 16, 17, 60, 61, 63, $72,73,77,81-84,86,89-94,105,109$, $111,112,117-119,121,124,127,129$, $133,134,142,143,148,151,160,169$, 220, 236, 237, 240, 253-255, 277-280, 282-285, 292-295, 299, 304, 308, 318, 322, 333, 337, 341, 347, 350, 359, 367, 376, 378-382, 386, 390, 391, 394, 398, 408, 409, 425, 429, 441, 444, 452, 454. $456,462,463,465,470,471,475,479-$ $481,505,532,544,545,556$

konzeptuelle Metapher 20, 51, 52, 59, 94, 109, 118, 121, 122, 125-128, 130-139, 141-143, 145-154, 160, 164, $165,167,168,169,196,197,203$, 204, 204, 210, 224, 225, 227, 228, 233, 237, 238, 253, 254, 255, 265-267, 273-286, 290, 292-295, 299-305, 307, 309-312, 317, 319, 321-324, 328, 329, 331, 333-335, 340, 342, 343, 348-352, $357,359,360,369,375,377-379,381$, $382,385,386,387,394,398,399$, 403, 407-409, 411-420, 422-425, 428, $429,432-434,438,440-442,444,446-$ 448, 451, 452, 456-458, 460-462, 469, 471, 479, 480, 513, 514

epistemische Metapher 20, 141, 145, $147,168,237,238,253,273,291$, 300, 309, 311, 317, 319, 324, 328, $329,331,335,343,348,352,359$, 415, 429, 430, 432, 434, 438, 440, 442, 446-448, 452, 464, 465, 469, 480 konzeptueller Inhalt (conceptual content) 85, 119, 505

Korpus 21, 26-28, 115, 161, 172, 179, 240-251, 267, 268-273, 293, 297, 315, 326, 345, 354, 367, 374, 386, 396, 406, 416, 417, 427, 436, 437, 450, 454, 475-478, 506-511, 519, 526, 527, 553, 558, 559 
korpusbasiert 191, 236, 242, 243, 248, 274, 302, 396, 424, 425, 475, 476, 537, 548, 553-555, 557

korpusgesteuert 27, 244, 249, 424, 555

\section{L}

Lexikalisierung 18, 33, 38, 47, 89, 141, $145,200,293,425,443,459,483$

literale Lesart 16, 19, 20, 37, 40, 41, $121,164,169,171-175,177-180,188$, 189, 191, 193, 194, 196, 205, 206, 210, 220-224, 227-229, 231, 233-235, 237, 239, 294, 336, 339, 341, 342, 351, 405, 430, 440, 465-469, 472, 479,481

phraseologisierte Lesart 19, 20, 40, 52, 171-175, 177-180, 188, 189, 193, 194, 196, 206, 210, 223, 224, 227, 228, 231, 233-235, 237, 239, 336, 343, 408, 430, 466-469, 472, 479

literale Sprache 139, 163-167, 236 non-literale Sprache 163, 164, 166 figurative Sprache 20, 123, 126, 133, 139, 163-167, 236, 238, 545, 548, 560 literal-first Hypothese 174 Logogene 100, 101, 505

\section{M}

Mappings 121, 130, 131, 133, 136-139, 141, 142, 144, 145, 147-149, $151,152,154,159,167,168,169$, 197, 203, 218, 228, 232, 233, 237, 238, 265, 274, 280, 283, 285, 294, 304, 306-308, 312, 317, 318, 320, 321, 324, 325, 330, 335-338, 346, 347, 350-352, 358, 359, 376, 411, 413, 415, $422,424,425,430,433,439,442$, 444, 447, 461, 463, 465, 469, 471, 480-482, 513-515, 528

markierter Gebrauch des Phraseologismus 36, 86, 175, 187, 211, 332, 338, 339, 341, 466 materielle Bilder 216, 221, 223, 234, 454, 473

mentales Bild 111, 215-217, 228, 231, 233, 235, 300, 309, 311, 317, 319, $324,329,335,348,430,434,448$, 464, 465, 480

Metapher 17, 19, 20, 37, 40, 41, 51, 52, $55,56,58,59,63,64,79,85,94,109$, $116,118,121-143,145-155,157-165$, 167-169, 172, 178, 193, 194, 196-199, 203-205, 208-210, 218, 220-222, 224, 225, 227, 228, 233, 234, 236-239, 253-255, 265-267, 273-286, 290-295, 299-305, 307-312, 317, 319, 321-324, 328, 329, 331, 333-337, 340-343, 347-352, 357-360, 362, 363, 369, 370, 375-387, 390-394, 398-400, 402, 403, 407-409, 411-415, 418-425, 428-430, 432-434, 438, 440-444, 446-448, 451, 452, 456-462, 464, 465, 469, 470, 471, 472, 479-482, 505, 506, 509, 513, 514, 519, 526, 537, 542, 543, 545, 548, 551, 553, 554, 558, 560

Metaphorisierung 37, 200, 271, 471, 478

durchsichtige Metaphorisierung 37 undurchsichtige Metaphorisierung 37 Metaphtonymie 161-163, 167, 169, 199, 210, 237, 239, 253, 273, 300, $305,313,375,380,381,399,401-403$, 412, 418-420, 428, 429, 431, 434, 458, 464, 467, 479, 481, 505, 506

Metonymie 19, 20, 40, 52, 56, 80, 121 , 122-127, 129, 131-133, 135, 137-139, 141, 143, 145, 147, 149, 151-155, 157-165, 167, 169, 172, 196-199, 208-210, 237, 239, 253, 273, 274, 284, 293, 300, 305, 309, 311, 313, $329,330,331,332,334,341,342$, 345-348, 351, 352, 357-364, 369, 371, 376, 385-387, 390-394, 407, 411-415, 418-420, 428, 429, 434, 440, 442, 446, 451, 452, 456, 459, 460, 464, 467, 
470, 479-482, 505, 506, 509, 513, 514, 523, 525, 528, 548, 554, 558

Modell der notwendigen und hinreichenden Merkmale (NHBModell) 65, 69

Modell der simultanen Idiomverarbeitung

Modellbildungen 45

Modifikation 33, 34, 70, 106, 175, 177 , 187, 200, 201, 211, 212, 247, 295, $314,316,320,324,343,351,364$, $372,394,404,426,433,434,435$, 448, 453, 476, 483, 498, 500-503, 515, $519,541,549$

Modularismus 49

morphosyntaktische Anomalien 32, 36

Motivation 78, 122, 192-195, 198-209, 226, 231, 430, 483, 506, 518, 524, 531

Motivierbarkeit 19, 172, 189, 192-195, 197, 198, 202, 207, 220

Motiviertheit 18, 19, 21, 23, 29, 35, 38, $40,41,47,63,145,168,171-173,180$, 189, 191-195, 197-199, 201-203, 205207, 209-213, 219, 220, 222, 233, 236, 237, 265, 274, 275, 291, 293, 294, $318,364,367,374,392,393,394$, 414, 415, 424, 425, 438, 470, 478-481, 506, 539, 554, 556, 557

multimodale

Repräsentationstheorie 96, 98, 100, 101

$\mathbf{N}$

Neologismus 271, 338, 465, 466 nominative Phraseologismen 43, 44 propositionale Phraseologismen 43, 44 Non-Kompositionalität 183, 190, 191, 207

O

objektivistischer Realismus 51, $54,58,64$ one shot image- Metapher 148

Onomasiologie 253

ontologische Metapher 59, 129, 138, 141, 142, 150, 151, 237, 238, 274, 382, 384, 441, 442, 447, 452

onymische Phraseologismen 26, 45 , 47, 198

opake Idiome 33, 40, 175, 179, 189, 191, 221, 227

Orientierungsmetapher 59, 127, 143, 278, 279, 294, 303, 317, 347, 375,385

$\mathbf{P}$

parallele Metaphorisierung 271, 478 Perceptual Symbol System 99, 103, 105, 108, 505, 518

perzeptuelle Symbole 102-104, 108110,120 phonologischer Pol 180 phraseologische Termini 26, 45, 47 phraseologisierte Lesart 19, 20, 40, 52, 171-175, 177-180, 188, 189, 193, 104, 196, 206, 210, 223, 224, 227, 228, 231, 233, 235, 237, 239, 336, 343, 408, 430, 466-469, 472, 479

Phraseologizitätsmerkmal 29, 38, 47 Polylexikalität 18, 23, 25, 28-30, 35, 47, 256, 479, 482, 536 prädikative Metonymien 158 primäre

Phraseologizitätsmerkmale 29 Invariabilität 130, 131 Unidirektionalität 130, 131, 136, 137 Profil 86, 103, 524

Profilierung 52, 81, 120, 153, 310, 331, 405, 414, 471,

Projektionsprozesse 239, 360, 362, 479-481

property attribution model 138-140, 144

Proposition 56, 97, 98, 109-111, 116, 121

propositionale Metapher 147, 148, 169 
propositionale Repräsentation 81,95 , 97, 215, 217

Prototyp 67, 68, 69, 82

Prototypikalität 68, 69, 153

\section{$\mathbf{R}$}

referenzielle Metonymie 155, 158

Reidiomatisierung 180

Rekurrenz 87, 121

Repräsentationsformat 52, 63, 94-99, 101, 103, 105, 107, 109, 111, 113, $115,117,119,120,215-217$

Reproduzierbarkeit 29, 33, 38, 47 rich image-Metaphern 147, 148, 169

S

Schematisierung 70, 75, 76, 87, 240

sekundäre Metaphorisierung 200, 478 sekundäre

Phraseologizitätsmerkmale 29, 38 semantische Basis 186, 195, 196, 208, 222, 476

semantischer Mehrwert 29, 38, 41, 172, 173, 237, 473, 481, 526, 541 semantischer Pol 74, 169, 214

Semasiologie 253

Simulation 61, 62, 102, 104-109, 111$113,121,505$

Simulator 62, 104, 105, 108, 111, 112,120

simultane Idiomverarbeitung 174 Somatismen 255, 359, 371, 382, 385, 386 source $96,117,127,130,131,137$, 148, 176, 177, 208, 225, 231, 465

Sprachgebrauchsereignis $87,88,222$, 240, 293

sprachliche Einheit 16, 18, 20, 23, 25, $27,28,30,31,38,39,46,49,51,52$, 59, 64, 66, 71, 74, 77-79, 82, 86-91, $93,95,96,101,108,110,121,153$, $169,180,182,214,215,232,236-241$, $243,246,248,249,384,387,465,475$ sprachliches Bild 216 sprachliches Weltbild 19, 63 sprachspielerischer Gebrauch 338, 374, 478, 499

Sprachüblichkeit 29, 39, 47, 172

Stabilität 18, 27-29, 31, 38, 39, 84, 172, 187, 192, 295, 301, 391, 476, 498, 546 strukturelle Idiomatizität 181,188 Strukturmetapher 127, 141, 323, 347, 348, 382, 419 symbolische Motivatheit 203, 205, 208, 430

Synekdoche 124, 161, 198, 199, 200, 208-210, 332

\author{
$\mathrm{T}$ \\ target 127, 130, 131, 137, 148, 152, \\ 176, 177, 208, 225, 230, 231 \\ Teil-Idiom 44, 179 \\ textbildende Potenzen 34, 466, \\ 523, 551 \\ Theorie des bildlichen Lexikons 148, \\ 204, 228, 229 \\ topische Formel 44 \\ tote Metapher 135, 146, 151 \\ transformationelle \\ Defektivität 32,181
}

U

undurchsichtige

Metaphorisierung 37

Unidirektionalität 130, 131, 136, 137

unikale Komponente 29, 33, 38-40,

47, 178, 188, 221, 290, 291

unitäre

Repräsentationstheorie 96, 98, 99 Univerbierung 30

V

Vagheit 16, 18, 81, 111, 237, 473

Varianten des Phraseologismus 33

Verwendungsprofile und Verwendungsmuster 254, 266, 270, 272, 315, 335-337, 374, 475-477, 498-503, 506-510, 515 
Vordergrund/Hintergrund-

Unterscheidung 50, 76

Vorstellungsschema BALANCE

(GLEICHWEWICHT) 116, 117, 299, 300, 384, 385

Vorstellungsschema CONTAINER

（BEHÄLteR） 117, 123, 129, 134, 157, $177,225,226,227$

Vorstellungsschema PATH (WEG) 117, 169, 277, 278, 294, 347

\section{W}

Weg-Metaphorik 275, 277-279, 294, $343,347,358,359,364,382,390$, $394,425,545$
Weltwissen 52, 53, 56, 70, 76, 82, 89, 93, 141, 144, 168, 171, 197, 200, 238, 253, 304, 335-339, 351, 376, 415, $471,478,480$

\section{$\mathbf{Z}$}

Zentralitätsgrad der Domänen 69,84

Zieldomäne 127, 131, 136, 137, 148, 159, 161, 168, 176, 177, 218, 233, $237,304,312,318,320,324,325$, $330,348,350-352,358,368,390$, 392, 407, 409, 430, 433, 439, 442, 447, 452, 461, 469, 513-515

Zwillingsformel 45, 187, 256 



\section{DANZIGER BEITRÄGE ZUR GERMANISTIK}

Herausgegeben von Prof. Dr. Andrzej Kątny, Dr. Katarzyna Lukas und Prof. Dr. Czesława Schatte

Band 1 Jacek Szczepaniak: Zu sprachlichen Realisierungsmitteln der Komik in ausgewählten aphoristischen Texten aus pragmalinguistischer Sicht. 2002.

Band 2 Monika Bielińska: Verben des Sterbens und des Tötens. Eine semantische Untersuchung. 2002.

Band 3 Wioletta Knütel: Verlorene Heimat als literarische Provinz. Stolp und seine pommersche Umgebung in der deutschen Literatur nach 1945. 2002.

Band 4 Anna Pilarski: Die Operation Merge im Verbalkomplex des Polnischen und des Deutschen. 2002.

Band 5 Eliza Pieciul: Literarische Personennamen in deutsch-polnischer Translation. Eine kontrastive Studie aufgrund von ausgewählten Prosawerken von Thomas Mann. 2003.

Band 6 Michail L. Kotin: Die werden-Perspektiven und die werden-Periphrasen im Deutschen. Historische Entwicklung und Funktionen in der Gegenwartssprache. 2003.

Band 7 Małgorzata Płomińska: Farben und Sprache. Deutsche und polnische Farbbezeichnungen aus kontrastiver Sicht. 2003.

Band 8 Magdalena Lisiecka-Czop: Verstehensmechanismen und Lesestrategien von fremdsprachigen Fachtexten. 2003.

Band 9 Barbara Komenda: Sekundäre Bedeutungen von Nationalitäts- und Länderbezeichnungen im Deutschen und Polnischen. Unter besonderer Berücksichtigung der semantischen Gebrauchstheorie. 2003.

Band 10 Marek Cieszkowski/Monika Szczepaniak (Hrsg.): Texte im Wandel der Zeit. Beiträge zur modernen Textwissenschaft. 2003.

Band 11 Marek Gładysz: Lexikalische Kollokationen in deutsch-polnischer Konfrontation. 2003.

Band 12 Grażyna Zenderowska-Korpus: Sprachliche Schematismen des Deutschen und ihre Vermittlung im Unterricht DaF. 2004.

Band 13 Sprachen leben und lieben: Festschrift für Zdzisław Wawrzyniak zum 60. Geburtstag. Herausgegeben von Zofia Bilut-Homplewicz und Zygmunt Tęcza. 2004.

Band 14 Aldona Sopata: Universalgrammatik und Fremdsprachendidaktik. 2004.

Band 15 Andrzej Kątny (Hrsg.): Das literarische und kulturelle Erbe von Danzig und Gdańsk. 2004. 
Band 16 Mariola Wierzbicka/Małgorzata Sieradzka/Jaromin Homa (Hrsg.): Moderne deutsche Texte. Beiträge der Internationalen Germanistenkonferenz Rzeszów 2004. 2005.

Band 17 Anna Pieczyńska-Sulik: Idiolektale Figurencharakteristik als Übersetzungsproblem. Am Beispiel der Unkenrufe von Günter Grass. 2005.

Band 18 Andrzej S. Feret: Das Partizip im Deutschen und Polnischen. Eine typologische Studie. 2005.

Band 19 Susanne Eva Patzke: Bedeutung von Appellativa der Nationszugehörigkeit am Beispiel „Deutscher“ und „Ausländer“. Eine empirisch-semantische Untersuchung. 2006.

Band 20 Paweł Bąk: Die Metapher in der Übersetzung. Studien zum Transfer der Aphorismen von Stanisław Jerzy Lec und der Gedichte von Wisława Szymborska. 2007.

Band 21 Aleksandra Łyp-Bielecka. Verben der Nahrungsaufnahme des Deutschen und des Polnischen. Eine semanto-syntaktische Vergleichsanalyse. 2007.

Band 22 Janusz Pociask: Zu Status und Funktion der idiomatischen Einheit in Pressetexten. Dargestellt an Textbeispielen aus der Neuen Zürcher Zeitung. 2007.

Band 23 Ryszard Lipczuk: Geschichte und Gegenwart des Fremdwortpurismus in Deutschland und Polen. 2007.

Band 24 Ilona Kromp: Eigennamen in der deutschen und polnischen Kinderliteratur unter textlinguistischem und translatorischem Aspekt. 2008.

Band 25 Peter Oliver Loew: Das literarische Danzig - 1793 bis 1945. Bausteine für eine lokale Kulturgeschichte. 2009.

Band 26 Hans-Jörg Schwenk: Die Semantik der Imperfektiv-Perfektiv-Opposition im Polnischen und ihr Niederschlag in polnisch-deutschen Wörterbüchern. Versuch einer aspektologisch-aspektographischen Neuorientierung. 2009.

Band 27 Robert Rduch: Unbehaustheit und Heimat. Das literarische Werk von Arnold Ulitz (1888-1971). 2009.

Band 28 Marta Turska: Internationalismen in der Fachsprache der Gastronomie und Kochkunst im fünfsprachigen Vergleich. 2009.

Band 29 Paweł Bąk/Małgorzata Sieradzka/Zdzisław Wawrzyniak (Hrsg.): Texte und Translation. 2010.

Band 30 Andrzej Kątny/Anna Socka (Hrsg.): Modalität/Temporalität in kontrastiver und typologischer Sicht. 2010.

Band 31 Lech Zieliński: Ideologie und Lexikographie. Die Ideologisierung des Wörterbuchs der deutschen Gegenwartssprache von Ruth Klappenbach und Wolfgang Steinitz. 2010. 
Band 32 Monika Bielińska: Lexikographische Metatexte. Eine Untersuchung nichtintegrierter Außentexte in einsprachigen Wörterbüchern des Deutschen als Fremdsprache. 2010.

Band 33 Maria Krysztofiak (Hrsg.): Probleme der Übersetzungskultur. 2010.

Band 34 Mariola Wierzbicka/Zdzisław Wawrzyniak (Hrsg.): Grammatik im Text und im Diskurs. 2011.

Band 35 Lech Zieliński/Klaus-Dieter Ludwig/Ryszard Lipczuk (Hrsg.): Deutsche und polnische Lexikographie nach 1945 im Spannungsfeld der Kulturgeschichte. Unter redaktioneller Mitwirkung von Patryk Mączyński. 2011.

Band 36 Katarzyna Bizukojć: Neue Nominalkomposita in deutschen Newsletter-Texten. 2011.

Band 37 Agnieszka Poźlewicz: Syntax, Semantik und Pragmatik der Operatorpartikeln des Deutschen. Versuch einer Systematik. 2011.

Band 38 Monika Schönherr: Modalität im Diskurs und im Kontext. Studien zur Verwendung von Modalitätsausdrücken im Althochdeutschen. 2011.

Band 39 Andrzej Kątny / Katarzyna Lukas (Hrsg.): Germanistik in Polen. Geschichte - Perspektiven - interdisziplinärer Dialog. 2011.

Band 40 Justyna Duch-Adamczyk: Funktionsdistribution der Abtönungspartikeln des Deutschen und des Polnischen. 2012.

Band 41 Olena Materynska: Typologie der Körperteilbenennungen. 2012.

Band 42 Jan Sikora: Sprechhandlungen im publizistischen Material der Danziger Neuesten Nachrichten. 2013.

Band 43 Zofia Bilut-Homplewicz: Prinzip Perspektivierung. Germanistische und polonistische Textlinguistik - Entwicklungen, Probleme, Desiderata. Teil I: Germanistische Textlinguistik. 2013.

Band 44 Werner Abraham: Schriften zur Synchronie und Diachronie des Deutschen. Herausgegeben von Andrzej Kątny, Michail Kotin, Elisabeth Leiss, Anna Socka. 2014.

Band 45 Elżbieta Kazimierska: Direktionalia im Deutschen und im Polnischen. 2014.

Band 46 Izabela Kujawa: Der politische Diskurs als Gegenstand der linguistischen Analyse am Beispiel der Integrationsdebatte in Deutschland 2006-2010. 2014.

Band 47 Magdalena Urbaniak-Elkholy: Komplexe deutsche Nominalphrasen und ihre polnischen Entsprechungen. Eine konfrontative Studie. 2014.

Band 48 Deutsch im Kontakt und im Kontrast. Festschrift für Prof. Andrzej Kątny zum 65. Geburtstag. Herausgegeben von Katarzyna Lukas und Izabela Olszewska. 2014. 
Band 49 Agnieszka Marta Kurzyńska: Das deutsche Poplied als Textsorte. Eine Studie über neue deutsche Liedtexte aus textuell-stilistischer Sicht. 2015.

Band 50 Magdalena Pieklarz-Thien: Gesprochene Sprache in der philologischen Sprachausbildung. Theoretische Grundlagen - Empirische Befunde - Exemplarische Anwendungen. 2015.

Band 51 Jolanta Mazurkiewicz-Sokołowska: Zur individuell-subjektiven Prägung der Bedeutung am Beispiel ausgewählter Ess- und Trinkwaren. 2015.

Band 52 Joanna Woźniak: Fachphraseologie am Beispiel der deutschen und der polnischen Fassung des Vertrags von Lissabon. 2016.

Band 53 Magdalena Duś / Robert Kołodziej / Tomasz Rojek (Hrsg.): Wort - Text Diskurs. 2016.

Band 54 Ewa Mazurkiewicz: Die gespiegelte Schweiz. Erzählte Zeitgeschichte in ausgewählten Romanen von Jakob Bosshart, Meinrad Inglin, Kurt Guggenheim und Charles Lewinsky. 2017.

Band 55 Jolanta Mazurkiewicz-Sokołowska: Ausgewählte Pronomen, ihr Bedeutungs- und Emotionspotenzial. Individuelle Konzeptualisierungsprozesse im Lichte Langackerscher Auffassung der Grammatik. 2017.

Band 56 Katarzyna Lukas: Fremdheit - Gedächtnis - Translation. Interpretationskategorien einer kulturorientierten Literaturwissenschaft. 2018.

Band 57 Anna Sulikowska: Kognitive Aspekte der Phraseologie. Konstituierung der Bedeutung von Phraseologismen aus der Perspektive der Kognitiven Linguistik. 2019.

Band 58 Katarzyna Grzywka-Kolago / Małgorzata Filipowicz / Maciej Jędrzejewski (Hrsg.): Texte komponieren, von Klängen erzählen. Studien zu den Beziehungen von Literatur und Musik 2019.

www.peterlang.com 